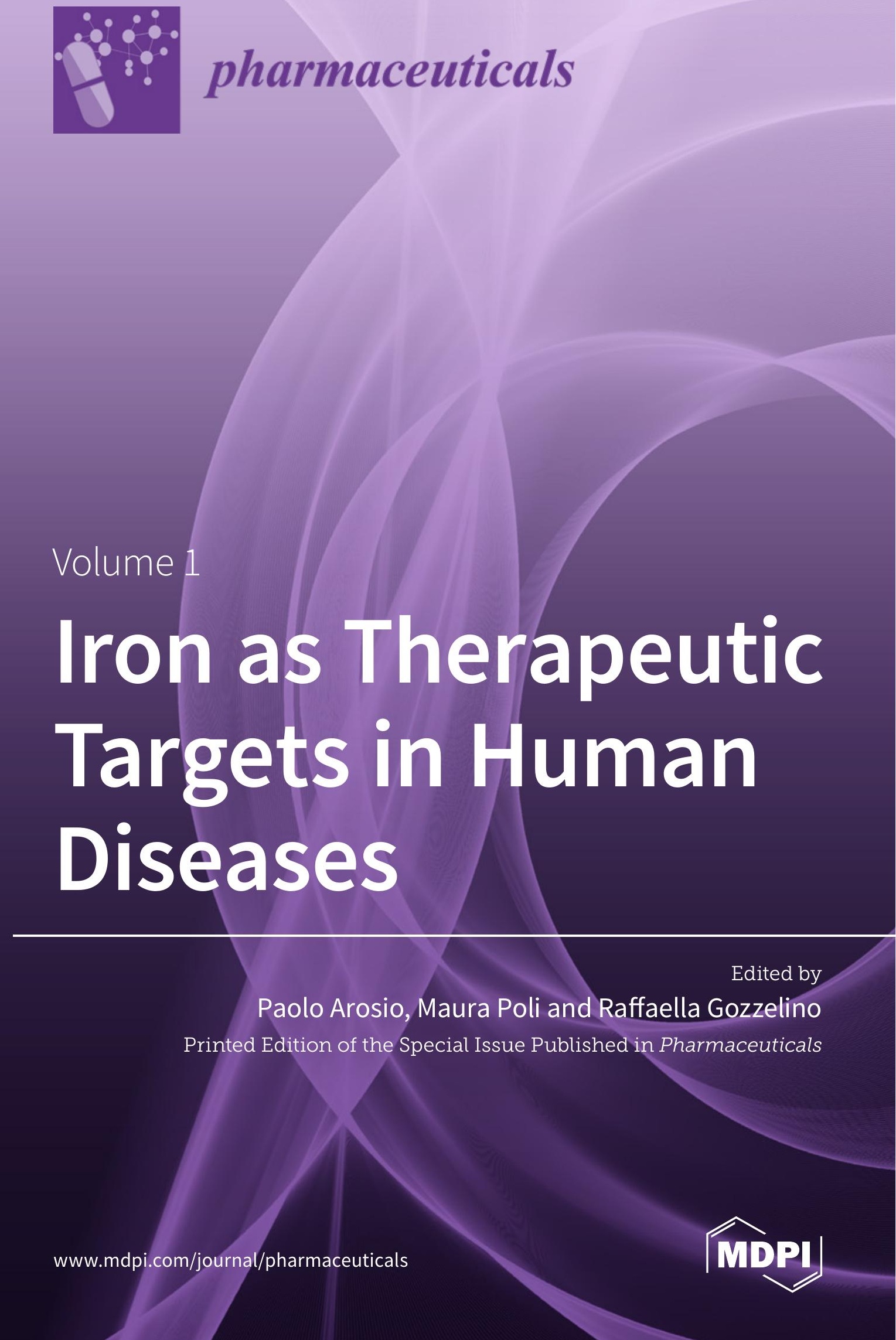




\section{Iron as Therapeutic Targets in Human Diseases}





\section{Iron as Therapeutic Targets in Human Diseases}

\section{Volume 1}

Special Issue Editors

Paolo Arosio

Maura Poli

Raffaella Gozzelino 
Special Issue Editors

Paolo Arosio

University of Brescia

Italy

Raffaella Gozzelino

NOVA University of Lisbon

Portugal
Maura Poli

University of Brescia

Itay

Editorial Office

MDPI

St. Alban-Anlage 66

4052 Basel, Switzerland

This is a reprint of articles from the Special Issue published online in the open access journal Pharmaceuticals (ISSN 1424-8247) from 2018 to 2019 (available at: https:/ /www.mdpi.com/journal/ pharmaceuticals/special_issues/Iron_TTHD).

For citation purposes, cite each article independently as indicated on the article page online and as indicated below:

LastName, A.A.; LastName, B.B.; LastName, C.C. Article Title. Journal Name Year, Article Number, Page Range.

Volume 1

ISBN 978-3-03928-082-7 (Pbk)

ISBN 978-3-03928-083-4 (PDF)
Volume 1-2

ISBN 978-3-03928-114-5 (Pbk)

ISBN 978-3-03928-115-2 (PDF)

(C) 2020 by the authors. Articles in this book are Open Access and distributed under the Creative Commons Attribution (CC BY) license, which allows users to download, copy and build upon published articles, as long as the author and publisher are properly credited, which ensures maximum dissemination and a wider impact of our publications.

The book as a whole is distributed by MDPI under the terms and conditions of the Creative Commons license CC BY-NC-ND. 


\section{Contents}

About the Special Issue Editors $\ldots \ldots \ldots \ldots \ldots \ldots \ldots \ldots \ldots \ldots$

Raffaella Gozzelino, Maura Poli and Paolo Arosio

Iron as Therapeutic Target in Human Diseases

Reprinted from: Pharmaceuticals 2019, 12, 178, doi:10.3390/ph12040178 . . . . . . . . . . 1

Robert R. Crichton, Roberta J. Ward and Robert C. Hider

The Efficacy of Iron Chelators for Removing Iron from Specific Brain Regions and the Pituitary-Ironing out the Brain

Reprinted from: Pharmaceuticals 2019, 12, 138, doi:10.3390/ph12030138 . . . . . . . . . . 10

\section{Marco T. Nuñez and Pedro Chana-Cuevas}

New Perspectives in Iron Chelation Therapy for the Treatment of Neurodegenerative Diseases

Reprinted from: Pharmaceuticals 2018, 11, 109, doi:10.3390/ph11040109 . . . . . . . . . . . 23

David Alsina, Rosa Purroy, Joaquim Ros and Jordi Tamarit

Iron in Friedreich Ataxia: A Central Role in the Pathophysiology or an Epiphenomenon?

Reprinted from: Pharmaceuticals 2018, 11, 89, doi:10.3390/ph11030089 . . . . . . . . . . . 45

Shashank Masaldan, Abdel Ali Belaidi, Scott Ayton and Ashley I. Bush

Cellular Senescence and Iron Dyshomeostasis in Alzheimer's Disease

Reprinted from: Pharmaceuticals 2019, 12, 93, doi:10.3390/ph12020093 . . . . . . . . . . . . 60

Israel C. Nnah and Marianne Wessling-Resnick

Brain Iron Homeostasis: A Focus on Microglial Iron

Reprinted from: Pharmaceuticals 2018, 11, 129, doi:10.3390/ph11040129 . . . . . . . . . . 71

Sonia Levi and Valeria Tiranti

Neurodegeneration with Brain Iron Accumulation Disorders: Valuable Models Aimed at Understanding the Pathogenesis of Iron Deposition

Reprinted from: Pharmaceuticals 2019, 12, 27, doi:10.3390/ph12010027 . . . . . . . . . . . 85

Veronica Fiorito, Deborah Chiabrando and Emanuela Tolosano

Mitochondrial Targeting in Neurodegeneration: A Heme Perspective

Reprinted from: Pharmaceuticals 2018, 11, 87, doi:10.3390/ph11030087 . . . . . . . . . . . . 107

Fadi Bou-Abdallah, John J. Paliakkara, Galina Melman and Artem Melman

Reductive Mobilization of Iron from Intact Ferritin: Mechanisms and Physiological Implication

Reprinted from: Pharmaceuticals 2018, 11, 120, doi:10.3390/ph12030120 . . . . . . . . . . 128

Stephanie Rockfield, Ravneet Chhabra, Michelle Robertson, Nabila Rehman, Richa Bisht and Meera Nanjundan

Links Between Iron and Lipids: Implications in Some Major Human Diseases

Reprinted from: Pharmaceuticals 2018, 11, 113, doi:10.3390/ph11040113 . . . . . . . . . . . 142

Ana Ferreira, Pedro Neves and Raffaella Gozzelino

Multilevel Impacts of Iron in the Brain: The Cross Talk between Neurophysiological

Mechanisms, Cognition, and Social Behavior

Reprinted from: Pharmaceuticals 2019, 12, 126, doi:10.3390/ph12030126 . . . . . . . . . . 156 
Wanting Shu and Joshua L. Dunaief

Potential Treatment of Retinal Diseases with Iron Chelators

Reprinted from: Pharmaceuticals 2018, 11, 112, doi:10.3390/ph11040112 . . . . . . . . . . . . . 182

Olivier Loréal, Thibault Cavey, François Robin, Moussa Kenawi, Pascal Guggenbuhl and Pierre Brissot

Iron as a Therapeutic Target in HFE-Related Hemochromatosis: Usual and Novel Aspects Reprinted from: Pharmaceuticals 2018, 11, 131, doi:10.3390/ph11040131 . . . . . . . . . . . . . 196

Graça Porto, Eugénia Cruz, Maria José Teles and Maria de Sousa

HFE Related Hemochromatosis: Uncovering the Inextricable Link between Iron Homeostasis and the Immunological System

Reprinted from: Pharmaceuticals 2019, 12, 122, doi:10.3390/ph12030122 . . . . . . . . . . . . 210

L. Tom Vlasveld, Roel Janssen, Edouard Bardou-Jacquet, Hanka Venselaar, Houda Hamdi-Roze, Hal Drakesmith and Dorine W. Swinkels

Twenty Years of Ferroportin Disease: A Review or An Update of Published Clinical, Biochemical, Molecular, and Functional Features

Reprinted from: Pharmaceuticals 2019, 12, 132, doi:10.3390/ph12030132 . . . . . . . . . . . . 222

Angeliki Katsarou and Kostas Pantopoulos

Hepcidin Therapeutics

Reprinted from: Pharmaceuticals 2018, 11, 127, doi:10.3390/ph11040127 . . . . . . . . . . . . . 251

Zachary J. Hawula, Daniel F. Wallace, V. Nathan Subramaniam and Gautam Rishi

Therapeutic Advances in Regulating the Hepcidin/Ferroportin Axis

Reprinted from: Pharmaceuticals 2019, 12, 170, doi:10.3390/ph12040170 . . . . . . . . . . . . . 281

Naveen Kumar Tangudu, Nils Buth, Pavel Strnad, Ion C. Cirstea and Maja Vujić Spasić

Deregulation of Hepatic Mek1/2-Erk1/2 Signaling Module in Iron Overload Conditions

Reprinted from: Pharmaceuticals 2019, 12,70, doi:10.3390/ph12020070 . . . . . . . . . . . . 303

Laura E. Diepeveen, Coby M. Laarakkers, Hilde P.E. Peters, Antonius E. van Herwaarden, Hans Groenewoud, Joanna IntHout, Jack F. Wetzels, Rachel P.L. van Swelm and Dorine W.

Swinkels

Unraveling Hepcidin Plasma Protein Binding: Evidence from Peritoneal Equilibration Testing Reprinted from: Pharmaceuticals 2019, 12, 123, doi:10.3390/ph12030123 . . . . . . . . . . . . 318

Beatriz Cadenas, Josep Fita-Torró, Mar Bermúdez-Cortés, Inés Hernandez-Rodriguez, José Luis Fuster, María Esther Llinares, Ana María Galera, Julia Lee Romero, Santiago Pérez-Montero, Cristian Tornador and Mayka Sanchez

L-Ferritin: One Gene, Five Diseases; from Hereditary Hyperferritinemia to Hypoferritinemia-Report of New Cases

Reprinted from: Pharmaceuticals 2019, 12,17, doi:10.3390/ph12010017 . . . . . . . . . . . . . 331

Brian Chiou and James R. Connor

Emerging and Dynamic Biomedical Uses of Ferritin

Reprinted from: Pharmaceuticals 2018, , 124, doi:10.3390/ph11040124 . . . . . . . . . . . . . 346

Naiara Santana-Codina and Joseph D. Mancias

The Role of NCOA4-Mediated Ferritinophagy in Health and Disease

Reprinted from: Pharmaceuticals 2018, 11, 114, doi:10.3390/ph11040114 . . . . . . . . . . . . . 364 
Veronika Markova, Charlotte Holm, Anja Bisgaard Pinborg, Lars Lykke Thomsen and Torben Moos

Impairment of the Developing Human Brain in Iron Deficiency: Correlations to Findings in Experimental Animals and Prospects for Early Intervention Therapy

Reprinted from: Pharmaceuticals 2019, 12, 120, doi:10.3390/ph12030120 . . . . . . . . . . . 380

Xuejiao Sha, Hai Chen, Jingsheng Zhang and Guanghua Zhao

Iron Release from Soybean Seed Ferritin Induced by Cinnamic Acid Derivatives

Reprinted from: Pharmaceuticals 2018, 11, 39, doi:10.3390/ph11020039 . .

Antonella Roetto, Mariarosa Mezzanotte and Rosa Maria Pellegrino

The Functional Versatility of Transferrin Receptor 2 and Its Therapeutic Value

Reprinted from: Pharmaceuticals 2018, 11, 115, doi:10.3390/ph11040115 . . . . . . . . . . . 406

Luis Montecinos, Jeffrey D. Eskew and Ann Smith

What Is Next in This "Age" of Heme-Driven Pathology and Protection by Hemopexin?

An Update and Links with Iron Reprinted from: Pharmaceuticals 2019, 12, 144,

doi:10.3390/ph12040144 . . . . . . . . . . . . . . . . . . . . . . . . 426 



\section{About the Special Issue Editors}

Paolo Arosio is full professor in Molecular Biology. He graduated in Milan, than as a post-doc worked at Tufts University in Boston, US. Then he moved to Italy, at the University of Milan and eventually at the University of Brescia in the medical school. He then retired in 2017. He has been working on proteins of iron metabolism, with particular attention to the ferritin structure, about which he wrote numerous research papers and also review articles of success. He then studied the role of ferritin in iron homeostasis, ferritin-linked disorders, some regulatory aspects of iron metabolism and the use of heparin as inhibitor of hepcidin expression. He directed a laboratory on iron metabolism first in San Raffaele Institute of Milan, and then in University of Brescia. He organized congresses of the European Iron Club and of the International Society of Bioiron. He has been guest editor of an issue of Frontiers in Pharmacology (2014) titled "The importance of Iron in Pathophysiologic Conditions", of IUBMB Life (2016) titled "Iron in Biology". He is coauthor in about 230 papers on international peer review journals that have been cited more than 15.000 times. He has an $\mathrm{H}$-index $¿ 65$.

Maura Poli is a professor in Biochemistry in the University of Brescia, Italy. She is working from more than 10 years in the University of Brescia in the Lab. of Molecular Biology with Prof. Arosio on iron metabolism. Prof. Maura Poli received her PhD in 2010, from the Faculty of Medicine of the University of Brescia, and the Clinical Biochemistry Specialization in 2011. She continues to work on iron field, first as post-doctoral fellow, then as researcher and finally as professor. Actually, she has her independent team of approximately 10 researchers, between PhD, Master and Bachelor students and she is involved in studies of different aspects of iron metabolism. She has been invited to national and international conferences. She is author of about 53 publications in peer review scientific journals and Co-Author of one European patent $\left(\mathrm{N}^{\circ} \mathrm{EP} 10192809\right)$ for the use of heparin derivatives to control hepcidin.

Raffaella Gozzelino is an Assistant Professor at NOVA Medical School, NOVA University of Lisbon and an Invited Professor to a number of national and international PhD and Master Programs. She is also an Invited Lecturer at the ENAGO Academy of Science, where she also provides consulting services. She is a Group Leader at the Chronic Diseases Research Center (CEDOC) in Lisbon, where she directs the Inflammation and Neurodegeneration Laboratory and a team of approximately 10 researchers, between PhD, Master and Bachelor students. She is also a member of the Scientific Advisory Board at Thelial Technologies S.A., and one of the Board of Directors of The International BioIron Society. 



\title{
Editorial
}

\section{Iron as Therapeutic Target in Human Diseases}

\author{
Raffaella Gozzelino ${ }^{1}$, Maura Poli ${ }^{2}$ and Paolo Arosio ${ }^{2, *}$ \\ 1 Chronic Diseases Research Center (CEDOC)/NOVA Medical School, Universidade NOVA de Lisboa, \\ 1180-052 Lisbon, Portugal; raffaellagozzelino@gmail.com \\ 2 University of Brescia, DMMT, Viale Europa 11, 25123 Brescia, Italy; maura.poli@unibs.it \\ * Correspondence: paolo.arosio@unibs.it
}

Received: 27 November 2019; Accepted: 28 November 2019; Published: 5 December 2019

Iron is essential for almost all organisms, being involved in oxygen transport, DNA synthesis, and respiration; however, it is also potentially toxic via the formation of free radicals. Thus, iron homeostasis is tightly controlled by mechanisms that have been partially elucidated. Numerous disorders have recently been linked to deregulation of iron homeostasis, leading iron metabolism to become an interesting therapeutic target for novel pharmacological treatments against these diseases. The targeting includes the hepcidin/ferroportin axis for the regulation of systemic iron homeostasis, the cytosolic machinery for the regulation of intracellular iron status and oxidative damage, proteins of iron metabolism such as ferritin and transferrin receptor, and the recently described form of programmed cell death named ferroptosis. Because of its tight link with anemia, iron metabolism has been mainly of interest in terms of the hematological pathologies, but, recently, clinicians have become aware of the importance of iron in non-hematological disorders, suggesting that iron could be a therapeutic target for various conditions. To verify whether this is the case and to try to gather together all the novel information in this developing field, we launched this issue in Pharmaceuticals, and we were glad to find that this attracted the attention of the 49 research groups that proposed papers. This result confirms the increasing importance of iron in various disorders.

From the articles received, it became clear that one of the fields that started to be highly investigated is the role of iron in the brain. Indeed, the recent evidence that excess iron occurs in the brains of subjects with neurodegenerative disorders suggested the therapeutic potential of iron targeting in this organ. In this issue, Crichton et al. [1] reviewed studies on iron chelators, which have been successful at removing excess iron from liver, spleen, heart, and pituitary gland in various iron-loading disorders. Oral deferiprone has been used to chelate brain iron overload in Parkinson's disease and Friederich's ataxia with encouraging results, and new and safer chelators are under study. The authors also suggested that the presence of inflammation might reduce the efficacy of these chelators, which is in agreement with other literature findings. Similarly, Nunez et al. [2] focused on the properties required for an optimal iron chelator to treat neurodegenerative diseases involving brain iron accumulation, a group of disorders that in addition to the already cited Parkinson's disease and Friedreich's ataxia, also includes pantothenate-kinase-associated neurodegeneration, Huntington's, and Alzheimer's disease (AD). While the ideal chelator should target the mitochondria, quench free radicals, have micromolar-iron-binding affinity, and be selective for neuronal cells, the current situation on available chelators was discussed by the authors in their manuscript. Studies on specific brain pathologies have also been included in this issue, as the work by Alsina et al. [3], which focused on the role of iron in Friedreich's ataxia, a genetic disorder caused by trinucleotide GAA expansions in the first intron of the frataxin gene that decrease its expression. In addition to discuss the proposed functions of this mitochondrial protein and how it is related to iron homeostasis, they also reported the beneficial effects of iron chelators as therapeutic agents for this disease. The role of iron in AD was reviewed by Masaldan et al. [4], who pointed out iron dyshomeostasis as a critical feature of this disease, given the participation of iron in the generation of free radicals and in the interaction with proteins known 
to cause of $\mathrm{AD}$ pathology. The hypothesis described by the authors is that iron accumulation might derive from an age-associated increase of senescent cells that drive inflammation, which predisposes to oxidative stress, cellular dysfunction and iron-dependent death. Elevated brain iron is associated with AD progression and cognitive decline, and it may be reduced pharmacologically. Nnah et al. [5] considered that microglia activation and secretion of proinflammatory cytokines are hallmarks of neurodegenerative disorders, including AD. However, it is still unclear whether increased brain iron augments the inflammatory responses of microglia and how these cells accumulate, store, and utilize intracellular iron to carry out their functions under normal and pathological conditions. This review describes known and emerging mechanisms involved in microglial cell iron transport and metabolism, as well as the inflammatory responses affecting the brain, in the context of AD. Neurodegeneration with brain iron accumulation (NBIA) was reviewed by Levi and Tiranti [6]. NBIA is a group of rare monogenetic diseases that are heterogeneous in onset and symptoms but characterized by specific brain iron deposition in the region of the basal ganglia. Fifteen NBIA genes have been described so far, but only two of these code for iron proteins. The review reports the recent data on new models of these disorders aimed at understanding the pathogenesis of iron deposition. The impairment of mitochondrial function, which also contributes to cause neurodegeneration, is discussed in the review published by Fiorito et al. [7], who proposed a new perspective regarding the impact of heme. Heme is synthesized in the mitochondria and its metabolism plays a central role in organelle function. Since some evidence indicates that alterations of heme metabolism are associated with neurodegenerative disorders, these studies may open new therapeutic avenues in the struggle against these disorders.

The importance of iron in the development of human brain was also described in this issue, in which Markova et al. [8] reviewed the recent findings on the effects of gestational and lactational iron deficiency on the correct formation of the central nervous system. In early embryonic life, iron is needed for the developing brain, which is characterized by a widespread expression of transferrin receptors. If iron deficiency occurs at this stage, the brain may not fully develop, weight less and present an impaired myelin formation, which result in chronic and irreversible damage affecting individual cognitive, memory, and motor skills. Studies on humans and animal models suggest the possibility to reverse these effects with iron substitution therapy. Rockfield et al. [9] argued that the maintenance of iron and lipid homeostasis is critical also to the brain. Since this is the fattiest organ in the body, many evidences point out the existence of a cross-talk between these pathways. In this article, the authors discuss human diseases involving iron and lipid alterations, with special emphasis on neurodegenerative disorders, and the therapeutic potential of iron reduction techniques for these patients. The mechanisms of iron action in the brain was also described by Ferreira et al. [10], who took a broader approach exploring in particular the cognitive and behavioral implications of disruption of iron homeostasis on the onset and progression of psychosocial disorders. In this review, the authors also discuss the links between iron and the biological, psychological, and social dimensions that contribute to the development of a diverse set of neuro-pathologies. Potential avenues of research are also outlined. Genetic diseases with brain iron accumulation were reported to also cause retinal degeneration, as discussed by Shu and Dunaief [11]. Iron dysregulation in the eye might also occur upon dietary or parenteral supplementation, which has been reported to elevate iron levels in the retinal pigment epithelium (RPE) and to promote retinal degeneration. While studies in mice and humans suggest that iron toxicity might contribute to the pathogenesis of age-related macular degeneration, iron chelators were found capable to protect photoreceptors and RPE in mouse models. So, their therapeutic potential is currently under investigation.

Although hereditary hemochromatosis $(\mathrm{HH})$ is the first iron overload disorder to be studied, there are still many aspects to be investigated, some of which considered in this issue. Loreal et al. [12] reviewed works on $\mathrm{HH}$, which are mainly related to the $\mathrm{C} 282 \mathrm{Y}$ mutation in the HFE gene. This mutation causes hepcidin deficiency and iron accumulation in liver, pancreas, heart, and bone. Treatment mainly consists of venesection for the removal of iron contained in red blood cells, which seems to be effective. Nevertheless, new approaches targeting hepcidin levels could be useful to better control 
iron parameters and especially some symptoms of this disease, like arthritis. The work by Porto et al. [13] described a 20 year follow up of three siblings, diagnosed with $\mathrm{HH}$ in their childhood, who were homozygous for the C282Y mutation of HFE. These patients were assessed yearly for the determination of iron indices and lymphocyte counts, and the analyses revealed an important transition of this disease from childhood to adult life. Emphasis on the tight link between iron status and the activation of immune cells was given by the authors. HH with dominant transmission, which is also known as ferroportin disease, was reviewed by Vlasveld et al. [14]. The authors reported phenotypes ranging from a loss of ferroportin function (LOF) to a gain of function (GOF) of this gene, with hepcidin resistance. The analyses of 359 patients with 60 ferroportin variants allowed the authors to conclude that the phenotypes of hepcidin-resistant GOF variants were indistinguishable from the other types of $\mathrm{HH}$. While these can be categorized as ferroportin-associated $\mathrm{HH}$, ferroportin disease may be confined to the LOF variants. Although many proteins are involved in the regulation of iron homeostasis, Katsarou and Pantoupolos [15] considered hepcidin as an interesting therapeutic target. Genetic defects of hepcidin expression lead to "hepcidinopathies", a series of pathologies ranging from $\mathrm{HH}$ to iron-refractory iron deficiency anemia. Indeed, dysregulation of hepcidin is a cofactor in iron-loading anemias with ineffective erythropoiesis and anemia of inflammation. Hence, this review summarized the state of the art on hepcidin agonists and antagonists, as well as inducers and inhibitors of hepcidin expression. The interaction between hepcidin and ferroportin in the regulation of systemic iron homeostasis was also the focus of the study published by Hawula et al. [16]. Indeed, this axis can be affected by various stimuli and its deregulation can lead to a variety of disorders, which include $\mathrm{HH}$. The treatment options for regulating iron levels in patients are limited, and efforts are being made to uncover approaches restoring hepcidin and ferroportin expression. In this review, the authors examined the current status of hepcidin and ferroportin agonists and antagonists, as well as inducers and inhibitors of these proteins and their regulatory pathways. Investigating the types of cellular events occurring in the liver during iron overload conditions, Tangudu et al. [17] examined the hepatic signaling pathways underlying acquired and genetic iron overload disorders. The authors found an association between these pathologies and the decline in the activation of the mitogen-activated protein kinase (MAPK)/extracellular signal-regulated kinase (Erk) kinase (Mek1/2) pathway, which selectively affects the phosphorylation of Erk1/2. The uncoupling of this signaling from iron-Bmp-Smad-mediated hepcidin induction indicates that it may contribute to a number of liver pathologies. A new approach to study the hepcidin-binding proteins was proposed by Diepeveen et al. [18], who observed that this method, in the serum, might influence hormone function and quantification. The authors used peritoneal dialysis to measure freely circulating solutes in blood and peritoneal fluid of patients undergoing a peritoneal equilibration test. The protein-bound fraction of hepcidin was calculated to be $40 \%( \pm 23 \%)$, which led the authors to conclude that a substantial proportion of hepcidin is freely circulating.

Other genetic disorders associated with dysregulated iron metabolism are those characterized by new mutations in the ferritin L gene, as described by Cadenas et al. [19]. These pathologies cause dominant L-ferritin deficiencies and hereditary hyperferritinemia cataract syndrome (HHCS). An accurate diagnosis is needed for the appropriate treatment of the multiple phenotypes caused by FTL gene mutations, and a novel diagnostic algorithm was proposed in this study for that purpose. As discussed by Chiou and Connor [20], ferritin is the main iron cellular storage molecule in the body, able to store a large amount of iron within its mineral core. Recently, ferritin was shown to have a range of abilities that go well beyond iron storage. This review aims at discussing novel functions and biomedical uses of ferritin in the processes of iron delivery, delivery of biologicals such as chemotherapies and contrast agents, and the utility of ferritin as a biomarker in a number of neurological diseases. The autophagic degradation of ferritin (known as "ferritinophagy") is necessary to maintain intracellular iron homeostasis and is mediated by the nuclear receptor coactivator 4 (NCOA4), as described by Santana-Codina and Mancias [21]. In this review, the authors related the biochemical regulation of NCOA4, its contribution to physiological processes, and its role in 
disease. Its potential to activate or inhibit ferritinophagy and ferroptosis for therapeutic purposes was also addressed. In line, Bou-Abdallah et al. [22] reviewed our current understanding of iron mobilization from ferritin by various reducing agents. The authors reported recent results supporting a mechanism that involves a one-electron transfer through the protein shell to the iron mineral core. The physiological significance of the iron-reductive mobilization from ferritin by the non-enzymatic FMN/NAD(P)H system is also discussed. Sha et al. [23] studied plant ferritin, a novel form of iron supplement, the absorption of which can be affected by phenolic acids of the plant. The authors found that cinnamic acid derivatives induce the release of iron from soybean ferritin, thus having a negative effect on iron stability. The authors also pointed out that the iron chelating activity and reducibility of these compounds may affect the iron availability of soybeans. Regulation of iron homeostasis is also provided by the role exerted by the transferrin receptor 2 (Tfr2), as described by Roetto et al. [24]. Tfr2 is one of the hepcidin regulators and mutations of this gene cause type $3 \mathrm{HH}$. While this review summarized the data on Tfr2 extrahepatic role, including the importance of the two main isoforms, $\operatorname{Tfr} 2 \alpha$ and Tfr $2 \beta$, the use of Tfr2 as therapeutic target for hepcidin control is also discussed. Finally, the systemic iron regulation, achieved by controlling heme metabolism, was described by Montecinos et al. [25], who reviewed the present knowledge on the heme-binding protein hemopexin (HPX) and provided information on its biochemistry. HPX prevents the toxicity induced by hemoglobin $(\mathrm{Hb})$-derived heme, which occurs in hemolytic conditions and can be triggered by the activation of the immune system. The review highlights some newly identified actions of heme and HPX, engaged especially when normal processes fail to maintain heme and iron homeostasis. The authors also presented data showing that the cytokine IL-6 cross talks with activation of the c-Jun N-terminal kinase pathway in response to heme-hemopexin in models of hepatocytes.

Recent studies have shown the importance of iron in kidney diseases. This particular topic was discussed by Vera-Aviles et al. [26], who reviewed evidence for iron-induced toxicity in chronic kidney disease (CKD) and the mechanisms by which histidine exerts cytoprotective functions. In fact, CKD is often associated with iron and histidine deficiency. This amino acid, which is essential for erythropoiesis and to enhance iron dietary absorption, was shown to have antioxidant properties capable to improve the oxidative stress in CKD. Balla et al. [27] discussed some of the most important findings relating to the role of iron and ferritin heavy chain in the context of kidney-related diseases and, in particular, in vascular calcification. The authors provided evidence that the ferroxidase activity of ferritin prevents this frequent complication of CKD. Nuhu and Bhandari [28] reviewed a specific cardio-renal morbidity in CKD, providing an understanding of the pathophysiology and impact of uremic toxins, inflammation and anemia, on oxidative stress. Anemia in CKD increases the risk of left ventricular hypertrophy and oxidative stress, thereby magnifying the deleterious consequences of uremic cardiomyopathy. This enhances its progression and increases the risk of sudden cardiac death.

Iron toxicity also affect the lungs. The continuous exposure of this organ to oxygen turns it highly sensitive to oxidative damage, which is enhanced in the presence of excess iron. This was discussed by Zhang et al. [29], who provided an overview of systemic and local lung iron regulation. The authors described the role of this metal in the development of lung infections, airway disease, and lung injury, offering important foundations for the development of therapeutic applications. Also Neves et al. [30] reviewed the current knowledge on the regulation of pulmonary iron homeostasis. In addition to report the functional importance of iron and its link in the development of lung disorders, the authors provide a better understanding of the association between pulmonary iron deregulations and the frequently correlated chronic obstructive pulmonary disease and lung cancer. Possible improvement of these pathologies with iron-related therapeutic strategies has also been described.

The interplay between iron and inflammation, elicited in the course of the infection, has long been observed. Petzer et al. [31] reviewed the association between anemia and chronic inflammatory diseases, addressing how iron levels could be improved with the resolution of the disease, supplementation and redistribution strategies. Moreover, investigations referring to the key role of hepcidin in these forms of anemia encouraged the development of novel therapeutic approaches, which were discussed in 
this review along with the current guidelines of iron replacement therapies. In chronic inflammatory diseases, these refer to oral versus parenteral iron supplementation. The authors also reported the emerging potential of hepcidin-antagonizing drugs, which are currently under preclinical and clinical investigations. Hepcidin regulation has been also reported as beneficial in patients with rheumatoid arthritis (RA), who are often treated with an anti-IL-6-receptor (anti-IL-6R) monoclonal antibody (tocilizumab) that inevitably influences iron metabolism. Ribeiro et al. [32] studied a cohort of patients under this treatment, identifying the association between higher serum iron and transferrin saturation, induced by the drug, and the risk of infection. Their study strongly indicates the need to monitor iron indices in RA patients on anti-IL-6R therapy to prevent infections. The most recent literature on infection and iron metabolism has been reviewed by Gomes et al. [33]. Special emphasis was given to iron changes induced by pathogens invasion, which culminate with the development of anemia, and to potential therapeutic approaches that, modulating iron metabolism, correct iron levels and control the infection. One of the most studied infectious diseases involving disruption of iron homeostasis is malaria. The increase in hepcidin during the development of this diseases has been reported by Muriuki and Atkinson [34], along with the higher levels of tumor necrosis factor- $\alpha$, as the cause that leads to poor iron absorption and recycling. While this may be an important driving factor of iron deficiency, its prevalence in children increases over a malaria season and decreases when it is interrupted, as described by the authors. Once the link between malaria and iron deficiency will be formally demonstrated, it would aid readjusting priorities for programs towards prevention and treatment of iron deficiency, which will benefit malaria control. Armitage and Moretti [35] reviewed the demand and supply of iron during early childhood, addressing its importance in aspects that refer to the physiology and development of young children coming from low- and middle-income countries, in particular. Thus, discussing the implications for interventions to improve iron status whilst minimizing infection-related risks is of utmost importance, since strategies should be adapted according to iron deficiency, inflammation status, and infection risk. It is known that macrophages play a central role in regulating iron homeostasis, especially during infections, like but not restricted to malaria. In their manuscript, Recalcati et al. [36] described how macrophages control iron levels and how this determines, in turn, their plasticity. Changes in the expression of genes coding for major proteins of iron metabolism may result in different iron content availabilities for the macrophage itself and other cells present in the microenvironment. This review also discussed the role of macrophages in immunometabolism, which cross-talks with erythropoiesis as reported by Sukhbaatar and Weichhart [37]. Coordination between spleen, liver, and bone marrow is essential for macrophages ensure proper iron recycling and erythroblast differentiation. This article also focuses on the role of distinct macrophage populations to maintain iron metabolism, describing the cellular and systemic mechanisms involved in iron-regulating processes. Macrophages are also the main target of Mycobacteria Tuberculosis, a pathogen that requires iron to proliferate, as pointed out by Agoro and Mura [38], who reasserted that Mycobacteria-infected hosts use systemic iron restriction and cellular iron distribution as defense mechanism against infection. The authors reviewed the importance of iron availability to elicit an immune response against Mycobacteria, which then dictates host susceptibility. Hence, the need for future therapeutic directions capable to prevent this disease were also pointed out. At this regards, specific chelators against infections caused by Mycobacterium avium have been reviewed by Rangel et al. [39], who described in particular a selected class of the 3-hydroxy-4-pyridinone ligand, which could be functionalized with the addition of fluorophores. This was shown to improve antimycobacterial activity and the affinity of chelators to biological membranes, thus indicating that "to label means to change". The authors further discuss the need of combined therapeutic approaches and the use of rhodamine B conjugates to target bacterial resistance and biofilm production.

More evidences point at iron deficiency as critically involved in the pathogenesis of different conditions. An example is provided by Lakhal-Littelton [40], who described the prevalence of iron deficiency in patients with cardiovascular disease and associated it with worse outcomes. Although, the mechanisms by which iron deficiency affects cardiovascular function are still unclear, this review 
discusses the benefits of therapeutic strategies aimed at restoring cellular iron homeostasis rather than approaches based on iron supplementation. These have been described in particular on two diseases: chronic heart failure and pulmonary arterial hypertension. Another compartment also affected by iron deficiency is the bone. As explained by Balogh et al. [41] bone homeostasis is based on the regulation between osteoclasts' function, which resorb the bone, and osteoblasts', which produce new bone. Both iron deficiency and iron overload disrupt this delicate balance, influencing skeletal health and emphasizing the need to develop novel therapeutic approaches to inhibit the pathological effects of altered iron levels in this tissue.

An important aspect of restoring iron homeostasis is how to supplement this metal in case of deficiency, since possible side effects of oxidative damage and changes in intestinal microbiota have been pointed out. The effects of oral treatments on iron deficiency were reviewed by Ginanjar et al. [42], who also considered the potential toxicity of plasma non-transferrin-bound iron (NTBI). The authors found that FeSO4 is more absorbed than NaFeEDTA, although causes a remarkable increase of NTBI. In a double-blind, randomized trial, they showed that a low dose of NaFeEDTA (6.5 mg), given with a meal, was highly effective for the treatment of iron deficiency, maintaining normal levels of NTBI. Bhandari et al. [43] discussed the inefficacy of oral iron replacement therapies in the treatment of some patients with iron deficiency. In these cases, replacement with intravenous (IV) iron therapies, now in their third generation, could increase iron levels without causing toxic effects. This review described the properties of different IV irons, and how differences in formulations might impact the current and future clinical practice. Novel innovative oral iron formulations were described by Gomez-Ramirez et al. [44]. Sucrosomial@iron (SI), in which ferric pyrophosphate is protected by a phospholipid bilayer plus a sucrester matrix (sucrosome) and absorbed via para-cellular and trans-cellular routes (M cells), was shown to increase iron bioavailability while having excellent gastrointestinal tolerance. An important concern, though, needs to be raised from a human nutritional point of view. The genetic selection for large litter sizes and high birth weights makes piglets severely iron-deficient, as described by Szudzik et al. [45]. In need for iron supplementation, these animals receive intramuscular injection of a large amount of iron dextran, which if from one side corrects the iron deficiency of the animal, on the other it may generate toxic effects. Whether this might also affect, in long term, the human population eating pork meat is not known. Therefore, new iron supplements need to be considered, turning iron-deficient piglets as a convenient animal model for pre-clinical studies. The influence of food compounds on iron absorption was also the focus of Lesjak and Srai's review [46], which discussed how iron homeostasis is affected by several dietary factors, such as flavonoids. Their ability to modulate the expression and activity of proteins involved in the systemic regulation of iron metabolism and uptake turn flavonoids clinically relevant for the potential treatment of both anemia and iron overload diseases. The influence of dietary iron absorption in the gut was discussed by Yilmaz and Li [47], who described the dynamic modulation of intestinal microbiota induced by different iron levels. The authors reviewed the current understanding of the effects of luminal iron on host-microbe interactions in human health and disease. The side effects induced by the excessive amount of unabsorbed iron at the interactive host-microbe interface of the human gastrointestinal tract was particularly described.

The involvement of iron in the development of tumors has long been studied, and Busti et al. [48] consider that anemia in cancer is multifactorial, and iron deficiency (ID) is a major contributor. Since the treatment of functional iron deficiency is complex and still controversial, this work discusses the possible approaches for the management of ID in cancer patients, in different clinical settings. Current guidelines and recommendations were also reported to emphasize the need for further research in the field. In agreement, one article in this issue studied the activity of the anticancer drug didox, which is thought to act by inhibiting ribonucleotide reductase, the rate-limiting enzyme for dNTP synthesis that is highly expressed in aggressive tumor cells. Asperti et al. [49] showed that didox cell killing was suppressed by iron supplementation, and capable to reduce iron availability by acting as 
an iron chelator. The authors indicated that this property might contribute to its antitumor activity by sequestering iron to enzymes, as the ribonucleotide reductase.

Altogether, this issue, which was published in Pharmaceuticals, provides an interesting overview on the complexity of the role of iron in health and disease conditions, emphasizing the need to control iron homeostasis. This is achieved by supplying iron in sufficient amount, when deficient, and removing it, when in excess. Regulating iron distribution among various tissues and compartment is also essential to prevent dysregulated levels of this metal and the occurrence of disorders like $\mathrm{HH}$, neurodegenerative and cardiovascular diseases, cancer, and infections.

Author Contributions: The three authors, R.G., M.P. and P.A. contributed to the design and writing of the manuscript.

Funding: This research received no external funding.

Conflicts of Interest: The authors declare no conflict of interests.

\section{References}

1. Crichton, R.R.; Ward, R.J.; Hider, R.C. The Efficacy of Iron Chelators for Removing Iron from Specific Brain Regions and the Pituitary-Ironing out the Brain. Pharmaceuticals 2019, 12, 138. [CrossRef] [PubMed]

2. Nuñez, M.T.; Chana-Cuevas, P. New Perspectives in Iron Chelation Therapy for the Treatment of Neurodegenerative Diseases. Pharmaceuticals 2018, 11, 109. [CrossRef] [PubMed]

3. Alsina, D.; Purroy, R.; Ros, J.; Tamarit, J. Iron in Friedreich Ataxia: A Central Role in the Pathophysiology or an Epiphenomenon? Pharmaceuticals 2018, 11, 89. [CrossRef] [PubMed]

4. Masaldan, S.; Belaidi, A.A.; Ayton, S.; Bush, A.I. Cellular Senescence and Iron Dyshomeostasis in Alzheimer's Disease. Pharmaceuticals 2019, 12, 93. [CrossRef] [PubMed]

5. Nnah, I.C.; Wessling-Resnick, M. Brain Iron Homeostasis: A Focus on Microglial Iron. Pharmaceuticals 2018, 11, 129. [CrossRef]

6. Levi, S.; Tiranti, V. Neurodegeneration with Brain Iron Accumulation Disorders: Valuable Models Aimed at Understanding the Pathogenesis of Iron Deposition. Pharmaceuticals 2019, 12, 27. [CrossRef]

7. Fiorito, V.; Chiabrando, D.; Tolosano, E. Mitochondrial Targeting in Neurodegeneration: A Heme Perspective. Pharmaceuticals 2018, 11, 87. [CrossRef]

8. Markova, V.; Holm, C.; Pinborg, A.B.; Thomsen, L.L.; Moos, T. Impairment of the Developing Human Brain in Iron Deficiency: Correlations to Findings in Experimental Animals and Prospects for Early Intervention Therapy. Pharmaceuticals 2019, 12, 120. [CrossRef]

9. Rockfield, S.; Chhabra, R.; Robertson, M.; Rehman, N.; Bisht, R.; Nanjundan, M. Links Between Iron and Lipids: Implications in Some Major Human Diseases. Pharmaceuticals 2018, 11, 113. [CrossRef]

10. Ferreira, A.; Neves, P.; Gozzelino, R. Multilevel Impacts of Iron in the Brain: The Cross Talk between Neurophysiological Mechanisms, Cognition, and Social Behavior. Pharmaceuticals 2019, 12, 126. [CrossRef]

11. Shu, W.; Dunaief, J.L. Potential Treatment of Retinal Diseases with Iron Chelators. Pharmaceuticals 2018, 11, 112. [CrossRef] [PubMed]

12. Loréal, O.; Cavey, T.; Robin, F.; Kenawi, M.; Guggenbuhl, P.; Brissot, P. Iron as a Therapeutic Target in. Pharmaceuticals 2018, 11, 131. [CrossRef] [PubMed]

13. Porto, G.; Cruz, E.; Teles, M.J.; de Sousa, M. HFE Related Hemochromatosis: Uncovering the Inextricable Link between Iron Homeostasis and the Immunological System. Pharmaceuticals 2019, 12, 122. [CrossRef] [PubMed]

14. Vlasveld, L.T.; Janssen, R.; Bardou-Jacquet, E.; Venselaar, H.; Hamdi-Roze, H.; Drakesmith, H.; Swinkels, D.W. Twenty Years of Ferroportin Disease: A Review or An Update of Published Clinical, Biochemical, Molecular, and Functional Features. Pharmaceuticals 2019, 12, 132. [CrossRef] [PubMed]

15. Katsarou, A.; Pantopoulos, K. Hepcidin Therapeutics. Pharmaceuticals 2018, 11, 127. [CrossRef]

16. Hawula, Z.J.; Wallace, D.F.; Subramaniam, V.N.; Rishi, G. Therapeutic Advances in Regulating the Hepcidin/Ferroportin Axis. Pharmaceuticals 2019, 12, 170. [CrossRef]

17. Tangudu, N.K.; Buth, N.; Strnad, P.; Cirstea, I.C.; Spasić, M.V. Deregulation of Hepatic Mek1/2-Erk1/2 Signaling Module in Iron Overload Conditions. Pharmaceuticals 2019, 12, 70. [CrossRef] 
18. Diepeveen, L.E.; Laarakkers, C.M.; Peters, H.P.E.; van Herwaarden, A.E.; Groenewoud, H.; IntHout, J.; Wetzels, J.F.; van Swelm, R.P.L.; Swinkels, D.W. Unraveling Hepcidin Plasma Protein Binding: Evidence from Peritoneal Equilibration Testing. Pharmaceuticals 2019, 12, 123. [CrossRef]

19. Cadenas, B.; Fita-Torró, J.; Bermúdez-Cortés, M.; Hernandez-Rodriguez, I.; Fuster, J.L.; Llinares, M.E.; Galera, A.M.; Romero, J.L.; Pérez-Montero, S.; Tornador, C.; et al. L-Ferritin: One Gene, Five Diseases; from Hereditary Hyperferritinemia to Hypoferritinemia-Report of New Cases. Pharmaceuticals 2019, 12, 17. [CrossRef]

20. Chiou, B.; Connor, J.R. Emerging and Dynamic Biomedical Uses of Ferritin. Pharmaceuticals 2018, 11, 124. [CrossRef]

21. Santana-Codina, N.; Mancias, J.D. The Role of NCOA4-Mediated Ferritinophagy in Health and Disease. Pharmaceuticals 2018, 11, 114. [CrossRef] [PubMed]

22. Bou-Abdallah, F.; Paliakkara, J.J.; Melman, G.; Melman, A. Reductive Mobilization of Iron from Intact Ferritin: Mechanisms and Physiological Implication. Pharmaceuticals 2018, 11, 120. [CrossRef] [PubMed]

23. Sha, X.; Chen, H.; Zhang, J.; Zhao, G. Iron Release from Soybean Seed Ferritin Induced by Cinnamic Acid Derivatives. Pharmaceuticals 2018, 11, 39. [CrossRef] [PubMed]

24. Roetto, A.; Mezzanotte, M.; Pellegrino, R.M. The Functional Versatility of Transferrin Receptor 2 and Its Therapeutic Value. Pharmaceuticals 2018, 11, 115. [CrossRef] [PubMed]

25. Montecinos, L.; Eskew, J.D.; Smith, A. What Is Next in This "Age" of Heme-Driven Pathology and Protection by Hemopexin? An Update and Links with Iron. Pharmaceuticals 2019, 12, 144. [CrossRef]

26. Vera-Aviles, M.; Vantana, E.; Kardinasari, E.; Koh, N.L.; Latunde-Dada, G.O. Protective Role of Histidine Supplementation Against Oxidative Stress Damage in the Management of Anemia of Chronic Kidney Disease. Pharmaceuticals 2018, 11, 111. [CrossRef]

27. Balla, J.; Balla, G.; Zarjou, A. Ferritin in Kidney and Vascular Related Diseases: Novel Roles for an Old Player. Pharmaceuticals 2019, 12, 96. [CrossRef]

28. Nuhu, F.; Bhandari, S. Oxidative Stress and Cardiovascular Complications in Chronic Kidney Disease, the Impact of Anaemia. Pharmaceuticals 2018, 11, 103. [CrossRef]

29. Zhang, V.; Nemeth, E.; Kim, A. Iron in Lung Pathology. Pharmaceuticals 2019, 12, 30. [CrossRef]

30. Neves, J.; Haider, T.; Gassmann, M.; Muckenthaler, M.U. Iron Homeostasis in the Lungs-A Balance between Health and Disease. Pharmaceuticals 2019, 12, 5. [CrossRef]

31. Petzer, V.; Theurl, I.; Weiss, G. Established and Emerging Concepts to Treat Imbalances of Iron Homeostasis in Inflammatory Diseases. Pharmaceuticals 2018, 11, 135. [CrossRef] [PubMed]

32. Ribeiro, R.; Batista, F.; Seguro Paula, F.; Delgado Alves, J. Changes in Iron Metabolism Induced by Anti-Interleukin-6 Receptor Monoclonal Antibody are Associated with an Increased Risk of Infection. Pharmaceuticals 2019, 12, 100. [CrossRef] [PubMed]

33. Gomes, A.C.; Moreira, A.C.; Mesquita, G.; Gomes, M.S. Modulation of Iron Metabolism in Response to Infection: Twists for All Tastes. Pharmaceuticals 2018, 11, 84. [CrossRef] [PubMed]

34. Muriuki, J.M.; Atkinson, S.H. How Eliminating Malaria May Also Prevent Iron Deficiency in African Children. Pharmaceuticals 2018, 11, 96. [CrossRef]

35. Armitage, A.E.; Moretti, D. The Importance of Iron Status for Young Children in Low- and Middle-Income Countries: A Narrative Review. Pharmaceuticals 2019, 12, 59. [CrossRef]

36. Recalcati, S.; Gammella, E.; Cairo, G. Ironing out Macrophage Immunometabolism. Pharmaceuticals 2019, 12, 94. [CrossRef]

37. Sukhbaatar, N.; Weichhart, T. Iron Regulation: Macrophages in Control. Pharmaceuticals 2018, $11,137$. [CrossRef]

38. Agoro, R.; Mura, C. Iron Supplementation Therapy, A Friend and Foe of Mycobacterial Infections? Pharmaceuticals 2019, 12, 75. [CrossRef]

39. Rangel, M.; Moniz, T.; Silva, A.M.N.; Leite, A. Tuning the Anti(myco)bacterial Activity of 3-Hydroxy-4-pyridinone Chelators through Fluorophores. Pharmaceuticals 2018, 11, 110. [CrossRef]

40. Lakhal-Littleton, S. Iron Deficiency as a Therapeutic Target in Cardiovascular Disease. Pharmaceuticals 2019, 12, 125. [CrossRef]

41. Balogh, E.; Paragh, G.; Jeney, V. Influence of Iron on Bone Homeostasis. Pharmaceuticals 2018, 11, 107. [CrossRef] [PubMed] 
42. Ginanjar, E.; Indrawati, L.; Setianingsih, I.; Atmakusumah, D.; Harahap, A.; Timan, I.S.; Marx, J.J.M. Iron Absorption in Iron-Deficient Women, Who Received $65 \mathrm{mg}$ Fe with an Indonesian Breakfast, Is Much Better from $\mathrm{NaFe}(\mathrm{III}) \mathrm{EDTA}$ than from $\mathrm{Fe}(\mathrm{II}) \mathrm{SO}_{4}$, with an Acceptable Increase of Plasma NTBI. A Randomized Clinical Trial. Pharmaceuticals 2018, 11, 85. [CrossRef] [PubMed]

43. Bhandari, S.; Pereira, D.I.A.; Chappell, H.F.; Drakesmith, H. Intravenous Irons: From Basic Science to Clinical Practice. Pharmaceuticals 2018, 11, 82. [CrossRef] [PubMed]

44. Gómez-Ramírez, S.; Brilli, E.; Tarantino, G.; Muñoz, M. Sucrosomial. Sucrosomial@Iron: A New Generation Iron for Improving Oral Supplementation. Pharmaceuticals 2018, 11, 97. [CrossRef]

45. Szudzik, M.; Starzyński, R.R.; Jończy, A.; Mazgaj, R.; Lenartowicz, M.; Lipiński, P. Correction: Mateusz, S., et al. Iron Supplementation in Suckling Piglets: An Ostensibly Easy Therapy of Neonatal Iron Deficiency Anemia. Pharmaceuticals 2018, 11, 128. Pharmaceuticals 2019, 12, 22. [CrossRef]

46. Lesjak, M.; KS Srai, S. Role of Dietary Flavonoids in Iron Homeostasis. Pharmaceuticals 2019, $12,119$. [CrossRef]

47. Yilmaz, B.; Li, H. Gut Microbiota and Iron: The Crucial Actors in Health and Disease. Pharmaceuticals 2018, 11, 98. [CrossRef]

48. Busti, F.; Marchi, G.; Ugolini, S.; Castagna, A.; Girelli, D. Anemia and Iron Deficiency in Cancer Patients: Role of Iron Replacement Therapy. Pharmaceuticals 2018, 11, 94. [CrossRef]

49. Asperti, M.; Cantamessa, L.; Ghidinelli, S.; Gryzik, M.; Denardo, A.; Giacomini, A.; Longhi, G.; Fanzani, A.; Arosio, P.; Poli, M. The Antitumor Didox Acts as an Iron Chelator in Hepatocellular Carcinoma Cells. Pharmaceuticals 2019, 12, 129. [CrossRef]

(C) 2019 by the authors. Licensee MDPI, Basel, Switzerland. This article is an open access article distributed under the terms and conditions of the Creative Commons Attribution (CC BY) license (http://creativecommons.org/licenses/by/4.0/). 


\title{
The Efficacy of Iron Chelators for Removing Iron from Specific Brain Regions and the Pituitary-Ironing out the Brain
}

\author{
Robert R. Crichton ${ }^{1}$, Roberta J. Ward ${ }^{2, *}$ and Robert C. Hider ${ }^{3}$ \\ 1 Faculty of Science, Universite catholique de Louvain, 1348 Louvain-la-Neuve, Belgium; \\ robert.crichton@uclouvain.be \\ 2 Division of Brain Sciences, Imperial College, London W12 ONN, UK \\ 3 Institute of Pharmaceutical Science, King's College London, London SE1 9NH, UK; robert.hider@kcl.ac.uk \\ * Correspondence: Rward2@ic.ac.uk
}

Received: 23 July 2019; Accepted: 11 September 2019; Published: 17 September 2019

\begin{abstract}
Iron chelation therapy, either subcutaneous or orally administered, has been used successfully in various clinical conditions. The removal of excess iron from various tissues, e.g., the liver spleen, heart, and the pituitary, in beta thalassemia patients, has become an essential therapy to prolong life. More recently, the use of deferiprone to chelate iron from various brain regions in Parkinson's Disease and Friederich's Ataxia has yielded encouraging results, although the side effects, in $<2 \%$ of Parkinson's Disease(PD) patients, have limited its long-term use. A new class of hydroxpyridinones has recently been synthesised, which showed no adverse effects in preliminary trials. A vital question remaining is whether inflammation may influence chelation efficacy, with a recent study suggesting that high levels of inflammation may diminish the ability of the chelator to bind the excess iron.
\end{abstract}

Keywords: iron; chelation; neurodegenerative diseases; pituitary; brain

\section{Introduction}

Iron is one of the essential elements in the body, the concentration of which is tightly regulated to prevent toxicity. Iron overload, particularly in the liver and spleen, is known to occur in several conditions, such as hereditary hemochromatosis, African iron overload, sickle cell disease, beta thalassemia, sideroblastic anaemia, enzyme deficiency (pyruvate kinase, glucose-6-phosphate dehydrogenase), and rare disorders of proteins involved in iron transport (atransferrinaemia, aceruloplasminemia). In certain conditions, e.g., sickle cell anaemia, beta thalassemia, and myelodysplasia, regular blood transfusions are an essential part of the therapy, thereby contributing to the increased iron stores, as the body is unable to excrete iron to any great extent. However, little focus has been directed at the brain iron concentrations in these conditions. Furthermore, it is also apparent that aging and neurodegenerative diseases, such as Parkinson's and Alzheimer's Disease, as well as Friederich's Ataxia, are associated with an increasing brain iron accumulation [1]. With the advent of several magnetic resonance imaging (MRI) techniques over the past 10 years it is now possible to measure pituitary and brain iron in specific brain regions and to monitor changes in its concentration after iron chelation therapy. Iron deposits are not assayed directly, but their effects on water protons as they diffuse in the magnetically inhomogeneous environment induced by iron deposition are assessed. The scanner transmits energy into the body as microwaves, followed by a waiting period, after which the energy is recalled, to be received by an antennae or coil. This process is known as relaxation and is characterised by relaxation rates $\mathrm{R} 2$ and $\mathrm{R} 2 *$ (measured in $\mathrm{Hz}$ ), which are mathematically inverse of the characteristic relaxation times $\mathrm{T} 2$ and $\mathrm{T} 2 *$ (measured in $\mathrm{ms}$ ). 


\section{Iron chelation}

The chelation of excessive amounts of iron from the liver and spleen and, more recently, from the pituitary gland and the brain, has been utilised as a therapeutic approach. In what follows, we will outline the development of the most important therapeutic application of iron chelation therapy to date, namely in the treatment of thalassemia [2-5] and neurodegenerative diseases [1].

\section{Iron Chelators in Current Clinical Use}

The hexadentate chelator, deferrioxamine (DFO) (Figure 1), a bacterial hydroxamate siderophore, was introduced in the early 1970s, and initially gave poor results because it was not active by oral administration, and had a short half-life (20-30 min). However, the development of continuous subcutaneous infusion of DFO by a portable pump [6] and the establishment of sensible schedules for the optimal use of the pump [7] meant that by the 1990s markedly prolonged cardiac disease-free survival in patents, who faithfully followed the Propper and Pippard regime, could be demonstrated in three independent studies [8-10]. However, sadly, half of the patients, who could not or would not comply, developed cardiac failure or arrhythmia much more rapidly [11]. What was urgently required was a chelator which could be used more easily, thereby improving compliance, and which was both effective and orally active.

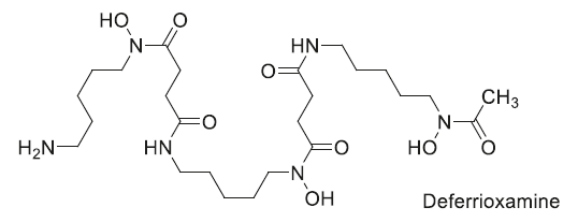

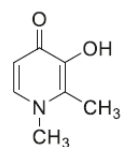

Deferiprone

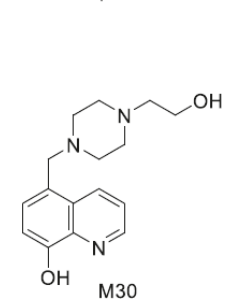

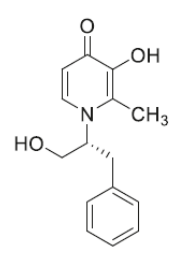

CN128

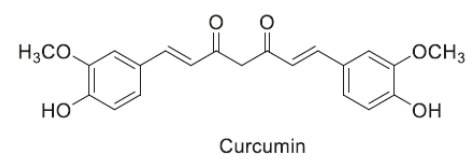

Figure 1. Chemical structures of iron chelators.

Deferiprone (DFP) a small, lipophilic bidentate chelator of the 3-hydroxypyridin-4-one family (Figure 1), was introduced into clinical practice in the 1980s [12]. Although it is orally active, its half-life is $3-4 \mathrm{~h}$, which means that it must be administered three times a day at doses of $75 \mathrm{mg} / \mathrm{kg} /$ day to maintain sufficient negative iron balance equivalent to $50 \mathrm{mg} / \mathrm{kg} /$ day of DFO [13,14]. DFP has good bioavailability, but its clearance is accelerated by rapid biotransformation: approximately $85 \%$ of the drug is metabolised to a nonchelating 3-O-glucuronide conjugate [15]. The most important side effects of deferiprone are agranulocytosis and milder forms of neutropenia, which require appropriate monitoring [16]. However, DFP enters cells and can access intracellular chelateable iron more readily than DFO [17]. DFP possesses cardioprotective effects [18], and a multi-centre prospective comparison 
showed that a combined DFP + DFO regimen was more effective in removing cardiac iron than DFO, and was superior in clearing hepatic iron than either DFO or DFP monotherapy [19].

In the years that followed the introduction of DFP, the search for other orally active chelators intensified [20]. The microbial tridentate chelator, desferrithiocin, discovered in 1980, was shown to be orally active and very effective in mobilising hepatic iron in a rat model with hepatic iron loading induced by a ferrocene derivative [21], and in iron-loaded monkeys [22,23]. However, ferrithiocin itself proved to be toxic in animals [24], and although many desferrithiocin derivatives were tested and found to be more effective than desferrithiocin, toxicity remained associated with this class of chelators [25]. The clinical development of Deferasirox (DFX) (ICL670) represents an investment, the magnitude of which has no precedent in the history of chelator research. In the search for a safe tridentate chelator, a completely new chemical class of iron chelators, the bis-hydroxyphenyltriazoles, was discovered. More than forty derivatives of the triazole series were synthesised at Novartis, and evaluated, together with more than 700 chelators from other chemical classes. The tridentate chelator 4-[(3,5-Bis-(2-hydroxyphenyl)-1,2,4) triazol-1-yl]-benzoic acid (ICL670, Figure 1) emerged as the chelator which best combined high oral potency and tolerability in animals [20]. DFX has a plasma half-life of 12-16 h, which allows it to be taken once per day, effectively eliminating non-transferrin bound iron (NTBI) from the circulation [26]. In clinical studies, DFX has proven to be as effective as DFO at doses of 20-30 mg/kg [27], and in an extensive study involving 1744 patients, it was shown that fixed starting doses of DFX, based on transfusional iron intake, with dose titration guided by serum ferritin trends and safety markers, provide clinically acceptable chelation in patients with transfusional hemosiderosis from various types of anaemia [28]. Side effects are minimal, although the use of DFX is associated with rash formation and renal toxicity [29].

\section{Thalassemia, Sickle-Cell Anaemia, and Haemoglobinopathies}

Thalassemia, sickle-cell disease, and other hereditary disorders of haemoglobin biosynthesis are the most prevalent monogenic diseases worldwide [5]. Thalassemia results from an inherited defect in the rate of synthesis of one of the two polypeptide chains of haemoglobin, resulting in imbalance in the $\alpha, \beta$-globin chain ratio, ineffective erythropoiesis, chronic haemolytic anaemia, and increased intestinal iron absorption. In the 1960s and 1970s, the only effective treatment for thalassemia was blood transfusion. Since humans cannot increase their iron excretion to compensate for iron loading, the transfusional iron overload, aggravated by increased intestinal iron absorption, results in massive and progressive iron overload. Each unit of transfused blood contains approximately $200 \mathrm{mg}$ of iron, and since the mean transfusional loading in thalassemia major is $0.4 \mathrm{mg} / \mathrm{kg} /$ day, it comes as no surprise that most patients faced certain death before the age of 20 years from heart failure. However, the incidence of heart failure was not directly related to the cardiac iron overload, but to the level of iron loading in the liver. The explanation for this lies in the demonstration by Chaim Hershko [30] of the presence in the serum of thalassemic patients of toxic non-transferrin-bound iron (NTBI) which was responsible for the cardiac damage. When the liver iron load attains a critical level, iron is released into the circulation, and once its concentration exceeds the binding capacity of the transferrin pool, NTBI is formed. NTBI is the main source of iron accumulation in iron loading in both thalassemia and hereditary hemochromatosis, notably in the heart, pancreas, and liver [31], as well as in the brain. The influx of NTBI seems to be mediated by the ZIP14 transporter in the liver [32,33], whereas in cardiomyocytes, two calcium channels transport $\mathrm{Fe}^{2+}$ with an affinity similar to that of $\mathrm{Ca}^{2+}[34,35]$, and their expression is insensitive to cardiac iron overload.

\subsection{Thalassemia-Iron Accumulation in the Pituitary}

Clinical hypogonadism is common in thalassemia patients (83\%) with detectable cardiac iron and is independently associated with pituitary iron deposition and gland shrinkage [36]. The pituitary gland maintains its anatomical and functional connections with the brain, yet sits outside the blood-brain barrier. Iron deposition in the anterior pituitary continues to pose a serious problem in homozygous 
beta thalassemia patients, particularly in terms of gonadal function. Magnetic resonance imaging (MRI) measurements are able to estimate the amount of iron in the pituitary, which can then be correlated with gonadal function. The anterior pituitary gland is particularly sensitive to free radicals produced by oxidative stress, such that exposure to these radicals injures the gland. MRI has shown that even a modest increase in iron deposition in the anterior pituitary can lead to dysfunction, such as abnormalities in the hypothalamic-pituitary growth hormone axis and growth hormone neurosecretory dysfunction, and low insulin-like growth-factor-1 levels. Abnormalities in the hypothalamic-pituitary-gonad axis will induce lower follicle stimulating hormone (FSH) and luteinizing hormone (LH) secretion, low LH/FSH response, and low sex steroid secretion from the gonads, i.e., testosterone (reviewed [37]). The spleen plays an important role in destroying abnormal red cells, sequesters $30-40 \%$ of the circulating platelet pool, and plays a role in the regulation of plasma volume. In thalassemic patients, the spleen may become enlarged, which can result in an increased propensity to recurrent infection, such that a splenectomy is required. Following splenectomy, the pituitary iron loading increases [38]. In early studies of four thalassemia patients, (Hb-E thalassemia and thalassemia major), the pituitary iron content, as assessed by MRI, was increased in all four patients compared to controls [39]. A subsequent MRI study of 84 patients with $\beta$-thalassemia established a correlation between pituitary iron overload, (evaluated by T2*) and both hepatic and cardiac iron load. In addition, pituitary MRI values correlated with serum ferritin and patient age, but not with height of the pituitary [38]. A study of 30 children and young adult thalassemic patients (13 females and 17 male patients) confirmed iron accumulation in the liver, myocardium, and the pituitary, a linear regression between pituitary iron and age in patients $>14 \mathrm{y}$, while MRI values between the pituitary and liver, and liver and myocardia, were only moderately correlated, $(\mathrm{r}=0.34$ and 0.42 , respectively). However, no correlation was evident between pituitary and myocardial MRI results, which were of interest, since it might be considered that NTBI would be taken up by both of these organs [40]. It is clear that a therapeutic approach based on the use of iron chelators offers a solution to many of these dilemmas, associated with systemic iron overload, and their development has resulted in innumerable lives being saved, and, just as importantly, has led to an enormous improvement in the quality of life of thalassemia patients all over the world [5]. Investigations have now been extended to monitor whether excessive amounts of iron in specific brain regions and the pituitary can be removed by iron chelators.

\subsection{Iron Chelation from the Pituitary Gland}

Iron chelators, such as deferoxamine, deferiprone, or deferasirox, could be used alone or in combination to induce negative iron balance and reverse hypogonadism and endocrine complications in severely iron-overloaded thalassemic patients. Therefore, it is of interest to ascertain whether iron chelation can reduce iron overload in the pituitary as well as the liver, heart, and spleen. Berkovitch et al. [41] investigated 33 patients $>15$ years old with transfusion-dependent homozygous beta thalassemia, all of whom had received DFO. Anterior pituitary function (gonadotrophin releasing hormone, GnRH, stimulating test) correlated well with the MRI results for iron deposition in the anterior pituitary, although there was no correlation between the MRI measurements, the GnRH stimulation test, and the clinical status of the patients. Interestingly, 28 out of the 33 patients achieved normal puberty. The deficit in endocrine function in thalassemic patients was confirmed in a study of 78 male thalassemic patients ( $4-11$ years) treated with frequent transfusions and long term DFO therapy, who were compared with 30 age- and sex-matched control children. The prevalence of hypogonadotropic hypogonadism in the thalassemic patients was $76.2 \%$, with a significant increase in serum ferritin $(\times 7)$, and significantly reduced the serum level of cortisol, growth hormone, stimulating hormones and testosterone [42].

Using the new oral chelator DFX for a two-year period, Wood et al. [43] investigated the pituitary iron content and volume in 31 chronically-transfused patients (28 thalassemia major and three Blackfan Diamond). MRI measurements were taken at the baseline, one, and two years. Twenty-six patients completed the study, 10 were prepubertal, 12 had achieved normal puberty, and four were hypogonadal 
at base line. Interestingly, the decreased pituitary volume at baseline returned to normal values after two years of DFX therapy, while pituitary iron content as assayed by R2* showed no net change. This latter result was of interest, as it was expected that with increasing age, pituitary iron would increase in parallel (predicted to be a 0.4 increase) [36].

Such studies indicate that iron chelators are able to reduce pituitary iron content as well as improve its function. It is clearly of interest to know whether brain regions are vulnerable to increased iron deposition in $\beta$-thalassemic patients. There have been three main studies which investigated other regions of the brain by quantitative MRI. In the studies of Duprez et al. [44] and Hasiloglu et al. [45], various MRI methodologies were utilised to identify an increase in iron in the choroid plexus of $\beta$-thalassemic patients. Qiu et al. [46] investigated the distribution of iron in different brain regions of 31 thalassemic patients, aged $25.3 \pm 5.9$ years, and 33 age matched healthy volunteers. Of the 31 patients, 27 exhibited abnormal iron deposition in one of the brain regions investigated by quantitative susceptibility, showing significantly lower susceptibility values in the globus pallidus and substantia nigra and significantly higher susceptibility in the red nucleus and choroid plexus. In the control subjects, there was a positive age effect on susceptibility value in the putamen, dentate nucleus, substantia nigra, and red nucleus. However, more information is needed with respect to the liver and heart iron deposition and the extent of chelation in each of the thalassemic patients for complete interpretation of these results. Surprisingly, there have been no studies on iron distribution in specific brain regions of thalassemic patients, before or after iron chelation. Whether continuous iron chelation in these patients will preclude such iron accumulation is unknown, nor whether there is preferential iron accumulation in specific brain regions. Further studies are clearly required.

\section{Parkinson's Disease-Iron Accumulation in the Substantia Nigra}

Parkinson's disease is the second most common form of motor system degeneration, and is characterised by a progressive loss of dopaminergic neurons in the substantia nigra pars compacta in the ventral midbrain. There is an increased accumulation of iron in the substantia nigra (SN) [47], with a smaller accumulation of iron in other brain regions, such as the red nuclei, globus pallidus, and the cortex of Parkinson's Disease (PD) patients. As the severity of the disease increases the total iron content increases in the $\mathrm{SN}$, which correlates with motor disability [48] and microgliosis [49]. Semi-quantitative histochemical studies of the SN show that iron deposits are present within the neurons and glia of the substantia nigra, putamen, and globus pallidus, with an increase in ferritin-loaded microglia cells in the substantia nigra [50]. The increase in iron in the $\mathrm{SN}$ of PD patients is associated with increased ferritin and neuromelanin iron loading [50,51], as well as increased expression of divalent metal transporter 1 , which may contribute to PD pathogenesis via its capacity to transport ferrous iron [52]. Intense microgliosis occurs around extra neuronal neuromelanin (released by dying neurons) in the substantia nigra of patients with Parkinson's disease [53,54], which could be an important factor in inducing iron accumulation within the microglia [49].

Preliminary reports suggested that identification of neuromelanin, NM, (rather than iron) by MRI might be feasible in patients with Parkinson's disease $[55,56]$. Indeed, the loss of neuromelanin in the locus coeruleus and substantia nigra, together with the associated loss in the ability to sequester iron, might be a characteristic sign of Parkinson's disease [56]. Recent studies have been able to discriminate neuromelanin in PD brains. For example, three-dimensional (3D) neuromelanin-sensitive ${ }^{31} \mathrm{MRI}$ [57] showed that signal densities and contrast ratios were significantly lower in the SN of PD patients compared to controls. Another study of 13 late stage PD patients (LSPD) and 12 de novo PD patients ( $2-5$ years duration) showed that the signal was significantly decreased in LSPD compared to de novo $\mathrm{PD}$, while in the lateral $\mathrm{SN}$ region, a decrease in the contrast ratios was detected in all PD groups compared to controls [58]. Interestingly, in this study, the NM signal area was significantly correlated with Hoehn Yahr Stage and Movement Disorder Society Unified Parkinson's Disease Rating Scale (MDS-UPDRS) part II, while a weak correlation was found with MDS-UPDRS part III. Such results 
may indicate that measurement of the neuromelanin content in the brain by MRI techniques could be an important diagnostic approach.

\section{Chelation of Iron in the Brains of Parkinson's Disease Patients}

Chelation of iron from the SN of PD brains was proposed many years ago. In our initial animal studies over 15 years ago $[59,60]$, we showed that iron chelators (DFO and DFP) already in clinical use for the treatment of iron loading systemic diseases were able to cross the blood brain barrier (BBB), reduce the iron content in various brain regions, and induce neuroprotection in an animal model of PD. In 2010, Kwiatkowski et al. [61] reported the beneficial use of DFP in one PD patient. After one year's administration of DFP, at $30 \mathrm{mg} / \mathrm{kg} /$ day, there was an improvement in the UPDRS score and a decrease in iron accumulation in the bilateral dentate nuclei, as well as the SN [61]. It is of interest that the time period to observe a beneficial action was approximately one year. Subsequent clinical trials in 2011 and 2013 confirmed that it was necessary to administer DFP for at least nine months at a comparable dose to observe a beneficial effect, reflected by changes in the UPDRS score. Both studies $[62,63]$ identified the beneficial effects of DFP. In the study of Devos et al. [62], R2* sequences were used to assess iron content in the SN, while UPDRS scores were acquired at various intervals to assess clinical parameters, and serum ferritin was assayed as a marker of iron stores. After six to nine months, decreases in SN iron content were quantitated by MRI, and there were improvements in both motor and UPDRS motor scores. In the second study, of six months duration [63], decreases in SN iron content were assayed by MRI T2* in patients receiving $30 \mathrm{mg} / \mathrm{kg} / \mathrm{day}$, and there were indications of an improvement in UPDRS. Interestingly, PD patients exhibiting high inflammatory markers in the blood, e.g., IL-6, did not respond well to iron chelation, leading to the suggestion that chelatable iron was not freely available for chelation. There was no evidence that the chelation therapy had an adverse effect on haematological parameters. Interestingly, in the study of Bastida et al. [63], the chelation of iron from other brain regions was also assessed. After three months, the caudate nucleus showed decreased iron content, while the dentate nucleus showed an iron decrease at six months. At this time there was also evidence for a decrease in substantia nigra iron content, which took up to nine months in the Davos study. Clearly, this indicates that there is a selective removal of iron from different brain regions. The major disadvantage of the use of DFP was the incidence of neutropenia and agranulocytosis, which occurred in $8 \%$ of the patients. This side effect resolved rapidly with cessation of the oral therapy. Such a side effect required that all PD patients entering the clinical trial undertook a weekly white cell count. These positive results from the clinical trials have confirmed that iron chelation therapy has potential as a therapeutic option for the treatment of PD; if the side effect could be eradicated, it would become a much more universal treatment. In addition, it remains unclear whether the long-term use of such chelators might alter oligodendrocyte function, since they have a large requirement for iron. It is therefore suggested that clinical studies that use iron chelation therapy for diseases associated with iron deposition should monitor white matter (WM) changes. A number of these diseases already report apparent hypomyelination, and further decline of WM integrity will impact the functional outcomes, since myelin integrity impacts movement and cognition. Currently, a multi-centre phase 2 clinical trial involving 300 patients from all over Europe is in place, centered at the University of Lille, France.

Over the past decade, work has been directed towards the design of hydroxypyridinones, which lack an effect on white blood count in rodents and primates. A lead compound, CN128 (Figure 1), has been identified, which possesses all of the therapeutic properties of DFP, including penetration of the blood-brain barrier, but lacks the side effects of induction of neutropenia and agranulocytosis in primates after prolonged exposure (nine months) [64]. CN128 is currently undergoing tests in a range of Parkinson's disease models. 


\section{Alzheimer's Disease}

Alzheimer's disease (AD) is a fatal age-related neurodegenerative disease which results in cognitive decline, memory loss, and psychosis. Clinically, AD is characterised by progressive dementia. Initial symptoms are short-term memory loss, which is followed by extensive neuronal loss in the hippocampus and selected cortical and subcortical area. There is abnormal protein processing, with accumulation of the $\beta$-amyloid peptide, which is deposited extracellularly and manifests itself as neuritic amyloid plaques, and of the hyperphosphorylated tau protein, in the form of neurofibrillary tangles. Both of these abnormal protein aggregates are definitive markers of the disease in post mortem material.

There is considerable evidence that there is defective homeostasis of iron in the AD brain. Increases in the iron content of $\mathrm{AD}$ have been reported for over 50 years. In a recent paper, which made a comprehensive systematic meta-analysis and review of over 2556 publications, 43 eligible studies were identified where the iron content in AD serum, cerebrospinal fluid (CSF), or brain tissue had been studied. In nineteen studies, the iron content in 12 selected brain regions was analyzed by separated meta-analysis, and it was concluded that eight specific brain regions (the temporal, parietal, and frontal lobes) had higher iron concentrations, which correlated with the clinical diagnosis of $\mathrm{AD}$ [65]. A recent laser ablation inductively coupled mass spectroscopy study also identified increases in iron in the frontal cortex [66].

\section{Alzheimer's Disease - Iron Chelation from the Cortex and Hippocampus}

Current therapies for Alzheimer disease (AD), such as the acetylcholinesterase inhibitors and the NMDA receptor inhibitors, may provide moderate symptomatic delay at various stages of the disease, but do not arrest the disease progression or induce meaningful remission. The confirmation of altered iron homeostasis in the brain of AD patients has opened the possibility of using iron chelators as a new therapeutic approach. Various animal models of AD have been utilised to investigate the therapeutic action of iron chelators. For example, the iron chelator (-) epigallocatechin-3-gallate and M-30 (Figure 1) reduced amyloid precursor protein (APP) expression in cultured cells $[67,68]$. Although it is known that there is an increase in iron in various brain regions in AD patients, there has been no clinical evidence which supports the use of chelating agents as an adjunctive treatment for AD. Tea polyphenols and curcumin (Figure 1) have been advocated as metal chelators for the treatment of AD, although the efficacy of such natural products awaits further investigation.

In 1991, McLachlan showed that DFO significantly reduced the behavioral and cognitive decline of AD patients [69]. However, since this ground-breaking study it is only now that further studies are being undertaken to investigate the therapeutic efficacy of iron chelators in AD. Currently, a phase 2 , randomised, placebo-controlled, multi-centre study to investigate the safety and efficacy of DFP has started recruiting. Approximately 171 participants with Prodromal Alzheimer's disease and mild Alzheimer's disease will be recruited for the study. Controlled release DFP will be used in an attempt to prevent the unwanted side effects of neutropenia and agranulocytosis. The aim of this study is to ascertain whether DFP (15 mg/kg BID orally) slows cognitive decline in Alzheimer's patients. MRI will ascertain the iron content of brain regions during the period of the study (Neuroscience Trials Australia-Clinical Trial Deferiprone to Delay orallyDementia).

Other compounds are in development for the treatment of $\mathrm{AD}$, which have multitargeting properties. They include a series of (3-hydroxy-4-pyridinone)-benzofuran hybrids [70] which mimic donepezil, an inhibitor of acetylcholinesterase, and possess additional properties, such as metal chelation, radical scavenging, and the inhibition of amyloid peptide aggregation. In addition, a series of thiosemicarbazones, (pyridoxal 4-N-(1-benzylpiperidin-4-yl) thiosemicarbazone compounds exhibit very low anti-proliferative activity, substantial iron chelation efficacy, inhibition of copper-mediated amyloid- $\beta$ aggregation, inhibition of oxidative stress, moderate acetylcholinesterase inhibitory activity, and autophagic induction [71]. Although such compounds show neuroprotective effects in vitro, 
it remains to be investigated whether they have a beneficial effect in either animal models of AD or AD patients.

\section{Friederich's Ataxia}

Friedreich's ataxia (FRDA) is one of a number of neurological disorders caused by the anomalous expansion of unstable nucleotide repeats in which, unlike Huntington's disease, the nucleotide expansion occurs in the non-coding part of the gene (the introns). FRDA is characterised by a progressive degeneration of large sensory neurons and cardiomyopathies [72]. Although rare, FRDA is the most frequent inherited ataxia, with an estimated prevalence of two to four people in 100,000 individuals. Most patients carry homozygous GAA expansions in the first intron of the frataxin gene on chromosome 9. Whereas the critical pathologic triplet repeat threshold is 66 repeats, the expansion can be as many as 890 GAA repeats. This results in the partial silencing of frataxin, a small mitochondrial protein which plays an essential role in iron-sulfur cluster (ISC) biogenesis, an essential metabolic pathway found in all organisms $[73,74]$. Frataxin interacts directly with the two central components of the ISC biogenesis machine, the NFS1/IscU complex [75]. Correct ISC synthesis in mitochondria is closely linked to cellular iron homeostasis [76], and a lack of frataxin therefore causes dysregulation of iron metabolism. As a consequence, failure to assemble mitochondrial Fe-S proteins results in increased cellular iron acquisition, mitochondrial iron overload [77], and mitochondrial iron deposits in some FRDA patients [78].

\section{Iron Chelation from the Dentate Nucleus in Friederich's Ataxia Patients}

In one clinical trial, deferiprone $(10-15 \mathrm{mg} / \mathrm{kg})$ was administered twice daily to FRDA patients in a small clinical trial over a six-month period to nine adolescent patients with no overt cardiomyopathy. Brain iron was reduced significantly in dentate nuclei. The chelator treatment caused no apparent hematologic or neurologic side effects, while reducing neuropathy and ataxic gait in the youngest patients [79]. In a second clinical trial, DFP $(10 \mathrm{mg} / \mathrm{kg})$ was administered in combination with idebenone $(20 \mathrm{mg} / \mathrm{kg}$ ) to 20 FRDA patients. No significant differences were observed in the total international cooperative ataxia rating score (ICARS) scores when comparing baseline status and the end of the study in the whole group of patients. Echocardiography data showed a significant reduction of the interventricular septum thickness and in the left ventricular mass index. After 11 months of treatment, iron was reduced in the dentate nuclei. However, there was a worsening of posture and gait compared to baseline [80].

\section{Conclusions}

The current longevity of the population will result in increasing iron loading in various brain regions, although this is not normally associated with toxicity. Exactly why and how the iron which accumulates in specific brain regions in neurodegenerative diseases is highly toxic is unclear. However, new studies of activated microglia indicate that these cells may, in part, be the source of the iron loading. Over the past 50 years chelation therapy has progressed from subcutaneous administration to oral administration, and it is hoped that toxicity that has been associated with the oral chelators will be eliminated with new formulation of the hydroxypyridinones.

Author Contributions: R.J.W. wrote the original text, which was reviewed and edited by R.R.C. and R.C.H.

Funding: This research received no external funding.

Conflicts of Interest: The authors declare no conflict of interest. 


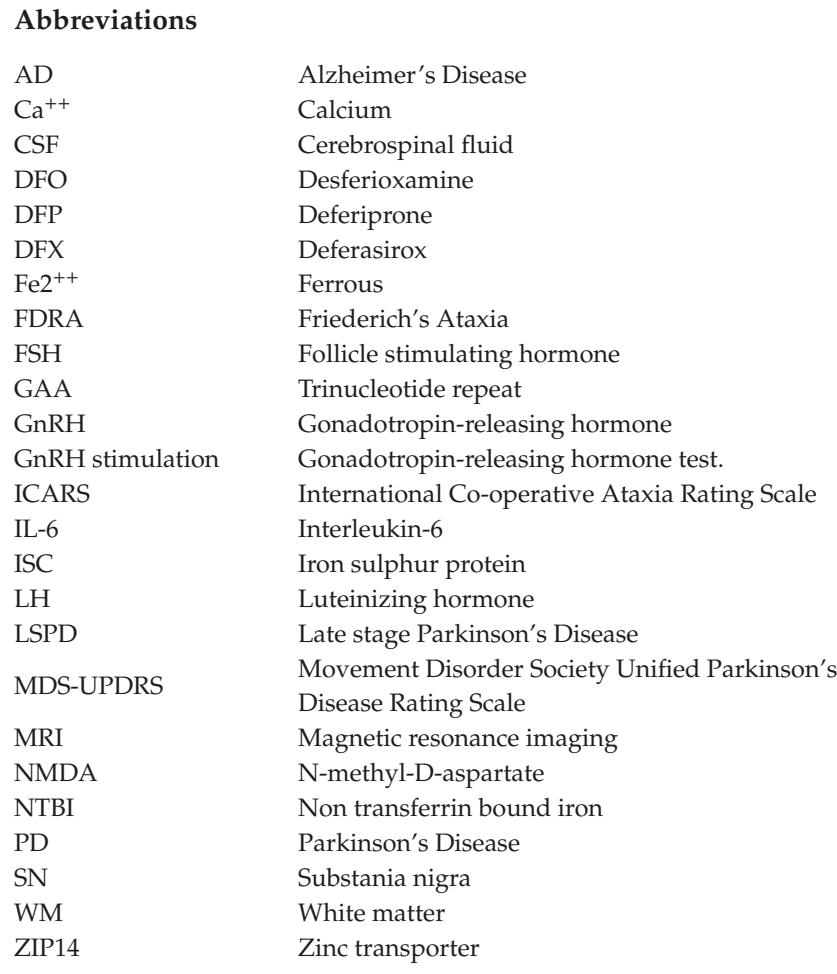

\section{References}

1. Ward, R.J.; Dexter, D.T.; Crichton, R.R. Neurodegenerative diseases and therapeutic strategies using iron chelators. J. Trace Elem. Med. Biol. 2015, 31, 267-273. [CrossRef]

2. Nathan, D.G. Thalassemia: The continued challenge. Ann. N. Y. Acad. Sci. 2005, 1054, 1-10. [CrossRef]

3. Nathan, D.G. Thalassemia: A look to the future. Ann. N. Y. Acad. Sci. 2016, 1368, 11-15. [CrossRef] [PubMed]

4. Hider, R.C.; Hoffbrand, A.V. The role of deferiprone in iron chelation. N. Engl. J. Med. 2018, 379, 2140-2150. [CrossRef] [PubMed]

5. Taher, A.T.; Weatherall, D.J.; Cappellini, M.D. Thalassemia. Lancet 2018, 391, 155-167. [CrossRef]

6. $\quad$ Propper, R.D.; Cooper, B.; Rufo, R.R.; Nienhuis, A.W.; Anderson, W.F.; Bunn, H.F.; Rosenthal, A.; Nathan, D.G. Continuous subcutaneous administration of deferoxamine in patients with iron overload. N. Engl. J. Med. 1977, 297, 418-423. [CrossRef] [PubMed]

7. Pippard, M.J.; Callender, S.T.; Weatherall, D.J. Chelation regimens with desferrioxamine. Lancet 1977, 1, 1101. [CrossRef]

8. Brittenham, G.M.; Griffith, P.M.; Nienhuis, A.W.; McLaren, C.E.; Young, N.S.; Tucker, E.E.; Allen, C.J.; Farrell, D.E.; Harris, J.W. Efficacy of deferoxamine in preventing complications of iron overload in patients with thalassemia major. N. Engl. J. Med. 1994, 331, 567-573. [CrossRef]

9. Borgna-Pignatti, C.; Rugolotto, S.; De Stefano, P.; Zhao, H.; Cappellini, M.D.; Del Vecchio, G.C.; Romeo, M.A.; Forni, G.L.; Gamberini, M.R.; Ghilardi, R.; et al. Survival and complications in patients with thalassemia major treated with transfusion and deferoxamine. Haematologica 2004, 89, 1187-1193. [PubMed]

10. Olivieri, N.F.; Nathan, D.G.; MacMillan, J.H.; Wayne, A.S.; Liu, P.P.; McGee, A.; Martin, M.; Koren, G.; Cohen, A.R. Survival in medically treated patients with homozygous beta thalassemia. N. Engl. J. Med. 1994, 331, 574-578. [CrossRef] [PubMed]

11. Modell, B.; Khan, M.; Darlison, M. Survival in beta-thalassaemia major in the UK: Data from the UK Thalassaemia Register. Lancet 2000, 355, 2051-2052. [CrossRef] 
12. Kontoghiorghes, G.J.; Aldouri, M.A.; Hoffbrand, A.V.; Barr, J.; Wonke, B.; Kourouclaris, T.; Sheppard, L. Effective chelation of iron in beta thalassaemia with the oral chelator 1,2-dimethyl-3-hydroxypyrid-4-one. Br. Med. J. (Clin. Res. Ed.) 1987, 295, 1509-1512. [CrossRef] [PubMed]

13. Olivieri, N.F.; Koren, G.; Hermann, C.; Bentur, Y.; Chung, D.; Klein, J.; St Louis, P.; Freedman, M.H.; McClelland, R.A.; Templeton, D.M. Comparison of oral iron chelator L1 and desferrioxamine in iron-loaded patients. Lancet 1990, 336, 1275-1279. [CrossRef]

14. Hoyes, K.P.; Porter, J.B. Subcellular distribution of desferrioxamine and hydroxypyridin-4-one chelators in K562 cells affects chelation of intracellular iron pools. Br. J. Haematol. 1993, 85, 393-400. [CrossRef] [PubMed]

15. Huang, X.P.; Spino, M.; Thiessen, J.J. Transport kinetics of iron chelators and their chelates in Caco-2 cells. Pharm. Res. 2006, 23, 280-290. [CrossRef] [PubMed]

16. Botzenhardt, S.; Li, N.; Chan, E.W.; Sing, C.W.; Wong, I.C.; Neubert, A. Safety profiles of iron chelators in young patients with haemoglobinopathies. Eur. J. Haematol. 2017, 98, 198-217. [CrossRef]

17. Hershko, C.; Link, G.; Pinson, A.; Peter, H.H.; Dobbin, P.; Hider, R.C. Ironmobilization from myocardial cells by 3-hydroxypyridin-4-one chelators: Studies in rat heart cells in culture. Blood 1991, 77, 2049-2053. [PubMed]

18. Anderson, L.J.; Wonke, B.; Prescott, E.; Holden, S.; Walker, J.M.; Pennell, D.J. Comparison of effects of oral deferiprone and subcutaneous desferrioxamine on myocardial iron concentrations and ventricular function in beta-thalassaemia. Lancet 2002, 9332, 516-520. [CrossRef]

19. Pepe, A.; Meloni, A.; Rossi, G.; Cuccia, L.; D’Ascola, G.D.; Santodirocco, M.; Cianciulli, P.; Caruso, V.; Romeo, M.A.; Filosa, A.; et al. Cardiac and hepatic iron and ejection fraction in thalassemia major: Multicentre prospective comparison of combined deferiprone and deferoxamine therapy against deferiprone or deferoxamine monotherapy. J. Cardiovasc. Magn. Reson. 2013, 15. [CrossRef]

20. Nick, H.; Acklin, P.; Lattmann, R.; Buehlmayer, P.; Hauffe, S.; Schupp, J.; Alberti, D. Development of tridentate iron chelators: From desferrithiocin to ICL670. Curr. Med. Chem. 2003, 10, 1065-1076. [CrossRef]

21. Longueville, A.; Crichton, R.R. An animal model of iron overload and its application to study hepatic ferritin iron mobilization by chelators. Biochem. Pharmacol. 1986, 35, 3669-3678. [CrossRef]

22. Wolfe, L.C.; Nicolosi, R.J.; Renaud, M.M.; Finger, J.; Hegsted, M.; Peter, H.; Nathan, D.G. A non-human primate model for the study of oral iron chelators. Br. J. Haematol. 1989, 72, 456-461. [CrossRef] [PubMed]

23. Bergeron, R.J.; Streiff, R.R.; Wiegand, J.; Vinson, J.R.; Luchetta, G.; Wiegand, J.; Moerker, T.; Peter, H.H. A comparative evaluation of iron clearance models. Ann. N. Y. Acad. Sci. 1990, 612, 378-393. [CrossRef] [PubMed]

24. Baker, E.; Wong, A.; Peter, H.; Jacobs, A. Desferrithiocin is an effective iron chelator in vivo and in vitro but ferrithiocin is toxic. Br. J. Haematol. 1992, 81, 424-431. [CrossRef] [PubMed]

25. Bergeron, R.J.; Wiegand, J.; McManis, J.S.; Bharti, N. Desferrithiocin: A search for clinically effective iron chelators. J. Med. Chem. 2014, 57, 9259-9291. [CrossRef] [PubMed]

26. Daar, S.; Pathare, A.; Nick, H.; Kriemler-Krahn, U.; Hmissi, A.; Habr, D.; Taher, A. Reduction in labile plasma iron during treatment with deferasirox, a once-daily oral iron chelator, in heavily loaded patients with beta-thalassaemia. Eur. J. Haematol. 2009, 82, 454-457. [CrossRef] [PubMed]

27. Cappellini, M.D.; Cohen, A.; Piga, A.; Bejaoui, M.; Perrotta, S.; Agaoglu, L.; Aydinok, Y.; Kattamis, A.; Kilinc, Y.; Porter, J.; et al. A phase 3 study of deferasirox (ICL670), a once-daily oral iron cheater in patients with best-thalassemia. Blood 2006, 207, 3455-3462. [CrossRef] [PubMed]

28. Cappellini, M.D.; Porter, J.D.; El-Beshlawy, A.; Li, C.K.; Seymour, J.F.; Elalfy, M.; Gattermann, N.; Giraudier, S.; Lee, J.W.; Chan, L.L.; et al. Tailoring iron chelation by iron intake and serum ferritin; the perspective EPIC study of deferasirox in 1744 patients with transfusion-dependent anemias. Haematologica 2010, 95, 557-566. [CrossRef] [PubMed]

29. Neufeld, E.J. Oral chelators deferasirox and deferiprone for transfusional iron overload in thalassemia major: New data, new questions. Blood 2006, 107, 3436-3441. [CrossRef] [PubMed]

30. Hershko, C.; Graham, G.; Bates, G.W.; Rachmilewitz, E.A. Non-specific serum iron in thalassaemia: An abnormal serum iron fraction of potential toxicity. Br. J. Haematol. 1978, 40, 255-263. [CrossRef] [PubMed]

31. Brissot, P.; Ropert, M.; Le Lan, C.; Loréal, O. Non-transferrin bound iron: A key role in iron overload and iron toxicity. Biochim. Biophys. Acta 2012, 1820, 403-410. [CrossRef] [PubMed] 
32. Pinilla-Tenas, J.J.; Sparkman, B.K.; Shawki, A.; Illing, A.C.; Mitchell, C.J.; Zhao, N.; Liuzzi, J.P.; Cousins, R.J.; Knutson, M.D.; Mackenzie, B. Zip14 is a complex broad-scope metal-ion transporter whose functional properties support roles in the cellular uptake of zinc and nontransferrin-bound iron. Am. J. Physiol. Cell Physiol. 2011, 301, C862-C871. [CrossRef] [PubMed]

33. Jenkitkasemwong, S.; Wang, C.Y.; Coffey, R.; Zhang, W.; Chan, A.; Biel, T.; Kim, J.S.; Hojyo, S.; Fukada, T.; Knutson, M.D. SLC39A14 Is Required for the Development of Hepatocellular Iron Overload in Murine Models of Hereditary Hemochromatosis. Cell Metab. 2015, 22, 138-150. [CrossRef] [PubMed]

34. Oudit, G.Y.; Sun, H.; Trivieri, M.G.; Koch, S.E.; Dawood, F.; Ackerley, C.; Yazdanpanah, M.; Wilson, G.J.; Schwartz, A.; Liu, P.P.; et al. L-type $\mathrm{Ca}^{2+}$ channels provide a major pathway for iron entry into cardiomyocytes in iron-overload cardiomyopathy. Nat. Med. 2003, 9, 1187-1194. [CrossRef] [PubMed]

35. Kumfu, S.; Chattipakorn, S.; Srichairatanakool, S.; Settakorn, J.; Fucharoen, S.; Chattipakorn, N. T-type calcium channel as a portal of iron uptake into cardiomyocytes of beta-thalassemic mice. Eur. J. Haematol. 2011, 86, 156-166. [CrossRef] [PubMed]

36. Noetzli, L.J.; Panigrahy, A.; Mittelman, S.D.; Hyderi, A.; Dongelyan, A.; Coates, T.D.; Wood, J.C. Pituitary iron and volume predict hypogonadism in transfusional iron overload. Am. J. Hematol. 2012, 87, 167-171. [CrossRef] [PubMed]

37. De Sanctis, V.; Soliman, A.T.; Elsedfy, H.; Soliman, N.A.; Elalaily, R. Late onset male hypogonadism and fertility potential in thalassaemia major: Two emerging patters. Mediterr. J. Haematol. 2015, 7, e2015047.

38. Çetinçakmak, M.; Hattapoğlu, S.; Menzilcioğlu, S.; Bircan, A.; Uluca, U.; Uçar, A.; S Mura, S.; Söker, M.; Bilic, A.J. MRI-based evaluation of the factors leading to pituitary iron overload in patients with thalassemia. J. Neuroradiol. 2016, 43, 297-302. [CrossRef] [PubMed]

39. Wang, Z.; Fischer, R.; Butensky, E.; Neumayr, L.; Singer, S.T.; Lee, P.; Chu, Z.; Hunte, J.V.; Firebaugh, J.; Vichinsky, E.; et al. MRI Assessment of Pituitary Iron and Volume in Thalassemia, and Relation to Hypothalamic-Pituitary-Gonadal Axis Function (HPG): A Feasibility Study. Blood 2006, 108, 1778.

40. Christoforidis, A.; Haritandi, A.; Tsitouridis, I.; Tsatra, I.; Tsantali, H.; Karyda, S.; Dimitriadis, A.S.; Athanassiou-Metaxa, M. Correlative study of iron accumulation in liver, myocardium, and pituitary assessed with MRI in young thalassemic patients. J. Pediatr. Hematol. Oncol. 2006, 28, 311-315. [CrossRef] [PubMed]

41. Berkovitch, M.; Bistritzer, T.; Milone, S.D.; Perlman, K.; Kucharczyk, W.; Olivieri, N.F. Iron deposition in the anterior pituitary in homozygous beta thalassemia: MRI evaluation and correlation with gonadal function. J. Pediatr. Endocrinol. Metab. 2000, 13, 179-184. [CrossRef] [PubMed]

42. Abdulzahra, M.S.; Al-Hakeim, H.K.; Ridha, M.M. Study of the effect of iron overload on the function of endocrine glands in male thalassemia patients. Asian J. Transfus. Sci. 2011, 5, 127-131. [PubMed]

43. Wood, J.C.; Kang, B.P.; Thompson, A.; Giardina, P.; Harmatz, P.; Glynos, T.; Paley, C.; Coates, T.D. The effect of deferasirox on cardiac iron in thalassemia major: Impact of total body iron stores. Blood 2010, 116, 537-543. [CrossRef] [PubMed]

44. Duprez, T.; Maite, D.; Cosnard, G. Transfusional haemochromatosis of the choroid plexus in beta thalassemia major. J. Comput. Assist. Tomogr. 2001, 25, 487-488. [CrossRef] [PubMed]

45. Hasiloglu, Z.I.; Asik, M.; Ure, E.; Ertem, F.; Apak, H.; Albayram, S. The utility of susceptibility-weighted imaging to evaluate the extent of iron accumulation in the choroid plexus of patients with $\hat{\mathrm{I}}^{2}$-thalassaemiamajor. Clin. Radiol. 2017, 72, 903.e1-903.e7. [CrossRef] [PubMed]

46. Qiu, D.; Chan, G.C.; Chu, J.; Chan, Q.; Ha, S.Y.; Moseley, M.E.; Khong, P.L. MR quantitative susceptibility imaging for the evaluation of iron loading in the brains of patients with $\beta$-thalassemia major. AJNR Am. J. Neuroradiol. 2014, 35, 1085-1090. [CrossRef] [PubMed]

47. Dexter, D.T.; Wells, F.R.; Agid, F.; Agid, Y.; Lees, A.J.; Jenner, P.; Marsden, C.D. Increased nigral iron content in postmortem parkinsonian brain. Lancet 1987, 21, 1219-1220. [CrossRef]

48. Fernandez, B.; Ferrer, I.; Fernando, G.; Hilfiker, S. Biomonitorization of iron accumulation in the substantia nigra from Lewy body disease patients. Toxicol. Rep. 2017, 4, 188-193. [CrossRef]

49. Martin-Bastida, A.; Tilley, B.; Alireza, T.; Bansal, S.; Dexter, D.T.; Ward, R.J. Parkinson's, Iron and Inflammation. Neurobiol. Dis. 2019, in press.

50. Jellinger, K.; Paulus, W.; Grundke-Iqbal, I.; Riederer, P.; Youdim, M.B. Brain iron and ferritin in Parkinson's and Alzheimer's diseases. J. Neural Transm. Park. Dis. Dement. Sect. 1990, 2, 327-340. [CrossRef]

51. Ben-Shachar, D.; Riederer, P.; Youdim, M.B. Iron-melanin interaction and lipid peroxidation: Implications for Parkinson's disease. J. Neurochem. 1991, 57, 1609-1614. [CrossRef] [PubMed] 
52. Hadzhieva, M.; Kirches, E.; Mawrin, C. Review: Iron metabolism and the role of iron in neurodegenerative disorders. Neuropathol. Appl. Neurobiol. 2014, 40, 240-257. [CrossRef] [PubMed]

53. Zecca, L.; Wilms, H.; Geick, S.; Claasen, J.H.; Brandenburg, L.O.; Holzknecht, C.; Panizza, M.L.; Zucca, F.A.; Deuschl, G.; Sievers, J.; et al. Human neuromelanin induces neuroinflammation and neurodegeneration in the rat substantia nigra: Implications for Parkinson's disease. Acta Neuropathol. 2008, 116, 47-55. [CrossRef] [PubMed]

54. Zhang, W.; Phillips, K.; Wielgus, A.R.; Liu, J.; Albertini, A.; Zucca, F.A.; Faust, R.; Qian, S.Y.; Miller, D.S.; Chignell, C.F.; et al. Neuromelanin activates microglia and induces degeneration of dopaminergic neurons: Implications for progression of Parkinson's disease. Neurotox. Res. 2011, 19, 63-72. [CrossRef] [PubMed]

55. Nakane, T.; Nihashi, T.; Kawai, H.; Naganawa, S. Visualization of neuromelanin in the Substantia nigra and locus ceruleus at $1.5 \mathrm{~T}$ using a 3D-gradient echo sequence with magnetization transfer contrast. Magn. Reson. Med. Sci. 2008, 7, 205-210. [CrossRef] [PubMed]

56. Sasaki, M.; Shibata, E.; Kudo, K.; Tohyama, K. Neuromelanin-Sensitive MRI. Clin. Neuroradiol. 2008, 18, 147-153. [CrossRef]

57. Prasad, S.; Stezin, A.; Lenka, A.; George, L.; Saini, J.; Yadav, R.; Pal, P.K. Three-dimensional neuromelanin-sensitive magnetic resonance imaging of the substantia nigra in Parkinson's disease. Eur. J. Neurol. 2018, 25, 680-686. [CrossRef]

58. Fabbri, M.; Reimão, S.; Carvalho, M.; Nunes, R.G.; Abreu, D.; Guedes, L.C.; Bouça, R.; Lobo, P.P.; Godinho, C.; Coelho, M.; et al. Substantia nigra neuromelanin as an imaging biomarker of disease progression in Parkinson's Disease. J. Park. Dis. 2017, 7, 491-501. [CrossRef]

59. Ward, R.J.; Dexter, D.; Florence, A.; Aouad, F.; Hider, R.; Jenner, P.; Crichton, R.R. Brain iron in the ferrocene-loaded rat: Its chelation and influence on dopamine metabolism. Biochem. Pharmacol. 1995, 49, 1821-1826. [CrossRef]

60. Dexter, D.T.; Ward, R.J.; Florence, A.; Jenner, P.; Crichton, R.R. Effects of desferrithiocin and its derivatives on peripheral iron and striatal dopamine and 5-hydroxytryptamine metabolism in the ferrocene-loaded rat. Biochem. Pharmacol. 1999, 58, 151-155. [CrossRef]

61. Kwiatkowski, J.L. Current recommendations for chelation for transfusion-dependent thalassemia. Ann. N. Y. Acad. Sci. 2016, 1368, 107-114. [CrossRef] [PubMed]

62. Devos, D.; Moreau, C.; Devedjian, J.C.; Kluza, J.; Petrault, M.; Laloux, C.; Jonneaux, A.; Ryckewaert, G.; Garçon, G.; Rouaix, N.; et al. Targeting chelatable iron as a therapeutic modality in Parkinson's disease. Antioxid. Redox Signal 2014, 21, 195-210. [CrossRef] [PubMed]

63. Martin-Bastida, A.; Ward, R.J.; Newbould, R.; Piccini, P.; Sharp, D.; Kabba, C.; Patel, M.C.; Spino, M.; Connelly, J.; Tricta, F.; et al. Brain iron chelation by deferiprone in a phase 2 randomised double-blinded placebo controlled clinical trial in Parkinson's disease. Sci. Rep. 2017, 7, 1398. [CrossRef] [PubMed]

64. Hider, R.; Liu, Z.; Liu, Y.; Li, Z. Chiral 3-Hydroxypyrid-4-one Derivative and Synthesis and Use Thereof. European Patent 2,692,724A1, 5 February 2014.

65. Tao, Y.; Wang, Y.; Rogers, J.T.; Wang, F. Perturbed iron distribution in Alzheimer's disease serum, cerebrospinal fluid, and selected brain regions: A systematic review and meta-analysis. J. Alzheimer's Dis. 2014, 42, 679-690. [CrossRef] [PubMed]

66. Hare, D.J.; Raven, E.P.; Roberts, B.R.; Bogeski, M.; Portbury, S.D.; McLean, C.A.; Masters, C.L.; Connor, J.R.; Bush, A.I.; Crouch, P.J.; et al. Laser ablation-inductively coupled plasma-mass spectrometry imaging of white and gray matter iron distribution in Alzheimer's disease frontal cortex. NeuroImage 2016, 137, 124-131. [CrossRef] [PubMed]

67. Reznichenko, L.; Amit, T.; Zheng, H.; Avarmovitch-Tirosh, Y.; Youdim, M.B.; Weinreb, O.; Mandel, S. Reduction of iron-regulated amyloid precursor protein and beta-amyloid peptide by (-)-epigallocatechin-3-gallate in cell cultures: Implications for iron chelation in Alzheimer's disease. J. Neurochem. 2006, 97, 527-536. [CrossRef] [PubMed]

68. Avramovich-Tirosh, Y.; Reznichenko, L.; Mit, T.; Zheng, H.; Fridkin, M.; Weinreb, O.; Mandel, S.; Youdim, M.B. Neurorescue activity, APP regulation and amyloid-beta peptide reduction by novel multi-functional brain permeable iron-chelating-antioxidants, M-30 and green tea polyphenol, EGCG. Curr. Alzheimer Res. 2007, 4, 403-411. [CrossRef] [PubMed] 
69. McLachlan, D.R.; Smith, W.L.; Kruck, T.P. Desferrioxamine and Alzheimer's disease: Video home behavior assessment of clinical course and measures of brain aluminium. Ther. Drug Monit. 1993, 15, 602-607. [CrossRef] [PubMed]

70. Hiremathad, A.; Chand, K.; Tolayan, L.; Rajeshwari Keri, R.S.; Esteves, A.R.; Cardoso, S.M.; Chaves, S.; Santos, M.A. Hydroxypyridinone-benzofuran hybrids with potential protective roles for Alzheimer's diseasetherapy. J. Inorg. Biochem. 2018, 179, 82-96. [CrossRef]

71. Palanimuthu, D.; Poon, R.; Sahni, S.; Anjum, R.; Hibbs, D.; Lin, H.Y.; Bernhardt, P.V.; Kalinowski, D.S.; Richardson, D.R. A novel class of thiosemicarbazones show multi-functional activity for the treatment of Alzheimer's disease. Eur. J. Med. Chem. 2017, 139, 612-632. [CrossRef] [PubMed]

72. Lupoli, F.; Vannocci, T.; Longo, G.; Niccolai, N.; Pastore, A. The role of oxidative stress in Friedreich's ataxia. FEBS Lett. 2018, 592, 718-727. [CrossRef] [PubMed]

73. Adinolfi, S.; Iannuzzi, C.; Prischi, F.; Pastore, C.; Iametti, S.; Martin, S.R.; Bonomi, F.; Pastore, A. Bacterial frataxin CyaY is the gatekeeper of iron-sulfur cluster formation catalyzed by IscS. Nat. Struct. Mol. Biol. 2009, 16, 390-396. [CrossRef] [PubMed]

74. Prischi, F.; Konarev, P.V.; Iannuzzi, C.; Pastore, C.; Adinolfi, S.; Martin, S.R.; Svergun, D.I.; Pastore, A. Structural bases for the interaction of frataxin with the central components of iron-sulphur cluster assembly. Nat. Commun. 2010, 1. [CrossRef] [PubMed]

75. Prischi, F.; Pastore, A. Hybrid Methods in Iron-Sulfur Cluster Biogenesis. Front. Mol. Biosci. 2017, 4. [CrossRef] [PubMed]

76. Huang, M.L.; Lane, D.J.; Richardson, D.R. Mitochondrial mayhem: The mitochondrion as a modulator of iron metabolism and its role in disease. Antioxid. Redox Signal 2011, 15, 3003-3019. [CrossRef] [PubMed]

77. Lill, R.; Hoffmann, B.; Molik, S.; Pierik, A.J.; Rietzschel, N.; Stehling, O.; Uzarska, M.A.; Webert, H.; Wilbrecht, C.; Mühlenhoff, U. The role of mitochondria in cellular iron-sulfur protein biogenesis and iron metabolism. Biochim. Biophys. Acta 2012, 1823, 1491-1508. [CrossRef] [PubMed]

78. Ramirez, R.L.; Qian, J.; Santambrogio, P.; Levi, S.; Koeppen, A.H. Relation of cytosolic iron excess to cardiomyopathy of Friedreich's ataxia. Am. J. Cardiol. 2012, 110, 1820-1827. [CrossRef] [PubMed]

79. Boddaert, N.; Le Quan Sang, K.H.; Rötig, A.; Leroy-Willig, A.; Gallet, S.; Brunelle, F.; Sidi, D.; Thalabard, J.C.; Munnich, A.; Cabantchik, Z.I. Selective iron chelation in Friedreich ataxia: Biologic and clinical implications. Blood 2007, 110, 401-408. [CrossRef]

80. Velasco-Sánchez, D.; Aracil, A.; Montero, R.; Mas, A.; Jiménez, L.; O’Callaghan, M.; Tondo, M.; Capdevila, A.; Blanch, J.; Artuch, R.; et al. Combined therapy with idebenone and deferiprone in patients with Friedreich's ataxia. Cerebellum 2011, 10, 1-8. [CrossRef]

(C) 2019 by the authors. Licensee MDPI, Basel, Switzerland. This article is an open access article distributed under the terms and conditions of the Creative Commons Attribution (CC BY) license (http://creativecommons.org/licenses/by/4.0/). 


\title{
New Perspectives in Iron Chelation Therapy for the Treatment of Neurodegenerative Diseases
}

\author{
Marco T. Nuñez ${ }^{1, *}$ and Pedro Chana-Cuevas ${ }^{2}$ \\ 1 Faculty of Sciences, Universidad de Chile, Las Palmeras 3425, Santiago 7800024, Chile \\ 2 Center for the Treatment of Movement Disorders, Universidad de Santiago de Chile, Belisario Prat 1597, \\ Santiago 83800000, Chile; pedro.chana@usach.cl \\ * Correspondence: mnunez@uchile.cl; Tel.: +562-29787360
}

Received: 25 June 2018; Accepted: 3 August 2018; Published: 19 October 2018

\begin{abstract}
Iron chelation has been introduced as a new therapeutic concept for the treatment of neurodegenerative diseases with features of iron overload. At difference with iron chelators used in systemic diseases, effective chelators for the treatment of neurodegenerative diseases must cross the blood-brain barrier. Given the promissory but still inconclusive results obtained in clinical trials of iron chelation therapy, it is reasonable to postulate that new compounds with properties that extend beyond chelation should significantly improve these results. Desirable properties of a new generation of chelators include mitochondrial destination, the center of iron-reactive oxygen species interaction, and the ability to quench free radicals produced by the Fenton reaction. In addition, these chelators should have moderate iron binding affinity, sufficient to chelate excessive increments of the labile iron pool, estimated in the micromolar range, but not high enough to disrupt physiological iron homeostasis. Moreover, candidate chelators should have selectivity for the targeted neuronal type, to lessen unwanted secondary effects during long-term treatment. Here, on the basis of a number of clinical trials, we discuss critically the current situation of iron chelation therapy for the treatment of neurodegenerative diseases with an iron accumulation component. The list includes Parkinson's disease, Friedreich's ataxia, pantothenate kinase-associated neurodegeneration, Huntington disease and Alzheimer's disease. We also review the upsurge of new multifunctional iron chelators that in the future may replace the conventional types as therapeutic agents for the treatment of neurodegenerative diseases.
\end{abstract}

Keywords: neurodegeneration with brain iron accumulation; iron chelation therapy; multifunctional iron chelators

\section{Introduction}

Iron content increases with age in several regions of the brain. Particularly, high levels of non-heme iron are found in the globus pallidus, the red nucleus, substantia nigra, cortex and putamen; in contrast, the iron content of the medulla oblongata does not change with age whereas the iron content of the thalamus decreases from age 30 to 90 [1-3]. The causes underlying the increase in brain iron with age remain elusive. It is unclear whether this increase is a reflection of total body iron, since a report shows that non-heme iron in the liver does not change with age [1], although body stores of iron, as determined by circulating ferritin levels, seem to increase with age [4].

Abundant evidence suggests that disturbed iron homeostasis and mitochondrial dysfunction play important roles in the development of an increasing number of neurodegenerative diseases [3,5-9]. The occurrence of high iron content in brain areas susceptible to neurodegeneration, in conjunction with the known ability of iron to generate reactive oxygen species (ROS) and induce the formation of protein aggregates, provides a relevant seed mechanism for downstream events leading to the death of affected neurons. It has been postulated that the high iron-ROS-mitochondrial dysfunction events 
undergo a positive feedback loop that further fosters oxidative damage, protein aggregation and cell death $[3,6,8]$.

The use of iron chelators for the treatment of systemic diseases such as thalassemia major and hemochromatosis is already a proven therapeutic approach [10]. As a norm, chelator treatment in iron overload patients induces substantial iron excretion and a negative iron balance [11-15]. On the basis of this experience, strategies to stop or slow neurodegenerative process with an iron accumulation component are now being tested in therapeutic trials.

A review on the current evidence of the benefits and drawbacks of iron chelation therapy, and the analysis of new compounds that could be used for the treatment of neurodegenerative diseases, follows.

\section{Neurodegenerative Diseases with an Iron Accumulation Component}

A wide variety of neurological diseases are characterized by the accumulation of iron in different areas of the central nervous system; these diseases include Parkinson's disease (PD) and other parkinsonisms such as Lewy bodies dementia, progressive supranuclear palsy, corticobasal degeneration [16-21], the Westfal variant of Huntington disease [22], Alzheimer's disease (AD) [23-27], Friedreich's ataxia [28], pantothenate kinase-associated neurodegeneration [29-31] and other neuropathologies associated with brain iron accumulation [32-34]. From the pathophysiological standpoint, different mechanisms are observed, so the clinical and therapeutic implications of iron accumulation may be different for each individual disease process [2,35].

There is ample evidence linking iron to the pathology of idiopathic PD. A good review on this subject can be found in the article by Moreau et al. [36]. Iron is particularly abundant in dopaminergic neurons, where it is needed for dopamine synthesis [37] and the production of energy through the electron transport chain [38,39]. In dopaminergic neurons, iron behaves as a double-edged sword since it also participates in the production of the noxious hydroxyl radical during dopamine auto-oxidation. Moreover, the nonenzymatic oxidation of dopamine produces the leukoaminochrome o-semiquinone radical, which reacts with oxygen to generate superoxide anion [40-42]. Since under physiological conditions iron reacts with superoxide and hydrogen peroxide [6], it is possible that iron dyshomeostasis plays a fundamental role in mediating oxidative damage in dopaminergic neurons. Indeed, the hydroxyl radical, the most reactive ROS in living matter, is formed by the Fenton reaction $\left(\mathrm{Fe}^{2+}+\mathrm{H}_{2} \mathrm{O}_{2} \rightarrow \mathrm{OH}^{-}+\mathrm{HO}^{\bullet}\right)$, a nonenzymatic reaction that obeys mass action law. Hence, there is a direct relationship between the concentration of redox-active iron and the production of hydroxyl radical.

The mechanisms of iron homeostasis that go awry in neurodegeneration form a cutting-edge question in metalloneurobiology [43]. Highly relevant to this point is the mitochondria-iron connection. The iron homeostasis regulator iron regulatory protein 1 (IRP1) is activated in idiopathic PD. Postmortem brain tissue from PD patients displays increased IRP1 activity when compared to tissue from control individuals [44]. Increased IRP1 activity was found also in the ipsilateral ventral mesencephalon of 6-OHDA-treated rats [44]. Studies performed in our laboratory showed that in SH-SY5Y cells, loss of mitochondrial function caused by inhibition of complex I results in decreased Fe-S cluster synthesis and increased IRP1 binding activity, accompanied by increased intracellular iron levels [45]. Further studies revealed that complex I inhibition is associated with increased levels of iron uptake proteins, and decreased levels of the iron efflux transporter ferroportin 1 [46]. Complex I inhibition also results in increased oxidative modifications and increased cysteine oxidation, while IRP1 silencing abolishes the increase in ${ }^{55} \mathrm{Fe}$ uptake activity and protects cells from death induced by complex I inhibition [46]. Thus, mitochondrial dysfunction initiates a positive feedback loop that also comprises increasing iron uptake and increased oxidative damage. In this view, iron accumulation, more than a primary cause, seems to be a consequence of other initiation factors.

An attractive hypothesis for the genesis of diseases with a redox-active metal accumulation component is the metal-based neurodegeneration hypothesis [3]. According to this hypothesis, redox-active metal ions like iron and copper generate ROS that cause the peroxidation of membrane 
phospholipids, which in turn leads to the formation of reactive aldehydes. Reactive aldehydes, together with other ROS, interact with proteins inducing their aggregation, which overwhelms the cellular protein degradation systems, resulting in their accumulation within intracellular inclusion bodies. Accordingly, this hypothesis suggests that protein aggregation occurs downstream of iron or copper dyshomeostasis.

In the specific case of idiopathic PD, $\alpha$-synuclein aggregation has been proposed to be a consequence of mitochondrial dysfunction/ROS production [47-49] or, inversely, mitochondrial dysfunction has been proposed to be a consequence of $\alpha$-synuclein aggregation [50-53]. Thus, it is possible that mitochondrial dysfunction, oxidative stress and $\alpha$-synuclein aggregation jointly establish a positive feedback cycle that taxes energy production and overloads the protein degradation systems [53-55]. This positive feedback concept is further augmented by the observation that iron induces $\alpha$-synuclein aggregation (see above). Since mitochondrial dysfunction increases iron accumulation, another positive feedback cycle could be formed that includes mitochondrial dysfunction, iron dyshomeostasis and $\alpha$-synuclein aggregation (Figure 1). It follows that any of the components of these two cycles (mitochondrial dysfunction, oxidative stress, iron dyshomeostasis and $\alpha$-synuclein aggregation) could initiate these processes. From the therapeutic stand point, multiple-task strategies targeting these events should provide more effective treatment to stop the progression of this disease.
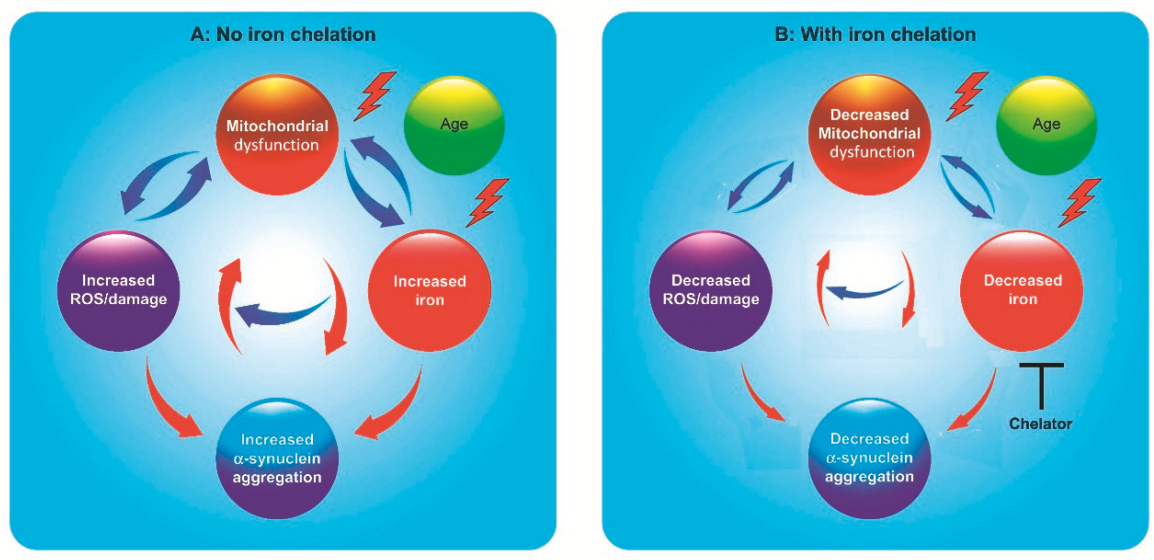

Figure 1. Self-feeding cycles in Parkinson's neurodegeneration. (A) Blue arrows: Mitochondrial dysfunction, caused by internal or external toxins, or derived from genetic factors, results in increased oxidative stress and in decreased synthesis of iron-sulfur clusters, which in turn results in the spurious activation of iron regulatory protein IRP1 and increased iron uptake. Both increased ROS and increased iron produce additional mitochondrial dysfunction through the generation of the hydroxyl radical. Red arrows: Increased ROS and increased iron levels induce $\alpha$-synuclein aggregation, establishing a positive feedback cycle including mitochondrial dysfunction, further taxing energy production. (B) Iron chelation decreases redox-active iron and the production of damaging ROS. The decrease in ROS and redox-active iron results in decreased $\alpha$-synuclein aggregation. The decrease in ROS and $\alpha$-synuclein aggregation also results in improved mitochondrial function. Thus, decreasing redox-active iron by chelation slows or stops the process of neuronal death. In this scheme, age is a neurodegeneration factor not influenced by iron chelation.

\section{Clinical Trials Using Iron Chelation}

Overwhelming evidence shows that iron accumulation in the brain may contribute to neurodegenerative processes, as shown in recent reviews [7,35,43,56,57]. A tempering view states that 
cellular iron homeostasis mechanisms are sufficient to limit its toxicity [58]. Nevertheless, excessive iron levels will increase hydroxyl radical generation, for which there are no cellular mechanisms to counteract its noxious effects.

Successful experiences support the use of iron chelation therapy for the treatment of systemic diseases with an iron accumulation component, such as thalassemia major, sickle cell disease and cardiomyopathy associated with hereditary hemochromatosis [59-67]. The chelators used in these therapies are deferoxamine, deferasirox, deferiprone and PBT2. Adherence to treatment by patients treated with deferoxamine is low since, as it does not permeate the intestinal barrier, it must be injected. Oral chelators such as deferasirox and deferiprone have better treatment compliance. Deferasirox (Exjade ${ }^{\circledR}$, Novartis Pharma AG, Basel, Switzerland) was the first oral chelator approved for human use in 2005, while Deferiprone (Ferriprox ${ }^{\circledR}$, Apotex Inc., Toronto, ON, Canada) was approved in 2011.

Recently, iron chelation has been introduced as a new therapeutic concept for the treatment of neurodegenerative diseases that have a component of metal ion accumulation [56,68-70]. Essentially, the iron chelator should be able to penetrate the cell membranes, as well as the blood-brain barrier, and should have the capacity to extract the chelated iron from the accumulation site and to transfer it to other biological acceptors such as circulating transferrin [68,71]. In addition, small doses of chelators must be used in order to minimize side effects [72,73].

A search in https: / / clinicaltrials.gov indicated 12 ongoing or finished trials of iron chelation for the treatment of neurodegenerative diseases: four trials for Parkinson's disease, three for Friedreich's ataxia, two for amyotrophic lateral sclerosis, one for mild Alzheimer's disease, one for pantothenate kinase-associated neurodegeneration and one for neurodegeneration with brain iron accumulation. A review on the results of finished trials with published results follows. A number of single-case reports that lack the appropriate controls will not be mentioned here (reviewed by Dusek et al. [70]).

\subsection{Parkinson's Disease}

A randomized pilot clinical trial tested 40 patients with early-stage PD, tried with deferiprone versus placebo. A dose of $30 \mathrm{mg} / \mathrm{kg} /$ day, during a period of six months, produced a decrease in the iron content of the sustantia nigra, evaluated by T3 magnetic resonance [69]. A significant improvement of the motor indicators of the progression of the disease was found. Nevertheless, once the treatment was suspended, iron accumulation reappeared, suggesting a reversal to the pathological state. In a second report of this same study, the usefulness of ceruloplasmin (CP) as a biomarker was emphasized, associating the low activity of this enzyme in Parkinson's disease with iron overload in the substantia nigra [72]. It was found that after six to 12 months of deferiprone treatment, greater reductions in substantia nigra iron levels and Unified Parkinson's Disease Rating Scale (UPDRS) motor scores were obtained in patients with higher serum and cerebrospinal fluid levels of CP-ferroxidase activity. A second stage of this project, under the acronym FAIRPARK, intends to enroll 338 participants (https: / / clinicaltrials.gov / ct2/show / NCT02655315?term=chelation\&cond= Parkinson+Disease\&draw $=2 \&$ rank $=1$ ).

In another series reported in Clinical Trials by researchers from the Imperial College London, good tolerance to deferiprone was reported in patients with Parkinson's disease, removing excess iron in dentate and caudate nucleus but with minimal effects on the symptoms of the disease [73].

In summary, the reported results on chelator treatment of Parkinson's disease discussed above are encouraging in terms of a possible slowdown of the disease progression, granting the development of further long-term trials.

\subsection{Friedreich's Ataxia}

This genetic disease presents a disorder of iron metabolism associated with chronic inflammation and iron accumulation at the level of the central nervous system, the peripheral system, the myocardium and the endocrine system [74]. It was suggested earlier that a reduction of iron accumulation could be a therapeutic alternative for Friedreich's ataxia patients [75-77]. Initial 
pilot studies in young patients with no overt cardiomyopathy showed that treatment with 20 to $30 \mathrm{mg} / \mathrm{kg} /$ day of deferiprone significantly decreased iron accumulation in the dentate nucleus in the cerebellum, while reducing neuropathy and ataxic gait. Nevertheless, the effects of this chelation therapy on neurological symptoms remained controversial [78]. In a follow-up of this study, a one-year open-label extension, it was determined that deferiprone dosed at $40 \mathrm{mg} / \mathrm{kg} /$ day worsened ataxia, as indicated by a four-point mean increase in International Cooperative Ataxia Rating Scale (ICARS) scores in this group (unpublished data, compiled in [79]). As in the first study, results using a dose of $20 \mathrm{mg} / \mathrm{kg} /$ day were inconclusive. Nevertheless, a significant reduction in cardiac hypertrophy was an interesting side effect of deferiprone treatment [79].

A study of co-administration of deferiprone and the coenzyme Q10 analog idebenone reported improvement in heart hypertrophy parameters and iron deposits in the dentate nucleus, but no improvements in ICARS [80]. Another study that used deferiprone in association with idebenone also failed to find significant improvement in neurological function. Nevertheless, an improvement in heart hypertrophy was reported as possible [81].

The largest series reported for the treatment of Friedreich's ataxia enrolled 72 patients, who were treated with varied doses of deferiprone, 20, 40, or $60 \mathrm{mg} / \mathrm{kg} /$ day in a six-month Phase-II placebo-controlled trial. The results confirmed the safety of deferiprone at doses lower than 20 $\mathrm{mg} / \mathrm{kg} /$ day, while the $60 \mathrm{mg} / \mathrm{kg} /$ day dose was discontinued due to worsening of ataxia in two patients [82]. Patients receiving $20 \mathrm{mg} / \mathrm{kg} /$ day of deferiprone showed a decline in the left ventricular mass index but did not present changes in ICARS scores [82]. The decrease in cardiomyopathy correlated with the decrease of iron in the cardiac muscle.

In a study with 13 Friedreich's ataxia patients, a triple therapy with deferiprone plus idebenone and riboflavin (both antioxidants) resulted in four patients discontinued due to adverse effects after 15-39 months of therapy. Other parameters, like the annual worsening rate scale, the scale for the assessment and rating of ataxia scores and cardiac function did not present significant changes [83]. The authors concluded that the benefits of this triple therapy are uncertain.

In summary, it has been established that therapeutic doses of deferiprone, $20 \mathrm{mg} / \mathrm{kg} /$ day, appear to be safe for long-term use for the treatment of Friedreich's ataxia. In most trials, this treatment produced some improvement in heart function, but no improvement of the neurological symptoms were apparent. In addition, doses higher than $40 \mathrm{mg} / \mathrm{kg} /$ day seemed to worsen the disease. The effects of long-term treatment at low doses on, for example, slowing or stopping disease progression, need to be evaluated.

\subsection{Neurodegeneration with Brain Iron Accumulation (NBIA) Disorders}

Within the spectrum of iron deposition disorders there is a group of genetic diseases that have in common a syndrome of NBIA [32,84-86]. These disorders include pantothenate kinase-associated neurodegeneration (PKAN, previously known as Hallervorden-Spatz syndrome) [87-90], PLA2G6 calcium-independent phospholipase A2 (PLAN) [91,92], infantile neuroaxonal dystrophy (INAD) $[93,94]$, mitochondrial membrane protein-associated neurodegeneration (MPAN) [95-98], beta-propeller protein-associated neurodegeneration (BPAN) [99,100], CoA synthase protein-associated neurodegeneration (CoPAN) [101-103], fatty acid-2 hydroxylase-associated neurodegeneration (FAHN) [104,105], Kufor-Rakeb disease [106-108], aceruloplasminemia [109,110] and neuroferritinopathy [111,112]. Of these diseases, iron chelation therapy has been tried in PKAN patients.

The PKAN neurodegenerative condition is characterized by the presence of iron deposits at the level of the basal ganglia, currently detected by MRI $[86,113,114]$. There have been several trials oriented to the use of deferiprone for the treatment of PKAN patients [115-118]. In all trials, deferiprone treatment decreased iron accumulation in the ganglia, in addition to an improvement in the Unified Parkinson's Disease Rating Scale [115-118]. Although the series is still too small to establish definitive conclusions, iron chelation may be a therapeutic option for the treatment of PKAN. Additionally, in 
a downside, treatment of a single BPAN patient with deferiprone had to be interrupted because of worsening of the parkinsonian symptoms [116].

\subsection{Huntington Disease}

In a study with early/mid-stage Huntington disease patients, patients were subjected to daily doses (250 mg or $100 \mathrm{mg}$ ) of 5,7-dichloro-2-[(dimethylamino)methyl]quinolin-8-ol (PBT2) or placebo [119]. After treatment for 26 weeks with this iron chelator, none or marginal improvements were found in cognitive tests. The authors concluded that PBT2 was generally safe and well tolerated, but the evaluation of potential benefits remains uncertain and in need of further studies.

\subsection{Alzheimer's Disease}

In an initial Phase-II trial with Alzheimer's disease patients, treatment with the iron-copper chelator clioquinol resulted in stabilization of Alzheimer's Disease Assessment Scale scores, compared to placebo-treated controls. In addition, plasma A $\beta 1-42$ levels declined in the clioquinol-treated group [120]. In a subsequent Phase-II double-blind trial, it was found that patients treated with doses of $250 \mathrm{mg}$ PBT2 exhibited a significant reduction in cerebrospinal fluid A $\beta 1-42$ concentration compared with those treated with placebo [121]. In addition, PBT2-treated patients showed significant improvement in executive function and cognition tests. No serious secondary effects were reported by patients receiving PBT2. The authors concluded that the findings of this study support larger-scale testing of PBT2 in Alzheimer's disease patients.

\section{Potential Risks of Iron Chelation Therapy}

Iron is vital to life, participating as an essential cofactor in essential cellular processes that include oxygen transport, energy production, DNA synthesis, and a myriad of hydrolysis and redox reactions [122]. Thus, therapeutic iron chelation may affect not only the intended target but also processes that are essential for cell function, generating cases in which "the cure is worse than the disease". Indeed, excessive iron depletion could result in cognitive decline, by decreasing the activity of enzymes and iron-containing complexes $[122,123]$ and the synthesis of neurotransmitters, such as dopamine, norepinephrine and serotonin [37,124-126]. Fortunately, cognitive decline has not been reported in clinical chelation trials for neurodegenerative diseases using therapeutic concentrations of deferasirox, deferiprone, PBT1 or PBT2 [115-119,121,127,128].

In thalassemia patients treated with high concentrations of deferiprone (75-99 mg/kg/day [129]), the most frequent adverse effects were arthritis, nausea and, more critically, agranulocytosis and neutropenia [130-133], whereas deferasirox was generally well tolerated, with mild gastrointestinal adverse effects [12,134]. A recent meta-analysis, which analyzed results from 34 studies with a total of 2040 young patients with hemoglobinopathies, found increased transaminase adverse effects (between $3.9 \%$ and $31.3 \%$ in the different studies) and gastrointestinal complaints for both deferiprone (3.7-18.4\%) and deferasirox (5.8-18.8\%) [135]. Other effects included arthritis, nausea and, most seriously, agranulocytosis in $0.6 \%$ to $4 \%$ of patients. This work concluded that there may be few but serious adverse reactions in performing iron chelation therapy with these chelators.

Another potential problem with iron chelation therapy is the depletion of other essential metal ions, in particular Zn and $\mathrm{Cu}[131,136,137]$. Accordingly, in a clinical trial of thalassemia with deferiprone, four of eight patients who received treatment for one year showed increased excretion of $\mathrm{Zn}$ in the urine and subnormal values of zinc in the serum, associated with areas of dry skin and itching. These symptoms were resolved with zinc supplementation [136].

There are no reports in the literature indicating that iron chelation therapy causes copper depletion. This is possibly because intracellular copper is not free but it is strongly bound to chaperones $[138,139]$.

From the previous analysis, it is clear that the concentration of the iron chelator should be finely tuned to achieve maximal effectiveness in removing excess redox-active iron, and at the same time avoiding toxicity and other side effects. 


\section{New Multifunctional Iron/Copper Chelators with Therapeutic Capacity}

The limited success of metal chelation therapy trials using deferiprone raises the need for novel multifunctional agents, which in addition to decreasing iron accumulation, will have the capacity to interfere with two or more symptoms of a given disease, thus improving the possibilities of stopping, and eventually reversing, the neurodegenerative process.

The question arises on what are the characteristics of an ideal compound for the therapeutic treatment of the vicious cycle of mitochondrial dysfunction-iron accumulation-oxidative damage-protein aggregation in neurodegenerative diseases (Figure 1). These basal properties include: (1) effectiveness via oral administration, which implies crossing the intestinal and blood-brain barrier without modification of its therapeutic properties. Compliance of treatment is better with oral drugs than those injected on a daily basis during long-term treatments [140]; (2) low molecular weight and high membrane permeability. The compound must fulfill the rule of 5 of Lipinski, an empirical model that allows one to evaluate qualitatively how a chemical compound could be absorbed once it is orally ingested as a medicine [141]. Desirable additional properties include (3) free radical quenching capacity independent of its iron chelation capacity. Free radical quenching should decrease lipid peroxidation, thus decreasing ferroptosis events [142]; (4) to undergo mitochondrial accumulation. The reason for this last property is that both high concentrations of ROS and high concentrations of iron coexist in the secluded space of the mitochondrion, which makes this organelle particularly prone to oxidative damage $[57,143,144]$; (5) to have intermediate $(\mu \mathrm{M})$ affinity and high specificity for iron, consequent with chelation of the redox-active (labile) iron pool, estimated to be in the micromolar range [134,135]; and (6) in addition, the chelator must have "shuttle" capacity, that is, the capacity to deliver excessive intracellular iron to innocuous acceptors such as transferrin or ferritin [145].

During the last two decades, several multifunctional agents (MFAs) have been reported to be effective in experimental models of Alzheimer's or Parkinson's disease. These agents are in an experimental phase, with no clinical trials associated with them. Table 1 shows the basic characteristics of these agents, including their metal chelation characteristics, their capacity to act as antioxidants/free-radical scavengers, their route of administration and blood-brain barrier permeability. We will review next the characteristics of MFAs that could become effective therapeutic agents.

Table 1. Iron chelators with multifunctional characteristics.

\begin{tabular}{|c|c|c|c|c|c|c|c|}
\hline Compound & Properties/Characteristics & Metal Specificity & $\begin{array}{l}\text { In-Vivo } \\
\text { Testing }\end{array}$ & $\begin{array}{c}\text { Route of } \\
\text { Administration }\end{array}$ & $\begin{array}{c}\text { Brain } \\
\text { Permeability }\end{array}$ & Disease Model & References \\
\hline EGCG & $\begin{array}{l}\text { Metal chelation; antioxidant; } \\
\text { neuroprotective; activation of } \\
\text { cell survival genes. }\end{array}$ & $\begin{array}{c}\mathrm{Cu}^{2+} ; \mathrm{Fe}^{3+} ; \mathrm{Al}^{3+} ; \\
\mathrm{Mn}^{2+}\end{array}$ & Yes & $\begin{array}{l}\text { Intraperitoneal; } \\
\text { Oral }\end{array}$ & Yes & $\mathrm{PD}, \mathrm{AD}$ & [146-150] \\
\hline $\begin{array}{l}\text { Hydroxyquinoline- } \\
\text { propargyl hybrids } \\
\text { M30, VAR10303 }\end{array}$ & $\begin{array}{c}\text { Metal chelation; MAO-B } \\
\text { inhibition; antiapoptotic; } \\
\text { activation of cell survival } \\
\text { genes; neuroprotective; } \\
\text { neuritogenic. }\end{array}$ & $\mathrm{Fe}^{3+}>\mathrm{Cu}^{2+}>\mathrm{Zn}^{2+}$ & Yes & Oral & Yes & $\begin{array}{c}\mathrm{PD}, \mathrm{AD}, \\
\text { amyotrophic lateral } \\
\text { sclerosis }\end{array}$ & [151-154] \\
\hline $\begin{array}{l}\text { Hydroxypyridinone } \\
\text { glycoconjugates } \\
\mathrm{H}_{2} \mathrm{GL}^{1}, \mathrm{H}_{2} \mathrm{GL}^{2}\end{array}$ & $\begin{array}{l}\text { Metal chelation; reduction of } \\
\text { amyloid-beta aggregation }\end{array}$ & $\mathrm{Cu}^{2+}>\mathrm{Zn}^{2+}$ & No & Not tested & $\begin{array}{l}\text { Not tested; } \\
\text { probably yes }\end{array}$ & $\mathrm{AD}$ & [155] \\
\hline Bis-tacrine hybrids & $\begin{array}{l}\text { Metal chelation; AChE } \\
\text { inhibition; reduction of } \\
\text { amyloid-beta aggregation }\end{array}$ & $\mathrm{Cu}^{2+}$ & No & Not tested & Not tested & $\mathrm{AD}$ & [156] \\
\hline
\end{tabular}


Table 1. Cont.

\begin{tabular}{|c|c|c|c|c|c|c|c|}
\hline Compound & Properties/Characteristics & Metal Specificity & $\begin{array}{l}\text { In-Vivo } \\
\text { Testing }\end{array}$ & $\begin{array}{c}\text { Route of } \\
\text { Administration }\end{array}$ & $\begin{array}{c}\text { Brain } \\
\text { Permeability }\end{array}$ & Disease Model & References \\
\hline $\begin{array}{l}\text { 8-OH-Quinoline- } \\
\text { tacrine hybrids }\end{array}$ & $\begin{array}{l}\text { Metal chelation; } \mathrm{AChE} \\
\text { inhibition }\end{array}$ & $\mathrm{Cu}^{2+}$ & No & Not tested & Probably yes & $\mathrm{AD}$ & [157] \\
\hline $\begin{array}{l}\text { Benzylamine-tacrine } \\
\text { hybrids }\end{array}$ & $\begin{array}{c}\text { Metal chelation; AChE } \\
\text { inhibition; inhibition of } \\
\text { amyloid-beta aggregation; } \\
\text { moderate antioxidant activity }\end{array}$ & $\mathrm{Cu}^{2+} ; \mathrm{Fe}^{2+} ; \mathrm{Zn}^{2+}$ & No & Not tested & Not tested & $\mathrm{AD}$ & {$[158]$} \\
\hline $\begin{array}{l}\text { Phenyl-benzimidazole- } \\
\text { tacrine hybrid }\end{array}$ & $\begin{array}{l}\text { AChE inhibition; metal } \\
\text { chelation; inhibition of } \\
\text { Cu-induced amyloid-beta } \\
\text { aggregation; free radical } \\
\text { scavenger }\end{array}$ & $\begin{array}{l}\mathrm{Cu}^{2+} \text {; other metals } \\
\text { not tested }\end{array}$ & No & Not tested & Not tested & $\mathrm{AD}$ & [159] \\
\hline $\begin{array}{l}\text { Coumarin-tacrine } \\
\text { hybrid }\end{array}$ & $\begin{array}{c}\text { Metal chelation; } \mathrm{AChE} \\
\text { inhibition; inhibition of } \\
\text { amyloid-beta aggregation; free } \\
\text { radical scavenger }\end{array}$ & $\begin{array}{l}\mathrm{Cu}^{2+} ; \text { other metals } \\
\text { not tested }\end{array}$ & No & Not tested & Not tested & $\mathrm{AD}$ & {$[160]$} \\
\hline $\begin{array}{l}\text { Piperazine-8-OH- } \\
\text { quinolone hybrids }\end{array}$ & $\begin{array}{l}\text { Metal chelation; dopamine } \\
\text { D2/D3 receptor agonists; } \\
\text { hydroxyl radical scavenger }\end{array}$ & $\mathrm{Fe}^{2+} ; \mathrm{Fe}^{3+}$ & Yes & Subcutaneous & Yes & $\mathrm{PD}$ & [161] \\
\hline $\begin{array}{l}\text { Dipyridyl-D2R/D3R } \\
\text { agonist hybrids }\end{array}$ & $\begin{array}{l}\text { Metal chelation; dopamine } \\
\text { D2/D3 receptor agonist; } \\
\text { antioxidant; neuroprotective }\end{array}$ & $\mathrm{Fe}^{2+}>>\mathrm{Fe}^{3+}$ & Yes & Intraperitoneal & Yes & $\mathrm{PD}$ & {$[162,163]$} \\
\hline Curcumin hybrids & $\begin{array}{l}\text { Metal chelation; antioxidant } \\
\text { activity; reduction of } \\
\text { amyloid-beta aggregation }\end{array}$ & $\mathrm{Cu}^{2+} ; \mathrm{Fe}^{2+}$ & No & Not tested & Not tested & $\mathrm{AD}$ & [164] \\
\hline $\begin{array}{l}\text { Benzyl-indanone } \\
\text { hybrid compound } 41\end{array}$ & $\begin{array}{c}\text { Metal chelation; antioxidant } \\
\text { activity; AChE inhibition; } \\
\text { inhibition of amyloid-beta } \\
\text { aggregation }\end{array}$ & $\mathrm{Cu}^{2+}$ & No & Not tested & Not tested & $\mathrm{AD}$ & [165] \\
\hline $\begin{array}{l}\text { Benzothiazole-linker- } \\
\text { pyridinone hybrids }\end{array}$ & $\begin{array}{l}\text { Metal chelation; antioxidant } \\
\text { activity; AChE inhibition; } \\
\text { inhibition of amyloid-beta } \\
\text { aggregation }\end{array}$ & $\mathrm{Fe}^{3+}$ & No & Not tested & Probably yes & $\mathrm{AD}$ & [166] \\
\hline $\begin{array}{c}\text { Clioquinol-selegiline } \\
\text { hybrids }\end{array}$ & $\begin{array}{c}\text { MAO-B inhibition; metal } \\
\text { chelation; antioxidant activity }\end{array}$ & $\mathrm{Cu}^{2+} ; \mathrm{Fe}^{2+} ; \mathrm{Zn}^{2+}$ & No & Not tested & Probably yes & $\mathrm{PD}$ & [167] \\
\hline $\begin{array}{l}\text { Deferiprone-H3 } \\
\text { receptor antagonist } \\
\text { hybrid C5 }\end{array}$ & $\begin{array}{l}\text { H3R inhibition; metal chelation; } \\
\text { antioxidant activity; reduction } \\
\text { of amyloid-beta aggregation }\end{array}$ & $\begin{array}{c}\mathrm{Cu}^{2+} \sim \mathrm{Fe}^{2+} \gg \gg \\
\mathrm{Zn}^{2+}\end{array}$ & Yes & Intraperitoneal & Yes & $\mathrm{AD}$ & [168] \\
\hline $\begin{array}{l}\text { 7,8-Dihydroxycoumarin } \\
\text { derivative DHC12 }\end{array}$ & $\begin{array}{l}\text { Metal chelation; } \mathrm{MAO}-\mathrm{B} \\
\text { inhibition; mitochondriotropic; } \\
\text { free radical scavenger; } \\
\text { neuroprotective }\end{array}$ & $\begin{aligned} \mathrm{Cu}^{2+} & \sim \mathrm{Fe}^{2+}>\mathrm{Zn}^{2+} \\
& >\mathrm{Fe}^{3+}\end{aligned}$ & Yes & Oral & Yes & $\mathrm{PD}$ & [169] \\
\hline $\begin{array}{c}\text { Coumarin-tris hybrid } \\
\text { CT51 }\end{array}$ & $\begin{array}{l}\text { Metal chelation; impedes } \\
\mathrm{Fe}^{2+} / \mathrm{Fe}^{3+} \text { cycling; antioxidant; } \\
\text { mitochondriotropic; calcium } \\
\text { upsurge blocker }\end{array}$ & $\mathrm{Fe}^{2+}>\mathrm{Fe}^{3+}$ & No & Not tested & Not tested & $\mathrm{PD}$ & {$[170]$} \\
\hline
\end{tabular}

\subsection{Epigallocatechin-3-Gallate (EGCG)}

The pioneering work of Youdim's group at Technion resulted in two of the best-characterized MFAs: EGCG, a component of green tea, and M30, an N-propargyl-8-hydroxyquinoline hybrid.

Epidemiological reports associate tea consumption with positive effects in the central nervous system function, such as reduced dementia incidence, delayed PD onset and diminished cognitive impairment in the elderly (reviewed in [171]). Additional studies have shown the neuroprotective effect of EGCG in the MPTP model of PD [146,149,150,172,173]. However, this neuroprotective effect may be secondary to the inhibition of the dopamine transporter (DAT) by EGCG $[148,174]$. Indeed, MPTP is metabolized to 1-methyl-4-phenylpyridinium (MPP+) by MAO-B in astrocytes; after release from astrocytes, MPP+ is transported into dopaminergic neurons via DAT $[175,176]$. Thus, ablation, or inhibition, of DAT results in neuroprotection against MPTP/MPP+ [177,178].

The protection exerted by EGCG probably involves direct scavenging of ROS such as superoxide, hydrogen peroxide and nitric oxide [179-181]. Nevertheless, the EGCG antioxidant effect is observed only at low concentrations. In-vitro studies show that high concentrations $(10-100 \mu \mathrm{M})$ of EGCG actually prompt pro-oxidant effects [182-186]. In rat hippocampal neurons, EGCG causes elevation of intracellular calcium and ROS in a dose-dependent way [185,187]. Downstream, high calcium/ROS levels were associated with reduction in the Bcl-2/Bax expression ratio, reduction of the mitochondrial membrane potential and apoptotic cell death $[185,188]$. 
In addition, EGCG has anti-inflammatory properties that may result in neuroprotection [189-191]. The administration of EGCG to rats subjected to restraint-induced stress improved open-field and step-through behavioral tests, through a mechanism that involves the restoration of PKC $\alpha$ and ERK1/2 expression, which were diminished by stress [192]. Furthermore, EGCG supplementation restores the production of ATP and the expression of the peroxisome proliferators-activated receptor- $\gamma$ coactivator-1 $\alpha$ (PGC-1 $\alpha$ ), a key regulator of energy production. The authors concluded that EGCG-mediated protection against stress-induced neural injuries is mediated by a PKC $\alpha$ and ERK1/2 signaling pathway linked to PGC- $1 \alpha$-mediated ATP production.

As shown in Table 1, EGCG is a rather promiscuous metal ion chelator, with affinity towards $\mathrm{Cu}$, $\mathrm{Fe}, \mathrm{Al}$ and $\mathrm{Mn}$. Since $\mathrm{Fe}, \mathrm{Cu}$ and $\mathrm{Mn}$ are redox-active, EGCG should decrease their redox cycling, thus decreasing the production of ROS.

In summary, EGCG has demonstrated antioxidant, anti-inflammatory and metal-binding properties that may be useful in the prevention of neuronal death. However, EGCG metal ion selectivity is poor, and high concentrations of EGCG promote oxidative damage and induce calcium upsurges that may end up in apoptotic cell death. The sum of these characteristics advises against the use of EGCG as an MFA in disease treatment.

\subsection{MAO-B Inhibitor Hybrids}

M30 was one of the first chelators designed with the purpose of multifunctionality, by linking the $\mathrm{Fe}^{3+}$ chelator 8-hydroxyquinoline to a propargyl group with MAO-B inhibition activity through a methyl-amino-methyl bridge [151]. M30 has been used successfully as a neuroprotective agent in models of PD, AD and ALS. In vivo, it is effective when given orally so most probably it crosses the intestinal and blood-brain barriers without loss of activity.

Multiple reports have shown the neuroprotective capacity of M30 in the MPTP model of PD. Since MPTP is metabolized to its active form MPP+ by MAO-B, and M30 inhibits the activity of MAO-B, an important caveat for the neuroprotection effect of M30 in the MPTP model is that it could be a reflection of deficient MPP+ formation.

Numerous effects, from antiapoptotic to neuritogenic, can be ascribed to the iron chelation capacity of M30 [193,194]. A major breakthrough was the finding that M30 activates the transcription factor HIF- $1 \alpha$ signaling pathway [195]. In fact, M30 stabilizes HIF- $1 \alpha$, by inactivating the prolyl hydroxylase that initiates its degradation, the activity of which depends on oxygen and Fe [196]. The stabilization of HIF $1 \alpha$ results in the increased transcription of HIF-1 $\alpha$-dependent genes, including vascular endothelial growth factor, erythropoietin, enolase-1, p21 and tyrosine hydroxylase. In addition, M30 also increases the expression levels of the transcripts of BDNF, GDNF and GAP-43 [195], and induces the expression of the antioxidant enzymes catalase, superoxide dismutase 1 (SOD1) and gGPx [152]. Immunoblot studies showed that M30 also enhances the phosphorylation of PKC, MAPK/ERK kinase, PKB/Akt and GSK-3 $\beta$ [152]. VAR10303, a derivative of M30, demonstrated properties similar to M30 [154], and was successfully tested in the SOD1(G93A) mice model of amyotrophic lateral sclerosis [197,198].

Discarding an effect of the propargyl moiety of M30 on gene expression, it is possible that the remarkable properties of M30 should be common to many iron chelators with the capacity to reach the brain at therapeutic doses. Importantly, the activation of HIF1 $\alpha$ by iron chelators opens a wide field of expectations for iron chelation therapy, evolving from merely inhibition of ROS production, which still holds, to the putative activation of neuroregenerative pathways.

\subsection{Glucose Hybrids}

A novel approach in the design of MFAs was the association of metal chelator moieties to glucose, under the consideration that these agents would be preferentially incorporated into the brain given the high density of hexose transporters (GLUTs) at the blood-brain barrier $[199,200]$. Once in the brain, these hybrids should be taken up by neurons and astrocytes, considered the cells of major energy consumption. Since astrocytes display preferential transport and metabolism of glucose compared 
to neurons [201], it would be expected that metal-hexose MFAs should preferentially accumulate in astrocytes. The hydroxypyridinone glycoconjugates $\mathrm{H}_{2} \mathrm{GL}^{1}$ and $\mathrm{H}_{2} \mathrm{GL}^{2}$ demonstrated substantial affinity for $\mathrm{Cu}^{2+}$ and $\mathrm{Zn}^{2+}$, and both agents decreased $\mathrm{A} \beta 1-40$ aggregation induced by $\mathrm{Cu}$ and $\mathrm{Zn}$. They also demonstrated antioxidant activity, probably through their phenolic moieties, capable of quenching free radicals by a hydroquinone/quinone conversion [155]. No in-vivo testing of these agents was reported, so their putative $\mathrm{Fe}^{3+}$-chelating and blood-brain barrier permeability properties remain undetermined.

\subsection{Acetyl Cholinesterase Inhibitor Hybrids}

Under the concept that inhibition of acetylcholinesterase (AChE) increases acetylcholine at cholinergic synapses, thus reducing the cognitive deficit [202,203], an approach for the putative treatment of $\mathrm{AD}$ is the design and synthesis of MFAs with AChE inhibition activity. This particular strategy is common for MFAs with a tacrine (a cholinesterase inhibitor) component [156-159] (Table 1). None of these compounds have been tested for brain permeability, although tacrine derivatives, without an iron chelator component, are brain-effective under intravenous and intranasal administrations [204]. At this stage, tests of effectiveness in animal models of AD are needed for further evaluation of their putative usefulness.

\subsection{Dopamine Receptor Agonist Hybrids}

19a, 19b and D-607 are dopamine D2/D3 receptor agonists and metal chelator hybrids, designed under the notion that D2/D3 receptor agonists have been used for the treatment of both motor and psychiatric syndromes in PD [179]. The three compounds demonstrated iron chelation and antioxidant capacity in vitro $[180,181]$. In addition, 19b partly reversed hypolocomotion in reserpinized rats, and reduced the rotational activity in a 6-OHDA/apomorphine model, thus demonstrating in-vivo neuroprotective activity [181]. D-607 was the product of a further D2/D3 agonist/chelator development by the same research group. The chelator moiety of D-607 was changed from 8-OH quinolone, a $\mathrm{Fe}^{3+}$ chelator, to bipyridyl, a Fe ${ }^{2+}$ chelator. D-607 was shown to suppress retinal degeneration in a Drosophila melanogaster PD model that expresses $\alpha$-synuclein A30P, a PD-causing variant of the protein [180]. In addition, D-607 was shown to confer significant neuroprotection in the mouse MPTP PD model under chronic MPTP administration [180]. Overall, the published evidence points to D-607 as a putative candidate for the pharmacological treatment of PD. A drawback is that D-607 is administrated intraperitoneally, and not orally, which may decrease hypothetical patient compliance.

\subsection{Curcumin Hybrids}

Curcumin analogs are proposed as potential anti-AD drugs, based on the radical scavenger $[182,183]$ and metal chelator $[184,185]$ properties of curcumin. Curcumin analogs A1-A10 were tested for their radical quenching activity and their ability to reduce metal-induced amyloid-beta aggregation [186]. A1, A2, A3 and A4 presented good radical quenching capacity in SH-SY5Y cells while the capacity of A5, A6, A7, A8, A9 and A10 was weak. All analogs, with the exception of A7, A8 and A10, presented the capacity to diminish amyloid beta self-aggregation at IC50s similar to curcumin. The authors reported $\mathrm{Fe}$ and $\mathrm{Cu}$ chelation capacity by A4 based on the red shift of absorbance peaks at $267 \mathrm{~nm}$ and $427 \mathrm{~nm}$. Nevertheless, A4 lacks the two adjacent ketone groups responsible for metal binding by coumarin [184] and it does not have putative metal binding groups in its structure, so the mechanism of iron binding is not apparent. No in-vivo studies were reported for these curcumin analogs.

\subsection{Benzothiazole-3-Hydroxy-4-Pyridine Hybrids}

Another approach for MFAs is the design of constructs of benzothiazole and 3-hydroxy-4-pyridine connected by a variable linker [83]. Given its hydrophobicity, benzothiazole has strong affinity for 
amyloid plaques $[84,85]$ while the 3-hydroxy-4-pyridine moiety (deferiprone) has strong $\mathrm{Fe}^{3+}$ chelation capacity. The linker between these two moieties was modelled in order to obtain AChE inhibitory capacity [83]. Of the tested compounds, $2 \mathrm{a}$ and $2 \mathrm{~d}$ formed $\mathrm{Fe}^{3+}$ chelates with affinities similar to deferiprone. The chelators displayed significant antioxidant properties, with compounds $1 \mathrm{a}, 1 \mathrm{~b}, 1 \mathrm{c}$ and $2 \mathrm{~d}$ having significant AChE inhibitory activity. Accordingly, these same hybrids presented good inhibitory capacity towards A $\beta 42$ self-aggregation, mostly above $40 \%$. In addition, hybrid $2 \mathrm{~d}$ inhibited zinc-induced A $\beta 1-42$ aggregation [83]. Overall, the hydroxypyridinone-spacer-benzothiazole hybrids appear as good candidate drugs for the treatment of $\mathrm{AD}$, but in-vivo testing is needed before further development.

\subsection{MAO-B Inhibitors}

On the basis of its moderate success in AD treatment [187], the MAO-B inhibitor selegiline has been used for the design of MFAs directed to the treatment of AD [188,189]. The most promising compounds are selegiline-clioquinol hybrids, which combine MAO-B inhibition with metal chelation capacity. Selegiline-clioquinol hybrids tested in vitro demonstrated inhibition of Cu-induced A $\beta 1-42$ aggregation, antioxidant activity and $\mathrm{Cu}^{2+}, \mathrm{Fe}^{2+}$ and $\mathrm{Zn}^{2+}$ chelation capacity [189]. Like other MFAs in a proof-of-concept step, demonstration of in-vivo effectiveness is needed.

\subsection{Histamine H3 Receptor Antagonists}

A different approach in the design of MFAs was the design of a histamine $\mathrm{H} 3$ receptor antagonist, 1-phenyl-3-hydroxy-4-pyridinone, and the 3-hydroxy-4-pyridinone iron chelator moiety of deferiprone [190], under the rationale that blocking the action of presynaptic $\mathrm{H} 3$ receptors produces increased secretion of histamine and other excitatory neurotransmitters [191]. H3 antagonist treatment results in modest effects on cognitive function [192]. The most promising compound, 5c, displayed H3 receptor antagonistic activity, free radical scavenging capacity, copper and iron chelation, and inhibition of self- and $\mathrm{Cu}^{2+}$-induced $\mathrm{A} \beta 1-42$ aggregation [190]. After intraperitoneal administration to Sprague Dawley rats, compound $5 \mathrm{c}$ demonstrated good blood-brain barrier penetration. In conclusion, the histamine $\mathrm{H} 3$ receptor antagonist-iron chelator hybrid $5 \mathrm{c}$ is brain-permeant and possesses four functions applicable for the treatment of $\mathrm{AD}$, which makes it a good therapeutic candidate.

\subsection{Coumarin Hybrids}

Two coumarin derivatives have been proposed as candidate drugs for the treatment of neurodegenerative conditions with an iron accumulation component $[193,194]$, based on the known qualities of hydroxycoumarins as free radical quenchers [195] and metal chelator [196,197] agents. DHC12 is a 7,8-dihydroxycoumarin with an amino substituent group at position four of the coumarin ring [193]. The molecule is small and quite simple; nevertheless, it has interesting neuroprotective features. DHC12 exhibited metal binding capacity for $\mathrm{Fe}^{2+}$ and $\mathrm{Cu}^{2+}$. $\mathrm{DHC12}$ distributed to mitochondria, where it chelated the mitochondrial and cytoplasmic labile iron pool. In a cell model of PD, DHC12 protected cells from plasma membrane and mitochondrial oxidative damage. Oral administration of DHC12 protected sustantia nigra neurons in the MPTP model of PD. On the whole, DHC12 emerges as a good candidate for further development as a PD treatment drug.

CT51 is a hybrid of 7-hydroxycoumarin linked through an acetomethyl group to tris(hydroxymethyl) aminomethane (tris). The hydroxyl group in the coumarin ring quenches free radicals [195] while the three hydroxyl residues of tris provide metal binding capacity [198]. In vitro, CT51 exhibited selective $\mathrm{Fe}^{2+}$ and $\mathrm{Fe}^{3+}$ binding with no apparent interaction with $\mathrm{Cu}^{2+}, \mathrm{Zn}^{2+}$ and other divalent cations. It also demonstrated free radical quenching capacity superior to Trolox. Interestingly, cyclic voltammetry analysis revealed irreversible binding of $\mathrm{Fe}^{3+}$ to CT51, an important finding since stopping $\mathrm{Fe}^{2+} / \mathrm{Fe}^{3+}$ cycling in cells should prevent hydroxyl radical production fostered by oxygen and intracellular reductants [8]. In SH-SY5Y cells, CT51 distributed to both mitochondria and cytoplasm bound iron reversibly and protected against rotenone-induced oxidative damage, while in primary hippocampal 
neurons, CT51 largely prevented the increase in intracellular calcium levels produced by an agonist of redox-sensitive RyR channels [194]. These capacities so-far demonstrated make CT51 a good therapeutic candidate for the treatment of PD, although in-vivo efficacy needs to be demonstrated.

\section{Conclusions}

The aging of the world population introduces an ever-increasing burden of neurodegenerative diseases on public health systems worldwide. Among these diseases, Parkinson's, Alzheimer's and other diseases with an iron accumulation component are at the top of the list. Based on initial trials using the iron chelators deferiprone and PBT2, the metalloneurobiology community has reached the conclusion that therapies targeted to decrease the iron content in specific areas of the brain is a viable course of action to slow or stop the progress of these diseases.

Given the multifactoriality of the neurodegenerative process, the use of multifunctional iron chelators is a promising developmental avenue. As discussed in the text, additional properties of future iron chelator drugs should comprise high selectivity for iron, free radical quenching capacity, mitochondrial distribution and the capacity to block protein aggregation. Several of the compounds now in experimental stages have one or more of these additional characteristics. Let us hope that further research will provide treatments that are both effective and affordable for public health systems.

Author Contributions: M.T.N. and P.C.-C. wrote the paper.

Acknowledgments: M.T.N. and P.C.-C. were supported by FONDEF project 17I10095 from National Commission of Science and Technology (CONICYT) of Chile. We thank Cecilia Hidalgo for the critical reviewing of this paper.

Conflicts of Interest: The authors declare no conflicts of interest.

\section{References}

1. Hallgren, B.; Sourander, P. The effect of age on the non-haemin iron in the human brain. J. Neurochem. 1958, 3, 41-51. [CrossRef] [PubMed]

2. Zecca, L.; Youdim, M.B.; Riederer, P.; Connor, J.R.; Crichton, R.R. Iron, brain ageing and neurodegenerative disorders. Nat. Rev. Neurosci. 2004, 5, 863-873. [CrossRef] [PubMed]

3. Crichton, R.R.; Dexter, D.T.; Ward, R.J. Brain iron metabolism and its perturbation in neurological diseases. J. Neural Transm. 2011, 118, 301-314. [CrossRef] [PubMed]

4. Garry, P.J.; Goodwin, J.S.; Hunt, W.C. Iron status and anemia in the elderly: New findings and a review of previous studies. J. Am. Geriatr. Soc. 1983, 31, 389-399. [CrossRef] [PubMed]

5. Ward, R.J.; Zucca, F.A.; Duyn, J.H.; Crichton, R.R.; Zecca, L. The role of iron in brain ageing and neurodegenerative disorders. Lancet Neurol. 2014, 13, 1045-1060. [CrossRef]

6. Nunez, M.T.; Urrutia, P.; Mena, N.; Aguirre, P.; Tapia, V.; Salazar, J. Iron toxicity in neurodegeneration. Biometals 2012, 25, 761-776. [CrossRef] [PubMed]

7. Apostolakis, S.; Kypraiou, A.M. Iron in neurodegenerative disorders: Being in the wrong place at the wrong time? Rev. Neurosci. 2017, 28, 893-911. [CrossRef] [PubMed]

8. Munoz, Y.; Carrasco, C.M.; Campos, J.D.; Aguirre, P.; Nunez, M.T. Parkinson's Disease: The MitochondriaIron Link. Parkinson Dis. 2016, 2016, 7049108.

9. Carocci, A.; Catalano, A.; Sinicropi, M.S.; Genchi, G. Oxidative stress and neurodegeneration: The involvement of iron. Biometals 2018. [CrossRef] [PubMed]

10. Kolnagou, A.; Kontoghiorghe, C.N.; Kontoghiorghes, G.J. New targeted therapies and diagnostic methods for iron overload diseases. Front. Biosci. 2018, 10, 1-20.

11. Kwiatkowski, J.L. Management of transfusional iron overload-Differential properties and efficacy of iron chelating agents. J. Blood Med. 2011, 2, 135-149. [CrossRef] [PubMed]

12. Poggiali, E.; Cassinerio, E.; Zanaboni, L.; Cappellini, M.D. An update on iron chelation therapy. Blood Transfus. 2012, 10, 411-422. [PubMed]

13. Saliba, A.N.; Harb, A.R.; Taher, A.T. Iron chelation therapy in transfusion-dependent thalassemia patients: Current strategies and future directions. J. Blood Med. 2015, 6, 197-209. [PubMed] 
14. Flaten, T.P.; Aaseth, J.; Andersen, O.; Kontoghiorghes, G.J. Iron mobilization using chelation and phlebotomy. J. Trace Elem. Med. Boil. 2012, 26, 127-130. [CrossRef] [PubMed]

15. Cohen, A.; Martin, M.; Schwartz, E. Depletion of excessive liver iron stores with desferrioxamine. Br. J. Haematol. 1984, 58, 369-373. [CrossRef] [PubMed]

16. Lee, J.H.; Han, Y.H.; Kang, B.M.; Mun, C.W.; Lee, S.J.; Baik, S.K. Quantitative assessment of subcortical atrophy and iron content in progressive supranuclear palsy and parkinsonian variant of multiple system atrophy. J. Neurol. 2013, 260, 2094-2101. [CrossRef] [PubMed]

17. Youdim, M.B.; Ben-Shachar, D.; Riederer, P. Is Parkinson's disease a progressive siderosis of substantia nigra resulting in iron and melanin induced neurodegeneration? Acta Neurol. Scand. Suppl. 1989, 126, 47-54. [CrossRef] [PubMed]

18. Savoiardo, M. Differential diagnosis of Parkinson's disease and atypical parkinsonian disorders by magnetic resonance imaging. Neurol. Sci. 2003, 24 (Suppl. S1), S35-S37. [CrossRef] [PubMed]

19. Lee, S.H.; Lyoo, C.H.; Ahn, S.J.; Rinne, J.O.; Lee, M.S. Brain regional iron contents in progressive supranuclear palsy. Park. Relat. Disord. 2017, 45, 28-32. [CrossRef] [PubMed]

20. Fernandez, B.; Ferrer, I.; Gil, F.; Hilfiker, S. Biomonitorization of iron accumulation in the substantia nigra from Lewy body disease patients. Toxicol. Rep. 2017, 4, 188-193. [CrossRef] [PubMed]

21. Martin-Bastida, A.; Lao-Kaim, N.P.; Loane, C.; Politis, M.; Roussakis, A.A.; Valle-Guzman, N.; Kefalopoulou, Z.; Paul-Visse, G.; Widner, H.; Xing, Y.; et al. Motor associations of iron accumulation in deep grey matter nuclei in Parkinson's disease: A cross-sectional study of iron-related magnetic resonance imaging susceptibility. Eur. J. Neurol. 2017, 24, 357-365. [CrossRef] [PubMed]

22. Bartzokis, G.; Cummings, J.; Perlman, S.; Hance, D.B.; Mintz, J. Increased basal ganglia iron levels in Huntington disease. Arch. Neurol. 1999, 56, 569-574. [CrossRef] [PubMed]

23. Smith, M.A.; Harris, P.L.; Sayre, L.M.; Perry, G. Iron accumulation in Alzheimer disease is a source of redox-generated free radicals. Proc. Natl. Acad. Sci. USA 1997, 94, 9866-9868. [CrossRef] [PubMed]

24. Perry, G.; Taddeo, M.A.; Petersen, R.B.; Castellani, R.J.; Harris, P.L.; Siedlak, S.L.; Cash, A.D.; Liu, Q.; Nunomura, A.; Atwood, C.S.; et al. Adventiously-bound redox active iron and copper are at the center of oxidative damage in Alzheimer disease. Biometals 2003, 16, 77-81. [CrossRef] [PubMed]

25. Lane, D.J.R.; Ayton, S.; Bush, A.I. Iron and Alzheimer's Disease: An Update on Emerging Mechanisms. J. Alzheimer's Dis. 2018, 64, S379-S395. [CrossRef] [PubMed]

26. Bartzokis, G.; Sultzer, D.; Cummings, J.; Holt, L.E.; Hance, D.B.; Henderson, V.W.; Mintz, J. In vivo evaluation of brain iron in Alzheimer disease using magnetic resonance imaging. Arch. Gen. Psychiatry 2000, 57, 47-53. [CrossRef] [PubMed]

27. Bulk, M.; Abdelmoula, W.M.; Nabuurs, R.J.A.; van der Graaf, L.M.; Mulders, C.W.H.; Mulder, A.A.; Jost, C.R.; Koster, A.J.; van Buchem, M.A.; Natte, R.; et al. Postmortem MRI and histology demonstrate differential iron accumulation and cortical myelin organization in early- and late-onset Alzheimer's disease. Neurobiol. Aging 2018, 62, 231-242. [CrossRef] [PubMed]

28. Chiang, S.; Kovacevic, Z.; Sahni, S.; Lane, D.J.; Merlot, A.M.; Kalinowski, D.S.; Huang, M.L.; Richardson, D.R. Frataxin and the molecular mechanism of mitochondrial iron-loading in Friedreich's ataxia. Clin. Sci. 2016, 130, 853-870. [CrossRef] [PubMed]

29. Fermin-Delgado, R.; Roa-Sanchez, P.; Speckter, H.; Perez-Then, E.; Rivera-Mejia, D.; Foerster, B.; Stoeter, P. Involvement of globus pallidus and midbrain nuclei in pantothenate kinase-associated neurodegeneration: Measurement of T2 and T2* time. Clin. Neuroradiol. 2013, 23, 11-15. [CrossRef] [PubMed]

30. Rossi, D.; De Grandis, E.; Barzaghi, C.; Mascaretti, M.; Garavaglia, B.; Zanotto, E.; Morana, G.; Biancheri, R. Early-onset neurodegeneration with brain iron accumulation due to PANK2 mutation. Brain Dev. 2012, 34, 536-538. [CrossRef] [PubMed]

31. Swaiman, K.F. Hallervorden-Spatz syndrome and brain iron metabolism. Arch. Neurol. 1991, 48, 1285-1293. [CrossRef] [PubMed]

32. Hayflick, S.J.; Kurian, M.A.; Hogarth, P. Neurodegeneration with brain iron accumulation. Handb. Clin. Neurol. 2018, 147, 293-305. [PubMed]

33. Poplawska-Domaszewicz, K.; Florczak-Wyspianska, J.; Kozubski, W. Update on neurodegeneration with brain iron accumulation. Neurol. I Neurochir. Polska 2014, 48, 206-213. [CrossRef] [PubMed]

34. Tonekaboni, S.H.; Mollamohammadi, M. Neurodegeneration with brain iron accumulation: An overview. Iran. J. Child Neurol. 2014, 8, 1-8. [PubMed] 
35. Wiethoff, S.; Houlden, H. Neurodegeneration with brain iron accumulation. Handb. Clin. Neurol. 2017, 145, 157-166. [PubMed]

36. Moreau, C.; Duce, J.A.; Rascol, O.; Devedjian, J.C.; Berg, D.; Dexter, D.; Cabantchik, Z.I.; Bush, A.I.; Devos, D. Iron as a therapeutic target for Parkinson's disease. Mov. Disord. 2018, 33, 568-574. [CrossRef] [PubMed]

37. Lehmann, W.D.; Heinrich, H.C. Impaired phenylalanine-tyrosine conversion in patients with iron-deficiency anemia studied by a L-(2H5)phenylalanine-loading test. Am. J. Clin. Nutr. 1986, 44, 468-474. [CrossRef] [PubMed]

38. Ohnishi, T. Iron-sulfur clusters/semiquinones in complex I. Biochim. Biophys. Acta 1998, 1364, 186-206. [CrossRef]

39. Stiban, J.; So, M.; Kaguni, L.S. Iron-Sulfur Clusters in Mitochondrial Metabolism: Multifaceted Roles of a Simple Cofactor. Biochem. 2016, 81, 1066-1080. [CrossRef] [PubMed]

40. Segura-Aguilar, J.; Metodiewa, D.; Welch, C.J. Metabolic activation of dopamine o-quinones to o-semiquinones by NADPH cytochrome P450 reductase may play an important role in oxidative stress and apoptotic effects. Biochim. Biophys. Acta 1998, 1381, 1-6. [CrossRef]

41. Arriagada, C.; Paris, I.; Sanchez de las Matas, M.J.; Martinez-Alvarado, P.; Cardenas, S.; Castaneda, P.; Graumann, R.; Perez-Pastene, C.; Olea-Azar, C.; Couve, E.; et al. On the neurotoxicity mechanism of leukoaminochrome o-semiquinone radical derived from dopamine oxidation: Mitochondria damage, necrosis, and hydroxyl radical formation. Neurobiol. Dis. 2004, 16, 468-477. [CrossRef] [PubMed]

42. Zoccarato, F.; Toscano, P.; Alexandre, A. Dopamine-derived dopaminochrome promotes $\mathrm{H}(2) \mathrm{O}(2)$ release at mitochondrial complex I: Stimulation by rotenone, control by $\mathrm{Ca}(2+)$, and relevance to Parkinson disease. J. Biol. Chem. 2005, 280, 15587-15594. [CrossRef] [PubMed]

43. Uranga, R.M.; Salvador, G.A. Unraveling the Burden of Iron in Neurodegeneration: Intersections with Amyloid Beta Peptide Pathology. Oxidative Med. Cell. Longev. 2018, 2018, 2850341. [CrossRef] [PubMed]

44. Salazar, J.; Mena, N.; Núñez, M.T. Iron dyshomeostasis in Parkinson's disease. J. Neural Transm. Suppl. 2006, 205-213.

45. Mena, N.P.; Bulteau, A.L.; Salazar, J.; Hirsch, E.C.; Núñez, M.T. Effect of mitochondrial complex I inhibition on Fe-S cluster protein activity. Biochem. Biophys. Res. Commun. 2011, 409, 241-246. [CrossRef] [PubMed]

46. Urrutia, P.J.; Aguirre, P.; Tapia, V.; Carrasco, C.M.; Mena, N.P.; Nunez, M.T. Cell death induced by mitochondrial complex I inhibition is mediated by Iron Regulatory Protein 1. Biochim. Biophys. Acta 2017. [CrossRef] [PubMed]

47. Lee, S.J. alpha-synuclein aggregation: A link between mitochondrial defects and Parkinson's disease? Antioxid. Redox Signal. 2003, 5, 337-348. [CrossRef] [PubMed]

48. Betarbet, R.; Canet-Aviles, R.M.; Sherer, T.B.; Mastroberardino, P.G.; McLendon, C.; Kim, J.H.; Lund, S.; $\mathrm{Na}$, H.M.; Taylor, G.; Bence, N.F.; et al. Intersecting pathways to neurodegeneration in Parkinson's disease: Effects of the pesticide rotenone on DJ-1, alpha-synuclein, and the ubiquitin-proteasome system. Neurobiol. Dis. 2006, 22, 404-420. [CrossRef] [PubMed]

49. Esteves, A.R.; Arduino, D.M.; Silva, D.F.; Oliveira, C.R.; Cardoso, S.M. Mitochondrial Dysfunction: The Road to Alpha-Synuclein Oligomerization in PD. Parkinson Dis. 2011, 2011, 693761. [CrossRef] [PubMed]

50. Karmacharya, M.B.; Hada, B.; Park, S.R.; Choi, B.H. Low-Intensity Ultrasound Decreases alpha-Synuclein Aggregation via Attenuation of Mitochondrial Reactive Oxygen Species in MPP(+)-Treated PC12 Cells. Mol. Neurobiol. 2017, 54, 6235-6244. [CrossRef] [PubMed]

51. Hashimoto, M.; Rockenstein, E.; Crews, L.; Masliah, E. Role of protein aggregation in mitochondrial dysfunction and neurodegeneration in Alzheimer's and Parkinson's diseases. Neuromol. Med. 2003, 4, 21-36. [CrossRef]

52. Reeve, A.K.; Ludtmann, M.H.; Angelova, P.R.; Simcox, E.M.; Horrocks, M.H.; Klenerman, D.; Gandhi, S.; Turnbull, D.M.; Abramov, A.Y. Aggregated alpha-synuclein and complex I deficiency: Exploration of their relationship in differentiated neurons. Cell Death Dis. 2015, 6, e1820. [CrossRef] [PubMed]

53. Rocha, E.M.; De Miranda, B.; Sanders, L.H. Alpha-synuclein: Pathology, mitochondrial dysfunction and neuroinflammation in Parkinson's disease. Neurobiol. Dis. 2018, 109, 249-257. [CrossRef] [PubMed]

54. Faustini, G.; Bono, F.; Valerio, A.; Pizzi, M.; Spano, P.; Bellucci, A. Mitochondria and alpha-Synuclein: Friends or Foes in the Pathogenesis of Parkinson's Disease? Genes 2017, 8, 377. [CrossRef] [PubMed]

55. Mullin, S.; Schapira, A. alpha-Synuclein and mitochondrial dysfunction in Parkinson's disease. Mol. Neurobiol. 2013, 47, 587-597. [CrossRef] [PubMed] 
56. Belaidi, A.A.; Bush, A.I. Iron neurochemistry in Alzheimer's disease and Parkinson's disease: Targets for therapeutics. J. Neurochem. 2015. [CrossRef] [PubMed]

57. Mena, N.P.; Urrutia, P.J.; Lourido, F.; Carrasco, C.M.; Núñez, M.T. Mitochondrial iron homeostasis and its dysfunctions in neurodegenerative disorders. Mitochondrion 2015, 21, 92-105. [CrossRef] [PubMed]

58. Eid, R.; Arab, N.T.; Greenwood, M.T. Iron mediated toxicity and programmed cell death: A review and a re-examination of existing paradigms. Biochim. Biophys. Acta 2017, 1864, 399-430. [CrossRef] [PubMed]

59. Murphy, C.J.; Oudit, G.Y. Iron-overload cardiomyopathy: Pathophysiology, diagnosis, and treatment. J. Card. Fail. 2010, 16, 888-900. [CrossRef] [PubMed]

60. Fisher, S.A.; Brunskill, S.J.; Doree, C.; Chowdhury, O.; Gooding, S.; Roberts, D.J. Oral deferiprone for iron chelation in people with thalassaemia. Cochrane Database Syst. Rev. 2013. [CrossRef] [PubMed]

61. Gulati, V.; Harikrishnan, P.; Palaniswamy, C.; Aronow, W.S.; Jain, D.; Frishman, W.H. Cardiac involvement in hemochromatosis. Cardiol. Rev. 2014, 22, 56-68. [CrossRef] [PubMed]

62. Brissot, P. Optimizing the diagnosis and the treatment of iron overload diseases. Expert Rev. Gastroenterol. Hepatol. 2016, 10, 359-370. [CrossRef] [PubMed]

63. Belmont, A.; Kwiatkowski, J.L. Deferiprone for the treatment of transfusional iron overload in thalassemia. Expert Rev. Hematol. 2017, 10, 493-503. [CrossRef] [PubMed]

64. Bollig, C.; Schell, L.K.; Rucker, G.; Allert, R.; Motschall, E.; Niemeyer, C.M.; Bassler, D.; Meerpohl, J.J. Deferasirox for managing iron overload in people with thalassaemia. Cochrane Database Syst. Rev. 2017, 8, Cd007476. [CrossRef] [PubMed]

65. Aydinok, Y. Iron Chelation Therapy as a Modality of Management. Hematol. Oncol. Clin. N. Am. 2018, 32, 261-275. [CrossRef] [PubMed]

66. Diez-Lopez, C.; Comin-Colet, J.; Gonzalez-Costello, J. Iron overload cardiomyopathy: From diagnosis to management. Curr. Opin. Cardiol. 2018, 33, 334-340. [CrossRef] [PubMed]

67. Ballas, S.K.; Zeidan, A.M.; Duong, V.H.; DeVeaux, M.; Heeney, M.M. The effect of iron chelation therapy on overall survival in sickle cell disease and beta-thalassemia: A systematic review. Am. J. Hematol. 2018. [CrossRef] [PubMed]

68. Ward, R.J.; Dexter, D.T.; Crichton, R.R. Neurodegenerative diseases and therapeutic strategies using iron chelators. J. Trace Elem. Med. Boil. 2015, 31, 267-273. [CrossRef] [PubMed]

69. Devos, D.; Moreau, C.; Devedjian, J.C.; Kluza, J.; Petrault, M.; Laloux, C.; Jonneaux, A.; Ryckewaert, G.; Garçon, G.; Rouaix, N.; et al. Targeting chelatable iron as a therapeutic modality in Parkinson's disease. Antioxid. Redox Signal. 2014, 21, 195-210. [CrossRef] [PubMed]

70. Dusek, P.; Schneider, S.A.; Aaseth, J. Iron chelation in the treatment of neurodegenerative diseases. J. Trace Elem. Med. Boil. 2016. [CrossRef] [PubMed]

71. Shvartsman, M.; Kikkeri, R.; Shanzer, A.; Cabantchik, Z.I. Non-transferrin-bound iron reaches mitochondria by a chelator-inaccessible mechanism: Biological and clinical implications. Am. J. Physiol. Cell Physiol. 2007, 293, C1383-C1394. [CrossRef] [PubMed]

72. Grolez, G.; Moreau, C.; Sablonniere, B.; Garcon, G.; Devedjian, J.C.; Meguig, S.; Gele, P.; Delmaire, C.; Bordet, R.; Defebvre, L.; et al. Ceruloplasmin activity and iron chelation treatment of patients with Parkinson's disease. BMC Neurol. 2015, 15, 74. [CrossRef] [PubMed]

73. Martin-Bastida, A.; Ward, R.J.; Newbould, R.; Piccini, P.; Sharp, D.; Kabba, C.; Patel, M.C.; Spino, M.; Connelly, J.; Tricta, F.; et al. Brain iron chelation by deferiprone in a phase 2 randomised double-blinded placebo controlled clinical trial in Parkinson's disease. Sci. Rep. 2017, 7, 1398. [CrossRef] [PubMed]

74. Pandolfo, M. Friedreich's ataxia: Clinical aspects and pathogenesis. Semin. Neurol. 1999, 19, 311-321. [CrossRef] [PubMed]

75. Gordon, N. Friedreich's ataxia and iron metabolism. Brain Dev. 2000, 22, 465-468. [CrossRef]

76. Richardson, D.R.; Mouralian, C.; Ponka, P.; Becker, E. Development of potential iron chelators for the treatment of Friedreich's ataxia: Ligands that mobilize mitochondrial iron. Biochim. Biophys. Acta 2001, 1536, 133-140. [CrossRef]

77. Richardson, D.R. Friedreich's ataxia: Iron chelators that target the mitochondrion as a therapeutic strategy? Expert Opin. Investig. Drugs 2003, 12, 235-245. [CrossRef] [PubMed]

78. Boddaert, N.; Le Quan Sang, K.H.; Rotig, A.; Leroy-Willig, A.; Gallet, S.; Brunelle, F.; Sidi, D.; Thalabard, J.C.; Munnich, A.; Cabantchik, Z.I. Selective iron chelation in Friedreich ataxia: Biologic and clinical implications. Blood 2007, 110, 401-408. [CrossRef] [PubMed] 
79. Pandolfo, M.; Hausmann, L. Deferiprone for the treatment of Friedreich's ataxia. J. Neurochem. 2013, 126 (Suppl. S1), 142-146. [CrossRef] [PubMed]

80. Velasco-Sanchez, D.; Aracil, A.; Montero, R.; Mas, A.; Jimenez, L.; O'Callaghan, M.; Tondo, M.; Capdevila, A.; Blanch, J.; Artuch, R.; et al. Combined therapy with idebenone and deferiprone in patients with Friedreich's ataxia. Cerebellum 2011, 10, 1-8. [CrossRef] [PubMed]

81. Elincx-Benizri, S.; Glik, A.; Merkel, D.; Arad, M.; Freimark, D.; Kozlova, E.; Cabantchik, I.; Hassin-Baer, S. Clinical Experience With Deferiprone Treatment for Friedreich Ataxia. J. Child Neurol. 2016, 31, 1036-1040. [CrossRef] [PubMed]

82. Pandolfo, M.; Arpa, J.; Delatycki, M.B.; Le Quan Sang, K.H.; Mariotti, C.; Munnich, A.; Sanz-Gallego, I.; Tai, G.; Tarnopolsky, M.A.; Taroni, F.; et al. Deferiprone in Friedreich ataxia: A 6-month randomized controlled trial. Ann. Neurol. 2014, 76, 509-521. [CrossRef] [PubMed]

83. Arpa, J.; Sanz-Gallego, I.; Rodriguez-de-Rivera, F.J.; Dominguez-Melcon, F.J.; Prefasi, D.; Oliva-Navarro, J.; Moreno-Yanguela, M. Triple therapy with deferiprone, idebenone and riboflavin in Friedreich's ataxia-Open-label trial. Acta Neurol. Scand. 2014, 129, 32-40. [CrossRef] [PubMed]

84. Limongi, J.C. Neurodegeneration with brain iron accumulation. Arq. Neuro-Psiquiatr. 2016, 74, 517-518. [CrossRef] [PubMed]

85. Meyer, E.; Kurian, M.A.; Hayflick, S.J. Neurodegeneration with Brain Iron Accumulation: Genetic Diversity and Pathophysiological Mechanisms. Annu. Rev Genom. Hum. Genet. 2015, 16, 257-279. [CrossRef] [PubMed]

86. Salomao, R.P.; Pedroso, J.L.; Gama, M.T.; Dutra, L.A.; Maciel, R.H.; Godeiro-Junior, C.; Chien, H.F.; Teive, H.A.; Cardoso, F.; Barsottini, O.G. A diagnostic approach for neurodegeneration with brain iron accumulation: Clinical features, genetics and brain imaging. Arq. Neuro-Psiquiatr. 2016, 74, 587-596. [CrossRef] [PubMed]

87. Gregory, A.; Hayflick, S.J. Pantothenate Kinase-Associated Neurodegeneration. In Genereviews $((R))$; Adam, M.P., Ardinger, H.H., Pagon, R.A., Wallace, S.E., Bean, L.J.H., Stephens, K., Amemiya, A., Eds.; University of Washington: Seattle, WA, USA, 2018.

88. Vakili, S.; Drew, A.L.; Von Schuching, S.; Becker, D.; Zeman, W. Hallervorden-Spatz syndrome. Arch. Neurol. 1977, 34, 729-738. [CrossRef] [PubMed]

89. Schaffert, D.A.; Johnsen, S.D.; Johnson, P.C.; Drayer, B.P. Magnetic resonance imaging in pathologically proven Hallervorden-Spatz disease. Neurology 1989, 39, 440-442. [CrossRef] [PubMed]

90. Koeppen, A.H.; Dickson, A.C. Iron in the Hallervorden-Spatz syndrome. Pediatr. Neurol. 2001, 25, 148-155. [CrossRef]

91. Gregory, A.; Kurian, M.A.; Maher, E.R.; Hogarth, P.; Hayflick, S.J. PLA2G6-Associated Neurodegeneration. In Genereviews((R)); Adam, M.P., Ardinger, H.H., Pagon, R.A., Wallace, S.E., Bean, L.J.H., Stephens, K., Amemiya, A., Eds.; University of Washington: Seattle, WA, USA, 1993.

92. Kurian, M.A.; Hayflick, S.J. Pantothenate kinase-associated neurodegeneration (PKAN) and PLA2G6-associated neurodegeneration (PLAN): Review of two major neurodegeneration with brain iron accumulation (NBIA) phenotypes. Int. Rev. Neurobiol. 2013, 110, 49-71. [PubMed]

93. Simonati, A.; Trevisan, C.; Salviati, A.; Rizzuto, N. Neuroaxonal dystrophy with dystonia and pallidal involvement. Neuropediatrics 1999, 30, 151-154. [CrossRef] [PubMed]

94. Wakabayashi, K.; Fukushima, T.; Koide, R.; Horikawa, Y.; Hasegawa, M.; Watanabe, Y.; Noda, T.; Eguchi, I.; Morita, T.; Yoshimoto, M.; et al. Juvenile-onset generalized neuroaxonal dystrophy (Hallervorden-Spatz disease) with diffuse neurofibrillary and lewy body pathology. Acta Neuropathol. 2000, 99, 331-336. [CrossRef] [PubMed]

95. Hogarth, P.; Gregory, A.; Kruer, M.C.; Sanford, L.; Wagoner, W.; Natowicz, M.R.; Egel, R.T.; Subramony, S.H.; Goldman, J.G.; Berry-Kravis, E.; et al. New NBIA subtype: Genetic, clinical, pathologic, and radiographic features of MPAN. Neurology 2013, 80, 268-275. [CrossRef] [PubMed]

96. Schulte, E.C.; Claussen, M.C.; Jochim, A.; Haack, T.; Hartig, M.; Hempel, M.; Prokisch, H.; Haun-Junger, U.; Winkelmann, J.; Hemmer, B.; et al. Mitochondrial membrane protein associated neurodegenration: A novel variant of neurodegeneration with brain iron accumulation. Mov. Disord. 2013, 28, 224-227. [CrossRef] [PubMed]

97. Hartig, M.; Prokisch, H.; Meitinger, T.; Klopstock, T. Mitochondrial membrane protein-associated neurodegeneration (MPAN). Int. Rev. Neurobiol. 2013, 110, 73-84. [PubMed]

98. Deutschlander, A.; Konno, T.; Ross, O.A. Mitochondrial membrane protein-associated neurodegeneration. Parkinsonism Relat. Disord. 2017, 39, 1-3. [CrossRef] [PubMed] 
99. Haack, T.B.; Hogarth, P.; Gregory, A.; Prokisch, H.; Hayflick, S.J. BPAN: The only X-linked dominant NBIA disorder. Int. Rev. Neurobiol. 2013, 110, 85-90. [PubMed]

100. Verhoeven, W.M.; Egger, J.I.; Koolen, D.A.; Yntema, H.; Olgiati, S.; Breedveld, G.J.; Bonifati, V.; van de Warrenburg, B.P. Beta-propeller protein-associated neurodegeneration (BPAN), a rare form of NBIA: Novel mutations and neuropsychiatric phenotype in three adult patients. Parkinsonism Relat. Disord. 2014, 20, 332-336. [CrossRef] [PubMed]

101. Evers, C.; Seitz, A.; Assmann, B.; Opladen, T.; Karch, S.; Hinderhofer, K.; Granzow, M.; Paramasivam, N.; Eils, R.; Diessl, N.; et al. Diagnosis of CoPAN by whole exome sequencing: Waking up a sleeping tiger's eye. Am. J. Med. Genet. Part A 2017. [CrossRef] [PubMed]

102. Annesi, G.; Gagliardi, M.; Iannello, G.; Quattrone, A.; Iannello, G.; Quattrone, A. Mutational analysis of COASY in an Italian patient with NBIA. Parkinsonism Relat. Disord. 2016, 28, 150-151. [CrossRef] [PubMed]

103. Dusi, S.; Valletta, L.; Haack, T.B.; Tsuchiya, Y.; Venco, P.; Pasqualato, S.; Goffrini, P.; Tigano, M.; Demchenko, N.; Wieland, T; et al. Exome sequence reveals mutations in CoA synthase as a cause of neurodegeneration with brain iron accumulation. Am. J. Hum. Genet. 2014, 94, 11-22. [CrossRef] [PubMed]

104. Kruer, M.C.; Paisan-Ruiz, C.; Boddaert, N.; Yoon, M.Y.; Hama, H.; Gregory, A.; Malandrini, A.; Woltjer, R.L.; Munnich, A.; Gobin, S.; et al. Defective FA2H leads to a novel form of neurodegeneration with brain iron accumulation (NBIA). Ann. Neurol. 2010, 68, 611-618. [CrossRef] [PubMed]

105. Garone, C.; Pippucci, T.; Cordelli, D.M.; Zuntini, R.; Castegnaro, G.; Marconi, C.; Graziano, C.; Marchiani, V.; Verrotti, A.; Seri, M.; et al. FA2H-related disorders: A novel c.270+3A>T splice-site mutation leads to a complex neurodegenerative phenotype. Dev. Med. Child Neurol. 2011, 53, 958-961. [CrossRef] [PubMed]

106. Najim al-Din, A.S.; Wriekat, A.; Mubaidin, A.; Dasouki, M.; Hiari, M. Pallido-pyramidal degeneration, supranuclear upgaze paresis and dementia: Kufor-Rakeb syndrome. Acta Neurol. Scand. 1994, 89, 347-352. [CrossRef] [PubMed]

107. Ramirez, A.; Heimbach, A.; Grundemann, J.; Stiller, B.; Hampshire, D.; Cid, L.P.; Goebel, I.; Mubaidin, A.F.; Wriekat, A.L.; Roeper, J.; et al. Hereditary parkinsonism with dementia is caused by mutations in ATP13A2, encoding a lysosomal type 5 P-type ATPase. Nat. Genet. 2006, 38, 1184-1191. [CrossRef] [PubMed]

108. Schneider, S.A.; Paisan-Ruiz, C.; Quinn, N.P.; Lees, A.J.; Houlden, H.; Hardy, J.; Bhatia, K.P. ATP13A2 mutations (PARK9) cause neurodegeneration with brain iron accumulation. Mov. Disord. 2010, 25, 979-984. [CrossRef] [PubMed]

109. Yazaki, M.; Yoshida, K.; Nakamura, A.; Furihata, K.; Yonekawa, M.; Okabe, T.; Yamashita, N.; Ohta, M.; Ikeda, S. A novel splicing mutation in the ceruloplasmin gene responsible for hereditary ceruloplasmin deficiency with hemosiderosis. J. Neurol. Sci. 1998, 156, 30-34. [CrossRef]

110. Nittis, T.; Gitlin, J.D. The copper-iron connection: Hereditary aceruloplasminemia. Semin. Hematol. 2002, 39, 282-289. [CrossRef] [PubMed]

111. Curtis, A.R.; Fey, C.; Morris, C.M.; Bindoff, L.A.; Ince, P.G.; Chinnery, P.F.; Coulthard, A.; Jackson, M.J.; Jackson, A.P.; McHale, D.P.; et al. Mutation in the gene encoding ferritin light polypeptide causes dominant adult-onset basal ganglia disease. Nat. Genet. 2001, 28, 350-354. [CrossRef] [PubMed]

112. Levi, S.; Rovida, E. Neuroferritinopathy: From ferritin structure modification to pathogenetic mechanism. Neurobiol. Dis. 2015, 81, 134-143. [CrossRef] [PubMed]

113. McNeill, A.; Birchall, D.; Hayflick, S.J.; Gregory, A.; Schenk, J.F.; Zimmerman, E.A.; Shang, H.; Miyajima, H.; Chinnery, P.F. T2* and FSE MRI distinguishes four subtypes of neurodegeneration with brain iron accumulation. Neurology 2008, 70, 1614-1619. [CrossRef] [PubMed]

114. Singh, P.; Saggar, K.; Kaur, M.; Pannu, D.S. Magnetic resonance imaging in pantothenate kinase-2-associated neurodegeneration. J. Pediatr. Neurosci. 2012, 7, 27-29. [CrossRef] [PubMed]

115. Zorzi, G.; Zibordi, F.; Chiapparini, L.; Bertini, E.; Russo, L.; Piga, A.; Longo, F.; Garavaglia, B.; Aquino, D.; Savoiardo, M.; et al. Iron-related MRI images in patients with pantothenate kinase-associated neurodegeneration (PKAN) treated with deferiprone: Results of a phase II pilot trial. Mov. Disord. 2011, 26, 1756-1759. [CrossRef] [PubMed]

116. Abbruzzese, G.; Cossu, G.; Balocco, M.; Marchese, R.; Murgia, D.; Melis, M.; Galanello, R.; Barella, S.; Matta, G.; Ruffinengo, U.; et al. A pilot trial of deferiprone for neurodegeneration with brain iron accumulation. Haematologica 2011, 96, 1708-1711. [CrossRef] [PubMed] 
117. Cossu, G.; Abbruzzese, G.; Matta, G.; Murgia, D.; Melis, M.; Ricchi, V.; Galanello, R.; Barella, S.; Origa, R.; Balocco, M.; et al. Efficacy and safety of deferiprone for the treatment of pantothenate kinase-associated neurodegeneration (PKAN) and neurodegeneration with brain iron accumulation (NBIA): Results from a four years follow-up. Parkinsonism Relat. Disord. 2014, 20, 651-654. [CrossRef] [PubMed]

118. Rohani, M.; Razmeh, S.; Shahidi, G.A.; Alizadeh, E.; Orooji, M. A pilot trial of deferiprone in pantothenate kinase-associated neurodegeneration patients. Neurol. Int. 2017, 9, 7279. [CrossRef] [PubMed]

119. Investigators, H.S.G.R.H. Safety, tolerability, and efficacy of PBT2 in Huntington's disease: A phase 2, randomised, double-blind, placebo-controlled trial. Lancet Neurol. 2015, 14, 39-47.

120. Ritchie, C.W.; Bush, A.I.; Mackinnon, A.; Macfarlane, S.; Mastwyk, M.; MacGregor, L.; Kiers, L.; Cherny, R.; Li, Q.X.; Tammer, A.; et al. Metal-protein attenuation with iodochlorhydroxyquin (clioquinol) targeting Abeta amyloid deposition and toxicity in Alzheimer disease: A pilot phase 2 clinical trial. Arch. Neurol. 2003, 60, 1685-1691. [CrossRef] [PubMed]

121. Lannfelt, L.; Blennow, K.; Zetterberg, H.; Batsman, S.; Ames, D.; Harrison, J.; Masters, C.L.; Targum, S.; Bush, A.I.; Murdoch, R.; et al. Safety, efficacy, and biomarker findings of PBT2 in targeting Abeta as a modifying therapy for Alzheimer's disease: A phase IIa, double-blind, randomised, placebo-controlled trial. Lancet Neurol. 2008, 7, 779-786. [CrossRef]

122. Winter, W.E.; Bazydlo, L.A.; Harris, N.S. The molecular biology of human iron metabolism. Lab. Med. 2014, 45, 92-102. [CrossRef] [PubMed]

123. Kontoghiorghes, G.J.; Kolnagou, A.; Peng, C.T.; Shah, S.V.; Aessopos, A. Safety issues of iron chelation therapy in patients with normal range iron stores including thalassaemia, neurodegenerative, renal and infectious diseases. Expert Opin. Drug Saf. 2010, 9, 201-206. [CrossRef] [PubMed]

124. Hasegawa, E.; Takeshige, K.; Oishi, T.; Murai, Y.; Minakami, S. 1-Methyl-4-phenylpyridinium (MPP+) induces NADH-dependent superoxide formation and enhances NADH-dependent lipid peroxidation in bovine heart submitochondrial particles. Biochem. Biophys. Res. Commun. 1990, 170, 1049-1055. [CrossRef]

125. Shukla, A.; Agarwal, K.N.; Shukla, G.S. Latent iron deficiency alters gamma-aminobutyric acid and glutamate metabolism in rat brain. Experientia 1989, 45, 343-345. [CrossRef] [PubMed]

126. Li, D. Effects of iron deficiency on iron distribution and gamma-aminobutyric acid (GABA) metabolism in young rat brain tissues. Hokkaido Igaku Zasshi 1998, 73, 215-225. [PubMed]

127. Fonderico, M.; Laudisi, M.; Andreasi, N.G.; Bigoni, S.; Lamperti, C.; Panteghini, C.; Garavaglia, B.; Carecchio, M.; Emanuele, E.A.; Forni, G.L.; et al. Patient Affected by Beta-Propeller Protein-Associated Neurodegeneration: A Therapeutic Attempt with Iron Chelation Therapy. Front. Neurol. 2017, 8, 385. [CrossRef] [PubMed]

128. Faux, N.G.; Ritchie, C.W.; Gunn, A.; Rembach, A.; Tsatsanis, A.; Bedo, J.; Harrison, J.; Lannfelt, L.; Blennow, K.; Zetterberg, H.; et al. PBT2 rapidly improves cognition in Alzheimer's Disease: Additional phase II analyses. J. Alzheimer's Dis. 2010, 20, 509-516. [CrossRef] [PubMed]

129. Kwiatkowski, J.L. Current recommendations for chelation for transfusion-dependent thalassemia. Ann. N. Y. Acad. Sci. 2016, 1368, 107-114. [CrossRef] [PubMed]

130. Porter, J.B. A risk-benefit assessment of iron-chelation therapy. Drug Saf. 1997, 17, 407-421. [CrossRef] [PubMed]

131. Galanello, R. Deferiprone in the treatment of transfusion-dependent thalassemia: A review and perspective. Ther. Clin. Risk Manag. 2007, 3, 795-805. [PubMed]

132. Cohen, A.R.; Galanello, R.; Piga, A.; De Sanctis, V.; Tricta, F. Safety and effectiveness of long-term therapy with the oral iron chelator deferiprone. Blood 2003, 102, 1583-1587. [CrossRef] [PubMed]

133. Henter, J.I.; Karlen, J. Fatal agranulocytosis after deferiprone therapy in a child with Diamond-Blackfan anemia. Blood 2007, 109, 5157-5159. [CrossRef] [PubMed]

134. Cappellini, M.D.; Cohen, A.; Piga, A.; Bejaoui, M.; Perrotta, S.; Agaoglu, L.; Aydinok, Y.; Kattamis, A.; Kilinc, Y.; Porter, J.; et al. A phase 3 study of deferasirox (ICL670), a once-daily oral iron chelator, in patients with beta-thalassemia. Blood 2006, 107, 3455-3462. [CrossRef] [PubMed]

135. Botzenhardt, S.; Li, N.; Chan, E.W.; Sing, C.W.; Wong, I.C.; Neubert, A. Safety profiles of iron chelators in young patients with haemoglobinopathies. Eur. J. Haematol. 2017, 98, 198-217. [CrossRef] [PubMed]

136. al-Refaie, F.N.; Wonke, B.; Wickens, D.G.; Aydinok, Y.; Fielding, A.; Hoffbrand, A.V. Zinc concentration in patients with iron overload receiving oral iron chelator 1,2-dimethyl-3-hydroxypyrid-4-one or desferrioxamine. J. Clin. Pathol. 1994, 47, 657-660. [CrossRef] [PubMed] 
137. Crisponi, G.; Nurchi, V.M.; Crespo-Alonso, M.; Sanna, G.; Zoroddu, M.A.; Alberti, G.; Biesuz, R. A Speciation Study on the Perturbing Effects of Iron Chelators on the Homeostasis of Essential Metal Ions. PLoS ONE 2015, 10, e0133050. [CrossRef] [PubMed]

138. Lalioti, V.; Muruais, G.; Tsuchiya, Y.; Pulido, D.; Sandoval, I.V. Molecular mechanisms of copper homeostasis. Front. Biosci. 2009, 14, 4878-4903. [CrossRef]

139. Rae, T.D.; Schmidt, P.J.; Pufahl, R.A.; Culotta, V.C.; O’Halloran, T.V. Undetectable intracellular free copper: The requirement of a copper chaperone for superoxide dismutase. Science 1999, 284, 805-808. [CrossRef] [PubMed]

140. Singh, R.; Singh, S.; Lillard, J.W., Jr. Past, present, and future technologies for oral delivery of therapeutic proteins. J. Pharm. Sci. 2008, 97, 2497-2523. [CrossRef] [PubMed]

141. Lipinski, C.A.; Lombardo, F.; Dominy, B.W.; Feeney, P.J. Experimental and computational approaches to estimate solubility and permeability in drug discovery and development settings. Adv. Drug Deliv. Rev. 2001, 46, 3-26. [CrossRef]

142. Yang, W.S.; Stockwell, B.R. Ferroptosis: Death by Lipid Peroxidation. Trends Cell Boil. 2016, 26, $165-176$. [CrossRef] [PubMed]

143. Aoun, M.; Tiranti, V. Mitochondria: A crossroads for lipid metabolism defect in neurodegeneration with brain iron accumulation diseases. Int. J. Biochem. Cell Boil. 2015, 63, 25-31. [CrossRef] [PubMed]

144. Urrutia, P.J.; Mena, N.P.; Núñez, M.T. The interplay between iron accumulation, mitochondrial dysfunction, and inflammation during the execution step of neurodegenerative disorders. Front. Pharmacol. 2014, 5, 38. [CrossRef] [PubMed]

145. Sohn, Y.S.; Breuer, W.; Munnich, A.; Cabantchik, Z.I. Redistribution of accumulated cell iron: A modality of chelation with therapeutic implications. Blood 2008, 111, 1690-1699. [CrossRef] [PubMed]

146. Levites, Y.; Weinreb, O.; Maor, G.; Youdim, M.B.; Mandel, S. Green tea polyphenol (-)-epigallocatechin-3gallate prevents $N$-methyl-4-phenyl-1,2,3,6-tetrahydropyridine-induced dopaminergic neurodegeneration. J. Neurochem. 2001, 78, 1073-1082. [CrossRef] [PubMed]

147. Mandel, S.; Maor, G.; Youdim, M.B. Iron and alpha-synuclein in the substantia nigra of MPTP-treated mice: Effect of neuroprotective drugs R-apomorphine and green tea polyphenol (-)-epigallocatechin-3-gallate. J. Mol. Neurosci. 2004, 24, 401-416. [CrossRef]

148. Pan, T.; Fei, J.; Zhou, X.; Jankovic, J.; Le, W. Effects of green tea polyphenols on dopamine uptake and on MPP+-induced dopamine neuron injury. Life Sci. 2003, 72, 1073-1083. [CrossRef]

149. Li, R.; Peng, N.; Du, F.; Li, X.P.; Le, W.D. Epigallocatechin gallate protects dopaminergic neurons against 1-methyl-4-phenyl-1,2,3,6-tetrahydropyridine-induced neurotoxicity by inhibiting microglial cell activation. Nan Fang Yi Ke Da Xue Xue Bao 2006, 26, 376-380. [PubMed]

150. Chen, M.; Wang, T.; Yue, F.; Li, X.; Wang, P.; Li, Y.; Chan, P.; Yu, S. Tea polyphenols alleviate motor impairments, dopaminergic neuronal injury, and cerebral alpha-synuclein aggregation in MPTP-intoxicated parkinsonian monkeys. Neuroscience 2015, 286, 383-392. [CrossRef] [PubMed]

151. Zheng, H.; Weiner, L.M.; Bar-Am, O.; Epsztejn, S.; Cabantchik, Z.I.; Warshawsky, A.; Youdim, M.B.; Fridkin, M. Design, synthesis, and evaluation of novel bifunctional iron-chelators as potential agents for neuroprotection in Alzheimer's, Parkinson's, and other neurodegenerative diseases. Bioorg. Med. Chem. 2005, 13, 773-783. [CrossRef] [PubMed]

152. Kupershmidt, L.; Weinreb, O.; Amit, T.; Mandel, S.; Bar-Am, O.; Youdim, M.B. Novel molecular targets of the neuroprotective/neurorescue multimodal iron chelating drug M30 in the mouse brain. Neuroscience 2011, 189, 345-358. [CrossRef] [PubMed]

153. Kupershmidt, L.; Amit, T.; Bar-Am, O.; Weinreb, O.; Youdim, M.B. Multi-target, neuroprotective and neurorestorative M30 improves cognitive impairment and reduces Alzheimer's-like neuropathology and age-related alterations in mice. Mol. Neurobiol. 2012, 46, 217-220. [CrossRef] [PubMed]

154. Bar-Am, O.; Amit, T.; Kupershmidt, L.; Aluf, Y.; Mechlovich, D.; Kabha, H.; Danovitch, L.; Zurawski, V.R.; Youdim, M.B.; Weinreb, O. Neuroprotective and neurorestorative activities of a novel iron chelator-brain selective monoamine oxidase-A/monoamine oxidase-B inhibitor in animal models of Parkinson's disease and aging. Neurobiol. Aging 2015, 36, 1529-1542. [CrossRef] [PubMed] 
155. Storr, T.; Merkel, M.; Song-Zhao, G.X.; Scott, L.E.; Green, D.E.; Bowen, M.L.; Thompson, K.H.; Patrick, B.O.; Schugar, H.J.; Orvig, C. Synthesis, characterization, and metal coordinating ability of multifunctional carbohydrate-containing compounds for Alzheimer's therapy. J. Am. Chem. Soc. 2007, 129, 7453-7463. [CrossRef] [PubMed]

156. Bolognesi, M.L.; Cavalli, A.; Valgimigli, L.; Bartolini, M.; Rosini, M.; Andrisano, V.; Recanatini, M.; Melchiorre, C. Multi-target-directed drug design strategy: From a dual binding site acetylcholinesterase inhibitor to a trifunctional compound against Alzheimer's disease. J. Med. Chem. 2007, 50, 6446-6449. [CrossRef] [PubMed]

157. Fernandez-Bachiller, M.I.; Perez, C.; Gonzalez-Munoz, G.C.; Conde, S.; Lopez, M.G.; Villarroya, M.; Garcia, A.G.; Rodriguez-Franco, M.I. Novel tacrine-8-hydroxyquinoline hybrids as multifunctional agents for the treatment of Alzheimer's disease, with neuroprotective, cholinergic, antioxidant, and copper-complexing properties. J. Med. Chem. 2010, 53, 4927-4937. [CrossRef] [PubMed]

158. Mao, F.; Huang, L.; Luo, Z.; Liu, A.; Lu, C.; Xie, Z.; Li, X. O-Hydroxyl- or o-amino benzylamine-tacrine hybrids: Multifunctional biometals chelators, antioxidants, and inhibitors of cholinesterase activity and amyloid-beta aggregation. Bioorg. Med. Chem. 2012, 20, 5884-5892. [CrossRef] [PubMed]

159. Hiremathad, A.; Keri, R.S.; Esteves, A.R.; Cardoso, S.M.; Chaves, S.; Santos, M.A. Novel Tacrine-Hydroxyphenylbenzimidazole hybrids as potential multitarget drug candidates for Alzheimer's disease. Eur. J. Med. Chem. 2018, 148, 255-267. [CrossRef] [PubMed]

160. Hamulakova, S.; Poprac, P.; Jomova, K.; Brezova, V.; Lauro, P.; Drostinova, L.; Jun, D.; Sepsova, V.; Hrabinova, M.; Soukup, O.; et al. Targeting copper(II)-induced oxidative stress and the acetylcholinesterase system in Alzheimer's disease using multifunctional tacrine-coumarin hybrid molecules. J. Inorg. Biochem. 2016, 161, 52-62. [CrossRef] [PubMed]

161. Ghosh, B.; Antonio, T.; Reith, M.E.; Dutta, A.K. Discovery of 4-(4-(2-((5-Hydroxy-1,2,3,4-tetrahydronaphthalen2-yl)(propyl)amino)ethyl)piperazin-1-yl)quinolin-8-ol and its analogues as highly potent dopamine D2/D3 agonists and as iron chelator: In vivo activity indicates potential application in symptomatic and neuroprotective therapy for Parkinson's disease. J. Med. Chem. 2010, 53, 2114-2125. [PubMed]

162. Das, B.; Kandegedara, A.; Xu, L.; Antonio, T.; Stemmler, T.; Reith, M.E.A.; Dutta, A.K. A Novel Iron(II) Preferring Dopamine Agonist Chelator as Potential Symptomatic and Neuroprotective Therapeutic Agent for Parkinson's Disease. ACS Chem. Neurosci. 2017, 8, 723-730. [CrossRef] [PubMed]

163. Das, B.; Rajagopalan, S.; Joshi, G.S.; Xu, L.; Luo, D.; Andersen, J.K.; Todi, S.V.; Dutta, A.K. A novel iron (II) preferring dopamine agonist chelator D-607 significantly suppresses alpha-syn- and MPTP-induced toxicities in vivo. Neuropharmacology 2017, 123, 88-99. [CrossRef] [PubMed]

164. Chen, S.Y.; Chen, Y.; Li, Y.P.; Chen, S.H.; Tan, J.H.; Ou, T.M.; Gu, L.Q.; Huang, Z.S. Design, synthesis, and biological evaluation of curcumin analogues as multifunctional agents for the treatment of Alzheimer's disease. Bioorg. Med. Chem. 2011, 19, 5596-5604. [CrossRef] [PubMed]

165. Huang, L.; Lu, C.; Sun, Y.; Mao, F.; Luo, Z.; Su, T.; Jiang, H.; Shan, W.; Li, X. Multitarget-directed benzylideneindanone derivatives: Anti-beta-amyloid (Abeta) aggregation, antioxidant, metal chelation, and monoamine oxidase B (MAO-B) inhibition properties against Alzheimer's disease. J. Med. Chem. 2012, 55, 8483-8492. [CrossRef] [PubMed]

166. Nunes, A.; Marques, S.M.; Quintanova, C.; Silva, D.F.; Cardoso, S.M.; Chaves, S.; Santos, M.A. Multifunctional iron-chelators with protective roles against neurodegenerative diseases. Dalton Trans. 2013, 42, 6058-6073. [CrossRef] [PubMed]

167. Xie, S.; Chen, J.; Li, X.; Su, T.; Wang, Y.; Wang, Z.; Huang, L.; Li, X. Synthesis and evaluation of selegiline derivatives as monoamine oxidase inhibitor, antioxidant and metal chelator against Alzheimer's disease. Bioorg. Med. Chem. 2015, 23, 3722-3729. [CrossRef] [PubMed]

168. Sheng, R.; Tang, L.; Jiang, L.; Hong, L.; Shi, Y.; Zhou, N.; Hu, Y. Novel 1-Phenyl-3-hydroxy-4-pyridinone Derivatives as Multifunctional Agents for the Therapy of Alzheimer's Disease. ACS Chem. Neurosci. 2016, 7, 69-81. [CrossRef] [PubMed]

169. Aguirre, P.; Garcia-Beltran, O.; Tapia, V.; Munoz, Y.; Cassels, B.K.; Nunez, M.T. Neuroprotective effect of a new 7,8-dihydroxycoumarin-based Fe2+/Cu2+ chelator in cell and animal models of Parkinson's disease. ACS Chem. Neurosci. 2017, 12, 178-185. [CrossRef] [PubMed]

170. Garcia-Beltran, O.; Mena, N.P.; Aguirre, P.; Barriga-Gonzalez, G.; Galdamez, A.; Nagles, E.; Adasme, T.; Hidalgo, C.; Nunez, M.T. Development of an iron-selective antioxidant probe with protective effects on neuronal function. PLoS ONE 2017, 12, e0189043. [CrossRef] [PubMed] 
171. Chen, S.Q.; Wang, Z.S.; Ma, Y.X.; Zhang, W.; Lu, J.L.; Liang, Y.R.; Zheng, X.Q. Neuroprotective Effects and Mechanisms of Tea Bioactive Components in Neurodegenerative Diseases. Molecules 2018, $23,512$. [CrossRef] [PubMed]

172. Mandel, S.; Reznichenko, L.; Amit, T.; Youdim, M.B. Green tea polyphenol (-)-epigallocatechin-3-gallate protects rat PC12 cells from apoptosis induced by serum withdrawal independent of P13-Akt pathway. Neurotox. Res. 2003, 5, 419-424. [CrossRef] [PubMed]

173. Xu, Q.; Langley, M.; Kanthasamy, A.G.; Reddy, M.B. Epigallocatechin Gallate Has a Neurorescue Effect in a Mouse Model of Parkinson Disease. J. Nutr. 2017, 147, 1926-1931. [CrossRef] [PubMed]

174. Li, R.; Peng, N.; Li, X.P.; Le, W.D. (-)-Epigallocatechin gallate regulates dopamine transporter internalization via protein kinase C-dependent pathway. Brain Res. 2006, 1097, 85-89. [CrossRef] [PubMed]

175. Miller, G.W.; Gainetdinov, R.R.; Levey, A.I.; Caron, M.G. Dopamine transporters and neuronal injury. Trends Pharmacol. Sci. 1999, 20, 424-429. [CrossRef]

176. McKinley, E.T.; Baranowski, T.C.; Blavo, D.O.; Cato, C.; Doan, T.N.; Rubinstein, A.L. Neuroprotection of MPTP-induced toxicity in zebrafish dopaminergic neurons. Brain Res. Mol. Brain Res. 2005, 141, 128-137. [CrossRef] [PubMed]

177. Gainetdinov, R.R.; Fumagalli, F.; Jones, S.R.; Caron, M.G. Dopamine transporter is required for in vivo MPTP neurotoxicity: Evidence from mice lacking the transporter. J. Neurochem. 1997, 69, 1322-1325. [CrossRef] [PubMed]

178. Bezard, E.; Gross, C.E.; Fournier, M.C.; Dovero, S.; Bloch, B.; Jaber, M. Absence of MPTP-induced neuronal death in mice lacking the dopamine transporter. Exp. Neurol. 1999, 155, 268-273. [CrossRef] [PubMed]

179. Wei, H.; Zhang, X.; Zhao, J.F.; Wang, Z.Y.; Bickers, D.; Lebwohl, M. Scavenging of hydrogen peroxide and inhibition of ultraviolet light-induced oxidative DNA damage by aqueous extracts from green and black teas. Free. Radic. Boil. Med. 1999, 26, 1427-1435. [CrossRef]

180. Nakagawa, T.; Yokozawa, T. Direct scavenging of nitric oxide and superoxide by green tea. Food Chem. Toxicol. 2002, 40, 1745-1750. [CrossRef]

181. Frei, B.; Higdon, J.V. Antioxidant activity of tea polyphenols in vivo: Evidence from animal studies. J. Nutr. 2003, 133, 3275s-3284s. [CrossRef] [PubMed]

182. Raza, H.; John, A. Green tea polyphenol epigallocatechin-3-gallate differentially modulates oxidative stress in PC12 cell compartments. Toxicol. Appl. Pharmacol. 2005, 207, 212-220. [CrossRef] [PubMed]

183. Noda, C.; He, J.; Takano, T.; Tanaka, C.; Kondo, T.; Tohyama, K.; Yamamura, H.; Tohyama, Y. Induction of apoptosis by epigallocatechin-3-gallate in human lymphoblastoid B cells. Biochem. Biophys. Res. Commun. 2007, 362, 951-957. [CrossRef] [PubMed]

184. Hsuuw, Y.D.; Chan, W.H. Epigallocatechin gallate dose-dependently induces apoptosis or necrosis in human MCF-7 cells. Ann. N. Y. Acad. Sci. 2007, 1095, 428-440. [CrossRef] [PubMed]

185. Yin, S.T.; Tang, M.L.; Deng, H.M.; Xing, T.R.; Chen, J.T.; Wang, H.L.; Ruan, D.Y. Epigallocatechin-3-gallate induced primary cultures of rat hippocampal neurons death linked to calcium overload and oxidative stress. Naunyn-Schmiedeberg's Arch. Pharmacol. 2009, 379, 551-564. [CrossRef] [PubMed]

186. Suh, K.S.; Chon, S.; Oh, S.; Kim, S.W.; Kim, J.W.; Kim, Y.S.; Woo, J.T. Prooxidative effects of green tea polyphenol (-)-epigallocatechin-3-gallate on the HIT-T15 pancreatic beta cell line. Cell Boil. Toxicol. 2010, 26, 189-199. [CrossRef] [PubMed]

187. Wang, J.H.; Cheng, J.; Li, C.R.; Ye, M.; Ma, Z.; Cai, F. Modulation of $\mathrm{Ca}(2)(+)$ signals by epigallocatechin-3gallate(EGCG) in cultured rat hippocampal neurons. Int. J. Mol. Sci. 2011, 12, 742-754. [CrossRef] [PubMed]

188. Qanungo, S.; Das, M.; Haldar, S.; Basu, A. Epigallocatechin-3-gallate induces mitochondrial membrane depolarization and caspase-dependent apoptosis in pancreatic cancer cells. Carcinogenesis 2005, 26, 958-967. [CrossRef] [PubMed]

189. Cavet, M.E.; Harrington, K.L.; Vollmer, T.R.; Ward, K.W.; Zhang, J.Z. Anti-inflammatory and anti-oxidative effects of the green tea polyphenol epigallocatechin gallate in human corneal epithelial cells. Mol. Vis. 2011, 17, 533-542. [PubMed] 
190. Wang, L.; Tian, X. Epigallocatechin-3-Gallate Protects against Homocysteine-Induced Brain Damage in Rats. Planta Med. 2018, 84, 34-41. [CrossRef] [PubMed]

191. Mandel, S.; Amit, T.; Bar-Am, O.; Youdim, M.B. Iron dysregulation in Alzheimer's disease: Multimodal brain permeable iron chelating drugs, possessing neuroprotective-neurorescue and amyloid precursor protein-processing regulatory activities as therapeutic agents. Prog. Neurobiol. 2007, 82, 348-360. [CrossRef] [PubMed]

192. Zhao, X.; Liu, F.; Jin, H.; Li, R.; Wang, Y.; Zhang, W.; Wang, H.; Chen, W. Involvement of PKCalpha and ERK1/2 signaling pathways in EGCG's protection against stress-induced neural injuries in Wistar rats. Neuroscience 2017, 346, 226-237. [CrossRef] [PubMed]

193. Youdim, M.B.; Kupershmidt, L.; Amit, T.; Weinreb, O. Promises of novel multi-target neuroprotective and neurorestorative drugs for Parkinson's disease. Parkinsonism Relat. Disord. 2014, 20 (Suppl. S1), S132-S136. [CrossRef]

194. Amit, T.; Bar-Am, O.; Mechlovich, D.; Kupershmidt, L.; Youdim, M.B.H.; Weinreb, O. The novel multitarget iron chelating and propargylamine drug M30 affects APP regulation and processing activities in Alzheimer's disease models. Neuropharmacology 2017, 123, 359-367. [CrossRef] [PubMed]

195. Avramovich-Tirosh, Y.; Bar-Am, O.; Amit, T.; Youdim, M.B.; Weinreb, O. Up-regulation of hypoxia-inducible factor (HIF)- $1 \alpha$ and HIF-target genes in cortical neurons by the novel multifunctional iron chelator anti-Alzheimer drug, M30. Curr. Alzheimer Res. 2010, 7, 300-306. [CrossRef] [PubMed]

196. Park, S.S.; Bae, I.; Lee, Y.J. Flavonoids-induced accumulation of hypoxia-inducible factor (HIF)-1alpha/2alpha is mediated through chelation of iron. J. Cell Biochem. 2008, 103, 1989-1998. [CrossRef] [PubMed]

197. Golko-Perez, S.; Amit, T.; Bar-Am, O.; Youdim, M.B.; Weinreb, O. A novel iron chelator-radical scavenger ameliorates motor dysfunction and improves life span and mitochondrial biogenesis in SOD1 G93A ALS mice. Neurotox. Res. 2017, 31, 230-244. [CrossRef] [PubMed]

198. Golko-Perez, S.; Amit, T.; Youdim, M.B.; Weinreb, O. Beneficial Effects of Multitarget Iron Chelator on Central Nervous System and Gastrocnemius Muscle in SOD1 G93A Transgenic ALS Mice. J. Mol. Neurosci. 2016, 59, 504-510. [CrossRef] [PubMed]

199. Qutub, A.A.; Hunt, C.A. Glucose transport to the brain: A systems model. Brain Res. Rev. 2005, 49, 595-617. [CrossRef] [PubMed]

200. Schugar, H.; Green, D.E.; Bowen, M.L.; Scott, L.E.; Storr, T.; Bohmerle, K.; Thomas, F.; Allen, D.D.; Lockman, P.R.; Merkel, M.; et al. Combating Alzheimer's disease with multifunctional molecules designed for metal passivation. Angew. Chem. 2007, 46, 1716-1718. [CrossRef] [PubMed]

201. Jakoby, P.; Schmidt, E.; Ruminot, I.; Gutierrez, R.; Barros, L.F.; Deitmer, J.W. Higher transport and metabolism of glucose in astrocytes compared with neurons: A multiphoton study of hippocampal and cerebellar tissue slices. Cereb. Cortex 2014, 24, 222-231. [CrossRef] [PubMed]

202. Tumiatti, V.; Minarini, A.; Bolognesi, M.L.; Milelli, A.; Rosini, M.; Melchiorre, C. Tacrine derivatives and Alzheimer's disease. Curr. Med. Chem. 2010, 17, 1825-1838. [CrossRef] [PubMed]

203. Giacobini, E. Modulation of brain acetylcholine levels with cholinesterase inhibitors as a treatment of Alzheimer disease. Keio J. Med. 1987, 36, 381-391. [CrossRef] [PubMed]

204. Jogani, V.V.; Shah, P.J.; Mishra, P.; Mishra, A.K.; Misra, A.R. Intranasal mucoadhesive microemulsion of tacrine to improve brain targeting. Alzheimer Dis. Assoc. Disord. 2008, 22, 116-124. [CrossRef] [PubMed]

(C) 2018 by the authors. Licensee MDPI, Basel, Switzerland. This article is an open access article distributed under the terms and conditions of the Creative Commons Attribution (CC BY) license (http:/ / creativecommons.org/licenses/by/4.0/). 
Review

\title{
Iron in Friedreich Ataxia: A Central Role in the Pathophysiology or an Epiphenomenon?
}

\author{
David Alsina, Rosa Purroy, Joaquim Ros and Jordi Tamarit * \\ Departament de Ciències Mèdiques Bàsiques, IRBLleida, Universitat de Lleida, 25198 Lleida, Spain; \\ david.alsina@cmb.udl.cat (D.A.); rosa.purroy@irblleida.udl.cat (R.P.); joaquim.ros@cmb.udl.cat (J.R.) \\ * Correspondence: jordi.tamarit@cmb.udl.cat; Tel.: +34-973-702-475
}

Received: 10 August 2018; Accepted: 17 September 2018; Published: 19 September 2018

\begin{abstract}
Friedreich ataxia is a neurodegenerative disease with an autosomal recessive inheritance. In most patients, the disease is caused by the presence of trinucleotide GAA expansions in the first intron of the frataxin gene. These expansions cause the decreased expression of this mitochondrial protein. Many evidences indicate that frataxin deficiency causes the deregulation of cellular iron homeostasis. In this review, we will discuss several hypotheses proposed for frataxin function, their caveats, and how they could provide an explanation for the deregulation of iron homeostasis found in frataxin-deficient cells. We will also focus on the potential mechanisms causing cellular dysfunction in Friedreich Ataxia and on the potential use of the iron chelator deferiprone as a therapeutic agent for this disease.
\end{abstract}

Keywords: Iron-sulfur; Friedreich Ataxia; Oxidative stress; Iron chelators

\section{The Disease}

Friedreich's Ataxia (FRDA) is a neurodegenerative disease described at the end of the 19th century by the German physician Nikolaus Friedreich from whom acquired the name. Friedreich observed in a group of patients that during the puberty a characteristic symptomatology began to manifest, specifically: ataxia, dysarthria, loss of sensitivity, muscle weakness, scoliosis, pes cavus, and heart symptoms. Later, a greater incidence of diabetes mellitus in patients than in the rest of the population was also reported [1]. It is considered a rare disease that follows a pattern of autosomal recessive inheritance. The frequency of carriers oscillates, depending on the area, between 1:50 and 1:100, while those affected by the disease are approximately 1:50,000, which makes this disease the most common form of hereditary ataxia [2].

The mutation responsible for the disease is an expansion of GAA trinucleotides in the first intron of the FXNor X25 gene (located in chromosome 9), which codes for the mitochondrial protein frataxin [3]. This expansion of triplets, which in patients can reach up to more than 1000 copies, results in a marked decrease in protein frataxin levels (below 5\%-30\% of normal levels) [4]. The number of GAA expansions has an inversely proportional relation to the age at which the first symptoms of the disease begin to manifest and it also determines their severity [5-7]. Besides GAA expansions, epigenetic modifications might also contribute to the variability in the onset and disease progression. Sarsero and collaborators reported differences in DNA methylation patterns between patients upstream and downstream the GAA expansion. Such differences caused variations in frataxin gene expression [8]. Finally, a small percentage of patients, around $4 \%$, are compound heterozygous for a GAA expansion and a frataxin (FXN) point mutation or deletion [9].

\section{Frataxin, an Ancestral Conserved Protein}

Frataxin is a highly conserved protein throughout evolution and homologues can be found in most species. Its structure is formed by two helix alpha joined by a series of antiparallel beta sheets 
and is highly conserved (Figure 1). Despite the high degree of conservation in the three-dimensional structure, the stability of this protein varies significantly between species. One of the factors that are responsible for the differences in the stability of the protein is the C-terminal endpoint. While in Yfh1 (the yeast's homologue), this region is virtually nonexistent, in the human protein this fragment is found inserted between the two alpha helixes. This protects the hydrophobic nucleus of the protein and increases its stability [10].

\section{hFxn}
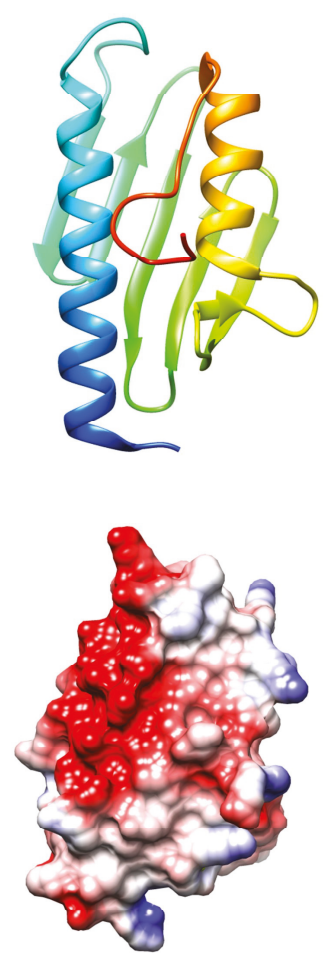

Yfh1
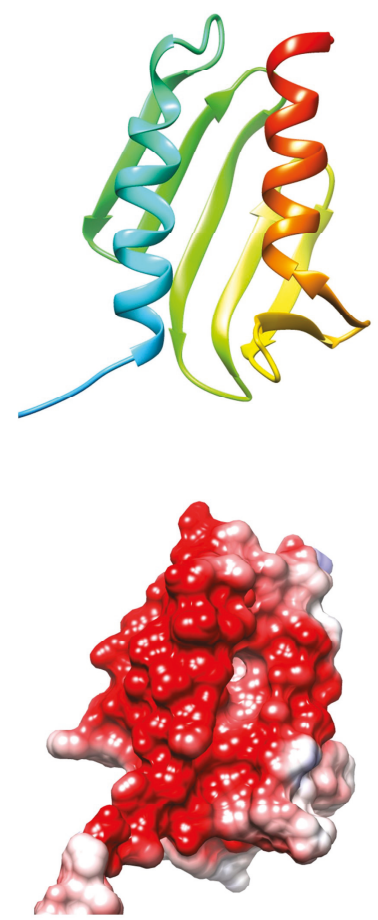

Figure 1. Structures of human frataxin (hFxn, pdb code $3 \mathrm{~s} 4 \mathrm{~m}$ ) and Yeast Frataxin Homologue 1 (Yfh1, pdb code 2fql). Top, ribbons representations showing the conserved alpha-beta-alpha structure. Structures are colored according to sequence, from dark blue ( $\mathrm{N}$-terminal) to red (C-terminal). In human frataxin the C-terminal region folds over the hydrophobic cavity formed between both alpha helices. Below, coulumbic surface coloring of the same structures. The red color indicates the presence of a marked acidic ridge, which may be involved in iron binding. Molecular graphics and analyses were performed with the UCSF Chimera package [11].

Frataxin is a mitochondrial protein, and as such, it has a signal peptide at its N-terminal end. It was soon identified, both for Yfh1 and for mouse frataxin, that Mitochondrial Processing Peptidase interacted with frataxin and was responsible for its processing $[12,13]$. This processing involves two sequential cleavages, which first produce an intermediate form of frataxin and subsequently the mature form. For human frataxin, the cleavage positions described are between amino acids 41-42 (intermediate form) and between amino acids 80-81 (mature form), although other less abundant forms that correspond to alternative cleavage sites (for instance, positions 55-56) have also been identified [14,15]. In these works, it was shown that the mature form of frataxin corresponds to FXN ${ }^{81-210}$. This form is fully active and capable of improving the survival and phenotypes of frataxin 
deficient cells. Despite the demonstration that the FXN ${ }^{81-210}$ form is the dominant form and that it is active, there is some debate over the role that could be developed by the intermediate forms, as these forms can also be detected in certain tissues (although at low levels) [16]. It was shown that processing of the intermediate form was slower than that of the precursor form, which suggested that this could be a mechanism for controlling the levels of the different frataxin forms [17]. More recently, it has been suggested that the different forms of frataxin might play different roles. This point will be discussed in the next section. In addition to post-translational processing, alternative splicing mechanisms have also been observed that may generate different isoforms of frataxin. Work by Xia and collaborators suggested that these alternative forms could be tissue-specific and could have different functions and locations [18]. However, there are not additional evidences about the nature and relevance of these alternative forms.

\section{Frataxin Function}

Although very early after the discovery of frataxin as the gene that was responsible for Friedreich's Ataxia, it was established that iron homeostasis was altered by frataxin deficiency, the specific function of this protein remains controversial. Over the years, different functions have been proposed for frataxin, most of them related to iron metabolism and the control of oxidative stress in mitochondria.

\subsection{Frataxin, an Iron Binding and Storage Protein}

It has been proposed that frataxin could work like a metalochaperone and iron storage protein. In several studies with purified protein, it has been observed that frataxin has the ability to interact with metal ions, but the coordination environment of these metal binding sites has not been properly defined. There is also uncertainty on the number of metal ions that are bound per frataxin monomer. It has been described that frataxin can bind divalent metal ions using a group of exposed acidic residues. These amino acids are located in a specific area of the protein forming an acidic ridge, quite conserved, different from the canonical iron binding motifs where cysteine and/or histidine amino acids are usually found. This acidic zone results in a weak and non-specific electrostatic bonding of iron, which also allows the coordination of other divalent metals [19]. The estimated $\mathrm{Kd}$ for $\mathrm{Fe}^{2+}$ and $\mathrm{Fe}^{3+}$ of this region was calculated on the micromolar range [20]. Gentry and collaborators reported the potential presence of a high affinity iron binding site. They showed that three metal ions could be bound by each frataxin monomer, and that His 86 was required for one of these binding sites. This residue is located in the disordered $\mathrm{N}$-terminal tail and had not been previously reported to be involved in metal coordination. They calculated that this site would have an affinity for $\mathrm{Fe}^{2+}$ higher than the iron chelator ferrozine, while the remaining two sites would have lower affinities [21]. His86 is not included in most of the frataxin structures that are found in the protein data bank nor is conserved in yeast and bacterial homologues. More recently, while using NMR to investigate iron binding, it was also proposed that frataxin tightly binds a single $\mathrm{Fe}^{2+}$ but not $\mathrm{Fe}^{3+}$ [22].

Isaya and collaborators noticed that iron binding to yeast and bacterial frataxin promoted its oligomerization to complexes of high molecular weight (850-1100 kDa) [23-25]. These oligomeric forms resembled those that were formed by ferritin, the main protein responsible for iron storage in eukaryotes. Indeed, oligomeric frataxin was shown to use a ferrooxidation reaction to build a ferrihydrite mineral core inside the particles. Therefore it was proposed that frataxin could act as a mitochondrial ferritin. Although this function would be redundant in higher eukaryotes due to the presence of a mitochondrial ferritin, this hypothesis acquired some strength when subsequent studies demonstrated that the expression of mitochondrial ferritin in frataxin deficient yeast was able to partially recover some of the observed phenotypes. Specifically, the heterologous expression of mitochondrial ferritin partially prevented the accumulation of iron, the cells were more resistant to oxidizing agents and they partially recovered the activities of enzymes with iron-sulfur centers (which is a common described consequence of frataxin deficiency) [26]. Regarding human frataxin, it has been claimed that the mature form $\left(\mathrm{FXN}^{81-210}\right)$ does not form aggregates [27] and that only the intermediate 
forms $\mathrm{FXN}^{42-210}$ and $\mathrm{FXN}^{56-210}$ would be assembled into larger structures. Based on this observation, it has been suggested that different frataxin proteoforms would perform different functions. The mature form would be monomeric and involved in iron binding and delivery to biochemical pathways requiring this metal, while $\mathrm{FXN}^{56-210}$ and $\mathrm{FXN}^{42-210}$ would be able to oligomerize and store iron. A caveat to these hypotheses is that the long frataxin isoforms are not observed in most tissues by western blot. Mass spectrometry data also suggests that these long frataxin isoforms may be present at very low concentrations: data collected in the PeptideAtlas repository indicates that the theoretically likely frataxin peptides between positions 42 and 81 have never been observed, while those from the FXN ${ }^{81-210}$ have been observed at least 400 times. (PeptideAtlas is a publicly accessible compendium of peptides identified in mass spectrometry proteomics experiments) [28]. Recently, it has been shown that $\mathrm{FXN}^{81-210}$ can also undergo oligomerization under certain conditions, although the stability of these oligomers would be lower than that of bacterial frataxin [29].

Nevertheless, there are other caveats on the ferritin-like hypothesis. It has been argued that physiological conditions of calcium and magnesium stabilize the monomeric frataxin form and consequently frataxin would not oligomerize in vivo [27]. It has also been shown that mitochondrial iron in yeast strains expressing different $Y$ fh 1 concentrations, presented nearly identical chemical and biochemical characteristics [30]. Another point to take into account is which could be the contribution of frataxin to mitochondrial iron storage or trafficking from a quantitative point of view. Most iron that is present in mitochondria is found at the active sites of proteins. Despite that, non-proteinaceous labile metal iron pools have also been detected within cells. These pools are thought to be involved in cellular trafficking, regulation, signaling, and/or storage of metal ions. Due to their lability (and their presence at low concentrations), their structure and functions are not completely understood. For instance, mitochondria contain $0.7-2 \mathrm{mM} \mathrm{Fe}$, but the proportion of labile iron is not completely known, with estimates ranging from 1 to $100 \mu \mathrm{M}$ [31,32]. These differences in the estimates may be due to real differences between the models or experimental conditions used, but also on the methodological approaches used to analyze this elusive iron pool. Also, the nature of these nonproteinaceous metal complexes is not known. Based on the abundance of GSH within the mitochondria it has been hypothesized that could be an FeII (GSH) adduct. Citrate, which is also present in the mitochondrial matrix at high concentrations, has also been considered as a potential ligand for non-proteinaceous iron complexes (reviewed in [32]). In yeast, by using Mössbauer spectroscopy, it has been shown that the proportion and nature of these labile iron pools may vary depending on the metabolic state of the cell. Respiring mitochondria where estimated to contain $\sim 15 \mu \mathrm{M}$ labile non-heme high spin $\mathrm{Fe}^{2+}$, while this pool in fermenting mitochondria increased to $\sim 150 \mu \mathrm{M}$. The concentration of yeast frataxin in mitochondria has been estimated to be three orders of magnitude lower, around $35 \mathrm{nM} \mathrm{[33].}$ Therefore, as monomeric frataxin has been claimed to bind three iron atoms, it cannot contribute significantly to store iron in a non-reactive easy deliverable form. However, it could play a role in iron trafficking as a temporary carrier or catalyzing its speciation between different forms. For instance, it could bind $\mathrm{Fe}^{2+}$ and promote its controlled oxidation to $\mathrm{Fe}^{3+}$, which would be then stored in the form of $\mathrm{Fe}^{3+}$-phosphate nanoparticles. Regarding oligomeric frataxin, the mineralization process would allow for this protein to bind much more iron atoms per subunit. The yeast 48 subunit oligomer can store $\sim 50-75$ iron atoms per subunit in 1-2 $\mathrm{nm}$ cores [34]. This raises the iron potentially bound by frataxin up to the $\mu \mathrm{M}$ range, but still this amount may not be a significant contribution to the whole mitochondrial iron pool. In comparison, around $35 \%$ of mitochondrial iron in fermenting mitochondria may be stored in the form of $\mathrm{Fe}^{3+}$ nanoparticles [33]. That said, the contribution of mitochondrial ferritin to iron storage in mitochondria is also intriguing, as the concentration of this protein according to the $\mathrm{PaxDb}$ database is much lower than that of frataxin (PaxDB is a database that contains protein abundance information across organisms and tissues) [35]. 


\subsection{Frataxin in the Biosynthesis of Iron Containing Proteins}

It has also been proposed that frataxin could participate in the biosynthesis of both heme groups and of iron-sulfur centers. This hypothesis has several fundamentals: (a) frataxin deficiency leads to a loss in proteins which contain iron-sulfur centers or heme groups; (b) frataxin has the ability to bind iron atoms; and, (c) several studies have shown the ability of frataxin to interact with proteins that areinvolved in heme or iron-sulfur biosynthesis.

\subsubsection{Biosynthesis of Heme Groups}

The incorporation of the iron atom into protoporphyrin IX is the last step in the biosynthesis of heme groups. This step is catalyzed by ferrochelatase, but it is not known how iron is provided to this enzyme. In in vitro studies, it was shown that there was a physical interaction between frataxin and ferrochelatase with a 1 to 2 stoichiometry, which seems logical, since ferrochelatase functions as a dimer. In addition, this interaction resulted in the formation of heme groups [36]. A study in which NMR spectroscopy was used to analyze the binding between both of the proteins suggested that ferrochelatase interacted with frataxin in a manner that included its iron-binding interface [37]. More recently, Söderberg and collaborators presented a model of the interaction of trimeric Yfh1 (yeast frataxin) and ferrochelatase in which one of the subunits of the Yfh1 trimer interacted with one subunit of the ferrochelatase dimer, whereas another trimer subunit was positioned for iron delivery [38]. These results support the hypothesis of frataxin acting as an iron donor in the biosynthesis of heme groups. However, heme deficiency is not always observed in frataxin-deficient cells and anemia has not been shown to be a symptom of FRDA. Indeed, no alterations where observed in heme synthesis in erythroid progenitor stem cells that were obtained from FRDA patients [39]. Moreover, experiments using either conditional frataxin-deficient T-Rex-293 cells or yeasts have shown that heme deficiency is a late consequence of frataxin deficiency [40,41]. These observations suggest that heme deficiency may be an epiphenomenon observed in certain frataxin-deficient cells which could be caused by poor iron availability or by metabolic remodeling. In this regard, we have shown in frataxin-deficient yeast that heme deficiency could be caused by the induction of $\mathrm{Cth} 2$, a protein induced in response to iron limitation, which promotes the degradation of mRNAs from iron-containing proteins [42].

\subsubsection{Biosynthesis of Iron-Sulfur Centers}

In addition to interacting with ferrochelatase, frataxin also interacts with the proteins that form the central biosynthesis machinery of iron-sulfur centers: IscU (Isu1 in yeast), Nfs1, and Isd11 [43,44]. Several authors have shown that this interaction facilitates the formation of an iron-sulfur center into IscU, the scaffold protein where these cofactors are first assembled. It was initially suggested that frataxin would act as an iron donor in the biosynthesis of these centers [45]. More recently, it has been suggested that frataxin would participate in the biosynthesis of iron-sulfur centers as an allosteric regulator and not as an iron donor. In works that were carried out in vitro with the CyaY protein (bacterial homologue of frataxin), it was shown that this protein had an inhibitory effect on the production of iron-sulfur centers. As this effect was increased in response to iron concentration, the authors suggested that frataxin could adapt the production of iron-sulfur to the number of final acceptor proteins [46]. Surprisingly, studies with human proteins demonstrated that eukaryotic frataxins would have a contrary effect. In this case, they stimulated the production of iron-sulfur centers by favoring the desulfurase activity of Nfs1 [47-49].

Today, despite the intense debate that is generated around the function or functions of frataxin, this non-essential activity in the metabolism of iron as an allosteric regulator of the biosynthesis of iron-sulfur centers has strong support from in vitro biochemical data and is the most accepted hypothesis. A detailed explanation of this complex biochemical process can be found in recent reviews [50,51]. However, this hypothesis also presents caveats when exposed to in vivo biological data. Remarkably, iron-sulfur cluster deficiency is not observed in several models of frataxin deficiency, 
such as flies [52], patient fibroblasts [53], or rat cardiac myocytes [54]. Moreover, detailed analysis of the cellular events that are caused by frataxin deficiency in yeast, have shown that iron-sulfur deficiency is an epiphenomenon that is caused by a metabolic remodeling program activated in response to disrupted iron homeostasis $[41,55]$. These observations question the role of frataxin in iron-sulfur biogenesis or at least suggest the possibility of additional functions for frataxin beyond iron-sulfur biogenesis. From these observations, it also becomes obvious that frataxin is not essential for iron-sulfur biogenesis.

\subsection{Control of Oxidative Stress and the Generation of Ros}

One of the phenotypes most consistently observed in frataxin-deficient cells is sensitivity to oxidizing agents [56,57]. Some authors have linked such sensitivity to oxidative stress to impaired biosynthesis of iron-sulfur centers. This hypothesis suggests that a vicious cycle would be created in which the deficient formation of iron-sulfur clusters would increase mitochondrial free iron that would increase the production of reactive oxygen species (ROS) through Fenton reaction. Then, ROS would further damage iron-sulfur clusters and promote the formation of more free iron. In fact, increased presence of labile iron has been reported in frataxin deficient yeast [58], T-Rex-293 cells [40] and in a mouse model of hepatic FXN deficiency [59]. However, no differences where observed between the mitochondrial iron pools from human lymphoblasts and fibroblasts that were obtained from either controls or FRDA patients [31]. Nevertheless, some observations suggest that oxidative stress could be the cause (and not the consequence) of iron-sulfur deficiency. For instance, in fibroblasts or lymphocytes from patients [53], or in frataxin-deficient cardiac myocytes [54], oxidative stress could be observed while the activities of iron-sulfur proteins remained unaltered. Moreover, there are evidences that iron-sulfur deficiency can be modulated by oxygen concentration or antioxidant treatment. In this regard, frataxin is not required for iron-sulfur biogenesis in yeasts grown at low oxygen tensions [60,61]. In some fly models, iron-sulfur deficiency is only observed under hyperoxic conditions [52], while in other models it can be prevented by antioxidants [62].

Which could be the origin of oxidative stress? Since frataxin has the ability to bind iron, a redox active metal, and oxidize it to $\mathrm{Fe}^{3+}$, it has been proposed that frataxin could prevent oxidative stress by limiting the presence of free $\mathrm{Fe}^{2+}$ through its binding and the subsequent controlled oxidation to $\mathrm{Fe}^{3+}$. This reaction would prevent the formation of reactive oxygen species through the reaction of $\mathrm{Fe}^{2+}$ with oxygen $[63,64]$. Therefore, the vicious cycle would have its origin in free iron than would then generate oxidative stress that would damage iron-sulfur clusters and generate more free iron. Another potential source of reactive oxygen species in frataxin-deficient cells could be the OXPHOS system. In this regard, an interaction was described between frataxin and mitochondrial electron transport chain proteins [65]. Also, decreased activity of the mitochondrial electron transport chain has been observed in several biological models of frataxin deficiency $[53,66,67]$. Any alteration in the OXPHOS system that was caused by frataxin deficiency could increase electron leakage and thus generate ROS [68].

Rustin and collaborators observed that frataxin-deficient cells could not properly activate the NRF2 signaling pathway in response to oxidative damage and in consequence they had a deficient response to oxidative insults and hypersensitivity to oxidative stress. They hypothesized that this impairment was related to actin remodeling [69]. This phenomenon has also been described in frataxin-deficient motor neurons [70], and in the frataxin-deficient YG8R mouse model where transcriptomic analysis showed a downregulation of NRF2-dependent antioxidant enzymes [71].

\section{Evidences of Iron Accumulation and Its Relation to Pathophysiology in FRDA}

Iron accumulation in a frataxin deficient cell model was first described in yeast $y f h 1$ mutants [72]. This early observation has been subsequently confirmed by several other researchers. Using Mössbauer spectroscopic analysis, Dancis and collaborators showed that in Dyfh1 mitochondria iron was present as amorphous nano-particles of ferric phosphate [73]. Iron accumulation is caused by increased iron uptake due to activation of the iron sensor Aft1 [58], but the mechanisms leading to such activation are 
not completely understood. It has been assumed that it would be caused by iron-sulfur cluster loss, as Aft1 is known to be regulated by the presence of these cofactors. However, previous research from our group using conditional Yfh1 mutants provided two observations that challenged this hypothesis: (i) activation of Aft1 was observed earlier than iron-sulfur loss [41]; and, (ii) loss of iron-sulfur containing proteins in Yfh1 deficient yeasts was not observed in cth 2 cells. Therefore iron-sulfur loss was an epiphenomenon mainly caused by Cth2, which is an Aft1 target that binds to mRNAs from iron-containing proteins and promotes its degradation [42]. Moreover, we have also observed that nitric oxide can prevent Aft1 activation in Yfh1-deficient cells, but not in cells that are deficient in iron-sulfur biogenesis [74]. This observation also indicates that in Yfh1 deficient yeast Aft1 may be activated by a mechanism different than iron-sulfur cluster deficiency. Besides yeast, iron deposits or accumulation have also been clearly observed in frataxin deficient flies $[75,76]$ and in cardiac muscles from frataxin deficient mice [77] and FRDA patients [78]. Iron in the heart from cardiac $\mathrm{KO}$ conditional mouse (the MCK mutant) was found in mitochondrial aggregates $100-400 \mathrm{~nm}$ in diameter, markedly different from those observed for mammalian ferritin. Energy-dispersive X-ray analysis showed that, in addition to iron, phosphorus and sulfur were present in these aggregates. Mössbauer spectra also confirmed that these aggregates where different than mammalian ferritin. The absorption profile observed was consistent with paramagnetic high-spin Fe(III) [79]. These observations are consistent with those that were obtained in frataxin-deficient yeast, and suggest that iron could be in the form of ferric-phosphate nanoparticles in both models. In other tissues or mammalian cell types, iron accumulation is not consistently observed. For instance, in fibroblasts or lymphoblasts from patients, there are no evidences of iron accumulation [31], while some authors have observed it in the nervous system [80]. Changes in the iron-responsive proteins, ferritin, divalent metal transporter 1 (DMT1), transferrin receptor 1 (TfR1), and ferroportin have been reported in the dentate nucleus of affected individuals [81]. Similar to yeast, iron deregulation in mammals might be caused by Iron-responding protein 1 (IRP1) activation [82,83], but the mechanisms causing this activation are not completely understood. It could be caused by deficiencies in iron supply to mitochondrial iron-dependent pathways that would activate the mechanisms of response to iron deficiency [59]. Frataxin has also been shown to interact with IRP1 and modulate the switch between its aconitase and RNA-binding forms. This function would be carried on by a cytosolic form of frataxin [84]. However, some authors are skeptical about the existence of an extra mitochondrial form of frataxin, and therefore question the physiological relevance of the observed interaction between IRP1 and frataxin.

As indicated above, many evidences support that frataxin deficiency causes a dysregulation in iron homeostasis, and it has also been shown in several models that the modulation of iron homeostasis ameliorates several phenotypes caused by frataxin deficiency [74,85]. However, the contribution of iron accumulation to the pathophysiology of FRDA has not been clearly determined. In this regard, several hypotheses have been formulated. It has been proposed that iron accumulation would be toxic and could be contributing to the formation of reactive oxygen species through the Fenton reaction. Iron overload could be also inducing the synthesis of sphingolipids, which, through the Pdk1/Mef2 pathway, would trigger neurodegeneration [76,80]. Iron toxicity could be also related to the formation of iron-phosphate aggregates that would compromise phosphate availability [86]. Nevertheless, it has also been suggested that iron accumulation would not be toxic per se, and that pathological consequences of frataxin deficiency would be mostly related to deficient iron supply to iron-dependent proteins. In this regard, it has been shown that IRP1 activation has a protective effect in a mouse model of hepatic FXN deficiency, as it contributes to sustain mitochondrial iron needs and mitochondrial function in these mice [59]. It has also been observed that dietary iron supplementation limits cardiac hypertrophy in MCK mutant mice [79].

These contradictory observations suggest that the pathological mechanisms could be more complex and specific for different models and tissues. For instance, in yeast, we have observed that activation of Aft1 causes the overexpression of $\mathrm{Cth} 2$, an mRNA binding protein that downregulates the expression of most iron-binding proteins that are required for aerobic growth. Thus, the activation 
of such pathway has a strong contribution to the alterations observed in yeast [42]. Beyond yeast, there are several evidences that frataxin deficiency may be causing perturbations in signaling pathways that could contribute to pathology. For instance, as mentioned before, neurodegeneration has been linked to the activation of the Pdk1/Mef2 pathway $[76,80]$. Cardiac hypertrophy could be related to the activation of the NFAT/calcineurin pathway, which has been observed in rat frataxin deficient cardiac myocytes [87]. Therefore, pathophysiology could be related to the pathways activated in different cells and tissues in response to the perturbations caused by frataxin deficiency.

Besides iron, some authors have reported deregulation of the homeostasis of other metals as a consequence of frataxin deficiency. In frataxin deficient yeast, we observed a decrease in manganese content and limited copper availability $[58,88]$. Subsequent studies using a conditional frataxin mutant indicated that manganese deficiency was caused by downregulation of Smf2, a Mn transporter that was degraded in response to iron accumulation [41]. In frataxin deficient flies it was found that the levels of zinc, copper, and manganese were increased, and that copper and zinc chelation improved the impaired motor performance of these flies [89]. In Dorsal Root Ganglia from FRDA patients, zinc and iron related proteins displayed major shifts in their cellular localization [90]. Alterations in calcium homeostasis have also been reported in several models of FRDA $[87,91]$. These alterations are mostly considered to be consequences of the deregulation of iron homeostasis, which may impact other metals. Nevertheless, frataxin is known to have also the capacity to chelate metals that are different than iron, such as manganese or copper [92]. The biological significance of these interactions has not been explored yet.

\section{Targeting Iron as a Therapeutic Approach in FRDA}

There is currently no cure for FRDA but several therapeutic approaches are being investigated. Some drugs have already entered clinical trials. Briefly, therapeutic approaches can be divided into compounds that improve mitochondrial function and reduce oxidative stress, drugs that modulate the altered metabolic pathways, and strategies to increase the expression or content of frataxin, either by promoting its expression, by supplying it through gene therapy (reviewed in [93]) or by protein replacement strategies [94].

Due to the alterations that were observed in iron homeostasis in different models and patients of FRDA, the use of iron chelators as a treatment to eliminate the excess iron accumulating in mitochondria was proposed many years ago. Deferoxamine was not considered to be a suitable iron chelator for depleting the intracellular iron deposits found in FRDA, as it does not cross the blood brain barrier and poorly penetrates biological membranes. It also has a high affinity for iron, which could compromise iron availability. The proposed alternative was deferiprone, an orally administered, lipidsoluble iron chelator that had been previously used to treat iron overload in polytransfused individuals with hemoglobinopathies. This compound can easily cross the blood-brain barrier and cellular membranes and therefore reach intracellular (or mitochondrial) iron deposits. In addition, since its affinity for iron is lower than that of transferrin, it has been shown that it can redistribute iron from intracellular iron deposits to this protein [95]. Indeed, the cellular properties that are affected by frataxin deficiency in HEK-293 cells were corrected by deferiprone treatment [96].

Several clinical trials have been performed with deferiprone in FRDA patients. In summary, these studies suggested that low doses of deferiprone would be beneficial on cardiac parameters. Higher doses of the drug worsened the condition and could result in agranulocytosis (reviewed in [97]). We can speculate that this dose dependent effect could be a consequence of different pathological mechanisms that are exerted by frataxin deficiency. Some of them would be caused by iron accumulation, while others would be caused by deficient iron availability. Therefore, low doses of the chelator would partially prevent the toxic effects that are caused by iron accumulation, while higher doses of deferiprone would compromise iron availability, and therefore worsen those pathological conditions caused by inefficient iron availability. Nevertheless, it has been proposed that deferiprone at low doses could be combined with other drugs. A pilot study with five FRDA patients suggested 
that combined therapy of deferiprone and idebenone (a Q10 analogue) was relatively safe and it could provide some benefits on neurological function and heart hypertrophy [98].

\section{Concluding Remarks}

Many evidences indicate that the lack of frataxin leads to alterations in iron cellular homeostasis. However, the precise mechanism(s) causing iron deregulation in frataxin-deficient cells are not completely understood. Several hypotheses have been formulated, but although most of them are well supported by in vitro data, all of them present caveats when exposed to biological data. In Figure 2, we have summarized two potential mechanisms which in our opinion could explain iron accumulation and oxidative stress: (1) the iron-sulfur hypothesis proposes that frataxin contributes to iron-sulfur biogenesis and its deficiency activates cellular iron sensors that would promote iron uptake; and, (2) the iron toxicity hypothesis assumes that frataxin would be involved in controlled iron ferrooxidation, and its deficiency would lead to ROS generation and the increased formation of ferric-phosphate nanoparticles. The iron-sulfur hypothesis is well supported by in vitro data, but its major caveat is the absence of iron-sulfur deficiency in many models of frataxin deficiency. On the other hand, the iron toxicity hypothesis does not provide a clear explanation for the activation of iron sensors.
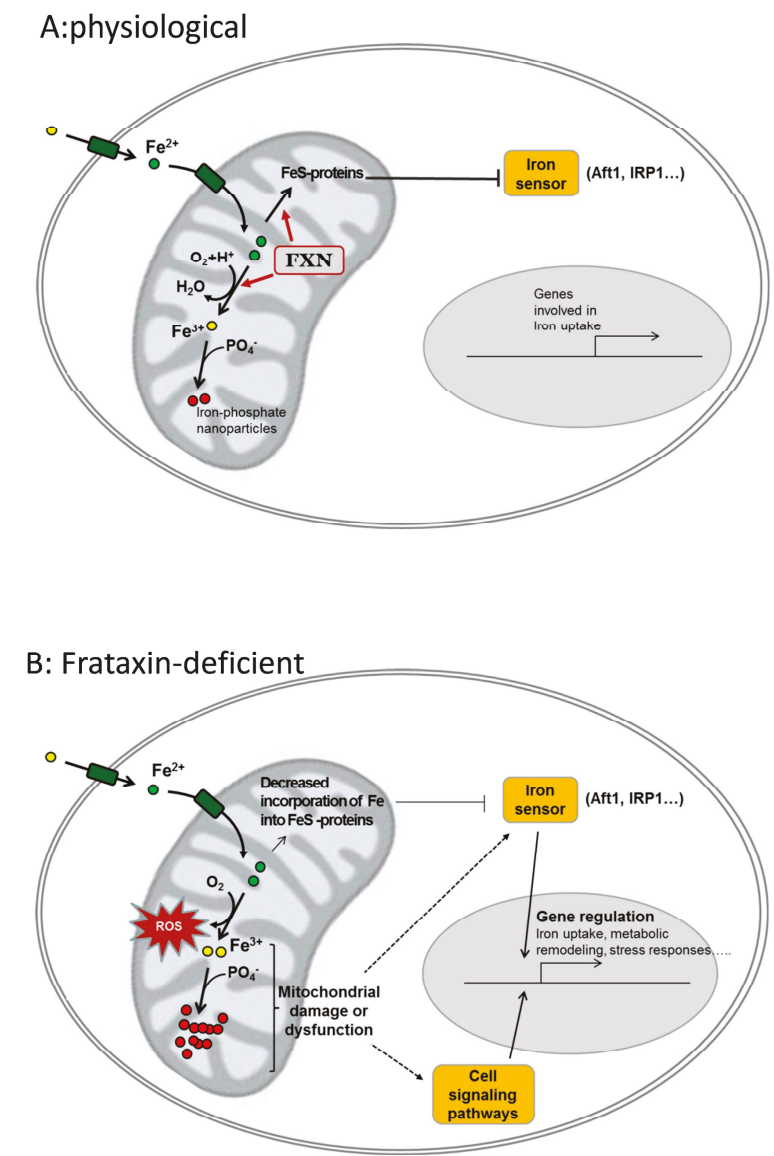

Figure 2. Potential contribution of frataxin to iron homeostasis and cellular consequences of its deficiency. (A), physiological: frataxin (FXN) binds $\mathrm{Fe}^{2+}$ and contributes to its controlled oxidation to 
$\mathrm{Fe}^{3+}$ and/or to incorporate it into Fe-containing proteins. These Fe-containing proteins (notably FeS proteins) keep the iron sensor inactive and genes involved in iron uptake are not expressed. Oxidized iron $\left(\mathrm{Fe}^{3+}\right)$ is stored in the form of ferric-phosphate nanoparticles. (B), frataxin-deficient: loss of frataxin leads to decreased incorporation of iron into Fe-proteins and/or uncontrolled oxidation of $\mathrm{Fe}^{2+}$ by $\mathrm{O}_{2}$. Such events lead to reactive oxygen species (ROS) generation, decreased phosphate availability, and mitochondrial dysfunction. Iron sensors and other cell signaling pathways are activated and regulate the expression of genes involved in iron uptake and/or other cell-specific pathways involved on metabolic remodeling, hypertrophy or neurodegeneration.

Also, it is not clear the contribution of iron to FRDA pathology, which could be related either to iron accumulation or to limited iron availability. Indeed, iron homeostasis deregulation could be an epiphenomenon that is not linked to pathology. In fact, many evidences suggest that the mechanisms causing cellular dysfunction could be tissue or model specific. They could also be related to the signaling pathways activated in response to the alterations that are caused by frataxin deficiency. This complexity may explain the limited effects of iron chelators on clinical trials, as these compounds would only prevent certain pathological mechanisms in a limited number of tissues.

Funding: This work has been supported by grant SAF2017-83883-R from Ministerio de Economia Industria y Competitividad (Spain).

Acknowledgments: Molecular graphics and analyses were performed with the UCSF Chimera package. Chimera is developed by the Resource for Biocomputing, Visualization, and Informatics at the University of California, San Francisco (supported by NIGMS P41-GM103311).

Conflicts of Interest: The authors declare no conflict of interest.

\section{References}

1. Ashby, D.W.; Tweedy, P.S. Friedreich's ataxia combined with diabetes mellitus in sisters. Br. Med. J. 1953, 1, 1418-1421. [CrossRef] [PubMed]

2. Koeppen, A.H. Friedreich's ataxia: Pathology, pathogenesis, and molecular genetics. J. Neurol. Sci. 2011, 303, 1-12. [CrossRef] [PubMed]

3. Campuzano, V.; Montermini, L.; Molto, M.D.; Pianese, L.; Cossee, M.; Cavalcanti, F.; Monros, E.; Rodius, F.; Duclos, F.; Monticelli, A.; et al. Friedreich's ataxia: Autosomal recessive disease caused by an intronic GAA triplet repeat expansion. Science 1996, 271, 1423-1427. [CrossRef] [PubMed]

4. Campuzano, V.; Montermini, L.; Lutz, Y.; Cova, L.; Hindelang, C.; Jiralerspong, S.; Trottier, Y.; Kish, S.J.; Faucheux, B.; Trouillas, P.; et al. Frataxin is Reduced in Friedreich Ataxia Patients and is Associated with Mitochondrial Membranes. Hum. Mol. Genet. 1997, 6, 1771-1780. [CrossRef] [PubMed]

5. Filla, A.; De Michele, G.; Cavalcanti, F.; Pianese, L.; Monticelli, A.; Campanella, G.; Cocozza, S. The relationship between trinucleotide (GAA) repeat length and clinical features in Friedreich ataxia. Am. J. Hum. Genet. 1996, 59, 554-560. [PubMed]

6. Isnard, R.; Kalotka, H.; Dürr, A.; Cossée, M.; Schmitt, M.; Pousset, F.; Thomas, D.; Brice, A.; Koenig, M.; Komajda, M. Correlation between left ventricular hypertrophy and GAA trinucleotide repeat length in Friedreich's ataxia. Circulation 1997, 95, 2247-2249. [CrossRef] [PubMed]

7. McDaniel, D.O.; Keats, B.; Vedanarayanan, V.; Subramony, S.H. Sequence variation in GAA repeat expansions may cause differential phenotype display in Friedreich's ataxia. Mov. Disord. 2001, 16, 1153-1158. [CrossRef] [PubMed]

8. $\quad$ Evans-Galea, M.V.; Carrodus, N.; Rowley, S.M.; Corben, L.A.; Tai, G.; Saffery, R.; Galati, J.C.; Wong, N.C.; Craig, J.M.; Lynch, D.R.; et al. FXN methylation predicts expression and clinical outcome in Friedreich ataxia. Ann. Neurol. 2012, 71, 487-497. [CrossRef] [PubMed]

9. Galea, C.A.; Huq, A.; Lockhart, P.J.; Tai, G.; Corben, L.A.; Yiu, E.M.; Gurrin, L.C.; Lynch, D.R.; Gelbard, S.; Durr, A.; et al. Compound heterozygous FXN mutations and clinical outcome in friedreich ataxia. Ann. Neurol. 2016, 79, 485-495. [CrossRef] [PubMed] 
10. Adinolfi, S.; Nair, M.; Politou, A.; Bayer, E.; Martin, S.; Temussi, P.; Pastore, A. The factors governing the thermal stability of frataxin orthologues: How to increase a protein's stability. Biochemistry 2004, 43, 6511-6518. [CrossRef] [PubMed]

11. Pettersen, E.F.; Goddard, T.D.; Huang, C.C.; Couch, G.S.; Greenblatt, D.M.; Meng, E.C.; Ferrin, T.E. UCSF Chimera-A visualization system for exploratory research and analysis. J. Comput. Chem. 2004, 25, 1605-1612. [CrossRef] [PubMed]

12. Koutnikova, H.; Campuzano, V.; Koenig, M. Maturation of wild-type and mutated frataxin by the mitochondrial processing peptidase. Hum. Mol. Genet. 1998, 7, 1485-1489. [CrossRef] [PubMed]

13. Branda, S.S.; Cavadini, P.; Adamec, J.; Kalousek, F.; Taroni, F.; Isaya, G. Yeast and human frataxin are processed to mature form in two sequential steps by the mitochondrial processing peptidase. J. Biol. Chem. 1999, 274, 22763-22769. [CrossRef] [PubMed]

14. Condò, I.; Ventura, N.; Malisan, F.; Rufini, A.; Tomassini, B.; Testi, R. In vivo maturation of human frataxin. Hum. Mol. Genet. 2007, 16, 1534-1540. [CrossRef] [PubMed]

15. Schmucker, S.; Argentini, M.; Carelle-Calmels, N.; Martelli, A.; Puccio, H. The in vivo mitochondrial two-step maturation of human frataxin. Hum. Mol. Genet. 2008, 17, 3521-3531. [CrossRef] [PubMed]

16. Gakh, O.; Bedekovics, T.; Duncan, S.F.; Smith, D.Y.; Berkholz, D.S.; Isaya, G. Normal and Friedreich ataxia cells express different isoforms of frataxin with complementary roles in iron-sulfur cluster assembly. J. Biol. Chem. 2010, 285, 38486-38501. [CrossRef] [PubMed]

17. Cavadini, P.; Adamec, J.; Taroni, F.; Gakh, O.; Isaya, G. Two-step Processing of Human Frataxin by Mitochondrial Processing Peptidase. J. Biol. Chem. 2000, 275, 41469-41475. [CrossRef] [PubMed]

18. Xia, H.; Cao, Y.; Dai, X.; Marelja, Z.; Zhou, D.; Mo, R.; Al-Mahdawi, S.; Pook, M.A.; Leimkühler, S.; Rouault, T.A.; et al. Novel frataxin isoforms may contribute to the pathological mechanism of Friedreich ataxia. PLoS ONE 2012, 7, e47847. [CrossRef] [PubMed]

19. Pastore, A.; Puccio, H. Frataxin: A protein in search for a function. J. Neurochem. 2013, 126, 43-52. [CrossRef] [PubMed]

20. Yoon, T.; Cowan, J.A. Iron-Sulfur Cluster Biosynthesis. Characterization of Frataxin as an Iron Donor for Assembly of [2 $\mathrm{Fe}^{-2} \mathrm{~S}$ ] Clusters in ISU-Type Proteins. J. Am. Chem. Soc. 2003, 125, 6078-6084. [CrossRef] [PubMed]

21. Gentry, L.E.; Thacker, M.A.; Doughty, R.; Timkovich, R.; Busenlehner, L.S. His86 from the N-Terminus of Frataxin Coordinates Iron and Is Required for Fe-S Cluster Synthesis. Biochemistry 2013, 52, 6085-6096. [CrossRef] [PubMed]

22. Cai, K.; Frederick, R.O.; Tonelli, M.; Markley, J.L. Interactions of iron-bound frataxin with ISCU and ferredoxin on the cysteine desulfurase complex leading to Fe-S cluster assembly. J. Inorg. Biochem. 2018, 183, 107-116. [CrossRef] [PubMed]

23. Adamec, J.; Rusnak, F.; Owen, W.G.; Naylor, S.; Benson, L.M.; Gacy, M.; Isaya, G. Iron-dependent self-assembly of recombinant yeast frataxin: Implications for Friedreich ataxia. Am. J. Hum. Genet. 2000, 67, 549-562. [CrossRef] [PubMed]

24. Cavadini, P.; O’Neill, H.A.; Benada, O.; Isaya, G. Assembly and iron-binding properties of human frataxin, the protein deficient in Friedreich ataxia. Hum. Mol. Genet. 2002, 11, 217-227. [CrossRef] [PubMed]

25. Schagerlof, U.; Elmlund, H.; Gakh, O.; Nordlund, G.; Hebert, H.; Lindahl, M.; Isaya, G.; Al-Karadaghi, S. Structural basis of the iron storage function of frataxin from single-particle reconstruction of the iron-loaded oligomer. Biochemistry 2008, 47, 4948-4954. [CrossRef] [PubMed]

26. Campanella, A.; Isaya, G.; O'Neill, H.A.; Santambrogio, P.; Cozzi, A.; Arosio, P.; Levi, S. The expression of human mitochondrial ferritin rescues respiratory function in frataxin-deficient yeast. Hum. Mol. Genet. 2004, 13, 2279-2288. [CrossRef] [PubMed]

27. Adinolfi, S.; Trifuoggi, M.; Politou, A.S.; Martin, S.; Pastore, A. A structural approach to understanding the iron-binding properties of phylogenetically different frataxins. Hum. Mol. Genet. 2002, 11, 1865-1877. [CrossRef] [PubMed]

28. Desiere, F.; Deutsch, E.W.; King, N.L.; Nesvizhskii, A.I.; Mallick, P.; Eng, J.; Chen, S.; Eddes, J.; Loevenich, S.N.; Aebersold, R. The PeptideAtlas project. Nucleic Acids Res. 2006, 34, D655-D658. [CrossRef] [PubMed]

29. Ahlgren, E.C.; Fekry, M.; Wiemann, M.; Söderberg, C.A.; Bernfur, K.; Gakh, O.; Rasmussen, M.; Højrup, P.; Emanuelsson, C.; Isaya, G.; et al. Iron-induced oligomerization of human FXN81-210 and bacterial CyaY frataxin and the effect of iron chelators. PLoS ONE 2017, 12, e0188937. [CrossRef] [PubMed] 
30. Seguin, A.; Sutak, R.; Bulteau, A.L.; Garcia-Serres, R.; Oddou, J.L.; Lefevre, S.; Santos, R.; Dancis, A.; Camadro, J.; Latour, J.; et al. Evidence that yeast frataxin is not an iron storage protein in vivo. Biochim. Biophys. Acta-Mol. Basis Dis. 2010, 1802, 531-538. [CrossRef] [PubMed]

31. Sturm, B.; Bistrich, U.; Schranzhofer, M.; Sarsero, J.P.; Rauen, U.; Scheiber-mojdehkar, B.; de Groot, H.; Ioannou, P.; Petrat, F. Friedreich's Ataxia, No Changes in Mitochondrial Labile Iron in Human Lymphoblasts and Fibroblasts A Decrease in Antioxidative Capacity? J. Biol. Chem. 2004, 280, 6701-6708. [CrossRef] [PubMed]

32. Lindahl, P.A.; Moore, M.J. Labile Low-Molecular-Mass Metal Complexes in Mitochondria: Trials and Tribulations of a Burgeoning Field. Biochemistry 2016, 55, 4140-4153. [CrossRef] [PubMed]

33. Garber-Morales, J.; Holmes-Hampton, G.P.; Miao, R.; Guo, Y.; Münck, E.; Lindahl, P.A. Biophysical characterization of iron in mitochondria isolated from respiring and fermenting yeast. Biochemistry 2010, 49, 5436-5444. [CrossRef] [PubMed]

34. Park, S.; Gakh, O.; O’Neill, H.; Mangravita, A.; Nichol, H.; Ferreira, G.C.; Isaya, G. Yeast frataxin sequentially chaperones and stores iron by coupling protein assembly with iron oxidation. J. Biol. Chem. 2003, 278, 31340-31351. [CrossRef] [PubMed]

35. Wang, M.; Herrmann, C.J.; Simonovic, M.; Szklarczyk, D.; von Mering, C. Version 4.0 of PaxDb: Protein abundance data, integrated across model organisms, tissues, and cell-lines. Proteomics 2015, 15, 3163-3168. [CrossRef] [PubMed]

36. Yoon, T.; Cowan, J.A. Frataxin-mediated iron delivery to ferrochelatase in the final step of heme biosynthesis. J. Biol. Chem. 2004, 279, 25943-25946. [CrossRef] [PubMed]

37. He, Y.; Alam, S.L.; Proteasa, S.V.; Zhang, Y.; Lesuisse, E.; Dancis, A.; Stemmler, T.L. Yeast frataxin solution structure, iron binding, and ferrochelatase interaction. Biochemistry 2004, 43, 16254-16262. [CrossRef] [PubMed]

38. Soderberg, C.G.; Gillam, M.E.; Ahlgren, E.C.; Hunter, G.A.; Gakh, O.; Isaya, G.; Ferreira, G.C.; $\mathrm{Al}-\mathrm{Karadaghi}$, S. The Structure of the Complex between Yeast Frataxin and Ferrochelatase: Characterization and pre-Steady State Reaction of Ferrous Iron Delivery and Heme Synthesis. J. Biol. Chem. 2016, 291, 11887-11898. [CrossRef] [PubMed]

39. Steinkellner, H.; Singh, H.N.; Muckenthaler, M.U.; Goldenberg, H.; Moganty, R.R.; Scheiber-Mojdehkar, B.; Sturm, B. No changes in heme synthesis in human Friedreich's ataxia erythroid progenitor cells. Gene 2017, 621, 5-11. [CrossRef] [PubMed]

40. Lu, C.; Cortopassi, G. Frataxin knockdown causes loss of cytoplasmic iron-sulfur cluster functions, redox alterations and induction of heme transcripts. Arch. Biochem. Biophys. 2007, 457, 111-122. [CrossRef] [PubMed]

41. Moreno-Cermeno, A.; Obis, E.; Belli, G.; Cabiscol, E.; Ros, J.; Tamarit, J. Frataxin Depletion in Yeast Triggers Up-regulation of Iron Transport Systems before Affecting Iron-Sulfur Enzyme Activities. J. Biol. Chem. 2010, 285, 41653-41664. [CrossRef] [PubMed]

42. Moreno-Cermeno, A.; Alsina, D.; Cabiscol, E.; Tamarit, J.; Ros, J. Metabolic remodeling in frataxin-deficient yeast is mediated by Cth2 and Adr1. Biochim. Biophys. Acta 2013, 1833, 3326-3337. [CrossRef] [PubMed]

43. Schmucker, S.; Martelli, A.; Colin, F.; Page, A.; Wattenhofer-Donze, M.; Reutenauer, L.; Puccio, H. Mammalian Frataxin: An Essential Function for Cellular Viability through an Interaction with a Preformed ISCU/NFS1/ISD11 Iron-Sulfur Assembly Complex. PLoS ONE 2011, 6, e16199. [CrossRef] [PubMed]

44. Wang, T.; Craig, E.A. Binding of yeast frataxin to the scaffold for Fe-S cluster biogenesis. J. Biol. Chem. 2008, 283, 12674-12679. [CrossRef] [PubMed]

45. Gerber, J.; Muhlenhoff, U.; Lill, R. An interaction between frataxin and Isu1/Nfs1 that is crucial for Fe/S cluster synthesis on Isu1. EMBO Rep. 2003, 4, 906-911. [CrossRef] [PubMed]

46. Adinolfi, S.; Iannuzzi, C.; Prischi, F.; Pastore, C.; Iametti, S.; Martin, S.R.; Bonomi, F.; Pastore, A. Bacterial frataxin CyaY is the gatekeeper of iron-sulfur cluster formation catalyzed by IscS. Nat. Struct. Mol. Biol. 2009, 16, 390-396. [CrossRef] [PubMed]

47. Bridwell-Rabb, J.; Fox, N.G.; Tsai, C.L.; Winn, A.M.; Barondeau, D.P. Human frataxin activates Fe-S cluster biosynthesis by facilitating sulfur transfer chemistry. Biochemistry 2014, 53, 4904-4913. [CrossRef] [PubMed]

48. Tsai, C.L.; Barondeau, D.P. Human frataxin is an allosteric switch that activates the Fe-S cluster biosynthetic complex. Biochemistry 2010, 49, 9132-9139. [CrossRef] [PubMed] 
49. Parent, A.; Elduque, X.; Cornu, D.; Belot, L.; Le Caer, J.P.; Grandas, A.; Toledano, M.B.; D’Autréaux, B. Mammalian frataxin directly enhances sulfur transfer of NFS1 persulfide to both ISCU and free thiols. Nat. Commun. 2015, 6, 5686. [CrossRef] [PubMed]

50. Rouault, T.A.; Maio, N. Biogenesis and functions of mammalian iron-sulfur proteins in the regulation of iron homeostasis and pivotal metabolic pathways. J. Biol. Chem. 2017, 292, 12744-12753. [CrossRef] [PubMed]

51. Braymer, J.J.; Lill, R. Iron-sulfur cluster biogenesis and trafficking in mitochondria. J. Biol. Chem. 2017, 292, 12754-12763. [CrossRef] [PubMed]

52. Llorens, J.; Navarro, J.; Martínez-Sebastián, M.J.; Baylies, M.K.; Schneuwly, S.; Botella, J.; Moltó, M.D. Causative role of oxidative stress in a Drosophila model of Friedreich ataxia. FASEB J. 2007, 21, 333-344. [CrossRef] [PubMed]

53. Rötig, A.; de Lonlay, P.; Chretien, D.; Foury, F.; Koenig, M.; Sidi, D.; Munnich, A.; Rustin, P. Aconitase and mitochondrial iron-sulphur protein deficiency in Friedreich ataxia. Nat. Genet. 1997, 17, 215-217. [CrossRef] [PubMed]

54. Obis, È.; Irazusta, V.; Sanchís, D.; Ros, J.; Tamarit, J. Frataxin deficiency in neonatal rat ventricular myocytes targets mitochondria and lipid metabolism. Free Radic. Biol. Med. 2014, 73, 21-33. [CrossRef] [PubMed]

55. Gabrielli, N.; Ayte, J.; Hidalgo, E. Cells lacking pfh1, a fission yeast homolog of Mammalian frataxin protein, display constitutive activation of the iron starvation response. J. Biol. Chem. 2012, 287, 43042-43051. [CrossRef] [PubMed]

56. Tamarit, J.; Obis, È.; Ros, J. Oxidative stress and altered lipid metabolism in Friedreich ataxia. Free Radic. Biol. Med. 2016, 100, 138-146. [CrossRef] [PubMed]

57. Bayot, A.; Santos, R.; Camadro, J.M.; Rustin, P. Friedreich's ataxia: The vicious circle hypothesis revisited. BMC Med. 2011, 9, 112-119. [CrossRef] [PubMed]

58. Irazusta, V.; Obis, E.; Moreno-Cermeño, A.; Cabiscol, E.; Ros, J.; Tamarit, J. Yeast frataxin mutants display decreased superoxide dismutase activity crucial to promote protein oxidative damage. Free Radic. Biol. Med. 2010, 48, 411-420. [CrossRef] [PubMed]

59. Martelli, A.; Schmucker, S.; Reutenauer, L.; Mathieu, J.R.R.; Peyssonnaux, C.; Karim, Z.; Puy, H.; Galy, B.; Hentze, M.W.; Puccio, H. Iron Regulatory Protein 1 Sustains Mitochondrial Iron Loading and Function in Frataxin Deficiency. Cell Metab. 2015, 21, 311-322. [CrossRef] [PubMed]

60. Bulteau, A.L.; Dancis, A.; Gareil, M.; Montagne, J.J.; Camadro, J.M.; Lesuisse, E. Oxidative stress and protease dysfunction in the yeast model of Friedreich ataxia. Free Radic. Biol. Med. 2007, 42, 1561-1570. [CrossRef] [PubMed]

61. Gibson, T.J.; Koonin, E.; Musco, G.; Pastore, A.; Bork, P. Friedreich's ataxia protein: Phylogenetic evidence for mitochondrial dysfunction. Trends Neurosci. 1996, 19, 465-468. [CrossRef]

62. Anderson, P.R.; Kirby, K.; Orr, W.C.; Hilliker, A.J.; Phillips, J.P. Hydrogen peroxide scavenging rescues frataxin deficiency in a Drosophila model of Friedreich's ataxia. Proc. Natl. Acad. Sci. USA 2008, 105, 611-616. [CrossRef] [PubMed]

63. O'Neill, H.A.; Gakh, O.; Park, S.; Cui, J.; Mooney, S.M.; Sampson, M.; Ferreira, G.C.; Isaya, G. Assembly of human frataxin is a mechanism for detoxifying redox-active iron. Biochemistry 2005, 44, 537-545. [CrossRef] [PubMed]

64. Gakh, O.; Park, S.; Liu, G.; Macomber, L.; Imlay, J.A.; Ferreira, G.C.; Isaya, G. Mitochondrial iron detoxification is a primary function of frataxin that limits oxidative damage and preserves cell longevity. Hum. Mol. Genet. 2006, 15, 467-479. [CrossRef] [PubMed]

65. Gonzalez-Cabo, P.; Vazquez-Manrique, R.P.; Garcia-Gimeno, M.A.; Sanz, P.; Palau, F. Frataxin interacts functionally with mitochondrial electron transport chain proteins. Hum. Mol. Genet. 2005, 14, 2091-2098. [CrossRef] [PubMed]

66. Koutnikova, H.; Campuzano, V.; Foury, F.; Dolle, P.; Cazzalini, O.; Koenig, M. Studies of human, mouse and yeast homologues indicate a mitochondrial function for frataxin. Nat. Genet. 1997, 16, 345-351. [CrossRef] [PubMed]

67. Lodi, R.; Rajagopalan, B.; Blamire, A.M.; Cooper, J.M.; Davies, C.H.; Bradley, J.L.; Styles, P.; Schapira, A. Cardiac energetics are abnormal in Friedreich ataxia patients in the absence of cardiac dysfunction and hypertrophy: An in vivo 31P magnetic resonance spectroscopy study. Cardiovasc. Res. 2001, 52, 111-119. [CrossRef] 
68. Armstrong, J.S.; Khdour, O.; Hecht, S.M. Does oxidative stress contribute to the pathology of Friedreich's ataxia? A radical question. FASEB J. 2010, 24, 2152-2163. [CrossRef] [PubMed]

69. Paupe, V.; Dassa, E.P.; Goncalves, S.; Auchere, F.; Lonn, M.; Holmgren, A.; Rustin, P. Impaired nuclear Nrf2 translocation undermines the oxidative stress response in Friedreich ataxia. PLoS ONE 2009, 4, e4253. [CrossRef] [PubMed]

70. D'Oria, V.; Petrini, S.; Travaglini, L.; Priori, C.; Piermarini, E.; Petrillo, S.; Carletti, B.; Bertini, E.; Piemonte, F. Frataxin deficiency leads to reduced expression and impaired translocation of NF-E2-related factor (Nrf2) in cultured motor neurons. Int. J. Mol. Sci. 2013, 14, 7853-7865. [CrossRef] [PubMed]

71. Shan, Y.; Schoenfeld, R.A.; Hayashi, G.; Napoli, E.; Akiyama, T.; Carstens, M.; Carstens, E.E.; Pook, M.A.; Cortopassi, G.A. Frataxin deficiency leads to defects in expression of antioxidants and Nrf2 expression in dorsal root ganglia of the Friedreich's ataxia YG8R mouse model. Antioxid. Redox Signal. 2013, 19, 1481-1493. [CrossRef] [PubMed]

72. Babcock, M.; de Silva, D.; Oaks, R.; Davis-Kaplan, S.; Jiralerspong, S.; Montermini, L.; Pandolfo, M.; Kaplan, J. Regulation of mitochondrial iron accumulation by Yfh1p, a putative homolog of frataxin. Science 1997, 276, 1709-1712. [CrossRef] [PubMed]

73. Lesuisse, E.; Santos, R.; Matzanke, B.F.; Knight, S.A.B.; Camadro, J.M.; Dancis, A. Iron use for haeme synthesis is under control of the yeast frataxin homologue (Yfh1). Hum. Mol. Genet. 2003, 12, 879-889. [CrossRef] [PubMed]

74. Alsina, D.; Ros, J.; Tamarit, J. Nitric oxide prevents Aft1 activation and metabolic remodeling in frataxin-deficient yeast. Redox Biol. 2018, 14, 131-141. [CrossRef] [PubMed]

75. Soriano, S.; Llorens, J.V.; Blanco-Sobero, L.; Gutiérrez, L.; Calap-Quintana, P.; Morales, M.P.; Moltó, M.D.; Martínez-Sebastián, M.J. Deferiprone and idebenone rescue frataxin depletion phenotypes in a Drosophila model of Friedreich's ataxia. Gene 2013, 521, 274-281. [CrossRef] [PubMed]

76. Chen, K.; Lin, G.; Haelterman, N.A.; Ho, T.S.Y.; Li, T.; Li, Z.; Duraine, L.; Graham, B.H.; Jaiswal, M.; Yamamoto, S.; et al. Loss of Frataxin induces iron toxicity, sphingolipid synthesis, and Pdk1/Mef2 activation, leading to neurodegeneration. Elife 2016, 5, e16043. [CrossRef] [PubMed]

77. Whitnall, M.; Rahmanto, Y.S.; Sutak, R.; Xu, X.; Becker, E.M.; Mikhael, M.R.; Ponka, P.; Richardson, D.R. The MCK mouse heart model of Friedreich's ataxia: Alterations in iron-regulated proteins and cardiac hypertrophy are limited by iron chelation. Proc. Natl. Acad. Sci. USA 2008, 105, 9757-9762. [CrossRef] [PubMed]

78. Ramirez, R.L.; Qian, J.; Santambrogio, P.; Levi, S.; Koeppen, A.H. Relation of Cytosolic Iron Excess to Cardiomyopathy of Friedreich's Ataxia. Am. J. Cardiol. 2012, 110, 1820-1827. [CrossRef] [PubMed]

79. Whitnall, M.; Rahmanto, Y.S.; Huang, M.L.H.; Saletta, F.; Lok, H.C.; Gutierrez, L.; Lázaro, F.J.; Fleming, A.J.; St. Pierre, T.G.; Mikhael, M.R.; et al. Identification of nonferritin mitochondrial iron deposits in a mouse model of Friedreich ataxia. Proc. Natl. Acad. Sci. USA 2012, 109, 20590-20595. [CrossRef] [PubMed]

80. Chen, K.; Ho, T.S.Y.; Lin, G.; Tan, K.L.; Rasband, M.N.; Bellen, H.J. Loss of Frataxin activates the iron/sphingolipid/PDK1/Mef2 pathway in mammals. Elife 2016, 5, e20732. [CrossRef] [PubMed]

81. Koeppen, A.H.; Michael, S.C.; Knutson, M.D.; Haile, D.J.; Qian, J.; Levi, S.; Santambrogio, P.; Garrick, M.D.; Lamarche, J.B. The dentate nucleus in Friedreich's ataxia: The role of iron-responsive proteins. Acta Neuropathol. 2007, 114, 163-173. [CrossRef] [PubMed]

82. Seznec, H.; Simon, D.; Monassier, L.; Criqui-Filipe, P.; Gansmuller, A.; Rustin, P.; Koenig, M.; Puccio, H. Idebenone delays the onset of cardiac functional alteration without correction of Fe-S enzymes deficit in a mouse model for Friedreich ataxia. Hum. Mol. Genet. 2004, 13, 1017-1024. [CrossRef] [PubMed]

83. Stehling, O.; Elsässer, H.P.; Brückel, B.; Mühlenhoff, U.; Lill, R. Iron-sulfur protein maturation in human cells: Evidence for a function of frataxin. Hum. Mol. Genet. 2004, 13, 3007-3015. [CrossRef] [PubMed]

84. Condò, I.; Malisan, F.; Guccini, I.; Serio, D.; Rufini, A.; Testi, R. Molecular control of the cytosolic aconitase/IRP1 switch by extramitochondrial frataxin. Hum. Mol. Genet. 2010, 19, 1221-1229. [CrossRef] [PubMed]

85. Navarro, J.A.; Botella, J.A.; Metzendorf, C.; Lind, M.I.; Schneuwly, S. Mitoferrin modulates iron toxicity in a Drosophila model of Friedreich's ataxia. Free Radic. Biol. Med. 2015, 85, 71-82. [CrossRef] [PubMed]

86. Seguin, A.; Santos, R.; Pain, D.; Dancis, A.; Camadro, J.M.; Lesuisse, E. Co-precipitation of phosphate and iron limits mitochondrial phosphate availability in Saccharomyces cerevisiae lacking the yeast frataxin homologue (YFH1). J. Biol. Chem. 2011, 286, 6071-6079. [CrossRef] [PubMed] 
87. Purroy, R.; Britti, E.; Delaspre, F.; Tamarit, J.; Ros, J. Mitochondrial pore opening and loss of $\mathrm{Ca}^{2+}$ exchanger NCLX levels occur after frataxin depletion. Biochim. Biophys. Acta-Mol. Basis Dis. 2018, 1864, 618-631. [CrossRef] [PubMed]

88. Irazusta, V.; Cabiscol, E.; Reverter-Branchat, G.; Ros, J.; Tamarit, J. Manganese is the link between frataxin and iron-sulfur deficiency in the yeast model of Friedreich ataxia. J. Biol. Chem. 2006, 281, 12227-12232. [CrossRef] [PubMed]

89. Soriano, S.; Calap-Quintana, P.; Llorens, J.V.; Al-Ramahi, I.; Gutiérrez, L.; Martínez-Sebastián, M.J.; Botas, J.; Moltó, M.D. Metal Homeostasis Regulators Suppress FRDA Phenotypes in a Drosophila Model of the Disease. PLoS ONE 2016, 11, e0159209. [CrossRef] [PubMed]

90. Koeppen, A.H.; Kuntzsch, E.C.; Bjork, S.T.; Ramirez, R.; Mazurkiewicz, J.E.; Feustel, P.J. Friedreich ataxia: Metal dysmetabolism in dorsal root ganglia. Acta Neuropathol. Commun. 2013, 1, 26. [CrossRef] [PubMed]

91. Mincheva-Tasheva, S.; Obis, E.; Tamarit, J.; Ros, J. Apoptotic cell death and altered calcium homeostasis caused by frataxin depletion in dorsal root ganglia neurons can be prevented by BH4 domain of Bcl-xL protein. Hum. Mol. Genet. 2013, 23, 1829-1841. [CrossRef] [PubMed]

92. Han, T.H.L.; Camadro, J.M.; Santos, R.; Lesuisse, E.; Chahine, J.M.; Ha-Duong, N.T. Mechanisms of iron and copper-frataxin interactions. Metallomics 2017, 9, 1073-1085. [CrossRef] [PubMed]

93. Tai, G.; Corben, L.A.; Yiu, E.M.; Milne, S.C.; Delatycki, M.B. Progress in the treatment of Friedreich ataxia. Neurol. Neurochir. Pol. 2018, 52, 129-139. [CrossRef] [PubMed]

94. Britti, E.; Delaspre, F.; Feldman, A.; Osborne, M.; Greif, H.; Tamarit, J.; Ros Salvador, J. Frataxin-deficient neurons and mice models of Friedreich ataxia are improved by TAT-MTScs-FXN treatment. J. Cell. Mol. Med. 2017, 22, 834-848. [CrossRef] [PubMed]

95. Sohn, Y.S.; Breuer, W.; Munnich, A.; Cabantchik, Z.I. Redistribution of accumulated cell iron: A modality of chelation with therapeutic implications. Blood 2008, 111, 1690-1699. [CrossRef] [PubMed]

96. Kakhlon, O.; Manning, H.; Breuer, W.; Melamed-Book, N.; Lu, C.; Cortopassi, G.; Munnich, A.; Cabantchik, Z. Cell functions impaired by frataxin deficiency are restored by drug-mediated iron relocation. Blood 2008, 112, 5219-5227. [CrossRef] [PubMed]

97. Pandolfo, M.; Hausmann, L. Deferiprone for the treatment of Friedreich's ataxia. J. Neurochem. 2013, 126, 142-146. [CrossRef] [PubMed]

98. Elincx-Benizri, S.; Glik, A.; Merkel, D.; Arad, M.; Freimark, D.; Kozlova, E.; Cabantchik, I.; Hassin-Baer, S. Clinical Experience With Deferiprone Treatment for Friedreich Ataxia. J. Child Neurol. 2016, 31, 1036-1040. [CrossRef] [PubMed]

(C) 2018 by the authors. Licensee MDPI, Basel, Switzerland. This article is an open access article distributed under the terms and conditions of the Creative Commons Attribution (CC BY) license (http:/ / creativecommons.org/licenses/by/4.0/). 


\title{
Review \\ Cellular Senescence and Iron Dyshomeostasis in Alzheimer's Disease
}

\author{
Shashank Masaldan, Abdel Ali Belaidi, Scott Ayton and Ashley I. Bush * \\ Melbourne Dementia Research Centre, The Florey Institute of Neuroscience and Mental Health, The University \\ of Melbourne, Parkville, VIC 3052, Australia; shashank.masaldan@florey.edu.au (S.M.); \\ abdel.belaidi@florey.edu.au (A.A.B.); scott.ayton@florey.edu.au (S.A.) \\ * Correspondence: ashley.bush@florey.edu.au; Tel.: +613-9035-6532
}

Received: 26 May 2019; Accepted: 17 June 2019; Published: 19 June 2019

\begin{abstract}
Iron dyshomeostasis is a feature of Alzheimer's disease (AD). The impact of iron on $\mathrm{AD}$ is attributed to its interactions with the central proteins of AD pathology (amyloid precursor protein and tau) and/or through the iron-mediated generation of prooxidant molecules (e.g., hydroxyl radicals). However, the source of iron accumulation in pathologically relevant regions of the brain and its contribution to AD remains unclear. One likely contributor to iron accumulation is the age-associated increase in tissue-resident senescent cells that drive inflammation and contribute to various pathologies associated with advanced age. Iron accumulation predisposes ageing tissue to oxidative stress that can lead to cellular dysfunction and to iron-dependent cell death modalities (e.g., ferroptosis). Further, elevated brain iron is associated with the progression of $\mathrm{AD}$ and cognitive decline. Elevated brain iron presents a feature of AD that may be modified pharmacologically to mitigate the effects of age/senescence-associated iron dyshomeostasis and improve disease outcome.
\end{abstract}

Keywords: Alzheimer's disease; iron homeostasis; ferroptosis; senescence; chelators

\section{Introduction}

Alzheimer's disease (AD) is the most common type of dementia. Pathological hallmarks of AD are the accumulation of extracellular amyloid plaques seeded by aggregated amyloid beta peptide $(A \beta)$ and intracellular neurofibrillary tangles (NFTs) composed of hyper-phosphorylated microtubule-associated protein tau. The accumulation of $A \beta$ is considered a toxic component of pathology and has been a primary target of clinical strategies [1]. However, strategies that have focused on reducing $A \beta$ burden, including those that have demonstrated the lowering of plaque burden to normal levels, have not been successful in slowing cognitive decline in $\mathrm{AD}$ patients [1-3]. A careful re-examination of the factors that may lead to $\mathrm{AD}$ and contribute to cognitive decline may facilitate the formulation of new therapeutic strategies to prevent or arrest disease processes. Homeostatic regulation of iron is one such pathway amenable to therapeutic targeting, and it has been observed to be perturbed in several neurodegenerative disorders in addition to $\mathrm{AD}$ [4].

Iron is essential for life processes and cellular functions. These include essential "housekeeping" functions such as cellular respiration, DNA synthesis, and cell division, as well as specialized cellular functions such as oxygen transport and neurotransmission [4-6]. The ability of iron to cycle through its oxidation states is fundamental to its biological utility but can lead to oxidative damage of biomolecules resulting in cellular dysfunction [4-6]. This has led to the evolution of tightly regulated homeostatic mechanisms to ensure iron availability and mitigate toxicity [4-6]. However, the brain accumulates iron with age and several neurodegenerative conditions are associated with increased iron levels in affected regions of the brain $[4,5]$.

The cause of age-associated iron accumulation in brain regions relevant to $\mathrm{AD}$ and its impact on disease are relevant questions to determine the utility of brain iron redistribution as a therapeutic 
strategy for AD. In this review we explore the contribution of iron to AD and describe the potential contribution of the proinflammatory senescence program to brain iron accumulation (Figure 1). Notably, while iron accumulation in AD may not be sufficiently high to result in iron toxicity [6], iron dyshomeostasis and elevated iron predisposes and enhances the susceptibility of brain tissue to oxidative dysfunction (e.g., lower glutathione, increased lipid peroxidation, and increased reactive oxygen species) and accelerates cell death modalities such as ferroptosis (reviewed in [4]). Finally, we describe the therapeutic opportunities that may be explored to alleviate AD through pharmacological chelation of iron in the brain.

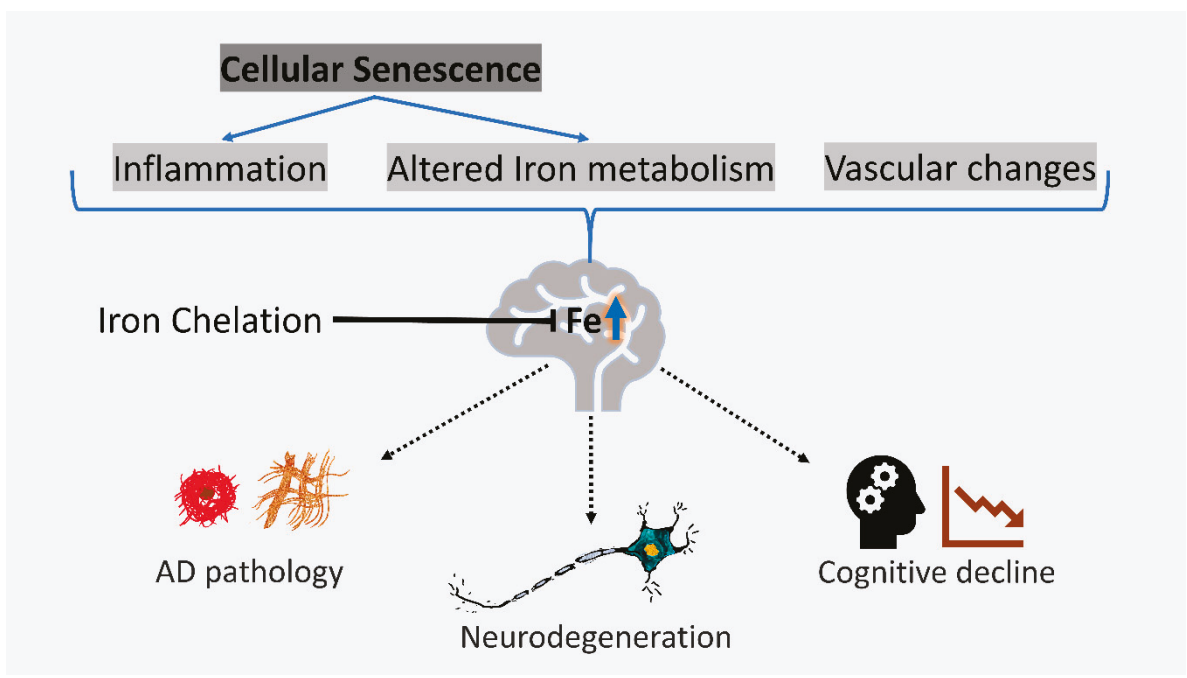

Figure 1. Cellular senescence is a potential contributor to the age-associated accumulation of brain iron. Factors that influence brain iron with age include inflammation, altered vasculature, and altered metabolism. Elevated brain iron is associated with Alzheimer's disease (AD) pathology, cognitive decline, and may lead to neuron loss via iron-dependent oxidative cell death such as ferroptosis. Iron chelation may mitigate some of these effects and alleviate AD progression.

\section{Iron Dyshomeostasis is Associated with AD}

In the brain, iron accumulation is observed in regions affected by AD such as the parietal cortex, motor cortex, and hippocampus [7-15]. The intensity of iron accumulation, observed by histology, in the frontal cortex is different between the subtypes of AD. This can be used to distinguish between sporadic (late onset) and familial (early onset) AD [16] and reflects disease severity [17,18]. Overall, patients with familial AD are affected more in magnetic resonance imaging (MRI) scores compared to patients with sporadic AD, which may reflect higher iron accumulation in familial AD [16]. Further, the forms of iron observed in AD patients vary in their magnetic moment (measured via superconducting quantum interference device magnetometry) when compared with those from age- and gender-matched controls [19]. Magnetic moment is the property of a substance that determines the torque it experiences when influenced by an external magnetic field. Thus, change in magnetic moment reflects a change in the molecular state of iron and indicates possible dysregulation of iron homeostasis [19]. For example, a higher magnetic moment in AD brain tissue vs. control tissue in the absence of changes in the concentration of magnetite (an oxide of iron that can be magnetized) may indicate the larger size of magnetite particles in AD brains. This in turn suggests a dysfunction of iron storage in ferritin (iron storage protein) and/or accumulation of $\mathrm{A} \beta$ in AD tissue [19]. Further, iron levels measured post-mortem are elevated in the inferior temporal cortex only in patients diagnosed with AD during their lives, with AD pathology confirmed post-mortem [20]. 
Iron is associated with the pathological lesions of $\mathrm{AD}[17,21-29]$. Some studies implicate iron as a direct contributor to $\mathrm{AD}$ pathology by promoting the aggregation and oligomerization of $\mathrm{A} \beta$ peptides $[17,26,28-33]$. Levels of iron and ferritin (iron storage protein) in brain tissue are associated with the amount of amyloid deposition [17,34,35]. Iron is accumulated in amyloid plaques as a mineralized magnetite species in mouse and human models of amyloid deposition [26-29]. A $\beta$ may enhance iron mineralization as $A \beta$ peptides can lead to the production of iron-mineral nanoparticles in vitro [36]. It is hypothesized that the oxidative damage associated with the aggregation of $A \beta$ is due to redox active metals (e.g., iron and copper) to which it binds, leading to the production of oxidants such as hydrogen peroxide [37,38].

Iron may impact the production of $\mathrm{A} \beta$ by enhancing the translation and amyloidogenic processing of amyloid precursor protein (APP) [39-45]. APP, when processed through a non-amyloidogenic pathway, is cleaved by $\alpha$-secretase followed by cleavage by $\gamma$-secretase. Iron availability may perturb this process through the aberrant binding of iron response proteins to putative iron response elements on APP mRNA [43-45]. Additionally, iron can mediate tau phosphorylation and aggregation [46-48]. These events can be mitigated by the chelation of iron [49]. Tau accumulation in NFTs is associated with an induction of heme oxygenase- 1 which can exacerbate oxidative stress through the release of iron by the breakdown of heme [45,50-52].

Brain iron and ferritin are associated with cognitive loss in AD. Iron was strongly associated with the rate of cognitive decline 12 years prior to death in the subjects from the Memory and Ageing Project $(n=209)$ [20]. While the direct measurement of brain iron is challenging, ferritin levels in cerebrospinal fluid can be used as a proximate reporter of brain iron load. While brain iron levels are reflected in CSF (cerebrospinal fluid) ferritin, they may also be impacted by the inflammation status of the brain. Regardless, CSF ferritin can predict cognitive decline and the transition from mild cognitive impairment to AD [53]. Ferritin in the CSF predicts the rate of decline in brain metabolism (proximate indicator of neurodegeneration), as measured by fluorodeoxyglucose positron emission tomography (FDG-PET) in subjects with high amyloid pathology (high CSF t-tau/A $\beta 42$ ratio) but not in subjects with low amyloid pathology [54]. Another longitudinal study conducted over six years determined that elevated magnetic susceptibility in the hippocampus, determined by an MRI technique called quantitative susceptibility mapping (QSM), is a strong predictor for an accelerated rate of cognitive decline in amyloid positive subjects [55]. QSM may also be used to longitudinally and non-invasively monitor amyloid accumulation and iron deposition, and may serve as a diagnostic aid for AD [35]. Taken together, these studies suggest that iron is important for cognitive deterioration when there is underlying pathology.

\section{Cellular Senescence is Associated with AD and Iron Dyshomeostasis}

Cellular senescence is a proinflammatory cell fate associated with several age-related disorders, including AD [56-58]. The senescence phenotype is classically described in cultured cells undergoing terminal replicative arrest [59] that display enlarged cell morphology and characteristic alterations of their chromatin, secretory profile (senescence-associated secretory phenotype (SASP)), and cell cycle regulatory proteins (cyclins and cyclin-dependent kinases) [60]. Senescence in culture is typically induced through sub-culturing to replicative exhaustion, inducing DNA damage (through oxidative stress, ionizing radiation, or pharmacological agents), or aberrant oncogenic activation (e.g., overexpression of $\mathrm{Hras}{ }^{\mathrm{V} 12}$ ) [60]. The occurrence of senescent cells in tissue is now widely accepted [61-65] and several functions have been ascribed to them, including involvement in wound healing [66,67], tissue repair [68], and embryonic development (developmental senescence) [69,70]. Despite these beneficial roles, the persistent accumulation of senescence in tissue with age is associated with age-associated pathologies and functional decline. The clearance of senescent cells from tissue in mice can alleviate pathologies related to ageing [56-58,71-81]. While the overall burden of senescent cells in ageing tissue is low, these cells persistently propagate degenerative and proinflammatory conditions in their microenvironment [56-58,71-83]. In the brain the senescence program can be 
triggered in astrocytes and microglia, with recent evidence suggesting that even neurons may display a senescent signature despite being post-mitotic. A more flexible definition of senescence based on the outcomes of senescent cell phenotypes (e.g., chronic inflammation) may be relevant to explain age-related pathologies in vivo. As the molecular changes associated with normal ageing that promote $\mathrm{AD}$ are yet to be fully defined, the impact of cellular senescence on age-related neuroinflammation, decline in cognition, and AD is currently unknown [75].

Evidence for the induction of senescence in cells of the brain and its links with neurodegenerative disorders is steadily increasing. In cell culture, astrocytes exposed to hydrogen peroxide (oxidative stress) or irradiation display markers of senescence, such as senescence-associated $\beta$ galactosidase staining (SA ßgal) (visualized by enzymatic activity assay for lysosomal $\beta$ galactosidase at $\mathrm{pH}$ 6.0) and elevated expression levels of p16 $6^{\mathrm{INK} 4 \mathrm{~A}}$ and $\mathrm{p} 21$ (measured via quantitative PCR for the increase in transcript levels or Western blotting to reflect changes in protein abundance), and develop a proinflammatory secretory phenotype similar to the SASP observed in senescent fibroblasts [84-86]. Similarly, irradiated neuronal cells show features of senescence (SA $\beta$ gal positivity) and become susceptible to the senolytic pharmacological cocktail of dasatinib (kinase inhibitor anti-cancer drug) and quercetin (plant-derived flavonoid) [58]. In human brain tissue an increase in the burden of $\mathrm{p} 16^{\text {INK4A }}$-expressing astrocytes is observed with age [87]. Cellular senescence in neuronal progenitor cells is implicated in the reduced remyelination observed in progressive multiple sclerosis [88]. In mouse models, senescence in the brain has been observed in response to physiological (e.g., obesity-induced [89]) and physical (e.g., traumatic brain injury following controlled cortical impact [90]) stressors.

In the context of $\mathrm{AD}$, astrocytes expressing $\mathrm{p} 16^{\mathrm{INK} 4 \mathrm{~A}}$ are enriched in the frontal cortex of $\mathrm{AD}$ patients compared to age-matched non-AD adults [87]. Further, oligodendrocyte progenitor cells displaying a senescent phenotype (high p21 expression) are associated with amyloid plaques in the brains of human AD patients [58]. Recently, studies using mouse models that overexpress mutant tau and phenocopy aspects of AD have indicated a strong link between the induction of cellular senescence and the appearance of AD pathology [56,57]. In particular, the ablation of senescent cells from the tissue of these mice led to a reduction in the phosphorylation and aggregation of tau [56,57]. In another mouse model of AD (APP/PS1), senolytic treatment, using a combination of dasatinib and quercetin that reduced the burden of senescent cells associated with amyloid plaque, lowered $A \beta$ load, reduced neuroinflammation, and reduced cognitive defects [58]. Interestingly, A $\beta$ can induce senescence in cultured oligodendrocyte progenitor cells [58] and drive SASP in cultured epithelial cells and fibroblasts via CD36 [91]. This may indicate that AD pathologies can further sustain/enhance tissue-resident senescence burden. Taken together, these studies suggest that senescence induction occurs in the brain and is associated with AD.

While the clearance of senescent cells in tissues of mice has now been demonstrated to mitigate age-associated pathologies, including $\mathrm{AD}$, the impact of removing them in tissues of longer-living mammals, including humans, is yet to be determined. A small $(n=14)$ first in-human clinical trial of the senolytic cocktail of dasatinib and quercetin in idiopathic pulmonary fibrosis (IPF), a fatal cellular senescence-associated disease [76], provided no conclusive evidence of senescence clearance or reduction in SASP despite achieving its primary endpoints (retention and completion rate; both $100 \%$ ) and some benefit in the physical function of patients [92]. Considering the known functional benefits of senescence in wound healing and tissue repair, as well as other potential benefits that may be currently unknown, the life-long clearance of senescent cells in humans may be deleterious. Further, therapeutic strategies based on the complete clearance of senescent cells may be difficult to administer in disorders like AD where the disease develops over several decades. An alternative strategy is to target specific phenotypic features of senescent cells that are relevant in certain disease settings. Iron accumulation is one such feature that is observed in senescent cells and is of relevance in AD [82].

Senescent cells in vitro display aberrant iron homeostasis [82], and there are some indications that their abundance influences iron levels in ageing tissue $[82,93,94]$. Senescent cells display elevated 
iron and a concomitant increase in ferritin and markers of oxidative stress in vitro [82,93-95]. Iron is known to promote the induction of senescence in cultured microglia [96]. Iron chelators such as deferoxamine and deferiprone can reduce and prevent the accumulation of iron and ferritin observed in cellular senescence in vitro [82]. The chelation of iron in Caenorhabditis elegans, a model organism of ageing that displays iron dysfunction in senescent intestinal cells [97], leads to a reduction in iron-dependent oxidation and cell death [98]. In the context of brain tissue, SASP may drive ferritin expression in neurons and glia as an acute phase response which may enhance their susceptibility to the iron-mediated cell death process, ferroptosis. The effects of iron chelation on senescence-associated iron accumulation and its impact on SASP or ferroptotic vulnerability are yet to be explored in vivo and present a therapeutic opportunity to treat AD (Figure 1).

\section{Iron as a Therapeutic Target in AD}

Iron neurochemistry as a modifiable feature to treat $\mathrm{AD}$ has generated renewed interest since clinical trials for iron chelators have shown promise recently in other neurodegenerative disorders such as Parkinson's disease (PD) and motor neuron disease (MND) [6,99-104]. The efforts towards the "iron hypothesis" of AD have also been bolstered by the unravelling of complex molecular crosstalk between iron regulatory proteins and the suspected players of AD pathology.

Historically, the first study that explored iron chelation against AD was published in 1991, which tested the effectiveness of intramuscular application of the iron chelator deferoxamine in 48 patients over two years [105]. The study showed that low-dose administration of this iron chelator slowed the clinical progression of dementia associated with $\mathrm{AD}$ compared with controls. A decade later, a pilot phase 2 clinical trial in patients with moderately severe AD using clioquinol (PBT1), a drug inhibiting zinc and copper ions from binding to $A \beta$, was conducted on 36 patients [106]. A positive clinical effect, corresponding to a reduction in the rate of cognitive decline, was seen in the more severely affected patients. Moreover, a biological effect corresponding to a decline in plasma A $\beta 42$ levels was observed. Currently, the safety and efficacy of deferiprone, an iron chelator that passes the blood-brain barrier, is under evaluation in a phase 2 randomized placebo-controlled clinical trial in participants with prodromal AD and mild AD (NCT03234686).

\section{Conclusions}

Despite the ever-increasing socioeconomic burden of $\mathrm{AD}$, there is frustratingly no disease-modifying treatment for this affliction. The historic and emerging evidence that iron contributes to the clinical progression of $\mathrm{AD}$ should not be ignored as a potential avenue for therapy development. The reported benefits for iron chelation in other neurodegenerative diseases such as PD and MND should open the possibility of pharmacological manipulation of brain iron as an alternative therapeutic approach for AD. The perturbed iron homeostasis observed in senescent cells presents a possible cell-specific target of iron chelation therapy which may enhance the efficacy of approaches aimed at lowering age/pathology-related iron accumulation. Further, the strategy to modify specific phenotypic features (e.g., reducing iron accumulation using chelators such as deferiprone) of senescent cells that contribute to pathology may be of benefit in the human context where the complete ablation of senescent cells from tissue may be difficult or even deleterious due to a loss of beneficial effects associated with senescence (e.g., tissue repair and wound healing). The consequence of cellular senescence on the iron homeostasis of the brain requires further characterization. This may open additional avenues for the development of new classes of drugs that may provide benefits for AD patients and provide strategies for halting their decline and delaying the onset of neurodegeneration.

Author Contributions: S.M. produced the original draft and figure. A.A.B., S.A. and A.I.B. reviewed and edited the manuscript and provided critical feedback.

Funding: Supported by funds from the Australian National Health and Medical Research Council (NHMRC: GNT1159403). Support from the Alzheimer's Association (AARFD-16-442821 to AAB) is gratefully acknowledged. 
A.I.B. is supported by funds from the National Health and Medical Research Council of Australia (GNT1103703, GNT1101533).

Acknowledgments: The Florey Institute of Neuroscience and Mental Health acknowledges support from the Victorian Government, particularly funding from the Operational Infrastructure Support Grant.

Conflicts of Interest: A.I.B. is a shareholder in Prana Biotechnology Ltd., Cogstate Ltd., Brighton Biotech LLC, Grunbiotics Pty Ltd., Eucalyptus Pty Ltd., and Mesoblast Ltd. He is a paid consultant for, and has a profit share interest in, Collaborative Medicinal Development Pty Ltd.

\section{References}

1. Nikseresht, S.; Bush, A.I.; Ayton, S. Treating Alzheimer's disease by targeting iron. Br. J. Pharmacol. 2019. [CrossRef] [PubMed]

2. Alborzinia, H.; Ignashkova, T.I.; Dejure, F.R.; Gendarme, M.; Theobald, J.; Wölfl, S.; Lindemann, R.K.; Reiling, J.H. Golgi stress mediates redox imbalance and ferroptosis in human cells. Commun. Biol. 2018, 1, 210. [CrossRef] [PubMed]

3. Biogen and Eisai to Discontinue Phase 3 Engage and Emerge Trials of Aducanumab in Alzheimer's Disease. Available online: http://investors.Biogen.Com/news-releases/news-release-details/biogen-andeisai-discontinue-phase-3-engage-and-emerge-trials (accessed on 24 April 2019).

4. Masaldan, S.; Bush, A.I.; Devos, D.; Rolland, A.S.; Moreau, C. Striking while the iron is hot: Iron metabolism and ferroptosis in neurodegeneration. Free Radic. Biol. Med. 2018, 133, 221-233. [CrossRef]

5. Belaidi, A.A.; Bush, A.I. Iron neurochemistry in Alzheimer's disease and Parkinson's disease: Targets for therapeutics. J. Neurochem. 2016, 139 (Suppl. 1), 179-197. [CrossRef] [PubMed]

6. Eid, R.; Arab, N.T.T.; Greenwood, M.T. Iron mediated toxicity and programmed cell death: A review and a re-examination of existing paradigms. Biochim. Biophys. Acta 2017, 1864, 399-430. [CrossRef] [PubMed]

7. Bartzokis, G.; Sultzer, D.; Mintz, J.; Holt, L.E.; Marx, P.; Phelan, C.K.; Marder, S.R. In vivo evaluation of brain iron in Alzheimer's disease and normal subjects using MRI. Biol. Psychiatry 1994, 35, 480-487. [CrossRef]

8. Bartzokis, G.; Tishler, T.A. MRI evaluation of basal ganglia ferritin iron and neurotoxicity in Alzheimer's and Huntingon's disease. Cell. Mol. Biol. 2000, 46, 821-833.

9. Ding, B.; Chen, K.M.; Ling, H.W.; Sun, F.; Li, X.; Wan, T.; Chai, W.M.; Zhang, H.; Zhan, Y.; Guan, Y.J. Correlation of iron in the hippocampus with MMSE in patients with Alzheimer's disease. J. Magn. Reson. Imaging 2009, 29, 793-798. [CrossRef]

10. Pfefferbaum, A.; Adalsteinsson, E.; Rohlfing, T.; Sullivan, E.V. MRI estimates of brain iron concentration in normal aging: Comparison of field-dependent (FDRI) and phase (SWI) methods. NeuroImage 2009, 47, 493-500. [CrossRef]

11. Bilgic, B.; Pfefferbaum, A.; Rohlfing, T.; Sullivan, E.V.; Adalsteinsson, E. MRI estimates of brain iron concentration in normal aging using quantitative susceptibility mapping. NeuroImage 2012, 59, 2625-2635. [CrossRef]

12. Luo, Z.; Zhuang, X.; Kumar, D.; Wu, X.; Yue, C.; Han, C.; Lv, J. The correlation of hippocampal T2-mapping with neuropsychology test in patients with Alzheimer's disease. PLoS ONE 2013, 8, e76203. [CrossRef] [PubMed]

13. Langkammer, C.; Ropele, S.; Pirpamer, L.; Fazekas, F.; Schmidt, R. MRI for iron mapping in Alzheimer's disease. Neuro Degener. Dis. 2014, 13, 189-191. [CrossRef] [PubMed]

14. Tao, Y.; Wang, Y.; Rogers, J.T.; Wang, F. Perturbed iron distribution in Alzheimer's disease serum, cerebrospinal fluid, and selected brain regions: A systematic review and meta-analysis. J. Alzheimer's Dis. 2014, 42, 679-690. [CrossRef] [PubMed]

15. Ghadery, C.; Pirpamer, L.; Hofer, E.; Langkammer, C.; Petrovic, K.; Loitfelder, M.; Schwingenschuh, P.; Seiler, S.; Duering, M.; Jouvent, E.; et al. R2* mapping for brain iron: Associations with cognition in normal aging. Neurobiol. Aging 2015, 36, 925-932. [CrossRef] [PubMed] 
16. Bulk, M.; Abdelmoula, W.M.; Nabuurs, R.J.A.; van der Graaf, L.M.; Mulders, C.W.H.; Mulder, A.A.; Jost, C.R.; Koster, A.J.; van Buchem, M.A.; Natte, R.; et al. Postmortem MRI and histology demonstrate differential iron accumulation and cortical myelin organization in early- and late-onset Alzheimer's disease. Neurobiol. Aging 2018, 62, 231-242. [CrossRef]

17. Bulk, M.; Kenkhuis, B.; van der Graaf, L.M.; Goeman, J.J.; Natte, R.; van der Weerd, L. Postmortem t2*weighted MRI imaging of cortical iron reflects severity of Alzheimer's disease. J. Alzheimer's Dis. 2018, 65, 1125-1137. [CrossRef]

18. Van Duijn, S.; Bulk, M.; van Duinen, S.G.; Nabuurs, R.J.A.; van Buchem, M.A.; van der Weerd, L.; Natte, R. Cortical iron reflects severity of Alzheimer's disease. J. Alzheimer's Dis. 2017, 60, 1533-1545. [CrossRef]

19. Bulk, M.; van der Weerd, L.; Breimer, W.; Lebedev, N.; Webb, A.; Goeman, J.J.; Ward, R.J.; Huber, M.; Oosterkamp, T.H.; Bossoni, L. Quantitative comparison of different iron forms in the temporal cortex of Alzheimer patients and control subjects. Sci. Rep. 2018, 8, 6898. [CrossRef]

20. Ayton, S.; Wang, Y.; Diouf, I.; Schneider, J.A.; Brockman, J.; Morris, M.C.; Bush, A.I. Brain iron is associated with accelerated cognitive decline in people with Alzheimer pathology. Mol. Psychiatry 2019, 24. [CrossRef]

21. Goodman, L. Alzheimer's disease: A clinico-pathologic analysis of twenty-three cases with a theory on pathogenesis. J. Nerv. Ment. Dis. 1953, 118, 97-130. [CrossRef]

22. Smith, M.A.; Harris, P.L.; Sayre, L.M.; Perry, G. Iron accumulation in Alzheimer disease is a source of redox-generated free radicals. Proc. Natl. Acad. Sci. USA 1997, 94, 9866-9868. [CrossRef] [PubMed]

23. Smith, C.D.; Chebrolu, H.; Wekstein, D.R.; Schmitt, F.A.; Jicha, G.A.; Cooper, G.; Markesbery, W.R. Brain structural alterations before mild cognitive impairment. Neurology 2007, 68, 1268-1273. [CrossRef] [PubMed]

24. Lovell, M.A.; Robertson, J.D.; Teesdale, W.J.; Campbell, J.L.; Markesbery, W.R. Copper, iron and zinc in Alzheimer's disease senile plaques. J. Neurol. Sci. 1998, 158, 47-52. [CrossRef]

25. Connor, J.R.; Snyder, B.S.; Beard, J.L.; Fine, R.E.; Mufson, E.J. Regional distribution of iron and iron-regulatory proteins in the brain in aging and Alzheimer's disease. J. Neurosci. Res. 1992, 31, 327-335. [CrossRef] [PubMed]

26. Meadowcroft, M.D.; Peters, D.G.; Dewal, R.P.; Connor, J.R.; Yang, Q.X. The effect of iron in MRI and transverse relaxation of amyloid-beta plaques in Alzheimer's disease. NMR Biomed. 2015, 28, 297-305. [CrossRef]

27. Everett, J.; Collingwood, J.F.; Tjendana-Tjhin, V.; Brooks, J.; Lermyte, F.; Plascencia-Villa, G.; Hands-Portman, I.; Dobson, J.; Perry, G.; Telling, N.D. Nanoscale synchrotron x-ray speciation of iron and calcium compounds in amyloid plaque cores from Alzheimer's disease subjects. Nanoscale 2018, 10, 11782-11796. [CrossRef]

28. Plascencia-Villa, G.; Ponce, A.; Collingwood, J.F.; Arellano-Jimenez, M.J.; Zhu, X.; Rogers, J.T.; Betancourt, I.; Jose-Yacaman, M.; Perry, G. High-resolution analytical imaging and electron holography of magnetite particles in amyloid cores of Alzheimer's disease. Sci. Rep. 2016, 6, 24873. [CrossRef]

29. Telling, N.D.; Everett, J.; Collingwood, J.F.; Dobson, J.; van der Laan, G.; Gallagher, J.J.; Wang, J.; Hitchcock, A.P. Iron biochemistry is correlated with amyloid plaque morphology in an established mouse model of Alzheimer's disease. Cell Chem. Biol. 2017, 24, 1205-1215. [CrossRef]

30. Mantyh, P.W.; Ghilardi, J.R.; Rogers, S.; DeMaster, E.; Allen, C.J.; Stimson, E.R.; Maggio, J.E. Aluminum, iron, and zinc ions promote aggregation of physiological concentrations of beta-amyloid peptide. J. Neurochem. 1993, 61, 1171-1174. [CrossRef]

31. Schubert, D.; Chevion, M. The role of iron in beta amyloid toxicity. Biochem. Biophys. Res. Commun. 1995, 216, 702-707. [CrossRef]

32. Huang, X.; Atwood, C.S.; Moir, R.D.; Hartshorn, M.A.; Tanzi, R.E.; Bush, A.I. Trace metal contamination initiates the apparent auto-aggregation, amyloidosis, and oligomerization of Alzheimer's Abeta peptides. J. Biol. Inorg. Chem. 2004, 9, 954-960. [CrossRef] [PubMed]

33. Liu, B.; Moloney, A.; Meehan, S.; Morris, K.; Thomas, S.E.; Serpell, L.C.; Hider, R.; Marciniak, S.J.; Lomas, D.A.; Crowther, D.C. Iron promotes the toxicity of amyloid beta peptide by impeding its ordered aggregation. J. Biol. Chem. 2011, 286, 4248-4256. [CrossRef]

34. Kwiatek-Majkusiak, J.; Dickson, D.W.; Tacik, P.; Aoki, N.; Tomasiuk, R.; Koziorowski, D.; Friedman, A. Relationships between typical histopathological hallmarks and the ferritin in the hippocampus from patients with Alzheimer's disease. Acta Neurobiol. Exp. 2015, 75, 391-398.

35. Gong, N.J.; Dibb, R.; Bulk, M.; van der Weerd, L.; Liu, C. Imaging beta amyloid aggregation and iron accumulation in Alzheimer's disease using quantitative susceptibility mapping MRI. NeuroImage 2019, 191, 176-185. [CrossRef] [PubMed] 
36. Tahirbegi, I.B.; Pardo, W.A.; Alvira, M.; Mir, M.; Samitier, J. Amyloid Abeta 42, a promoter of magnetite nanoparticle formation in Alzheimer's disease. Nanotechnology 2016, 27, 465102. [CrossRef]

37. Huang, X.; Cuajungco, M.P.; Atwood, C.S.; Hartshorn, M.A.; Tyndall, J.D.; Hanson, G.R.; Stokes, K.C.; Leopold, M.; Multhaup, G.; Goldstein, L.E.; et al. Cu(ii) potentiation of Alzheimer Abeta neurotoxicity. Correlation with cell-free hydrogen peroxide production and metal reduction. J. Biol. Chem. 1999, 274, 37111-37116. [CrossRef] [PubMed]

38. Jomova, K.; Vondrakova, D.; Lawson, M.; Valko, M. Metals, oxidative stress and neurodegenerative disorders. Mol. Cell. Biochem. 2010, 345, 91-104. [CrossRef]

39. Rogers, J.T.; Leiter, L.M.; McPhee, J.; Cahill, C.M.; Zhan, S.S.; Potter, H.; Nilsson, L.N. Translation of the Alzheimer amyloid precursor protein mRNA is up-regulated by interleukin- 1 through $5^{\prime}$-untranslated region sequences. J. Biol. Chem. 1999, 274, 6421-6431. [CrossRef]

40. Rogers, J.T.; Randall, J.D.; Cahill, C.M.; Eder, P.S.; Huang, X.; Gunshin, H.; Leiter, L.; McPhee, J.; Sarang, S.S.; Utsuki, T.; et al. An iron-responsive element type ii in the $5^{\prime}$-untranslated region of the Alzheimer's amyloid precursor protein transcript. J. Biol. Chem. 2002, 277, 45518-45528. [CrossRef] [PubMed]

41. Caldwell, J.H.; Klevanski, M.; Saar, M.; Muller, U.C. Roles of the amyloid precursor protein family in the peripheral nervous system. Mech. Dev. 2013, 130, 433-446. [CrossRef]

42. Huang, Y.A.; Zhou, B.; Wernig, M.; Sudhof, T.C. Apoe2, apoe3, and apoe4 differentially stimulate app transcription and abeta secretion. Cell 2017, 168, 427-441. [CrossRef] [PubMed]

43. Bodovitz, S.; Falduto, M.T.; Frail, D.E.; Klein, W.L. Iron levels modulate alpha-secretase cleavage of amyloid precursor protein. J. Neurochem. 1995, 64, 307-315. [CrossRef] [PubMed]

44. Silvestri, L.; Camaschella, C. A potential pathogenetic role of iron in Alzheimer's disease. J. Cell. Mol. Med. 2008, 12, 1548-1550. [CrossRef] [PubMed]

45. Ward, R.J.; Zucca, F.A.; Duyn, J.H.; Crichton, R.R.; Zecca, L. The role of iron in brain ageing and neurodegenerative disorders. The Lancet. Neurology 2014, 13, 1045-1060. [PubMed]

46. Yamamoto, A.; Shin, R.W.; Hasegawa, K.; Naiki, H.; Sato, H.; Yoshimasu, F.; Kitamoto, T. Iron (iii) induces aggregation of hyperphosphorylated tau and its reduction to iron (ii) reverses the aggregation: Implications in the formation of neurofibrillary tangles of Alzheimer's disease. J. Neurochem. 2002, 82, 1137-1147. [CrossRef] [PubMed]

47. Lovell, M.A.; Xiong, S.; Xie, C.; Davies, P.; Markesbery, W.R. Induction of hyperphosphorylated tau in primary rat cortical neuron cultures mediated by oxidative stress and glycogen synthase kinase-3. J. Alzheimer's Dis. 2004, 6, 659-671, discussion 673-681. [CrossRef]

48. Chan, A.; Shea, T.B. Dietary and genetically-induced oxidative stress alter tau phosphorylation: Influence of folate and apolipoprotein e deficiency. J. Alzheimer's Dis. 2006, 9, 399-405. [CrossRef]

49. Amit, T.; Avramovich-Tirosh, Y.; Youdim, M.B.; Mandel, S. Targeting multiple Alzheimer's disease etiologies with multimodal neuroprotective and neurorestorative iron chelators. FASEB J. 2008, 22, 1296-1305. [CrossRef]

50. Wang, D.; Hui, Y.; Peng, Y.; Tang, L.; Jin, J.; He, R.; Li, Y.; Zhang, S.; Li, L.; Zhou, Y.; et al. Overexpression of heme oxygenase 1 causes cognitive decline and affects pathways for tauopathy in mice. J. Alzheimer's Dis. 2015, 43, 519-534. [CrossRef]

51. Perry, G.; Nunomura, A.; Hirai, K.; Zhu, X.; Perez, M.; Avila, J.; Castellani, R.J.; Atwood, C.S.; Aliev, G.; Sayre, L.M.; et al. Is oxidative damage the fundamental pathogenic mechanism of Alzheimer's and other neurodegenerative diseases? Free Radic. Biol. Med. 2002, 33, 1475-1479. [CrossRef]

52. Schipper, H.M.; Bennett, D.A.; Liberman, A.; Bienias, J.L.; Schneider, J.A.; Kelly, J.; Arvanitakis, Z. Glial heme oxygenase-1 expression in Alzheimer disease and mild cognitive impairment. Neurobiol. Aging 2006, 27, 252-261. [CrossRef] [PubMed]

53. Ayton, S.; Faux, N.G.; Bush, A.I.; Weiner, M.W.; Aisen, P.; Petersen, R.; Jack Jr, C.R.; Jagust, W.; Trojanowki, J.Q.; Toga, A.W. Ferritin levels in the cerebrospinal fluid predict Alzheimer's disease outcomes and are regulated by apoe. Nat. Commun. 2015, 6, 6760. [CrossRef] [PubMed]

54. Diouf, I.; Fazlollahi, A.; Bush, A.I.; Ayton, S.; Alzheimer's disease Neuroimaging, I. Cerebrospinal fluid ferritin levels predict brain hypometabolism in people with underlying beta-amyloid pathology. Neurobiol. Dis. 2019, 124, 335-339. [CrossRef] [PubMed] 
55. Ayton, S.; Fazlollahi, A.; Bourgeat, P.; Raniga, P.; Ng, A.; Lim, Y.Y.; Diouf, I.; Farquharson, S.; Fripp, J.; Ames, D. Cerebral quantitative susceptibility mapping predicts amyloid- $\beta$-related cognitive decline. Brain 2017, 140, 2112-2119. [CrossRef] [PubMed]

56. Bussian, T.J.; Aziz, A.; Meyer, C.F.; Swenson, B.L.; van Deursen, J.M.; Baker, D.J. Clearance of senescent glial cells prevents tau-dependent pathology and cognitive decline. Nature 2018, 562, 578-582. [CrossRef] [PubMed]

57. Musi, N.; Valentine, J.M.; Sickora, K.R.; Baeuerle, E.; Thompson, C.S.; Shen, Q.; Orr, M.E. Tau protein aggregation is associated with cellular senescence in the brain. Aging Cell 2018, 17, e12840. [CrossRef] [PubMed]

58. Zhang, P.; Kishimoto, Y.; Grammatikakis, I.; Gottimukkala, K.; Cutler, R.G.; Zhang, S.; Abdelmohsen, K.; Bohr, V.A.; Misra Sen, J.; Gorospe, M.; et al. Senolytic therapy alleviates A $\beta$-associated oligodendrocyte progenitor cell senescence and cognitive deficits in an Alzheimer's disease model. Nat. Neurosci. 2019, 22, 719-728. [CrossRef]

59. Hayflick, L. The limited in vitro lifetime of human diploid cell strains. Exp. Cell Res. 1965, 37, 614-636. [CrossRef]

60. Van Deursen, J.M. The role of senescent cells in ageing. Nature 2014, 509, 439-446. [CrossRef]

61. Dimri, G.P.; Lee, X.; Basile, G.; Acosta, M.; Scott, G.; Roskelley, C.; Medrano, E.E.; Linskens, M.; Rubelj, I.; Pereira-Smith, O.; et al. A biomarker that identifies senescent human cells in culture and in aging skin in vivo. Proc. Natl. Acad. Sci. USA 1995, 92, 9363-9367. [CrossRef]

62. Choi, J.; Shendrik, I.; Peacocke, M.; Peehl, D.; Buttyan, R.; Ikeguchi, E.F.; Katz, A.E.; Benson, M.C. Expression of senescence-associated beta-galactosidase in enlarged prostates from men with benign prostatic hyperplasia. Urology 2000, 56, 160-166. [CrossRef]

63. Te Poele, R.H.; Okorokov, A.L.; Jardine, L.; Cummings, J.; Joel, S.P. DNA damage is able to induce senescence in tumor cells in vitro and in vivo. Cancer Res. 2002, 62, 1876-1883. [PubMed]

64. Vasile, E.; Tomita, Y.; Brown, L.F.; Kocher, O.; Dvorak, H.F. Differential expression of thymosin beta-10 by early passage and senescent vascular endothelium is modulated by VPF/VEGF: Evidence for senescent endothelial cells in vivo at sites of atherosclerosis. FASEB J. 2001, 15, 458-466. [CrossRef] [PubMed]

65. Minamino, T.; Miyauchi, H.; Yoshida, T.; Ishida, Y.; Yoshida, H.; Komuro, I. Endothelial cell senescence in human atherosclerosis. Circulation 2002, 105, 1541. [CrossRef] [PubMed]

66. Jun, J.I.; Lau, L.F. The matricellular protein cen1 induces fibroblast senescence and restricts fibrosis in cutaneous wound healing. Nat. Cell Biol. 2010, 12, 676-685. [CrossRef] [PubMed]

67. Demaria, M.; Ohtani, N.; Youssef, S.A.; Rodier, F.; Toussaint, W.; Mitchell, J.R.; Laberge, R.M.; Vijg, J.; Van Steeg, H.; Dolle, M.E.; et al. An essential role for senescent cells in optimal wound healing through secretion of pdgf-aa. Dev. Cell 2014, 31, 722-733. [CrossRef] [PubMed]

68. Krizhanovsky, V.; Yon, M.; Dickins, R.A.; Hearn, S.; Simon, J.; Miething, C.; Yee, H.; Zender, L.; Lowe, S.W. Senescence of activated stellate cells limits liver fibrosis. Cell 2008, 134, 657-667. [CrossRef]

69. Rajagopalan, S.; Long, E.O. Cellular senescence induced by cd158d reprograms natural killer cells to promote vascular remodeling. Proc. Natl. Acad. Sci. USA 2012, 109, 20596-20601. [CrossRef]

70. Storer, M.; Mas, A.; Robert-Moreno, A.; Pecoraro, M.; Ortells, M.C.; Di Giacomo, V.; Yosef, R.; Pilpel, N.; Krizhanovsky, V.; Sharpe, J.; et al. Senescence is a developmental mechanism that contributes to embryonic growth and patterning. Cell 2013, 155, 1119-1130. [CrossRef]

71. Baker, D.J.; Childs, B.G.; Durik, M.; Wijers, M.E.; Sieben, C.J.; Zhong, J.; Saltness, R.A.; Jeganathan, K.B.; Verzosa, G.C.; Pezeshki, A.; et al. Naturally occurring p16(ink4a)-positive cells shorten healthy lifespan. Nature 2016, 530, 184-189. [CrossRef]

72. Baker, D.J.; Wijshake, T.; Tchkonia, T.; LeBrasseur, N.K.; Childs, B.G.; van de Sluis, B.; Kirkland, J.L.; van Deursen, J.M. Clearance of p16ink4a-positive senescent cells delays ageing-associated disorders. Nature 2011, 479, 232-236. [CrossRef] [PubMed]

73. Yousefzadeh, M.J.; Zhu, Y.; McGowan, S.J.; Angelini, L.; Fuhrmann-Stroissnigg, H.; Xu, M.; Ling, Y.Y.; Melos, K.I.; Pirtskhalava, T.; Inman, C.L.; et al. Fisetin is a senotherapeutic that extends health and lifespan. EBioMedicine 2018, 36, 18-28. [CrossRef] [PubMed]

74. Baar, M.P.; Brandt, R.M.C.; Putavet, D.A.; Klein, J.D.D.; Derks, K.W.J.; Bourgeois, B.R.M.; Stryeck, S.; Rijksen, Y.; van Willigenburg, H.; Feijtel, D.A.; et al. Targeted apoptosis of senescent cells restores tissue homeostasis in response to chemotoxicity and aging. Cell 2017, 169, 132-147. [CrossRef] [PubMed] 
75. Baker, D.J.; Petersen, R.C. Cellular senescence in brain aging and neurodegenerative diseases: Evidence and perspectives. J. Clin. Investig. 2018, 128, 1208-1216. [CrossRef]

76. Schafer, M.J.; White, T.A.; Iijima, K.; Haak, A.J.; Ligresti, G.; Atkinson, E.J.; Oberg, A.L.; Birch, J.; Salmonowicz, H.; Zhu, Y.; et al. Cellular senescence mediates fibrotic pulmonary disease. Nat. Commun. 2017, 8, 14532. [CrossRef] [PubMed]

77. Ogrodnik, M.; Miwa, S.; Tchkonia, T.; Tiniakos, D.; Wilson, C.L.; Lahat, A.; Day, C.P.; Burt, A.; Palmer, A.; Anstee, Q.M.; et al. Cellular senescence drives age-dependent hepatic steatosis. Nat. Commun. 2017, 8, 15691. [CrossRef]

78. Chang, J.; Wang, Y.; Shao, L.; Laberge, R.M.; Demaria, M.; Campisi, J.; Janakiraman, K.; Sharpless, N.E.; Ding, S.; Feng, W.; et al. Clearance of senescent cells by abt263 rejuvenates aged hematopoietic stem cells in mice. Nat. Med. 2016, 22, 78-83. [CrossRef]

79. Roos, C.M.; Zhang, B.; Palmer, A.K.; Ogrodnik, M.B.; Pirtskhalava, T.; Thalji, N.M.; Hagler, M.; Jurk, D.; Smith, L.A.; Casaclang-Verzosa, G.; et al. Chronic senolytic treatment alleviates established vasomotor dysfunction in aged or atherosclerotic mice. Aging Cell 2016, 15, 973-977. [CrossRef]

80. Zhu, Y.; Tchkonia, T.; Fuhrmann-Stroissnigg, H.; Dai, H.M.; Ling, Y.Y.; Stout, M.B.; Pirtskhalava, T.; Giorgadze, N.; Johnson, K.O.; Giles, C.B.; et al. Identification of a novel senolytic agent, navitoclax, targeting the bcl-2 family of anti-apoptotic factors. Aging Cell 2016, 15, 428-435. [CrossRef]

81. Zhu, Y.; Tchkonia, T.; Pirtskhalava, T.; Gower, A.C.; Ding, H.; Giorgadze, N.; Palmer, A.K.; Ikeno, Y.; Hubbard, G.B.; Lenburg, M.; et al. The achilles' heel of senescent cells: From transcriptome to senolytic drugs. Aging Cell 2015, 14, 644-658. [CrossRef]

82. Masaldan, S.; Clatworthy, S.A.S.; Gamell, C.; Meggyesy, P.M.; Rigopoulos, A.T.; Haupt, S.; Haupt, Y.; Denoyer, D.; Adlard, P.A.; Bush, A.I.; et al. Iron accumulation in senescent cells is coupled with impaired ferritinophagy and inhibition of ferroptosis. Redox Biol. 2018, 14, 100-115. [CrossRef] [PubMed]

83. Saint-Germain, E.; Mignacca, L.; Vernier, M.; Bobbala, D.; Ilangumaran, S.; Ferbeyre, G. Socs1 regulates senescence and ferroptosis by modulating the expression of p53 target genes. Aging 2017, 9, 2137-2162. [CrossRef] [PubMed]

84. Zou, Y.; Zhang, N.; Ellerby, L.M.; Davalos, A.R.; Zeng, X.; Campisi, J.; Desprez, P.Y. Responses of human embryonic stem cells and their differentiated progeny to ionizing radiation. Biochem. Biophys. Res. Commun. 2012, 426, 100-105. [CrossRef] [PubMed]

85. Pertusa, M.; Garcia-Matas, S.; Rodriguez-Farre, E.; Sanfeliu, C.; Cristofol, R. Astrocytes aged in vitro show a decreased neuroprotective capacity. J. Neurochem. 2007, 101, 794-805. [CrossRef] [PubMed]

86. Bitto, A.; Sell, C.; Crowe, E.; Lorenzini, A.; Malaguti, M.; Hrelia, S.; Torres, C. Stress-induced senescence in human and rodent astrocytes. Exp. Cell Res. 2010, 316, 2961-2968. [CrossRef] [PubMed]

87. Bhat, R.; Crowe, E.P.; Bitto, A.; Moh, M.; Katsetos, C.D.; Garcia, F.U.; Johnson, F.B.; Trojanowski, J.Q.; Sell, C.; Torres, C. Astrocyte senescence as a component of Alzheimer's disease. PLoS ONE 2012, 7, e45069. [CrossRef] [PubMed]

88. Nicaise, A.M.; Wagstaff, L.J.; Willis, C.M.; Paisie, C.; Chandok, H.; Robson, P.; Fossati, V.; Williams, A.; Crocker, S.J. Cellular senescence in progenitor cells contributes to diminished remyelination potential in progressive multiple sclerosis. Proc. Natl. Acad. Sci. USA 2019, 116, 9030-9039. [CrossRef]

89. Ogrodnik, M.; Zhu, Y.; Langhi, L.G.P.; Tchkonia, T.; Kruger, P.; Fielder, E.; Victorelli, S.; Ruswhandi, R.A.; Giorgadze, N.; Pirtskhalava, T.; et al. Obesity-induced cellular senescence drives anxiety and impairs neurogenesis. Cell Metab. 2019, 29, 1061-1077. [CrossRef]

90. Tominaga, T.; Shimada, R.; Okada, Y.; Kawamata, T.; Kibayashi, K. Senescence-associated-beta-galactosidase staining following traumatic brain injury in the mouse cerebrum. PLoS ONE 2019, 14, e0213673. [CrossRef]

91. Chong, M.; Yin, T.; Chen, R.; Xiang, H.; Yuan, L.; Ding, Y.; Pan, C.C.; Tang, Z.; Alexander, P.B.; Li, Q.J. CD36 initiates the secretory phenotype during the establishment of cellular senescence. EMBO Rep. 2018, 19, e45274. [CrossRef]

92. Justice, J.N.; Nambiar, A.M.; Tchkonia, T.; LeBrasseur, N.K.; Pascual, R.; Hashmi, S.K.; Prata, L.; Masternak, M.M.; Kritchevsky, S.B.; Musi, N.; et al. Senolytics in idiopathic pulmonary fibrosis: Results from a first-in-human, open-label, pilot study. EBioMedicine 2019, 40, 554-563. [CrossRef] [PubMed]

93. Killilea, D.W.; Wong, S.L.; Cahaya, H.S.; Atamna, H.; Ames, B.N. Iron accumulation during cellular senescence. Ann. N. Y. Acad. Sci. 2004, 1019, 365-367. [CrossRef] [PubMed] 
94. Ott, C.; Konig, J.; Hohn, A.; Jung, T.; Grune, T. Reduced autophagy leads to an impaired ferritin turnover in senescent fibroblasts. Free Radic. Biol. Med. 2016, 101, 325-333. [CrossRef] [PubMed]

95. Masaldan, S.; Clatworthy, S.A.S.; Gamell, C.; Smith, Z.M.; Francis, P.S.; Denoyer, D.; Meggyesy, P.M.; Fontaine, S.; Cater, M.A. Copper accumulation in senescent cells: Interplay between copper transporters and impaired autophagy. Redox Biol. 2018, 16, 322-331. [CrossRef] [PubMed]

96. Angelova, D.M.; Brown, D.R. Altered processing of beta-amyloid in sh-sy5y cells induced by model senescent microglia. ACS Chem. Neurosci. 2018, 9, 3137-3152. [CrossRef] [PubMed]

97. James, S.A.; Roberts, B.R.; Hare, D.J.; de Jonge, M.D.; Birchall, I.E.; Jenkins, N.L.; Cherny, R.A.; Bush, A.I.; McColl, G. Direct in vivo imaging of ferrous iron dyshomeostasis in ageing Caenorhabditis elegans. Chem. Sci. 2015, 6, 2952-2962. [CrossRef] [PubMed]

98. Jenkins, N.L.; James, S.A.; Salim, A.; Sumardy, F.; Speed, T.P.; Conrad, M.; Richardson, D.R.; Bush, A.I.; McColl, G. Ferrous-glutathione coupling mediates ferroptosis and frailty in Caenorhabditis elegans. bioRxiv 2019. [CrossRef]

99. Martin-Bastida, A.; Ward, R.J.; Newbould, R.; Piccini, P.; Sharp, D.; Kabba, C.; Patel, M.C.; Spino, M.; Connelly, J.; Tricta, F.; et al. Brain iron chelation by deferiprone in a phase 2 randomised double-blinded placebo controlled clinical trial in Parkinson's disease. Sci. Rep. 2017, 7, 1398. [CrossRef]

100. Moreau, C.; Danel, V.; Devedjian, J.C.; Grolez, G.; Timmerman, K.; Laloux, C.; Petrault, M.; Gouel, F.; Jonneaux, A.; Dutheil, M.; et al. Could conservative iron chelation lead to neuroprotection in amyotrophic lateral sclerosis? Antioxid. Redox Signal. 2018, 29, 742-748. [CrossRef]

101. Devos, D.; Moreau, C.; Devedjian, J.C.; Kluza, J.; Petrault, M.; Laloux, C.; Jonneaux, A.; Ryckewaert, G.; Garcon, G.; Rouaix, N.; et al. Targeting chelatable iron as a therapeutic modality in Parkinson's disease. Antioxid. Redox Signal. 2014, 21, 195-210. [CrossRef]

102. Morris, G.P.; Clark, I.A.; Vissel, B. Inconsistencies and controversies surrounding the amyloid hypothesis of Alzheimer's disease. Acta Neuropathol. Commun. 2014, 2, 135. [CrossRef]

103. Ayton, S.; Lei, P.; Bush, A.I. Metallostasis in Alzheimer's disease. Free Radic Biol. Med. 2013, 62, 76-89. [CrossRef] [PubMed]

104. Bush, A.I.; Tanzi, R.E. Therapeutics for Alzheimer's disease based on the metal hypothesis. Neurotherapeutics 2008, 5, 421-432. [CrossRef] [PubMed]

105. Crapper McLachlan, D.R.; Dalton, A.J.; Kruck, T.P.; Bell, M.Y.; Smith, W.L.; Kalow, W.; Andrews, D.F. Intramuscular desferrioxamine in patients with Alzheimer's disease. Lancet 1991, 337, 1304-1308. [CrossRef]

106. Ritchie, C.W.; Bush, A.I.; Mackinnon, A.; Macfarlane, S.; Mastwyk, M.; MacGregor, L.; Kiers, L.; Cherny, R.; Li, Q.X.; Tammer, A.; et al. Metal-protein attenuation with iodochlorhydroxyquin (clioquinol) targeting Abeta amyloid deposition and toxicity in Alzheimer disease: A pilot phase 2 clinical trial. Arch. Neurol. 2003, 60, 1685-1691. [CrossRef] [PubMed]

(C) 2019 by the authors. Licensee MDPI, Basel, Switzerland. This article is an open access article distributed under the terms and conditions of the Creative Commons Attribution (CC BY) license (http://creativecommons.org/licenses/by/4.0/). 


\title{
Brain Iron Homeostasis: A Focus on Microglial Iron
}

\author{
Israel C. Nnah and Marianne Wessling-Resnick* \\ Department of Genetics and Complex Diseases, Harvard TH Chan School of Public Health, Boston, MA 02115, \\ USA; innah@hsph.harvard.edu \\ * Correspondence: wessling@hsph.harvard.edu
}

Received: 17 October 2018; Accepted: 19 November 2018; Published: 23 November 2018

\begin{abstract}
Iron is an essential trace element required for important brain functions including oxidative metabolism, synaptic plasticity, myelination, and the synthesis of neurotransmitters. Disruptions in brain iron homeostasis underlie many neurodegenerative diseases. Increasing evidence suggests that accumulation of brain iron and chronic neuroinflammation, characterized by microglia activation and secretion of proinflammatory cytokines, are hallmarks of neurodegenerative disorders including Alzheimer's disease. While substantial efforts have led to an increased understanding of iron metabolism and the role of microglial cells in neuroinflammation, important questions still remain unanswered. Whether or not increased brain iron augments the inflammatory responses of microglial cells, including the molecular cues that guide such responses, is still unclear. How these brain macrophages accumulate, store, and utilize intracellular iron to carry out their various functions under normal and disease conditions is incompletely understood. Here, we describe the known and emerging mechanisms involved in microglial cell iron transport and metabolism as well as inflammatory responses in the brain, with a focus on AD.
\end{abstract}

Keywords: Alzheimer's disease; neuroinflammation; neurodegeneration; cytokines; neuroimmune responses

\section{Introduction}

The brain is among the most metabolically active organs in the body and accounts for at least $20 \%$ of the body's energy consumption. Accordingly, an adequate supply of iron is necessary to sustain its high-energy needs [1-4]. Our understanding of the role of iron in normal brain function has improved tremendously over the last decade, with much attention directed towards deciphering the cellular and molecular cues that guide brain iron transport and metabolism. These efforts have described the essential roles of iron as a co-factor for several physiological processes including oxidative metabolism, myelination, and the biosynthesis of neurotransmitters [5-7]. However, excess iron is known to contribute to homeostatic dysregulation due to oxidative stress and has been linked to a number of neurological disorders. Being redox active, iron exists in both ferrous $\left(\mathrm{Fe}^{2+}\right)$ and ferric $\left(\mathrm{Fe}^{3+}\right)$ forms and constantly cycles between the two states. Under aerobic conditions, this redox cycling has the potential to generate highly reactive free radicals through Fenton chemistry, resulting in oxidative stress and damage to macromolecules. Thus, the metal is directly implicated in the disease known as neurodegeneration with brain iron accumulation (NBIA), and, in addition to other trace elements implicated in neurodegeneration, including copper [8], manganese [9], and zinc [10], increasing evidence support iron's role in several other sporadic or genetic neurodegenerative disorders such as Alzheimer's disease (AD), Parkinson's disease (PD), Huntington's disease (HD), amyotrophic lateral sclerosis (ALS), and multiple sclerosis (MS) [11-14].

Microglia make up 5 to $12 \%$ of the population of cells found in mouse brain and about 0.5 to $16 \%$ of those in the human brain $[15,16]$. These resident macrophages are largely involved in immune responses and, depending on the stimuli, they can adopt a range of pro- or anti-inflammatory states 
to help maintain the integrity of the neural environment [17-19]. In addition to their roles in the neuroinflammatory response, microglia participate in neurogenesis $[19,20]$, shaping and maintaining synaptic density and connectivity in the adult and developing central nervous system (CNS) [16,21-24], oligodendrocyte differentiation [25], synaptic pruning [26], and myelin repair [16]. Microglia require iron as a co-factor to carry out all of these varied functions [27]. Over the years, multiple studies have reported the roles these immune cells play in brain iron homeostasis $[1,27,28]$. This review will examine the influence of brain iron on microglial metabolism and corresponding inflammatory responses under normal and neurodegenerative conditions, with a particular focus on AD.

\section{Brain Iron}

Brain iron levels are tightly regulated to ensure the normal function of the CNS [29,30]. The major route of iron acquisition begins with intestinal absorption, as dietary $\mathrm{Fe}^{3+}$ is reduced to $\mathrm{Fe}^{2+}$ by duodenal cytochrome B (DcytB) at the apical surface of enterocytes [31]. Divalent metal transporter-1 (DMT1) imports $\mathrm{Fe}^{2+}$ into the intestinal cells, while the iron exporter ferroportin (Fpn) mediates its exit across this epithelial barrier. On the serosal side, the multicopper ferroxidases ceruloplasmin and/or hephaestin oxidize $\mathrm{Fe}^{2+}$ to $\mathrm{Fe}^{3+}$, thereby promoting its binding to the iron carrier protein transferrin (Tf) [32]. Dietary absorption of iron is tightly regulated to respond to the body's iron needs, such that uptake is enhanced by iron deficiency but reduced under iron-loading conditions [29]. Thus, iron supplied to the brain from the diet reflects nutrient demands, while limiting the potential for excessive accumulation.

Once in the circulation, the entry of iron into the brain from the blood is controlled by the blood-brain barrier (BBB) [33]. The BBB is formed by brain microvascular endothelial cells (BMVECs), pericytes, and astrocytes [33-35]. Tf-bound iron circulating in the blood outside the CNS cannot cross the BBB directly, and, therefore, iron must enter the brain through BMVECs in a multi-step transcellular pathway. Binding of $\mathrm{Tf}$ to $\mathrm{Tf}$ receptors (TfR) at the lumen of the brain microvasculature facilitates iron uptake via receptor-mediated endocytosis $[30,34,36]$. The subsequent fate of the Tf-TfR complex within brain endothelial cells is not entirely clear, and exactly how iron is released to the brain remains controversial. The transcytosis model suggests that the ligand-receptor complex traverses the cell, such that $\mathrm{Tf}$ is released to the interstitium. However, how Tf might dissociate from its receptor at the abluminal membrane remains unexplained. An alternative model is that iron is released to the cytoplasm of BMVECs after receptor-mediated endocytosis of Tf. The endocytic uptake pathway for iron is much better understood and involves the release of $\mathrm{Fe}^{3+}$ from $\mathrm{Tf}$ in the acidic endosomal environment, its reduction to $\mathrm{Fe}^{2+}$, and DMT1-mediated export from the endosome [29]. However, whether BMVECs express DMT1 or if its function is required for entry of iron into the brain is unclear, since different groups have reported conflicting data [37-42]. An alternative membrane transport mechanism could involve transient receptor potential mucolipin-1 (TRPML1) channels which function in the release of iron from endolysosomal compartments [43]. A recent study has shown that loss of TRPML1 in mice promotes dysregulation of brain homeostasis and decreased myelination, suggesting a potential role in brain iron uptake [44]. Regardless of which transporter is responsible for iron's exit from endocytic compartments, the metal would then be utilized for metabolic purposes by the endothelial cells, stored in endothelial cell ferritin (Ftn), or released to the brain via Fpn [45]. Re-oxidation of $\mathrm{Fe}^{2+}$ to $\mathrm{Fe}^{3+}$ and subsequent incorporation into apo-Tf would provide for its circulation in the brain [46-48]. It is possible that hepcidin, which is produced by the brain endothelium, plays a role in regulating this process. An in-depth review of iron uptake into BMVECs and its release has been published elsewhere [33].

It is important to note that the amount of Tf in the brain interstitial fluid is thought to be much lower than the levels in the systemic circulation, while non-Tf-bound iron (NTBI) levels may be quite high [49]. Thus, although Tf is apparently involved in moving iron across the BBB, there is some evidence to suggest that Tf-iron-binding sites may become saturated in the brain, such that NTBI is a major source of iron delivery to neurons and other cells in the brain. Another alternative 
source of iron is ferritin which plays an important role in brain iron homeostasis. In fact, genetic loss of ferritin function leads to brain iron dyshomeostasis [11,50-52]. The brain may acquire ferritin exogenously by transcellular transport across the BBB, or it may be produced by endothelial cells and released upon demand [53]. Other endogenous sources of brain ferritin are possible, including its synthesis by microglia [28]. The ferritin pathway of iron delivery is particularly important for mouse oligodendrocytes and their function in myelination and neuronal repair. These express the ferritin receptor Tim-2, a member of the $\mathrm{T}$ cell immunoglobulin and mucin domain family, and specifically take up ferritin $[6,54]$. In humans, the transferrin receptor may bind to and mediate the internalization of ferritin $[55,56]$.

\section{Functions of Iron in the Brain}

Iron plays an indispensable role during ATP production by serving as a cofactor for cytochromes and iron-sulfur complexes of the oxidative chain [57]. The major substrate for brain energy production is glucose which becomes fully oxidized; ketone bodies can fulfill energy needs under some conditions. The brain consumes nearly $20 \%$ of the body's energy, although representing only about $2 \%$ of its weight. About $75-80 \%$ of the energy supports neuronal activity, with the remainder utilized to maintain the "housekeeping" functions of astrocytes, oligodendrocytes, and microglia [4]. Neuronal energy needs represent both axonal and synaptic signaling, but the majority is utilized post-synaptically [58]. The mitochondrial function must provide this supply of ATP with the iron requirements to support oxidative phosphorylation, as shown in Figure 1.

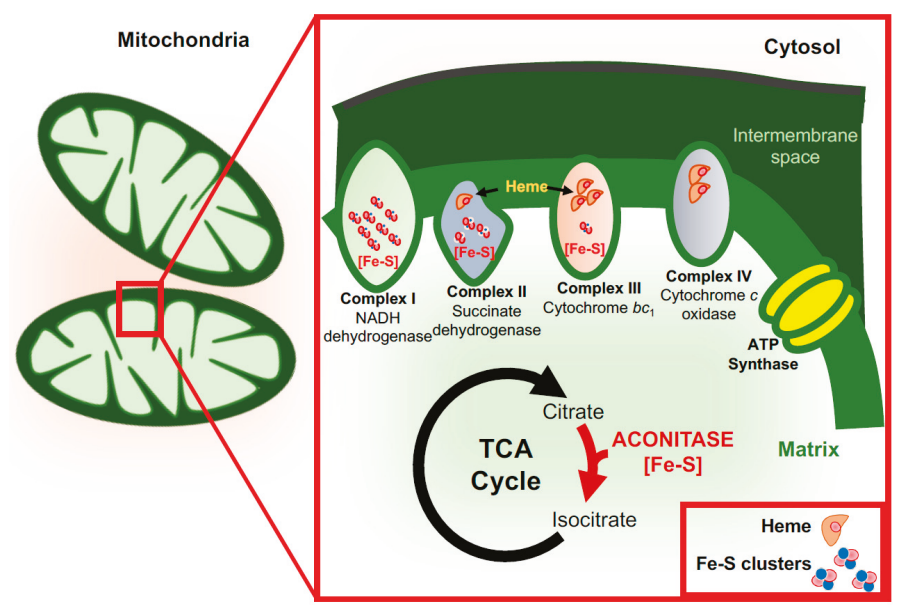

Figure 1. Iron and mitochondrial function. The mitochondrial electron transport chain contains multiple iron-sulfur clusters and heme-containing proteins necessary for ATP synthesis. NADH dehydrogenase (complex I) contains eight Fe-S clusters, succinate dehydrogenase (complex II) contains three Fe-S clusters and one heme moiety, while complex III (cytochrome bc1) contains one Fe-S cluster and several heme groups vital for its functions. Complex IV (cytochrome c oxidase) also contains two heme moieties. Aconitase, a key enzyme that catalyzes the stereo-specific isomerization of citrate to isocitrate through cis-aconitate in the tricarboxylic acid (TCA) cycle contain Fe-S clusters.

Oligodendrocytes, which are responsible for producing myelin, also require high amounts of ATP [59]. Not only do many of the enzymes involved in ATP production require a supply of iron, but also pathways for cholesterol and fatty acid synthesis necessary for myelination are iron-dependent. Some of the enzymes involved in this pathway include NADH dehydrogenase, HMG-CoA reductase, succinate dehydrogenase, dioxygenase, and glucose-6-phosphate dehydrogenase, all of which are abundant in oligodendrocytes compared to other cell types of the CNS [59]. The need for an adequate 
supply of iron during myelination is reflected in the results of animal studies demonstrating that dietary iron restriction reduces the amount and composition of myelin during gestation and early post-natal periods $[60,61]$.

Neurotransmitters serve as means of communication between neurons. The process of this communication includes biosynthesis and transport of neurotransmitters, packaging of neurotransmitters into vesicles for storage and controlled release, and binding of neurotransmitters to receptors on post-synaptic neurons with induction of cellular responses. The role of iron in each of these processes has been reviewed extensively, particularly in the case of monoamine neurotransmitters such as dopamine and serotonin that are involved in the regulation of cognitive processes including emotion and arousal behaviors [1,62-65]. For example, the synthesis of monoamine neurotransmitters depends on tyrosine hydroxylase which is an iron-requiring enzyme [66,67]. The activity of this enzyme is significantly reduced in patients suffering from PD with compromised brain iron homeostasis [67]. Iron deficiency further alters the functioning of the dopaminergic systems, with specific effects on dopamine $D_{1}$ and $D_{2}$ receptors $[1,68]$. Studies carried out by Youdim and colleagues demonstrated that the densities of dopamine $\mathrm{D}_{2}$ receptors are significantly lower in the striatum of rats deficient in iron [69-71]. Also, microdialysis studies demonstrated an elevation of extracellular dopamine in the striatum of iron-deficient rats and the return to basal levels when brain iron content and iron status returned to normal [72]. In the case of serotonin, tryptophan hydroxylase carries out the rate-determining step in the synthesis of this neurotransmitter and can be inhibited by iron chelators [66,73]. Another neurotransmitter whose biosynthesis is compromised under iron-deficient conditions is gamma-aminobutyric acid (GABA), the main inhibitory neurotransmitter in the CNS. Iron deficiency is associated with significant reduction in the activity of glutamate dehydrogenase and GABA transaminase, key enzymes responsible for the synthesis and degradation of GABA [74,75].

\section{Microglia and Iron}

Microglial activation in response to pro- and anti-inflammatory stimuli is often characterized either as classical M1 or as alternative M2, similar to the nomenclature used for systemic macrophages [76,77]. M1 activation is pro-inflammatory and neurotoxic and primarily induced through the activation of toll-like receptor (TLR) and interferon gamma (IFN- $\gamma$ ) signaling pathway [19]. M1 microglia synthesize and secrete pro-inflammatory cytokines and chemokines such as tumor necrosis factor-alpha (TNF- $\alpha$ ), some members of the interleukin family of cytokines interleukin-6 (IL-6), interleukin 1-beta (IL-1 $\beta$ ), interleukin-12 (IL-12), and C-C Motif Chemokine Ligand 2 (CCL2). In this reactive state, microglia also express inducible nitric oxide synthase (iNOS), which converts arginase into nitric oxide [19]. Accumulation of nitric oxide increases the toxic effects of glutamate and consequently potentiates $\mathrm{N}$-methyl-D-aspartate (NMDA) receptor-mediated neurotoxicity [19,78,79].

In the M2 state, microglia release anti-inflammatory cytokines such as interleukin-10 (IL-10) and transforming growth factor-beta (TGF- $\beta$ ). M2 microglia also induce arginase 1 to promote the conversion of arginine into polyamines [80]. These cells can secrete insulin-like growth factor I (IGF-I), fibroblast growth factor (FGF), and neurotrophic factors including nerve growth factor (NGF) and brain-derived neurotrophic factor (BDNF), in the effort to resolve inflammation and promote synaptic plasticity [19].

The use of the terms "M1 versus M2" oversimplifies a complex process for microglial activity, since transcriptome studies have revealed that activation is quite variable and context-dependent $[18,81]$. Indeed, microglia adopt a homeostatic (M0) state under normal conditions in the CNS, and their transcriptome profile reflects their immunosurveillance activities in this state [18,81-83]. Conversely, microglia can express both neurotoxic and neuroprotective factors under disease conditions $[19,81,84]$.

One prominent hallmark of neuroinflammation is the activation and increased acquisition of extracellular iron and subsequent downregulation of iron-interacting proteins, causing the intracellular sequestration of iron [13]. Systemically, such innate immune responses are orchestrated to deprive invading pathogens of iron, necessary for their survival [85]. This "iron withdrawal" phenomenon 
could play a similar role in the brain to reduce the metal's availability. However, accumulation of intracellular iron is associated with neuronal degeneration that underlies most neurological disorders [86], and microglial secretion of the inflammatory cytokines TNF- $\alpha$ and IL-1 $\beta$ enhances neuronal iron uptake [87]. In turn, these pro-inflammatory mediators have been shown to strongly influence microglia iron transport and metabolism [13,88-90].

Microglial cells interact with both Tf bound-iron (TBI) and NTBI [91], and pathways for each transport substrate have been characterized [28]. For NTBI uptake, an endogenous cell surface ferrireductase reduces $\mathrm{Fe}^{3+}$ to $\mathrm{Fe}^{2+}$ for uptake by DMT1 in a $\mathrm{pH}$-dependent manner at the cell surface. TBI is taken up by endocytosis of the Tf-TfR complex; after the release of iron in the acidic milieu of the endosome, it is translocated into the cytosol by DMT1 or other transporters, as described above [92].

Early studies of rat microglia raised the idea that microglial polarization and iron uptake are coordinated [89]. More recently, our group has shown that microglial iron transport pathways are differentially active in response to pro- and anti-inflammatory stimuli at both the transcript and the protein levels. Pro-inflammatory mediators increase the uptake of NTBI and expand the ferritin storage pool. These changes reflect the upregulation of both DMT1 and ferritin [28]. The uptake of NTBI by microglia would limit free extracellular iron and reduce potentially damaging reactive oxygen species (ROS) in the neural environment. In this M1 pro-inflammatory state, microglial cells also have increased glycolysis, with extracellular acidification supporting changes in the microenvironment favoring NTBI uptake by the $\mathrm{pH}$-dependent transporter DMT1. Inflammatory mediators also reduce oxidative respiration, induce heme oxygenase-1, and diminish the levels of intracellular heme. These changes are associated with increased intracellular "labile iron", suggesting that microglia can sequester both intracellular iron released by heme catabolism and extracellular iron taken up by DMT1. In contrast, anti-inflammatory IL-4 increases the expression of TfR to promote the uptake of TBI [28]. It is possible that this shift in iron transport is associated with the release of ferritin stores by M2 microglia to support the regeneration of neurons and the activity of oligodendrocytes. On the basis of these data, we propose a model by which microglia actively modify transport pathways and metabolism in response to the iron status of their environment (Figure 2).
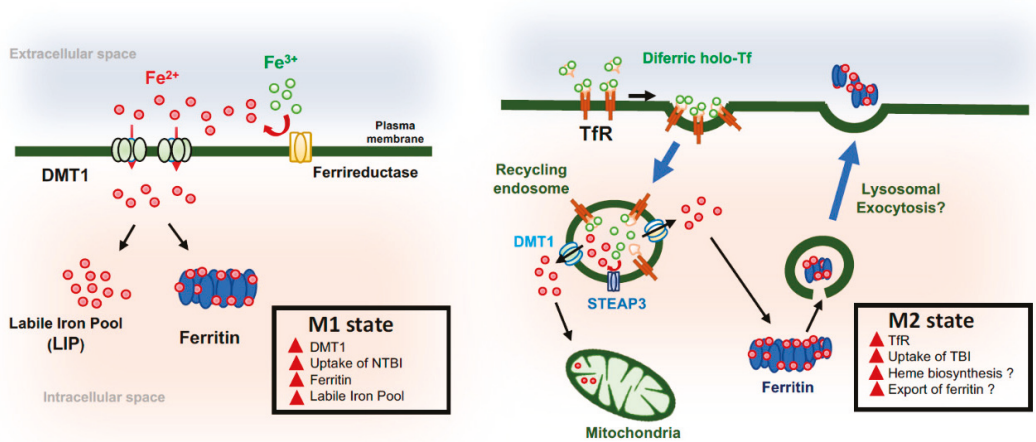

Figure 2. Iron trafficking and microglial cell polarization. (Left) Pro-inflammatory stimuli upregulate the expression of divalent metal transporter-1 (DMT-1) and the uptake of non-Tf-bound iron (NTBI). These effects are associated with increased labile iron and an expanded pool of ferritin. These changes reflect M1 polarization. (Right) Anti-inflammatory stimuli increase transferrin receptor (TfR) levels to upregulate Tf-bound iron (TBI) uptake by receptor-mediated endocytosis. In recycling endosomes, the low $\mathrm{pH}$ promotes the release of $\mathrm{Fe}^{3+}$ for ferrireduction, most likely by STEAP3. $\mathrm{Fe}^{2+}$ may be released into the cytosol through DMTI or another channel for use in mitochondria to promote heme production. We speculate that, under anti-inflammatory conditions, microglia may release ferritin (Ftn)-bound iron through lysosomal exocytosis to help oligodendrocyte function and neuronal repair. 


\section{Microglia Activation and Alzheimer's Disease}

Alzheimer's Disease (AD) is a neurodegenerative disorder and the most common form of dementia involving the progressive loss of substantive cortical and hippocampal neurons over time $[93,94]$. This disorder is characterized by extracellular deposition of amyloid beta $(A \beta)$ in senile plaques and intraneuronal accumulation of hyperphosphorylated tau proteins. These events lead to neuronal and synaptic loss, chronic inflammation, and oxidative stress $[19,89,95,96]$.

Genetic studies of familial Alzheimer's disease (FAD) have demonstrated that mutations in the amyloid precursor protein and in components of the gamma-secretase complex generate $\mathrm{A} \beta 1-42$ which can misfold and aggregate $[19,93,97]$. The more common sporadic form (SAD) of the disease is largely associated with aging. Although the pathophysiological mechanisms that underlie the role of aging in the onset of $\mathrm{AD}$ is poorly understood, accumulating evidence indicates that the onset of SAD is closely associated with brain iron and oxidative stress, both of which increase with age $[95,98-103]$. In AD, the observation that iron is present in local areas of neuronal cell death further supports the metal theory of dementia which proposes that iron promotes neurodegeneration [104]. Furthermore, as brain microglia are implicated in iron handling, it has been shown that iron accumulates in microglial cells that cluster around amyloid plaques in AD mouse models and post-mortem brain tissues of AD patients [105].

Iron is a key player during the induction of oxidative stress because of its function as a redox-active transition metal $[13,96,106]$. Indeed, the levels of damaging ROS are significantly higher in the AD brain compared to healthy control brains $[96,107]$. Importantly, several studies have reported that, by promoting neurotoxic oligomerization of $\mathrm{A} \beta$ peptides and tau tangles $[94,108]$, oxidative stress potentiates the activation of microglia $[96,109,110]$. Whether these events advance or hinder the disease is subject to active debate. For example, while anti-inflammatory activities of microglia would appear to be beneficial, some studies have reported that prolonged stimulation of microglia with $\mathrm{A} \beta$ peptides provokes chronic inflammation [111].

Microglial cells express multiple receptors including CD36, TLR2, TLR4, and TLR6 [111-113], all of which can bind $\mathrm{A} \beta$ and induce pro-inflammatory effects. The sporadic form of AD is associated with genetic variants of triggering receptor expressed on myeloid cells 2 (TREM2) [114]. TREM2 is an immune transmembrane glycoprotein receptor expressed in microglia that interacts with phospholipids, apoptotic cells, and lipoproteins [115-118]. These variants, as well as the loss-of-function mouse models of $\mathrm{AD}$, appear to limit microglial proliferation around $\mathrm{A} \beta$ plaques, causing increased plaque buildup and disease progression [119-122]. Why defective TREM2 function or expression impacts microglia responses to $\mathrm{AD}$ lesion is still incompletely understood. The role of TREM2 and other immune receptors identified as risk factors, including CD33, have been reviewed elsewhere [19].

SAD is also associated with the polymorphism of apolipoprotein E (apoE), a lipid-binding protein involved in lipid metabolism [123-125]. The apoE4 allele is strongly associated with an increased risk of $\mathrm{AD}$, while apoE2 serves a protective role [123]. Microglia produce apoE, which has been shown to moderate the inflammatory response while enhancing the phagocytosis of $A \beta$ aggregates by microglia [124-128]. However, in carriers of apoE4, increased levels of ferritin have been reported in the cerebral spinal fluid, suggesting that iron metabolism is altered in these individuals to promote increased iron retention [129]. This evidence reinforces the concept that increased brain iron adversely affects patients with AD. In fact, patients with HFE-associated hemochromatosis are subject to earlier onset of AD [130]. Since there is clinical evidence that iron chelation is beneficial to AD patients [131,132], the relationship between microglia, iron, and neurodegeneration appears to be well worth exploring.

\section{Concluding Remarks}

Understanding the role of iron in chronic inflammatory responses elicited by microglia is essential for finding new therapeutic strategies to treat neurodegenerative diseases. Although a substantial amount of effort has been put into deciphering the molecular network directly involved in brain iron 
metabolism, we still must pursue an in-depth understanding of how specific brain cells accumulate and use iron to carry out their various functions, both in normal and in disease conditions.

Author Contributions: I.C.N. and M.W.-R. wrote, reviewed, and edited this manuscript.

Funding: Supported by the National Institutes of Diabetes and Digestive and Kidney Disease under the award R01 DK064750. ICN is supported by the National Institute of Environmental Health Sciences under the award T32 ES016645.

Conflicts of Interest: The authors declare no conflict of interest.

\begin{tabular}{|c|c|}
\hline Alzheimer's disease & $\mathrm{AD}$ \\
\hline familial Alzheimer's disease & FAD \\
\hline sporadic Alzheimer's disease & SAD \\
\hline neurodegeneration with brain iron accumulation & NBIA \\
\hline Parkinson's disease & PD \\
\hline Huntington's disease & HD \\
\hline amyotrophic lateral sclerosis & ALS \\
\hline multiple sclerosis & MS \\
\hline amyloid beta & $A \beta$ \\
\hline transferrin & $\mathrm{Tf}$ \\
\hline Tf-bound iron & TBI \\
\hline transferrin receptor & TfR \\
\hline non-transferrin-bound iron & NTBI \\
\hline divalent metal transporter-1 & DMT1 \\
\hline labile iron pool & LIP \\
\hline central nervous system & CNS \\
\hline Blood-brain barrier & BBB \\
\hline brain microvascular endothelial cell & BMVEC \\
\hline transient receptor potential mucolipin-1 & TRPML1 \\
\hline ferritin & Ftn \\
\hline reactive oxygen species & ROS \\
\hline gamma-aminobutyric acid & GABA \\
\hline inducible nitric oxidase & iNOS \\
\hline N-methyl-D-aspartate & NMDA \\
\hline adenosine triphosphate & ATP \\
\hline 3-hydroxy-3-methyl-glutaryl-coenzyme A & $\mathrm{HMG}-\mathrm{CoA}$ \\
\hline tricarboxylic acid & TCA \\
\hline interferon gamma & IFN- $\gamma$ \\
\hline toll-like receptor & TLR \\
\hline tumor necrosis factor-alpha & TNF- $\alpha$ \\
\hline interleukin-6 & IL-6 \\
\hline interleukin 1-beta & IL-1 $\beta$ \\
\hline interleukin-12 & IL-12 \\
\hline interleukin-10 & IL-10 \\
\hline C-C motif chemokine ligand-2 & CCL2 \\
\hline transforming growth factor-beta & TGF- $\beta$ \\
\hline insulin-like growth factor-1 & IGF-1 \\
\hline fibroblast growth factor & FGF \\
\hline nerve growth factor & NGF \\
\hline brain-derived growth factor & BDNF \\
\hline toll-like receptor 2 & TLR2 \\
\hline toll-like receptor 4 & TLR4 \\
\hline toll-like receptor 6 & TLR6 \\
\hline cluster of differentiation 33 & CD33 \\
\hline
\end{tabular}


cluster of differentiation 36

triggering receptor expressed on myeloid cells 2

apolipoprotein E

apolipoprotein E4

apolipoprotein E2
CD36

TREM2

apoE

apoE4

apoE2

\section{References}

1. Beard, J.L.; Connor, J.R. Iron status and neural functioning. Annu. Rev. Nutr. 2003, 23, 41-58. [CrossRef] [PubMed]

2. Hidalgo, C.; Carrasco, M.A.; Muñoz, P.; Núñez, M.T. A Role for Reactive Oxygen/Nitrogen Species and Iron on Neuronal Synaptic Plasticity. Antioxid. Redox Signal. 2007, 9, 245-255. [CrossRef] [PubMed]

3. Falkowska, A.; Gutowska, I.; Goschorska, M.; Nowacki, P.; Chlubek, D.; Baranowska-Bosiacka, I. Energy Metabolism of the Brain, Including the Cooperation between Astrocytes and Neurons, Especially in the Context of Glycogen Metabolism. Int. J. Mol. Sci. 2015, 16, 25959-25981. [CrossRef] [PubMed]

4. Magistretti, P.J.; Allaman, I. A cellular perspective on brain energy metabolism and functional imaging. Neuron 2015, 86, 883-901. [CrossRef] [PubMed]

5. Madsen, E.; Gitlin, J.D. Copper and Iron Disorders of the Brain. Annu. Rev. Neurosci. 2007, 30, 317-337. [CrossRef] [PubMed]

6. Todorich, B.; Zhang, X.; Slagle-Webb, B.; Seaman, W.E.; Connor, J.R. Tim-2 is the receptor for H-ferritin on oligodendrocytes. J. Neurochem. 2008, 107, 1495-1505. [CrossRef] [PubMed]

7. Salvador, G.A. Iron in neuronal function and dysfunction. Biofactors 2010, 36, 103-110. [CrossRef] [PubMed]

8. Giampietro, R.; Spinelli, F.; Contino, M.; Colabufo, N.A. The Pivotal Role of Copper in Neurodegeneration: A New Strategy for the Therapy of Neurodegenerative Disorders. Mol. Pharm. 2018, 15, 808-820. [CrossRef] [PubMed]

9. Bowman, A.B.; Kwakye, G.F.; Herrero Hernandez, E.; Aschner, M. Role of manganese in neurodegenerative diseases. J. Trace Elem. Med. Biol. 2011, 25, 191-203. [CrossRef] [PubMed]

10. Szewczyk, B. Zinc homeostasis and neurodegenerative disorders. Front. Aging Neurosci. 2013, 5, 33. [CrossRef] [PubMed]

11. Muhoberac, B.B.; Vidal, R. Abnormal iron homeostasis and neurodegeneration. Front. Aging Neurosci. 2013, 5, 32. [CrossRef] [PubMed]

12. Ward, R.J.; Zucca, F.A.; Duyn, J.H.; Crichton, R.R.; Zecca, L. The role of iron in brain ageing and neurodegenerative disorders. Lancet Neurol. 2014, 13, 1045-1060. [CrossRef]

13. Thomsen, M.S.; Andersen, M.V.; Christoffersen, P.R.; Jensen, M.D.; Lichota, J.; Moos, T. Neurodegeneration with inflammation is accompanied by accumulation of iron and ferritin in microglia and neurons. Neurobiol. Dis. 2015, 81, 108-118. [CrossRef] [PubMed]

14. Li, K.; Reichmann, H. Role of Iron in Neurodegenerative Diseases. J. Neural Transm. 2016, 123, 389-399. [CrossRef] [PubMed]

15. Mittelbronn, M.; Dietz, K.; Schluesener, H.J.; Meyermann, R. Local distribution of microglia in the normal adult human central nervous system differs by up to one order of magnitude. Acta Neuropathol. 2001, 101, 249-255. [PubMed]

16. Lloyd, A.F.; Davies, C.L.; Miron, V.E. Microglia: Origins, homeostasis, and roles in myelin repair. Curr. Opin. Neurobiol. 2017, 47, 113-120. [CrossRef] [PubMed]

17. Prinz, M.; Tay, T.L.; Wolf, Y.; Jung, S. Microglia: Unique and common features with other tissue macrophages. Acta Neuropathol. 2014, 128, 319-331. [CrossRef] [PubMed]

18. Ransohoff, R.M. A polarizing question: Do M1 and M2 microglia exist? Nat. Neurosci. 2016, 19, 987-991. [CrossRef] [PubMed]

19. Colonna, M.; Butovsky, O. Microglia Function in the Central Nervous System During Health and Neurodegeneration. Annu. Rev. Immunol. 2017, 35, 441-468. [CrossRef] [PubMed]

20. Squarzoni, P.; Thion, M.S.; Garel, S. Neuronal and microglial regulators of cortical wiring: Usual and novel guideposts. Front. Neurosci. 2015, 9, 248. [CrossRef] [PubMed]

21. Pollard, J.W. Trophic macrophages in development and disease. Nat. Rev. Immunol. 2009, 9, $259-270$. [CrossRef] [PubMed] 
22. Murray, P.J.; Wynn, T.A. Protective and pathogenic functions of macrophage subsets. Nat. Rev. Immunol. 2011, 11, 723-737. [CrossRef] [PubMed]

23. Tremblay, M.E.; Stevens, B.; Sierra, A.; Wake, H.; Bessis, A.; Nimmerjahn, A. The role of microglia in the healthy brain. J. Neurosci. 2011, 31, 16064-16069. [CrossRef] [PubMed]

24. Wake, H.; Moorhouse, A.J.; Miyamoto, A.; Nabekura, J. Microglia: Actively surveying and shaping neuronal circuit structure and function. Trends Neurosci. 2013, 36, 209-217. [CrossRef] [PubMed]

25. Erblich, B.; Zhu, L.; Etgen, A.M.; Dobrenis, K.; Pollard, J.W. Absence of colony stimulation factor-1 receptor results in loss of microglia, disrupted brain development and olfactory deficits. PLoS ONE 2011, 6, e26317. [CrossRef] [PubMed]

26. Schafer, D.P.; Lehrman, E.K.; Kautzman, A.G.; Koyama, R.; Mardinly, A.R.; Yamasaki, R.; Ransohoff, R.M.; Greenberg, M.E.; Barres, B.A.; Stevens, B. Microglia Sculpt Postnatal Neural Circuits in an Activity and Complement-Dependent Manner. Neuron 2012, 74, 691-705. [CrossRef] [PubMed]

27. Rathnasamy, G.; Ling, E.-A.; Kaur, C. Consequences of iron accumulation in microglia and its implications in neuropathological conditions. CNS Neurol. Dis. Drug Targets 2013, 12, 785-798. [CrossRef]

28. McCarthy, R.C.; Sosa, J.C.; Gardeck, A.M.; Baez, A.S.; Lee, C.H.; Wessling-Resnick, M. Inflammation-induced iron transport and metabolism by brain microglia. J. Biol. Chem. 2018, 293, 7853-7863. [CrossRef] [PubMed]

29. Hentze, M.W.; Muckenthaler, M.U.; Andrews, N.C. Review Balancing Acts: Molecular Control of Mammalian Iron Metabolism sequences of systemic iron overload result from chronic iron accumulation in tissues. Cell 2004, 117, 285-297. [CrossRef]

30. Moos, T.; Nielsen, T.R.; Skjørringe, T.; Morgan, E.H. Iron trafficking inside the brain. J. Neurochem. 2007, 103, 1730-1740. [CrossRef] [PubMed]

31. Anderson, G.J.; Frazer, D.M. Current understanding of iron homeostasis. Am. J. Clin. Nutr. 2017, 106, 1559S-1566S. [CrossRef] [PubMed]

32. Wessling-Resnick, M. Iron imports. III. Transfer of iron from the mucosa into circulation. Am. J. Physiol. Gastrointest. Liver Physiol. 2006, 290, G1-G6. [CrossRef] [PubMed]

33. McCarthy, R.C.; Kosman, D.J. Iron transport across the blood-brain barrier: Development, neurovascular regulation and cerebral amyloid angiopathy. Cell. Mol. Life Sci. 2015, 72, 709-727. [CrossRef] [PubMed]

34. Abbott, N.J.; Rönnbäck, L.; Hansson, E. Astrocyte-endothelial interactions at the blood-brain barrier. Nat. Rev. Neurosci. 2006, 7, 41-53. [CrossRef] [PubMed]

35. Rouault, T.A.; Cooperman, S. Brain Iron Metabolism. Semin. Pediatr. Neurol. 2006, 13, 142-148. [CrossRef] [PubMed]

36. Ke, Y.; Qian, Z.M. Brain iron metabolism: Neurobiology and neurochemistry. Prog. Neurobiol. 2007, 83, 149-173. [CrossRef] [PubMed]

37. Gunshin, H.; Mackenzie, B.; Berger, U.V.; Gunshin, Y.; Romero, M.F.; Boron, W.F.; Nussberger, S.; Gollan, J.L.; Hediger, M.A. Cloning and characterization of a mammalian proton-coupled metal-ion transporter. Nature 1997, 388, 482-488. [CrossRef] [PubMed]

38. Burdo, J.R.; Menzies, S.L.; Simpson, I.A.; Garrick, L.M.; Garrick, M.D.; Dolan, K.G.; Haile, D.J.; Beard, J.L.; Connor, J.R. Distribution of divalent metal transporter 1 and metal transport protein 1 in the normal and Belgrade rat. J. Neurosci. Res. 2001, 66, 1198-1207. [CrossRef] [PubMed]

39. Siddappa, A.J.M.; Rao, R.B.; Wobken, J.D.; Leibold, E.A.; Connor, J.R.; Georgieff, M.K. Developmental changes in the expression of iron regulatory proteins and iron transport proteins in the perinatal rat brain. J. Neurosci. Res. 2002, 68, 761-775. [CrossRef] [PubMed]

40. Enerson, B.E.; Drewes, L.R. The Rat Blood-Brain Barrier Transcriptome. J. Cereb. Blood Flow Metab. 2006, 26, 959-973. [CrossRef] [PubMed]

41. Moos, T.; Skjoerringe, T.; Gosk, S.; Morgan, E.H. Brain capillary endothelial cells mediate iron transport into the brain by segregating iron from transferrin without the involvement of divalent metal transporter 1. J. Neurochem. 2006, 98, 1946-1958. [CrossRef] [PubMed]

42. Skjorringe, T.; Burkhart, A.; Johnsen, K.B.; Moos, T. Divalent metal transporter 1 (DMT1) in the brain: Implications for a role in iron transport at the blood-brain barrier, and neuronal and glial pathology. Front. Mol. Neurosci. 2015, 8, 19. [PubMed]

43. Dong, X.-P.; Cheng, X.; Mills, E.; Delling, M.; Wang, F.; Kurz, T.; Xu, H. The type IV mucolipidosis-associated protein TRPML1 is an endolysosomal iron release channel. Nature 2008, 455, 992-996. [CrossRef] [PubMed] 
44. Grishchuk, Y.; Pena, K.A.; Coblentz, J.; King, V.E.; Humphrey, D.M.; Wang, S.L.; Kiselyov, K.I.; Slaugenhaupt, S.A. Impaired myelination and reduced brain ferric iron in the mouse model of mucolipidosis IV. Dis. Models Mech. 2015, 8, 1591-1601. [CrossRef] [PubMed]

45. Simpson, I.A.; Ponnuru, P.; Klinger, M.E.; Myers, R.L.; Devraj, K.; Coe, C.L.; Lubach, G.R.; Carruthers, A.; Connor, J.R. A novel model for brain iron uptake: Introducing the concept of regulation. J. Cereb. Blood Flow Metab. 2015, 35, 48-57. [CrossRef] [PubMed]

46. McCarthy, R.C.; Kosman, D.J. Ferroportin and exocytoplasmic ferroxidase activity are required for brain microvascular endothelial cell iron efflux. J. Biol. Chem. 2013, 288, 17932-17940. [CrossRef] [PubMed]

47. McCarthy, R.C.; Kosman, D.J. Glial cell ceruloplasmin and hepcidin differentially regulate iron efflux from brain microvascular endothelial cells. PLoS ONE 2014, 9, e89003. [CrossRef] [PubMed]

48. Duck, K.A.; Connor, J.R. Iron uptake and transport across physiological barriers. Biometals 2016, $29,573-591$. [CrossRef] [PubMed]

49. Gutteridge, J.M. Ferrous ions detected in cerebrospinal fluid by using bleomycin and DNA damage. Clin. Sci. 1992, 82, 315-320. [CrossRef] [PubMed]

50. Ferreira, C.; Bucchini, D.; Martin, M.E.; Levi, S.; Arosio, P.; Grandchamp, B.; Beaumont, C. Early embryonic lethality of $\mathrm{H}$ ferritin gene deletion in mice. J. Biol. Chem. 2000, 275, 3021-3024. [CrossRef] [PubMed]

51. Thompson, K.; Menzies, S.; Muckenthaler, M.; Torti, F.M.; Wood, T.; Torti, S.V.; Hentze, M.W.; Beard, J.; Connor, J. Mouse brains deficient in $\mathrm{H}$-ferritin have normal iron concentration but a protein profile of iron deficiency and increased evidence of oxidative stress. J. Neurosci. Res. 2003, 71, 46-63. [CrossRef] [PubMed]

52. Li, W.; Garringer, H.J.; Goodwin, C.B.; Richine, B.; Acton, A.; VanDuyn, N.; Muhoberac, B.B.; Irimia-Dominguez, J.; Chan, R.J.; Peacock, M.; et al. Systemic and Cerebral Iron Homeostasis in Ferritin Knock-Out Mice. PLoS ONE 2015, 10, e0117435. [CrossRef] [PubMed]

53. Chiou, B.; Neal, E.H.; Bowman, A.B.; Lippmann, E.S.; Simpson, I.A.; Connor, J.R. Endothelial cells are critical regulators of iron transport in a model of the human blood-brain barrier. J. Cereb. Blood Flow Metab. 2018. [CrossRef] [PubMed]

54. Todorich, B.; Zhang, X.; Connor, J.R. H-ferritin is the major source of iron for oligodendrocytes. Glia 2011, 59, 927-935. [CrossRef] [PubMed]

55. Li, L.; Fang, C.J.; Ryan, J.C.; Niemi, E.C.; Lebron, J.A.; Bjorkman, P.J.; Arase, H.; Torti, F.M.; Torti, S.V.; Nakamura, M.C.; et al. Binding and uptake of H-ferritin are mediated by human transferrin receptor-1. Proc. Natl. Acad. Sci. USA 2010, 107, 3505-3510. [CrossRef] [PubMed]

56. Sakamoto, S.; Kawabata, H.; Masuda, T.; Uchiyama, T.; Mizumoto, C.; Ohmori, K.; Koeffler, H.P.; Kadowaki, N.; Takaori-Kondo, A. H-Ferritin Is Preferentially Incorporated by Human Erythroid Cells through Transferrin Receptor 1 in a Threshold-Dependent Manner. PLoS ONE 2015, 10, e0139915. [CrossRef] [PubMed]

57. Lill, R.; Hoffmann, B.; Molik, S.; Pierik, A.J.; Rietzschel, N.; Stehling, O.; Uzarska, M.A.; Webert, H.; Wilbrecht, C.; Mühlenhoff, U. The role of mitochondria in cellular iron-sulfur protein biogenesis and iron metabolism. Biochim. Biophys. Acta (BBA) Mol. Cell Res. 2012, 1823, 1491-1508. [CrossRef] [PubMed]

58. Alle, H.; Roth, A.; Geiger, J.R.P. Energy-efficient action potentials in hippocampal mossy fibers. Science 2009, 325, 1405-1408. [CrossRef] [PubMed]

59. Todorich, B.; Pasquini, J.M.; Garcia, C.I.; Paez, P.M.; Connor, J.R. Oligodendrocytes and myelination: The role of iron. Glia 2009, 57, 467-478. [CrossRef] [PubMed]

60. Yu, G.S.; Steinkirchner, T.M.; Rao, G.A.; Larkin, E.C. Effect of prenatal iron deficiency on myelination in rat pups. Am. J. Pathol. 1986, 125, 620-624. [PubMed]

61. Ortiz, E.; Pasquini, J.M.; Thompson, K.; Felt, B.; Butkus, G.; Beard, J.; Connor, J.R. Effect of manipulation of iron storage, transport, or availability on myelin composition and brain iron content in three different animal models. J. Neurosci. Res. 2004, 77, 681-689. [CrossRef] [PubMed]

62. Ashkenazi, R.; Ben-Shachar, D.; Youdim, M.B.H. Nutritional iron and dopamine binding sites in the rat brain. Pharmacol. Biochem. Behav. 1982, 17, 43-47. [CrossRef]

63. Adhami, V.M.; Husain, R.; Husain, R.; Seth, P.K. Influence of Iron Deficiency and Lead Treatment on Behavior and Cerebellar and Hippocampal Polyamine Levels in Neonatal Rats. Neurochem. Res. 1996, 21, 915-922. [CrossRef] [PubMed] 
64. Kwik-Uribe, C.L.; Gietzen, D.; German, J.B.; Golub, M.S.; Keen, C.L. Chronic Marginal Iron Intakes during Early Development in Mice Result in Persistent Changes in Dopamine Metabolism and Myelin Composition. J. Nutr. 2000, 130, 2821-2830. [CrossRef] [PubMed]

65. Kim, J.; Wessling-Resnick, M. Iron and mechanisms of emotional behavior. J. Nutr. Biochem. 2014, 25, 1101-1107. [CrossRef] [PubMed]

66. Kuhn, D.M.; Ruskin, B.; Lovenberg, W. Tryptophan Hydroxylase The role of oxygen, iron, and sulfhydryl groups as determinants of stability and catalytic activity. J. Biol. Chem. 1980, 255, 4137-4143. [PubMed]

67. Glinka, Y.; Gassen, M.; Youdim, M.B.H. Iron and Neurotransmitter Function in the Brain. In Metals and Oxidative Damage in Neurological Disorders; Connor, J.R., Ed.; Springer: Boston, MA, USA, 1997; pp. 1-22.

68. Bianco, L.E.; Wiesinger, J.; Earley, C.J.; Jones, B.C.; Beard, J.L. Iron deficiency alters dopamine uptake and response to L-DOPA injection in Sprague-Dawley rats. J. Neurochem. 2008, 106, 205-215. [CrossRef] [PubMed]

69. Yehuda, S.; Youdim, M.B. Brain iron: A lesson from animal models. Am. J. Clin. Nutr. 1989, 50, 618-629. [CrossRef] [PubMed]

70. Yehuda, S. Neurochemical basis of behavioral effects of brain iron deficiency in animals. In Brain, Behavior and Iron in the Infant Diet; Dobbing, J., Ed.; Springer: London, UK, 1990; pp. 63-76.

71. Erikson, K.M.; Jones, B.C.; Hess, E.J.; Zhang, Q.; Beard, J.L. Iron deficiency decreases dopamine D 1 and D 2 receptors in rat brain. Pharmacol. Biochem. Behav. 2001, 69, 409-418. [CrossRef]

72. Chen, Q.; Connor, J.R.; Beard, J.L. Brain Iron, Transferrin and Ferritin Concentrations Are Altered in Developing Iron-Deficient Rats. J. Nutr. 1995, 125, 1529-1535. [PubMed]

73. Waldmeier, P.C.; Buchle, A.M.; Steulet, A.F. Inhibition of catechol-O-methyltransferase (COMT) as well as tyrosine and tryptophan hydroxylase by the orally active iron chelator, 1,2-dimethyl-3-hydroxypyridin-4-one (L1, CP20), in rat brain in vivo. Biochem. Pharmacol. 1993, 45, 2417-2424. [CrossRef]

74. Taneja, V.; Mishra, K.; Agarwal, K.N. Effect of early iron deficiency in rat on the gamma-aminobutyric acid shunt in brain. J. Neurochem. 1986, 46, 1670-1674. [CrossRef] [PubMed]

75. Li, D. Effects of iron deficiency on iron distribution and gamma-aminobutyric acid (GABA) metabolism in young rat brain tissues. Hokkaido J. Med. Sci. 1998, 73, 215-225. [PubMed]

76. Appel, S.H.; Zhao, W.; Beers, D.R.; Henkel, J.S. The Microglial-Motoneuron dialogue in ALS. Acta Myol. 2011, 30, 4. [PubMed]

77. Sica, A.; Mantovani, A. Macrophage plasticity and polarization: In vivo veritas. J. Clin. Investig. 2012, 122, 787-795. [CrossRef] [PubMed]

78. Farber, N.B.; Kim, S.H.; Dikranian, K.; Jiang, X.P.; Heinkel, C. Receptor mechanisms and circuitry underlying NMDA antagonist neurotoxicity. Mol. Psychiatry 2002, 7, 32-43. [CrossRef] [PubMed]

79. Bai, N.; Aida, T.; Yanagisawa, M.; Katou, S.; Sakimura, K.; Mishina, M.; Tanaka, K. NMDA receptor subunits have different roles in NMDA-induced neurotoxicity in the retina. Mol. Brain 2013, 6, 34. [CrossRef] [PubMed]

80. Franca-Costa, J.; Van Weyenbergh, J.; Boaventura, V.S.; Luz, N.F.; Malta-Santos, H.; Oliveira, M.C.; Santos de Campos, D.C.; Saldanha, A.C.; dos-Santos, W.L.; Bozza, P.T.; et al. Arginase I, polyamine, and prostaglandin E2 pathways suppress the inflammatory response and contribute to diffuse cutaneous leishmaniasis. J. Infect. Dis. 2015, 211, 426-435. [CrossRef] [PubMed]

81. Wes, P.D.; Holtman, I.R.; Boddeke, E.W.; Moller, T.; Eggen, B.J. Next generation transcriptomics and genomics elucidate biological complexity of microglia in health and disease. Glia 2016, 64, 197-213. [CrossRef] [PubMed]

82. Butovsky, O.; Jedrychowski, M.P.; Moore, C.S.; Cialic, R.; Lanser, A.J.; Gabriely, G.; Koeglsperger, T.; Dake, B.; Wu, P.M.; Doykan, C.E.; et al. Identification of a unique TGF- $\beta$-dependent molecular and functional signature in microglia. Nat. Neurosci. 2014, 17, 131-143. [CrossRef] [PubMed]

83. Hickman, S.E.; Kingery, N.D.; Ohsumi, T.; Borowsky, M.; Wang, L.-C.; Means, T.K.; Khoury, J.E. The Microglial Sensome Revealed by Direct RNA Sequencing. Nat. Neurosci. 2013, 16, 1896-1905. [CrossRef] [PubMed]

84. Chiu, I.M.; Morimoto, E.T.A.; Goodarzi, H.; Liao, J.T.; O’Keeffe, S.; Phatnani, H.P.; Muratet, M.; Carroll, M.C.; Levy, S.; Tavazoie, S.; et al. A neurodegeneration-specific gene-expression signature of acutely isolated microglia from an amyotrophic lateral sclerosis mouse model. Cell Rep. 2013, 4, 385-401. [CrossRef] [PubMed] 
85. Wessling-Resnick, M. Iron homeostasis and the inflammatory response. Annu. Rev. Nutr. 2010, 30, 105-122. [CrossRef] [PubMed]

86. Xu, H.; Wang, Y.; Song, N.; Wang, J.; Jiang, H.; Xie, J. New Progress on the Role of Glia in Iron Metabolism and Iron-Induced Degeneration of Dopamine Neurons in Parkinson's Disease. Front. Mol. Neurosci. 2018, 10, 455. [CrossRef] [PubMed]

87. Wang, J.; Song, N.; Jiang, H.; Wang, J.; Xie, J. Pro-inflammatory cytokines modulate iron regulatory protein 1 expression and iron transportation through reactive oxygen/nitrogen species production in ventral mesencephalic neurons. Biochim. Biophys. Acta 2013, 1832, 618-625. [CrossRef] [PubMed]

88. Kaur, C.; Ling, E.A. Increased expression of transferrin receptors and iron in amoeboid microglial cells in postnatal rats following an exposure to hypoxia. Neurosci. Lett. 1999, 262, 183-186. [CrossRef]

89. Urrutia, P.; Aguirre, P.; Esparza, A.; Tapia, V.; Mena, N.P.; Arredondo, M.; Gonzalez-Billault, C.; Nunez, M.T. Inflammation alters the expression of DMT1, FPN1 and hepcidin, and it causes iron accumulation in central nervous system cells. J. Neurochem. 2013, 126, 541-549. [CrossRef] [PubMed]

90. Holland, R.; McIntosh, A.L.; Finucane, O.M.; Mela, V.; Rubio-Araiz, A.; Timmons, G.; McCarthy, S.A.; Gun'ko, Y.K.; Lynch, M.A. Inflammatory microglia are glycolytic and iron retentive and typify the microglia in APP/PS1 mice. Brain Behav. Immun. 2018, 68, 183-196. [CrossRef] [PubMed]

91. Gaasch, J.A.; Lockman, P.R.; Geldenhuys, W.J.; Allen, D.D.; Van der Schyf, C.J. Brain Iron Toxicity: Differential Responses of Astrocytes, Neurons, and Endothelial Cells. Neurochem. Res. 2007, 32, 1196-1208. [CrossRef] [PubMed]

92. Wessling-Resnick, M. Crossing the Iron Gate: Why and How Transferrin Receptors Mediate Viral Entry. Annu. Rev. Nutr. 2018, 38, 431-458. [CrossRef] [PubMed]

93. Tanzi, R.E. The Genetics of Alzheimer Disease. Cold Spring Harb. Perspect. Med. 2012, 2, a006296. [CrossRef] [PubMed]

94. Belaidi, A.A.; Bush, A.I. Iron neurochemistry in Alzheimer's disease and Parkinson's disease: Targets for therapeutics. J. Neurochem. 2016, 139, 179-197. [CrossRef] [PubMed]

95. Praticò, D. Oxidative stress hypothesis in Alzheimer's disease: A reappraisal. Trends Pharmacol. Sci. 2008, 29, 609-615. [CrossRef] [PubMed]

96. Lane, D.J.R.; Ayton, S.; Bush, A.I. Iron and Alzheimer's Disease: An Update on Emerging Mechanisms. J. Alzheimers Dis. 2018, 64, S379-S395. [CrossRef] [PubMed]

97. Reddy, K.; Cusack, C.L.; Nnah, I.C.; Khayati, K.; Saqcena, C.; Huynh, T.B.; Noggle, S.A.; Ballabio, A.; Dobrowolski, R. Dysregulation of Nutrient Sensing and CLEARance in Presenilin Deficiency. Cell Rep. 2016, 14, 2166-2179. [CrossRef] [PubMed]

98. Smith, C.D.; Carney, J.M.; Starke-Reed, P.E.; Oliver, C.N.; Stadtman, E.R.; Floyd, R.A.; Markesbery, W.R. Excess brain protein oxidation and enzyme dysfunction in normal aging and in Alzheimer disease. Proc. Natl. Acad. Sci. USA 1991, 88, 10540-10543. [CrossRef] [PubMed]

99. Mecocci, P.; MacGarvey, U.; Beal, M.F. Oxidative damage to mitochondrial DNA is increased in Alzheimer's disease. Ann. Neurol. 1994, 36, 747-751. [CrossRef] [PubMed]

100. Good, P.F.; Werner, P.; Hsu, A.; Olanow, C.W.; Perl, D.P. Evidence for Neuronal Oxidative Damage in Alzheimer's Disease. Am. J. Pathol. 1996, 149, 21-28. [PubMed]

101. Lovell, M.A.; Ehmann, W.D.; Butler, S.M.; Markesbery, W.R. Elevated thiobarbituric acid-reactive substances and antioxidant enzyme activity in the brain in Alzheimer's disease. Neurology 1995, 45, 1594-1601. [CrossRef] [PubMed]

102. Zhu, X.; Su, B.; Wang, X.; Smith, M.A.; Perry, G. Causes of oxidative stress in Alzheimer disease. Cell. Mol. Life Sci. 2007, 64, 2202-2210. [CrossRef] [PubMed]

103. Bonda, D.J.; Wang, X.; Perry, G.; Nunomura, A.; Tabaton, M.; Zhu, X.; Smith, M.A. Oxidative stress in Alzheimer disease: A possibility for prevention. Neuropharmacology 2010, 59, 290-294. [CrossRef] [PubMed]

104. Bush, A.I. The metal theory of Alzheimer's disease. J. Alzheimers Dis. 2013, 33 (Suppl. 1), S277-S281. [CrossRef] [PubMed]

105. Zeineh, M.M.; Chen, Y.; Kitzler, H.H.; Hammond, R.; Vogel, H.; Rutt, B.K. Activated iron-containing microglia in the human hippocampus identified by magnetic resonance imaging in Alzheimer disease. Neurobiol. Aging 2015, 36, 2483-2500. [CrossRef] [PubMed]

106. Filomeni, G.; Bolaños, J.P.; Mastroberardino, P.G. Redox Status and Bioenergetics Liaison in Cancer and Neurodegeneration. Int. J. Cell Biol. 2012, 2012, 659645. [CrossRef] [PubMed] 
107. Di Paolo, G.; Kim, T.-W. Linking lipids to Alzheimer's disease: Cholesterol and beyond. Nat. Rev. Neurosci. 2011, 12, 284-296. [CrossRef] [PubMed]

108. Peters, D.G.; Pollack, A.N.; Cheng, K.C.; Sun, D.; Saido, T.; Haaf, M.P.; Yang, Q.X.; Connor, J.R.; Meadowcroft, M.D. Dietary lipophilic iron alters amyloidogenesis and microglial morphology in Alzheimer's disease knock-in APP mice. Metallomics 2018, 10, 426-443. [CrossRef] [PubMed]

109. Yu, J.; Guo, Y.; Sun, M.; Li, B.; Zhang, Y.; Li, C. Iron is a potential key mediator of glutamate excitotoxicity in spinal cord motor neurons. Brain Res. 2009, 1257, 102-107. [CrossRef] [PubMed]

110. Yang, W.S.; Stockwell, B.R. Ferroptosis: Death by Lipid Peroxidation. Trends Cell. Biol. 2016, 26, 165-176. [CrossRef] [PubMed]

111. Heneka, M.T.; Carson, M.J.; Khoury, J.E.; Landreth, G.E.; Brosseron, F.; Feinstein, D.L.; Jacobs, A.H.; Wyss-Coray, T.; Vitorica, J.; Ransohoff, R.M.; et al. Neuroinflammation in Alzheimer's disease. Lancet Neurol. 2015, 14, 388-405. [CrossRef]

112. El Khoury, J.B.; Moore, K.J.; Means, T.K.; Leung, J.; Terada, K.; Toft, M.; Freeman, M.W.; Luster, A.D. CD36 mediates the innate host response to beta-amyloid. J. Exp. Med. 2003, 197, 1657-1666. [CrossRef] [PubMed]

113. Heneka, M.T.; Kummer, M.P.; Stutz, A.; Delekate, A.; Schwartz, S.; Vieira-Saecker, A.; Griep, A.; Axt, D.; Remus, A.; Tzeng, T.-C.; et al. NLRP3 is activated in Alzheimer's disease and contributes to pathology in APP/PS1 mice. Nature 2013, 493, 674-678. [CrossRef] [PubMed]

114. Guerreiro, R.; Wojtas, A.; Bras, J.; Carrasquillo, M.; Rogaeva, E.; Majounie, E.; Cruchaga, C.; Sassi, C.; Kauwe, J.S.K.; Younkin, S.; et al. Alzheimer Genetic Analysis Group, T.A.G.A. TREM2 variants in Alzheimer's disease. N. Engl. J. Med. 2013, 368, 117-127. [CrossRef] [PubMed]

115. Atagi, Y.; Liu, C.-C.; Painter, M.M.; Chen, X.-F.; Verbeeck, C.; Zheng, H.; Li, X.; Rademakers, R.; Kang, S.S.; $\mathrm{Xu}, \mathrm{H}$.; et al. Apolipoprotein E Is a Ligand for Triggering Receptor Expressed on Myeloid Cells 2 (TREM2). J. Biol. Chem. 2015, 290, 26043-26050. [CrossRef] [PubMed]

116. Bailey, C.C.; DeVaux, L.B.; Farzan, M. The Triggering Receptor Expressed on Myeloid Cells 2 Binds Apolipoprotein E. J. Biol. Chem. 2015, 290, 26033-26042. [CrossRef] [PubMed]

117. Wang, Y.; Cella, M.; Mallinson, K.; Ulrich, J.D.; Young, K.L.; Robinette, M.L.; Gilfillan, S.; Krishnan, G.M.; Sudhakar, S.; Zinselmeyer, B.H.; et al. TREM2 Lipid Sensing Sustains the Microglial Response in an Alzheimer's Disease Model. Cell 2015, 160, 1061-1071. [CrossRef] [PubMed]

118. Yeh, F.L.; Wang, Y.; Tom, I.; Gonzalez, L.C.; Sheng, M. TREM2 Binds to Apolipoproteins, Including APOE and CLU/APOJ, and Thereby Facilitates Uptake of Amyloid-Beta by Microglia. Neuron 2016, 91, 328-340. [CrossRef] [PubMed]

119. Yuan, P.; Condello, C.; Keene, C.D.; Wang, Y.; Bird, T.D.; Paul, S.M.; Luo, W.; Colonna, M.; Baddeley, D.; Grutzendler, J. TREM2 Haplodeficiency in Mice and Humans Impairs the Microglia Barrier Function Leading to Decreased Amyloid Compaction and Severe Axonal Dystrophy. Neuron 2016, 90, 724-739. [CrossRef] [PubMed]

120. Jay, T.R.; Hirsch, A.M.; Broihier, M.L.; Miller, C.M.; Neilson, L.E.; Ransohoff, R.M.; Lamb, B.T.; Landreth, G.E. Disease Progression-Dependent Effects of TREM2 Deficiency in a Mouse Model of Alzheimer's Disease. J. Neurosci. 2017, 37, 637-647. [CrossRef] [PubMed]

121. Ulland, T.K.; Song, W.M.; Huang, S.C.-C.; Ulrich, J.D.; Sergushichev, A.; Beatty, W.L.; Loboda, A.A.; Zhou, Y.; Cairns, N.J.; Kambal, A.; et al. TREM2 Maintains Microglial Metabolic Fitness in Alzheimer's Disease. Cell 2017, 170, 649-663. [CrossRef] [PubMed]

122. Zhao, Y.; Wu, X.; Li, X.; Jiang, L.L.; Gui, X.; Liu, Y.; Sun, Y.; Zhu, B.; Pina-Crespo, J.C.; Zhang, M.; et al. TREM2 Is a Receptor for beta-Amyloid that Mediates Microglial Function. Neuron 2018, 97, 1023-1031. [CrossRef] [PubMed]

123. Hyman, B.T.; Holtzman, D.M. Apolipoprotein E levels and Alzheimer risk. Ann. Neurol. 2015, 77, $204-205$. [CrossRef] [PubMed]

124. Terwel, D.; Steffensen, K.R.; Verghese, P.B.; Kummer, M.P.; Gustafsson, J.-A.; Holtzman, D.M.; Heneka, M.T. Critical Role of Astroglial Apolipoprotein E and Liver X Receptor- $\alpha$ Expression for Microglial A $\beta$ Phagocytosis. J. Neurosci. 2011, 31, 7049-7059. [CrossRef] [PubMed]

125. Cammer, W. Oligodendrocyte-Associated Enzymes. In Oligodendroglia. Advances in Neurochemistry; William, N., Ed.; Springer: Boston, MA, USA, 1984; pp. 199-232. 
126. Xu, Q.; Li, Y.; Cyras, C.; Sanan, D.A.; Cordell, B. Isolation and characterization of apolipoproteins from murine microglia. Identification of a low density lipoprotein-like apolipoprotein J-rich but E-poor spherical particle. J. Biol. Chem. 2000, 275, 31770-31777. [CrossRef] [PubMed]

127. Cudaback, E.; Li, X.; Montine, K.S.; Montine, T.J.; Keene, C.D. Apolipoprotein E isoform-dependent microglia migration. FASEB J. 2011, 25, 2082-2091. [CrossRef] [PubMed]

128. Mandrekar-Colucci, S.; Karlo, J.C.; Landreth, G.E. Mechanisms underlying the rapid peroxisome proliferator-activated receptor- $\gamma$-mediated amyloid clearance and reversal of cognitive deficits in a murine model of Alzheimer's disease. J. Neurosci. 2012, 32, 10117-10128. [CrossRef] [PubMed]

129. Ayton, S.; Faux, N.G.; Bush, A.I. Alzheimer's Disease Neuroimaging Initiative, A.s.D.N. Ferritin levels in the cerebrospinal fluid predict Alzheimer's disease outcomes and are regulated by APOE. Nat. Commun. 2015, 6, 6760. [CrossRef] [PubMed]

130. Ali-Rahmani, F.; Schengrund, C.-L.; Connor, J.R. HFE gene variants, iron, and lipids: A novel connection in Alzheimer's disease. Front. Pharmacol. 2014, 5, 165. [CrossRef] [PubMed]

131. McLachlan, D.R.C.; Kruck, T.P.A.; Kalow, W.; Andrews, D.F.; Dalton, A.J.; Bell, M.Y.; Smith, W.L. Intramuscular desferrioxamine in patients with Alzheimer's disease. Lancet 1991, 337, 1304-1308. [CrossRef]

132. Palanimuthu, D.; Poon, R.; Sahni, S.; Anjum, R.; Hibbs, D.; Lin, H.Y.; Bernhardt, P.V.; Kalinowski, D.S.; Richardson, D.R. A novel class of thiosemicarbazones show multi-functional activity for the treatment of Alzheimer's disease. Eur. J. Med. Chem. 2017, 139, 612-632. [CrossRef] [PubMed]

(C) 2018 by the authors. Licensee MDPI, Basel, Switzerland. This article is an open access article distributed under the terms and conditions of the Creative Commons Attribution (CC BY) license (http:/ / creativecommons.org/licenses/by/4.0/). 


\title{
Neurodegeneration with Brain Iron Accumulation Disorders: Valuable Models Aimed at Understanding the Pathogenesis of Iron Deposition
}

\author{
Sonia Levi ${ }^{1,2, *}$ and Valeria Tiranti ${ }^{3}$ \\ 1 School of Medicine, University Vita-Salute San Raffaele, 20132 Milano, Italy \\ 2 San Raffaele Scientific Institute, Division of Neuroscience, 20132 Milano, Italy \\ 3 Fondazione IRCCS Istituto Neurologico Carlo Besta, 20126 Milano, Italy; Valeria.Tiranti@istituto-besta.it \\ * Correspondence: levi.sonia@hsr.it; Tel.: +39-0226434755
}

Received: 19 December 2018; Accepted: 29 January 2019; Published: 9 February 2019

\begin{abstract}
Neurodegeneration with brain iron accumulation (NBIA) is a set of neurodegenerative disorders, which includes very rare monogenetic diseases. They are heterogeneous in regard to the onset and the clinical symptoms, while the have in common a specific brain iron deposition in the region of the basal ganglia that can be visualized by radiological and histopathological examinations. Nowadays, 15 genes have been identified as causative for NBIA, of which only two code for iron-proteins, while all the other causative genes codify for proteins not involved in iron management. Thus, how iron participates to the pathogenetic mechanism of most NBIA remains unclear, essentially for the lack of experimental models that fully recapitulate the human phenotype. In this review we reported the recent data on new models of these disorders aimed at highlight the still scarce knowledge of the pathogenesis of iron deposition.
\end{abstract}

Keywords: iron; neurodegeneration; NBIA

\section{Introduction}

The acronym NBIA (neurodegeneration with brain iron accumulation) designates a clinically and genetically heterogeneous group of neurodegenerative diseases, the majority of which is hallmarked by iron deposits in the brain [1]. Iron accumulation, is detected in vivo by MRI analysis, and affects mainly the basal ganglia regions, such as globus pallidus (GP) and substantia nigra (SN), although other regions including the cortex and cerebellum can be involved. These disorders are inherited as Mendelian traits (autosomal recessive, dominant, or X-linked), and typical features are extra pyramidal symptoms, namely, dystonia, parkinsonism, spasticity, variably associated with neuropsychiatric abnormalities, and optic atrophy or retinal degeneration [1]. Disorders belonging to the NBIA group are rare, between one and three per million individuals in the general population, and 15 causative genes, whose products are involved in a wide spectrum of biological activities, have been so far discovered. Although the presence of brain iron accumulation enables the diseases to be included in the NBIA group, the pathogenic mechanisms linking specific disease-genes mutations to iron metabolism are unclear [2]. $C P$ (ceruloplasmin) and FTL1 (ferritin light chain) are directly associated to iron homeostasis (Table 1). The remaining genes (PANK2, COASY, PLA2G6, C19orf12, FA2H, ATP13A2, WDR45, DCAF17, SCP2, GTPBP2, AP4M1, REPS1, and CRAT) are unrelated to iron metabolism, being involved in diverse metabolic pathways (Table 1). 


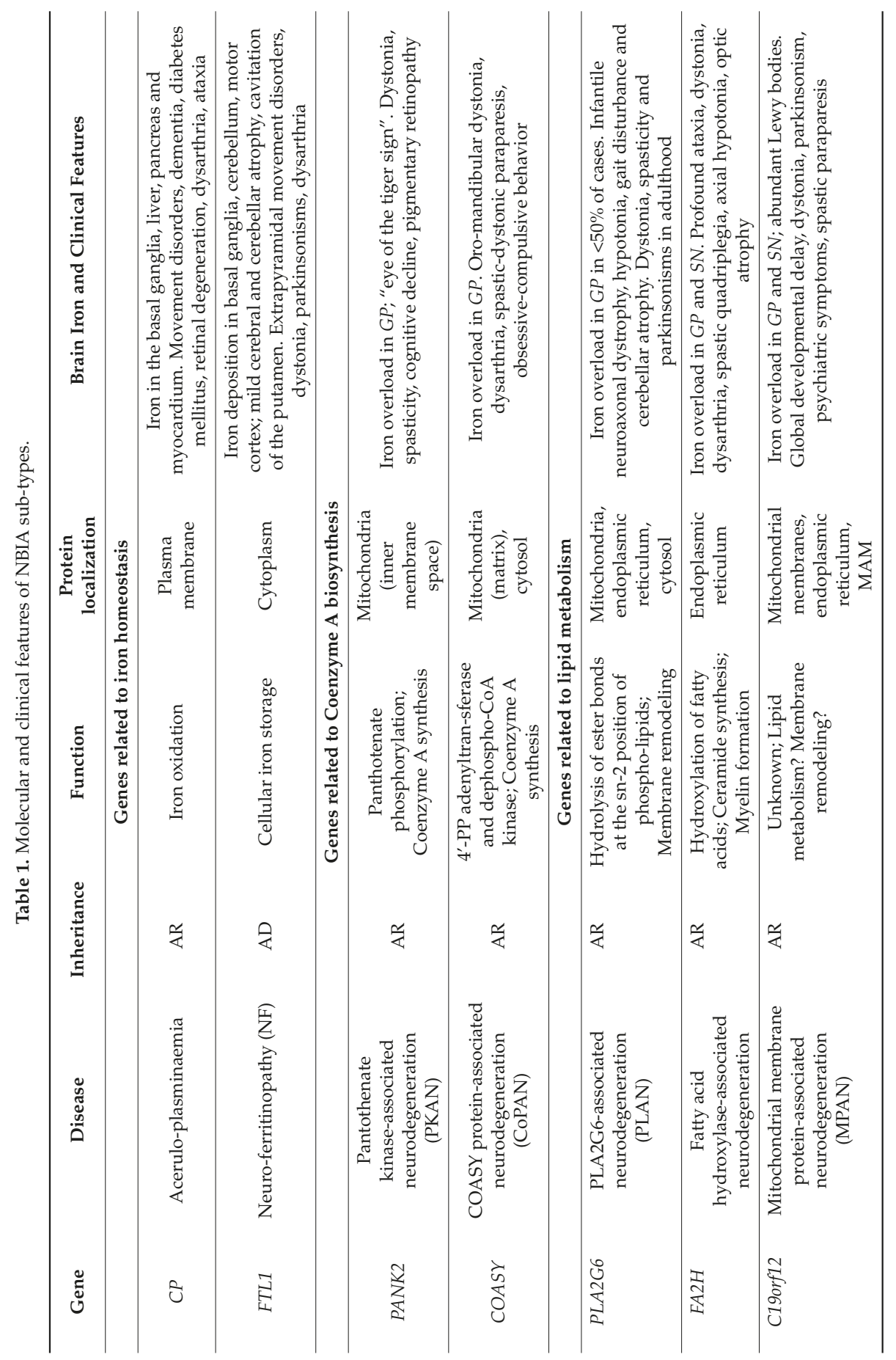




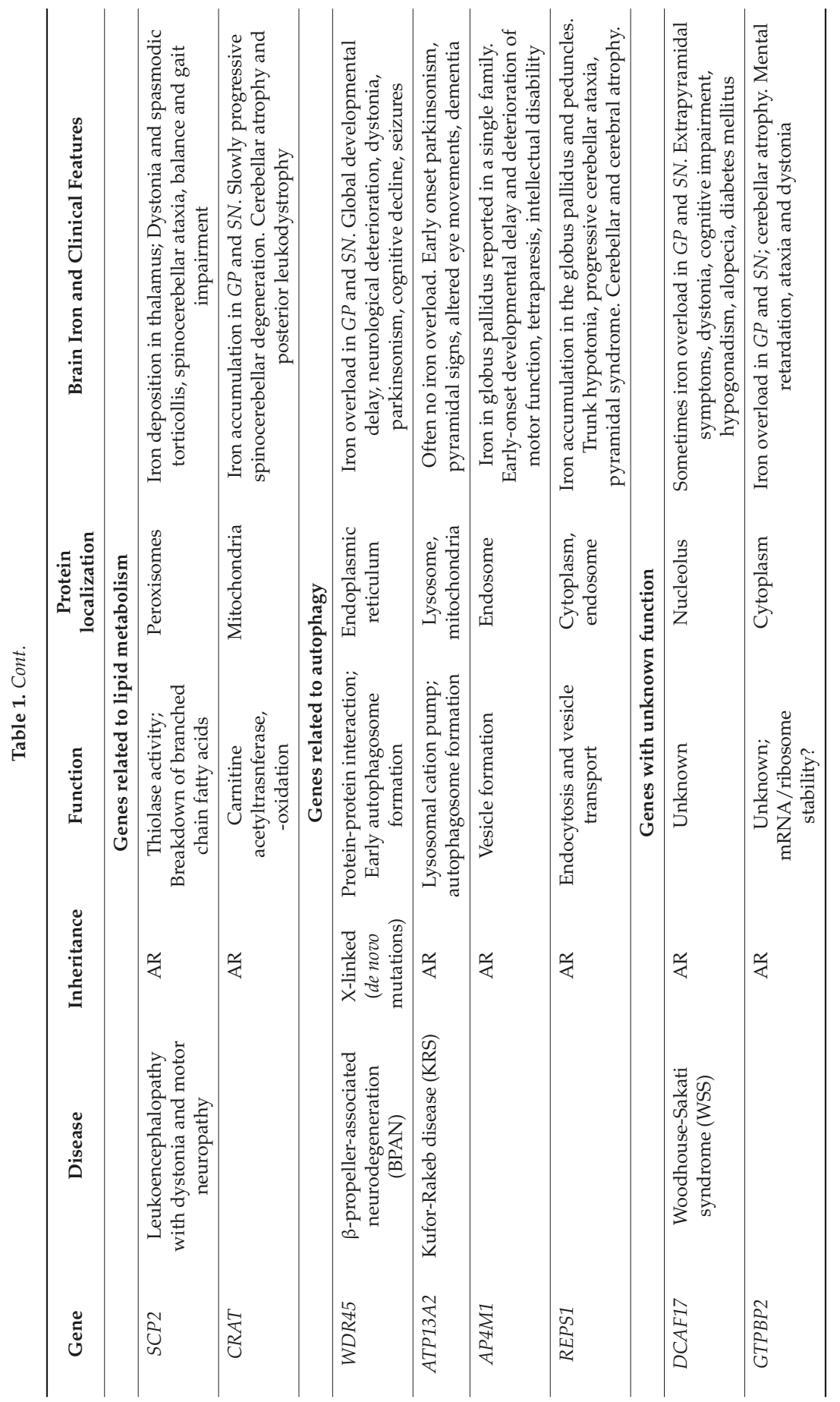


PANK2 (pantothenate kinase type 2) and COASY (CoA synthase) code for enzymes in the crucial biochemical pathway responsible for coenzyme A (CoA) production. PLA2G6 (phospholipase A2 group 6), FA2H (fatty acid hydroxylase 2), C19orf12, SCP2 (sterol carrier protein type 2) and CRAT (carnitine acetyltransferase) genes code for proteins involved in lipid metabolism, membrane integrity and mitochondrial function. WDR45, ATP13A2, and possibly AP4M1 are genes coding for factors involved in the autophagic process. The GTPBP2 gene product plays a putative role in chain elongation during protein synthesis at the ribosome, REPS1 (RALBP1-associated EPS domain-containing protein 1) is involved in endocytosis and vesicle transport, while the DCAF17 (also known as C2orf37) gene encodes for a protein with still not clarified cellular localization, probably in the nucleolus, and with undefined activity (Figure 1). Around one third of the NBIA causative genes namely PANK2, COASY, PLA2G6, C19orf12, and CRAT) are associated to mitochondria, suggesting that these organelles play a crucial role in triggering the disorders. Thus, these pathologies represent an unprecedented chance to investigate the molecular mechanisms involved in iron management in the brain and the connection with mitochondrial function and neurodegeneration. In this review, we will focus on what we have learned from available in vivo and in vitro models about iron metabolism and its connection with the different underlying genetic mutations of NBIA.

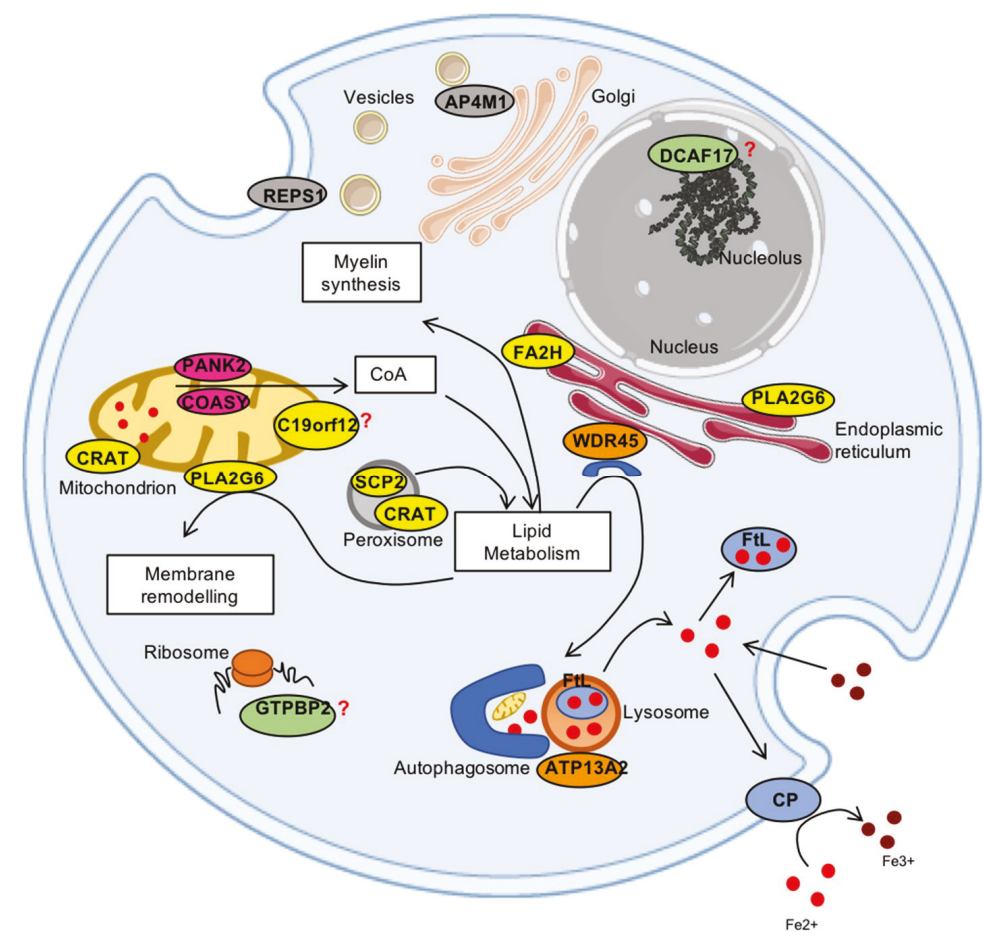

Figure 1. Scheme of the proteins associated to NBIA disorders and their cellular localization. The iron proteins (CP and FtL) are represented in light blue; in pink are the proteins (PANK2 and COASY) are involved in CoA synthesis; in yellow are the proteins related to lipid metabolism (PLA2G6, FA2H, SCP2, CRAT, C19orf12); in orange are the proteins (WDR45, ATP13A2) involved in autophagy; in grey are the proteins (RESP1 and AP4M1) associated to vesicle trafficking; and the proteins (DCAF17 and GTPBP2) in green still have unknown functions. 


\subsection{Iron Homeostasis in Diseases Caused by Mutations in Iron-Related Genes}

\subsubsection{CP (OMIM*117700)}

Aceruloplasminemia (OMIM \#604290) is the first disease in which the alteration of an iron-related protein has been linked to neurodegeneration. It is inherited as an autosomal recessive trait and was originally described in a female from Japan [3] where the prevalence of mutations is around one in $2,000,000$ individuals. The genetic analysis of patients affected by aceruloplasminemia revealed about 50 distinct causative mutations (listed in http:/ / www.hgmd.cf.ac.uk/ac/index.php) scattered along the gene and identified in more than 60 families [4,5]. CP gene is located on chromosome 3q21-24 and encodes ceruloplasmin (Cp), a plasma membrane glycoprotein with ferro-oxidase function containing many copper atoms, which facilitates ferroportin-mediated cellular iron export [6].

Onset of symptoms is in adulthood and the clinical features include neurological signs like blepharospasm, grimacing, facial and neck dystonia, tremors, chorea and ataxia, and cognitive dysfunction. Additional signs, generally preceding neurological symptoms are diabetes mellitus, retinal degeneration and microcytic anemia [5]. The disease is also hallmarked by alteration of hematological parameters such as: very low or undetectable serum ceruloplasmin, high levels of serum ferritin and low levels of iron [7]. Iron depositions affect the striatum, thalamus, and dentate nucleus as showed by abnormal low intensities on T1 and T2 weighted images obtained by MRI analysis [8]. Neuropathology investigations demonstrate aberrant basal ganglia and dentate nucleus, with consistent iron accumulation in neuronal and glial cells [9-12]. Characteristic neuropathological findings are enlarged or deformed astrocytes and spheroid-like globular structures caused by iron accumulation localized to terminal astrocytic processes [11]. Iron overload was also detected in the cerebral cortex, retina, and cerebellum, and in non-cerebral tissues, such as the pancreas and myocardium [12].

Mutations of $C P$ determine structural modifications of the protein $(\mathrm{Cp})$ which are responsible for retention of $\mathrm{Cp}$ in the $\mathrm{ER}$, miss-incorporation of copper atoms into apo-ceruloplasmin or defective ferro-oxidase activity [13-15]. Overall, this malfunctioning causes impairment of iron export from the cell, which in the end is responsible for iron overload.

Investigations of the pathogenetic mechanisms underlining aceruloplasminemia were performed by analyzing the effect of Cp mutants' expression in mammalian cell culture [13-15] and by characterizing various aceruloplasminaemia mouse models [16-18]. Overall these data indicated that, in the presence of an aberrant ceruloplasmin, iron entering the CNS as ferrous iron could not be oxidized. As a consequence, cells can internalize large quantities of ferrous iron through non-regulated internalization pathways of non-transferrin-bound iron [19]. Accumulation of iron inside astrocytes observed in the pathology is due not only to the excess of import, but also to the inability of the cells to export iron though ferroportin, in the absence of ceruloplasmin. In this way iron would remain "locked" in the astrocytes and could not reach the neurons, which would paradoxically die from iron deficiency and from toxic compounds released by degenerating astrocytes. Additionally, it has been proposed that some mutated $\mathrm{Cp}$ forms could also accumulate in aggregates leading to death of astrocytes through an iron-independent pathway [20].

The specific degeneration of astrocytes and neurons is explained by their strict dependence on ceruloplasmin ferro-oxidase activity. On the contrary, other cells in the CNS, including oligodendrocytes, depend on the action of hephaestin, a protein similar in structure and function to ceruloplasmin. In fact, only the simultaneous ablation of $C P$ and hephaestin $(H E P H)$ genes in mice is able to recapitulate symptoms consistent with those shown by aceruloplasminemia patients, suggesting that hephaestin can compensate the lack of CP in mice, but not in humans [21,22]. This double knock-out mouse model showed iron accumulation in gray and white matter oligodendrocytes [22], macular degeneration, iron overload, and increased oxidative stress in the retina [23]. Treatment of these mice orally with DFP showed to be protective against oxidative stress, retinal degeneration and accumulation of lipofuscin, and was able to reduce ataxia and increase life span [24]. Despite the good 
results obtained in mice, iron chelation therapy in patients was disappointing since it only partially reduced systemic iron deposition in liver and pancreas [25], but it was ineffective in reducing the brain iron accumulation and thus in controlling neurodegeneration [12,26].

Another proposed therapeutic approach is based on enzyme replacement therapy (ERT) with ceruloplasmin. Recently, it was demonstrated that the parental administration of human ceruloplasmin to $\mathrm{CP}$-/- mice was able to restore normal levels of the protein in the brain, as well as its ferro-oxidase activity [27]. Interestingly, in treated mice, the reduced brain iron deposition led to motor coordination improvement, suggesting ERT as a possible therapeutic option for aceruloplasminemia [27].

\subsubsection{FTL (OMIM*134790)}

Neuropherritinopathy (NF) is an extremely rare autosomal dominant disease described for the first time in 2001 [28] and linked to mutations of FTL1, the gene coding for L-ferritin subunit that, together with the $\mathrm{H}$-ferritin subunit, forms the major iron storage protein.

The most frequent mutation is the 460InsA (or c.460dupA) described in 41 cases [29] presenting with focal onset chorea or focal dystonia and history of movement disorders. Serum ferritin level was generally low. MRI was abnormal in all reported cases and showed lesions in the globus pallidus, putamen, and dentate nuclei. Few cases of NF presented with the "eye of the tiger" sign (typical of PKAN), a hypointense MRI signal, which is pathognomonic for iron accumulation, surrounding a central region of hyperintensity, which is due to gliosis and/or necrosis, in the anteriomedial globus pallidus on the $\mathrm{T} 2^{*}$ sequence [8]. A typical pathological feature found in astrocytes and oligodendroglia in the grey and white matter, was the presence of intranuclear and intracytoplasmic bodies containing ferritin and iron in insoluble form. The same bodies were also present in fibroblasts, tubular epithelium of the kidney, and endothelial cells of muscle capillaries. Neurons and glia also showed swollen or vacuolated nuclei containing iron and ferritin [30].

Biochemical studies performed by overexpression of mutants 460InsA and 498InsTC (or c.497_498dupTC) in human cells, demonstrated instability of mutant proteins, a different solubility and a lower capacity to incorporate iron as compared to wild-type ferritin [31-35]. These cellular models showed that the expression of these ferritin mutants not only increased cellular free iron pool, but also induced oxidative damage and the impairment of proteasome activity [33,34].

Brain iron accumulation and increased production of reactive oxygen species, are present in mouse models generated by transgene expression of FTL1 cDNAs coding for variants of the human ferritin protein. These mice showed features of neurological deterioration, decreased motor activity and coordination, reduced lifespan together with the presence of ferritin aggregates in the nucleus and cytoplasm [36-39].

Specifically, mice overexpressing the human mutant c.497_498dupTC recapitulate features typical of the human disease, including abnormalities of brain iron homeostasis [36,37]. Further investigation of post-natal hippocampal neurons in transgenic mice with a different genetic background, revealed high susceptibility to chronic iron overload and/or acute oxidative stress in comparison to wild-type neurons [37]. Moreover, ultrastructural analyses of specific brain regions such as cerebellum and striatum, showed an accumulation of lipofuscin granules associated with iron deposits, particularly evident in aged mice [37]. Altogether, these data indicate that the combination of increased oxidative stress and lipofuscin accumulation play a key role in the etiopathogenesis of human NF. The only data available on human naïve fibroblasts derived from a patient carrying the c.497_498dupTC, demonstrated a consistent increase of intracellular iron, altered iron management, ferritin accumulation and the presence of oxidative stress markers, as previously demonstrated in patients and transgenic mice [40].

From the overall data, the emerging hypothesis suggests that the decreased ability of ferritin to sequester iron excess has two major consequences: (i) the unbound metal precipitating on proteins promotes their aggregation [31]; (ii) the higher free iron-dependent oxidative damage required the need for the cell to increase degradation of oxidized molecules. Both these effects cause the engulfing 
of the cellular recycling systems (i.e., proteasome and lysosome), and in the long-term leads to cellular death. These events occur despite the regulation system of iron entry into the cell seeming to work properly [33]; in fact, the level of the main iron-importer protein, the transferrin receptor, appears strongly reduced in different experimental models [32-34]. Thus, apparently, iron may be efficiently internalized by transferrin/transferrin-receptor independent pathway in neuronal compartment. This pathogenetic mechanism seems to be harmful mainly in non-dividing cells, partly explaining the specificity of the symptomatology. Interestingly, since the rate of lipofuscin accumulation is known to correlate negatively with longevity, the NF pathogenesis may replicate the cascade of events that occur during the physiological process of aging.

The most simple and rational way to reduce iron accumulation is the utilization of iron-chelating compounds such as desferrioxamine (DFO) or deferiprone (DFP). These treatments were tested both in animal models and in patients, with comparable results. DFP treatment in mice was effective in reducing iron accumulation in the brain [41] and had significant effects on systemic iron homeostasis [42]. As already discussed for the aceruloplasminemia, also in this case the outcome of the treatment with iron chelators is not as effective in humans. Iron-chelating based therapies in NF patients had severe detrimental effects on systemic iron level causing iron depletion without improving clinical conditions $[29,43]$. This may be due to a lower penetrability of the iron chelator in the basal ganglia of human and/or to a late treatment in humans, which develop symptoms when the brain region has already degenerated.

\subsection{Iron Homeostasis in Inborn Errors of Coenzyme A Biosynthesis}

\section{PANK2 (OMIM*606157) and COASY (OMIM*609855)}

Mutations in genes coding for the first (PANK2) and the last (COASY) enzyme of the biosynthetic pathway that produces Coenzyme-A (CoA) cause NBIA subtypes known as pantothenate kinase-associated neurodegeneration (PKAN) and CoA synthase protein-associated neurodegeneration (CoPAN), respectively.

PKAN accounts for a large fraction of NBIA cases [44] while CoPAN appears more rare, being so far identified in few individuals worldwide [45-48]. These two disorders display an impressively similar phenotype, presenting with early-onset spastic-dystonic paraparesis with a later appearance of parkinsonian features, cognitive impairment, obsessive-compulsive disorder, and brain iron accumulation [45]. PKAN typically manifests in early childhood with gait disturbances and rapidly progresses to a severe movement deficit with dystonia, dysarthria and dysphagia [49]. The hallmark of PKAN is the "eye-of-the-tiger" signal in the globus pallidus on T2-weighted magnetic resonance imaging, which reflects the focal accumulation of iron in this area [50]. CoPAN also accumulates iron in GP. The $S N$ is as well affected in CoPAN and to a lesser extent in PKAN. The iron accumulation correlates with neural damage. It is often associated with axonal expansions (spheroids), but it also appears as a granular form in perivascular location [51]. Although iron accumulation hallmarks PKAN and CoPAN, its relationship with CoA dysfunctional biosynthesis is not clear.

Despite several efforts have been made during the last years to understand the connection between iron homeostasis and mutations in PANK2 or COASY, no models, either in vitro or in vivo, have been so far able to recapitulate the presence of iron deposits. Pank2 null mice showed growth reduction, azoospermia [52] and impaired mitochondrial function [53], but did not show signs of neurodegeneration or iron accumulation and did not display movement disorders. Only by increasing the fat content in the diet of these mice it was possible to unravel a neurodegenerative phenotype characterized by motor dysfunction, bioenergetic failure, and brain cytoplasmic accumulation of abnormal ubiquinated proteins [54], features observed in the brains of PKAN patients [51]. The simultaneous knockout of Pank1/Pank2 led to severe reduction of CoA levels in the brain but iron accumulation was not reported [55]. The combined ablation of Pank2/Pank3 or Pank1/Pank3 in mice is associated with a lethal phenotype [55]. Altogether, these experiments imply that, in mice, Pank2 
loss is counterbalanced by the other Pank genes, but the simultaneous elimination of Pank3 with either Pank2 or Pank1 is incompatible with life.

Drosophila possesses only one pantothenate kinase isoform (fumble) and its ablation determines brain vacuolization with defective neurological functions but without brain iron overload [56], resulting in flies with severe motor impairment [57]. The down-regulation of pank2 in Zebrafish induced defects in neuronal development and an aberrant organization of the vascular system [58].

PKAN patients' fibroblasts have been helpful to reveal some defects in mitochondrial activity and iron metabolism associated with PANK2 deficiency [59], however, the pathological neurodegenerative processes cannot be appreciated in these cells.

Insight on the neurodegenerative process started emerging thanks to the generation of iPSC-derived glutamatergic neurons from PKAN patients and from healthy subjects. Their compared analysis showed alteration of mitochondria functionality in PKAN patients. The altered phenotype included impairment of mitochondrial iron-dependent biosynthesis that caused iron dys-homeostasis and consequent enhanced ROS production, leading to major membrane excitability defects. In particular, the cells inability to maintain Fe/S biosynthesis simulated a cellular iron deficient phenotype that promoted cellular iron uptake increasing the translation of the TfR1 [60].

A second paper reported data on iPSCs derived cortical neuronal cells obtained from fibroblasts of an atypical PKAN patient [61], in which the PANK2 protein was not completely absent but reduced as compared to control cells. In this case, CoA homeostasis and cellular iron handling were normal, but mitochondrial functionality resulted affected, with increased production of reactive oxygen species and lipid peroxidation [61].

Neither glutamatergic nor cortical neurons displayed iron deposits and iron chelation in cortical neurons exacerbated the mitochondrial phenotype in both control and patient neuronal cells [61]. Thus, both these investigations on human neurons agree to conclude that mitochondrial impairment is an early feature of the disease process and the consequent ROS formation a main actor in the pathogenesis, while iron chelation treatment did not seem a good option. Data on efficacy and safety of deferiprone for the treatment of PKAN were available through clinical trials on small cohorts of patients and showed controversial results [50,62].

Data on the efficacy of DFP treatment collected in a wide clinical trial involving around 100 PKAN patients in the world are still under analysis and will be available shortly (https:/ / tircon.eu). While DFP efficacy is still under investigation, the work performed in vitro on glutamatergic neurons demonstrated that CoA supplementation prevented neuronal death and reduced ROS formation by restoring mitochondrial and neuronal functionality, suggesting CoA treatment as a possible therapeutic intervention [60].

Very recently, an allosteric PANK activator has been identified by compounds library screening. The compound denominated PZ-2891 crosses the blood brain barrier and oral administration to wild-type mice increases coenzyme A levels in the brain and liver. Moreover, PZ-2891 treatment of a knockout mouse model of brain CoA deficiency presenting with weight loss, severe locomotor impairment and early death, was able to rescue the weight, to improve locomotor activity and to extend life span [63].

Analysis of fibroblasts derived from CoPAN patients, showed impaired, but not completely abolished, de-novo synthesis of CoA and dephospho-CoA. This would suggest the presence of alternative routes for CoA production, or the preservation of a residual catalytic activity of the mutant CoA synthase protein [45]. More recently, mutations of COASY associated with the complete absence of the protein were reported in two cases of pontocerebellar hypoplasia, microcephaly, and arthrogryposis [48] with an invariable lethal phenotype, probably due to the complete absence of CoA.

In the yeast Saccaromices cerevisiae, CoA synthesis is carried out by five sequential enzymes (CAB1 to CAB5) deletion of which, leads to a lethal phenotype. Re-expression of wild-type yeast CAB5 or human COASY protein was able to rescue the lethal phenotype while mutant CAB5 or 
COASY expression determined a phenotype characterized by reduced growth, auxotrophy for panthotenate, and decreased amount of CoA in isolated mitochondria [45]. Additional features included mitochondrial dysfunctions characterized by impairment of the respiratory chain and revealed iron accumulation and impaired lipid content [64].

In zebrafish the complete down-regulation of Coasy, obtained by morpholino-mediated approach, was associated with impaired development and premature death, while a partial down-regulation gave rise to a milder phenotype [65]. Main phenotypic features of morphants included: reduced size of the brain with less defined brain structures, disorganization of the vascular system in the brain and trunk, and reduced levels of CoA in the fish embryos. Rescue of these features was obtained by adding CoA to the fish water or by re-expression of the human wild-type gene, indicating a causative role of impaired CoA synthesis in determining the pathological phenotypes.

Hence, the connection between COASY dysfunction and iron metabolism needs to be clarified although a potential link was highlighted by the identification of an iron responsive element (IRE) in the $3^{\prime}$ region of this gene that could stabilize the COASY mRNA in the presence of iron [2].

Mutations in PPCS encoding for the second enzyme in the CoA biosynthetic pathway converting 4 '-Phosphopantothenate into phosphopantothenoylcysteine, have been described in two unrelated families showing a very severe pediatric phenotype characterized by dilated cardiomyopathy associated with reduced level of CoA [66]. In the affected individuals neurodegeneration and iron accumulation were not investigated or not present because of a premature death of some patients. At the moment, it is not clear why PPCS mutations lead to cardiac alteration instead of neurodegeneration and further investigation will be required. We have decided to mention this gene for the sake of completeness despite that PPCS cannot be included in the NBIA disease genes, at least from the knowledge available at the time of writing.

\subsection{Iron Homeostasis and Mutations in Lipid Metabolism Related Genes}

Globally these sub-types of NBIA disorders typically begin in childhood with a combination of clinical signs, which are also present in spastic paraplegia complex forms and in several cases the genetic cause of the disease is shared by the two category of diseases. The accumulation of iron is not a consistent finding and is often documented in advanced disease stages suggesting that it could contribute to disease progression but is not the primary cause [67].

\subsubsection{PLA2G6 (OMIM*603604)}

PLA2G6-associated neurodegeneration (PLAN) is an autosomal recessive heterogeneous group of related neurodegenerative conditions comprising infantile neuroaxonal dystrophy (INAD, OMIM \#256600) and atypical neuroaxonal dystrophy (ANAD, OMIM \#610217) caused by mutations in PLA2G6, mapping on human chromosome 22q13.1 and encoding for calcium-independent phospholipase A2 group VI (iPLA2 $\beta$ or iPLA2VI) [68].

Onset of disease is typically in childhood and presents as neuroaxonal dystrophy with psychomotor regression and axial hypotonia, accompanied by neuropathy with spheroidal bodies in the peripheral nerves, detectable by analysis of sural nerve biopsy. Cerebellar atrophy is detected in the majority of the cases by brain MRI while iron accumulation is present in only half of the affected individuals. PLA2G6 protein is ubiquitously expressed and is localized in the cytosol and mitochondria, playing a role in phospholipids metabolism and membrane remodelling. Malfunctioning of the protein may lead to alteration of neuronal membranes integrity and fluidity [69] determining neuronal suffering.

A Pla2g6 knock-out mouse model recapitulate in a precise way the human disease and showed cerebellar atrophy, loss of Purkinje cells, pronounced neuroinflammation, age-dependent accumulation of spheroids but not iron accumulation, which is not, however, a consistent finding neither in the affected patients [69]. 
This mouse model was also characterized by the presence of ultrastructural alteration of mitochondria in the brain with a consistent accumulation of cardiolipin, a phospholipid formed from two phosphatidic groups connected by a glycerol molecule [70], which is highly enriched in the mitochondrial inner membrane. In fact, first pathological signs in neurons of Pla2g6-null mice is the disorganization of the cristae in the mitochondrial inner membrane with the consequent destruction of the mitochondrion, the release of cytochrome $\mathrm{c}$, and the formation of swollen and degenerated axons as the disease progresses. Presynaptic membranes are altered in this animal model, demonstrating the role of PLA2G6 may be to remodel cardiolipin and eliminate fatty acids damaged by oxidative stress [71]. Recently, an age-dependent iron accumulation in SN, ST, and GP brain regions was reported on Pla $2 g 6$ -/- mice. These mice showed an increased level of iron-proteins (TfR1, DMT1 and IRPs), decreased FPN1, enhanced lipid peroxidation and mitochondrial dysfunction. These alterations precede the sign of neuronal death, suggesting that iron-dependent ROS formation might be a primary cause of neurodegeneration [71].

The similarity between PKAN and PLAN phenotypes can be traced back to the fact that PANK2 and PLA2G6 enzymes would take part to cardiolipin synthesis or remodelling in the inner mitochondrial membrane [72].

\subsection{2. $F A 2 H\left(\mathrm{OMIM}^{*} 611026\right)$}

Fatty acid hydroxylase-associated neurodegeneration (FAHN) (OMIM \#612319) was first described in two consanguineous families, of Italian and Albanian origin respectively and is a sub-type of neurodegeneration with brain iron accumulation transmitted as an autosomal recessive trait [73]. The gene responsible for the disorder is the fatty acid hydroxylase-2 $(F A 2 H)$, that maps on human chromosome 16q23.1 and codes for a NADPH-dependent mono-oxygenase localized on ER membranes [73,74]. The same gene is also mutated in cases of leukodystrophy and a form of spastic paraplegia [75]. Main clinical features of the disease are spasticity, ataxia, dystonia, optic atrophy, and oculomotor abnormalities followed by cognitive disorders and epilepsy. Magnetic resonance studies in patients have shown iron overload in the globus pallidus, substantia nigra, and subcortical and periventricular regions [76], as well as abnormalities of the white matter distribution, cerebellar atrophy, and thinning of the corpus callosum.

FA2H enzymatic activity is responsible for the hydroxylation of fatty acids, which are incorporated in the sphingolipids and its impairment causes myelination defects with the consequent impairment of the axonal function [77]. Mice lacking the Fa2h gene, either constitutively or limited to the glia cells, showed degeneration and loss of myelin sheath in the spinal cord and in sciatic nerves [77,78].

Finally, in the N-terminus of FA2H is present a cytochrome b5-like heme binding domain and a fatty acid hydroxylase domain with an active site for the binding of non-heme di-iron. The presence of these domains has been suggested to allow a direct interaction with iron-containing moieties, thus indicating a possible link between gene function and iron accumulation [73], although this hypothesis is not supported by experimental evidences. A recent in silico protein modelling report demonstrated that the FAHN causative missense mutations alter the heme-binding site or disrupt the hydroxylase domain impairing the enzyme catalytic activity. However, the mechanism by which reduced FA2H activity generates the iron deposition was not investigated [79].

\subsubsection{C19orf12 (OMIM*614297)}

Mutations in C19orf12 cause a rare form of NBIA, transmitted as an autosomal recessive trait, denominated mitochondrial membrane protein-associated neurodegeneration (MPAN) (OMIM \#624298). C19orf12 maps on human chromosome 19 and encodes for a mitochondrial protein associated with the membranes and with a putative role in lipid metabolism [80,81].

Mutations in C19orf12 cause other neurodegenerative disorders such as: pallido-pyramidal syndrome [82], hereditary spastic paraplegia phenotype 43 (SPG43) [83] and ALS [84]. The main clinical features of MPAN include: progressive spastic para/tetraparesis, dystonia, motor axonal 
neuropathy, parkinsonisms, psychiatric symptoms, retinal abnormalities, and optic atrophy $[80,85,86]$. Iron accumulation is present in the globus pallidus and substantia nigra, as highlighted by MRI analysis, showing T2-weighted hypo-intensity [87]. Neuropathological analysis of patients' brains demonstrated the presence of axonal spheroids, Lewy bodies, axonal swellings, and hyperphosphorylated tau in the cortex, GP, caudate/putamen, $S N$, and brain stem.

In silico evaluation of the C19orf12 protein indicated that it contains a transmembrane glycine zipper. The protein has two isoforms deriving from different start codons: the longer isoform has multiple sub-cellular localization: it is present into mitochondria, endoplasmic reticulum [88], and a small fraction in the MAM, contact regions between mitochondria and ER functionally-relevant for phospholipids metabolism [88]. The protein has high levels of expression in the brain, blood cells and adipocytes, while transcriptome analysis indicated aco-regulation with genes involved in lipid metabolism with a possible connection with CoA synthesis [80]. The function of the protein is still not clarified and the simultaneous knock-down of two C19orf12 orthologs CG3740 and CG11671 in Drosophila, demonstrated a defect in climbing activity, bang sensitivity, and the presence of vacuoles in the brain and optical lobe but the absence of iron accumulation [89].

\subsubsection{SCP2 (OMIM*184755) and CRAT (OMIM*600184)}

Mutations in the sterol carrier protein-2 (SCP2) gene (OMIM \#613724) cause a complex phenotype characterized by leukencephalopathy, dystonia, torticollis, azoospermia, cerebellar ataxia, and gait impairment [90,91]. Brain MRI analysis showed bilateral hyperintense signals in the thalamus, indicating iron overload, butterfly-like lesions in the pons, and lesions in the occipital region. The SCP2 gene is located on chromosome 1p32.3 and exons 1-16 encode for the sterol carrier protein X (SCPx), while exons 12-16 encode the sterol carrier protein 2 (SCP2) [92]. Both enzymes have thiolase activity required for the breakdown of branched chain fatty acids and are located into peroxisomes. The pathogenic effects are probably due to elevated levels of branched chain fatty acids in patients with SCP2 mutations [93]. Abnormal fatty-acid acyl-CoA metabolism is again suggested as the culprit for a disease belonging to the big group of NBIA, highlighting the role of lipids as a common pathogenic mechanism for this category of disorders.

Mutations in CRAT, coding fora protein involved in the transfer of acyl groups from carnitine to coenzyme A and in the transport of fatty acids for beta-oxidation have been recently identified in one subject with an NBIA phenotype [94]. Intensive investigations of fibroblasts derived from patients with CRAT and REPS1 [92] mutations as well as fibroblasts derived from patients with PANK2, PLA2G6, C19orf12, and FA2H mutations, led to the identification of a common pathogenic mechanism shared by the different diseases. Iron overload was found to be due to abnormalities in transferrin receptor (TFR1) recycling and reduction of its palmitoylation [94]. This is the first time that a common pathogenic mechanism has been, not only hypothesized, but also experimentally demonstrated. Interestingly enough, it was also showed that the antimalarian drug artesunate, was able to increase TfR1 palmitoylation and decrease ferritin levels in fibroblasts of different NBIA subgroups [94].

This potential therapeutic treatment of NBIA should be seriously taken into consideration and could also be relevant for other more common neurodegenerative disorders, such as Parkinson's or Alzheimer's, in which iron overload is a common finding.

\subsection{Iron Homeostasis and Autophagosome/Lysosome Regulation}

Three genes, whose mutations cause neurodegeneration with brain iron accumulation related to malfunctioning of the autophagosome and or lysosome activity, will be described in this chapter and include: WDR45, ATP13A2, and possibly AP4M1.

\subsubsection{WDR45 (OMIM*300526)}

Mutations in the WD repeat domain 45 (WDR45) gene are responsible for $\beta$-propeller-associated neurodegeneration (BPAN) (OMIM \#300894), a very peculiar disorder mapping on $\mathrm{X}$ chromosome, 
in which the deleterious mutations are invariable de novo. Patients of both gender display similar symptoms characterized since male patients were shown to have somatic or germline mosaicism [95]. Onset of the disease is in childhood but remains somehow silent until adulthood when neurological deterioration manifests as dystonia, parkinsonism, cognitive decline, and seizures. Iron overload in GP and SN was revealed by MRI that also showed, on T1 sequence, a dark central band surrounded by a halo of hyperintense signal in $S N$ and cerebral peduncles.

WDR45 belongs to the WD40 scaffold-protein family involved in protein-protein interactions. It is the human ortholog of the yeast $\operatorname{atg} 18$, which has been demonstrated to be crucial for the formation of the autophagosome. In fact, the phosphotidylinositide-3-phosphate binding motif present in atg18 determines its binding to the ER membrane, allowing the formation of protein complex [96]. A possible link between WDR45 autophagosome and mitochondria has been suggested by the evidence that proteins coded by atg genes are found transiently associated to the outer membranes of mitochondria [97].

Recently, it was reported that a brain-specific Wdr45 knock-out mouse model showed learning and memory defect, axonal swelling, and impaired autophagic flux. The hippocampus and caudate nucleus revealed the presence of aggregates, which stained positive for ubiquitin, but the presence of high levels of iron was not observed [98]. Finally, Ingrassia et al. [99] demonstrated in fibroblasts of two BPAN individuals under conditions of nutrient deprivation, up-regulation of the divalent metal transporter 1 (DMT1), which is essential for uptake of iron in the cells, and the simultaneous down-regulation of the Transferrin receptor (TfR1) causing accumulation of ferrous iron within the cells. TfR1 down-regulation is in line with what observed in other NBIA derived fibroblasts [94] and could again represent a common pathogenic mechanism unifying several different forms of the disease. It is possible that the presence of altered autophagy process, as observed in fibroblasts carrying WDR45 mutations, could affect the removal of proteins such as DMT1, determining iron overload [99].

\subsubsection{ATP13A2 (OMIM*610513)}

Kufor-Rakeb syndrome (KRS), an extremely rare autosomal recessive disorder characterized by early onset parkinsonism, pyramidal signs, dementia, and eye movements alteration, belongs to the NBIA group since some patients show iron accumulation in basal ganglia at MRI analysis [100]. Mutations in ATP13A2, located on chromosome 1p36.13 and encoding for a P-type ATPase, are causative of this disorders but have also been reported in different neurodegenerative diseases, such as juvenile onset parkinsonism and dementia (PARK9), and Ceroid-Lipofuscinosis [101]. This protein works mainly in the lysosome membranes as a cation pump, although modulation of its expression results in a variety of effects ranging from reduced intracellular calcium levels in cortical neurons to mitochondrial fragmentation [102]. Patients' fibroblasts showed increased fragmentation of mitochondrial network, disrupted mitochondrial DNA integrity, increased ROS production, reduced ATP production [103]. ATP13A2 deficiency leads to lysosomal dysfunctions, which could ultimately cause impaired degradation of substrates and damage of autophagosome clearance [104]. Alteration of autophagy, cell death, and accumulation of -synuclein occur after down-regulation of ATP13A2 in dopaminergic neurons and primary cortical neurons derived from mice [105].

Ablation of Atp13a2 gene in mice causes lipofuscin and $\alpha$-synuclein accumulation, gliosis, increased level of ubiquitinated proteins, endolysosomal abnormalities, and deficiency of sensory and motor coordination probably due to dopaminergic pathology [106,107].

The only experimental evidence, demonstrating a direct role of this P-type ATPase in iron intracellular handling, was reported by Rajagopalan et al. [108]. The authors identified ATP13A2 as a gene target of HIF1 and, therefore, it is subjected to the iron-dependent regulation of the PHD2-HIF1 signaling pathway [108]. This study suggests that the perturbation of lysosomes and acidic endosomes functions, which are important for iron homeostasis, may promote iron accumulation observed in the brains of KRS patients. 


\subsubsection{AP4M1 (OMIM*602296) and REPS1 (OMIM*614825)}

Iron accumulation in the globus pallidus has been recently reported in three patients from a large consanguineous Moroccan family affected by early-onset developmental delay and deterioration of motor function, tetraparesis and intellectual disability. WES analysis of the affected members revealed mutations in a gene denominated AP4M1 [109]. Mutations in this gene have been previously described in cases with severe congenital microcephaly [110], and in an autosomal-recessive type of tetraplegic cerebral palsy with mental retardation, reduction of cerebral white matter, and atrophy of the cerebellum [111]. The clinical and neuroradiological features of the Moroccan family are not only very different from the previously reported cases, but represent the first time in which iron accumulation is documented in association with AP4M1 mutations.

AP4M1 encodes for the mu subunit of the heterotetrameric adaptor protein complex-4 (AP-4), which is ubiquitously expressed in the CNS and involved in vesicle formation, post-Golgi protein trafficking, and sorting processes. AP-4 dysfunction might impair endosomal formation and affect autophagic process, which has already been demonstrated to play a pathogenic role in other NBIA forms related to ATP13A2 and WDR45 mutations.

Mutations in REPS1 were identified by exome sequencing in two sisters, of unrelated healthy parents, presenting with typical clinical features of NBIA and iron overload in the globus pallidi and peduncles revealed by $\mathrm{T}^{*}$ evidence. MRI also showed progressive cerebellar and cerebral atrophy. REPS1 codes for a protein involved in endocytosis and vesicle transport [94]. As previously discussed for the CRAT gene [92], a defective TfR1 palmitoylation is present in fibroblasts derived from REPS1 mutant patients, and artesunate treatment is able to increase TfR1 palmitoylation and decrease steady-state ferritin levels, which could be considered as indirect evidence of total iron content reduction [92].

\subsection{Iron Homeostasis in Disease Genes with Unknown Functions}

\subsubsection{DCAF17 (OMIM*612515)}

Woodhouse-Sakati syndrome (WSS) (OMIM \#241080) is a rare disease transmitted as autososmal recessive trait and characterized by a combination of movement and metabolic impairment. Iron overload is present in the GP and $S N$ in a fraction of affected patients [112]. The disorder is caused by mutations in DCAF17 (C2orf37) gene, located on chromosome 2q31.1 and encoding for a protein located in the nucleolus. DCAF17 is the acronym for DDB1 and CUL4-associated factor 17 and the gene belongs to the $D C A F$ gene family, which encode receptor proteins for specific ubiquitin ligases involved in DNA damage and cell cycle control [113], but the exact role of the DCAF17 protein remains to be defined.

Dcaf17 constitutive knockout mice showed male infertility due to abnormal sperm development [114]. An additional mouse model generated by CRISPR/Cas9 approach determining loss of function mutation in exon 2 of Dcaf17, showed also female subfertility in addition to male infertility [115]. This phenotype recapitulates hypogonadism and infertility, which are consistent findings in patients carrying DCAF17 mutations [112] and indicates that this gene plays a role in mammalian gonadal development. It is however, not clear why loss of function mutations of DCAF17 lead to the complex clinical presentation of affected patients and why knock-out mice only develop infertility and no other signs typical of the human disorder.

\subsubsection{GTPBP2 (OMIM*607434)}

Mutations in this gene have been reported for the first time in four subjects presenting with mental retardation, ataxia and dystonic features. Cerebellar atrophy and hypointensity in the GP and SN suggestive of iron overload were detected by MRI [116]. More recently, biallelic inactivating variants in the same gene have been reported in three unrelated families with a neurological phenotype different from the previously published family and displaying agenesia of the corpus callosum without signs 
of iron accumulation [117]. The GTPBP2 is located on human chromosome 6.p21.1 and encodes for a GTP-binding protein, which could play a role as regulator and adaptor of the exosome-mediated mRNA turnover pathway [118].

In mice, a homozygous GTPBP2 mutation interfering with the normal splicing process, determined a neurodegenerative phenotype characterized by apoptosis of neurons accompanied by locomotor dysfunctions, and degeneration of the retinal neurons [119]. These features are evident only in a mouse strain harboring an additional mutation in a gene, expressed in the brain and encoding tRNAArg $\mathrm{UCU}_{\text {, }}$ indicating that GTPBP-2 may play a role in mRNA surveillance and ribosome-associated quality control. A recent study aimed at understanding the role of GTPBP1 and GTPBP2, demonstrates that although GTPBP2's function involves interaction with aa-tRNA, it deos not stimulate exosomal degradation and have a different function as compared to GTPBP1 [120].

\section{Conclusions}

Iron overload in the brain is a distinct finding in rare neurodegenerative disorders classified as NBIA, but is also observed in common neurodegenerative disorders, including Parkinson's, Alzheimer's, and ALS. Two NBIA gene products play a direct role in iron homeostasis, but whether other NBIA-related gene products also control iron metabolism in the human brain, and whether high levels of iron contribute to the progression of neurodegeneration is still a matter of investigation. An interesting study based on a systems biology approach aimed at clarifying the pathogenic mechanisms of these disorders and identifying the network connecting known NBIA transcripts with specific partners. This analysis indicated that multiple cell types contribute to the clinically heterogeneous group of NBIA disorders, revealed strong links with iron metabolism and demonstrated the presence of common pathways shared by NBIAs and overlapping neurodegenerative disorders [121].

More recently, interesting unifying mechanisms relating altered iron metabolism to the different NBIA sub-types start to be experimentally proved. The impairment of transferrin receptor palmitoylation and recycling was demonstrated to be common to fibroblasts derived from patients carrying mutations in PANK2, PLA2G6, C19orf12, FA2H, and in two recently identified disease genes CRAT and REPS1 [94]. An altered recycling of transferrin receptor was also independently demonstrated in WDR45 mutant fibroblasts [99]. Additional investigations revealed that iron accumulation might be also related to dysfunctions of neural cells caused by alterations of mitochondrial activities, lipid metabolism, membrane remodeling, and autophagy [122]. Alteration of the structure of mitochondrial cristae is a common feature in NBIA sub-types [60,71] and can cause energy deficiency determined by defective assembly of respiratory chain super complexes $[53,64]$.

Mitochondria and their interaction with the endoplasmic reticulum play a crucial role in lipid metabolism and in the formation of autophagosomes. Finally, mitochondria are crucial organelles for the regulation of iron metabolism in other neurodegenerative disorders, such as Parkinson's and Alzheimer's, but also Friedreich ataxia and X-linked sideroblastic anaemia and ataxia [72].

During the last years the research in this field have massively contributed to the clarification of the pathogenic mechanisms, which are now emerging specially for the most frequent causes of NBIA. Nevertheless, the intricate connection between all the different players acting in NBIA remains to be clarified, paving the way to the identification of tailored approaches to therapy.

Funding: The financial support from Telethon-Italy (grant GGP16234 to S.L. and V.T.) and from Mariani Foundation (to VT) of Milan is gratefully acknowledged.

Acknowledgments: The authors are grateful to Chiara Paolizzi for assisting with the figure preparation.

Conflicts of Interest: The authors declare no conflict of interest. 


\section{References}

1. Gregory, A.; Hayflick, S. Neurodegeneration with Brain Iron Accumulation Disorders Overview; Adam, M.P., Ardinger, H.H., Pagon, R.A., Wallace, S.E., Bean, L.J.H., Stephens, K., Amemiya, A., Eds.; University of Washington: Seattle, WA, USA, 2013.

2. Arber, C.E.; Li, A.; Houlden, H.; Wray, S. Review: Insights into molecular mechanisms of disease in neurodegeneration with brain iron accumulation: Unifying theories. Neuropathol. Appl. Neurobiol. 2016, 42, 220-241. [CrossRef] [PubMed]

3. Miyajima, H.; Nishimura, Y.; Mizoguchi, K.; Sakamoto, M.; Shimizu, T.; Honda, N. Familial apoceruloplasmin deficiency associated with blepharospasm and retinal degeneration. Neurology 1987, 37, 761-767. [CrossRef] [PubMed]

4. Kono, S. Aceruloplasminemia: An update. Int. Rev. Neurobiol. 2013, 110, 125-151. [PubMed]

5. Miyajima, H. Aceruloplasminemia. Neuropathology 2015, 35, 83-90. [CrossRef] [PubMed]

6. Patel, B.N.; Dunn, R.J.; Jeong, S.Y.; Zhu, Q.; Julien, J.-P.; David, S. Ceruloplasmin regulates iron levels in the CNS and prevents free radical injury. J. Neurosci. 2002, 22, 6578-6586. [CrossRef] [PubMed]

7. Ogimoto, M.; Anzai, K.; Takenoshita, H.; Kogawa, K.; Akehi, Y.; Yoshida, R.; Nakano, M.; Yoshida, K.; Ono, J. Criteria for early identification of aceruloplasminemia. Intern. Med. 2011, 50, 1415-1418. [CrossRef] [PubMed]

8. McNeill, A.; Birchall, D.; Hayflick, S.J.; Gregory, A.; Schenk, J.F.; Zimmerman, E.A.; Shang, H.; Miyajima, H.; Chinnery, P.F.A. T2* and FSE MRI distinguishes four subtypes of neurodegeneration with brain iron accumulation. Neurology 2008, 70, 1614-1619. [CrossRef] [PubMed]

9. Yoshida, T.; Tanaka, M.; Sotomatsu, A.; Hirai, S. Activated microglia cause superoxide-mediated release of iron from ferritin. Neurosci. Lett. 1995, 190, 21-24. [CrossRef]

10. Morita, H.; Ikeda, S.; Yamamoto, K.; Morita, S.; Yoshida, K.; Nomoto, S.; Kato, M.; Yanagisawa, N. Hereditary ceruloplasmin deficiency with hemosiderosis: A clinicopathological study of a Japanese family. Ann. Neurol. 1995, 37, 646-656. [CrossRef] [PubMed]

11. Gonzalez-Cuyar, L.F.; Perry, G.; Miyajima, H.; Atwood, C.S.; Riveros-Angel, M.; Lyons, P.F.; Siedlak, S.L.; Smith, M.A.; Castellani, R.J. Redox active iron accumulation in aceruloplasminemia. Neuropathology 2008, 28, 466-471. [CrossRef] [PubMed]

12. Kaneko, K.; Hineno, A.; Yoshida, K.; Ohara, S.; Morita, H.; Ikeda, S. Extensive brain pathology in a patient with aceruloplasminemia with a prolonged duration of illness. Hum. Pathol. 2012, 43, 451-456. [CrossRef] [PubMed]

13. Di Patti, M.C.B.; Maio, N.; Rizzo, G.; De Francesco, G.; Persichini, T.; Colasanti, M.; Polticelli, F.; Musci, G. Dominant mutants of ceruloplasmin impair the copper loading machinery in aceruloplasminemia. J. Biol. Chem. 2009, 284, 4545-4554. [CrossRef] [PubMed]

14. Hellman, N.E.; Kono, S.; Mancini, G.M.; Hoogeboom, A.J.; de Jong, G.J.; Gitlin, J.D. Mechanisms of copper incorporation into human ceruloplasmin. J. Biol. Chem. 2002, 277, 46632-46638. [CrossRef] [PubMed]

15. Kono, S.; Suzuki, H.; Oda, T.; Shirakawa, K.; Takahashi, Y.; Kitagawa, M.; Miyajima, H. Cys-881 is essential for the trafficking and secretion of truncated mutant ceruloplasmin in aceruloplasminemia. J. Hepatol. 2007, 47, 844-850. [CrossRef] [PubMed]

16. Harris, Z.L.; Durley, A.P.; Man, T.K.; Gitlin, J.D. Targeted gene disruption reveals an essential role for ceruloplasmin in cellular iron efflux. Proc. Natl. Acad. Sci. USA 1999, 96, 10812-10817. [CrossRef] [PubMed]

17. Yamamoto, K.; Yoshida, K.; Miyagoe, Y.; Ishikawa, A.; Hanaoka, K.; Nomoto, S.; Kaneko, K.; Ikeda, S.; Takeda, S. Quantitative evaluation of expression of iron-metabolism genes in ceruloplasmin-deficient mice. Biochim. Biophys. Acta 2002, 1588, 195-202. [CrossRef]

18. Texel, S.J.; Camandola, S.; Ladenheim, B.; Rothman, S.M.; Mughal, M.R.; Unger, E.L.; Cadet, J.L.; Mattson, M.P. Ceruloplasmin deficiency results in an anxiety phenotype involving deficits in hippocampal iron, serotonin, and BDNF. J. Neurochem. 2012, 120, 125-134. [CrossRef] [PubMed]

19. Brissot, P.; Ropert, M.; le Lan, C.; Loreal, O. Non-transferrin bound iron: A key role in iron overload and iron toxicity. Biochim. Biophys. Acta 2012, 1820, 403-410. [CrossRef] [PubMed]

20. Kono, S.; Suzuki, H.; Oda, T.; Miyajima, H.; Takahashi, Y.; Shirakawa, K.; Ishikawa, K.; Kitagawa, M. Biochemical features of ceruloplasmin gene mutations linked to aceruloplasminemia. Neuromol. Med. 2006, 8, 361-374. [CrossRef] 
21. Hahn, P.; Qian, Y.; Dentchev, T.; Chen, L.; Beard, J.; Harris, Z.L.; Dunaief, J.L. Disruption of ceruloplasmin and hephaestin in mice causes retinal iron overload and retinal degeneration with features of age-related macular degeneration. Proc. Natl. Acad. Sci. USA 2004, 101, 13850-13855. [CrossRef] [PubMed]

22. Schulz, K.; Vulpe, C.D.; Harris, L.Z.; David, S. Iron efflux from oligodendrocytes is differentially regulated in gray and white matter. J. Neurosci. 2011, 31, 13301-13311. [CrossRef] [PubMed]

23. Hadziahmetovic, M.; Dentchev, T.; Song, Y.; Haddad, N.; He, X.; Hahn, P.; Pratico, D.; Wen, R.; Harris, Z.L.; Lambris, J.D.; et al. Ceruloplasmin/hephaestin knockout mice model morphologic and molecular features of AMD. Invest. Ophthalmol. Vis. Sci. 2008, 49, 2728-2736. [CrossRef] [PubMed]

24. Hadziahmetovic, M.; Song, Y.; Wolkow, N.; Iacovelli, J.; Grieco, S.; Lee, J.; Lyubarsky, A.; Pratico, D.; Connelly, J.; Spino, M.; et al. The oral iron chelator deferiprone protects against iron overload-induced retinal degeneration. Invest. Ophthalmol. Vis. Sci. 2011, 52, 959-968. [CrossRef] [PubMed]

25. Finkenstedt, A.; Wolf, E.; Höfner, E.; Gasser, B.I.; Bösch, S.; Bakry, R.; Creus, M.; Kremser, C.; Schocke, M.; Theurl, M.; et al. Hepatic but not brain iron is rapidly chelated by deferasirox in aceruloplasminemia due to a novel gene mutation. J. Hepatol. 2010, 53, 1101-1107. [CrossRef] [PubMed]

26. Do, R.F.; Roberti, M.; Borges Filho, H.M.; Goncalves, C.H.; Lima, F.L. Aceruloplasminemia: A rare disease-Diagnosis and treatment of two cases. Rev. Bras. Hematol. Hemoter. 2011, 33, 389-392.

27. Zanardi, A.; Conti, A.; Cremonesi, M.; D’Adamo, P.; Gilberti, E.; Apostoli, P.; Cannistraci, C.V.; Piperno, A.; David, S.; Alessio, M. Ceruloplasmin replacement therapy ameliorates neurological symptoms in a preclinical model of aceruloplasminemia. EMBO Mol. Med. 2018, 10, 91-106. [CrossRef] [PubMed]

28. Curtis, A.R.J.; Fey, C.; Morris, C.M.; Bindoff, L.A.; Ince, P.G.; Chinnery, P.F.; Coulthard, A.; Jackson, M.J.; Jackson, A.P.; McHale, D.P.; et al. Mutation in the gene encoding ferritin light polypeptide causes dominant adult-onset basal ganglia disease. Nat. Genet. 2001, 28, 350-354. [CrossRef] [PubMed]

29. Chinnery, P.F.; Crompton, D.E.; Birchall, D.; Jackson, M.J.; Coulthard, A.; Lombès, A.; Quinn, N.; Wills, A.; Fletcher, N.; Mottershead, J.P.; et al. Clinical features and natural history of neuroferritinopathy caused by the FTL1 460InsA mutation. Brain 2007, 130, 110-119. [CrossRef] [PubMed]

30. Mancuso, M.; Davidzon, G.; Kurlan, R.M.; Tawil, R.; Bonilla, E.; Di Mauro, S.; Powers, J.M. Hereditary ferritinopathy: A novel mutation, its cellular pathology, and pathogenetic insights. J. Neuropathol. Exp. Neurol. 2005, 64, 280-294. [CrossRef] [PubMed]

31. Baraibar, M.A.; Barbeito, A.G.; Muhoberac, B.B.; Vidal, R. Iron-mediated aggregation and a localized structural change characterize ferritin from a mutant light chain polypeptide that causes neurodegeneration. J. Biol. Chem. 2008, 283, 31679-31689. [CrossRef] [PubMed]

32. Baraibar, M.A.; Muhoberac, B.B.; Garringer, H.J.; Hurley, T.D.; Vidal, R. Unraveling of the E-helices and disruption of 4 -fold pores are associated with iron mishandling in a mutant ferritin causing neurodegeneration. J. Biol. Chem. 2010, 285, 1950-1956. [CrossRef] [PubMed]

33. Cozzi, A.; Santambrogio, P.; Corsi, B.; Campanella, A.; Arosio, P.; Levi, S. Characterization of the l-ferritin variant 460InsA responsible of a hereditary ferritinopathy disorder. Neurobiol. Dis. 2006, 23, 644-652. [CrossRef] [PubMed]

34. Cozzi, A.; Rovelli, E.; Frizzale, G.; Campanella, A.; Amendola, M.; Arosio, P.; Levi, S. Oxidative stress and cell death in cells expressing L-ferritin variants causing neuroferritinopathy. Neurobiol. Dis. 2010, 37, 77-85. [CrossRef] [PubMed]

35. Vidal, R.; Ghetti, B.; Takao, M.; Brefel-Courbon, C.; Uro-Coste, E.; Glazier, B.S.; Siani, V.; Benson, M.D.; Calvas, P.; Miravalle, L.; et al. Intracellular ferritin accumulation in neural and extraneural tissue characterizes a neurodegenerative disease associated with a mutation in the ferritin light polypeptide gene. J. Neuropathol. Exp. Neurol. 2004, 63, 363-380. [CrossRef] [PubMed]

36. Deng, X.; Vidal, R.; Englander, E.W. Accumulation of oxidative DNA damage in brain mitochondria in mouse model of hereditary ferritinopathy. Neurosci. Lett. 2010, 479, 44-48. [CrossRef] [PubMed]

37. Maccarinelli, F.; Pagani, A.; Cozzi, A.; Codazzi, F.; Di Giacomo, G.; Capoccia, S.; Rapino, S.; Finazzi, D.; Politi, L.S.; Cirulli, F.; et al. A novel neuroferritinopathy mouse model (FTL 498InsTC) shows progressive brain iron dysregulation, morphological signs of early neurodegeneration and motor coordination deficits. Neurobiol. Dis. 2015, 81, 119-133. [CrossRef] [PubMed]

38. Barbeito, A.G.; Garringer, H.J.; Baraibar, M.A.; Gao, X.; Arredondo, M.; Núñez, M.T.; Smith, M.A.; Ghetti, B.; Vidal, R. Abnormal iron metabolism and oxidative stress in mice expressing a mutant form of the ferritin light polypeptide gene. J. Neurochem. 2009, 109, 1067-1078. [CrossRef] [PubMed] 
39. Vidal, R.; Miravalle, L.; Gao, X.; Barbeito, A.G.; Baraibar, M.A.; Hekmatyar, S.K.; Widel, M.; Bansal, N.; Delisle, M.B.; Ghetti, B.R. Expression of a mutant form of the ferritin light chain gene induces neurodegeneration and iron overload in transgenic mice. J. Neurosci. 2008, 28, 60-67. [CrossRef] [PubMed]

40. Barbeito, A.G.; Levade, T.; Delisle, M.B.; Ghetti, B.; Vidal, R. Abnormal iron metabolism in fibroblasts from a patient with the neurodegenerative disease hereditary ferritinopathy. Mol. Neurodegener. 2010, 5, 50. [CrossRef] [PubMed]

41. Capoccia, S.; Maccarinelli, F.; Buffoli, B.; Rodella, L.F.; Cremona, O.; Arosio, P.; Cirulli, F. Behavioral characterization of mouse models of neuroferritinopathy. PLoS ONE 2015, 10, e0118990. [CrossRef] [PubMed]

42. Garringer, H.J.; Irimia, J.M.; Li, W.; Goodwin, C.B.; Richine, B.; Acton, A.; Chan, R.J.; Peacock, M.; Muhoberac, B.B.; Ghetti, B.; et al. Effect of Systemic Iron Overload and a Chelation Therapy in a Mouse Model of the Neurodegenerative Disease Hereditary Ferritinopathy. PLoS ONE 2016, 11, e0161341. [CrossRef] [PubMed]

43. Kubota, A.; Hida, A.; Ichikawa, Y.; Momose, Y.; Goto, J.; Igeta, Y.; Hashida, H.; Yoshida, K.; Ikeda, S.; Kanazawa, I.; et al. A novel ferritin light chain gene mutation in a Japanese family with neuroferritinopathy: Description of clinical features and implications for genotype-phenotype correlations. Mov. Disord. 2009, 24, 441-445. [CrossRef] [PubMed]

44. Schneider, S.A.; Dusek, P.; Hardy, J.; Westenberger, A.; Jankovic, J.; Bhatia, K.P. Genetics and Pathophysiology of Neurodegeneration with Brain Iron Accumulation (NBIA). Curr. Neuropharmacol. 2013, 11, 59-79. [PubMed]

45. Dusi, S.; Valletta, L.; Haack, T.B.; Tsuchiya, Y.; Venco, P.; Pasqualato, S.; Goffrini, P.; Tigano, M.; Demchenko, N.; Wieland, T; et al. Exome sequence reveals mutations in CoA synthase as a cause of neurodegeneration with brain iron accumulation. Am. J. Hum. Genet. 2014, 94, 11-22. [CrossRef] [PubMed]

46. Evers, C.; Seitz, A.; Assmann, B.; Opladen, T.; Karch, S.; Hinderhofer, K.; Granzow, M.; Paramasivam, N.; Eils, R.; Diessl, N.; et al. Diagnosis of CoPAN by whole exome sequencing: Waking up a sleeping tiger's eye. Am. J. Med. Genet. A 2017. [CrossRef] [PubMed]

47. Annesi, G.; Gagliardi, M.; Iannello, G.; Quattrone, A.; Iannello, G.; Quattrone, A. Mutational analysis of COASY in an Italian patient with NBIA. Parkinsonism Relat. Disord. 2016, 28, 150-151. [CrossRef] [PubMed]

48. Van Dijk, T.; Ferdinandusse, S.; Ruiter, J.P.N.; Alders, M.; Mathijssen, I.B.; Parboosingh, J.S.; Innes, A.M.; Meijers-Heijboer, H.; Poll-The, B.T.; Bernier, F.P.; et al. Biallelic loss of function variants in COASY cause prenatal onset pontocerebellar hypoplasia, microcephaly, and arthrogryposis. Eur. J. Hum. Genet. 2018, 26, 1752-1758. [CrossRef] [PubMed]

49. Kurian, M.A.; Hayflick, S.J. Pantothenate kinase-associated neurodegeneration (PKAN) and PLA2G6-associated neurodegeneration (PLAN): Review of two major neurodegeneration with brain iron accumulation (NBIA) phenotypes. Int. Rev. Neurobiol. 2013, 110, 49-71. [PubMed]

50. Zorzi, G.; Zibordi, F.; Chiapparini, L.; Bertini, E.; Russo, L.; Piga, A.; Longo, F.; Garavaglia, B.; Aquino, D.; Savoiardo, M.; et al. Iron-related MRI images in patients with pantothenate kinase-associated neurodegeneration (PKAN) treated with deferiprone: Results of a phase II pilot trial. Mov. Disord. 2011, 26, 1756-1759. [CrossRef] [PubMed]

51. Kruer, M.C.; Hiken, M.; Gregory, A.; Malandrini, A.; Clark, D.; Hogarth, P.; Grafe, M.; Hayflick, S.J.; Woltjer, R.L. Novel histopathologic findings in molecularly-confirmed pantothenate kinase-associated neurodegeneration. Brain 2011, 134, 947-958. [CrossRef] [PubMed]

52. Kuo, Y.-M.; Duncan, J.L.; Westaway, S.K.; Yang, H.; Nune, G.; Xu, E.Y.; Hayflick, S.J.; Gitschier, J. Deficiency of pantothenate kinase 2 (Pank2) in mice leads to retinal degeneration and azoospermia. Hum. Mol. Genet. 2005, 14, 49-57. [CrossRef] [PubMed]

53. Brunetti, D.; Dusi, S.; Morbin, M.; Uggetti, A.; Moda, F.; D'Amato, I.; Giordano, C.; d'Amati, G.; Cozzi, A.; Levi, S.; et al. Pantothenate kinase-associated neurodegeneration: Altered mitochondria membrane potential and defective respiration in Pank2 knock-out mouse model. Hum. Mol. Genet. 2012, 21, 5294-5305. [CrossRef] [PubMed]

54. Brunetti, D.; Dusi, S.; Giordano, C.; Lamperti, C.; Morbin, M.; Fugnanesi, V.; Marchet, S.; Fagiolari, G.; Sibon, O.; Moggio, M.; et al. Pantethine treatment is effective in recovering the disease phenotype induced by ketogenic diet in a pantothenate kinase-associated neurodegeneration mouse model. Brain 2014, 137, 57-68. [CrossRef] [PubMed] 
55. Garcia, M.; Leonardi, R.; Zhang, Y.-M.; Rehg, J.E.; Jackowski, S. Germline deletion of pantothenate kinases 1 and 2 reveals the key roles for CoA in postnatal metabolism. PLoS ONE 2012, 7, e40871. [CrossRef] [PubMed]

56. Bosveld, F.; Rana, A.; van der Wouden, P.E.; Lemstra, W.; Ritsema, M.; Kampinga, H.H.; Sibon, O.C. De novo CoA biosynthesis is required to maintain DNA integrity during development of the Drosophila nervous system. Hum. Mol. Genet. 2008, 17, 2058-2069. [CrossRef] [PubMed]

57. Yang, Y.; Wu, Z.; Kuo, Y.M.; Zhou, B. Dietary rescue of fumble-A Drosophila model for pantothenate-kinase-associated neurodegeneration. J. Inherit. Metab. Dis. 2005, 28, 1055-1064. [CrossRef] [PubMed]

58. Zizioli, D.; Tiso, N.; Guglielmi, A.; Saraceno, C.; Busolin, G.; Giuliani, R.; Khatri, D.; Monti, E.; Borsani, G.; Argenton, F.; et al. Knock-down of pantothenate kinase 2 severely affects the development of the nervous and vascular system in zebrafish, providing new insights into PKAN disease. Neurobiol. Dis. 2016, 85, 35-48. [CrossRef] [PubMed]

59. Santambrogio, P.; Dusi, S.; Guaraldo, M.; Rotundo, L.I.; Broccoli, V.; Garavaglia, B.; Tiranti, V.; Levi, S. Mitochondrial iron and energetic dysfunction distinguish fibroblasts and induced neurons from pantothenate kinase-associated neurodegeneration patients. Neurobiol. Dis. 2015, 81, 144-153. [CrossRef] [PubMed]

60. Orellana, D.I.; Santambrogio, P.; Rubio, A.; Yekhlef, L.; Cancellieri, C.; Dusi, S.; Giannelli, S.G.; Venco, P.; Mazzara, P.G.; Cozzi, A.; et al. Coenzyme A corrects pathological defects in human neurons of PANK2-associated neurodegeneration. EMBO Mol. Med. 2016, 8, 1197-1211. [CrossRef] [PubMed]

61. Arber, C.; Angelova, P.R.; Wiethoff, S.; Tsuchiya, Y.; Mazzacuva, F.; Preza, E.; Bhatia, K.P.; Mills, K.; Gout, I.; Abramov, A.Y.; et al. iPSC-derived neuronal models of PANK2-associated neurodegeneration reveal mitochondrial dysfunction contributing to early disease. PLoS ONE 2017, 12, e0184104. [CrossRef] [PubMed]

62. Abbruzzese, G.; Cossu, G.; Balocco, M.; Marchese, R.; Murgia, D.; Melis, M.; Galanello, R.; Barella, S.; Matta, G.; Ruffinengo, U.; et al. A pilot trial of deferiprone for neurodegeneration with brain iron accumulation. Haematologica 2011, 96, 1708-1711. [CrossRef] [PubMed]

63. Sharma, L.K.; Subramanian, C.; Yun, M.K.; Frank, M.W.; White, S.W.; Rock, C.O.; Lee, R.E.; Jackowski, S.A. A therapeutic approach to pantothenate kinase associated neurodegeneration. Nat. Commun. 2018, 9, 4399. [CrossRef] [PubMed]

64. Berti, C.C.; Dallabona, C.; Lazzaretti, M.; Dusi, S.; Tosi, E.; Tiranti, V.; Goffrini, P. Modeling human Coenzyme A synthase mutation in yeast reveals altered mitochondrial function, lipid content and iron metabolism. Microb. Cell (Graz, Austria) 2015, 2, 126-135. [CrossRef] [PubMed]

65. Khatri, D.; Zizioli, D.; Tiso, N.; Facchinello, N.; Vezzoli, S.; Gianoncelli, A.; Memo, M.; Monti, E.; Borsani, G.; Finazzi, D. Down-regulation of coasy, the gene associated with NBIA-VI, reduces Bmp signaling, perturbs dorso-ventral patterning and alters neuronal development in zebrafish. Sci. Rep. 2016, 6, 37660. [CrossRef] [PubMed]

66. Iuso, A.; Wiersma, M.; Schüller, H.J.; Pode-Shakked, B.; Marek-Yagel, D.; Grigat, M.; Schwarzmayr, T.; Berutti, R.; Alhaddad, B.; Kanon, B.; et al. Mutations in PPCS, Encoding Phosphopantothenoylcysteine Synthetase, Cause Autosomal-Recessive Dilated Cardiomyopathy. Am. J. Hum. Genet. 2018, 102, 1018-1030. [CrossRef] [PubMed]

67. Dusek, P.; Schneider, S.A. Neurodegeneration with brain iron accumulation. Curr. Opin. Neurol. 2012, 25, 499-506. [CrossRef] [PubMed]

68. Zhao, Z.; Zhang, X.; Zhao, C.; Choi, J.; Shi, J.; Song, K.; Turk, J.; Ma, Z.A. Protection of pancreatic beta-cells by group VIA phospholipase A(2)-mediated repair of mitochondrial membrane peroxidation. Endocrinology 2010, 151, 3038-3048. [CrossRef] [PubMed]

69. Malik, I.; Turk, J.; Mancuso, D.J.; Montier, L.; Wohltmann, M.; Wozniak, D.F.; Schmidt, R.E.; Gross, R.W.; Kotzbauer, P.T. Disrupted membrane homeostasis and accumulation of ubiquitinated proteins in a mouse model of infantile neuroaxonal dystrophy caused by PLA2G6 mutations. Am. J. Pathol. 2008, 172, 406-416. [CrossRef] [PubMed]

70. Claypool, S.M.; Koehler, C.M. The complexity of cardiolipin in health and disease. Trends Biochem. Sci. 2012, 37, 32-41. [CrossRef] [PubMed]

71. Beck, G.; Sugiura, Y.; Shinzawa, K.; Kato, S.; Setou, M.; Tsujimoto, Y.; Sakoda, S.; Sumi-Akamaru, H. Neuroaxonal dystrophy in calcium-independent phospholipase A2beta deficiency results from insufficient remodeling and degeneration of mitochondrial and presynaptic membranes. J. Neurosci. 2011, 31, 11411-11420. [CrossRef] [PubMed] 
72. Rouault, T.A. Biogenesis of iron-sulfur clusters in mammalian cells: New insights and relevance to human disease. Dis. Model. Mech. 2012, 5, 155-164. [CrossRef] [PubMed]

73. Kruer, M.C.; Paisán-Ruiz, C.; Boddaert, N.; Yoon, M.Y.; Hama, H.; Gregory, A.; Malandrini, A.; Woltjer, R.L.; Munnich, A.; Gobin, S.; et al. Defective FA2H leads to a novel form of neurodegeneration with brain iron accumulation (NBIA). Ann. Neurol. 2010, 68, 611-618. [CrossRef] [PubMed]

74. Eckhardt, M.; Yaghootfam, A.; Fewou, S.N.; Zoller, I.; Gieselmann, V. A mammalian fatty acid hydroxylase responsible for the formation of alpha-hydroxylated galactosylceramide in myelin. Biochem. J. 2005, 388, 245-254. [CrossRef] [PubMed]

75. Schneider, S.A.; Bhatia, K.P. Syndromes of neurodegeneration with brain iron accumulation. Semin. Pediatr. Neurol. 2012, 19, 57-66. [CrossRef] [PubMed]

76. Gregory, A.; Hayflick, S.J. Genetics of neurodegeneration with brain iron accumulation. Curr. Neurol. Neurosci. Rep. 2011, 11, 254-261. [CrossRef] [PubMed]

77. Potter, K.A.; Kern, M.J.; Fullbright, G.; Bielawski, J.; Scherer, S.S.; Yum, S.W.; Li, J.J.; Cheng, H.; Han, X.; Venkata, J.K.; et al. Central nervous system dysfunction in a mouse model of FA2H deficiency. Glia 2011, 59, 1009-1021. [CrossRef] [PubMed]

78. Zoller, I.; Meixner, M.; Hartmann, D.; Büssow, H.; Meyer, R.; Gieselmann, V.; Eckhardt, M. Absence of 2-hydroxylated sphingolipids is compatible with normal neural development but causes late-onset axon and myelin sheath degeneration. J. Neurosci. 2008, 28, 9741-9754. [CrossRef] [PubMed]

79. Mari, F.; Berti, B.; Romano, A.; Baldacci, J.; Rizzi, R.; Grazia Alessandrì, M.; Tessa, A.; Procopio, E.; Rubegni, A.; Lourenço, C.M.; et al. Clinical and neuroimaging features of autosomal recessive spastic paraplegia 35 (SPG35): Case reports, new mutations, and brief literature review. Neurogenetics 2018, 19, 123-130. [CrossRef] [PubMed]

80. Hartig, M.B.; Iuso, A.; Haack, T.; Kmiec, T.; Jurkiewicz, E.; Heim, K.; Roeber, S.; Tarabin, V.; Dusi, S.; Krajewska-Walasek, M.; et al. Absence of an orphan mitochondrial protein, c19orf12, causes a distinct clinical subtype of neurodegeneration with brain iron accumulation. Am. J. Hum. Genet. 2011, 89, 543-550. [CrossRef] [PubMed]

81. Panteghini, C.; Zorzi, G.; Venco, P.; Dusi, S.; Reale, C.; Brunetti, D.; Chiapparini, L.; Zibordi, F.; Siegel, B.; Garavaglia, B.; et al. C19orf12 and FA2H mutations are rare in Italian patients with neurodegeneration with brain iron accumulation. Semin. Pediatr. Neurol. 2012, 19, 75-81. [CrossRef] [PubMed]

82. Kruer, M.C.; Salih, M.A.; Mooney, C.; Alzahrani, J.; Elmalik, S.A.; Kabiraj, M.M.; Khan, A.O.; Paudel, R.; Houlden, H.; Azzedine, H.; et al. C19orf12 mutation leads to a pallido-pyramidal syndrome. Gene 2014, 537, 352-356. [CrossRef] [PubMed]

83. Landoure, G.; Zhu, P.P.; Lourenço, C.M.; Johnson, J.O.; Toro, C.; Bricceno, K.V.; Rinaldi, C.; Meilleur, K.G.; Sangaré, M.; Diallo, O.; et al. Hereditary spastic paraplegia type 43 (SPG43) is caused by mutation in C19orf12. Hum. Mutat. 2013, 34, 1357-1360. [CrossRef] [PubMed]

84. Deschauer, M.; Gaul, C.; Behrmann, C.; Prokisch, H.; Zierz, S.; Haack, T.B. C19orf12 mutations in neurodegeneration with brain iron accumulation mimicking juvenile amyotrophic lateral sclerosis. J. Neurol. 2012, 259, 2434-2439. [CrossRef] [PubMed]

85. Horvath, R.; Holinski-Feder, E.; Neeve, V.C.; Pyle, A.; Griffin, H.; Ashok, D.; Foley, C.; Hudson, G.; Rautenstrauss, B.; Nürnberg, G.; et al. A new phenotype of brain iron accumulation with dystonia, optic atrophy, and peripheral neuropathy. Mov. Disord. 2012, 27, 789-793. [CrossRef] [PubMed]

86. Langwinska-Wosko, E.; Skowronska, M.; Kmiec, T.; Czlonkowska, A. Retinal and optic nerve abnormalities in neurodegeneration associated with mutations in C19orf12 (MPAN). J. Neurol. Sci. 2016, 370, 237-240. [CrossRef] [PubMed]

87. Skowronska, M.; Kmiec, T.; Czlonkowska, A.; Kurkowska-Jastrzebska, I. Transcranial Sonography in Mitochondrial Membrane Protein-Associated Neurodegeneration. Clin. Neuroradiol. 2018, 28, 385-392. [CrossRef] [PubMed]

88. Venco, P.; Bonora, M.; Giorgi, C.; Papaleo, E.; Iuso, A.; Prokisch, H.; Pinton, P.; Tiranti, V. Mutations of C19orf12, coding for a transmembrane glycine zipper containing mitochondrial protein, cause mis-localization of the protein, inability to respond to oxidative stress and increased mitochondrial $\mathrm{Ca}(2)(+)$. Front. Genet. 2015, 6, 185. [CrossRef] [PubMed] 
89. Iuso, A.; Sibon, O.C.; Gorza, M.; Heim, K.; Organisti, C.; Meitinger, T.; Prokisch, H. Impairment of Drosophila orthologs of the human orphan protein C19orf12 induces bang sensitivity and neurodegeneration. PLoS ONE 2014, 9, e89439. [CrossRef] [PubMed]

90. Ferdinandusse, S.; Kostopoulos, P.; Denis, S.; Rusch, H.; Overmars, H.; Dillmann, U.; Reith, W.; Haas, D.; Wanders, R.J.; Duran, M.; et al. Mutations in the gene encoding peroxisomal sterol carrier protein X (SCPx) cause leukencephalopathy with dystonia and motor neuropathy. Am. J. Hum. Genet. 2006, 78, 1046-1052. [CrossRef] [PubMed]

91. Horvath, R.; Lewis-Smith, D.; Douroudis, K.; Duff, J.; Keogh, M.; Pyle, A.; Fletcher, N.; Chinnery, P.F. SCP2 mutations and neurodegeneration with brain iron accumulation. Neurology 2015, 85, 1909-1911. [CrossRef] [PubMed]

92. Seedorf, U.; Raabe, M.; Ellinghaus, P.; Kannenberg, F.; Fobker, M.; Engel, T.; Denis, S.; Wouters, F.; Wirtz, K.W.; Wanders, R.J.; et al. Defective peroxisomal catabolism of branched fatty acyl coenzyme A in mice lacking the sterol carrier protein-2/sterol carrier protein-x gene function. Genes Dev. 1998, 12, 1189-1201. [CrossRef] [PubMed]

93. Wanders, R.J.; Vreken, P.; Ferdinandusse, S.; Jansen, G.A.; Waterham, H.R.; van Roermund, C.W.; Van Grunsven, E.G. Peroxisomal fatty acid alpha- and beta-oxidation in humans: Enzymology, peroxisomal metabolite transporters Peroxisomal fatty acid alpha- and beta-oxidation in humans: Enzymology, peroxisomal metabolite transporters and peroxisomal diseases. Biochem. Soc. Trans. 2001, 29, 250-267. [CrossRef] [PubMed]

94. Drecourt, A.; Babdor, J.; Dussiot, M.; Petit, F.; Goudin, N.; Garfa-Traoré, M.; Habarou, F.; Bole-Feysot, C.; Nitschké, P.; Ottolenghi, C.; et al. Impaired Transferrin Receptor Palmitoylation and Recycling in Neurodegeneration with Brain Iron Accumulation. Am. J. Hum. Genet. 2018, 102, 266-277. [CrossRef] [PubMed]

95. Haack, T.B.; Hogarth, P.; Kruer, M.C.; Gregory, A.; Wieland, T.; Schwarzmayr, T.; Graf, E.; Sanford, L.; Meyer, E.; Kara, E.; et al. Exome sequencing reveals de novo WDR45 mutations causing a phenotypically distinct, X-linked dominant form of NBIA. Am. J. Hum. Genet. 2012, 91, 1144-1149. [CrossRef] [PubMed]

96. Proikas-Cezanne, T.; Waddell, S.; Gaugel, A.; Frickey, T.; Lupas, A.; Nordheim, A. WIPI-1alpha (WIPI49), a member of the novel 7-bladed WIPI protein family, is aberrantly expressed in human cancer and is linked to starvation-induced autophagy. Oncogene 2004, 23, 9314-9325. [CrossRef] [PubMed]

97. Hailey, D.W.; Rambold, A.S.; Satpute-Krishnan, P.; Mitra, K.; Sougrat, R.; Kim, P.K.; Lippincott-Schwartz, J. Mitochondria supply membranes for autophagosome biogenesis during starvation. Cell 2010, 141, 656-667. [CrossRef] [PubMed]

98. Zhao, Y.G.; Sun, L.; Miao, G.; Ji, C.; Zhao, H.; Sun, H.; Miao, L.; Yoshii, S.R.; Mizushima, N.; Wang, X.; Zhang, H. The autophagy gene Wdr45/Wipi4 regulates learning and memory function and axonal homeostasis. Autophagy 2015, 11, 881-890. [CrossRef] [PubMed]

99. Ingrassia, R.; Memo, M.; Garavaglia, B. Ferrous Iron Up-regulation in Fibroblasts of Patients with Beta Propeller Protein-Associated Neurodegeneration (BPAN). Front. Genet. 2017, 8, 18. [CrossRef] [PubMed]

100. Schneider, S.A.; Paisán-Ruiz, C.; Quinn, N.P.; Lees, A.J.; Houlden, H.; Hardy, J.; Bhatia, K.P. ATP13A2 mutations (PARK9) cause neurodegeneration with brain iron accumulation. Mov. Disord. 2010, 25, 979-984. [CrossRef] [PubMed]

101. Bras, J.; Verloes, A.; Schneider, S.A.; Mole, S.E.; Guerreiro, R.J. Mutation of the parkinsonism gene ATP13A2 causes neuronal ceroid-lipofuscinosis. Hum. Mol. Genet. 2012, 21, 2646-2650. [CrossRef] [PubMed]

102. Ramonet, D.; Podhajska, A.; Stafa, K.; Sonnay, S.; Trancikova, A.; Tsika, E.; Pletnikova, O.; Troncoso, J.C.; Glauser, L.; Moore, D.J. PARK9-associated ATP13A2 localizes to intracellular acidic vesicles and regulates cation homeostasis and neuronal integrity. Hum. Mol. Genet. 2012, 21, 1725-1743. [CrossRef] [PubMed]

103. Grunewald, A.; Arns, B.; Seibler, P.; Rakovic, A.; Münchau, A.; Ramirez, A.; Sue, C.M.; Klein, C. ATP13A2 mutations impair mitochondrial function in fibroblasts from patients with Kufor-Rakeb syndrome. Neurobiol. Aging 2012, 33, 1843.e1-1843.e7. [CrossRef] [PubMed]

104. Usenovic, M.; Tresse, E.; Mazzulli, J.R.; Taylor, J.P.; Krainc, D. Deficiency of ATP13A2 leads to lysosomal dysfunction, alpha-synuclein accumulation, and neurotoxicity. J. Neurosci. 2012, 32, 4240-4246. [CrossRef] [PubMed] 
105. Tsunemi, T.; Hamada, K.; Krainc, D. ATP13A2/PARK9 regulates secretion of exosomes and alpha-synuclein. J. Neurosci. 2014, 34, 15281-15287. [CrossRef] [PubMed]

106. Schultheis, P.J.; Fleming, S.M.; Clippinger, A.K.; Lewis, J.; Tsunemi, T.; Giasson, B.; Dickson, D.W.; Mazzulli, J.R.; Bardgett, M.E.; Haik, K.L.; et al. Atp13a2-deficient mice exhibit neuronal ceroid lipofuscinosis, limited alpha-synuclein accumulation and age-dependent sensorimotor deficits. Hum. Mol. Genet. 2013, 22, 2067-2082. [CrossRef] [PubMed]

107. Kett, L.R.; Stiller, B.; Bernath, M.M.; Tasset, I.; Blesa, J.; Jackson-Lewis, V.; Chan, R.B.; Zhou, B.; Di Paolo, G.; Przedborski, S.; et al. alpha-Synuclein-independent histopathological and motor deficits in mice lacking the endolysosomal Parkinsonism protein Atp13a2. J. Neurosci. 2015, 35, 5724-5742. [CrossRef] [PubMed]

108. Rajagopalan, S.; Rane, A.; Chinta, S.J.; Andersen, J.K. Regulation of ATP13A2 via PHD2-HIF1alpha Signaling Is Critical for Cellular Iron Homeostasis: Implications for Parkinson's Disease. J. Neurosci. 2016, 36, 1086-1095. [CrossRef] [PubMed]

109. Roubertie, A.; Hieu, N.; Roux, C.J.; Leboucq, N.; Manes, G.; Charif, M.; Echenne, B.; Goizet, C.; Guissart, C.; Meyer, P.; et al. AP4 deficiency: A novel form of neurodegeneration with brain iron accumulation? Neurol. Genet. 2018, 4, e217. [CrossRef] [PubMed]

110. Duerinckx, S.; Verhelst, H.; Perazzolo, C.; David, P.; Desmyter, L.; Pirson, I.; Abramowicz, M. Severe congenital microcephaly with AP4M1 mutation, a case report. BMC Med. Genet. 2017, 18, 48. [CrossRef] [PubMed]

111. Verkerk, A.J.M.H.; Schot, R.; Dumee, B.; Schellekens, K.; Swagemakers, S.; Bertoli-Avella, A.M.; Lequin, M.H.; Dudink, J.; Govaert, P.; van Zwol, A.L.; et al. Mutation in the AP4M1 gene provides a model for neuroaxonal injury in cerebral palsy. Am. J. Hum. Genet. 2009, 85, 40-52. [CrossRef] [PubMed]

112. Alazami, A.M.; Al-Saif, A.; Al-Semari, A.; Bohlega, S.; Zlitni, S.; Alzahrani, F.; Bavi, P.; Kaya, N.; Colak, D.; Khalak, H.; et al. Mutations in C2orf37, encoding a nucleolar protein, cause hypogonadism, alopecia, diabetes mellitus, mental retardation, and extrapyramidal syndrome. Am. J. Hum. Genet. 2008, 83, 684-691. [CrossRef] [PubMed]

113. Jin, J.; Arias, E.E.; Chen, J.; Harper, J.W.; Walter, J.C. A family of diverse Cul4-Ddb1-interacting proteins includes Cdt2, which is required for S phase destruction of the replication factor Cdt1. Mol. Cell 2006, 23, 709-721. [CrossRef] [PubMed]

114. Ali, A.; Mistry, B.V.; AAhmed, H.; Abdulla, R.; AAmer, H.; Prince, A.; MAlazami, A.; SAlkuraya, F.; Assiri, A. Deletion of DDB1- and CUL4-associated factor-17 (Dcaf17) gene causes spermatogenesis defects and male infertility in mice. Sci. Rep. 2018, 8, 9202. [CrossRef] [PubMed]

115. Gurbuz, F.; Desai, S.; Diao, F.; Turkkahraman, D.; Wranitz, F.; Wood-Trageser, M.; Shin, Y.H.; Kotan, L.D.; Jiang, H.; Witchel, S.; et al. Novel inactivating mutations of the DCAF17 gene in American and Turkish families cause male infertility and female subfertility in the mouse model. Clin. Genet. 2018, 93, 853-859. [CrossRef] [PubMed]

116. Jaberi, E.; Rohani, M.; Shahidi, G.A.; Nafissi, S.; Arefian, E.; Soleimani, M.; Rasooli, P.; Ahmadieh, H.; Daftarian, N.; KaramiNejadRanjbar, M.; et al. Identification of mutation in GTPBP2 in patients of a family with neurodegeneration accompanied by iron deposition in the brain. Neurobiol. Aging 2016, 38, 216.e11-216.e18. [CrossRef] [PubMed]

117. Bertoli-Avella, A.M.; Garcia-Aznar, J.M.; Brandau, O.; Al-Hakami, F.; Yüksel, Z.; Marais, A.; Grüning, N.M.; Abbasi Moheb, L.; Paknia, O.; Alshaikh, N.; et al. Biallelic inactivating variants in the GTPBP2 gene cause a neurodevelopmental disorder with severe intellectual disability. Eur. J. Hum. Genet. 2018, 26, 592-598. [CrossRef] [PubMed]

118. Woo, K.-C.; Kim, T.-D.; Lee, K.-H.; Kim, D.-Y.; Kim, S.; Lee, H.-R.; Kang, H.J.; Chung, S.J.; Senju, S.; Nishimura, Y.; et al. Modulation of exosome-mediated mRNA turnover by interaction of GTP-binding protein 1 (GTPBP1) with its target mRNAs. FASEB J. 2011, 25, 2757-2769. [CrossRef] [PubMed]

119. Ishimura, R.; Nagy, G.; Dotu, I.; Zhou, H.; Yang, X.-L.; Schimmel, P.; Senju, S.; Nishimura, Y.; Chuang, J.H.; Ackerman, S.L. RNA function. Ribosome stalling induced by mutation of a CNS-specific tRNA causes neurodegeneration. Science 2014, 345, 455-459. [CrossRef] [PubMed]

120. Zinoviev, A.; Goyal, A.; Jindal, S.; LaCava, J.; Komar, A.A.; Rodnina, M.V.; Hellen, C.U.T.; Pestova, T.V. Functions of unconventional mammalian translational GTPases GTPBP1 and GTPBP2. Genes Dev. 2018, 32, 1226-1241. [CrossRef] [PubMed] 
121. Bettencourt, C.; Forabosco, P.; Wiethoff, S.; Heidari, M.; Johnstone, D.M.; Botía, J.A.; Collingwood, J.F.; Hardy, J. Gene co-expression networks shed light into diseases of brain iron accumulation. Neurobiol. Dis. 2016, 87, 59-68. [CrossRef] [PubMed]

122. Tello, C.; Darling, A.; Lupo, V.; Perez-Duenas, B.; Espinos, C. On the complexity of clinical and molecular bases of neurodegeneration with brain iron accumulation. Clin. Genet. 2018, 93, 731-740. [CrossRef] [PubMed]

(C) 2019 by the authors. Licensee MDPI, Basel, Switzerland. This article is an open access article distributed under the terms and conditions of the Creative Commons Attribution (CC BY) license (http:/ / creativecommons.org/licenses/by/4.0/). 


\title{
nawe \\ Mitochondrial Targeting in Neurodegeneration: A Heme Perspective
}

\author{
Veronica Fiorito ${ }^{*}{ }^{\dagger}$, Deborah Chiabrando $^{\dagger}$ and Emanuela Tolosano \\ Department of Molecular Biotechnology and Health Sciences, Molecular Biotechnology Center, \\ University of Torino, 10126 Torino, Italy; deborah.chiabrando@unito.it (D.C.); emanuela.tolosano@unito.it (E.T.) \\ * Correspondence: veronica.fiorito@unito.it; Tel.: +39-011-670-6423 \\ † These authors equally contributed.
}

Received: 18 July 2018; Accepted: 14 September 2018; Published: 18 September 2018

\begin{abstract}
Mitochondrial dysfunction has achieved an increasing interest in the field of neurodegeneration as a pathological hallmark for different disorders. The impact of mitochondria is related to a variety of mechanisms and several of them can co-exist in the same disease. The central role of mitochondria in neurodegenerative disorders has stimulated studies intended to implement therapeutic protocols based on the targeting of the distinct mitochondrial processes. The review summarizes the most relevant mechanisms by which mitochondria contribute to neurodegeneration, encompassing therapeutic approaches. Moreover, a new perspective is proposed based on the heme impact on neurodegeneration. The heme metabolism plays a central role in mitochondrial functions, and several evidences indicate that alterations of the heme metabolism are associated with neurodegenerative disorders. By reporting the body of knowledge on this topic, the review intends to stimulate future studies on the role of heme metabolism in neurodegeneration, envisioning innovative strategies in the struggle against neurodegenerative diseases.
\end{abstract}

Keywords: neurodegeneration; mitochondria; therapy; heme; haem

\section{Implication of Heme in Neurodegeneration}

Heme is a molecule composed by protoporphyrin IX and iron produced by all the cells in the organism, including neurons. Heme mediates a series of functions that encompass oxygen transport, the regulation of gene expression and the modulation of enzyme activity, just to cite the most relevant ones. Moreover, heme can also promote oxidative stress, thus performing as a double-face molecule with both positive and negative properties [1]. This concept is also true for neuronal cells. Indeed, on one hand heme is required for the survival and differentiation of neuronal cells, as demonstrated by the observation that heme deficiency interferes with neurite outgrowth in nerve growth factor (NGF)-induced PC12 cells [2,3] and results in apoptosis in PC12 pheochromocytoma cells, SHSY5Y neuroblastoma cells and U373 astrocytoma cells, as well as in rat primary hippocampal neurons [2-4]. However, on the other hand, an excess of free-heme is associated with neurodegeneration. The large amount of hemoglobin and heme released in the brain during intracerebral or subarachnoid hemorrhages promotes oxidative stress, lipid peroxidation, inflammatory response and finally, neuronal cell death [5-7]. Moreover, loss of the heme scavenger hemopexin (Hx) causes defective myelination in mice [8-10]. Furthermore, impairment of cellular heme export reduces SHSY5Y cells survival [11]. Together, these data indicate that both heme deficiency and excess are deleterious for the survival of neuronal cells (Figure 1), thus suggesting that heme levels must be finely controlled both at the systemic and cellular level. At the systemic level, circulating free-heme is scavenged by the plasma proteins haptoglobin and hemopexin $[6-8,10,12-14]$. However, at cellular level, the amount of intracellular free-heme (labile heme or heme regulatory pool) is regulated at multiple steps: heme synthesis, incorporation into hemoproteins, catabolism, import and export $[1,15]$. 
Although this tight regulation has been extensively studied in non-neuronal cells, similar mechanisms likely occur in the nervous system. Indeed, the main proteins involved in the control of labile heme are also expressed in the nervous system [16].

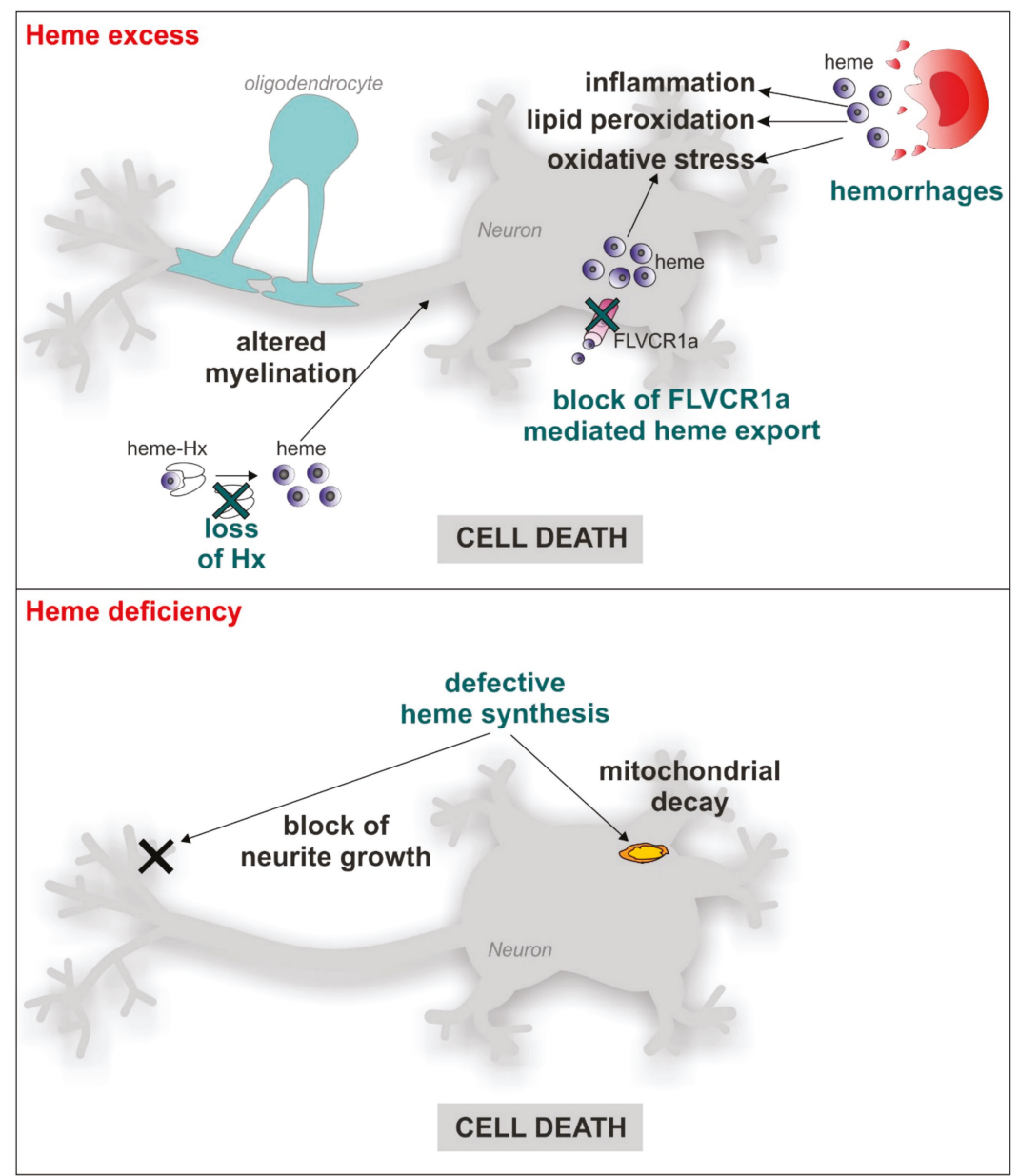

Figure 1. Implication of heme in neurodegeneration. Both heme excess and heme deficiency contribute to neurodegeneration. Heme released during hemorrhages leads to inflammation, lipid peroxidation and oxidative stress; the loss of the heme scavenger Hx causes defective myelination of axons; the impairment of intracellular heme export by FLVCR1a is associated with increased oxidative stress. On the other hand, heme deficiency, due to defective synthesis, leads to mitochondrial decay and the blocking of neurite growth. These events all result in neuronal cell death. In the figure, neurons are represented as the main target for heme-mediated effects; however, other cell types of the nervous system could be affected by the same phenomena.

Neurodegenerative disorders are a common and growing cause of mortality and morbidity worldwide [17]. Recently, a series of rare neurodegenerative disorders have been directly linked to alterations of heme metabolism (see Table 1). Defective heme synthesis causes porphyrias, some of which are associated with a wide array of neurological disturbances involving both the central and peripheral nervous systems (neuropathic porphyria). Neuropathic porphyria includes acute 
intermittent porphyria (AIP), hereditary coproporphyria (HCP), variegate porphyria (VP) and 5-aminolevulinate dehydratase deficiency (ALAD deficiency) [18-20]. Furthermore, reduced heme synthesis has been observed in Friederich Ataxia (FRDA), an autosomal recessive disorder caused by mutations in Frataxin (FXN), a mitochondrial iron chaperone involved in iron-sulfur (Fe-S) clusters and heme biosynthesis [21-24]. Finally, reduced heme synthesis has been observed during aging [4,25].

Table 1. Rare neurodegenerative disorders linked to defective heme metabolism.

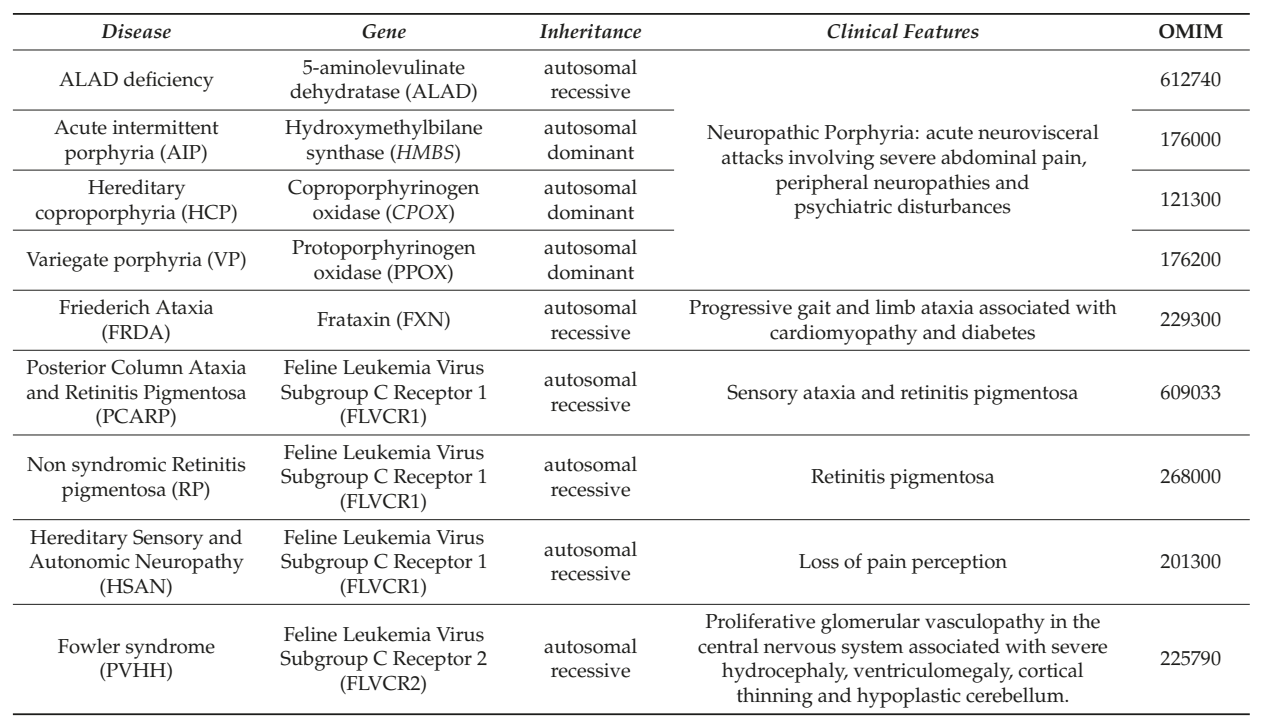

In addition, other rare neurodegenerative disorders have been associated with defective heme transport across membranes. Several proteins are involved in this process [1,15]. Among them, Feline Leukemia Virus Subgroup C Receptor 1 (FLVCR1) and 2 (FLVCR2) are implicated in heme export and import, respectively [11,26-31]. Mutations in the heme exporter FLVCR1 are associated with three distinct disorders affecting the sensory nervous system: posterior column ataxia and retinitis pigmentosa (PCARP) [32-34], non-syndromic retinitis pigmentosa (RP) $[35,36]$ and hereditary sensory and autonomic neuropathy (HSAN) [11,37]. Mutations in the heme importer FLVCR2 are responsible for the Fowler syndrome, a proliferative glomerular vasculopathy $[30,38,39]$.

Furthermore, several lines of evidence suggest that heme may also contribute to the pathogenesis of common neurodegenerative disorders. The deregulation of enzymes critically involved in heme synthesis has been reported in both Alzheimer's disease (AD) and Parkinson's disease (PD). Reduced 5-aminolevulinate synthase 1 (ALAS1) and porphobilinogen deaminase (PBGD) mRNA were observed in AD brains [40], suggesting decreased heme synthesis rates in AD. Moreover, heme deficiency has been reported in the brain of patients with $\mathrm{AD}$ [41]. It has been proposed that heme deficiency may arise from either decreased heme synthesis rates or heme depletion as a consequence of heme binding to amyloid- $\beta$ [41-43]. However, increased Ferrochelatase (FECH) levels were reported in another study [41].

Heme binding to $\alpha$-Synuclein has also been reported [44], suggesting that heme depletion may also occur in PD. In addition, blood transcriptomic meta-analysis showed downregulation of 5-aminolevulinate synthase 2 (ALAS2) and FECH in PD [45]. However, within PD erythroid cells, $\alpha$-synuclein gene (SNCA) was co-expressed with crucial enzymes involved in heme metabolism, including ALAS2, FECH and biliverdin reductase B (BLVRB) [46]. Moreover, increased striatal 5-aminolevulinate dehydratase (ALAD) activity was observed in the MPTP-induced mouse model of $\mathrm{PD}$, indicative of increased heme synthesis rates [47]. It is difficult to conclude from these studies 
whether heme synthesis is increased or reduced in AD and PD. Data are still controversial due to the low amount of human samples analyzed and the different experimental approaches adopted. Further studies are required to definitively determine heme synthesis rates in these pathological conditions. Mouse models of AD and PD will be extremely useful to analyze in detail the role of heme metabolism in these disorders.

A role for heme derived from extracellular sources in the pathogenesis of neurodegenerative disorders has also been proposed. The heme scavenger Hx has been found strongly increased in the cerebrospinal fluid of AD patients [48-50]. Similarly, altered expression of the hemoglobin scavenger haptoglobin was shown in AD [51,52], PD [53,54] and Huntington's disease (HD) [55]. The induction of heme oxygenase 1 (HO1), the enzyme responsible for heme degradation, is common in patients affected by neurodegenerative conditions. Although $\mathrm{HO} 1$ is induced by a plethora of stimuli, it has been proposed that $\mathrm{HO} 1$ overexpression in $\mathrm{AD}$ and $\mathrm{PD}$ may be a consequence of increased brain-blood barrier permeability and hemoglobin-derived heme levels in AD and PD [16]. Moreover, increased expression of $\mathrm{HO} 1$ was reported in a mouse model of amyotrophic lateral sclerosis (ALS) [56] and ALS patients [57].

All the reported examples highlight the importance of the maintenance of heme homeostasis in the context of neurodegeneration. However, the molecular mechanisms underlying these disorders and the precise mechanism through which heme participates to them remains elusive and requires further investigations.

\section{Role of Mitochondria in Neurodegenerative Diseases}

Neurodegeneration can be elicited by several systems. Among them, mitochondrial-dependent processes have become increasingly relevant [58-63]. Several mechanisms account for mitochondriadependent neurodegeneration (see Figure 2 for a graphic list of them) and below we attempt to summarize the most important ones.

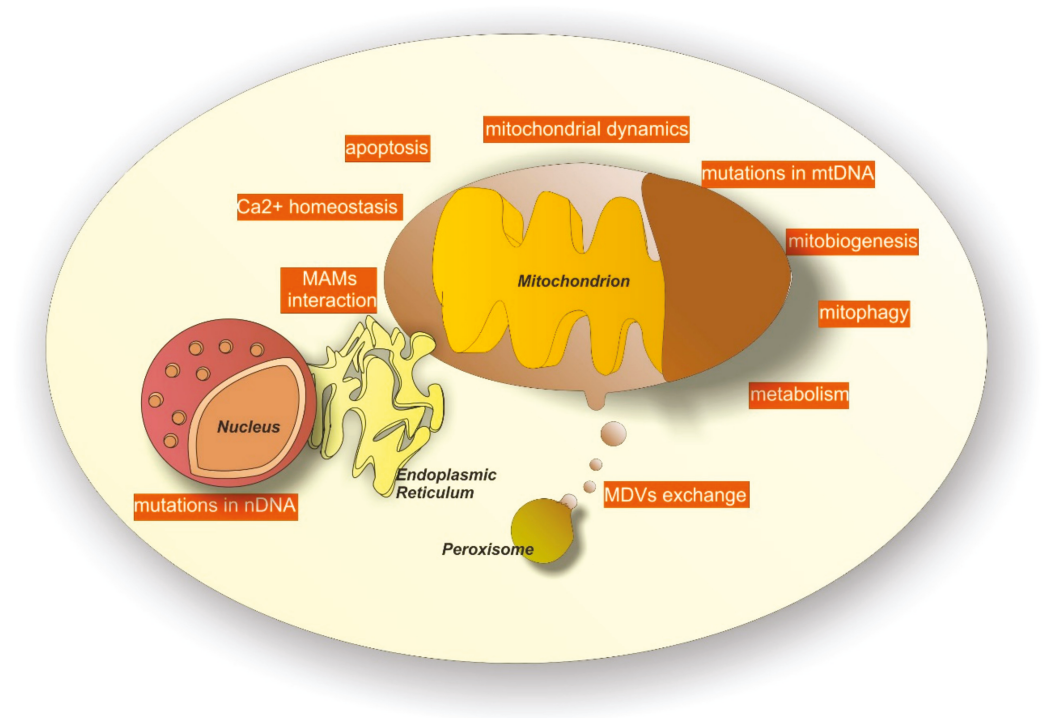

Figure 2. Mitochondrial dependent mechanisms in neurodegeneration. Mitochondria contribute to neurodegeneration by several mechanisms, including alterations in calcium homeostasis, mitochondrial 
biogenesis (mitobiogenesis), mitochondrial dynamics, metabolism and mitophagy. Moreover, mutations in mitochondrial DNA (mtDNA) and inappropriate activation of apoptosis can be alternative mechanisms. Finally, additional systems include mutations in nuclear DNA (nDNA) at the level of genes encoding for mitochondrial proteins, the compromised exchange of mitochondria-derived vesicles (MDVs) among mitochondria and peroxisomes and the inefficient interaction among mitochondria and the endoplasmic reticulum at the level of mitochondrial associated membranes (MAMs).

\subsection{Mutations on Mitochondrial DNA (mtDNA) Genes}

Mitochondria contain their own genome, which is made of multiple copies of a circular double stranded molecule, which is $16.6 \mathrm{~kb}$ long in humans. It comprises 37 genes, 13 encoding for proteins involved in adenosine triphosphate (ATP) production and the other 24 encoding for two rRNAs and 22 tRNAs. Cells contain thousands of molecules of mtDNA and the majority of them have the same sequence, a condition known as homoplasmy. Inefficient mtDNA repair, localized oxidative environment and increased replication, however, can promote mtDNA mutations that, due to the polyploidy nature of mtDNA, often co-exist with their wildtype counterpart in various proportions (a condition termed heteroplasmy). mtDNA mutations are usually responsible for defects in the respiratory chain functions, but only if they are present above a certain threshold level.

The replication of mtDNA occurs independently on cell cycle, and a particular mtDNA molecule may be strongly replicated (or not at all) during cell division. Moreover, replication occurs also in postmitotic cells. These phenomena account for the clonal expansion of mutated mtDNA molecules and in association with heteroplasmy, result in mosaicism, with the levels of mutated mtDNA varying dramatically between tissues in the same organism and in different regions of the same tissue.

Somatic mtDNA mutations accumulate during a person's lifetime and undergo clonal expansion, so aging is typically associated with mosaic occurrence of respiratory chain-deficient cells in tissues [64].

Mitochondrial reactive oxygen species (ROS) production is the major cause for the higher mtDNA nucleotide instability when compared with nDNA.

Mitochondrial DNA mutations potently affect tissue that require a large amount of ATP to function, such as heart and brain. Some haplogroups [65] (evolutionary selected population subgroups carrying neutral single-base pair variants of mtDNA) have been associated with susceptibility to a variety of human diseases, including age-related neurodegenerative disorders such as PD and AD. Moreover, inherited point mutations and sporadic rearrangements on mtDNA have been described in association with neurodegeneration [65-69].

Although the presence of mtDNA deletions below a certain threshold is not sufficient to induce $\mathrm{PD}$, small changes inside the genome of mitochondria could represent a risk factor for this pathology [70-74]. In addition, the accumulation of mutations in mtDNA over the course of PD has been observed to correlate with severity and burden of the disease [75]. Accumulation of mtDNA damage is also considered a possible mechanism of neurodegeneration over the course of HD [76]. Moreover, mtDNA mutations have been associated with AD [77], although the degree of mtDNA damage does not seem to correlate with the severity of AD symptoms [78].

As stated before, mtDNA alterations often result in defects on a particular component of the electron transport chain (ETC). The three main mechanisms through which mtDNA damage can contribute to neurodegeneration are therefore consequences of ETC alteration and include the decrease of ATP synthesis, the increase of ROS production and the enhanced sensitivity to neurotoxins associated to ETC disruption.

\subsection{Mutations on Nuclear DNA Genes Encoding Proteins Crucial for Mitochondrial Functionality}

Besides mutations on mitochondrial DNA, mutations in nuclear DNA (nDNA) at the level of genes encoding for mitochondrial proteins have also been associated with neurodegenerative disorders. For example, many of the identified ALS genes have a role in mitochondrial-associated functions (see [79] for a comprehensive description on this topic). In addition, mitochondrial dysfunction 
and oxidative stress in PD have been linked to mutations in genes encoding for parkin RBR E3 ubiquitin protein ligase (PRKN, commonly referred to as parkin), PTEN induced putative kinase 1 (PINK1, a protein that acts in the same pathway of parkin) and parkinsonism associated deglycase (DJ-1) [80], just to cite some of them. Parkin promotes autophagy of damaged mitochondria [81] and its deficiency is associated with defects in mitochondria morphology [82] and low levels of proteins involved in mitochondrial functions, thus resulting in decreased mitochondrial respiration [83]. Similarly, mutations in PINK1 gene lead to decreased mitochondrial respiration [84] and alterations in mitochondria functions [85-88]. Regarding DJ-1, this protein localizes into mitochondria [89] and exerts crucial antioxidant functions [80,90-92]. Mutations in DJ-1 impair mitochondrial respiration, reduce mitochondrial membrane potential, increase ROS within the mitochondria and alter mitochondrial morphology [93]. Also, nDNA encoded proteins implicated in AD, like presenilin-1 and presenilin 2 (PSEN1 and 2) are related to mitochondria [94,95].

\subsection{Alterations of Mitochondrial Dynamics (Fusion, Fission, Motility)}

Mitochondria are not rigidly structured. They form a complex reticulum that undergoes regulated processes of fusion (the combination of two smaller mitochondria into a single organelle) and fission (the division of one large mitochondrion into two smaller fragments). Fusion allows mitochondria to mix their contents, enabling protein complementation, mtDNA repair and equal distribution of metabolites. Fission facilitates equal segregation of mitochondria into daughter cells during cellular division, enhances the distribution of mitochondria along cytoskeletal tracts and participates in the targeting of damaged segments of mitochondria to the autophagic process. Fusion and fission also contribute to the movement of mitochondria necessary for mitochondria distribution along neuronal axons and dendrites. Mitochondrial dynamics are crucial for neurotransmission, synaptic maintenance and neuronal survival. Proper mitochondrial trafficking is particularly important in neurons compared to other cell types, due to their exceptional cellular morphology. Indeed, neurons extend their axons and dendrites for very long distances that, in the case of human peripheral nerves or corticospinal tracts, extend up to a meter. Thus, the neuron represents an extreme case of mitochondrial distribution: dysfunctions in mitochondrial distribution that are not dangerous for other cells could be fatal for neuronal survival [96].

Alterations in mitochondria motility have been reported in several neurodegenerative disorders and neuropathies [97,98]. Aberrant activity of the fission-fusion machinery contributes to the pathogenesis of PD [99-102]. Moreover, alterations of mitochondrial dynamics have been observed in AD [61,102] and HD [100,103]. Particularly in HD, mitochondrial fission is promoted and mitochondrial fusion proteins are downregulated as the severity of the pathology increases [104]. Finally, defects in mitochondrial dynamics and disruption of the axonal transport of mitochondria have been reported in ALS [60,105-107].

\subsection{Inappropriate Activation of Cell Apoptosis by Mitochondria}

Mitochondria are pivotal organelles for the execution of apoptosis. The inappropriate activation of apoptosis leads to the disruption of the cellular proliferation-death balance. Neurodegenerative disorders are believed to partly depend on alterations of this equilibrium. PINK1 loss-of-function mutations lead to early signals for apoptosis, promoting neurodegeneration in the context of PD [108]. Moreover, the low levels of PTPA (phosphotyrosyl phosphatase activator) observed in $\mathrm{AD}$ affected-people contribute to induce cell apoptosis in the brain of these patients [109]. Furthermore, caspase-6, an effector of the caspase-dependent apoptotic pathway, is known to be involved in the cleavage of mutant huntingtin resulting in neurodegeneration in HD patients [110]. Finally, in ALS the mutant SOD1 can trigger cytochrome c release from mitochondria to operate apoptosis [111]. 


\subsection{Alteration of Mitochondria-Dependent $\mathrm{Ca}^{2+}$ Homeostasis}

An additional neurodegenerative mechanism related to dysfunctions of mitochondria concerns the modulation of calcium. Mitochondria are involved in $\mathrm{Ca}^{2+}$ homeostasis as they are able to both accumulate and release $\mathrm{Ca}^{2+}$. Mitochondrial $\mathrm{Ca}^{2+}$ concentration is fundamental for the regulation of specific mitochondrial key functions, such as the apoptotic process and the activity of several mitochondrial enzymes. The deregulation of $\mathrm{Ca}^{2+}$ homeostasis is a hallmark of different neurodegenerative diseases including PD, AD, HD and ALS [112,113]. Moreover, alterations of calcium levels have been observed in neuropathies. Neuropathic pain phenotypes include chemotherapy induced neuropathy, diabetic neuropathy, human immunodeficiency virus (HIV)-associated neuropathy and Charcot-Marie-Tooth neuropathy. Neuropathies have been associated with mitochondrial dysfunctions [63], and particularly in diabetic neuropathy, impaired cellular calcium homeostasis, including alterations in mitochondrial $\mathrm{Ca}^{2+}$ concentration, has been reported. Indeed, in the context of diabetes, sensory neurons, above all the lumbar dorsal root ganglia neurons (which have the longest axons), show an increased intracellular $\mathrm{Ca}^{2+}$ concentration that triggers elevated mitochondrial $\mathrm{Ca}^{2+}$ levels. This condition induces mitochondrial membrane depolarization and can favor the generation of reactive oxygen species (ROS) and oxidative stress, as well as alterations in mitochondrial functionality that can ultimately lead to neuronal damage [114].

2.6. Additional Alterations of Mitochondrial-Related Processes: Biogenesis, Mitophagy, Mdvs Exchange, Interaction with Mams, Control of Cellular Metabolism

Besides the mechanisms reported above, a series of additional mechanisms involving mitochondria have been described. Among them, neurodegeneration has been associated with the impairment of mitochondrial biogenesis. Particularly, the deficit of peroxisome proliferator-activated receptor gamma coactivator- $1 \alpha$ (PGC- $1 \alpha)$, a key regulator of mitochondrial biogenesis, has been associated with HD, PD and AD [115-120].

Mitophagy is also linked to neurodegenerative disorders [121-123]. Mitophagy is the selective autophagic process responsible for the elimination of damaged or excess mitochondria. In this process, a peculiar role is played by PINK1, that recruits parkin to dysfunctional mitochondria, where it induces their degradation by mitophagy [124]. Thus, it is not surprising that in addition to other neurodegenerative disorders, defective mitophagy is highly implicated in PD and is considered one of the major pathological mechanisms of mitochondrial dysfunction in autosomal recessive forms of PD [125].

Mitophagy is a cellular process that eliminates whole mitochondria, but other mechanisms exist to partially eliminate portions or components of mitochondria [122]. Mitochondria-derived vesicles (MDVs) exchange between mitochondria and peroxisomes represent one of these possible mechanisms. MDVs are crucial for the transport of cargo from mitochondria to peroxisomes. This process is regulated by the retromer complex. Studies on vacuolar protein sorting 35 (VPS35), a component of the retromer complex, indicate that mutations or alterations in VPS35 expression are associated to PD $[126,127]$. Moreover, it has been demonstrated that Parkin and PINK1, two genes highly implicated in PD, play crucial roles in the control of this process [128,129].

Other than with peroxisomes, mitochondria also physically interact with other subcellular organelles to ensure efficient and rapid metabolism and signaling. For example, the interaction between mitochondria and the endoplasmic reticulum (ER) occurs at the level of MAMs (mitochondrial associated membranes), a subdomain of the ER. The proteins involved in neurodegenerative diseases such as DRP1 (dynamin related protein 1) and MFN2 (mitofusin 2) are enriched in MAMs [130,131] and the perturbation of mitochondria-ER contacts has been described in neurodegenerative disorders, including PD, AD and ALS [132].

A further mitochondrial-dependent mechanism has been highlighted in neurodegeneration. This is the impairment of cell metabolism [133]. Mitochondria are the main energy-producing organelles of the cell, thus any process impairing mitochondrial functionality may lead to metabolic switching 
aimed to compensate for their decreased ATP production. Among the different neurodegenerative disorders, many lines of evidence suggest that mitochondria-dependent mechanisms are responsible for the metabolic changes observed in dopaminergic neurons in the context of PD. Mitochondrial ROS are particularly abundant in dopaminergic neurons due to dopamine oxidative metabolism, enhanced Fenton's reaction initiated by the high iron content of these cells, and the high rate of ATP production required to sustain the activity of a particular L-type voltage dependent $\mathrm{Ca}^{2+}$ channel expressed by these neurons. An excess of mitochondrial ROS can induce a series of cellular modifications, including hypoxia inducible factor $1 \alpha(\mathrm{HIF} 1 \alpha)$-dependent up-regulation of glucose transporters [134], favoring the switch of energy metabolism towards glycolysis. When sustained for a long period, this metabolic change can be deleterious for dopaminergic neurons. Indeed, neurons need to deliver glucose in the pentose phosphate pathway (PPP), a process that produces NADPH (nicotinamide adenine dinucleotide phosphate), crucial for the recycling of the antioxidant glutathione. PPP is especially important in neurons as these cells show less robust antioxidant systems and are more vulnerable to oxidative stress than other cell types. Switching from PPP to glycolysis promotes oxidative stress and, consequently, neurodegeneration [135].

\section{Heme and Mitochondrial Dysfunction Related to Neurodegenerative Diseases}

The examples reported above sustain the notion that mitochondrial dysfunctions play a critical role in neurodegenerative disorders. The mitochondrion is a critical organelle for cells, representing a crossroad for a plethora of reactions contributing to a variety of metabolic processes, including heme metabolism. Considering the impact of impaired heme homeostasis in several neurodegenerative disorders and the interesting potential that heme takes on for the research in the context of neurodegeneration, it is curious to notice that heme is an under-investigated molecule in the field. This discrepancy could be due to the lack of knowledge on the possible systems through which heme can influence pivotal processes implicated in neurodegeneration. Among the possible ways, it is tempting to speculate that heme could directly or indirectly affect many of the mitochondrial-dependent mechanisms of neurodegeneration described in the previous paragraphs. Indeed, the relationship between heme and mitochondria is based on several elements (Figure 3): heme is produced through a series of reactions that occur partly in the mitochondria and partly in the cytosol [136]; heme acts as a cofactor for cytochromes $\mathrm{c}$ and cytochromes in complexes II-III-IV of the mitochondrial ETC [137]; heme has been reported to directly or indirectly influence ATP translocation between mitochondria and cytosol [138-140] mediated by adenine nucleotide translocases (ANTs); finally, heme biosynthesis is considered a cataplerotic pathway for the Kreb's cycle due to the fact that the first step of heme production consumes succynil-CoA [141,142]. Thus, modulation of heme homeostasis can affect mitochondrial functions.

Considering the mechanisms by which mitochondria contribute to neurodegeneration, it is interesting to note that heme levels can influence iron homeostasis, and both iron deficiency and iron excess are reported to cause damage on mitochondria $[143,144]$ and on mitochondrial DNA $[145,146]$. Moreover, a decrease in heme itself leads to mitochondrial decay [4,147].

Furthermore, a connection exists between heme and nDNA genes encoding mitochondrial proteins typically implicated in neurodegenerative disorders. Indeed, it has been demonstrated that amyloid precursor protein, particularly when mutated, interacts and negatively regulates the heme-degrading enzyme HO1 [148]. Also PINK1 mutation is related to alterations in HO1 expression [149]. Moreover, DJ1 regulates nuclear factor-E2-related factor 2 (NRF2) [150], a key transcription factor for the induction of HO1 expression [151]. 


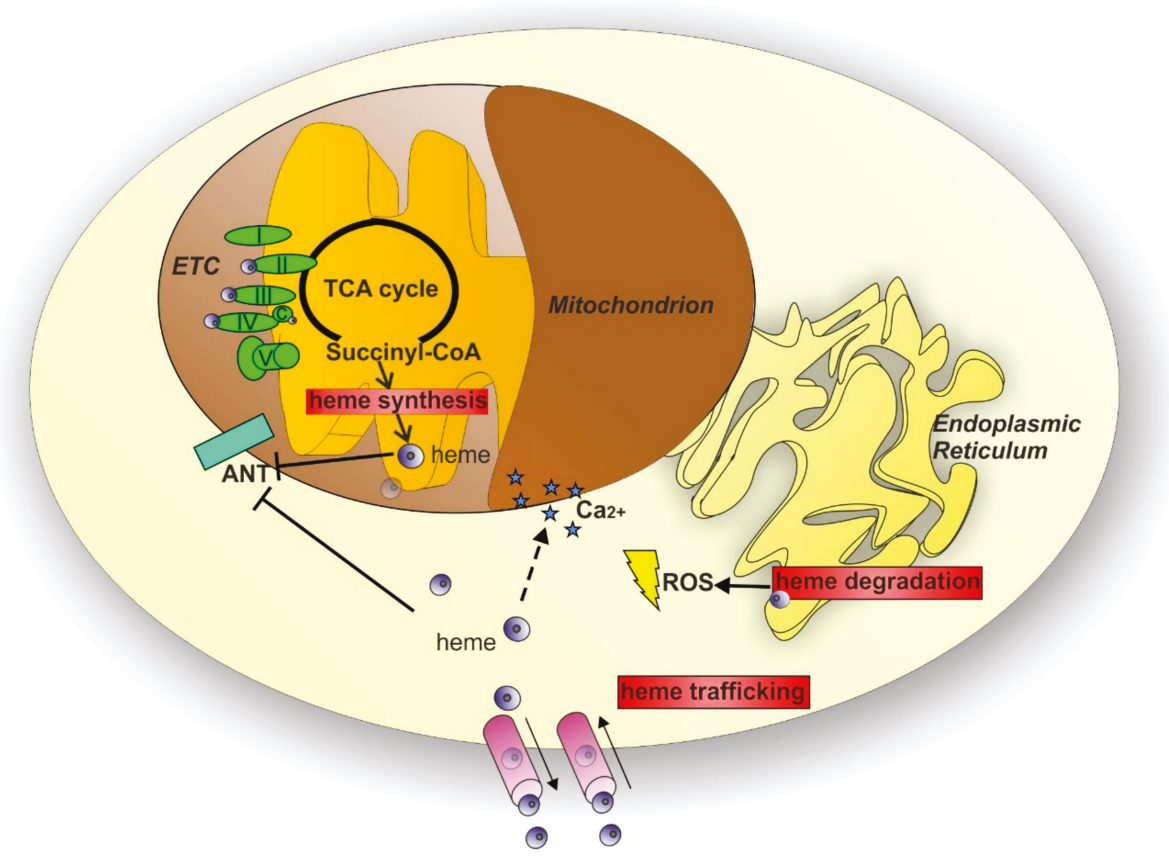

Figure 3. The "heme-mitochondria" relationship and the putative heme-related targets for the therapy of neurodegenerative disorders. Heme and mitochondria share a strong relationship based on several elements: heme synthesis occurs partly in the mitochondrion and acts as a cataplerotic pathway for the Kreb's cycle; heme is a cofactor for cytochromes c and cytochromes in complexes II-III-IV of the mitochondrial ETC [137]; heme influences the ATP translocation between mitochondria and cytosol mediated by adenine nucleotide translocases (ANTs); heme export influences calcium $\left(\mathrm{Ca}^{2+}\right.$ ) flux in mitochondria. Therefore, modulation of heme metabolism can lead to modification of mitochondrial functions. The control of intracellular heme levels is achieved by a balance among synthesis, catabolism and proper trafficking of heme. Thus, all these processes (highlighted with red boxes in the figure) represent putative good targets for the therapy of neurodegenerative disorder.

In addition, heme and the heme-degrading enzyme HO1 are implicated in the regulation of mitophagy, mitochondrial biogenesis and morphology [152-154].

In endothelial cells, it has been demonstrated that alterations in heme metabolism, in addition to promoting lipid peroxidation and activation of autophagy, induce mitophagy and apoptosis, indicating mitochondrial dysfunction [155]. Similarly, FLVCR1 loss is associated with alterations in mitochondrial morphology in human microvascular endothelial cells [26].

Furthermore, FLVCR1-deficient HeLa cells show impaired mitochondrial calcium uptake [156].

These data have been obtained in non-neuronal cells. However, similar mechanisms could also occur in neuronal cells.

Finally, compromised ETC complexes activity has been observed in the brain of a mouse model for acute intermittent porphyria, a type of porphyric neuropathy caused by alterations of heme biosynthesis [157]. Moreover, in three cases of Fowler syndrome it was suggested to be the presence of a defect in complex III and IV of the ETC [158,159].

These examples directly suggest that a connection between heme-mitochondrianeurodegeneration exists and open the possibility that future studies on this topic will further strengthen this notion. 


\section{Current Therapies and Potential Future Approaches to Face Mitochondrial Dysfunction in Neurodegenerative Diseases}

Currently, there is no cure for reversing neurodegeneration and the treatment of neurodegenerative disorders is mainly symptomatic [160]. In order to face neurodegeneration, several pathways could be targeted to improve and/or restore mitochondrial functions, including mitochondrial biogenesis and metabolic flexibility, mitochondrial dynamics and mitophagy [161].

There are several pharmacological approaches to induce mitochondrial biogenesis and metabolic flexibility, that is the ability to switch from one fuel source to another. Several compounds have been generated to target the upstream sensors of energy production, including AMP-activated protein kinase (AMPK), mammalian target of rapamycin (mTOR) and sirtuins, or downstream transcriptional factors and co-factors, such as nuclear receptors, nuclear respiratory factor 1 (NRF1) and mitochondrial transcription factor A (TFAM) [161]. The therapeutic potential of these drugs has been evaluated mostly in the context of metabolic diseases, but also seems promising for neurodegeneration. For example, resveratrol is a natural compound that mimics caloric restriction and activates the sirtuin family of histone deacetylases. In humans, resveratrol improves mitochondrial function in obese patients and type 2 diabetes [162]. Furthermore, resveratrol counteracts neurodegeneration in worms and mice [163].

As described above, the disruption of the balance between mitochondrial fusion and fission contributes to neurodegeneration. Therefore, targeting mitochondrial dynamics represents another important strategy to improve mitochondrial function in neurodegenerative diseases. Strategies aimed at increasing mitochondrial fusion or inhibiting mitochondrial fission might improve mitochondrial function and are therapeutically interesting. The promotion of mitochondrial fusion by the overexpression of key components of the fusion machinery, like MFN2 or OPA1, rescues ATP production and mitochondrial morphology in a cellular model of PD [164]. Similar results were obtained with the inhibition of fission through the genetic deletion of DRP1 [164,165]. Although the understanding of the regulation of mitochondrial dynamics is still in its infancy, novel compounds have been identified to promote fusion or inhibit fission [166]. M1 hydrazone [167] and S3-derivative [168] promote mitochondrial fusion in cells deficient for mitofusin 1 (MFN1) and MFN2. Mdivi-1 (mitochondrial division inhibitor) attenuates fission in yeast and mammalian cells by inhibiting DRP1. In vitro, Mdivi-1 delays apoptosis by inhibiting mitochondrial outer membrane permeabilization and blocking cytochrome c release from mitochondria [169]. The therapeutic potential of Mdivi-1 seems promising for neurodegenerative disorders. Indeed, the administration of Mdivi-1 in mouse and cellular models of PD attenuates disease-associated phenotypes [165,170]. Although initially reported as an inhibitor of fission, Mdivi-1 was recently reported to reversibly inhibit complex I in a DRP1-independent manner [171]. The complete inhibition of complex I in vivo would be expected to cause neurodegeneration. Indeed, rotenone completely inhibits complex I, induces ROS levels and causes parkinsonian neurodegeneration in mice [172]. In contrast, Mdivi-1 lacks neuronal toxicity in vivo and is neuroprotective. This is likely due to the ability of Mdivi-1 to attenuate complex I-dependent reverse electron transfer (RET)-mediated ROS production. Indeed, Mdivi-1 fails to increase ROS levels in intact neurons and in isolated brain mitochondria [171].

The accumulation of dysfunctional mitochondria is another key event in several neurodegenerative conditions [173,174]. In this context, mitophagy is essential for the maintenance of mitochondrial integrity. As stated before in this review, the impairment of autophagy/mitophagy is common in neurodegenerative disorders. Therefore, mitophagy may be an additional pathway amenable for therapeutic intervention to ameliorate mitochondria function and counteract neurodegeneration [161,175]. Interestingly, both genetic and pharmacological induction of the mitochondrial autophagy receptor Nip3-like protein X (NIX) restores mitophagy in patient-derived fibroblasts [176].

Considering the crucial role of heme in maintaining mitochondrial function, it is tempting to speculate that targeting heme metabolism might be a promising strategy for the treatment of 
neurodegenerative diseases. Multiple approaches can be used to target heme metabolism (Figure 3); theoretically, targeting any of the enzymes involved in the heme biosynthetic pathway or proteins involved in the control of the intracellular heme pool may be a good strategy. Among these methods, HO1 represents a potentially interesting target. Due to its anti-oxidant and anti-inflammatory properties, HO1 plays a well-established neuroprotective role. The improvement of $\mathrm{HO} 1$ expression has been initially proposed for neurodegenerative conditions [177]. However, it has been reported that the overexpression of HO1 induces oxidative mitochondrial damage [178,179] and macroautophagy [179] in cultured astroglia. More importantly, $\mathrm{HO} 1$ induction has been associated with the later phases of neurodegeneration [180] and the deletion of HO1 has been proposed as a therapeutic option [181]. $\mathrm{HO} 1$ activity can be suppressed by synthetic metalloporphyrin compounds that unfortunately present important limitations [182]. However, novel HO1 inhibitors have been synthesized to overcome these side effects. Interestingly, these inhibitors confer neuroprotection in a mouse model of AD [182]. Considering the complex role of $\mathrm{HO} 1$ in neurodegeneration and the still controversial data reported in literature [180], further work is needed to fully elucidate the therapeutic potential of HO1 targeting. Recently, long-term 5-aminolevulinic acid (ALA) treatment has been exploited as a therapeutic approach in a mouse model of AD. Omori C. et al. reported that the oral administration of ALA increased cytochrome $c$ oxidase (COX) activity and protein expression as well as mitochondrial membrane potential in the brain of treated mice [183]. Additional studies are required to understand more in detail the functional consequences of ALA administration in AD pathogenesis and the translation of this therapeutic approach to other neurodegenerative disorders. Considering that ALA formulations are already used for photodynamic therapy in a variety of cancer types [184], results obtained by Omori C. et al. are extremely encouraging for therapeutic purposes and further research in this direction is desirable.

\section{Conclusions}

The information reported over the course of the present review showed that mitochondria participate to neurodegenerative disorders by different mechanisms, encompassing DNA mutations, mitobiogenesis, mitophagy, mitochondrial dynamics, metabolism and mitochondrial interactions with other organelles. The literary contributions on the role of mitochondria in neurodegeneration are constantly growing and the present review attempted to make an excursus on the most important mechanisms by which these crucial organelles contribute to neurodegenerative diseases, with the awareness that not all the wide literature on this topic has been covered. Some of these mechanisms are currently considered as strategic targets for pharmacological interventions to counteract neurodegeneration. However, the investigation on additional elements contributing to the control of mitochondrial functions in neuronal cells will offer a wider window of intervention. In this perspective, heme metabolism provides an interesting opportunity. Indeed, as reported above in the review, heme participates to crucial processes occurring in mitochondria, influencing their functions and properties. The tight relationship between heme and the mitochondrion has been curiously underestimated and poorly investigated in the context of neurodegeneration. However, the implication of heme in crucial mitochondrial functions and the involvement of heme in a subset of neurodegenerative diseases strongly suggest an implication of heme in these disorders.

The comprehension of these mechanisms will allow the consideration of possible therapies based on the targeting of heme metabolism as an additional option to promote mitochondrial function. Alternatively, targeting heme metabolism may improve the efficacy of other drugs targeting mitochondria. The hope is that the understanding of the role of heme in mitochondria and its implication in neurodegeneration will open new perspectives in the struggle against neurodegenerative diseases.

Funding: This research was funded by University of Torino (Bando Ricerca Locale ex-60\%).

Conflicts of Interest: The authors declare no conflicts of interest. 


\section{References}

1. Chiabrando, D.; Vinchi, F.; Fiorito, V.; Mercurio, S.; Tolosano, E. Heme in pathophysiology: A matter of scavenging, metabolism and trafficking across cell membranes. Front. Pharmacol. 2014, 5, 61. [CrossRef] [PubMed]

2. Zhu, Y.; Hon, T.; Ye, W.; Zhang, L. Heme deficiency interferes with the Ras-mitogen-activated protein kinase signaling pathway and expression of a subset of neuronal genes. Cell Growth Differ. 2002, 13, 431-439. [PubMed]

3. Sengupta, A.; Hon, T.; Zhang, L. Heme deficiency suppresses the expression of key neuronal genes and causes neuronal cell death. Brain Res. Mol. Brain Res. 2005, 137, 23-30. [CrossRef] [PubMed]

4. Atamna, H.; Killilea, D.W.; Killilea, A.N.; Ames, B.N. Heme deficiency may be a factor in the mitochondrial and neuronal decay of aging. Proc. Natl. Acad. Sci. USA 2002, 99, 14807-14812. [CrossRef] [PubMed]

5. Righy, C.; Bozza, M.T.; Oliveira, M.F.; Bozza, F.A. Molecular, Cellular and Clinical Aspects of Intracerebral Hemorrhage: Are the Enemies Within? Curr. Neuropharmacol. 2016, 14, 392-402. [CrossRef] [PubMed]

6. Ma, B.; Day, J.P.; Phillips, H.; Slootsky, B.; Tolosano, E.; Doré, S. Deletion of the hemopexin or heme oxygenase-2 gene aggravates brain injury following stroma-free hemoglobin-induced intracerebral hemorrhage. J. Neuroinflamm. 2016, 13, 26. [CrossRef] [PubMed]

7. Hahl, P.; Davis, T.; Washburn, C.; Rogers, J.T.; Smith, A. Mechanisms of neuroprotection by hemopexin: Modeling the control of heme and iron homeostasis in brain neurons in inflammatory states. J. Neurochem. 2013, 125, 89-101. [CrossRef] [PubMed]

8. Morello, N.; Tonoli, E.; Logrand, F.; Fiorito, V.; Fagoonee, S.; Turco, E.; Silengo, L.; Vercelli, A.; Altruda, F.; Tolosano, E. Haemopexin affects iron distribution and ferritin expression in mouse brain. J. Cell. Mol. Med. 2009, 13, 4192-4204. [CrossRef] [PubMed]

9. Morello, N.; Bianchi, F.T.; Marmiroli, P.; Tonoli, E.; Rodriguez Menendez, V.; Silengo, L.; Cavaletti, G.; Vercelli, A.; Altruda, F.; Tolosano, E. A role for hemopexin in oligodendrocyte differentiation and myelin formation. PLoS ONE 2011, 6, e20173. [CrossRef] [PubMed]

10. Tolosano, E.; Fagoonee, S.; Morello, N.; Vinchi, F.; Fiorito, V. Heme scavenging and the other facets of hemopexin. Antioxid. Redox Signal. 2010, 12, 305-320. [CrossRef] [PubMed]

11. Chiabrando, D.; Castori, M.; di Rocco, M.; Ungelenk, M.; Gießelmann, S.; Di Capua, M.; Madeo, A.; Grammatico, P.; Bartsch, S.; Hübner, C.A.; et al. Mutations in the Heme Exporter FLVCR1 Cause Sensory Neurodegeneration with Loss of Pain Perception. PLoS Genet. 2016, 12, e1006461. [CrossRef] [PubMed]

12. Chiabrando, D.; Vinchi, F.; Fiorito, V.; Tolosano, E. Haptoglobin and Hemopexin in Heme Detoxification and Iron Recycling. In Acute Phase Proteins Francisco Veas; IntechOpen: London, UK, 2011; pp. 262-288.

13. Blackburn, S.L.; Kumar, P.T.; McBride, D.; Zeineddine, H.A.; Leclerc, J.; Choi, H.A.; Dash, P.K.; Grotta, J.; Aronowski, J.; Cardenas, J.C.; et al. Unique Contribution of Haptoglobin and Haptoglobin Genotype in Aneurysmal Subarachnoid Hemorrhage. Front. Physiol. 2018, 9, 592. [CrossRef] [PubMed]

14. Marro, S.; Barisani, D.; Chiabrando, D.; Fagoonee, S.; Muckenthaler, M.U.; Stolte, J.; Meneveri, R.; Haile, D.; Silengo, L.; Altruda, F.; et al. Lack of haptoglobin affects iron transport across duodenum by modulating ferroportin expression. Gastroenterology 2007, 133, 1261-1271. [CrossRef] [PubMed]

15. Reddi, A.R.; Hamza, I. Heme Mobilization in Animals: A Metallolipid's Journey. Acc. Chem. Res. 2016, 49, 1104-1110. [CrossRef] [PubMed]

16. Gozzelino, R. The Pathophysiology of Heme in the Brain. Curr. Alzheimer Res. 2016, 13, 174-184. [CrossRef] [PubMed]

17. Erkkinen, M.G.; Kim, M.O.; Geschwind, M.D. Clinical Neurology and Epidemiology of the Major Neurodegenerative Diseases. Cold Spring Harb. Perspect. Biol. 2018, 10, a033118. [CrossRef] [PubMed]

18. Tracy, J.A.; Dyck, P.J. Porphyria and its neurologic manifestations. Handb. Clin. Neurol. 2014, 120, 839-849. [CrossRef] [PubMed]

19. Albers, J.W.; Fink, J.K. Porphyric neuropathy. Muscle Nerve 2004, 30, 410-422. [CrossRef] [PubMed]

20. Simon, N.G.; Herkes, G.K. The neurologic manifestations of the acute porphyrias. J. Clin. Neurosci. 2011, 18, 1147-1153. [CrossRef] [PubMed]

21. Campuzano, V.; Montermini, L.; Moltò, M.D.; Pianese, L.; Cossée, M.; Cavalcanti, F.; Monros, E.; Rodius, F.; Duclos, F.; Monticelli, A.; et al. Friedreich's ataxia: Autosomal recessive disease caused by an intronic GAA triplet repeat expansion. Science 1996, 271, 1423-1427. [CrossRef] [PubMed] 
22. Yoon, T.; Cowan, J.A. Frataxin-mediated iron delivery to ferrochelatase in the final step of heme biosynthesis. J. Biol. Chem. 2004, 279, 25943-25946. [CrossRef] [PubMed]

23. Lange, H.; Mühlenhoff, U.; Denzel, M.; Kispal, G.; Lill, R. The heme synthesis defect of mutants impaired in mitochondrial iron-sulfur protein biogenesis is caused by reversible inhibition of ferrochelatase. J. Biol. Chem. 2004, 279, 29101-29108. [CrossRef] [PubMed]

24. Schoenfeld, R.A.; Napoli, E.; Wong, A.; Zhan, S.; Reutenauer, L.; Morin, D.; Buckpitt, A.R.; Taroni, F.; Lonnerdal, B.; Ristow, M.; et al. Frataxin deficiency alters heme pathway transcripts and decreases mitochondrial heme metabolites in mammalian cells. Hum. Mol. Genet. 2005, 14, 3787-3799. [CrossRef] [PubMed]

25. Chernova, T.; Nicotera, P.; Smith, A.G. Heme deficiency is associated with senescence and causes suppression of $\mathrm{N}$-methyl-D-aspartate receptor subunits expression in primary cortical neurons. Mol. Pharmacol. 2006, 69, 697-705. [CrossRef] [PubMed]

26. Petrillo, S.; Chiabrando, D.; Genova, T.; Fiorito, V.; Ingoglia, G.; Vinchi, F.; Mussano, F.; Carossa, S.; Silengo, L.; Altruda, F.; et al. Heme accumulation in endothelial cells impairs angiogenesis by triggering paraptosis. Cell Death Differ. 2018, 25, 573-588. [CrossRef] [PubMed]

27. Vinchi, F.; Ingoglia, G.; Chiabrando, D.; Mercurio, S.; Turco, E.; Silengo, L.; Altruda, F.; Tolosano, E. Heme exporter FLVCR1a regulates heme synthesis and degradation and controls activity of cytochromes P450. Gastroenterology 2014, 146, 1325-1338. [CrossRef] [PubMed]

28. Fiorito, V.; Neri, F.; Pala, V.; Silengo, L.; Oliviero, S.; Altruda, F.; Tolosano, E. Hypoxia controls Flvcr1 gene expression in Caco2 cells through HIF2 $\alpha$ and ETS1. Biochim. Biophys. Acta 2014, 1839, 259-264. [CrossRef] [PubMed]

29. Fiorito, V.; Forni, M.; Silengo, L.; Altruda, F.; Tolosano, E. Crucial Role of FLVCR1a in the Maintenance of Intestinal Heme Homeostasis. Antioxid. Redox Signal. 2015, 23, 1410-1423. [CrossRef] [PubMed]

30. Duffy, S.P.; Shing, J.; Saraon, P.; Berger, L.C.; Eiden, M.V.; Wilde, A.; Tailor, C.S. The Fowler syndromeassociated protein FLVCR2 is an importer of heme. Mol. Cell. Biol. 2010, 30, 5318-5324. [CrossRef] [PubMed]

31. Quigley, J.G.; Yang, Z.; Worthington, M.T.; Phillips, J.D.; Sabo, K.M.; Sabath, D.E.; Berg, C.L.; Sassa, S.; Wood, B.L.; Abkowitz, J.L. Identification of a human heme exporter that is essential for erythropoiesis. Cell 2004, 118, 757-766. [CrossRef] [PubMed]

32. Rajadhyaksha, A.M.; Elemento, O.; Puffenberger, E.G.; Schierberl, K.C.; Xiang, J.Z.; Putorti, M.L.; Berciano, J.; Poulin, C.; Brais, B.; Michaelides, M.; et al. Mutations in FLVCR1 cause posterior column ataxia and retinitis pigmentosa. Am. J. Hum. Genet. 2010, 87, 643-654. [CrossRef] [PubMed]

33. Ishiura, H.; Fukuda, Y.; Mitsui, J.; Nakahara, Y.; Ahsan, B.; Takahashi, Y.; Ichikawa, Y.; Goto, J.; Sakai, T.; Tsuji, S. Posterior column ataxia with retinitis pigmentosa in a Japanese family with a novel mutation in FLVCR1. Neurogenetics 2011, 12, 117-121. [CrossRef] [PubMed]

34. Shaibani, A.; Wong, L.J.; Wei Zhang, V.; Lewis, R.A.; Shinawi, M. Autosomal recessive posterior column ataxia with retinitis pigmentosa caused by novel mutations in the FLVCR1 gene. Int. J. Neurosci. 2015, 125, 43-49. [CrossRef] [PubMed]

35. Tiwari, A.; Bahr, A.; Bähr, L.; Fleischhauer, J.; Zinkernagel, M.S.; Winkler, N.; Barthelmes, D.; Berger, L.; Gerth-Kahlert, C.; Neidhardt, J.; et al. Next generation sequencing based identification of disease-associated mutations in Swiss patients with retinal dystrophies. Sci. Rep. 2016, 6, 28755. [CrossRef] [PubMed]

36. Yusuf, I.H.; Shanks, M.E.; Clouston, P.; MacLaren, R.E. A splice-site variant in FLVCR1 produces retinitis pigmentosa without posterior column ataxia. Ophthalmic Genet. 2018, 39, 263-267. [CrossRef] [PubMed]

37. Castori, M.; Morlino, S.; Ungelenk, M.; Pareyson, D.; Salsano, E.; Grammatico, P.; Tolosano, E.; Kurth, I.; Chiabrando, D. Posterior column ataxia with retinitis pigmentosa coexisting with sensory-autonomic neuropathy and leukemia due to the homozygous p.Pro221Ser FLVCR1 mutation. Am. J. Med. Genet. B Neuropsychiatr. Genet. 2017, 174, 732-739. [CrossRef] [PubMed]

38. Meyer, E.; Ricketts, C.; Morgan, N.V.; Morris, M.R.; Pasha, S.; Tee, L.J.; Rahman, F.; Bazin, A.; Bessières, B.; Déchelotte, P.; et al. Mutations in FLVCR2 are associated with proliferative vasculopathy and hydranencephaly-hydrocephaly syndrome (Fowler syndrome). Am. J. Hum. Genet. 2010, 86, 471-478. [CrossRef] [PubMed]

39. Kvarnung, M.; Taylan, F.; Nilsson, D.; Albåge, M.; Nordenskjöld, M.; Anderlid, B.M.; Nordgren, A.; Syk Lundberg, E. Mutations in FLVCR2 associated with Fowler syndrome and survival beyond infancy. Clin. Genet. 2016, 89, 99-103. [CrossRef] [PubMed] 
40. Dwyer, B.E.; Smith, M.A.; Richardson, S.L.; Perry, G.; Zhu, X. Down-regulation of aminolevulinate synthase, the rate-limiting enzyme for heme biosynthesis in Alzheimer's disease. Neurosci. Lett. 2009, 460, 180-184. [CrossRef] [PubMed]

41. Atamna, H.; Frey, W.H. A role for heme in Alzheimer's disease: Heme binds amyloid beta and has altered metabolism. Proc. Natl. Acad. Sci. USA 2004, 101, 11153-11158. [CrossRef] [PubMed]

42. Atamna, H. Heme binding to Amyloid-beta peptide: Mechanistic role in Alzheimer's disease. J. Alzheimers Dis. 2006, 10, 255-266. [CrossRef] [PubMed]

43. Smith, A.G.; Raven, E.L.; Chernova, T. The regulatory role of heme in neurons. Metallomics 2011, 3, $955-962$. [CrossRef] [PubMed]

44. Hayden, E.Y.; Kaur, P.; Williams, T.L.; Matsui, H.; Yeh, S.R.; Rousseau, D.L. Heme Stabilization of $\alpha$-Synuclein Oligomers during Amyloid Fibril Formation. Biochemistry 2015, 54, 4599-4610. [CrossRef] [PubMed]

45. Santiago, J.A.; Potashkin, J.A. Blood Transcriptomic Meta-analysis Identifies Dysregulation of Hemoglobin and Iron Metabolism in Parkinson' Disease. Front. Aging Neurosci. 2017, 9, 73. [CrossRef] [PubMed]

46. Scherzer, C.R.; Grass, J.A.; Liao, Z.; Pepivani, I.; Zheng, B.; Eklund, A.C.; Ney, P.A.; Ng, J.; McGoldrick, M.; Mollenhauer, B.; et al. GATA transcription factors directly regulate the Parkinson's disease-linked gene alpha-synuclein. Proc. Natl. Acad. Sci. USA 2008, 105, 10907-10912. [CrossRef] [PubMed]

47. Sampaio, T.B.; Marcondes Sari, M.H.; Pesarico, A.P.; Nogueira, C.W. $\delta$-Aminolevulinate Dehydratase Activity is Stimulated in a MPTP Mouse Model of Parkinson's Disease: Correlation with Myeloperoxidase Activity. Cell. Mol. Neurobiol. 2017, 37, 911-917. [CrossRef] [PubMed]

48. Ringman, J.M.; Schulman, H.; Becker, C.; Jones, T.; Bai, Y.; Immermann, F.; Cole, G.; Sokolow, S.; Gylys, K.; Geschwind, D.H.; et al. Proteomic changes in cerebrospinal fluid of presymptomatic and affected persons carrying familial Alzheimer disease mutations. Arch. Neurol. 2012, 69, 96-104. [CrossRef] [PubMed]

49. Roher, A.E.; Maarouf, C.L.; Sue, L.I.; Hu, Y.; Wilson, J.; Beach, T.G. Proteomics-derived cerebrospinal fluid markers of autopsy-confirmed Alzheimer's disease. Biomarkers 2009, 14, 493-501. [CrossRef] [PubMed]

50. Castaño, E.M.; Roher, A.E.; Esh, C.L.; Kokjohn, T.A.; Beach, T. Comparative proteomics of cerebrospinal fluid in neuropathologically-confirmed Alzheimer's disease and non-demented elderly subjects. Neurol. Res. 2006, 28, 155-163. [CrossRef] [PubMed]

51. Song, I.U.; Kim, Y.D.; Chung, S.W.; Cho, H.J. Association between serum haptoglobin and the pathogenesis of Alzheimer's disease. Intern. Med. 2015, 54, 453-457. [CrossRef] [PubMed]

52. Cocciolo, A.; Di Domenico, F.; Coccia, R.; Fiorini, A.; Cai, J.; Pierce, W.M.; Mecocci, P.; Butterfield, D.A.; Perluigi, M. Decreased expression and increased oxidation of plasma haptoglobin in Alzheimer disease: Insights from redox proteomics. Free Radic. Biol. Med. 2012, 53, 1868-1876. [CrossRef] [PubMed]

53. de Farias, C.C.; Maes, M.; Bonifacio, K.L.; Matsumoto, A.K.; Bortolasci, C.C.; Nogueira, A.S.; Brinholi, F.F.; Morimoto, H.K.; de Melo, L.B.; Moreira, E.G.; et al. Parkinson's Disease is Accompanied by Intertwined Alterations in Iron Metabolism and Activated Immune-inflammatory and Oxidative Stress Pathways. CNS Neurol. Disord. Drug Targets 2017, 16, 484-491. [CrossRef] [PubMed]

54. Argüelles, S.; Venero, J.L.; García-Rodriguez, S.; Tomas-Camardiel, M.; Ayala, A.; Cano, J.; Machado, A. Use of haptoglobin and transthyretin as potential biomarkers for the preclinical diagnosis of Parkinson's disease. Neurochem. Int. 2010, 57, 227-234. [CrossRef] [PubMed]

55. Huang, Y.C.; Wu, Y.R.; Tseng, M.Y.; Chen, Y.C.; Hsieh, S.Y.; Chen, C.M. Increased prothrombin, apolipoprotein A-IV, and haptoglobin in the cerebrospinal fluid of patients with Huntington's disease. PLoS ONE 2011, 6, e15809. [CrossRef] [PubMed]

56. Gajowiak, A.; Styś, A.; Starzyński, R.R.; Bednarz, A.; Lenartowicz, M.; Staroń, R.; Lipiński, P. Mice Overexpressing Both Non-Mutated Human SOD1 and Mutated SOD1(G93A) Genes: A Competent Experimental Model for Studying Iron Metabolism in Amyotrophic Lateral Sclerosis. Front. Mol. Neurosci. 2015, 8, 82. [CrossRef] [PubMed]

57. Calingasan, N.Y.; Chen, J.; Kiaei, M.; Beal, M.F. Beta-amyloid 42 accumulation in the lumbar spinal cord motor neurons of amyotrophic lateral sclerosis patients. Neurobiol. Dis. 2005, 19, 340-347. [CrossRef] [PubMed]

58. Arun, S.; Liu, L.; Donmez, G. Mitochondrial Biology and Neurological Diseases. Curr. Neuropharmacol. 2016, 14, 143-154. [CrossRef] [PubMed]

59. Bose, A.; Beal, M.F. Mitochondrial dysfunction in Parkinson's disease. J. Neurochem. 2016, 139 (Suppl. 1), 216-231. [CrossRef] 
60. Shi, P.; Gal, J.; Kwinter, D.M.; Liu, X.; Zhu, H. Mitochondrial dysfunction in amyotrophic lateral sclerosis. Biochim. Biophys. Acta 2010, 1802, 45-51. [CrossRef] [PubMed]

61. Cabezas-Opazo, F.A.; Vergara-Pulgar, K.; Pérez, M.J.; Jara, C.; Osorio-Fuentealba, C.; Quintanilla, R.A. Mitochondrial Dysfunction Contributes to the Pathogenesis of Alzheimer's Disease. Oxid. Med. Cell. Longev. 2015, 2015, 509654. [CrossRef] [PubMed]

62. Costa, V.; Scorrano, L. Shaping the role of mitochondria in the pathogenesis of Huntington's disease. EMBO J. 2012, 31, 1853-1864. [CrossRef] [PubMed]

63. Bennett, G.J.; Doyle, T.; Salvemini, D. Mitotoxicity in distal symmetrical sensory peripheral neuropathies. Nat. Rev. Neurol. 2014, 10, 326-336. [CrossRef] [PubMed]

64. Larsson, N.G. Somatic mitochondrial DNA mutations in mammalian aging. Annu. Rev. Biochem. 2010, 79, 683-706. [CrossRef] [PubMed]

65. Chinnery, P.F.; Hudson, G. Mitochondrial genetics. Br. Med. Bull. 2013, 106, 135-159. [CrossRef] [PubMed]

66. Keogh, M.J.; Chinnery, P.F. Mitochondrial DNA mutations in neurodegeneration. Biochim. Biophys. Acta 2015, 1847, 1401-1411. [CrossRef] [PubMed]

67. Cha, M.Y.; Kim, D.K.; Mook-Jung, I. The role of mitochondrial DNA mutation on neurodegenerative diseases. Exp. Mol. Med. 2015, 47, e150. [CrossRef] [PubMed]

68. Nissanka, N.; Moraes, C.T. Mitochondrial DNA damage and reactive oxygen species in neurodegenerative disease. FEBS Lett. 2018, 592, 728-742. [CrossRef] [PubMed]

69. Pinto, M.; Moraes, C.T. Mitochondrial genome changes and neurodegenerative diseases. Biochim. Biophys. Acta 2014, 1842, 1198-1207. [CrossRef] [PubMed]

70. Kraytsberg, Y.; Kudryavtseva, E.; McKee, A.C.; Geula, C.; Kowall, N.W.; Khrapko, K. Mitochondrial DNA deletions are abundant and cause functional impairment in aged human substantia nigra neurons. Nat. Genet. 2006, 38, 518-520. [CrossRef] [PubMed]

71. Bender, A.; Krishnan, K.J.; Morris, C.M.; Taylor, G.A.; Reeve, A.K.; Perry, R.H.; Jaros, E.; Hersheson, J.S.; Betts, J.; Klopstock, T.; et al. High levels of mitochondrial DNA deletions in substantia nigra neurons in aging and Parkinson disease. Nat. Genet. 2006, 38, 515-517. [CrossRef] [PubMed]

72. Ikebe, S.; Tanaka, M.; Ozawa, T. Point mutations of mitochondrial genome in Parkinson's disease. Brain Res. Mol. Brain Res. 1995, 28, 281-295. [CrossRef]

73. Perier, C.; Bender, A.; García-Arumí, E.; Melià, M.J.; Bové, J.; Laub, C.; Klopstock, T.; Elstner, M.; Mounsey, R.B.; Teismann, P.; et al. Accumulation of mitochondrial DNA deletions within dopaminergic neurons triggers neuroprotective mechanisms. Brain 2013, 136, 2369-2378. [CrossRef] [PubMed]

74. Dai, Y.; Clark, J.; Zheng, K.; Kujoth, G.C.; Prolla, T.A.; Simon, D.K. Somatic mitochondrial DNA mutations do not increase neuronal vulnerability to MPTP in young POLG mutator mice. Neurotoxicol. Teratol. 2014, 46, 62-67. [CrossRef] [PubMed]

75. Parkinson, G.M.; Dayas, C.V.; Smith, D.W. Increased mitochondrial DNA deletions in substantia nigra dopamine neurons of the aged rat. Curr. Aging Sci. 2014, 7, 155-160. [CrossRef] [PubMed]

76. Siddiqui, A.; Rivera-Sánchez, S.; Castro, M.E.R.; Acevedo-Torres, K.; Rane, A.; Torres-Ramos, C.A.; Nicholls, D.G.; Andersen, J.K.; Ayala-Torres, S. Mitochondrial DNA damage is associated with reduced mitochondrial bioenergetics in Huntington's disease. Free Radic. Biol. Med. 2012, 53, 1478-1488. [CrossRef] [PubMed]

77. Phillips, N.R.; Simpkins, J.W.; Roby, R.K. Mitochondrial DNA deletions in Alzheimer's brains: A review. Alzheimers Dement. 2014, 10, 393-400. [CrossRef] [PubMed]

78. Gerschütz, A.; Heinsen, H.; Grünblatt, E.; Wagner, A.K.; Bartl, J.; Meissner, C.; Fallgatter, A.J.; Al-Sarraj, S.; Troakes, C.; Ferrer, I.; et al. Neuron-specific mitochondrial DNA deletion levels in sporadic Alzheimer's disease. Curr. Alzheimer Res. 2013, 10, 1041-1046. [CrossRef] [PubMed]

79. Smith, E.F.; Shaw, P.J.; De Vos, K.J. The role of mitochondria in amyotrophic lateral sclerosis. Neurosci. Lett. 2017. [CrossRef] [PubMed]

80. Bekris, L.M.; Mata, I.F.; Zabetian, C.P. The genetics of Parkinson disease. J. Geriatr. Psychiatry Neurol. 2010, 23, 228-242. [CrossRef] [PubMed]

81. Narendra, D.; Tanaka, A.; Suen, D.F.; Youle, R.J. Parkin is recruited selectively to impaired mitochondria and promotes their autophagy. J. Cell Biol. 2008, 183, 795-803. [CrossRef] [PubMed] 
82. Greene, J.C.; Whitworth, A.J.; Kuo, I.; Andrews, L.A.; Feany, M.B.; Pallanck, L.J. Mitochondrial pathology and apoptotic muscle degeneration in Drosophila parkin mutants. Proc. Natl. Acad. Sci. USA 2003, 100, 4078-4083. [CrossRef] [PubMed]

83. Palacino, J.J.; Sagi, D.; Goldberg, M.S.; Krauss, S.; Motz, C.; Wacker, M.; Klose, J.; Shen, J. Mitochondrial dysfunction and oxidative damage in parkin-deficient mice. J. Biol. Chem. 2004, 279, 18614-18622. [CrossRef] [PubMed]

84. Gautier, C.A.; Kitada, T.; Shen, J. Loss of PINK1 causes mitochondrial functional defects and increased sensitivity to oxidative stress. Proc. Natl. Acad. Sci. USA 2008, 105, 11364-11369. [CrossRef] [PubMed]

85. Heeman, B.; Van den Haute, C.; Aelvoet, S.A.; Valsecchi, F.; Rodenburg, R.J.; Reumers, V.; Debyser, Z.; Callewaert, G.; Koopman, W.J.; Willems, P.H.; et al. Depletion of PINK1 affects mitochondrial metabolism, calcium homeostasis and energy maintenance. J. Cell Sci. 2011, 124, 1115-1125. [CrossRef] [PubMed]

86. Clark, I.E.; Dodson, M.W.; Jiang, C.; Cao, J.H.; Huh, J.R.; Seol, J.H.; Yoo, S.J.; Hay, B.A.; Guo, M. Drosophila pink1 is required for mitochondrial function and interacts genetically with parkin. Nature 2006, 441, 1162-1166. [CrossRef] [PubMed]

87. Park, J.; Lee, S.B.; Lee, S.; Kim, Y.; Song, S.; Kim, S.; Bae, E.; Kim, J.; Shong, M.; Kim, J.M.; et al. Mitochondrial dysfunction in Drosophila PINK1 mutants is complemented by parkin. Nature 2006, 441, 1157-1161. [CrossRef] [PubMed]

88. Truban, D.; Hou, X.; Caulfield, T.R.; Fiesel, F.C.; Springer, W. PINK1, Parkin, and Mitochondrial Quality Control: What can we Learn about Parkinson's Disease Pathobiology? J. Parkinsons Dis. 2017, 7, 13-29. [CrossRef] [PubMed]

89. Zhang, L.; Shimoji, M.; Thomas, B.; Moore, D.J.; Yu, S.W.; Marupudi, N.I.; Torp, R.; Torgner, I.A.; Ottersen, O.P.; Dawson, T.M.; et al. Mitochondrial localization of the Parkinson's disease related protein DJ-1: Implications for pathogenesis. Hum. Mol. Genet. 2005, 14, 2063-2073. [CrossRef] [PubMed]

90. Taira, T.; Saito, Y.; Niki, T.; Iguchi-Ariga, S.M.; Takahashi, K.; Ariga, H. DJ-1 has a role in antioxidative stress to prevent cell death. EMBO Rep. 2004, 5, 213-218. [CrossRef] [PubMed]

91. Zhou, W.; Freed, C.R. DJ-1 up-regulates glutathione synthesis during oxidative stress and inhibits A53T alpha-synuclein toxicity. J. Biol. Chem. 2005, 280, 43150-43158. [CrossRef] [PubMed]

92. Yokota, T.; Sugawara, K.; Ito, K.; Takahashi, R.; Ariga, H.; Mizusawa, H. Down regulation of DJ-1 enhances cell death by oxidative stress, ER stress, and proteasome inhibition. Biochem. Biophys. Res. Commun. 2003, 312, 1342-1348. [CrossRef] [PubMed]

93. Krebiehl, G.; Ruckerbauer, S.; Burbulla, L.F.; Kieper, N.; Maurer, B.; Waak, J.; Wolburg, H.; Gizatullina, Z.; Gellerich, F.N.; Woitalla, D.; et al. Reduced basal autophagy and impaired mitochondrial dynamics due to loss of Parkinson's disease-associated protein DJ-1. PLoS ONE 2010, 5, e9367. [CrossRef] [PubMed]

94. Ankarcrona, M.; Hultenby, K. Presenilin-1 is located in rat mitochondria. Biochem. Biophys. Res. Commun. 2002, 295, 766-770. [CrossRef]

95. Area-Gomez, E.; de Groof, A.J.; Boldogh, I.; Bird, T.D.; Gibson, G.E.; Koehler, C.M.; Yu, W.H.; Duff, K.E.; Yaffe, M.P.; Pon, L.A.; et al. Presenilins are enriched in endoplasmic reticulum membranes associated with mitochondria. Am. J. Pathol. 2009, 175, 1810-1816. [CrossRef] [PubMed]

96. Schwarz, T.L. Mitochondrial trafficking in neurons. Cold Spring Harb. Perspect. Biol. 2013, 5, a011304. [CrossRef] [PubMed]

97. Burté, F.; Carelli, V.; Chinnery, P.F.; Yu-Wai-Man, P. Disturbed mitochondrial dynamics and neurodegenerative disorders. Nat. Rev. Neurol. 2015, 11, 11-24. [CrossRef] [PubMed]

98. Dupuis, L. Mitochondrial quality control in neurodegenerative diseases. Biochimie 2014, 100, 177-183. [CrossRef] [PubMed]

99. Ryan, B.J.; Hoek, S.; Fon, E.A.; Wade-Martins, R. Mitochondrial dysfunction and mitophagy in Parkinson's: From familial to sporadic disease. Trends Biochem. Sci. 2015, 40, 200-210. [CrossRef] [PubMed]

100. Franco-Iborra, S.; Vila, M.; Perier, C. Mitochondrial Quality Control in Neurodegenerative Diseases: Focus on Parkinson's Disease and Huntington's Disease. Front. Neurosci. 2018, 12, 342. [CrossRef] [PubMed]

101. Van Laar, V.S.; Berman, S.B. The interplay of neuronal mitochondrial dynamics and bioenergetics: Implications for Parkinson's disease. Neurobiol. Dis. 2013, 51, 43-55. [CrossRef] [PubMed]

102. Yan, M.H.; Wang, X.; Zhu, X. Mitochondrial defects and oxidative stress in Alzheimer disease and Parkinson disease. Free Radic. Biol. Med. 2013, 62, 90-101. [CrossRef] [PubMed] 
103. Carmo, C.; Naia, L.; Lopes, C.; Rego, A.C. Mitochondrial Dysfunction in Huntington's Disease. Adv. Exp. Med. Biol. 2018, 1049, 59-83. [CrossRef] [PubMed]

104. Shirendeb, U.; Reddy, A.P.; Manczak, M.; Calkins, M.J.; Mao, P.; Tagle, D.A.; Reddy, P.H. Abnormal mitochondrial dynamics, mitochondrial loss and mutant huntingtin oligomers in Huntington's disease: Implications for selective neuronal damage. Hum. Mol. Genet. 2011, 20, 1438-1455. [CrossRef] [PubMed]

105. De Vos, K.J.; Chapman, A.L.; Tennant, M.E.; Manser, C.; Tudor, E.L.; Lau, K.F.; Brownlees, J.; Ackerley, S.; Shaw, P.J.; McLoughlin, D.M.; et al. Familial amyotrophic lateral sclerosis-linked SOD1 mutants perturb fast axonal transport to reduce axonal mitochondria content. Hum. Mol. Genet. 2007, 16, 2720-2728. [CrossRef] [PubMed]

106. Gao, J.; Wang, L.; Liu, J.; Xie, F.; Su, B.; Wang, X. Abnormalities of Mitochondrial Dynamics in Neurodegenerative Diseases. Antioxidants 2017, 6, 25. [CrossRef] [PubMed]

107. Carrì, M.T.; Cozzolino, M. SOD1 and mitochondria in ALS: A dangerous liaison. J. Bioenerg. Biomembr. 2011, 43, 593-599. [CrossRef] [PubMed]

108. Wood-Kaczmar, A.; Gandhi, S.; Yao, Z.; Abramov, A.Y.; Abramov, A.S.; Miljan, E.A.; Keen, G.; Stanyer, L.; Hargreaves, I.; Klupsch, K.; et al. PINK1 is necessary for long term survival and mitochondrial function in human dopaminergic neurons. PLoS ONE 2008, 3, e2455. [CrossRef]

109. Luo, D.J.; Feng, Q.; Wang, Z.H.; Sun, D.S.; Wang, Q.; Wang, J.Z.; Liu, G.P. Knockdown of phosphotyrosyl phosphatase activator induces apoptosis via mitochondrial pathway and the attenuation by simultaneous tau hyperphosphorylation. J. Neurochem. 2014, 130, 816-825. [CrossRef] [PubMed]

110. Wang, X.J.; Cao, Q.; Zhang, Y.; Su, X.D. Activation and regulation of caspase-6 and its role in neurodegenerative diseases. Annu. Rev. Pharmacol. Toxicol. 2015, 55, 553-572. [CrossRef] [PubMed]

111. Takeuchi, H.; Kobayashi, Y.; Ishigaki, S.; Doyu, M.; Sobue, G. Mitochondrial localization of mutant superoxide dismutase 1 triggers caspase-dependent cell death in a cellular model of familial amyotrophic lateral sclerosis. J. Biol. Chem. 2002, 277, 50966-50972. [CrossRef] [PubMed]

112. Calì, T.; Ottolini, D.; Brini, M. Mitochondrial $\mathrm{Ca}^{2+}$ and neurodegeneration. Cell Calcium 2012, $52,73-85$. [CrossRef] [PubMed]

113. Pelizzoni, I.; Macco, R.; Zacchetti, D.; Grohovaz, F.; Codazzi, F. Iron and calcium in the central nervous system: A close relationship in health and sickness. Biochem. Soc. Trans. 2008, 36, 1309-1312. [CrossRef] [PubMed]

114. Fernyhough, P.; Roy Chowdhury, S.K.; Schmidt, R.E. Mitochondrial stress and the pathogenesis of diabetic neuropathy. Expert Rev. Endocrinol. Metab. 2010, 5, 39-49. [CrossRef] [PubMed]

115. Jones, A.W.; Yao, Z.; Vicencio, J.M.; Karkucinska-Wieckowska, A.; Szabadkai, G. PGC-1 family coactivators and cell fate: Roles in cancer, neurodegeneration, cardiovascular disease and retrograde mitochondria-nucleus signalling. Mitochondrion 2012, 12, 86-99. [CrossRef] [PubMed]

116. Weydt, P.; Pineda, V.V.; Torrence, A.E.; Libby, R.T.; Satterfield, T.F.; Lazarowski, E.R.; Gilbert, M.L.; Morton, G.J.; Bammler, T.K.; Strand, A.D.; et al. Thermoregulatory and metabolic defects in Huntington's disease transgenic mice implicate PGC-1alpha in Huntington's disease neurodegeneration. Cell Metab. 2006, 4, 349-362. [CrossRef] [PubMed]

117. Cui, L.; Jeong, H.; Borovecki, F.; Parkhurst, C.N.; Tanese, N.; Krainc, D. Transcriptional repression of PGC-1alpha by mutant huntingtin leads to mitochondrial dysfunction and neurodegeneration. Cell 2006, 127, 59-69. [CrossRef] [PubMed]

118. Qin, W.; Haroutunian, V.; Katsel, P.; Cardozo, C.P.; Ho, L.; Buxbaum, J.D.; Pasinetti, G.M. PGC-1alpha expression decreases in the Alzheimer disease brain as a function of dementia. Arch. Neurol. 2009, 66, 352-361. [CrossRef] [PubMed]

119. St-Pierre, J.; Drori, S.; Uldry, M.; Silvaggi, J.M.; Rhee, J.; Jäger, S.; Handschin, C.; Zheng, K.; Lin, J.; Yang, W.; et al. Suppression of reactive oxygen species and neurodegeneration by the PGC-1 transcriptional coactivators. Cell 2006, 127, 397-408. [CrossRef] [PubMed]

120. Zheng, B.; Liao, Z.; Locascio, J.J.; Lesniak, K.A.; Roderick, S.S.; Watt, M.L.; Eklund, A.C.; Zhang-James, Y.; Kim, P.D.; Hauser, M.A.; et al. PGC- $1 \alpha$, a potential therapeutic target for early intervention in Parkinson's disease. Sci. Transl. Med. 2010, 2, 52ra73. [CrossRef] [PubMed]

121. Chu, C.T. Mechanisms of selective autophagy and mitophagy: Implications for neurodegenerative diseases. Neurobiol. Dis. 2018. [CrossRef] [PubMed] 
122. Martinez-Vicente, M. Neuronal Mitophagy in Neurodegenerative Diseases. Front. Mol. Neurosci. 2017, 10, 64. [CrossRef] [PubMed]

123. Rodolfo, C.; Campello, S.; Cecconi, F. Mitophagy in neurodegenerative diseases. Neurochem. Int. 2018, 117, 156-166. [CrossRef] [PubMed]

124. Kondapalli, C.; Kazlauskaite, A.; Zhang, N.; Woodroof, H.I.; Campbell, D.G.; Gourlay, R.; Burchell, L.; Walden, H.; Macartney, T.J.; Deak, M.; et al. PINK1 is activated by mitochondrial membrane potential depolarization and stimulates Parkin E3 ligase activity by phosphorylating Serine 65. Open Biol. 2012, 2, 120080. [CrossRef] [PubMed]

125. Moon, H.E.; Paek, S.H. Mitochondrial Dysfunction in Parkinson's Disease. Exp. Neurobiol. 2015, 24, $103-116$. [CrossRef] [PubMed]

126. Vilariño-Güell, C.; Wider, C.; Ross, O.A.; Dachsel, J.C.; Kachergus, J.M.; Lincoln, S.J.; Soto-Ortolaza, A.I.; Cobb, S.A.; Wilhoite, G.J.; Bacon, J.A.; et al. VPS35 mutations in Parkinson disease. Am. J. Hum. Genet. 2011, 89, 162-167. [CrossRef] [PubMed]

127. Zimprich, A.; Benet-Pagès, A.; Struhal, W.; Graf, E.; Eck, S.H.; Offman, M.N.; Haubenberger, D.; Spielberger, S.; Schulte, E.C.; Lichtner, P.; et al. A mutation in VPS35, encoding a subunit of the retromer complex, causes late-onset Parkinson disease. Am. J. Hum. Genet. 2011, 89, 168-175. [CrossRef] [PubMed]

128. McLelland, G.L.; Soubannier, V.; Chen, C.X.; McBride, H.M.; Fon, E.A. Parkin and PINK1 function in a vesicular trafficking pathway regulating mitochondrial quality control. EMBO J. 2014, 33, 282-295. [CrossRef] [PubMed]

129. Shlevkov, E.; Schwarz, T.L. Have you seen? For parkin, it's not all or nothing. EMBO J. 2014, 33, $277-279$. [CrossRef] [PubMed]

130. Friedman, J.R.; Lackner, L.L.; West, M.; DiBenedetto, J.R.; Nunnari, J.; Voeltz, G.K. ER tubules mark sites of mitochondrial division. Science 2011, 334, 358-362. [CrossRef] [PubMed]

131. de Brito, O.M.; Scorrano, L. Mitofusin 2 tethers endoplasmic reticulum to mitochondria. Nature 2008, 456, 605-610. [CrossRef] [PubMed]

132. Liu, Y.; Zhu, X. Endoplasmic reticulum-mitochondria tethering in neurodegenerative diseases. Transl. Neurodegener. 2017, 6, 21. [CrossRef] [PubMed]

133. Camandola, S.; Mattson, M.P. Brain metabolism in health, aging, and neurodegeneration. EMBO J. 2017, 36, 1474-1492. [CrossRef] [PubMed]

134. Requejo-Aguilar, R.; Lopez-Fabuel, I.; Fernandez, E.; Martins, L.M.; Almeida, A.; Bolaños, J.P. PINK1 deficiency sustains cell proliferation by reprogramming glucose metabolism through HIF1. Nat. Commun. 2014, 5, 4514. [CrossRef] [PubMed]

135. Herrero-Mendez, A.; Almeida, A.; Fernández, E.; Maestre, C.; Moncada, S.; Bolaños, J.P. The bioenergetic and antioxidant status of neurons is controlled by continuous degradation of a key glycolytic enzyme by APC/C-Cdh1. Nat. Cell Biol. 2009, 11, 747-752. [CrossRef] [PubMed]

136. Chiabrando, D.; Mercurio, S.; Tolosano, E. Heme and erythropoieis: More than a structural role. Haematologica 2014, 99, 973-983. [CrossRef] [PubMed]

137. Kim, H.J.; Khalimonchuk, O.; Smith, P.M.; Winge, D.R. Structure, function, and assembly of heme centers in mitochondrial respiratory complexes. Biochim. Biophys. Acta 2012, 1823, 1604-1616. [CrossRef] [PubMed]

138. Sabová, L.; Zeman, I.; Supek, F.; Kolarov, J. Transcriptional control of AAC3 gene encoding mitochondrial ADP / ATP translocator in Saccharomyces cerevisiae by oxygen, heme and ROX1 factor. Eur. J. Biochem. 1993, 213, 547-553. [CrossRef] [PubMed]

139. Giraud, S.; Bonod-Bidaud, C.; Wesolowski-Louvel, M.; Stepien, G. Expression of human ANT2 gene in highly proliferative cells: GRBOX, a new transcriptional element, is involved in the regulation of glycolytic ATP import into mitochondria. J. Mol. Biol. 1998, 281, 409-418. [CrossRef] [PubMed]

140. Azuma, M.; Kabe, Y.; Kuramori, C.; Kondo, M.; Yamaguchi, Y.; Handa, H. Adenine nucleotide translocator transports haem precursors into mitochondria. PLoS ONE 2008, 3, e3070. [CrossRef] [PubMed]

141. Frezza, C.; Zheng, L.; Folger, O.; Rajagopalan, K.N.; MacKenzie, E.D.; Jerby, L.; Micaroni, M.; Chaneton, B.; Adam, J.; Hedley, A.; et al. Haem oxygenase is synthetically lethal with the tumour suppressor fumarate hydratase. Nature 2011, 477, 225-228. [CrossRef] [PubMed]

142. Fukuda, Y.; Wang, Y.; Lian, S.; Lynch, J.; Nagai, S.; Fanshawe, B.; Kandilci, A.; Janke, L.J.; Neale, G.; Fan, Y.; et al. Upregulated heme biosynthesis, an exploitable vulnerability in MYCN-driven leukemogenesis. JCI Insight 2017, 2. [CrossRef] [PubMed] 
143. Paul, B.T.; Manz, D.H.; Torti, F.M.; Torti, S.V. Mitochondria and Iron: Current questions. Expert Rev. Hematol. 2017, 10, 65-79. [CrossRef] [PubMed]

144. Horowitz, M.P.; Greenamyre, J.T. Mitochondrial iron metabolism and its role in neurodegeneration. J. Alzheimers Dis. 2010, 20 (Suppl. 2), S551-S568. [CrossRef] [PubMed]

145. Walter, P.B.; Knutson, M.D.; Paler-Martinez, A.; Lee, S.; Xu, Y.; Viteri, F.E.; Ames, B.N. Iron deficiency and iron excess damage mitochondria and mitochondrial DNA in rats. Proc. Natl. Acad. Sci. USA 2002, 99, 2264-2269. [CrossRef] [PubMed]

146. Gao, X.; Campian, J.L.; Qian, M.; Sun, X.F.; Eaton, J.W. Mitochondrial DNA damage in iron overload. J. Biol. Chem. 2009, 284, 4767-4775. [CrossRef] [PubMed]

147. Atamna, H.; Newberry, J.; Erlitzki, R.; Schultz, C.S.; Ames, B.N. Biotin deficiency inhibits heme synthesis and impairs mitochondria in human lung fibroblasts. J. Nutr. 2007, 137, 25-30. [CrossRef] [PubMed]

148. Takahashi, M.; Doré, S.; Ferris, C.D.; Tomita, T.; Sawa, A.; Wolosker, H.; Borchelt, D.R.; Iwatsubo, T.; Kim, S.H.; Thinakaran, G.; et al. Amyloid precursor proteins inhibit heme oxygenase activity and augment neurotoxicity in Alzheimer's disease. Neuron 2000, 28, 461-473. [CrossRef]

149. Sheng, X.J.; Tu, H.J.; Chien, W.L.; Kang, K.H.; Lu, D.H.; Liou, H.H.; Lee, M.J.; Fu, W.M. Antagonism of proteasome inhibitor-induced heme oxygenase-1 expression by PINK1 mutation. PLoS ONE 2017, 12, e0183076. [CrossRef] [PubMed]

150. Clements, C.M.; McNally, R.S.; Conti, B.J.; Mak, T.W.; Ting, J.P. DJ-1, a cancer- and Parkinson's disease-associated protein, stabilizes the antioxidant transcriptional master regulator Nrf2. Proc. Natl. Acad. Sci. USA 2006, 103, 15091-15096. [CrossRef] [PubMed]

151. Alam, J.; Stewart, D.; Touchard, C.; Boinapally, S.; Choi, A.M.; Cook, J.L. Nrf2, a Cap'n'Collar transcription factor, regulates induction of the heme oxygenase-1 gene. J. Biol. Chem. 1999, 274, 26071-26078. [CrossRef] [PubMed]

152. Hull, T.D.; Boddu, R.; Guo, L.; Tisher, C.C.; Traylor, A.M.; Patel, B.; Joseph, R.; Prabhu, S.D.; Suliman, H.B.; Piantadosi, C.A.; et al. Heme oxygenase-1 regulates mitochondrial quality control in the heart. JCI Insight 2016, 1, e85817. [CrossRef] [PubMed]

153. Atamna, H.; Walter, P.B.; Ames, B.N. The role of heme and iron-sulfur clusters in mitochondrial biogenesis, maintenance, and decay with age. Arch. Biochem. Biophys. 2002, 397, 345-353. [CrossRef] [PubMed]

154. Suliman, H.B.; Keenan, J.E.; Piantadosi, C.A. Mitochondrial quality-control dysregulation in conditional HO-1. JCI Insight 2017, 2, e89676. [CrossRef] [PubMed]

155. Higdon, A.N.; Benavides, G.A.; Chacko, B.K.; Ouyang, X.; Johnson, M.S.; Landar, A.; Zhang, J.; Darley-Usmar, V.M. Hemin causes mitochondrial dysfunction in endothelial cells through promoting lipid peroxidation: The protective role of autophagy. Am. J. Physiol. Heart Circ. Physiol. 2012, 302, H1394-H1409. [CrossRef] [PubMed]

156. Chiabrando, D.; Marro, S.; Mercurio, S.; Giorgi, C.; Petrillo, S.; Vinchi, F.; Fiorito, V.; Fagoonee, S.; Camporeale, A.; Turco, E.; et al. The mitochondrial heme exporter FLVCR1b mediates erythroid differentiation. J. Clin. Investig. 2012, 122, 4569-4579. [CrossRef] [PubMed]

157. Homedan, C.; Laafi, J.; Schmitt, C.; Gueguen, N.; Lefebvre, T.; Karim, Z.; Desquiret-Dumas, V.; Wetterwald, C.; Deybach, J.C.; Gouya, L.; et al. Acute intermittent porphyria causes hepatic mitochondrial energetic failure in a mouse model. Int. J. Biochem. Cell Biol. 2014, 51, 93-101. [CrossRef] [PubMed]

158. Castro-Gago, M.; Alonso, A.; Pintos-Martínez, E.; Beiras-Iglesias, A.; Campos, Y.; Arenas, J.; Novo-Rodríguez, M.I.; Eirís-Puñal, J. Congenital hydranencephalic-hydrocephalic syndrome associated with mitochondrial dysfunction. J. Child Neurol. 1999, 14, 131-135. [CrossRef] [PubMed]

159. Castro-Gago, M.; Pintos-Martínez, E.; Forteza-Vila, J.; Iglesias-Diz, M.; Ucieda-Somoza, R.; Silva-Villar, I.; Codesido-López, J.; Viso-Lorenzo, A.; Campos, Y.; Arenas, J.; et al. Congenital hydranencephalichydrocephalic syndrome with proliferative vasculopathy: A possible relation with mitochondrial dysfunction. J. Child Neurol. 2001, 16, 858-862. [CrossRef] [PubMed]

160. Kiaei, M. New hopes and challenges for treatment of neurodegenerative disorders: Great opportunities for young neuroscientists. Basic Clin. Neurosci. 2013, 4, 3-4. [PubMed]

161. Andreux, P.A.; Houtkooper, R.H.; Auwerx, J. Pharmacological approaches to restore mitochondrial function. Nat. Rev. Drug Discov. 2013, 12, 465-483. [CrossRef] [PubMed] 
162. Timmers, S.; Konings, E.; Bilet, L.; Houtkooper, R.H.; van de Weijer, T.; Goossens, G.H.; Hoeks, J.; van der Krieken, S.; Ryu, D.; Kersten, S.; et al. Calorie restriction-like effects of 30 days of resveratrol supplementation on energy metabolism and metabolic profile in obese humans. Cell Metab. 2011, 14, 612-622. [CrossRef] [PubMed]

163. Douglas, P.M.; Dillin, A. Protein homeostasis and aging in neurodegeneration. J. Cell Biol. 2010, 190, 719-729. [CrossRef] [PubMed]

164. Lutz, A.K.; Exner, N.; Fett, M.E.; Schlehe, J.S.; Kloos, K.; Lämmermann, K.; Brunner, B.; Kurz-Drexler, A.; Vogel, F.; Reichert, A.S.; et al. Loss of parkin or PINK1 function increases Drp1-dependent mitochondrial fragmentation. J. Biol. Chem. 2009, 284, 22938-22951. [CrossRef] [PubMed]

165. Rappold, P.M.; Cui, M.; Grima, J.C.; Fan, R.Z.; de Mesy-Bentley, K.L.; Chen, L.; Zhuang, X.; Bowers, W.J.; Tieu, K. Drp1 inhibition attenuates neurotoxicity and dopamine release deficits in vivo. Nat. Commun. 2014, 5, 5244. [CrossRef] [PubMed]

166. Lackner, L.L.; Nunnari, J. Small molecule inhibitors of mitochondrial division: Tools that translate basic biological research into medicine. Chem. Biol. 2010, 17, 578-583. [CrossRef] [PubMed]

167. Wang, D.; Wang, J.; Bonamy, G.M.; Meeusen, S.; Brusch, R.G.; Turk, C.; Yang, P.; Schultz, P.G. A small molecule promotes mitochondrial fusion in mammalian cells. Angew. Chem. Int. Ed. Engl. 2012, 51, 9302-9305. [CrossRef] [PubMed]

168. Yue, W.; Chen, Z.; Liu, H.; Yan, C.; Chen, M.; Feng, D.; Wu, H.; Du, L.; Wang, Y.; Liu, J.; et al. A small natural molecule promotes mitochondrial fusion through inhibition of the deubiquitinase USP30. Cell Res. 2014, 24, 482-496. [CrossRef] [PubMed]

169. Cassidy-Stone, A.; Chipuk, J.E.; Ingerman, E.; Song, C.; Yoo, C.; Kuwana, T.; Kurth, M.J.; Shaw, J.T.; Hinshaw, J.E.; Green, D.R.; et al. Chemical inhibition of the mitochondrial division dynamin reveals its role in Bax/Bak-dependent mitochondrial outer membrane permeabilization. Dev. Cell 2008, 14, 193-204. [CrossRef] [PubMed]

170. Cui, M.; Tang, X.; Christian, W.V.; Yoon, Y.; Tieu, K. Perturbations in mitochondrial dynamics induced by human mutant PINK1 can be rescued by the mitochondrial division inhibitor mdivi-1. J. Biol. Chem. 2010, 285, 11740-11752. [CrossRef] [PubMed]

171. Bordt, E.A.; Clerc, P.; Roelofs, B.A.; Saladino, A.J.; Tretter, L.; Adam-Vizi, V.; Cherok, E.; Khalil, A.; Yadava, N.; Ge, S.X.; et al. The Putative Drp1 Inhibitor mdivi-1 Is a Reversible Mitochondrial Complex I Inhibitor that Modulates Reactive Oxygen Species. Dev. Cell 2017, 40, 583-594. [CrossRef] [PubMed]

172. Sherer, T.B.; Betarbet, R.; Testa, C.M.; Seo, B.B.; Richardson, J.R.; Kim, J.H.; Miller, G.W.; Yagi, T.; Matsuno-Yagi, A.; Greenamyre, J.T. Mechanism of toxicity in rotenone models of Parkinson's disease. J. Neurosci. 2003, 23, 10756-10764. [CrossRef] [PubMed]

173. Lezi, E.; Swerdlow, R.H. Mitochondria in neurodegeneration. Adv. Exp. Med. Biol. 2012, 942, $269-286$. [CrossRef] [PubMed]

174. Witte, M.E.; Mahad, D.J.; Lassmann, H.; van Horssen, J. Mitochondrial dysfunction contributes to neurodegeneration in multiple sclerosis. Trends Mol. Med. 2014, 20, 179-187. [CrossRef] [PubMed]

175. Green, D.R.; Galluzzi, L.; Kroemer, G. Mitochondria and the autophagy-inflammation-cell death axis in organismal aging. Science 2011, 333, 1109-1112. [CrossRef] [PubMed]

176. Koentjoro, B.; Park, J.S.; Sue, C.M. Nix restores mitophagy and mitochondrial function to protect against PINK1/Parkin-related Parkinson's disease. Sci. Rep. 2017, 7, 44373. [CrossRef] [PubMed]

177. Chen, J. Heme oxygenase in neuroprotection: From mechanisms to therapeutic implications. Rev. Neurosci. 2014, 25, 269-280. [CrossRef] [PubMed]

178. Song, W.; Su, H.; Song, S.; Paudel, H.K.; Schipper, H.M. Over-expression of heme oxygenase-1 promotes oxidative mitochondrial damage in rat astroglia. J. Cell Physiol. 2006, 206, 655-663. [CrossRef] [PubMed]

179. Zukor, H.; Song, W.; Liberman, A.; Mui, J.; Vali, H.; Fillebeen, C.; Pantopoulos, K.; Wu, T.D.; Guerquin-Kern, J.L.; Schipper, H.M. HO-1-mediated macroautophagy: A mechanism for unregulated iron deposition in aging and degenerating neural tissues. J. Neurochem. 2009, 109, 776-791. [CrossRef] [PubMed]

180. Nitti, M.; Piras, S.; Brondolo, L.; Marinari, U.M.; Pronzato, M.A.; Furfaro, A.L. Heme Oxygenase 1 in the Nervous System: Does It Favor Neuronal Cell Survival or Induce Neurodegeneration? Int. J. Mol. Sci. 2018, 19, 2260. [CrossRef] [PubMed]

181. Schipper, H.M.; Gupta, A.; Szarek, W.A. Suppression of glial HO-1 activity as a potential neurotherapeutic intervention in AD. Curr. Alzheimer Res. 2009, 6, 424-430. [CrossRef] [PubMed] 
182. Gupta, A.; Lacoste, B.; Pistell, P.J.; Pistel, P.J.; Ingram, D.K.; Hamel, E.; Alaoui-Jamali, M.A.; Szarek, W.A.; Vlahakis, J.Z.; Jie, S.; et al. Neurotherapeutic effects of novel HO-1 inhibitors in vitro and in a transgenic mouse model of Alzheimer's disease. J. Neurochem. 2014, 131, 778-790. [CrossRef] [PubMed]

183. Omori, C.; Motodate, R.; Shiraki, Y.; Chiba, K.; Sobu, Y.; Kimura, A.; Nakaya, T.; Kondo, H.; Kurumiya, S.; Tanaka, T.; et al. Facilitation of brain mitochondrial activity by 5 -aminolevulinic acid in a mouse model of Alzheimer's disease. Nutr. Neurosci. 2017, 20, 538-546. [CrossRef] [PubMed]

184. Gomes, A.T.P.C.; Neves, M.G.P.M.; Cavaleiro, J.A.S. Cancer, Photodynamic Therapy and Porphyrin-Type Derivatives. An. Acad. Bras. Cienc. 2018, 90, 993-1026. [CrossRef] [PubMed]

(C) 2018 by the authors. Licensee MDPI, Basel, Switzerland. This article is an open access article distributed under the terms and conditions of the Creative Commons Attribution (CC BY) license (http:/ / creativecommons.org/licenses/by/4.0/). 


\title{
Reductive Mobilization of Iron from Intact Ferritin: Mechanisms and Physiological Implication
}

\author{
Fadi Bou-Abdallah ${ }^{1, *}$, John J. Paliakkara ${ }^{1}$, Galina Melman ${ }^{2}$ and Artem Melman ${ }^{2, *}$ \\ 1 Department of Chemistry, State University of New York at Potsdam, Potsdam, NY 13676, USA; \\ paliakjj199@potsdam.edu \\ 2 Department of Chemistry \& Biomolecular Science, Clarkson University, Potsdam, NY 13699, USA; \\ gmelman@clarkson.edu \\ * Correspondence: bouabdf@potsdam.edu (F.B.-A.); amelman@clarkson.edu (A.M.); \\ Tel.: +1-315-267-2268 (F.B.-A.); +1-315-268-4405 (A.M.)
}

Received: 14 October 2018; Accepted: 1 November 2018; Published: 5 November 2018

\begin{abstract}
Ferritins are highly conserved supramolecular protein nanostructures composed of two different subunit types, $\mathrm{H}$ (heavy) and L (light). The two subunits co-assemble into a 24-subunit heteropolymer, with tissue specific distributions, to form shell-like protein structures within which thousands of iron atoms are stored as a soluble inorganic ferric iron core. In-vitro (or in cell free systems), the mechanisms of iron(II) oxidation and formation of the mineral core have been extensively investigated, although it is still unclear how iron is loaded into the protein in-vivo. In contrast, there is a wide spread belief that the major pathway of iron mobilization from ferritin involves a lysosomal proteolytic degradation of ferritin, and the dissolution of the iron mineral core. However, it is still unclear whether other auxiliary iron mobilization mechanisms, involving physiological reducing agents and/or cellular reductases, contribute to the release of iron from ferritin. In vitro iron mobilization from ferritin can be achieved using different reducing agents, capable of easily reducing the ferritin iron core, to produce soluble ferrous ions that are subsequently chelated by strong iron(II)-chelating agents. Here, we review our current understanding of iron mobilization from ferritin by various reducing agents, and report on recent results from our laboratory, in support of a mechanism that involves a one-electron transfer through the protein shell to the iron mineral core. The physiological significance of the iron reductive mobilization from ferritin by the non-enzymatic FMN/NAD $(\mathrm{P}) \mathrm{H}$ system is also discussed.
\end{abstract}

Keywords: ferritin; iron mobilization; chaotropes; flavin nucleotide; electron transfer; kinetics

\section{Introduction}

Iron is an essential element required for virtually all living organisms and is involved in numerous biological reactions including respiration, oxygen transport, electron transfer, oxidative metabolism, deoxyribonucleotide synthesis, and gene regulation [1,2]. Due to the wide range of redox potentials of $\mathrm{Fe}^{3+} / \mathrm{Fe}^{2+}$ metal complexes (from approximately -500 to $+600 \mathrm{mV}$ ), iron cations are indispensable cofactors for numerous enzymes catalyzing oxidation-reduction reactions [3-5]. Almost all iron cations in living cells are tightly bound to metalloproteins, leaving less than one percent as "labile iron pool" in the cytosol. The pool contains "free" or loosely bound iron cations predominantly in the reduced $\mathrm{Fe}^{2+}$ form. The labile iron pool serves as the main source of iron for the synthesis of iron proteins. However, the presence of labile ferrous ions constitutes a considerable problem for all aerobic organisms, due to their involvement in Fenton reaction in the presence of hydrogen peroxide, an inevitable byproduct of cellular respiration. The resultant hydroxyl radicals react rapidly with cellular biopolymers, including proteins, lipids, and nucleic acids, resulting in their oxidation and loss of functionality. In living cells iron(III) cations produced via Fenton reaction can be rapidly reduced back to iron(II) cations, 
leading to a continuous cycle of hydroxyl radicals (HOm) production. To avoid this dangerous cycle of hydroxyl radicals formation, the concentration of labile iron is regulated by a strict control of the rates of iron uptake and mobilization in iron transport and storage proteins. While cellular iron trafficking is suggested to occur via iron chaperons [6], the reported affinity of such chaperones to iron cations is relatively low, suggesting an easy iron exchange mechanism with the labile iron pool.

The most efficient way to protect cells from the toxic effect of elevated levels of labile iron cations is ferritin, a ubiquitous and well-characterized iron storage and detoxification protein. A single ferritin molecule is capable of sequestering up to thousands of iron atoms, in the form of insoluble inorganic ferrihydrite core [7-10]. In bacteria, plants, fish, and amphibians, ferritins are generally homopolymers composed of H-type subunits, while in animals, ferritin is a heteropolymer, typically consisting of 24 subunits of two types, $\mathrm{H}$ and $\mathrm{L}$ (Figure 1) $[10,11]$. The resultant protein nanocage, separating the inner cavity of ferritin from the outside environment is remarkably stable in the $\mathrm{pH}$ range of 3-9, and temperatures up to $80^{\circ} \mathrm{C}$. Small molecules and various cations have been shown to enter the ferritin interior through eight narrow hydrophilic three-fold channels, and possibly through six hydrophobic four-fold channels as well [10]. The natural $\mathrm{Fe}^{2+}$ cations rapidly diffuse through the ferritin shell, where it is oxidized to insoluble iron(III) cations to form the inorganic ferrihydrite core. In mammals, the H-subunit is responsible for the rapid oxidation of Fe(II) to Fe(III) by molecular oxygen (or by hydrogen peroxide) at a dinuclear center, while the L-subunit helps iron clearance from the center in support of iron nucleation and mineralization [12-15]. Ferritin composed exclusively of L-subunits is still capable of oxidizing iron(II) cations, although at a much lower rate.

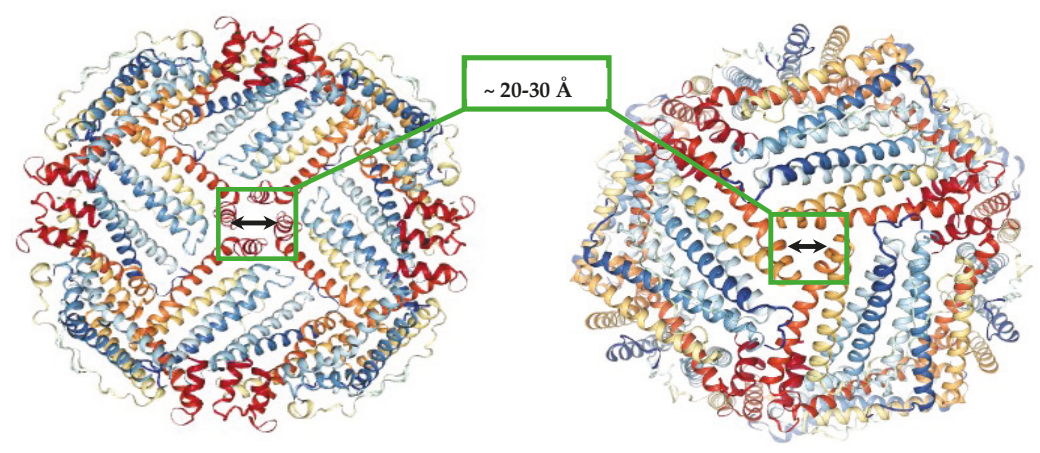

Figure 1. Ferritin molecule (PDB 1R03) with highlighted hydrophobic four-fold (left), and hydrophilic three-fold channels (right), that allow the transport of small molecules and ions to the inner cavity.

Bacteria can express at least four types of ferritin-like proteins with iron storage capability, two of which (FtnA and FtnB) are structurally similar to conventional ferritins, in term of subunit arrangement and the formation of nanocages (i.e., composed of 24 identical H-like subunits) [16]. The third type, bacterioferritin (Bfr), contains up to 12 protoporphyrin IX heme groups sandwiched between two-fold symmetry-related subunits, where they are bound covalently to methionine groups. The fourth ferritin type is called Dps (or DNA-binding protein from starved cells), contains 12 identical subunits, and thus has half the size of typical ferritins $[17,18]$. All ferritin types (except FtnB) possess rapid ferroxidase activity, and form ferrihydrite iron cores similar to conventional ferritins $[19,20]$. In bacteria, iron release from ferritin occurs through reduction of the inorganic iron core by bacterioferritin associated ferredoxin (Bfd) $[19,20]$. Transfer of electron from Bfd to the iron hydroxide core is mediated by bacterioferritin-bound heme molecules, most likely through electron transfer mechanisms [21]. However, very little is known about how the mechanisms of oxidative storage and reductive mobilization of iron are regulated in bacteria. 


\section{Brief Overview of Iron Reductive Mobilization from Intact Ferritin}

While iron uptake and oxidation in conventional ferritin is relatively well understood, the mechanism of iron mobilization is rather controversial [22-26]. It is well established that the major pathway of iron mobilization from ferritin is based on proteolytic degradation, which involves transport of ferritin molecules into the lysosomes, followed by dissolution of the exposed iron hydroxide core $[22,27,28]$. The half-life of ferritin circulation in eukaryotic cells is about $19-24 \mathrm{~h}$, under conditions of iron deficiency, but is much longer in iron-abundant environments [29], suggesting a tightly regulated cellular iron mobilization, although the exact mechanism remains unclear. We still do not know if proteolytic degradation of ferritin is the only mechanism by which iron is released from the protein, and whether other auxiliary iron mobilization mechanisms for the immediate access of cells to iron exist. Multiple reports on the reductive mobilization of iron cations from intact ferritin appeared in the literature, demonstrating the easy reduction of the iron core by a variety of one electron reducing agents, including flavin mononucleotide [30,31], ascorbate [32,33], sodium dithionite [34] and superoxide $[35,36]$. The rate of reduction is strongly dependent on the reduction potential of the electron donor [30]. In contrast, while two electron reductants, such as NADH [23] and glutathione [31], possess strongly negative reduction potentials, they generally reduce ferritin very slowly. One notable exception is thioglycolic acid [37], which reacts much more rapidly with the ferritin iron core, and is commonly used in the preparation of iron-free apoferritin. It has been shown that FtnA ferritin, from Pseudomonas aeruginosa, undergoes reductive mobilization of iron(III) by treatment with NADPH in the presence of ferredoxin-NADP ${ }^{+}$reductase and 2,2'-bipyridine; however, the physiological relevance of this process is not clear, even for anaerobic conditions [19,38].

The reduction of ferritin iron by these reducing agents, produces soluble Fe(II) cations that exit the ferritin internal cavity, through the eight hydrophilic three-fold channels, and join the cellular labile iron pool (Figure 2). The newly formed Fe(II) cations can be easily re-oxidized to Fe(III), through the catalytic activity of the ferritin's ferroxidase centers. The rate of ferrous ions re-oxidation is very high [39,40], and their concentration is likely very low, and difficult to observe. This difficulty in detecting reduced iron(II) cations, can be resolved by the addition of iron(II) specific chelate ligands, such as $1,1^{\prime}$-bipyridine, phenanthroline, or ferrozine. The presence of excess chelators prevents the re-oxidation of iron(II) cations, and provides straightforward spectrophotometric detection of the resultant $\mathrm{Fe}(\mathrm{II})$-chelate complexes, which typically have high $\left(\sim 10^{3}-10^{4} \mathrm{M}^{-1} \mathrm{~cm}^{-1}\right)$ absorbance metal-to-ligand-charge-transfer (MLCT) bands [41].

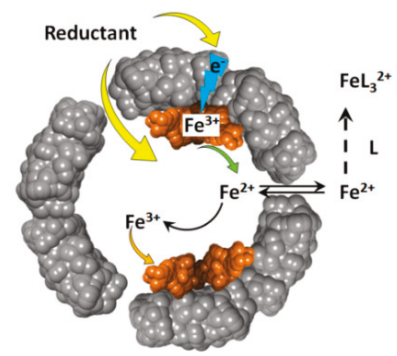

Figure 2. Schematic depiction of the oxidative deposition and reductive mobilization of iron in ferritin.

Amongst the most potent ferritin reducing agents in cell free systems are reduced flavins, including FMNH2 and FADH2 [31]. Reduced flavins can be prepared by chemical reduction of flavins, under oxygen-free conditions [31], or by in-situ reduction of NADH or NADPH. The latter reaction can be catalyzed by $\mathrm{NAD}(\mathrm{P}) \mathrm{H}$ :flavin oxidoreductase [30], or can proceed without enzymatic catalysis at higher concentrations of flavins and NADH [42]. Because a significant concentration (several $\mathrm{mM}$ ) of flavins is commonly found in the cytosol of living cells, reduced flavins are possible candidates for the hypothetical reductive mobilization of iron cations from intact ferritins [30,31], 
although the physiological relevance of this mechanism is far from being obvious. Free reduced flavins, such as FMNH2 and FADH2, that are not protein-bound, are rapidly oxidized by molecular oxygen [43]. While FMN can be reduced back to FMNH2 by cellular NAD(P)H:flavin oxidoreductases [30], the rate constants for the re-oxidation of reduced flavins by molecular oxygen are very high [43], suggesting that the stationary concentrations of reduced flavins is extremely low. Unfortunately, there have been multiple studies on the reduction of ferritin iron by NADH without any consideration of the amount of dissolved oxygen present in solutions.

\section{Iron Mobilization by the FMN-NADH System}

To clarify the influence of each player on the reductive mobilization of iron from intact ferritins, we studied the kinetics of iron reduction by the FMN-NADH system, using horse spleen ferritin (HosF), and recombinant human heteropolymer apoferritin ( $21 \mathrm{H}$ - and 3L-subunits, referred to as HuHLF), under a tight control of $\mathrm{O}_{2}$ concentration [23]. In both cases (Figure 3), the iron release kinetics showed a biphasic behavior. The initial lag phase was followed by a second phase featuring a rapid iron release kinetic. The initial lag phase exhibited a small increase in absorption at $530 \mathrm{~nm}$, indicating a slow iron release process. The second phase is characterized by a dramatic increase in the iron release rates, which depend on the concentrations of FMN and NADH, but not on the concentration of ferritin. The linear increase in the rates of iron mobilization suggests that the generation of FMNH2 by the FMN-NADH system, is the rate-limiting step under these conditions. Notably, the gradual decrease in the rates of iron mobilization from ferritin (as observed towards the end of the reactions in Figure 3 (right), is due to the depletion of the iron(III) hydroxide core, such as the reduction of the ferritin iron core becomes the rate limiting step [23].
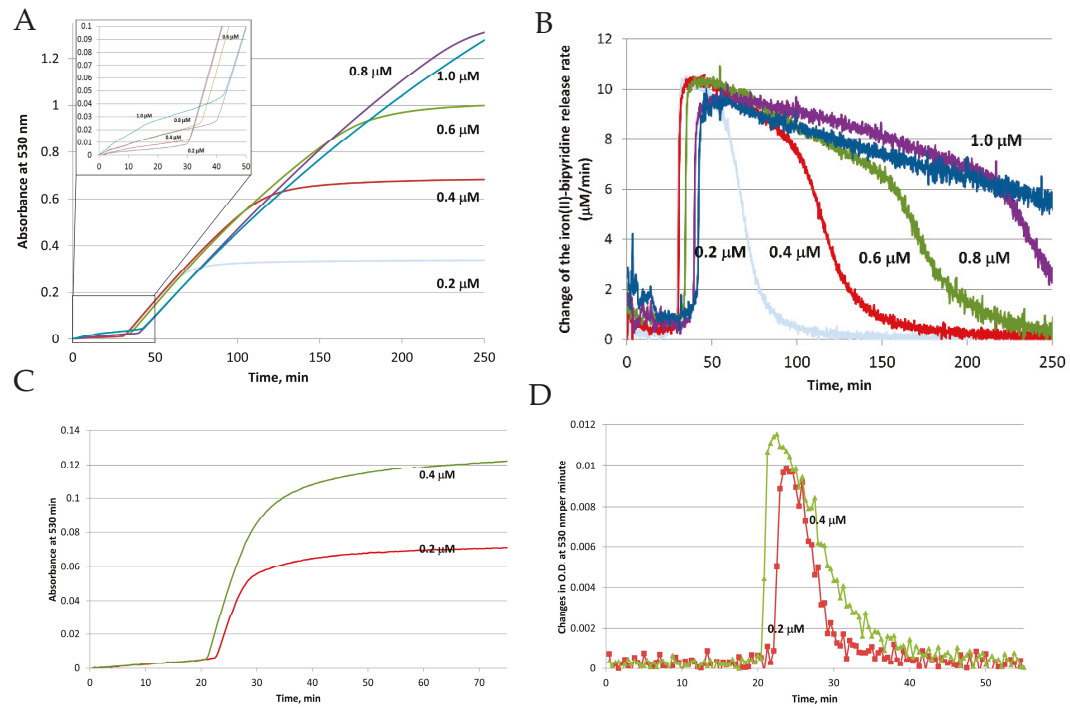

Figure 3. Reductive mobilization of iron from HosF containing $2250 \mathrm{Fe} /$ shell. Conditions: $0.2-1 \mu \mathrm{M}$ ferritin, $2 \mathrm{mM}$ NADH, $200 \mu \mathrm{M}$ FMN, $2 \mathrm{mM}$ 2,2'-bipyridine, $2650 \mathrm{U} / \mathrm{mL}$ catalase, at $\mathrm{pH} 7.0$ and $22{ }^{\circ} \mathrm{C}$. (A) Absorbance change of $\left[\mathrm{Fe}(\text { bipy })_{3}\right]^{2+}$ as a function of time. (B) Change of the iron(II)-bipyridine release rate versus time for different concentrations of HosF. (C,D) Reductive mobilization of iron from human recombinant heteropolymer ferritin $(0.2$ and $0.4 \mu \mathrm{M})$ loaded with $500 \mathrm{Fe} /$ protein, in the presence of $2 \mathrm{mM} \mathrm{NADH}, 200 \mu \mathrm{M}$ FMN, $2 \mathrm{mM} \mathrm{2,2}$-bipyridine, $2650 \mathrm{U} / \mathrm{mL}$ catalase, at $\mathrm{pH}$ 7.0 and $28{ }^{\circ} \mathrm{C}$. (C) Absorbance change of $\left[\mathrm{Fe}(\text { bipy })_{3}\right]^{2+}$ as a function of time. (D) Change of the iron(II)-bipyridine release rate versus time, for different concentrations of heteropolymer ferritin. Reprinted with permission from Ref. [23]. 
The significant release of iron from ferritin does not occur until essentially all the dissolved oxygen has been depleted, as observed in Figure 3 (left). The duration of the lag phase depends on the concentration of dissolved oxygen, as well as the concentrations of NADH and FMN, but not on the concentration of ferritin. This indicates that most of the FMNH2, produced from the reaction between FMN and NADH, is re-oxidized back to FMN by dissolved molecular oxygen, without an appreciable release of iron. This re-oxidation reaction is very fast, even at a low concentration of dissolved oxygen, which can be expected, since the rate of FMNH2 oxidation by oxygen is much faster than that of iron reduction [43].

To further determine the effect of oxygen on the amount and rate of iron release from ferritin, the experiments were repeated, while simultaneously monitoring the concentration of molecular oxygen by a MI 730 Clark oxygen microelectrode [23]. As shown in Figure 4, the concentration of dissolved oxygen decreases sharply during the induction period (lag period), without any noticeable iron release. Only when oxygen concentration reaches a level of $\sim 5 \mu \mathrm{M}$, that iron reduction and chelation by bipyridine is observed [23]. Because oxygen concentration in this experiment is well below typical normoxic conditions, the results presented in Figure 4 suggest that free reduced flavins are unlikely to serve as ferritin-reducing agents, in normally oxygenated cells. Significantly, under these conditions, the rates of iron mobilization from ferritin would be too low, even in the absence of inevitable re-oxidation of newly formed iron(II) cations. It is also highly improbable that the rates of iron mobilization are strongly dependent on cells oxygenation level, which is known to vary widely under different circumstances.
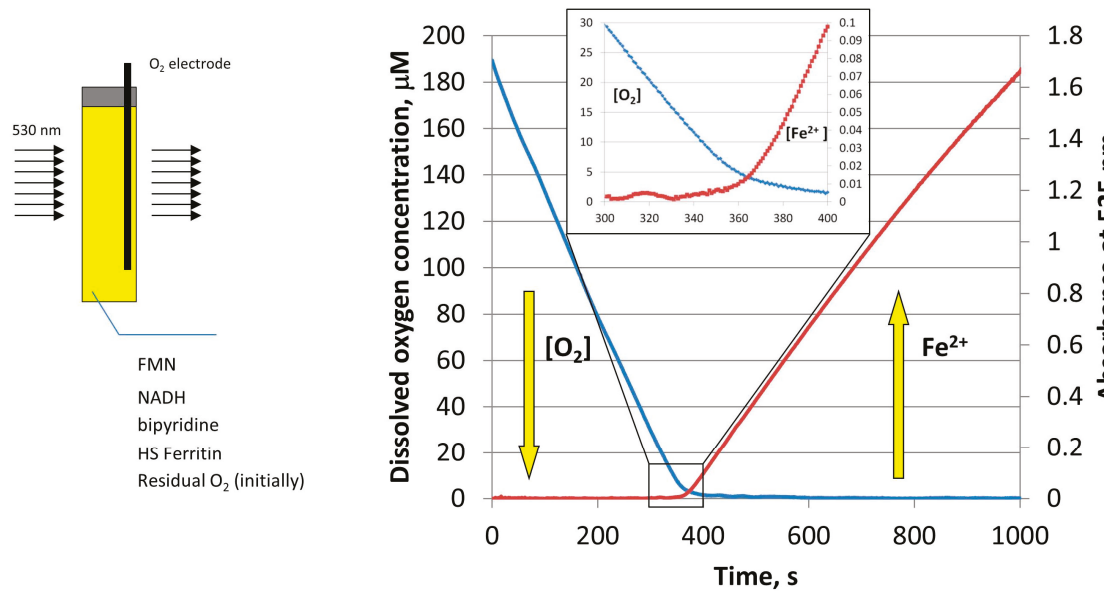

Figure 4. Schematic of the simultaneous monitoring of the dissolved oxygen concentration (blue curve), and light absorption of $\mathrm{Fe}(\mathrm{II})$-bipyridine complex at $530 \mathrm{~nm}$ (red curve), during the reductive release of iron from HosF $(0.6 \mu \mathrm{M})$, in the presence of $2 \mathrm{mM} \mathrm{NADH}, 2 \mathrm{mM}$ FMN, and $2 \mathrm{mM}$ 2,2'-bipyridine. Reprinted with permission from Ref. [23].

\section{Iron Mobilization by Reduced Flavins}

Reduction of ferritin iron cores by reduced flavins (and other reductants) has been the subject of intense investigation $[23,25,26,30,31,44-46]$. Iron reduction can proceed through two possible mechanisms that involve either a passive diffusion of reducing agents across the ferritin's shell [30], or the transfer of electrons through specific pathways along the protein shell [46] (Figure 5). Literature evidence in support of the diffusion mechanism is based on two experiments, the first of which employed agarose-bound FMNH2, produced by a reaction of agarose-bound FMN with NADH [30]. The inability of agarose-immobilized FMNH2 to induce reductive mobilization of iron cations from horse spleen ferritin [31], was considered as proof of the inability of FMNH2 to diffuse to the protein's 
interior, and that ferritin iron reduction reactions can only proceed through FMNH2 diffusion into ferritin. The problem with this experiment is that it failed to account for possible changes in the reactivity of reduced flavins caused by agarose binding. Alternatively, derivatization of agarose by FMN may occur at the surface of the agarose grains, but also inside the agarose beads, which may not be available for ferritin diffusion and subsequent iron reduction [31].

The second piece of evidence is the observation of increased rates of iron reductive mobilization in the presence of chaotropes, or specific peptide molecules in solution [42,47,48]. It was shown that the presence of $1 \mathrm{M}$ urea resulted in a dramatic (more than five-fold) increase in the rates of iron reduction in ferritin, by the FMN-NADH system, in the presence of 2,2'-bipyridine [42]. The data were interpreted as a weakening of the ferritin inter-subunits interactions, which resulted in an enlarged diameter of the three-fold or four-fold axes, thus facilitating the diffusion of FMNH2 molecules into the ferritin interior. Furthermore, certain short peptide sequences (i.e., HSNTYYFPKGG) were shown to exhibit more than three-fold increased iron release rates from ferritin [48]. These later results, however, cannot be easily interpreted, given that the rates of iron reduction in ferritin by the non-enzymatic FMN-NADH system are limited by the rate of FMNH2 production [23], and not by the rate of iron reduction. Additionally, these experiments did not disclose the initial amount of dissolved oxygen in solution, or the possibility of oxygen diffusion inside the reaction cell, which, as reported above, dramatically alters the amount, and rates of iron release from ferritin.

Evidence for electron transfer reactions across the protein shell are based on the rapid oxidation of iron(II) cations inside the ferritin cavity, under anaerobic conditions, by large electron acceptors, such as plastocyanin, cytochrome c, or stellavyanin [26,46,49]. Because of the large size of these proteins, and their inability to diffuse across the protein shell, iron oxidation reactions can only be explained by electron transfer, from iron(II) cations to these electron acceptors. In further support of this mechanism, iron oxidation and deposition reactions were also observed in L-subunit ferritins, which lack ferroxidase centers, and therefore ferroxidase activity [49]. Such a long range electron transport across the $2 \mathrm{~nm}$ protein shell, can be facilitated by the redox activity of the protein shell [46].

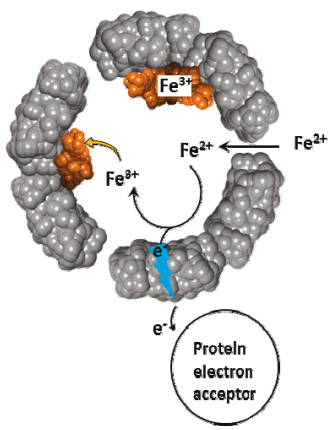

Figure 5. Schematic of $\mathrm{Fe}^{2+}$ cations diffusion and electron transfer across the ferritin shell, followed by $\mathrm{Fe}^{2+}$ oxidation and deposition.

To further understand the iron reductive mobilization from ferritin, and differentiate between the two mechanisms (diffusion vs. electron transfer), more data is needed, using different types of ferritin (i.e., heteropolymer horse spleen ferritin (HosF), homopolymer human H-chain or L-chain ferritin (HuHF or HuLF), and heteropolymer human H/L ferritin (HuHLF)). Recent experiments from our laboratory [25], using the FMN-NADH system (or reduced flavin FMNH2), were performed with $\mathrm{HosF}$ and $\mathrm{HuHF}$, under controlled concentration of oxygen. In contrast to literature reports, our data showed no (or insignificant) difference in the reaction rates, in the presence of 0-2 $\mathrm{M}$ urea, guanidine chloride, or Triton X100 (Figure 6), suggesting that the kinetics of iron release from ferritin by flavins are independent on the type, or amount of chaotropes present. Additional experiments performed 
under strict anaerobic conditions, using solutions of $\mathrm{FMNH}_{2}$ prepared by catalytic hydrogenation with Adams catalyst, revealed much faster reduction reactions, with no effect from chaotropes on the rates of the iron mobilization reactions [25].
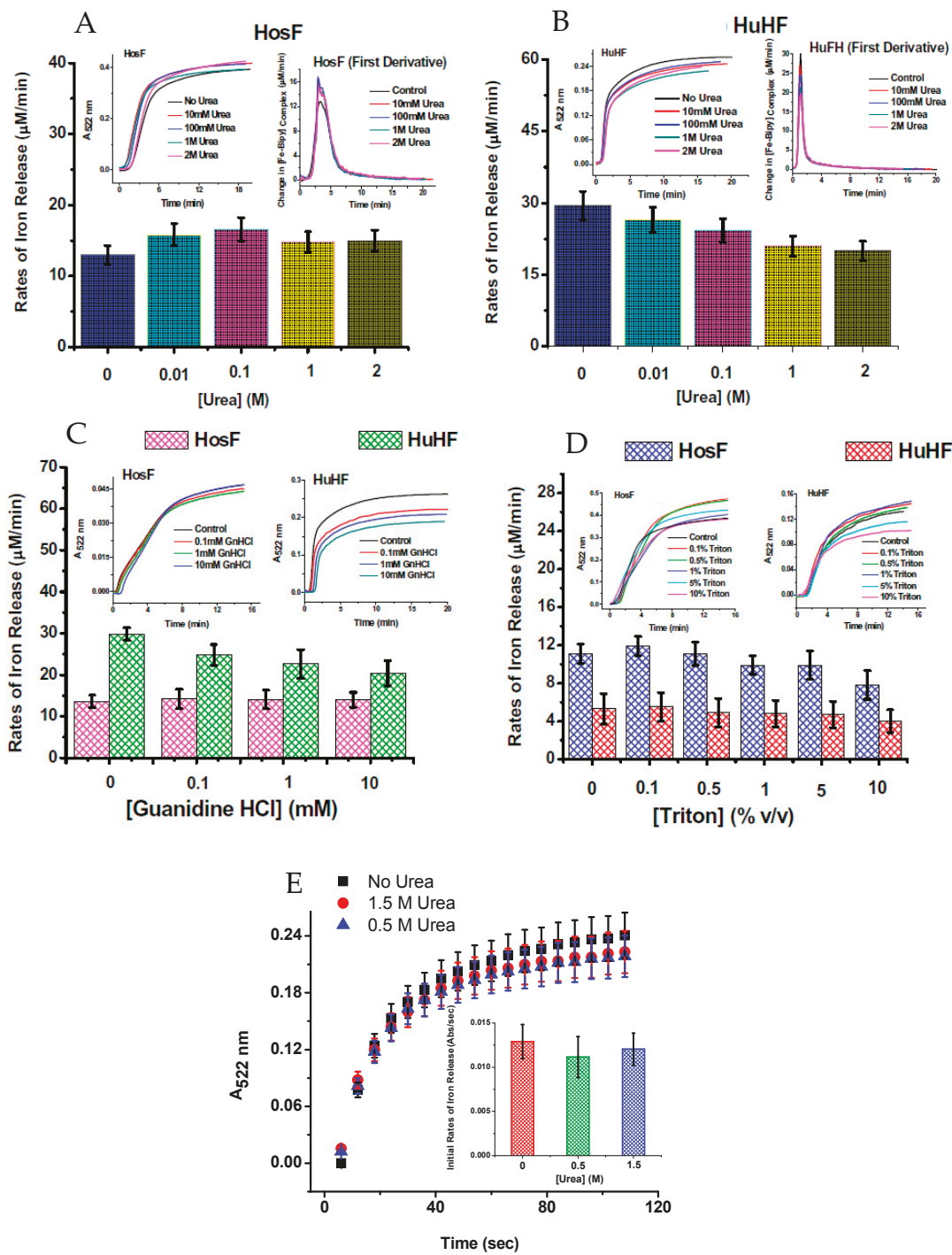

Figure 6. Rates of iron release from HosF and HuHF by the FMN-NADH system (A-D), and by $\mathrm{FMNH}_{2}(\mathrm{E})$, in the absence or presence of different concentrations of chaotropes. In both experiments, the presence of urea does not affect the rates of iron mobilization. Reprinted with permission from Ref. [25].

The above results suggest that the earlier studies may have been inaccurately interpreted, and that the diffusion mechanism should be revisited. If FMNH2 is able to diffuse into the ferritin interior and reduce the iron(III) hydroxide core, then the produced FMN should be able to diffuse out of ferritin. Notably, the diffusion of various molecules of similar size to FMN, including cisplatin [50], 
curcumin [51], or anthocyanin [52] is known to be extremely slow, suggesting that diffusion of FMNH2 is unlikely to be responsible for the observed fast rates of iron reduction. To further explore the origin of these discrepancies, we carried out an experiment to unambiguously demonstrate that, neither FMN, nor FMNH2, both of which possess virtually identical steric size, can diffuse through the ferritin shell [25]. All of the aforementioned molecules, including FMN, can be trapped inside the inner cavity of ferritin, by first denaturing the protein down to its individual subunits at $\mathrm{pH} 2$, followed by their re-assembly at neutral $\mathrm{pH}$, and dialysis [50-53]. The resulting ferritin-FMN entrapped molecules, were found to be stable for days, without any sign of diffusing out. These results clearly indicate that the ferritin channels are too small for FMN (or FMNH2) diffusion, implying that electron transfer is most likely the pathway by which ferritin iron core is reduced by flavins. Given the thickness of the protein shell $(\sim 2 \mathrm{~nm})$, it is reasonable to assume that these electron transfer processes are not arbitrary, but rather a conserved evolutionary feature of ferritin, accompanied by specific protein structural arrangements. Interestingly, recent reports demonstrated the importance of electron transfer reactions, carried by three aromatic residues surrounding the diiron center of $E$. coli bacterial ferritin in the formation of the iron mineral core [54,55].

We propose that these electron transfer pathways might be physiologically important processes for iron reductive mobilization from ferritin. However, as discussed above, FMNH2 is an unlikely electron donor candidate in cells. Protein-bound reduced flavins are more stable complexes in the presence of oxygen, and could serve as potential reducing agents, similarly to the ferredoxin-bacterioferritin complex $[19,21]$, but this is purely speculative at the moment and requires further investigation. Some exogenous one-electron reducing agents, with less negative reduction potential than FMNH2, were reported to reduce ferritin iron cores in the presence of oxygen [56]; however, these measurements were conducted without the continuous monitoring of oxygen concentration in solution, and require further clarification.

\section{Iron Mobilization by Other Reducing Agents}

It has been reported that ascorbate and glutathione are capable of mobilizing iron(II) cations from ferritin [31]. While the rates of iron reduction were substantially lower than with reduced flavins, the high intracellular concentration (several $\mathrm{mM}$ ) of the reduced forms of ascorbate and glutathione, could be sufficient for significant mobilization of iron from cellular ferritin, under physiological conditions. Surprisingly, under anaerobic conditions, iron core reduction by ascorbate and glutathione in horse spleen ferritin comes to a complete stop only after $~ 17-18 \%$ of the total iron has been reduced, in direct contrast with reduced flavins and dithionite, where complete iron mobilization was observed. The sudden halt of iron mobilization cannot be the result of a thermodynamic equilibrium, since the reduction potential of both ascorbate and glutathione is much more negative than that of iron(III). Damaged horse spleen ferritin molecules that cannot protect the inorganic iron core from reducing agents, is one possible explanation for this partial iron mobilization. If this were true, then iron(III) cations in undamaged ferritin can NOT be reduced by ascorbate and glutathione under anaerobic conditions, at least in the absence of other agents. In that regard, it is interesting to compare the iron reducing ability of glutathione, with that of thiolactic acid, which is known to induce complete iron mobilization from ferritin. This clear difference in outcome can be rationalized by the small size of thiolactate molecules, and their ability to easily diffuse through ferritin channels, in contrast to glutathione. Under anaerobic conditions, iron mobilization from ferritin by ascorbate is extremely slow, but the presence of oxygen, iron, or copper cations causes a dramatic increase in the rates of iron reduction $[57,58]$. This effect can be ascribed to the formation of different redox species, most likely free radical species [59].

Superoxide anion radicals were also reported to induce reductive mobilization of iron from ferritin $[35,36]$. Because superoxide anions are continuously produced by mitochondria, as a byproduct of oxidative phosphorylation, its tiny size would allow its fast diffusion into the ferritin interior, and the subsequent reduction of the inorganic iron core. However, the physiological importance of this 
process is questionable, since the stationary concentration of superoxide anions is very low $\left(10^{-10} \mathrm{M}\right)$, due to the presence of cellular superoxide dismutases [60].

Other compounds reported to induce reductive mobilization of iron from ferritin, include polyphenols [61,62], which are abundant in certain foods. While too large to diffuse inside ferritin, they have the ability to donate one electron, and thus reduce the iron core through electron transfer, but more studies are needed to confirm these electron transfer reactions. The challenges of these studies is that these reactions are often accompanied by the auto-oxidation of polyphenol compounds at neutral $\mathrm{pH}$, giving rise to colored products that absorb light at the same wavelength as iron(II)-(bipy) 3 complexes, and other commonly used Fe(II)-complexes [63].

\section{Iron Mobilization by Specific Iron(III) Chelating Agents}

Iron is a typical "hard" metal capable of binding to a variety of "hard" chelate ligands, including catechols, carboxylates, phosphates, and hydroxamates. Several endogenous chelate ligands of that type, that exist in millimolar concentration in cells, include citrate and ATP [64]. Several other chelate ligands (i.e., DFO, DFX, and BHT; Figure 7), with very high affinity to iron(III) cations have been developed for the treatment of iron overload diseases, such as beta-thalassemia $[1,65]$. While citrate or EDTA are unable to significantly mobilize iron from ferritin, simple hydroxamates, such as acetylor benzoylhydroxamic acid (Figure 7), are able of slowly mobilizing iron from ferritin, presumably because their small size allow them to diffuse across the ferritin shell, and remove iron cations [66].<smiles>CC(=O)N(O)CCCCCNC(=O)CCC(=O)N(O)CCCCCNC(=O)CCC(=O)N(O)CCCCCN</smiles><smiles>[R]Oc1ccccc1-c1nc(-c2ccccc2O)n(-c2ccc(C(=O)O)cc2)n1</smiles>

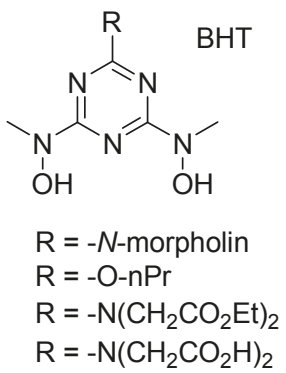<smiles>CC(=O)NO</smiles>
acetylhydroxamic acid<smiles>O=C(NO)c1ccccc1</smiles>

phenylhydroxamic acid

Figure 7. Structures of specific iron(III) chelators.

Surprisingly, relatively high rates of iron(III) mobilization were observed with large molecules, such as DFO and BHT [24]. These molecules, and their respective 1:1 or 2:1 iron(III) complexes, have molecular sizes too large to diffuse through ferritin channels. The mechanism and the iron release kinetics by these molecules are rather complicated, and strongly depend on the concentration of dissolved oxygen, and the presence of antioxidants, such as mannitol, urea, and superoxide dismutase [24]. Nonetheless, we have proposed a plausible mechanism that is mediated by superoxide anion radicals, which can readily diffuse into the ferritin interior to reduce the iron core, allowing the reduced and soluble iron(II) cations to exit out of ferritin, and be chelated by DFO or BHT ligands [24]. Because of the highly negative reduction potential of the Fe(II)-DFO, and the Fe(II)-BHT complexes (below $-0.4 \mathrm{~V}$ vs. hydrogen electrode), they act as powerful electron donors capable of reducing dissolved molecular oxygen, thus replenishing superoxide anions (Figure 8). This theoretical cyclic process requires only a catalytic amount of superoxide anions, since they are regenerated after oxidation of the released iron(II) cations to iron(III). However, superoxide anions are unstable species, and can undergo disproportionation. One possible source for the regeneration of superoxide anions is iron(II) 
hydroxides, embedded within the iron(III) hydroxide core forming a magnetite phase [67]. Reduction of magnetite by one superoxide anion can produce two iron(II) cations, instead of one iron(II) cation in the case of a ferrihydrite phase (composed of only iron(III) hydroxides), thus continuously "breeding" superoxide anions.

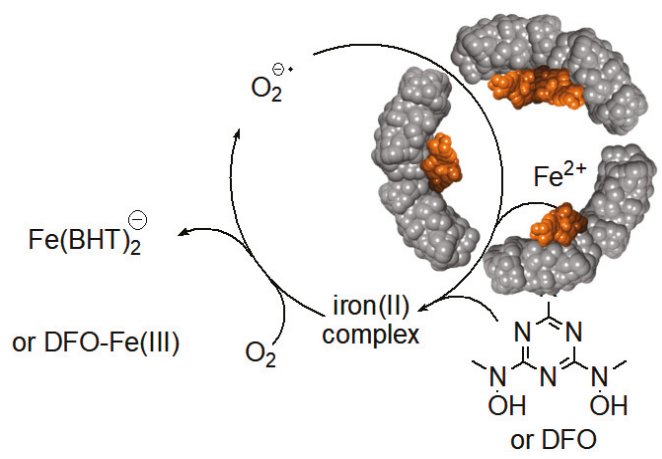

Figure 8. Superoxide mediated mobilization of iron(III) cations from the ferritin iron core by BHT (or DFO) chelators.

This unusual iron reduction mechanism is highly specific for exogenous chelators, possessing very high affinity to iron(III) cations, and is unlikely to be physiologically relevant for cells not exposed to these ligands. Endogenous iron(III) specific ligands with strong affinity for iron(III) (i.e., at least equal to that of pyrophosphate with a $\log \beta=22.2$ ), including nucleic acids [68] and nucleotide triphosphates, should be considered, although their ability to reach the inner cavity of ferritin is unknown. Smaller ions having lower affinity to iron(III) cations, such as phosphate, lactate, glutamate, or citrate may represent a better option that could assist with the dissolution of the inorganic iron core, similarly to that observed with acetohydroxamate [66]. In this latter case, iron(III) cations, complexed with these small chelates, are released from the interior cavity of ferritin, which upon exiting the ferritin shell encounter the stronger chelate agents (i.e., nucleotide triphosphate), followed by complexation and reduction to iron(II). Such process could constitute a futile cycle for the release of small amounts of iron cations, to help maintain the labile iron pool, under conditions that do not require large spikes in iron protein synthesis.

\section{Conclusions and Perspective}

Under anaerobic conditions, the reductive mobilization of iron from ferritin, in cell free systems, proceeds via electron transfer reactions across the protein shell. This process is likely to be physiologically relevant in anaerobic bacteria, where ferredoxin serves as the electron source, but its relevance under aerobic conditions is unknown. Reduced flavins are one-electron reducing agents that react much more rapidly with molecular oxygen than with the ferritin iron core, and are unlikely relevant iron reducing agents in oxygenated cells. Although some phenazine derivatives have been described as more efficient electron transfer mediators that facilitate the mobilization of iron from ferritin, even in the presence of dissolved oxygen [68], the exact mechanism of this electron mediation process is unclear. Additionally, the efficiency of these mediators in the presence of different concentration of molecular oxygen, and the relevance of this mechanism in vivo, remains to be determined. Nonetheless, this potential chemoselectivity for ferritin iron core reduction vs. oxygen reduction, is an attractive possibility that could support an auxiliary iron mobilization mechanism, in addition to ferritin proteolytic degradation. Other endogenous compounds including oxidoreductases are also worth exploring as potential ferritin-reducing agents. 
Author Contributions: Conceptualization, F.B.-A. and A.M.; Methodology, F.B.-A. and A.M.; Software, F.B.-A., A.M., J.J.P. and G.M.; Validation, F.B.-A., A.M., J.J.P. and G.M.; Formal Analysis, F.B.-A., A.M., J.J.P. and G.M.; Investigation, F.B.-A., A.M., J.J.P. and G.M.; Resources, F.B.-A. and A.M.; Data Curation, F.B.-A., A.M., J.J.P. and G.M.; Writing-Original Draft Preparation, F.B.-A. and A.M.; Writing-Review \& Editing, F.B.-A., A.M., J.J.P. and G.M.; Visualization, F.B.-A., A.M., J.J.P. and G.M.; Supervision, F.B.-A. and A.M.; Project Administration, F.B.-A. and A.M.; Funding Acquisition, F.B.-A. and A.M.

Funding: We wish to acknowledge the National Institute of Health, award R15GM104879 (F.B.-A.) and the National Science Foundation, award CHE 1150768 (A.M.) for the financial support.

Conflicts of Interest: The authors declare no conflict of interest.

\section{References}

1. Britton, R.S.; Leicester, K.L.; Bacon, B.R. Iron toxicity and chelation therapy. Int. J. Hematol. 2002, 76, $219-228$. [CrossRef] [PubMed]

2. Theil, E.C.; Goss, D.J. Living with Iron (and Oxygen): Questions and Answers about Iron Homeostasis. Chem. Rev. 2009, 109, 4568-4579. [CrossRef] [PubMed]

3. Cammack, R. Iron-Sulfur Clusters in Enzymes-Themes and Variations. Adv. Inorg. Chem. 1992, 38, $281-322$.

4. Shaik, S.; Hirao, H.; Kumar, D. Reactivity of high-valent iron-oxo species in enzymes and synthetic reagents: A tale of many states. Acc. Chem. Res. 2007, 40, 532-542. [CrossRef] [PubMed]

5. Bruijnincx, P.C.A.; van Koten, G.; Gebbink, R. Mononuclear non-heme iron enzymes with the 2-His-1-carboxylate facial triad: Recent developments in enzymology and modeling studies. Chem. Soc. Rev. 2008, 37, 2716-2744. [CrossRef] [PubMed]

6. Shi, H.F.; Bencze, K.Z.; Stemmler, T.L.; Philpott, C.C. A cytosolic iron chaperone that delivers iron to ferritin. Science 2008, 320, 1207-1210. [CrossRef] [PubMed]

7. Bou-Abdallah, F. The iron redox and hydrolysis chemistry of the ferritins. BBA-Gen. Subj. 2010, 1800, 719-731. [CrossRef] [PubMed]

8. Harrison, P.M.; Arosio, P. The ferritins: Molecular properties, iron storage function and cellular regulation. BBA-Bioenerg. 1996, 1275, 161-203. [CrossRef]

9. Chasteen, N.D. Ferritin. Uptake, storage, and release of iron. Met. Ions Biol. Syst. 1998, 35, 479-514. [PubMed]

10. Arosio, P.; Ingrassia, R.; Cavadini, P. Ferritins: A family of molecules for iron storage, antioxidation and more. BBA-Gen. Subj. 2009, 1790, 589-599. [CrossRef] [PubMed]

11. Mehlenbacher, M.; Poli, M.; Arosio, P.; Santambrogio, P.; Levi, S.; Chasteen, N.D.; Bou-Abdallah, F. Iron oxidation and core formation in recombinant heteropolymeric human ferritins. Biochemistry 2017, 56, 3900-3912. [CrossRef] [PubMed]

12. Zhao, G.; Bou-Abdallah, F.; Arosio, P.; Levi, S.; Janus-Chandler, C.; Chasteen, N.D. Multiple pathways for mineral core formation in mammalian apoferritin. The role of hydrogen peroxide. Biochemistry 2003, 42, 3142-3150. [CrossRef] [PubMed]

13. Bou-Abdallah, F.; Yang, H.; Awomolo, A.; Cooper, B.; Woodhall, M.R.; Andrews, S.C.; Chasteen, N.D. Functionality of the three-site ferroxidase center of Escherichia coli bacterial ferritin (EcFtnA). Biochemistry 2014, 53, 483-495. [CrossRef] [PubMed]

14. Bou-Abdallah, F.; Zhao, G.; Biasiotto, G.; Poli, M.; Arosio, P.; Chasteen, N.D. Facilitated diffusion of iron(II) and dioxygen substrates into human $\mathrm{H}$-chain ferritin. A fluorescence and absorbance study employing the ferroxidase center substitution Y34W. J. Am. Chem. Soc. 2008, 130, 17801-17811. [CrossRef] [PubMed]

15. Theil, E.C. Ferritin: The protein nanocage and iron biomineral in health and in disease. Inorg. Chem. 2013, 52, 12223-12233. [CrossRef] [PubMed]

16. Honarmand Ebrahimi, K.; Hagedoorn, P.-L.; Hagen, W.R. Unity in the Biochemistry of the iron-storage proteins ferritin and bacterioferritin. Chem. Rev. 2014, 115, 295-326. [CrossRef] [PubMed]

17. Haikarainen, T.; Papageorgiou, A.C. Dps-like proteins: Structural and functional insights into a versatile protein family. Cell. Mol. Life Sci. 2010, 67, 341-351. [CrossRef] [PubMed]

18. Zeth, K. Dps biomineralizing proteins: Multifunctional architects of nature. Biochem. J. 2012, 445, $297-311$. [CrossRef] [PubMed]

19. Rivera, M. Bacterioferritin: Structure, Dynamics, and Protein-Protein Interactions at Play in Iron Storage and Mobilization. Acc. Chem. Res. 2017, 50, 331-340. [CrossRef] [PubMed] 
20. Eshelman, K.; Yao, H.; Hewage, A.N.D. P.; Deay, J.J.; Chandler, J.R.; Rivera, M. Inhibiting the BfrB: Bfd interaction in Pseudomonas aeruginosa causes irreversible iron accumulation in bacterioferritin and iron deficiency in the bacterial cytosol. Metallomics 2017, 9, 646-659. [CrossRef] [PubMed]

21. Weeratunga, S.K.; Gee, C.E.; Lovell, S.; Zeng, Y.; Woodin, C.L.; Rivera, M. Binding of Pseudomonas aeruginosa apobacterioferritin-associated ferredoxin to bacterioferritin B promotes heme mediation of electron delivery and mobilization of core mineral iron. Biochemistry 2009, 48, 7420-7431. [CrossRef] [PubMed]

22. Linder, M.C. Mobilization of stored iron in mammals: A review. Nutrients 2013, 5, 4022-4050. [CrossRef] [PubMed]

23. Melman, G.; Bou-Abdallah, F.; Vane, E.; Maura, P.; Arosio, P.; Melman, A. Iron release from ferritin by flavin nucleotides. BBA-Gen. Subj. 2013, 1830, 4669-4674. [CrossRef] [PubMed]

24. Bou-Abdallah, F.; McNally, J.; Liu, X.X.; Melman, A. Oxygen catalyzed mobilization of iron from ferritin by iron(III) chelate ligands. Chem. Commun. 2011, 47, 731-733. [CrossRef] [PubMed]

25. Johnson, L.E.; Wilkinson, T.; Arosio, P.; Melman, A.; Bou-Abdallah, F. Effect of chaotropes on the kinetics of iron release from ferritin by flavin nucleotides. BBA-Gen. Subj. 2017, 1861, 3257-3262. [CrossRef] [PubMed]

26. Watt, R.K.; Hilton, R.J.; Graff, D.M. Oxido-reduction is not the only mechanism allowing ions to traverse the ferritin protein shell. BBA-Gen. Subj. 2010, 1800, 745-759. [CrossRef] [PubMed]

27. Kidane, T.Z.; Sauble, E.; Linder, M.C. Release of iron from ferritin requires lysosomal activity. Am. J. Physiol. Cell Physiol. 2006, 291, C445-C455. [CrossRef] [PubMed]

28. La, A.; Nguyen, T.; Tran, K.; Sauble, E.; Tu, D.; Gonzalez, A.; Kidane, T.Z.; Soriano, C.; Morgan, J.; Doan, M. Mobilization of iron from ferritin: New steps and details. Metallomics 2018, 10, 154-168. [CrossRef] [PubMed]

29. Truty, J.; Malpe, R.; Linder, M.C. Iron prevents ferritin turnover in hepatic cells. J. Biol. Chem. 2001, 276, 48775-48780. [CrossRef] [PubMed]

30. Jones, T.; Spencer, R.; Walsh, C. Mechanism and kinetics of iron release from ferritin by dihydroflavins and dihydroflavin analogs. Biochemistry 1978, 17, 4011-4017. [CrossRef] [PubMed]

31. Sirivech, S.; Frieden, E.; Osaki, S. The release of iron from horse spleen ferritin by reduced flavins. Biochem. J. 1974, 143, 311-315. [CrossRef] [PubMed]

32. Boyer, R.F.; Grabill, T.W.; Petrovich, R.M. Reductive release of ferritin iron: A kinetic assay. Anal. Biochem. 1988, 174, 17-22. [CrossRef]

33. Sakurai, K.; Nabeyama, A.; Fujimoto, Y. Ascorbate-mediated iron release from ferritin in the presence of alloxan. Biometals 2006, 19, 323-333. [CrossRef] [PubMed]

34. Funk, F.; Lenders, J.P.; Crichton, R.R.; Schneider, W. Reductive mobilisation of ferritin iron. FEBS J. 1985, 152, 167-172. [CrossRef]

35. Bolann, B.J.; Ulvik, R.J. Release of iron from ferritin by xanthine oxidase. Role of the superoxide radical. Biochem. J. 1987, 243, 55-59. [CrossRef] [PubMed]

36. Monteiro, H.P.; Winterbourn, C.C. The superoxide-dependent transfer of iron from ferritin to transferrin and lactoferrin. Biochem. J. 1988, 256, 923-928. [CrossRef] [PubMed]

37. Joo, M.S.; Tourillon, G.; Sayers, D.E.; Theil, E.C. Rapid reduction of iron in horse spleen ferritin by thioglycolic acid measured by dispersive X-ray absorption spectroscopy. Biol. Met. 1990, 3, 171-175. [CrossRef] [PubMed]

38. Yao, H.; Jepkorir, G.; Lovell, S.; Nama, P.V.; Weeratunga, S.; Battaile, K.P.; Rivera, M. Two Distinct Ferritin-like Molecules in Pseudomonas aeruginosa: The Product of the bfrA Gene Is a Bacterial Ferritin (FtnA) and Not a Bacterioferritin (Bfr). Biochemistry 2011, 50, 5236-5248. [CrossRef] [PubMed]

39. Orino, K.; Kamura, S.; Natsuhori, M.; Yamamoto, S.; Watanabe, K. Two pathways of iron uptake in bovine spleen apoferritin dependent on iron concentration. Biometals 2002, 15, 59-63. [CrossRef] [PubMed]

40. Sun, S.; Arosio, P.; Levi, S.; Chasteen, N.D. Ferroxidase kinetics of human liver apoferritin, recombinant H-chain apoferritin, and site-directed mutants. Biochemistry 1993, 32, 9362-9369. [CrossRef] [PubMed]

41. Haas, K.L.; Franz, K.J. Application of metal coordination chemistry to explore and manipulate cell biology. Chem. Rev. 2009, 109, 4921-4960. [CrossRef] [PubMed]

42. Liu, X.; Jin, W.; Theil, E.C. Opening protein pores with chaotropes enhances Fe reduction and chelation of Fe from the ferritin biomineral. Proc. Natl. Acad. Sci. USA 2003, 100, 3653-3658. [CrossRef] [PubMed]

43. Gibson, Q.H.; Hastings, J.W. The oxidation of reduced flavin mononucleotide by molecular oxygen. Biochem. J. 1962, 83, 368-377. [CrossRef] [PubMed] 
44. Topham, R.; Goger, M.; Pearce, K.; Schultz, P. The mobilization of ferritin iron by liver cytosol. A comparison of xanthine and NADH as reducing substrates. Biochem. J. 1989, 261, 137-143. [CrossRef] [PubMed]

45. Theil, E.C.; Tosha, T.; Behera, R.K. Solving Biology's Iron Chemistry Problem with Ferritin Protein Nanocages. Acc. Chem. Res. 2016, 49, 784-791. [CrossRef] [PubMed]

46. Watt, G.D.; Jacobs, D.; Frankel, R.B. Redox reactivity of bacterial and mammalian ferritin: Is reductant entry into the ferritin interior a necessary step for iron release? Proc. Natl. Acad. Sci. USA 1988, 85, 7457-7461. [CrossRef] [PubMed]

47. Theil, E.C.; Liu, X.S.; Tosha, T. Gated pores in the ferritin protein nanocage. Inorg. Chim. Acta 2008, 361, 868-874. [CrossRef] [PubMed]

48. Liu, X.S.; Patterson, L.D.; Miller, M.J.; Theil, E.C. Peptides selected for the protein nanocage pores change the rate of iron recovery from the ferritin mineral. J. Biol. Chem. 2007, 282, 31821-31825. [CrossRef] [PubMed]

49. Carmona, U.; Li, L.; Zhang, L.; Knez, M. Ferritin light-chain subunits: Key elements for the electron transfer across the protein cage. Chem. Commun. 2014, 50, 15358-15361. [CrossRef] [PubMed]

50. Pontillo, N.; Pane, F.; Messori, L.; Amoresano, A.; Merlino, A. Cisplatin encapsulation within a ferritin nanocage: A high-resolution crystallographic study. Chem. Commun. 2016, 52, 4136-4139. [CrossRef] [PubMed]

51. Chen, L.; Bai, G.; Yang, S.; Yang, R.; Zhao, G.; Xu, C.; Leung, W. Encapsulation of curcumin in recombinant human H-chain ferritin increases its water-solubility and stability. Food Res. Int. 2014, 62, 1147-1153. [CrossRef]

52. Zhang, T.; Lv, C.; Chen, L.; Bai, G.; Zhao, G.; Xu, C. Encapsulation of anthocyanin molecules within a ferritin nanocage increases their stability and cell uptake efficiency. Food Res. Int. 2014, 62, 183-192. [CrossRef]

53. Chen, L.; Bai, G.; Yang, R.; Zang, J.; Zhou, T.; Zhao, G. Encapsulation of beta-carotene within ferritin nanocages greatly increases its water-solubility and thermal stability. Food Chem. 2014, 149, 307-312. [CrossRef] [PubMed]

54. Bradley, J.M.; Svistunenko, D.A.; Lawson, T.L.; Hemmings, A.M.; Moore, G.R.; Le Brun, N.E. Three Aromatic Residues are Required for Electron Transfer during Iron Mineralization in Bacterioferritin. Angew. Chem. Int. Ed. Engl. 2015, 54, 14763-14767. [CrossRef] [PubMed]

55. Bradley, J.M.; Svistunenko, D.A.; Moore, G.R.; Le Brun, N.E. Tyr25, Tyr58 and Trp133 of Escherichia coli bacterioferritin transfer electrons between iron in the central cavity and the ferroxidase centre. Metallomics 2017, 9, 1421-1428. [CrossRef] [PubMed]

56. Koochana, P.K.; Mohanty, A.; Das, S.; Subhadarshanee, B.; Satpati, S.; Dixit, A.; Sabat, S.C.; Behera, R.K. Releasing iron from ferritin protein nanocage by reductive method: The role of electron transfer mediator. Biochim. Biophys. Acta Gen. Subj. 2018, 1862, 1190-1198. [CrossRef] [PubMed]

57. Bienfait, H.F.; Van Den Briel, M.L. Rapid mobilization of ferritin iron by ascorbate in the presence of oxygen. BBA-Gen. Subj. 1980, 631, 507-510. [CrossRef]

58. Badu-Boateng, C.; Naftalin, R.J. Ascorbate and ferritin interactions: Consequences for iron release in vitro and in vivo and implications for inflammation. Free Radic. Biol. Med. 2018, in press. [CrossRef] [PubMed]

59. Badu-Boateng, C.; Pardalaki, S.; Wolf, C.; Lajnef, S.; Peyrot, F.; Naftalin, R.J. Labile iron potentiates ascorbate-dependent reduction and mobilization of ferritin iron. Free Radic. Biol. Med. 2017, 108, 94-109. [CrossRef] [PubMed]

60. Gardner, P.R. Aconitase: Sensitive target and measure of superoxide. Methods Enzymol. 2002, 349, 9-23. [PubMed]

61. Hynes, M.J.; Coinceanainn, M.O. Investigation of the release of iron from ferritin by naturally occurring antioxidants. J. Inorg. Biochem. 2002, 90, 18-21. [CrossRef]

62. Ahmad, S.; Singh, V.; Rao, G.S. Release of iron from ferritin by 1, 2, 4-benzenetriol. Chem. Biol. Interact. 1995, 96, 103-111. [CrossRef]

63. Dangles, O.; Fargeix, G.; Dufour, C. One-electron oxidation of quercetin and quercetin derivatives in protic and non protic media. J. Chem. Soc. Perkin Trans. 2 1999, 1387-1396. [CrossRef]

64. Bennett, B.D.; Kimball, E.H.; Gao, M.; Osterhout, R.; Van Dien, S.J.; Rabinowitz, J.D. Absolute metabolite concentrations and implied enzyme active site occupancy in Escherichia coli. Nat. Chem. Biol. 2009, 5, 593-599. [CrossRef] [PubMed]

65. Chaston, T.B.; Richardson, D.R. Iron Chelators for the treatment of iron overload disease: Relationship between structure, redox activity, and toxicity. Am. J. Hematol. 2003, 73, 200-210. [CrossRef] [PubMed] 
66. Galvez, N.; Ruiz, B.; Cuesta, R.; Colacio, E.; Dominguez-Vera, J.M. Release of iron from ferritin by aceto-and benzohydroxamic acids. Inorg. Chem. 2005, 44, 2706-2709. [CrossRef] [PubMed]

67. Galvez, N.; Fernandez, B.; Sanchez, P.; Cuesta, R.; Ceolin, M.; Clemente-Leon, M.; Trasobares, S.; Lopez-Haro, M.; Calvino, J.J.; Stephan, O.; et al. Comparative structural and chemical studies of ferritin cores with gradual removal of their iron contents. J. Am. Chem. Soc. 2008, 130, 8062-8068. [CrossRef] [PubMed]

68. Netto, L.E.S.; Da Costa Ferreira, A.M.; Augusto, O. Iron(III) binding in DNA solutions: Complex formation and catalytic activity in the oxidation of hydrazine derivatives. Chem. Biol. Interact. 1991, 79, 1-14. [CrossRef]

(C) 2018 by the authors. Licensee MDPI, Basel, Switzerland. This article is an open access article distributed under the terms and conditions of the Creative Commons Attribution (CC BY) license (http:/ / creativecommons.org/licenses/by/4.0/). 


\title{
Links Between Iron and Lipids: Implications in Some Major Human Diseases
}

\author{
Stephanie Rockfield, Ravneet Chhabra, Michelle Robertson, Nabila Rehman, Richa Bisht and \\ Meera Nanjundan * \\ Department of Cell Biology, Microbiology and Molecular Biology, University of South Florida, Tampa, \\ FL 336200, USA; srockfie@mail.usf.edu (S.R.); chhabra@mail.usf.edu (R.C.); mrobertson1@mail.usf.edu (M.R.); \\ nabila1@mail.usf.edu (N.R.); richabisht@mail.usf.edu (R.B.) \\ * Correspondence: mnanjund@usf.edu; Tel.: +1-813-974-8133
}

Received: 31 August 2018; Accepted: 19 October 2018; Published: 22 October 2018

\begin{abstract}
Maintenance of iron homeostasis is critical to cellular health as both its excess and insufficiency are detrimental. Likewise, lipids, which are essential components of cellular membranes and signaling mediators, must also be tightly regulated to hinder disease progression. Recent research, using a myriad of model organisms, as well as data from clinical studies, has revealed links between these two metabolic pathways, but the mechanisms behind these interactions and the role these have in the progression of human diseases remains unclear. In this review, we summarize literature describing cross-talk between iron and lipid pathways, including alterations in cholesterol, sphingolipid, and lipid droplet metabolism in response to changes in iron levels. We discuss human diseases correlating with both iron and lipid alterations, including neurodegenerative disorders, and the available evidence regarding the potential mechanisms underlying how iron may promote disease pathogenesis. Finally, we review research regarding iron reduction techniques and their therapeutic potential in treating patients with these debilitating conditions. We propose that iron-mediated alterations in lipid metabolic pathways are involved in the progression of these diseases, but further research is direly needed to elucidate the mechanisms involved.
\end{abstract}

Keywords: iron; lipid; obesity; cancer; neurodegeneration; iron chelation; phlebotomy

\section{Introduction}

Iron, one of the most essential elements in the human body and indispensable for life, exists in complex forms, including (a) the iron storage complex in which iron is trapped (i.e., hemosiderin), (b) heme containing proteins (i.e., hemoglobin), (c) heme-containing enzymes, (d) transferrin (i.e., holo-transferrin), and (e) the ferritin complex (comprised of $4500 \mathrm{Fe}(\mathrm{III})$ molecules in a complex with ferritin heavy and light chains) [1]. This metal is essential for cellular processes, including metabolic reactions, oxygen transport via hemoglobin, and DNA synthesis [2]. An average adult has $3-5 \mathrm{~g}$ of iron in their body [3], while only $1-2 \mathrm{mg}$ of iron is normally absorbed in the intestinal tract, which would then be available for body-wide circulation [4]. Free iron also exists intracellularly in the labile iron pool (LIP) and leads to the production of reactive oxygen species (ROS) via the reaction of hydrogen peroxide $\left(\mathrm{H}_{2} \mathrm{O}_{2}\right)$ with $\mathrm{Fe}(\mathrm{II})$, a process known as the Fenton reaction $[5,6]$ :

$$
\mathrm{Fe}(\mathrm{II})+\mathrm{H}_{2} \mathrm{O}_{2}+\mathrm{H}^{+} \rightarrow \mathrm{Fe}(\mathrm{III})+\left[{ }^{\bullet} \mathrm{OH}\right]+\mathrm{H}_{2} \mathrm{O} .
$$

Since the body has no mechanism to eliminate excess iron (other than conditions like pregnancy, menstruation, and blood-letting [3]), iron levels must be appropriately maintained to hinder the potentially toxic effects if present in excess [7]. On the other hand, insufficient quantities of iron also leads to detrimental cellular processes [7]. Normal body serum iron levels range from 9-27 $\mu \mathrm{M}$; 
however, acute toxicity will be observed in excess of $45 \mu \mathrm{M}$. This can result in death if $>160 \mu \mathrm{M}$, which can be induced by taking iron supplements [3]. On the other hand, chronic iron overload will arise in response to sublethal doses over extended periods of time (i.e., blood transfusions) leading to development of diseases, including cancer [3]. Indeed, the carcinogenic effects of excessive iron have been well established [8]. In this regard, it is interesting that medical conditions, such as hereditary hemochromatosis and $\beta$-thalassemia, are associated with an increased risk of developing cancer [3].

Specific mechanisms, such as iron absorption, iron recycling, and iron mobilization, are in place to regulate iron content at both a cellular and systemic level [1]; for comprehensive reviews, see [2,9]. Briefly, uptake of iron, either as transferrin-bound iron (TBI, holo-transferrin bound Fe(III)) or as non-transferrin bound iron (NTBI, Fe(II)), is mediated, respectively, via the transferrin receptor (CD71) and by solute carrier family 39 member 8 (SLC39A8/ZIP8) or solute carrier family 39 member 14 (SLC39A14/ZIP14) [10-12]. For uptake of NTBI in liver enterocytes, Fe(III) is oxidized to Fe(II) by duodenal cytochrome $b$ (DCYTB) before being imported into the cell by the divalent metal transporter 1 (DMT1) [13]. After TBI is endocytosed, Fe(III) is released from transferrin and then reduced to Fe(II) by the ferrireductase STEAP3 (six-transmembrane epithelial antigen of prostate 3) [14] prior to its release from the endosome via the DMT1 channel. Cytosolic iron may then (a) remain available for use in the LIP, (b) be transported to mitochondria to generate iron-sulfur (Fe-S) clusters, or (c) be stored within the ferritin complex (a process mediated by poly(RC) binding protein 1 (PCBP1) $[9,15]$. Iron is released from the ferritin complex via the action of nuclear receptor coactivator 4 (NCOA4), which is involved in autophagy-mediated degradation of these iron complexes $[16,17]$. With regards to iron export, ferroportin (FPN1), the only known iron exporter [12], is tightly regulated by hepcidin (HAMP), a protein hormone that is secreted in a controlled manner from the hepatic tissue [12]. The exported iron (in the Fe(II) form) is then oxidized via hephaestin (HEPH) to Fe(III) [18].

Increased circulating transferrin saturation leads to elevated NTBI, which is deposited primarily into the heart, pancreas, liver, and brain [19-23]. Such iron deposits can be observed via transmission electron microscopy (TEM) and are present prior to the development of iron overload symptoms [3]. Under these conditions, ROS accumulates-which can then mediate damage to proteins, lipids, nucleic acids, and other cellular components $[3,24,25]$. In addition, elevated ROS can induce a ferroptotic response, which is characterized by accumulation of lipid peroxides $[15,26]$. Activation of ferroptosis promotes cell death in various pathological conditions, such as diffuse large B-cell lymphoma, acute kidney failure, chromophobe kidney cancer, and periventricular leukomalacia [27]. As described later in Section 3, dysregulated iron levels have also been implicated in the development of neurodegenerative disorders, including Alzheimer's disease, Parkinson's disease, and Amyotrophic lateral sclerosis [28], as well as in cancer [8].

In addition to systemic iron overload, localized increases in this metal can give rise to conditions, such as endometriosis, a benign gynecological disorder characterized by the presence of endometriotic cysts, which contain old blood components (including heme and its breakdown products) [29]. This source of redox active iron present within these cysts or that arising from follicular fluid, retrograde menstrual effluent, and the process of ovulation have been proposed to contribute to ovarian cancer risk [30-32]. Consumption of red meat as a source of dietary iron may also contribute to development of other cancers, namely colorectal cancers [33].

Similar to iron, lipid levels must be regulated in an appropriate manner to ensure cellular homeostasis. Lipids are a critical source of cellular energy and also have roles as signaling metabolites [34]. When these are in excess, they are stored within lipid droplets to hinder the detrimental effects of lipotoxicity [35]. On the other hand, when lipids are depleted, cellular biosynthetic pathways are activated to generate these macromolecules [35]. Within the body, lipids are primarily stored in adipose tissue, an organ that is also involved in endocrine signaling to regulate energy balance and insulin resistance [36]. Deregulated lipid biosynthetic and catabolic pathways may therefore interfere with crucial biological processes, ultimately producing deleterious effects and potentially causing serious medical issues. Herein, we present a review of the literature pertaining 
to altered lipid metabolism in response to dysregulated iron pathways. We discuss associations between iron and lipid alterations derived from model organisms (cell lines, Saccharomyces cerevisiae, Caenorhabditis elegans, Mus musculus, and Drosophila melanogaster) and patient specimens. As shown in Figure 1, key elements of cholesterol and lipid biosynthesis, iron metabolism, and ferroptosis are summarized, particularly focusing on the interconnections between these pathways, as identified in the studies presented in this review.

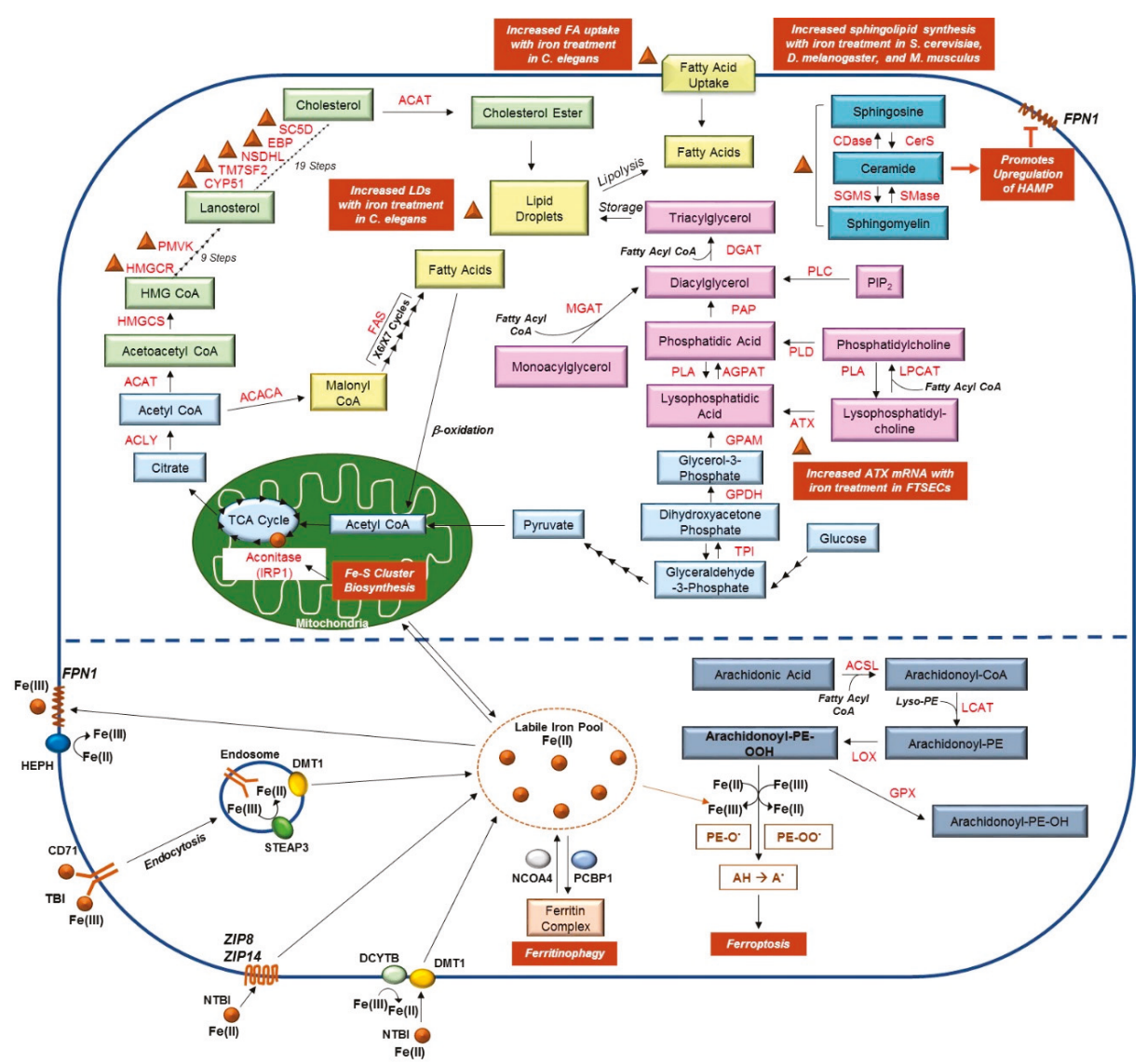

Figure 1. Links between Lipid and Iron Metabolic Pathways. (Top) Pyruvate, a product of glycolysis, is converted to acetyl-CoA in the mitochondria. Acetyl-CoA feeds into the Krebs (TCA) cycle, illustrated in light blue, to generate citrate; the conversion of citrate to isocitrate is mediated by the enzyme aconitase and requires binding to Fe-S clusters (as indicated by the brown circle). Citrate can also be transported from the mitochondria to the cytosolic compartment where it is used to generate acetyl-CoA; this molecule can then feed into either the cholesterol biosynthetic pathway (green) or the fatty acid synthesis pathway (yellow). Elevated liver iron concentrations correlated with increased mRNA expression of several genes involved in cholesterol biosynthesis (namely, HMGCR, PMVK, CYP51, TM7SF2, NSDHL, EBP, and SC5D), as indicated with brown triangles (see Section 2.1). Exogenous fatty acids can also be imported into the cell; together, fatty acids, triacylglycerides, and cholesterol esters are essential components of lipid droplets. As detailed in Section 2.4, iron can promote both fatty acid 
import and lipid droplet formation. Synthesis of triacylglycerides, as well as phospholipids (and their modification), are presented in pink, whereas the sphingolipid metabolic pathway is displayed in dark blue. Iron can promote the production of ceramide (indicated with a brown triangle), and in turn induces HAMP expression, which negatively regulates FPN1 (refer to Section 2.2). Furthermore, our own unpublished work suggests iron treatment in human fallopian tube secretory epithelial cells (FTSECs) increases mRNA expression of autotaxin (ATX), which is involved in generating lysophosphatidic acid (see Section 2.5). (Bottom) TBI can be imported via endocytosis by binding to $\mathrm{CD} 71$; $\mathrm{Fe}(\mathrm{III})$ is then converted to Fe(II) by STEAP3 prior to being transported from the endosomal compartment to the cytosolic LIP by DMT1. Alternatively, NTBI can be imported into cells by DMT1 (following conversion of Fe(III) to Fe(II) by DCYTB), ZIP8, or ZIP14 [37]. From the LIP, iron may be (a) transported to the mitochondria for use in Fe-S cluster generation, (b) loaded to ferritin by PCBP1, or (c) used by the cell for other cellular processes. Iron can also be released from the ferritin complex via NCOA4-mediated ferritinophagy. Increased iron levels in the cell can promote the formation of lipid peroxides, a process critical for ferroptosis (shown in grey). Please see [2,38-45] for comprehensive reviews of these pathways and the contributing enzymes.

\section{Interactions between Iron and Lipids in Model Systems}

\subsection{Iron and Cholesterol}

Cell membranes are comprised of not only protein, but also lipids and cholesterol, which play important roles in cell signaling and maintenance of cell structure [46]. Similar to iron, excess levels of cholesterol can also elicit a toxic effect by elevating oxidative stress responses [47]. Specifically, hepatic iron levels were correlated with increased cholesterol content, which was associated with elevated mRNA levels of seven key enzymes involved in the cholesterol biosynthetic pathway: 3-hydroxy-3-methylglutarate-CoA reductase (HMGCR), lanosterol-14 $\alpha$ demethylase (CYP51), $\Delta 14$-sterol reductase (TM7SF2), sterol-4 $\alpha$-carboxylate-3-dehydrogenase (NSDHL), cholestenol- $\Delta$-isomerase (EBP), phosphomevalonate kinase (PMVK), and lathosterol oxidase (SC5D) [47]. The authors of this work propose that these changes could contribute to the development of fatty liver disease [47].

Cholesterol is also found in lipoprotein particles along with apolipoproteins, such as apolipoprotein E (ApoE), a major brain Apo, which is critical for learning, memory, and brain repair [48]. In Alzheimer's disease, current evidence implicates impaired levels of ApoE4 (which correlates with neurodegeneration while also being able to bind to metals, such as iron) in the sequestration of iron to amyloid- $\beta$ deposits [48]. Although elevated levels of iron contribute to increased ApoE mRNA and protein expression, the secretion of this apolipoprotein was reduced [49]. In addition to altered ApoE levels, patients with Alzheimer's disease have increased ferritin levels in their cerebrospinal fluid (CSF), a marker of brain iron content [50-52]. Interestingly, patients with elevated ApoE4 (specifically, the $\varepsilon 4$ variant) have $>20 \%$ increase in CSF ferritin correlating with increased kinetics of cellular degeneration in the hippocampus, as well as with cognitive decline [50-52].

The effects of ApoE extend beyond its role in neurodegenerative diseases. For example, ApoE is proposed to protect against NASH (non-alcoholic steatohepatitis) as ApoE knockout mice were characterized by hepatosteatosis [53]. A link to iron was identified in a recent SILAC proteomic study in which adipocytes were treated with ferric ammonium citrate (FAC, a source of NTBI) resulting in an 11-fold increase in ApoE (amongst two other markers), although ApoE secretion was reduced by $>55 \%$ [53]. Further studies are needed to elucidate the mechanism underlying increased ApoE expression in spite of its reduced secretion.

\subsection{Iron and Sphingolipids}

Like cholesterol, sphingolipids (i.e., sphingomyelin, ceramide, and sphingosine amongst others) are essential membrane and signaling components [54]. The initial link between iron and sphingolipid regulation in eukaryotic systems was derived from S. cerevisiae in which iron-induced toxicity was 
correlated with increased synthesis of sphingolipids [55]. More recently, this finding has been extended to D. melanogaster and M. musculus, as well as in mammalian cell lines [56,57] in which iron-induced toxicity was mediated by a deficiency in frataxin, a key modulator of iron-sulfur cluster biogenesis, also lacking in patients with Friedreich's ataxia [58].

Intriguingly, iron uptake via CD71 is increased following cellular treatment with C2-ceramide, a sphingolipid involved in lipid signaling in bovine aortic endothelial cells (BAECs), and could be reversed with an iron chelator (deferoxamine (DFO)) or with an antibody targeting endocytosis of CD71 [59]. C2-ceramide treatment in human hepatocellular carcinoma (HepG2) cells was found to transcriptionally upregulate HAMP mRNA via the JAK/STAT3 signaling cascade [60]. In another report, loss of sphingomyelin in murine lymphoma cells (WR19L) hindered clathrin-mediated endocytosis of CD71 whereas overexpression of sphingomyelin synthase, as well as presentation of exogenous sphingomyelin increased transferrin uptake [61]. Whether alterations in other elements of iron signaling are induced in response to ceramide and other sphingolipids has yet to be determined.

\subsection{Iron-Sulfur Cluster and Lipids}

Iron-sulfur cluster containing proteins play key roles in the Krebs (TCA) cycle (i.e., aconitase) [62] and the electron transport chain (i.e., complex I) [63], which contribute to ATP production. Iron-sulfur clusters are also needed for regulation of enzymes involved in key cellular processes (i.e., DNA polymerase, base excision repair) in addition to iron-sensing molecules (i.e., iron response proteins IRPs) [62]. In human embryonic kidney cells (HEK293) overexpressing a dominant negative form of ISCU (an iron-sulfur cluster assembly enzyme), a 10-fold increase in citrate levels (as a result of a deficiency in aconitase activity) was noted; this citrate was redirected for its use in fatty acid biosynthesis, which increased lipid droplet formation [64,65]. The mitochondrial phospholipid, cardiolipin, is also involved in multiple processes for generating cellular energy by regulating activities of protein complexes involved in the electron transport chain and mitochondrial membrane dynamics [66]. Using the yeast model, researchers identified that deficiency in cardiolipin synthase $(\mathrm{crd} \Delta)$ increased expression of the iron regulon (iron uptake genes for mitochondria) and biogenesis of iron-sulfur clusters in the mitochondria and their export to the cytosol [67]. Additional investigations into cardiolipin regulation needs to be addressed to have an improved understanding of iron-sulfur cluster biogenesis.

\subsection{Iron, Lipid Droplets, and Leptin}

According to the World Health Organization (WHO), obesity (defined as a body-mass index (BMI) $\geq 30$ ) has increased 3-fold over the past 40-decades throughout the world [68]. Additionally, patients who are obese (characterized by a gain in adipose tissues (including visceral and subcutaneous) [69]) are at an increased risk of developing co-morbidities, including cancer [70]. Adipocytes, the major component of these tissues, contain $\sim 100 \mu \mathrm{m}$ large-sized lipid droplets, composed of triacylglycerides and cholesterol esters [71]. In C. elegans, iron supplementation significantly increased the abundance and size of lipid droplets [72]. Specifically, iron treatment in this model organism increased the expression of sgk-1 (an ortholog for mammalian glucocorticoid-induced kinase), which was found to increase expression of acs20 (mammalian homolog, FATP1/4) involved in fatty acid import and thus transport to lipid droplets while simultaneously promoting iron storage in ferritin [72].

Leptin is an adipokine that is produced by adipocytes to regulate hunger [73]. In HuH7, a human hepatoma cell line, leptin treatment resulted in increased HAMP mRNA, which was regulated by the JAK2/STAT3 signaling cascade [74]. Additionally, using mice deficient in leptin (ob/ob), leptin treatment increased both plasma HAMP levels and liver HAMP mRNA, which were associated with an increase in liver iron levels [75]. Interestingly, in mice lacking mediators important for iron efflux (hephaestin and ceruloplasmin), leptin levels were reduced [76]. Furthermore, C57BL/6 mice, fed a high-fat diet, showed increased leptin levels and increased liver HAMP mRNA associated with increased liver iron [77]. Whether leptin alters other elements of iron signaling has yet to be determined. 


\subsection{Iron, LPP1, and Other Enzymes Involved in Lysophospholipid Metabolism}

Recent work has identified that overexpression of LIPIN1, an enzyme involved in the conversion of phosphatidic acid (PA) to diacylglycerol (DAG), can reduce iron levels in human hepatic cancer cells (BEL7402) [78]; this phenomenon appeared to be mediated by FPN1, which was increased upon LIPIN1 expression [78]. On the other hand, from our own work (unpublished results, Rockfield and Nanjundan), we have identified that addition of exogenous NTBI iron (presented as FAC) to transformed gynecological cell lines induced autotaxin (ATX) mRNA. ATX, an adipokine, catalyzes the conversion from lysophosphatidylcholine (LPC) to lysophosphatidic acid (LPA) and is noted to be altered in multiple cancer types, including non-small cell lung cancer, glioblastoma multiforme, melanoma, thyroid cancer, follicular lymphoma, ovarian cancer, hepatocellular carcinoma, breast cancer, and colon cancer $[79,80]$. To our knowledge, the only other reported link between ATX/LPA and iron is in the H9c2 cardiomyoblast cells; ATX overexpression protected these cells from ferroptotic cell death (an iron-dependent cellular response) by reducing the levels of intracellular ROS [81]. Further work must be performed to improve our understanding of these initial findings.

\subsection{Iron and Fatty Acid Metabolism}

Cancer cells are described to be "addicted" to iron [8]; indeed, their increased proliferative capacity is negatively regulated upon cellular treatment with iron chelators [82]. Links between iron and lipid pathways in cancer are only beginning to come to the forefront. Recent work using a systems biological approach (using existing microarray datasets followed by data mining approaches) implicates associations between the iron pathway and fatty acid synthesis and regulation in high-grade serous epithelial ovarian carcinomas [83]. Specifically, peroxisome proliferator-activated receptor gamma (PPARG), sterol regulatory element binding transcription factor 1 (SREBF1), ATP citrate lyase (ACLY), fatty acid synthase (FAS), acyl-CoA synthetase long-chain (ACSLx)), fatty acid desaturation (fatty acid desaturase 2 (FADS2), stearoyl-CoA desaturase (SCD), elongation of very long chain fatty acid elongase 2 (ELOVL2), elongation of very long chain fatty elongase 5 (ELOVL5)), and glycerolipid metabolic pathways (1-acylglycerol-3-phosphate O-acyltransferase (AGPATx), DGAT1, LIPIN1, LIPIN2, glycerol kinase (GK), glycerol-3-phosphate-acyltransferase (GPAM)) were perturbed along with iron-related genes (iron-ion binding, as well as intracellular iron regulation) [83]. The functional outcomes of these initial associations must be further investigated.

\subsection{Ferroptosis and Lipids}

Lipid peroxides are a form of ROS, which serve as signaling molecules that can alter the properties of cell membranes, lipid interactions, and protein functions. In addition, these ROS promote cellular apoptosis, including iron-dependent ferroptotic cell death [84]. In ferroptosis, recent research has identified alterations in lipid metabolic pathways in addition to the well-established lipid peroxidation [85]. Using retrovirus-generated insertional mutagenesis in KBM7 (haploid chronic myeloid leukemia cells), 9 genes were identified as increased upon ferroptosis induction with multiple small molecule ferroptosis inducers, including ACSL4 (acyl-coA synthetase long-chain family member 4, which produces the arachadonic acid metabolite 5-HETE (5-hydroxyeicosatetraenoic acid)) and LPCAT3 (lysophosphatidylcholine acyl-transferase 3) [86]. Similarly, in a genome wide CRISPR-mediated genetic screen and microarray screen involving ferroptosis resistant cells, ACSL4 was also identified as a regulator of this pathway [87]. Furthermore, ACSL4 mRNA and protein were reduced in ferroptosis-resistant ( $\mathrm{LnCaP}$ and $\mathrm{K} 562$ ) cells relative to sensitive (HL60 and HepG2) cancer cells [85]. Likewise, in breast cancer cell lines, ACSL4 expression corresponded with ferroptosis sensitivity [87]. When ACSL4 is reduced (via shRNA-mediated knockdown) in HL60 and HepG2 cells, ferroptosis is inhibited; in contrast, when it is overexpressed in LnCaP and K562 cells, ACSL4 promotes ferroptosis [85]. 
In a ferroptosis mouse model for which glutathione peroxidase 4 (GPX4) is deficient, inhibition of ACSL4 was found to improve tissue health [87]. Furthermore, a novel ferroptosis-inducing compound (CIL56) was identified to be dependent on the activity of acetyl-coA carboxylase 1 (ACC1, the rate-limiting enzyme involved in fatty acid biosynthesis) [86]. Upon knockout of ACC1 via CRISPR-Cas9, a 5-fold increased resistance to ferroptosis was noted in response to CIL56 [86]. In another study, researchers identified LSH (lymphoid specific helicase, a DNA methylase modified, which is part of the SNF2 chromatin remodeling ATPase family) as hindering ferroptosis through its interaction with WD repeat domain 76 (WDR76, via direct promoter binding activity). This in turn corresponded with increased expression of fatty acid desaturases (i.e., FADS2 and FADS5) and was dependent on both iron and lipid peroxidation [88]. In HepG2 and Hep3B liver cancer cells, knocking out the expression of iron sulfur domain 1 (CISD1, localized to the outer mitochondrial membrane) also was found to promote lipid peroxidation and ferroptosis [89]. The clinical utility of such ferroptosis inhibitors could be tested in future work.

\section{Iron and Lipids: Neurodegenerative Diseases}

\subsection{Brain Iron Localization}

Neurodegenerative diseases (i.e., Alzheimer's, Parkinson's, and Huntington's, among others) are considered age-related diseases, in part due to accumulation of iron, and its physiological consequences [90]. Notably, this metal causes inflammation of the brain and thus, its degeneration [90]. Iron response proteins (IRP1 and IRP2) increase amyloid precursor protein (APP) expression, which is the precursor to amyloid- $\beta$ in Alzheimer's disease, as well as the expression of $\alpha$-synuclein, which is a critical component of the Lewy bodies in Parkinson's disease [90]. The mTOR pathway can regulate expression of CD71, which is responsible for cellular iron uptake [90]; indeed, it has been recently proposed that inhibition of mTOR could reduce iron accumulation and thus, lessen the neurodegenerative effects induced by this metal [90]. Specific brain regions that accumulate iron include the hippocampus [91], the globus pallidus, red nucleus, substantia nigra, dentate nucleus, and caudate-putamen [92], whereas increased iron content in the basal ganglia is a unique feature of a rare brain disease called neurodegeneration with brain iron accumulation (NBIA) [93].

\subsection{Iron-Mediated Lipid Peroxidation and Ferroptosis}

As mentioned earlier, iron participates in the Fenton reaction to generate ROS, which damage lipids via peroxidation [6], a phenomenon observed in neurodegenerative diseases [94]. Indeed, increased redox active iron in certain regions of the brain contributes to the development of neurological diseases, which is associated with programmed cell death [95]. The exact mechanism contributing to this cell death process has been unclear until recently. It is now recognized that iron-dependent cell death pathway, namely ferroptosis, may be involved in the development of such neurodegenerative diseases $[95,96]$.

Lipoxygenases (iron-dependent enzymes) can also promote oxidation of polyunsaturated fatty acids and are localized to the hippocampal region of the brain [97]. One oxidative stress stimulator, namely tert-butylhydroperoxide (t-BHP), promotes cell death via ferroptosis in PC12 cells (a model cell line for neurobiology) by reducing GPX4 protein and glutathione (GSH) levels leading to increased lipid peroxidation [98]. Mitochondrial alterations, including (a) reduced mitochondrial membrane potential, (b) reduced ATP levels, and (c) increased ROS in the mitochondria, were also noted [98]. They further identified that these effects could be reversed upon treatment with ferrostatin or iron chelation with DFO [98]. Neurons in the forebrain (cerebral cortex and hippocampus) are susceptible to ferroptosis [99]. Interestingly, an inducible tissue-specific GPX4 knockout mouse (specifically in forebrain neurons) resulted in massive deficits in cognitive and memory functions concurrently with increased lipid peroxidation, increased MAPK pathway activation, and increased oxidative damage [99]. Furthermore, maintaining these mice on a vitamin E (an antioxidant) deficient diet 
accelerated the neurodegenerative processes in these mice, whereas treatment with a ferroptosis inhibitor (liproxstatin-1) ameliorated brain functions [99]. In a model of Huntington's disease using brain slices, ferrostatin-1 was also found to reduce cell death [100]. The clinical application of these ferroptotic inhibitors could be tested in the future.

\subsection{Iron and the Sphingolipid Pathway}

In addition to iron-induced lipid peroxidation, iron can also promote sphingomyelin breakdown via activation of sphingomyelinases, generating the product ceramide (which is involved in mediating the regulated cell death response) [101] that then contributes to neuronal apoptosis, a feature of neurodegenerative diseases. In support, increased levels of sphingomyelin coinciding with reduced ceramide content is associated with neuronal protection and may thus be a targetable pathway (using iron chelators) for treatment [102]. In D. melanogaster and M. musculus, targeting of frataxin (via mutations or knockout strategies) led to iron-induced toxicity, which was mediated through the sphingolipid/PDK1/MEF2 signaling cascade [56,57]; this was detrimental to the health of these model organisms and recapitulated the neurodegenerative disease, Friedreich's ataxia [56,57]. Links between iron and the sphingolipid metabolic cascade have been identified in other neurodegenerative diseases, including NBIA; in this disease, sphingolipids were enriched in the compartment with the highest iron levels (i.e., basal ganglia), identified via gene network analyses [93]. The functional contribution of this observation needs to be investigated further in NBIA and in other neurodegenerative diseases.

\section{Treatments and Concluding Perspectives}

Targeting iron and its downstream effectors (i.e., alterations in lipid peroxidation and/or lipid metabolism) would be of high benefit to patients afflicted by detrimental effects of iron accumulation. Methods of iron reduction thus far utilized include iron chelators and the process of bloodletting.

In the case of neurodegenerative diseases, iron treatment with DFO reduced symptoms of Alzheimer's disease in an amyloid precursor protein (APP) overexpressing transgenic mouse model; specifically, amyloid- $\beta$ deposits were reduced coinciding with improved cognitive functions [103]. However, in patient studies for a variety of neurological disorders (such as pantothenae kinase-associated neurodegeneration (PKAN), aceruloplasminemia, NBIA, Friedreich's ataxia, superficial siderosis, Parkinson's disease, Alzheimer's disease, and multiple sclerosis), only low to moderate improvement of clinical symptoms was noted in a small proportion of conducted studies, with most observing no improvement [104]. Similarly in cancer, the use of iron chelators, such as DFO, has shown some efficacy in both animal models and clinical studies [105]; for additional iron chelators used in cancer studies, please see citation [105] for more details.

To the best of our knowledge, improvements in health following iron reduction via the process of phlebotomy have been assessed in six independent studies. Patients afflicted with nonalcoholic fatty liver disease (NAFLD) that underwent bloodletting had reduced blood ferritin levels [106]. Administration of phlebotomy in metabolic syndrome (METS) patients reduced blood pressure and heightened insulin sensitivity [107]. Similarly, phlebotomy administration in type II diabetics, characterized by high blood ferritin, had a marked reduction in not only ferritin (at 4-month follow-up), but also in insulin resistance [108]. With respect to cancer patients, there has been a variation in cancer incidence following such bloodletting procedures. In one study, phlebotomy reduced risk of cancer development in $36 \%$ of patients [109] while another reported only $4 \%$ [110]. Yet another showed a lack of association between iron reduction and overall risk of cancer [111]. Further investigations into implementation of iron reduction therapies can be pursued in future studies.

Although ferroptosis inhibitors have been utilized in in vivo animal studies, as well as in vitro studies, novel inhibitors could be designed that could be utilized to treat patients with neurological diseases described herein. 
Author Contributions: M.N. (corresponding author) conceived the overall content and developed the independent topics for this review. M.N. and S.R. performed PubMed literature searches and co-wrote the first draft of this review. R.C., M.R., N.R., R.B. contributed to literature review and writing specific aspects of the topics for this article. R.C., S.R., and M.N. generated Figure 1. All authors critically reviewed and approved the manuscript for final submission.

Funding: We gratefully acknowledge funding to support this work provided by NCI R21 CA178468-01A1 awarded to Meera Nanjundan.

Acknowledgments: We kindly thank the assistance of Nicole Schneider (Department of Cell Biology, Microbiology, and Molecular Biology, University of South Florida, Tampa, Florida) in the development of the review. We regret not having cited all articles relevant to this topic within this review due to space limitations.

Conflicts of Interest: The authors declare no conflict of interest.

\section{References}

1. Abbaspour, N.; Hurrell, R.; Kelishadi, R. Review on iron and its importance for human health. J. Res. Med. Sci. 2014, 19, 164-174. [PubMed]

2. Wang, J.; Pantopoulos, K. Regulation of cellular iron metabolism. Biochem. J. 2011, 434, 365-381. [CrossRef] [PubMed]

3. Eid, R.; Arab, N.T.; Greenwood, M.T. Iron mediated toxicity and programmed cell death: A review and a re-examination of existing paradigms. Biochim. Biophys. Acta Mol. Cell Res. 2017, 1864, 399-430. [CrossRef] [PubMed]

4. Andrews, N.C. Disorders of iron metabolism. N. Engl. J. Med. 1999, 341, 1986-1995. [CrossRef] [PubMed]

5. Sadrzadeh, S.M.; Graf, E.; Panter, S.S.; Hallaway, P.E.; Eaton, J.W. Hemoglobin. A biologic fenton reagent. J. Biol. Chem. 1984, 259, 14354-14356. [PubMed]

6. Winterbourn, C.C. Toxicity of iron and hydrogen peroxide: The Fenton reaction. Toxicol. Lett. 1995, 82-83, 969-974. [CrossRef]

7. Wallace, D.F. The Regulation of Iron Absorption and Homeostasis. Clin. Biochem. Rev. 2016, 37, 51-62. [PubMed]

8. Manz, D.H.; Blanchette, N.L.; Paul, B.T.; Torti, F.M.; Torti, S.V. Iron and cancer: Recent insights. Ann. N. Y. Acad. Sci. 2016, 1368, 149-161. [CrossRef] [PubMed]

9. Rockfield, S.; Raffel, J.; Mehta, R.; Rehman, N.; Nanjundan, M. Iron overload and altered iron metabolism in ovarian cancer. Biol. Chem. 2017, 398, 995-1007. [CrossRef] [PubMed]

10. Aydemir, T.B.; Cousins, R.J. The Multiple Faces of the Metal Transporter ZIP14 (SLC39A14). J. Nutr. 2018, 148, 174-184. [CrossRef] [PubMed]

11. Liuzzi, J.P.; Aydemir, F.; Nam, H.; Knutson, M.D.; Cousins, R.J. Zip14 (Slc39a14) mediates non-transferrin-bound iron uptake into cells. PNAS 2006, 103, 13612-13617. [CrossRef] [PubMed]

12. Wang, C.Y.; Jenkitkasemwong, S.; Duarte, S.; Sparkman, B.K.; Shawki, A.; Mackenzie, B.; Knutson, M.D. ZIP8 is an iron and zinc transporter whose cell-surface expression is up-regulated by cellular iron loading. J. Biol. Chem. 2012, 287, 34032-34043. [CrossRef] [PubMed]

13. Lane, D.J.; Bae, D.H.; Merlot, A.M.; Sahni, S.; Richardson, D.R. Duodenal cytochrome b (DCYTB) in iron metabolism: An update on function and regulation. Nutrients 2015, 7, 2274-2296. [CrossRef] [PubMed]

14. Sendamarai, A.K.; Ohgami, R.S.; Fleming, M.D.; Lawrence, C.M. Structure of the membrane proximal oxidoreductase domain of human Steap3, the dominant ferrireductase of the erythroid transferrin cycle. PNAS 2008, 105, 7410-7415. [CrossRef] [PubMed]

15. Shi, H.; Bencze, K.Z.; Stemmler, T.L.; Philpott, C.C. A cytosolic iron chaperone that delivers iron to ferritin. Science 2008, 320, 1207-1210. [CrossRef] [PubMed]

16. Dowdle, W.E.; Nyfeler, B.; Nagel, J.; Elling, R.A.; Liu, S.; Triantafellow, E.; Menon, S.; Wang, Z.; Honda, A.; Pardee, G.; et al. Selective VPS34 inhibitor blocks autophagy and uncovers a role for NCOA4 in ferritin degradation and iron homeostasis in vivo. Nat. Cell Biol. 2014, 16, 1069-1079. [CrossRef] [PubMed]

17. Mancias, J.D.; Wang, X.; Gygi, S.P.; Harper, J.W.; Kimmelman, A.C. Quantitative proteomics identifies NCOA4 as the cargo receptor mediating ferritinophagy. Nature 2014, 509, 105-109. [CrossRef] [PubMed]

18. Petrak, J.; Vyoral, D. Hephaestin-A ferroxidase of cellular iron export. Int. J. Biochem. Cell Biol. 2005, 37, 1173-1178. [CrossRef] [PubMed] 
19. Brissot, P.; Ropert, M.; Le Lan, C.; Loreal, O. Non-transferrin bound iron: A key role in iron overload and iron toxicity. Biochim. Biophys. Acta 2012, 1820, 403-410. [CrossRef] [PubMed]

20. Craven, C.M.; Alexander, J.; Eldridge, M.; Kushner, J.P.; Bernstein, S.; Kaplan, J. Tissue distribution and clearance kinetics of non-transferrin-bound iron in the hypotransferrinemic mouse: A rodent model for hemochromatosis. PNAS 1987, 84, 3457-3461. [CrossRef] [PubMed]

21. Iancu, T.C.; Shiloh, H.; Raja, K.B.; Simpson, R.J.; Peters, T.J.; Perl, D.P.; Hsu, A.; Good, P.F. The hypotransferrinaemic mouse: Ultrastructural and laser microprobe analysis observations. J. Pathol. 1995, 177, 83-94. [CrossRef] [PubMed]

22. Nam, H.; Wang, C.Y.; Zhang, L.; Zhang, W.; Hojyo, S.; Fukada, T.; Knutson, M.D. ZIP14 and DMT1 in the liver, pancreas, and heart are differentially regulated by iron deficiency and overload: Implications for tissue iron uptake in iron-related disorders. Haematologica 2013, 98, 1049-1057. [CrossRef] [PubMed]

23. Tripathi, A.K.; Karmakar, S.; Asthana, A.; Ashok, A.; Desai, V.; Baksi, S.; Singh, N. Transport of Non-Transferrin Bound Iron to the Brain: Implications for Alzheimer's Disease. J. Alzheimers Dis. 2017, 58, 1109-1119. [CrossRef] [PubMed]

24. Chattopadhyaya, R. Oxidative damage to DNA constituents by iron-mediated Fenton reactions-the thymidine family. J. Biomol. Struct. Dyn. 2014, 32, 155-169. [CrossRef] [PubMed]

25. Chattopadhyaya, R.; Goswami, B. Oxidative damage to DNA constituents by iron-mediated Fenton reactions: The deoxyadenosine family. J. Biomol. Struct. Dyn. 2012, 30, 394-406. [CrossRef] [PubMed]

26. Xie, Y.; Hou, W.; Song, X.; Yu, Y.; Huang, J.; Sun, X.; Kang, R.; Tang, D. Ferroptosis: Process and function. Cell Death Differ. 2016, 23, 369-379. [CrossRef] [PubMed]

27. Yang, W.S.; Stockwell, B.R. Ferroptosis: Death by Lipid Peroxidation. Trends Cell Biol. 2016, 26, $165-176$. [CrossRef] [PubMed]

28. Masaldan, S.; Bush, A.I.; Devos, D.; Rolland, A.S.; Moreau, C. Striking while the iron is hot: Iron metabolism and Ferroptosis in neurodegeneration. Free Radic Biol. Med. 2018. [CrossRef] [PubMed]

29. Kobayashi, H.; Yamada, Y.; Kanayama, S.; Furukawa, N.; Noguchi, T.; Haruta, S.; Yoshida, S.; Sakata, M.; Sado, T.; Oi, H. The role of iron in the pathogenesis of endometriosis. Gynecol. Endocrinol. 2009, 25, 39-52. [CrossRef] [PubMed]

30. Yamaguchi, K.; Mandai, M.; Toyokuni, S.; Hamanishi, J.; Higuchi, T.; Takakura, K.; Fujii, S. Contents of endometriotic cysts, especially the high concentration of free iron, are a possible cause of carcinogenesis in the cysts through the iron-induced persistent oxidative stress. Clin. Cancer Res. 2008, 14, 32-40. [CrossRef] [PubMed]

31. Sanchez, A.M.; Papaleo, E.; Corti, L.; Santambrogio, P.; Levi, S.; Vigano, P.; Candiani, M.; Panina-Bordignon, P. Iron availability is increased in individual human ovarian follicles in close proximity to an endometrioma compared with distal ones. Hum Reprod. 2014, 29, 577-583. [CrossRef] [PubMed]

32. Vercellini, P.; Crosignani, P.; Somigliana, E.; Vigano, P.; Buggio, L.; Bolis, G.; Fedele, L. The 'incessant menstruation' hypothesis: A mechanistic ovarian cancer model with implications for prevention. Hum. Reprod. 2011, 26, 2262-2273. [CrossRef] [PubMed]

33. Ashmore, J.H.; Rogers, C.J.; Kelleher, S.L.; Lesko, S.M.; Hartman, T.J. Dietary Iron and Colorectal Cancer Risk: A Review of Human Population Studies. Crit. Rev. Food Sci. Nutr. 2016, 56, 1012-1020. [CrossRef] [PubMed]

34. Walther, T.C.; Farese, R.V., Jr. Lipid droplets and cellular lipid metabolism. Annu. Rev. Biochem. 2012, 81, 687-714. [CrossRef] [PubMed]

35. Petan, T.; Jarc, E.; Jusovic, M. Lipid Droplets in Cancer: Guardians of Fat in a Stressful World. Molecules 2018, 23, 1941. [CrossRef] [PubMed]

36. Kuri-Harcuch, W.; Velez-delValle, C.; Vazquez-Sandoval, A.; Hernandez-Mosqueira, C.; Fernandez-Sanchez, V. A cellular perspective of adipogenesis transcriptional regulation. J. Cell. Phys. 2018. [CrossRef] [PubMed]

37. Lane, D.J.; Merlot, A.M.; Huang, M.L.; Bae, D.H.; Jansson, P.J.; Sahni, S.; Kalinowski, D.S.; Richardson, D.R. Cellular iron uptake, trafficking and metabolism: Key molecules and mechanisms and their roles in disease. Biochim. Biophys. Acta 2015, 1853, 1130-1144. [CrossRef] [PubMed]

38. Ahmadian, M.; Duncan, R.E.; Jaworski, K.; Sarkadi-Nagy, E.; Sul, H.S. Triacylglycerol metabolism in adipose tissue. Futur. Lipidol. 2007, 2, 229-237. [CrossRef] [PubMed] 
39. Altman, B.J.; Stine, Z.E.; Dang, C.V. From Krebs to clinic: Glutamine metabolism to cancer therapy. Nat. Rev. Cancer. 2016, 16, 619-634. [CrossRef] [PubMed]

40. Liu, Q.; Luo, Q.; Halim, A.; Song, G. Targeting lipid metabolism of cancer cells: A promising therapeutic strategy for cancer. Cancer Lett. 2017, 401, 39-45. [CrossRef] [PubMed]

41. Nakanaga, K.; Hama, K.; Aoki, J. Autotaxin-An LPA producing enzyme with diverse functions. J. Biochem. 2010, 148, 13-24. [CrossRef] [PubMed]

42. Shi, L.; Tu, B.P. Acetyl-CoA and the regulation of metabolism: Mechanisms and consequences. Curr. Opin. Cell Biol. 2015, 33, 125-131. [CrossRef] [PubMed]

43. Hannun, Y.A.; Obeid, L.M. Sphingolipids and their metabolism in physiology and disease. Nat. Rev. Mol. Cell Biol. 2018, 19, 175-191. [CrossRef] [PubMed]

44. Jo, Y.; Debose-Boyd, R.A. Control of cholesterol synthesis through regulated ER-associated degradation of HMG CoA reductase. Crit. Rev. Biochem. Mol. Biol. 2010, 45, 185-198. [CrossRef] [PubMed]

45. Stoyanovsky, D.A.; Tyurina, Y.Y.; Shrivastava, I.; Bahar, I.; Tyurin, V.A.; Protchenko, O.; Jadhav, S.; Bolevich, S.B.; Kozlov, A.V.; Vladimirov, Y.A.; et al. Iron catalysis of lipid peroxidation in ferroptosis: Regulated enzymatic or random free radical reaction? Free Radic Biol. Med. 2018. [CrossRef] [PubMed]

46. Ingolfsson, H.I.; Melo, M.N.; van Eerden, F.J.; Arnarez, C.; Lopez, C.A.; Wassenaar, T.A.; Periole, X.; de Vries, A.H.; Tieleman, D.P.; Marrink, S.J. Lipid organization of the plasma membrane. J. Am. Chem. Soc. 2014, 136, 14554-14559. [CrossRef] [PubMed]

47. Graham, R.M.; Chua, A.C.; Carter, K.W.; Delima, R.D.; Johnstone, D.; Herbison, C.E.; Firth, M.J.; O'Leary, R.; Milward, E.A.; Olynyk, J.K.; et al. Hepatic iron loading in mice increases cholesterol biosynthesis. Hepatology 2010, 52, 462-471. [CrossRef] [PubMed]

48. Xu, H.; Finkelstein, D.I.; Adlard, P.A. Interactions of metals and Apolipoprotein E in Alzheimer's disease. Front. Aging Neurosci. 2014, 6, 121. [CrossRef] [PubMed]

49. Xu, H.; Perreau, V.M.; Dent, K.A.; Bush, A.I.; Finkelstein, D.I.; Adlard, P.A. Iron Regulates Apolipoprotein E Expression and Secretion in Neurons and Astrocytes. J. Alzheimers Dis. 2016, 51, 471-487. [CrossRef] [PubMed]

50. Ayton, S.; Faux, N.G.; Bush, A.I. Ferritin levels in the cerebrospinal fluid predict Alzheimer's disease outcomes and are regulated by APOE. Nat. Commun. 2015, 6, 6760. [CrossRef] [PubMed]

51. Mahoney-Sanchez, L.; Belaidi, A.A.; Bush, A.I.; Ayton, S. The Complex Role of Apolipoprotein E in Alzheimer's Disease: An Overview and Update. J. Mol. Neurosci. 2016, 60, 325-335. [CrossRef] [PubMed]

52. Wood, H. Alzheimer disease: Iron-The missing link between ApoE and Alzheimer disease? Nat. Rev. Neurol. 2015, 11, 369. [CrossRef] [PubMed]

53. Britton, L.J.; Bridle, K.; Jaskowski, L.A.; He, J.; Ng, C.; Ruelcke, J.E.; Mohamed, A.; Reiling, J.; Santrampurwala, N.; Hill, M.M.; et al. Iron Inhibits the Secretion of Apolipoprotein E in Cultured Human Adipocytes. Cell. Mol. Gastroenterol. Hepatol. 2018, 6, 215-217.e8. [CrossRef] [PubMed]

54. Kraft, M.L. Sphingolipid Organization in the Plasma Membrane and the Mechanisms That Influence It. Front. Cell. Dev. Biol. 2016, 4, 154. [CrossRef] [PubMed]

55. Lee, Y.J.; Huang, X.; Kropat, J.; Henras, A.; Merchant, S.S.; Dickson, R.C.; Chanfreau, G.F. Sphingolipid signaling mediates iron toxicity. Cell Metab. 2012, 16, 90-96. [CrossRef] [PubMed]

56. Chen, K.; Ho, T.S.; Lin, G.; Tan, K.L.; Rasband, M.N.; Bellen, H.J. Loss of Frataxin activates the iron/sphingolipid/PDK1/Mef2 pathway in mammals. eLife 2016, 5, e20732. [CrossRef] [PubMed]

57. Chen, K.; Lin, G.; Haelterman, N.A.; Ho, T.S.; Li, T.; Li, Z.; Duraine, L.; Graham, B.H.; Jaiswal, M.; Yamamoto, S.; et al. Loss of Frataxin induces iron toxicity, sphingolipid synthesis, and Pdk1/Mef2 activation, leading to neurodegeneration. eLife 2016, 5, e16043. [CrossRef] [PubMed]

58. Vaubel, R.A.; Isaya, G. Iron-sulfur cluster synthesis, iron homeostasis and oxidative stress in Friedreich ataxia. Mol. Cell. Neurosci. 2013, 55, 50-61. [CrossRef] [PubMed]

59. Matsunaga, T.; Kotamraju, S.; Kalivendi, S.V.; Dhanasekaran, A.; Joseph, J.; Kalyanaraman, B. Ceramide-induced intracellular oxidant formation, iron signaling, and apoptosis in endothelial cells: Protective role of endogenous nitric oxide. J. Biol. Chem. 2004, 279, 28614-28624. [CrossRef] [PubMed]

60. Lu, S.; Natarajan, S.K.; Mott, J.L.; Kharbanda, K.K.; Harrison-Findik, D.D. Ceramide Induces Human Hepcidin Gene Transcription through JAK/STAT3 Pathway. PLoS ONE 2016, 11, e0147474. [CrossRef] [PubMed] 
61. Shakor, A.B.; Taniguchi, M.; Kitatani, K.; Hashimoto, M.; Asano, S.; Hayashi, A.; Nomura, K.; Bielawski, J.; Bielawska, A.; Watanabe, K.; et al. Sphingomyelin synthase 1-generated sphingomyelin plays an important role in transferrin trafficking and cell proliferation. J. Biol. Chem. 2011, 286, 36053-36062. [CrossRef] [PubMed]

62. Rouault, T.A. Mammalian iron-sulphur proteins: Novel insights into biogenesis and function. Nat. Rev. Mol. Cell Biol. 2015, 16, 45-55. [CrossRef] [PubMed]

63. Martin, D.R.; Matyushov, D.V. Electron-transfer chain in respiratory complex I. Sci. Rep. 2017, 7, 5495. [CrossRef] [PubMed]

64. Crooks, D.R.; Maio, N.; Lane, A.N.; Jarnik, M.; Higashi, R.M.; Haller, R.G.; Yang, Y.; Fan, T.W.; Linehan, W.M.; Rouault, T.A. Acute loss of iron-sulfur clusters results in metabolic reprogramming and generation of lipid droplets in mammalian cells. J. Biol. Chem. 2018, 293, 8297-8311. [CrossRef] [PubMed]

65. Berteau, O. A missed Fe-S cluster handoff causes a metabolic shakeup. J. Biol. Chem. 2018, 293, 8312-8313. [CrossRef] [PubMed]

66. Paradies, G.; Paradies, V.; De Benedictis, V.; Ruggiero, F.M.; Petrosillo, G. Functional role of cardiolipin in mitochondrial bioenergetics. Biochim. Biophys. Acta 2014, 1837, 408-417. [CrossRef] [PubMed]

67. Patil, V.A.; Fox, J.L.; Gohil, V.M.; Winge, D.R.; Greenberg, M.L. Loss of cardiolipin leads to perturbation of mitochondrial and cellular iron homeostasis. J. Biol. Chem. 2013, 288, 1696-1705. [CrossRef] [PubMed]

68. WHO. Obesity and Overweight Fact Sheet. 2018. Available online: http://www.who.int/en/news-room/ fact-sheets/detail/obesity-and-overweight (accessed on 21 October 2018).

69. Lee, M.J.; Wu, Y.; Fried, S.K. Adipose tissue remodeling in pathophysiology of obesity. Curr. Opin. Clin. Nutr. Metab. Care 2010, 13, 371-376. [CrossRef] [PubMed]

70. Greenberg, A.S.; Obin, M.S. Obesity and the role of adipose tissue in inflammation and metabolism. Am. J. Clin. Nutr. 2006, 83, 461S-465S. [CrossRef] [PubMed]

71. Fujimoto, T.; Parton, R.G. Not just fat: The structure and function of the lipid droplet. Cold Spring Harb Perspect. Biol. 2011, 3, a004838. [CrossRef] [PubMed]

72. Wang, H.; Jiang, X.; Wu, J.; Zhang, L.; Huang, J.; Zhang, Y.; Zou, X.; Liang, B. Iron Overload Coordinately Promotes Ferritin Expression and Fat Accumulation in Caenorhabditis elegans. Genetics 2016, 203, 241-253. [CrossRef] [PubMed]

73. Coimbra, S.; Catarino, C.; Santos-Silva, A. The role of adipocytes in the modulation of iron metabolism in obesity. Obes. Rev. 2013, 14, 771-779. [CrossRef] [PubMed]

74. Chung, B.; Matak, P.; McKie, A.T.; Sharp, P. Leptin increases the expression of the iron regulatory hormone hepcidin in HuH7 human hepatoma cells. J. Nutr. 2007, 137, 2366-2370. [CrossRef] [PubMed]

75. Yamamoto, K.; Kuragano, T.; Kimura, T.; Nanami, M.; Hasuike, Y.; Nakanishi, T. Interplay of adipocyte and hepatocyte: Leptin upregulates hepcidin. Biochem. Biophys. Res. Commun. 2018, 495, 1548-1554. [CrossRef] [PubMed]

76. Zheng, J.; Chen, M.; Liu, G.; Xu, E.; Chen, H. Ablation of hephaestin and ceruloplasmin results in iron accumulation in adipocytes and type 2 diabetes. FEBS Lett. 2018, 592, 394-401. [CrossRef] [PubMed]

77. Citelli, M.; Fonte-Faria, T.; Nascimento-Silva, V.; Renovato-Martins, M.; Silva, R.; Luna, A.S.; Silva, S.V.; Barja-Fidalgo, C. Obesity promotes alterations in iron recycling. Nutrients 2015, 7, 335-348. [CrossRef] [PubMed]

78. Wang, J.; Wang, S.; Sun, P.; Cao, F.; Li, H.; Sun, J.; Peng, M.; Liu, W.; Shi, P. Iron depletion participates in the suppression of cell proliferation induced by lipin1 overexpression. Metallomics 2018. [CrossRef] [PubMed]

79. Liu, S.; Murph, M.; Panupinthu, N.; Mills, G.B. ATX-LPA receptor axis in inflammation and cancer. Cell Cycle 2009, 8, 3695-3701. [CrossRef] [PubMed]

80. Valdes-Rives, S.A.; Gonzalez-Arenas, A. Autotaxin-Lysophosphatidic Acid: From Inflammation to Cancer Development. Mediators Inflamm. 2017, 2017, 9173090. [CrossRef] [PubMed]

81. Bai, Y.T.; Chang, R.; Wang, H.; Xiao, F.J.; Ge, R.L.; Wang, L.S. ENPP2 protects cardiomyocytes from erastin-induced ferroptosis. Biochem. Biophys. Res. Commun. 2018, 499, 44-51. [CrossRef] [PubMed]

82. Basuli, D.; Tesfay, L.; Deng, Z.; Paul, B.; Yamamoto, Y.; Ning, G.; Xian, W.; McKeon, F.; Lynch, M.; Crum, C.P.; et al. Iron addiction: A novel therapeutic target in ovarian cancer. Oncogene 2017, 36, 4089-4099. [CrossRef] [PubMed] 
83. Konstorum, A.; Lynch, M.L.; Torti, S.V.; Torti, F.M.; Laubenbacher, R.C. A Systems Biology Approach to Understanding the Pathophysiology of High-Grade Serous Ovarian Cancer: Focus on Iron and Fatty Acid Metabolism. OMICS 2018, 22, 502-513. [CrossRef] [PubMed]

84. Agmon, E.; Stockwell, B.R. Lipid homeostasis and regulated cell death. Curr. Opin. Chem. Biol. 2017, 39, 83-89. [CrossRef] [PubMed]

85. Yuan, H.; Li, X.; Zhang, X.; Kang, R.; Tang, D. Identification of ACSL4 as a biomarker and contributor of ferroptosis. Biochem. Biophys. Res. Commun. 2016, 478, 1338-1343. [CrossRef] [PubMed]

86. Dixon, S.J.; Winter, G.E.; Musavi, L.S.; Lee, E.D.; Snijder, B.; Rebsamen, M.; Superti-Furga, G.; Stockwell, B.R. Human Haploid Cell Genetics Reveals Roles for Lipid Metabolism Genes in Nonapoptotic Cell Death. ACS Chem. Biol. 2015, 10, 1604-1609. [CrossRef] [PubMed]

87. Doll, S.; Proneth, B.; Tyurina, Y.Y.; Panzilius, E.; Kobayashi, S.; Ingold, I.; Irmler, M.; Beckers, J.; Aichler, M.; Walch, A.; et al. ACSL4 dictates ferroptosis sensitivity by shaping cellular lipid composition. Nat. Chem. Biol. 2017, 13, 91-98. [CrossRef] [PubMed]

88. Jiang, Y.; Mao, C.; Yang, R.; Yan, B.; Shi, Y.; Liu, X.; Lai, W.; Liu, Y.; Wang, X.; Xiao, D.; et al. EGLN1/c-Myc Induced Lymphoid-Specific Helicase Inhibits Ferroptosis through Lipid Metabolic Gene Expression Changes. Theranostics 2017, 7, 3293-3305. [CrossRef] [PubMed]

89. Yuan, H.; Li, X.; Zhang, X.; Kang, R.; Tang, D. CISD1 inhibits ferroptosis by protection against mitochondrial lipid peroxidation. Biochem. Biophys. Res. Commun. 2016, 478, 838-844. [CrossRef] [PubMed]

90. Jodeiri Farshbaf, M.; Ghaedi, K. Does any drug to treat cancer target mTOR and iron hemostasis in neurodegenerative disorders? Biometals. 2017, 30,1-16. [CrossRef] [PubMed]

91. Fretham, S.J.; Carlson, E.S.; Georgieff, M.K. The role of iron in learning and memory. Adv. Nutr. 2011, 2, 112-121. [CrossRef] [PubMed]

92. Piñero, D.J.; Connor, J.R. Iron in the Brain: An Important Contributor in Normal and Diseased States. Neuroscientist 2000, 6, 435-453. [CrossRef]

93. Bettencourt, C.; Forabosco, P.; Wiethoff, S.; Heidari, M.; Johnstone, D.M.; Botia, J.A.; Collingwood, J.F.; Hardy, J.; Milward, E.A.; Ryten, M.; et al. Gene co-expression networks shed light into diseases of brain iron accumulation. Neurobiol. Dis. 2016, 87, 59-68. [CrossRef] [PubMed]

94. Obulesu, M.; Venu, R.; Somashekhar, R. Lipid peroxidation in Alzheimer's disease: Emphasis on metal-mediated neurotoxicity. Acta Neurol. Scand. 2011, 124, 295-301. [CrossRef] [PubMed]

95. Lane, D.J.R.; Ayton, S.; Bush, A.I. Iron and Alzheimer's Disease: An Update on Emerging Mechanisms. J. Alzheimers Dis. 2018, 64, S379-S395. [CrossRef] [PubMed]

96. Wu, J.R.; Tuo, Q.Z.; Lei, P. Ferroptosis, a Recent Defined Form of Critical Cell Death in Neurological Disorders. J. Mol. Neurosci. 2018. [CrossRef] [PubMed]

97. Czapski, G.A.; Czubowicz, K.; Strosznajder, J.B.; Strosznajder, R.P. The Lipoxygenases: Their Regulation and Implication in Alzheimer's Disease. Neurochem. Res. 2016, 41, 243-257. [CrossRef] [PubMed]

98. Wu, C.; Zhao, W.; Yu, J.; Li, S.; Lin, L.; Chen, X. Induction of ferroptosis and mitochondrial dysfunction by oxidative stress in PC12 cells. Sci. Rep. 2018, 8, 574. [CrossRef] [PubMed]

99. Hambright, W.S.; Fonseca, R.S.; Chen, L.; Na, R.; Ran, Q. Ablation of ferroptosis regulator glutathione peroxidase 4 in forebrain neurons promotes cognitive impairment and neurodegeneration. Redox Biol. 2017, 12, 8-17. [CrossRef] [PubMed]

100. Skouta, R.; Dixon, S.J.; Wang, J.; Dunn, D.E.; Orman, M.; Shimada, K.; Rosenberg, P.A.; Lo, D.C.; Weinberg, J.M.; Linkermann, A.; et al. Ferrostatins inhibit oxidative lipid damage and cell death in diverse disease models. J. Am. Chem. Soc. 2014, 136, 4551-4556. [CrossRef] [PubMed]

101. Alessenko, A.V.; Shupik, M.A.; Bugrova, A.E.; Dudnik, L.B.; Shingarova, L.N.; Mikoyan, A.; Vanin, A.F. The relation between sphingomyelinase activity, lipid peroxide oxidation and NO-releasing in mice liver and brain. FEBS Lett. 2005, 579, 5571-5576. [CrossRef] [PubMed]

102. Levenson, C.W.; Cutler, R.G.; Ladenheim, B.; Cadet, J.L.; Hare, J.; Mattson, M.P. Role of dietary iron restriction in a mouse model of Parkinson's disease. Exp. Neurol. 2004, 190, 506-514. [CrossRef] [PubMed]

103. Guo, C.; Wang, T.; Zheng, W.; Shan, Z.Y.; Teng, W.P.; Wang, Z.Y. Intranasal deferoxamine reverses iron-induced memory deficits and inhibits amyloidogenic APP processing in a transgenic mouse model of Alzheimer's disease. Neurobiol. Aging 2013, 34, 562-575. [CrossRef] [PubMed]

104. Dusek, P.; Schneider, S.A.; Aaseth, J. Iron chelation in the treatment of neurodegenerative diseases. J. Trace. Elem. Med. Biol. 2016, 38, 81-92. [CrossRef] [PubMed] 
105. Richardson, D.R.; Kalinowski, D.S.; Lau, S.; Jansson, P.J.; Lovejoy, D.B. Cancer cell iron metabolism and the development of potent iron chelators as anti-tumour agents. Biochim. Biophys. Acta 2009, 1790, 702-717. [CrossRef] [PubMed]

106. Aigner, E.; Theurl, I.; Theurl, M.; Lederer, D.; Haufe, H.; Dietze, O.; Strasser, M.; Datz, C.; Weiss, G. Pathways underlying iron accumulation in human nonalcoholic fatty liver disease. Am. J. Clin. Nutr. 2008, 87, 1374-1383. [CrossRef] [PubMed]

107. Houschyar, K.S.; Ludtke, R.; Dobos, G.J.; Kalus, U.; Broecker-Preuss, M.; Rampp, T.; Brinkhaus, B.; Michalsen, A. Effects of phlebotomy-induced reduction of body iron stores on metabolic syndrome: Results from a randomized clinical trial. BMC Med. 2012, 10, 54. [CrossRef] [PubMed]

108. Fernandez-Real, J.M.; Penarroja, G.; Castro, A.; Garcia-Bragado, F.; Hernandez-Aguado, I.; Ricart, W. Blood letting in high-ferritin type 2 diabetes: Effects on insulin sensitivity and beta-cell function. Diabetes 2002, 51, 1000-1004. [CrossRef] [PubMed]

109. Zacharski, L.R.; Chow, B.K.; Howes, P.S.; Shamayeva, G.; Baron, J.A.; Dalman, R.L.; Malenka, D.J.; Ozaki, C.K.; Lavori, P.W. Decreased cancer risk after iron reduction in patients with peripheral arterial disease: Results from a randomized trial. J. Natl. Cancer Inst. 2008, 100, 996-1002. [CrossRef] [PubMed]

110. Edgren, G.; Tran, T.N.; Hjalgrim, H.; Rostgaard, K.; Shanwell, A.; Titlestad, K.; Wikman, A.; Norda, R.; Jersild, C.; Wideroff, L.; et al. Improving health profile of blood donors as a consequence of transfusion safety efforts. Transfusion 2007, 47, 2017-2024. [CrossRef] [PubMed]

111. Edgren, G.; Reilly, M.; Hjalgrim, H.; Tran, T.N.; Rostgaard, K.; Adami, J.; Titlestad, K.; Shanwell, A.; Melbye, M.; Nyren, O. Donation frequency, iron loss, and risk of cancer among blood donors. J. Natl. Cancer Inst. 2008, 100, 572-579. [CrossRef] [PubMed]

(C) 2018 by the authors. Licensee MDPI, Basel, Switzerland. This article is an open access article distributed under the terms and conditions of the Creative Commons Attribution (CC BY) license (http:/ / creativecommons.org/licenses/by/4.0/). 


\title{
Multilevel Impacts of Iron in the Brain: The Cross Talk between Neurophysiological Mechanisms, Cognition, and Social Behavior
}

\author{
Ana Ferreira ${ }^{1}$, Pedro Neves ${ }^{2}$ and Raffaella Gozzelino ${ }^{3, *}$ \\ 1 Centro Interdisciplinar de Ciências Sociais (CICS.NOVA), Faculdade de Ciências Sociais e Humanas da \\ Universidade NOVA de Lisboa (NOVA FCSH), 1069-061 Lisbon, Portugal \\ 2 School of Business and Economics, NOVA University of Lisbon, 2775-405 Lisbon, Portugal \\ 3 Chronic Diseases Research Center (CEDOC)/NOVA Medical School, Universidade NOVA de Lisboa, \\ 1180-052, 1150-082 Lisbon, Portugal \\ * Correspondence: raffaella.gozzelino@nms.unl.pt
}

Received: 5 August 2019; Accepted: 27 August 2019; Published: 29 August 2019

\begin{abstract}
Iron is a critical element for most organisms, which plays a fundamental role in the great majority of physiological processes. So much so, that disruption of iron homeostasis has severe multi-organ impacts with the brain being particularly sensitive to such modifications. More specifically, disruption of iron homeostasis in the brain can affect neurophysiological mechanisms, cognition, and social behavior, which eventually contributes to the development of a diverse set of neuro-pathologies. This article starts by exploring the mechanisms of iron action in the brain and follows with a discussion on cognitive and behavioral implications of iron deficiency and overload and how these are framed by the social context. Subsequently, we scrutinize the implications of the disruption of iron homeostasis for the onset and progression of psychosocial disorders. Lastly, we discuss the links between biological, psychological, and social dimensions and outline potential avenues of research. The study of these interactions could ultimately contribute to a broader understanding of how individuals think and act under physiological and pathophysiological conditions.
\end{abstract}

Keywords: iron; brain; neurophysiology; cognition; social behavior

\section{Introduction}

Iron is a vital element for most organisms. Iron actively participates in many physiological processes, such as oxygen transportation, cellular respiration, energy production, cell growth and differentiation, DNA synthesis, and more. Its ability to transfer electrons among different substrates is a property that renders this metal essential for life. However, it also implies the existence of fine-tuned regulatory mechanisms strictly controlling iron homeostasis, since minimum disruption of iron balance significantly alters organs' functionality [1]. Many mechanisms contribute to maintain iron homeostasis, with a vast number of genes being involved in iron uptake, storage, and recycling. So far, there is no description of physiological mechanisms of iron excretion.

In the specific case of the brain, which is a metabolically active organ and particularly sensitive to changes in iron homeostasis [2], there are still many uncertainties. This is the case since the distribution and roles of genes devoted to iron homeostasis are still under discussion. Current knowledge points at iron crossing the blood brain barrier (BBB) as iron-loaded transferrin (holotransferrin, HTf) complexes. In addition, binding of iron to transferrin receptors on capillary endothelium results in their subsequent internalization by forming endocytic vesicles. Iron is then pumped out via the expression of divalent metal transporter 1 (DMT1) in its ferrous form. In the cytosol, ceruloplasmin is the oxidase responsible for converting this metal into its ferric form, which can be exported in the extracellular 
space by ferroportin [3]. In the brain, disruption of iron homeostasis significantly impairs oxidative metabolism of neural cells, with dramatic consequences for synaptic plasticity, myelination, and synthesis of neurotransmitters [4,5]. This means that both iron deficiency and overload are associated with disruption of neurophysiological mechanisms, which were previously associated with impaired cognition and altered social behavior, as described in the following sections of this paper.

Regarding iron deficiency, which is the most common nutrient deficiency worldwide [6,7], the absence of mobilizable iron stores and compromised supply of iron to tissues, including erythrocytes, can identify it. The most severe form of iron deficiency, i.e., iron deficiency anemia, is characterized by the levels of iron associated with hemoglobin lower than two standard deviations of the distribution of mean hemoglobin in a population of the same age, sex, living at the same altitude, and without any other pathologies [6]. The causes underlying iron deficiency are diverse and include: inadequate oral iron intake, resulting from poor diets, excessive milk intake or vegetarian diets, inadequate iron absorption, as a result of Celiac disease and others, or excessive iron loss, mainly occurring via blood loss or as a result of parasitic infection (Figure 1) [6,8]. Although individuals can suffer from iron deficiency at any stage in life, the most severe consequences of iron deficiency are present in early childhood, which is a period of rapid growth and high needs for iron intake. These range from the disruption of neurophysiological mechanisms, to impaired cognitive and altered social behavior. Most importantly, iron deficiency has been reported in low-income and high-income countries, with increased prevalence of iron deficiency in lower socio-economic groups. These have been concomitantly characterized by worse eating habits, lower levels of education, and acknowledgement of the impacts of nutritional patterns in physical and cognitive development and health [9-15]. In this population, dietary iron intake was shown not only to be influenced by personal taste, attitude, and knowledge, but also by food access and cost, which render low-income groups at a multiple disadvantageous position from the go ahead $[9,16]$. Altogether, this could explain the higher risk for iron deficiency in lower socio-economic groups.

Currently, the World Health Organization (WHO) recommends iron replacement therapies as an initial intervention to address iron deficiency [17]. These supplementations have been successful in the control of anemia and iron deficiency in different age groups. However, the long-term deficits in motor and cognitive functions, as well as the modifications in social behavior, were mostly shown to persist and deserve great attention and debate $[8,18-20]$. Several reasons can account for the absence of (or very small, in a few cases) motor, cognitive, and behavioral effects. On the one hand, methodological insufficiencies (i.e., study design limitations, indirectness of presented evidence, imprecisions, or reporting bias) and heterogeneity of intervention protocols (precluding a straight comparison among studies) can partly account for the reported inconsistences. On the other hand, these studies mostly assume that correction of the nutrient deficiency per se, would suffice to address long-term motor and cognitive impairments, as well as modifications in social behavior. However, as we will discuss in the following sections of this paper, one can argue that there seems to be an overlap between the biological effects of a nutrient insufficient diet and its effects on neurophysiological mechanisms and cognition, as well as a potential absence of social stimuli to promote adequate physical and cognitive development. Most studies do not take into account, or analyze superficially at most, the interactions between biological, psychological, and social dimensions of a nutrient deficiency, subsequent multi-organ disruption of iron homeostasis, and its impacts on motor deficits, cognitive impairments, and modifications of social behavior. Future research should address these interactions much more profoundly, by integrating the immense knowledge patrimony of diverse scientific disciplines, and characterizing the role of each dimension, their interactions, and potential contributions for the multiple reported outcomes. This has not been previously done.

On the opposite pole of iron deficiency, we have iron overload, which is present, for instance, in the aging population and in protein misfolding neurodegenerative diseases, such as Alzheimer's or Parkinson's disease (AD and PD, respectively) (Figure 1) [21]. In the specific case of AD and PD patients, mental decline, as evaluated by the Dementia Rating Scale and the total Frontal Systems 
Behavior Scale, was shown to be present [22]. More specifically, AD patients have difficulties in storing information and learning new data. PD patients are unable to prevent memory retrieval and mind forgetfulness, which are characteristics that can alter the cognitive and behavioral profiles of these subjects [23]. Lastly, AD and PD progression are associated with depression, anxiety, psychotic symptoms, and sleep disturbances [24,25] and likely impacted by a dysregulation of neural circuitries. This dysregulation can be triggered by the brain iron accumulation present in these patients.

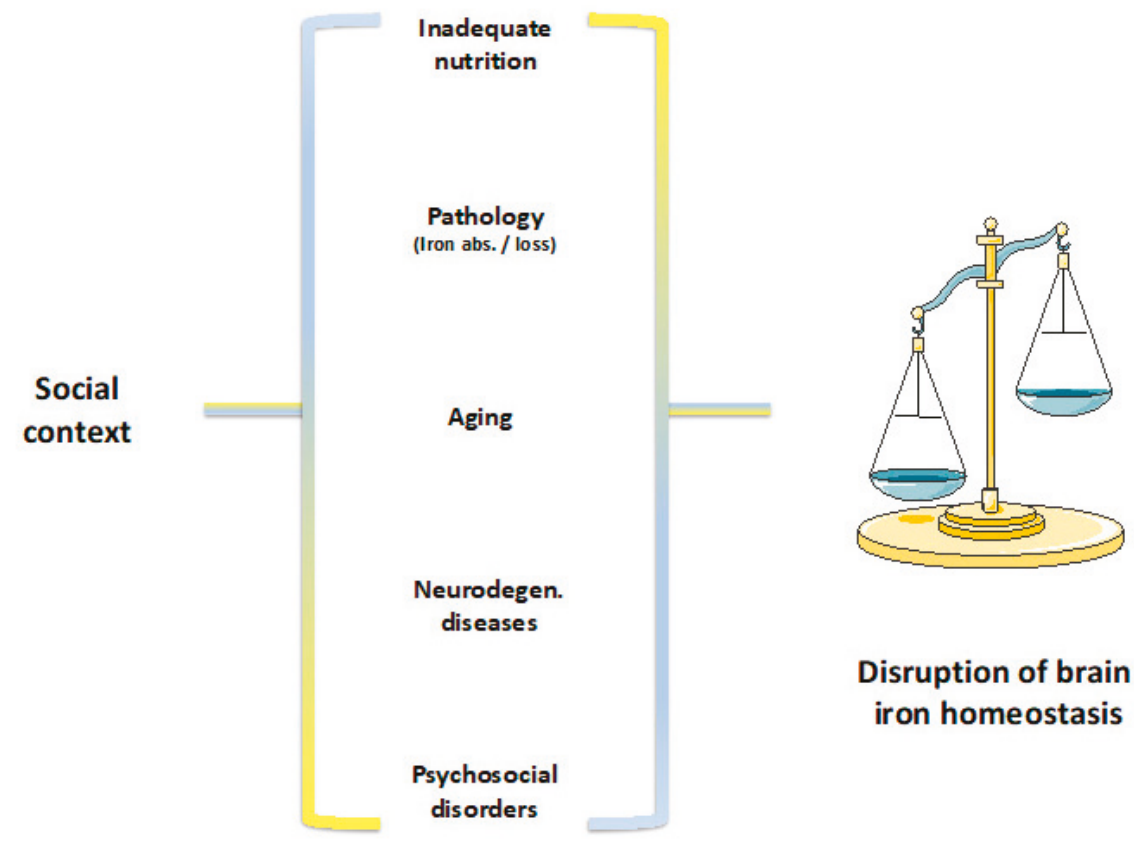

Figure 1. Processes underlying disruption of brain iron homeostasis. Social context, integrating structural (e.g., socio-economic context, life trajectories, socio-economic status, education, knowledge and skills, norms and values), social interactions (e.g., the specific context of interactions; who is present) and individual dimensions (e.g., appraisal, perceptions, motivations and expectations, and reflexivity) frames the pathophysiological mechanisms of an inadequate nutrition (e.g., poor diets, excessive milk intake, vegetarian diets), pathologies associated with inadequate iron absorption (e.g., Celiac disease) or excessive iron loss (e.g., blood loss, parasitic infections), aging, neurodegenerative diseases (e.g., Alzheimer's and Parkinson's disease) or psychosocial disorders (e.g., chronic social defeat stress, anxiety, depression). All these conditions are associated with a disruption of brain iron homeostasis.

In psychosocial disorders like chronic social defeat stress, anxiety, and depression, iron's ability to modulate the levels of neurotransmitters released in the synaptic clefts was shown to contribute to commonly observed cognitive impairments and behavioral modifications [26]. These conditions are also characterized by changes in both structure and function of the prefrontal cortex, where the expression of genes regulating iron metabolism appears to be significantly altered. This means that brain iron accumulation is likely involved in the outcome of stress-induced depression, and pathophysiological changes typical of mood and anxiety disorders (Figure 1) [27]. In the body, $80 \%$ of iron is incorporated within the protoporphyrin ring of heme molecules, which is the prosthetic group of heme proteins. Among heme proteins, hemoglobin is the most abundant [2,28]. Interestingly, studies in animal models revealed an increase in hemoglobin gene expression in the brain of animals that were exposed to certain levels of stress. Even though the function of hemoglobin in the brain is still unknown, it has been proposed to control the vascular tone. If that is the case, its increase might 
protect neurons against stressful social encounters that could, otherwise, compromise brain functions by damaging its vascular system [29]. In mice, the expression of genes that directly regulate iron metabolism was also found to be changed under stressful conditions. A reduction in the iron importer Transferrin Receptor 1 was observed in response to stress. This reduction could possibly prevent further intracellular iron entry, which would subsequently harm neurons in the pre-frontal cortex, i.e., an area that is mainly involved in conscious decision-making and social action [27]. Conversely, an increased expression of lipocalin 2, which is an iron transporting protein that regulates the morphology and excitability of neurons in the hippocampus and amygdala when mice are exposed to stress [27,30], was associated with a number of modifications in behavioral responses, depression, neuronal excitability, and anxiety [31]. The reasoning for this is that, in the absence of a neutralizing system, an increased brain iron accumulation is capable of promoting oxidative stress and neuronal death, processes that could be undermining cognition, which potentially frames social behavior and eventually leads to pathological development [32].

Given the increasing life expectancy of the world's population, as well as the increasing prevalence of both mentioned neurodegenerative and psychosocial disorders, the study of iron overload and of its etiology is of the utmost relevance. Since the role of iron in neurodegenerative pathologies was the focus of several reviews [3,33-36], for the purpose of this article, we will only address its impacts in psychosocial disorders. As for iron deficiency, we will review previous studies, and discuss the pressing need for research integrating the causes underlying iron overload and its impacts on neurophysiological mechanisms, as well as on concomitant modifications of motor, psychological, and social processes of populations affected by excessive iron.

This paper argues that brain iron dysregulation has profound neurophysiological impacts and is associated with cognitive and behavioral modifications that could be further exacerbated by social contexts that do not promote regular cognitive function and normative social behavior (Figure 2). Hence, this review starts by exploring the mechanisms of iron action in the brain and presents an overview of iron metabolism and of its cytotoxic mechanisms of action. A discussion of cognitive, behavioral, and pathological implications of iron deficiency and overload, and how these can be framed by the social context, will follow. The links between biological, psychological, and social dimensions will be explored and potential avenues of research will be pointed out.

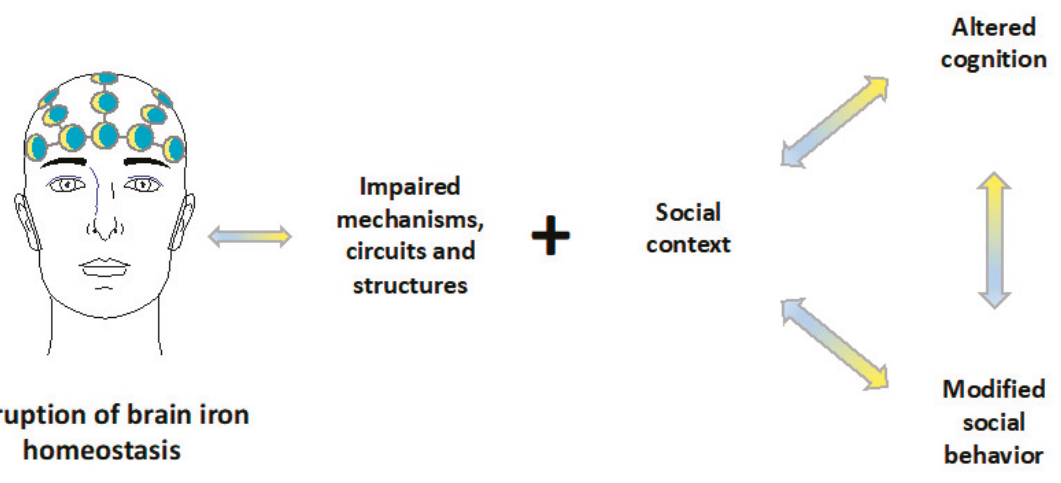

Figure 2. Impacts of disruption of brain iron homeostasis. Dysregulation of brain iron metabolism profoundly affects neurophysiological mechanisms (e.g., neurotransmitter synthesis and metabolism, axon myelination, neural transmission), neural circuits (e.g., mesocortical, mesolimbic, nigrostriatal, and tuberohypophyseal dopaminergic pathways) and brain structures. In the presence of a social context that does not provide stimuli to promote regular cognition and normative social behavior, disruption of brain iron homeostasis is associated with altered cognition (e.g., executive function, attention, memory) and modified social behavior (e.g., functional isolation, wariness, and hesitance behaviors). 


\section{Iron in the Brain}

It has been previously shown that the brain is particularly sensitive to changes in iron homeostasis $[2,4,5]$. This is the case since iron is critical for maintenance of the high metabolic and energetic requirements of neuronal tissues, neurogenesis, axon myelination, synaptic development, neurotransmitter synthesis, and metabolism [37]. As such, the brain requires considerable amounts of iron, particularly in periods of rapid growth, such as early childhood. These levels are mainly up-taken from the blood, which is the source of brain iron through adult life, when its up-take is considerably lower. In addition, presenting a considerable variation is the distribution of iron in the brain. More specifically, the highest concentrations of iron are found in the basal ganglia, particularly in the substantia nigra, globus pallidus, nucleus caudate, red nucleus, and putamen [38]. Since brain iron is mainly up-taken from the blood, the brain iron status is directly affected by peripheral iron levels and nutrition. In fact, iron deficiency, which is the most prevalent nutrient deficiency worldwide, has been proposed to impact motor function, cognition, and social behavior [26]. In contrast, accumulation of iron in the brain has been associated with aging, neurodegenerative diseases, and psychosocial disorders [26,32,39]. This raises the question about potential adverse effects induced by iron food biofortification, which, in the long term, might contribute to tissue iron accumulation and, ultimately, mediated damage. Nevertheless, iron overload was mostly studied in animal models and the results might not be fully translatable into human subjects, especially in studies exposing mice to non-physiological levels of dietary iron. It is not surprising that behavioral dysfunctions and neurological effects appear when animals are fed with exacerbated concentrations of this nutrient [26,40]. Similar manifestations may also occur in response to other micronutrients excess, as observed upon acute overexposure to the metalloid selenium [41]. As such, a tight regulation of brain iron homeostasis is of the utmost importance.

One of the processes for which the maintenance of iron homeostasis is vital is the regulation of axon myelination and, subsequently, neural transmission. In fact, a great number of studies present iron deficiency in early development as capable of disrupting synaptic function, with potential long-lasting effects that were shown to be associated with impaired cognitive and/or altered social behavior [26,42-44]. However, the importance of iron in the brain further relies on iron being part of the structure of many enzymes involved in energy metabolism and neurodevelopmental mechanisms [42,45]. In many of those, iron acts as a co-factor, which ensures proper functioning. This is the case for cytochrome c oxidase, which is a central enzyme for energy metabolism, tyrosine hydroxylase, which is responsible for dopamine synthesis, and for tryptophan hydroxylase, which is responsible for serotonin synthesis. Iron deficiency anemia has also been associated with decreased monoamine oxidase activity in humans, which promotes a disruption of the metabolism of monoamines, including dopamine and serotonin. In addition to iron's role in the monoaminergic system, it further regulates the balance between inhibitory and excitatory neurotransmitters, $\gamma$-aminobutyric acid (GABA) and glutamate, respectively. Moreover, iron was shown to interact with other metals such as zinc, and to be involved in processes such as dendritogenesis, neuro-metabolism, gene profiles, and protein profiles [26,42,46].

Among all age populations, infants and young children are the most sensitive to variations in iron levels $[20,47]$. Presumably, this is associated with their rapid growth, which requires iron to prevent a decline in functions that are mainly exerted by the basal ganglia and that could lead to an impaired psychomotor development, as well as disrupted cognition and behavior [43]. Contrary to expectations, the effects of iron supplementation to children affected by iron deficiency are still controversial. These interventions were able to correct for iron deficiency and anemia, but their impacts on motor, cognitive, and behavioral outputs are ambiguous. This has been reasoned to result from methodological insufficiencies and heterogeneity of the study design $[8,18,20]$. These data will be thoroughly discussed under the section "Linking iron deficiency to cognition and social behavior in human subjects."

While there is widespread acknowledgment of the highly deleterious effects of an increased iron status, particularly in the brain, the use of iron-enriched foods and beverages, used to overcome the negative impacts of iron deficiency, is widespread. However, the potential negative impacts of very 
high iron intake have not been established [48]. As such, several studies have started to address the effects of high iron intake or high peripheral iron status on neurophysiological mechanisms, cognition, and pathological development. While, in mice, there seems to be very strong indications that high iron intake in early post-natal life has adverse effects on cognition and neuropathological outcomes. The results of studies with human subjects are controversial. This is presumably due to methodological variations. Moreover, the effects of iron supplementation on cognition and pathological progression were only addressed in adults. While the findings are somewhat supportive, high iron intake in adults contributes to the degradation of neuronal function and pathophysiological development. No studies have addressed whether and how iron supplementation in early childhood impacts on adult cognition and behavior, as well as on brain aging and health [32]. Data addressing potential links between iron accumulation, cognition, and social behavior are either inconsistent or absent. Before discussing this topic in depth, we will focus on the details of iron metabolism and cytotoxicity, since these mechanisms are critical for understanding the processes involved in disruption of iron homeostasis and its potential impacts.

\section{Iron Metabolism}

Since the disruption of iron homeostasis has such severe consequences, the levels of systemic and intracellular iron need to be tightly regulated. In fact, many mechanisms contribute to maintain iron homeostasis, with a vast number of genes being responsible for the control of iron uptake, storage, and recycling. As for iron excretion, no physiological mechanisms have been described so far, with iron losses being presently described through menstruation and skin desquamation [49].

In the specific case of the brain, iron crosses the blood brain barrier (BBB), as iron-loaded transferrin (holotransferrin, HTf). Internalization of the complex iron-Tf:Tf receptors (TfR), expressed on the luminal side of brain capillary endothelial cells, allows its endocytosis. Subsequently, iron is released in acidic endosomes from Tf, and then released from the Tf-TfR complex. Once reduced to ferrous iron, it is translocated into the cytosol by the action of DMT-1. This iron contributes to the labile ferrous iron pool. However, poor expression of DMT-1 on brain capillary endothelial cells raised concerns about the requirement of this transporter for iron entry to the brain. In fact, alternative mechanisms indicated that iron could also be released from endosomal compartments via the expression of transient receptor potential mucolipin-1 (TRPML1) channels. Disrupted iron homeostasis observed in the brain of TRPML1-deficient mice further supports this notion. In addition, dysregulated iron metabolism has been observed in patients suffering from mucolipidosis type IV (ML4), which is a neurodegenerative disease in which a TRPML1 mutation is responsible for reduced brain ferric iron. This could lead to impaired myelination and neuronal damage [50,51]. Whether other iron transporters, like TRPML2 or ZIP8, can also play a role in regulating iron metabolism in brain capillary endothelial cells has not been fully elucidated.

Similarly to DMT-1, TRPML1 transports ferrous but not ferric iron. This suggests that a ferric reductase is required for TRPML1 to release iron from endosomal compartments. Whether this is ensured by one of the Steap family members remains to be established, but the ubiquitous brain expression of Steap 1 and high levels of Steap 2 render these proteins to be strong candidates for this function. Thus, the enzymatic activity of these proteins might increase iron uptake into the cells [52]. Additionally, stromal cell-derived receptor-2 (SDR2), which is a homologue of duodenal ferrireductase DcytB, is expressed in the brain, although its specific localization and function remain to be fully established [53].

Still the object of the discussion is the possibility of iron entering the brain via a transcytosis mechanism. This implies the exocytosis of the recycling endosome, which contains iron-Tf complexes. Their dissociation from TfR at the abluminal membrane results in the detachment of iron from Tf and subsequent release of Tf into the brain interstitium [54]. This potential mechanism of iron entry into the brain is supported by the reported normal amounts of iron in the brain of hypo-transferrinemic mice, i.e., animals presenting less than $1 \%$ of circulating Tf [55]. Regardless of the mechanisms, once inside the cells, iron is either directed to mitochondria, to participate in processes ensuring cellular function, or is stored in the cytosol, within the multimeric ferritin L and $\mathrm{H}$ chain subunits $[33,56]$. 
Excess iron is then exported to the extracellular space by ferroportin, which is the only iron exporter that has been identified so far [57]. The expression of ferroportin on the abluminal membrane of brain capillary endothelial cells is coupled with ceruloplasmin, which presents a ferroxidase activity capable of re-oxidizing ferrous iron into ferric iron and allowing it to enter the Tf distribution cycle. This has led the scientific community to hypothesize that endothelial cells regulate iron entry into the brain by acting as gate-keepers for iron and releasing it when required.

Most importantly, levels of circulating Tf in the brain interstitium are quite low, which implies Tf to become saturated with small amounts of iron. This justifies non-Tf bound iron (NTBI) to be the main source of iron delivery to neural cells. NTBI might have entered neural cells by binding to DMT- 1 and should be, subsequently, redistributed to the extracellular space in the brain parenchyma. High levels of ferrous iron can also be found in the cerebrospinal fluid [58], and possibly represent the biological underpinning of the existence of multiple mechanisms guaranteeing iron homeostasis. NTBI can also be up-taken by neurons and enter these cells via DMT-1, Zip-14, or other molecules ensuring non-vesicular import mechanisms [59]. Ferritin can also bind NTBI and cross the BBB via a transcellular transport through the T-cell immunoglobulin and mucin domain-containing 1 receptor 1 (TIM-1) [60], which is the human homologous of the rodent gene TIM-2. This mechanism ensures endocytic iron reutilization in oligodendrocytes [61]. Moreover, the relevance of ferritin as a possible route for iron delivery to the brain was also shown in microglia. These cells can act as an exogenous iron source considering their ability to increase ferritin expression when attempting to limit the amount of extracellular-free iron in the brain. This means that the upregulation of ferritin in microglia is a direct consequent of NTBI uptake [62].

Fenestrated capillaries of the choroid plexus are also playing a dominant role in regulating iron entry into the brain. Their peculiar permeability facilitates not only the diffusion of molecules of different sizes to which iron can bind, but also their regulated entry into the brain through the ferroportin-hepcidin axis present in these cells [63]. In the brain, iron can be transported as described or bound to low-molecular-weight agents such as citrate, ascorbate, or ATP [4]. While ATP and other nucleotides may contribute to the release of iron via the exocytosis-dependent abluminal membrane transport [64], the higher concentrations of citrate and ascorbate when compared to their concentrations in circulation could be justified by the need to prevent NTBI from dysregulating iron homeostasis. Although the affinity of these molecules for iron is lower than that of $\mathrm{Tf}$, their abundance allows to bind significant amounts of NTBI.

Another major player in iron metabolism is hepcidin, which is the iron regulatory hormone. Contrarily to hepcidin role in the peripheral compartment, its role in the brain is still under debate. Currently, it is known that hepcidin targets ferroportin in the brain. However, growing evidence supports the ability of systemic hepcidin to cross the BBB and enter the brain. On the other hand, the existence of an autonomous mechanism justifies the absence of brain iron accumulation in mice or patients presenting hepcidin mutations, such as in hemochromatosis. Additional mechanisms can then be responsible for the maintenance of brain iron homeostasis. These mechanisms should involve microglia and astrocytes, which are the brain cells producing higher levels of hepcidin [65].

Despite the numerous mechanisms regulating iron homeostasis in the brain, this tight regulation can still be disrupted. The following section addresses these mechanisms and the impacts of their disruption.

\section{The Cytotoxicity of Iron in the Brain}

The main causes underlying brain iron accumulation still need to be studied in more detail. Nonetheless, and in addition to other types of brain iron deposits and superficial siderosis, the literature points at cerebral microbleeds as one of the major factors involved in brain iron overload [66]. These microbleeds are brain microhemorrhages that can occur physiologically in the elderly and affect both brain tissue and ventricles. Microbleeds are often asymptomatic and a recurrent headache is the major complaint. However, they are not always silent. This is the case upon release of hemoglobin into 
intracranial cavities, which can lead to clinical manifestations such as weakness, vomiting, seizures, decreased level of consciousness, neck stiffness, and others [67].

When unlocked from cells, hemoglobin is oxidized and rapidly broken-down to its by-products, heme, and iron [2]. Therefore, depending on the extent of cerebral microbleed, brain iron accumulation can compromise synaptic transmission and neuronal functions [68]. This suggests that individuals that are more susceptible to vasculature impairments, such as patients affected by genetic blood disorders like sickle cell or thalassemia, could present higher risk of cerebral microbleeds. Those microhemorrhages could contribute to neurological conditions that these subjects might suffer from [69]. In fact, this is supported by a study with children affected by hemoglobinopathies [70], and developing a reversible neurological complication, known as leukoencephalopathy syndrome, upon blood transfusion [71]. This means that blood treatments might cause long-term effects to organs such as the brain, which might result from potential iron accumulation over time. Still, iron toxicity is prevented by storing excess iron in ferritin and intracellular vacuolar-like structures, like lysosomes. Therefore, this does not come as a surprise regarding the importance attributed to lysosomal impairment during aging [72]. The role of lysosomes in ferritin degradation [73] allows us to understand their strict relationship with brain pathologies [74] like neurodegenerative diseases such as Alzheimer's disease [75,76]. These disorders have been defined as iron storage diseases, pathologies in which iron accumulates as encapsulated iron, i.e., iron contained within vesicles [77,78]. Currently, it remains to be elucidated whether this iron is toxic or accumulates in response to chronic stress, acting as a stress responsive intracellular second messenger, as recently proposed [79]. It is, therefore, possible that iron becomes toxic only after certain thresholds. All these questions will remain opened until final results of iron chelation therapy on neurodegenerative diseases, such as Alzheimer's and Parkinson's disease, are fully disclosed. Nevertheless, the reduction of iron accumulation in patients with Parkinson's disease and treated with deferiprone was considered satisfactory [80,81]. New compounds, like the chiral 3-hydroxypyrid-4-one derivative, which present the same properties but prevent the side effects of neutropenia and agranulocytosis after prolonged exposure to iron chelation treatment, are currently being tested in different models of Parkinson's disease models.

Despite the numerous mechanisms to prevent iron cytotoxity, the ability of iron to transfer electrons allows its participation in the Fenton chemistry and the generation of highly reactive and harmful hydroxyl radicals $(\mathrm{HO} \bullet)$, from the conversion of diffusible $\mathrm{H}_{2} \mathrm{O}_{2}$ [82]. Once produced, reactive oxygen species (ROS) can damage lipids, proteins, and nucleic acids, which leads, ultimately, to cell death. In the specific case of the brain, the high abundance of lipids renders it very susceptible to oxidative stress. Since these lipids are ensuring neuronal communication by mediating impulse transmission, brain oxidative stress is considered among the etiology of most brain disorders $[34,83]$. In addition, the irreversible damage caused by iron fueling ROS production in the brain is also due to the lower tolerability and repair capacity of this organ when compared to other tissues [84].

Therapeutic interventions based on antioxidant administration have not been successful to prevent the neural toxicity of iron-driven oxidative stress. The inefficiency of drugs to cross the BBB could justify the lack of positive outcomes. However, this could also be influenced by the need of a small amount of ROS production for cell metabolism, which these drugs are suppressing. For example, microglia produce ROS to activate phagocytosis and eliminate possible harmful stimuli in the brain parenchyma. ROS further regulate the activity of both kinases and phosphatases, and modulate signaling pathways activated by transcription factors. In neurons, most ROS are derived by oxygen consumption, as by-products of mitochondria energy production [85]. The abundance and intense activity of these organelles in the brain, as they provide the energy for daily activities, renders the brain highly susceptible to oxidative stress. For example, meta-analytic studies have shown that increases in oxidative stress are associated with depressive disorders, including major depressive disorder and bipolar disorder [86]. This notion is also supported by the fact that mitochondria are the main source of intracellular iron [87]. A link between chronic exposure to stressors, maladaptive mitochondrial changes, and neurodegenerative disorders like dementia and $\mathrm{AD}$, has also been suggested. Both 
heme synthesis and assembly of iron-sulphur clusters occur in the mitochondria, where density and activity vary, according to brain regions. This explains the existence of areas that are more sensitive to iron-driven oxidative damage than others. As an example, the substantia nigra and the striatum are areas where iron mostly accumulates and reaches higher concentrations when compared to the hippocampus, cortex, pons, and medulla. These latter regions present the lowest amount of iron [33]. The oxidation of dopamine to neurotoxic metabolites, which occurs in the substantia nigra and is coupled to increased iron levels, further boosts oxidative damage and justifies the sensitivity of this region to neuronal death [88]. As mentioned above, the main target of ROS production in the brain is neuronal membranes rich in polyunsaturated fatty acids (PUFA). Lipid peroxidation is a key feature defining iron-mediated cell death, also known as ferroptosis [34,89]. Still, iron's role in impairing brain activity, cognitive functions, neuroplasticity synaptogenesis, and synaptic transmission remains to be elucidated. Nevertheless, epidemiological studies with PUFAs supplementation were shown to reduce the risk of neurological and psychosocial disorders [90]. Thus, a better understanding of causes leading to iron-driven oxidative stress is important for the development of effective therapies that prevent neuronal damage and functional impairment. The following section will precisely start to address the potential links between the neural circuits involved in iron regulation, cognition, and social behavior.

\section{Neural Circuits and Social Behavior}

Social behavior is one of the main areas of current research in fields as diverse as anthropology, sociology, psychology, or neuroscience. Simply put, social behavior is how we do things in social contexts. If one focuses on human social behavior, we are talking, for instance, about how we perform our jobs or how we spend our holidays, how we discuss things with others, or how we run away from them. Any of the above-mentioned behaviors are framed by knowledge and dispositions that we have embodied through our life trajectories, perceptions of the situation that we are being confronted with, and its broader social-economic contexts, our motivations, and expectations, as well as biological factors, mechanisms, and the more general physiological status. Changes in these processes characterize many neuropsychiatric disorders and psychosocial dysfunctions. This justifies an increasing interest in understanding the molecular mechanisms regulating neural circuits involved in the development of social behaviors. Since most genes are conserved across species, once again, research in rodents was fundamental to dissect specific brain networks involved in the development of social behavior. In human subjects, the brain structures involved in cognitive processes were originally identified through magnetic resonance imaging (MRI) studies, which revealed activation of specific regions upon the development of specific social tasks [91]. The somatosensory and temporal cortex are involved in perception and recognition of facial emotions [92]. The amygdala is involved in fear processing and threat detection [93] and the prefrontal cortex is responsible for decision-making and behavior, as well as performing executive functions [94]. Changes in the amygdala response can result in social anxiety disorders, and damages to the frontal cortex can underlie psychopathological and antisocial behavior [95]. Still, the existence of neural circuits interlinking specialized cortical and sub-cortical structures ensure that these areas work together to ensure that a certain behavior takes place [91].

From a molecular point of view, a series of neurotransmitters and neuromodulators regulate the activity and maturation of these brain areas. Although glutamate, GABA, serotonin, and noradrenaline contribute to modulate pre-frontal-striatal circuits, among neurotransmitters, dopamine stands out. The involvement of dopaminergic projections is responsible to exert functions resulting from the cooperation of all previously described areas for sustained attention, memory storage and retrieval, emotion regulation, and motivation. Since iron impairs dopamine synthesis, by influencing the activity of the enzyme that produces it, i.e., tyrosine hydroxylase, and fosters the production of ROS through dopamine catabolism [96], others have suggested that the outcomes of neurocognitive tasks are highly influenced by any disturbance in iron homeostasis [47]. It is precisely the link between brain iron homeostasis, cognition, and social behavior that will be addressed in the following sections of this article. Special attention will be devoted to studies with human subjects. 


\section{Linking Iron Deficiency to Cognition and Social Behavior in Human Subjects}

Many studies have shown that iron deficiency with or without anemia is associated with short-term and long-term impacts on psychomotor development, cognition, and social behavior in human subjects (Figure 3). While iron deficiency is more prevalent and studied in early childhood, which is a period of rapid growth and high needs for iron, an elevated risk for iron deficiency is also present in women of reproductive age, as a result of regular blood loss during menstrual cycles, and during pregnancy, which is characterized by increased iron requirements [8]. In fact, some of the previously mentioned neurophysiological, cognitive, and behavioral features of early iron deficiency were also reported to be present in iron deficient women of reproductive age [97-99]. During pregnancy, iron deficiency anemia has been associated with prematurity, low birthweight neonates, maternal morbidity, and impaired mental and psychomotor development $[4,8,100]$. Even though the number of studies is presently limited, future studies should address whether these modifications are the strict result of iron deficiency or, rather, of its interactions with other factors.

In what concerns the mechanisms connecting a disruption of iron status to neurophysiological and cognitive impairments and alterations in social behaviors, it has been previously suggested that an iron-induced disruption of major dopamine pathways (i.e., mesocortical, mesolimbic, nigrostriatal, and tuberohypophyseal), would possibly impair its ability to propagate neuronal impulses. This disruption could potentially lead to motor and cognitive impairments, altered social behavior, and/or pathological development [47]. A different line of research has suggested that iron deficiency can be deleterious to axon myelination. In fact, it has been documented that early iron deficiency is associated with short-term and long-term latency delays in visual and auditory evoked potential studies. The latest study results that are consistent with impaired axon myelination have lower amplitude in the variability of heart rate in the sleep-wake cycle [101-103]. This could be due to the documented alterations in iron status, but also due to its impacts on different neurotransmitters such as serotonin, norephinephrine, or others. It is also possible to find some studies in which the evoked potential analysis was inconclusive and the results were attributed to problems in the study design [104].

Specifically, regarding the dopamine-dependent pathways, studies have shown that children and young adults with chronic, severe iron deficiency with or without anemia in infancy, present altered dopamine frontal-striatal circuits, known to be involved in the control of executive functions, sustained attention, memory, emotion regulation, and motivation. In particular, the authors show that early severe iron deficiency was most likely contributing to impairments in neurocognitive and motor functioning and modifications in social behavioral in infancy, at 5 years of age and at 11-14 years of age. At the age of 19, cognitive impairment, as revealed by poor inhibitory control and executive functioning, was shown to be present $[47,103]$.

The negative impacts of iron unbalance on dopamine action can also affect the mesolimbic pathway, which connects the ventral tegmental area in the midbrain to the ventral striatum of the basal ganglia in the forebrain. Alterations in this region, where dopamine plays a central role in behavioral activation, inhibition, positive affect, and reward [105,106], were proposed to be involved in increased prevalence of wariness and hesitance behaviors, lack of positive affect, diminished response to novelty, and social engagement. These modifications, present in infants with iron deficiency, with or without anemia, seem to show a dose response to the severity of the iron deficiency [43,107-114].

The dopamine nigrostriatal pathway is involved in movement control and regulation. In fact, infants with iron deficiency with or without anemia were shown to have impaired motor sequencing and bi-manual coordination, which is a symptom that was more severe in anemic infants $[115,116]$. In a different study, iron deficient infants, with or without anemia, presented a lower rate of spontaneous eye blink, which is a widely accepted measure of the nigrostriatal pathway (anemic infants had the lowest levels). The study further showed that a spontaneous eye blink could be partly corrected with iron supplementation in anemic infants [117]. Children with iron deficiency also present a disrupted learning process, which results in impaired cognition and altered social behavior. 
Lastly, the involvement of the dopaminergic tuberohypophyseal pathway has been studied fewer times. Nevertheless, dopamine production by the hypothalamus inhibits prolactin release by the anterior pituitary. As such, decreased dopamine function as present in iron deficiency should be associated with increased prolactin levels. This was shown to be the case in iron deficiency anemia in infancy [118]. Even though these results are indicative of an impaired tuberohypophyseal pathway and long-term dysregulation of prolactin, one should note that the regulation of prolactin is complex and involves other neurotransmitters such as serotonin.

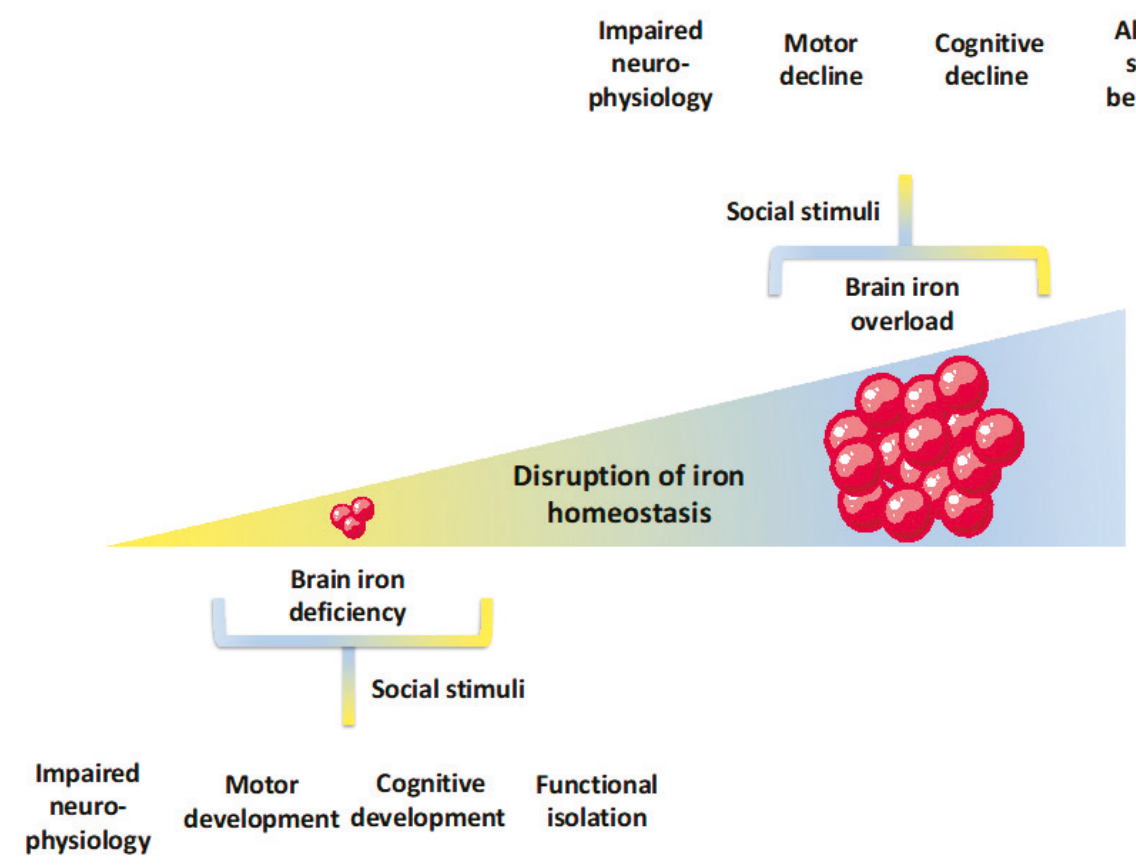

Figure 3. Multilevel repercussions of iron deficiency and iron overload in the brain. Brain iron deficiency is associated with disruption of neurophysiological mechanisms that, within a social context that does not provide regular stimuli, compromises motor and cognitive development (e.g., impaired motor sequencing and bi-manual coordination, poor executive function, attention, and memory). Subsequently, these can impact social behavior, which leads to, for instance, functional isolation. As for the impaired neurophysiological mechanisms associated with brain iron overload (e.g., exacerbated brain oxidative stress, neuronal cell death), these are associated with motor and cognitive declines (e.g., motor slowing, insufficient adjustment and altered feedback processing and sensitivity, memory loss, and impaired decision-making). Within a social context that does not provide suitable stimuli, these might impact social behavior leading to, for instance, hesitant behavior and unwillingness to interact with others.

At this point, there are several important arguments to put forward. First, the brain works as an integrated system and, as such, responses are unlikely the result of impairments in the action of specific neurotransmitters, regions, circuits or processes, but rather result from the concerted action of interconnected and interdependent neurotransmitters, processes, circuits, and regions. Second, other dimensions could have a role in mediating or potentiating the biological and neurophysiological impacts of iron deficiency. In this line of reasoning, a very important dimension to consider when analyzing the impacts of iron deficiency in cognition and social behavior in human subjects was not yet addressed in this section. What is the role, if any, of the social dimension? Social psychology and 
sociology have shown that the social context in which individuals are embedded influences individual cognition and action. However, there is little, if any, evidence of how it acts concertedly with the neurophysiological impacts of iron deficiency.

In fact, some studies have started to give innovative inputs into this discussion. In 2013, Algarín and colleagues developed a study with 10-year-old children who had early iron deficiency anemia and were given iron supplementation for at least six months [103]. At 10, these children presented hemoglobin levels within a normal range but still had impaired executive functions, as assessed by slower reaction times, less accuracy, and poorer inhibitory control as compared with children that did not present early iron deficiency anemia. Since the iron deficiency anemia and the control groups were matched for a socio-economic status, Algarín and colleagues discarded the potential effects of the social context. In line with the "critical period hypothesis," stating that an absence of adequate nutrients in critical developmental periods results in permanent structural deficits that cannot be corrected with nutrient supplementation after that period [119], the authors argue that these results are consistent with long-term effects of iron deficiency anemia on axon myelination and dopamine-dependent prefrontal-striatal circuits. These results could also be consistent with the "Altered-regulation hypothesis," which states that early nutrient deficiency modifies the brain epigenetic landscape via CpG methylation, histone modification, or hydroxymethylation [120].

In a different study, Carter and colleagues have shown that nine-month old infants with iron deficiency anemia presented poorer attention and recognition memory than infants without anemia (both with and without iron deficiency) [121]. These effects were at least partially mediated by a decreased ability to engage affectively with the environment and by other socio-emotional modifications. The authors further show that there was no relation between the impairment of cognitive function and maternal socio-demographics. These data raise questions about the role of the social dimension in the cognitive and behavioral factors that characterized these children, which shows that it probably involves other factors beyond socio-demographic characteristics.

However, one could easily argue that cognition and behavior are framed by a multitude of psychological and social dimensions (including norms, beliefs, knowledge and dispositions, interaction context, actors' perceptions, appraisals, expectations and motivations, among others) $[122,123]$. To give a specific example, one of these processes is known as personal reflexivity, which is the capacity that individuals have to think about themselves and the world, their decisions and interactions, as well as to project future behavior [124-126]. The authors have found diverse profiles of personal reflexivity, framed, among others, by the individuals' social origins. The social-economic contexts in which they live, their life trajectories and interactions, as well as the available resources. Most importantly, these profiles of individual reflexivity impacted not only how individuals think about themselves and the world, but also how they planned for their future and acted in social contexts. As such, cognition and behavior cannot be subsumed to a one-to-one linear relation either with the social-economic status or with the maternal socio-demographics. In fact, an immense number of studies have shown that the development of executive functions and subsequent social behavior, are also highly dependent on the stimulation cues that one receives from the social environment throughout their lives. These cues characterize social interactions in general (i.e., who you interact with, what type of interactions you have, how frequently you have them and others), as well as interactions during formal learning processes [127]. More specifically, it has been consistently shown that environmental interventions can potentiate cognitive functions, such as working memory [128-130]. If this is the case, an analysis of the social-economic status, or of the maternal socio-demographics, in spite of providing most relevant inputs, is not able to capture the complexity of the social environment and the individuals' appraisal of that same environment. Given the above, even though these studies do present clear associations between early iron deficiency anemia and cognition, they definitely do not allow us to rule out the role of the social dimension in cognition.

In fact, a couple of studies already shed some light into this discussion. One study shows that five-year-old children with early iron deficiency anemia are less active, more inhibited, and shy in 
a mother-child interaction [131]. These behavioral patterns are similar to the ones presented by other malnourished children $[132,133]$. Concomitantly, the same study reports that the mothers of children with normal iron status are more responsive and have richer interactions with their children. As such, the modifications that children present in social behavior could result from the combined effect of early iron deficiency anemia and decreased social interaction patterns that these children were subjected to. Adding on to this line of reasoning, more recent studies have confirmed children with iron deficiency to be less active, emotionally dull, and disengaged [112]. In addition, iron-deficient children seek and receive less stimulation from caregivers, which is a process described as "functional isolation" [134-136]. The authors argue that, over time, these behaviors result in smaller motor, cognitive, and social inputs from the environment and could interfere with social learning processes and development. To address this issue, it has been proposed that interventions for iron-deficient children should target social interactions [135]. In fact, this strategy was already mobilized on a study combining iron supplementation with a home intervention, designed to foster child development by providing support to the mother-infant relationship and has shown some positive effects on cognition and behavior [137]. Other authors have suggested that iron supplementation should be accompanied with cognitive training [138], such as working memory training, shown to present positive outcomes in cognitive functions [127].

Altogether, this clearly points to a role of iron deficiency and psychological and social processes in the development of cognition and social behaviors. The point being made here is that, despite the relevance of iron and of its neurophysiological action, these mechanisms are most likely interdependent with psychological and social dimensions, as individuals live in social contexts, grow in social contexts, learn in social contexts, and construct their memories in social contexts. Future studies should provide an in-depth characterization of all these dimensions, as well as of the specific interconnections among them.

\section{Increased Iron Levels, Cognition, and Social Behavior in Human Subjects}

The link between cognitive impairment, modifications of social behavior, and brain iron accumulation in human subjects is not well-understood. The few studies focusing on the impacts of elevated iron levels in human subjects are characterized by wide differences in research design and socio-demographic characteristics of the analyzed population. Furthermore, wide variations on population size and outcome measures render available data to present inconsistencies that are difficult to reconcile [32]. Additionally, unavailability is a characterization of social behaviors and social contexts of the studied population, which is a characterization that, as previously pointed out, is of major relevance when studying cognitive processes. In addition, while it would be of major relevance to understand whether high iron intake in the early childhood period, a common supplementation for neonate/infant iron deficiency, impacts brain mechanisms and cognition in adult life, no studies have addressed this issue. These studies are necessarily timely and costly, but, considering the increasing life expectancy, prevalence of neurodegenerative diseases as well as the relatively widespread intake of iron-enriched food and beverages to prevent or overcome early iron deficiency, these studies are of the utmost relevance [32].

Nevertheless, previous scientific studies still present some hints that should be taken with careful consideration when discussing potential impacts of iron overload in cognition and social behavior (Figure 3). Studies with human subjects have mostly focused on whether high iron intake or high peripheral iron in adults were associated with poorer cognitive outcomes (we will address the impacts of brain iron accumulation in psychosocial disorders in the following sections of this paper). In this line of research, some studies have shown no associations between plasma or serum iron levels and cognitive outcomes [139-141] (one cross sectional study with 2000 subjects with more than 65 years old and two cohort studies with approximately 800 subjects with ages above 50 years). Still, other studies present the opposite outcome, which reveals an association between diverse measures of iron status and cognition. More specifically, a cross sectional study involving 1451 subjects (mean age of 75 years 
old) revealed an association between plasma iron levels and cognition [142]. On their hand, Umer and colleagues have shown that mild cognitive impairment is present upon high serum iron ( $98 \%$ ), ferritin $(56 \%)$, and transferrin saturation (107\%). This was a cross sectional study, developed on 87 nursing home residents with more than 65 years old and who presented no neurologic diagnosis [143]. In 2012, Mueller and colleagues have shown, in a relatively small study, that the progression from mild cognitive impairment to Alzheimer's disease was associated with serum copper to non-heme iron ratio (19 control subjects, 11 cases of stable mild cognitive impairment, 7 cases of progressive cognitive impairment, and 19 cases of early dementia, mean age of 78 years old). Lastly, pre-menopausal and peri-menopausal women presented an association between improved cognitive outcomes and lower serum ferritin levels ( $n=4959$ men and women, 35-60 years old) [144]. Taken together, the data gathered with human subjects with results obtained with animal models, which show a clear association between increased iron and cognitive impairment [32], there seems to be some indications for a link between systemic iron status and cognition that needs to be studied in more detail.

A diverse approach further addressed iron's impacts on cognitive decline in older populations. These studies focused on the association between cognitive function and brain iron deposits, which are shown to be present in several brain regions. The presence of these deposits has been mainly attributed to impairments in the regulation of brain iron [145], brain microbleeds, focal micro-hemorrhages, with iron deposits in lobar white matter, basal ganglia, and internal capsule [67], and superficial siderosis, which are accumulations of hemosiderin in subapial layers of the brain [146]. These studies have reported that increased iron deposit volume was associated with decreased cognitive ability [147-153]. However, the association of aging, iron deposits, and impaired cognition remains to be clarified. While one extant cross-sectional study presented data consistent with such a notion [150], the only longitudinal approach to the role of iron aging-associated cognitive decline failed to confirm the previous results [151]. Despite the divergences in the scientific literature, since the reported patterns of iron deposition in the brain of healthy human subjects were similar to the ones present in neurodegenerative diseases, it has been proposed that iron deposits could be used as an indicator of early prediction and diagnosis of neuropathological progression [152].

There is yet a different line of studies focusing on the relation between increased iron levels, neuronal mechanisms, cognition, and social behavior, which could reveal some interesting cues. Studies focusing on iron-induced oxidative stress [86] suggest that iron might play a key role in reactions to psychosocial stress, which impact neuronal mechanisms and cognition. In fact, it has been shown that psychosocial stress, which was previously associated with oxidative stress in animal models and human subjects $[154,155]$, can lead to iron accumulation in the brain, which exacerbates brain oxidative stress and leads to a neuronal cell in rats [156]. This mechanism is aggravated by iron overload [157], which is a condition with increasing prevalence in healthy men, postmenopausal women, and the elderly population and has been attributed to changes in dietary habits $[158,159]$. These data suggest a reinforcement mechanism. Not only stress can disrupt brain iron homeostasis, contributing to iron accumulation in the brain, but also increased iron uptake further impairs brain oxidative balance and, subsequently, brain functioning. Taking in account the increasing age of the world's population and changes in diet, it would be particularly relevant to have a more complete understanding of the mechanisms mediating stress-induced iron accumulation, iron overload, and brain functioning.

In order to have a full sketch of this system, one should look further at the relation between psychosocial stress and cognition. In fact, it is known that decision-making, the process of choosing between alternative courses of action, can become impaired under stressful conditions [160]. Decision-making processes develop via neurophysiological mechanisms and are framed by broad social-cultural contexts, perceptions, and appraisal of the situation, available knowledge, decision content, motivations, and expectations [161-163]. Furthermore, it was also shown that psychosocial stress activates internal biological processes favoring the occurrence of an inflammatory response [164-166]. This strict correlation between stress and inflammation is detectable even in healthy individuals but overwhelmed with time constraints and increased task demand $[167,168]$. Upon 
prolonged stressful conditions, neuronal activity, motivation, and goal-directed motor behavior start to decrease, which is an effect that is dependent on increased levels of pro-inflammatory cytokines [169]. Lastly, these changes in brain function result in anhedonia, fatigue, motor slowing, psychomotor retardation, and isolation in mice [170]. In human subjects, stress promotes the mobilization of dysfunctional strategies such as looking for premature closure and non-systematic scanning, insufficient adjustment, and altered feedback processing and sensitivity [160]. Additionally, the association between stress and decision-making was shown to be shaped by several social moderators, such as the nature of the stressor, the individual stress reaction, or individual characteristics [171]. Research also shows that the appraisal of the stressor itself, either as a challenge (i.e., the situation is seen as an opportunity for mastery or personal growth) or as a threat (i.e., when demands are seen as exceeding the available resources), should be taken into account, since it influences performance [172]. As such, we know that brain iron accumulation is present under conditions of psychosocial stress. We also know that psychosocial stress impacts on cognitive processes such as decision-making as well as psychological and social dimensions are critical for decision-making processes in the presence or absence of stressful conditions. It remains to be ascertained whether and how iron accumulation plays a role in these processes, directly or indirectly contributing to compromising cognitive function, including impaired appraisal of the environment and decision-making processes. Some hints can be given by looking closely at studies focusing on chronic social defeat stress (CSDS), which is a neuropathology that we will focus on in the following section.

Lastly, as for iron deficiency, it is our understanding that future studies should definitely consider an integrated analysis of iron neurophysiological mechanisms, cognitive processes, and thoroughly characterize social behaviors and its contexts. This is the case since it is known that cognition and behavior are also dependent on the stimulation cues one is subjected to from the social context in which we live in [128-130] as well as by broader social-cultural structures, interaction contexts, actors' perceptions, dispositions to act, motivations, and expectations [162,163]. These social cues, which are expected to act concertedly with the biological mechanisms, could interfere with the biological footprints of an iron dysregulation on cognition and behavior. This renders it difficult to understand the mechanisms at stake.

\section{Linking Iron with Chronic Stress, Anxiety, and Depression}

Social behavior and stress are deeply connected, and this interrelation was firstly revealed by experiments conducted in animal models describing how social interactions in rodents can cause stress and how social behavior can change in response to environmental stressors [173]. In human subjects, stress caused by social interactions was shown to profoundly impact individuals' health and well-being [174]. In fact, both biological and neurobiological mechanisms underlying social behavior are influenced by molecular changes characterizing stress, which are understood as the physiological or psychological response to a prolonged internal or external stressful event (i.e., a stressor), even when it is no longer physically present but is recollected by the individual [175]. When stress is prolonged, the constant state of alertness that individuals are subjected to results in the development of chronic stress, which is associated with chronic fatigue and characterized by low levels of vitality, vigor, and energy [176]. Chronic stress leads to worse cognitive performance and impairs decision-making, including information processing, learning, and risk-taking [177].

Chronic stress has a major impact on the human brain, which alters the structure, connectivity, and neurochemistry of affected areas. Profound changes are mainly observed in hippocampal morphology, function, and neurogenesis [178], which are then associated with a neuroinflammatory profile and impaired neuronal plasticity. Dysfunction in neuronal connections of the basolateral amygdala can be triggered by stress, and compromise the structure, connectivity, and density of excitatory and inhibitory neurons of this region [179]. The release of molecules known as stress mediators and their binding to correspondent receptors activates biological mechanisms, which allows a subsequent adaptation to the challenging situation and shifts the physiological balance toward a new homeostasis. In this phase, 
oxidative damage and cognitive decline were pointed out as capable of modulating the response to chronic stress and the brain's ability to fight against it [180].

From a molecular point of view, exposure to chronic stress activates a neuroendocrine response, which results in the production of the stress hormone, cortisol, and in its subsequent release into circulation. Although there is little research on the ability of iron to modulate the neuroendocrine system in human subjects, lower cortisol levels were shown to be produced in conditions of serum iron deficiency [181]. The correlation between cortisol and iron could be justified by the notion that the enzyme necessary for the synthesis of this stress hormone is an iron-containing protein. Hence, cortisol synthesis strictly depends on iron levels [182].

The autonomic nervous system and endocrine signals involved in cortisol modulation of neural and behavioral responses are influenced by the circadian rhythm, which, in turn, is highly dependent on the levels of circulating iron [183]. More specifically, while cortisol levels are low around midnight, rise approximately three hours after and reach their peak in the morning [184], the opposite occurs for serum iron. Assessed as transferrin saturation, iron is higher at night and starts to gradually decrease during the morning. No circadian variations have been detected for transferrin receptors or ferritin expression [185]. The impact of iron on the circadian regulation of cortisol is due to most clock-related genes being iron-containing molecules [186], so one can extrapolate the effects of iron deficiency or iron accumulation for the production of this hormone. Since iron and stress were shown to have strong impacts on circadian rhythms, one can speculate that variations in this mechanism could be the basis of modifications in social behavior, and, eventually, a decline in health and well-being.

Disruption of the circadian clock is also associated with anxiety, which can be conceptualized as the response to stress and dangerous situations, and is present in more than $12 \%$ of the entire population. Anxiety is described by the current Diagnostic and Statistical Manual (DSM-5), published by the American Psychiatric Association (APA), as "characterized by feelings of tension, worried thoughts, and physical changes like increased blood pressure." Thus, under the definition of anxiety disorders, the APA refers to those that share "features of excessive fear and anxiety and related behavioral disturbances" [187]. Anxiety is characterized by a high arousal negative state [188]. In the later decades of the twentieth century, its prevalence and consistent increase led researchers to claim that we live in "the age of anxiety" [189]. A number of different factors can trigger anxiety, and these were shown to be modulated by iron levels. As the first example, the more intuitive, anxious feelings are associated with iron deficiency, since low iron levels translate into a lack of oxygen to tissues. This means that this anxiety state can be reverted as soon as normal iron levels are restored [190]. The negative influence of iron on dopamine synthesis, as previously described, also contributes to develop a state of anxiety, given the importance of this neurotransmitter in maintaining attention and focus. While conditions of iron deficiency compromise the activity of tyrosine hydroxylase and results in lower dopamine production, the same occurs with excess iron, since this metal causes dopaminergic neurodegeneration by exacerbating the oxidative stress produced by dopamine degradation. Consequently, individuals suffer from cognitive changes, altered performance, and memory loss. In mice, the development of anxiety is likely accompanied with the accumulation of iron in the brain, which occurs upon a reduced expression of antioxidant enzymes and oxidative-mediated damage to catecholaminergic innervated regions of the anterior forebrain [191]. In rodents, anxious behavior can be improved by restoring the redox balance in these areas through the uptake of dietary or pharmacological antioxidants. Whether this occurs in human subjects needs to be fully elucidated. However, the consumption of fish-derived omega- 3 poly-unsaturated fatty acids as well as docosahexaenoic and eicosapentaenoic acid aids preserve cognitive capacities via a mechanism that can possibly reduce iron-driven oxidative damage and restore the expression of antioxidant enzymes [90]. This further points at the need to monitor iron levels in psychosocial disorders, since the development of new interventions maintaining iron homeostasis could contribute to better outcomes.

The effects of iron deficiency on psychosocial disorders were further reported in depression. Several studies indicate anemia as a pre-disposing factor [192,193] for a condition that, unlike anxiety, 
is characterized by a low arousal negative state accompanied by pervasive negative thoughts and emotions about oneself and the future [188]. Individuals with major depressive disorder have difficulties engaging in cognitive reappraisal (i.e., an effort to change the subjective evaluation of a situation in order to modify its emotional impact), which is a key emotional regulation strategy to deal with stressful or uncontrollable events [194]. Early adversity, conflict occurrences, maternal depression, socioeconomic status, and others, can be considered as major causes for depression, and have been associated with low-grade inflammation. This is corroborated by prospective, longitudinal, and meta-analyses research. These studies show depression to be correlated to an increased immune response. Inflammatory cytokines, such as tumor necrosis factor (TNF), interleukin (IL)-6, C-reactive protein, the hemoglobin scavenger protein, and haptoglobin, have been found in the peripheral blood of patients suffering from severe depressive symptoms [195,196]. Thus, given the cross-talk between iron metabolism and inflammation [197], one can understand the involvement of genes controlling iron hemostasis in the pathogenesis of this disorder.

Studies in mice show that stress-induced depression causes brain iron overload and affects specific regions of this organ, such as the hippocampus. Administration of iron chelation therapy to these animals prevents neuronal loss [198], which is an effect that is also observed in human subjects with depression when subjected to a similar treatment. Widespread iron deposition was found in the brain of these individuals and was recognized as capable of predicting both depression and memory impairment [199].

Thus, although the biological basis of chronic stress, anxiety, and depression remains very elusive [26,31,191,200,201], overall, iron is considered to be a key biological marker for psychosocial disorders associated with impaired cognitive functions and altered social behavior. As previously discussed, the potential effectiveness of iron-dependent treatment strategies should take into consideration that, even though cognition and behavior do develop through iron-dependent physiological and neurophysiological mechanisms, they are unequivocally framed by psychological and social processes that should also be addressed in future research.

\section{Discussion}

Dysregulation of iron levels in human subjects is a relatively common phenomenon. On the one hand, we have iron deficiency, which is the most prevalent nutrient deficiency worldwide, and, on the other hand, iron overload, which is common in the increasing aging population as well as in pathologies such as neurodegenerative diseases and psychosocial disorders. For both cases, the impacts of iron dysregulation in neurophysiological structures and mechanisms have been studied, with consistent data published in both animal models and human subjects. The association between iron dysfunction and motor and cognitive impairment, as well as modified social behavior, is also very consistent. However, while most studies show that iron interventions could correct for altered iron levels, this type of intervention was mostly unable to revert cognitive or behavioral modifications. Within the iron community, many authors either underline the methodological insufficiencies of intervention studies or argue that iron dysregulation during critical periods, cannot be reverted. Other authors argue that correction of iron levels necessarily needs to be complemented with cognitive stimuli and other types of social interventions, which is a proposal that is completely in line with the findings of social psychology and sociology.

It is our understanding that, while biological impacts or iron dysregulation are undeniable and deserve to be studied and discussed in great detail, its associated cognitive and social blueprints could be further exacerbated by psychosocial contexts that do not promote regular cognitive function and normative social behavior. The study of these interactions is of the utmost relevance for the design of future research aiming to understand how individuals think and act under physiological and pathophysiological conditions.

Author Contributions: A.F., P.N., and R.G. conceptualized, elaborated, and wrote the manuscript. All figures were prepared using a template on the Servier medical art website (http://www.servier.fr/servier-medical-art). 
Funding: A.F. is funded by national funds through the FCT - Fundação para a Ciência e a Tecnologia, I.P., under the Norma Transitória - DL57/2016/CP1453/CT0077, and receives research funding from FCT/MCTES grant PTDC/IVC-ESCT/0073/2014. PN is funded through FCT - Fundação para a Ciência e a Tecnologia (UID/ECO/00124/2013, UID/ECO/00124/2019 and Social Sciences DataLab, LISBOA-01-0145-FEDER-022209), POR Lisboa (LISBOA-01-0145-FEDER-007722, LISBOA-01-0145-FEDER-022209), and POR Norte (LISBOA-010145-FEDER-022209). RG is funded by FCT - Fundação para a Ciência e a Tecnologia (IF/01495/2015) and receives research funding from FCT-PAC (03/SAICT/2015) and EOS MODEL-IDI 30826052. A.F., P.N., and R.G. also received research funding from Santander Totta/NOVA University of Lisbon (Collaborative Investigation Price 2017).

Conflicts of Interest: The authors declare no conflict of interest.

\section{References}

1. Gozzelino, R.; Arosio, P. The importance of iron in pathophysiologic conditions. Front. Pharmacol. 2015, 6, 26. [CrossRef] [PubMed]

2. Gozzelino, R. The Pathophysiology of Heme in the Brain. Curr. Alzheimer Res. 2016, 13, 174-184. [CrossRef] [PubMed]

3. Rouault, T.A. Iron metabolism in the CNS: Implications for neurodegenerative diseases. Nat. Rev. Neurosci. 2013, 14, 551-564. [CrossRef] [PubMed]

4. Beard, J.L.; Connor, J.R. IRON STATUS AND NEURAL FUNCTIONING. Annu. Rev. Nutr. 2003, 23, 41-58. [CrossRef] [PubMed]

5. Nnah, I.C.; Wessling-Resnick, M. Brain Iron Homeostasis: A Focus on Microglial Iron. Pharmaceuticals 2018, 11, 129. [CrossRef]

6. World Health Organization. Iron deficiency anaemia: Assessment, prevention and control. A Guide for Programme Managers; WHO Press: Geneva, Switzerland, 2001.

7. Petry, N.; Olofin, I.; Hurrell, R.F.; Boy, E.; Wirth, J.P.; Moursi, M.; Donahue Angel, M.; Rohner, F. The Proportion of Anemia Associated with Iron Deficiency in Low, Medium, and High Human Development Index Countries: A Systematic Analysis of National Surveys. Nutrients 2016, 8, 693. [CrossRef] [PubMed]

8. Low, M.S.; Grigoriadis, G. Iron deficiency and new insights into therapy. Med. J. Aust. 2017, 207, 81-87. [CrossRef]

9. James, P.W.; Nelson, M.; Ralph, A.; Leather, S. Socioeconomic determinants of health: The contribution of nutrition to inequalities in health. BMJ 1997, 314, 1545. [CrossRef]

10. Watt, R.G.; Dykes, J.; Sheiham, A. Socio-economic determinants of selected dietary indicators in British pre-school children. Public Health Nutr. 2001, 4, 1229-1233. [CrossRef]

11. Keskin, Y.; Moschonis, G.; mitriou Sur, H.; Kocaoglu, B.; Hayran, O.; Manios, Y. Prevalence of iron deficiency among schoolchildren of different socio-economic status in urban Turkey. Eur. J. Clin. Nutr. 2005, 59, 1602035. [CrossRef]

12. Brotanek, J.M.; Gosz, J.; Weitzman, M.; Flores, G. Secular Trends in the Prevalence of Iron Deficiency Among US Toddlers, 1976-2002. Arch. Pediat. Adol. Med. 2008, 162, 374-381. [CrossRef] [PubMed]

13. Wieser, S.; Plessow, R.; Eichler, K.; Malek, O.; Capanzana, M.V.; Agdeppa, I.; Bruegger, U. Burden of micronutrient deficiencies by socio-economic strata in children aged 6 months to 5 years in the Philippines. BMC Public Health 2013, 13, 1167. [CrossRef] [PubMed]

14. Ferrara, M.; Bertocco, F.; Ricciardi, A.; Ferrara, D.; Incarnato, L.; Capozzi, L. Iron deficiency screening in the first three years of life: A three-decade-long retrospective case study. Hematology 2014, 19, $239-243$. [CrossRef] [PubMed]

15. Plessow, R.; Arora, N.; Brunner, B.; Tzogiou, C.; Eichler, K.; Brügger, U.; Wieser, S. Social Costs of Iron Deficiency Anemia in 6-59-Month-Old Children in India. PLoS ONE 2015, 10, e0136581. [CrossRef] [PubMed]

16. Lang, T.; Caraher, M. Access to healthy foods: Part II. Food poverty and shopping deserts: What are the implications for health promotion policy and practice? Health Educ. J. 1998, 57, 202-211. [CrossRef]

17. World Health Organization. Guideline: Daily Iron Supplementation in Adult Women and Adolescent Girls; WHO Press: Geneva, Switzerland, 2016.

18. Jáuregui-Lobera, I. Iron deficiency and cognitive functions. Neuropsychiatr. Dis. Treat. 2014, 10, $2087-2095$. [CrossRef] [PubMed]

19. Larson, L.M.; Phiri, K.S.; Pasricha, S.R. Iron and Cognitive Development: What Is the Evidence? Ann. Nutr. Metab. 2017, 71, 25-38. [CrossRef] 
20. Armitage, A.E.; Moretti, D. The Importance of Iron Status for Young Children in Low- and Middle-Income Countries: A Narrative Review. Pharmaceuticals 2019, 12, 59. [CrossRef]

21. Belaidi, A.A.; Bush, A.I. Iron neurochemistry in Alzheimer's disease and Parkinson's disease: Targets for therapeutics. J. Neurochem. 2016, 139, 179-197. [CrossRef]

22. Cahn-Weiner, D.A.; Grace, J.; Ott, B.R.; Fernandez, H.H.; Friedman, J.H. Cognitive and behavioral features discriminate between Alzheimer's and Parkinson's disease. Cogn. Behav. Neurol. 2002, 15, 79-87.

23. Meireles, J.; Massano, J. Cognitive Impairment and Dementia in Parkinson's Disease: Clinical Features, Diagnosis, and Management. Front. Neurol. 2012, 3, 88. [CrossRef] [PubMed]

24. Miyasaki, J.; Shannon, K.; Voon, V.; Ravina, B.; Kleiner-Fisman, G.; Anderson, K.; Shulman, L.M.; Gronseth, G.; Weiner, W.J. Practice Parameter: Evaluation and treatment of depression, psychosis, and dementia in Parkinson disease (an evidence-based review) Report of the Quality Standards Subcommittee of the American Academy of Neurology. Neurology 2006, 66, 996-1002. [CrossRef] [PubMed]

25. Lanctôt, K.L.; Amatniek, J.; Ancoli-Israel, S.; Arnold, S.E.; Ballard, C.; Cohen-Mansfield, J.; Ismail, Z.; Lyketsos, C.; Miller, D.S.; Musiek, E.; et al. Neuropsychiatric signs and symptoms of Alzheimer's disease: New treatment paradigms. Alzheimer's Dement. Transl. Res. Clin. Interv. 2017, 3, 440-449. [CrossRef] [PubMed]

26. Kim, J.; Wessling-Resnick, M. Iron and mechanisms of emotional behavior. J. Nutritional. Biochem. 2014, 25, 1101-1107. [CrossRef] [PubMed]

27. Lehmann, M.L.; Weigel, T.K.; Elkahloun, A.G.; Herkenham, M. Chronic social defeat reduces myelination in the mouse medial prefrontal cortex. Sci. Rep. UK 2017, 7, 46548. [CrossRef]

28. Gozzelino, R.; Arosio, P. Iron Homeostasis in Health and Disease. Int. J. Mol. Sci. 2016, 17, 130. [CrossRef] [PubMed]

29. Sankiewicz, A.; Goscik, J.; Swiergiel, A.H.; Majewska, A.; Wieczorek, M.; Juszczak, G.R.; Lisowski, P. Social stress increases expression of hemoglobin genes in mouse prefrontal cortex. BMC Neurosci. 2014, 15, 130. [CrossRef]

30. Mucha, M.; Skrzypiec, A.E.; Schiavon, E.; Attwood, B.K.; Kucerova, E.; Pawlak, R. Lipocalin-2 controls neuronal excitability and anxiety by regulating dendritic spine formation and maturation. Proc. Natl. Acad. Sci. USA 2011, 108, 18436-18441. [CrossRef]

31. Jha, M.; Lee, S.; Park, D.; Kook, H.; Park, K.G.; Lee, I.K.; Suk, K. Diverse functional roles of lipocalin-2 in the central nervous system. Neurosci. Biobehav. Rev. 2015, 49, 135-156. [CrossRef]

32. Agrawal, S.; Berggren, K.L.; Marks, E.; Fox, J.H. Impact of high iron intake on cognition and neurodegeneration in humans and in animal models: A systematic review. Nutr. Rev. 2017, 75, 456-470. [CrossRef]

33. Ward, R.J.; Zucca, F.A.; Duyn, J.H.; Crichton, R.R.; Zecca, L. The role of iron in brain ageing and neurodegenerative disorders. Lancet Neurol. 2014, 13, 1045-1060. [CrossRef]

34. Stockwell, B.R.; Angeli, J.; Bayir, H.; Bush, A.I.; Conrad, M.; Dixon, S.J.; Fulda, S.; Gascón, S.; Hatzios, S.K.; Kagan, V.E.; et al. Ferroptosis: A Regulated Cell Death Nexus Linking Metabolism, Redox Biology, and Disease. Cell 2017, 171, 273-285. [CrossRef] [PubMed]

35. Nuñez, M.T.; Chana-Cuevas, P. New Perspectives in Iron Chelation Therapy for the Treatment of Neurodegenerative Diseases. Pharmaceuticals 2018, 11, 109. [CrossRef] [PubMed]

36. Masaldan, S.; Bush, A.I.; Devos, D.; Rolland, A.; Moreau, C. Striking while the iron is hot: Iron metabolism and ferroptosis in neurodegeneration. Free Radic. Biol. Med. 2019, 133, 221-233. [CrossRef] [PubMed]

37. Ward, R.J.; Crichton, R.R. Essential Metals in Medicine: Therapeutic Use and Toxicity of Metal Ions in the Clinic. Metal Ions Life Sci. 2019, 19, 87-122. [CrossRef]

38. Andraca, I.; Castillo, M.; Walter, T. Psychomotor Development and Behavior in Iron-deficient Anemic Infants. Nutr. Rev. 1997, 55, 125-132. [CrossRef] [PubMed]

39. Crichton, R.R.; Ward, R.J. Metal-Based Neurodegeneration: From Molecular Mechanisms to Therapeutic Strategies, 2nd ed.; Wiley: Chichester, UK, 2013; ISBN 978-1-119-97714-8.

40. Sobotka, T.J.; Whittaker, P.; Sobotka, J.M.; Brodie, R.E.; Wander, D.Y.; Robl, M.; Bryant, M.; Barton, C. Neurobehavioral dysfunctions associated with dietary iron overload. Physiol. Behav. 1996, 59, $213-219$. [CrossRef]

41. Vinceti, M.; Mandrioli, J.; Borella, P.; Michalke, B.; Tsatsakis, A.; Finkelstein, Y. Selenium neurotoxicity in humans: Bridging laboratory and epidemiologic studies. Toxicol. Lett. 2014, 230, 295-303. [CrossRef]

42. Youdim, M.B. Brain iron deficiency and excess; cognitive impairment and neurodegenration with involvement of striatum and hippocampus. Neurotox. Res. 2008, 14, 45-56. [CrossRef] 
43. Lozoff, B. Iron Deficiency and Child Development. Food Nutr. Bull. 2007, 28, S560-S571. [CrossRef]

44. Rudisill, S.S.; Martin, B.R.; Mankowski, K.M.; Tessier, C.R. Iron Deficiency Reduces Synapse Formation in the Drosophila Clock Circuit. Biol. Trace Elem. Res. 2019, 189, 241-250. [CrossRef] [PubMed]

45. Beard, J. Recent Evidence from Human and Animal Studies Regarding Iron Status and Infant Development. J. Nutr. 2007, 137, 524S-530S. [CrossRef] [PubMed]

46. Lozoff, B.; Beard, J.; Connor, J.; Felt, B.; Georgieff, M.; Schallert, T. Long-Lasting Neural and Behavioral Effects of Iron Deficiency in Infancy. Nutr. Rev. 2006, 64, S34-S43. [CrossRef] [PubMed]

47. Lozoff, B. Early Iron Deficiency Has Brain and Behavior Effects Consistent with Dopaminergic Dysfunction. J. Nutr. 2011, 141, 740S-746S. [CrossRef] [PubMed]

48. Bailey, R.L.; Gahche, J.J.; Lentino, C.V.; Dwyer, J.T.; Engel, J.S.; Thomas, P.R.; Betz, J.M.; Sempos, C.T.; Picciano, M.F. Dietary Supplement Use in the United States, 2003-2006. J. Nutr. 2011, 141, 261-266. [CrossRef]

49. Eid, R.; Arab, N.; Greenwood, M.T. Iron mediated toxicity and programmed cell death: A review and a re-examination of existing paradigms. Biochim. Biophys. Acta BBA Mol. Cell Res. 2017, 1864, 399-430. [CrossRef] [PubMed]

50. Sun, M.; Goldin, E.; Stahl, S.; Falardeau, J.L.; Kennedy, J.C.; Acierno, J.S., Jr.; Bove, C.; Kaneski, C.R.; Nagle, J.; Bromley, M.C.; et al. Mucolipidosis type IV is caused by mutations in a gene encoding a novel transient receptor potential channel. Hum. Mol. Genet. 2000, 9, 2471-2478. [CrossRef]

51. Dong, X.P.; Cheng, X.; Mills, E.; Delling, M.; Wang, F.; Kurz, T.; Xu, H. The type IV mucolipidosis-associated protein TRPML1 is an endolysosomal iron release channel. Nature 2008, 455, 992. [CrossRef]

52. Ohgami, R.S.; Campagna, D.R.; McDonald, A.; Fleming, M.D. The Steap proteins are metalloreductases. Blood 2006, 108, 1388-1394. [CrossRef]

53. Vargas, J.D.; Herpers, B.; McKie, A.T.; Gledhill, S.; nnell, J.; van den Heuvel, M.; Davies, K.E.; Ponting, C.P. Stromal cell-derived receptor 2 and cytochrome b561 are functional ferric reductases. Biochim. Biophys. Acta BBA Proteins Proteom. 2003, 1651, 116-123. [CrossRef]

54. Fishman, J.; Rubin, J.; Handrahan, J.; Connor, J.; Fine, R. Receptor-mediated transcytosis of transferrin across the blood-brain barrier. J. Neurosci. Res. 1987, 18, 299-304. [CrossRef] [PubMed]

55. Beard, J.L.; Wiesinger, J.A.; Li, N.; Connor, J.R. Brain iron uptake in hypotransferrinemic mice: Influence of systemic iron status. J. Neurosci. Res. 2005, 79, 254-261. [CrossRef] [PubMed]

56. Arosio, P.; Carmona, F.; Gozzelino, R.; Maccarinelli, F.; Poli, M. The importance of eukaryotic ferritins in iron handling and cytoprotection. Biochem. J. 2015, 472, 1-15. [CrossRef] [PubMed]

57. Nemeth, E.; Tuttle, M.S.; Powelson, J.; Vaughn, M.B.; Donovan, A.; Ward, D.M.; Ganz, T.; Kaplan, J. Hepcidin Regulates Cellular Iron Efflux by Binding to Ferroportin and Inducing Its Internalization. Science 2004, 306, 2090-2093. [CrossRef] [PubMed]

58. Gutteridge, J.M. Ferrous ions detected in cerebrospinal fluid by using bleomycin and DNA damage. Clin. Sci. 1992, 82, 315-320. [CrossRef] [PubMed]

59. Mills, E.; Dong, X.; Wang, F.; Xu, H. Mechanisms of brain iron transport: Insight into neurodegeneration and CNS disorders. Future Med. Chem. 2010, 2, 51-64. [CrossRef] [PubMed]

60. Chiou, B.; Lucassen, E.; Sather, M.; Kallianpur, A.; Connor, J. Semaphorin4A and H-ferritin utilize Tim-1 on human oligodendrocytes: A novel neuro-immune axis. Glia 2018, 66, 1317-1330. [CrossRef]

61. Todorich, B.; Zhang, X.; Slagle-Webb, B.; Seaman, W.E.; Connor, J.R. Tim-2 is the receptor for H-ferritin on oligodendrocytes. J. Neurochem. 2008, 107, 1495-1505. [CrossRef]

62. McCarthy, R.C.; Sosa, J.; Gardeck, A.M.; Baez, A.S.; Lee, C.H.; Wessling-Resnick, M. Inflammation-induced iron transport and metabolism by brain microglia. J. Biol. Chem. 2018, 293, 7853-7863. [CrossRef]

63. Hubert, V.; Chauveau, F.; Dumot, C.; Ong, E.; Berner, L.P.; Canet-Soulas, E.; Ghersi-Egea, J.F.; Wiart, M. Clinical Imaging of Choroid Plexus in Health and in Brain Disorders: A Mini-Review. Front. Mol. Neurosci. 2019, 12, 34. [CrossRef]

64. Moos, T.; Nielsen, T.; Skjørringe, T.; Morgan, E.H. Iron trafficking inside the brain. J. Neurochem. 2007, 103, 1730-1740. [CrossRef] [PubMed]

65. Vela, D. The Dual Role of Hepcidin in Brain Iron Load and Inflammation. Front. Neurosci. 2018, $12,740$. [CrossRef] [PubMed]

66. McAuley, G.; Schrag, M.; Barnes, S.; Obenaus, A.; Dickson, A.; Holshouser, B.; Kirsch, W. Iron quantification of microbleeds in postmortem brain. Magnet. Reson. Med. 2011, 65, 1592-1601. [CrossRef] [PubMed] 
67. Martinez-Ramirez, S.; Greenberg, S.M.; Viswanathan, A. Cerebral microbleeds: Overview and implications in cognitive impairment. Alzheimer's Res. Ther. 2014, 6, 33. [CrossRef] [PubMed]

68. Yip, S.; Sastry, B.R. Effects of hemoglobin and its breakdown products on synaptic transmission in rat hippocampal CA1 neurons. Brain Res. 2000, 864, 1-12. [CrossRef]

69. Noorbakhsh-Sabet, N.; Pulakanti, V.; Zand, R. Uncommon Causes of Cerebral Microbleeds. J. Stroke Cerebrovasc. Dis. 2017, 26, 2043-2049. [CrossRef] [PubMed]

70. Alharbi, H.; Khawar, N.; Kulpa, J.; Bellin, A.; Proteasa, S.; Sundaram, R. Neurological Complications following Blood Transfusions in Sickle Cell Anemia. Case Rep. Hematol. 2017, 2017, 1-3. [CrossRef]

71. Lee, V.H.; Wijdicks, E.F.; Manno, E.M.; Rabinstein, A.A. Clinical Spectrum of Reversible Posterior Leukoencephalopathy Syndrome. Arch. Neurol. 2008, 65, 205-210. [CrossRef]

72. Carmona-Gutierrez, D.; Hughes, A.L.; Madeo, F.; Ruckenstuhl, C. The crucial impact of lysosomes in aging and longevity. Ageing Res. Rev. 2016, 32, 2-12. [CrossRef]

73. Asano, T.; Komatsu, M.; Yamaguchi-Iwai, Y.; Ishikawa, F.; Mizushima, N.; Iwai, K. Distinct Mechanisms of Ferritin Delivery to Lysosomes in Iron-Depleted and Iron-Replete Cells. Mol. Cell Biol. 2011, 31, 2040-2052. [CrossRef]

74. Mancias, J.D.; Wang, X.; Gygi, S.P.; Harper, W.J.; Kimmelman, A.C. Quantitative proteomics identifies NCOA4 as the cargo receptor mediating ferritinophagy. Nature 2014, 509, 105. [CrossRef] [PubMed]

75. Del Rey, M.; Mancias, J.D. NCOA4-Mediated Ferritinophagy: A Potential Link to Neurodegeneration. Front. Neurosci. 2019, 13, 238. [CrossRef] [PubMed]

76. Levi, S.; Tiranti, V. Neurodegeneration with Brain Iron Accumulation Disorders: Valuable Models Aimed at Understanding the Pathogenesis of Iron Deposition. Pharmaceuticals 2019, 12, 27. [CrossRef] [PubMed]

77. Dusek, P.; Schneider, S.A.; Aaseth, J. Iron chelation in the treatment of neurodegenerative diseases. J. Trace Elem. Med. Bio. 2016, 38, 81-92. [CrossRef] [PubMed]

78. Andersen, H.; Johnsen, K.; Moos, T. Iron deposits in the chronically inflamed central nervous system and contributes to neurodegeneration. Cell Mol. Life Sci. 2014, 71, 1607-1622. [CrossRef]

79. Zhou, D.R.; Eid, R.; Miller, K.A.; Boucher, E.; Mandato, C.A.; Greenwood, M.T. Intracellular second messengers mediate stress inducible hormesis and Programmed Cell Death: A review. Biochim. Biophys. Acta BBA Mol. Cell Res. 2019, 1866, 773-792. [CrossRef] [PubMed]

80. Devos, D.; Moreau, C.; Devedjian, J.; Kluza, J.; Petrault, M.; Laloux, C.; Jonneaux, A.; Ryckewaert, G.; Garçon, G.; Rouaix, N.; et al. Targeting Chelatable Iron as a Therapeutic Modality in Parkinson's Disease. Antioxid. Redox Sign. 2014, 21, 195-210. [CrossRef]

81. Martin-Bastida, A.; Ward, R.J.; Newbould, R.; Piccini, P.; Sharp, D.; Kabba, C.; Patel, M.C.; Spino, M.; Connelly, J.; Tricta, F.; et al. Brain iron chelation by deferiprone in a phase 2 randomised double-blinded placebo controlled clinical trial in Parkinson's disease. Sci. Rep. UK 2017, 7, 1398. [CrossRef]

82. Fenton, H.J.; Jackson, H.J.I. The oxidation of polyhydric alcohols in presence of iron. J. Chem. Soc. Trans. 1899, 75, 1-11. [CrossRef]

83. Weiland, A.; Wang, Y.; Wu, W.; Lan, X.; Han, X.; Li, Q.; Wang, J. Ferroptosis and Its Role in Diverse Brain Diseases. Mol. Neurobiol. 2019, 56, 4880-4893. [CrossRef]

84. Wang, Y.; Wu, Y.; Li, T.; Wang, X.; Zhu, C. Iron Metabolism and Brain Development in Premature Infants. Front. Physiol. 2019, 10, 463. [CrossRef] [PubMed]

85. Halliwell, B. Role of Free Radicals in the Neurodegenerative Diseases. Drug Aging 2001, 18, 685-716. [CrossRef] [PubMed]

86. Black, C.N.; Bot, M.; Scheffer, P.G.; Cuijpers, P.; Penninx, B. Is depression associated with increased oxidative stress? A systematic review and meta-analysis. Psychoneuroendocrinology 2015, 51, 164-175. [CrossRef] [PubMed]

87. Horowitz, M.P.; Greenamyre, T.J. Mitochondrial Iron Metabolism and Its Role in Neurodegeneration. J. Alzheimer's Dis. 2010, 20, S551-S568. [CrossRef] [PubMed]

88. Zucca, F.A.; Segura-Aguilar, J.; Ferrari, E.; Muñoz, P.; Paris, I.; Sulzer, D.; Sarna, T.; Casella, L.; Zecca, L. Interactions of iron, dopamine and neuromelanin pathways in brain aging and Parkinson's disease. Prog. Neurobiol. 2017, 155, 96-119. [CrossRef] [PubMed]

89. Fearnhead, H.O.; Vandenabeele, P.; Berghe, T. How do we fit ferroptosis in the family of regulated cell death? Cell Death Differ. 2017, 24, 1991-1998. [CrossRef] [PubMed] 
90. Reimers, A.; Ljung, H. The emerging role of omega-3 fatty acids as a therapeutic option in neuropsychiatric disorders. Ther. Adv. Psychopharmacol. 2019, 9, 2045125319858901. [CrossRef]

91. Kennedy, D.P.; Adolphs, R. The social brain in psychiatric and neurological disorders. Trends Cogn. Sci. 2012, 16, 559-572. [CrossRef]

92. Adolphs, R.; Damasio, H.; Tranel, D.; Cooper, G.; Damasio, A.R. A Role for Somatosensory Cortices in the Visual Recognition of Emotion as Revealed by Three-Dimensional Lesion Mapping. J. Neurosci. 2000, 20, 2683-2690. [CrossRef]

93. Pessoa, L.; Adolphs, R. Emotion processing and the amygdala: From a "low road" to "many roads" of evaluating biological significance. Nat. Rev. Neurosci. 2010, 11, 773. [CrossRef]

94. Nelson, E.E.; Guyer, A.E. The development of the ventral prefrontal cortex and social flexibility. Dev. Cogn. Neurosci. 2011, 1, 233-245. [CrossRef] [PubMed]

95. Barrash, J.; Tranel, D.; Anderson, S.W. Acquired Personality Disturbances Associated with Bilateral Damage to the Ventromedial Prefrontal Region. Dev. Neuropsychol. 2000, 18, 355-381. [CrossRef] [PubMed]

96. Meiser, J.; Weindl, D.; Hiller, K. Complexity of dopamine metabolism. Cell Commun. Signal. 2013, 11, 34. [CrossRef] [PubMed]

97. Murray-Kolb, L.E. Iron status and neuropsychological consequences in women of reproductive age: What do we know and where are we headed? J. Nutr. 2011, 141, 747S-755S. [CrossRef] [PubMed]

98. McClung, J.P.; Murray-Kolb, L.E. Iron Nutrition and Premenopausal Women: Effects of Poor Iron Status on Physical and Neuropsychological Performance. Annu. Rev. Nutr. 2013, 33, 271-288. [CrossRef] [PubMed]

99. Low, M.; Speedy, J.; Styles, C.E.; De-Regil, L.; Pasricha, S. Daily iron supplementation for improving anaemia, iron status and health in menstruating women. Cochrane Database Syst. Rev. 2016, 4, CD009747. [CrossRef] [PubMed]

100. Breymann, C. Iron Deficiency Anemia in Pregnancy. Semin. Hematol. 2015, 52, 339-347. [CrossRef]

101. Algarín, C.; Peirano, P.; Garrido, M.; Pizarro, F.; Lozoff, B. Iron Deficiency Anemia in Infancy. Pediatr. Res. 2003, 53, 217-223. [CrossRef]

102. Walter, T. Effect of Iron-Deficiency Anemia on Cognitive Skills and Neuromaturation in Infancy and Childhood. Food Nutr. Bull. 2003, 24, S104-S110. [CrossRef]

103. Algarín, C.; Nelson, C.A.; Peirano, P.; Westerlund, A.; Reyes, S.; Lozoff, B. Iron-deficiency anemia in infancy and poorer cognitive inhibitory control at age 10 years. Dev. Med. Child Neurol. 2013, 55, 453-458. [CrossRef]

104. McCann, J.C.; Ames, B.N. An overview of evidence for a causal relation between iron deficiency during development and deficits in cognitive or behavioral function. Am. J. Clin. Nutr. 2007, 85, 931-945. [CrossRef] [PubMed]

105. Bressan, R.; Crippa, J. The role of dopamine in reward and pleasure behavior-Review of data from preclinical research. Acta Psychiat. Scand. 2005, 111, 14-21. [CrossRef] [PubMed]

106. Wild, B.; Rodden, F.A.; Grodd, W.; Ruch, W. Neural correlates of laughter and humour. Brain 2003, 126, 2121-2138. [CrossRef] [PubMed]

107. Oski, F.; Honig, A.; Helu, B.; Howanitz, P. Effect of iron therapy on behavior performance in nonanemic, iron-deficient infants. Pediatrics 1983, 71, 877-880. [PubMed]

108. Walter, T.; Kovalskys, J.; Stekel, A. Effect of mild iron deficiency on infant mentaldevelopment scores. J. Pediatrics 1983, 102, 519-522. [CrossRef]

109. Lozoff, B.; Wolf, A.W.; Urrutia, J.J.; Viteri, F.E. Abnormal Behavior and Low Developmental Test Scores in Iron-Deficient Anemic Infants. J. Dev. Behav. Pediatrics 1985, 6, 69-75. [CrossRef]

110. Deinard, A.S.; List, A.; Lindgren, B.; Hunt, J.V.; Chang, P.N. Cognitive deficits in iron-deficient and iron-deficient anemic children. J. Pediatrics 1986, 108, 681-689. [CrossRef]

111. Lozoff, B.; Klein, N.K.; Prabucki, K.M. Iron-Deficient Anemic Infants at Play. J. Dev. Behav. Pediatrics 1986, 7, 152-158. [CrossRef]

112. Lozoff, B.; Klein, N.K.; Nelson, E.C.; McClish, D.K.; Manuel, M.; Chacon, M. Behavior of Infants with Iron-Deficiency Anemia. Child Dev. 1998, 69, 24-36. [CrossRef]

113. Lozoff, B.; Clark, K.M.; Jing, Y.; Armony-Sivan, R.; Angelilli, M.; Jacobson, S.W. Dose-Response Relationships between Iron Deficiency with or without Anemia and Infant Social-Emotional Behavior. J. Pediatrics 2008, 152, 696-702. [CrossRef]

114. Honig, A.; Oski, F.A. Solemnity: A clinical risk index for iron deficient infants. Early Child Dev. Care 2010, 16, 69-83. [CrossRef] 
115. Shafir, T.; Angulo-Barroso, R.; Jing, Y.; Angelilli, M.; Jacobson, S.W.; Lozoff, B. Iron deficiency and infant motor development. Early Hum. Dev. 2008, 84, 479-485. [CrossRef] [PubMed]

116. Hokama, T.; Ken, G.M.; Nosoko, N. Iron Deficiency Anaemia and Child Development. Asia Pac. J. Public Health 2005, 17, 19-21. [CrossRef] [PubMed]

117. Lozoff, B.; Armony-Sivan, R.; Kaciroti, N.; Jing, Y.; Golub, M.; Jacobson, S.W. Eye-Blinking Rates Are Slower in Infants with Iron-Deficiency Anemia than in Nonanemic Iron-Deficient or Iron-Sufficient Infants. J. Nutr. 2010, 140, 1057-1061. [CrossRef] [PubMed]

118. Lozoff, B.; Felt, B.T.; Nelson, E.C.; Wolf, A.W.; Meltzer, H.W.; Jimenez, E. Serum prolactin levels and behavior in infants. Biol. Psychiat. 1995, 37, 4-12. [CrossRef]

119. Hensch, T.K. Critical period regulation. Annu. Rev. Neurosci. 2004, 27, 549-579. [CrossRef] [PubMed]

120. Gluckman, P.D.; Hanson, M.A. Living with the Past: Evolution, Development, and Patterns of Disease. Science 2004, 305, 1733-1736. [CrossRef] [PubMed]

121. Carter, C.R.; Jacobson, J.L.; Burden, M.J.; Armony-Sivan, R.; Dodge, N.C.; Angelilli, M.; Lozoff, B.; Jacobson, S.W. Iron Deficiency Anemia and Cognitive Function in Infancy. Pediatrics 2010, 126, e427-e434. [CrossRef] [PubMed]

122. Kivisto, P. Social Theory: Roots and Branches, 5th ed.; Oxford University Press: Oxford, UK; New York, NY, USA, 2013; ISBN 978-0199937127.

123. Collins, R. Four Sociological Traditions, Revised \& Enlarged edition; Oxford University Press: Oxford, UK; New York, NY, USA, 1994; ISBN 978-0195082081.

124. Archer, M. Structure, Agency and the Internal Conversation; Cambridge University Press: Cambridge, UK, 2003; ISBN 978-1139087315.

125. Caetano, A. Coping with Life: A Typology of Personal Reflexivity. Sociol. Q. 2016, 58, 32-50. [CrossRef]

126. Caetano, A. Designing social action: The impact of reflexivity on practice. J. Theor. Soc. Behav. 2019, 49, 146-160. [CrossRef]

127. Alloway, T.; Bibile, V.; Lau, G. Computerized working memory training: Can it lead to gains in cognitive skills in students? Comput. Hum. Behav. 2013, 29, 632-638. [CrossRef]

128. Buschkuehl, M.; Jaeggi, S.M.; Jonides, J. Neuronal effects following working memory training. Dev. Cogn. Neurosci. 2012, 2, S167-S179. [CrossRef] [PubMed]

129. Jaeggi, S.M.; Buschkuehl, M.; Jonides, J.; Shah, P. Short- and long-term benefits of cognitive training. Proc. Natl. Acad. Sci. USA 2011, 108, 10081-10086. [CrossRef] [PubMed]

130. Morrison, A.B.; Chein, J.M. Does working memory training work? The promise and challenges of enhancing cognition by training working memory. Psychon. Bull. Rev. 2011, 18, 46-60. [CrossRef] [PubMed]

131. Oyarzún, D.I.; Aliaga, S.I.; de la Cieciwa, P.A.; López, G.B. Mother-child interaction and child behavior in preschool children with a history of iron-deficiency anemia in infancy. Arch. Latinoam. Nutr. 1993, 43, 191-198.

132. Brown, L.J.; Pollitt, E. Malnutrition, Poverty and Intellectual Development. Sci. Am. 1996, 274, 38-43. [CrossRef] [PubMed]

133. Levitsky, D.A.; Strupp, B.J. Malnutrition and the Brain: Changing Concepts, Changing Concerns. J. Nutr. 1995, 125, 2212S-2220S. [CrossRef]

134. Corapci, F.; Radan, A.E.; Lozoff, B. Iron Deficiency in Infancy and Mother-Child Interaction at 5 Years. J. Dev. Behav. Pediatrics 2006, 27, 371-378. [CrossRef]

135. Armony-Sivan, R.; Kaplan-Estrin, M.; Jacobson, S.W.; Lozoff, B. Iron-Deficiency Anemia in Infancy and Mother-Infant Interaction During Feeding. J. Dev. Behav. Pediatrics 2010, 31, 326-332. [CrossRef] [PubMed]

136. East, P.; Lozoff, B.; Blanco, E.; Delker, E.; Delva, J.; Encina, P.; Gahagan, S. Infant Iron Deficiency, Child Affect, and Maternal Unresponsiveness: Testing the Long-Term Effects of Functional Isolation. Dev. Psychol. 2017, 53, 2233-2244. [CrossRef]

137. Lozoff, B.; Smith, J.B.; Clark, K.M.; Perales, C.; Rivera, F.; Castillo, M. Home Intervention Improves Cognitive and Social-Emotional Scores in Iron-Deficient Anemic Infants. Pediatrics 2010, 126, e884-e894. [CrossRef] [PubMed]

138. Alloway, T.P. What do we know about the long-term cognitive effects of iron-deficiency anemia in infancy? Dev. Med. Child Neurol. 2013, 55, 401-402. [CrossRef] [PubMed] 
139. Gao, S.; Jin, Y.; Unverzagt, F.W.; Ma, F.; Hall, K.S.; Murrell, J.R.; Cheng, Y.; Shen, J.; Ying, B.; Ji, R.; et al. Trace Element Levels and Cognitive Function in Rural Elderly Chinese. J. Gerontol. Ser. 2008, 63, 635-641. [CrossRef] [PubMed]

140. Milward, E.A.; Bruce, D.G.; Knuiman, M.W.; Divitini, M.L.; Cole, M.; Inderjeeth, C.A.; Clarnette, R.M.; Maier, G.; Jablensky, A.; Olynyk, J.K. A Cross-Sectional Community Study of Serum Iron Measures and Cognitive Status in Older Adults. J. Alzheimer's Dis. 2010, 20, 617-623. [CrossRef] [PubMed]

141. Schiepers, O.J.; van Boxtel, M.P.; de Groot, R.H.; Jolles, J.; de Kort, W.L.; Swinkels, D.W.; Kok, F.J.; Verhoef, P.; Durga, J. Serum Iron Parameters, HFE C282Y Genotype, and Cognitive Performance in Older Adults: Results from the FACIT Study. J. Gerontol. Ser. 2010, 65, 1312-1321. [CrossRef]

142. Lam, P.; Kritz-Silverstein, D.; Barrett-Connor, E.; Milne, D.; Nielsen, F.; Gamst, A.; Morton, D.; Wingard, D. Plasma trace elements and cognitive function in older men and women: The Rancho Bernardo study. J. Nutr. Health Aging 2008, 12, 22-27. [CrossRef]

143. Umur, E.E.; Oktenli, C.; Celik, S.; Tangi, F.; Sayan, O.; Sanisoglu, Y.S.; Ipcioglu, O.; Terekeci, H.M.; Top, C.; Nalbant, S.; et al. Increased iron and oxidative stress are separately related to cognitive decline in elderly. Geriatr. Gerontol. Int. 2011, 11, 504-509. [CrossRef]

144. Andreeva, V.A.; Galan, P.; Arnaud, J.; Julia, C.; Hercberg, S.; Kesse-Guyot, E. Midlife Iron Status Is Inversely Associated with Subsequent Cognitive Performance, Particularly in Perimenopausal Women. J. Nutr. 2013, 143, 1974-1981. [CrossRef]

145. McCarthy, R.C.; Kosman, D.J. Glial Cell Ceruloplasmin and Hepcidin Differentially Regulate Iron Efflux from Brain Microvascular Endothelial Cells. PLoS ONE 2014, 9, e89003. [CrossRef]

146. Kumar, N. Neuroimaging in Superficial Siderosis: An In-Depth Look. Am. J. Neuroradiol. 2010, 31, 5-14. [CrossRef]

147. Van Es, A.; van der Grond, J.; de Craen, A.; Admiraal-Behloul, F.; Blauw, G.J.; van Buchem, M.A. Caudate nucleus hypointensity in the elderly is associated with markers of neurodegeneration on MRI. Neurobiol. Aging 2008, 29, 1839-1846. [CrossRef] [PubMed]

148. Sullivan, E.V.; Adalsteinsson, E.; Rohlfing, T.; Pfefferbaum, A. Relevance of Iron Deposition in Deep Gray Matter Brain Structures to Cognitive and Motor Performance in Healthy Elderly Men and Women: Exploratory Findings. Brain Imaging Behav. 2009, 3, 167-175. [CrossRef] [PubMed]

149. Penke, L.; Hernandéz, M.C.; Maniega, S.; Gow, A.J.; Murray, C.; Starr, J.M.; Bastin, M.E.; Deary, I.J.; Wardlaw, J.M. Brain iron deposits are associated with general cognitive ability and cognitive aging. Neurobiol. Aging 2012, 33, 510-517. [CrossRef] [PubMed]

150. Rodrigue, K.M.; Daugherty, A.M.; Haacke, M.E.; Raz, N. The Role of Hippocampal Iron Concentration and Hippocampal Volume in Age-Related Differences in Memory. Cereb. Cortex. 2013, 23, 1533-1541. [CrossRef] [PubMed]

151. Daugherty, A.M.; Haacke, M.E.; Raz, N. Striatal Iron Content Predicts Its Shrinkage and Changes in Verbal Working Memory after Two Years in Healthy Adults. J. Neurosci. 2015, 35, 6731-6743. [CrossRef] [PubMed]

152. Del Hernández, M.C.; Ritchie, S.; Glatz, A.; Allerhand, M.; Maniega, S.; Gow, A.J.; Royle, N.A.; Bastin, M.E.; Starr, J.M.; Deary, I.J.; et al. Brain iron deposits and lifespan cognitive ability. Age 2015, 37, 100. [CrossRef] [PubMed]

153. Hernández, V.M.; Allerhand, M.; Glatz, A.; Clayson, L.; Maniega, M.S.; Gow, A.; Royle, N.; Bastin, M.; Starr, J.; Deary, I.; et al. Do white matter hyperintensities mediate the association between brain iron deposition and cognitive abilities in older people? Eur. J. Neurol. 2016, 23, 1202-1209. [CrossRef]

154. Scarpellini, F.; Sia, M.; Scarpellini, L. Psychological Stress and Lipoperoxidation in Miscarriage. Ann. N. Y. Acad. Sci. 1994, 709, 210-213. [CrossRef]

155. Miyashita, T.; Yamaguchi, T.; Motoyama, K.; Unno, K.; Nakano, Y.; Shimoi, K. Social stress increases biopyrrins, oxidative metabolites of bilirubin, in mouse urine. Biochem. Biophys. Res. Commun. 2006, 349, 775-780. [CrossRef]

156. Wang, L.; Wang, W.; Zhao, M.; Ma, L.; Li, M. Psychological stress induces dysregulation of iron metabolism in rat brain. Neuroscience 2008, 155, 24-30. [CrossRef]

157. Yu, S.; Feng, Y.; Shen, Z.; Li, M. Diet supplementation with iron augments brain oxidative stress status in a rat model of psychological stress. Nutrition 2011, 27, 1048-1052. [CrossRef] [PubMed] 
158. Fleming, D.J.; Tucker, K.L.; Jacques, P.F.; Dallal, G.E.; Wilson, P.W.; Wood, R.J. Dietary factors associated with the risk of high iron stores in the elderly Framingham Heart Study cohort. Am. J. Clin. Nutr. 2002, 76, 1375-1384. [CrossRef] [PubMed]

159. Milman, N.; Byg, K.; Ovesen, L.; Kirchhoff, M.; Jürgensen, K. Iron status in Danish men 1984-94: A cohort comparison of changes in iron stores and the prevalence of iron deficiency and iron overload. Eur. J. Haematol. 2002, 68, 332-340. [CrossRef] [PubMed]

160. Starcke, K.; Brand, M. Decision making under stress: A selective review. Neurosci. Biobehav. Rev. 2012, 36, 1228-1248. [CrossRef] [PubMed]

161. Ferreira, A.; Teixeira, A. Intra- and extra-organisational foundations of innovation process-The information and communication technology sector under the crisis in Portugal. Int. J. Innov. Manag. 2016, 20, 1650056. [CrossRef]

162. Ferreira, A. Reconnecting Nature and Culture: A Model of Social Decision-making in Innovation. Int. J. Interdiscip. Organ. Study 2014, 8, 13-18. [CrossRef]

163. Ferreira, A. Reasoning on Emotions: Drawing an Integrative Approach. In Complexity Sciences: Theoretical and Empirical Approaches to Social Action; Cambridge Scholars Publishing: Newcastle upon Tyne, UK, 2018; pp. $125-139$.

164. Steptoe, A.; Hamer, M.; Chida, Y. The effects of acute psychological stress on circulating inflammatory factors in humans: A review and meta-analysis. Brain Behav. Immun. 2007, 21, 901-912. [CrossRef]

165. Weik, U.; Herforth, A.; Kolb-Bachofen, V.; Deinzer, R. Acute Stress Induces Proinflammatory Signaling at Chronic Inflammation Sites. Psychosom. Med. 2008, 70, 906-912. [CrossRef]

166. Morey, J.N.; Boggero, I.A.; Scott, A.B.; Segerstrom, S.C. Current directions in stress and human immune function. Curr. Opin. Psychol. 2015, 5, 13-17. [CrossRef]

167. Slavich, G.M.; Way, B.M.; Eisenberger, N.I.; Taylor, S.E. Neural sensitivity to social rejection is associated with inflammatory responses to social stress. Proc. Natl. Acad. Sci. USA 2010, 107, 14817-14822. [CrossRef]

168. Yu, R. Stress potentiates decision biases: A stress induced deliberation-to-intuition (SIDI) model. Neurobiol. Stress 2016, 3, 83-95. [CrossRef] [PubMed]

169. Felger, J.C.; Treadway, M.T. Inflammation Effects on Motivation and Motor Activity: Role of Dopamine. Neuropsychopharmacol 2016, 42, 216-241. [CrossRef] [PubMed]

170. Slavich, G.M.; Irwin, M.R. From stress to inflammation and major depressive disorder: A social signal transduction theory of depression. Psychol. Bull. 2014, 140, 774. [CrossRef] [PubMed]

171. Starcke, K.; Brand, M. Effects of Stress on Decisions Under Uncertainty: A Meta-Analysis. Psychol. Bull. 2016, 142, 909-933. [CrossRef] [PubMed]

172. González-Morales, G.M.; Neves, P. When stressors make you work: Mechanisms linking challenge stressors to performance. Work Stress 2015, 29, 213-229. [CrossRef]

173. Beery, A.K.; Kaufer, D. Stress, social behavior, and resilience: Insights from rodents. Neurobiol. Stress 2015, 1, 116-127. [CrossRef] [PubMed]

174. Sapolsky, R.M. The Influence of Social Hierarchy on Primate Health. Science 2005, 308, 648-652. [CrossRef]

175. American Psychology Association. APA Dictionary of Psychology: Chronic Stress. Available online: https://dictionary.apa.org/chronic-stress (accessed on 30 July 2019).

176. Ford, M.T.; Cerasoli, C.P.; Higgins, J.A.; Decesare, A.L. Relationships between psychological, physical, and behavioural health and work performance: A review and meta-analysis. Work Stress 2011, 25, 185-204. [CrossRef]

177. Porcelli, A.J.; Delgado, M.R. Stress and decision making: Effects on valuation, learning, and risk-taking. Curr. Opin. Behav. Sci. 2017, 14, 33-39. [CrossRef]

178. McEwen, B.S.; Magarinos, A. Stress and hippocampal plasticity: Implications for the pathophysiology of affective disorders. Hum. Psychopharmacol. Clin. Exp. 2001, 16, S7-S19. [CrossRef]

179. Pesarico Extracortical Regions. Front. Cell Neurosci. 2019, 13, 197. [CrossRef]

180. Drevets, W.C.; Price, J.L.; Furey, M.L. Brain structural and functional abnormalities in mood disorders: Implications for neurocircuitry models of depression. Brain Struct. Funct. 2008, 213, 93-118. [CrossRef] [PubMed]

181. Felt, B.T.; Peirano, P.; Algarín, C.; Chamorro, R.; Sir, T.; Kaciroti, N.; Lozoff, B. Long-term neuroendocrine effects of iron-deficiency anemia in infancy. Pediatr. Res. 2012, 71, 707. [CrossRef] [PubMed] 
182. Saad, M.; Morais, S.L.; Saad, S. Reduced Cortisol Secretion in Patients with Iron Deficiency. Ann. Nutr. Metab. 1991, 35, 111-115. [CrossRef] [PubMed]

183. Kalhan, S.C.; Ghosh, A. Dietary Iron, Circadian Clock, and Hepatic Gluconeogenesis. Diabetes 2015, 64, 1091-1093. [CrossRef]

184. Debono, M.; Ghobadi, C.; Rostami-Hodjegan, A.; Huatan, H.; Campbell, M.J.; Newell-Price, J.; Darzy, K.; Merke, D.P.; Arlt, W.; Ross, R.J. Modified-release hydrocortisone to provide circadian cortisol profiles. J. Clin. Endocrinol. Metabolism 2009, 94, 1548-1554. [CrossRef]

185. Ridefelt, P.; Larsson, A.; Rehman, J.; Axelsson, J. Influences of sleep and the circadian rhythm on iron-status indices. Clin. Biochem. 2010, 43, 1323-1328. [CrossRef]

186. Reinke, H.; Asher, G. Crosstalk between metabolism and circadian clocks. Nat. Rev. Mol. Cell Biol. 2019, 20, 1. [CrossRef]

187. American Psychiatric Association. APA Diagnostic and Statistical Manual of Mental Disorders; DSM Library, American Psychiatric Association: Philadelphia, PA, USA, 2013. [CrossRef]

188. Beck, A.T.; Brown, G.; Steer, R.A.; Eidelson, J.I.; Riskind, J.H. Differentiating anxiety and depression: A test of the cognitive content-specificity hypothesis. J. Abnorm. Psychol. 1987, 96, 179. [CrossRef]

189. Twenge, J.M. The age of anxiety? The birth cohort change in anxiety and neuroticism, 1952-1993. J. Personal. Soc. Psychol. 2000, 79, 1007. [CrossRef]

190. Lozoff, B.; Jimenez, E.; Hagen, J.; Mollen, E.; Wolf, A.W. Poorer Behavioral and Developmental Outcome More Than 10 Years After Treatment for Iron Deficiency in Infancy. Pediatrics 2000, 105, e51. [CrossRef] [PubMed]

191. Shelton, R.; Brown, L. Mechanisms of action in the treatment of anxiety. J. Clin. Psychiatry 2001, 62, 10-15. [PubMed]

192. Eizadi-Mood, N.; Ahmadi, R.; Babazadeh, S.; Yaraghi, A.; Sadeghi, M.; Peymani, P.; Sabzghabaee, A.M. Anemia, depression, and suicidal attempts in women: Is there a relationship? J. Res. Pharm. Pract. 2018, 7, 136-140. [CrossRef] [PubMed]

193. Hidese, S.; Saito, K.; Asano, S.; Kunugi, H. Association between iron-deficiency anemia and depression: A web-based Japanese investigation. Psychiatry Clin. Neurosci. 2018, 72, 513-521. [CrossRef] [PubMed]

194. Dryman, T.M.; Heimberg, R.G. Emotion regulation in social anxiety and depression: A systematic review of expressive suppression and cognitive reappraisal. Clin. Psychol. Rev. 2018, 65, 17-42. [CrossRef]

195. Howren, B.M.; Lamkin, D.M.; Suls, J. Associations of Depression With C-Reactive Protein, IL-1, and IL-6\&colon; A Meta-Analysis. Psychosom. Med. 2009, 71, 171-186. [CrossRef] [PubMed]

196. Dowlati, Y.; Herrmann, N.; Swardfager, W.; Liu, H.; Sham, L.; Reim, E.K.; Lanctôt, K.L. A Meta-Analysis of Cytokines in Major Depression. Biol. Psychiatry 2010, 67, 446-457. [CrossRef]

197. Martins, A.C.; Almeida, J.I.; Lima, I.S.; Kapitão, A.S.; Gozzelino, R. Iron Metabolism and the Inflammatory Response. IUBMB Life 2017, 69, 442-450. [CrossRef]

198. Mehrpouya, S.; Nahavandi, A.; Khojasteh, F.; Soleimani, M.; Ahmadi, M.; Barati, M. Iron administration prevents BDNF decrease and depressive-like behavior following chronic stress. Brain Res. 2015, 1596, 79-87. [CrossRef]

199. Mizuno, Y.; Ozeki, M.; Iwata, H.; Takeuchi, T.; Ishihara, R.; Hashimoto, N.; Kobayashi, H.; Iwai, K.; Ogasawara, S.; Ukai, K.; et al. A case of clinically and neuropathologically atypical corticobasal degeneration with widespread iron deposition. Acta Neuropathol. 2002, 103, 288-294. [CrossRef]

200. Farajdokht, F.; Soleimani, M.; Mehrpouya, S.; Barati, M.; Nahavandi, A. The role of hepcidin in chronic mild stress-induced depression. Neurosci. Lett. 2015, 588, 120-124. [CrossRef] [PubMed]

201. Hughes, M.M.; Connor, T.J.; Harkin, A. Stress-Related Immune Markers in Depression: Implications for Treatment. Int. J. Neuropsychoph. 2016, 19, pyw001. [CrossRef] [PubMed] 


\title{
Review \\ Potential Treatment of Retinal Diseases with Iron Chelators
}

\author{
Wanting Shu ${ }^{1,2}$ and Joshua L. Dunaief ${ }^{1, *}$ \\ 1 F.M. Kirby Center for Molecular Ophthalmology, Scheie Eye Institute, Perelman School of Medicine at the \\ University of Pennsylvania, 305 Stellar-Chance Laboratory, Philadelphia, PA 19104, USA; \\ shuwanting@sjtu.edu.cn \\ 2 Department of Ophthalmology, Shanghai General Hospital, Shanghai Jiao Tong University School of \\ Medicine, Shanghai Key Laboratory of Ocular Fundus Diseases, Shanghai Engineering Center for Visual \\ Science and Photomedicine, Shanghai 200080, China \\ * Correspondence: jdunaief@pennmedicine.upenn.edu; Tel.: +1-215-898-5235
}

Received: 1 September 2018; Accepted: 10 October 2018; Published: 22 October 2018

\begin{abstract}
Iron is essential for life, while excess iron can be toxic. Iron generates hydroxyl radical, which is the most reactive free radical, causing oxidative stress. Since iron is absorbed through the diet but not excreted from the body, it accumulates with age in tissues, including the retina, consequently leading to age-related toxicity. This accumulation is further promoted by inflammation. Hereditary diseases such as aceruloplasminemia, Friedreich's ataxia, pantothenate kinase-associated neurodegeneration, and posterior column ataxia with retinitis pigmentosa involve retinal degeneration associated with iron dysregulation. In addition to hereditary causes, dietary or parenteral iron supplementation has been recently reported to elevate iron levels in the retinal pigment epithelium (RPE) and promote retinal degeneration. Ocular siderosis from intraocular foreign bodies or subretinal hemorrhage can also lead to retinopathy. Evidence from mice and humans suggests that iron toxicity may contribute to age-related macular degeneration pathogenesis. Iron chelators can protect photoreceptors and RPE in various mouse models. The therapeutic potential for iron chelators is under investigation.
\end{abstract}

Keywords: chelation; iron; retina; age-related macular degeneration (AMD)

\section{Introduction}

Iron is essential for life. In the retina, iron is particularly significant for phototransduction. Each day, photoreceptors shed and regenerate disc membranes, using the iron-containing enzyme fatty acid desaturase to synthesize lipids used in disc membrane generation [1]. RPE65 is an iron-dependent enzyme used by the retinal pigment epithelium (RPE) to catalyze the conversion of all-trans-retinyl ester to 11-cis-retinol, a critical step in the visual cycle [2,3].

While iron is essential for retinal metabolism and the visual cycle, excess iron can be toxic. Ferrous iron can catalyze the conversion of hydrogen peroxide to the highly reactive oxygen species (ROS), hydroxyl radical. Hydroxyl radicals cause oxidative damage to proteins, DNA, and lipids [4]. Hydroxyl radicals have also been implicated in the pathogenesis of the neurodegenerative diseases Alzheimer's [5] and Parkinson's [6], and iron chelation is currently in clinical trials for these diseases [7-9]. The retina is prone to oxidative stress due to the combination of photo-oxidation and high oxygen tension due to high perfusion. Photoreceptor outer segments, which are phagocytosed by RPE cells daily, are rich in easily oxidized lipids. Hence, iron must be tightly regulated to provide needed iron while shielding retinal cells from iron-induced oxidative damage.

This regulation is provided in the retina by a series of iron handling proteins. The transferrin receptor (TfR) takes transferrin bound iron into retinal cells. Iron can then be transported to 
mitochondria to initiate its incorporation into numerous metabolic proteins, or can be stored safely within cytosolic ferritin. The iron can be exported from cells by the iron exporter ferroportin (Fpn), working in conjunction with the ferroxidases ceruloplasmin $(\mathrm{Cp})$ or hephaestin $(\mathrm{Hp})$. The localization of Fpn on the abluminal surface of the vascular endothelial cells and basolateral surface of the RPE suggests that iron is trafficked from the retinal vasculature, through the neural retina, and eventually out of the RPE into the choriocapillaris (Figure 1).
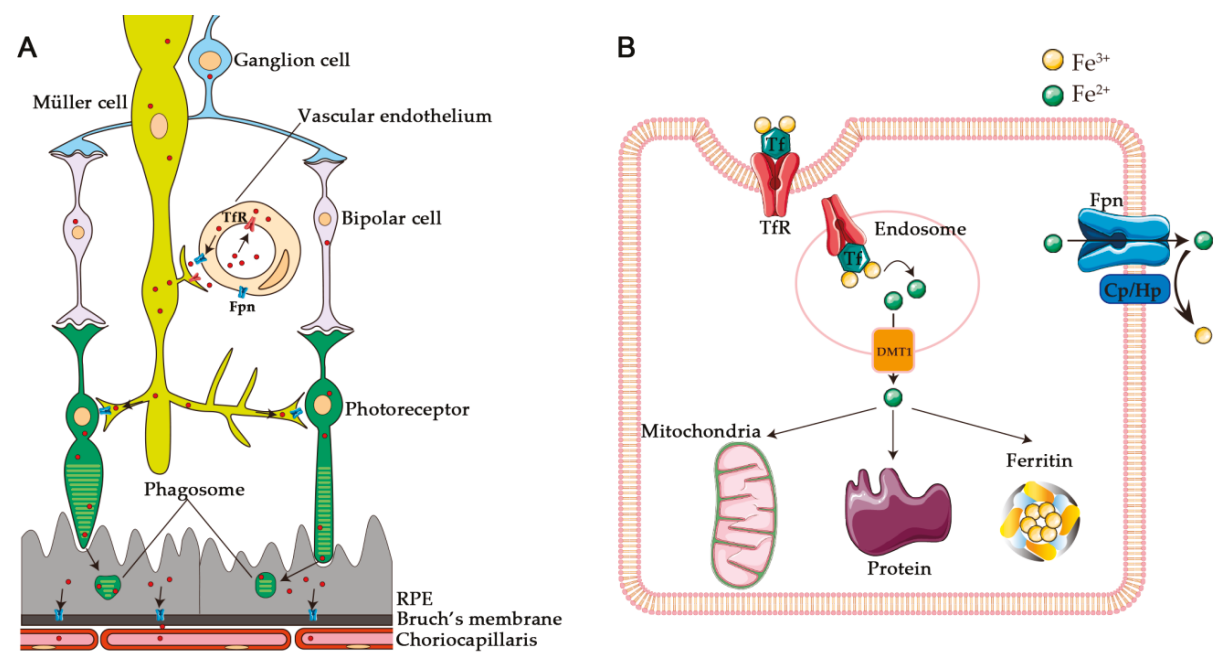

Figure 1. Schematic illustration of retinal iron transport. (A) Iron (red dots) moves through the retina as shown by arrows. Based on immunolocalization of TfR and Fpn, iron can enter retinal vascular endothelial cells by TfR-mediated endocytosis. It exits the vascular endothelial cells through Fpn (transmembrane protein indicated in blue). It is distributed through the neural retina by Müller glial cells. Iron is transferred from photoreceptors to the RPE through daily phagocytosis of the photoreceptor outer segments by the RPE. It is then exported by Fpn on the basolateral RPE into the choriocapillaris. (B) Iron transport at the cellular level. Iron can be taken into the cell by TfR, exported from the endosome by Dmt1, imported into mitochondria, stored in ferritin, or exported from the cell by Fpn in cooperation with ferroxidases Cp or Hp. Cp, ceruloplasmin; Dmt1, divalent metal transporter-1; Fpn, ferroportin; Hp, hephaestin; Tf, transferrin; TfR, transferrin receptor. "Channels", "Mitochondria" and "Protein" by Servier Medical Art by Servier are licensed under CC BY 3.0.

\section{Retinal Degeneration Resulting from Iron Dysregulation}

Abnormal iron homeostasis in hereditary diseases can lead to retinal iron overload and degeneration. In addition to hereditary iron overload, ocular siderosis from an iron-containing intraocular foreign body or from iron released from red blood cells after intraocular hemorrhage can promote retinopathy. Recent evidence suggests that iron toxicity can contribute to the pathogenesis of age-related macular degeneration. Dietary or injected iron contributes to systemic iron overload and may promote retinal degeneration. Antioxidants and iron chelators could be beneficial in the prevention or treatment of these retinal disorders.

\subsection{Hereditary Iron Overload}

Several forms of hereditary iron overload have been associated with retinal disorders: aceruloplasminemia, hereditary hemochromatosis, pantothenate kinase-associated neurodegeneration, and Friedreich's ataxia. 


\subsubsection{Aceruloplasminemia}

Aceruloplasminemia is a rare autosomal recessive disease resulting from mutations in the gene encoding ceruloplasmin [10]. Ceruloplasmin promotes iron export by converting ferrous to ferric iron, the only form of iron that can bind to transferrin. There is iron export impairment-induced iron overload in the brain, retinas, and pancreas of patients with aceruloplasminemia. Clinical manifestations of aceruloplasminemia include retinal degeneration, diabetes mellitus, dementia, and cerebellar ataxia [11]. Cases of aceruloplasminemia-related retinopathy have been reported. In the case of a 56-year-old Japanese woman, fundus photography showed generalized yellow discoloration of the retinas in both eyes [12]. Fluorescein angiography (FA) revealed RPE atrophy, visible as window defects in the maculae and mid-periphery. In comparison, in the case of a 47-year-old Caucasian patient, subretinal lesions were found in the macula, similar to drusen in AMD patients [13]. The drusen, as well as RPE iron accumulation, hypertrophy, and RPE cells with increased or decreased melanin were all revealed through the histopathology of this case [14].

Mice that model human aceruloplasminemia through knockout of ceruloplasmin $(C p)$ and hephaestin $(H p)$, its homolog, have been studied, showing progressive retinal degeneration [15]. In the $\mathrm{Cp} / \mathrm{Hp}$ double-knockout mice aged six to nine months, as in the aceruloplasminemia case, RPE cells were iron overloaded, and hypertrophic. Electron microscopy showed increased numbers of lipofuscin-containing vesicles in the RPE, and wide-spaced collagen in sub-RPE deposits. Focal areas of RPE hyperplasia, photoreceptor degeneration, and subretinal neovascularization were also observed.

\subsubsection{Hereditary Hemochromatosis}

Hereditary hemochromatosis is a common condition caused by enhanced absorption of dietary iron. This disease can be caused by the mutation of any of several genes. Most commonly, it is caused by the mutation of the histocompatibility leukocyte antigen class I-like protein involved in iron homeostasis (HFE) gene [16]. Normally, HFE regulates iron uptake into the cell through transferrin receptor, and also regulates levels of the iron regulatory hormone hepcidin [17]. Patients with the HFE gene mutation form fewer transferrin receptor complexes, leaving more transferrin receptor available to bind transferrin, resulting in more iron intake into the tissues. Mutations in the genes transferrin receptor 2 (TfR2), ferroportin, and hemojuvelin $(H J V)$ can also cause hemochromatosis [18]. In most forms of hemochromatosis, deficiency of the iron regulatory hormone hepcidin appears to be the ultimate cause of excess iron [19]. Hepcidin deficiency leads to iron overload because hepcidin normally triggers degradation of ferroportin on the membranes of gut enterocytes, preventing iron export from the enterocytes into the bloodstream. High serum iron levels lead to iron accumulation in heart, liver and pancreas [20]. The reported ocular studies on patients with hereditary hemochromatosis show peri-papillary RPE pigment changes, with mild iron accumulation in this region [21]. These minimal findings in patients with presumed HFE point mutations (by far the most common cause of hereditary hemochromatosis) suggest that the degree of blood iron elevation in these patients may not lead to retinal degeneration. The genetic penetrance of hemochromatosis in patients with HFE mutations is highly variable, so it would be worthwhile to screen for retinal abnormalities in those with the highest blood ferritin and iron levels. In animal studies, HFE and HJV were found to be expressed in mouse retina and RPE cells, suggesting that they can play roles in retinal iron homeostasis [22,23]. Complete knockout of each gene led to retinal iron accumulation as well as degeneration [24,25]. Knockout of hepcidin also causes severe retinal iron overload and degeneration [26].

\subsubsection{Friedreich's Ataxia (FRDA)}

Friedreich's ataxia (FRDA) is an autosomal recessive hereditary disease involving progressive neurodegeneration. The FXN gene encodes the iron-binding mitochondrial protein frataxin. FXN trinucleotide repeat expansion causes reduction of frataxin messenger RNA and protein levels in diverse tissues. A result of frataxin deficiency is mitochondrial iron overload, which is 
potentially damaging. Symptoms of Friedreich's ataxia include progressive ataxia, dysarthria, and cardiomyopathy [27]. Ocular manifestations include a progressive optic neuropathy, which can result in severe vision loss. A case reported by Porter showed a 59-year-old woman who had optic neuropathy with rapid-onset severe vision loss [28]. She was a compound heterozygote for the GAA expansion and a Cly130Val missense mutation. Color fundus photos revealed a pale optic nerve and multiple yellowish flecks in both maculas and nasal to the optic discs on her first visit. These deposits were auto-fluorescent, suggesting RPE lipofuscin accumulation. In 12 months, her visual acuities dropped from 6/6 OD and 6/24 OS to bilateral light perception only.

\subsubsection{Pantothenate Kinase Associated Neurodegeneration (PKAN)}

Pantothenate kinase-associated neurodegeneration (PKAN) is an autosomal recessive neurodegenerative disease with iron accumulation [29]. Patients harbor mutations in the pantothenate kinase 2 gene (PANK2) [30]. Pantothenate kinases produce phosphopantothenate, which condenses with cysteine during coenzyme A synthesis. In patients with PKAN, PANK2 mutation causes reduced levels of phosphopantothenate and increased levels of cysteine, which can bind iron, potentially explaining the iron accumulation in the brain. The regions in the brain that have the most iron in normal subjects are those that are most affected by PKAN, including the medial globus pallidus and subtantia nigra pars reticulata. In the photoreceptors, where coenzyme A is in high demand for disc membrane regeneration, coenzyme A deficiency is likely. Since rod photoreceptor cells shed outer segment tips daily and generate membrane discs, this may contribute to the retinopathy resulting from PKAN. Patients with PKAN also have childhood-onset movement disorder and dementia [29]. Vision loss is associated with pigmentary retinopathy. A pair of dizygotic twins with PKAN showed retinopathy at the age of seven, including hyperpigmented foveas and depigmented posterior poles [31]. In a histopathological report, a 10-year-old girl had retinal abnormalities visible upon ophthalmoscopy, including retinal flecks, bone spicules, and bull's eye maculopathy [32]. The flecks and bull's eye corresponded histologically to macrophages containing melanolipofuscin and hypertrophic RPE cells containing melanolipofuscin aggregates. The photoreceptor inner and outer segments were absent through the retina. A mouse with PANK2 knockout also exhibited progressive photoreceptor degeneration, providing a PKAN retinopathy model [33]. Whether iron toxicity contributes to the retinopathy is a topic requiring further study.

\subsection{Age-Related Macular Degeneration (AMD)}

Age-related macular degeneration is a major cause of irreversible vision loss worldwide [34]. AMD is divided into several stages based on the histopathological features. Drusen, extracellular deposits that are rich in proteins and lipids sitting between RPE and Bruch's membrane, are features of early and intermediate AMD. Advanced AMD includes geographic atrophy (GA) and neovascular AMD [35]. Although the pathogenesis of AMD is still incompletely understood, oxidative stress and free radical damage most likely play a role [36]. The Age-Related Eye Disease Study (AREDS) reported in 2001 that antioxidant vitamins plus zinc were effective in reducing the risk of AMD progression [37]. During 10 years of follow-up, the protection against neovascular AMD persisted [38].

Iron is likely to be an important cause of oxidative stress in AMD. Compared to healthy age-matched controls, AMD-affected maculas have increased iron detected by enhanced Perls' Prussian blue stain, especially in the RPE and Bruch's membrane of early AMD, GA and neovascular AMD retinas [39]. The iron chelator deferoxamine was used to treat sections, showing that a portion of the iron in these tissue sections was chelatable. In another lab, sections from six post-mortem eyes of AMD donors and seven age-matched healthy donors were investigated using Analytical Electron Microscopy, showing that more iron accumulated in RPE melanosomes and within calcified Bruch's membrane of donors with AMD compared to age-matched controls [40]. Elevated iron levels have also been found in the photoreceptor layer of the post mortem macula of a patient with GA [41]. Perls' stain showed iron in the photoreceptors of this donor. In contrast, the stain was not sensitive enough to 
detect any signal in the photoreceptors of nine control elderly donors with normal retinas. The maculas from the GA patient also had higher levels of ferroportin and ferritin, proteins whose abundance is increased by iron, in the photoreceptors than the normal donor retinas. In addition, when iron levels in aqueous humor were measured in patients having cataract surgery, they were found to be increased by more than two-fold in patients with non-exudative AMD [42].

Though iron accumulation was discovered in AMD retinas, its role in the pathogenesis remains unproven, but several lines of evidence suggest a causal link. First, retinal iron levels increase with age [43]. Eyes from donors younger than 35 and older than 65 were dissected. Atomic absorption spectrophotometry (AAS) revealed significantly increased iron levels in the retinas of older versus younger eyes, and no increase detected in RPE/choroid. Since photoreceptors are the cell type containing the highest iron levels in the rat retina, and they are the most abundant retinal cell type, elevated photoreceptor iron levels most likely contributed to the increased AAS reading. [44]. Second, as mentioned above, a patient with RPE iron overload caused by aceruloplasminemia had drusen-like deposits in the retina at an uncharacteristically young age [13]. Third, $\mathrm{Cp} / \mathrm{Hp}$ double knockout mice with iron accumulation in the neural retina and RPE have retinal degeneration sharing features of AMD [15]. Among these features is sub-RPE wide-spaced collagen, which is associated with drusen in humans; RPE hypertrophy with lipofuscin-containing vesicles; and RPE death. In addition, they have focal photoreceptor degeneration and subretinal neovascularization. Fourth, iron is a potent catalyst of radicals and causes photoreceptor/RPE toxicity when it accumulates locally in conditions like ocular siderosis. Even though siderosis leads to pan-retinal photoreceptor degeneration, but not drusen, GA, or choroidal neovascularization, this difference in retinal manifestations could be explained by the different iron delivery route, as well as the spatial and temporal differences in iron accumulation. Last but not the least, the extracellular iron binding protein transferrin is upregulated in AMD retinas [45]. Transferrin mRNA levels are increased in both dry and wet AMD. Consistent with this, Western analysis revealed an increase in transferrin protein levels in AMD retinas compared to normal controls and immunohistochemistry showed increased transferrin labeling in AMD retinas, which were localized to drusen, photoreceptors, and Müller glia.

The mechanisms of iron accumulation in AMD retinas are an area of active investigation. Plausible pathways include oxidative stress, inflammation, and hypoxia, all of which are involved in AMD pathogenesis. Inflammation has been shown to induce cellular iron sequestration through IL-6-mediated upregulation of hepcidin [46]. Hypoxia leads to elevated iron uptake through HIF-mediated increases in DMT1 and TfR1, both of which are cellular iron importer genes [47]. Oxidative stress can also upregulate TfR1 [48]. Further, subretinal hemorrhage in a rabbit model led to iron accumulation in photoreceptors and RPE cells following its release from lysing red blood cells [49].

\subsection{Iron Overload from Supplementation}

In addition to an inherited abnormality in a specific iron metabolic protein or pathway, systemic or focal iron accumulation and the resulting toxicity can result from dietary or parenteral iron supplementation. It has been reported that anemia occurs in one-quarter of the world's population [50], primarily in preschool-aged children and women, making it a global public health problem [51]. Iron deficiency anemia (IDA) is the leading cause of anemia [52]. In developing countries, IDA typically results from inadequate dietary iron intake, blood loss due to intestinal worm infection, or both. In developed countries, low-iron diets (e.g., a vegetarian diet or no red meat intake), iron malabsorption, or chronic blood loss from menorrhagia or intestinal bleeding are the most common reasons. In addition to identification of the source of iron loss, dietary iron supplementation is a common treatment for IDA patients. Iron deficiency makes the body increase its ability to take up any available dietary iron, primarily by downregulating hepcidin production [53]. Standard therapy for IDA in adults is oral administration of a 300-mg tablet of ferrous sulfate three or four times daily, but excessive iron supplement could theoretically be harmful to the retina. Rats placed on a high iron diet had increased 
retinal iron levels, oxidative stress, and photoreceptor death [54]. Mice placed on a high iron diet for 10 months had RPE iron accumulation, but not enough to cause degeneration [55].

Heme iron is found at much higher levels in red meat than white meat. Heme, the iron-containing porphyrin pigment of meat, is not only a prooxidant in itself, but also responsible for the endogenous intestinal N-nitroso compounds in humans arising from red meat $[39,56]$. A cohort study of 6734 people aged 58-69 years was conducted in Australia to evaluate the association between red meat or chicken intake and AMD [57]. Higher red meat intake was associated with early AMD, with an odds ratio for red meat consumption more than 10 times per week versus fewer than five times per week of 1.47. In contrast, consumption of chicken more than 3.5 times per week versus fewer than 1.5 times per week was inversely associated with late AMD (Odds ratio: 0.43).

Parenteral iron therapy for iron deficiency increases hemoglobin levels more rapidly than oral iron because it circumvents the limitations of intestinal iron absorption $[58,59]$. The established indications for parenteral iron therapy include failure of oral iron to increase the hematocrit, oral iron intolerance, most often due to constipation, or the need for quick recovery. However, in intravenous iron-injected mice, serum iron levels increased and caused elevated iron levels in the RPE and neurosensory retina despite an intact blood-retinal barrier [60]. In a similar study, intravenous iron not only elevated mouse serum and RPE iron levels, but also led to AMD-like histological lesions, including Bruch's membrane thickening showing complement $\mathrm{C} 3$ deposition, as well as hypertrophy and vacuolization of the RPE [61]. A 43-year-old patient with IDA who received IV iron therapy developed numerous retinal drusen within 11 months of receiving the iron, suggesting that intravenous iron therapy may have caused retinal iron accumulation that promoted early AMD [61]. We are currently conducting clinical studies to determine whether intravenous iron can promote drusen formation in susceptible individuals.

Acquired hemochromatosis can also result from multiple blood transfusions, since red blood cells contain abundant iron. Patients with sickle cell anemia or thalassemia often receive numerous transfusions. These diseases have been associated with retinal abnormalities, including RPE atrophy and angioid streaks. Since these patients have iron overload, chelation therapy and intraocular hemorrhage, it is difficult to separate the effects of each of these on the retina. Nevertheless, several patients with thalassemia exhibited retinopathy in the absence of any iron chelation [62].

\subsection{Siderosis}

Ocular siderosis results from intraocular iron deposition following ocular penetration of a metallic foreign body. In this condition, ferrous iron generates radicals and causes oxidative stress. [63]. The clinical features include corneal iron deposition, iris heterochromia, pupillary mydriasis, accommodation failure, anterior subcapsular cataract, lens discoloration, retinal arteriolar narrowing, retinal detachment, retinal pigment epithelium clumping and RPE atrophy. Glaucoma may occur if the trabecular meshwork and Schlemm's canal are involved [63-65]. Electroretinography (ERG) results vary in different stages of the disease [66]. ERG a- and b-wave amplitudes may increase initially, and gradually decrease as the siderosis progresses and photoreceptors degenerate.

Animal models of the disease have illustrated the histopathologic and functional effects on the retina. Retinal changes in squirrel monkeys after they received intravitreous injection of iron-containing solutions were studied, finding geographic patches of retinal whitening and RPE disruption by ophthalmoscopy [67]. ERG changes occurred as soon as the first few hours, with reduced amplitudes or absent signals with higher doses. In another animal model, solid iron foreign bodies were placed into the rabbit vitreous, and degeneration of the outer nuclear layer and RPE was observed 10 days later [68]. ERG results were consistent with morphological changes, showing decreased a- and b- wave amplitudes under both scotopic and photopic conditions. 


\subsection{Subretinal Hemorrhage}

Subretinal hemorrhage, which may lead to vision loss, occurs in several conditions, most commonly associated with neovascular AMD, but also occurring in presumed ocular histoplasmosis, angioid streaks, myopic degeneration, and trauma. A clinical study on the patients with intra and subretinal hemorrhage in 1983 showed that the visual acuity loss significantly depended on hemorrhage size and the ability of the tissue to clear the blood [69]. Possible mechanisms of vision loss followed by subretinal hemorrhage include iron toxicity to the photoreceptors and RPE, mechanical damage, development of a fibrovascular membrane, or separation of photoreceptors from the RPE [69]. Fresh autologous blood injection into the rabbit subretinal space caused progressive photoreceptor degeneration with edematous change, as well as iron accumulation in the photoreceptor outer segments and RPE [70]. An iron chelator, deferoxamine, was shown to protect these rabbits as measured by ERG [71]. In a similar rabbit model, iron was detected by Perls' stain in photoreceptors and RPE, and triamcinolone acetonide intravitreal injection reduced apoptosis of photoreceptors [49]. In vitro, oxyhemoglobin causes lipid peroxidation in retinal tissue, and oxyhemoglobin in subretinal blood may similarly cause damage to the retina after it is released from red blood cells [72]. Hemopexin, the hemoglobin-binding protein, may protect retina from heme-mediated toxicity. In addition, RPE cells can bind and internalize the heme-hemopexin complex, facilitating clearance of heme from the retina [73].

\section{The Potential for Retinal Protection by Iron Chelators}

Since iron overload-induced oxidative damage may be involved in the pathogenesis of AMD and other retinal diseases, iron chelators may help reduce the occurrence and progression of AMD. Several reports suggested that iron chelators could be helpful in the treatment of neurological diseases, such as Alzheimer's, Parkinson's, Huntington's, and FRDA [74,75]. Iron chelators may also be beneficial in the treatment of retinal diseases associated with iron overload. Studies in mouse models support this assertion (see below). The iron chelators that have been approved by the U.S. Food and Drug Administration (FDA) approved for treatment of patients with systemic iron overload include deferoxamine, deferasirox, and deferiprone. Another iron chelator, salicylaldehyde isonicotinoyl hydrazine is effective in cell culture but has not yet been tested extensively in vivo. In this review, the chelators' potential protective role in the retina is discussed.

\subsection{Deferoxamine}

Deferoxamine (DFO) was the first iron chelator approved by the FDA, in 1968, for the treatment of acute iron intoxication and for chronic iron overload in patients with transfusion-dependent anemias. Synthesized by a bacterium to steal iron from the host, this hexadentate molecule binds iron in a 1:1 ratio. Despite the remarkable effect on reduction of serum ferritin level, DFO has many limitations. As a hydrophilic iron chelator, DFO must be administered as a slow subcutaneous infusion, intramuscularly or intravenously [76]. It has a short plasma half-life, so continuous injection is often required for patients with iron overload. For patients who need chronic treatment, DFO is costly and inefficient. The most common side effects of DFO are local skin reactions and infections. Visual neurotoxicity of DFO has been reported, including defects in the visual field, diminished visual acuity, color vision defects, and decreased ERG and electrooculogram responses [77-79], making DFO a poor candidate to treat AMD or other iron-related ocular diseases. The retinal toxicity of DFO may result from its high affinity for iron, causing retinal iron deficiency.

Modification of DFO, in a DFO-zinc complex, however, attenuates retinal degeneration in the rd10 mouse model of retinitis pigmentosa [80]. DFO-zinc delivery to rd10 mice resulted in protected ERG responses and more photoreceptor survival, with retinal ferritin and lipid peroxidation levels reduced. Intraperitoneal DFO also protects albino rats from light damage. In rats treated with DFO, 
there was partial preservation of photoreceptor nuclei and fewer subretinal macrophages than in the control rats [81].

\subsection{Deferasirox}

Deferasirox (DFX), a tridentate molecule, which binds iron in a 2:1 ratio, was approved by the FDA in 2005. DFX is administrated orally, and its long half-life allows for once-daily dosing [82]. Because of its relatively small molecular weight, DFX is better absorbed, showing over twofold increase in potency compared to DFO for iron mobilization from tissue [83]. DFX has a well-characterized safety profile that requires regular monitoring both adult and pediatric patients [84-86]. The most common side effects include abdominal pain, gastrointestinal upset, vomiting, and transient skin rashes [87]. Higher doses may cause hepatic, renal and ocular toxicities. Several cases of retinopathy or lens opacities have been reported among patients with thalassemia major treated with DFX $[88,89]$. The pathogenesis of the retinopathy and cataract development was unclear but age-related. Given that DFO, a structurally unrelated molecule, can also cause retinopathy, the most likely mechanism is RPE iron deficiency $[90,91]$.

\subsection{Deferiprone}

Deferiprone (DFP), a bidentate iron chelator that binds iron in a 3:1 ratio, was approved by the FDA in 2011. DFP has a shorter half-life than DFX, requiring a three-times-daily oral administration. Side effects can include increased liver enzymes, gastrointestinal disorders or arthralgia. The most serious adverse effects are agranulocytosis and neutropenia with an incidence of 0.2 and 2.8 per 100 patients over one year. These are reversible by discontinuing the medication [92]. Importantly, DFP, which has a lower affinity for iron than DFO or DFX, has not been reported to cause retinal toxicity in human patients or mice. In animal studies, our team reported that DFP could diminish retinal iron levels and oxidative stress, and thereby protecting $\mathrm{Cp} / \mathrm{Hp}$ double-knockout mice and hepcidin knockout mice against iron overload-induced retinal degeneration [93,94]. While it is difficult to measure mouse retinal iron levels directly, it was possible to show that DFP caused an increase in neural retina transferrin receptor mRNA levels, indicating that DFP diminished levels of potentially toxic labile (free) iron. It may have done this by removing iron from the retina, or by redistributing labile iron to proteins that can bind it tightly and safely, such as transferrin. DFP also protected mice against retinal degeneration initiated by rd6 mutation, sodium iodate $\left(\mathrm{NaIO}_{3}\right)$ treatment or light exposure, indicating that iron chelation can be retina-protective even when iron toxicity is not the primary cause $[95,96]$. Presumably, iron potentiates photoreceptor cell death even when iron overload isn't the initial insult. Therefore, retinal diseases in which iron levels are not elevated but free iron still potentiates oxidative stress might be protected by chelation of labile iron. It may do so by increasing oxidative stress or through a recently characterized form of iron-dependent cell death called ferroptosis [97].

\subsection{Salicylaldehyde Isonicotinoyl Hydrazine}

Salicylaldehyde isonicotinoyl hydrazine $(\mathrm{SIH})$ is a tridentate iron chelator that binds iron in a 2:1 ratio. Due to its lipophilicity, SIH can be administered orally, easily penetrating cell membranes and firmly chelating intracellular $\mathrm{Fe}^{3+}$ [98]. SIH showed cardioprotective potential in vivo [99,100]. It is also highly effective in the protection of cultured RPE cells against oxidative damage induced by diverse stimuli [101]. SIH provided better protection for ARPE-19 against $\mathrm{H}_{2} \mathrm{O}_{2}$-induced cell death than the antioxidant N-acetyl cysteine (NAC) and other iron chelators, including DFP and the extracellular iron chelator diethylenetriaminepentaacetic acid (DTPA). It is notable that SIH can also play a protective role by activating Nrf2 transcription factor, which regulates the expression of antioxidant genes [102]. Despite all the positive outcomes, multiple studies revealed a short biological half-life of SIH due to the rapid hydrolysis of its hydrazine bond in plasma [103]. Hopefully a stabilized, optimized form of $\mathrm{SIH}$ can become another potent agent for iron chelation therapy. 


\section{Future Directions}

The association of iron with several retinal diseases and the development of mouse models of iron-induced retinopathy have paved the way for studies on the therapeutic potential of retinal iron chelation. The oral iron chelator DFP reduces retinal iron levels and protects the retina against a broad range of insults in animal models, without causing retinal toxicity. The future testing of iron chelators for retinal disease will need to take into account the potential for systemic toxicities, including iron deficiency. Careful dosing of relatively lower affinity iron chelators, such as DFP, has the potential to chelate loosely-bound, toxic iron, while avoiding cellular or systemic iron deficiency. Taken together, new iron chelators in development provide promise for the treatment of retinal diseases.

Author Contributions: W.S. reviewed the literature and wrote the manuscript; J.L.D. edited the manuscript.

Funding: This research was supported by NIH EY015240, Research to Prevent Blindness, the China Scholarship Council (CSC, No. 201706230076), the Paul and Evanina Bell Mackall Foundation Trust, and the FM Kirby Foundation.

Conflicts of Interest: J.L.D. holds a patent on the use of SIH for prevention and treatment of AMD.

\section{References}

1. Shichi, H. Microsomal electron transfer system of bovine retinal pigment epithelium. Exp. Eye Res. 1969, 8, 60-68. [CrossRef]

2. Moiseyev, G.; Chen, Y.; Takahashi, Y.; Wu, B.X.; Ma, J.X. Rpe65 is the isomerohydrolase in the retinoid visual cycle. Proc. Natl. Acad. Sci. USA 2005, 102, 12413-12418. [CrossRef] [PubMed]

3. Moiseyev, G.; Takahashi, Y.; Chen, Y.; Gentleman, S.; Redmond, T.M.; Crouch, R.K.; Ma, J.X. Rpe65 is an iron(II)-dependent isomerohydrolase in the retinoid visual cycle. J. Biol. Chem. 2006, 281, 2835-2840. [CrossRef] [PubMed]

4. Halliwell, B.; Gutteridge, J.M. Oxygen toxicity, oxygen radicals, transition metals and disease. Biochem. J. 1984, 219, 1-14. [CrossRef] [PubMed]

5. Smith, M.A.; Harris, P.L.; Sayre, L.M.; Perry, G. Iron accumulation in alzheimer disease is a source of redox-generated free radicals. Proc. Natl. Acad. Sci. USA 1997, 94, 9866-9868. [CrossRef] [PubMed]

6. Ben-Shachar, D.; Riederer, P.; Youdim, M.B. Iron-melanin interaction and lipid peroxidation: Implications for parkinson's disease. J. Neurochem. 1991, 57, 1609-1614. [CrossRef] [PubMed]

7. Grolez, G.; Moreau, C.; Sablonniere, B.; Garcon, G.; Devedjian, J.C.; Meguig, S.; Gele, P.; Delmaire, C.; Bordet, R.; Defebvre, L.; et al. Ceruloplasmin activity and iron chelation treatment of patients with parkinson's disease. BMC Neurol. 2015, 15, 74. [CrossRef] [PubMed]

8. Lannfelt, L.; Blennow, K.; Zetterberg, H.; Batsman, S.; Ames, D.; Harrison, J.; Masters, C.L.; Targum, S.; Bush, A.I.; Murdoch, R.; et al. Safety, efficacy, and biomarker findings of pbt2 in targeting abeta as a modifying therapy for alzheimer's disease: A phase iia, double-blind, randomised, placebo-controlled trial. Lancet Neurol. 2008, 7, 779-786. [CrossRef]

9. Velasco-Sanchez, D.; Aracil, A.; Montero, R.; Mas, A.; Jimenez, L.; O'Callaghan, M.; Tondo, M.; Capdevila, A.; Blanch, J.; Artuch, R.; et al. Combined therapy with idebenone and deferiprone in patients with friedreich's ataxia. Cerebellum 2011, 10, 1-8. [CrossRef] [PubMed]

10. Harris, Z.L.; Takahashi, Y.; Miyajima, H.; Serizawa, M.; MacGillivray, R.T.; Gitlin, J.D. Aceruloplasminemia: Molecular characterization of this disorder of iron metabolism. Proc. Natl. Acad. Sci. USA 1995, 92, 2539-2543. [CrossRef] [PubMed]

11. Xu, X.; Pin, S.; Gathinji, M.; Fuchs, R.; Harris, Z.L. Aceruloplasminemia: An inherited neurodegenerative disease with impairment of iron homeostasis. Ann. N. Y. Acad. Sci. 2004, 1012, 299-305. [CrossRef] [PubMed]

12. Yamaguchi, K.; Takahashi, S.; Kawanami, T.; Kato, T.; Sasaki, H. Retinal degeneration in hereditary ceruloplasmin deficiency. Ophthalmologica 1998, 212, 11-14. [CrossRef] [PubMed]

13. Dunaief, J.L.; Richa, C.; Franks, E.P.; Schultze, R.L.; Aleman, T.S.; Schenck, J.F.; Zimmerman, E.A.; Brooks, D.G. Macular degeneration in a patient with aceruloplasminemia, a disease associated with retinal iron overload. Ophthalmology 2005, 112, 1062-1065. [CrossRef] [PubMed] 
14. Wolkow, N.; Song, Y.; Wu, T.D.; Qian, J.; Guerquin-Kern, J.L.; Dunaief, J.L. Aceruloplasminemia: Retinal histopathologic manifestations and iron-mediated melanosome degradation. Arch. Ophthalmol. 2011, 129, 1466-1474. [CrossRef] [PubMed]

15. Hahn, P.; Qian, Y.; Dentchev, T.; Chen, L.; Beard, J.; Harris, Z.L.; Dunaief, J.L. Disruption of ceruloplasmin and hephaestin in mice causes retinal iron overload and retinal degeneration with features of age-related macular degeneration. Proc. Natl. Acad. Sci. USA 2004, 101, 13850-13855. [CrossRef] [PubMed]

16. Feder, J.N.; Gnirke, A.; Thomas, W.; Tsuchihashi, Z.; Ruddy, D.A.; Basava, A.; Dormishian, F.; Domingo, R., Jr.; Ellis, M.C.; Fullan, A.; et al. A novel mhc class I-like gene is mutated in patients with hereditary haemochromatosis. Nat. Genet. 1996, 13, 399-408. [CrossRef] [PubMed]

17. Feder, J.N.; Penny, D.M.; Irrinki, A.; Lee, V.K.; Lebron, J.A.; Watson, N.; Tsuchihashi, Z.; Sigal, E.; Bjorkman, P.J.; Schatzman, R.C. The hemochromatosis gene product complexes with the transferrin receptor and lowers its affinity for ligand binding. Proc. Natl. Acad. Sci. USA 1998, 95, 1472-1477. [CrossRef] [PubMed]

18. Pietrangelo, A. Non-hfe hemochromatosis. Semin. Liver Dis. 2005, 25, 450-460. [CrossRef] [PubMed]

19. Nemeth, E.; Ganz, T. Regulation of iron metabolism by hepcidin. Annu. Rev. Nutr. 2006, 26, 323-342. [CrossRef] [PubMed]

20. Pietrangelo, A. Hereditary hemochromatosis. Biochim. Biophys. Acta 2006, 1763, 700-710. [CrossRef] [PubMed]

21. Roth, A.M.; Foos, R.Y. Ocular pathologic changes in primary hemochromatosis. Arch. Ophthalmol. 1972, 87, 507-514. [CrossRef] [PubMed]

22. Martin, P.M.; Gnana-Prakasam, J.P.; Roon, P.; Smith, R.G.; Smith, S.B.; Ganapathy, V. Expression and polarized localization of the hemochromatosis gene product hfe in retinal pigment epithelium. Investig. Ophthalmol. Vis. Sci. 2006, 47, 4238-4244. [CrossRef] [PubMed]

23. Gnana-Prakasam, J.P.; Zhang, M.; Martin, P.M.; Atherton, S.S.; Smith, S.B.; Ganapathy, V. Expression of the iron-regulatory protein haemojuvelin in retina and its regulation during cytomegalovirus infection. Biochem. J. 2009, 419, 533-543. [CrossRef] [PubMed]

24. Gnana-Prakasam, J.P.; Tawfik, A.; Romej, M.; Ananth, S.; Martin, P.M.; Smith, S.B.; Ganapathy, V. Iron-mediated retinal degeneration in haemojuvelin-knockout mice. Biochem. J. 2012, 441, 599-608. [CrossRef] [PubMed]

25. Gnana-Prakasam, J.P.; Thangaraju, M.; Liu, K.; Ha, Y.; Martin, P.M.; Smith, S.B.; Ganapathy, V. Absence of iron-regulatory protein Hfe results in hyperproliferation of retinal pigment epithelium: Role of cystine/glutamate exchanger. Biochem. J. 2009, 424, 243-252. [CrossRef] [PubMed]

26. Hadziahmetovic, M.; Song, Y.; Ponnuru, P.; Iacovelli, J.; Hunter, A.; Haddad, N.; Beard, J.; Connor, J.R.; Vaulont, S.; Dunaief, J.L. Age-dependent retinal iron accumulation and degeneration in hepcidin knockout mice. Investig. Ophthalmol. Vis. Sci. 2011, 52, 109-118. [CrossRef] [PubMed]

27. Abrahao, A.; Pedroso, J.L.; Braga-Neto, P.; Bor-Seng-Shu, E.; de Carvalho Aguiar, P.; Barsottini, O.G. Milestones in friedreich ataxia: More than a century and still learning. Neurogenetics 2015, 16, 151-160. [CrossRef] [PubMed]

28. Porter, N.; Downes, S.M.; Fratter, C.; Anslow, P.; Nemeth, A.H. Catastrophic visual loss in a patient with friedreich ataxia. Arch. Ophthalmol. 2007, 125, 273-274. [CrossRef] [PubMed]

29. Koeppen, A.H.; Dickson, A.C. Iron in the hallervorden-spatz syndrome. Pediatr. Neurol. 2001, 25, 148-155. [CrossRef]

30. Zhou, B.; Westaway, S.K.; Levinson, B.; Johnson, M.A.; Gitschier, J.; Hayflick, S.J. A novel pantothenate kinase gene (pank2) is defective in hallervorden-spatz syndrome. Nat. Genet. 2001, 28, 345-349. [CrossRef] [PubMed]

31. Newell, F.W.; Johnson, R.O., 2nd; Huttenlocher, P.R. Pigmentary degeneration of the retina in the hallervorden-spatz syndrome. Am. J. Ophthalmol. 1979, 88, 467-471. [CrossRef]

32. Luckenbach, M.W.; Green, W.R.; Miller, N.R.; Moser, H.W.; Clark, A.W.; Tennekoon, G. Ocular clinicopathologic correlation of hallervorden-spatz syndrome with acanthocytosis and pigmentary retinopathy. Am. J. Ophthalmol. 1983, 95, 369-382. [CrossRef]

33. Kuo, Y.M.; Duncan, J.L.; Westaway, S.K.; Yang, H.; Nune, G.; Xu, E.Y.; Hayflick, S.J.; Gitschier, J. Deficiency of pantothenate kinase 2 (pank2) in mice leads to retinal degeneration and azoospermia. Hum. Mol. Genet. 2005, 14, 49-57. [CrossRef] [PubMed] 
34. Lim, L.S.; Mitchell, P.; Seddon, J.M.; Holz, F.G.; Wong, T.Y. Age-related macular degeneration. Lancet 2012, 379, 1728-1738. [CrossRef]

35. Coleman, H.R.; Chan, C.C.; Ferris, F.L., 3rd; Chew, E.Y. Age-related macular degeneration. Lancet 2008, 372, 1835-1845. [CrossRef]

36. Zarbin, M.A. Current concepts in the pathogenesis of age-related macular degeneration. Arch. Ophthalmol. 2004, 122, 598-614. [CrossRef] [PubMed]

37. Age-Related Eye Disease Study Research Group. A randomized, placebo-controlled, clinical trial of high-dose supplementation with vitamins $\mathrm{C}$ and $\mathrm{E}$, beta carotene, and zinc for age-related macular degeneration and vision loss: Areds report No. 8. Arch. Ophthalmol. 2001, 119, 1417-1436. [CrossRef]

38. Chew, E.Y.; Clemons, T.E.; Agron, E.; Sperduto, R.D.; Sangiovanni, J.P.; Kurinij, N.; Davis, M.D.; Age-Related Eye Disease Study Research Group. Long-term effects of vitamins C and E, beta-carotene, and zinc on age-related macular degeneration: Areds report No. 35. Ophthalmology 2013, 120, 1604-1611. [CrossRef] [PubMed]

39. Hahn, P.; Milam, A.H.; Dunaief, J.L. Maculas affected by age-related macular degeneration contain increased chelatable iron in the retinal pigment epithelium and bruch's membrane. Arch. Ophthalmol. 2003, 121, 1099-1105. [CrossRef] [PubMed]

40. Biesemeier, A.; Yoeruek, E.; Eibl, O.; Schraermeyer, U. Iron accumulation in bruch's membrane and melanosomes of donor eyes with age-related macular degeneration. Exp. Eye Res. 2015, 137, 39-49. [CrossRef] [PubMed]

41. Dentchev, T.; Hahn, P.; Dunaief, J.L. Strong labeling for iron and the iron-handling proteins ferritin and ferroportin in the photoreceptor layer in age-related macular degeneration. Arch. Ophthalmol. 2005, 123, 1745-1746. [CrossRef] [PubMed]

42. Junemann, A.G.; Stopa, P.; Michalke, B.; Chaudhri, A.; Reulbach, U.; Huchzermeyer, C.; Schlotzer-Schrehardt, U.; Kruse, F.E.; Zrenner, E.; Rejdak, R. Levels of aqueous humor trace elements in patients with non-exsudative age-related macular degeneration: A case-control study. PLoS ONE 2013, 8, e56734. [CrossRef] [PubMed]

43. Hahn, P.; Ying, G.S.; Beard, J.; Dunaief, J.L. Iron levels in human retina: Sex difference and increase with age. Neuroreport 2006, 17, 1803-1806. [CrossRef] [PubMed]

44. Ugarte, M.; Grime, G.W.; Lord, G.; Geraki, K.; Collingwood, J.F.; Finnegan, M.E.; Farnfield, H.; Merchant, M.; Bailey, M.J.; Ward, N.I.; et al. Concentration of various trace elements in the rat retina and their distribution in different structures. Metallomics 2012, 4, 1245-1254. [CrossRef] [PubMed]

45. Chowers, I.; Wong, R.; Dentchev, T.; Farkas, R.H.; Iacovelli, J.; Gunatilaka, T.L.; Medeiros, N.E.; Presley, J.B.; Campochiaro, P.A.; Curcio, C.A.; et al. The iron carrier transferrin is upregulated in retinas from patients with age-related macular degeneration. Investig. Ophthalmol. Vis. Sci. 2006, 47, 2135-2140. [CrossRef] [PubMed]

46. Fraenkel, P.G. Anemia of inflammation: A review. Med. Clin. N. Am. 2017, 101, 285-296. [CrossRef] [PubMed]

47. Yang, L.; Fan, M.; Du, F.; Gong, Q.; Bi, Z.G.; Zhu, Z.J.; Zhu, L.L.; Ke, Y. Hypoxic preconditioning increases iron transport rate in astrocytes. Biochim. Biophys. Acta 2012, 1822, 500-508. [CrossRef] [PubMed]

48. Fonseca, A.M.; Pereira, C.F.; Porto, G.; Arosa, F.A. Red blood cells upregulate cytoprotective proteins and the labile iron pool in dividing human $t$ cells despite a reduction in oxidative stress. Free Radic. Biol. Med. 2003, 35, 1404-1416. [CrossRef] [PubMed]

49. Bhisitkul, R.B.; Winn, B.J.; Lee, O.T.; Wong, J.; Pereira Dde, S.; Porco, T.C.; He, X.; Hahn, P.; Dunaief, J.L. Neuroprotective effect of intravitreal triamcinolone acetonide against photoreceptor apoptosis in a rabbit model of subretinal hemorrhage. Investig. Ophthalmol. Vis. Sci. 2008, 49, 4071-4077. [CrossRef] [PubMed]

50. McLean, E.; Cogswell, M.; Egli, I.; Wojdyla, D.; de Benoist, B. Worldwide prevalence of anaemia, who vitamin and mineral nutrition information system, 1993-2005. Public Health Nutr. 2009, 12, 444-454. [CrossRef] [PubMed]

51. Stevens, G.A.; Finucane, M.M.; De-Regil, L.M.; Paciorek, C.J.; Flaxman, S.R.; Branca, F.; Pena-Rosas, J.P.; Bhutta, Z.A.; Ezzati, M.; Nutrition Impact Model Study Group. Global, regional, and national trends in haemoglobin concentration and prevalence of total and severe anaemia in children and pregnant and non-pregnant women for 1995-2011: A systematic analysis of population-representative data. Lancet Glob. Health 2013, 1, e16-e25. [CrossRef] 
52. Kassebaum, N.J.; Jasrasaria, R.; Naghavi, M.; Wulf, S.K.; Johns, N.; Lozano, R.; Regan, M.; Weatherall, D.; Chou, D.P.; Eisele, T.P.; et al. A systematic analysis of global anemia burden from 1990 to 2010. Blood 2014, 123, 615-624. [CrossRef] [PubMed]

53. Zimmermann, M.B.; Hurrell, R.F. Nutritional iron deficiency. Lancet 2007, 370, 511-520. [CrossRef]

54. Kumar, P.; Nag, T.C.; Jha, K.A.; Dey, S.K.; Kathpalia, P.; Maurya, M.; Gupta, C.L.; Bhatia, J.; Roy, T.S.; Wadhwa, S. Experimental oral iron administration: Histological investigations and expressions of iron handling proteins in rat retina with aging. Toxicology 2017, 392, 22-31. [CrossRef] [PubMed]

55. Bhoiwala, D.L.; Song, Y.; Cwanger, A.; Clark, E.; Zhao, L.L.; Wang, C.; Li, Y.; Song, D.; Dunaief, J.L. Cd1 mouse retina is shielded from iron overload caused by a high iron diet. Investig. Ophthalmol. Vis. Sci. 2015, 56, 5344-5352. [CrossRef] [PubMed]

56. Cross, A.J.; Pollock, J.R.; Bingham, S.A. Haem, not protein or inorganic iron, is responsible for endogenous intestinal n-nitrosation arising from red meat. Cancer Res. 2003, 63, 2358-2360. [PubMed]

57. Chong, E.W.; Simpson, J.A.; Robman, L.D.; Hodge, A.M.; Aung, K.Z.; English, D.R.; Giles, G.G.; Guymer, R.H. Red meat and chicken consumption and its association with age-related macular degeneration. Am. J. Epidemiol. 2009, 169, 867-876. [CrossRef] [PubMed]

58. Onken, J.E.; Bregman, D.B.; Harrington, R.A.; Morris, D.; Acs, P.; Akright, B.; Barish, C.; Bhaskar, B.S.; Smith-Nguyen, G.N.; Butcher, A.; et al. A multicenter, randomized, active-controlled study to investigate the efficacy and safety of intravenous ferric carboxymaltose in patients with iron deficiency anemia. Transfusion 2014, 54, 306-315. [CrossRef] [PubMed]

59. Vadhan-Raj, S.; Strauss, W.; Ford, D.; Bernard, K.; Boccia, R.; Li, J.; Allen, L.F. Efficacy and safety of iv ferumoxytol for adults with iron deficiency anemia previously unresponsive to or unable to tolerate oral iron. Am. J. Hematol. 2014, 89, 7-12. [CrossRef] [PubMed]

60. Zhao, L.; Li, Y.; Song, D.; Song, Y.; Theurl, M.; Wang, C.; Cwanger, A.; Su, G.; Dunaief, J.L. A high serum iron level causes mouse retinal iron accumulation despite an intact blood-retinal barrier. Am. J. Pathol. 2014, 184, 2862-2867. [CrossRef] [PubMed]

61. Song, D.; Kanu, L.N.; Li, Y.; Kelly, K.L.; Bhuyan, R.K.; Aleman, T.; Morgan, J.I.; Dunaief, J.L. Amd-like retinopathy associated with intravenous iron. Exp. Eye Res. 2016, 151, 122-133. [CrossRef] [PubMed]

62. Bhoiwala, D.L.; Dunaief, J.L. Retinal abnormalities in beta-thalassemia major. Surv. Ophthalmol. 2016, 61, 33-50. [CrossRef] [PubMed]

63. Cibis, P.A.; Yamashita, T.; Rodriguez, F. Clinical aspects of ocular siderosis and hemosiderosis. AMA Arch. Ophthalmol. 1959, 62, 180-187. [PubMed]

64. Talamo, J.H.; Topping, T.M.; Maumenee, A.E.; Green, W.R. Ultrastructural studies of cornea, iris and lens in a case of siderosis bulbi. Ophthalmology 1985, 92, 1675-1680. [CrossRef]

65. Sneed, S.R. Ocular siderosis. Arch. Ophthalmol. 1988, 106, 997. [CrossRef] [PubMed]

66. Knave, B. Long-term changes in retinal function induced by short, high intensity flashes. Experientia 1969, 25, 379-380. [CrossRef] [PubMed]

67. Masciulli, L.; Anderson, D.R.; Charles, S. Experimental ocular siderosis in the squirrel monkey. Am. J. Ophthalmol. 1972, 74, 638-661. [CrossRef]

68. Declercq, S.S.; Meredith, P.C.; Rosenthal, A.R. Experimental siderosis in the rabbit: Correlation between electroretinography and histopathology. Arch. Ophthalmol. 1977, 95, 1051-1058. [CrossRef] [PubMed]

69. Gillies, A.; Lahav, M. Absorption of retinal and subretinal hemorrhages. Ann. Ophthalmol. 1983, 15, $1068-1074$. [PubMed]

70. Glatt, H.; Machemer, R. Experimental subretinal hemorrhage in rabbits. Am. J. Ophthalmol. 1982, 94, 762-773. [CrossRef]

71. Youssef, T.A.; Trese, M.T.; Hartzer, M.; Mahgoub, M.; Raza, H.; Azrak, M.; Allredge, C. Deferoxamine reduces retinal toxicity from subretinal blood. Investig. Ophthalmol. Vis. Sci. 2002, 43, U845.

72. Ito, T.; Nakano, M.; Yamamoto, Y.; Hiramitsu, T.; Mizuno, Y. Hemoglobin-induced lipid peroxidation in the retina: A possible mechanism for macular degeneration. Arch. Biochem. Biophys. 1995, 316, 864-872. [CrossRef] [PubMed]

73. Hunt, R.C.; Handy, I.; Smith, A. Heme-mediated reactive oxygen species toxicity to retinal pigment epithelial cells is reduced by hemopexin. J. Cell. Physiol. 1996, 168, 81-86. [CrossRef] 
74. Zheng, H.; Youdim, M.B.; Weiner, L.M.; Fridkin, M. Novel potential neuroprotective agents with both iron chelating and amino acid-based derivatives targeting central nervous system neurons. Biochem. Pharmacol. 2005, 70, 1642-1652. [CrossRef] [PubMed]

75. Richardson, D.R. Novel chelators for central nervous system disorders that involve alterations in the metabolism of iron and other metal ions. Ann. N. Y. Acad. Sci. 2004, 1012, 326-341. [CrossRef] [PubMed]

76. Brittenham, G.M. Iron-chelating therapy for transfusional iron overload. N. Engl. J. Med. 2011, 364, $146-156$. [CrossRef] [PubMed]

77. Davies, S.C.; Marcus, R.E.; Hungerford, J.L.; Miller, M.H.; Arden, G.B.; Huehns, E.R. Ocular toxicity of high-dose intravenous desferrioxamine. Lancet 1983, 2, 181-184. [CrossRef]

78. Lakhanpal, V.; Schocket, S.S.; Jiji, R. Deferoxamine (desferal)-induced toxic retinal pigmentary degeneration and presumed optic neuropathy. Ophthalmology 1984, 91, 443-451. [CrossRef]

79. Bene, C.; Manzler, A.; Bene, D.; Kranias, G. Irreversible ocular toxicity from single "challenge" dose of deferoxamine. Clin. Nephrol. 1989, 31, 45-48. [PubMed]

80. Obolensky, A.; Berenshtein, E.; Lederman, M.; Bulvik, B.; Alper-Pinus, R.; Yaul, R.; Deleon, E.; Chowers, I.; Chevion, M.; Banin, E. Zinc-desferrioxamine attenuates retinal degeneration in the rd10 mouse model of retinitis pigmentosa. Free Radic. Biol. Med. 2011, 51, 1482-1491. [CrossRef] [PubMed]

81. Li, Z.L.; Lam, S.; Tso, M.O. Desferrioxamine ameliorates retinal photic injury in albino rats. Curr. Eye Res. 1991, 10, 133-144. [CrossRef] [PubMed]

82. Vanorden, H.E.; Hagemann, T.M. Deferasirox-an oral agent for chronic iron overload. Ann. Pharmacother. 2006, 40, 1110-1117. [CrossRef] [PubMed]

83. Galanello, R.; Piga, A.; Alberti, D.; Rouan, M.C.; Bigler, H.; Sechaud, R. Safety, tolerability, and pharmacokinetics of icl670, a new orally active iron-chelating agent in patients with transfusion-dependent iron overload due to beta-thalassemia. J. Clin. Pharmacol. 2003, 43, 565-572. [CrossRef] [PubMed]

84. Cappellini, M.D.; Porter, J.; El-Beshlawy, A.; Li, C.K.; Seymour, J.F.; Elalfy, M.; Gattermann, N.; Giraudier, S.; Lee, J.W.; Chan, L.L.; et al. Tailoring iron chelation by iron intake and serum ferritin: The prospective epic study of deferasirox in 1744 patients with transfusion-dependent anemias. Haematologica 2010, 95, 557-566. [CrossRef] [PubMed]

85. Cappellini, M.D.; Cohen, A.; Piga, A.; Bejaoui, M.; Perrotta, S.; Agaoglu, L.; Aydinok, Y.; Kattamis, A.; Kilinc, Y.; Porter, J.; et al. A phase 3 study of deferasirox (icl670), a once-daily oral iron chelator, in patients with beta-thalassemia. Blood 2006, 107, 3455-3462. [CrossRef] [PubMed]

86. Cappellini, M.D.; Bejaoui, M.; Agaoglu, L.; Canatan, D.; Capra, M.; Cohen, A.; Drelichman, G.; Economou, M.; Fattoum, S.; Kattamis, A.; et al. Iron chelation with deferasirox in adult and pediatric patients with thalassemia major: Efficacy and safety during 5 years' follow-up. Blood 2011, 118, 884-893. [CrossRef] [PubMed]

87. Sharma, A.; Arora, E.; Singh, H. Hypersensitivity reaction with deferasirox. J. Pharmacol. Pharmacother. 2015, 6, 105-106. [CrossRef] [PubMed]

88. Gartaganis, S.; Ismiridis, K.; Papageorgiou, O.; Beratis, N.G.; Papanastasiou, D. Ocular abnormalities in patients with beta thalassemia. Am. J. Ophthalmol. 1989, 108, 699-703. [CrossRef]

89. Sorcinelli, R.; Sitzia, A.; Figus, A.; Lai, M.E. Ocular findings in beta-thalassemia. Metab. Pediatr. Syst. Ophthalmol. 1990, 13, 23-25.

90. Bloomfield, S.E.; Markenson, A.L.; Miller, D.R.; Peterson, C.M. Lens opacities in thalassemia. J. Pediatr. Ophthalmol. Strabismus 1978, 15, 154-156. [PubMed]

91. De Virgiliis, S.; Congia, M.; Turco, M.P.; Frau, F.; Dessi, C.; Argiolu, F.; Sorcinelli, R.; Sitzia, A.; Cao, A. Depletion of trace elements and acute ocular toxicity induced by desferrioxamine in patients with thalassaemia. Arch. Dis. Child. 1988, 63, 250-255. [CrossRef] [PubMed]

92. Galanello, R. Deferiprone in the treatment of transfusion-dependent thalassemia: A review and perspective. Ther. Clin. Risk Manag. 2007, 3, 795-805. [PubMed]

93. Hadziahmetovic, M.; Song, Y.; Wolkow, N.; Iacovelli, J.; Grieco, S.; Lee, J.; Lyubarsky, A.; Pratico, D.; Connelly, J.; Spino, M.; et al. The oral iron chelator deferiprone protects against iron overload-induced retinal degeneration. Investig. Ophthalmol. Vis. Sci. 2011, 52, 959-968. [CrossRef] [PubMed]

94. Song, D.; Zhao, L.; Li, Y.; Hadziahmetovic, M.; Song, Y.; Connelly, J.; Spino, M.; Dunaief, J.L. The oral iron chelator deferiprone protects against systemic iron overload-induced retinal degeneration in hepcidin knockout mice. Investig. Ophthalmol. Vis. Sci. 2014, 55, 4525-4532. [CrossRef] [PubMed] 
95. Hadziahmetovic, M.; Pajic, M.; Grieco, S.; Song, Y.; Song, D.; Li, Y.; Cwanger, A.; Iacovelli, J.; Chu, S.; Ying, G.S.; et al. The oral iron chelator deferiprone protects against retinal degeneration induced through diverse mechanisms. Transl. Vis. Sci. Technol. 2012, 1, 7. [CrossRef] [PubMed]

96. Song, D.; Song, Y.; Hadziahmetovic, M.; Zhong, Y.; Dunaief, J.L. Systemic administration of the iron chelator deferiprone protects against light-induced photoreceptor degeneration in the mouse retina. Free Radic. Biol. Med. 2012, 53, 64-71. [CrossRef] [PubMed]

97. Dixon, S.J.; Lemberg, K.M.; Lamprecht, M.R.; Skouta, R.; Zaitsev, E.M.; Gleason, C.E.; Patel, D.N.; Bauer, A.J.; Cantley, A.M.; Yang, W.S.; et al. Ferroptosis: An iron-dependent form of nonapoptotic cell death. Cell 2012, 149, 1060-1072. [CrossRef] [PubMed]

98. Jansova, H.; Bures, J.; Machacek, M.; Haskova, P.; Jirkovska, A.; Roh, J.; Wang, Q.; Franz, K.J.; Kovarikova, P.; Simunek, T. Characterization of cytoprotective and toxic properties of iron chelator sih, prochelator bsih and their degradation products. Toxicology 2016, 350-352, 15-24. [CrossRef] [PubMed]

99. Haskova, P.; Kovarikova, P.; Koubkova, L.; Vavrova, A.; Mackova, E.; Simunek, T. Iron chelation with salicylaldehyde isonicotinoyl hydrazone protects against catecholamine autoxidation and cardiotoxicity. Free Radic. Biol. Med. 2011, 50, 537-549. [CrossRef] [PubMed]

100. Sterba, M.; Popelova, O.; Simunek, T.; Mazurova, Y.; Potacova, A.; Adamcova, M.; Guncova, I.; Kaiserova, H.; Palicka, V.; Ponka, P.; et al. Iron chelation-afforded cardioprotection against chronic anthracycline cardiotoxicity: A study of salicylaldehyde isonicotinoyl hydrazone (sih). Toxicology 2007, 235, 150-166. [CrossRef] [PubMed]

101. Lukinova, N.; Iacovelli, J.; Dentchev, T.; Wolkow, N.; Hunter, A.; Amado, D.; Ying, G.S.; Sparrow, J.R.; Dunaief, J.L. Iron chelation protects the retinal pigment epithelial cell line arpe-19 against cell death triggered by diverse stimuli. Investig. Ophthalmol. Vis. Sci. 2009, 50, 1440-1447. [CrossRef] [PubMed]

102. Caro, A.A.; Commissariat, A.; Dunn, C.; Kim, H.; Garcia, S.L.; Smith, A.; Strang, H.; Stuppy, J.; Desrochers, L.P.; Goodwin, T.E. Prooxidant and antioxidant properties of salicylaldehyde isonicotinoyl hydrazone iron chelators in hepg2 cells. Biochim. Biophys. Acta 2015, 1850, 2256-2264. [CrossRef] [PubMed]

103. Buss, J.L.; Ponka, P. Hydrolysis of pyridoxal isonicotinoyl hydrazone and its analogs. Biochim. Biophys. Acta 2003, 1619, 177-186. [CrossRef]

(C) 2018 by the authors. Licensee MDPI, Basel, Switzerland. This article is an open access article distributed under the terms and conditions of the Creative Commons Attribution (CC BY) license (http:/ / creativecommons.org/licenses/by/4.0/). 
Review

\title{
Iron as a Therapeutic Target in HFE-Related Hemochromatosis: Usual and Novel Aspects
}

\author{
Olivier Loréal *, Thibault Cavey, François Robin, Moussa Kenawi, Pascal Guggenbuhl and \\ Pierre Brissot \\ INSERM, Univ Rennes, INRA, CHU Rennes, Institut NUMECAN (Nutrition Metabolisms and Cancer), \\ F-35033 Rennes, France; thibault.cavey@chu-rennes.fr (T.C.); francois.robin@chu-rennes.fr (F.R.); \\ moussa.kenawi@univ-rennes1.fr (M.K.); pascal.guggenbuhl@univ-rennes1.fr (P.G.); \\ pierre.brissot@univ-rennes1.fr (P.B.) \\ * Correspondence: olivier.loreal@univ-rennes1.fr; Tel: +33-22-323-3865
}

Received: 28 August 2018; Accepted: 19 November 2018; Published: 26 November 2018

\begin{abstract}
Genetic hemochromatosis is an iron overload disease that is mainly related to the C282Y mutation in the HFE gene. This gene controls the expression of hepcidin, a peptide secreted in plasma by the liver and regulates systemic iron distribution. Homozygous C282Y mutation induces hepcidin deficiency, leading to increased circulating transferrin saturation, and ultimately, iron accumulation in organs such as the liver, pancreas, heart, and bone. Iron in excess may induce or favor the development of complications such as cirrhosis, liver cancer, diabetes, heart failure, hypogonadism, but also complaints such as asthenia and disabling arthritis. Iron depletive treatment mainly consists of venesections that permit the removal of iron contained in red blood cells and the subsequent mobilization of stored iron in order to synthesize hemoglobin for new erythrocytes. It is highly efficient in removing excess iron and preventing most of the complications associated with excess iron in the body. However, this treatment does not target the biological mechanisms involved in the iron metabolism disturbance. New treatments based on the increase of hepcidin levels, by using hepcidin mimetics or inducers, or inhibitors of the iron export activity of ferroportin protein that is the target of hepcidin, if devoid of significant secondary effects, should be useful to better control iron parameters and symptoms, such as arthritis.
\end{abstract}

Keywords: iron; genetic hemochromatosis; non transferrin bound iron; hepcidin; ferroportin; venesections

Iron metabolism must be tightly controlled in order to avoid deleterious situations, including iron overload diseases, especially HFE-related hemochromatosis. In such conditions an iron depletive treatment is engaged in order to avoid the development of complications. However, iron depletive therapy targets only iron excess and alternative, possibly complementary, novel approaches are needed.

\section{Normal Iron Metabolism}

\subsection{The Ferroportin/Hepcidin Duo Controls Systemic Iron Metabolism}

Systemic iron metabolism is characterized by a continuous distribution of iron from plasma toward cells which require its presence for participating in biological functions, including oxygen transport and enzymatic processes [1]. Plasma iron must be continuously renewed. Plasma iron originates predominantly from macrophages that recycle iron from senescent erythrocytes during the erythrophagocytosis process. The erythropoietic cells contains $70 \%$ of total body iron. The macrophages provide schematically $19 \mathrm{mg}$ out of the $20 \mathrm{mg}$ of iron required from the plasma by cells every day. The second source of iron is digestive absorption. Iron is absorbed in two steps from the nutrients. The first step takes place at the apical pole of the enterocytes, non-heme and heme iron 
being transferred from nutrients to the enterocyte cytoplasm. The transfer of non-heme iron implicates DMT1 (divalent metal transporter 1) that takes up ferrous iron [2] after reduction by the ferrireductase $\mathrm{dCy}$ tb [3]. Heme iron is taken up through a receptor that could be HCP1 (heme carrier protein1) (controversial) [4-6]. The second step of iron absorption is the transfer of iron from the cytoplasm toward the plasma through the basal membrane of the enterocyte. This process limits the iron entry into the body, and only 1-2 mg are transferred each day toward the plasma, whereas the remaining iron is transiently stored within the cytoplasm and will be lost during enterocyte desquamation. This selective process is the classical mucosal block [7]. Ferroportin is the iron export protein that allows iron egress from enterocytes (concerning both the non-heme and heme iron absorbed at the apical side) and macrophages toward the plasma [8-10]. Once transferred into the plasma, and after its oxidation by ferroxidase enzymes—ceruloplasmin [11] and/or hephaestin [12]—ferric iron is associated to transferrin, the protein that can link up to two iron atoms and delivers iron to cells. Cellular uptake of transferrin iron is mediated by the transferrin receptor 1 (TFR1) [13]. Thereafter, endocytosis of the complex permits the transport of iron into endocytic vesicles and subsequently, its transfer to the cytosol by DMT1, that is also expressed in endocytic vesicles, after oxidation of iron by STEAP3 (Six-Transmembrane Epithelial Antigen of the Prostate 3) [14]. Another transferrin receptor, transferrin receptor 2 (TFR2) is expressed by cells, especially hepatocytes, but its affinity coefficient for transferrin is very low [15] so that its function is related to iron sensing rather than iron transport [16].

Hepcidin is a small cysteine rich peptide [17-19], mainly expressed by hepatocytes and secreted in the plasma, that interacts with ferroportin [20], the only known protein involved in cellular iron export. An increase of plasma hepcidin level leads to a decrease of both digestive iron absorption and iron leakage by macrophages [21]. Hepcidin decreases plasma iron concentration and the saturation of transferrin by iron. Conversely, a decrease of hepcidin expression favors cell membrane expression of ferroportin, and, in turn, the iron release from cells into the plasma, thus, increasing the transferrin saturation by iron. The regulation of hepcidin expression plays a major role in the maintenance of iron homeostasis.

\subsection{Regulation of Hepcidin Expression}

Hepcidin expression is regulated by many factors, including iron status [19] and inflammation [19,22] that induce an upregulation of hepcidin expression, and hypoxia/erythropoiesis activity [23-25] that decrease hepcidin expression. Mechanisms related to the induction of hepcidin expression by iron status are mainly transcriptional.

The first iron-related mechanism that regulates hepcidin expression is reported to be linked to transferrin saturation level in plasma [26,27]. This pathway involves the HFE gene, located on the chromosome 6, that encodes a HLA like class I protein that is expressed on cell membrane in association with the $\$ 2$-microglobulin [28]. It has been reported that HFE protein may interact either with TFR1 $[29,30]$ or TFR2. The mechanism potentially involved in such regulation is a decrease of the physical interaction between TFR1 and HFE proteins when transferrin saturation increases [31]. This could lead to the stimulation of a MAP (mitogen-activated protein kinase) signaling pathway that promotes the hepcidin transcription level [27]. However, while the HFE/TFR2 interaction has been documented in in vitro experiments, the in vivo relevance of these findings is questionable [32]. The increase of hepcidin expression promotes ferroportin degradation, and thus, reduces plasma iron concentration and transferrin saturation by iron (Figure 1). 


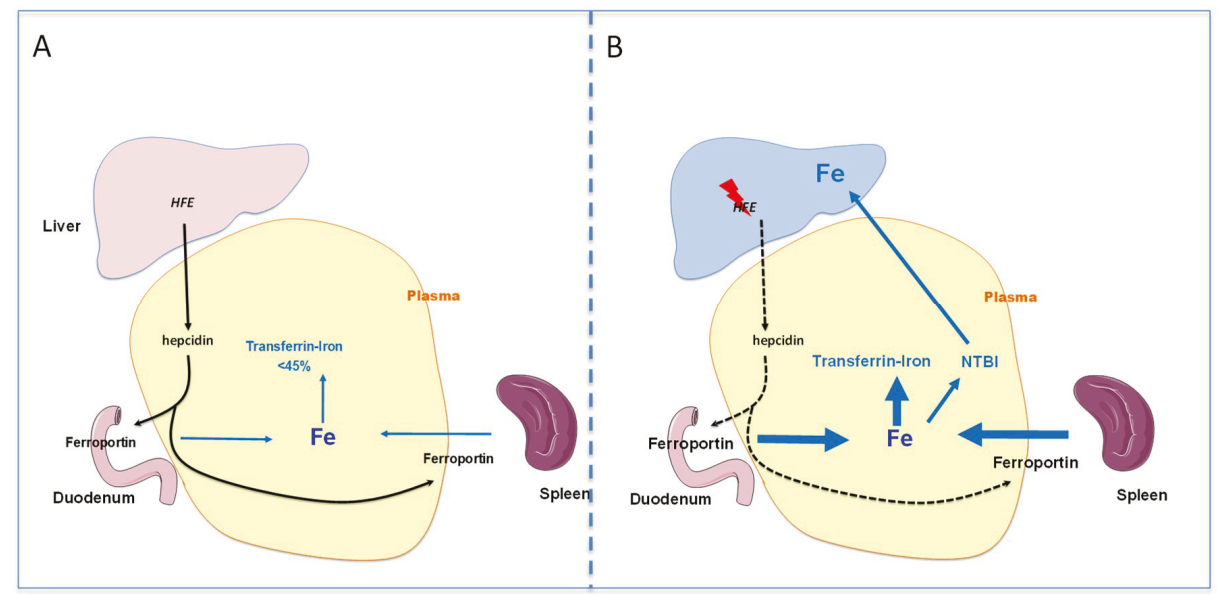

Figure 1. Schematic representation of the pathophysiological mechanisms leading to the development of iron overload during HFE-related hemochromatosis. (A): Normal situation with adequate HFE signaling allowing control of transferrin saturation level $(<45 \%)$. (B): Genetic hemochromatosis with low activity of HFE-related signaling that limits hepcidin expression and in turn favors iron release in plasma, despite the presence of a sufficient amount of iron. Thus, the transferrin saturation increases and non-transferrin bound iron appears and targets organs such as liver, leading to abnormal iron accumulation.

The second regulatory mechanism implicates the bone morphogenetic protein/hemojuvelin/son of mothers against decapentaplegic homolog (BMP/HJV/SMAD) pathway [33-36]. When cell iron concentration increases, BMP6 and BMP2 proteins are produced and secreted by hepatocytes and more likely sinusoidal cells [37-39]. BMPs interact with BMP receptor proteins that are associated to HJV, acting as BMPs co-receptor. The interaction induces a phosphorylation of SMADs (Son of Mothers Against Decapentaplegic) 1, 5, 8 that are translocated toward the nucleus after association with SMAD4 in the nucleus [40,41]. Then, they interact with BMP-responsive element sequence within the hepcidin gene promoter and promote hepcidin transcription [35,36,42].

It is noteworthy that the hemochromatosis proteins HFE and HJV form a membrane-associated protein complex for hepcidin regulation. This suggests that the two pathways are not fully independent $[43,44]$, and further work should help to better specify the respective roles of the different actors.

\section{Pathophysiology of HFE Hemochromatosis}

\subsection{HFE Hemochromatosis}

HFE hemochromatosis is a disease mainly related to homozygosity of the C282Y (p.Cys282Tyr) mutation in the HFE gene [45]. The $p$.Cys282Tyr mutation alters the structure of the HFE protein due to the substitution of a cysteine that is engaged in intra-molecular disulfide bounds, that play a role in the protein shape, by a threonine. Thus, the expression of HFE protein on cell membrane, as well as its interaction with the Beta2 microglobulin are altered [29]. Some exceptional private mutations in the HFE gene can also lead to hemochromatosis, when present either at the homozygous state or in association with the C282Y mutation [46]. Homozygosity for H63D ( $p$.His63Asp) that is present at homozygous state in approximately $2 \%$ of the Caucasian population cannot by itself generate clinically significant iron excess, so that, when associated to iron overload, one must search for associated genetic or acquired associated factors that promote iron excess [47]. It must be pointed out that the penetrance of HFE-related hemochromatosis is very incomplete. In terms of clinical penetrance, some studies 
have estimated a prevalence of $25-60 \%$, while a single study reported a prevalence of $28 \%$ in males and $1 \%$ in females [48]. However, in the same study the biochemical penetrance, assessed by increased ferritinemia, was much higher ( $82 \%$ and $55 \%$, respectively) [48].

\subsection{Pathophysiology of Iron Overload during HFE Hemochromatosis}

In hemochromatosis, iron overload is a two-hit phenomenon.

The first hit (Figure 1), which is related to the structural change of the protein is a deficiency in hepcidin expression and secretion-meaning hepcidin deficiency—compared to the iron stores [22,26]. In other words, hepcidin expression is lower than expected when considering plasma transferrin saturation and body iron stores [49]. This hepcidin deficiency results from the mutation in the HFE gene that alters the efficacy of the transduction pathway regulating hepcidin expression. Consecutively, despite iron excess, ferroportin expression on cell membranes of enterocytes and macrophages remains elevated and favors an increase of both plasma iron concentration and transferrin iron saturation [20]. As previously mentioned, transferrin iron ingress into cells is modulated by the expression level of its receptor TFR1. In physiological situation, TFR1 expression on cell membranes is downregulated when cellular iron is in excess [50], in order to avoid cellular iron accumulation with subsequent toxicity, especially through the production of reactive oxygen species (ROS) [51,52]. The iron responsive element/iron regulatory protein system (IRE/IRP) regulates TFR1 and ferritin expression, adapting iron entry into the cell (TFR1) and the capacity of iron storage in cells (ferritin), to the variations of cellular iron content $[50,53]$.

The second hit (Figure 1) involved in the development of iron overload in hemochromatosis results from the appearance of the non-transferrin-bound form of iron (NTBI) [54]. Indeed, transferrin saturation increase favors the presence of NTBI in plasma [55]. The NTBI is constituted of low molecular forms of iron linked to citrate or acetate [56]. The NTBI, in contrast to transferrin iron, constantly enters the cells, especially through the Zip14 transporter [57], even when they are already overloaded [58,59], whereas transferrin iron ingress is physiologically reduced due to the decrease of TFR1 on cell membrane $[60,61]$. The transporters involved in the uptake of NTBI are mainly expressed in the liver, the pancreas $[57,62]$, and the heart, explaining that these organs are the primary targets of iron excess.

It is important to note that rare or very rare non-HFE mutations may also favor hepcidin deficiency. Homozygous and compound heterozygous mutations in the HAMP [63] or HJV [64] genes induce an early and severe iron overload disease (juvenile hemochromatosis) that is related to severe hepcidin deficiency with major complications that quickly impact well-being and life expectancy. In addition, mutations in the TFR 2 gene induce an hepcidin deficiency that provokes a clinical iron overload phenotype which is in between juvenile hemochromatosis and the classical HFE-related hemochromatosis form [65].

\subsection{Pathophysiology of Organ Damage in Hemochromatosis}

Complications of HFE-related genetic hemochromatosis, and more globally of hemochromatosis related to hepcidin deficiency, include hepatic damage with the development of liver fibrosis, with the risks of cirrhosis and hepatocellular carcinoma, diabetes, and at a lesser degree, heart dysfunction, which are sources of morbidity and mortality [66,67]. The risk of hepatic fibrosis increases with the severity of iron overload [68], and it is recommended to perform a liver biopsy in patients exhibiting very high levels of ferritinemia [69]. This risk is associated with the presence of sideronecrotic lesions of hepatocytes [70], that likely corresponds to the recently identified ferroptotic cell death process [71,72], a new cell death pathway in cells containing high iron content. Whereas hepatocyte iron loading is the pathophysiological basic feature of iron overload in hemochromatosis, it is noteworthy that Kupffer cell iron load finally occurs in advanced iron hemochromatosis and also represents a risk for the development of hepatic damage [70]. The role of an iron-related induction of TGF (transforming growth factor)-beta in the development of fibrosis has been reported [73,74]. It should be underlined 
that hepatocellular carcinoma, that mostly develops in patients with a cirrhotic liver, can also be rarely found in non-cirrhotic patients which suggests the role of iron itself [75] and / or additional cofactors in the development of hepatocellular carcinoma (HCC) (see below). Finally, patients exhibiting cirrhosis before iron depletive treatment still present a risk for developing HCC even despite completion of iron depletive treatment [67].

Other complications may include hypogonadism — mostly in juvenile hemochromatosis—and much more frequently osteoporosis and arthritis that have a strong impact on the quality of life. Arthritis is characterized by absence of systemic inflammation and sometimes presence of calcium pyrophosphate crystals in the synovial fluids and visible on X-rays (review in [76]).

The ability of excessive iron to generate oxygen reactive species (ROS) (Figure 2) through the Haber-Weiss and Fenton reactions is strongly involved in the development of tissue lesions [77]. Indeed, ROS induces peroxidation that alters lipids, proteins, and DNA, generating dysfunctions of organelles, including mitochondria and cells, thus leading to tissue and organ damage [78-80]. One of the abnormal forms of NTBI, called Labile Plasma iron-LPI (or reactive plasma iron), is found in plasma when transferrin saturation reaches $80 \%$ [81]. This iron species is highly reactive and participates strongly in oxidative stress. Labile plasma iron is considered as a major determinant in the development of organ damage during hemochromatosis [82].

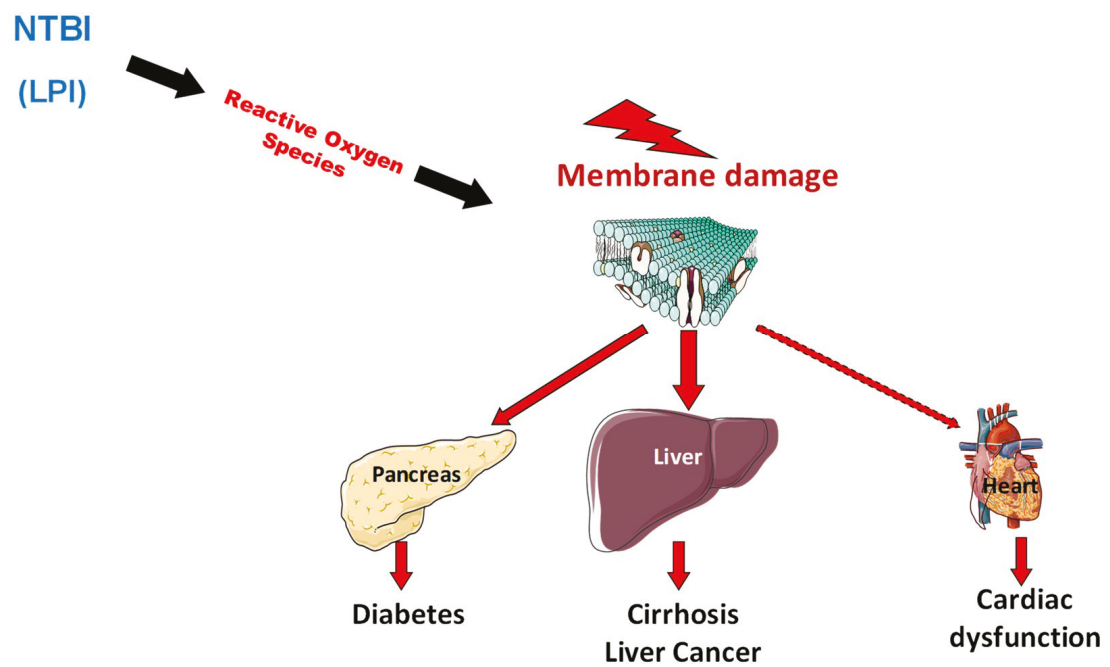

Figure 2. The appearance of non-transferrin bound forms of iron in plasma favors organ iron deposition but also the occurrence of oxidative stress that alters organelles in cells especially in iron overloaded organs.

In addition to the typical disease causing mutations associated with hemochromatosis, additional genetic modifiers have recently been described to elucidate in part, the large disparity in disease manifestations in patients. In this context, the importance of gene polymorphisms, e.g., GNPAT (glyceronephosphate O-acyltransferase) remains controversial and awaits additional confirmatory studies [83-88]. Alcohol consumption [68,89], non-alcoholic fatty liver disease [90], and viral hepatitis $[91,92]$ may also be involved in disease penetrance, as well as a polymorphism in the PCSK7 [93] or PNPLA3 [94] genes.

\section{Iron Is Presently the Main Therapeutic Target in HFE-Related Hemochromatosis}

It is well known that iron depletion is a treatment of choice for hemochromatosis patients [95]. Indeed, when performed in patients prior to severe complications, the iron depletive treatment 
restores normal life expectancy, meaning that hepatic, pancreatic, and cardiac dysfunctions can be fully prevented [67]. In addition, partial regression of liver fibrosis after completion of iron removal has been reported [96].

\subsection{Venesections Are the Mainstay Treatment for Iron Removal}

The principle of repeated venesections [47,95] (Figure 3) is to remove red blood cells that are known to be very rich in iron, as part of hemoglobin. Erythropoiesis is stimulated to compensate hematocrit loss, and iron is taken up from the plasma by erythroblasts to produce new erythrocytes. In order to maintain enough plasma iron for the stimulated erythropoiesis, iron is released from macrophages and enterocytes but also from iron storage cells, including parenchymal cells such as hepatocytes. Removing iron at a faster rate than that excessively reaccumulated by intestinal absorption is critical to negative iron balance, but determining this rate prior to starting depletive treatment is difficult due to individual differences between hemochromatosis patients. It should also be recalled that hepcidin synthesis can be further suppressed by increasing erythropoiesis as a consequence of erythroferrone production. In practice, the depletive treatment includes two successive phases. The first one, called induction phase, aims at totally removing the iron excess present at the time of diagnosis. It usually consists of weekly venesections ( $\leq 7.5 \mathrm{~mL} / \mathrm{kg}$ body weight per venesection). Once excess iron has been removed, the second phase, called maintenance therapy, aims to avoid recurrent iron overload using lifelong venesections, performed every 1-4 months.

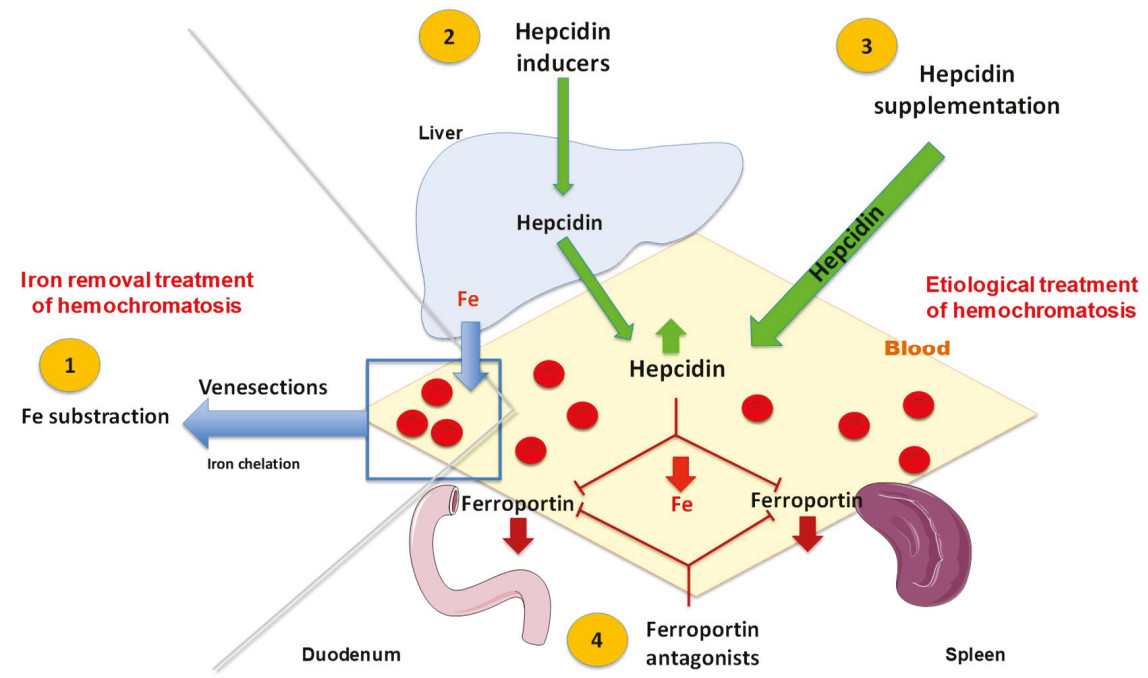

Figure 3. Schematic representation of currently used iron removal treatments during hemochromatosis and potential pathophysiological actions. (1) Iron depletive treatment is classically operated through repeated venesections that remove red blood cells. In some rare cases, iron chelators can be also used as complementary or suppletive treatment. (2) Hepcidin supplementation by endogenous or exogenous hepcidin. (3) Alternatively (4) the use of ferroportin antagonists could be also a way of treatment.

\subsection{Use of Chelation Therapy}

Another way to remove iron is the use of iron chelators that promote iron mobilization and excretion. However, in contrast to venesections, these drugs, including mainly today new oral iron-chelators, may have potential side effects [97]. Therefore during genetic hemochromatosis, oral chelation is only used, and as an off-label drug, in rare situations including cardiac failure, 
recent cerebral ischemic stroke, venous access problems limiting the possibility of venesections, or psychological intolerance to venesections.

\subsection{Biochemical Follow-Up of Venesection Therapy}

Three main parameters are classically followed: plasma ferritin and transferrin saturation levels that reflect the efficacy of iron depletive treatment, whereas hemoglobin levels reflect the tolerance of venesections. During the induction phase ferritinemia-that reliably reflects the amount of iron excess in hemochromatosis (provided other frequent acquired causes of hyperferritinemia have been excluded, such as inflammation, alcoholism, cytolysis or metabolic syndrome; genetic hyperferritinemia, as seen in the ferritin-cataract syndrome, is much rarer)—is the first parameter that decreases. This decrease is only slowly progressive, especially in patients exhibiting a severe iron load phenotype. Conversely, the decrease of transferrin saturation levels, that reflect plasma iron bioavailability, is a very late event. Normalization of transferrin saturation occurs only when the induction treatment is in its final phase. It is noteworthy that during hemochromatosis, despite the impressive frequency of venesections, hemoglobin levels remain stable due to the high capacity of cellular iron release by ferroportin hyperactivity, related to hepcidin deficiency. However, transient hypoxia and relative iron deficiency occurring after venesection, together with increased erythropoiesis, tend to decrease hepcidin plasma levels, thus contributing to further enhance iron entry into the plasma $[98,99]$. When considering NTBI during the induction therapy, its plasma concentration decreases parallel to transferrin saturation levels [55]. Altogether, these data suggest that induction therapy must be fully completed to remove iron excess, but also to prevent the appearance of toxic forms of iron, including plasma NTBI.

During the maintenance phase, it is essential to pursue the patient follow-up in order to ideally maintain both transferrin saturation and ferritin levels in the normal range $[47,95]$.

\section{Iron Removal Is not the Unique Therapeutic Target in HFE-Related Hemochromatosis}

\subsection{Other Preventive Actions to Avoid Iron Overload Complications}

Besides iron removal, it is important to prevent associated causes of organ damage, as mentioned previously. This holds especially true for hepatic lesions knowing the impact of excessive alcohol intake and viral hepatitis as cofactors of liver fibrosis, cirrhosis, and hepatocellular carcinoma. Moreover, NAFLD (Non Alcoholic Fatty Liver Disease) with the risk of NASH (Non-Alcoholic Steato-Hepatitis) represents an additional risk for hemochromatosis patients. The practitioner must complete the iron removal approach by nutritional recommendations on alcohol and glucido-lipidic regimens [47,95]. Moreover, avoiding the occurrence of viral B hepatitis through vaccination is critical. In addition, tea [100] has been demonstrated to limit iron absorption, and therefore, could be used as adjuvant to avoid recurrence of excessive iron stores after completion of iron removal. In the same way, the use of therapeutic oral calcium channel blockers has also been proposed due to its positive impact on urinary iron excretion related to DMT1 activity increase in the kidney [101]. The use of proton-pump inhibitors could also represent an interesting adjunct [102].

\subsection{The Development of a Pathophysiological Treatment Is a Major Goal}

Iron removal is a treatment that only cures iron excess, but clearly does not correct the hepcidin deficiency that generates iron metabolism disturbances, and some clinical observations do suggest that the removal of iron excess is not sufficient to treat hemochromatosis. Considering arthropathy, it is noteworthy that, despite a well-conducted iron depletive treatment, the symptomatology may persist and even become more severe [76]. This suggests that: (i) synovial iron deposition [103] may represent an inaccessible compartment for iron depletion by venesections because synovial fluid is not contiguous with serum; (ii) synovitis, that has been documented in hemochromatosis $[104,105]$ is irreversible despite effective iron depletion; and/or (iii) hepcidin deficiency leading to iron excess 
could be involved directly in symptomatic arthropathy and/or (iv) the mutations of the HFE gene, that encodes an HLA-like class I protein, could be involved directly in disease expression [106].

Considering the biochemical follow-up of patients, it is noteworthy that transferrin saturation levels may be found to be frequently increased during the maintenance therapeutic period, despite the absence of increased body iron stores. This could contribute to the appearance of clinical manifestations such as fatigue and arthropathy. It should be emphasized that, during the maintenance period, serum hepcidin levels are even lower than in iron overloaded patients $[98,107]$. Such hypohepcidinemia is expected to favor transferrin saturation increase and the appearance of NTBI that could participate in the arthritis of hemochromatosis patients.

Targeted treatment in the setting of hepcidin deficiency itself could represent an efficient way, as suggested by clinical observations obtained in hemochromatosis patients that have been transplanted for hepatocellular carcinoma [108]. The development of substitutive hepcidin treatment and/or of drugs stimulating hepcidin expression is under development and could be useful to complete the therapeutic arsenal, as suggested by results obtained with mini-hepcidins [109] and BMP known to induce hepcidin expression [110]. Clinical trials with hepcidin supplementation are ongoing (Clinical.trial.gov). Using antisense oligonucleotides for increasing hepcidin synthesis [111] or ferroportin antagonists [112] represents also further interesting innovative approaches. These different treatments could be especially indicated as an adjunct to venesections during the induction phase, and possibly as replacing venesections during maintenance therapy. Considering the overall safety and efficacy of the venesections, every putative treatment of hemochromatosis targeting iron metabolism must be without side-effects and easy to follow, suggesting especially that oral treatments providing exogenous hepcidin or inducing endogenous hepcidin synthesis might be preferable.

\section{Conclusions}

Iron remains the major therapeutic target during HFE-related hemochromatosis. However, targeting directly the iron stores by iron depletive treatment does not correct the pathophysiological defect of the disease. The development of treatments aimed at restoring iron homeostasis, especially by correcting hepcidin deficiency, could be useful to optimize the treatment, especially during the maintenance phase by controlling transferrin saturation with hopefully a favorable impact on the arthritis of hemochromatosis patients.

Funding: This research received no external funding.

Acknowledgments: The authors thank the Associations Fer-Métaux Essentiels-Recherche-Santé (AFeMERS), Fédération Française des Associations de Malades de l'Hémochromatose (FFAMH) and Association Hémochromatose Ouest for their supports.

Conflicts of Interest: The authors have no conflict of interest regarding this work.

\section{References}

1. Andrews, N.C. Disorders of iron metabolism. N. Engl. J. Med. 1999, 341, 1986-1995. [CrossRef] [PubMed]

2. Gunshin, H.; Mackenzie, B.; Berger, U.V.; Gunshin, Y.; Romero, M.F.; Boron, W.F.; Nussberger, S.; Gollan, J.L.; Hediger, M.A. Cloning and characterization of a mammalian proton-coupled metal-ion transporter. Nature 1997, 388, 482-488. [CrossRef] [PubMed]

3. McKie, A.T.; Barrow, D.; Latunde-Dada, G.O.; Rolfs, A.; Sager, G.; Mudaly, E.; Mudaly, M.; Richardson, C.; Barlow, D.; Bomford, A.; et al. An Iron-Regulated Ferric Reductase Associated with the Absorption of Dietary Iron. Science 2001, 291, 1755-1759. [CrossRef] [PubMed]

4. Shayeghi, M.; Latunde-Dada, G.O.; Oakhill, J.S.; Laftah, A.H.; Takeuchi, K.; Halliday, N.; Khan, Y.; Warley, A.; McCann, F.E.; Hider, R.C.; et al. Identification of an intestinal heme transporter. Cell 2005, 122, 789-801. [CrossRef] [PubMed]

5. Qiu, A.; Jansen, M.; Sakaris, A.; Min, S.H.; Chattopadhyay, S.; Tsai, E.; Sandoval, C.; Zhao, R.; Akabas, M.H.; Goldman, I.D. Identification of an intestinal folate transporter and the molecular basis for hereditary folate malabsorption. Cell 2006, 127, 917-928. [CrossRef] [PubMed] 
6. Bergamaschi, G.; Di Sabatino, A.; Pasini, A.; Ubezio, C.; Costanzo, F.; Grataroli, D.; Masotti, M.; Alvisi, C.; Corazza, G.R. Intestinal expression of genes implicated in iron absorption and their regulation by hepcidin. Clin. Nutr. Edinb. Scotl. 2017, 36, 1427-1433. [CrossRef] [PubMed]

7. Bothwell, T.H.; Pirzio-Biroli, G.; Finch, C.A. Iron absorption. I. Factors influencing absorption. J. Lab. Clin. Med. 1958, 51, 24-36. [PubMed]

8. McKie, A.T.; Marciani, P.; Rolfs, A.; Brennan, K.; Wehr, K.; Barrow, D.; Miret, S.; Bomford, A.; Peters, T.J.; Farzaneh, F; ; et al. A novel duodenal iron-regulated transporter, IREG1, implicated in the basolateral transfer of iron to the circulation. Mol. Cell 2000, 5, 299-309. [CrossRef]

9. Donovan, A.; Brownlie, A.; Zhou, Y.; Shepard, J.; Pratt, S.J.; Moynihan, J.; Paw, B.H.; Drejer, A.; Barut, B.; Zapata, A.; et al. Positional cloning of zebrafish ferroportin1 identifies a conserved vertebrate iron exporter. Nature 2000, 403, 776-781. [CrossRef] [PubMed]

10. Abboud, S.; Haile, D.J. A novel mammalian iron-regulated protein involved in intracellular iron metabolism. J. Biol. Chem. 2000, 275, 19906-19912. [CrossRef] [PubMed]

11. Osaki, S.; Johnson, D.A.; Frieden, E. The possible significance of the ferrous oxidase activity of ceruloplasmin in normal human serum. J. Biol. Chem. 1966, 241, 2746-2751. [PubMed]

12. Vulpe, C.D.; Kuo, Y.M.; Murphy, T.L.; Cowley, L.; Askwith, C.; Libina, N.; Gitschier, J.; Anderson, G.J. Hephaestin, a ceruloplasmin homologue implicated in intestinal iron transport, is defective in the sla mouse. Nat. Genet. 1999, 21, 195-199. [CrossRef] [PubMed]

13. Levy, J.E.; Jin, O.; Fujiwara, Y.; Kuo, F.; Andrews, N.C. Transferrin receptor is necessary for development of erythrocytes and the nervous system. Nat. Genet. 1999, 21, 396-399. [CrossRef] [PubMed]

14. Ohgami, R.S.; Campagna, D.R.; Greer, E.L.; Antiochos, B.; McDonald, A.; Chen, J.; Sharp, J.J.; Fujiwara, Y.; Barker, J.E.; Fleming, M.D. Identification of a ferrireductase required for efficient transferrin-dependent iron uptake in erythroid cells. Nat. Genet. 2005, 37, 1264-1269. [CrossRef] [PubMed]

15. Camaschella, C.; Roetto, A.; Cali, A.; De Gobbi, M.; Garozzo, G.; Carella, M.; Majorano, N.; Totaro, A.; Gasparini, P. The gene TFR2 is mutated in a new type of haemochromatosis mapping to 7q22. Nat. Genet. 2000, 25, 14-15. [CrossRef] [PubMed]

16. Griffiths, W.J.; Cox, T.M. Co-localization of the mammalian hemochromatosis gene product (HFE) and a newly identified transferrin receptor (TFR2) in intestinal tissue and cells. J. Histochem. Cytochem. 2003, 51, 613-624. [CrossRef] [PubMed]

17. Krause, A.; Neitz, S.; Magert, H.J.; Schulz, A.; Forssmann, W.G.; Schulz-Knappe, P.; Adermann, K. LEAP-1, a novel highly disulfide-bonded human peptide, exhibits antimicrobial activity. FEBS Lett. 2000, 480, 147-150. [CrossRef]

18. Park, C.H.; Valore, E.V.; Waring, A.J.; Ganz, T. Hepcidin, a urinary antimicrobial peptide synthesized in the liver. J. Biol. Chem. 2001, 276, 7806-7810. [CrossRef] [PubMed]

19. Pigeon, C.; Ilyin, G.; Courselaud, B.; Leroyer, P.; Turlin, B.; Brissot, P.; Loreal, O. A new mouse liver-specific gene, encoding a protein homologous to human antimicrobial peptide hepcidin, is overexpressed during iron overload. J. Biol. Chem. 2001, 276, 7811-7819. [CrossRef] [PubMed]

20. Nemeth, E.; Tuttle, M.S.; Powelson, J.; Vaughn, M.B.; Donovan, A.; Ward, D.M.; Ganz, T.; Kaplan, J. Hepcidin regulates cellular iron efflux by binding to ferroportin and inducing its internalization. Science 2004, 306, 2090-2093. [CrossRef] [PubMed]

21. Nicolas, G.; Bennoun, M.; Devaux, I.; Beaumont, C.; Grandchamp, B.; Kahn, A.; Vaulont, S. Lack of hepcidin gene expression and severe tissue iron overload in upstream stimulatory factor 2 (USF2) knockout mice. Proc. Natl. Acad. Sci. USA 2001, 98, 8780-8785. [CrossRef] [PubMed]

22. Nemeth, E.; Rivera, S.; Gabayan, V.; Keller, C.; Taudorf, S.; Pedersen, B.K.; Ganz, T. IL-6 mediates hypoferremia of inflammation by inducing the synthesis of the iron regulatory hormone hepcidin. J. Clin. Investig. 2004, 113, 1271-1276. [CrossRef] [PubMed]

23. Nicolas, G.; Viatte, L.; Bennoun, M.; Beaumont, C.; Kahn, A.; Vaulont, S. Hepcidin, A New Iron Regulatory Peptide. Blood Cells Mol. Dis. 2002, 29, 327-335. [CrossRef] [PubMed]

24. Peyssonnaux, C.; Nizet, V.; Johnson, R.S. Role of the hypoxia inducible factors HIF in iron metabolism. Cell Cycle 2008, 7, 28-32. [CrossRef] [PubMed]

25. Kautz, L.; Jung, G.; Valore, E.V.; Rivella, S.; Nemeth, E.; Ganz, T. Identification of erythroferrone as an erythroid regulator of iron metabolism. Nat. Genet. 2014, 46, 678-684. [CrossRef] [PubMed] 
26. Gehrke, S.G.; Kulaksiz, H.; Herrmann, T.; Riedel, H.D.; Bents, K.; Veltkamp, C.; Stremmel, W. Expression of hepcidin in hereditary hemochromatosis: Evidence for a regulation in response to serum transferrin saturation and non-transferrin-bound iron. Blood 2003, 102, 371-376. [CrossRef] [PubMed]

27. Ramey, G.; Deschemin, J.C.; Vaulont, S. Cross-talk between the mitogen activated protein kinase and bone morphogenetic protein/hemojuvelin pathways is required for the induction of hepcidin by holotransferrin in primary mouse hepatocytes. Haematologica 2009, 94, 765-772. [CrossRef] [PubMed]

28. Feder, J.N.; Tsuchihashi, Z.; Irrinki, A.; Lee, V.K.; Mapa, F.A.; Morikang, E.; Prass, C.E.; Starnes, S.M.; Wolff, R.K.; Parkkila, S.; et al. The hemochromatosis founder mutation in HLA-H disrupts beta2-microglobulin interaction and cell surface expression. J. Biol. Chem. 1997, 272, 14025-14028. [CrossRef] [PubMed]

29. Feder, J.N.; Penny, D.M.; Irrinki, A.; Lee, V.K.; Lebron, J.A.; Watson, N.; Tsuchihashi, Z.; Sigal, E.; Bjorkman, P.J.; Schatzman, R.C. The hemochromatosis gene product complexes with the transferrin receptor and lowers its affinity for ligand binding. Proc. Natl. Acad. Sci. USA 1998, 95, 1472-1477. [CrossRef] [PubMed]

30. Schmidt, P.J.; Toran, P.T.; Giannetti, A.M.; Bjorkman, P.J.; Andrews, N.C. The transferrin receptor modulates HFE-dependent regulation of hepcidin expression. Cell Metab. 2008, 7, 205-214. [CrossRef] [PubMed]

31. Goswami, T.; Andrews, N.C. Hereditary hemochromatosis protein, HFE, interaction with transferrin receptor 2 suggests a molecular mechanism for mammalian iron sensing. J. Biol. Chem. 2006, 281, 28494-28498. [CrossRef] [PubMed]

32. Schmidt, P.J.; Fleming, M.D. Transgenic HFE-dependent induction of hepcidin in mice does not require transferrin receptor-2. Am. J. Hematol. 2012, 87, 588-595. [CrossRef] [PubMed]

33. Meynard, D.; Kautz, L.; Darnaud, V.; Canonne-Hergaux, F.; Coppin, H.; Roth, M.P. Lack of the bone morphogenetic protein BMP6 induces massive iron overload. Nat. Genet. 2009, 41, 478-481. [CrossRef] [PubMed]

34. Andriopoulos, B., Jr.; Corradini, E.; Xia, Y.; Faasse, S.A.; Chen, S.; Grgurevic, L.; Knutson, M.D.; Pietrangelo, A.; Vukicevic, S.; Lin, H.Y.; et al. BMP6 is a key endogenous regulator of hepcidin expression and iron metabolism. Nat. Genet. 2009, 41, 482-487. [CrossRef] [PubMed]

35. Casanovas, G.; Mleczko-Sanecka, K.; Altamura, S.; Hentze, M.W.; Muckenthaler, M.U. Bone morphogenetic protein (BMP)-responsive elements located in the proximal and distal hepcidin promoter are critical for its response to HJV/BMP/SMAD. J. Mol. Med. 2009, 87, 471-480. [CrossRef] [PubMed]

36. Island, M.L.; Jouanolle, A.M.; Mosser, A.; Deugnier, Y.; David, V.; Brissot, P.; Loreal, O. A new mutation in the hepcidin promoter impairs its BMP response and contributes to a severe phenotype in HFE related hemochromatosis. Haematologica 2009, 94, 720-724. [CrossRef] [PubMed]

37. Canali, S.; Zumbrennen-Bullough, K.B.; Core, A.B.; Wang, C.-Y.; Nairz, M.; Bouley, R.; Swirski, F.K.; Babitt, J.L. Endothelial cells produce bone morphogenetic protein 6 required for iron homeostasis in mice. Blood 2017, 129, 405-414. [CrossRef] [PubMed]

38. Rausa, M.; Pagani, A.; Nai, A.; Campanella, A.; Gilberti, M.E.; Apostoli, P.; Camaschella, C.; Silvestri, L. Bmp6 expression in murine liver non parenchymal cells: A mechanism to control their high iron exporter activity and protect hepatocytes from iron overload? PLOS ONE 2015, 10, e0122696. [CrossRef] [PubMed]

39. Koch, P.-S.; Olsavszky, V.; Ulbrich, F.; Sticht, C.; Demory, A.; Leibing, T.; Henzler, T.; Meyer, M.; Zierow, J.; Schneider, S.; et al. Angiocrine Bmp2 signaling in murine liver controls normal iron homeostasis. Blood 2017, 129, 415-419. [CrossRef] [PubMed]

40. Wang, R.H.; Li, C.; Xu, X.; Zheng, Y.; Xiao, C.; Zerfas, P.; Cooperman, S.; Eckhaus, M.; Rouault, T.; Mishra, L.; et al. A role of SMAD4 in iron metabolism through the positive regulation of hepcidin expression. Cell Metab. 2005, 2, 399-409. [CrossRef] [PubMed]

41. Kautz, L.; Meynard, D.; Monnier, A.; Darnaud, V.; Bouvet, R.; Wang, R.H.; Deng, C.; Vaulont, S.; Mosser, J.; Coppin, H.; et al. Iron regulates phosphorylation of Smad1/5/8 and gene expression of Bmp6, Smad7, Id1, and Atoh8 in the mouse liver. Blood 2008, 112, 1503-1509. [CrossRef] [PubMed]

42. Verga Falzacappa, M.V.; Casanovas, G.; Hentze, M.W.; Muckenthaler, M.U. A bone morphogenetic protein (BMP)-responsive element in the hepcidin promoter controls HFE2-mediated hepatic hepcidin expression and its response to IL-6 in cultured cells. J. Mol. Med. 2008, 86, 531-540. [CrossRef] [PubMed] 
43. D'Alessio, F.; Hentze, M.W.; Muckenthaler, M.U. The hemochromatosis proteins HFE, TFR2, and HJV form a membrane-associated protein complex for hepcidin regulation. J. Hepatol. 2012, 57, 1052-1060. [CrossRef] [PubMed]

44. Pantopoulos, K. Iron regulation of hepcidin through HFE and HJV: Common or distinct pathways? Hepatology 2015, 62, 1922-1923. [CrossRef] [PubMed]

45. Brissot, P.; Loreal, O. Iron metabolism and related genetic diseases: A cleared land, keeping mysteries. J. Hepatol 2016, 64, 505-515. [CrossRef] [PubMed]

46. Hamdi-Roze, H.; Beaumont-Epinette, M.P.; Ben Ali, Z.; Le Lan, C.; Loustaud-Ratti, V.; Causse, X.; Loreal, O.; Deugnier, Y.; Brissot, P.; Jouanolle, A.M.; et al. Rare HFE variants are the most frequent cause of hemochromatosis in non-c282y homozygous patients with hemochromatosis. Am. J. Hematol. 2016, 91, 1202-1205. [CrossRef] [PubMed]

47. Brissot, P.; Pietrangelo, A.; Adams, P.C.; de Graaff, B.; McLaren, C.E.; Loréal, O. Haemochromatosis. Nat. Rev. Dis. Primer 2018, 4, 18016. [CrossRef] [PubMed]

48. Allen, K.J.; Gurrin, L.C.; Constantine, C.C.; Osborne, N.J.; Delatycki, M.B.; Nicoll, A.J.; McLaren, C.E.; Bahlo, M.; Nisselle, A.E.; Vulpe, C.D.; et al. Iron-overload-related disease in HFE hereditary hemochromatosis. N. Engl. J. Med. 2008, 358, 221-230. [CrossRef] [PubMed]

49. Van Dijk, B.A.C.; Laarakkers, C.M.M.; Klaver, S.M.; Jacobs, E.M.G.; van Tits, L.J.H.; Janssen, M.C.H.; Swinkels, D.W. Serum hepcidin levels are innately low in HFE-related haemochromatosis but differ between C282Y-homozygotes with elevated and normal ferritin levels. Br. J. Haematol. 2008, 142, 979-985. [CrossRef] [PubMed]

50. Hentze, M.W.; Kuhn, L.C. Molecular control of vertebrate iron metabolism: mRNA-based regulatory circuits operated by iron, nitric oxide, and oxidative stress. Proc. Natl. Acad. Sci. USA 1996, 93, 8175-8182. [CrossRef] [PubMed]

51. Ponka, P. Cellular iron metabolism. Kidney Int. Suppl. 1999, 69, S2-S11. [CrossRef] [PubMed]

52. Ponka, P.; Lok, C.N. The transferrin receptor: Role in health and disease. Int. J. Biochem. Cell Biol. 1999, 31, 1111-1137. [CrossRef]

53. Arosio, P.; Carmona, F.; Gozzelino, R.; Maccarinelli, F.; Poli, M. The importance of eukaryotic ferritins in iron handling and cytoprotection. Biochem. J. 2015, 472, 1-15. [CrossRef] [PubMed]

54. Hershko, C.; Peto, T.E. Non-transferrin plasma iron. Br. J. Haematol 1987, 66, 149-151. [CrossRef] [PubMed]

55. Loreal, O.; Gosriwatana, I.; Guyader, D.; Porter, J.; Brissot, P.; Hider, R.C. Determination of non-transferrin-bound iron in genetic hemochromatosis using a new HPLC-based method. J. Hepatol. 2000, 32, 727-733. [CrossRef]

56. Grootveld, M.; Bell, J.D.; Halliwell, B.; Aruoma, O.I.; Bomford, A.; Sadler, P.J. Non-transferrin-bound iron in plasma or serum from patients with idiopathic hemochromatosis. Characterization by high performance liquid chromatography and nuclear magnetic resonance spectroscopy. J. Biol. Chem. 1989, 264, 4417-4422. [PubMed]

57. Liuzzi, J.P.; Aydemir, F.; Nam, H.; Knutson, M.D.; Cousins, R.J. Zip14 (Slc39a14) mediates non-transferrin-bound iron uptake into cells. Proc. Natl. Acad. Sci. USA 2006, 103, 13612-13617. [CrossRef] [PubMed]

58. Brissot, P.; Wright, T.L.; Ma, W.L.; Weisiger, R.A. Efficient clearance of non-transferrin-bound iron by rat liver. Implications for hepatic iron loading in iron overload states. J. Clin. Investig. 1985, 76, 1463-1470. [CrossRef] [PubMed]

59. Brissot, P.; Bolder, U.; Schteingart, C.D.; Arnaud, J.; Hofmann, A.F. Intestinal absorption and enterohepatic cycling of biliary iron originating from plasma non-transferrin-bound iron in rats. Hepatology 1997, 25, 1457-1461. [CrossRef] [PubMed]

60. Hubert, N.; Lescoat, G.; Sciot, R.; Moirand, R.; Jego, P.; Leroyer, P.; Brissot, P. Regulation of ferritin and transferrin receptor expression by iron in human hepatocyte cultures. J. Hepatol. 1993, 18, 301-312. [CrossRef]

61. Sciot, R.; Verhoeven, G.; Van Eyken, P.; Cailleau, J.; Desmet, V.J. Transferrin receptor expression in rat liver: Immunohistochemical and biochemical analysis of the effect of age and iron storage. Hepatology 1990, 11, 416-427. [CrossRef] [PubMed]

62. Jenkitkasemwong, S.; Wang, C.Y.; Coffey, R.; Zhang, W.; Chan, A.; Biel, T.; Kim, J.S.; Hojyo, S.; Fukada, T.; Knutson, M.D. SLC39A14 Is Required for the Development of Hepatocellular Iron Overload in Murine Models of Hereditary Hemochromatosis. Cell Metab. 2015, 22, 138-150. [CrossRef] [PubMed] 
63. Roetto, A.; Papanikolaou, G.; Politou, M.; Alberti, F.; Girelli, D.; Christakis, J.; Loukopoulos, D.; Camaschella, C. Mutant antimicrobial peptide hepcidin is associated with severe juvenile hemochromatosis. Nat. Genet. 2003, 33, 221-222. [CrossRef] [PubMed]

64. Papanikolaou, G.; Samuels, M.E.; Ludwig, E.H.; MacDonald, M.L.; Franchini, P.L.; Dube, M.P.; Andres, L.; MacFarlane, J.; Sakellaropoulos, N.; Politou, M.; et al. Mutations in HFE2 cause iron overload in chromosome 1q-linked juvenile hemochromatosis. Nat. Genet. 2004, 36, 77-82. [CrossRef] [PubMed]

65. Bardou-Jacquet, E.; Cunat, S.; Beaumont-Epinette, M.-P.; Kannengiesser, C.; Causse, X.; Sauvion, S.; Pouliquen, B.; Deugnier, Y.; David, V.; Loréal, O.; et al. Variable age of onset and clinical severity in transferrin receptor 2 related haemochromatosis: Novel observations. Br. J. Haematol. 2013, 162, $278-281$. [CrossRef] [PubMed]

66. Niederau, C.; Fischer, R.; Sonnenberg, A.; Stremmel, W.; Trampisch, H.J.; Strohmeyer, G. Survival and causes of death in cirrhotic and in noncirrhotic patients with primary hemochromatosis. N. Engl. J. Med. 1985, 313, 1256-1262. [CrossRef] [PubMed]

67. Niederau, C.; Fischer, R.; Purschel, A.; Stremmel, W.; Haussinger, D.; Strohmeyer, G. Long-term survival in patients with hereditary hemochromatosis [see comments]. Gastroenterology 1996, 110, 1107-1119. [CrossRef] [PubMed]

68. Loreal, O.; Deugnier, Y.; Moirand, R.; Lauvin, L.; Guyader, D.; Jouanolle, H.; Turlin, B.; Lescoat, G.; Brissot, P. Liver fibrosis in genetic hemochromatosis. Respective roles of iron and non-iron-related factors in 127 homozygous patients. J. Hepatol. 1992, 16, 122-127. [PubMed]

69. Guyader, D.; Jacquelinet, C.; Moirand, R.; Turlin, B.; Mendler, M.H.; Chaperon, J.; David, V.; Brissot, P.; Adams, P.; Deugnier, Y. Noninvasive prediction of fibrosis in C282Y homozygous hemochromatosis. Gastroenterology 1998, 115, 929-936. [CrossRef]

70. Deugnier, Y.M.; Loreal, O.; Turlin, B.; Guyader, D.; Jouanolle, H.; Moirand, R.; Jacquelinet, C.; Brissot, P. Liver pathology in genetic hemochromatosis: A review of 135 homozygous cases and their bioclinical correlations. Gastroenterology 1992, 102, 2050-2059. [CrossRef]

71. Dixon, S.J.; Lemberg, K.M.; Lamprecht, M.R.; Skouta, R.; Zaitsev, E.M.; Gleason, C.E.; Patel, D.N.; Bauer, A.J.; Cantley, A.M.; Yang, W.S.; et al. Ferroptosis: An iron-dependent form of nonapoptotic cell death. Cell 2012, 149, 1060-1072. [CrossRef] [PubMed]

72. Dixon, S.J.; Stockwell, B.R. The role of iron and reactive oxygen species in cell death. Nat. Chem. Biol. 2014, 10, 9-17. [CrossRef] [PubMed]

73. Houglum, K.; Bedossa, P.; Chojkier, M. TGF-beta and collagen-alpha 1 (I) gene expression are increased in hepatic acinar zone 1 of rats with iron overload. Am. J. Physiol. 1994, 267, G908-G913. [CrossRef] [PubMed]

74. Gualdi, R.; Casalgrandi, G.; Montosi, G.; Ventura, E.; Pietrangelo, A. Excess iron into hepatocytes is required for activation of collagen type I gene during experimental siderosis. Gastroenterology 1994, 107, 1118-1124. [CrossRef]

75. Deugnier, Y.M.; Guyader, D.; Crantock, L.; Lopez, J.M.; Turlin, B.; Yaouanq, J.; Jouanolle, H.; Campion, J.P.; Launois, B.; Halliday, J.W.; et al. Primary liver cancer in genetic hemochromatosis: A clinical, pathological, and pathogenetic study of 54 cases. Gastroenterology 1993, 104, 228-234. [CrossRef]

76. Guggenbuhl, P.; Brissot, P.; Loreal, O. Miscellaneous non-inflammatory musculoskeletal conditions. Haemochromatosis: The bone and the joint. Best Pract. Res. Clin. Rheumatol 2011, 25, 6649-6664. [CrossRef]

77. Wardman, P.; Candeias, L.P. Fenton chemistry: An introduction. Radiat. Res. 1996, 145, 523-531. [CrossRef] [PubMed]

78. Bacon, B.R.; Britton, R.S. Hepatic injury in chronic iron overload. Role of lipid peroxidation. Chem. Biol. Interact. 1989, 70, 183-226. [CrossRef]

79. Bacon, B.R.; Tavill, A.S.; Brittenham, G.M.; Park, C.H.; Recknagel, R.O. Hepatic lipid peroxidation in vivo in rats with chronic iron overload. J. Clin. Investig. 1983, 71, 429-439. [CrossRef] [PubMed]

80. Bacon, B.R.; O'Neill, R.; Britton, R.S. Hepatic mitochondrial energy production in rats with chronic iron overload. Gastroenterology 1993, 105, 1134-1140. [CrossRef]

81. Le Lan, C.; Loreal, O.; Cohen, T.; Ropert, M.; Glickstein, H.; Laine, F.; Pouchard, M.; Deugnier, Y.; Le Treut, A.; Breuer, W.; et al. Redox active plasma iron in C282Y/C282Y hemochromatosis. Blood 2005, 105, 4527-4531. [CrossRef] [PubMed]

82. Cabantchik, Z.I.; Breuer, W.; Zanninelli, G.; Cianciulli, P. LPI-labile plasma iron in iron overload. Best Pr. Res. Clin. Haematol 2005, 18, 277-287. [CrossRef] [PubMed] 
83. Milet, J.; Dehais, V.; Bourgain, C.; Jouanolle, A.M.; Mosser, A.; Perrin, M.; Morcet, J.; Brissot, P.; David, V.; Deugnier, Y.; et al. Common variants in the BMP2, BMP4, and HJV genes of the hepcidin regulation pathway modulate HFE hemochromatosis penetrance. Am. J. Hum. Genet. 2007, 81, 799-807. [CrossRef] [PubMed]

84. De Tayrac, M.; Roth, M.-P.; Jouanolle, A.-M.; Coppin, H.; le Gac, G.; Piperno, A.; Férec, C.; Pelucchi, S.; Scotet, V.; Bardou-Jacquet, E.; et al. Genome-wide association study identifies TF as a significant modifier gene of iron metabolism in HFE hemochromatosis. J. Hepatol. 2015, 62, 664-672. [CrossRef] [PubMed]

85. McLaren, C.E.; Emond, M.J.; Subramaniam, V.N.; Phatak, P.D.; Barton, J.C.; Adams, P.C.; Goh, J.B.; McDonald, C.J.; Powell, L.W.; Gurrin, L.C.; et al. Exome sequencing in HFE C282Y homozygous men with extreme phenotypes identifies a GNPAT variant associated with severe iron overload. Hepatology 2015, 62, 429-439. [CrossRef] [PubMed]

86. Tchernitchko, D.; Scotet, V.; Lefebvre, T.; L'Hostis, C.; Gourlaouen, I.; Merour, M.-C.; Rebah, K.; Peoc'h, K.; Assari, S.; Ferec, C.; et al. GNPAT polymorphism rs11558492 is not associated with increased severity in a large cohort of HFE p.Cys282Tyr homozygous patients. Hepatology 2017, 65, 1069-1071. [CrossRef] [PubMed]

87. Levstik, A.; Stuart, A.; Adams, P.C. GNPAT variant (D519G) is not associated with an elevated serum ferritin or iron removed by phlebotomy in patients referred for C282Y-linked hemochromatosis. Ann. Hepatol. 2016, 15, 907-910. [CrossRef] [PubMed]

88. Greni, F.; Valenti, L.; Mariani, R.; Pelloni, I.; Rametta, R.; Busti, F.; Ravasi, G.; Girelli, D.; Fargion, S.; Galimberti, S.; et al. GNPAT rs11558492 is not a Major Modifier of Iron Status: Study of Italian Hemochromatosis Patients and Blood Donors. Ann. Hepatol. 2017, 16, 451-456. [CrossRef] [PubMed]

89. Fletcher, L.M.; Dixon, J.L.; Purdie, D.M.; Powell, L.W.; Crawford, D.H.G. Excess alcohol greatly increases the prevalence of cirrhosis in hereditary hemochromatosis. Gastroenterology 2002, 122, 281-289. [CrossRef] [PubMed]

90. Nelson, J.E.; Bhattacharya, R.; Lindor, K.D.; Chalasani, N.; Raaka, S.; Heathcote, E.J.; Miskovsky, E.; Shaffer, E.; Rulyak, S.J.; Kowdley, K.V. HFE C282Y mutations are associated with advanced hepatic fibrosis in Caucasians with nonalcoholic steatohepatitis. Hepatology 2007, 46, 723-729. [CrossRef] [PubMed]

91. Pollicino, T.; Vegetti, A.; Saitta, C.; Ferrara, F.; Corradini, E.; Raffa, G.; Pietrangelo, A.; Raimondo, G. Hepatitis B virus DNA integration in tumour tissue of a non-cirrhotic HFE-haemochromatosis patient with hepatocellular carcinoma. J. Hepatol. 2013, 58, 190-193. [CrossRef] [PubMed]

92. Diwakaran, H.H.; Befeler, A.S.; Britton, R.S.; Brunt, E.M.; Bacon, B.R. Accelerated hepatic fibrosis in patients with combined hereditary hemochromatosis and chronic hepatitis C infection. J. Hepatol. 2002, 36, 687-691. [CrossRef]

93. Stickel, F.; Buch, S.; Zoller, H.; Hultcrantz, R.; Gallati, S.; Österreicher, C.; Finkenstedt, A.; Stadlmayr, A.; Aigner, E.; Sahinbegovic, E.; et al. Evaluation of genome-wide loci of iron metabolism in hereditary hemochromatosis identifies PCSK7 as a host risk factor of liver cirrhosis. Hum. Mol. Genet. 2014, 23, 3883-3890. [CrossRef] [PubMed]

94. Valenti, L.; Maggioni, P.; Piperno, A.; Rametta, R.; Pelucchi, S.; Mariani, R.; Dongiovanni, P.; Fracanzani, A.L.; Fargion, S. Patatin-like phospholipase domain containing-3 gene I148M polymorphism, steatosis, and liver damage in hereditary hemochromatosis. World J. Gastroenterol. 2012, 18, 2813-2820. [CrossRef] [PubMed]

95. Adams, P.; Altes, A.; Brissot, P.; Butzeck, B.; Cabantchik, I.; Cançado, R.; Distante, S.; Evans, P.; Evans, R.; Ganz, T.; et al. Contributors and Hemochromatosis International Taskforce Therapeutic recommendations in HFE hemochromatosis for p.Cys282Tyr (C282Y/C282Y) homozygous genotype. Hepatol. Int. 2018, 12, 83-86. [CrossRef] [PubMed]

96. Falize, L.; Guillygomarc'h, A.; Perrin, M.; Laine, F.; Guyader, D.; Brissot, P.; Turlin, B.; Deugnier, Y. Reversibility of hepatic fibrosis in treated genetic hemochromatosis: A study of 36 cases. Hepatology 2006, 44, 472-477. [CrossRef] [PubMed]

97. Phatak, P.; Brissot, P.; Wurster, M.; Adams, P.C.; Bonkovsky, H.L.; Gross, J.; Malfertheiner, P.; McLaren, G.D.; Niederau, C.; Piperno, A.; et al. A phase 1/2, dose-escalation trial of deferasirox for the treatment of iron overload in HFE-related hereditary hemochromatosis. Hepatology 2010, 52, 1671-1779. [CrossRef] [PubMed]

98. Rombout-Sestrienkova, E.; Koek, G.H.; Neslo, R.; van Kraaij, M.; Menheere, P.P.; Masclee, A.; Swinkels, D.W. Course of iron parameters in HFE-hemochromatosis patients during initial treatment with erythrocytapheresis compared to phlebotomy. J. Clin. Apheresis 2016, 31, 564-570. [CrossRef] [PubMed] 
99. Mast, A.E.; Schlumpf, K.S.; Wright, D.J.; Johnson, B.; Glynn, S.A.; Busch, M.P.; Olbina, G.; Westerman, M.; Nemeth, E.; Ganz, T. NHLBI Retrovirus Epidemiology Donor Study-II (REDS-II) Hepcidin level predicts hemoglobin concentration in individuals undergoing repeated phlebotomy. Haematologica 2013, 98, 1324-1330. [CrossRef] [PubMed]

100. Kaltwasser, J.P.; Werner, E.; Schalk, K.; Hansen, C.; Gottschalk, R.; Seidl, C. Clinical trial on the effect of regular tea drinking on iron accumulation in genetic haemochromatosis. Gut 1998, 43, 699-704. [CrossRef] [PubMed]

101. Ludwiczek, S.; Theurl, I.; Muckenthaler, M.U.; Jakab, M.; Mair, S.M.; Theurl, M.; Kiss, J.; Paulmichl, M.; Hentze, M.W.; Ritter, M.; et al. Ca2+ channel blockers reverse iron overload by a new mechanism via divalent metal transporter-1. Nat. Med. 2007, 13, 448-454. [CrossRef] [PubMed]

102. Vanclooster, A.; van Deursen, C.; Jaspers, R.; Cassiman, D.; Koek, G. Proton Pump Inhibitors Decrease Phlebotomy Need in HFE Hemochromatosis: Double-Blind Randomized Placebo-Controlled Trial. Gastroenterology 2017, 153, 678-680. [CrossRef] [PubMed]

103. Schumacher, H.R. Articular cartilage in the degenerative arthropathy of hemochromatosis. Arthritis Rheum. 1982, 25, 1460-1468. [CrossRef] [PubMed]

104. Heiland, G.R.; Aigner, E.; Dallos, T.; Sahinbegovic, E.; Krenn, V.; Thaler, C.; Weiss, G.; Distler, J.H.; Datz, C.; Schett, G.; et al. Synovial immunopathology in haemochromatosis arthropathy. Ann. Rheum. Dis. 2010, 69, 1214-1219. [CrossRef] [PubMed]

105. Carroll, G.J.; Sharma, G.; Upadhyay, A.; Jazayeri, J.A. Ferritin concentrations in synovial fluid are higher in osteoarthritis patients with HFE gene mutations (C282Y or H63D). Scand. J. Rheumatol. 2010, 39, 413-420. [CrossRef] [PubMed]

106. Reuben, A.; Chung, J.W.; Lapointe, R.; Santos, M.M. The hemochromatosis protein HFE 20 years later: An emerging role in antigen presentation and in the immune system. Immun. Inflamm. Dis. 2017, 5, $218-232$. [CrossRef] [PubMed]

107. Bardou-Jacquet, E.; Lainé, F.; Guggenbuhl, P.; Morcet, J.; Jézéquel, C.; Guyader, D.; Moirand, R.; Deugnier, Y. Worse Outcomes of Patients with HFE Hemochromatosis With Persistent Increases in Transferrin Saturation During Maintenance Therapy. Clin. Gastroenterol. Hepatol. 2017, 15, 1620-1627. [CrossRef] [PubMed]

108. Bardou-Jacquet, E.; Philip, J.; Lorho, R.; Ropert, M.; Latournerie, M.; Houssel-Debry, P.; Guyader, D.; Loreal, O.; Boudjema, K.; Brissot, P. Liver transplantation normalizes serum hepcidin level and cures iron metabolism alterations in HFE hemochromatosis. Hepatology 2014, 59, 839-847. [CrossRef] [PubMed]

109. Preza, G.C.; Ruchala, P.; Pinon, R.; Ramos, E.; Qiao, B.; Peralta, M.A.; Sharma, S.; Waring, A.; Ganz, T.; Nemeth, E. Minihepcidins are rationally designed small peptides that mimic hepcidin activity in mice and may be useful for the treatment of iron overload. J. Clin. Investig. 2011, 121, 4880-4888. [CrossRef] [PubMed]

110. Corradini, E.; Schmidt, P.J.; Meynard, D.; Garuti, C.; Montosi, G.; Chen, S.; Vukicevic, S.; Pietrangelo, A.; Lin, H.Y.; Babitt, J.L. BMP6 treatment compensates for the molecular defect and ameliorates hemochromatosis in HFE knockout mice. Gastroenterology 2010, 139, 1721-1729. [CrossRef] [PubMed]

111. Guo, S.; Casu, C.; Gardenghi, S.; Booten, S.; Aghajan, M.; Peralta, R.; Watt, A.; Freier, S.; Monia, B.P.; Rivella, S. Reducing TMPRSS6 ameliorates hemochromatosis and $\beta$-thalassemia in mice. J. Clin. Investig. 2013, 123, 1531-1541. [CrossRef] [PubMed]

112. Ross, S.L.; Biswas, K.; Rottman, J.; Allen, J.R.; Long, J.; Miranda, L.P.; Winters, A.; Arvedson, T.L. Identification of Antibody and Small Molecule Antagonists of Ferroportin-Hepcidin Interaction. Front. Pharmacol. 2017, 8, 838. [CrossRef] [PubMed]

(C) 2018 by the authors. Licensee MDPI, Basel, Switzerland. This article is an open access article distributed under the terms and conditions of the Creative Commons Attribution (CC BY) license (http:/ / creativecommons.org/licenses/by/4.0/). 


\title{
HFE Related Hemochromatosis: Uncovering the Inextricable Link between Iron Homeostasis and the Immunological System
}

\author{
Graça Porto ${ }^{1,2,3, *}$, Eugénia Cruz ${ }^{1,2}$, Maria José Teles ${ }^{1,4}$ and Maria de Sousa ${ }^{2}$ \\ 1 Hematology, Centro Hospitalar Universitário do Porto (CHUP), 4099-001 Porto, Portugal \\ 2 Basic \& Clinical Research on Iron Biology, Instituto de Investigação e Inovação em Saúde (I3S) \& Instituto de \\ Biologia Molecular e Celular (IBMC), 4200-135 Porto, Portugal \\ 3 Molecular Pathology and Immunology, Instituto de Ciências Biomédicas Abel Salazar (ICBAS), \\ Universidade do Porto, 4050-313 Porto, Portugal \\ 4 Clinical Pathology, Centro Hospitalar Universitário de S. João (CHUSJ), 4200-319 Porto, Portugal \\ * Correspondence: gporto@ibmc.up.pt
}

Received: 15 July 2019; Accepted: 15 August 2019; Published: 22 August 2019

\begin{abstract}
The HFE gene (OMIM 235200), most commonly associated with the genetic iron overload disorder Hemochromatosis, was identified by Feder et al. in 1996, as a major histocompatibilty complex (MHC) class I like gene, first designated human leukocyte antigen-H (HLA-H). This discovery was thus accomplished 20 years after the realization of the first link between the then "idiopathic" hemochromatosis and the human leukocyte antigens (HLA). The availability of a good genetic marker in subjects homozygous for the $\mathrm{C} 282 \mathrm{Y}$ variant in HFE (hereditary Fe), the reliability in serum markers such as transferrin saturation and serum ferritin, plus the establishment of noninvasive methods for the estimation of hepatic iron overload, all transformed hemochromatosis into a unique age related disease where prevention became the major goal. We were challenged by the finding of iron overload in a 9-year-old boy homozygous for the C282Y HFE variant, with two brothers aged 11 and 5 also homozygous for the mutation. We report a 20 year follow-up during which the three boys were seen yearly with serial determinations of iron parameters and lymphocyte counts. This paper is divided in three sections: Learning, applying, and questioning. The result is the illustration of hemochromatosis as an age related disease in the transition from childhood to adult life and the confirmation of the inextricable link between iron overload and the cells of the immune system.
\end{abstract}

Keywords: hemochromatosis; HFE; natural history; T lymphocytes; MHC; CD8+ T cells; prevention

\section{Introduction}

The practice of vaccination and the use of antibiotics provoked a significant decrease of infectious disease in the spectrum of modern clinical practice. That decrease uncovered simultaneously the appearance of other diseases whose presentation relates mainly to age. HFE-related hemochromatosis is a genetic disorder of iron overload. The combination of some luck, progress in the immunology of transplantation, progress of the understanding of the regulation of iron metabolism, progress in genomics, progress in the development of transgenic mice and in the characterization of adaptive immunity cell populations resulted in a sequence of events responsible for permitting today the early diagnosis and prevention of the iron overload induced clinical manifestations of the disease. Human HFE-related hemochromatosis has been the subject of several reviews by prominent researchers in the field [1,2]. In general, emphasis in the pathophysiology of the disease has been focused on the role of hepcidin in iron homeostasis [3,4]. Less attention has been directed to the role of HFE in immunology [5-7] and to the potential contribution of lymphoid cell numbers to that same pathophysiology [8-10]. 
In the present paper, under "learning", we briefly review the evidence sustaining the importance of immunology in HFE-related hemochromatosis, starting by the improbable discovery of its link with HLA to the discovery of the HFE gene as a MHC class I-like gene and its later association with selected immune defects. Under "applying", we report a 20 year follow up of iron parameters and lymphocyte counts in three children homozygous for the C282Y HFE variant who started to express signs of iron overload in their transition from childhood to adult life. Under "questioning", we explore the issue of the still unexplained immunological functions of HFE. The paper concludes with a brief overview of its implications for the clinical practice and for the immunological theory.

\section{Learning: A Brief Historical Sequence Where the Improbable Led to Discovery}

In 1975 it was improbable to think that HLA could be of clinical importance beyond histocompatibility or diseases with an immunological background. However, Simon thought the improbable and encountered in Fauchet an immunogeneticist open to doing the HLA typing of 20 "idiopathic" hemochromatosis" patients to find 17 with HLA A3 [11]. The result was the discovery, first published in 1975 in French [11] and in 1976 in the Lancet paper with the title, "HLA and "non-immunological" disease: idiopathic haemochromatosis" [12].

The publications of Simon, Fauchet and coworkers were to provide some background to a postulate published in 1978 saying that the immunological system could have a role in the surveillance of iron toxicity [13]. That postulate was followed by a series of studies of immunological cell populations in patients with "idiopathic" hemochromatosis [8,9,14,15], preceding the finding by Feder et al. in 1996 of the hemochromatosis gene as a novel MHC class I-like gene [16], closing a circle of 21 years from the improbable to the discovery.

Radical changes followed the discovery of the hemochromatosis gene and its association with the C282Y HFE variant. The introduction of genetic testing, combined with Magnetic Resonance Imaging (MRI) as a non-invasive measure of liver iron concentration, the systematic family screening, approaches to disease penetrance from large population studies, all led to a radical change in the clinical presentation and timing of diagnosis well demonstrated by the decreasing frequency of severe liver disease [17].

HFE-related hemochromatosis appears thus as a "dream like" age related disease, with a strong genetic marker, reliable and reproducible serum biochemical markers, namely transferrin saturation and serum ferritin, and confirmatory non-invasive tools all enabling diagnosis much before the clinical presentation of the disease.

The surprise, however, arises from the fact that a disease thought of as non-immunological, can be seen inevitably as an immunological disease. Firstly, the gene is an MHC class I like gene in strong linkage with other genes within the MHC cluster $[18,19]$. Secondly, the very early studies of lymphoid cell populations in patients with (at the time) idiopathic hemochromatosis demonstrated abnormally high CD4/CD8 ratios in those with a more severe iron overload [14]. At that time, it was also demonstrated that after complete iron depletion by repeated phlebotomies, entry of iron measured by changes in transferrin saturation was faster in patients with the highest CD4/CD8 ratios [14]. Later, a greater importance was attributed to the finding of low numbers of CD8+ T cells associated with the severity of iron overload $[9,20]$ and the demonstration that the low CD8+ T lymphocyte numbers in hemochromatosis are due to defects in the most mature effector memory cells [21]. When those defects were described, they generated some surprise and confusion amongst researchers and clinicians because of the previously existing evidence of iron induced expansions of T lymphocyte populations, namely, relative expansions of CD8+ T lymphocytes, both in experimental models of Fe-citrate injection [22,23] and in clinical models of transfusional iron overload [24,25]. The reciprocal effect, i.e., that primary immune defects could, in turn, contribute to iron overload, was next confirmed with a number of experimental studies examining and confirming the presence of iron overload in mice deficient in selected [26-28] or total lymphocytes [29] and a more severe phenotype in mice lacking 
both HFE and $\beta 2$-microglobulin [30]. Surprisingly, mice lacking only classical MHC class I molecules also developed iron overload [31].

The mechanisms underlying the lymphocyte defects in hemochromatosis are still poorly understood. The most recent evidence points to the possibility of a continuous effect where iron may sustain a constant activation, self-renewal and proliferation of CD8+ cells, and this may eventually lead to exhaustion of the effector memory T cells [32].

Regarding the mechanism "how" could lymphocyte defects contribute to iron overload, it is not until 2014 that Pinto and co-workers, in an extensive analysis of the interaction of lymphocytes with non-transferrin bound iron (NTBI), demonstrated that lymphocytes can take in NTBI in vitro [33] and that in vivo lymphocyte transfer can correct the iron overload of immune-deficient mice [10], closing thus another circle: From firm but unexplained observations to the demonstration of how lymphoid cell numbers could have a role in the control of iron overload, i.e., by acting as a circulating pool capable of "buffering" NTBI.

Evidence of the inextricable connection between iron homeostasis and the adaptive immune system recently gained a novel impulse with the demonstration that patients with a homozygous p.Tyr20His mutation in the transferrin receptor 1 (TfR1) have a combined immunodeficiency characterized by normal numbers but impaired function of $\mathrm{T}$ and $\mathrm{B}$ cells [34]. Besides TfR1, other iron regulatory genes had also been previously found to be critical for lymphocyte activation and function, namely H-ferritin, whose conditional deletion in mice was shown to reduce $\mathrm{B}$ and $\mathrm{T}$ lymphocyte populations [35] or hepcidin, whose expression is increased during lymphocyte activation and shown to be necessary for proper lymphocyte proliferation [36].

With regard to the cells of the mononuclear/phagocytic system, their role in the recycling of senescent red blood cells provides perhaps the most significant illustration of the close interactions between iron metabolism and the immunological system [24]. In the case of secondary iron overload, as a result of dyserythropoiesis, hemolysis, or transfusions, macrophages are heavily loaded with iron which is released in the form of low-molecular weight (LMW) iron. This leads not only to increased transferrin saturation but also iron circulating as NTBI that will inappropriately enter tissues and cells [37]. In HFE-related hemochromatosis, the scenario is somehow different. In spite of the high transferrin saturation and circulating NTBI, as a result of increased iron absorption, little iron is seen in the Kupffer cells and other macrophages, while hepatocytes already show iron overload [2]. In a previous study of iron release by monocytes after erythrophagocytosis, Moura and co-workers demonstrated that monocytes from hemochromatosis patients released twice as much iron in a LMW form as control cells [38]. Based on those observations, they proposed for the first time the existence of a basic abnormality in the retention of iron in macrophages and probably from intestinal mucosal cells [38], a mechanism that is presently well established with the demonstration that hepcidin, which is functionally defective in hemochromatosis, regulates cellular iron efflux by binding to ferroportin and inducing its internalization [3]. Finally, one may question how the handling of iron in other compartments of the mononuclear/phagocytic system may also impact in their response to other types of toxicity. As an example, increasing evidence suggests that the accumulation of iron in the brain and the consequent microglia activation are hallmarks of neurodegenerative disorders, including Alzheimer's disease [39]. However, substantial efforts are still needed to fully understand this and many other aspects of the complex interactions of iron with inflammation and immunity. In our view, HFE hemochromatosis continues to offer a particularly good model to approach new questions.

\section{Results}

\subsection{Applying: A Case and Family Report}

Armed with all the tools available in 1999 and the possibility to perform at our center systematic individual longitudinal studies, we were in a position to follow the real natural course of a disease, not just the course deduced from cross sectional data at different ages. Every clinician following a 
patient with an age related disease hopes to be able to have tools for an early detection of the disease, and fortunately, this is the case for hemochromatosis. We were challenged by the finding, by an attentive pediatrician, of a 9-year-old boy with an abnormally high transferrin saturation. This case, the subsequent family study with detection of two additional cases, and their clinical progression are described below. Highly motivated by the search of the reciprocal interactions between iron and the immunological system, we included in our clinical follow-up not only the iron related parameters but also the lymphocyte counts.

The proband was thus a 9-year-old boy, referred to our center for investigation of an abnormally high transferrin saturation (TS) value (65\%) accidentally found on a routine examination and confirmed on a second determination (70\%). He had a normal healthy growth and no signs or symptoms of any disease; the physical examination was normal and had normal blood counts for age. Serum ferritin (SF) was normal $(79 \mathrm{ng} / \mathrm{mL})$. HFE genotyping was performed with the parents' informed consent and revealed homozygosity for the $\mathrm{C} 282 \mathrm{Y}$ variant. Genetic counseling was offered to the family and consent obtained to perform HFE genotyping in the parents and in the two only brothers of 5 and 11 years of age, all apparently healthy. Results of the family screening are illustrated in Figure 1, showing that both mother and father were heterozygous for the $\mathrm{C} 282 \mathrm{Y}$ variant, with normal iron parameters.

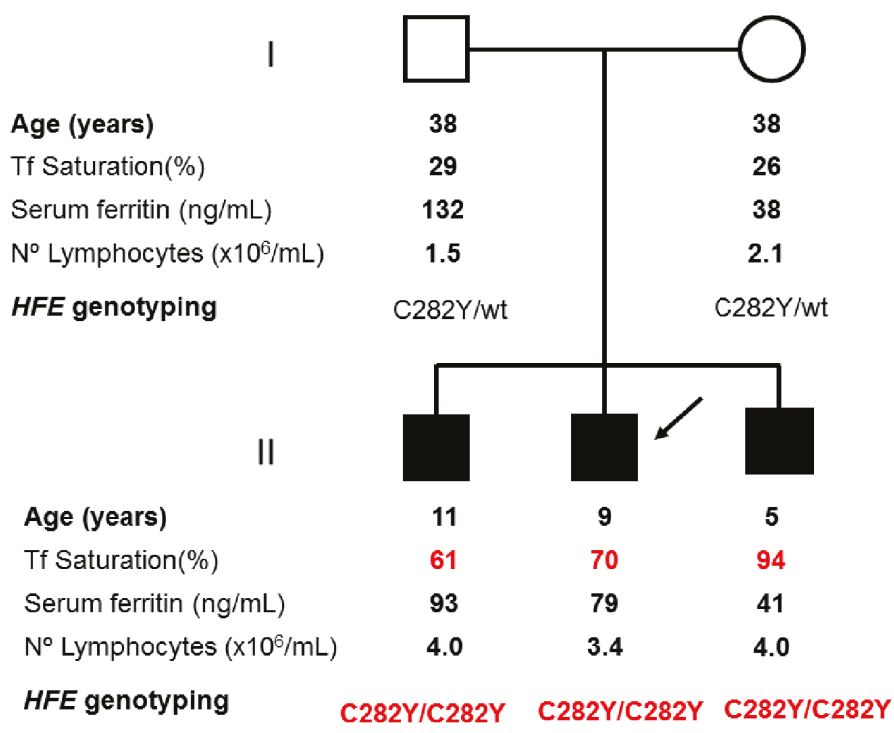

Figure 1. Family Pedigree of the case study. Age, serum markers of iron metabolism, total lymphocyte counts, and HFE (OMIM 235200) genotype are shown for each subject. The C282Y variant in the HFE gene is characteristically found in the homozygous form in patients with hemochromatosis. Homozygous subjects (C282Y/C282Y) are here represented by solid symbols and heterozygous (C282Y/wt) for half solid symbols. The proband is indicated by an arrow. Values in red are outside normal range.

Surprisingly, the two brothers were C282Y homozygous, with abnormally high TS (respectively $94 \%$ and $61 \%$ ) with normal SF values of $41 \mathrm{ng} / \mathrm{mL}$ and $93 \mathrm{ng} / \mathrm{mL}$, respectively. Of note, all 3 siblings had high lymphocyte counts as appropriate for their age. All procedures involving the collection of human samples and data were carried out following the rules of the Declaration of Helsinki of 1975, revised in 2013 [40], with the approval of the Ethical Committee of Centro Hospitalar Universitário do Porto.

The 3 siblings were regularly followed at our center with longitudinal determinations of iron parameters and lymphocyte counts for the last 20 years. They were recommended to become volunteer 
blood donors at the age of 18. Results of the follow-up are shown in the graphs on Figure 2 with the illustration of a representative case.

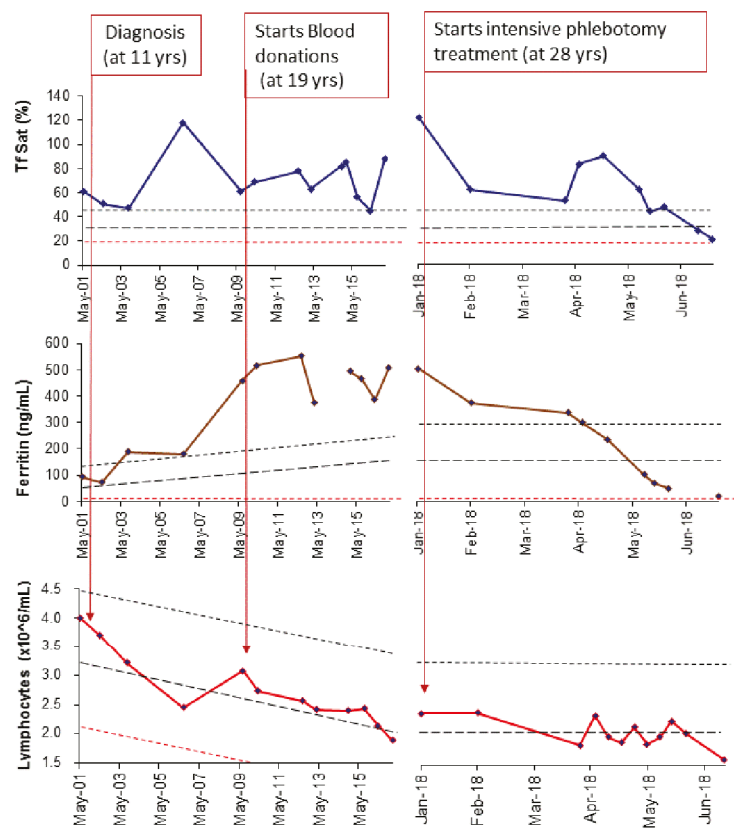

Figure 2. Follow-up of transferrin saturation (TfSat), serum ferritin, and total lymphocyte counts during a 17-year period. A representative case is shown (case II-1). Time at diagnosis, start of blood donation, and beginning of intensive phlebotomy treatment are marked in graphs by arrows. The large dashed lines represent the expected average values depending on age, derived from the simple regression equations in a population of sex and age matched normal controls recruited in the context of family studies. The small dashed lines represent the upper (in blue) and lower (in red) $95 \%$ confidence limits for each regression.

The profiles of SF progression together with the change of lymphocyte counts offer a remarkable illustration of how early does iron start to accumulate in C282Y homozygous subjects, how it progresses during the transition from childhood to adult life and how the total numbers of lymphocytes may influence that progression. In all cases, SF started to be elevated before adult age ( $<18$ years) and continued to rise inversely to the fall of lymphocyte counts that continued to decline until reaching the adult levels at around 25 years (only case II- 3 did not reach yet 25 years of age). The graphs also illustrate that intervention with intensive treatment was necessary to normalize SF in spite of regular blood donation. A better illustration of the inverse correlation between SF values and lymphocyte counts, before the impact of intensive treatment, is given in Figure 3 where the individual values in all 3 cases are plotted against age. 


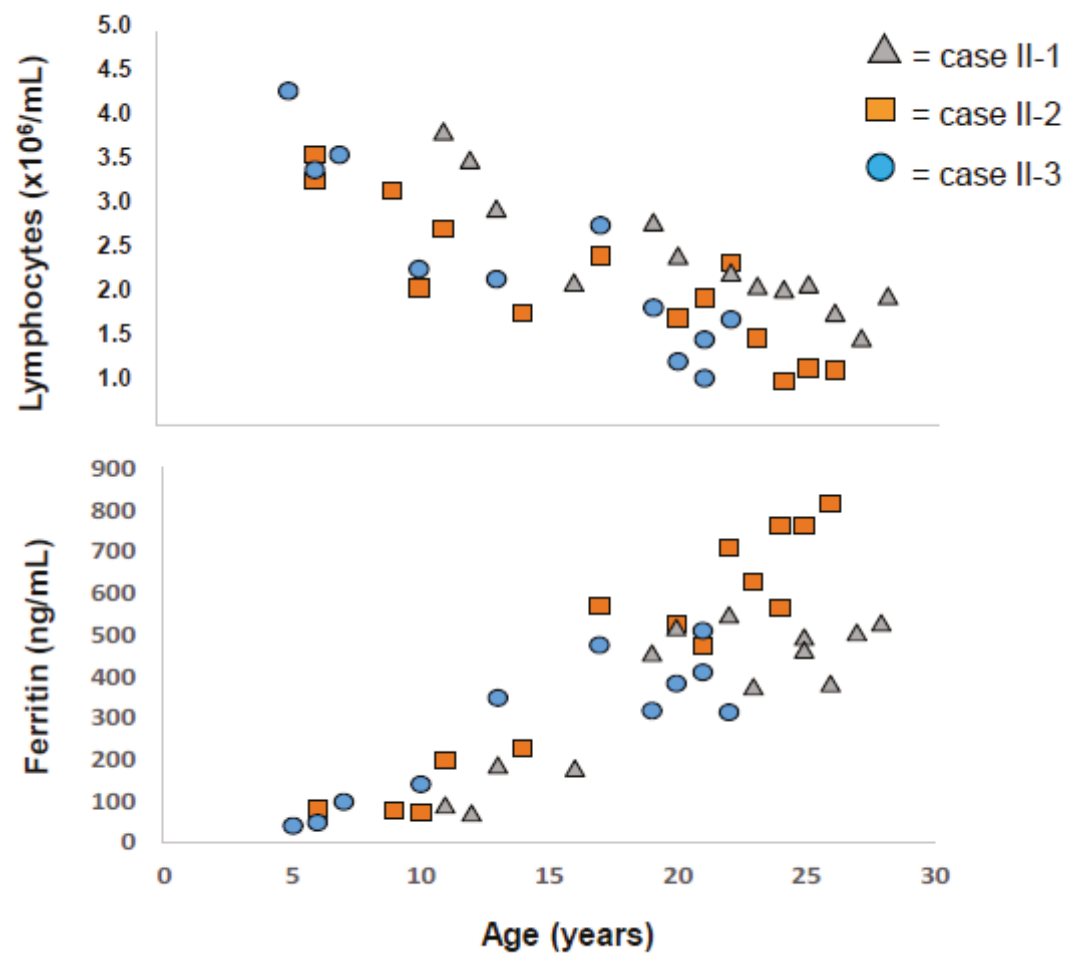

Figure 3. Inverse correlations between lymphocyte counts (A) and serum ferritin (B) before intensive treatment. Individual values from all three cases (II-1, II-2 and II-3) are plotted against age.

Notably, case II-2, whose lymphocytes declined to values $<1.5 \times 10^{6} / \mathrm{mL}$ (considered lymphopenia) at the age of 26 , reached SF levels much higher $(>700 \mathrm{ng} / \mathrm{mL})$ than his brother, case II- 1 , whom, at the same age, had lymphocytes stabilized at around $2.0 \times 10^{6} / \mathrm{mL}$, and a lower SF value $(500 \mathrm{ng} / \mathrm{mL})$.

In order to determine which sub-populations contributed the most for the setting of lymphocyte total numbers, we also determined, by flow cytometry analysis, the numbers of CD4+ T cells, CD8+ T cells and non-T subpopulations along the follow-up time. The results are shown in Figure 4 where it is clear that the change in lymphocyte counts is due to the continuous decline in $\mathrm{T}$ cell numbers and not related to the numbers of non-T cell populations (a combination of B and natural killer cells), which are more variable and probably related to immune responses against foreign antigens.

Naturally, the question could be raised if it is the lymphocyte depletion that is contributing to the progressive iron accumulation or, on the contrary, is the lymphocyte depletion a consequence of iron overload? In order to answer that question, we retrospectively reviewed the iron parameters and lymphocyte populations determined in 190 apparently healthy, non-C282Y homozygous family members of hemochromatosis patients, aged 5-20 years, who were studied in the context of a systematic family screening program at our center. The results, illustrated in Figure 5, confirm that the decline in lymphocyte counts is a normal physiological process and that, although SF slightly increases with age (particularly in males), it never reaches abnormal levels above $200 \mathrm{ng} / \mathrm{mL}$ in females or $300 \mathrm{ng} / \mathrm{mL}$ in males. These findings come to support the notion that, in order to start accumulating iron in hemochromatosis, it is necessary to combine two conditions: The genetic predisposition given by $\mathrm{C} 282 \mathrm{Y}$ homozygosity to increase the iron in circulation and the lack of a sufficiently high number of $\mathrm{T}$ lymphocytes to buffer the excessive serum iron. 


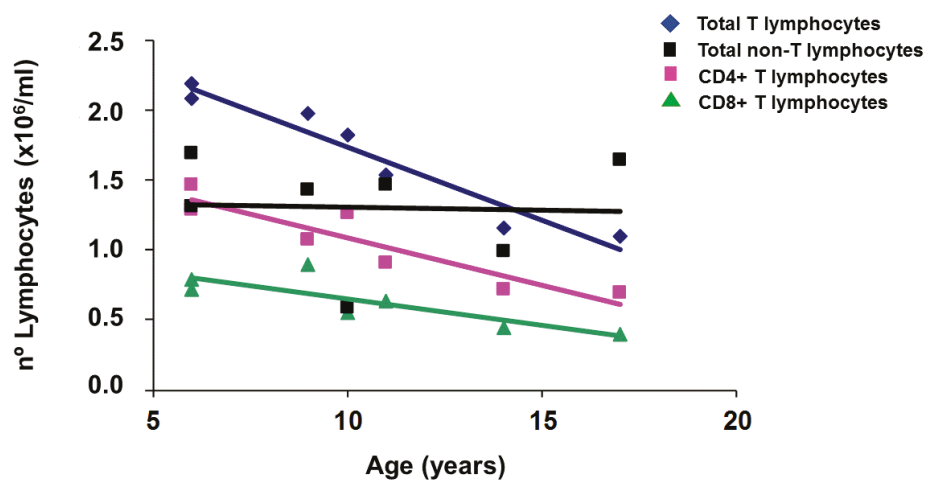

Figure 4. Follow-up of lymphocyte subpopulations. Total T-lymphocytes, CD4 and CD8 T lymphocytes, and non-T lymphocyte counts from a representative case (II-2) are plotted against age. Total T lymphocytes were calculated by the sum of CD4+ and CD8+ T cells. Non-T lymphocytes were calculated from the difference between the absolute lymphocyte numbers and the total T lymphocytes.
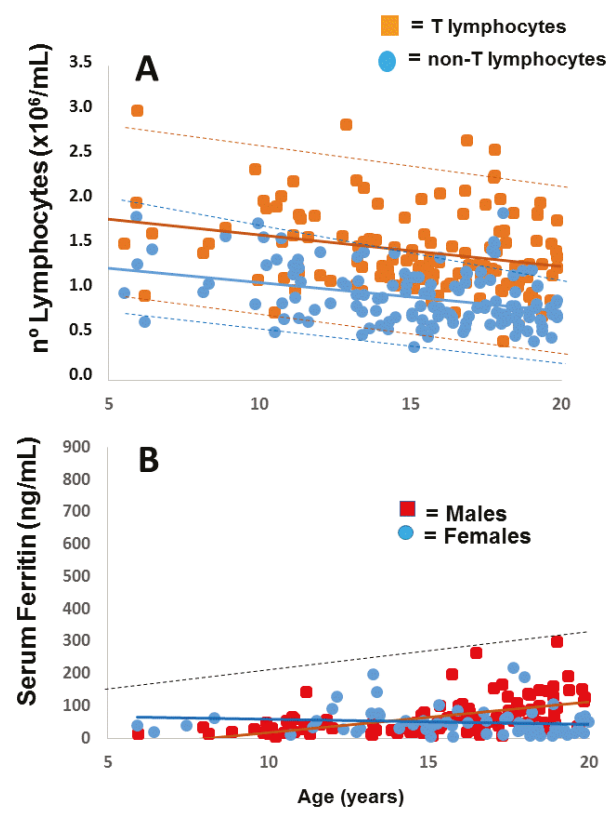

Figure 5. (A) Change in total $\mathrm{T}$ and non-T lymphocytes with age in non-homozygous apparently healthy family members screened before 20 years of age $(n=190)$. (B) Variation in serum ferritin with age in the same subjects, grouped as males or females. Full lines represent the regression lines for each correlation. Dashed lines in panel A represent the upper and lower $95 \%$ confidence limits for $\mathrm{T}$ (in brown) and non-T (in blue) lymphocytes. The dashed line in panel B represents the upper $95 \%$ limits.

\subsection{Questioning: A Dual Function for HFE?}

In spite of all advances supporting the cross-relationships between iron and adaptive immunity, many questions still remain unexplored and may keep immunologists and iron biologists busy for some time. Among them, perhaps the most critical question relates to the HFE function and how does it impact simultaneously on iron metabolism and on the adaptive immune functions. Interestingly, 20 
years before the discovery of HFE, Svejgaard and Ryder postulated that HLA alloantigens could interfere with ligand/receptor interactions not directly involved in immune reactions, and those interactions could under certain conditions explain some associations between HLA and non-immunological diseases giving as an example hemochromatosis [41]. This view came to be vindicated with the demonstration that HFE, a non-classical HLA molecule, interacts with both the TfR1 to regulate transferrin-mediated iron uptake [42] and with transferrin receptor 2 (TfR2) as an iron sensor for hepcidin signaling [43]. The role of HFE, however, is not limited to iron metabolism; it is also implicated in adaptive immune functions. Sometime ago, it was suggested that HFE could be immunogenic [44], and more recently Reuben and co-workers proposed that HFE could have a role in antigen processing and presentation leading to an inhibition of CD8+ T-lymphocyte activation [7]. These were in vitro studies based on several T-lymphocyte activation read-outs in cells transfected with wild type and mutated HFE molecules. The first demonstration in vivo that HFE acts as a negative regulator of CD8+ T-lymphocyte activation and differentiation was provided with the study by Costa et al. [32] of lymphocyte gene expression signatures from HFE-related hemochromatosis patients and mouse models, where it was shown that the lack of HFE impacts on several activation markers in CD8+ T lymphocytes [32]. Whatever the mechanism how this interaction may happen, it may imply the cross-talk between HFE and the MHC class I antigen presentation pathway, as suggested by Almeida et al in their study of peripheral blood mononuclear cells from patients homozygous for the p.C282Y variant in HFE [5]. In that study they found a reduced cell-surface expression of MHC class I due to an enhanced endocytosis rate of MHC class I molecules caused by premature peptide and $\beta 2$-microglobulin dissociation [5]. Whether this could happen through a direct effect or through the indirect influence of an unfolded protein response [45], this remains a pending question.

In summary, the mutated HFE can be now appropriately defined with a Janus like nature, implicated in two relevant pathways: Regulation of systemic iron homeostasis, through its interaction with the transferrin receptors and hepcidin signaling [42,43]; and the core of the immune system, by influencing MHC assembly and surface expression [5], and CD8+ lymphocyte expansion [7,32]. Failure of this dual function may explain the phenotypes observed in hemochromatosis of both iron overload and defective numbers of CD8+T lymphocytes. To better illustrate this view, we present in Figure 6a diagram summarizing how iron is essential for lymphocyte functions and, in turn, how lymphocytes, equipped with the capacity to uptake, hold and mobilize iron, contributing to the control of systemic iron homeostasis and the protection against iron toxicity.

At the systemic level, HFE is one of the players of the complex regulatory machinery of iron sensing and hepcidin signaling [43], thus contributing to the prevention of inappropriate iron accumulation. In HFE-related hemochromatosis, this regulation fails and the consequence is systemic iron overload. One of the multiple physiological implications of a well-controlled systemic iron homeostasis is the maintenance of appropriate adaptive immune functions. Lymphocyte responses depend on the interplay between the MHC dependent activation pathway, and their capacity to proliferate and differentiate, for which iron availability is essential through TfR1 mediated endocytosis [34]. The control of ferroportin mediated iron export through autocrine hepcidin signaling also impacts on the lymphocyte proliferation capacity of relevance [36], the hemochromatosis protein HFE was shown to have an additional role in the assembly and expression of the classical MHC class I for antigen presentation [5]. In the event of acquired systemic iron overload, such as occurs in transfusion dependent thalassemia patients or in experimental models with iron injection, lymphocytes (particularly CD8+ T lymphocytes) will be activated and expand in response to iron [22]. The recent demonstration that lymphocytes have the capacity to uptake the non-transferrin bound iron (NTBI) [33] and by doing so, to act as "buffers" of the systemic iron overload and protect from the iron accumulation in other tissues [10], came to vindicate the postulated reciprocal role of lymphocytes in the protection against iron toxicity [13]. Of relevance, the hemochromatosis protein HFE also has a role in this setting, by influencing the CD8+ T lymphocyte gene expression of molecules involved in activation and differentiation that finally have an impact on the number of circulating CD8+ T cells and consequently [32], on its NTBI 
"buffering" capacity. In summary, iron is essential for lymphocyte functions and, in turn, lymphocytes equipped with the capacity to uptake, hold, and mobilize iron contribute to the control of systemic iron homeostasis and the protection against iron toxicity. Pharmaceutical and/or therapeutic targets in the context of this new awareness are not completely obvious but evidence consistently points to TFR1 [34] and HFE as key molecules in the regulation of the crosstalk between the two systems. The molecule responsible for NTBI uptake by lymphocytes remains to be discovered. In summary, as usual, answers can only be found when the importance of the questions is acknowledged, and that takes time. The authors hope that the openness of Pharmaceuticals to the views presented here is a sign that the distance between questions and answers is being shortened.

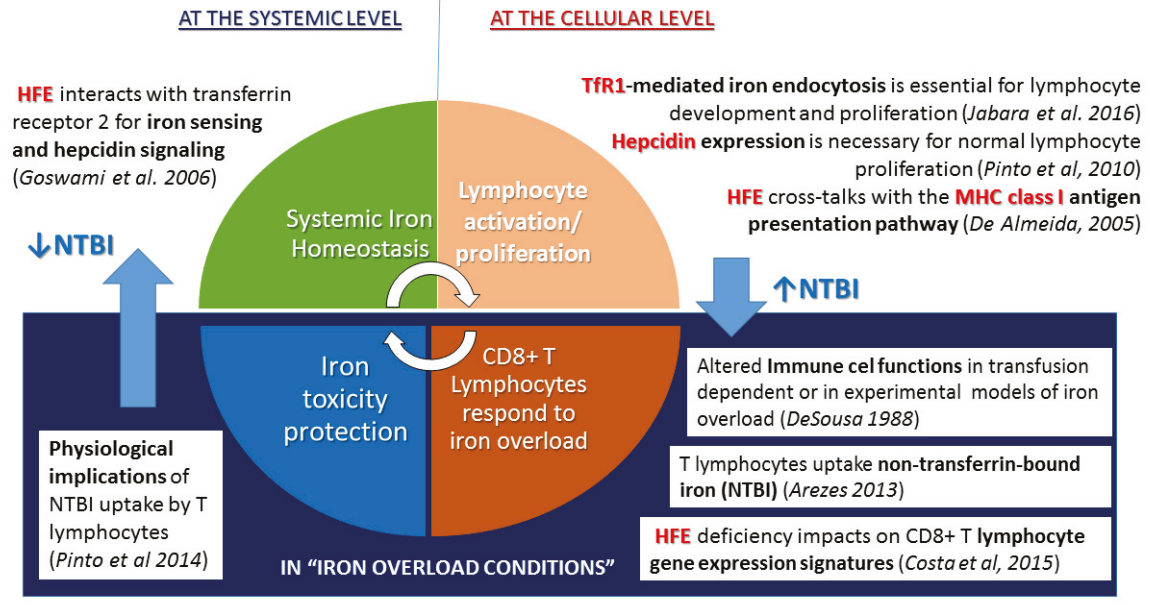

Figure 6. Diagram representation of the dual role of the human hemochromatosis protein HFE as a critical molecule in the reciprocal interactions between iron homeostasis, the major histocompatibility complex (MHC) and lymphocyte functions.

\section{Discussion}

\subsection{Implications for Disease Prevention in HFE-Related Hemochromatosis}

The prevailing view regarding the onset of HFE-related hemochromatosis is that patients develop symptoms only at around 30-40 years of age [2]; it is well established, however, that they may have biochemical evidence of iron overload some time before [46]. Although early diagnosis is well accepted as the best certainty of therapy in this age related disease, no available guidelines specifically address the question of when should biochemical screening be performed on a population basis. Two large population-based prospective studies with long-term follow-up of untreated p.C282Y homozygous subjects described the progression of iron overload with age but including only subjects older than 35 years in one study [47] and older than 40 years in another [48]. In another HH cohort study with a long-term (24 years) follow-up of subjects screened by family or primary medical practice screening, it was estimated that the mean age of homozygotes who could develop a severe liver iron overload would be approximately 21 years after the hepatic iron stores begin to increase in both men and women [49]. In spite of this knowledge, the average age of diagnosis of $\mathrm{HH}$ patients continues to be at around 40 years [17], and there is still no evidence-based recommendation for screening earlier. The results described above challenge this view by showing that markers of the disease may be found much before adulthood and that, at least in some cases, at the age of 28 years there may be already a significant amount of iron accumulated. Knowing the silent toxicity of iron, the question of when should screening be ideally performed deserves a wider discussion. 


\subsection{Implications for Immunological Theory}

The consistent associations found between iron overload and lymphocyte numbers or function vindicate the postulated notion that the immunological system has a surveillance role of the toxicity of iron [13] much before iron becomes a threat posed by its use by microbes [50]. How exactly that role is exercised is still not fully understood. Searching first in the $\beta 2$-microglobulin $(\beta 2 \mathrm{~m})$ knock-out mice, spontaneous iron overload was found in organs such as liver and pancreas [26]. The subsequent finding of spontaneous hepatic iron overload in mice lacking classical MHC Class I molecules was surprising and signals the involvement of MHC class I itself in the exercise of control of iron overload [31]. A similar explanation may apply to the finding in the two separate studies by Rodrigues et al. [51] and Levy et al. [30] of higher hepatic iron overload in older $\beta 2 \mathrm{~m}$ deficient mice than in HFE deficient mice. No matter how results affirm themselves, MHC class I appears always as a "culprit" or a motive for tissue iron accumulation: Either by its absence, such as in $\beta 2 \mathrm{~m}$ knock out mice, or because its assembly and expression are affected by the $\mathrm{C} 282 \mathrm{Y}$ mutated HFE.

Author Contributions: Conceptualization, G.P. and M.d.S.; Data curation, G.P., E.C. and M.J.T.; Formal analysis, G.P. and E.C.; Investigation, G.P., E.C. and M.J.T.; Methodology, G.P., E.C. and M.J.T.; Supervision, M.d.S.; Validation, M.d.S.; Writing-original draft, G.P. and M.d.S.; Writing-review \& editing, G.P. and M.d.S.

Funding: This research was partially supported by FEDER funds through COMPETE - and by Norte 2020 Portugal Regional Operational Programme (Norte-01-0145-FEDER-000012).

Acknowledgments: The authors wish to express their gratitude to nurse Graça Melo, whom during these last 20 years has been treating and supporting the patients at the Hemochromatosis Clinic of CHUP, and the Portuguese Hemochromatosis Association for their support in the recruitment of patients for research studies.

Conflicts of Interest: The authors declare no conflicts of interest.

\section{References}

1. Adams, P.C.; Barton, J.C. Haemochromatosis. Lancet 2007, 370, 1855-1860. [CrossRef]

2. Brissot, P.; Pietrangelo, A.; Adams, P.C.; Graaff, B.; McLaren, C.E.; Loreal, O. Haemochromatosis. Nat. Revs. Dis. Primers 2018, 4, 18016. [CrossRef] [PubMed]

3. Nemeth, E.; Tuttle, M.S.; Powelson, J.; Vaughn, M.B.; Donovan, A.; Ward, D.M.; Ganz, T.; Kaplan, J. Hepcidin regulates cellular iron efflux by binding to ferroportin and inducing its internalization. Science 2004, 306, 2090-2093. [CrossRef] [PubMed]

4. Ganz, T.; Nemeth, E. Hepcidin and iron homeostasis. Biochimica Et Biophysica Acta 2012, 1823, 1434-1443. [CrossRef] [PubMed]

5. de Almeida, S.F.; Carvalho, I.F.; Cardoso, C.S.; Cordeiro, J.V.; Azevedo, J.E.; Neefjes, J.; de Sousa, M. HFE cross-talks with the MHC class I antigen presentation pathway. Blood 2005, 106, 971-977. [CrossRef] [PubMed]

6. Rohrlich, P.S.; Kanellopoulos, J.; Lemonnier, F.A. HFE, a MHC class Ib molecule that regulates iron metabolism. Med. Sci. M/S 2006, 22, 24-26. [PubMed]

7. Reuben, A.; Chung, J.W.; Lapointe, R.; Santos, M.M. The hemochromatosis protein HFE 20 years later: An emerging role in antigen presentation and in the immune system. Immun. Inflamm. Dis. 2017, 5, 218-232. [CrossRef] [PubMed]

8. Arosa, F.A.; Oliveira, L.; Porto, G.; da Silva, B.M.; Kruijer, W.; Veltman, J.; de Sousa, M. Anomalies of the CD8+ T cell pool in haemochromatosis: HLA-A3-linked expansions of CD8+CD28- T cells. Clin. Exp. Immunol. 1997, 107, 548-554. [CrossRef]

9. Porto, G.; Reimao, R.; Goncalves, C.; Vicente, C.; Justica, B.; de Sousa, M. Haemochromatosis as a window into the study of the immunological system: A novel correlation between CD8+ lymphocytes and iron overload. Eur. J. Haematol. 1994, 52, 283-290. [CrossRef]

10. Pinto, J.P.; Arezes, J.; Dias, V.; Oliveira, S.; Vieira, I.; Costa, M.; Vos, M.; Carlsson, A.; Rikers, Y.; Rangel, M.; et al. Physiological implications of NTBI uptake by T lymphocytes. Frontiers. Pharmacol. 2014, 5, 24.

11. Simon, M.; Pawlotsky, Y.; Bourel, M.; Fauchet, R.; Genetet, B. Letter: Idiopathic hemochromatosis associated with HL-A 3 tissular antigen. Nouv. Presse Med. 1975, 4, 1432. [PubMed] 
12. Simon, M.; Bourel, M.; Fauchet, R.; Genetet, B. HLA and "non-immunological" disease: Idiopathic haemochromatosis. Lancet 1976, 308, 973-974. [CrossRef]

13. de Sousa, M. Lymphoid cell positioning: A new proposal for the mechanism of control of lymphoid cell migration. Sympo. Soc. Exp. Biol. 1978, 32, 393-410.

14. Reimao, R.; Porto, G.; de Sousa, M. Stability of CD4/CD8 ratios in man: New correlation between CD4/CD8 profiles and iron overload in idiopathic haemochromatosis patients. C. R. A. Sci. 1991, 313, 481-487.

15. Porto, G.; Vicente, C.; Teixeira, M.A.; Martins, O.; Cabeda, J.M.; Lacerda, R.; Goncalves, C.; Fraga, J.; Macedo, G.; Silva, B.M.; et al. Relative impact of HLA phenotype and CD4-CD8 ratios on the clinical expression of hemochromatosis. Hepatology 1997, 25, 397-402. [CrossRef] [PubMed]

16. Feder, J.N.; Gnirke, A.; Thomas, W.; Tsuchihashi, Z.; Ruddy, D.A.; Basava, A.; Dormishian, F.; Domingo, R., Jr.; Ellis, M.C.; Fullan, A.; et al. A novel MHC class I-like gene is mutated in patients with hereditary haemochromatosis. Nat. Genet. 1996, 13, 399-408. [CrossRef] [PubMed]

17. Deugnier, Y.; Morcet, J.; Laine, F.; Hamdi-Roze, H.; Bollard, A.S.; Guyader, D.; Moirand, R.; Bardou-Jacquet, E. Reduced phenotypic expression in genetic hemochromatosis with time: Role of exposure to non-genetic modifiers. J. Hepatol. 2019, 70, 118-125. [CrossRef]

18. Cruz, E.; Vieira, J.; Almeida, S.; Lacerda, R.; Gartner, A.; Cardoso, C.S.; Alves, H.; Porto, G. A study of 82 extended HLA haplotypes in HFE-C282Y homozygous hemochromatosis subjects: Relationship to the genetic control of CD8+ T-lymphocyte numbers and severity of iron overload. BMC MED. GENET. 2006, 7, 16. [CrossRef]

19. Costa, M.; Cruz, E.; Barton, J.C.; Thorstensen, K.; Morais, S.; da Silva, B.M.; Pinto, J.P.; Vieira, C.P.; Vieira, J.; Acton, R.T.; et al. Effects of highly conserved major histocompatibility complex (MHC) extended haplotypes on iron and low CD8+ T lymphocyte phenotypes in HFE C282Y homozygous hemochromatosis patients from three geographically distant areas. PloS ONE 2013, 8, e79990. [CrossRef]

20. Cruz, E.; Melo, G.; Lacerda, R.; Almeida, S.; Porto, G. The CD8+ T-lymphocyte profile as a modifier of iron overload in HFE hemochromatosis: An update of clinical and immunological data from $70 \mathrm{C} 282 \mathrm{Y}$ homozygous subjects. Blood Cells Mol. Dis. 2006, 37, 33-39. [CrossRef]

21. Macedo, M.F.; Porto, G.; Costa, M.; Vieira, C.P.; Rocha, B.; Cruz, E. Low numbers of CD8+ T lymphocytes in hereditary haemochromatosis are explained by a decrease of the most mature CD8+ effector memory $\mathrm{T}$ cells. Clin. Exp. Immunol. 2010, 159, 363-371. [CrossRef]

22. de Sousa, M.; Dynesius-Trentham, R.; Mota-Garcia, F.; da Silva, M.T.; Trentham, D.E. Activation of rat synovium by iron. Arthritis Rheum. 1988, 31, 653-661. [CrossRef] [PubMed]

23. Breedveld, F.C.; Dynesius-Trentham, R.; de Sousa, M.; Trentham, D.E. Collagen arthritis in the rat is initiated by CD4+ T cells and can be amplified by iron. Cell. Immunol. 1989, 121, 1-12. [CrossRef]

24. de Sousa, M. Immune cell functions in iron overload. Clin. Exp. Immunol. 1989, 75, 1-6. [PubMed]

25. de Sousa, M.; Reimao, R.; Porto, G.; Grady, R.W.; Hilgartner, M.W.; Giardina, P. Iron and lymphocytes: Reciprocal regulatory interactions. In Biotechnology of Plasma Proteins; Karger Publishers: Berlin, Germany, 1991; Volume 58, pp. 171-177.

26. de Sousa, M.; Reimao, R.; Lacerda, R.; Hugo, P.; Kaufmann, S.H.; Porto, G. Iron overload in $\beta$ 2-microglobulin-deficient mice. Immunol. Lett. 1994, 39, 105-111. [CrossRef]

27. Santos, M.; Schilham, M.W.; Rademakers, L.H.; Marx, J.J.; de Sousa, M.; Clevers, H. Defective iron homeostasis in $\beta$ 2-microglobulin knockout mice recapitulates hereditary hemochromatosis in man. J. Exp. Med. 1996, 184, 1975-1985. [CrossRef] [PubMed]

28. Muckenthaler, M.U.; Rodrigues, P.; Macedo, M.G.; Minana, B.; Brennan, K.; Cardoso, E.M.; Hentze, M.W.; de Sousa, M. Molecular analysis of iron overload in $\beta 2$-microglobulin-deficient mice. Blood Cells Mol. Dis. 2004, 33, 125-131. [CrossRef]

29. Santos, M.M.; de Sousa, M.; Rademakers, L.H.; Clevers, H.; Marx, J.J.; Schilham, M.W. Iron overload and heart fibrosis in mice deficient for both $\beta 2$-microglobulin and Rag1. Am. J. Pathol. 2000, 157, 1883-1892. [CrossRef]

30. Levy, J.E.; Montross, L.K.; Andrews, N.C. Genes that modify the hemochromatosis phenotype in mice. J. Clin. Invest. 2000, 105, 1209-1216. [CrossRef]

31. Cardoso, E.M.; Macedo, M.G.; Rohrlich, P.; Ribeiro, E.; Silva, M.T.; Lemonnier, F.A.; de Sousa, M. Increased hepatic iron in mice lacking classical MHC class I molecules. Blood 2002, 100, 4239-4241. [CrossRef] 
32. Costa, M.; Cruz, E.; Oliveira, S.; Benes, V.; Ivacevic, T.; Silva, M.J.; Vieira, I.; Dias, F.; Fonseca, S.; Gonçalves, M.; et al. Lymphocyte gene expression signatures from patients and mouse models of hereditary hemochromatosis reveal a function of HFE as a negative regulator of CD8+ T-lymphocyte activation and differentiation in vivo. PLoS ONE 2015, 10, e0124246. [CrossRef]

33. Arezes, J.; Costa, M.; Vieira, I.; Dias, V.; Kong, X.L.; Fernandes, R.; Vos, M.; Carlsson, A.; Rikers, Y.; Porto, G.; et al. Non-transferrin-bound iron (NTBI) uptake by T lymphocytes: Evidence for the selective acquisition of oligomeric ferric citrate species. PLoS ONE 2013, 8, e79870. [CrossRef]

34. Jabara, H.H.; Boyden, S.E.; Chou, J.; Ramesh, N.; Massaad, M.J.; Benson, H.; Bainter, W.; Fraulino, D.; Rahimov, F.; Sieff, C.; et al. A missense mutation in TFRC, encoding transferrin receptor 1, causes combined immunodeficiency. Nat. Genet. 2016, 48, 74-78. [CrossRef]

35. Vanoaica, L.; Richman, L.; Jaworski, M.; Darshan, D.; Luther, S.A.; Kuhn, L.C. Conditional deletion of ferritin $\mathrm{h}$ in mice reduces $\mathrm{B}$ and T lymphocyte populations. PLoS ONE 2014, 9, e89270. [CrossRef]

36. Pinto, J.P.; Dias, V.; Zoller, H.; Porto, G.; Carmo, H.; Carvalho, F.; de Sousa, M. Hepcidin messenger RNA expression in human lymphocytes. Immunology 2010, 130, 217-230. [CrossRef]

37. Knutson, M.D. Non-transferrin-bound iron transporters. Free Radic. Biol. Med. 2019, 133, 101-111. [CrossRef]

38. Moura, E.; Noordermeer, M.A.; Verhoeven, N.; Verheul, A.F.; Marx, J.J. Iron release from human monocytes after erythrophagocytosis in vitro: An investigation in normal subjects and hereditary hemochromatosis patients. Blood 1998, 92, 2511-2519.

39. Nnah, I.; Wessling-Resnick, M. Brain Iron Homeostasis: A Focus on Microglial Iron. Pharmaceuticals 2018, 11, 19.

40. Available online: https://jamanetwork.com/journals/jama/fullarticle/1760318 (accessed on 27 November 2013).

41. Svejgaard, A.; Ryder, L.P. Interaction of HLA molecules with non-immunological ligands as an explanation of HLA and disease associations. Lancet 1976, 2, 547-549. [CrossRef]

42. Roy, C.N.; Penny, D.M.; Feder, J.N.; Enns, C.A. The hereditary hemochromatosis protein, HFE, specifically regulates transferrin-mediated iron uptake in HeLa cells. J. Biol. Chems. 1999, 274, 9022-9028. [CrossRef]

43. Goswami, T.; Andrews, N.C. Hereditary hemochromatosis protein, HFE, interaction with transferrin receptor 2 suggests a molecular mechanism for mammalian iron sensing. J. Biol. Chems. 2006, 281, 28494-28498. [CrossRef]

44. Boucherma, R.; Kridane-Miledi, H.; Vives, F.L.; Vauchy, C.; Borg, C.; Kleinclauss, F.; Fiette, L.; Tiberghien, P.; Lemonnier, F.A.; Rohrlich, P.S.; et al. Loss of central and peripheral CD8+ T-cell tolerance to HFE in mouse models of human familial hemochromatosis. Eur J. Immunol. 2012, 42, 851-862. [CrossRef]

45. de Almeida, S.F.; de Sousa, M. The unfolded protein response in hereditary haemochromatosis. J. Cell. Mol. Med. 2008, 12, 421-434. [CrossRef]

46. Barton, J.C.; Acton, R.T.; Leiendecker-Foster, C.; Lovato, L.; Adams, P.C.; McLaren, G.D.; Eckfeldt, J.H.; McLaren, C.E.; Reboussin, D.M.; Gordeuk, V.R.; et al. HFE C282Y homozygotes aged 25-29 years at HEIRS Study initial screening. Genet. Test. 2007, 11, 269-275. [CrossRef]

47. Andersen, R.V.; Tybjaerg-Hansen, A.; Appleyard, M.; Birgens, H.; Nordestgaard, B.G. Hemochromatosis mutations in the general population: Iron overload progression rate. Blood 2004, 103, 2914-2919. [CrossRef]

48. Allen, K.J.; Bertalli, N.A.; Osborne, N.J.; Constantine, C.C.; Delatycki, M.B.; Nisselle, A.E.; Nicoll, A.J.; Gertig, D.M.; McLaren, C.E.; Giles, G.G.; et al. HFE Cys282Tyr homozygotes with serum ferritin concentrations below 1000 microg/L are at low risk of hemochromatosis. Hepatology 2010, 52, 925-933. [CrossRef]

49. Powell, L.W.; Dixon, J.L.; Ramm, G.A.; Purdie, D.M.; Lincoln, D.J.; Anderson, G.J.; Subramaniam, V.N.; Hewett, D.G.; Searle, J.W.; Fletcher, L.M.; et al. Screening for hemochromatosis in asymptomatic subjects with or without a family history. Arch. Intern. Med. 2006, 166, 294-301. [CrossRef]

50. Soares, M.P.; Weiss, G. The Iron age of host-microbe interactions. EMBO Rep. 2015, 16, 1482-1500. [CrossRef]

51. Rodrigues, P.; Lopes, C.; Mascarenhas, C.; Arosio, P.; Porto, G.; de Sousa, M. Comparative study between Hfe-/-and $\beta 2 \mathrm{~m}-/-$ mice: Progression with age of iron status and liver pathology. Int. J. Exp. Pathol. 2006, 87,317-324. [CrossRef]

(C) 2019 by the authors. Licensee MDPI, Basel, Switzerland. This article is an open access article distributed under the terms and conditions of the Creative Commons Attribution (CC BY) license (http://creativecommons.org/licenses/by/4.0/). 


\title{
Twenty Years of Ferroportin Disease: A Review or An Update of Published Clinical, Biochemical, Molecular, and Functional Features
}

\author{
L. Tom Vlasveld ${ }^{1}$, Roel Janssen ${ }^{2}$, Edouard Bardou-Jacquet ${ }^{3}$, Hanka Venselaar ${ }^{4}$, \\ Houda Hamdi-Roze ${ }^{5}$, Hal Drakesmith ${ }^{6}$ and Dorine W. Swinkels ${ }^{2, *}$ \\ 1 Department of Internal Medicine, Haaglanden MC-Bronovo, 2597AX The Hague, The Netherlands \\ 2 Department of Laboratory Medicine, Translational Metabolic Laboratory, Radboud University Medical \\ Center, P.O. Box 9101, 6500 HB Nijmegen, The Netherlands \\ 3 Liver Diseases Department, French Reference Centre for Rare Iron Overload Diseases of Genetic Origin, \\ University Hospital Pontchaillou, 35033 Rennes, France \\ 4 Centre for Molecular and Biomolecular Informatics, Radboud Institute for Molecular Life Sciences, Radboud, \\ University Medical Center, P.O. Box 9191, 6500 HB Nijmegen, The Netherlands \\ 5 Molecular Genetics Department, French Reference Centre for Rare Iron Overload Diseases of Genetic Origin, \\ University Hospital Pontchaillou, 35033 Rennes, France \\ 6 MRC Human Immunology Unit, Weatherall Institute of Molecular Medicine, University of Oxford, \\ Oxford OX39DS, UK \\ * Correspondence: dorine.swinkels@radboudumc.nl
}

Received: 12 July 2019; Accepted: 20 August 2019; Published: 9 September 2019

\begin{abstract}
Iron overloading disorders linked to mutations in ferroportin have diverse phenotypes in vivo, and the effects of mutations on ferroportin in vitro range from loss of function (LOF) to gain of function (GOF) with hepcidin resistance. We reviewed 359 patients with 60 ferroportin variants. Overall, macrophage iron overload and low/normal transferrin saturation (TSAT) segregated with mutations that caused LOF, while GOF mutations were linked to high TSAT and parenchymal iron accumulation. However, the pathogenicity of individual variants is difficult to establish due to the lack of sufficiently reported data, large inter-assay variability of functional studies, and the uncertainty associated with the performance of available in silico prediction models. Since the phenotypes of hepcidin-resistant GOF variants are indistinguishable from the other types of hereditary hemochromatosis $(\mathrm{HH})$, these variants may be categorized as ferroportin-associated $\mathrm{HH}$, while the entity ferroportin disease may be confined to patients with LOF variants. To further improve the management of ferroportin disease, we advocate for a global registry, with standardized clinical analysis and validation of the functional tests preferably performed in human-derived enterocytic and macrophagic cell lines. Moreover, studies are warranted to unravel the definite structure of ferroportin and the indispensable residues that are essential for functionality.
\end{abstract}

Keywords: SLC40A1; ferroportin; iron overload; non-HFE; ferritin; hemochromatosis

\section{Introduction}

Hereditary hemochromatosis (HH) type 4 or ferroportin disease (OMIM-code: 606069 Orphanet-code: 139491) is associated with variants in SLC40A1 and inherited in an autosomal-dominant manner. Since 1999, ferroportin disease was classified into two entities [1-3], based on experimental in vitro models of genetic variants found in patients [4-10]. Classical ferroportin disease (Type 4A) is associated with loss-of-function (LOF) variants with diminished cell surface expression of ferroportin and lower iron export capacity, and is characterized by macrophage iron retention and iron restriction for erythropoiesis. It is clinically recognized by the presence of high serum ferritin concentrations with 
low to normal transferrin saturation (TSAT) and poor tolerance to phlebotomy. Non-classical (atypical, type 4B) ferroportin disease is associated with gain-of-function (GOF) variants that render ferroportin protein resistant to hepcidin, resulting in continued iron export, and leading to a phenotype that mimics classical HFE HH characterized by parenchymal (hepatocellular) iron overload with elevated serum ferritin and TSAT.

Systematic and narrative reviews on ferroportin disease revealed the great variety in iron parameters among patients with ferroportin variants and emphasize the poor correlation between iron export capacity in functional studies and clinical characteristics (phenotype) $[7,9-11]$ and question the pathogenicity of various variants $[8,12]$.

To better guide the management of this disorder, a better understanding of the clinical and biochemical features of ferroportin disease and its underlying pathological mechanisms is required. In this report, we evaluated and describe clinical and laboratory data of patients reported between 1999 and June 2019, in whom the identified ferroportin variant was assumed to be associated with the defined state of iron overload. The relation between patient's clinical features and the functional in vitro features of underlying variants is assessed in context of current knowledge on the function and structure of ferroportin and its regulatory mechanisms. We comment on the shortcomings of describing the phenotype based on case and family reports, and review the limited applicability of functional studies and available in silico prediction models to determine pathogenicity. We recommend the institution of a global registry with a (1) standardized diagnostic protocol, (2) validated functional tests, and (3) studies to establish the definite secondary and tertiary structure of ferroportin and residues involved in its binding with hepcidin for ubiquitination and to ferroportin for iron transport.

\section{Methods}

\subsection{Data Collection and Selection}

Identification, Demographic Characteristics, and Iron Parameters

A literature search was done using Medline and Embase (searching strategy: \#1 (SLC40A1 or ferroportin or IREG or IREG-1 or FPN or FPN1 or non-HFE hemochromatosis), \#2 (mutation or variant) from 1999 to June 2019. Papers with only an abstract in English were also selected. We included all the cases (including family studies) of ferroportin variants that are associated with unexplained elevated serum ferritin concentration. Since the aim of this analysis was to evaluate the relation between the clinical features and the functional in vitro characteristics in experimental cell lines of the various potentially pathogenic variants, we excluded variants for which these functional studies have not been performed, e.g., variants in promoter and untranslated regions, splicing variants as well as variants leading to synonymous amino acids such as Iso109Iso, Leu129Leu, and Val221Val [13-17]. In addition, we excluded patients with previously established neutral or (possibly) iron-modifying polymorphisms with a variant population frequency $>1 \%$, such as the African Gln248His variant and variants in residues Leu348 and Leu384 [7,18-21].

Only patients with reported numerical value of at least transferrin saturation (TSAT) or ferritin concentration were selected. Demographic features, presenting symptoms, blood test results (hemoglobin $(\mathrm{Hb})$, mean corpuscular volume $(\mathrm{MCV})$, serum iron, TSAT, ferritin, and alanine aminotransferase (ALT)), hepatic iron content and hepatic histology, data on tolerability of phlebotomy (including the amount of iron removed), and the presence of p.Cys282Tyr and p.His63Asp HFE variants and other potential confounders, such as alcohol consumption and signs of metabolic syndrome, were collected. Organ iron accumulation as assessed by MRI and histologic examination was evaluated. Hepatic damage was histologically scored using the Meta-analysis of Histological Data in Viral Hepatitis (METAVIR) score $(0=$ no fibrosis, $1=$ mild fibrosis (portal fibrosis without septa), 2 = moderate fibrosis (portal fibrosis and few septa), 3 = severe fibrosis (numerous septa without cirrhosis), and 4 = cirrhosis). Differences between categorical variables were compared with the Chi-square test with Yates correction while the comparison of continuous variables was done with the Mann-Whitney U-test 
and Student's-t -test of independent means. A two-sided $p$-value $<0.05$ was considered significant. The correlation between variables was determined by the Pearson correlation coefficient.

\subsection{Variant Classification Based on Functional In Vitro Studies}

Functional studies on iron export and/or ferroportin expression were performed in cell lines transfected with the ferroportin protein variant. We reviewed the reported functional studies on iron export capacity and ferroportin expression that were performed in cell lines transfected with the wild-type and the variant ferroportin protein. We assigned a variant as an LOF variant when the iron export capacity was significantly reduced, in comparison to the wild-type (WT) protein. The variant was assigned as a GOF variant when the iron transport capacity was preserved. When the addition of hepcidin significantly inhibited the iron export capacity and/or ferroportin expression, the variant was defined as hepcidin-sensitive, and the variant was hepcidin-resistant in the absence of a modulating effect of hepcidin. A variant was scored as "non-classified" when no relevant functional data were available, and as "conflicting" when data on the hepcidin effect were inconsistent or inconclusive.

\subsection{Bioinformatics Prediction Software Analysis}

To assess co-segregation in multiple affected family members, the simplified method of segregation analysis (SISA) was applied [22,23] and classified according to recent recommendations to define co-segregation to fit the guidelines of the American College of Medical Genetics and Genomics and the Association for Molecular Pathology (ACMG-AMP) [22,24]. Briefly, to determine the co-segregation we used the classification suggested by Jarvik et al. and the method to calculate the probability that the phenotype of a variant carrier is caused by chance rather than genotype, as suggested by Moller et al. [22,23]. This probability is described as $(1 / 2)^{\mathrm{n}}$, wherein $\mathrm{n}$ is the number of informative meiosis and will be the number of the carriers with the affected phenotype of interest and all the carriers in between them, minus one. The genome aggregation data base (gnomAD), was applied to determine of the allele frequency of a variant. In order to further determine the potential pathogenicity of the various variants three commonly used algorithms were applied [25]. Polyphen2 predicts the impact of amino acid substitution on the structure and function of human protein using physical and comparative considerations [26]. The method "Sorts intolerant from Tolerant" (SIFT) (http://www.blocks.fhcrc.org/sift/SIFT.html) classifies non-synonymous single nucleotide polymorphisms on the basis of the evolutionary conservation of amino acids within protein families [27]. Align-GVGD predicts variants in the query sequence based on a combination of Grantham Variation (GV) which measures the evolutionary variation at a particular position in the alignment and Grantham Deviation (GD), measuring the biochemical difference between the reference and amino acid encoded by the variant [28].

\section{Evaluation and Analysis}

\subsection{Description of the Phenotype of Patients (Including Related Family Members) in Relation Findings in Functional Studies}

\subsubsection{Patients Characteristics}

Ferroportin Disease Occurs in Different Parts of the World and Has no Specific Symptoms

We retrieved 359 individuals with 60 variants (59 missense variants and one deletion) in the ferroportin protein (Table 1). The reported patients, were predominantly male and of European descent. When reported, fatigue and arthralgia were the major presenting symptoms. Overall, patients had normal $\mathrm{Hb}$ and $\mathrm{MCV}$ with a serum iron level and TSAT at the upper range of normal and moderately elevated ferritin levels. 
Table 1. Patient Characteristics. MCV: mean corpuscular volume, TSAT: transferrin saturation.

\begin{tabular}{|c|c|c|c|}
\hline Characteristics & $n$ & Value (Median) & Range \\
\hline Patients & 359 & & \\
\hline Probands & & 68 & \\
\hline Relatives from probands & & 191 & \\
\hline Individual patients & & 88 & \\
\hline Gender & 342 & & \\
\hline Female & & 131 & \\
\hline Male & & 211 & \\
\hline Age (years) & 322 & 41 & $2-87$ \\
\hline Continent & 352 & & \\
\hline Europe & & 258 & \\
\hline North-South America & & 37 & \\
\hline Asia & & 44 & \\
\hline Australia/Oceania & & 13 & \\
\hline Presenting clinical symptoms & 71 & & \\
\hline Fatigue & & 34 & \\
\hline Elevated liver enzymes / hepatomegaly & & 30 & \\
\hline Joint complaints/arthralgia & & 36 & \\
\hline Miscellaneous & & 47 & \\
\hline Referral because of high ferritin level & 131 & & \\
\hline \multicolumn{4}{|l|}{ Hematological Parameters } \\
\hline \multicolumn{4}{|l|}{ Hemoglobin $(\mathrm{g} / \mathrm{dL})^{\#}$} \\
\hline Female & 60 & 13.1 & $7.5-16.3$ \\
\hline Male & 92 & 15.0 & $6.5-18.4$ \\
\hline \multicolumn{4}{|l|}{$\operatorname{MCV}(\mathrm{fl})$} \\
\hline Female & 38 & 91 & 77-107 \\
\hline Male & 46 & 91 & 70-108 \\
\hline \multicolumn{4}{|l|}{ Serum iron $(\mu \mathrm{mol} / \mathrm{L})$} \\
\hline Female & 34 & 20.9 & $6.7-94.0$ \\
\hline Male & 56 & 26.3 & $6.2-86.0$ \\
\hline \multicolumn{4}{|l|}{ TSAT $(\%)$} \\
\hline Female & 116 & 31.5 & $2.0-100.0$ \\
\hline Male & 180 & 38.0 & $7.0-104.0$ \\
\hline \multicolumn{4}{|l|}{ Ferritin $(\mu \mathrm{g} / \mathrm{L})$} \\
\hline Female & 122 & 1026 & $4-8943$ \\
\hline Male & 201 & 1514 & $12-18695$ \\
\hline
\end{tabular}

Iron Parameters are Determined by Gender and Age. ${ }^{\#}$ Significant difference between females and males $(p<0.05$, also after correcting for multiple testing according to Bonferroni $(<0.01)$.

Women had significantly lower $\mathrm{Hb}$, TSAT, and serum ferritin concentration (Table 1). There was a weak correlation between age and TSAT $(r=0.1796)$ and serum ferritin $(r=0.3461)$ (Figure S1a-c). Probands were significantly older than affected family members (45.5 versus 34 years) with significantly higher (1896 versus $948 \mu \mathrm{g} / \mathrm{L}$ ) serum ferritin levels (Table S1). Ten percent (20/191) of affected family's members (6/14 males/females, median age 42 years) had no biochemical signs of iron overload (ferritin level $\leq 200 \mu \mathrm{g} / \mathrm{L}$ and normal TSAT). 
Modification by Additional Hereditary and Acquired Conditions

We found no effect of the presence of p.Cys282Tyr (13 heterozygotes) and p.His63Asp ( 35 heterozygotes, five homozygotes) HFE variants on iron parameters (Table S2). In only 84 patients, the current alcohol consumption was reported without demonstrable effect (Table S3). The reported clinical data were insufficient for the proper determination of the presence of metabolic syndrome to explore its modifying effect.

\subsection{Relation between In Vitro Functional Studies of Ferroportin Variants on Clinical Features}

We identified 27 different GOF variants (110 patients), 21 LOF variants (205 patients), and 12 unclassified variants (33 patients) (Table 2). A total of 355 cases involved heterozygosity for ferroportin variants. One homozygous Gly204Ser GOF variant was reported in a 52-year-old female with ferritin concentration of $5236 \mu \mathrm{g} / \mathrm{L}$, TSAT of $100 \%$, and symptoms of hepatic fibrosis revealed by radiology [15]. A patient with homozygosity for the GOF variant Arg561Gly had biochemical signs of severe iron overload reflected by a serum ferritin of $2750 \mu \mathrm{g} / \mathrm{L}$ and TSAT of $84 \%$ [29]. 


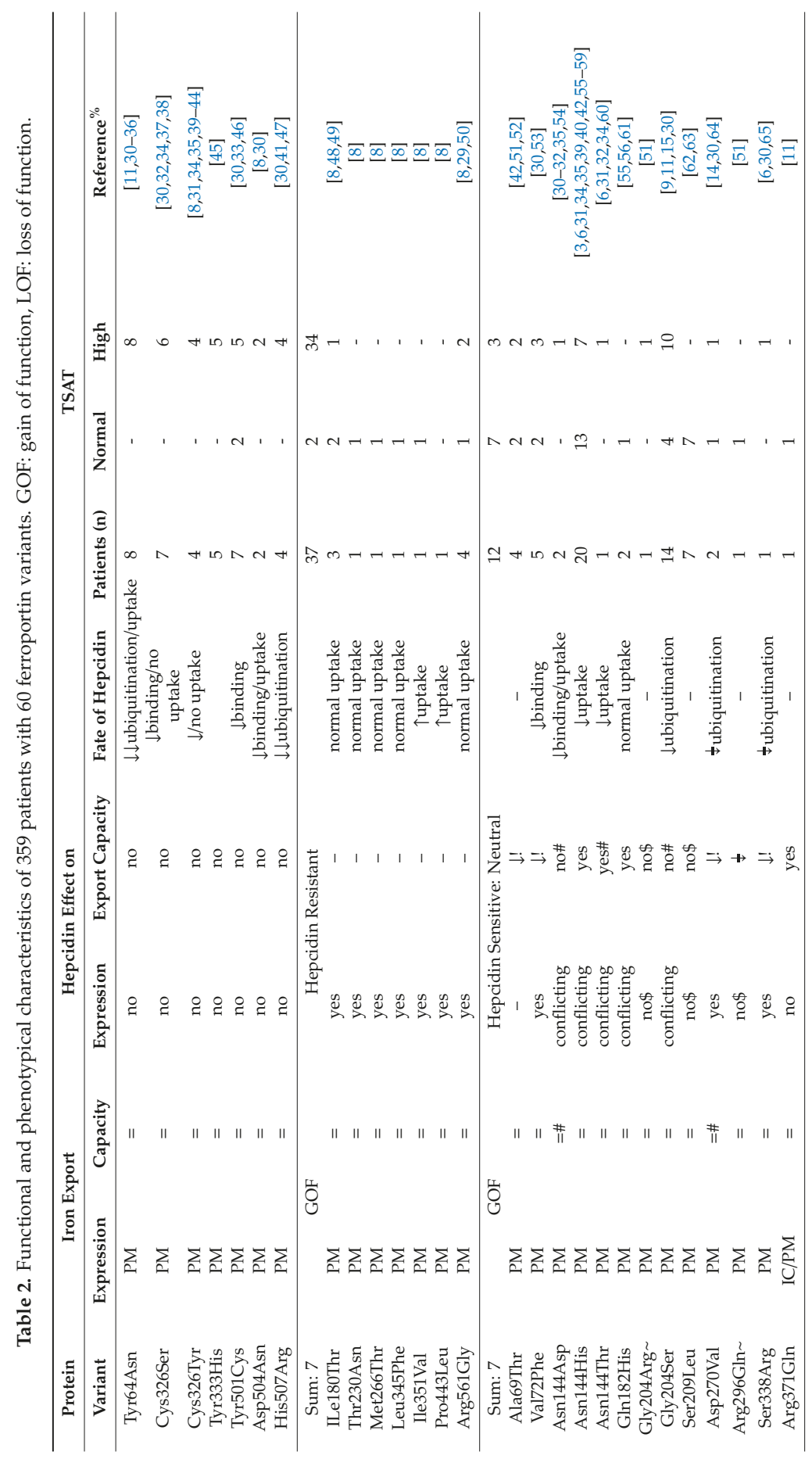


Pharmaceuticals 2019, 12, 132

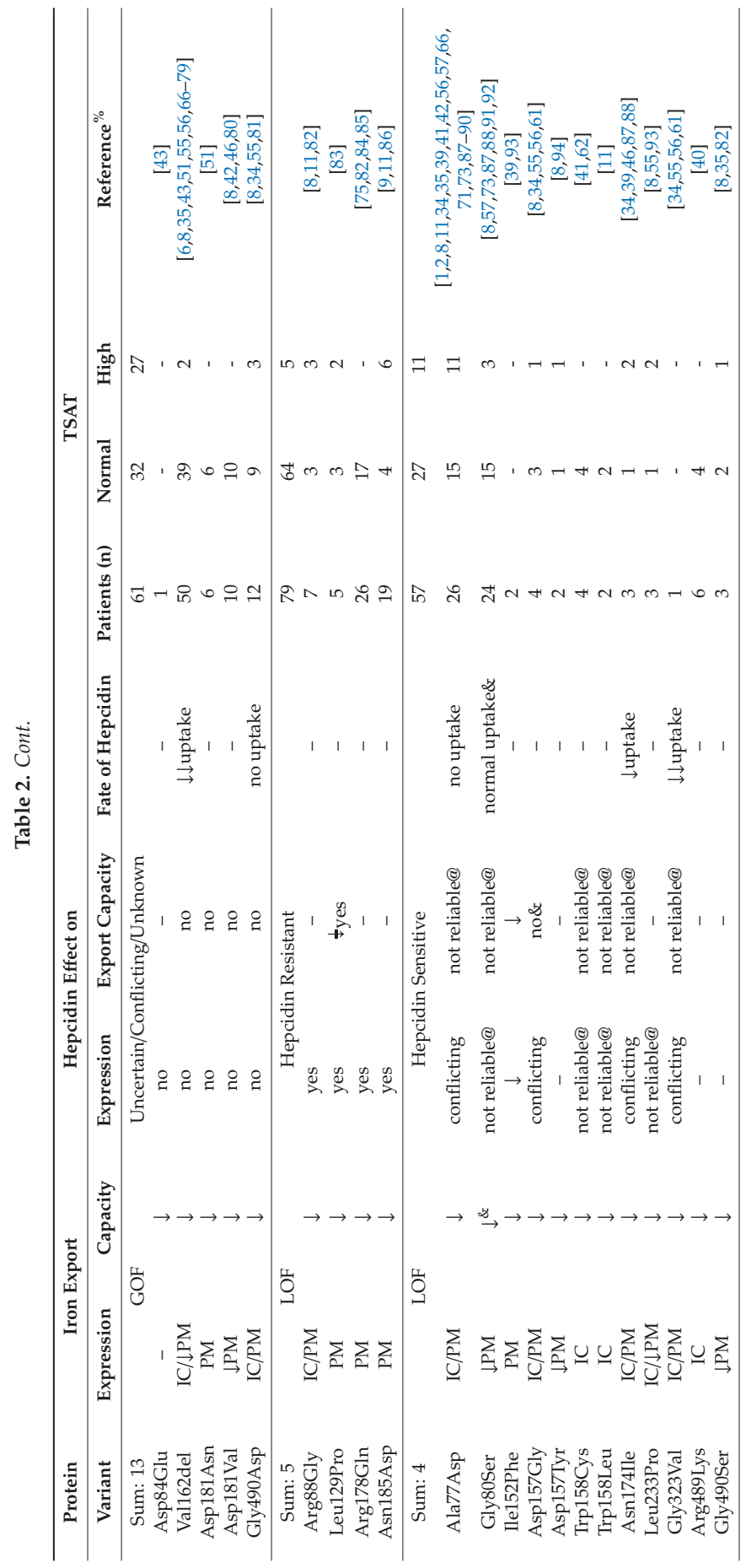


Pharmaceuticals 2019, 12, 132

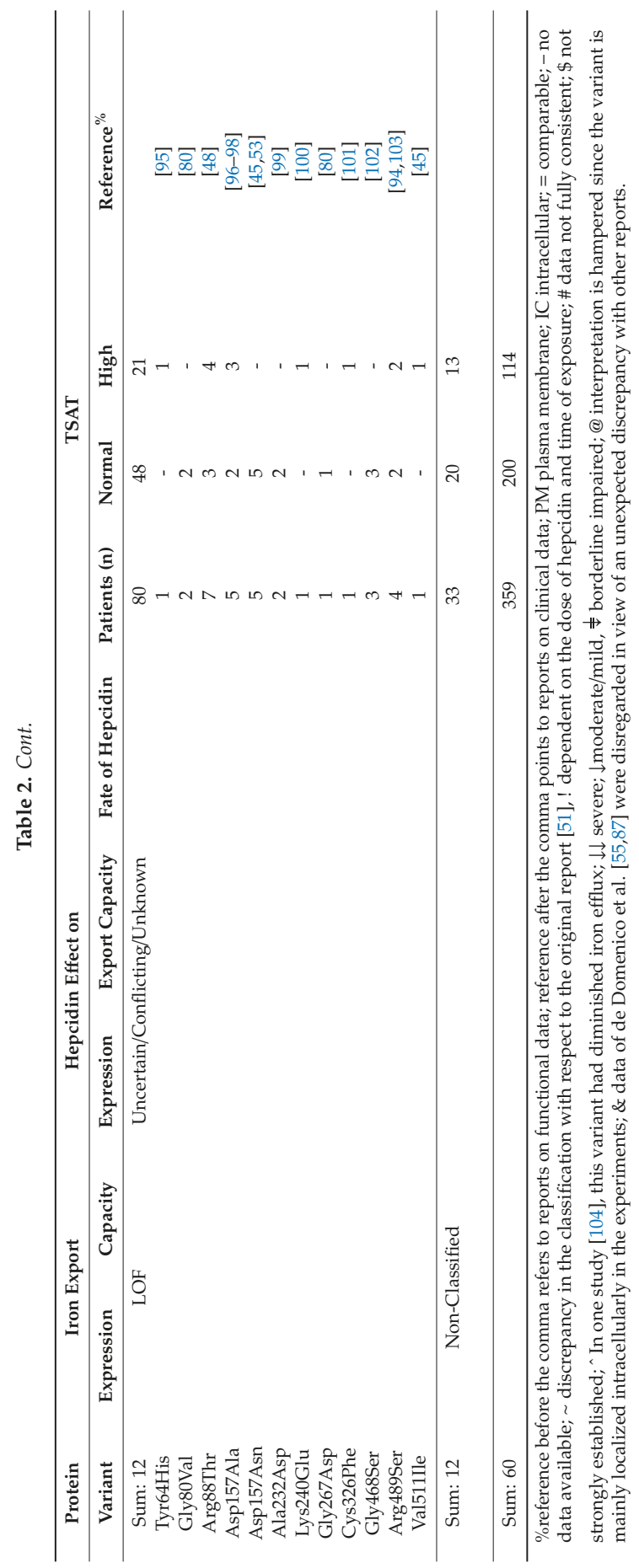




\subsubsection{Clear Distinct Phenotypical Features in Patients with GOF and LOF Variants}

Patients with GOF variants had significantly lower ferritin $(755 \mu \mathrm{g} / \mathrm{L}$ versus $1595 \mu \mathrm{g} / \mathrm{L})$ concentration (Table 3) and higher serum iron $(36.0 \mu \mathrm{mol} / \mathrm{L}$ versus $17.5 \mu \mathrm{mol} / \mathrm{L})$ concentration and TSAT (62\% versus $32 \%$ ) than patients with LOF variants. Inter-individual variation in TSAT levels was high in both LOF and GOF patients (Figure 1). In contrast to previous reports $[7,105]$ and the prevailing opinion [10], patients with LOF and GOF variants were found to have a comparable $\mathrm{Hb}$ and prevalence of anemia (according to the World Health Organization criteria). While hepatic iron content was similar in patients with LOF and GOF variants, patients with LOF variants display iron deposition predominantly in macrophages (Kupffer cells), while the iron in GOF patients is predominantly present in hepatocytes, and is associated with more hepatic damage as reflected by the significantly higher serum ALT and amount of fibrosis (scored according to the METAVIR scale).

Table 3. Phenotypic features by ferroportin functional gene variant.

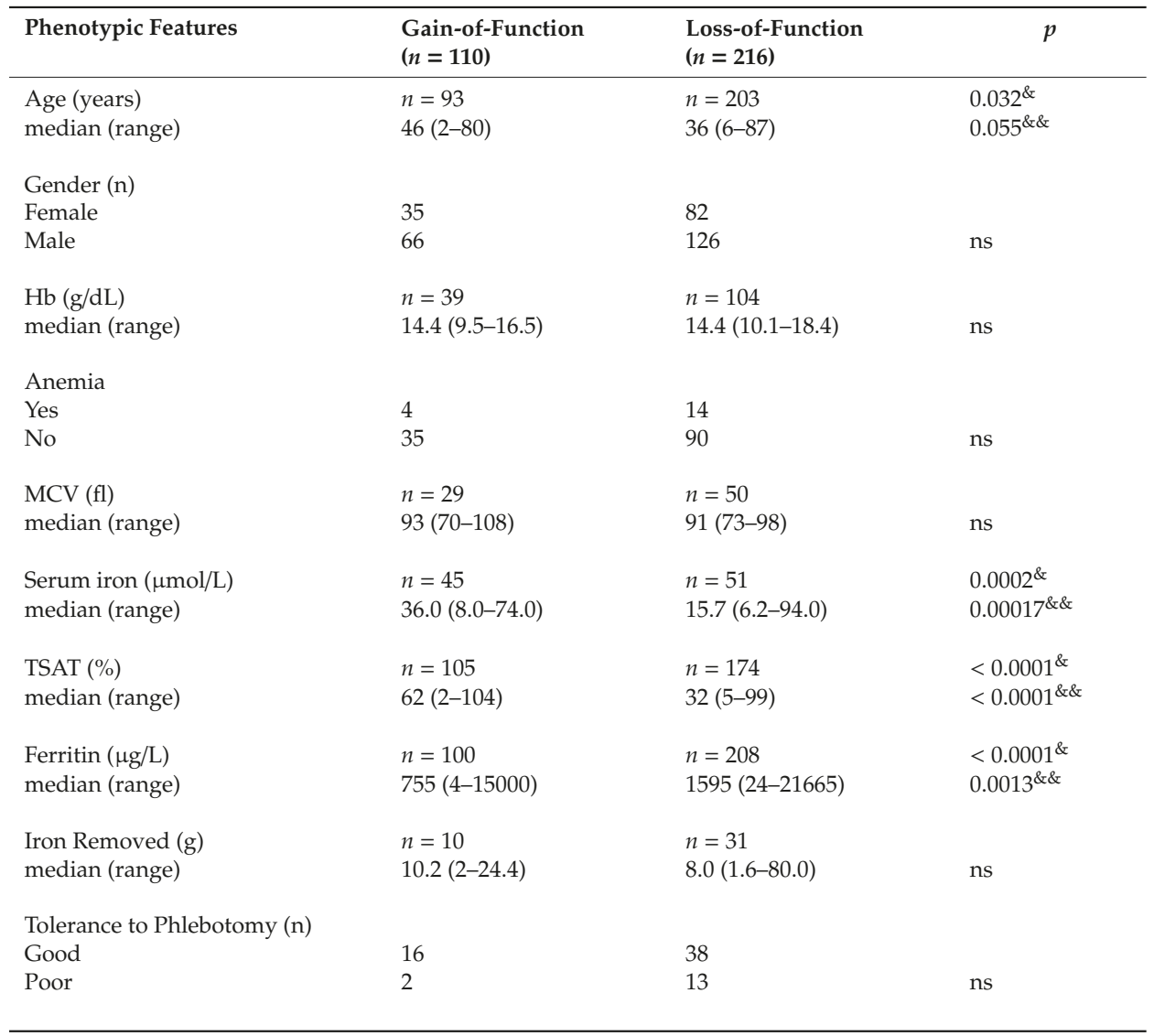


Table 3. Cont.

\begin{tabular}{|c|c|c|c|}
\hline Phenotypic Features & $\begin{array}{l}\text { Gain-of-Function } \\
(n=110)\end{array}$ & $\begin{array}{l}\text { Loss-of-Function } \\
(n=216)\end{array}$ & $p$ \\
\hline $\mathrm{HIC}(\mu \mathrm{g} / \mathrm{g})$ & $n=19$ & $n=53$ & \\
\hline median (range) & $11718(925-38665)$ & $10052(307-58590)$ & $\mathrm{ns}$ \\
\hline \multicolumn{4}{|l|}{ Grade of fibrosis } \\
\hline $0-2$ & 14 & 20 & \\
\hline $3-4$ & 10 & 2 & 0.012 \\
\hline \multicolumn{4}{|l|}{ Hepatic Iron distribution } \\
\hline Hepatic (predominant) & 18 & 7 & $<0.00001^{@}$ \\
\hline Macrophagic (predominant) & 0 & 28 & \\
\hline Mixed & 10 & 16 & $<0.00001^{@ @ ~}$ \\
\hline ALT (IU/L) & $n=31$ & $n=48$ & $0.0026^{\&}$ \\
\hline median (range) & $52.0(14.0-304.0)$ & $29.5(6.0-98.0)$ & $0.004^{\& \&}$ \\
\hline
\end{tabular}

HIC, hepatic iron content; ALT, alanine aminotransferase. ${ }^{\&}$ Mann-Whitney U-test, \&\&Student's t-test of independent means, $\mathrm{p}$ is significant $<0.0033$ when corrected for multiple testing according to Bonferroni. ${ }^{\circledR}$ difference between hepatic and macrophagic, ${ }^{\circledR}$ difference between hepatic, macrophagic, and mixed.

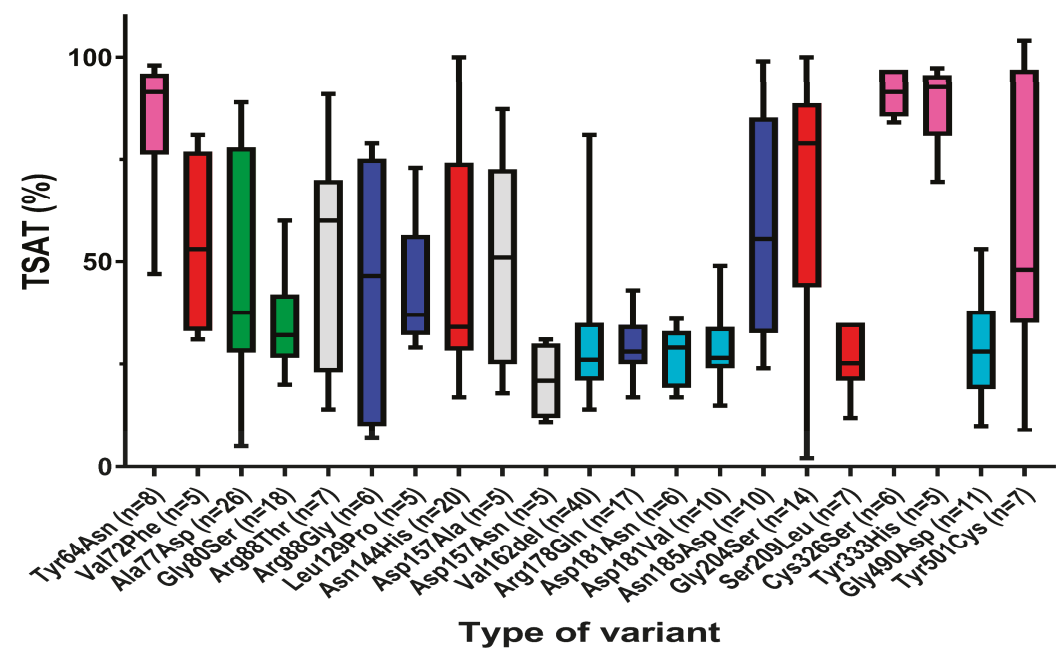

Figure 1. Box plots (Whiskers: min to max) of transferrin saturation (TSAT) in individuals with ferroportin variants. Only the variants with at least five reported TSAT levels in patients are included. Red: GOF without or conflicting data about hepcidin sensitivity; Pink: GOF hepcidin-resistant variants; Green: LOF without or conflicting data about hepcidin sensitivity; Light blue: LOF hepcidin-resistant variants; Blue: LOF hepcidin-sensitive variants; Gray: No data available.

Long-term follow-up information and data to determine a difference in clinical course between GOF and LOF variant patients are limited $[12,106]$. We found three documented deaths related to ferroportin disease: fatal hepatocellular carcinoma in one GOF and one LOF variant patient $[48,82]$. One patient with a GOF mutation died of multiorgan failure due to widespread iron deposition [50].

3.2.2. Strong Association of Hepcidin Sensitivity of Ferroportin Functional Gene Variants with Serum Iron Parameters

In vitro hepcidin sensitivity studies were performed in 45 variants. We identified seven hepcidin-resistant and seven hepcidin-sensitive GOF variants, and five hepcidin-resistant and four 
hepcidin-sensitive LOF variants (Table 2). Twelve LOF and 13 GOF variants were designated as uncertain/conflicting/unknown, including those variants with partial resistance or sensitivity.

Patients with hepcidin-resistant LOF variants had significantly lower TSAT (27\% versus $35 \%$ ) and serum iron $(14.1 \mu \mathrm{mol} / \mathrm{L}$ versus $28.7 \mu \mathrm{mol} / \mathrm{L})$ but higher ferritin $(1810 \mu \mathrm{g} / \mathrm{L}$ versus $1066 \mu \mathrm{g} / \mathrm{L})$ than patients with a hepcidin-sensitive LOF variant (Table S4, Figure 2).

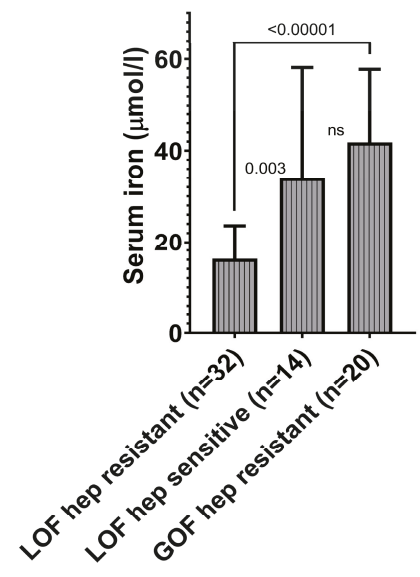

(A)

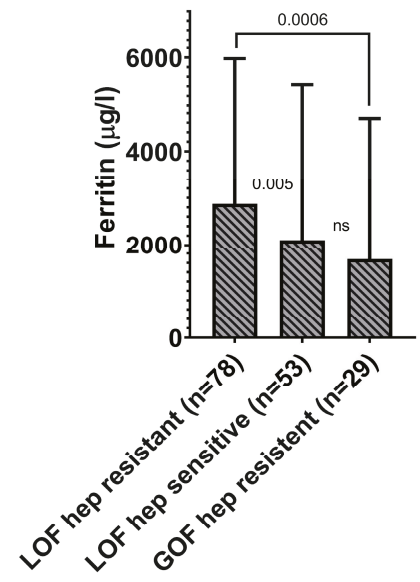

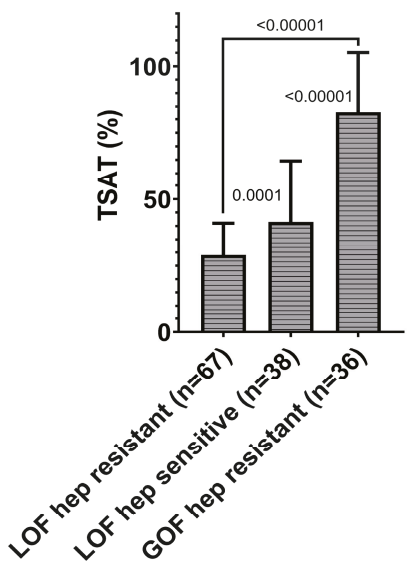

(B)

(C)

Figure 2. Iron parameters for the different ferroportin variants. Mean (+ SD) of (A) serum iron, (B) transferrin saturation, and (C) ferritin as measured in patient samples for the function of variant (LOF = loss-of-function, GOF = gain-of-function) and the effect of hepcidin (hep resistant = hepcidin-resistant, hep sensitive = hepcidin-sensitive) on the iron transport capacity, as assessed by in vitro functional tests. TSAT $=$ transferrin saturation. The Student's t-test was applied to determine the difference between serum iron and TSAT, while the Mann-Whitney U-test test was applied for ferritin. Displayed p values, serum iron, and TSAT are according to the Student's t-test. Displayed p values ferritin according to the Mann-Whitney U-test.

However, patients with hepcidin-resistant GOF variants had highly significant higher serum iron $(44.0 \mu \mathrm{mol} / \mathrm{L}$ versus $14.0 \mu \mathrm{mol} / \mathrm{L})$ and TSAT $(92 \%$ versus $28 \%)$ and lower ferritin $(642 \mu \mathrm{g} / \mathrm{L}$ versus 
$1810 \mu \mathrm{g} / \mathrm{L}$ ) concentration than patients with hepcidin-resistant LOF variants (Table S5, Figure 2). All seven patients with a hepatocyte predominant iron deposition carried a hepcidin-resistant GOF variant, while all nine patients with a macrophage predominant iron deposition had a hepcidin-resistant LOF variant.

\subsection{Therapeutic Considerations}

In patients with primary iron overload, phlebotomy is the cornerstone of treatment. In 93 of 102 patients who were reported to be phlebotomized, the tolerance of the phlebotomy was reported. A total of 73 patients tolerated phlebotomy without side effects. In 17 of 20 patients with poor tolerance to phlebotomy, the cause of the intolerance could be analyzed. In 12 of the 14 patients with intolerance to phlebotomy due to the development of early anemia, phlebotomy could be continued by the application of a less intensive phlebotomy schedule. In one patient, anemia subsided despite the continuation of the same regimen. In three additional patients, the administration of erythropoietin resulted in an increase of $\mathrm{Hb}$ and continuation of the phlebotomy regimen $[59,107]$. In two patients, phlebotomy was discontinued because of the occurrence of anemia. Treatment with deferasirox resulted in a dramatic decrease in serum ferritin concentration in two patients, but was not successful in another $[52,76,96]$.

In contrast to the current consensus $[1,2,4,6,8,40,71,83,92,105]$, patients with LOF variants were not less tolerant to phlebotomy than patients with GOF variants (Table 3). Nevertheless, in five of 22 (23\%) patients with hepcidin-resistant LOF variants the reported phlebotomy was poorly tolerated (Table S5) due to early anemia.

\section{Critical Annotations on Pathogenicity of Variants}

In Table 4, we depicted the potential pathogenicity of the various variants derived from available clinical, epidemiological, and genetic data from the original reports. We scored the likelihood of the pathogenicity of a variant based on the available data from the genome aggregation data base (gnomAD), data derived from the functional tests, at the molecular level in context of the current knowledge of the function and structure of the ferroportin molecule, and based on three in silico predicting models.

Table 4. Likelihood of pathogenicity derived from the reported data, and current databases and prediction models.

\begin{tabular}{|c|c|c|c|c|c|c|c|c|c|}
\hline Variant & Pheno-Type & Co-Segregation & $\mathrm{VO} /$ Controls & gnomAD & Functional & Molecular & Poly-phen2 & $\frac{\text { ico Pre }}{\text { SIFT }}$ & $\frac{\text { ediction }}{\text { Align-GVGD }}$ \\
\hline Tyr64Asn & +++ & +++ & $0 / 100$ & & ++++ & ++ & ++ & 0 & 0 \\
\hline Tyr64His & $+++\&$ & & & & & ++ & ++ & 0 & 0 \\
\hline Ala69Thr & $+++\&$ & 0 & & & ++ & 0 & ++ & + & 0 \\
\hline Val72Phe & + & + & & & +++ & 0 & ++ & 0 & 0 \\
\hline Ala77Asp & +++ &,$+++++\#$ & $0 / 100$ & & +++ & 0 & ++ & + & 0 \\
\hline Gly80Ser & ++ & & $0 / 734$ & & +++ & + & ++ & + & 0 \\
\hline Gly80Val & ++ & & $0 / 100$ & & & + & ++ & + & 0 \\
\hline Asp84Glu & $+++\&$ & & & & ++ & + & ++ & + & 0 \\
\hline Arg88Gly & +++ & & $0 / 734$ & & ++ & + & ++ & + & 0 \\
\hline Arg88Thr & ++ & +++ & $0 / 60$ & & & + & ++ & + & 0 \\
\hline Leu129Pro & 0 & + & & & ++++ & 0 & ++ & + & +++ \\
\hline Asn144Asp & +++ & & & & +++ & + & ++ & 0 & 0 \\
\hline Asn144His & 0 & +++ & $0 / 200$ & & +++ & + & + & 0 & 0 \\
\hline Asn144Thr & $0^{\&}$ & & $0 / 100$ & & +++ & + & ++ & 0 & 0 \\
\hline Ile152Phe & +++ & + & & & +++ & + & ++ & 0 & 0 \\
\hline Asp157Ala & ++ & ++ & & & & + & ++ & + & 0 \\
\hline Asp157Asn & ++ & 0 & & & & + & ++ & 0 & 0 \\
\hline Asp157Gly & +++ & & $0 / 80,0 / 734$ & & +++ & + & + & 0 & 0 \\
\hline Asp157Tyr & +++ & & $0 / 734$ & & + & + & ++ & + & + \\
\hline Trp158Cys & +++ & $0,+$ & $0 / 50$ & & +++ & 0 & ++ & + & ++ \\
\hline Trp158Leu & +++ & & & & +++ & 0 & + & 0 & 0 \\
\hline Val162del & ++ &,++++ & $\begin{array}{l}0 / 100,0 / 103 \\
0 / 734\end{array}$ & & ++++ & 0 & @ & @ & (a) \\
\hline
\end{tabular}


Table 4. Cont.

\begin{tabular}{|c|c|c|c|c|c|c|c|c|c|}
\hline Variant & Pheno-Type & Co-Segregation & VO/Controls & gnomAD & Functional & Molecular & $\underset{\text { Poly-phen2 }}{\stackrel{\text { In sili }}{\text { Phen }}}$ & $\frac{\text { ico Pre }}{\text { SIFT }}$ & $\frac{\text { ediction }}{\text { Align-GVGD }}$ \\
\hline Asn174Ile & +++ & & & & +++ & + & ++ & + & +++ \\
\hline Arg178Gln & +++ & $0-+++\# \#$ & & & ++ & +++ & ++ & 0 & 0 \\
\hline Ile180Thr & 0 & 0 & $0 / 100$ & $7.076^{-5}$ & ++ & 0 & ++ & + & +++ \\
\hline Asp181Asn & ++ & & & & ++ & + & ++ & + & + \\
\hline Asp181Val & ++ &,+++ & $0 / 100,0 / 734$ & & ++ & + & ++ & + & +++ \\
\hline Gln182His & +++ & & $0 / 80$ & & +++ & 0 & ++ & + & + \\
\hline Asn185Asp & +++ &,++++ & $0 / 50$ & & + & 0 & ++ & + & + \\
\hline Gly204Arg & $+++\&$ & & & & ++ & 0 & ++ & + & +++ \\
\hline Gly204Ser & + & +++ & $2 / 100$ & $7.955^{-6}$ & +++ & 0 & ++ & 0 & 0 \\
\hline Ser209Leu & 0 & ++ & & $1.485^{-4}$ & +++ & 0 & 0 & 0 & + \\
\hline Thr230Asn & $0^{\&}$ & & $0 / 734$ & $1.096^{-4}$ & ++ & 0 & + & 0 & 0 \\
\hline Ala232Asp & 0 & & & $4.95^{-5}$ & & 0 & + & 0 & + \\
\hline Leu233Pro & +++ & 0 & $0 / 734$ & & ++ & 0 & ++ & + & +++ \\
\hline Lys240Glu & $+++\&$ & & $0 / 50$ & & & 0 & 0 & + & 0 \\
\hline Met266Thr & $0^{\&}$ & & $0 / 734$ & & ++ & 0 & 0 & + & 0 \\
\hline Gly267Asp & $++\&$ & & $0 / 100$ & $4.382^{-5}$ & & 0 & + & 0 & 0 \\
\hline Asp270Val & + & & $4 / 100,1 / 516$ & $7.09^{-5}$ & +++ & 0 & 0 & 0 & 0 \\
\hline Arg296Gln & $0^{\&}$ & & & & ++ & 0 & + & 0 & ++ \\
\hline Gly323Val & $+++\&$ & & $0 / 80$ & & +++ & 0 & ++ & + & +++ \\
\hline Cys326Phe & $+++\&$ & 0 & & & & ++ & ++ & 0 & + \\
\hline Cys326Ser & +++ & +++ & & & ++++ & +++ & + & 0 & 0 \\
\hline Cys326Tyr & +++ & & $0 / 800$ & & ++++ & ++ & + & 0 & 0 \\
\hline Tyr333His & +++ & & $0 / 40$ & & ++ & + & ++ & + & +++ \\
\hline Ser338Arg & $+++\&$ & & & & +++ & 0 & 0 & 0 & 0 \\
\hline Leu345Phe & $0^{\&}$ & & $0 / 734$ & & ++ & 0 & ++ & 0 & 0 \\
\hline Ile351Val & $0^{\&}$ & & $0 / 734$ & $2.125^{-5}$ & ++ & 0 & 0 & 0 & 0 \\
\hline Arg371Gln & $0^{\&}$ & & & $2.388^{-5}$ & +++ & 0 & 0 & 0 & 0 \\
\hline Pro443Leu & $0^{\&}$ & & $0 / 734$ & $5.87^{-4}$ & ++ & 0 & 0 & 0 & 0 \\
\hline Gly468Ser & ++ & 0 & & $4.005^{-6}$ & & 0 & ++ & 0 & + \\
\hline Arg489Lys & +++ & +++ & $0 / 50$ & & + & + & ++ & + & +++ \\
\hline Arg489Ser & + & & $0 / 734$ & & & + & ++ & + & +++ \\
\hline Gly490Asp & +++ & 0 & $0 / 734$ & & ++++ & 0 & ++ & 0 & 0 \\
\hline Gly490Ser & +++ & & $0 / 734$ & & + & 0 & ++ & 0 & 0 \\
\hline Tyr501Cys & + & & $0 / 200$ & $3.184^{-5}$ & ++++ & +++ & + & 0 & + \\
\hline Asp504Asn & +++ & & $0 / 734$ & & ++++ & +++ & ++ & 0 & 0 \\
\hline His507Arg & +++ & + & $0 / 50$ & & ++++ & ++ & ++ & 0 & 0 \\
\hline Val5111le & $+++\&$ & & & & & 0 & ++ & + & ++ \\
\hline Arg561Gly & + & & $0 / 734$ & $1.638^{-3}$ & ++ & 0 & 0 & 0 & 0 \\
\hline
\end{tabular}

Open space: no data available. Phenotype: bold: at least five patients; $0=<50 \%,+=51-80 \%,++=81-99 \%$, $+++=100 \%$ presence of an elevated TSAT in GOF patients and elevated ferritin in LOF patients. Variants in italic are unclassified; + = elevated TSAT and/or ferritin (but not in all patients), ++ = elevated TSAT or ferritin in all patients, $+++=$ elevated TSAT and ferritin in all patients. \& only one reported patient. \# enumeration of a limited number of studies; \#\# range in multiple studies. Co-segregation from pedigrees in the original reports using the simplified method of segregation analysis (SISA) according to the following scoring system: single family: $0=$ no evidence, $+=\leq 1 / 8$ (supporting), $++=\leq 1 / 16$ (moderate), $+++=\leq 1 / 32$ (strong); bold: multiple family studies: $0=$ no evidence, $+=\leq 1 / 4$ (supporting),$+=\leq 1 / 8$ (moderate),$+++=\leq 1 / 16$ (strong); all according to the recommendations of Jarvik et al. [22] to define co-segregation as criteria to fit the ACMG-AMP guidelines [24]. VO/Controls: Variant Occurrence in controls reported in the original reports. GnomAD: allele frequency derived from GnomAD data base [25]; the variants for which no allele frequency are given are absent in the database and thus extremely rare. Functional: $+=$ effect of hepcidin not performed, $++=$ effect of hepcidin established only on membrane expression or iron transport, $+++=$ conflicting or unreliable results on the effect of hepcidin, with reported fate of hepcidin, $++++=$ established effect of hepcidin on membrane expression and iron export with/without reported fate of hepcidin; Bold $=\geq 3$ independent studies. Molecular: $0=$ variant present on a site without established role in ferroportin molecule, $+=$ variant present at a site potentially involved in the formation of the intracellular and extracellular gate, internalization and degradation of the ferroportin molecule or at a site potentially involved in iron binding or egress, $++=$ variant present at a site with established function in hepcidin binding, $+++=$ variant present at a site leading to established conformational changes in the structure of the ferroportin molecule as predicted in the available three-dimensional (3D) models. In silico prediction: Polyphen 2: $0=$ benign,$+=$ possibly damaging, $++=$ probably damaging; "Sorts intolerant from Intolerant" (SIFT): $0=$ tolerated, $+=$ deleterious; Align-GVGD: $0=$ class $0,+=$ Class $15,++=$ Class 25 and $35,+++=$ Class 55 and $65 ; @=$ It is not possible to test deletions in Polyphen2, SIFT, and Align-GVGD.

\subsection{Shortcomings in Description of Clinical Phenotypes}

The collected data to describe the clinical phenotype were derived from extensively documented family studies to isolated patients with minimal reported clinical data as part of national surveys of patients with iron overload. So, the available clinical, biochemical, radiological, and histological data 
were the most heterogenous. In addition, in family studies, relatives were more than 10 years younger with a milder phenotype, including $11 \%$ with normal iron parameters. In many patients, a genetic diagnosis was made after referral, and reported iron parameters may potentially have been affected by previous phlebotomies. The demonstrated lack of effect on the presence of additional acquired iron-modulating conditions must be interpreted with caution in view of insufficient reported data. The presence of polymorphisms in ferroportin may affect the degree of iron overload in homozygotic patients for p.Cys282Tyr variants in the HFE molecule [13]. The lack of effect of presence of HFE variants on the iron parameters in our analysis is likely to be explained by the absence of patients with homozygotic p.Cys282Tyr HFE variants.

The phenotype of a number of reported variants raised doubt on the pathogenicity of these variants. An elevated TSAT is considered to be the hallmark of GOF variants. In 41 of $116 \mathrm{GOF}$ patients, TSAT was normal. Since 13 of them also had a ferritin level $\leq 200 \mu \mathrm{g} / \mathrm{L}, 11 \%$ of GOF patients had normal serum iron parameters, especially patients with Asn144His (8/20 pts) and Val72Phe (2/5 pts) variants. Also, 7/9 reported patients with the seven hepcidin-sensitive GOF variants had a normal TSAT. The Gly204Ser GOF variant displayed evident pathologic iron parameters in a homozygous patient, with normal iron parameters in the two heterozygous relatives, and four of 14 additional reported patients had normal TSAT. Six of 197 LOF patients had normal reported ferritin level including 3/5 Leu129Pro variant patients. In a 10-year follow-up study of a proband and his father with a Arg489Ser variant, the serum iron spontaneously decreased with a slight reduction in the MRI estimated HIC [12].

\subsection{Shortcomings in Establishment of Pathogenicity}

\subsubsection{Co-Segregation with Disease in the Family}

SISA was applicable for 26 variants and hampered by the small pedigrees in most reports. In 13 variants, there was no or only supporting evidence for pathogenicity; in nine variants, evidence was moderate or strong, and for four variants, the score for pathogenicity was inconclusive (Table 4).

\subsubsection{Variant Occurrence and Allele Frequency}

In the original reports, variant occurrence in healthy controls was determined for 37 variants in relatively small cohorts (range 40 to 734 persons) with an established occurrence of $<1 / 100$ for 26 variants. In the genome aggregation data base (gnomAD, [25]), 213 missense variants were observed with subsequent determination of the allele frequency. Of these, only 13 variants displayed clinical symptoms to be reported and analyzed in the current review. Notably, 47/60 variants in our analysis are so rare that the allele frequency is not depicted in gnomAD.

\subsubsection{Limitations of Functional In Vitro Tests}

In most of the transfection studies HEK293T, a human embryonic kidney cell line, was used $[6,8,11,31-33,35,39-42,46,55-57,83,87,93]$ and occasionally Xenophus oocytes, colon carcinoma $\mathrm{CaCo}-2$, or hepatoma HuH7 cell lines $[6,57,66]$. Protocols are not standardized. Iron loading was done with 1 to $2 \mathrm{mg} / \mathrm{mL}$ of holotransferrin [8,41], 1 to $4 \mathrm{mg} / \mathrm{mL}$ of ${ }^{55} \mathrm{Fe}[8,33,35,39,46], 20$ to $40 \mu \mathrm{g} / \mathrm{mL}$ of ${ }^{59} \mathrm{Fe}$ bound to transferrin [31,40,42], nitrilotriacetate [46] or ascorbate [66], or 10 to $100 \mu \mathrm{M}$ of ferric ammonium citrate $[6,32,55,57,83,93]$ for $24 \mathrm{~h}$ before to $48 \mathrm{~h}[8,31-33,39,40,42,46,55,66,83,87]$ after transfection. Cells were lysed 4 to $72 \mathrm{~h}$ after iron loading [8,31,33,46,56]. Iron export capacity was determined either by the measurement of radioactive Fe $[8,31,33,35,39,40,42,46,56,66]$ or ferritin concentration $[6,8,11,32,33,35,41,42,55,57,83,87,93]$ in lysed cells $[6,32,33,35,40,42,57,93]$ or in the supernatant $[8,11,31,33,35,39,46,56,83]$. Results obtained in cells transfected with the variant ferroportin were compared with results in untransfected cells and in cells transfected with wild-type ferroportin. The effect of hepcidin on iron export capacity and the expression of the variant ferroportin protein were analyzed. Experimental conditions are also not standardized; specific differences include: (i) applied hepcidin concentration, which varied between 0.01 and $10 \mu \mathrm{M}$, and (ii) incubation times, 
which varied between 3 and $56 \mathrm{~h}[11,31-34,39,41,42,55,56,83,87,93]$. The membrane expression of variant ferroportin proteins was determined by surface biotinylation and Western blotting [8,39], immunofluorescence $[6,31-33,40,42,46,55-57,65,87]$ and confocal microscopy $[11,34,41,83]$, or flow cytometry $[31,35,41,42,56]$. These differences may be responsible for the variable results reported on the effect of hepcidin on the membrane expression and iron export capacity of cells transfected with WT ferroportin.

In a significant number of the tested variants, the effect of hepcidin was determined by means of ferroportin expression and not by changes in iron export. Furthermore, in the vast majority of the transfected LOF variants, the membrane expression of the protein was strongly reduced or even absent, and therefore the effect of hepcidin is difficult to determine reliably. In a number of variants, the inhibitory effect of hepcidin was tested at various concentrations of hepcidin and/or exposure times, which resulted in a time and/or concentration dependent effect, ranging from hepcidin resistant to more or less hepcidin sensitive $[6,30,42,65]$. Therefore it is not unthinkable that the same variant is considered hepcidin resistant by one investigator and hepcidin sensitive by the other, depending on the design of the applied assay.

So, large inter-assay variation may not only lead to conflicting results in ferroportin variants tested in multiple studies, but also to reluctance to draw firm conclusions for data obtained in a single study. In addition, our definition of LOF (i.e. a significant reduced iron transport in functional tests) and hepcidin sensitivity (i.e. a significant reduction in iron transport or ferroportin expression in functional assays upon the addition of hepcidin) may lead to discrepancies in the interpretation of the functional characterization of some individual variants such as Gly204Arg and Arg296Gln, between us and the authors of the original publication [51].

\subsubsection{Lack of Concordance between Various In Silico Prediction Models}

As illustrated in Table 4, the concordance between the three methods is poor, with a weak albeit significant correlation between SIFT and Align-GVGD $(r=0.5441)$, polyphen2 and SIFT $(r=0.3832)$, and polyphen 2 and Align-GVGD $(r=0.3066)$.

\subsection{Assessment of Pathogenicity of Ferroportin Variants on Molecular Level in Context of Current Knowledge} on the Function and Structure of Ferroportin

\subsubsection{Ferroportin, the Protein, Its Variants, and Function: Current Knowledge}

Ferroportin is a 571 amino acid cation transporter of the major facilitator superfamily (MFS) encoded by the SLC40A1 gene [46,108-111]. It is the only known cellular iron exporter, and primarily expressed in the basolateral membrane of duodenal enterocytes, macrophages, and hepatocytes [108,110-112]. In the most widely accepted secondary structure, ferroportin comprises 12 helices located in 12 transmembrane (TM) domains bound via six extracellular (ES) and five intracellular (IS) segments with a large intracellular loop between the sixth and seventh transmembrane helix and intracellularly located $N$ and $C$ terminus $[6,8,34,46,56,113]$. Although the amount of polymerization is still a matter of debate, most investigators assume that ferroportin is expressed on the membrane as a dimer $[6,34,35,55,114]$. Available three-dimensional models are based on comparison with ferroportin from other species with only 10-24\% sequence homology and $40 \%$ similarity $[8,39,46,115]$. Recent studies reveal an open-inward and an open-outward structure with an intracellular and extracellular gate between the sixth and seventh transmembrane domain. Extrapolating the experimental model to the human protein reveals that residues Asp84, Arg88, Asp157, Asn174, Gln481, Glu486, and Arg489, which are located at IS1, IS2 and IS5, are important in intracellular gate interaction, while the residues Phe44, Val48, Val 51, Leu58, Asp325, Thr329, Leu342, and Phe520, which are located at TM1, TM12, ES1 and ES4, are involved in extracellular gate interaction (Figure 3) [46,115]. It is postulated that intracellular iron is transported outside the cell, and that 
extracellular hepcidin is transported inside the cell through this gate via a so called "rocker-switch" mechanism $[46,115,116]$.

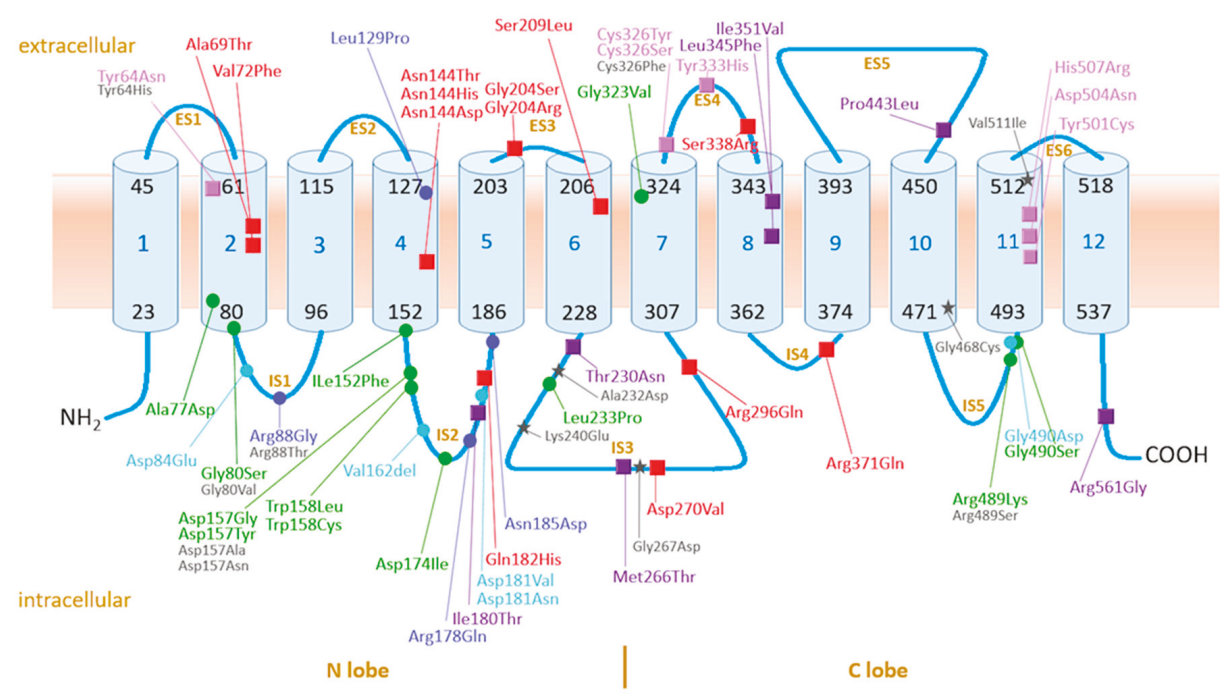

Figure 3. The two-dimensional (2D) structure of ferroportin protein adapted from Liu and Wallace [6,56], revealing 12 transmembrane helices and six extracellular and five intracellular segments. All the variants described in this review are shown as hepcidin-resistant (pink), hepcidin-sensitive or neutral (purple) and hepcidin conflicting/uncertain/unknown (red) GOF variants (squares). and hepcidin resistant (light blue), hepcidin sensitive (dark blue), and hepcidin conflicting-uncertain-unknown (green) LOF variants (dots), or non-classified variants (grey asterix).

Since sites containing an Asp, Glu, His, or Tyr residue are reported be involved in iron binding, Asp39, Glu52, Tyr54, Asp181, Tyr318, Asp325, Tyr331, Tyr501, and Glu518 are potential iron binding sites and Arg88, As157, Asn174, and Arg489 are involved in the intracellular gate interaction [46,115]. Functional studies revealed cation binding at Ser35, Asp39, Asn212, and Ser215 and site mutagenesis studies suggest that Asp39 and Asp181 are essential iron binding sites [46,115]. The residues Arg88, Ile152, and Asn174 are thought to be directly involved in iron egress [39].

Ferroportin-mediated cellular iron export is systemically regulated by the hepatocyte-derived peptide hormone hepcidin. The way hepcidin binding inhibits iron efflux is not fully elucidated [117-119]. Functional studies reveal the internalization of ferroportin upon hepcidin binding with subsequent endosomal and lysosomal degradation resulting in the diminution of cellular iron export, while three-dimensional (3D) structural studies suggest that hepcidin binding disrupts the conformational transition into the intracellular gate with the subsequent inhibition of the access of cytoplasmatic iron to the substrate binding-sites $[115,120,121]$. Site mutagenesis studies and the exploration of various three dimensional models suggests that the Phe324, Cys326, Tyr333, Asp504, and His507 residues are important binding and docking sites for hepcidin [32,39,46,115]. Recent structural models indicate that these hepcidin binding residues are clustered in the extracellular gate in the open-outward structure. Residues found to be involved in internalization include Tyr64, Gly80, andAsn144, and the residues Lys229, Lys253, and Lys269 are present in the large intracellular loop, and seem to be involved in the degradation of ferroportin [39,114,122].

In an effort to unravel the pathogenicity of ferroportin variants, we depicted the various variants in the structure of ferroportin molecule. For the two-dimensional (2D) model (Figure 3), we adapted the structure constructed by Liu and Wallace [6,56] and for three-dimensional (3D) model (Figure 4), we used 
the recently developed model (Bacterial ferroportin, PDB file 5AYN) and homology modeling in the Yet Another Scientific Artificial Reality Application (YASARA) [123] and WHAT IF Twinset [124] programs.

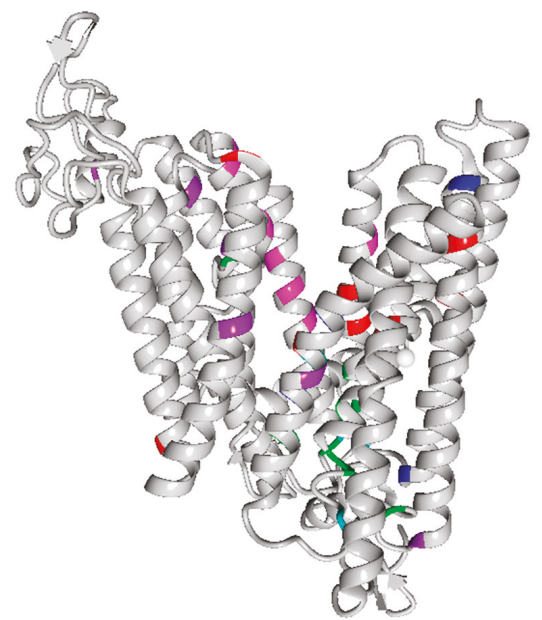

(A)

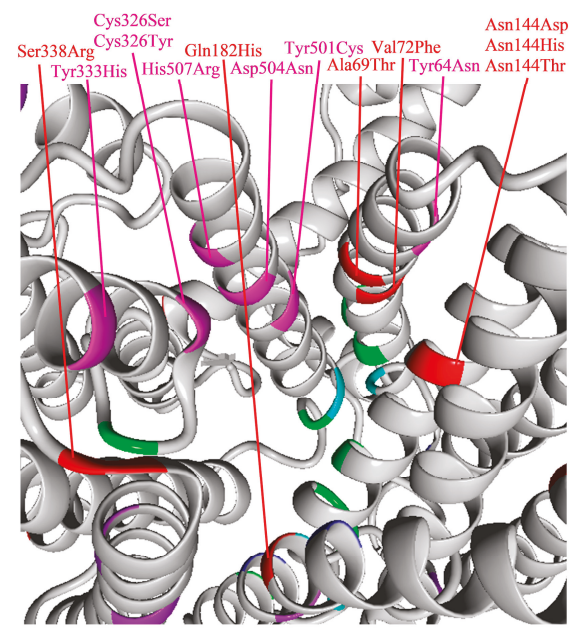

(B)

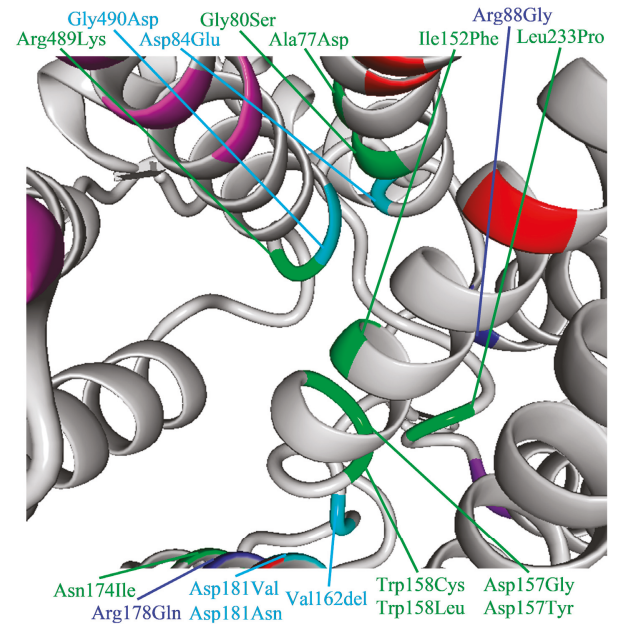

(C)

Figure 4. 3D model of ferroportin. (A). Overview. Ferroportin facing outward position. Top: extracellular; Bottom: intracellular. (B). Localization of hepcidin-resistant GOF variants. View inside the "channel" from extracellular to intracellular. Six (Cys326Tyr, Cys326Ser, Tyr333His, Tyr501Cys, Asp504Asn, and His507Arg) of the seven residues of GOF hepcidin-resistant variants are located inside the channel. The Ala69, Val72, Asn144, Gln182, and Ser338 residues are also located inside the channel. However, these variants have conflicting or no data on hepcidin sensitivity. (C). Clustering of LOF variants at the intracellular side of ferroportin. View inside the channel from extracellular to intracellular. Red: GOF without or conflicting data about hepcidin sensitivity; Pink: GOF hepcidin-resistant variants; Purple: GOF hepcidin-sensitive or neutral variants; Green: LOF without or conflicting data about hepcidin sensitivity; Light blue: LOF hepcidin-resistant variants; Blue: LOF hepcidin-sensitive variants. We used bacterial ferroportin for the 3D model (PDB file 5AYN). 


\subsubsection{GOF Variants}

We identified Tyr64Asn, Cys326Tyr, Cys326Ser, Tyr501Cys, Asp504Asn, and His507Arg as definitely hepcidin-resistant GOF variants, and a co-culture of hepcidin with cells transfected with these variants does not lead to the internalization of the ferroportin variant with maintained iron export capacity and variant membrane expression $[8,11,31-35,39-42,46]$. Consequently, there is increased iron export from enterocytes and macrophages leading to hepatocellular iron overload. Observations in mice with the Cys326Ser variant reveal that increased dietary iron absorption is maintained by the upregulation of the Duodenal cytochrome b (Dcytb) and Divalent Metal Transporter 1 (DMT1) at the apical site of the enterocyte, which is likely to compensate for the pending intraenterocytic iron depletion [125]. For Cys326Tyr, Cys326Ser, Tyr501Cys and Asp504Asn, the blocked internalization of ferroportin on hepcidin exposure has been attributed to the impaired binding of hepcidin to ferroportin in the extracellular gate, while for Tyr64Asn and His507Arg—of which the location in relation to this gate varies between the available models—-the impaired ubiquitination of hepcidin, which was most likely due to interference with conformation, is the most likely mechanism (Figure 4B) [30]. The Tyr333Ala, Tyr333His (both hepcidin-resistant variants in a functional test) and Tyr333Phe (hepcidin-sensitive) GOF variants display both membrane localization and intact iron export, but impaired ubiquitination after normal hepcidin binding; however, there are no data on configural changes due to presence of these variants $[30,45]$.

The Ile180Thr, Thr230Asn, Met266Thr, Leu345Phe, Ile351Val, Pro443Leu, and Arg561Gly were designated as hepcidin-sensitive GOF variants. In functional studies, the iron export capacity, hepcidin uptake, and hepcidin-induced reduction of the cell surface expression of these variants were comparable with WT ferroportin $[8,11,31,35]$. None of these variants are located at residues that are known to be involved in hepcidin binding, ferroportin ubiquitination, or iron binding/egress. Notwithstanding that these seven variants behaved as WT ferroportin in functional studies and are located at residues without an established functional role, the reported 16 patients had otherwise unexplained mild iron overload, which was reflected by a median TSAT of $42.5 \%$ and serum ferritin concentration of $980 \mu \mathrm{g} / \mathrm{l}$. Nevertheless, the pathogenicity of the variants may be questioned, and therefore, the variants may as well be classified as neutral [8].

\subsubsection{LOF Variants}

Except for Leu129 and Gly323, the residues of the alterations that are associated with LOF variants are located at the intracellular site of the molecule, especially in the IS1, IS2, and IS5 (Figure 3) structures, which are involved in the formation of the intracellular gate responsible for iron transport (Figure 4C) [115]. In transfected cells, the majority of LOF variants are reported to be located intracellularly or have reduced membrane expression, although the data are not consistent for some variants (Table 2). Alteration in these residues may lead to conformational changes due to improper folding with mislocalization and disrupted intracellular gate formation. The substitution of Arg by Gly at residue 88 may lead to direct impaired iron handling with disrupted iron egress. That four hepcidin-sensitive variants display more or less intact membrane expression suggests intact extracellular gate formation enabling hepcidin binding. It was recently demonstrated that the hepcidin-sensitive LOF variant Arg178Gln, which is properly localized on the cellular membrane with disappearance after hepcidin exposure, is likely to form a non-covalent interaction between Arg178 and Asp473, which are located on the $\mathrm{N}$ and $\mathrm{C}$ lobe, respectively. This interaction may lead to a loss of stabilization of the open-outward conformation that is needed to preserve iron egress [84]. Residues of the four hepcidin-resistant LOF variants are not involved in hepcidin binding, so hepcidin resistance is likely to result from conformational changes in the extracellular gate, even though these variants have demonstrable but reduced membrane expression.

Overall, we conclude from that for most variants, clinical, functional, molecular, and in silico assessments of pathogenicity are not fully concordant, complicating the assessment of their likelihood of being the disease-causing variant (Table 4). For instance, the hepcidin-resistant GOF variants 
Tyr64Asn Cys326Ser, Cys326Tyr, Asp504Asn, and His507Arg are benign in two of the predicting in silico models, while clearly damaging variants in the three applied prediction models such as Leu129Pro and Ile180Thr were clinically likely to be benign. On the other hand, six out of the seven hepcidin-sensitive GOF variants had a low likelihood for pathogenicity both on clinical and molecular ground as well as in the predicting models.

\subsection{Is the Mode of Iron Overload in LOF Variants Related to a Difference in Ferroportin Expression and} Activation between Enterocytes and Macrophages?

Despite clear differences in iron distribution between patients with GOF and LOF variants, hepatic iron content and iron that is needed to be removed by phlebotomy to obtain a normalized iron phenotype are not found to differ, which might suggest that the total amount of absorbed iron in GOF and LOF patients is similar. Therefore, we hypothesize that in enterocytes, all the pathogenic ferroportin variants are associated with increased iron transport, irrespective of the (in vitro) function of the variant, while iron transport in macrophages and thereby the mode of systemic iron distribution is dependent on variant function. For patients with LOF variants, this hypothesis includes iron export being relatively decreased in macrophages, and being increased in enterocytes.

Ferroportin knock-out mice are not viable [110]. Mice with mono-allelic expression of wild-type (WT) ferroportin [111] and TMPRSS6 knock-out mice with subsequent reduced ferroportin expression on enterocytic membrane, develop iron deficiency anemia with intra-enterocytic iron retention [126] and patients with TMPRSS6 variants develop Iron Refractory Iron Deficiency Anemia (IRIDA) due to impaired intestinal iron absorption [127-129]. In contrast, patients heterozygous for LOF variants, which fail to export iron in functional tests, do not develop iron deficiency anemia; instead, they develop systemic, predominantly reticuloendothelial iron overload with limited but consistent proof for iron depletion in the enterocytes [79,88].

It has been recently suggested that differences in amount of intracellular iron turnover between enterocytes and macrophages may influence iron export capacity of these cells in patients with ferroportin disease due to LOF variants [130]. The monoallelic-expressed WT ferroportin protein would be sufficient to preserve iron export in cells with low iron turnover, such as enterocytes, but insufficient to maintain iron export capacity in cells with high iron turnover, such as splenic and hepatic macrophages, with subsequent intracellular iron retention in these cells. However, this hypothesis is insufficient to explain the state of iron overload. Functional consequences of a variant leading to the designation LOF is foremost established in HEK293T, which is a human embryonic kidney cell line, and are in accordance with events as observed in macrophages but fail to elucidate events that must be present in the enterocytes. So, HEK293T cells might not be the most appropriate experimental cell line to predict the functional consequences of at least LOF variants.

Experimental data provide evidence for differences in ferroportin expression and the activation between enterocytes and macrophages. Ferroportin is expressed on the enterocytic basolateral membrane and predominantly in intramacrophagic vesicles $[108,131]$, and there are indications that the mode of hepcidin-induced internalization differs in macrophages [120,132].

Intracellular transcription and the translation of SLC40A1 is primarily regulated by iron and oxygen in enterocytes and heme and iron in macrophages, [113,131,133]; also, the modulatory capacity by the iron-regulatory protein-iron-responsive element (IRP-IRE) system may differ between both cell types [134-138]. After iron egress from enterocytes, ferrous iron is oxidized by membrane-bound hephaestin, co-located with ferroportin, while ferrous iron release from macrophages is oxidized by circulating ceruloplasmin $[139,140]$.

Ferroportin expression differs between enterocytes and macrophages in response to systemic regulatory stimuli such as erythropoietin and hepcidin, changes in iron state, and inflammation (hepcidin independent) in experimental animals, as well as in isolated cell cultures [132,141-152]. 
Taken together, these experimental data suggest a regulation difference of ferroportin production and activation, between enterocytes and macrophages [153]. However, the extrapolation of results obtained from experimental models to physiology must be done with caution.

\section{Conclusions}

We analyzed 60 low-frequency missense variants in the coding sequence of the ferroportin gene reported over the past 20 years, which has been assumed to be responsible for iron overload in individual patients reported in the English literature with or without subsequent evaluation of the relatives. The clinical and laboratory features of the patients (phenotype) with these ferroportin variants were correlated with data on variant properties in functional in vitro tests, which were available for $80 \%$ of the variants. However, the reported clinical features are often incomplete and functional tests are artificial, not standardized, or unvalidated, which impedes the interpretation of the correlation between the functional properties and phenotype. The establishment of variant pathogenicity is hampered by a lack of sufficiently reported data regarding the presence of iron-modifying confounders and because the outcomes of available in silico prediction models is limited in the absence of a fully elucidated structure and function. Therefore, it is likely that not all reported variants are indeed pathogenic, but from the available data, it is nearly impossible to accurately establish the pathogenicity of individual variants. Notwithstanding these limitations, we can conclude that ferroportin disease is a heterogeneous iron overload disorder. Clinical symptoms are non-specific, and mostly consist of fatigue and arthralgia. At presentation, patients are generally middle aged with strongly elevated ferritin concentrations and mildly elevated TSAT and iron concentrations. Iron parameters and the severity of iron overload show considerable inter-individual variation and are also related to gender, age, and type of variant. The mode of organ iron distribution is primarily determined by the effect of ferroportin variants on macrophage iron export, which is comparable with that observed in functional in vitro studies. LOF variants are associated with macrophage iron retention with a high serum ferritin and low to normal TSAT, in contrast to GOF variants, which are associated with high TSAT and hepatocellular iron deposition. These distinct phenotypes are typically present in patients with hepcidin-resistant variants. Patients with GOF variants had a higher prevalence and higher grade of hepatic fibrosis, indicating that parenchymal iron deposition is more toxic than macrophage iron overload. This corroborates the notion that high TSAT facilitates parenchymal iron deposition, which is considered to be more toxic than macrophage iron overload [154]. On the other hand, with regard to toxicity in macrophages, it has been stated that macrophage iron overload is resistant to iron withdrawal, and that iron-loaded Kupffer cells may contribute to the development of hepatic fibrosis and even carcinogenesis [106].

Since iron distribution patterns and clinical features of patients with hepcidin-resistant GOF variants are indistinguishable from patients with other types of $\mathrm{HH}$, we support the proposition to categorize these variants as ferroportin-associated $\mathrm{HH}$, and to confine the entity ferroportin disease to patients with LOF variants [116]. For both entities, repeated phlebotomies to normalize the iron parameters in order to prevent organ damage remain the mainstay of treatment. Although we found no increased intolerance to phlebotomy in patients with LOF variants, we advocate for the regular determination of $\mathrm{Hb}$ levels during the phlebotomy program, especially in patients with hepcidinresistant LOF variants, to avoid the occurrence of early anemia.

The pathophysiology, especially of the LOF variants, is only partially understood. The iron handling within the various human cell types is not fully clarified, and the mechanisms by which ferroportin transports iron and is degraded are still not fully elucidated. To improve patient management, there is an unmet need for a better understanding of yet unresolved issues on the pathophysiology. A global registry, with a standardized diagnostic work-up and evaluation of the clinical, biochemical, radiological, and histological features of the liver and spleen, is needed, such as the registry sponsored by the European Association for the Study of the Liver (EASL) (http://non-hfe.com/) [155], a collaboration between various European Expert centers, or registries launched by the European Reference Network (ERN) of rare Hematological Disorders 
(EUROBLOODNET). Also, the histologic and molecular examination of enterocytes in duodenal biopsies of these patients by assessing iron content, as well as the expression of iron storage and transport proteins, will add to a better understanding of the iron handling. The secondary and tertiary structure of ferroportin as well as the identification of residues that are involved in hepcidin binding, ferroportin ubiquitination, and iron transport need to be further elucidated. Finally, the standardization of validated functional tests, which are preferably performed in human-derived enterocytic and macrophagic cell lines, will enable exploring iron transport and the modulating effect of hepcidin of known and yet unclassified variants, and will improve our insights of the pathophysiology of ferroportin disease.

Supplementary Materials: The following are available online at http:/www.mdpi.com/1424-8247/12/3/132/s1, Figure 1S: Relation between age and serum iron/TSAT/ferritin, Table 1S: Characteristics and iron parameters of probands versus probands' relatives, Table 2S: Phenotypical features by the reported presence of hereditary HFE and non-HFE iron overload conditions, Table 3S: Phenotypical features by the reported current use of alcohol, Table 4S: Phenotypical features of patients with functional LOF ferroportin variant by hepcidin sensitivity, Table 5S: Phenotypical features by hepcidin resistant GOF and LOF ferroportin variants.

Author Contributions: L.T.V. and D.W.S. designed the study, L.T.V. and R.J. wrote the manuscript, prepared the tables and figures, and performed and interpreted the statistical analysis, H.V. constructed the 3D model, all the authors contributed to the interpretation of tables and figures, D.W.S., H.D., H.V., E.B.-J., and H.H.-R. critically read and revised the manuscript. All the authors approved the final version of the manuscript.

Funding: This research received no external funding.

Acknowledgments: We thank Heinz Zoller for his critical revision on earlier versions of this work.

Conflicts of Interest: The authors declare no conflict of interest.

\section{References}

1. Pietrangelo, A.; Montosi, G.; Totaro, A.; Garuti, C.; Fraquelli, M.; Sardini, C.; Vasta, F.; Pietrangelo, A.; Conte, D.; Cassanelli, S.; et al. Hereditary hemochromatosis in adults without pathogenic mutations in the hemochromatosis gene. N. Engl. J. Med. 1999, 341, 725-732. [CrossRef] [PubMed]

2. Montosi, G.; Donovan, A.; Totaro, A.; Garuti, C.; Pignatti, E.; Cassanelli, S.; Trenor, C.C.; Gasparini, P.; Andrews, N.C.; Pietrangelo, A. Autosomal-dominant hemochromatosis is associated with a mutation in the ferroportin (SLC11A3) gene. J. Clin. Investig. 2001, 108, 619-623. [CrossRef] [PubMed]

3. Njajou, O.T.; Vaessen, N.; Joosse, M.; Berghuis, B.; Van Dongen, J.W.; Breuning, M.H.; Snijders, P.J.; Rutten, W.P.; Sandkuijl, L.A.; Oostra, B.A.; et al. A mutation in SLC11A3 is associated with autosomal dominant hemochromatosis. Nat. Genet. 2001, 28, 213-214. [CrossRef] [PubMed]

4. Nemeth, E. Ferroportin mutations: A tale of two phenotypes. Blood 2005, 105, 3763-3764. [CrossRef]

5. Fleming, R.E.; Sly, W.S. Ferroportin mutation in autosomal dominant hemochromatosis: Loss of function, gain in understanding. J. Clin. Investig. 2001, 108, 521-522. [CrossRef]

6. Wallace, D.F.; Harris, J.M.; Subramaniam, V.N. Functional analysis and theoretical modeling of ferroportin reveals clustering of mutations according to phenotype. Am. J. Physiol. Cell Physiol. 2010, 298, C75-C84. [CrossRef]

7. Mayr, R.; Janecke, A.R.; Schranz, M.; Griffiths, W.J.; Vogel, W.; Pietrangelo, A.; Zoller, H. Ferroportin disease: A systematic meta-analysis of clinical and molecular findings. J. Hepatol. 2010, 53, 941-949. [CrossRef]

8. Callebaut, I.; Joubrel, R.; Pissard, S.; Kannengiesser, C.; Gérolami, V.; Ged, C.; Cadet, E.; Cartault, F.; Ka, C.; Gourlaouen, I.; et al. Comprehensive functional annotation of 18 missense mutations found in suspected hemochromatosis type 4 patients. Hum. Mol. Genet. 2014, 23, 4479-4490. [CrossRef]

9. Le Lan, C.; Mosser, A.; Ropert, M.; Détivaud, L.; Loustaud-Ratti, V.; Vital-Durand, D.; Roget, L.; Bardou-Jacquet, E.; Turlin, B.; David, V.; et al. Sex and acquired cofactors determine phenotypes of ferroportin disease. Gastroenterology 2011, 140, 1199-1207. [CrossRef]

10. Pietrangelo, A.; Caleffi, A.; Corradini, E. Non-HFE hepatic iron overload. Semin. Liver Dis. 2011, 31, 302-318. [CrossRef]

11. Detivaud, L.; Island, M.L.; Jouanolle, A.M.; Ropert, M.; Bardou-Jacquet, E.; Le Lan, C.; Mosser, A.; Leroyer, P.; Deugnier, Y.; David, V. Ferroportin diseases: Functional studies, a link between genetic and clinical phenotype. Hum. Mutat. 2013, 34, 1529-1536. [CrossRef] [PubMed] 
12. Hayashi, H.; Yano, M.; Urawa, N.; Mizutani, A.; Hamaoka, S.; Araki, J.; Kojima, Y.; Naito, Y.; Kato, A.; Tatsumi, Y.; et al. A 10-year follow-up study of a Japanese family with ferroportin disease A: Mild iron overload with mild hyperferritinemia co-occurring with hyperhepcidinemia may be benign. Intern. Med. 2018, 57, 2865-2871. [CrossRef] [PubMed]

13. Altes, A.; Bach, V.; Ruiz, A.; Esteve, A.; Remacha, A.F.; Sarda, M.P.; Felez, J.; Baiget, M. Does the SLC40A1 gene modify HFE-related haemochromatosis phenotypes? Annu. Hematol. 2009, 88, 341-345. [CrossRef] [PubMed]

14. Zaahl, M.G.; Merryweather-Clarke, A.T.; Kotze, M.J.; van der Merwe, S.; Warnich, L.; Robson, K.J. Analysis of genes implicated in iron regulation in individuals presenting with primary iron overload. Hum. Genet. 2004, 115, 409-417. [CrossRef] [PubMed]

15. Santos, P.C.; Cancado, R.D.; Pereira, A.C.; Schettert, I.T.; Soares, R.A.; Pagliusi, R.A.; Hirata, R.D.; Hirata, M.H.; Teixeira, A.C.; Figueiredo, M.S.; et al. Hereditary hemochromatosis: Mutations in genes involved in iron homeostasis in Brazilian patients. Blood Cells Mol. Dis. 2011, 46, 302-307. [CrossRef]

16. Barton, J.C.; LaFreniere, S.A.; Li, H.; Acton, R.T.; Press, R.D.; Eckfeldt, J.H.; Leiendecker-Foster, C.; Leiendecker-Foster, C. HFE, SLC40A1, HAMP, HJV, TFR2, and FTL mutations detected by denaturing high-performance liquid chromatography after iron phenotyping and HFE C282Y and H63D genotyping in 785 HEIRS study participants. Am. J. Hematol. 2009, 84, 710-714. [CrossRef] [PubMed]

17. Lee, P.L.; Gelbart, T.; West, C.; Halloran, C.; Felitti, V.; Beutler, E. A study of genes that may modulate the expression of hereditary hemochromatosis: Transferrin receptor-1, ferroportin, ceruloplasmin, ferritin light and heavy chains, iron regulatory proteins (IRP)-1 and -2, and hepcidin. Blood Cells Mol. Dis. 2001, 27, 783-802. [CrossRef]

18. McNamara, L.; Gordeuk, V.R.; MacPhail, A.P. Ferroportin (Q248H) mutations in African families with dietary iron overload. J. Gastroenterol. Hepatol. 2005, 20, 1855-1858. [CrossRef]

19. Rivers, C.A.; Barton, J.C.; Gordeuk, V.R.; Acton, R.T.; Speechley, M.R.; Snively, B.M.; Leiendecker-Foster, C.; Press, R.D.; Adams, P.C.; McLaren, G.D.; et al. Association of ferroportin Q248H polymorphism with elevated levels of serum ferritin in African Americans in the hemochromatosis and iron overload screening (HEIRS) study. Blood Cells Mol. Dis. 2007, 38, 247-252. [CrossRef]

20. Albuquerque, D.; Manco, L.; Loua, K.M.; Arez, A.P.; Trovoada, M.D.J.; Relvas, L.; Milimono, T.S.; Rath, S.L.; Lopes, D.; Nogueira, F.; et al. SLC40A1 Q248H allele frequencies and associated SLC40A1 haplotypes in three West African population samples. Ann. Hum. Biol. 2011, 38, 378-381. [CrossRef]

21. Beutler, E.; Barton, J.C.; Felitti, V.J.; Gelbart, T.; West, C.; Lee, P.L.; Waalen, J.; Vulpe, C. Ferroportin 1 (SCL40A1) variant associated with iron overload in African-Americans. Blood Cells Mol. Dis. 2003, 31, 305-309. [CrossRef]

22. Jarvik, G.P.; Browning, B.L. Consideration of cosegregation in the pathogenicity classification of Genomic variants. Am. J. Hum. Gen. 2016, 98, 1077-1781. [CrossRef] [PubMed]

23. Moller, P.; Clark, N.; Maehle, L. A simplified method for segregation analysis (SISA) to determine penetrance and expression of a genetic variant in a family. Hum. Mutat. 2011, 32, 568-571. [CrossRef] [PubMed]

24. Richards, S.; Aziz, N.; Bale, S.; Bick, D.; Das, S.; Gastier-Foster, J.; Grody, W.W.; Hegde, M.; Lyon, E.; Spector, E.; et al. Standards and guidelines for the interpretation of sequence variants: A joint consensus recommendation of the American college of medical genetics and genomics and the Association for molecular pathology. Off. J. Am. Coll. Med. Gen. 2015, 17, 405-424. [CrossRef] [PubMed]

25. Broad Institute. Available online: http://gnomad.broadinstitute.org (accessed on 12 July 2019).

26. PolyPhen-2 Prediction of Functional Effects of Human nsSNPs. Available online: http://genetics.bwh.harvard. edu/pph2 (accessed on 12 July 2019).

27. Sorting Intolerant from Tolerant. Available online: http://www.blocks.fhcrc.org/sift/SIFT.html (accessed on 12 July 2019).

28. Align-GVGD. Available online: http://agvgd.hci.utah.edu (accessed on 12 July 2019).

29. Duca, L.; Delbini, P.; Nava, I.; Vaja, V.; Fiorelli, G.; Cappellini, M.D. Mutation analysis of hepcidin and ferroportin genes in Italian prospective blood donors with iron overload. Am. J. Hematol. 2009, 84, 592-593. [CrossRef] [PubMed]

30. Aschemeyer, S.; Qiao, B.; Stefanova, D.; Valore, E.V.; Sek, A.C.; Ruwe, T.A.; Vieth, K.R.; Jung, G.; Casu, C.; Rivella, S.; et al. Structure-function analysis of ferroportin defines the binding site and an alternative mechanism of action of hepcidin. Blood 2018, 131, 899-910. [CrossRef] [PubMed] 
31. Drakesmith, H.; Schimanski, L.M.; Ormerod, E.; Merryweather-Clarke, A.T.; Viprakasit, V.; Edwards, J.P.; Sweetland, E.; Bastin, J.M.; Cowley, D.; Chinthammitr, Y.; et al. Resistance to hepcidin is conferred by hemochromatosis-associated mutations of ferroportin. Blood 2005, 106, 1092-1097. [CrossRef] [PubMed]

32. Fernandes, A.; Preza, G.C.; Phung, Y.; De Domenico, I.; Kaplan, J.; Ganz, T.; Nemeth, E. The molecular basis of hepcidin-resistant hereditary hemochromatosis. Blood 2009, 114, 437-443. [CrossRef]

33. Letocart, E.; Le Gac, G.; Majore, S.; Ka, C.; Radio, F.C.; Gourlaouen, I.; De Bernardo, C.; Ferec, C.; Grammatico, P. A novel missense mutation in SLC40A1 results in resistance to hepcidin and confirms the existence of two ferroportin-associated iron overload diseases. Br. J. Haematol. 2009, 147, 379-385. [CrossRef]

34. Rice, A.E.; Mendez, M.J.; Hokanson, C.A.; Rees, D.C.; Bjorkman, P.J. Investigation of the biophysical and cell biological properties of ferroportin, a multipass integral membrane protein iron exporter. J. Mol. Biol. 2009, 386, 717-732. [CrossRef]

35. Schimanski, L.M.; Drakesmith, H.; Merryweather-Clarke, A.T.; Viprakasit, V.; Edwards, J.P.; Sweetland, E.; Bastin, J.M.; Cowley, D.; Chinthammitr, Y.; Robson, K.J.; et al. In vitro functional analysis of human ferroportin (FPN) and hemochromatosis-associated FPN mutations. Blood 2005, 105, 4096-4102. [CrossRef] [PubMed]

36. Rivard, S.R.; Lanzara, C.; Grimard, D.; Carella, M.; Simard, H.; Ficarella, R.; Simard, R.; D'Adamo, A.P.; De Braekeleer, M.; Gasparini, P. Autosomal dominant reticuloendothelial iron overload (HFE type 4) due to a new missense mutation in the FERROPORTIN 1 gene (SLC11A3) in a large French-Canadian family. Haematologica 2003, 88, 824-826. [PubMed]

37. Sham, R.L.; Phatak, P.D.; Nemeth, E.; Ganz, T. Hereditary hemochromatosis due to resistance to hepcidin: high hepcidin concentrations in a family with C326S ferroportin mutation. Blood 2009, 114, 493-494. [CrossRef] [PubMed]

38. Sham, R.L.; Phatak, P.D.; West, C.; Lee, P.; Andrews, C.; Beutler, E. Autosomal dominant hereditary hemochromatosis associated with a novel ferroportin mutation and unique clinical features. Blood Cells Mol. Dis. 2005, 34, 157-161. [CrossRef] [PubMed]

39. Le Gac, G.; Ka, C.; Joubrel, R.; Gourlaouen, I.; Lehn, P.; Mornon, J.P.; Ferec, C.; Callebaut, I. Structure-function analysis of the human ferroportin iron exporter (SLC40A1): Effect of hemochromatosis type 4 disease mutations and identification of critical residues. Hum. Mutat. 2013, 34, 1371-1380. [CrossRef] [PubMed]

40. Griffiths, W.J.; Mayr, R.; McFarlane, I.; Hermann, M.; Halsall, D.J.; Zoller, H.; Cox, T.M. Clinical presentation and molecular pathophysiology of autosomal dominant hemochromatosis caused by a novel ferroportin mutation. Hepatology 2010, 51, 788-795. [CrossRef] [PubMed]

41. Mayr, R.; Griffiths, W.J.; Hermann, M.; McFarlane, I.; Halsall, D.J.; Finkenstedt, A.; Douds, A.; Davies, S.E.; Janecke, A.R.; Vogel, W.; et al. Identification of mutations in SLC40A1 that affect ferroportin function and phenotype of human ferroportin iron overload. Gastroenterology 2011, 140, 2056-2063.e1. [CrossRef]

42. Praschberger, R.; Schranz, M.; Griffiths, W.J.; Baumgartner, N.; Hermann, M.; Lomas, D.J.; Pietrangelo, A.; Cox, T.M.; Vogel, W.; Zoller, H. Impact of D181V and A69T on the function of ferroportin as an iron export pump and hepcidin receptor. Biochimica et Biophysica Acta 2014, 1842, 1406-1412. [CrossRef]

43. Wallace, D.F.; McDonald, C.J.; Ostini, L.; Iser, D.; Tuckfield, A.; Subramaniam, V.N. The dynamics of hepcidin-ferroportin internalization and consequences of a novel ferroportin disease mutation. Am. J. Hematol. 2017, 92, 1052-1061. [CrossRef]

44. Lok, C.Y.; Merryweather-Clarke, A.T.; Viprakasit, V.; Chinthammitr, Y.; Srichairatanakool, S.; Limwongse, C.; Oleesky, D.; Robins, A.J.; Hudson, J.; Wai, P.; et al. Iron overload in the Asian community. Blood 2009, 114, 20-25. [CrossRef]

45. Zhang, W.; Xu, A.; Li, Y.; Zhao, S.; Zhou, D.; Wu, L.; Zhang, B.; Zhao, X.; Wang, Y.; Wang, X.; et al. A novel SLC40A1 p.Y333H mutation with gain of function of ferroportin: A recurrent cause of haemochromatosis in China. Liver Int. Off. J. Int. Assoc. Study Liver 2019, 39, 1120-1127. [CrossRef] [PubMed]

46. Bonaccorsi di Patti, M.C.; Polticelli, F.; Cece, G.; Cutone, A.; Felici, F.; Persichini, T.; Musci, G. A structural model of human ferroportin and of its iron binding site. FEBS J. 2014, 281, 2851-2860. [CrossRef]

47. Yamakawa, N.; Oe, K.; Yukawa, N.; Murakami, K.; Nakashima, R.; Imura, Y.; Yoshifuji, H.; Ohmura, K.; Miura, Y.; Tomosugi, N.; et al. A Novel Phenotype of a Hereditary Hemochromatosis Type 4 with Ferroportin-1 Mutation, Presenting with Juvenile Cataracts. Intern. Med. 2016, 55, 2697-2701. [CrossRef] [PubMed] 
48. Bach, V.; Remacha, A.; Altes, A.; Barcelo, M.J.; Molina, M.A.; Baiget, M. Autosomal dominant hereditary hemochromatosis associated with two novel Ferroportin 1 mutations in Spain. Blood Cells Mol. Dis. 2006, 36, 41-45. [CrossRef] [PubMed]

49. Del-Castillo-Rueda, A.; Moreno-Carralero, M.I.; Cuadrado-Grande, N.; Alvarez-Sala-Walther, L.A.; Enriquez-de-Salamanca, R.; Mendez, M.; Moran-Jimenez, M.J. Mutations in the HFE, TFR2, and SLC40A1 genes in patients with hemochromatosis. Gene 2012, 508, 15-20. [CrossRef] [PubMed]

50. Sussman, N.L.; Lee, P.L.; Dries, A.M.; Schwartz, M.R.; Barton, J.C. Multi-organ iron overload in an African-American man with ALAS2 R452S and SLC40A1 R561G. Acta Haematol. 2008, 120, 168-173. [CrossRef] [PubMed]

51. Majore, S.; Bonaccorsi di Patti, M.C.; Valiante, M.; Polticelli, F.; Cortese, A.; Di Bartolomeo, S.; De Bernardo, C.; De Muro, M.; Faienza, F.; Radio, F.C.; et al. Characterization of three novel pathogenic SLC40A1 mutations and genotype/phenotype correlations in 7 Italian families with type 4 hereditary hemochromatosis. Biochim. Biophys. Acta. Mol. Basis Dis. 2018, 1864, 464-470. [CrossRef]

52. Ferbo, L.; Manzini, P.M.; Badar, S.; Campostrini, N.; Ferrarini, A.; Delledonne, M.; Francisci, T.; Tassi, V.; Valfre, A.; Dall'omo, A.M.; et al. Detection of a rare mutation in the ferroportin gene through targeted next generation sequencing. Blood Transfus. 2016, 1-4.

53. Pelucchi, S.; Mariani, R.; Salvioni, A.; Bonfadini, S.; Riva, A.; Bertola, F.; Trombini, P.; Piperno, A. Novel mutations of the ferroportin gene (SLC40A1): analysis of 56 consecutive patients with unexplained iron overload. Clin Genet 2008, 73, 171-178. [CrossRef]

54. Wallace, D.F.; Clark, R.M.; Harley, H.A.; Subramaniam, V.N. Autosomal dominant iron overload due to a novel mutation of ferroportin1 associated with parenchymal iron loading and cirrhosis. J. Hepatol. 2004, 40, 710-713. [CrossRef]

55. De Domenico, I.; Ward, D.M.; Nemeth, E.; Vaughn, M.B.; Musci, G.; Ganz, T.; Kaplan, J. The molecular basis of ferroportin-linked hemochromatosis. Proc. Natl. Acad. Sci. USA 2005, 102, 8955-8960. [CrossRef] [PubMed]

56. Liu, X.B.; Yang, F.; Haile, D.J. Functional consequences of ferroportin 1 mutations. Blood Cells Mol. Dis. 2005, 35, 33-46. [CrossRef] [PubMed]

57. McDonald, C.J.; Wallace, D.F.; Ostini, L.; Bell, S.J.; Demediuk, B.; Subramaniam, V.N. G80S-linked ferroportin disease: classical ferroportin disease in an Asian family and reclassification of the mutant as iron transport defective. J. Hepatol. 2011, 54, 538-544. [CrossRef] [PubMed]

58. Njajou, O.T.; de Jong, G.; Berghuis, B.; Vaessen, N.; Snijders, P.J.; Goossens, J.P.; Wilson, J.H.; Breuning, M.H.; Oostra, B.A.; Heutink, P.; et al. Dominant hemochromatosis due to N144H mutation of SLC11A3: Clinical and biological characteristics. Blood Cells Mol. Dis. 2002, 29, 439-443. [CrossRef] [PubMed]

59. Rosmorduc, O.; Wendum, D.; Arrive, L.; Elnaggar, A.; Ennibi, K.; Hannoun, L.; Charlotte, F.; Grange, J.D.; Poupon, R. Phenotypic expression of ferroportin disease in a family with the N144H mutation. Gastroenterol. Clin. Biol. 2008, 32, 321-327. [CrossRef] [PubMed]

60. Arden, K.E.; Wallace, D.F.; Dixon, J.L.; Summerville, L.; Searle, J.W.; Anderson, G.J.; Ramm, G.A.; Powell, L.W.; Subramaniam, V.N. A novel mutation in ferroportin1 is associated with haemochromatosis in a Solomon Islands patient. Gut 2003, 52, 1215-1217. [CrossRef] [PubMed]

61. Hetet, G.; Devaux, I.; Soufir, N.; Grandchamp, B.; Beaumont, C. Molecular analyses of patients with hyperferritinemia and normal serum iron values reveal both L ferritin IRE and 3 new ferroportin (slc11A3) mutations. Blood 2003, 102, 1904-1910. [CrossRef]

62. An, P.; Jiang, L.; Guan, Y.; Wang, H.; Wang, J.; Tian, Y.; Yang, W.; Shi, Y.; Xue, J.; Min, J.; et al. Identification of hereditary hemochromatosis pedigrees and a novel SLC40A1 mutation in Chinese population. Blood Cells Mol. Dis. 2017, 63, 34-36. [CrossRef]

63. Wang, Y.; Du, Y.; Liu, G.; Guo, S.; Hou, B.; Jiang, X.; Han, B.; Chang, Y.; Nie, G. Identification of novel mutations in HFE, HFE2, TfR2, and SLC40A1 genes in Chinese patients affected by hereditary hemochromatosis. Int. J. Hematol. 2016, 105, 521-525. [CrossRef]

64. Lee, P.L.; Gaasterland, T.; Barton, J.C. Mild iron overload in an African American man with SLC40A1 D270V. Acta Haematol. 2012, 128, 28-32. [CrossRef]

65. Wallace, D.F.; Dixon, J.L.; Ramm, G.A.; Anderson, G.J.; Powell, L.W.; Subramaniam, V.N. A novel mutation in ferroportin implicated in iron overload. J. Hepatol. 2007, 46, 921-926. [CrossRef] [PubMed] 
66. McGregor, J.A.; Shayeghi, M.; Vulpe, C.D.; Anderson, G.J.; Pietrangelo, A.; Simpson, R.J.; McKie, A.T. Impaired iron transport activity of ferroportin 1 in hereditary iron overload. J. Membr. Biol. 2005, 206, 3-7. [CrossRef] [PubMed]

67. Akoum, R. Point mutations in ferroportin disease: genotype/phenotype correlation. In Point Mutation; Logie, C., Ed.; InTech: London, UK, 2012; pp. 285-300.

68. Cazzola, M.; Cremonesi, L.; Papaioannou, M.; Soriani, N.; Kioumi, A.; Charalambidou, A.; Paroni, R.; Romtsou, K.; Levi, S.; Ferrari, M.; et al. Genetic hyperferritinaemia and reticuloendothelial iron overload associated with a three base pair deletion in the coding region of the ferroportin gene (SLC11A3). Br. J. Haematol. 2002, 119, 539-546. [CrossRef] [PubMed]

69. Galicia-Poblet, G.; Cid-Paris, E.; Lopez-Andres, N.; Losada-Pajares, A.; Jurado-Lopez, J.C.; Moreno-Carralero, M.I.; Moran-Jimenez, M.J. A Pediatric Case Report of Ferroportin Disease. J. Pediatr. Gastroenterol. Nutr. 2015, 63, e205-e207. [CrossRef]

70. Ikuta, K.; Hatayama, M.; Addo, L.; Toki, Y.; Sasaki, K.; Tatsumi, Y.; Hattori, A.; Kato, A.; Kato, K.; Hayashi, H.; et al. Iron overload patients with unknown etiology from national survey in Japan. Int. J. Hematol. 2017, 105, 353-360. [CrossRef] [PubMed]

71. Lim, F.L.; Dooley, J.S.; Roques, A.W.; Grellier, L.; Dhillon, A.P.; Walker, A.P. Hepatic iron concentration, fibrosis and response to venesection associated with the A77D and V162del "loss of function" mutations in ferroportin disease. Blood Cells Mol. Dis. 2008, 40, 328-333. [CrossRef] [PubMed]

72. Papanikolaou, G.; Tzilianos, M.; Christakis, J.I.; Bogdanos, D.; Tsimirika, K.; MacFarlane, J.; Goldberg, Y.P.; Sakellaropoulos, N.; Ganz, T.; Nemeth, E. Hepcidin in iron overload disorders. Blood 2005, 105, 4103-4105. [CrossRef] [PubMed]

73. Pietrangelo, A.; Corradini, E.; Ferrara, F.; Vegetti, A.; De Jong, G.; Luca Abbati, G.; Paolo Arcuri, P.; Martinelli, S.; Cerofolini, E. Magnetic resonance imaging to identify classic and nonclassic forms of ferroportin disease. Blood Cells Mol. Dis. 2006, 37, 192-196. [CrossRef]

74. Roetto, A.; Merryweather-Clarke, A.T.; Daraio, F.; Livesey, K.; Pointon, J.J.; Barbabietola, G.; Piga, A.; Mackie, P.H.; Robson, K.J.; Camaschella, C. A valine deletion of ferroportin 1: A common mutation in hemochromastosis type 4. Blood 2002, 100, 733-734. [CrossRef]

75. Speletas, M.; Kioumi, A.; Loules, G.; Hytiroglou, P.; Tsitouridis, J.; Christakis, J.; Germenis, A.E. Analysis of SLC40A1 gene at the mRNA level reveals rapidly the causative mutations in patients with hereditary hemochromatosis type IV. Blood Cells Mol. Dis. 2008, 40, 353-359. [CrossRef]

76. Unal, S.; Piperno, A.; Gumruk, F. Iron chelation with deferasirox in a patient with de-novo ferroportin mutation. J. Trace Elem. Med. Biol. 2015, 30, 1-3. [CrossRef] [PubMed]

77. Wallace, D.F.; Browett, P.; Wong, P.; Kua, H.; Ameratunga, R.; Subramaniam, V.N. Identification of ferroportin disease in the Indian subcontinent. Gut 2005, 54, 567-568. [CrossRef] [PubMed]

78. Wallace, D.F.; Pedersen, P.; Dixon, J.L.; Stephenson, P.; Searle, J.W.; Powell, L.W.; Subramaniam, V.N. Novel mutation in ferroportin1 is associated with autosomal dominant hemochromatosis. Blood 2002, 100, 692-694. [CrossRef] [PubMed]

79. Zoller, H.; McFarlane, I.; Theurl, I.; Stadlmann, S.; Nemeth, E.; Oxley, D.; Ganz, T.; Halsall, D.J.; Cox, T.M.; Vogel, W. Primary iron overload with inappropriate hepcidin expression in V162del ferroportin disease. Hepatology 2005, 42, 466-472. [CrossRef] [PubMed]

80. Cremonesi, L.; Forni, G.L.; Soriani, N.; Lamagna, M.; Fermo, I.; Daraio, F.; Galli, A.; Pietra, D.; Malcovati, L.; Ferrari, M.; et al. Genetic and clinical heterogeneity of ferroportin disease. Br. J. Haematol. 2005, 131, 663-670. [CrossRef] [PubMed]

81. Jouanolle, A.M.; Douabin-Gicquel, V.; Halimi, C.; Loreal, O.; Fergelot, P.; Delacour, T.; de Lajarte-Thirouard, A.S.; Turlin, B.; Le Gall, J.Y.; Cadet, E.; et al. Novel mutation in ferroportin 1 gene is associated with autosomal dominant iron overload. J. Hepatol. 2003, 39, 286-289. [CrossRef]

82. Cunat, S.; Giansily-Blaizot, M.; Bismuth, M.; Blanc, F.; Dereure, O.; Larrey, D.; Quellec, A.L.; Pouderoux, P.; Rose, C.; Raingeard, I.; et al. Global sequencing approach for characterizing the molecular background of hereditary iron disorders. Clin. Chem. 2007, 53, 2060-2069. [CrossRef]

83. Moreno-Carralero, M.I.; Munoz-Munoz, J.A.; Cuadrado-Grande, N.; Lopez-Rodriguez, R.; Jose Hernandez-Alfaro, M.; del-Castillo-Rueda, A.; Enriquez-de-Salamanca, R.; Mendez, M.; Moran-Jimenez, M.J. A novel mutation in the SLC40A1 gene associated with reduced iron export in vitro. Am. J. Hematol. 2014, 89, 689-694. [CrossRef] 
84. Ka, C.; Guellec, J.; Perpermans, X.; Kannengiesser, C.; Ged, C.; Wuyts, W.; Cassiman, D.; de Ledinghen, V.; Varet, B.; de Kerguenec, C.; et al. The SLC40A1 R178Q mutation is a recurrent cause of hemochromatosis and is associated with a novel pathogenic mechanism. Haematologica 2018, 103, 1796-1805. [CrossRef]

85. Speletas, M.; Kioumi, A.; Germenis, A.E. Reply to: "SLC40A1-R178G or R178Q and ferroportin disease? A call for vigilance in mutation reporting". J. Hepatol. 2013, 59, 397. [CrossRef]

86. Morris, T.J.; Litvinova, M.M.; Ralston, D.; Mattman, A.; Holmes, D.; Lockitch, G. A novel ferroportin mutation in a Canadian family with autosomal dominant hemochromatosis. Blood Cells Mol. Dis. 2005, 35, 309-314. [CrossRef] [PubMed]

87. De Domenico, I.; McVey Ward, D.; Nemeth, E.; Ganz, T.; Corradini, E.; Ferrara, F.; Musci, G.; Pietrangelo, A.; Kaplan, J. Molecular and clinical correlates in iron overload associated with mutations in ferroportin. Haematologica 2006, 91, 1092-1095. [PubMed]

88. Corradini, E.; Montosi, G.; Ferrara, F.; Caleffi, A.; Pignatti, E.; Barelli, S.; Garuti, C.; Pietrangelo, A. Lack of enterocyte iron accumulation in the ferroportin disease. Blood Cells Mol. Dis. 2005, 35, 315-318. [CrossRef] [PubMed]

89. Relvas, L.C.M.; Bento, M.C.; Ribeiro, L. Novel human pathological mutation: Gene Symbol: SLC40A1; Disease: Haemochromatosis, type IV. Hum. Genet. 2009, 125, 338. [PubMed]

90. Subramaniam, V.N.; Wallace, D.F.; Dixon, J.L.; Fletcher, L.M.; Crawford, D.H. Ferroportin disease due to the A77D mutation in Australia. Gut 2005, 54, 1048-1049. [CrossRef] [PubMed]

91. Mougiou, A.; Pietrangelo, A.; Caleffi, A.; Kourakli, A.; Karakantza, M.; Zoumbos, N. G80S-linked ferroportin disease: the first clinical description in a Greek family. Blood Cells Mol. Dis. 2008, 41, 138-139. [CrossRef] [PubMed]

92. Wolff, F.; Bailly, B.; Gulbis, B.; Cotton, F. Monitoring of hepcidin levels in a patient with G80S-linked ferroportin disease undergoing iron depletion by phlebotomy. Clin. Chim. Acta 2014, 430, 20-21. [CrossRef]

93. Girelli, D.; De Domenico, I.; Bozzini, C.; Campostrini, N.; Busti, F.; Castagna, A.; Soriani, N.; Cremonesi, L.; Ferrari, M.; Colombari, R.; et al. Clinical, pathological, and molecular correlates in ferroportin disease: A study of two novel mutations. J. Hepatol. 2008, 49, 664-671. [CrossRef]

94. Hattori, A.; Miyajima, H.; Tomosugi, N.; Tatsumi, Y.; Hayashi, H.; Wakusawa, S. Clinicopathological study of Japanese patients with genetic iron overload syndromes. Pathol. Int. 2012, 62, 612-618. [CrossRef]

95. Raszeja-Wyszomirska, J.; Caleffi, A.; Milkiewicz, P.; Pietrangelo, A. Ferroportin-related haemochromatosis associated with novel Y64H mutation of the SCL40A1 gene. Prz. Gastroenterol. 2014, 9, 307-309. [CrossRef]

96. Muehlenberg, K.; Faltermeier, N.; Lohse, P.; Tannapfel, A.; Pech, O. [Family with marked hyperferritinemia as a result of hemochromatosis type 4 (ferroportin disease)]. Z. Gastroenterol. 2014, 52, 1075-1080. [PubMed]

97. Saja, K.; Bignell, P.; Robson, K.; Provan, D. A novel missense mutation c.470 A >C (p.D157A) in the SLC40A1 gene as a cause of ferroportin disease in a family with hyperferritinaemia. Br. J. Haematol. 2010, 149, 914-916. [CrossRef] [PubMed]

98. Yamashita, T.; Morotomi, N.; Sohda, T.; Hayashi, H.; Yoshida, N.; Ochi, K.; Ohkura, I.; Karita, M.; Fujiwara, H.; Yamashita, H.; et al. A male patient with ferroportin disease B and a female patient with iron overload similar to ferroportin disease B. Clin. J. Gastroenterol. 2014, 7, 260-264. [CrossRef] [PubMed]

99. Caetano, G.; Relvas, L.; Bento, C.; Silveira, M.P.; Ribeiro, L. Atypical iron deficiency anemia-Association of two new mutations in ferroportin and TMPRSS6 genes. In Proceedings of the International BioIron Society Annual Meeting, Porto, Portugal, 7-11 June 2009.

100. Del-Castillo-Rueda, A.; Moreno-Carralero, M.I.; Alvarez-Sala-Walther, L.A.; Cuadrado-Grande, N.; Enriquez-de-Salamanca, R.; Mendez, M.; Moran-Jimenez, M.J. Two novel mutations in the SLC40A1 and HFE genes implicated in iron overload in a Spanish man. Eur. J. Haematol. 2011, 86, 260-264. [CrossRef] [PubMed]

101. Chen, S.R.; Yang, L.Q.; Chong, Y.T.; Jie, Y.S.; Wu, Y.K.; Yang, J.; Lin, G.L.; Li, X.H. Novel gain of function mutation in the SLC40A1 gene associated with hereditary haemochromatosis type 4. Intern. Med. J. 2015, 45, 672-676. [CrossRef] [PubMed]

102. Lee, P.L.; Gelbart, T.; West, C.; Barton, J.C. SLC40A1 c.1402G->a results in aberrant splicing, ferroportin truncation after glycine 330, and an autosomal dominant hemochromatosis phenotype. Acta Haematol. 2007, 118, 237-241. [CrossRef] [PubMed] 
103. Koyama, C.; Wakusawa, S.; Hayashi, H.; Ueno, T.; Suzuki, R.; Yano, M.; Saito, H.; Okazaki, T. A Japanese family with ferroportin disease caused by a novel mutation of SLC40A1 gene: hyperferritinemia associated with a relatively low transferrin saturation of iron. Intern. Med. 2005, 44, 990-993. [CrossRef]

104. Nekhai, S.; Xu, M.; Foster, A.; Kasvosve, I.; Diaz, S.; Machado, R.F.; Castro, O.L.; Kato, G.J.; Taylor, J.G.; Gordeuk, V.R. Reduced sensitivity of the ferroportin Q248H mutant to physiological concentrations of hepcidin. Haematologica 2013, 98, 455-463. [CrossRef] [PubMed]

105. Pietrangelo, A. The ferroportin disease. Blood Cells Mol. Dis. 2004, 32, 131-138. [CrossRef] [PubMed]

106. Corradini, E.; Ferrara, F.; Pollicino, T.; Vegetti, A.; Abbati, G.L.; Losi, L.; Raimondo, G.; Pietrangelo, A. Disease progression and liver cancer in the ferroportin disease. Gut 2007, 56, 1030-1032. [CrossRef]

107. Devalia, V.; Carter, K.; Walker, A.P.; Perkins, S.J.; Worwood, M.; May, A.; Dooley, J.S. Autosomal dominant reticuloendothelial iron overload associated with a 3-base pair deletion in the ferroportin 1 gene (SLC11A3). Blood 2002, 100, 695-697. [CrossRef] [PubMed]

108. Abboud, S.; Haile, D.J. A novel mammalian iron-regulated protein involved in intracellular iron metabolism. J. Biol. Chem. 2000, 275, 19906-19912. [CrossRef] [PubMed]

109. McKie, A.T.; Marciani, P.; Rolfs, A.; Brennan, K.; Wehr, K.; Barrow, D.; Miret, S.; Bomford, A.; Peters, T.J.; Farzaneh, F; et al. A novel duodenal iron-regulated transporter, IREG1, implicated in the basolateral transfer of iron to the circulation. Mol. Cell 2000, 5, 299-309. [CrossRef]

110. Donovan, A.; Brownlie, A.; Zhou, Y.; Shepard, J.; Pratt, S.J.; Moynihan, J.; Paw, B.H.; Drejer, A.; Barut, B.; Zapata, A.; et al. Positional cloning of zebrafish ferroportin1 identifies a conserved vertebrate iron exporter. Nature 2000, 403, 776-781. [CrossRef] [PubMed]

111. Donovan, A.; Lima, C.A.; Pinkus, J.L.; Pinkus, G.S.; Zon, L.I.; Robine, S.; Andrews, N.C. The iron exporter ferroportin/Slc40a1 is essential for iron homeostasis. Cell Metab. 2005, 1, 191-200. [CrossRef] [PubMed]

112. Thomas, C.; Oates, P.S. Ferroportin/IREG-1/MTP-1/SLC40A1 modulates the uptake of iron at the apical membrane of enterocytes. Gut 2004, 53, 44-49. [CrossRef] [PubMed]

113. Drakesmith, H.; Nemeth, E.; Ganz, T. Ironing out Ferroportin. Cell Metab. 2015, 22, 777-787. [CrossRef] [PubMed]

114. Ward, D.M.; Kaplan, J. Ferroportin-mediated iron transport: expression and regulation. Biochimica Biophysica Acta 2012, 1823, 1426-1433. [CrossRef] [PubMed]

115. Taniguchi, R.; Kato, H.E.; Font, J.; Deshpande, C.N.; Wada, M.; Ito, K.; Ishitani, R.; Jormakka, M.; Nureki, O. Outward- and inward-facing structures of a putative bacterial transition-metal transporter with homology to ferroportin. Nat. Commun. 2015, 6, 8545. [CrossRef] [PubMed]

116. Pietrangelo, A. The ferroportin disease: pathogenesis, diagnosis and treatment. Haematologica 2017. [CrossRef] [PubMed]

117. Ross, S.L.; Tran, L.; Winters, A.; Lee, K.J.; Plewa, C.; Foltz, I.; King, C.; Miranda, L.P.; Allen, J.; Beckman, H.; et al. Molecular mechanism of hepcidin-mediated ferroportin internalization requires ferroportin lysines, not tyrosines or JAK-STAT. Cell Metab. 2012, 15, 905-917. [CrossRef] [PubMed]

118. De Domenico, I.; Lo, E.; Ward, D.M.; Kaplan, J. Hepcidin-induced internalization of ferroportin requires binding and cooperative interaction with Jak2. Proc. Natl. Acad. Sci. USA 2009, 106, 3800-3805. [CrossRef] [PubMed]

119. Le Tertre, M.; Ka, C.; Guellec, J.; Gourlaouen, I.; Ferec, C.; Callebaut, I.; Le Gac, G. Deciphering the molecular basis of ferroportin resistance to hepcidin: Structure/function analysis of rare SLC40A1 missense mutations found in suspected hemochromatosis type 4 patients. Transfusion Clinique et Biologique: Journal de la Societe Francaise de Transfusion Sanguine 2017, 24, 462-467. [CrossRef] [PubMed]

120. Nemeth, E.; Tuttle, M.S.; Powelson, J.; Vaughn, M.B.; Donovan, A.; Ward, D.M.; Ganz, T.; Kaplan, J. Hepcidin regulates cellular iron efflux by binding to ferroportin and inducing its internalization. Science 2004, 306, 2090-2093. [CrossRef] [PubMed]

121. Clark, R.J.; Tan, C.C.; Preza, G.C.; Nemeth, E.; Ganz, T.; Craik, D.J. Understanding the structure/activity relationships of the iron regulatory peptide hepcidin. Chem. Biol. 2011, 18, 336-343. [CrossRef] [PubMed]

122. Qiao, B.; Sugianto, P.; Fung, E.; Del-Castillo-Rueda, A.; Moran-Jimenez, M.J.; Ganz, T.; Nemeth, E. Hepcidin-induced endocytosis of ferroportin is dependent on ferroportin ubiquitination. Cell Metab. 2012, 15, 918-924. [CrossRef] [PubMed]

123. Krieger, E.; Koraimann, G.; Vriend, G. Increasing the precision of comparative models with YASARA NOVA-a self-parameterizing force field. Proteins 2002, 47, 393-402. [CrossRef] [PubMed] 
124. Vriend, G. WHAT IF: a molecular modeling and drug design program. J. Mol. Graph. 1990, 8, 52-56. [CrossRef]

125. Altamura, S.; Kessler, R.; Grone, H.J.; Gretz, N.; Hentze, M.W.; Galy, B.; Muckenthaler, M.U. Resistance of ferroportin to hepcidin binding causes exocrine pancreatic failure and fatal iron overload. Cell Metab. 2014, 20, 359-367. [CrossRef]

126. Folgueras, A.R.; de Lara, F.M.; Pendas, A.M.; Garabaya, C.; Rodriguez, F.; Astudillo, A.; Bernal, T.; Cabanillas, R.; Lopez-Otin, C.; Velasco, G. Membrane-bound serine protease matriptase-2 (Tmprss6) is an essential regulator of iron homeostasis. Blood 2008, 112, 2539-2545. [CrossRef]

127. De Falco, L.; Sanchez, M.; Silvestri, L.; Kannengiesser, C.; Muckenthaler, M.U.; Iolascon, A.; Gouya, L.; Camaschella, C.; Beaumont, C. Iron refractory iron deficiency anemia. Haematologica 2013, 98, 845-853. [CrossRef] [PubMed]

128. McDonald, C.J.; Ostini, L.; Bennett, N.; Subramaniam, N.; Hooper, J.; Velasco, G.; Wallace, D.F.; Subramaniam, V.N. Functional analysis of matriptase-2 mutations and domains: insights into the molecular basis of iron-refractory iron deficiency anemia. Am. J. Physiol. Cell Physiol. 2015, 308, C539-C547. [CrossRef] [PubMed]

129. Donker, A.E.; Raymakers, R.A.; Vlasveld, L.T.; van Barneveld, T.; Terink, R.; Dors, N.; Brons, P.P.; Knoers, N.V.; Swinkels, D.W. Practice guidelines for the diagnosis and management of microcytic anemias due to genetic disorders of iron metabolism or heme synthesis. Blood 2014, 123, 3873-3886, quiz 4005. [CrossRef] [PubMed]

130. Sabelli, M.; Montosi, G.; Garuti, C.; Caleffi, A.; Oliveto, S.; Biffo, S.; Pietrangelo, A. Human macrophage ferroportin biology and the basis for the ferroportin disease. Hepatology 2017, 65, 1512-1525. [CrossRef] [PubMed]

131. Delaby, C.; Pilard, N.; Goncalves, A.S.; Beaumont, C.; Canonne-Hergaux, F. Presence of the iron exporter ferroportin at the plasma membrane of macrophages is enhanced by iron loading and down-regulated by hepcidin. Blood 2005, 106, 3979-3984. [CrossRef] [PubMed]

132. Nairz, M.; Schroll, A.; Demetz, E.; Tancevski, I.; Theurl, I.; Weiss, G. 'Ride on the ferrous wheel'-the cycle of iron in macrophages in health and disease. Immunobiology 2015, 220, 280-294. [CrossRef] [PubMed]

133. Taylor, M.; Qu, A.; Anderson, E.R.; Matsubara, T.; Martin, A.; Gonzalez, F.J.; Shah, Y.M. Hypoxia-inducible factor-2alpha mediates the adaptive increase of intestinal ferroportin during iron deficiency in mice. Gastroenterology 2011, 140, 2044-2055. [CrossRef]

134. Muckenthaler, M.U.; Galy, B.; Hentze, M.W. Systemic iron homeostasis and the iron-responsive element/iron-regulatory protein (IRE/IRP) regulatory network. Annu. Rev. Nutr. 2008, 28, 197-213. [CrossRef]

135. Wilkinson, N.; Pantopoulos, K. The IRP/IRE system in vivo: insights from mouse models. Front. Pharmacol. 2014, 5, 176. [CrossRef]

136. Zhang, D.L.; Ghosh, M.C.; Rouault, T.A. The physiological functions of iron regulatory proteins in iron homeostasis-An update. Front. Pharmacol. 2014, 5, 124. [CrossRef]

137. Lymboussaki, A.; Pignatti, E.; Montosi, G.; Garuti, C.; Haile, D.J.; Pietrangelo, A. The role of the iron responsive element in the control of ferroportin1/IREG1/MTP1 gene expression. J. Hepatol. 2003, 39, 710-715. [CrossRef]

138. Zhang, D.L.; Hughes, R.M.; Ollivierre-Wilson, H.; Ghosh, M.C.; Rouault, T.A. A ferroportin transcript that lacks an iron-responsive element enables duodenal and erythroid precursor cells to evade translational repression. Cell Metab. 2009, 9, 461-473. [CrossRef] [PubMed]

139. Han, O.; Kim, E.Y. Colocalization of ferroportin-1 with hephaestin on the basolateral membrane of human intestinal absorptive cells. J. Cell. Biochem. 2007, 101, 1000-1010. [CrossRef] [PubMed]

140. Musci, G.; Polticelli, F.; Bonaccorsi di Patti, M.C. Ceruloplasmin-ferroportin system of iron traffic in vertebrates. World J. Biol. Chem. 2014, 5, 204-215. [PubMed]

141. Canonne-Hergaux, F.; Donovan, A.; Delaby, C.; Wang, H.J.; Gros, P. Comparative studies of duodenal and macrophage ferroportin proteins. Am. J. Physiol. Gastrointest. Liver Physiol. 2006, 290, G156-G163. [CrossRef] [PubMed]

142. Theurl, I.; Aigner, E.; Theurl, M.; Nairz, M.; Seifert, M.; Schroll, A.; Sonnweber, T.; Eberwein, L.; Witcher, D.R.; Murphy, A.T.; et al. Regulation of iron homeostasis in anemia of chronic disease and iron deficiency anemia: Diagnostic and therapeutic implications. Blood 2009, 113, 5277-5286. [CrossRef] 
143. Jacolot, S.; Ferec, C.; Mura, C. Iron responses in hepatic, intestinal and macrophage/monocyte cell lines under different culture conditions. Blood Cells Mol. Dis. 2008, 41, 100-108. [CrossRef]

144. Mena, N.P.; Esparza, A.; Tapia, V.; Valdes, P.; Nunez, M.T. Hepcidin inhibits apical iron uptake in intestinal cells. Am. J. Physiol. Gastrointest. Liver Physiol. 2008, 294, G192-G198. [CrossRef]

145. Yamaji, S.; Sharp, P.; Ramesh, B.; Srai, S.K. Inhibition of iron transport across human intestinal epithelial cells by hepcidin. Blood 2004, 104, 2178-2180. [CrossRef]

146. Chaston, T.; Chung, B.; Mascarenhas, M.; Marks, J.; Patel, B.; Srai, S.K.; Sharp, P. Evidence for differential effects of hepcidin in macrophages and intestinal epithelial cells. Gut 2008, 57, 374-382. [CrossRef]

147. Bergamaschi, G.; Di Sabatino, A.; Pasini, A.; Ubezio, C.; Costanzo, F.; Grataroli, D.; Masotti, M.; Alvisi, C.; Corazza, G.R. Intestinal expression of genes implicated in iron absorption and their regulation by hepcidin. Clin. Nutr. 2016. [CrossRef] [PubMed]

148. Guida, C.; Altamura, S.; Klein, F.A.; Galy, B.; Boutros, M.; Ulmer, A.J.; Hentze, M.W.; Muckenthaler, M.U. A novel inflammatory pathway mediating rapid hepcidin-independent hypoferremia. Blood 2015, 125, 2265-2275. [CrossRef] [PubMed]

149. Enculescu, M.; Metzendorf, C.; Sparla, R.; Hahnel, M.; Bode, J.; Muckenthaler, M.U.; Legewie, S. Modelling Systemic Iron Regulation during Dietary Iron Overload and Acute Inflammation: Role of Hepcidin-Independent Mechanisms. PLoS Comput. Biol. 2017, 13, e1005322. [CrossRef] [PubMed]

150. Deschemin, J.C.; Vaulont, S. Role of hepcidin in the setting of hypoferremia during acute inflammation. PLoS ONE 2013, 8, e61050. [CrossRef] [PubMed]

151. Agoro, R.; Mura, C. Inflammation-induced up-regulation of hepcidin and down-regulation of ferroportin transcription are dependent on macrophage polarization. Blood Cells Mol. Dis. 2016, 61, 16-25. [CrossRef] [PubMed]

152. Biswas, S.K.; Mantovani, A. Orchestration of metabolism by macrophages. Cell Metab. 2012, 15, $432-437$. [CrossRef] [PubMed]

153. Vlasveld, L.T.; Swinkels, D.W. Loss-of-function ferroportin disease: novel mechanistic insights and unanswered questions. Haematologica 2018, 103, 1753-1755. [CrossRef] [PubMed]

154. Wang, W.; Knovich, M.A.; Coffman, L.G.; Torti, F.M.; Torti, S.V. Serum ferritin: Past, present and future. Biochimica et Biophysica Acta 2010, 1800, 760-769. [CrossRef] [PubMed]

155. NON-HFE Registry. Available online: http://non-hfe.com/ (accessed on 12 July 2019).

(C) 2019 by the authors. Licensee MDPI, Basel, Switzerland. This article is an open access article distributed under the terms and conditions of the Creative Commons Attribution (CC BY) license (http://creativecommons.org/licenses/by/4.0/). 


\title{
Hepcidin Therapeutics
}

\author{
Angeliki Katsarou and Kostas Pantopoulos * \\ Lady Davis Institute for Medical Research, Jewish General Hospital, Department of Medicine, McGill University, \\ Montreal, QC H3T 1E2, Canada; ageliki.katsarou@mail.mcgill.ca \\ * Correspondence: kostas.pantopoulos@mcgill.ca; Tel.: +1-(514)-340-8260 (ext. 25293)
}

Received: 3 November 2018; Accepted: 19 November 2018; Published: 21 November 2018

\begin{abstract}
Hepcidin is a key hormonal regulator of systemic iron homeostasis and its expression is induced by iron or inflammatory stimuli. Genetic defects in iron signaling to hepcidin lead to "hepcidinopathies" ranging from hereditary hemochromatosis to iron-refractory iron deficiency anemia, which are disorders caused by hepcidin deficiency or excess, respectively. Moreover, dysregulation of hepcidin is a pathogenic cofactor in iron-loading anemias with ineffective erythropoiesis and in anemia of inflammation. Experiments with preclinical animal models provided evidence that restoration of appropriate hepcidin levels can be used for the treatment of these conditions. This fueled the rapidly growing field of hepcidin therapeutics. Several hepcidin agonists and antagonists, as well as inducers and inhibitors of hepcidin expression have been identified to date. Some of them were further developed and are currently being evaluated in clinical trials. This review summarizes the state of the art.
\end{abstract}

Keywords: iron metabolism; hepcidin; ferroportin; hemochromatosis; anemia

\section{Systemic Iron Homeostasis}

Iron is an essential constituent of cells and organisms and participates in vital biochemical activities, such as DNA synthesis, oxygen transfer, and energy metabolism. The biological functions of iron are based on its capacity to interact with proteins and on its propensity to switch between the ferrous $\left(\mathrm{Fe}^{2+}\right)$ and ferric $\left(\mathrm{Fe}^{3+}\right)$ oxidation states. In spite of the high abundance of iron on the earth's crust, its bioavailability is limited by the fact that under aerobic conditions, ferrous iron is readily oxidized to insoluble ferric. Accumulation of excess iron in cells is toxic, because "free" ferrous iron catalyzes the generation of hydroxyl radicals via Fenton chemistry, which attack and inactivate cellular macromolecules [1]. The intricate chemistry of iron poses a major challenge for iron homeostasis: To satisfy metabolic needs and limit toxic side effects [2]. Mammals have developed mechanisms to efficiently acquire and retain dietary iron in the body and store, but not excrete the iron excess.

Approximately $70 \%$ of body iron ( $\sim 3-5 \mathrm{~g}$ in adult humans) is bound to heme and used in hemoglobin of red blood cells [3]. Another $2-3 \%$ is present in muscles, where it is mostly utilized in the heme moiety of myoglobin. Excess of body iron accumulates in liver hepatocytes, where it is stored within ferritin and can be mobilized for erythropoiesis under iron deficiency. On a daily basis, erythropoiesis requires up to $30 \mathrm{mg}$ of iron, while non-erythroid cell requirements are $\sim 5 \mathrm{mg}$. Bone marrow erythroblasts and non-erythroid cells in other tissues acquire iron from plasma transferrin. This protein not only serves as an iron carrier, but also keeps circulating iron in a redox-inactive state. Under physiological conditions, only $\sim 30 \%$ of transferrin molecules are saturated with $\mathrm{Fe}^{3+}$ and the iron-free apo-transferrin offers a redox buffering capacity. The iron content of transferrin $(\sim 3 \mathrm{mg})$ represents a small, but a highly dynamic fraction of body iron, which turns over more than 10 times per day to satisfy metabolic needs. It is mainly replenished by iron recycled from effete red blood cells via tissue macrophages during erythrophagocytosis. Dietary iron absorption (1-2 mg/day) 
contributes to the buildup of iron stores during development; in adults it mainly serves to compensate for non-specific iron losses, for instance via bleeding or cell desquamation.

\section{Hepcidin: The Key Iron Regulatory Hormone}

Serum iron levels are under the control of hepcidin, a liver-derived peptide hormone and master regulator of iron metabolism [4]. It operates by binding to the iron exporter ferroportin in iron-releasing target cells, mainly tissue macrophages and duodenal enterocytes, but also other cell types (Figure 1). The binding of hepcidin occludes iron efflux [5] and triggers ubiquitination, internalization and lysosomal degradation of ferroportin [6]. This leads to intracellular iron retention and eventually to hypoferremia.

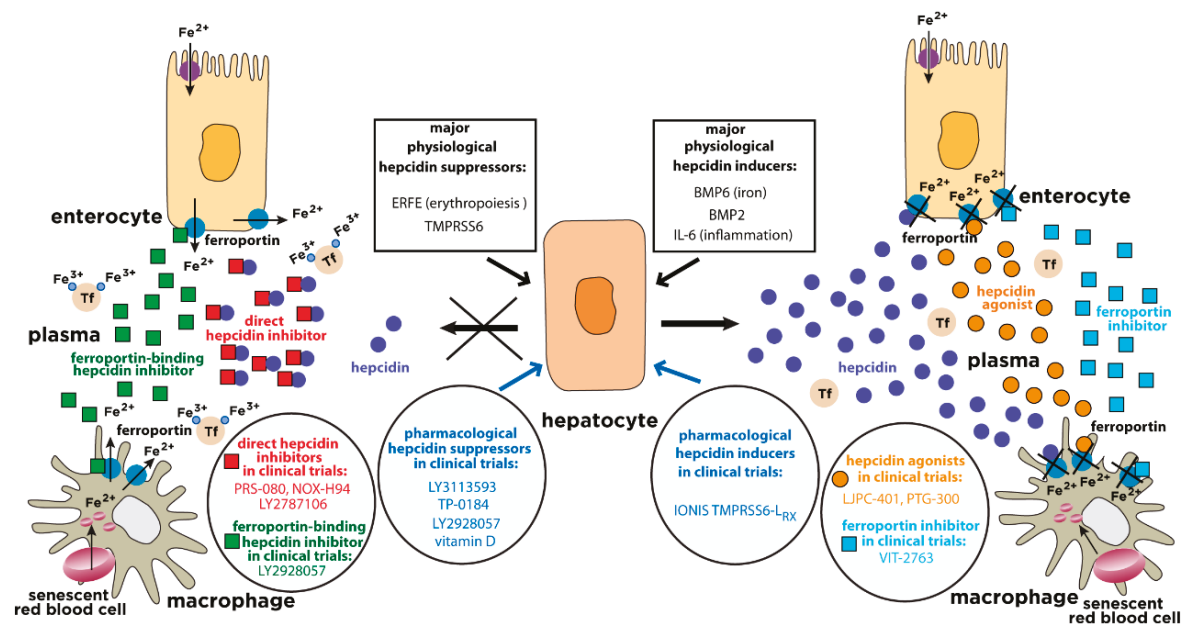

Figure 1. Physiological and pharmacological regulation of hepcidin activity. Hepcidin is synthesized in hepatocytes in response to iron or inflammatory stimuli. It operates by targeting the iron exporter ferroportin in tissue macrophages and duodenal enterocytes. The binding of hepcidin promotes ferroportin degradation, iron retention in target cells and hypoferremia. Suppression of hepcidin by erythropoietic stimuli allows iron efflux from cells into plasma via ferroportin. The expression of hepcidin can be manipulated pharmacologically with drugs that target hepatocytes (blue arrows). Hepcidin responses can be mimicked by hepcidin agonists (orange circles) or ferroportin inhibitors (light blue squares). Conversely, hepcidin responses can be antagonized by direct hepcidin inhibitors (red squares) or ferroportin-binding hepcidin inhibitors (green squares). The insets highlight major physiological hepcidin inducers or suppressors, as well as clinically relevant drugs that modulate the hepcidin-ferroportin axis and are currently being evaluated in randomized controlled trials for the treatment of hepcidin-related disorders ("hepcidinopathies"). Tf, transferrin.

The HAMP gene encodes pre-pro-hepcidin, an 84 amino acids long precursor, which is primarily expressed by hepatocytes in the liver, and at much lower levels by other cells in extrahepatic tissues. Pre-pro-hepcidin is processed to pro-hepcidin upon removal of its endoplasmic reticulum targeting sequence, consisting of $24 \mathrm{~N}$-terminal amino acids. Further cleavage at the C-terminus yields matures, bioactive hepcidin, an evolutionary conserved, cysteine-rich peptide of 25-amino acids with antimicrobial properties. It folds to a distorted $\beta$-sheet with an unusual disulfide bridge between adjacent $\mathrm{C} 13-\mathrm{C} 14$ at the turn of a hairpin loop; according to this model, the structure is stabilized by further disulfide bonding between C7-C23, C10-C22 and C11-C19 [7] (Figure 2, left). An alternative structural model postulates disulfide bond connectivity between C7-C23, C10-C13, C11-C19 and C14-C22 [8] (Figure 2, right). Interestingly, the structural organization of hepcidin based on disulfide 
bonding is not essential for iron-regulatory function, since the substitution of cysteines or the deletion of cysteine-containing segments do not impair hormonal activity $[9,10]$.

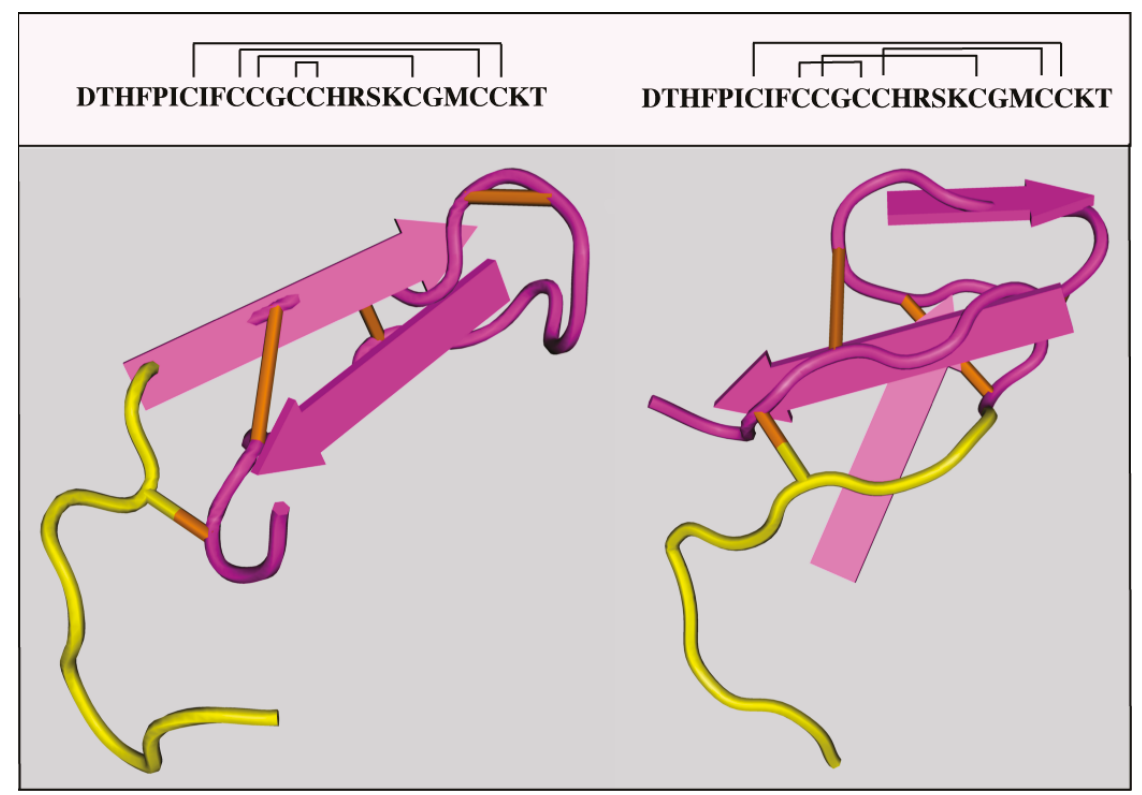

Figure 2. Proposed crystal structures of hepcidin. A structure with disulfide bonds between C7-C23, C10-C22, C13-C14 and C11-C19 (PDB ID: 1M4F) is shown on the left. An alternative structure with disulfide bonds between C7-C23, C10-C13, C11-C19 and C14-C22 (PDB ID: 2KEF) is shown on the right. The N-terminal amino acids which are essential for binding to ferroportin are highlighted in yellow.

Hepatocellular hepcidin expression responds to multiple stimuli, yet the major regulators are iron, inflammation and erythropoiesis [11]. Increases in serum or tissue iron trigger transcriptional induction of hepcidin via BMP/SMAD (Bone Morphogenetic Protein/Small Mothers Against Decapentaplegic) signaling (Figure 3). The mechanism involves secretion of bone morphogenetic protein 6 (BMP6) from liver sinusoidal endothelial cells, which binds to type I (ALK2, ALK3, ALK6) and type II (ActRIIA, BMPRII) BMP receptors on hepatocytes and thereby activates the SMAD signaling cascade. Efficient iron signaling to hepcidin requires auxiliary factors, such as BMP2, the BMP co-receptor hemojuvelin $(\mathrm{HJV})$, the hemochromatosis protein HFE, and the diferric transferrin sensor transferrin receptor 2 (TfR2) [12]. The pathway is negatively controlled by the transmembrane serine protease matriptase- 2 (also known as TMPRSS6), a hepcidin suppressor that appears to cleave HJV and other components of the hepcidin signaling pathway [13]. Iron-dependent upregulation of hepcidin serves to prevent excessive iron absorption when body iron stores are high.

Inflammatory cytokines promote hepcidin induction by several mechanisms. The most critical involves JAK/STAT (Janus Kinase/Signal Transducer and Activator of Transcription) signaling, which is activated in response to IL-6 (Figure 3). There is increasing evidence for a cross-talk between JAK/STAT and BMP6/SMAD signaling during inflammatory hepcidin induction [14-16]. Activin B, a JAK/STAT-induced ligand of BMP receptors can activate SMAD signaling to hepcidin [17], but its function is not essential [18]. On the other hand, BMP6 and HJV are critical components of the inflammatory hepcidin pathway $[19,20]$, which is considered as an innate immune response to deprive invading bacteria of iron [21]. This is part of a broader iron withholding strategy within the context of "nutritional immunity" [22]. Under conditions of an increased erythropoietic drive, hepcidin 
expression is suppressed by erythroferrone (ERFE), a hormone secreted by erythroblasts in response to erythropoietin [23] that neutralizes BMP6 [24]. This allows iron mobilization for erythropoiesis; the involvement of further erythropoietin-induced hepcidin suppressors in this response is also possible. Dysregulation of hepcidin expression leads to "hepcidinopathies", which are iron-related disorders of hepcidin deficiency or excess (Table 1).

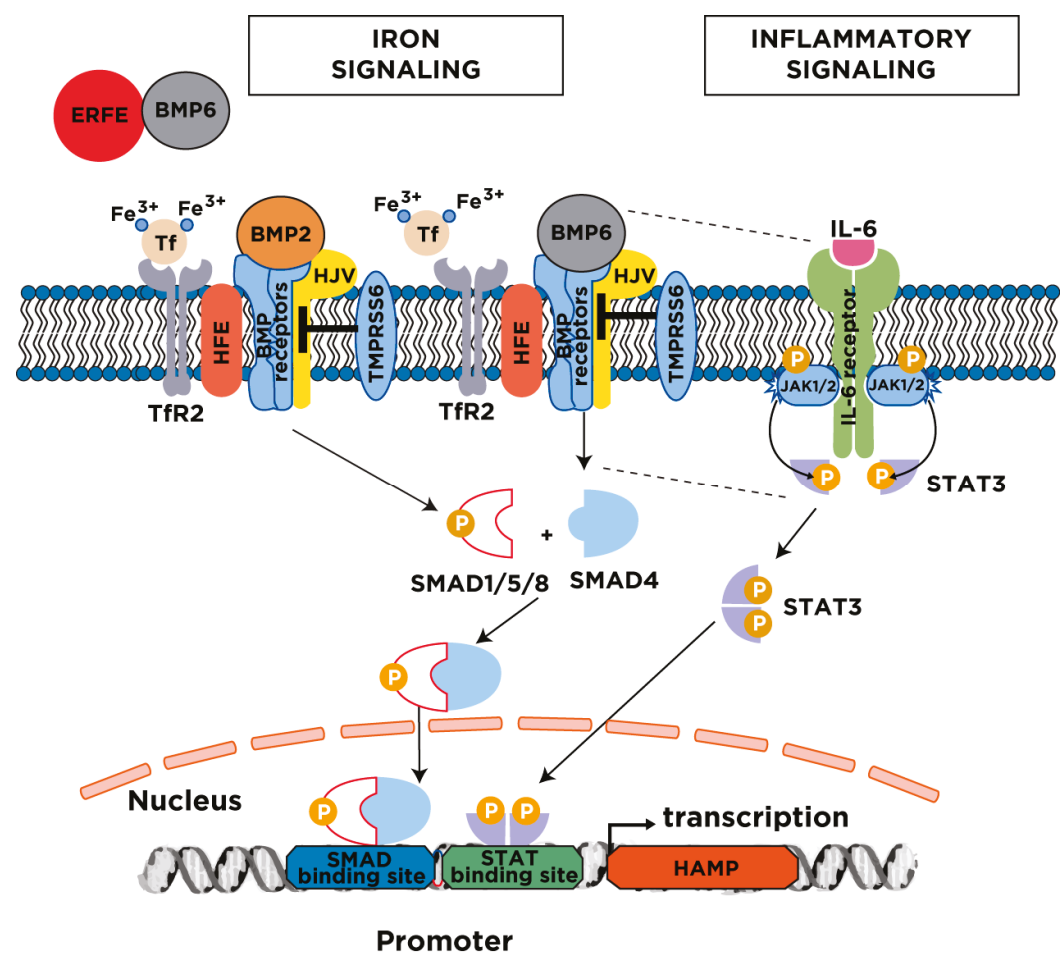

Figure 3. Major mechanisms for hepcidin regulation. Serum and tissue iron induce hepcidin transcription via the BMP/SMAD signaling pathway. The cascade is initiated following an increase in transferrin saturation and the secretion of BMP6 from liver sinusoidal endothelial cells; BMP2 is likewise secreted from liver sinusoidal endothelial cells but is less responsive to iron. Diferric transferrin binds to TfR2, while BMP6 and BMP2 bind to type I and II BMP receptors on hepatocytes. These events trigger phosphorylation of regulatory SMAD1/5/8, recruitment of SMAD4, and translocation of the SMAD complex to the nucleus for activating hepcidin transcription upon binding to BMP response elements in the HAMP promoter. Efficient iron signaling to hepcidin requires the BMP co-receptor HJV and the hemochromatosis protein HFE, and is negatively regulated by the transmembrane serine protease matriptase-2 (TMPRSS6). Under conditions of high iron demand for erythropoiesis, the erythropoietic regulator erythroferrone (ERFE) is released from bone marrow erythroblasts and suppresses hepcidin by sequestering BMP6. The inflammatory cytokine IL-6 induces hepcidin transcription via the JAK/STAT3 signaling pathway. The binding of IL-6 triggers dimerization of IL-6 receptors on hepatocytes, which leads to activation of associated JAK1/2 and subsequent phosphorylation of STAT3. Phospho-STAT3 dimerizes and translocates to the nucleus, where it activates hepcidin transcription upon binding to a STAT binding site in the HAMP promoter. Efficient hepcidin induction by the inflammatory pathway requires a threshold of BMP6/SMAD signaling (indicated by the dotted lines). BMP, Bone Morphogenetic Protein; SMAD, Small Mothers Against Decapentaplegic; HFE, high iron (Fe); HJV, hemojuvelin; TfR2, transferrin receptor 2; JAK, Janus kinase; STAT, Signal Transducer and Activator of Transcription. 
Table 1. Iron-related disorders of hepcidin dysregulation. Deficiency or excess of hepcidin has a different physiological effect on intestinal iron absorption, iron release by macrophages, serum iron, and tissue iron. HH, Hereditary Hemochromatosis; CLD, Chronic Liver Disease; IRIDA, Iron-Refractory Iron Deficiency Anemia; AI, Anemia of Inflammation.

\begin{tabular}{|c|c|c|c|c|c|c|c|c|c|}
\hline & \multicolumn{9}{|c|}{ Disorders } \\
\hline & \multicolumn{3}{|c|}{ Hepcidin Deficiency } & \multicolumn{2}{|c|}{$\begin{array}{l}\text { Hepcidin Resistance or } \\
\text { Ferroportin Deficiency }\end{array}$} & \multicolumn{3}{|c|}{$\begin{array}{l}\text { Systemic Hepcidin } \\
\text { Overexpression }\end{array}$} & \multirow{2}{*}{$\begin{array}{c}\begin{array}{c}\text { Local Hepcidin } \\
\text { Overexpression }\end{array} \\
\text { Cancer }\end{array}$} \\
\hline & HH & $\begin{array}{l}\text { Iron-Loading } \\
\text { Anemias }\end{array}$ & CLD & $\begin{array}{c}\text { Ferroportin } \\
\text { Hemochromatosis }\end{array}$ & $\begin{array}{c}\text { Ferroportin } \\
\text { Disease }\end{array}$ & IRIDA & AI & $\begin{array}{c}\text { Castleman } \\
\text { Disease }\end{array}$ & \\
\hline Hepcidin & $\downarrow$ & $\downarrow$ & $\downarrow$ & $\uparrow$ & $\uparrow$ & $\uparrow$ & $\uparrow$ & $\uparrow$ & $\begin{array}{c}\uparrow \\
\text { (in cancer cells) }\end{array}$ \\
\hline $\begin{array}{l}\text { Intestinal Fe } \\
\text { absorption }\end{array}$ & $\uparrow$ & $\uparrow$ & $\uparrow$ & $\uparrow$ & $\uparrow$ & $\downarrow$ & $\downarrow$ & $\downarrow$ & Normal \\
\hline $\begin{array}{l}\text { Macrophage } \\
\text { Fe release }\end{array}$ & $\uparrow$ & $\uparrow$ & $\uparrow$ & $\uparrow$ & $\downarrow$ & $\downarrow$ & $\downarrow$ & $\downarrow$ & Normal \\
\hline Serum Fe & $\uparrow$ & $\uparrow$ & $\uparrow$ & $\uparrow$ & $\downarrow$ & $\downarrow$ & $\downarrow$ & $\downarrow$ & Normal \\
\hline Tissue Fe & $\uparrow$ & $\uparrow$ & $\uparrow$ & $\uparrow$ & $\uparrow$ & Normal & Normal & Normal & Normal \\
\hline
\end{tabular}

\section{Disorders with Hepcidin Deficiency}

Hepcidin expression is suppressed in hereditary hemochromatosis $(\mathrm{HH})$, in iron-loading anemias with ineffective erythropoiesis and in some chronic liver diseases.

\subsection{Hereditary Hemochromatosis}

Inactivating mutations in upstream regulators of hepcidin or direct disruption of hepcidin cause $\mathrm{HH}$, an endocrine disorder of systemic iron overload [25]. As a result, hepcidin deficiency leads to increased dietary iron absorption (up to $8-10 \mathrm{mg} /$ day) and uncontrolled release of iron to plasma, due to unrestricted expression of ferroportin in duodenal enterocytes and tissue macrophages. This promotes gradual saturation of plasma transferrin and buildup of unshielded non-transferrin-bound iron (NTBI), which accumulates within tissue parenchymal cells. Clinical complications of $\mathrm{HH}$ include liver cirrhosis, hepatocellular cancer, cardiomyopathy, diabetes mellitus, endocrinopathy, arthritis and osteoporosis. In addition, $\mathrm{HH}$ patients are susceptible to infection with siderophilic bacteria, but also various other pathogens [26,27].

$\mathrm{HH}$ is genetically heterogenous and its severity depends on the degree of hepcidin suppression relative to body iron stores [28]. The major form is linked to mutations in HFE (especially C282Y) and constitutes the most frequent genetic disorder in Caucasians. However, the clinical penetrance is variable and depends on further genetic and environmental factors. The disease phenotype is relatively mild, and symptoms typically develop after the fourth decade of life. Other forms of $\mathrm{HH}$ are rare and typically associated with more severe phenotypes. Thus, inactivation of either HJV or hepcidin cause juvenile hemochromatosis $(\mathrm{JH})$ with early-onset iron overload in the late teens or early twenties. Inactivation of TfR2 yields an intermediate clinical phenotype compared to HFE-related $\mathrm{HH}$ and JH.

\subsection{Iron-Loading Anemias}

Hereditary or acquired anemias, such as thalassemias, congenital dyserythropoietic anemias, sideroblastic anemias or myelodysplastic syndromes, are associated with bone marrow hyperplasia and ineffective erythropoiesis [29]. Patients with severe forms of these diseases are often treated with blood transfusions, causing secondary iron overload. Ineffective erythropoiesis stimulates expression of ERFE and other factors, such as GDF15, which suppress hepcidin expression. This in turn promotes a hemochromatosis-like phenotype of iron overload in non-transfused patients with milder forms of disease; in addition, it aggravates the already existing secondary iron overload in transfused patients. Importantly, repressive erythropoietic signals dominate over the stimulating iron signals creating a vicious cycle in iron homeostasis and hepcidin expression [3]. 


\subsection{Chronic Liver Diseases}

Patients with alcoholic liver disease and chronic hepatitis $C$ often exhibit some degree of hepatocellular iron overload that aggravates liver disease progression to advanced stages (cirrhosis and hepatocellular carcinoma). This is linked to hepcidin suppression by oxidative stress and possibly additional mechanisms. Hepatic iron overload is also observed in patients with non-alcoholic fatty liver disease (NAFLD). The pattern of excessive iron distribution is variable with preference in either hepatocytes or macrophages, which may underlie differential hepcidin regulation by positive and negative stimuli [30,31]. In advanced liver disease of any etiology, the expression of hepcidin decreases dramatically due to severe injury of hepatocytes, and hepcidin levels offer a potential biomarker for liver disease progression [32].

Interestingly, experimental data provided evidence for a protective role of hepcidin against liver fibrosis. Thus, adenoviral expression of hepcidin attenuated the development of liver fibrosis in mice subjected to $\mathrm{CCl}_{4}$ intoxication or to bile duct ligation [33]. The underlying mechanism involves a hepcidin-mediated increase in the iron content of hepatic stellate cells, which prevents their differentiation from collagen-secreting myofibroblasts. Another study using Tmprss6-/- mice showed that genetic hepcidin overexpression protected these animals against high fat diet-induced obesity and liver steatosis by stimulating lipolytic pathways [34]. These data highlight a critical role of hepcidin in liver disease pathogenesis.

\section{Disorders with Hepcidin Resistance or Ferroportin Deficiency}

Ferroportin hemochromatosis is a distinct clinical entity that develops as a result of "gain-of-function" ferroportin mutations that prevent the binding of hepcidin [35]. Conversely, "loss-of-function" ferroportin mutations that inhibit intracellular trafficking of the protein are the hallmark of ferroportin disease, which is characterized by macrophage iron loading. Hepcidin levels are elevated rather than suppressed in these ferroportin-associated disorders of hepcidin resistance, or ferroportin deficiency, respectively. It should be noted that both ferroportin hemochromatosis and ferroportin disease are transmitted in an autosomal dominant fashion, contrary to all other forms of $\mathrm{HH}$, which are autosomal recessive.

\section{Disorders with Systemic Hepcidin Overexpression}

Systemic overexpression of hepcidin occurs in anemias with iron-restricted erythropoiesis, such as iron-refractory iron deficiency anemia (IRIDA), anemia of inflammation (AI; also known as anemia of chronic disease) or Castleman disease. Local overexpression of hepcidin has been reported in tumors.

\subsection{Iron-Refractory Iron Deficiency Anemia}

IRIDA is an autosomal recessive disease caused by loss-of-function mutations in the hepcidin suppressor matriptase-2 (TMPRSS6), which lead to hepcidin overexpression [36]. It is characterized by hypochromic microcytic anemia, hyperhepcidinemia, hypoferremia, low transferrin saturation and unresponsiveness to oral iron therapy.

\subsection{Anemia of Inflammation}

$\mathrm{AI}$ is a heterogenous disorder caused by chronic inflammation due to infections, inflammatory bowel disease, inflammatory rheumatic disease, chronic kidney disease (CKD) or obesity [37]. It is also observed in cancer patients (see Section 6) and in frail, elderly persons. AI is the most common type of anemia among hospitalized patients in the developed world. Unresolved inflammatory induction of hepcidin is one of the contributors to AI, because it causes hypoferremia and iron sequestration in tissues, limiting its availability for erythropoiesis. Other contributing factors are reduced proliferation of erythroblasts, reduced expression of erythropoietin, impaired erythropoietin signaling and increased erythrophagocytosis. In CKD, hyperhepcidinemia is aggravated by ineffective renal clearance [38]. 
AI is normochromic and normocytic, but this phenotype can be affected by chronic blood loss or dietary iron malabsorption, which result in smaller and hypochromic red blood cells [39].

\subsection{Castleman Disease}

Castleman disease is a rare lymphoproliferative disorder characterized by generalized lymphadenopathy and multiple organ involvement that is linked to chronic overproduction of IL-6 [40]. Castleman disease patients present with iron-refractory hypochromic microcytic anemia, which develops in response to IL-6-mediated upregulation of hepcidin [41].

\section{Disorders with Local Hepcidin Overexpression}

Hepcidin is produced at lower levels in several extrahepatic tissues, including the heart or the brain, where it exerts local cell autonomous functions [42,43]. Interestingly, many tumor cells produce and utilize hepcidin for their own advantage. Thus, hepcidin targets ferroportin in tumor cells in an autocrine manner and thereby promotes retention of iron, which is essential for cell proliferation and tumor growth [44]. This mechanism has been documented in breast [45], prostate [46] and thyroid [47] cancers. It should also be noted that in advanced disease stages, the immune response against primary or metastatic tumor cells may trigger hepcidin induction in hepatocytes and thereby lead to systemic hepcidin overproduction. This may result in AI due to hepcidin-mediated iron sequestration in tissues and inhibition in iron absorption.

\section{The Need for Hepcidin Therapeutics}

Targeting the hepcidin-ferroportin axis could offer therapeutic benefits to patients with disorders related to aberrant hepcidin expression [48-50]. Hepcidin therapeutics could complement or even replace current treatment modalities, which have several limitations.

\subsection{Narrowing the Management Gap in Iron Overload Disorders Linked to Hepcidin Deficiency}

The standard of care for $\mathrm{HH}$ is therapeutic phlebotomy, which reduces circulating iron burden and also promotes iron mobilization from stores [51]. This approach is effective and essentially normalizes the life-span of $\mathrm{HH}$ patients without liver cirrhosis and diabetes [52]. However, there is no evidence base for optimal start time, frequency, duration and endpoint of phlebotomy. Moreover, this treatment cannot reverse liver cirrhosis, diabetes, arthritis, cardiomyopathy or hypogonadism, while a few patients may not tolerate, or exhibit low compliance, to life-long treatment. Another limitation is that phlebotomy stimulates dietary iron absorption by further suppressing hepcidin via erythropoietic regulators.

Iron overload in iron-loading anemias is managed by iron chelation therapy. Clinically approved iron chelating drugs include desferrioxamine (DFO), deferiprone (DFP) and deferasirox (DFX). DFO was first utilized for the treatment of transfused $\beta$-thalassemia patients in the 1970s. Due to the accumulated $>40$-year long experience and its low cost, it remains a first line therapeutic option in many guidelines [53]. However, DFO is poorly absorbed in the gastrointestinal tract and has a short ( 20 min) plasma half-life. Thus, to reach effective pharmacological concentrations the drug is administered parenterally with the aid of a portable infusion pump at least $4-5$ days per week for $8-10 \mathrm{~h}$ each time. The cumbersome procedure reduces compliance and significantly compromises the quality of patients' life. This prompted the development of the orally absorbed iron chelators DFP and DFX, which exhibit better pharmacokinetics, with plasma half-lives of 1-3 h and 8-16 h, respectively. Nevertheless, the use of iron chelating drugs is associated with the risk of side effects, such as neutropenia/agranulocytosis, skin rash, gastrointestinal disturbances, retinopathy or bone abnormalities. Another problem is that these drugs cannot prevent dietary iron absorption, which is highly induced in patients with iron-loading anemias, due to erythropoietic suppression of hepcidin.

Thus, hepcidin replacement therapy could provide an etiologic cure of $\mathrm{HH}$, and correct aggravating dietary iron absorption in transfusional iron overload. Proof of principle is provided by 
experiments with mouse models of $\mathrm{HH}(\mathrm{Hfe}-/-)$ and $\beta$-thalassemia $\left(\mathrm{Hbb}^{\mathrm{th} 3 /+}\right)$. Thus, iron overload was corrected when these animals were crossed with mice overexpressing transgenic hepcidin [54,55], or with Tmprss6-/- mice overexpressing endogenous hepcidin [56,57]. Moreover, the increased hepcidin expression by these manipulations led to improved erythropoiesis in $\mathrm{Hbb}^{\text {th } 3 /+}$ mice $[55,57]$.

In light of the experimental evidence for the protective effects of hepcidin against liver fibrosis and obesity [33,34], hepcidin agonists, or inducers of hepcidin expression, could also be used for the treatment of these highly prevalent disorders. Finally, hepcidin agonists/inducers could enhance "nutritional immunity" during infection with extracellular pathogens.

\subsection{Narrowing the Management Gap in Anemias and Other Disorders Linked to Hepcidin Overexpression}

IRIDA patients are typically managed with intermittent parenteral iron therapy that only partially corrects anemia [36]. Improvement may need repeated dosing, which is associated with potential side effects and the risk for reticuloendothelial iron overload. Control of hepcidin overexpression by using hepcidin antagonists is expected to improve responses of IRIDA patients not only to parenteral, but also oral iron formulations.

AI can be corrected by treating the underlying cause of the primary disease, but this is not always feasible. Alternatively, AI patients can be treated with oral or parenteral iron administration, which increases the risk of bacteremia and allergic reactions [58]. Another option is the administration of erythropoiesis stimulating agents (ESA) based on recombinant human erythropoietin, often together with intravenous iron; however, prolonged use of ESAs may lead to cerebrocardiovascular complications [59]. When AI is combined with severe iron deficiency, blood transfusion is the preferred treatment; however, this is limited by the risk of infections, immune reactions or lung injury [60]. A major drawback that compromises efficiency of all these approaches is the inflammatory overexpression of hepcidin, which sequesters iron to tissues and reduces its availability for erythropoiesis. Thus, iron/ESA therapy could be complemented (and in some cases even replaced) by the use of hepcidin antagonists.

Proof of principle has been provided by pharmacological experiments showing improvement of anemia following hepcidin neutralization in a rat model of AI, based on injection with group A streptococcal peptidoglycan-polysaccharide (PG-APS) [15,61]. Moreover, inoculation of Hamp-/- or IL6-/mice with heat-killed Brucella abortus yielded a milder AI phenotype [62,63].

\section{Inducers of Hepcidin Expression}

Various molecules exhibit pharmacological potential to induce hepcidin expression. These include recombinant BMP6, TMPRSS6-silencing oligonucleotides, and a wide range of natural or synthetic small molecules. A detailed list is shown in Table 2. Clinically relevant hepcidin inducers currently undergoing evaluation in randomized controlled trials for disorders with hepcidin deficiency are highlighted in Figure 1.

\subsection{Recombinant BMP6}

Treatment of Hfe-/- mice with the major hepcidin inducer BMP6 was shown to increase hepatic hepcidin expression, which in turn caused a decrease in serum iron levels, due to iron retention in the spleen and the duodenum [64]. However, this was associated with peritoneal calcifications, possibly because BMP6 was administered intraperitoneally. Based on these findings, the off-target effects of BMP6 and other BMPs in bone metabolism appear to limit their clinical applications in the context of iron overload.

\subsection{TMPRSS6-Silencing Oligonucleotides}

Silencing of Tmprss6 mRNA using lipid nanoparticle formulated small interfering RNAs (siRNAs) or antisense oligonucleotides (ASOs) was shown to induce hepcidin and improve the phenotypes of hemochromatotic Hfe-/- and thalassemic $\mathrm{Hbb}^{\text {th } 3 /+}$ mice $[65,66]$. Of note, combined treatments of 
$\mathrm{Hbb}^{\text {th } 3 /+}$ mice with Tmprss6 siRNAs or ASOs, together with the oral iron chelator deferiprone, resulted in better correction of erythropoiesis and prevention of secondary iron overload $[67,68]$. When conjugated with triantennary N-acetyl galactosamine (GalNAc) for targeted delivery to hepatocytes, the Tmprss6-ASOs exhibited improved efficacy [69]. GalNAc-conjugated Tmprss6 siRNAs demonstrated a therapeutic potential in splenectomised $\mathrm{Hbb}^{\text {th } 3 /+}$ mice [70], a finding of clinical interest for splenectomised thalassemic patients. Ionis Pharmaceuticals Inc. developed TMPRSS6-silencing molecules with the commercial name IONIS-TMPRSS6- $L_{R X}$, which are currently being tested in phase 1 clinical trials (ClinicalTrials.gov Identifier: NCT03165864).

\subsection{Small Molecule Hepcidin Inducers}

Several small molecules were shown to activate hepcidin pathways. A high-throughput chemical screen in zebrafish identified three steroid molecules i.e., progesterone, epitiostanol and mifepristone as potent hepcidin inducers. They operate via a pathway involving the progesterone receptor membrane component-1 (PRMC-1) [71]. A small-scale chemical screen in zebrafish embryos uncovered the hepcidin-inducing capacity of genistein, a phytoestrogen that is abundant in soybean. Genistein was shown to upregulate hepcidin in HepG2 hepatoma cells and zebrafish embryos by promoting STAT3 phosphorylation [72].

A subsequent high-throughput screen of small molecules in HepG2 cells identified ipriflavone and vorinostat, which are synthetic drugs that inhibit bone resorption or histone deacetylase activity and are clinically applied for the treatment of osteoporosis or cutaneous T cell lymphoma, respectively. They both stimulate expression of hepcidin and other BMP- and STAT3-dependent genes without affecting SMAD1/5/8 or STAT3 phosphorylation, and exhibit 10-fold higher potency than genistein [73]. Ipriflavone was further tested in vivo and was shown to alleviate dietary iron overload in wild type mice; however, it failed to reduce iron overload in $\mathrm{Hbb}^{\text {th } 3 /+}$ mice [74]. The hepcidin-stimulating effects of vorinostat in Huh7 hepatoma cells were also validated in another study [75], and are consistent with earlier data showing that the histone deacetylase inhibitor trichostatin A induces hepcidin by inhibiting the binding of C/EBP $\alpha$ and STAT3 in the HAMP promoter [76]. Nevertheless, vorinostat failed to induce hepcidin in mice [75]. The non-steroidal anti-inflammatory drug diclofenac likewise stimulated hepcidin expression in vitro, but not in vivo [75]. In a screen of natural compounds, icariin, a plant flavonol glycoside, was documented to stimulate hepcidin expression in HepG2 cells by inducing SMAD1/5/8 or STAT3 phosphorylation. These findings were validated in mice, while similar results were obtained with the icariin analogue epimedin C [77]. Several polyphenolic small molecules or phytoestrogens that are found in fruits and vegetables likewise induced hepcidin in HepG2 cells and in rats. These include resveratrol, quercetin, kaemferol, naringenin, epi-gallo-catechin-3-gallate, and operate by activating Nrf2 for binding to an antioxidant response element (ARE) in the HAMP promoter [78].

A genetic siRNA screen revealed that Ras/Raf/MAPK and PI3K/Akt/mTOR signaling suppress hepcidin; consequently, pharmacological inhibitors of these pathways, such as sorafenib, wortmannin, rapamycin and metformin were shown to induce hepcidin in hepatoma cells and primary hepatocytes [79]. In another setting, dietary supplementation of Hfe-/- mice with adenine was reported to induce hepcidin and attenuate iron overload by a mechanism requiring BMP/SMAD and cAMP/protein kinase A (PKA) signaling [80]. While some data obtained with small molecule hepcidin inducers are interesting, the potential for these drugs for clinical application in the context of hepcidin deficiency appears limited, due to lack of specificity. 
Table 2. Inducers of hepcidin expression. Nrf2, nuclear factor (erythroid-derived 2)-like 2; PTGIS, prostaglandin I2 (prostacyclin) synthase; MAPK, mitogen-activated protein kinase; PRMC-1, progesterone receptor membrane component-1; PKA, protein kinase A.

\begin{tabular}{|c|c|c|c|c|}
\hline & Drug & Target & Evidence & Reference \\
\hline \multirow{7}{*}{$\begin{array}{l}\text { In vitro } \\
\text { studies }\end{array}$} & Genistein (small molecule) & STAT3 & Hepatoma cells & Zhen et al. 2013 [72] \\
\hline & Ipriflavone (small molecule) & $\begin{array}{c}\text { Histone deacetylase, } \\
\text { BMP-, STAT3-dependent genes }\end{array}$ & Hepatoma cells & Gaun et al. 2014 [73] \\
\hline & Vorinostat (small molecule) & $\begin{array}{c}\text { Histone deacetylase, } \\
\text { BMP-, STAT3-dependent genes }\end{array}$ & Hepatoma cells & $\begin{array}{c}\text { Gaun et al. } 2014 \text { [73] } \\
\text { Mleczko-Sanecka et al. } 2017 \\
{[75]}\end{array}$ \\
\hline & Diclofenac (small molecule) & $\begin{array}{l}\text { Not specified; independent of } \\
\text { PTGIS and cyclooxygenases }\end{array}$ & Hepatoma cells & $\begin{array}{c}\text { Mleczko-Sanecka et al. } 2017 \\
{[75]}\end{array}$ \\
\hline & Icariin (small molecule) & SMAD1/5/8, STAT3 & Hepatoma cells & Zhang et al. 2016 [77] \\
\hline & $\begin{array}{l}\text { Resveratrol, querqetin, } \\
\text { kaemferol, naringenin, } \\
\text { epi-galoo-catechin-3-gallate } \\
\text { (small molecules) }\end{array}$ & Nrf2 & Hepatoma cells & Bayele et al. 2015 [78] \\
\hline & $\begin{array}{l}\text { Sorafenib, wortmannin, } \\
\text { rapamycin, metformin } \\
\text { (small molecules) }\end{array}$ & $\begin{array}{l}\text { Ras/RAF/MAPK and mTOR } \\
\text { signaling }\end{array}$ & $\begin{array}{c}\text { Hepatoma cells, } \\
\text { Primary } \\
\text { hepatocytes }\end{array}$ & $\begin{array}{c}\text { Mleczko-Sanecka et al. } 2014 \\
{[79]}\end{array}$ \\
\hline \multirow{10}{*}{$\begin{array}{l}\text { Preclinical } \\
\text { studies }\end{array}$} & BMP6 & BMP receptors & $\begin{array}{c}\text { Mouse model of } \\
\text { adult } \mathrm{HH}\end{array}$ & Corradini et al. 2010 [64] \\
\hline & siRNAs & Matriptase-2 & $\begin{array}{l}\text { Mouse model of } \\
\text { adult HH } \\
\text { Mouse model of } \\
\beta \text {-thalassemia }\end{array}$ & Schmidt et al. 2013 [65] \\
\hline & $\begin{array}{l}\text { Antisense oligonucleotides } \\
\text { (ASOs) }\end{array}$ & Matriptase-2 & $\begin{array}{l}\text { Mouse model of } \beta \text { - } \\
\text { thalassemia }\end{array}$ & Guo et al. 2013 [66] \\
\hline & GalNac-ASOs & Matriptase-2 & $\begin{array}{c}\text { Mouse model of } \beta- \\
\text { thalassemia, } \\
\text { splenectomised }\end{array}$ & Schmidt et al. 2018 [70] \\
\hline & $\begin{array}{c}\text { Progesterone, epitiostanol, } \\
\text { mifepristone }\end{array}$ & PRMC-1 & Zebrafish & Li et al. 2016 [71] \\
\hline & Ipriflavone (small molecule) & BMP-, STAT3-dependent genes & Wild type mice & Gaun et al. 2014 [73] \\
\hline & Icariin (small molecule) & SMAD1/5/8, STAT3 & Wild type mice & Zhang et al. 2016 [77] \\
\hline & Epimedin C (small molecule) & SMAD1/5/8, STAT3 & Wild type mice & Zhang et al. 2016 [77] \\
\hline & $\begin{array}{c}\text { Resveratrol, querqetin, } \\
\text { kaemferol, naringenin, } \\
\text { epi-gallo-catechin-3-gallate } \\
\text { (small molecules) }\end{array}$ & Nrf2 & Wild type rats & Bayele et al. 2015 [78] \\
\hline & Adenine (small molecule) & SMAD1/5/8 and cAMP/PKA & $\begin{array}{l}\text { Mouse model of } \\
\text { adult } \mathrm{HH}\end{array}$ & Zhang et al. 2018 [80] \\
\hline $\begin{array}{l}\text { Clinical } \\
\text { trials }\end{array}$ & $\begin{array}{c}\text { IONIS-TMPRSS6-Lrx } \\
\text { (Antisense oligonucleotide) } \\
\text { By: Ionis Pharmaceuticals Inc. }\end{array}$ & Matriptase-2 & $\begin{array}{l}\text { Healthy } \\
\text { subjects-Phase } 1 \\
\text { (Active) }\end{array}$ & $\begin{array}{c}\text { ClinicalTrials.gov Identifier: } \\
\text { NCT03165864 }\end{array}$ \\
\hline
\end{tabular}

\section{Hepcidin Agonists}

Administration of synthetic hepcidin can effectively reduce plasma iron levels in wild type [81] or Hfe-/- mice [82]. However, the clinical value of this approach is limited by the high cost of manufacturing correctly folded, bioactive hepcidin, and by the rapid clearance of native hepcidin peptide in the blood. This prompted the development of cheaper hepcidin derivatives with improved pharmacological and pharmacokinetic properties. A detailed list is shown in Table 3a. Clinically relevant hepcidin agonists currently undergoing evaluation in randomized controlled trials for disorders with hepcidin deficiency are highlighted in Figure 1.

\subsection{Minihepcidins}

Mutational studies revealed that the N-terminus of hepcidin is necessary and sufficient for binding to ferroportin, and the remaining sequence is permissive to mutations [9]. This paved the way for the development of stable, bioactive truncated hepcidin derivatives. The first generation minihepcidins consist of 7 to 9 N-terminal amino acids with a free sulfhydryl group at C7; among them Hep9 was the most potent in in vitro ferroportin internalization assays [83]. Minihepcidins were 
further optimized by chemical modifications. To improve stability, peptides were circularized, but this resulted in decreased potency compared to Hep9. For protection against proteolysis, unusual amino acids, including $\mathrm{N}$-substituted, beta-homo, and D-amino acids were introduced to the initial chemical structure resulting in retro-inverso (ri-) analogues (i.e., reversed sequence of parental L-peptides). To improve intestinal absorption, ri- analogues were conjugated to fatty acids (palmitoyl- groups) or chenodeoxycholic or ursodeoxycholic bile acids (cheno- and urso- groups, respectively). Modified minihepcidins where then tested in vivo. Injection of unmodified Hep9 into wild type mice failed to cause any effect on serum iron. By contrast, ri-hep9 and palmitoyl-ri-hep9 promoted hypoferremia, while high doses of the latter had almost the same effect on serum iron levels to equivalent doses of full-length hepcidin [83].

Administration of PR65, another optimized minihepcidin, prevented iron loading and corrected iron distribution in previously iron-depleted Hamp-/- mice. However, excessive amounts of the compound led to iron-restrictive anemia, underlying the need for dose optimization. The effects of PR65 in iron-loaded Hamp-/- mice were less compelling, and limited to partial iron re-distribution from the liver to the spleen [84].

Because free sulfhydryl groups exhibit non-specific reactivity and may cause dermatological side effects, an S-protection strategy was used to develop the PR73 minihepcidin [85]. Daily administration of PR73 to Hamp-/- mice for one week led to significant iron redistribution from pancreatic acinar cells to macrophages [86]. Attempts to further improve PR73 were made. Cyclization resulted in agonist mHS17, the most active analogue of PR73, but this was several times less active than PR73 in vitro and ineffective in vivo [87]. Thiol-protection with activated vinyl thioethers yielded the S-vinyl-PR73SH derivative, which exhibited almost the same potency with the parental compound in vitro and in vivo [85].

PR73 was also evaluated for possible protective effects in mouse models of bacterial infections. Treatment of Hamp-/- mice with PR73, pre- or 3 h post-infection with siderophilic Vibrio vulnificus, caused hypoferremia and eventually repressed bacterial growth and reduced mortality [88]. Similar results were obtained in Hamp-/- or iron-loaded wild type mice infected with siderophilic Yersinia enterocolitica [89], or non-siderophilic Klebsiella pneumoniae or Escherichia coli [90,91]. These data uncover a therapeutic potential of minihepcidins, and probably other hepcidin agonists, against bacterial infections.

Merganser Biotech Inc., a start-up company, developed minihepcidins M004 and M009. The latter is a prodrug with an extra S-methyl group at C7, which is converted to M004 upon S-methyl removal in the blood. Daily injections of young $\mathrm{Hbb}^{\text {th } 3 /+}$ mice with M004, or biweekly injections of old $\mathrm{Hbb}^{\text {th } 3 /+}$ mice with M009, improved erythropoiesis and reduced splenomegaly and iron accumulation in the liver and kidneys within 6 weeks [92]. Further improvement was observed when M009 administration was combined with the iron chelator deferiprone. Interestingly, M009 was also shown to reduce erythrocytosis and splenomegaly in a mouse model of polycythemia vera [92].

\subsection{Other Hepcidin Derivatives}

La Jolla Pharmaceutical Company developed LJPC-401, a proprietary formulation of hepcidin. The molecule completed phase 1 clinical trials and has initiated phase 2 in patients with $\mathrm{HH}$ (ClinicalTrials.gov Identifier: NCT03395704) or transfusion-dependent $\beta$-thalassemia with myocardial iron overload (ClinicalTrials.gov Identifier: NCT03381833). Data from phase 1 show that LJPC-401 effectively reduces serum iron levels in a dose-dependent manner with a maximum at $8 \mathrm{~h}$ post injection, and in the absence of significant adverse effects [93].

Protagonist Therapeutics Inc. launched PTG-300, another proprietary hepcidin formulation. The compound reduces serum iron in cynomolgus monkeys and improves erythropoiesis in the $\mathrm{Hbb}^{\text {th } 3 /+}$ mouse model of $\beta$-thalassemia [94]. PTG-300 recently completed phase 1 clinical trial in healthy volunteers. The data show that the drug is well tolerated and reduces serum iron in a dose-dependent manner; notably this response is sustained for 6 days [95]. A phase 2 clinical trial 
evaluating the effects of PTG-300 in $\beta$-thalassemia patients is expected to start in the fourth quarter of 2018 (http: / / www.protagonist-inc.com/randd-pipeline.php\#ptg300).

Table 3a. Hepcidin agonists.

\begin{tabular}{|c|c|c|c|c|}
\hline & Drug & Target & Evidence & Reference \\
\hline \multirow{4}{*}{$\begin{array}{l}\text { Preclinical } \\
\text { studies }\end{array}$} & $\begin{array}{l}\text { Palmitoyl-ri-hep9 } \\
\text { (minihepcidin) }\end{array}$ & Ferroportin & $\begin{array}{c}\text { Mouse model of juvenile } \\
\text { HH }\end{array}$ & Preza et al. 2011 [83] \\
\hline & PR65 (minihepcidin) & Ferroportin & $\begin{array}{c}\text { Wild type mice } \\
\text { Mouse model of juvenile } \\
\mathrm{HH}\end{array}$ & Ramos et al. 2012 [84] \\
\hline & PR73 (minihepcidin) & Ferroportin & $\begin{array}{c}\text { Mouse model of adult } \mathrm{HH} \\
\text { Mouse model of adult } \mathrm{HH} \text {, } \\
\text { bacteria-infected }\end{array}$ & $\begin{array}{c}\text { Arezes et al. } 2015 \text { [88] } \\
\text { Lunova et al. } 2017 \text { [86] } \\
\text { Stefanova et al. } 2017 \text { [89] } \\
\text { Michels et al. } 2017 \text { [90] } \\
\text { Stefanova et al. } 2018 \text { [91] }\end{array}$ \\
\hline & $\begin{array}{c}\text { M004, M009 } \\
\text { (minihepcidins) }\end{array}$ & Ferroportin & $\begin{array}{c}\text { Mouse model of } \\
\beta \text {-thalassemia } \\
\text { Mouse model of } \\
\text { polycythemia vera }\end{array}$ & Casu et al. 2016 [92] \\
\hline \multirow{2}{*}{$\begin{array}{l}\text { Clinical } \\
\text { trials }\end{array}$} & $\begin{array}{c}\text { LJPC-401 (hepcidin } \\
\text { formulation) } \\
\text { By: La Jolla } \\
\text { Pharmaceutical Company }\end{array}$ & Ferroportin & $\begin{array}{c}\mathrm{HH}, \beta \text {-thalassemic } \\
\text { patients-Phase } 1 \\
\text { (Completed) } \\
\text { Phase } 2 \text { (Recruiting) }\end{array}$ & $\begin{array}{l}\text { Phase 1: Lal et al. } 2018 \text { [93] } \\
\text { (congress presentation) } \\
\text { Phase 2: ClinicalTrials.gov } \\
\text { Identifiers NCT03395704, } \\
\text { NCT03381833 }\end{array}$ \\
\hline & $\begin{array}{l}\text { PTG-300 (hepcidin } \\
\text { formulation) } \\
\text { By: Protagonist } \\
\text { Therapeutics Inc. }\end{array}$ & Ferroportin & $\begin{array}{l}\text { Healthy subjects-Phase } 1 \\
\text { (Completed) } \\
\text { Phase } 2 \text { expected to start end } \\
\text { of } 2018\end{array}$ & $\begin{array}{l}\text { Bourne et al. } 2018 \text { [94] } \\
\text { Nicholls et al. } 2018 \text { [95] } \\
\text { (congress presentations) }\end{array}$ \\
\hline
\end{tabular}

Table 3b. Ferroportin inhibitors.

\begin{tabular}{c|c|c|c|c}
\hline & Drug & Target & Evidence & Reference \\
\hline $\begin{array}{c}\text { Clinical } \\
\text { trials }\end{array}$ & $\begin{array}{c}\text { VIT-2763 (small molecule) } \\
\text { By: Vifor Pharma }\end{array}$ & Ferroportin & Phase 1 planned in 2018 & $\begin{array}{c}\text { http://www.viforpharma. } \\
\text { com/en } / \text { media/press- } \\
\text { releases } / 201802 / 2167159\end{array}$ \\
\hline
\end{tabular}

\section{Inhibitors of Ferroportin Activity}

Theoretically, the pharmacological effects of hepcidin replacement therapy could also be achieved by inhibiting the synthesis or the iron-exporting activity of ferroportin. Moreover, these approaches would be appropriate for the treatment of ferroportin hemochromatosis, which is caused by hepcidin resistance rather than deficiency. Currently, there is no reported attempt for therapeutic targeting of ferroportin synthesis, but efforts have been made to develop ferroportin inhibitors. Thus, Vifor Pharma has generated an orally administered small molecule that binds to ferroportin and inhibits iron efflux (Table 3b and Figure 1). The drug (VIT-2763) was expected to enter phase 1 clinical trial in early 2018 (http:/ / www.viforpharma.com/en/media/press-releases/201802/2167159).

\section{Inhibitors of Hepcidin Expression}

Several inhibitors of hepcidin expression have been identified. These include macromolecular inhibitors of BMP6 or HJV, small molecule inhibitors of BMP/SMAD signaling, neutralizing antibodies against IL-6 receptor or IL6, small molecule inhibitors of JAK/STAT3 signaling, sex hormones, and vitamin D. A detailed list is shown in Table 4. Clinically relevant hepcidin inhibitors currently undergoing evaluation in randomized controlled trials for AI are highlighted in Figure 1.

\subsection{Inhibitors of $B M P 6 / H J V$}

BMP6 and HJV are essential for appropriate hepcidin induction during inflammation [19,20]. Thus, targeting these proteins is expected to be beneficial in disorders associated with hepcidin overexpression. Eli Lilly and Company developed LY3113593, a monoclonal humanized antibody 
against BMP6, for the treatment of anemia in patients with CKD. The BMP6-neutralizing drug has been evaluated for safety and pharmacokinetics in two phase 1 clinical trials with healthy volunteers and CKD patients (ClinicalTrials.gov Identifiers: NCT02144285 and NCT02604160). The studies are completed, but the results are not yet publicly available.

Another BMP6-blocking strategy involves heparin, a glycosaminoglycan produced by mast cells, which is used in clinical settings as an anticoagulant. Biochemical experiments showed that heparin binds with high affinity to BMP6 and abolishes its hepcidin signaling function. Moreover, administration of heparin to mice downregulated hepcidin expression and increased serum iron, while a similar phenotype was documented in patients treated with heparin to prevent deep vein thrombosis [96]. Heparin was also shown to inhibit hepcidin expression in Mycobacterium tuberculosis-infected human macrophages [97]; however, the role of macrophage hepcidin in AI is not well understood. Modified glycol-split and oversulfated heparins lacking coagulant activity retain hepcidin suppressive properties. Thus, treatment with these drugs improved anemia in a heat-killed Brucella abortus mouse model of AI, and even further suppressed hepcidin in Bmp6-/- mice [98,99]. Clearly, these promising results highlight the need for comprehensive evaluation of heparin derivatives for efficacy and safety in clinical trials.

Erythroferrone was recently identified as a potent competitive inhibitor of BMP6 [24]. This finding raises the interesting possibility for using this hormone to treat anemias with excessive hepcidin expression. The pharmacological potential of erythroferrone awaits experimental validation. Nevertheless, since erythroferrone moonlights as myokine (myonectin/CTRP15) with metabolism-modulating properties [23,100], potential pleiotropic effects should be considered.

A soluble HJV construct fused with the Fc domain of IgG (sHJV.Fc) specifically inhibits HJV-mediated induction of hepcidin in cultured hepatoma cells and in mice by competitive binding to BMP6 [101,102]. Moreover, sHJV.Fc was shown to correct hepcidin levels and anemia in the PG-APS rat model of AI [15]. FerruMax Pharmaceuticals, a start-up biotech company, aimed to investigate the pharmacological potential of sHJV.Fc for the treatment of AI in two phase 1 clinical trials with CKD patients (ClinicalTrials.gov Identifiers: NCT01873534 and NCT02228655). However, the trials were terminated early due to "inability to recruit patients meeting eligibility criteria".

Abbvie developed humanized monoclonal antibodies against HJV. A single-dose of the HJV-neutralizing antibodies ABT-207 or H5F9-AM8 in rats and cynomolgus monkeys had long-lasting suppressing effects on hepcidin and promoted an increase in serum iron [103]. H5F9-AM8 was further evaluated in preclinical models of AI (chronic arthritis in rats, aseptic inflammation in mice) and IRIDA (Tmprss6-/- mice). In all conditions tested, the antibody suppressed hepcidin and improved anemia [104]. H5F9-AM8 also reduced systemic and local tumor hepcidin in a mouse xenograft model; however, the suppression of hepcidin expression in cancer cells was not associated with inhibition of tumor growth [105].

\subsection{Small Molecule Inhibitors of BMP/SMAD Signaling}

Dorsomorphin was identified in a chemical screen as the first small molecule inhibitor of the BMP/SMAD signaling pathway [106], which is essential for inflammatory induction of hepcidin [14-16]. It operates by targeting type I BMP receptors, thereby blocking phosphorylation of SMAD1/5/8. The optimized dorsomorphin derivative LDN-193189 inhibited BMP/SMAD signaling to hepcidin in hepatocytes, which in turn stimulated erythropoiesis and attenuated anemia in the PG-APS rat model of AI $[15,61]$. Orally administered LDN-193189 was also shown to increase hemoglobinization in turpentine-challenged mice [107]. Surprisingly, hepcidin induction by activin B, which is mediated by ALK2 and the type II BMP receptor ActRIIA, is insensitive to LDN-193189 [108]. A major limitation of LDN-193189 as hepcidin inhibitor is its broad specificity that leads to off-target effects $[109,110]$. LDN-212854, another dorsomorphin derivative with increased selectivity to ALK2 versus ALK3, was shown to suppress IL-6-induced hepcidin expression in HepG2 cells, yet less effectively compared to LDN-193189 [111]. 
Further chemical screens identified additional compounds with inhibitory activity on BMP/SMAD signaling to hepcidin. The dietary flavonoid myricetin was shown to prevent lipopolysaccharide-induced hypoferremia in mice [112]. An indazole molecule was derivatized to several indazole-based inhibitors [113], including DS28120313 [114] and orally active DS79182026, which could antagonize induction of hepcidin in mice injected with IL-6 [115]. Phenotypic screening by applying chemical proteomics and a radioactive compound-binding assay in HepG2 cells identified ALK2 and ALK3 as the primary targets of DS79182026 [116].

Tolero Pharmaceuticals, Inc., Lehi, UT, USA, launched TP-0184, a small molecule inhibitor of ALK2. The drug is currently undergoing a phase 1 clinical trial to determine its maximum tolerated dose and dose-limiting toxicities in patients with advanced solid tumors (ClinicalTrials.gov Identifier: NCT03429218). In preclinical mouse models of inflammation- and cancer-induced anemia, TP-0184 decreased hepatic hepcidin mRNA and improved hemoglobinization [117,118].

The value of ALK2 as a critical regulator of inflammatory hepcidin induction has been verified by independent studies using momelotinib, a JAK $1 / 2$ inhibitor that is under clinical evaluation for the treatment of myelofibrosis. A completed phase $1 / 2$ clinical trial with myelofibrosis patients showed that this drug also improves anemia [119]. This finding was surprising because JAK1/2 signaling is required for erythropoiesis stimulation via erythropoieitin [120]. Experiments with the PG-APS rat model of AI confirmed that momelotinib ameliorates anemia in response to hepcidin inhibition; moreover, they demonstrated that this response is caused by momelotinib-mediated targeting of ALK2 [121].

Evaluation of data from a genome-wide RNAi screen for hepcidin regulators, with a focus on targets of clinically applied drugs, identified spironolactone and imatinib as hepcidin suppressors [75]. Spironolactone is an aldosterone antagonist commonly used to treat hypertension and congestive heart failure, while imatinib is a tyrosine kinase inhibitor that is used in cancer therapy. Both drugs appear to reduce hepcidin expression in hepatoma cells, in primary hepatocytes and in mice. The mechanism is not well understood, but appears to require intact BMP/SMAD signaling.

\subsection{Neutralizing Antibodies against IL-6 Receptor or IL-6}

IL-6 is critical for inflammatory induction of hepcidin, and Il6-/- (IL-6 knockout) mice exhibit an impaired hypoferremic response to acute inflammation [122]. Thus, neutralizing IL-6 or its receptor offers another potential option for the management of AI. Tocilizumab, a humanized anti-IL-6 receptor antibody, has a good safety profile and is used as an immunosuppressive drug mainly for the treatment of rheumatoid arthritis [123]. Clinical studies showed that it can also significantly reduce serum hepcidin and improve anemia in rheumatoid arthritis patients [124-126]. In addition, tocilizumab [127], as well as the anti-IL-6 antibody siltuximab [128], lowered hepcidin and ameliorated anemia in multicentric Castleman disease patients. Tocilizumab or another IL-6 receptor antibody (MR16-1) had similar therapeutic effects in a cynomolgus monkey model of collagen-induced arthritis [129], and in a mouse model of cancer-related anemia [130], respectively. Nevertheless, the high cost of these drugs may restrict their applicability beyond the treatment of rheumatoid arthritis and Castleman disease.

\subsection{Small Molecule Inhibitors of JAK/STAT3 Signaling}

There are no appropriate small molecule inhibitors of hepcidin that specifically target the JAK/STAT3 signaling pathway downstream of IL-6 and the IL-6 receptor. Another caveat is that any specific inhibitors of JAK $1 / 2$ would also be incompatible with the requirement of this protein in erythropoietin signaling [120]. STAT3 inhibitors, such as curcumin, AG490 or PpYLKTK were reported to inhibit inflammatory induction of hepcidin in cultured cells [131], and in case of AG490 also in mice [132]. Moreover, a single oral dose of curcuma containing 2\% curcumin decreased hepcidin in healthy volunteers; however, this had no effect on serum iron [133]. Acetylsalicylic acid (aspirin) was shown to downregulate hepcidin by decreasing JAK2 and STAT3 phosphorylation in murine BV-2 microglia [134] and rat PC12 pheochromocytoma cells [135], but the relevance of this finding to 
hepatocellular hepcidin is unknown. Generally, STAT3 inhibitors exhibit low target specificity and selectivity, and therefore do not appear optimal candidates for the treatment of AI. Nevertheless, some promising data have been obtained in preclinical models.

For instance, maresin 1, a macrophage-derived $\omega-3$ fatty acid metabolite, exhibited protective anti-inflammatory effects in Il10-/- (IL-10 knockout) mice, which develop colitis with iron deficiency anemia [136]. Further experiments showed that maresin 1 inhibits hepcidin by reducing STAT3 phosphorylation, and thereby ameliorates anemia in this model [137]. A polysaccharide isolated from the roots of the medicinal herb Angelica sinensis was found to repress hepcidin expression in HepG2 cells and to relieve anemia in rat models of AI. The polysaccharide appears to operate by inhibiting both JAK/STAT3 and BMP/SMAD signaling pathways [138-140].

Hydrogen sulfide $\left(\mathrm{H}_{2} \mathrm{~S}\right)$ is a gasotransmitter with signaling properties [141]. Pharmacological administration of $\mathrm{H}_{2} \mathrm{~S}$ was shown to suppress hepcidin in mouse models of acute lipopolysaccharide-induced or chronic turpentine-induced inflammation; mechanistic experiments revealed that $\mathrm{H}_{2} \mathrm{~S}$ inhibits IL-6 production and STAT3 phosphorylation in response to IL-6 signaling [142,143]. Further studies showed that $\mathrm{H}_{2} \mathrm{~S}$ promotes JAK2 degradation by a pathway involving adenosine 5'-monophosphate-activated protein kinase (AMPK), a metabolic enzyme that controls intracellular AMP/ATP ratio. Moreover, activation of AMPK by metformin, a widely used antidiabetic drug, inhibited hepcidin expression and thereby relieved hypoferremia and anemia in mouse models of inflammation. Notably, metformin intake was also associated with low circulating hepcidin and reduced anemia morbidity in diabetic patients [144]. On the other hand, activation of AMPK by metformin was reported to induce hepcidin in cultured Huh7 hepatoma cells [79]; these seemingly conflicting data highlight the need for more mechanistic studies.

An in-silico screen identified guanosine 5'-diphosphate (GDP) as a hepcidin-binding molecule. GDP was further shown to operate as a competitive inhibitor of hepcidin that prevents hepcidin-mediated internalization of ferroportin in cultured cells. GDP (combined with ferrous sulfate) also inhibited hepcidin and improved anemia in a mouse model of inflammation, which was partly due to reduced STAT3 phosphorylation [145].

\subsection{Sex Hormones}

Testosterone, the primary male sex hormone and anabolic steroid, inhibits hepcidin by enhancing epidermal growth factor receptor (EGFR) signaling [146] and by reducing BMP/SMAD signaling [147]. Along these lines, testosterone therapy is known to cause erythrocytosis [148]. In female heat-killed Brucella abortus-inoculated mice, administration of testosterone improved hemoglobinization by suppressing hepcidin and stimulating erythropoiesis [149]. Similar effects were observed in clinical trials with healthy or anemic men [150-152] and men with type 2 diabetes and concurrent hypogonadotropic hypogonadism [153]. Conversely, androgen deprivation therapy reduced erythropoiesis and increased hepcidin in men with prostate cancer [154]. These findings suggest that testosterone could be valuable for the treatment of AI; however, cardiovascular adverse effects associated with testosterone administration limit its clinical applications [155].

$17 \beta$-Estradiol, the major female sex hormone, was shown to suppress hepcidin transcription in Huh7 and HepG2 hepatoma cells via an estrogen responsive element half-site located in HAMP promoter. Nonetheless, while administration of $17 \beta$-estradiol to mice reduced hepcidin, it did not affect serum iron levels [156]. These findings are in line with a study demonstrating a significant reduction in serum hepcidin without correlation with serum iron in female patients with elevated estrogens, due to fertility treatments [157]. On the other hand, in a study with premenopausal women during various phases of their monthly cycle, serum $17 \beta$-estradiol was negatively correlated with hepcidin and positively correlated with iron [158]. Definitely, more work is required to clarify the mechanism and physiological relevance of hepcidin regulation by estrogens before considering any therapeutic applications. 


\subsection{Vitamin D}

Vitamin D exerts various biological functions upon binding to vitamin D receptor (VDR); these include the stimulation of intestinal absorption of calcium, magnesium and phosphate, but also modulation of signaling pathways [159]. There is increasing evidence that vitamin D levels are inversely associated with anemia in chronic inflammatory diseases [160]. Experiments in cultured hepatoma cells, monocytic cells and peripheral blood monocytes demonstrated that vitamin D inhibits expression of inflammatory cytokines; and suppresses hepcidin by a mechanism involving VDR binding to the HAMP promoter [161,162]. Moreover, vitamin D supplementation to healthy volunteers decreased circulating hepcidin levels [161]. This finding was further validated in randomized controlled trials with healthy adults [163], stage 2-3 CKD patients [162] and mechanically ventilated critically ill patients [164]. However, in other randomized controlled trials, vitamin D supplementation failed to correct hepcidin in non-dialysis stage $2-5$ pediatric CKD patients [165] and stage 3-4 adult CKD patients [166]. These controversial findings do not provide compelling evidence that vitamin D has a pharmacological value as a hepcidin-lowering agent in AI. Nevertheless, they may be confounded by differences in nutritional forms of vitamin D, dosage, and severity of disease. The interest in this area of research remains high, as illustrated by several clinical trials that are currently underway (ClinicalTrials.gov Identifiers: NCT03001687, NCT03145896, NCT02714361, NCT03166280, NCT01632761, NCT03718182, NCT03472833), which may provide more conclusive answers.

Table 4. Inhibitors of hepcidin expression. ALK, activin receptor-like kinase; IL-6, interleukin 6; EGFR, epidermal growth factor receptor; CKD, chronic kidney disease.

\begin{tabular}{|c|c|c|c|c|}
\hline & Drug & Target & Evidence & Reference \\
\hline \multirow{14}{*}{$\begin{array}{l}\text { In vitro } \\
\text { studies }\end{array}$} & Genistein (small molecule) & BMP6 & Macrophages & Abreu et al. 2018 [97] \\
\hline & Erythroferrone & BMP6 & Hepatoma cells & Arezes et al. 2018 [24] \\
\hline & $\begin{array}{l}\text { sHJV.Fc (antibody-like fused } \\
\text { protein) }\end{array}$ & BMP6 & $\begin{array}{l}\text { Hepatoma cells, } \\
\text { Kidney cells }\end{array}$ & $\begin{array}{c}\text { Babitt et al. 2007 [101] } \\
\text { Andriopoulos et al. } 2009 \\
{[102]}\end{array}$ \\
\hline & $\begin{array}{l}\text { Dorsomorphin } \\
\text { (small molecule) }\end{array}$ & $\begin{array}{l}\text { Type I BMP } \\
\text { receptors } \\
(\mathrm{ALK} 2 / 3 / 6)\end{array}$ & Hepatoma cells & Yu et al. 2008 [106] \\
\hline & $\begin{array}{c}\text { LDN-193189 } \\
\text { (dorsomorphin derivative) }\end{array}$ & $\begin{array}{c}\text { Type I BMP } \\
\text { receptors } \\
\text { (mainly ALK2) } \\
\end{array}$ & Primary hepatocytes & Theurl et al. 2011 [15] \\
\hline & $\begin{array}{c}\text { LDN-212854 } \\
\text { (dorsomorphin derivative) }\end{array}$ & $\begin{array}{c}\text { Type I BMP } \\
\text { receptors } \\
\text { (mainly ALK2) }\end{array}$ & Hepatoma cells & Mohedas et al. 2013 [111] \\
\hline & $\begin{array}{l}\text { Spironolactone (aldosterone } \\
\text { antagonist used to treat } \\
\text { hypertension) }\end{array}$ & $\begin{array}{l}\mathrm{BMP} / \mathrm{SMAD} \\
\text { signaling? }\end{array}$ & $\begin{array}{l}\text { Hepatoma cells } \\
\text { Primary hepatocytes }\end{array}$ & $\begin{array}{c}\text { Mleczko-Sanecka et al. } 2017 \\
{[75]}\end{array}$ \\
\hline & $\begin{array}{l}\text { Imatinib (tyrosine kinase } \\
\text { inhibitor used in cancer } \\
\text { therapy) }\end{array}$ & $\begin{array}{l}\mathrm{BMP} / \mathrm{SMAD} \\
\text { signaling? }\end{array}$ & $\begin{array}{l}\text { Hepatoma cells } \\
\text { Primary hepatocytes }\end{array}$ & $\begin{array}{c}\text { Mleczko-Sanecka et al. } 2017 \\
{[75]}\end{array}$ \\
\hline & $\begin{array}{c}\text { AG490, PpYLKTK, } \\
\text { curcumin (small molecules) }\end{array}$ & STAT3 & Differentiated hepatocytes & Fatih et al. 2010 [131] \\
\hline & $\begin{array}{c}\text { Aspirin (cyclooxygenase } \\
\text { inhibitor for pain treatment) }\end{array}$ & JAK2, STAT3 & $\begin{array}{c}\text { Microglia cells } \\
\text { Pheochromocytoma cells }\end{array}$ & $\begin{array}{c}\text { Li et al. } 2016 \text { [134] } \\
\text { Huang et al. } 2018 \text { [135] }\end{array}$ \\
\hline & $\begin{array}{c}\text { Angelica sinensis } \\
\text { polysaccharide } \\
\text { (small molecule) }\end{array}$ & SMAD4, STAT3/5 & Hepatoma cells & Wang et al. 2017 [139] \\
\hline & GDP & STAT3 & $\begin{array}{c}\text { Hepatoma cells } \\
\text { Colorectal adenocarcinoma cells }\end{array}$ & Angmo et al. 2017 [145] \\
\hline & $17 \beta$-Estradiol & $\begin{array}{l}\text { Estrogen } \\
\text { responsive } \\
\text { promoter }\end{array}$ & Hepatoma cells & Yang et al. 2012 [156] \\
\hline & Calcitriol & Vitamin D receptor & $\begin{array}{l}\text { Hepatoma cells } \\
\text { Leukemia cells }\end{array}$ & $\begin{array}{l}\text { Bacchetta et al. } 2014 \text { [161] } \\
\text { Zughaier et al. } 2014 \text { [162] }\end{array}$ \\
\hline
\end{tabular}


Table 4. Cont.

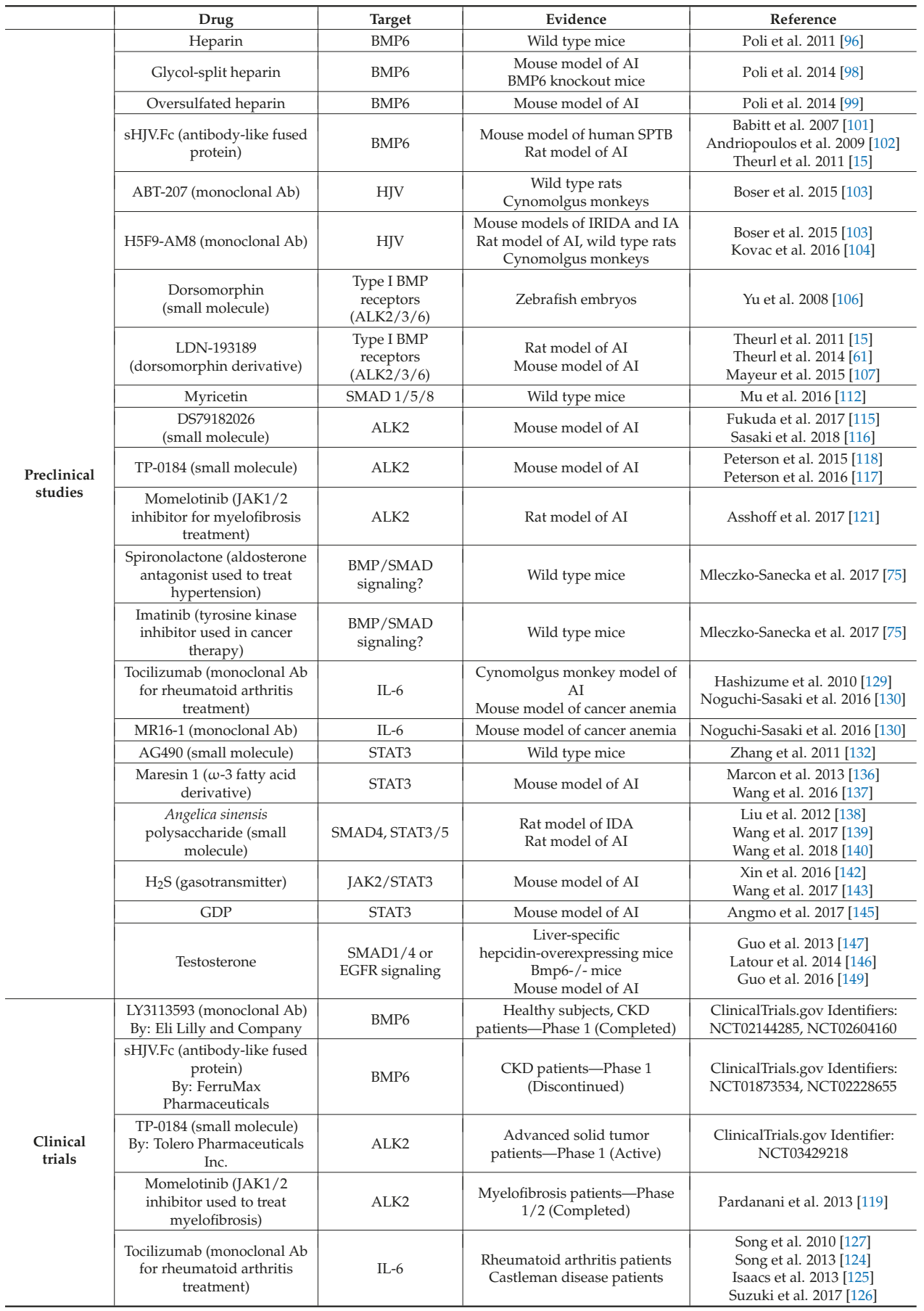


Table 4. Cont.

\begin{tabular}{|c|c|c|c|c|}
\hline & Drug & Target & Evidence & Reference \\
\hline \multirow{6}{*}{$\begin{array}{l}\text { Clinical } \\
\text { trials }\end{array}$} & $\begin{array}{c}\text { Siltuximab (monoclonal } \mathrm{Ab} \\
\text { for neoplastic disease } \\
\text { treatment) }\end{array}$ & IL-6 & Castleman disease patients & Casper et al. 2015 [128] \\
\hline & Curcumin (small molecule) & STAT3 & Healthy subjects & Laine et al. 2017 [133] \\
\hline & Testosterone & $\begin{array}{l}\text { SMAD1/4 or } \\
\text { EGFR signaling }\end{array}$ & $\begin{array}{c}\text { Type } 2 \text { diabetes patients with } \\
\text { hypogonadotropic } \\
\text { hypogonadism }\end{array}$ & Dhindsa et al. 2016 [153] \\
\hline & $17 \beta$-Estradiol & $\begin{array}{l}\text { Estrogen } \\
\text { responsive } \\
\text { promoter }\end{array}$ & $\begin{array}{c}\text { Patients with growth hormone } \\
\text { deficiency/hyperthyroidism/ } \\
\text { hyperprolactinemia } \\
\text { Premenopausal women }\end{array}$ & $\begin{array}{l}\text { Lehtihet et al. } 2016 \text { [157] } \\
\text { Bajbouj et al. } 2018 \text { [158] }\end{array}$ \\
\hline & Vitamin $\mathrm{D}_{2}$ & Vitamin D receptor & Healthy subjects & Bacchetta et al. 2014 [161] \\
\hline & Vitamin $\mathrm{D}_{3}$ & Vitamin D receptor & $\begin{array}{l}\text { CKD patients } \\
\text { Healthy subjects } \\
\text { Critically ill patients }\end{array}$ & $\begin{array}{l}\text { Zughaier et al. } 2014 \text { [162] } \\
\text { Smith et al. } 2017 \text { [163] } \\
\text { Smith et al. } 2018 \text { [164] }\end{array}$ \\
\hline
\end{tabular}

\section{Hepcidin Antagonists}

Hepcidin can be antagonized directly by hepcidin-binding inhibitors, which neutralize hepcidin and reduce its availability to interact with ferroportin. Alternatively, hepcidin can be antagonized indirectly by molecules that bind to ferroportin and competitively inhibit the binding of hepcidin without affecting iron export. A detailed list is shown in Table 5. Clinically relevant hepcidin antagonists currently undergoing evaluation in randomized controlled trials for AI are highlighted in Figure 1.

\subsection{Direct Hepcidin Inhibitors}

Administration of human hepcidin antibodies effectively neutralized hepcidin and triggered responses to hepcidin deficiency in human hepcidin knock-in mice $[167,168]$ and in cynomolgus monkeys $[168,169]$. Furthermore, the therapeutic use of hepcidin antibodies improved hemoglobinization in the heat-killed Brucella abortus model of AI, established in hepcidin knock-in mice [167,168]. Eli Lily and Company developed LY2787106, a human hepcidin monoclonal antibody. Its safety profile and efficacy to improve erythropoiesis were evaluated in a phase 1 randomized controlled clinical trial with patients having cancer-associated anemia. LY2787106 was well tolerated and promoted an increase in serum iron and transferrin saturation within $24-48 \mathrm{~h}$. However, the changes were temporary, and values returned to baseline within a week after dosing. Moreover, there was no correction of anemia, even when the LY2787106 treatment was combined with iron supplementation [170].

Anticalins are engineered polypeptides that derive from human lipocalins and mimic antibody activity by binding to protein targets [171]. Like other therapeutic proteins, anticalins can be PEGylated (coupled with polyethylene glycol) to improve pharmacological properties, such as solubility, stability and plasma half-life [172]. Pieris Pharmaceuticals Inc launched PRS-080, a hepcidin-neutralizing PEGylated anticalin. The safety profile and efficacy of PRS-080 were verified in a phase 1 clinical trial with healthy subjects. Apart from mild adverse effects (mostly headache) in some patients, PRS-080 was well tolerated and decreased hepcidin one hour after infusion. This in turn led to increased serum iron, transferrin saturation and ferritin [173]. PRS-080 is currently being evaluated in phase $1 \mathrm{~b}$ and 2a clinical trials with CDK patients undergoing hemodialysis (ClinicalTrials.gov Identifiers: NCT02754167 and NCT03325621, respectively).

Spiegelmers are synthetic aptamers made of L-oligoribonucleotides, which are engineered to bind with high affinity and selectivity to low-molecular weight protein or peptide targets [174]. NOXXON Pharma AG developed NOX-H94 (or Lexaptepid Pegol), a PEGylated Spiegelmer that binds to and inactivates hepcidin. In preliminary tests NOX-H94 effectively antagonized hepcidin-induced ferroportin internalization in cultured J774 macrophages, and reversed inflammation-related hypoferremia in cynomolgus monkeys [175]. In a phase 1 randomized control clinical trial with healthy volunteers, NOX-H94 inhibited hepcidin in a dose-dependent manner and promoted 
increases in serum iron levels with only minor adverse effects (mild increase in transaminases at high doses) [176]. In another phase 1 trial with human volunteers who developed endotoxemia following lipopolysaccharide injections, NOX-H94 neutralized high levels of hepcidin and corrected endotoxin-induced hypoferremia [177]. In a phase $2 \mathrm{~b}$ clinical trial with ESA-hyporesponsive CKD patients undergoing hemodialysis, NOX-H94 significantly elevated serum iron and improved hemoglobinization [178]. Similar effects were observed in a phase 2a clinical trial with patients having cancer-related anemia [179].

Table 5. Hepcidin antagonists.

\begin{tabular}{|c|c|c|c|c|}
\hline & Drug & Target & Evidence & Reference \\
\hline \multirow{2}{*}{$\begin{array}{l}\text { In vitro } \\
\text { studies }\end{array}$} & $\begin{array}{l}\text { Fursultiamine } \\
\text { (small molecule) }\end{array}$ & Ferroportin & Kidney cells & Fung et al. 2013 [180] \\
\hline & $\begin{array}{c}\text { Quinoxaline } \\
\text { (small molecule) }\end{array}$ & Ferroportin & $\begin{array}{l}\text { Kidney cells, breast cells, leukemia } \\
\text { cells }\end{array}$ & Ross et al. 2017 [181] \\
\hline $\begin{array}{l}\text { Preclinical } \\
\text { studies }\end{array}$ & LY2928057 (monoclonal Ab) & Ferroportin & Cynomolgus monkeys & Witcher et al. 2013 [182] \\
\hline \multirow{4}{*}{$\begin{array}{l}\text { Clinical } \\
\text { trials }\end{array}$} & $\begin{array}{l}\text { LY2787106 (monoclonal Ab) } \\
\text { By: Eli Lily and Company }\end{array}$ & Hepcidin & $\begin{array}{l}\text { Patients with cancer-associated } \\
\text { anemia-Phase } 1 \text { (Completed) }\end{array}$ & Vadhan-Raj et al. 2017 [170] \\
\hline & $\begin{array}{c}\text { PRS-080 } \\
\text { (Pegylated anticalin) } \\
\text { By: Pieris Pharmaceuticals } \\
\text { GmbH }\end{array}$ & Hepcidin & $\begin{array}{c}\text { Anemic CKD patients-Phase } \\
1 \mathrm{~b} / 2 \mathrm{a} \text { (Recruiting) }\end{array}$ & $\begin{array}{l}\text { ClinicalTrials.gov Identifiers: } \\
\text { NCT02754167, NCT03325621 }\end{array}$ \\
\hline & $\begin{array}{c}\text { NOX-H94 } \\
\text { (Pegylated spiegelmer) }\end{array}$ & Hepcidin & $\begin{array}{c}\text { Healthy subjects-Phase } 1 \\
\text { (Completed) } \\
\text { Endotoxemia-induced in } \\
\text { volunteers-Phase } 1 \text { (Completed) } \\
\text { Patients with cancer-associated } \\
\text { anemia-Phase 2a (Completed) } \\
\text { ESA-hyporesponsive anemia in } \\
\text { CKD patients-Phase 2b } \\
\text { (Completed) }\end{array}$ & $\begin{array}{c}\text { Boyce et al. } 2016 \text { [176] } \\
\text { Van Eijk et al. } 2014 \text { [177] } \\
\text { Macdougall et al. } 2015 \text { [178] } \\
\text { Georgiev et al. } 2014 \text { [179] }\end{array}$ \\
\hline & $\begin{array}{l}\text { LY2928057 (monoclonal Ab) } \\
\text { By: Eli Lily and Company }\end{array}$ & Ferroportin & $\begin{array}{l}\text { Healthy subjects and hemodialyzed } \\
\text { patients-Phase } 1 \text { (Completed) }\end{array}$ & Barrington et al. 2016 [183] \\
\hline
\end{tabular}

\subsection{Ferroportin-Binding Hepcidin Inhibitors}

High-throughput screens have been performed to identify small molecule ferroportin-binding hepcidin inhibitors. In one of them the best hit was fursultiamine, a thiamine (vitamin $B_{1}$ ) derivative. This drug irreversibly reacts with the C326 thiol residue in ferroportin that is essential for binding to hepcidin. Consequently, fursultiamine efficiently prevented hepcidin-mediated internalization of ferroportin in an in vitro assay. However, it failed to elicit biologic responses in vivo, presumably due to its conversion to inactive metabolites in the bloodstream [180]. Another screen identified sulfonyl quinoxaline, a synthetic compound that likewise reacts with C326 in ferroportin and prevents its hepcidin-mediated internalization in vitro [181]; the in vivo efficacy of this drug is currently unknown. The screen also identified compounds that inhibit ferroportin internalization without interfering with the binding of hepcidin; however, these were shown to be non-specific [181].

Eli Lily and Company developed LY2928057, a humanized monoclonal ferroportin antibody that recognizes the fifth extracellular loop of ferroportin and thereby precludes the binding of hepcidin. LY2928057 maintains iron efflux from ferroportin in the presence of hepcidin, and promotes a dose-dependent increase in serum iron and hepcidin levels in cynomolgus monkeys [182]. The antibody recently completed phase 1 clinical trials and was well tolerated in hemodialyzed CKD patients. As expected, it caused an increase in serum iron and transferrin saturation; however, the effects on hemoglobinization were modest [183]. Further monoclonal antibodies against human ferroportin that recognize epitopes in the fifth extracellular loop were developed by Amgen. They were shown to partially prevent hepcidin-mediated ferroportin internalization [181], but their therapeutic potential has not been evaluated yet. 


\section{Conclusions}

Within a few years after its discovery in 2001, hepcidin emerged as a therapeutic target for the treatment of iron-related "hepcidinopathies", and possibly also for metabolic and infectious disorders. The clinical relevance for pharmacological manipulation of hepcidin pathways was established by experiments in preclinical animal models of $\mathrm{HH}$, iron-loading anemias, IRIDA and AI. This led to the development of hepcidin therapeutics. Drugs that enhance or reduce hepcidin action are currently being tested in randomized controlled trials and some of them are expected to reach the clinic.

Funding: This research was funded by a grant from the Canadian Institutes for Health Research (CIHR; PJT-159730).

Conflicts of Interest: The authors declare no conflict of interest.

\section{References}

1. Papanikolaou, G.; Pantopoulos, K. Iron metabolism and toxicity. Toxicol. Appl. Pharmacol. 2005, 202, $199-211$. [CrossRef] [PubMed]

2. Aisen, P.; Enns, C.; Wessling-Resnick, M. Chemistry and biology of eukaryotic iron metabolism. Int. J. Biochem. Cell Biol. 2001, 33, 940-959. [CrossRef]

3. Papanikolaou, G.; Pantopoulos, K. Systemic iron homeostasis and erythropoiesis. IUBMB Life 2017, 69, 399-413. [CrossRef] [PubMed]

4. Ganz, T. Systemic iron homeostasis. Physiol. Rev. 2013, 93, 1721-1741. [CrossRef] [PubMed]

5. Aschemeyer, S.; Qiao, B.; Stefanova, D.; Valore, E.V.; Sek, A.C.; Ruwe, T.A.; Vieth, K.R.; Jung, G.; Casu, C.; Rivella, S.; et al. Structure-function analysis of ferroportin defines the binding site and an alternative mechanism of action of hepcidin. Blood 2018, 131, 899-910. [CrossRef] [PubMed]

6. Nemeth, E.; Tuttle, M.S.; Powelson, J.; Vaughn, M.B.; Donovan, A.; Ward, D.M.; Ganz, T.; Kaplan, J. Hepcidin regulates cellular iron efflux by binding to ferroportin and inducing its internalization. Science 2004, 306, 2090-2093. [CrossRef] [PubMed]

7. Hunter, H.N.; Fulton, D.B.; Ganz, T.; Vogel, H.J. The solution structure of human hepcidin, a peptide hormone with antimicrobial activity that is involved in iron uptake and hereditary hemochromatosis. J. Biol. Chem. 2002, 277, 37597-37603. [CrossRef] [PubMed]

8. Jordan, J.B.; Poppe, L.; Haniu, M.; Arvedson, T.; Syed, R.; Li, V.; Kohno, H.; Kim, H.; Schnier, P.D.; Harvey, T.S.; et al. Hepcidin revisited, disulfide connectivity, dynamics, and structure. J. Biol. Chem. 2009, 284, 24155-24167. [CrossRef] [PubMed]

9. Nemeth, E.; Preza, G.C.; Jung, C.L.; Kaplan, J.; Waring, A.J.; Ganz, T. The N-terminus of hepcidin is essential for its interaction with ferroportin: Structure-function study. Blood 2006, 107, 328-333. [CrossRef] [PubMed]

10. Pandur, E.; Fekete, Z.; Tamasi, K.; Grama, L.; Varga, E.; Sipos, K. The C19S Substitution Enhances the Stability of Hepcidin While Conserving Its Biological Activity. Protein J. 2018, 37, 113-121. [CrossRef] [PubMed]

11. Rishi, G.; Wallace, D.F.; Subramaniam, V.N. Hepcidin: Regulation of the master iron regulator. Biosci. Rep. 2015, 35. [CrossRef] [PubMed]

12. Muckenthaler, M.U.; Rivella, S.; Hentze, M.W.; Galy, B. A Red Carpet for Iron Metabolism. Cell 2017, 168, 344-361. [CrossRef] [PubMed]

13. Wahedi, M.; Wortham, A.M.; Kleven, M.D.; Zhao, N.; Jue, S.; Enns, C.A.; Zhang, A.S. Matriptase-2 suppresses hepcidin expression by cleaving multiple components of the hepcidin induction pathway. J. Biol. Chem. 2017, 292, 18354-18371. [CrossRef] [PubMed]

14. Steinbicker, A.U.; Sachidanandan, C.; Vonner, A.J.; Yusuf, R.Z.; Deng, D.Y.; Lai, C.S.; Rauwerdink, K.M.; Winn, J.C.; Saez, B.; Cook, C.M.; et al. Inhibition of bone morphogenetic protein signaling attenuates anemia associated with inflammation. Blood 2011, 117, 4915-4923. [CrossRef] [PubMed]

15. Theurl, I.; Schroll, A.; Sonnweber, T.; Nairz, M.; Theurl, M.; Willenbacher, W.; Eller, K.; Wolf, D.; Seifert, M.; Sun, C.C.; et al. Pharmacologic inhibition of hepcidin expression reverses anemia of chronic inflammation in rats. Blood 2011, 118, 4977-4984. [CrossRef] [PubMed]

16. Mayeur, C.; Lohmeyer, L.K.; Leyton, P.; Kao, S.M.; Pappas, A.E.; Kolodziej, S.A.; Spagnolli, E.; Yu, B.; Galdos, R.L.; Yu, P.B.; et al. The type I BMP receptor Alk3 is required for the induction of hepatic hepcidin gene expression by interleukin-6. Blood 2014, 123, 2261-2268. [CrossRef] [PubMed] 
17. Besson-Fournier, C.; Latour, C.; Kautz, L.; Bertrand, J.; Ganz, T.; Roth, M.P.; Coppin, H. Induction of activin $\mathrm{B}$ by inflammatory stimuli up-regulates expression of the iron-regulatory peptide hepcidin through Smad1/5/8 signaling. Blood 2012, 120, 431-439. [CrossRef] [PubMed]

18. Besson-Fournier, C.; Gineste, A.; Latour, C.; Gourbeyre, O.; Meynard, D.; Martin, P.; Oswald, E.; Coppin, H.; Roth, M.P. Hepcidin upregulation by inflammation is independent of Smad1/5/8 signaling by activin B. Blood 2017, 129, 533-536. [CrossRef] [PubMed]

19. Latour, C.; Besson-Fournier, C.; Gourbeyre, O.; Meynard, D.; Roth, M.P.; Coppin, H. Deletion of BMP6 worsens the phenotype of HJV-deficient mice and attenuates hepcidin levels reached after LPS challenge. Blood 2017, 130, 2339-2343. [CrossRef] [PubMed]

20. Fillebeen, C.; Wilkinson, N.; Charlebois, E.; Katsarou, A.; Wagner, J.; Pantopoulos, K. Hepcidin-mediated hypoferremic response to acute inflammation requires a threshold of Bmp6/Hjv/Smad signaling. Blood 2018, 132, 1829-1841. [CrossRef] [PubMed]

21. Ganz, T.; Nemeth, E. Iron homeostasis in host defence and inflammation. Nat. Rev. Immunol. 2015, 15, 500-510. [CrossRef] [PubMed]

22. Nunez, G.; Sakamoto, K.; Soares, M.P. Innate Nutritional Immunity. J. Immunol. 2018, 201, 11-18. [CrossRef] [PubMed]

23. Kautz, L.; Jung, G.; Valore, E.V.; Rivella, S.; Nemeth, E.; Ganz, T. Identification of erythroferrone as an erythroid regulator of iron metabolism. Nat. Genet. 2014, 46, 678-684. [CrossRef] [PubMed]

24. Arezes, J.; Foy, N.; McHugh, K.; Sawant, A.; Quinkert, D.; Terraube, V.; Brinth, A.; Tam, M.; Lavallie, E.; Taylor, S.; et al. Erythroferrone inhibits the induction of hepcidin by BMP6. Blood 2018, 132, 1473-1477. [CrossRef] [PubMed]

25. Brissot, P.; Pietrangelo, A.; Adams, P.C.; de Graaff, B.; McLaren, C.E.; Loreal, O. Haemochromatosis. Nat. Rev. Dis. Primers 2018, 4, 18016. [CrossRef] [PubMed]

26. Khan, F.A.; Fisher, M.A.; Khakoo, R.A. Association of hemochromatosis with infectious diseases: Expanding spectrum. Int. J. Infect. Dis. 2007, 11, 482-487. [CrossRef] [PubMed]

27. Frank, K.M.; Schneewind, O.; Shieh, W.J. Investigation of a researcher's death due to septicemic plague. N. Engl. J. Med. 2011, 364, 2563-2564. [CrossRef] [PubMed]

28. Pantopoulos, K. Inherited Disorders of Iron Overload. Front. Nutr. 2018, 5, 103. [CrossRef] [PubMed]

29. Gupta, R.; Musallam, K.M.; Taher, A.T.; Rivella, S. Ineffective Erythropoiesis: Anemia and Iron Overload. Hematol. Oncol. Clin. N. Am. 2018, 32, 213-221. [CrossRef] [PubMed]

30. Kowdley, K.V. Iron Overload in Patients with Chronic Liver Disease. Gastroenterol. Hepatol. (N. Y.) 2016, 12, 695-698.

31. Pietrangelo, A. Iron and the liver. Liver Int. 2016, 36 (Suppl. 1), 116-123. [CrossRef]

32. Vela, D. Low hepcidin in liver fibrosis and cirrhosis; a tale of progressive disorder and a case for a new biochemical marker. Mol. Med. 2018, 24, 5. [CrossRef] [PubMed]

33. Han, C.Y.; Koo, J.H.; Kim, S.H.; Gardenghi, S.; Rivella, S.; Strnad, P.; Hwang, S.J.; Kim, S.G. Hepcidin inhibits Smad3 phosphorylation in hepatic stellate cells by impeding ferroportin-mediated regulation of Akt. Nat. Commun. 2016, 7, 13817. [CrossRef] [PubMed]

34. Folgueras, A.R.; Freitas-Rodriguez, S.; Ramsay, A.J.; Garabaya, C.; Rodriguez, F.; Velasco, G.; Lopez-Otin, C. Matriptase-2 deficiency protects from obesity by modulating iron homeostasis. Nat. Commun. 2018, 9, 1350. [CrossRef] [PubMed]

35. Pietrangelo, A. Ferroportin disease: Pathogenesis, diagnosis and treatment. Haematologica 2017, 102, 1972-1984. [CrossRef] [PubMed]

36. Heeney, M.M.; Finberg, K.E. Iron-Refractory Iron Deficiency Anemia (IRIDA). Hematol. Oncol. Clin. N. Am. 2014, 28, 637-652. [CrossRef] [PubMed]

37. Fraenkel, P.G. Anemia of Inflammation: A Review. Med. Clin. N. Am. 2017, 101, 285-296. [CrossRef] [PubMed]

38. Ueda, N.; Takasawa, K. Role of Hepcidin-25 in Chronic Kidney Disease: Anemia and Beyond. Curr. Med. Chem. 2017, 24, 1417-1452. [CrossRef] [PubMed]

39. Nairz, M.; Theurl, I.; Wolf, D.; Weiss, G. Iron deficiency or anemia of inflammation?: Differential diagnosis and mechanisms of anemia of inflammation. Wien. Med. Wochenschr. 2016, 166, 411-423. [CrossRef] [PubMed] 
40. Yoshizaki, K.; Matsuda, T.; Nishimoto, N.; Kuritani, T.; Taeho, L.; Aozasa, K.; Nakahata, T.; Kawai, H.; Tagoh, H.; Komori, T.; et al. Pathogenic significance of interleukin-6 (IL-6/BSF-2) in Castleman's disease. Blood 1989, 74, 1360-1367. [PubMed]

41. Arlet, J.B.; Hermine, O.; Darnige, L.; Ostland, V.; Westerman, M.; Badoual, C.; Pouchot, J.; Capron, L. Iron-deficiency anemia in Castleman disease: Implication of the interleukin 6/hepcidin pathway. Pediatrics 2010, 126, e1608-e1612. [CrossRef] [PubMed]

42. Lakhal-Littleton, S.; Wolna, M.; Chung, Y.J.; Christian, H.C.; Heather, L.C.; Brescia, M.; Ball, V.; Diaz, R.; Santos, A.; Biggs, D.; et al. An essential cell-autonomous role for hepcidin in cardiac iron homeostasis. eLife 2016, 5. [CrossRef] [PubMed]

43. You, L.H.; Yan, C.Z.; Zheng, B.J.; Ci, Y.Z.; Chang, S.Y.; Yu, P.; Gao, G.F.; Li, H.Y.; Dong, T.Y.; Chang, Y.Z. Astrocyte hepcidin is a key factor in LPS-induced neuronal apoptosis. Cell Death Dis. 2017, 8, e2676. [CrossRef] [PubMed]

44. Torti, S.V.; Manz, D.H.; Paul, B.T.; Blanchette-Farra, N.; Torti, F.M. Iron and Cancer. Annu. Rev. Nutr. 2018, 38, 97-125. [CrossRef] [PubMed]

45. Pinnix, Z.K.; Miller, L.D.; Wang, W.; D'Agostino, R., Jr.; Kute, T.; Willingham, M.C.; Hatcher, H.; Tesfay, L.; Sui, G.; Di, X.; et al. Ferroportin and iron regulation in breast cancer progression and prognosis. Sci. Transl. Med. 2010, 2, 43ra56. [CrossRef] [PubMed]

46. Tesfay, L.; Clausen, K.A.; Kim, J.W.; Hegde, P.; Wang, X.; Miller, L.D.; Deng, Z.; Blanchette, N.; Arvedson, T.; Miranti, C.K.; et al. Hepcidin regulation in prostate and its disruption in prostate cancer. Cancer Res. 2015, 75, 2254-2263. [CrossRef] [PubMed]

47. Zhou, Q.; Chen, J.; Feng, J.; Wang, J. E4BP4 promotes thyroid cancer proliferation by modulating iron homeostasis through repression of hepcidin. Cell Death Dis. 2018, 9, 987. [CrossRef] [PubMed]

48. Sebastiani, G.; Wilkinson, N.; Pantopoulos, K. Pharmacological Targeting of the Hepcidin/Ferroportin Axis. Front. Pharmacol. 2016, 7, 160. [CrossRef] [PubMed]

49. Crielaard, B.J.; Lammers, T.; Rivella, S. Targeting iron metabolism in drug discovery and delivery. Nat. Rev. Drug Discov. 2017, 16, 400-423. [CrossRef] [PubMed]

50. Casu, C.; Nemeth, E.; Rivella, S. Hepcidin agonists as therapeutic tools. Blood 2018, 131, 1790-1794. [CrossRef] [PubMed]

51. Sivakumar, M.; Powell, L.W. Management of human factors engineering-associated hemochromatosis: A 2015 update. World J. Hepatol. 2016, 8, 395-400. [CrossRef] [PubMed]

52. Niederau, C.; Fischer, R.; Sonnenberg, A.; Stremmel, W.; Trampisch, H.J.; Strohmeyer, G. Survival and causes of death in cirrhotic and in noncirrhotic patients with primary hemochromatosis. N. Engl. J. Med. 1985, 313, 1256-1262. [CrossRef] [PubMed]

53. Musallam, K.M.; Angastiniotis, M.; Eleftheriou, A.; Porter, J.B. Cross-talk between available guidelines for the management of patients with beta-thalassemia major. Acta Haematol. 2013, 130, 64-73. [CrossRef] [PubMed]

54. Nicolas, G.; Viatte, L.; Lou, D.Q.; Bennoun, M.; Beaumont, C.; Kahn, A.; Andrews, N.C.; Vaulont, S. Constitutive hepcidin expression prevents iron overload in a mouse model of hemochromatosis. Nat. Genet. 2003, 34, 97-101. [CrossRef] [PubMed]

55. Gardenghi, S.; Ramos, P.; Marongiu, M.F.; Melchiori, L.; Breda, L.; Guy, E.; Muirhead, K.; Rao, N.; Roy, C.N.; Andrews, N.C.; et al. Hepcidin as a therapeutic tool to limit iron overload and improve anemia in beta-thalassemic mice. J. Clin. Investig. 2010, 120, 4466-4477. [CrossRef] [PubMed]

56. Finberg, K.E.; Whittlesey, R.L.; Andrews, N.C. Tmprss6 is a genetic modifier of the Hfe-hemochromatosis phenotype in mice. Blood 2011, 117, 4590-4599. [CrossRef] [PubMed]

57. Nai, A.; Pagani, A.; Mandelli, G.; Lidonnici, M.R.; Silvestri, L.; Ferrari, G.; Camaschella, C. Deletion of TMPRSS6 attenuates the phenotype in a mouse model of beta-thalassemia. Blood 2012, 119, 5021-5029. [CrossRef] [PubMed]

58. Besarab, A.; Coyne, D.W. Iron supplementation to treat anemia in patients with chronic kidney disease. Nat. Rev. Nephrol. 2010, 6, 699-710. [CrossRef] [PubMed]

59. Biggar, P.; Kim, G.H. Treatment of renal anemia: Erythropoiesis stimulating agents and beyond. Kidney Res. Clin. Pract. 2017, 36, 209-223. [CrossRef] [PubMed] 
60. Tzounakas, V.L.; Seghatchian, J.; Grouzi, E.; Kokoris, S.; Antonelou, M.H. Red blood cell transfusion in surgical cancer patients: Targets, risks, mechanistic understanding and further therapeutic opportunities. Transfus. Apheresis Sci. 2017, 56, 291-304. [CrossRef] [PubMed]

61. Theurl, M.; Nairz, M.; Schroll, A.; Sonnweber, T.; Asshoff, M.; Haschka, D.; Seifert, M.; Willenbacher, W.; Wilflingseder, D.; Posch, W.; et al. Hepcidin as a predictive factor and therapeutic target in erythropoiesis-stimulating agent treatment for anemia of chronic disease in rats. Haematologica 2014, 99, 1516-1524. [CrossRef] [PubMed]

62. Kim, A.; Fung, E.; Parikh, S.G.; Valore, E.V.; Gabayan, V.; Nemeth, E.; Ganz, T. A mouse model of anemia of inflammation: Complex pathogenesis with partial dependence on hepcidin. Blood 2014, 123, 1129-1136. [CrossRef] [PubMed]

63. Gardenghi, S.; Renaud, T.M.; Meloni, A.; Casu, C.; Crielaard, B.J.; Bystrom, L.M.; Greenberg-Kushnir, N.; Sasu, B.J.; Cooke, K.S.; Rivella, S. Distinct roles for hepcidin and interleukin-6 in the recovery from anemia in mice injected with heat-killed Brucella abortus. Blood 2014, 123, 1137-1145. [CrossRef] [PubMed]

64. Corradini, E.; Schmidt, P.J.; Meynard, D.; Garuti, C.; Montosi, G.; Chen, S.; Vukicevic, S.; Pietrangelo, A.; Lin, H.Y.; Babitt, J.L. BMP6 treatment compensates for the molecular defect and ameliorates hemochromatosis in Hfe knockout mice. Gastroenterology 2010, 139, 1721-1729. [CrossRef] [PubMed]

65. Schmidt, P.J.; Toudjarska, I.; Sendamarai, A.K.; Racie, T.; Milstein, S.; Bettencourt, B.R.; Hettinger, J.; Bumcrot, D.; Fleming, M.D. An RNAi therapeutic targeting Tmprss6 decreases iron overload in Hfe $(-/-)$ mice and ameliorates anemia and iron overload in murine beta-thalassemia intermedia. Blood 2013, 121, 1200-1208. [CrossRef] [PubMed]

66. Guo, S.; Casu, C.; Gardenghi, S.; Booten, S.; Aghajan, M.; Peralta, R.; Watt, A.; Freier, S.; Monia, B.P.; Rivella, S. Reducing TMPRSS6 ameliorates hemochromatosis and beta-thalassemia in mice. J. Clin. Investig. 2013, 123, 1531-1541. [CrossRef] [PubMed]

67. Schmidt, P.J.; Racie, T.; Westerman, M.; Fitzgerald, K.; Butler, J.S.; Fleming, M.D. Combination therapy with a Tmprss6 RNAi-therapeutic and the oral iron chelator deferiprone additively diminishes secondary iron overload in a mouse model of beta-thalassemia intermedia. Am. J. Hematol. 2015, 90, 310-313. [CrossRef] [PubMed]

68. Casu, C.; Aghajan, M.; Oikonomidou, P.R.; Guo, S.; Monia, B.P.; Rivella, S. Combination of Tmprss6- ASO and the iron chelator deferiprone improves erythropoiesis and reduces iron overload in a mouse model of beta-thalassemia intermedia. Haematologica 2016, 101, e8-e11. [CrossRef] [PubMed]

69. Aghajan, M.; Casu, C.; Lo Presti, V.; Booten, S.; Monia, B.P.; Rivella, S.; Guo, G. Developing a Galnac-Conjugated TMPRSS6 Antisense Therapy for the Treatment of $\beta$-Thalassemia. Blood 2016, 128, 1013.

70. Schmidt, P.J.; Liu, K.; Visner, G.; Fitzgerald, K.; Fishman, S.; Racie, T.; Hettinger, J.L.; Butler, J.S.; Fleming, M.D. RNAi-mediated reduction of hepatic Tmprss6 diminishes anemia and secondary iron overload in a splenectomized mouse model of beta-thalassemia intermedia. Am. J. Hematol. 2018, 93, 745-750. [CrossRef] [PubMed]

71. Li, X.; Rhee, D.K.; Malhotra, R.; Mayeur, C.; Hurst, L.A.; Ager, E.; Shelton, G.; Kramer, Y.; McCulloh, D.; Keefe, D.; et al. Progesterone receptor membrane component-1 regulates hepcidin biosynthesis. J. Clin. Investig. 2016, 126, 389-401. [CrossRef] [PubMed]

72. Zhen, A.W.; Nguyen, N.H.; Gibert, Y.; Motola, S.; Buckett, P.; Wessling-Resnick, M.; Fraenkel, E.; Fraenkel, P.G. The small molecule, genistein, increases hepcidin expression in human hepatocytes. Hepatology 2013, 58, 1315-1325. [CrossRef] [PubMed]

73. Gaun, V.; Patchen, B.; Volovetz, J.; Zhen, A.W.; Andreev, A.; Pollastri, M.P.; Fraenkel, P.G. A chemical screen identifies small molecules that regulate hepcidin expression. Blood Cells Mol. Dis. 2014, 53, 231-240. [CrossRef] [PubMed]

74. Patchen, B.; Koppe, T.; Cheng, A.; Seo, Y.A.; Wessling-Resnick, M.; Fraenkel, P.G. Dietary supplementation with ipriflavone decreases hepatic iron stores in wild type mice. Blood Cells Mol. Dis. 2016, 60, 36-43. [CrossRef] [PubMed]

75. Mleczko-Sanecka, K.; da Silva, A.R.; Call, D.; Neves, J.; Schmeer, N.; Damm, G.; Seehofer, D.; Muckenthaler, M.U. Imatinib and spironolactone suppress hepcidin expression. Haematologica 2017, 102, 1173-1184. [CrossRef] [PubMed] 
76. Miura, K.; Taura, K.; Kodama, Y.; Schnabl, B.; Brenner, D.A. Hepatitis C virus-induced oxidative stress suppresses hepcidin expression through increased histone deacetylase activity. Hepatology 2008, 48, 1420-1429. [CrossRef] [PubMed]

77. Zhang, M.; Liu, J.; Guo, W.; Liu, X.; Liu, S.; Yin, H. Icariin regulates systemic iron metabolism by increasing hepatic hepcidin expression through Stat3 and Smad1/5/8 signaling. Int. J. Mol. Med. 2016, 37, 1379-1388. [CrossRef] [PubMed]

78. Bayele, H.K.; Balesaria, S.; Srai, S.K. Phytoestrogens modulate hepcidin expression by Nrf2: Implications for dietary control of iron absorption. Free Radic. Biol. Med. 2015, 89, 1192-1202. [CrossRef] [PubMed]

79. Mleczko-Sanecka, K.; Roche, F.; da Silva, A.R.; Call, D.; D’Alessio, F.; Ragab, A.; Lapinski, P.E.; Ummanni, R.; Korf, U.; Oakes, C.; et al. Unbiased RNAi screen for hepcidin regulators links hepcidin suppression to proliferative Ras/RAF and nutrient-dependent mTOR signaling. Blood 2014, 123, 1574-1585. [CrossRef] [PubMed]

80. Zhang, Y.; Wang, X.; Wu, Q.; Wang, H.; Zhao, L.; Wang, X.; Mu, M.; Xie, E.; He, X.; Shao, D.; et al. Adenine alleviates iron overload by cAMP/PKA mediated hepatic hepcidin in mice. J. Cell. Physiol. 2018, 233, 7268-7278. [CrossRef] [PubMed]

81. Rivera, S.; Nemeth, E.; Gabayan, V.; Lopez, M.A.; Farshidi, D.; Ganz, T. Synthetic hepcidin causes rapid dose-dependent hypoferremia and is concentrated in ferroportin-containing organs. Blood 2005, 106, 2196-2199. [CrossRef] [PubMed]

82. Moran-Jimenez, M.J.; Mendez, M.; Santiago, B.; Rodriguez-Garcia, M.E.; Moreno-Carralero, M.I.; Sanchez-Lucio, A.C.; Grau, M.; Enriquez-de-Salamanca, R. Hepcidin treatment in Hfe-/ - mice diminishes plasma iron without affecting erythropoiesis. Eur. J. Clin. Investig. 2010, 40, 511-517. [CrossRef] [PubMed]

83. Preza, G.C.; Ruchala, P.; Pinon, R.; Ramos, E.; Qiao, B.; Peralta, M.A.; Sharma, S.; Waring, A.; Ganz, T.; Nemeth, E. Minihepcidins are rationally designed small peptides that mimic hepcidin activity in mice and may be useful for the treatment of iron overload. J. Clin. Investig. 2011, 121, 4880-4888. [CrossRef] [PubMed]

84. Ramos, E.; Ruchala, P.; Goodnough, J.B.; Kautz, L.; Preza, G.C.; Nemeth, E.; Ganz, T. Minihepcidins prevent iron overload in a hepcidin-deficient mouse model of severe hemochromatosis. Blood 2012, 120, 3829-3836. [CrossRef] [PubMed]

85. Fung, E.; Chua, K.; Ganz, T.; Nemeth, E.; Ruchala, P. Thiol-derivatized minihepcidins retain biological activity. Bioorg. Med. Chem. Lett. 2015, 25, 763-766. [CrossRef] [PubMed]

86. Lunova, M.; Schwarz, P.; Nuraldeen, R.; Levada, K.; Kuscuoglu, D.; Stutzle, M.; Vujic Spasic, M.; Haybaeck, J.; Ruchala, P.; Jirsa, M.; et al. Hepcidin knockout mice spontaneously develop chronic pancreatitis owing to cytoplasmic iron overload in acinar cells. J. Pathol. 2017, 241, 104-114. [CrossRef] [PubMed]

87. Chua, K.; Fung, E.; Micewicz, E.D.; Ganz, T.; Nemeth, E.; Ruchala, P. Small cyclic agonists of iron regulatory hormone hepcidin. Bioorg. Med. Chem. Lett. 2015, 25, 4961-4969. [CrossRef] [PubMed]

88. Arezes, J.; Jung, G.; Gabayan, V.; Valore, E.; Ruchala, P.; Gulig, P.A.; Ganz, T.; Nemeth, E.; Bulut, Y. Hepcidin-induced hypoferremia is a critical host defense mechanism against the siderophilic bacterium Vibrio vulnificus. Cell Host Microbe 2015, 17, 47-57. [CrossRef] [PubMed]

89. Stefanova, D.; Raychev, A.; Arezes, J.; Ruchala, P.; Gabayan, V.; Skurnik, M.; Dillon, B.J.; Horwitz, M.A.; Ganz, T.; Bulut, Y.; et al. Endogenous hepcidin and its agonist mediate resistance to selected infections by clearing non-transferrin-bound iron. Blood 2017, 130, 245-257. [CrossRef] [PubMed]

90. Michels, K.R.; Zhang, Z.; Bettina, A.M.; Cagnina, R.E.; Stefanova, D.; Burdick, M.D.; Vaulont, S.; Nemeth, E.; Ganz, T.; Mehrad, B. Hepcidin-mediated iron sequestration protects against bacterial dissemination during pneumonia. JCI Insight 2017, 2, e92002. [CrossRef] [PubMed]

91. Stefanova, D.; Raychev, A.; Deville, J.; Humphries, R.; Campeau, S.; Ruchala, P.; Nemeth, E.; Ganz, T.; Bulut, Y. Hepcidin Protects against Lethal Escherichia coli Sepsis in Mice Inoculated with Isolates from Septic Patients. Infect. Immun. 2018, 86. [CrossRef] [PubMed]

92. Casu, C.; Oikonomidou, P.R.; Chen, H.; Nandi, V.; Ginzburg, Y.; Prasad, P.; Fleming, R.E.; Shah, Y.M.; Valore, E.V.; Nemeth, E.; et al. Minihepcidin peptides as disease modifiers in mice affected by beta-thalassemia and polycythemia vera. Blood 2016, 128, 265-276. [CrossRef] [PubMed]

93. Lal, A.; Piga, A.; Viprakasit, V.; Maynard, J.; Kattamis, A.; Yaeger, D.; Byrnes, B.; Chawla, L.; Tidmarsh, G. A phase 1, open-label study to determine the safety, tolerability, and pharmacokinetics of escalating doses of LJPC-401 (synthetic human hepcidin) in patients with iron overload. In Proceedings of the 23rd European Hematology Association Congress, Stockholm, Sweden, 14-17 June 2018. Abstract \#S894. 
94. Bourne, G.; Zhao, L.; Bhandari, A.; Frederick, B.; McMahon, J.; Tran, V.; Annamalai, T.; Mattheakis, L.; Patel, D.; Smythe, M.; et al. Hepcidin Mimetic PTG-300 for Treatment of Ineffective Erythropoiesis and Chronic Anemia in Hemoglobinopathy Disease. In Proceedings of the 23rd European Hematology Association Congress, Stockholm, Sweden, 14-17 June 2018. Abstract \#S843.

95. Nicholls, A.; Lickliter, J.; Tozzi, L.; Liu, D.; Shames, R. Hepcidin mimetic PTG-300 induces dose-related and sustained reductions in serum iron and transferrin saturation in healthy subjects. In Proceedings of the 23rd European Hematology Association Congress, Stockholm, Sweden, 14-17 June 2018. Abstract \#S895.

96. Poli, M.; Girelli, D.; Campostrini, N.; Maccarinelli, F.; Finazzi, D.; Luscieti, S.; Nai, A.; Arosio, P. Heparin: A potent inhibitor of hepcidin expression in vitro and in vivo. Blood 2011, 117, 997-1004. [CrossRef] [PubMed]

97. Abreu, R.; Essler, L.; Loy, A.; Quinn, F.; Giri, P. Heparin inhibits intracellular Mycobacterium tuberculosis bacterial replication by reducing iron levels in human macrophages. Sci. Rep. 2018, 8, 7296. [CrossRef] [PubMed]

98. Poli, M.; Asperti, M.; Naggi, A.; Campostrini, N.; Girelli, D.; Corbella, M.; Benzi, M.; Besson-Fournier, C.; Coppin, H.; Maccarinelli, F.; et al. Glycol-split nonanticoagulant heparins are inhibitors of hepcidin expression in vitro and in vivo. Blood 2014, 123, 1564-1573. [CrossRef] [PubMed]

99. Poli, M.; Asperti, M.; Ruzzenenti, P.; Mandelli, L.; Campostrini, N.; Martini, G.; Di Somma, M.; Maccarinelli, F.; Girelli, D.; Naggi, A.; et al. Oversulfated heparins with low anticoagulant activity are strong and fast inhibitors of hepcidin expression in vitro and in vivo. Biochem. Pharmacol. 2014, 92, 467-475. [CrossRef] [PubMed]

100. Seldin, M.M.; Tan, S.Y.; Wong, G.W. Metabolic function of the CTRP family of hormones. Rev. Endocr. Metab. Disord. 2014, 15, 111-123. [CrossRef] [PubMed]

101. Babitt, J.L.; Huang, F.W.; Xia, Y.; Sidis, Y.; Andrews, N.C.; Lin, H.Y. Modulation of bone morphogenetic protein signaling in vivo regulates systemic iron balance. J. Clin. Investig. 2007, 117, 1933-1939. [CrossRef] [PubMed]

102. Andriopoulos Jr, B.; Corradini, E.; Xia, Y.; Faasse, S.A.; Chen, S.; Grgurevic, L.; Knutson, M.D.; Pietrangelo, A.; Vukicevic, S.; Lin, H.Y.; et al. BMP6 is a key endogenous regulator of hepcidin expression and iron metabolism. Nat. Genet. 2009, 41, 482-487. [CrossRef] [PubMed]

103. Böser, P.; Seemann, D.; Liguori, M.J.; Fan, L.; Huang, L.; Hafner, M.; Popp, A.; Mueller, B.K. Anti-repulsive Guidance Molecule C (RGMc) Antibodies Increases Serum Iron in Rats and Cynomolgus Monkeys by Hepcidin Downregulation. AAPS J. 2015, 17, 930-938. [CrossRef] [PubMed]

104. Kovac, S.; Boser, P.; Cui, Y.; Ferring-Appel, D.; Casarrubea, D.; Huang, L.; Fung, E.; Popp, A.; Mueller, B.K.; Hentze, M.W. Anti-hemojuvelin antibody corrects anemia caused by inappropriately high hepcidin levels. Haematologica 2016, 101, e173-e176. [CrossRef] [PubMed]

105. Torti, S.V.; Lemler, E.; Mueller, B.K.; Popp, A.; Torti, F.M. Effects of Anti-repulsive Guidance Molecule C (RGMc/Hemojuvelin) Antibody on Hepcidin and Iron in Mouse Liver and Tumor Xenografts. Clin. Exp. Pharmacol. 2016, 6. [CrossRef]

106. Yu, P.B.; Hong, C.C.; Sachidanandan, C.; Babitt, J.L.; Deng, D.Y.; Hoyng, S.A.; Lin, H.Y.; Bloch, K.D.; Peterson, R.T. Dorsomorphin inhibits BMP signals required for embryogenesis and iron metabolism. Nat. Chem. Biol. 2008, 4, 33-41. [CrossRef] [PubMed]

107. Mayeur, C.; Kolodziej, S.A.; Wang, A.; Xu, X.; Lee, A.; Yu, P.B.; Shen, J.; Bloch, K.D.; Bloch, D.B. Oral administration of a bone morphogenetic protein type I receptor inhibitor prevents the development of anemia of inflammation. Haematologica 2015, 100, e68-e71. [CrossRef] [PubMed]

108. Kanamori, Y.; Sugiyama, M.; Hashimoto, O.; Murakami, M.; Matsui, T.; Funaba, M. Regulation of hepcidin expression by inflammation-induced activin B. Sci. Rep. 2016, 6, 38702. [CrossRef] [PubMed]

109. Boergermann, J.H.; Kopf, J.; Yu, P.B.; Knaus, P. Dorsomorphin and LDN-193189 inhibit BMP-mediated Smad, p38 and Akt signalling in C2C12 cells. Int. J. Biochem. Cell Biol. 2010, 42, 1802-1807. [CrossRef] [PubMed]

110. Vogt, J.; Traynor, R.; Sapkota, G.P. The specificities of small molecule inhibitors of the TGFss and BMP pathways. Cell. Signal. 2011, 23, 1831-1842. [CrossRef] [PubMed]

111. Mohedas, A.H.; Xing, X.; Armstrong, K.A.; Bullock, A.N.; Cuny, G.D.; Yu, P.B. Development of an ALK2-biased BMP type I receptor kinase inhibitor. ACS Chem. Biol. 2013, 8, 1291-1302. [CrossRef] [PubMed] 
112. Mu, M.; An, P.; Wu, Q.; Shen, X.; Shao, D.; Wang, H.; Zhang, Y.; Zhang, S.; Yao, H.; Min, J.; et al. The dietary flavonoid myricetin regulates iron homeostasis by suppressing hepcidin expression. J. Nutr. Biochem. 2016, 30, 53-61. [CrossRef] [PubMed]

113. Fukuda, T.; Ueda, K.; Ishiyama, T.; Goto, R.; Muramatsu, S.; Hashimoto, M.; Watanabe, K.; Tanaka, N. Synthesis and SAR studies of 3,6-disubstituted indazole derivatives as potent hepcidin production inhibitors. Bioorg. Med. Chem. Lett. 2017, 27, 2148-2152. [CrossRef] [PubMed]

114. Fukuda, T.; Goto, R.; Kiho, T.; Ueda, K.; Muramatsu, S.; Hashimoto, M.; Aki, A.; Watanabe, K.; Tanaka, N. Discovery of DS28120313 as a potent orally active hepcidin production inhibitor: Design and optimization of novel 4,6-disubstituted indazole derivatives. Bioorg. Med. Chem. Lett. 2017, 27, 5252-5257. [CrossRef] [PubMed]

115. Fukuda, T.; Goto, R.; Kiho, T.; Ueda, K.; Muramatsu, S.; Hashimoto, M.; Aki, A.; Watanabe, K.; Tanaka, N. Discovery of DS79182026: A potent orally active hepcidin production inhibitor. Bioorg. Med. Chem. Lett. 2017, 27, 3716-3722. [CrossRef] [PubMed]

116. Sasaki, M.; Ueda, K.; Fukuda, T.; Tanaka, N.; Shimizu, H.; Kubota, K. Target identification of hepcidin production inhibitors by a combination of chemical proteomics and radioactive compound binding assay. Biochem. Biophys. Res. Commun. 2018, 503, 2878-2884. [CrossRef] [PubMed]

117. Peterson, P.; Kim, W.; Haws, H.; Whatcott, C.J.; Siddiqui-Jain, A.; Bearss, D.J.; Warner, S.L. The ALK-2 Inhibitor, TP-0184, Demonstrates High Distribution to the Liver Contributing to Significant Preclinical Efficacy in Mouse Models of Anemia of Chronic Disease (Abstract). Blood 2016, 128, 263.

118. Peterson, P.; Soh, K.K.; Lee, Y.S.; Kim, W.; Whatcott, C.J.; Siddiqui-Jain, A.; Bearss, D.J.; Warner, S.L. ALK2 Inhibition via TP-0184 Abrogates Inflammation-Induced Hepcidin Expression and Is a Potential Therapeutic for Anemia of Chronic Disease (Abstract). Blood 2015, 126, 273.

119. Pardanani, A.; Laborde, R.R.; Lasho, T.L.; Finke, C.; Begna, K.; Al-Kali, A.; Hogan, W.J.; Litzow, M.R.; Leontovich, A.; Kowalski, M.; et al. Safety and efficacy of CYT387, a JAK1 and JAK2 inhibitor, in myelofibrosis. Leukemia 2013, 27, 1322-1327. [CrossRef] [PubMed]

120. Kuhrt, D.; Wojchowski, D.M. Emerging EPO and EPO receptor regulators and signal transducers. Blood 2015, 125, 3536-3541. [CrossRef] [PubMed]

121. Asshoff, M.; Petzer, V.; Warr, M.R.; Haschka, D.; Tymoszuk, P.; Demetz, E.; Seifert, M.; Posch, W.; Nairz, M.; Maciejewski, P.; et al. Momelotinib inhibits ACVR1/ALK2, decreases hepcidin production, and ameliorates anemia of chronic disease in rodents. Blood 2017, 129, 1823-1830. [CrossRef] [PubMed]

122. Nemeth, E.; Rivera, S.; Gabayan, V.; Keller, C.; Taudorf, S.; Pedersen, B.K.; Ganz, T. IL-6 mediates hypoferremia of inflammation by inducing the synthesis of the iron regulatory hormone hepcidin. J. Clin. Investig. 2004, 113, 1271-1276. [CrossRef] [PubMed]

123. Jones, G.; Ding, C. Tocilizumab: A review of its safety and efficacy in rheumatoid arthritis. Clin. Med. Insights Arthritis Musculoskelet. Disord. 2010, 3, 81-89. [CrossRef] [PubMed]

124. Song, S.N.; Iwahashi, M.; Tomosugi, N.; Uno, K.; Yamana, J.; Yamana, S.; Isobe, T.; Ito, H.; Kawabata, H.; Yoshizaki, K. Comparative evaluation of the effects of treatment with tocilizumab and TNF-alpha inhibitors on serum hepcidin, anemia response and disease activity in rheumatoid arthritis patients. Arthritis Res. Ther. 2013, 15, R141. [CrossRef] [PubMed]

125. Isaacs, J.D.; Harari, O.; Kobold, U.; Lee, J.S.; Bernasconi, C. Effect of tocilizumab on haematological markers implicates interleukin-6 signalling in the anaemia of rheumatoid arthritis. Arthritis Res. Ther. 2013, 15, R204. [CrossRef] [PubMed]

126. Suzuki, S.; Nakano, S.; Ando, S.; Matsudaira, R.; Kanai, Y.; Yamanaka, K.; Takasaki, Y. Hepcidin-25 gives an indication of the therapeutic effectiveness of tocilizumab in rheumatoid arthritis-Relationship between disease activity of rheumatoid arthritis and anemia. Rev. Bras. Reumatol. Engl. Ed. 2017, 57, 637-640. [CrossRef] [PubMed]

127. Song, S.N.; Tomosugi, N.; Kawabata, H.; Ishikawa, T.; Nishikawa, T.; Yoshizaki, K. Down-regulation of hepcidin resulting from long-term treatment with an anti-IL-6 receptor antibody (tocilizumab) improves anemia of inflammation in multicentric Castleman disease. Blood 2010, 116, 3627-3634. [CrossRef] [PubMed]

128. Casper, C.; Chaturvedi, S.; Munshi, N.; Wong, R.; Qi, M.; Schaffer, M.; Bandekar, R.; Hall, B.; van de Velde, H.; Vermeulen, J.; et al. Analysis of Inflammatory and Anemia-Related Biomarkers in a Randomized, Double-Blind, Placebo-Controlled Study of Siltuximab (Anti-IL6 Monoclonal Antibody) in Patients with Multicentric Castleman Disease. Clin. Cancer Res. 2015, 21, 4294-4304. [CrossRef] [PubMed] 
129. Hashizume, M.; Uchiyama, Y.; Horai, N.; Tomosugi, N.; Mihara, M. Tocilizumab, a humanized anti-interleukin-6 receptor antibody, improved anemia in monkey arthritis by suppressing IL-6-induced hepcidin production. Rheumatol. Int. 2010, 30, 917-923. [CrossRef] [PubMed]

130. Noguchi-Sasaki, M.; Sasaki, Y.; Shimonaka, Y.; Mori, K.; Fujimoto-Ouchi, K. Treatment with anti-IL-6 receptor antibody prevented increase in serum hepcidin levels and improved anemia in mice inoculated with IL-6-producing lung carcinoma cells. BMC Cancer 2016, 16, 270. [CrossRef] [PubMed]

131. Fatih, N.; Camberlein, E.; Island, M.L.; Corlu, A.; Abgueguen, E.; Detivaud, L.; Leroyer, P.; Brissot, P.; Loreal, O. Natural and synthetic STAT3 inhibitors reduce hepcidin expression in differentiated mouse hepatocytes expressing the active phosphorylated STAT3 form. J. Mol. Med. (Berl.) 2010, 88, 477-486. [CrossRef] [PubMed]

132. Zhang, S.P.; Wang, Z.; Wang, L.X.; Liu, S.J. AG490: An inhibitor of hepcidin expression in vivo. World J. Gastroenterol. 2011, 17, 5032-5034. [CrossRef] [PubMed]

133. Laine, F.; Laviolle, B.; Bardou-Jacquet, E.; Fatih, N.; Jezequel, C.; Collet, N.; Ropert, M.; Morcet, J.; Hamon, C.; Reymann, J.M.; et al. Curcuma decreases serum hepcidin levels in healthy volunteers: A placebo-controlled, randomized, double-blind, cross-over study. Fundam. Clin. Pharmacol. 2017, 31, 567-573. [CrossRef] [PubMed]

134. Li, W.Y.; Li, F.M.; Zhou, Y.F.; Wen, Z.M.; Ma, J.; Ya, K.; Qian, Z.M. Aspirin down Regulates Hepcidin by Inhibiting NF-kappaB and IL6/JAK2/STAT3 Pathways in BV-2 Microglial Cells Treated with Lipopolysaccharide. Int. J. Mol. Sci. 2016, 17, 1921. [CrossRef] [PubMed]

135. Huang, S.N.; Ruan, H.Z.; Chen, M.Y.; Zhou, G.; Qian, Z.M. Aspirin increases ferroportin 1 expression by inhibiting hepcidin via the JAK/STAT3 pathway in interleukin 6-treated PC-12 cells. Neurosci. Lett. 2018, 662, 1-5. [CrossRef] [PubMed]

136. Marcon, R.; Bento, A.F.; Dutra, R.C.; Bicca, M.A.; Leite, D.F.; Calixto, J.B. Maresin 1, a proresolving lipid mediator derived from omega-3 polyunsaturated fatty acids, exerts protective actions in murine models of colitis. J. Immunol. 2013, 191, 4288-4298. [CrossRef] [PubMed]

137. Wang, H.; Shi, P.; Huang, C.; Liu, Q. Maresin 1 ameliorates iron-deficient anemia in IL-10(-/-) mice with spontaneous colitis by the inhibition of hepcidin expression though the IL-6/STAT3 pathway. Am. J. Transl. Res. 2016, 8, 2758-2766. [PubMed]

138. Liu, J.Y.; Zhang, Y.; You, R.X.; Zeng, F.; Guo, D.; Wang, K.P. Polysaccharide isolated from Angelica sinensis inhibits hepcidin expression in rats with iron deficiency anemia. J. Med. Food 2012, 15, 923-929. [CrossRef] [PubMed]

139. Wang, K.; Wu, J.; Cheng, F.; Huang, X.; Zeng, F.; Zhang, Y. Acidic Polysaccharide from Angelica sinensis Reverses Anemia of Chronic Disease Involving the Suppression of Inflammatory Hepcidin and NF-kappaB Activation. Oxid. Med. Cell. Longev. 2017, 2017, 7601592. [CrossRef] [PubMed]

140. Wang, K.; Wu, J.; Xu, J.; Gu, S.; Li, Q.; Cao, P.; Li, M.; Zhang, Y.; Zeng, F. Correction of Anemia in Chronic Kidney Disease with Angelica sinensis Polysaccharide via Restoring EPO Production and Improving Iron Availability. Front. Pharmacol. 2018, 9, 803. [CrossRef] [PubMed]

141. Olas, B. Hydrogen sulfide in signaling pathways. Clin. Chim. Acta 2015, 439, 212-218. [CrossRef] [PubMed]

142. Xin, H.; Wang, M.; Tang, W.; Shen, Z.; Miao, L.; Wu, W.; Li, C.; Wang, X.; Xin, X.; Zhu, Y.Z. Hydrogen Sulfide Attenuates Inflammatory Hepcidin by Reducing IL-6 Secretion and Promoting SIRT1-Mediated STAT3 Deacetylation. Antioxid. Redox Signal. 2016, 24, 70-83. [CrossRef] [PubMed]

143. Wang, M.; Tang, W.; Xin, H.; Zhu, Y.Z. S-Propargyl-Cysteine, a Novel Hydrogen Sulfide Donor, Inhibits Inflammatory Hepcidin and Relieves Anemia of Inflammation by Inhibiting IL-6/STAT3 Pathway. PLoS ONE 2016, 11, e0163289. [CrossRef] [PubMed]

144. Wang, M.; Xin, H.; Tang, W.; Li, Y.; Zhang, Z.; Fan, L.; Miao, L.; Tan, B.; Wang, X.; Zhu, Y.Z. AMPK Serves as a Therapeutic Target Against Anemia of Inflammation. Antioxid. Redox Signal. 2017, 27, 251-268. [CrossRef] [PubMed]

145. Angmo, S.; Tripathi, N.; Abbat, S.; Sharma, S.; Singh, S.S.; Halder, A.; Yadav, K.; Shukla, G.; Sandhir, R.; Rishi, V.; et al. Identification of Guanosine 5'-diphosphate as Potential Iron Mobilizer: Preventing the Hepcidin-Ferroportin Interaction and Modulating the Interleukin-6/Stat-3 Pathway. Sci. Rep. 2017, 7, 40097. [CrossRef] [PubMed] 
146. Latour, C.; Kautz, L.; Besson-Fournier, C.; Island, M.L.; Canonne-Hergaux, F.; Loreal, O.; Ganz, T.; Coppin, H.; Roth, M.P. Testosterone perturbs systemic iron balance through activation of epidermal growth factor receptor signaling in the liver and repression of hepcidin. Hepatology 2014, 59, 683-694. [CrossRef] [PubMed]

147. Guo, W.; Bachman, E.; Li, M.; Roy, C.N.; Blusztajn, J.; Wong, S.; Chan, S.Y.; Serra, C.; Jasuja, R.; Travison, T.G.; et al. Testosterone administration inhibits hepcidin transcription and is associated with increased iron incorporation into red blood cells. Aging Cell 2013, 12, 280-291. [CrossRef] [PubMed]

148. Ohlander, S.J.; Varghese, B.; Pastuszak, A.W. Erythrocytosis Following Testosterone Therapy. Sex. Med. Rev. 2018, 6, 77-85. [CrossRef] [PubMed]

149. Guo, W.; Schmidt, P.J.; Fleming, M.D.; Bhasin, S. Effects of Testosterone on Erythropoiesis in a Female Mouse Model of Anemia of Inflammation. Endocrinology 2016, 157, 2937-2946. [CrossRef] [PubMed]

150. Bachman, E.; Feng, R.; Travison, T.; Li, M.; Olbina, G.; Ostland, V.; Ulloor, J.; Zhang, A.; Basaria, S.; Ganz, T.; et al. Testosterone suppresses hepcidin in men: A potential mechanism for testosterone-induced erythrocytosis. J. Clin. Endocrinol. Metab. 2010, 95, 4743-4747. [CrossRef] [PubMed]

151. Bachman, E.; Travison, T.G.; Basaria, S.; Davda, M.N.; Guo, W.; Li, M.; Connor Westfall, J.; Bae, H.; Gordeuk, V.; Bhasin, S. Testosterone induces erythrocytosis via increased erythropoietin and suppressed hepcidin: Evidence for a new erythropoietin/hemoglobin set point. J. Gerontol. A Biol. Sci. Med. Sci. 2014, 69, 725-735. [CrossRef] [PubMed]

152. Beggs, L.A.; Yarrow, J.F.; Conover, C.F.; Meuleman, J.R.; Beck, D.T.; Morrow, M.; Zou, B.; Shuster, J.J.; Borst, S.E. Testosterone alters iron metabolism and stimulates red blood cell production independently of dihydrotestosterone. Am. J. Physiol. Endocrinol. Metab. 2014, 307, E456-E461. [CrossRef] [PubMed]

153. Dhindsa, S.; Ghanim, H.; Batra, M.; Kuhadiya, N.D.; Abuaysheh, S.; Green, K.; Makdissi, A.; Chaudhuri, A.; Dandona, P. Effect of testosterone on hepcidin, ferroportin, ferritin and iron binding capacity in patients with hypogonadotropic hypogonadism and type 2 diabetes. Clin. Endocrinol. (Oxf.) 2016, 85, 772-780. [CrossRef] [PubMed]

154. Gagliano-Juca, T.; Pencina, K.M.; Ganz, T.; Travison, T.G.; Kantoff, P.W.; Nguyen, P.L.; Taplin, M.E.; Kibel, A.S.; Li, Z.; Huang, G.; et al. Mechanisms Responsible for Reduced Erythropoiesis during Androgen Deprivation Therapy in Men with Prostate Cancer. Am. J. Physiol. Endocrinol. Metab. 2018. [CrossRef] [PubMed]

155. Basaria, S.; Coviello, A.D.; Travison, T.G.; Storer, T.W.; Farwell, W.R.; Jette, A.M.; Eder, R.; Tennstedt, S.; Ulloor, J.; Zhang, A.; et al. Adverse events associated with testosterone administration. N. Engl. J. Med. 2010, 363, 109-122. [CrossRef] [PubMed]

156. Yang, Q.; Jian, J.; Katz, S.; Abramson, S.B.; Huang, X. 17beta-Estradiol inhibits iron hormone hepcidin through an estrogen responsive element half-site. Endocrinology 2012, 153, 3170-3178. [CrossRef] [PubMed]

157. Lehtihet, M.; Bonde, Y.; Beckman, L.; Berinder, K.; Hoybye, C.; Rudling, M.; Sloan, J.H.; Konrad, R.J.; Angelin, B. Circulating Hepcidin-25 Is Reduced by Endogenous Estrogen in Humans. PLoS ONE 2016, 11, e0148802. [CrossRef] [PubMed]

158. Bajbouj, K.; Shafarin, J.; Allam, H.; Madkour, M.; Awadallah, S.; El-Serafy, A.; Sandeep, D.; Hamad, M. Elevated Levels of Estrogen Suppress Hepcidin Synthesis and Enhance Serum Iron Availability in Premenopausal Women. Exp. Clin. Endocrinol. Diabetes 2018, 126, 453-459. [CrossRef] [PubMed]

159. Bikle, D.D. Vitamin D metabolism, mechanism of action, and clinical applications. Chem. Biol. 2014, 21, 319-329. [CrossRef] [PubMed]

160. Smith, E.M.; Tangpricha, V. Vitamin D and anemia: Insights into an emerging association. Curr. Opin. Endocrinol. Diabetes Obes. 2015, 22, 432-438. [CrossRef] [PubMed]

161. Bacchetta, J.; Zaritsky, J.J.; Sea, J.L.; Chun, R.F.; Lisse, T.S.; Zavala, K.; Nayak, A.; Wesseling-Perry, K.; Westerman, M.; Hollis, B.W.; et al. Suppression of iron-regulatory hepcidin by vitamin D. J. Am. Soc. Nephrol. 2014, 25, 564-572. [CrossRef] [PubMed]

162. Zughaier, S.M.; Alvarez, J.A.; Sloan, J.H.; Konrad, R.J.; Tangpricha, V. The role of vitamin D in regulating the iron-hepcidin-ferroportin axis in monocytes. J. Clin. Transl. Endocrinol. 2014, 1, 19-25. [CrossRef] [PubMed]

163. Smith, E.M.; Alvarez, J.A.; Kearns, M.D.; Hao, L.; Sloan, J.H.; Konrad, R.J.; Ziegler, T.R.; Zughaier, S.M.; Tangpricha, V. High-dose vitamin D3 reduces circulating hepcidin concentrations: A pilot, randomized, double-blind, placebo-controlled trial in healthy adults. Clin. Nutr. 2017, 36, 980-985. [CrossRef] [PubMed] 
164. Smith, E.M.; Jones, J.L.; Han, J.E.; Alvarez, J.A.; Sloan, J.H.; Konrad, R.J.; Zughaier, S.M.; Martin, G.S.; Ziegler, T.R.; Tangpricha, V. High-Dose Vitamin D3 Administration Is Associated with Increases in Hemoglobin Concentrations in Mechanically Ventilated Critically Ill Adults: A Pilot Double-Blind, Randomized, Placebo-Controlled Trial. JPEN J. Parenter. Enter. Nutr. 2018, 42, 87-94. [CrossRef] [PubMed]

165. Atkinson, M.A.; Juraschek, S.P.; Bertenthal, M.S.; Detrick, B.; Furth, S.L.; Miller, E.R., 3rd. Pilot study of the effect of cholecalciferol supplementation on hepcidin in children with chronic kidney disease: Results of the D-fense Trial. Pediatr. Nephrol. 2017, 32, 859-868. [CrossRef] [PubMed]

166. Panwar, B.; McCann, D.; Olbina, G.; Westerman, M.; Gutierrez, O.M. Effect of calcitriol on serum hepcidin in individuals with chronic kidney disease: A randomized controlled trial. BMC Nephrol. 2018, 19, 35. [CrossRef] [PubMed]

167. Sasu, B.J.; Cooke, K.S.; Arvedson, T.L.; Plewa, C.; Ellison, A.R.; Sheng, J.; Winters, A.; Juan, T.; Li, H.; Begley, C.G.; et al. Antihepcidin antibody treatment modulates iron metabolism and is effective in a mouse model of inflammation-induced anemia. Blood 2010, 115, 3616-3624. [CrossRef] [PubMed]

168. Cooke, K.S.; Hinkle, B.; Salimi-Moosavi, H.; Foltz, I.; King, C.; Rathanaswami, P.; Winters, A.; Steavenson, S.; Begley, C.G.; Molineux, G.; et al. A fully human anti-hepcidin antibody modulates iron metabolism in both mice and nonhuman primates. Blood 2013, 122, 3054-3061. [CrossRef] [PubMed]

169. Krzyzanski, W.; Xiao, J.J.; Sasu, B.; Hinkle, B.; Perez-Ruixo, J.J. Pharmacodynamic Model of Hepcidin Regulation of Iron Homeostasis in Cynomolgus Monkeys. AAPS J. 2016, 18, 713-727. [CrossRef] [PubMed]

170. Vadhan-Raj, S.; Abonour, R.; Goldman, J.W.; Smith, D.A.; Slapak, C.A.; Ilaria, R.L., Jr.; Tiu, R.V.; Wang, X.; Callies, S.; Cox, J.; et al. A first-in-human phase 1 study of a hepcidin monoclonal antibody, LY2787106, in cancer-associated anemia. J. Hematol. Oncol. 2017, 10, 73. [CrossRef] [PubMed]

171. Rothe, C.; Skerra, A. Anticalin((R)) Proteins as Therapeutic Agents in Human Diseases. BioDrugs 2018, 32, 233-243. [CrossRef] [PubMed]

172. Veronese, F.M.; Mero, A. The impact of PEGylation on biological therapies. BioDrugs 2008, 22, 315-329. [CrossRef] [PubMed]

173. Moebius, U.; Feuerer, W.; Fenzl, E.; van Swelm, R.; Swinkels, D.W.; Hohlbaum, A. A Phase I Study Investigating the Safety, Tolerability, Pharmacokinetics and Pharmacodynamic Activity of the Hepcidin Antagonist PRS-080\#022. Results from a Randomized, Placebo Controlled, Double-Blind Study Following Single Administration to Healthy Subjects. Blood 2015, 126, 536.

174. Vater, A.; Klussmann, S. Turning mirror-image oligonucleotides into drugs: The evolution of Spiegelmer((R)) therapeutics. Drug Discov. Today 2015, 20, 147-155. [CrossRef] [PubMed]

175. Schwoebel, F.; van Eijk, L.T.; Zboralski, D.; Sell, S.; Buchner, K.; Maasch, C.; Purschke, W.G.; Humphrey, M.; Zollner, S.; Eulberg, D.; et al. The effects of the anti-hepcidin Spiegelmer NOX-H94 on inflammation-induced anemia in cynomolgus monkeys. Blood 2013, 121, 2311-2315. [CrossRef] [PubMed]

176. Boyce, M.; Warrington, S.; Cortezi, B.; Zollner, S.; Vauleon, S.; Swinkels, D.W.; Summo, L.; Schwoebel, F.; Riecke, K. Safety, pharmacokinetics and pharmacodynamics of the anti-hepcidin Spiegelmer lexaptepid pegol in healthy subjects. Br. J. Pharmacol. 2016, 173, 1580-1588. [CrossRef] [PubMed]

177. van Eijk, L.T.; John, A.S.; Schwoebel, F.; Summo, L.; Vauleon, S.; Zollner, S.; Laarakkers, C.M.; Kox, M.; van der Hoeven, J.G.; Swinkels, D.W.; et al. Effect of the antihepcidin Spiegelmer lexaptepid on inflammation-induced decrease in serum iron in humans. Blood 2014, 124, 2643-2646. [CrossRef] [PubMed]

178. Macdougall, I.C.; Rumjon, A.; Cinco, J.; Goldstein, L.; Summo, L.; Vauleon, S.; Riecke, K. Pharmacokinetics and pharmacodynamics of lexaptepid, a novel anti-hepcidin molecule, in ESA-resistant haemodialysis patients. Nephrol. Dial. Transplant. 2015, 20. [CrossRef]

179. Georgiev, P.; Lazaroiu, M.; Ocroteala, L.; Grudeva-Popova, J.; Gheorghita, E.; Vasilica, M.; Popescu, S.M.; Cucuianu, A.; Summo, L.; Schwoebel, F.; et al. The anti-hepcidin Spiegelmer ${ }^{\circledR}$ Lexaptepid Pegol (NOX-H94) as treatment of anemia of chronic disease in patients with multiple myeloma, low grade lymphoma, and CLL: A phase II pilot study. Cancer Res. 2014, 74. [CrossRef]

180. Fung, E.; Sugianto, P.; Hsu, J.; Damoiseaux, R.; Ganz, T.; Nemeth, E. High-throughput screening of small molecules identifies hepcidin antagonists. Mol. Pharmacol. 2013, 83, 681-690. [CrossRef] [PubMed]

181. Ross, S.L.; Biswas, K.; Rottman, J.; Allen, J.R.; Long, J.; Miranda, L.P.; Winters, A.; Arvedson, T.L. Identification of Antibody and Small Molecule Antagonists of Ferroportin-Hepcidin Interaction. Front. Pharmacol. 2017, 8, 838. [CrossRef] [PubMed] 
182. Witcher, D.R.; Leung, D.; Hill, K.A.; De Rosa, D.C.; Xu, J.; Manetta, J.; Wroblewski, V.J.; Benschop, R.J. LY2928057, An Antibody Targeting Ferroportin, Is a Potent Inhibitor Of Hepcidin Activity and Increases Iron Mobilization In Normal Cynomolgus Monkeys. Blood 2013, 122, 3433.

183. Barrington, P.; Sheetz, M.J.; Callies, S.; Waters, D.G.; Berg, P.H.; Pappas, D.; Marbury, T.C.; Decker, B.S.; Berg, J.K. Safety, Tolerability, Pharmacokinetics and Pharmacodynamics of an Anti-Ferroportin Antibody in Patients with Anemia Due to Chronic Renal Failure (Abstract). Blood 2016, 128, 1280.

(C) 2018 by the authors. Licensee MDPI, Basel, Switzerland. This article is an open access article distributed under the terms and conditions of the Creative Commons Attribution (CC BY) license (http:/ / creativecommons.org/licenses/by/4.0/). 
Review

\title{
Therapeutic Advances in Regulating the Hepcidin/Ferroportin Axis
}

\author{
Zachary J. Hawula ${ }^{1,2}$, Daniel F. Wallace ${ }^{1,2}$, V. Nathan Subramaniam ${ }^{1,2, *}$ and Gautam Rishi ${ }^{1,2, *}$ \\ 1 Institute of Health and Biomedical Innovation, Queensland University of Technology (QUT), Brisbane, \\ Queensland 4059, Australia; zachary.hawula@hdr.qut.edu.au (Z.J.H.); d5.wallace@qut.edu.au (D.F.W.) \\ 2 School of Biomedical Sciences, Queensland University of Technology (QUT), Brisbane, \\ Queensland 4059, Australia \\ * Correspondence: nathan.subramaniam@qut.edu.au (V.N.S.); gautam.rishi@qut.edu.au (G.R.)
}

Received: 7 October 2019; Accepted: 19 November 2019; Published: 25 November 2019

\begin{abstract}
The interaction between hepcidin and ferroportin is the key mechanism involved in regulation of systemic iron homeostasis. This axis can be affected by multiple stimuli including plasma iron levels, inflammation and erythropoietic demand. Genetic defects or prolonged inflammatory stimuli results in dysregulation of this axis, which can lead to several disorders including hereditary hemochromatosis and anaemia of chronic disease. An imbalance in iron homeostasis is increasingly being associated with worse disease outcomes in many clinical conditions including multiple cancers and neurological disorders. Currently, there are limited treatment options for regulating iron levels in patients and thus significant efforts are being made to uncover approaches to regulate hepcidin and ferroportin expression. These approaches either target these molecules directly or regulatory steps which mediate hepcidin or ferroportin expression. This review examines the current status of hepcidin and ferroportin agonists and antagonists, as well as inducers and inhibitors of these proteins and their regulatory pathways.
\end{abstract}

Keywords: iron metabolism; hepcidin; iron homeostasis; ferroportin

\section{Introduction}

Iron is an essential component of many cellular processes including oxygen transport, DNA replication and repair and as an enzyme cofactor [1,2]. While iron is abundant within the Earth's crust, ferrous $\left(\mathrm{Fe}^{2+}\right)$ iron spontaneously reacts with oxygen to form ferric $\left(\mathrm{Fe}^{3+}\right)$ iron, which is insoluble under physiological conditions [3]. This presents the first of many challenges that organisms face in meeting their needs for adequate iron absorption, as organisms require mechanisms to convert $\mathrm{Fe}^{3+}$ to $\mathrm{Fe}^{2+}$. The second challenge organisms face is iron's ability to undergo redox reactions via Fenton chemistry, which result in reactive oxygen species (ROS). These destructive ROS have the potential to damage proteins, lipid membranes and nucleic acids and result in tissue damage [3,4]. As there is currently no known export mechanism for excess iron, its metabolism is tightly regulated through transcriptional, post-transcriptional, translational, and post-translational mechanisms to prevent toxic iron excess while maintaining the metabolic needs of the organism $[5,6]$.

An adult human body contains $3-5 \mathrm{~g}$ of iron, much of which is supplied to developing erythroblasts for incorporation within the haem group of haemoglobin (70\% of bodily iron) [3]. Other tissues which are major users of iron include the muscles $(2-3 \%)$ where it is present in the haem group of myoglobin, tissue macrophages (5\%) involved in red blood cell (RBC) recycling and liver hepatocytes $(20 \%)$ where excess iron is stored within ferritin. Humans require around $20-25 \mathrm{mg}$ of iron per day for the synthesis of new RBCs; however, only about 1-2 mg of iron is absorbed per day via the enterocytes of the duodenum. The majority of iron $(90 \%)$ is supplied by the recycling of RBCs by macrophages $[2,6]$. 


\section{Hepcidin Regulation}

Hepcidin is an 84-amino-acid long prepropeptide produced in hepatocytes and excreted in urine as a 25-amino-acid mature form [7]. It was originally thought to function solely as an antimicrobial peptide as it is upregulated under inflammatory conditions and as such is considered to be a type two acute-phase reactant due to its regulation via interleukin 6 (IL-6) [7-9]. The 24-amino-acid N-terminal signal peptide of pre-prohepcidin is cleaved to produce prohepcidin, comprising 60 amino acids [10]. The mature 25-amino-acid form of hepcidin [7] is generated via cleavage of the pro-region by furin-like prohormone convertases [10]. The carboxy terminus of the mature hepcidin, comprising four highly conserved disulphide bonds, forms a $\beta$-hairpin; the $\mathrm{N}$-terminus is unstructured and essential for ferroportin (FPN) interaction [11]. This interaction results in reduced membrane concentrations of FPN, thus lowering levels iron availability to tissues [12].

The interplay between the iron exporter FPN and the hepatic peptide hormone, hepcidin, is central to iron homeostasis. Hepcidin binds to membrane-bound FPN and induces its internalisation and eventual degradation. The expression of these two proteins is highly regulated. The main regulatory pathway for liver hepcidin expression is the bone morphogenetic protein/Sma mothers against decapentaplegic (BMP/SMAD) pathway (Figure 1). The ligand BMP6, believed to be produced by liver sinusoidal endothelial cells [13], has been found to be the primary BMP associated with hepcidin transcription $[14,15]$. However, BMPs 2, 4 and 9 have also been shown to increase hepcidin expression [16,17]. Increased body iron stores induce BMP6 expression in the liver; BMP6 then binds to membrane-bound BMP receptors (BMPRs) with hemojuvelin (HJV) acting as a co-receptor [18]. BMPRs type 1 (activin-like kinase (ALK) 2 and ALK3) and type 2 (BMPR2 and ActR2A) are critical for iron balance $[19,20]$. BMP6 binding to BMPRs results in the phosphorylation of intracellular SMAD1/5/8 [21]. Phosphorylated SMAD1/5/8 then complexes with SMAD4, which translocates to the nucleus [22], where it binds to BMP-responsive elements (BMP-RE) on the hepcidin gene promoter inducing hepcidin expression [23].

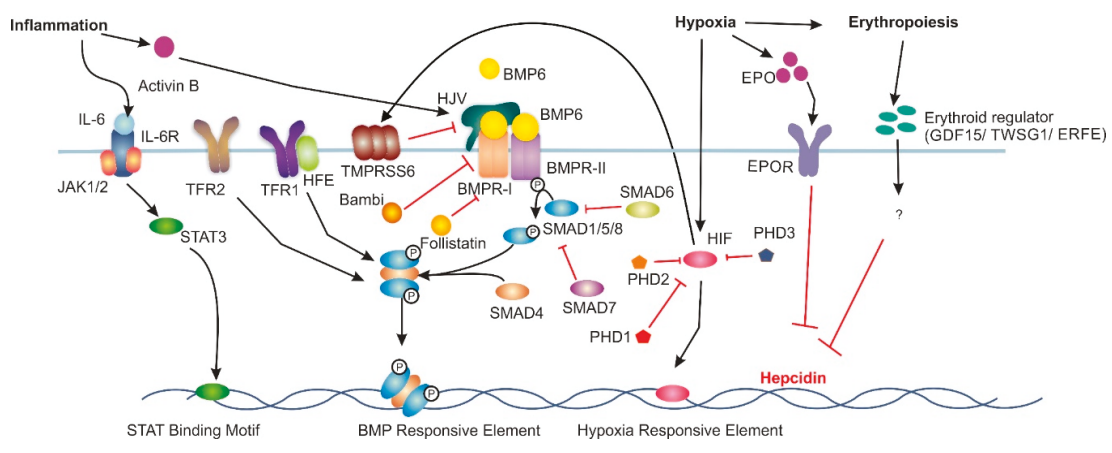

Figure 1. Major Signalling Pathways Involved in Hepcidin Regulation. Increased BMP6 levels induce hepcidin mRNA expression via the bone morphogenic protein (BMP)/sma and mothers against decapentaplegic homologue (SMAD) pathway. Under inflammatory conditions, interleukin 6 (IL-6) induces hepcidin mRNA via the Jak/signal transducer and activator of transcription (STAT) pathway. Hypoxia induces hepcidin downregulation through increases in erythropoietin (EPO) expression. Hypoxia Inducible Factor (HIF) can also directly downregulate hepcidin. Additionally, HIF upregulates matriptase-2 expression, which results in decreased hepcidin expression. Lastly, erythropoiesis has been theorised to reduce hepcidin expression acting through growth differentiation factor 15 (GDF-15), twisted gastrulation factor 1 (TWSG1) or erythroferrone (ERFE), however the exact mechanism is not understood. Interleukin-6 Receptor (IL6-R), Transferrin Receptor 1 (TFR1), Hemojuvelin (HJV), Bone Morphogenic Protein Receptor Type 1 (BMPR-I), Bone Morphogenic Protein Receptor Type 2 (BMPR-II), Erythropoietin Receptor (EPOR) and prolyl hydroxylase domain containing enzymes (PHD) are involved in hepcidin regulation. 
An et al. demonstrated that phosphorylation of SMAD1/5/8 is regulated by the inhibitory SMADs 6 and 7 [24]. Hepatocyte-specific Smad7 knockout mice demonstrated a decrease in non-haem iron within the liver and spleen, in addition to decreases in L-ferritin and FPN levels [24]. Conversely, hepcidin and phosphorylated SMAD1/5/8 levels were increased in these mice [24]. SMAD6, BMP, activin membrane-bound inhibitor homolog (Bambi) and follistatin have been shown to be inhibitors of hepcidin expression in a Smad7 knockout mouse model fed an iron-rich diet [24]. SMAD6 is known to inhibit the phosphorylation of other SMAD proteins while both Bambi and follistatin inhibit the BMP pathway through interacting with the BMPRs and BMPs respectively [24]. Interestingly, An et al. found that SMAD6 and Bambi were controlled by the BMP/SMAD pathway, while follistatin was unaffected [24]. This may indicate why SMAD6 and Bambi are unable to substitute for SMAD7 under normal iron conditions.

BMP6 and iron levels have also been shown to increase the expression of the transmembrane serine protease, matriptase-2 (TMPRSS6) [25]. TMPRSS6 acts as a negative regulator of hepcidin, having been shown to cleave HJV and thus reduce the available membrane-bound HJV [26]. In addition, Lin et al. found that soluble HJV (sHJV) competes with membrane-bound HJV for ligation with BMPs resulting in hepcidin suppression [27].

Hepcidin regulation under inflammatory conditions involves the IL6/signal transducer and activator of transcription (IL6/STAT) pathway [28]. IL6 released during inflammation binds to its receptors, which in turn induce Janus kinase 1 (JAK) to phosphorylate STAT3 [29]. STAT3 translocates to the nucleus where binding to the STAT binding motif on the Hepcidin gene promoter activates expression [28]. Interestingly, intact SMAD1/5/8 function is required for maximal induction of hepcidin via the IL6/STAT3 pathway [30]. It has been suggested that activin B may be responsible for the cross talk between the IL6/STAT3 and BMP/SMAD pathways. Activin B promotes hepcidin activation, acting as a surrogate ligand for SMAD1/5/8 in the BMP/SMAD pathway during infection. Activin B interacts with type 2 BMPR ActR2A and type 1 receptors ALK2 and ALK3 to stimulate hepcidin expression via SMAD1/5/8 phosphorylation as described above [30,31].

In addition to the BMP6/SMAD and IL6/STAT pathways, iron levels are also regulated by hypoxia. Hypoxia Inducible Factor (HIFs), members of the heterodimeric nuclear transcription factor family are the main protein complexes that result in changes in gene expression under hypoxic conditions [32].

HIF complexes regulate a large variety of genes, although the current review focuses on the genes involved with iron regulation. One of the most well studied iron pathway genes regulated by HIF is erythropoietin (EPO). Initially, it was believed that HIF1 $\alpha$ was the major HIF isoform involved with EPO regulation, however multiple knockout studies in mice have confirmed that HIF $2 \alpha$ is the primary regulator of hypoxia induced EPO expression $[33,34]$. This led to the discovery of EPO-dependent mechanisms of hepcidin downregulation. Lui et al. discovered HIF suppression of hepcidin required EPO-induced erythropoiesis in a $\mathrm{Vhl} / \mathrm{Epo}^{-/-}$mouse model [35]. EPO independent mechanisms for HIF regulation of hepcidin have also been discovered. Peyssonnax et al. found murine and human hepcidin contains a Hypoxia-Response Element (HRE) within the hepcidin promoter that results in its down regulation [36]. The ability of HIF1 $\alpha$ to downregulate hepcidin was shown in vivo using a Hif-1 $\alpha^{\text {floxfflox }}$ mouse model given an iron-deficient diet for 20 days that resulted in a 10-fold increase in hepcidin when compared with WT [36]. However, the direct role of HIF1 $\alpha$ on human hepcidin has come into question with subsequent studies suggesting no direct role for HIF [37].

HIF1 also indirectly regulates hepcidin through proteins involved with the previously mentioned BMP6/SMAD pathway. As previously discussed TMPRSS6 cleaves HJV decreasing the levels of membrane-associated HJV which acts to reduce hepcidin production [38]. Maurer et al. discovered a HRE within the promoter region of TMPRSS6 [39]. Lakhal et al. also demonstrated that TMPRSS6 expression increased in a HIF1-dependent manner during hypoxia [40].

Erythroblasts are responsible for utilising the largest proportion of iron within the body to produce haemoglobin [41]. Previous studies have shown that stimulated erythropoiesis supresses hepcidin expression [41]; thus, it was long theorised that an erythroid regulator of hepcidin exists. However, the 
exact molecular mechanism for this regulation is currently unclear. Several candidate molecules have been proposed as the erythroid regulator of iron homeostasis. Growth differentiation factor 15 (GDF-15) and twisted gastrulation factor 1 (TWSG1) are both cytokines produced by erythroblasts which have been found to supress hepcidin expression in human liver cells [42,43]. However, in a Gdf-15 knockout mouse, where erythropoiesis was stimulated via phlebotomy, there was no decrease in hepcidin expression [44]. Similarly, Twsgg1 was not increased in various mouse models of anaemia [45]. Currently, the most likely candidate for the erythroid regulator for hepcidin suppression is erythroferrone (ERFE). Erfe knockout mice have been shown to fail to supress hepcidin following stimulated erythropoiesis, whereas heterozygotes display an intermediate degree of suppression [46]. In addition, knockout of Erfe in the $\mathrm{Hbb}^{(\mathrm{Th} 3 /+)}$ thalassemia intermedia mouse model restored proper hepcidin expression with partial protection from iron overload [46]. However, Erfe knockout mice displayed no significant difference from control mice, suggesting erythroferrone plays a role as a stress erythropoiesis specific regulator and not the main erythropoiesis regulator [47].

\section{Extrahepatic Hepcidin}

In addition to the liver, hepcidin is also synthesised in a number of other organs including adipose tissue, brain kidney, heart, spleen, pancreas and stomach [48]. Within the kidney, where hepcidin is produced in the cortical thick ascending limb, hepcidin was been shown to play a role in the absorption of non-haem iron through the down regulation of both divalent metal transport 1 (DMT1) and FPN [48]. The role of hepcidin within the spleen, stomach and the brain appear to be linked with its antimicrobial ability. Several macrophage cell types have been found to synthesise hepcidin when challenged with pathogens. Sow et al. infected RAW264.7 macrophages, mouse bone marrow-derived macrophages and human THP-1 monocytic cell with Mycobacterium sp., which stimulated hepcidin mRNA and protein synthesis [49]. Within the stomach, hepcidin expression is regulated by bacterial infection and involved with gastric acid production [50]. Hepcidin in the brain has been found to be upregulated via inflammatory responses [51,52]. Hepcidin synthesis in adipose tissue has also been reported; however, the exact role of this type of hepcidin remains largely unknown [48]. Lastly, hepcidin production within the pancreas has been suggested to play a role in the regulation of insulin [48]. These secondary roles of hepcidin will need to be considered when drug candidates undergo animal studies and clinical trials to ensure these critical roles of hepcidin are not altered.

\section{Regulation of FPN}

The sole iron exporter FPN was identified by three independent research groups in early 2000 [53-55]. FPN is highly expressed in the liver Kupffer cells, periportal hepatocytes, duodenal enterocytes, splenic red pulp macrophages, and the placental syncytiotrophoblast [6]. FPN typifies the multilevel regulatory pathway of iron homeostasis (Figure 2). The primary method of FPN regulation is post-translationally via hepcidin [11]. Once hepcidin has bound to FPN, it results in its ubiquitination, internalisation and degradation [56]. Thus, this interaction between hepcidin and FPN plays a central role in the regulation of bodily iron levels. 


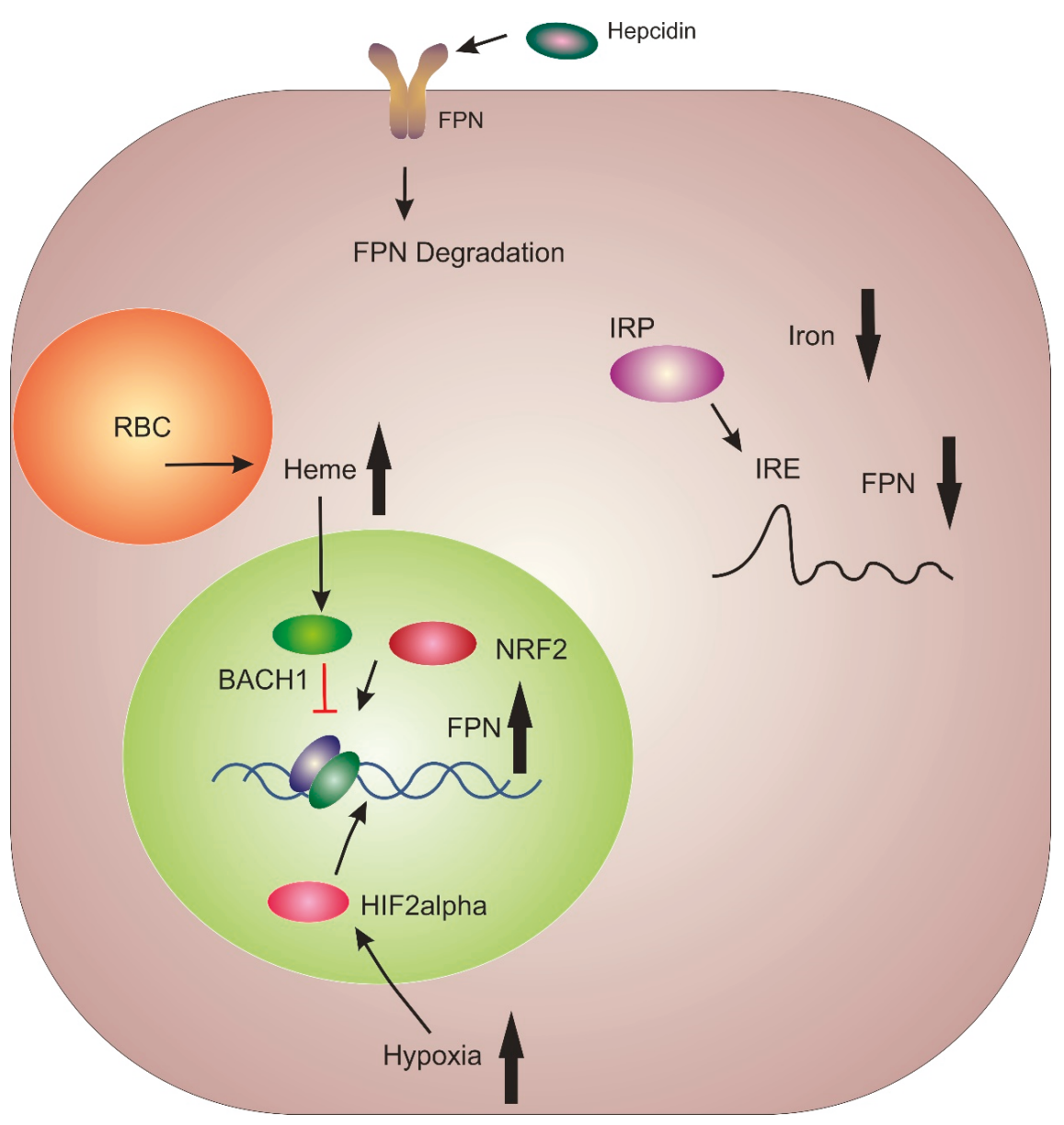

Figure 2. Major Regulatory mechanisms for ferroportin. BTB Domain and CNC Homolog 1 (BACH1) and Nuclear factor erythroid 2-related factor 2 (NRF2) act as a transcriptional repressor and activator of ferroportin (FPN) transcription, respectively. Cytoplasmic iron levels regulate the interaction between iron-responsive element-binding proteins (IRPs) and the iron response element (IRE) located on the $5^{\prime}$ end of FPN mRNA. Decreased iron levels result in IRP binding to the IRE and reduced FPN expression. Enterocytes express a variant of FPN that lacks the 5' IRE. Hypoxia induces FPN transcription in enterocytes via hypoxia inducible factor $2 \alpha$. Lastly, FPN is controlled post-translationally through complexation with hepcidin, which results in internalisation and degradation.

Btb and cnc homology 1 (BACH1) and nuclear factor erythroid 2-like (NRF2) proteins act as transcriptional repressors and activators, respectively, for FPN, in response to cytosolic haem levels within macrophages [57]. At the post-transcriptional level, microRNA (miRNA) miR-485-3p has been shown to inhibit FPN expression during iron deficiency [58]. Translational regulation of FPN occurs via iron-responsive element-binding proteins (IRPs) binding to the iron response element (IRE) located in the 5' UTR of FPN mRNA [57]. This results in suppression of FPN mRNA translation in enterocytes and macrophages under low iron conditions $[59,60]$. Within the duodenum, hypoxia results in the stabilisation of HIF2 $\alpha$, which has been shown to increase FPN expression [6]. Additionally, a variant of FPN which lacks the 5' UTR is predominantly expressed in enterocytes which results in sustained FPN expression in enterocytes even under iron deficiency conditions [6]. 
FPN expression has also been shown to be downregulated in both liver and peritoneal macrophages by lipopolysaccharide (LPS) injections [61]. This regulation of FPN mRNA was shown to be a result of macrophage polarisation. Wortmannin (a phosphoinositide 3-kinase inhibitor) abolished FPN deregulation in LPS-challenged macrophages while the p38-mitogen-activated protein kinase inhibitor, SB203580, intensified FPN mRNA down-regulation [61]. Toll-like receptors 2, 3 and 4 have also been found to effect FPN downregulation under inflammatory conditions. However, their mode of action is only partially understood [6]. This has led to FPN being classified as a negative acute-phase protein [62].

\section{Hepcidin/FPN Axis Dysregulation}

Dysregulation of the hepcidin-FPN axis has been associated with the development of cancer. This most likely results from higher rates of cell proliferation requiring greater demand for iron [63]. Thus, reduced hepatic hepcidin was found to offer a protective effect against the progression of lung [64] and breast cancer $[65,66]$. In addition, the over-expression of FPN also displayed a protective effect as FPN overexpression reduced cell division and colony formation in vitro and in vivo [64,65]. Transferrin receptor 1 and divalent metal transporter 1 have also been found to be upregulated in breast cancer cells [67]. Decreased FPN in triple negative breast cancer cells has also been found to stimulate cell proliferation and migration likely a result of increase cellular iron levels [68]. Hepcidin promoter DNA has been found to be hyper-methylated in human hepatocellular carcinoma resulting in its transcriptional repression [69]. In prostate cancer, the prostate epithelial cells markedly increase synthesis of hepcidin leading to cancer growth and progression [70]. Overexpression of BMPs 2, 4 and 7 have all been linked to increased hepcidin expression in a number of cancers including prostate [70] and lung [71]. Lastly, TMPRSS6 has been found to be downregulated in triple negative breast cancer [72].

Iron levels have also been suggested to play a role in the progression of Alzheimer's disease. Rogers et al. discovered that amyloid-beta precursor proteins (A $\beta P P)$ mRNA contains IREs in the 5' untranslated region UTR. These IREs interact with IRPs to stabilise the mRNA [73]. In addition, $\mathrm{A} \beta \mathrm{PP}$ has been demonstrated to assist in retaining FPN on the cell surface of neurons. However, how $\mathrm{A} \beta \mathrm{PP}$ supports FPN retention is still unclear [74]. Altered function of the protein $\alpha$-synuclein has been demonstrated to play a pivotal role in the pathology of Parkinson's disease [75]. Increased iron levels within the substantia nigra region of the brain have also been associated with the pathogenesis of Parkinson's disease [76]. This iron overload is believed to result from the dysregulated expression of ferritin, divalent metal transporter 1 and ferroxidase [75].

An understanding of how hepcidin and FPN are regulated has provided us with candidates which can be tested to target the expression of hepcidin and FPN with the aim to modulate iron levels. An increasing body of evidence suggesting that altered iron levels play a role in disease progression in multiple conditions warrants development of therapeutic strategies to modulate iron levels. One of the ways to do this is to regulate the hepcidin-FPN axis. Several promising candidates have been tested in laboratories, of which several are undergoing clinical trials. The following sections summarise the current status of these approaches.

\section{Current Therapeutic Treatments for Hepcidin Deficiency}

A reduction or loss of hepcidin expression or function leads to increased iron being released into the blood. The current treatment for the iron overload disorder hereditary hemochromatosis (HH) involves weekly phlebotomy as tolerated by the patient (usually totalling no more than $500 \mathrm{~mL}$ ) until the patient reaches a plasma ferritin level of approximately 50-100 $\mu \mathrm{g} / \mathrm{L}[77,78]$. Once this has been achieved, the goal of the treatment is to maintain these levels. This is normally achieved through additional phlebotomy every three to six months to maintain normal body iron levels $[77,78]$. However, phlebotomy is not effective for reversing arthropathy, diabetes, cardiomyopathy, cirrhosis and hypogonadism [77-79], which are some of the related symptoms/pathologies that develop in hemochromatosis patients. 
In addition to phlebotomy, several iron chelators including deferoxamine (DFO), deferiprone (DFP) and deferasirox (DFX) have also been used in the treatment of hereditary hemochromatosis (HH) [80].

\section{Current Therapeutic Treatments for Lowering Hepcidin}

\subsection{Direct Hepcidin Inhibitors}

\subsubsection{Anti-Hepcidin Antibodies}

Since the discovery of hepcidin as a key player in the regulation of iron homeostasis, it has been the target of multiple drug candidates to prevent it from interacting with FPN. Direct hepcidin inhibition has been investigated as a possible route for normalising hepcidin levels in patients suffering from hepcidin over expression, such as the anaemia of chronic disease (ACD) and iron-refractory iron-deficiency anaemia (IRIDA). Humanised monoclonal antibodies have been developed that display high affinity towards hepcidin leading to its premature degradation. Antibody (Ab) LY2787106 was shown to be well tolerated during its phase one clinical trial, demonstrating a significant increase in serum iron levels. Unfortunately, these increases were only transient and after eight days returned to baseline [81]. Sasu et al. developed the antibody, Ab2.7 which when used in combination with erythropoietin stimulating agents (ESAs) was shown to reverse hepcidin induced anaemia in a heat killed Brucella abortus induced mouse model [82]. The combined treatment was also shown to increase reticulocyte numbers. However, when compared with another direct hepcidin inhibitor, short hairpin RNA (shRNA), the antibody delivered a lower level of hepcidin inhibition. This may have been due to the affinity of the antibody or due to the high turnover of hepcidin within mouse models [82].

\subsubsection{Short Interfering and Short Hairpin RNA}

Short interfering RNA (siRNA) causing HEPCIDIN gene silencing represents another area of active development into the treatment of anaemia. Short hairpin RNAs (shRNAs) targeting hepcidin (H6 and H10) developed by Amgen were demonstrated to cause a reduction in hepcidin mRNA and anaemia when used in conjunction with ESAs [82]. As discussed above, these shRNAs displayed a more robust hepcidin inhibition than the anti-hepcidin antibodies (Ab2.7). Either H6 or H10 treated anaemic mice displayed increased serum iron compared to anaemic control mice treated with shRNAs [82]. The siRNA, ALN-HPN has also been shown to decrease hepcidin mRNA (> 80\%) and increase serum iron (approximately two-fold) with a single intravenous dose [83].

\subsubsection{Hepcidin-Binding Molecules}

Anticalins are therapeutic ligand binding proteins developed from lipocalins [84]. Lipocalins are responsible for the transport of hydrophobic and chemically sensitive molecules in the human body [84]. PRS-080 is a human neutrophil gelatinase-associated lipocalin-derived anticalin engineered for hepcidin binding which results in decreased hepcidin protein levels and subsequently increased iron and transferrin saturation [85]. PRS-080 specifically binds human hepcidin with a dissociation constant $\left(\mathrm{K}_{\mathrm{d}}\right)$ in the subnanomolar range $(0.07 \pm 0.05 \mathrm{nM})$ and cynomolgus monkey hepcidin $(0.07 \pm 0.06 \mathrm{nM})$ [86]. To decrease the rate of kidney filtration for PRS-080, multiple (20, 30 and $40 \mathrm{kDa})$ polyethylene glycol moieties were conjugated to PRS-080, which showed no change in activity compared with unmodified PRS-080, while increasing the half-life in cynomolgus monkey $(18.8 \pm 1.1,43.5 \pm 6.0$ and $167.5 \pm 10.6 \mathrm{~h}$, respectively) [86]. PRS-080 conjugated to the $30 \mathrm{kDa}$ PEG (PRS-080\#22) has undergone phase one clinical trials [87]. Healthy male patients were treated with IV doses of $0.08-16 \mathrm{mg} / \mathrm{kg}$ over a $2-\mathrm{h}$ period. Decreases in serum hepcidin levels were recorded 1-h post infusion, with corresponding increases in serum iron and transferrin saturation from doses $0.4 \mathrm{mg} / \mathrm{kg}$ and higher [87]. Prolonged elevated serum iron and transferrin saturation levels were demonstrated to be dose dependent with increases from $18 \mathrm{~h}(0.4 \mathrm{mg} / \mathrm{kg})$ to $120 \mathrm{~h}(16 \mathrm{mg} / \mathrm{kg})$ [87]. These promising results have resulted in 
PRS-080 progressing towards repeat dosage clinical trials. Another phase 1 clinical trial for PRS-080\#22 displayed no adverse effects when given to healthy patients $(16 \mathrm{mg} / \mathrm{kg})$ and chronic kidney disease (CKD) patients undergoing haemodialysis $(8 \mathrm{mg} / \mathrm{kg})$. In addition, serum iron and transferrin saturation were both increased with PRS-808\#22 treatment with the authors suggesting this indicates that the iron was transferrin bound and therefore highly functional [88].

In parallel, the organic phosphate guanosine 5,-diphosphate (GDP) has been shown to complex with hepcidin at the active site via multiple stable hydrogen bonds [89]. This complex then prevents hepcidin from interacting with FPN, resulting in reduced internalisation of FPN in HepG2 and Caco-2 cell lines. GDP appears to be unique in this sense, as other organic phosphates do not affect FPN degradation [89].

\subsubsection{Hepcidin-Binding L-RNA Aptamers (Spiegelmers)}

Aptamers are an emerging class of synthetic, structured oligonucleotide therapeutics. They consist of DNA, RNA or nucleotides ordered around a modified sugar backbone which display high affinity and specificity [90]. Nox-H94, a PEGylated anti-hepcidin L-RNA aptamer, has been shown to minimise hepcidin-induced FPN degradation and ferritin expression in cynomolgus monkeys [91]. A human study involving healthy adults investigated the safety, pharmacokinetics and pharmacodynamics of Nox-H94 and showed no serious adverse health effects [92] while resulting in an increase in serum iron and transferrin saturation levels [92] (Table 1).

Table 1. Summary table of hepcidin and ferroportin agonists and antagonists.

\begin{tabular}{|c|c|c|}
\hline Model & Drug & Target \\
\hline \multicolumn{3}{|c|}{ Direct Hepcidin Inhibitors } \\
\hline In vitro & Guanosine 5, -diphosphate (GDP) [89] & \multirow{3}{*}{ Hepcidin } \\
\hline In vivo & Ab2.7, H6 and H10 [82], ALN-HPN [83] & \\
\hline Clinical trial & LY2787106 [81], PRS-080 [87], Nox-H94 [92] & \\
\hline \multicolumn{3}{|c|}{ Inhibitors of Hepcidin Production/Synthesis } \\
\hline \multirow{4}{*}{ In vitro } & Unfractionated heparin & \multirow{4}{*}{ BMP6 } \\
\hline & Enoxaparin, Fondaparinux [93] & \\
\hline & RO-68 and RO-82 [94] & \\
\hline & SSLMWH-19 [95] & \\
\hline \multirow{10}{*}{ In vivo } & Dorsomorphin [96], LDN-1913189 [97] & Type 1 BMPRs \\
\hline & Momelotinib [98], TP-0184 [99] & ALK2 \\
\hline & Imatinib, spironolactone [100] & BMP/SMAD Pathway \\
\hline & sHJV.Fc [97] & BMP6 \\
\hline & ABT-207, h5F9-AM8 [101] & HJV \\
\hline & RNAi [83] & TFR2 \\
\hline & AG490 [102] & JAK \\
\hline & PpYLKTK [103] & STAT3 \\
\hline & Metformin [104] & AMPK \\
\hline & Indazole [105], DS79182026 [106] & ALK2 and ALK3 \\
\hline Clinical Trail & Siltuximab [107], Tocilizumab [108] & IL-6 \\
\hline \multicolumn{3}{|c|}{ Hypoxia-Inducible Factors (HIF) Stabilisers } \\
\hline Clinical trial & $\begin{array}{c}\text { Vadadustat [109], Roxadustat [110], } \\
\text { Daproustat [111] }\end{array}$ & PHD \\
\hline \multicolumn{3}{|c|}{ Ferroportin Agonists } \\
\hline In vitro & Fursultiamine [112], Anti-FPN mouse antibody [113] & FPN \\
\hline
\end{tabular}


Table 1. Cont.

\begin{tabular}{ccc}
\hline Model & Drug & Target \\
\hline \multirow{3}{*}{ In vitro } & Hepcidin Agonists & \\
\cline { 2 - 3 } & Sorafenib, Wortmannin, Rapamycin [115] & FPN \\
\cline { 2 - 3 } & Epitiostanol, Progesterone, Mifepristone [116] & RAS/RAF and PI3 \\
\cline { 2 - 3 } & PR73 [117], PR65 [118], mHS17, mHS26 [119], \\
& M004, M009 [120] & PGRMC1 \\
\cline { 2 - 3 } & TMPRSS6-ASO\#1 [121], TMPRSS6-ASO\#2 [121], & FPN \\
\cline { 2 - 3 } In vivo & NalNAc-ASO [122], RNAi-GalNAc [123], & TMPRSS6 \\
\cline { 2 - 3 } & Naringenin, Quercetin, Resveratrol [124] & NRF2 \\
\cline { 2 - 3 } & Adenine [125] & BMP6/SMAD pathway \\
\cline { 2 - 3 } & Genistein [126] & BMP-RE and STAT \\
\cline { 2 - 3 } & Ipriflavone, Vorinostat [127] & BMP6 and STAT3 \\
\hline Clinical Trial & Icariin, Epimedin [128] & TMPT3 and Smad1/5/8 \\
\hline & LJPC-401 [129] & FPN \\
\hline
\end{tabular}

\subsection{Inhibitors of Hepcidin Production/Synthesis}

One of the most important pathways involved in regulating systemic hepcidin levels in response to several stimuli is the BMP-SMAD pathway [131]. Several studies have focussed on targeting this pathway to alter hepcidin levels and normalise iron levels. This section summarises a number of these approaches.

\subsubsection{Heparin-Based Targeting of the BMP/SMAD Pathway}

Heparin is comprised of repeating units of uronic acid and D-glucosamine or D-glucosamine $\mathrm{N}$-sulphate. Unfractionated heparin $(>4 \mu \mathrm{g} / \mathrm{mL})$ was shown to sequester BMPs and block SMAD phosphorylation, which then resulted in reduced hepcidin mRNA in HepG2 cells [93]. This hepcidin lowering effect was also found with low molecular weight heparin, enoxaparin and fondaparinux [93]. These types of heparins require significantly greater concentrations $(40 \mu \mathrm{g} / \mathrm{mL}$ and $>200 \mu \mathrm{g} / \mathrm{mL}$, respectively) to repress hepcidin levels. However, the anticoagulant effect of heparin makes it difficult to use in mouse models [94]. Glycol-split variants, RO-68 and RO-82 have both been shown to lack anti-thrombin binding while remaining potent hepcidin inhibitors [94]. Super-sulphated heparin SSLMWH-19 was demonstrated to exhibit an even greater degree of hepcidin inhibition than either RO-68 or RO-82. However, SSLMWH-19 still retained marginal anticoagulant properties [95].

\subsubsection{Bone Morphogenetic Protein Receptor (BMPR) Inhibitors}

Dorsomorphin has been shown to inhibit type 1 BMPRs, which in turn results in decreased SMAD1/5/8 phosphorylation in zebrafish and mouse models [96]. LDN-193189, a dorsomorphin derivative, has been demonstrated to inhibit BMP4-mediated SMAD1/5/8 phosphorylation in rats with ACD, followed by an increase in serum iron and FPN levels and decrease in ferritin levels in the spleen [97]. Asshoff et al. recently developed the antibody momelotinib that targets ALK2 leading to a reduction in hepcidin production in anaemic rats [98]. Lastly, TP-0184 demonstrated an inhibitory effect against ALK2 with two oral doses eight hours apart ameliorating turpentine oil mediated anaemia in mice [99]. While both momelotinib and TP-0184 appear to be specific for only ALK2, both dorsomorphin and LDN-1913189 have been found to have off target effects, which reduces their potential as a therapeutic agents [132].

Two clinically approved drugs (imatinib and spironolactone) were identified that decrease hepcidin through the BMP6 pathway in a variety of cell types (HuH7 and primary hepatocytes of both human 
and mouse origin) and in male wild-type C57BL/6 mice [100]. Unfortunately, imatinib is not a suitable target for drug re-purposing due to several adverse effects including fatigue, nausea, vomiting, rash, peripheral oedema and abdominal pain. In contrast, spironolactone displays generally minor side effects [100].

\subsubsection{Hemojuvelin (HJV) and Transferrin Receptor 2 (TFR2) Inhibitors}

The BMP co-receptor HJV has been a major focus for hepcidin inhibition with a variety of techniques developed. Soluble HJV (sHJV) has previously been implicated in hepcidin inhibition [27]. sHJV fused with immunoglobulin fragment crystallisable region (sHJV.Fc) also displays hepcidin inhibitory ability via decreased SMAD1/5/8 phosphorylation. Treatment of ACD in rats with sHJV.Fc significantly increased haemoglobin levels after a 21-day period of Streptococcal peptidoglycan-polysaccharide treatment [97]. Boser et al. created HJV targeting antibodies (ABT-207 or h5F9-AM8) that after a single dose have been shown to increase serum iron and decrease unsaturated iron binding capacity (UIBC) in a rat model [101].

Several studies in humans and mice have shown that TFR2 is required for the proper regulation of hepcidin [133-135]. TFR2 also plays a role in the interaction of erythropoietin (EPO) and its receptor (EPO-R) [136]. TRF2 is required for the transport of the EPO-R from the endoplasmic reticulum to the cells surface [137]. Therefore, therapeutics have been developed that target the expression TFR2 with the aim of reducing hepcidin expression. A single IV dose of RNAi against TFR2 in mice led to a marked decrease in TFR2 and hepcidin mRNA while concurrently increasing transferrin saturation [83].

\subsubsection{Targeting the IL-6/STAT3 Pathway}

IL-6-mediated JAK-STAT activation of hepcidin is another major pathway involved in hepcidin regulation. Hence, blocking the IL-6 pathway has also been investigated as a therapeutic treatment for ACD. IL-6 targeting chimeric antibody siltuximab demonstrated decreased hepcidin levels in $97 \%$ of multiple myeloma and Castleman disease patients, with $75 \%$ of these patients showing haemoglobin increases of $>1.5 \mathrm{~g} / \mathrm{dL}$ [107]. Another IL-6 targeting antibody, tocilizumab, decreased IL-6 mediated serum hepcidin in multicentric Castleman disease with hepcidin levels falling to within the normal limit in a two-week period [108].

The small molecule AG490 has been shown to be an inhibitor of JAK2 [138]. After a single injection of AG490, a 37\% reduction in hepcidin levels was evident after $24 \mathrm{~h}$ in an ACD mouse model [102]. The synthetic STAT3 inhibitor phosphopeptide PpYLKTK, which affects STAT dimerisation [103], decreased hepcidin mRNA expression by $35 \% 2 \mathrm{~h}$ post infection in a mouse derived hepatocyte model [103].

AMP-activated protein kinase (AMPK) has recently been demonstrated to be involved in the regulation of hepcidin through inhibition of STAT3 [104]. Wang et al. subcutaneously injected C57BL/6 mice with $100 \mu \mathrm{L} / 20 \mathrm{~g}$ body weight turpentine for four weeks to induce anaemia of chronic inflammation [104]. Mice were injected with $250 \mathrm{mg} / \mathrm{kg}$ metformin (an AMPK activator) displayed increased serum iron and transferrin saturation while the serum hepcidin, Jak2 and phospho-Stat 3 levels were reduced [104]. In addition, pre-treatment of C57BL/6 mice with metformin before treatment with IL-6 ( $3 \mu \mathrm{L} / 20 \mathrm{~g}$ body weight) reduced hepcidin mRNA and protein levels and restored serum iron levels.

In a retrospective analysis of 83 Chinese type two diabetes mellitus patients, metformin therapy was associated with a decrease in serum hepcidin levels in men [104]. Previously, Fukuda et al. found that intraperitoneal administration of indazole lowered hepcidin levels in mice [105]. However, this molecule had no effect when administered orally [105]. Using this molecule as a base, a specific oral inhibitor of hepcidin, DS79182026, was generated [106]. This molecule has been shown to display low off target kinase inhibition and a dose of $30 \mathrm{mg} / \mathrm{kg}$ in an acute inflammatory mouse model significantly reduced serum hepcidin levels [106]. 


\subsubsection{Hypoxia-Inducible Factors (HIF) Stabilisers}

HIF stabilisers are another class of drugs initially designed to increase EPO levels in anaemia patients; however, they were also found to indirectly reduce hepcidin levels. These stabilisers act by inhibiting prolyl hydroxylase, which is responsible for degrading the alpha subunits of the HIF complex during normoxia [139].

Pergola et al. are currently developing an oral hypoxia-inducible factor prolyl hydroxylase inhibitor called vadadustat for use in the treatment of anaemia in CKD patients [109]. In a 20-week, double-blinded, randomised, placebo-controlled phase $2 \mathrm{~B}$ clinical trial, vadaustat was found to significantly increase haemoglobin with decreases in hepcidin levels by six [109]. Another HIF stabiliser, roxadustat developed by Besarab et al. underwent a proof of concept phase $2 \mathrm{~B}$ trial in 2015 on newly initiated dialysis patients who previously had not taken EPO analogues [110]. After four-week roxadustat treatment, hepcidin levels significantly decreased in all patient cohorts [110]. Recently, roxadustat has undergone two phase three trials in China undertaken with CDK patients who displayed an increase in haemoglobin levels above those of the controls $[140,141]$. Lastly, daproustat a competitive reversible inhibitor of PHDs through its interactions with the catalytic iron and subsequent blocking of substrate entry [142] has also been tested as a hepcidin targeting molecule. In a phase 2A randomised trial of stage 3-5 CKD patients, a decrease in hepcidin and subsequent increase in total iron levels in the daprodustat treated cohort was observed [111].

\section{Current Therapeutic Treatments Targeting Ferroportin}

Ferroportin Agonists

Instead of inhibiting the expression of hepcidin, preventing FPN degradation has also been investigated as a therapeutic treatment for high hepcidin disorders. A high-throughput screen discovered that a thiamine derivative, fursultiamine, inhibited hepcidin binding to FPN, thus stabilising iron export in the HEK293-FPN-GFP cell line [112]. Unfortunately, in vivo assessment of fursultiamine showed no effect on FPN levels, as fursultiamine is a therapeutic replacement for thiamine and is thus rapidly metabolised within the body. However, the metabolite thiamine was found not to attenuate FPN internalisation [112].

In 2012, Eli Lilly filed a patent for an anti-FPN mouse antibody that inhibits hepcidin-mediated internalisation resulting in maintained FPN function [113]. However, to our knowledge, no further progress has been made with this antibody.

Ross et al. described anti-hepcidin antibodies (38G6 and 38C8) that when pre-incubated with Hek-RExTMFPN-V5/BLA cells demonstrated a marginal ability to inhibit hepcidin induced internalisation of FPN [143]. A small molecule screen conducted by Ross et al. also discovered that sulfonyl can inhibit RhoG-hepcidin at concentrations of $141 \mathrm{nM}$ by interacting with cysteine 326 [143]. Further, Sulfonyl quinoxaline has been shown to form an irreversible complex with FPN and demonstrates some affinity of towards the mature FPN [143].

\section{Current Therapeutic Treatments for Increasing Hepcidin}

\subsection{Hepcidin Agonists}

Minihepcidins containing the first 7-9 N-terminal amino acids of hepcidin have been shown to function using a similar mechanism to full length hepcidin, reducing FPN and iron levels in mouse livers [144]. Minihepcidin molecules are rationally designed peptides generated via mutagenesis of both the hepcidin amino acid sequence discussed above and ferroportin's hepcidin binding motif [144]. The minihepcidin, PR73 caused hypoferremia and increased the survival of Hepcidin-/- mice when infected with Vibrio vulnificus. In contrast, a significant number of untreated Hepcidin ${ }^{-1}$ mice died due to infection [117]. Similarly, a single dose of PR65 in iron overloaded Hepcidin ${ }^{-1}$ mice resulted in an $85 \%$ reduction in serum iron levels after a $24 \mathrm{~h}$ period, with iron levels returning to baseline after $48 \mathrm{~h}$ [118]. 
In an attempt to reduce the cost of generating minihepcidins resulting from the use of non-natural amino acids, Chua et al. developed a series of cyclic minihepcidins with mHS17 and mHS26 displaying the highest ferroportin binding affinity [119]. While the cost to manufacture these cyclic minihepcidins is significantly lower than PR73 (67\% and 76\% decrease in cost, respectively), both displayed a 10-fold decrease in half maximal effective concentration $\left(\mathrm{EC}_{50}\right)$ when compared to PR73 in vitro [119]. In addition, in vivo neither mHS17 nor mHS26 displayed any effect on serum iron levels [119].

Casu et al. recently developed two minihepcidins molecules, M004 and M009 [120]. M004 was shown to decrease FPN expression and serum iron over a 24-h period. However, it was discontinued due to the higher stability of M009. In a $\beta$-thalassaemia mouse model, $H b b^{(t h 3 /+)}$ mice, treatment with low dose M009 resulted in decreased transferrin saturation and normalised red blood cell counts while high dose M009 resulted in a worsening of anaemia [120]. In a phase one study another mini-hepcidin, LJPC-401 resulted in a dose-dependent reduction in serum iron in 15 patients with iron overload [129].

Therapeutic targeting of other molecules involved in the downregulation of hepcidin production has also been tried. TMPRSS6 reduces hepcidin expression via reduced membrane HJV. Inhibiting TMPRSS6 expression has thus been an active area of research. RNAi containing lipid nanoparticles (LNP) targeting TMPRSS6 have been shown to decrease TMPRSS6 mRNA while simultaneously increasing hepcidin expression [130]. Treatment with two anti-sense oligonucleotides (ASO) (TMPRSS6-ASO\#1 and TMPRSS6-ASO\#2) resulted in a 90\% reduction in TMPRSS6 mRNA with a subsequent 4-5-fold increase in hepcidin mRNA expression [145]. The effectiveness of TMPRSS6-ASOs were further validated in a 2015 study by Gou et al., where they found 30\% reduction in transferrin saturation and $40-50 \%$ reduction in liver iron levels in a $\beta$-thalassemia mouse model [121]. In addition, sustained dosing of TMPRSS6-ASO in a monkey model reduced serum iron levels [121]. Aghajan et al. developed TMPRSS6-ASO conjugated to triantennary N-acetyl galactosamine (GalNAc). When compared with the unconjugated ASO, the GalNAc-ASO demonstrated a 10-fold improvement in $\mathrm{EC}_{50}$ and resulted in a similar decrease in serum iron [122]. Recently, Schmidt et al. conjugated siRNA conjugated to GalNAc, which resulted in a two-fold increase in hepcidin expression in splenectomised $\mathrm{Hbb}^{(t h 3 /+)}$ mice [123].

Based upon the success of TMPRSS6-ASOs, Casu et al. performed a six-week study on $\mathrm{Hbb}^{(\text {th } 3 /+)}$ mice treated with TMPRSS6-ASOs or TMPRSS6-ASOs in combination with deferiprone (DFP) [146]. As expected, administration of TMPRSS6-ASO either alone or with DFP increased hepcidin levels, while DFP alone did not. TMPRSS6-ASO and DFP treatment displayed a synergistic effect on liver iron content [146]. The success of inhibiting TMPRSS6 with concomitant chelator treatment was also shown by Schimdt et al. using TMPRSS6 RNAi and DFP to reduce secondary iron overload in $\mathrm{Hbb}^{(\text {th }} 3 /+$ ) mice [147]. These positive results have formed the basis for a clinical trial that commenced in 2017 [122].

\subsection{Hepcidin Analogues}

Mature hepcidin contains eight highly conserved disulphide bonds at positions cysteine (Cys) seven and Cys23, Cys10 and Cys13, Cys11 and Cys19, and Cys14 and Cys22 [114]. Recently, Pandur et al. created a hepcidin analogue that displayed similar FPN binding and ubiquitination characteristics as wild type (WT) hepcidin [114]. Using site directed mutagenesis, Pandur et al. probed the effect of replacing each cysteine residue with serine residues on the binding and activity of the mature peptide. They revealed that cysteine 19 is not essential, as the mutation still retained full biologic activity [114]. In addition, intracellular iron levels increased within cells treated with either WT hepcidin or the Cys19 mutant, a result not seen in any other cysteine mutants. Lastly, Pandur et al. demonstrated using ELISA that over a 96-h period the cys19ser mutant hepcidin remained in a higher active concentration when incubated in media compared to WT hepcidin [114]. As mentioned previously minihepcidins are costly to produce due to unnatural amino acids and C-terminal lipid tails. Thus, the lack of unnatural amino acids and C-terminal lipid tail should make this hepcidin mutant a promising therapeutic candidate. 


\subsection{Small Molecule Hepcidin Agonists}

Several phytoestrogens (naringenin, quercetin and resveratrol) found in fruits and vegetables have been shown to increase hepcidin expression through interactions with Nrf2 and an antioxidant response element located within the hepcidin promoter within a rat model [124]. HepG2 cells treated for six hours with naringenin, quercetin and resveratrol displayed an increase in hepcidin expression of approximately 2.5-, 3.5- and 3.5-fold, respectively [124]. In rats treated with quercetin, hepcidin expression was increased by 500 -fold, wWhile naringenin and resveratrol increased hepcidin expression approximately 4 - and 12.5-fold, respectively [124].

Mleczko-Sanecka et al. employed siRNA and small molecule screens, which highlighted the role of Ras GTPase (RAS)/RAF proto-oncogene serine/threonine-protein kinase (RAF) and phosphoinositide-3 kinase (PI3K) pathway inhibitors (sorafenib, wortmannin and rapamycin) as inducers of hepcidin mRNA in Hep3B cells [115]. Another screen of 22 water-soluble and fat-soluble vitamins conducted by Zhang et al. identified adenine (vitamin B4) as a potent activator of hepcidin which acts through the BMP6/SMAD pathway [125]. HUH7 cells treated with $50 \mu \mathrm{M}$ adenine for $12 \mathrm{~h}$ displayed an increase of 4.6-fold in hepcidin expression. When iron loaded C57/BL6 mice were fed a diet containing $0.2 \%(w / w)$ adenine for up to 10 days, hepcidin mRNA expression was increased with subsequent reductions in serum iron and liver iron and transferrin saturation [125].

Recently, a Kuntiz-type hepatocyte growth factor activator inhibitor two (HAI-2) that targets and inhibits the proteolytic activity of TMPRSS6 was discovered [148]. HAI-2 prevented HJV cleavage by forming a series of hydrogen bonds and a disulphide bond within the TMPRSS6 active site which prevents hepcidin downregulation [148].

Zhen et al. found that the isoflavone, genistein was able to increase hepcidin expression levels in zebrafish embryos, while the inactive form of genistein, genistin and other related compounds diazdein (isoflavone) and apigenin (flavone) had no effect on hepcidin transcription [126]. This hepcidin induction requires both BMP/SMAD and JAK/STAT3 pathways as BMP-RE and STAT binding motifs are critical for proper genistein activity [126]. However, genistiein appears to also act through BMP-RE independent mechanisms as HepG2 cells treated with both dorsmorphin and genistein displayed increased hepcidin expression levels over dorsomorphin treated cells alone. Unfortunately, genistein was found to inhibit cell proliferation and increase STAT3 phosphorylation in high concentrations $(25-100 \mu \mathrm{M})$. It also increases apoptosis at $200 \mu \mathrm{M}$ [149]. In addition, Chau et al. found that transgenic adenocarcinoma mouse prostate (TRAMP) mice treated with $250 \mathrm{mg} / \mathrm{kg}$ of genistein had a three-fold increase in prostate weight due to increases in telomerase activity [150].

Gaun, V. et al. employed a small molecule library screen to determine modulators of hepcidin expression. This screen of over 10,000 molecules using HepG2 cells expressing the luciferase gene under the control of the hepcidin promoter, identified 20 agonists and one antagonist [127]. The activity of these 21 molecules was then screened using real time PCR. Sixteen of the identified agonists increased both luciferase and endogenous hepcidin expression [127]. Meanwhile, the lone antagonist increased hepcidin transcription levels despite decreasing hepcidin-luciferase activity. The majority of chemicals identified (six) were shown to increase hepcidin expression through the BMP6 pathway, while only four chemicals increased hepcidin expression through the STAT3 pathway and the remaining six chemicals were found to work through both the BMP6 and STAT3 pathway [127]. Of note, ipriflavone and vorinostat were found to elicit an effect on hepcidin expression at concentrations 10-fold lower than those required for genistein [127]. Due to the higher potency of ipriflavone, C57BL/6 male mice were treated with increasing concentrations of ipriflavone for 50 days to determine changes in iron content, hepcidin and ferroportin expression levels [151]. The treated mice displayed a significant reduction in liver iron content of approximately $40 \%$ compared to control untreated mice. Ipriflavone also resulted in an approximate two-fold increase in hepcidin mRNA levels [151]. The hepcidin inducing effect of vorinstat was further confirmed in another study using HUH7 and primary hepatocytes from both human and mice origin [100]. Unfortunately, these effects were not seen in a C57BL/6 mouse model [100]. Another high-throughput screen conducted in zebrafish by Li et al. discovered 
three steroid molecules, namely epitiostanol, progesterone, and mifepristone, which increase hepcidin expression [116]. These molecules were found to activate hepcidin synthesis through the progesterone receptor membrane component 1 (PGRMC1) [116]. Zhang et al. in 2016 employed a natural product screen using traditional Chinese herbal medicinal plants that identified icariin as an inducer of hepcidin expression in HepG2 and Hepa 1-6 cells as well as in wild-type ICR mice [128]. Icariin was found to interact with the hepcidin regulatory pathway through increased phosphorylation of both STAT3 and Smad1/5/8 [128]. Similar results were seen for icariin analogues epimedin A, B and C when administered to mice, with epimedin $\mathrm{C}$ demonstrating the most significant increase in expression. A second compound berberine was also found to increase hepcidin expression in cell lines. However, berberine failed to increase hepcidin expression in vivo [128].

\section{Conclusion}

The important biological role iron plays in health and disease is exemplified by the myriad of therapeutics currently under development for the regulation of hepcidin and ferroportin. Most promisingly, some of these drug candidates are currently undergoing clinical trials, e.g., roxadustat, which has recently completed phase three trials. However, many of these developing treatments must still overcome significant challenges before they can be used as therapeutic agents. For instance, RNAi technologies still require improvements in design to avoid off-target interactions, increased stability to enable an appropriate half-life for action and a compatible delivery system for proper localisation within the body [152]. In addition, many of the aforementioned SMAD and STAT therapeutics lack the specificity to target only the pathways involved with hepcidin regulation [2,100]. Continued research into the molecular mechanism of the hepcidin/ferroportin axis will likely provide additional targets which may overcome the abovementioned limitations of the current lot of in development therapeutic treatments.

Funding: ZH is supported by a QUT Postgraduate Research Award. This work was supported in part by Project Grants (APP1082224 and APP1100088) from the National Health and Medical Research Council (NHMRC) of Australia to VNS. VNS is the recipient of an NHMRC Senior Research Fellowship (APP1118888).

Acknowledgments: The authors thank Eriza Secondes for assistance with generation of the figures in this manuscript.

Conflicts of Interest: The authors declare no conflict of interest.

\section{References}

1. Liu, J.; Sun, B.; Yin, H.; Liu, S. Hepcidin: A promising therapeutic target for iron disorders: A systematic review. Medicine 2016, 95, e3150. [CrossRef]

2. Sebastiani, G.; Wilkinson, N.; Pantopoulos, K. Pharmacological targeting of the hepcidin/ferroportin axis. Front. Pharmacol. 2016, 7, 160. [CrossRef] [PubMed]

3. Papanikolaou, G.; Pantopoulos, K. Systemic iron homeostasis and erythropoiesis. IUBMB Life 2017, 69, 399-413. [CrossRef] [PubMed]

4. Papanikolaou, G.; Pantopoulos, K. Iron metabolism and toxicity. Toxicol. Appl. Pharmacol. 2005, 202, $199-211$. [CrossRef] [PubMed]

5. Muckenthaler, M.U.; Rivella, S.; Hentze, M.W.; Galy, B. A red carpet for iron metabolism. Cell 2017, 168, 344-361. [CrossRef]

6. Drakesmith, H.; Nemeth, E.; Ganz, T. Ironing out ferroportin. Cell Metab. 2015, 22, 777-787. [CrossRef]

7. Park, C.H.; Valore, E.V.; Waring, A.J.; Ganz, T. Hepcidin, a urinary antimicrobial peptide synthesized in the liver. J. Biol. Chem. 2001, 276, 7806-7810. [CrossRef]

8. Nemeth, E.; Valore, E.V.; Territo, M.; Schiller, G.; Lichtenstein, A.; Ganz, T. Hepcidin, a putative mediator of anemia of inflammation, is a type II acute-phase protein. Blood 2003, 101, 2461-2463. [CrossRef]

9. Krause, A.; Sillard, R.; Kleemeier, B.; Kluver, E.; Maronde, E.; Conejo-Garcia, J.R.; Forssmann, W.G.; Schulz-Knappe, P.; Nehls, M.C.; Wattler, F.; et al. Isolation and biochemical characterization of LEAP-2, a novel blood peptide expressed in the liver. Protein Sci. 2003, 12, 143-152. [CrossRef] 
10. Valore, E.V.; Ganz, T. Posttranslational processing of hepcidin in human hepatocytes is mediated by the prohormone convertase furin. Blood Cells Mol. Dis. 2008, 40, 132-138. [CrossRef]

11. Nemeth, E.; Preza, G.C.; Jung, C.L.; Kaplan, J.; Waring, A.J.; Ganz, T. The N-terminus of hepcidin is essential for its interaction with ferroportin: Structure-function study. Blood 2006, 107, 328-333. [CrossRef] [PubMed]

12. Ganz, T. Systemic iron homeostasis. Physiol. Rev. 2013, 93, 1721-1741. [CrossRef] [PubMed]

13. Canali, S.; Zumbrennen-Bullough, K.B.; Core, A.B.; Wang, C.Y.; Nairz, M.; Bouley, R.; Swirski, F.K.; Babitt, J.L. Endothelial cells produce bone morphogenetic protein 6 required for iron homeostasis in mice. Blood 2017, 129, 405-414. [CrossRef] [PubMed]

14. Andriopoulos, B.; Corradini, E.; Xia, Y.; Faasse, S.A.; Chen, S.Z.; Grgurevic, L.; Knutson, M.D.; Pietrangelo, A.; Vukicevic, S.; Lin, H.Y.; et al. BMP6 is a key endogenous regulator of hepcidin expression and iron metabolism. Nat. Genet. 2009, 41, 482-487. [CrossRef]

15. Meynard, D.; Kautz, L.; Darnaud, V.; Canonne-Hergaux, F.; Coppin, H.; Roth, M.P. Lack of the bone morphogenetic protein BMP6 induces massive iron overload. Nat. Genet. 2009, 41, 478-481. [CrossRef]

16. Truksa, J.; Peng, H.; Lee, P.; Beutler, E. Bone morphogenetic proteins 2, 4, and 9 stimulate murine hepcidin 1 expression independently of Hfe, transferrin receptor 2 (Tfr2), and IL-6. Proc. Natl. Acad. Sci. USA 2006, 103, 10289-10293. [CrossRef]

17. Canali, S.; Wang, C.-Y.; Zumbrennen-Bullough, K.B.; Bayer, A.; Babitt, J.L. Bone morphogenetic protein 2 controls iron homeostasis in mice independent of Bmp6. Am. J. Hematol. 2017, 92, 1204-1213. [CrossRef]

18. Babitt, J.L.; Huang, F.W.; Wrighting, D.M.; Xia, Y.; Sidis, Y.; Samad, T.A.; Campagna, J.A.; Chung, R.T.; Schneyer, A.L.; Woolf, C.J.; et al. Bone morphogenetic protein signaling by hemojuvelin regulates hepcidin expression. Nat. Genet. 2006, 38, 531-539. [CrossRef]

19. Steinbicker, A.U.; Bartnikas, T.B.; Lohmeyer, L.K.; Leyton, P.; Mayeur, C.; Kao, S.M.; Pappas, A.E.; Peterson, R.T.; Bloch, D.B.; Yu, P.B.; et al. Perturbation of hepcidin expression by BMP type I receptor deletion induces iron overload in mice. Blood 2011, 118, 4224-4230. [CrossRef]

20. Mayeur, C.; Leyton, P.A.; Kolodziej, S.A.; Yu, B.L.; Bloch, K.D. BMP type II receptors have redundant roles in the regulation of hepatic hepcidin gene expression and iron metabolism. Blood 2014, 124, 2116-2123. [CrossRef]

21. Miyazono, K.; Kamiya, Y.; Morikawa, M. Bone morphogenetic protein receptors and signal transduction. J. Biochem. 2010, 147, 35-51. [CrossRef] [PubMed]

22. Wang, R.H.; Li, C.; Xu, X.; Zheng, Y.; Xiao, C.; Zerfas, P.; Cooperman, S.; Eckhaus, M.; Rouault, T.; Mishra, L.; et al. A role of SMAD4 in iron metabolism through the positive regulation of hepcidin expression. Cell Metab. 2005, 2, 399-409. [CrossRef] [PubMed]

23. Truksa, J.; Lee, P.; Beutler, E. Two BMP responsive elements, STAT, and bZIP/HNF4/COUP motifs of the hepcidin promoter are critical for BMP, SMAD1, and HJV responsiveness. Blood 2009, 113, 688-695. [CrossRef] [PubMed]

24. An, P.; Wang, H.; Wu, Q.; Wang, J.; Xia, Z.; He, X.; Wang, X.; Chen, Y.; Min, J.; Wang, F. Smad7 deficiency decreases iron and haemoglobin through hepcidin up-regulation by multilayer compensatory mechanisms. J. Cell. Mol. Med. 2018, 22, 3035-3044. [CrossRef]

25. Meynard, D.; Vaja, V.; Sun, C.C.; Corradini, E.; Chen, S.; Lopez-Otin, C.; Grgurevic, L.; Hong, C.C.; Stirnberg, M.; Gutschow, M.; et al. Regulation of TMPRSS6 by BMP6 and iron in human cells and mice. Blood 2011, 118, 747-756. [CrossRef]

26. Silvestri, L.; Pagani, A.; Nai, A.; De Domenico, I.; Kaplan, J.; Camaschella, C. The serine protease matriptase-2 (TMPRSS6) inhibits hepcidin activation by cleaving membrane hemojuvelin. Cell Metab. 2008, 8, 502-511. [CrossRef]

27. Lin, L.; Goldberg, Y.P.; Ganz, T. Competitive regulation of hepcidin mRNA by soluble and cell-associated hemojuvelin. Blood 2005, 106, 2884-2889. [CrossRef]

28. Verga Falzacappa, M.V.; Vujic Spasic, M.; Kessler, R.; Stolte, J.; Hentze, M.W.; Muckenthaler, M.U. STAT3 mediates hepatic hepcidin expression and its inflammatory stimulation. Blood 2007, 109, 353-358. [CrossRef]

29. Ganz, T.; Nemeth, E. Iron homeostasis in host defence and inflammation. Nat. Rev. Immunol. 2015, 15, 500-510. [CrossRef] 
30. Canali, S.; Core, A.B.; Zumbrennen-Bullough, K.B.; Merkulova, M.; Wang, C.Y.; Schneyer, A.L.; Pietrangelo, A.; Babitt, J.L. Activin B induces noncanonical SMAD1/5/8 signaling via BMP type I receptors in hepatocytes: Evidence for a role in hepcidin induction by inflammation in male mice. Endocrinology 2016, 157, 1146-1162. [CrossRef]

31. Kanamori, Y.; Sugiyama, M.; Hashimoto, O.; Murakami, M.; Matsui, T.; Funaba, M. Regulation of hepcidin expression by inflammation-induced activin B. Sci. Rep. 2016, 6, 38702. [CrossRef] [PubMed]

32. Kaelin, W.G., Jr.; Ratcliffe, P.J. Oxygen sensing by metazoans: The central role of the HIF hydroxylase pathway. Mol. Cell 2008, 30, 393-402. [CrossRef] [PubMed]

33. Kapitsinou, P.P.; Liu, Q.; Unger, T.L.; Rha, J.; Davidoff, O.; Keith, B.; Epstein, J.A.; Moores, S.L.; Erickson-Miller, C.L.; Haase, V.H. Hepatic HIF-2 regulates erythropoietic responses to hypoxia in renal anemia. Blood 2010, 116, 3039-3048. [CrossRef] [PubMed]

34. Morita, M.; Ohneda, O.; Yamashita, T.; Takahashi, S.; Suzuki, N.; Nakajima, O.; Kawauchi, S.; Ema, M.; Shibahara, S.; Udono, T.; et al. HLF/HIF-2alpha is a key factor in retinopathy of prematurity in association with erythropoietin. EMBO J. 2003, 22, 1134-1146. [CrossRef] [PubMed]

35. Liu, Q.; Davidoff, O.; Niss, K.; Haase, V.H. Hypoxia-inducible factor regulates hepcidin via erythropoietin-induced erythropoiesis. J. Clin. Investig. 2012, 122, 4635-4644. [CrossRef]

36. Peyssonnaux, C.; Zinkernagel, A.S.; Schuepbach, R.A.; Rankin, E.; Vaulont, S.; Haase, V.H.; Nizet, V.; Johnson, R.S. Regulation of iron homeostasis by the hypoxia-inducible transcription factors (HIFs). J. Clin. Investig. 2007, 117, 1926-1932. [CrossRef]

37. Volke, M.; Gale, D.P.; Maegdefrau, U.; Schley, G.; Klanke, B.; Bosserhoff, A.K.; Maxwell, P.H.; Eckardt, K.U.; Warnecke, C. Evidence for a lack of a direct transcriptional suppression of the iron regulatory peptide hepcidin by hypoxia-inducible factors. PLoS ONE 2009, 4, e7875. [CrossRef]

38. Silvestri, L.; Pagani, A.; Camaschella, C. Furin-mediated release of soluble hemojuvelin: A new link between hypoxia and iron homeostasis. Blood 2008, 111, 924-931. [CrossRef]

39. Maurer, E.; Gutschow, M.; Stirnberg, M. Matriptase-2 (TMPRSS6) is directly up-regulated by hypoxia inducible factor-1: Identification of a hypoxia-responsive element in the TMPRSS6 promoter region. Biol. Chem. 2012, 393, 535-540. [CrossRef]

40. Lakhal, S.; Schodel, J.; Townsend, A.R.; Pugh, C.W.; Ratcliffe, P.J.; Mole, D.R. Regulation of type II transmembrane serine proteinase TMPRSS6 by hypoxia-inducible factors: New link between hypoxia signaling and iron homeostasis. J. Biol. Chem. 2011, 286, 4090-4097. [CrossRef]

41. Pasricha, S.R.; McHugh, K.; Drakesmith, H. Regulation of hepcidin by erythropoiesis: The story so far. Annu. Rev. Nutr. 2016, 36, 417-434. [CrossRef] [PubMed]

42. Tanno, T.; Bhanu, N.V.; Oneal, P.A.; Goh, S.H.; Staker, P.; Lee, Y.T.; Moroney, J.W.; Reed, C.H.; Luban, N.L.; Wang, R.H.; et al. High levels of GDF15 in thalassemia suppress expression of the iron regulatory protein hepcidin. Nat. Med. 2007, 13, 1096-1101. [CrossRef]

43. Tanno, T.; Porayette, P.; Sripichai, O.; Noh, S.J.; Byrnes, C.; Bhupatiraju, A.; Lee, Y.T.; Goodnough, J.B.; Harandi, O.; Ganz, T.; et al. Identification of TWSG1 as a second novel erythroid regulator of hepcidin expression in murine and human cells. Blood 2009, 114, 181-186. [CrossRef] [PubMed]

44. Casanovas, G.; Vujic Spasic, M.; Casu, C.; Rivella, S.; Strelau, J.; Unsicker, K.; Muckenthaler, M.U. The murine growth differentiation factor 15 is not essential for systemic iron homeostasis in phlebotomized mice. Haematologica 2013, 98, 444-447. [CrossRef] [PubMed]

45. Mirciov, C.S.; Wilkins, S.J.; Dunn, L.A.; Anderson, G.J.; Frazer, D.M. Characterization of putative erythroid regulators of hepcidin in mouse models of anemia. PLoS ONE 2017, 12, e0171054. [CrossRef] [PubMed]

46. Kautz, L.; Jung, G.; Du, X.; Gabayan, V.; Chapman, J.; Nasoff, M.; Nemeth, E.; Ganz, T. Erythroferrone contributes to hepcidin suppression and iron overload in a mouse model of beta-thalassemia. Blood 2015, 126, 2031-2037. [CrossRef] [PubMed]

47. Kautz, L.; Jung, G.; Valore, E.V.; Rivella, S.; Nemeth, E.; Ganz, T. Identification of erythroferrone as an erythroid regulator of iron metabolism. Nat. Genet. 2014, 46, 678-684. [CrossRef]

48. Daher, R.; Lefebvre, T.; Puy, H.; Karim, Z. Extrahepatic hepcidin production: The intriguing outcomes of recent years. World J. Clin. Cases 2019, 7, 1926-1936. [CrossRef]

49. Sow, F.B.; Florence, W.C.; Satoskar, A.R.; Schlesinger, L.S.; Zwilling, B.S.; Lafuse, W.P. Expression and localization of hepcidin in macrophages: A role in host defense against tuberculosis. J. Leukoc. Biol. 2007, 82, 934-945. [CrossRef] 
50. Schwarz, P.; Kübler, J.A.M.; Strnad, P.; Müller, K.; Barth, T.F.E.; Gerloff, A.; Feick, P.; Peyssonnaux, C.; Vaulont, S.; Adler, G.; et al. Hepcidin is localised in gastric parietal cells, regulates acid secretion and is induced by Helicobacter pylori infection. Gut 2012, 61, 193-201. [CrossRef]

51. Qian, Z.M.; He, X.; Liang, T.; Wu, K.C.; Yan, Y.C.; Lu, L.N.; Yang, G.; Luo, Q.Q.; Yung, W.H.; Ke, Y. Lipopolysaccharides upregulate hepcidin in neuron via microglia and the IL-6/STAT3 signaling pathway. Mol. Neurobiol. 2014, 50, 811-820. [CrossRef] [PubMed]

52. Urrutia, P.; Aguirre, P.; Esparza, A.; Tapia, V.; Mena, N.P.; Arredondo, M.; Gonzalez-Billault, C.; Nunez, M.T. Inflammation alters the expression of DMT1, FPN1 and hepcidin, and it causes iron accumulation in central nervous system cells. J. Neurochem. 2013, 126, 541-549. [CrossRef] [PubMed]

53. McKie, A.T.; Marciani, P.; Rolfs, A.; Brennan, K.; Wehr, K.; Barrow, D.; Miret, S.; Bomford, A.; Peters, T.J.; Farzaneh, F; i et al. A novel duodenal iron-regulated transporter, IREG1, implicated in the basolateral transfer of iron to the circulation. Mol. Cell 2000, 5, 299-309. [CrossRef]

54. Donovan, A.; Brownlie, A.; Zhou, Y.; Shepard, J.; Pratt, S.J.; Moynihan, J.; Paw, B.H.; Drejer, A.; Barut, B.; Zapata, A.; et al. Positional cloning of zebrafish ferroportin1 identifies a conserved vertebrate iron exporter. Nature 2000, 403, 776-781. [CrossRef] [PubMed]

55. Abboud, S.; Haile, D.J. A novel mammalian iron-regulated protein involved in intracellular iron metabolism. J. Biol. Chem. 2000, 275, 19906-19912. [CrossRef] [PubMed]

56. Qiao, B.; Sugianto, P.; Fung, E.; del-Castillo-Rueda, A.; Moran-Jimenez, M.J.; Ganz, T.; Nemeth, E. Hepcidin-induced endocytosis of ferroportin is dependent on ferroportin ubiquitination. Cell Metab. 2012, 15, 918-924. [CrossRef] [PubMed]

57. Marro, S.; Chiabrando, D.; Messana, E.; Stolte, J.; Turco, E.; Tolosano, E.; Muckenthaler, M.U. Heme controls ferroportin1 (FPN1) transcription involving Bach1, Nrf2 and a MARE/ARE sequence motif at position-7007 of the FPN1 promoter. Haematologica 2010, 95, 1261-1268. [CrossRef]

58. Sangokoya, C.; Doss, J.F.; Chi, J.T. Iron-responsive miR-485-3p regulates cellular iron homeostasis by targeting ferroportin. PLoS Genet. 2013, 9, e1003408. [CrossRef]

59. Galy, B.; Ferring-Appel, D.; Becker, C.; Gretz, N.; Grone, H.J.; Schumann, K.; Hentze, M.W. Iron regulatory proteins control a mucosal block to intestinal iron absorption. Cell Rep. 2013, 3, 844-857. [CrossRef]

60. Nairz, M.; Ferring-Appel, D.; Casarrubea, D.; Sonnweber, T.; Viatte, L.; Schroll, A.; Haschka, D.; Fang, F.C.; Hentze, M.W.; Weiss, G.; et al. Iron regulatory proteins mediate host resistance to salmonella infection. Cell Host Microbe 2015, 18, 254-261. [CrossRef]

61. Agoro, R.; Mura, C. Inflammation-induced up-regulation of hepcidin and down-regulation of ferroportin transcription are dependent on macrophage polarization. Blood Cells Mol. Dis. 2016, 61, 16-25. [CrossRef] [PubMed]

62. Yang, F.; Liu, X.B.; Quinones, M.; Melby, P.C.; Ghio, A.; Haile, D.J. Regulation of reticuloendothelial iron transporter MTP1 (Slc11a3) by inflammation. J. Biol. Chem. 2002, 277, 39786-39791. [CrossRef] [PubMed]

63. Vela, D.; Vela-Gaxha, Z. Differential regulation of hepcidin in cancer and non-cancer tissues and its clinical implications. Exp. Mol. Med. 2018, 50, e436. [CrossRef] [PubMed]

64. Guo, W.; Zhang, S.; Chen, Y.; Zhang, D.; Yuan, L.; Cong, H.; Liu, S. An important role of the hepcidin-ferroportin signaling in affecting tumor growth and metastasis. Acta Biochim. Biophys. Sin. 2015, 47, 703-715. [CrossRef] [PubMed]

65. Pinnix, Z.K.; Miller, L.D.; Wang, W.; D’Agostino, R., Jr.; Kute, T.; Willingham, M.C.; Hatcher, H.; Tesfay, L.; Sui, G.; Di, X.; et al. Ferroportin and iron regulation in breast cancer progression and prognosis. Sci. Transl. Med. 2010, 2, 43ra56. [CrossRef]

66. Zhang, S.; Chen, Y.; Guo, W.; Yuan, L.; Zhang, D.; Xu, Y.; Nemeth, E.; Ganz, T.; Liu, S. Disordered hepcidin-ferroportin signaling promotes breast cancer growth. Cell. Signal. 2014, 26, 2539-2550. [CrossRef]

67. Jiang, X.P.; Elliott, R.L.; Head, J.F. Manipulation of iron transporter genes results in the suppression of human and mouse mammary adenocarcinomas. Anticancer Res. 2010, 30, 759-765.

68. Shan, Z.; Wei, Z.; Shaikh, Z.A. Suppression of ferroportin expression by cadmium stimulates proliferation, EMT, and migration in triple-negative breast cancer cells. Toxicol. Appl. Pharmacol. 2018, 356, 36-43. [CrossRef]

69. Udali, S.; Guarini, P.; Ruzzenente, A.; Ferrarini, A.; Guglielmi, A.; Lotto, V.; Tononi, P.; Pattini, P.; Moruzzi, S.; Campagnaro, T.; et al. DNA methylation and gene expression profiles show novel regulatory pathways in hepatocellular carcinoma. Clin. Epigenet. 2015, 7, 43. [CrossRef] 
70. Tesfay, L.; Clausen, K.A.; Kim, J.W.; Hegde, P.; Wang, X.; Miller, L.D.; Deng, Z.; Blanchette, N.; Arvedson, T.; Miranti, C.K.; et al. Hepcidin regulation in prostate and its disruption in prostate cancer. Cancer Res. 2015, 75, 2254-2263. [CrossRef]

71. Chen, Q.; Wang, L.; Ma, Y.; Wu, X.; Jin, L.; Yu, F. Increased hepcidin expression in non-small cell lung cancer tissue and serum is associated with clinical stage. Thorac. Cancer 2014, 5, 14-24. [CrossRef] [PubMed]

72. Tuhkanen, H.; Hartikainen, J.M.; Soini, Y.; Velasco, G.; Sironen, R.; Nykopp, T.K.; Kataja, V.; Eskelinen, M.; Kosma, V.M.; Mannermaa, A. Matriptase-2 gene (TMPRSS6) variants associate with breast cancer survival, and reduced expression is related to triple-negative breast cancer. Int. J. Cancer 2013, 133, 2334-2340. [CrossRef] [PubMed]

73. Rogers, J.T.; Randall, J.D.; Cahill, C.M.; Eder, P.S.; Huang, X.; Gunshin, H.; Leiter, L.; McPhee, J.; Sarang, S.S.; Utsuki, T.; et al. An iron-responsive element type II in the $5^{\prime}$-untranslated region of the Alzheimer's amyloid precursor protein transcript. J. Biol. Chem. 2002, 277, 45518-45528. [CrossRef] [PubMed]

74. Wong, B.X.; Tsatsanis, A.; Lim, L.Q.; Adlard, P.A.; Bush, A.I.; Duce, J.A. Beta-amyloid precursor protein does not possess ferroxidase activity but does stabilize the cell surface ferrous iron exporter ferroportin. PLoS ONE 2014, 9, e114174. [CrossRef] [PubMed]

75. Belaidi, A.A.; Bush, A.I. Iron neurochemistry in Alzheimer's disease and Parkinson's disease: Targets for therapeutics. J. Neurochem. 2016, 139 (Suppl. 1), 179-197. [CrossRef]

76. Wang, J.Y.; Zhuang, Q.Q.; Zhu, L.B.; Zhu, H.; Li, T.; Li, R.; Chen, S.F.; Huang, C.P.; Zhang, X.; Zhu, J.H. Meta-analysis of brain iron levels of Parkinson's disease patients determined by postmortem and MRI measurements. Sci. Rep. 2016, 6, 36669. [CrossRef]

77. Bacon, B.R.; Adams, P.C.; Kowdley, K.V.; Powell, L.W.; Tavill, A.S.; American Association for the Study of Liver Diseases. Diagnosis and management of hemochromatosis: 2011 practice guideline by the American Association for the Study of Liver Diseases. Hepatology 2011, 54, 328-343. [CrossRef]

78. European Association for the Study of the Liver. EASL clinical practice guidelines for HFE hemochromatosis. J. Hepatol. 2010, 53, 3-22. [CrossRef]

79. Katsarou, A.; Pantopoulos, K. Hepcidin therapeutics. Pharmaceuticals 2018, 11, 127. [CrossRef]

80. Brissot, P. Optimizing the diagnosis and the treatment of iron overload diseases. Expert Rev. Gastroenterol. Hepatol. 2016, 10, 359-370. [CrossRef]

81. Vadhan-Raj, S.; Abonour, R.; Goldman, J.W.; Smith, D.A.; Slapak, C.A.; Ilaria, R.L., Jr.; Tiu, R.V.; Wang, X.; Callies, S.; Cox, J.; et al. A first-in-human phase 1 study of a hepcidin monoclonal antibody, LY2787106, in cancer-associated anemia. J. Hematol. Oncol. 2017, 10, 73. [CrossRef] [PubMed]

82. Sasu, B.J.; Cooke, K.S.; Arvedson, T.L.; Plewa, C.; Ellison, A.R.; Sheng, J.; Winters, A.; Juan, T.; Li, H.Y.; Begley, C.G.; et al. Antihepcidin antibody treatment modulates iron metabolism and is effective in a mouse model of inflammation-induced anemia. Blood 2010, 115, 3616-3624. [CrossRef] [PubMed]

83. Alnylam Pharmaceuticals. Targeting the Hepcidin Pathway with RNAi Therapeutics for the Treatment of Anemia. Available online: http://www.alnylam.com/web/assets/HPN-ALNY-ASH2011-Anemia.pdf (accessed on 1 November 2019).

84. Schlehuber, S.; Skerra, A. Lipocalins in drug discovery: From natural ligand-binding proteins to 'anticalins'. Drug Discov. Today 2005, 10, 23-33. [CrossRef]

85. Pieris Pharmaceuticals. PRS-080: Best-in-Class Hepcidin Antagonist for Anemia. Available online: http: //www.pieris.com/pipeline/anemia-and-other-disease-areas/prs-080 (accessed on 17 April 2018).

86. Hohlbaum, A.M.; Gille, H.; Trentmann, S.; Kolodziejczyk, M.; Rattenstetter, B.; Laarakkers, C.M.; Katzmann, G.; Christian, H.J.; Andersen, N.; Allersdorfer, A.; et al. Sustained plasma hepcidin suppression and iron elevation by Anticalin-derived hepcidin antagonist in cynomolgus monkey. Br. J. Pharmacol. 2018, 175, 1054-1065. [CrossRef] [PubMed]

87. Moebius, U.; Feuerer, W.; Fenzl, E.; van Swelm, R.; Swinkels, D.W.; Hohlbaum, A. A phase I study investigating the safety, tolerability, pharmacokinetics and pharmacodynamic activity of the hepcidin antagonist PRS-080\#022. Results from a randomized, placebo controlled, double-blind study following single administration to healthy subjects. Blood 2015, 126, 536.

88. Renders, L.; Budde, K.; Rosenberger, C.; van Swelm, R.; Swinkels, D.; Dellanna, F.; Feuerer, W.; Wen, M.; Erley, C.; Bader, B.; et al. First-in-human phase I studies of PRS-080\#22, a hepcidin antagonist, in healthy volunteers and patients with chronic kidney disease undergoing hemodialysis. PLoS ONE 2019, 14, e0212023. [CrossRef] 
89. Angmo, S.; Tripathi, N.; Abbat, S.; Sharma, S.; Singh, S.S.; Halder, A.; Yadav, K.; Shukla, G.; Sandhir, R.; Rishi, V.; et al. Identification of guanosine $5^{\prime}$-diphosphate as potential iron mobilizer: Preventing the hepcidin-ferroportin interaction and modulating the interleukin-6/Stat-3 pathway. Sci. Rep. 2017, 7, 40097. [CrossRef]

90. Pendergrast, P.S.; Marsh, H.N.; Grate, D.; Healy, J.M.; Stanton, M. Nucleic acid aptamers for target validation and therapeutic applications. J. Biomol. Tech. 2005, 16, 224-234.

91. Schwoebel, F.; van Eijk, L.T.; Zboralski, D.; Sell, S.; Buchner, K.; Maasch, C.; Purschke, W.G.; Humphrey, M.; Zollner, S.; Eulberg, D.; et al. The effects of the anti-hepcidin Spiegelmer NOX-H94 on inflammation-induced anemia in cynomolgus monkeys. Blood 2013, 121, 2311-2315. [CrossRef]

92. Boyce, M.; Warrington, S.; Cortezi, B.; Zollner, S.; Vauleon, S.; Swinkels, D.W.; Summo, L.; Schwoebel, F.; Riecke, K. Safety, pharmacokinetics and pharmacodynamics of the anti-hepcidin Spiegelmer lexaptepid pegol in healthy subjects. Br. J. Pharmacol. 2016, 173, 1580-1588. [CrossRef]

93. Poli, M.; Girelli, D.; Campostrini, N.; Maccarinelli, F.; Finazzi, D.; Luscieti, S.; Nai, A.; Arosio, P. Heparin: A potent inhibitor of hepcidin expression in vitro and in vivo. Blood 2011, 117, 997-1004. [CrossRef] [PubMed]

94. Poli, M.; Asperti, M.; Naggi, A.; Campostrini, N.; Girelli, D.; Corbella, M.; Benzi, M.; Besson-Fournier, C.; Coppin, H.; Maccarinelli, F.; et al. Glycol-split nonanticoagulant heparins are inhibitors of hepcidin expression in vitro and in vivo. Blood 2014, 123, 1564-1573. [CrossRef] [PubMed]

95. Poli, M.; Asperti, M.; Ruzzenenti, P.; Mandelli, L.; Campostrini, N.; Martini, G.; Di Somma, M.; Maccarinelli, F.; Girelli, D.; Naggi, A.; et al. Oversulfated heparins with low anticoagulant activity are strong and fast inhibitors of hepcidin expression in vitro and in vivo. Biochem. Pharmacol. 2014, 92, 467-475. [CrossRef] [PubMed]

96. Yu, P.B.; Hong, C.C.; Sachidanandan, C.; Babitt, J.L.; Deng, D.Y.; Hoyng, S.A.; Lin, H.Y.; Bloch, K.D.; Peterson, R.T. Dorsomorphin inhibits BMP signals required for embryogenesis and iron metabolism. Nat. Chem. Biol. 2008, 4, 33-41. [CrossRef]

97. Theurl, I.; Schroll, A.; Sonnweber, T.; Nairz, M.; Theurl, M.; Willenbacher, W.; Eller, K.; Wolf, D.; Seifert, M.; Sun, C.C.; et al. Pharmacologic inhibition of hepcidin expression reverses anemia of chronic inflammation in rats. Blood 2011, 118, 4977-4984. [CrossRef]

98. Asshoff, M.; Petzer, V.; Warr, M.R.; Haschka, D.; Tymoszuk, P.; Demetz, E.; Seifert, M.; Posch, W.; Nairz, M.; Maciejewski, P.; et al. Momelotinib inhibits ACVR1/ALK2, decreases hepcidin production, and ameliorates anemia of chronic disease in rodents. Blood 2017, 129, 1823-1830. [CrossRef]

99. Peterson, P.; Soh, K.K.; Lee, Y.S.; Kim, W.; Whatcott, C.J.; Siddiqui-Jain, A.; Bearss, D.J.; Warner, S.L. ALK2 inhibition via TP-0184 abrogates inflammation-induced hepcidin expression and is a potential therapeutic for anemia of chronic disease. Blood 2015, 126, 273. [CrossRef]

100. Mleczko-Sanecka, K.; da Silva, A.R.; Call, D.; Neves, J.; Schmeer, N.; Damm, G.; Seehofer, D.; Muckenthaler, M.U. Imatinib and spironolactone suppress hepcidin expression. Haematologica 2017, 102, 1173-1184. [CrossRef]

101. Boser, P.; Seemann, D.; Liguori, M.J.; Fan, L.; Huang, L.; Hafner, M.; Popp, A.; Mueller, B.K. Anti-repulsive guidance molecule $\mathrm{C}$ (RGMc) antibodies increases serum iron in rats and cynomolgus monkeys by hepcidin downregulation. AAPS J. 2015, 17, 930-938. [CrossRef]

102. Zhang, S.P.; Wang, Z.; Wang, L.X.; Liu, S.J. AG490: An inhibitor of hepcidin expression in vivo. World J. Gastroenterol. 2011, 17, 5032-5034. [CrossRef]

103. Turkson, J.; Ryan, D.; Kim, J.S.; Zhang, Y.; Chen, Z.; Haura, E.; Laudano, A.; Sebti, S.; Hamilton, A.D.; Jove, R. Phosphotyrosyl peptides block Stat3-mediated DNA binding activity, gene regulation, and cell transformation. J. Biol. Chem. 2001, 276, 45443-45455. [CrossRef] [PubMed]

104. Wang, M.; Xin, H.; Tang, W.; Li, Y.; Zhang, Z.; Fan, L.; Miao, L.; Tan, B.; Wang, X.; Zhu, Y.Z. AMPK serves as a therapeutic target against anemia of inflammation. Antioxid. Redox Signal. 2017, 27, 251-268. [CrossRef] [PubMed]

105. Fukuda, T.; Ueda, K.; Ishiyama, T.; Goto, R.; Muramatsu, S.; Hashimoto, M.; Watanabe, K.; Tanaka, N. Synthesis and SAR studies of 3,6-disubstituted indazole derivatives as potent hepcidin production inhibitors. Bioorg. Med. Chem. Lett. 2017, 27, 2148-2152. [CrossRef] [PubMed]

106. Fukuda, T.; Goto, R.; Kiho, T.; Ueda, K.; Muramatsu, S.; Hashimoto, M.; Aki, A.; Watanabe, K.; Tanaka, N. Discovery of DS79182026: A potent orally active hepcidin production inhibitor. Bioorg. Med. Chem. Lett. 2017, 27, 3716-3722. [CrossRef] 
107. Kurzrock, R.; Voorhees, P.M.; Casper, C.; Furman, R.R.; Fayad, L.; Lonial, S.; Borghaei, H.; Jagannath, S.; Sokol, L.; Usmani, S.Z.; et al. A phase I, open-label study of siltuximab, an anti-IL-6 monoclonal antibody, in patients with B-cell non-Hodgkin lymphoma, multiple myeloma, or Castleman disease. Clin. Cancer Res. 2013, 19, 3659-3670. [CrossRef]

108. Song, S.N.; Tomosugi, N.; Kawabata, H.; Ishikawa, T.; Nishikawa, T.; Yoshizaki, K. Down-regulation of hepcidin resulting from long-term treatment with an anti-IL-6 receptor antibody (tocilizumab) improves anemia of inflammation in multicentric Castleman disease. Blood 2010, 116, 3627-3634. [CrossRef]

109. Pergola, P.E.; Spinowitz, B.S.; Hartman, C.S.; Maroni, B.J.; Haase, V.H. Vadadustat, a novel oral HIF stabilizer, provides effective anemia treatment in nondialysis-dependent chronic kidney disease. Kidney Int. 2016, 90 , 1115-1122. [CrossRef]

110. Besarab, A.; Chernyavskaya, E.; Motylev, I.; Shutov, E.; Kumbar, L.M.; Gurevich, K.; Chan, D.T.; Leong, R.; Poole, L.; Zhong, M.; et al. Roxadustat (FG-4592): Correction of anemia in incident dialysis patients. J. Am. Soc. Nephrol. 2016, 27, 1225-1233. [CrossRef]

111. Brigandi, R.A.; Johnson, B.; Oei, C.; Westerman, M.; Olbina, G.; de Zoysa, J.; Roger, S.D.; Sahay, M.; Cross, N.; McMahon, L.; et al. A novel hypoxia-inducible factor-prolyl hydroxylase inhibitor (GSK1278863) for anemia in CKD: A 28-day, phase 2A randomized trial. Am. J. Kidney Dis. 2016, 67, 861-871. [CrossRef]

112. Fung, E.; Sugianto, P.; Hsu, J.; Damoiseaux, R.; Ganz, T.; Nemeth, E. High-throughput screening of small molecules identifies hepcidin antagonists. Mol. Pharmacol. 2013, 83, 681-690. [CrossRef]

113. Leung, D.D.M.; Luan, P.; Manetta, J.V.; Tang, Y.; Witcher, D.R. Anti-Ferroportin 1 Monoclonal Antibodies and Uses Thereof. U.S. Patent 8,183,346B2, 22 May 2012.

114. Pandur, E.; Fekete, Z.; Tamasi, K.; Grama, L.; Varga, E.; Sipos, K. The C19S substitution enhances the stability of hepcidin while conserving its biological activity. Protein J. 2018, 37, 113-121. [CrossRef] [PubMed]

115. Mleczko-Sanecka, K.; Roche, F.; da Silva, A.R.; Call, D.; D’Alessio, F.; Ragab, A.; Lapinski, P.E.; Ummanni, R.; Korf, U.; Oakes, C.; et al. Unbiased RNAi screen for hepcidin regulators links hepcidin suppression to proliferative Ras/RAF and nutrient-dependent mTOR signaling. Blood 2014, 123, 1574-1585. [CrossRef] [PubMed]

116. Li, X.; Rhee, D.K.; Malhotra, R.; Mayeur, C.; Hurst, L.A.; Ager, E.; Shelton, G.; Kramer, Y.; McCulloh, D.; Keefe, D.; et al. Progesterone receptor membrane component-1 regulates hepcidin biosynthesis. J. Clin. Investig. 2016, 126, 389-401. [CrossRef] [PubMed]

117. Arezes, J.; Jung, G.; Gabayan, V.; Valore, E.; Ruchala, P.; Gulig, P.A.; Ganz, T.; Nemeth, E.; Bulut, Y. Hepcidin-induced hypoferremia is a critical host defense mechanism against the siderophilic bacterium vibrio vulnificus. Cell Host Microbe 2015, 17, 47-57. [CrossRef]

118. Ramos, E.; Ruchala, P.; Goodnough, J.B.; Kautz, L.; Preza, G.C.; Nemeth, E.; Ganz, T. Minihepcidins prevent iron overload in a hepcidin-deficient mouse model of severe hemochromatosis. Blood 2012, 120, 3829-3836. [CrossRef]

119. Chua, K.; Fung, E.; Micewicz, E.D.; Ganz, T.; Nemeth, E.; Ruchala, P. Small cyclic agonists of iron regulatory hormone hepcidin. Bioorg. Med. Chem. Lett. 2015, 25, 4961-4969. [CrossRef]

120. Casu, C.; Oikonomidou, P.R.; Chen, H.Y.; Nandi, V.; Ginzburg, Y.; Prasad, P.; Fleming, R.E.; Shah, Y.M.; Valore, E.V.; Nemeth, E.; et al. Minihepcidin peptides as disease modifiers in mice affected by beta-thalassemia and polycythemia vera. Blood 2016, 128, 265-276. [CrossRef]

121. Guo, S.; Aghajan, M.; Casu, C.; Gardenghi, S.; Booten, S.; Rivella, S.; Monia, B.P. Targeting TMPRSS6 using antisense technology for the treatment of beta-thalassemia. Blood 2015, 126, 753. [CrossRef]

122. Aghajan, M.; Casu, C.; lo Presti, V.; Booten, S.; Monia, B.P.; Rivella, S.; Guo, S. Developing a galnac-conjugated tmprss6 antisense therapy for the treatment of $\beta$-thalassemia. Blood 2016, 128, 1013. [CrossRef]

123. Schmidt, P.J.; Liu, K.; Visner, G.; Fitzgerald, K.; Fishman, S.; Racie, T.; Hettinger, J.L.; Butler, J.S.; Fleming, M.D. RNAi-mediated reduction of hepatic Tmprss6 diminishes anemia and secondary iron overload in a splenectomized mouse model of beta-thalassemia intermedia. Am. J. Hematol. 2018, 93, 745-750. [CrossRef]

124. Bayele, H.K.; Balesaria, S.; Srai, S.K. Phytoestrogens modulate hepcidin expression by Nrf2: Implications for dietary control of iron absorption. Free Radic. Biol. Med. 2015, 89, 1192-1202. [CrossRef] [PubMed]

125. Zhang, Y.; Wang, X.; Wu, Q.; Wang, H.; Zhao, L.; Wang, X.; Mu, M.; Xie, E.; He, X.; Shao, D.; et al. Adenine alleviates iron overload by cAMP/PKA mediated hepatic hepcidin in mice. J. Cell. Physiol. 2018, 233, 7268-7278. [CrossRef] [PubMed] 
126. Zhen, A.W.; Nguyen, N.H.; Gibert, Y.; Motola, S.; Buckett, P.; Wessling-Resnick, M.; Fraenkel, E.; Fraenkel, P.G. The small molecule, genistein, increases hepcidin expression in human hepatocytes. Hepatology 2013, 58, 1315-1325. [CrossRef] [PubMed]

127. Gaun, V.; Patchen, B.; Volovetz, J.; Zhen, A.W.; Andreev, A.; Pollastri, M.P.; Fraenkel, P.G. A chemical screen identifies small molecules that regulate hepcidin expression. Blood Cells Mol. Dis. 2014, 53, 231-240. [CrossRef]

128. Zhang, M.; Liu, J.; Guo, W.; Liu, X.; Liu, S.; Yin, H. Icariin regulates systemic iron metabolism by increasing hepatic hepcidin expression through Stat3 and Smad1/5/8 signaling. Int. J. Mol. Med. 2016, 37, 1379-1388. [CrossRef]

129. Yaeger, D.; Piga, A.; Lal, A.; Kattamis, A.; Salman, S.; Byrnes, B.; Tidmarsh, G.; Chawla, L. A Phase 1, Placebo-Controlled Study to Determine the Safety, Tolerability, and Pharmacokinetics of Escalating Subcutaneous Doses of LJPC-401 (Synthetic Human Hepcidin) in Healthy Adults. Available online: http://lajollapharmaceutical. com/wp-content/uploads/2018/06/EHA_Poster.pdf (accessed on 1 November 2019).

130. Schmidt, P.J.; Toudjarska, I.; Sendamarai, A.K.; Racie, T.; Milstein, S.; Bettencourt, B.R.; Hettinger, J.; Bumcrot, D.; Fleming, M.D. An RNAi therapeutic targeting Tmprss6 decreases iron overload in Hfe(-/-) mice and ameliorates anemia and iron overload in murine beta-thalassemia intermedia. Blood 2013, 121, 1200-1208. [CrossRef]

131. Silvestri, L.; Nai, A.; Dulja, A.; Pagani, A. Hepcidin and the BMP-SMAD pathway: An unexpected liaison. Vitam. Horm. 2019, 110, 71-99. [CrossRef]

132. Boergermann, J.H.; Kopf, J.; Yu, P.B.; Knaus, P. Dorsomorphin and LDN-193189 inhibit BMP-mediated Smad, p38 and Akt signalling in C2C12 cells. Int. J. Biochem. Cell Biol. 2010, 42, 1802-1807. [CrossRef]

133. Wallace, D.F.; Summerville, L.; Subramaniam, V.N. Targeted disruption of the hepatic transferrin receptor 2 gene in mice leads to iron overload. Gastroenterology 2007, 132, 301-310. [CrossRef]

134. Fleming, R.E.; Feng, Q.; Britton, R.S. Knockout mouse models of iron homeostasis. Annu. Rev. Nutr. 2011, 31, 117-137. [CrossRef]

135. Camaschella, C.; Roetto, A.; Calì, A.; De Gobbi, M.; Garozzo, G.; Carella, M.; Majorano, N.; Totaro, A.; Gasparini, P. The gene TFR2 is mutated in a new type of haemochromatosis mapping to 7q22. Nat. Genet. 2000, 25, 14-15. [CrossRef] [PubMed]

136. Kawabata, H. Transferrin and transferrin receptors update. Free Radic. Biol. Med. 2019, 133, 46-54. [CrossRef] [PubMed]

137. Forejtnikovà, H.; Vieillevoye, M.; Zermati, Y.; Lambert, M.; Pellegrino, R.M.; Guihard, S.; Gaudry, M.; Camaschella, C.; Lacombe, C.; Roetto, A.; et al. Transferrin receptor 2 is a component of the erythropoietin receptor complex and is required for efficient erythropoiesis. Blood 2010, 116, 5357-5367. [CrossRef] [PubMed]

138. De Vos, J.; Jourdan, M.; Tarte, K.; Jasmin, C.; Klein, B. JAK2 tyrosine kinase inhibitor tyrphostin AG490 downregulates the mitogen-activated protein kinase (MAPK) and signal transducer and activator of transcription (STAT) pathways and induces apoptosis in myeloma cells. Br. J. Haematol. 2000, 109, 823-828. [CrossRef] [PubMed]

139. Gupta, N.; Wish, J.B. Hypoxia-inducible factor prolyl hydroxylase inhibitors: A potential new treatment for anemia in patients with CKD. Am. J. Kidney Dis. 2017, 69, 815-826. [CrossRef] [PubMed]

140. Chen, N.; Hao, C.; Liu, B.C.; Lin, H.; Wang, C.; Xing, C.; Liang, X.; Jiang, G.; Liu, Z.; Li, X.; et al. Roxadustat treatment for anemia in patients undergoing long-term dialysis. N. Engl. J. Med. 2019, 381, 1011-1022. [CrossRef] [PubMed]

141. Chen, N.; Hao, C.; Peng, X.; Lin, H.; Yin, A.; Hao, L.; Tao, Y.; Liang, X.; Liu, Z.; Xing, C.; et al. Roxadustat for anemia in patients with kidney disease not receiving dialysis. N. Engl. J. Med. 2019, 381, 1001-1010. [CrossRef] [PubMed]

142. Ariazi, J.L.; Duffy, K.J.; Adams, D.F.; Fitch, D.M.; Luo, L.; Pappalardi, M.; Biju, M.; DiFilippo, E.H.; Shaw, T.; Wiggall, K.; et al. Discovery and preclinical characterization of GSK1278863 (daprodustat), a small molecule hypoxia inducible factor-prolyl hydroxylase inhibitor for anemia. J. Pharmacol. Exp. Ther. 2017, 363, 336-347. [CrossRef]

143. Ross, S.L.; Biswas, K.; Rottman, J.; Allen, J.R.; Long, J.; Miranda, L.P.; Winters, A.; Arvedson, T.L. Identification of antibody and small molecule antagonists of ferroportin-hepcidin interaction. Front. Pharmacol. 2017, 8, 838. [CrossRef] 
144. Preza, G.C.; Ruchala, P.; Pinon, R.; Ramos, E.; Qiao, B.; Peralta, M.A.; Sharma, S.; Waring, A.; Ganz, T.; Nemeth, E. Minihepcidins are rationally designed small peptides that mimic hepcidin activity in mice and may be useful for the treatment of iron overload. J. Clin. Investig. 2011, 121, 4880-4888. [CrossRef]

145. Guo, S.; Casu, C.; Gardenghi, S.; Booten, S.; Aghajan, M.; Peralta, R.; Watt, A.; Freier, S.; Monia, B.P.; Rivella, S. Reducing TMPRSS6 ameliorates hemochromatosis and beta-thalassemia in mice. J. Clin. Investig. 2013, 123, 1531-1541. [CrossRef] [PubMed]

146. Casu, C.; Aghajan, M.; Oikonomidou, P.R.; Guo, S.; Monia, B.P.; Rivella, S. Combination of Tmprss6-ASO and the iron chelator deferiprone improves erythropoiesis and reduces iron overload in a mouse model of beta-thalassemia intermedia. Haematologica 2016, 101, e8-e11. [CrossRef] [PubMed]

147. Schmidt, P.J.; Racie, T.; Westerman, M.; Fitzgerald, K.; Butler, J.S.; Fleming, M.D. Combination therapy with a Tmprss6 RNAi-therapeutic and the oral iron chelator deferiprone additively diminishes secondary iron overload in a mouse model of beta-thalassemia intermedia. Am. J. Hematol. 2015, 90, 310-313. [CrossRef] [PubMed]

148. Beckmann, A.M.; Maurer, E.; Lulsdorff, V.; Wilms, A.; Furtmann, N.; Bajorath, J.; Gutschow, M.; Stirnberg, M. En route to new therapeutic options for iron overload diseases: Matriptase-2 as a target for kunitz-type inhibitors. Chembiochem 2016, 17, 595-604. [CrossRef] [PubMed]

149. Jagadeesh, S.; Kyo, S.; Banerjee, P.P. Genistein represses telomerase activity via both transcriptional and posttranslational mechanisms in human prostate cancer cells. Cancer Res. 2006, 66, 2107-2115. [CrossRef] [PubMed]

150. Chau, M.N.; El Touny, L.H.; Jagadeesh, S.; Banerjee, P.P. Physiologically achievable concentrations of genistein enhance telomerase activity in prostate cancer cells via the activation of STAT3. Carcinogenesis 2007, 28, 2282-2290. [CrossRef] [PubMed]

151. Patchen, B.; Koppe, T.; Cheng, A.; Seo, Y.A.; Wessling-Resnick, M.; Fraenkel, P.G. Dietary supplementation with ipriflavone decreases hepatic iron stores in wild type mice. Blood Cells Mol. Dis. 2016, 60, $36-43$. [CrossRef]

152. Akhtar, S.; Benter, I.F. Nonviral delivery of synthetic siRNAs in vivo. J. Clin. Investig. 2007, 117, 3623-3632. [CrossRef]

(C) 2019 by the authors. Licensee MDPI, Basel, Switzerland. This article is an open access article distributed under the terms and conditions of the Creative Commons Attribution (CC BY) license (http://creativecommons.org/licenses/by/4.0/). 


\title{
Deregulation of Hepatic Mek1/2-Erk1/2 Signaling Module in Iron Overload Conditions
}

\author{
Naveen Kumar Tangudu ${ }^{1,+}{ }^{+}$, Nils Buth ${ }^{1,+}$, Pavel Strnad ${ }^{2}$, Ion C. Cirstea ${ }^{1}$ and \\ Maja Vujić Spasić ${ }^{1, *}$ \\ 1 Institute of Comparative Molecular Endocrinology, University of Ulm, Ulm 89081, Germany; \\ naveen.tangudu@uni-ulm.de (N.K.T.); nils.buth@uni-ulm.de (N.B.); ion.cirstea@uni-ulm.de (I.C.C.) \\ 2 Department of Medicine III and IZKF, University Hospital Aachen, Aachen 52074, Germany; \\ pstrnad@ukaachen.de \\ * Correspondence: maja.vujic@uni-ulm.de; Tel.: +49-731-50-32635 \\ + These authors contributed equally to this work.
}

Received: 25 February 2019; Accepted: 5 May 2019; Published: 7 May 2019

\begin{abstract}
The liver, through the production of iron hormone hepcidin, controls body iron levels. High liver iron levels and deregulated hepcidin expression are commonly observed in many liver diseases including highly prevalent genetic iron overload disorders. In spite of a number of breakthrough investigations into the signals that control hepcidin expression, little progress has been made towards investigations into intracellular signaling in the liver under excess of iron. This study examined hepatic signaling pathways underlying acquired and genetic iron overload conditions. Our data demonstrate that hepatic iron overload associates with a decline in the activation of mitogen-activated protein kinase (MAPK)/extracellular signal-regulated kinase (Erk) kinase (Mek1/2) pathway by selectively affecting the phosphorylation of Erk1/2. We propose that Mek1/2-Erk1/2 signaling is uncoupled from iron-Bmp-Smad-mediated hepcidin induction and that it may contribute to a number of liver pathologies in addition to toxic effects of iron. We believe that our findings will advance the understanding of cellular signaling events in the liver during iron overload of different etiologies.
\end{abstract}

Keywords: liver; iron; hepcidin; Mek/Erk; Hfe; Bmp/Smad

\section{Introduction}

In vertebrates, the liver is an essential metabolic hub. It hosts numerous biochemical processes and regulates the storage of many essential nutrients, vitamins, and minerals, as well as their release when there is a physiological need for them. The liver is the main parenchymal iron repository and at the same time the principal organ controlling systemic iron fluxes through the production of the iron hormone hepcidin [1]. High hepatic iron levels are commonly observed in many liver diseases including highly prevalent genetic iron overload disorders (i.e., hereditary hemochromatosis), hematologic disorders (i.e., thalassemia and sickle cell disease), chronic hepatitis $\mathrm{C}$, alcoholic liver disease and non-alcoholic fatty liver disease $1[2,3]$. The main pathological effects of hepatic iron overload include liver fibrosis, cirrhosis and hepatocellular carcinoma.

The sensing of plasma iron levels (i.e., transferrin-bound iron) by liver hepatocytes involves a multiprotein membrane-bound complex consisting of transferrin receptors 1 and 2 (TfR1, TfR2), MHC I-like protein Hfe, hemojuvelin, and the bone morphogenetic protein (Bmp) receptors type I such as activin receptor-like kinase 1 (Alk2/Acvr1) and Alk3/Bmpr1a [4-12]. The Bmp-Alk2/3-Smad1/5/8 cascade is currently considered as the central intracellular relay communicating high plasma iron levels to hepcidin, since mice and patients with genetic disruption in the iron-sensing molecules show impaired Bmp/Smad signaling, low hepcidin expression and consequently develop hepatic iron overload [12-15]. Furthermore, the contribution of the extracellular signal-regulated kinases 1 
and 2 (Erk1/2) to hepcidin regulation was proposed: studies in erythroleukemia K562 cells, exposed to holo-transferrin, demonstrated activation of ERK1/2 and p38 MAP kinases, a process that was dependent on TfR2 [16]; consequently, silencing of TfR2 and Hfe in HepG2 cells and in mice resulted in decreased ERK1/2 signaling and low hepcidin expression in the liver [8,17]. It was proposed that ERK1/2 might act in concert with Bmp-Smad signaling to control hepcidin expression [18].

The mitogen-activated protein kinases (MAPKs) are among the largest protein families in eukaryotes that transduce a variety of extracellular signals to regulate a plethora of cellular responses [19,20]. MAPKs consist of many protein kinases but three major protein kinases are extensively studied: the ERK1/2, activated by broad spectrum of extracellular ligands such as mitogens/growth factors and differentiation signals [21], and c-Jun amino terminal kinases (JNK1/2/3) and p38 kinases that are activated by stress stimuli $[19,20,22]$. MAPK-dependent signal transduction is required to maintain physiological metabolic adaptation while inappropriate MAPK signaling has been increasingly associated with the development of metabolic syndrome [23]. In the liver, the MAPKs play an important role in processes that regulate metabolism [23-26]. In particular, activation of stress-responsive p38MAPKs and JNKs was associated with hepatic metabolic dysfunction [20,23,26-28], whereas constitutive Erk1 or liver-specific Erk2 deficiency in mice was proposed to affect hepatic glucose and lipid metabolism, promote insulin resistance and ER stress $[27,29,30]$.

In this study, we examined the association between hepatic iron overload in mice, caused by parenteral, nutritional and genetic iron overload, and the activity of Mek1/2-Erk1/2 signaling. Our data demonstrate decreased Mek1/2-Erk1/2 signaling output in iron overloaded conditions, suggesting that Mek1/2-Erk1/2 signaling is uncoupled from Bmp-Smad1/5/8-mediated hepcidin induction and that it may play an important role in liver diseases characterized by hepatic iron excess.

\section{Results and Discussion}

\subsection{Classical and Stress-Induced MAPKs Activation in Iron-Loaded Livers}

The aim of this study was to investigate the activity of intracellular signaling pathways in the livers under excessive iron overload. To this end, we used our previously established mouse model of parenteral iron overload, which is characterized by severe hepatic iron overload, high circulating iron levels, and increased hepcidin mRNA expression [15]. We measured the phosphorylation status of nine intracellular proteins including Mek1 (Ser217/Ser221) and Erk1/2 (Thr202/Tyr204, Thr185/Tyr187), as classical MAPK backbone components, stress-responsive MAPKs, such as JNK (Thr183/Tyr185) and p38 MAPK (Thr180/Tyr182), and effector molecules of MAPKs including p90 RSK (Ser380), Stat3 (Ser727), ATF-2 (Thr71), HSP27 (Ser78), and p53 (Ser15), using Bio-Plex Pro Cell Signaling MAPK Panel 9-plex (BioRad Laboratories, Germany). This analysis revealed a decrease in the phosphorylation levels of Mek1 and p90 RSK in iron-loaded livers, and only marginally in case of Stat3 $(p<0.0571)$; similarly, the levels of pErk1/2 showed a trend towards a decrease however the data were under the level of statistical significance (Figure 1). The levels of pJNK, p38MAPK, pHSP27, p53, and pATF-2 showed no statistically significant differences (Figure 1). 

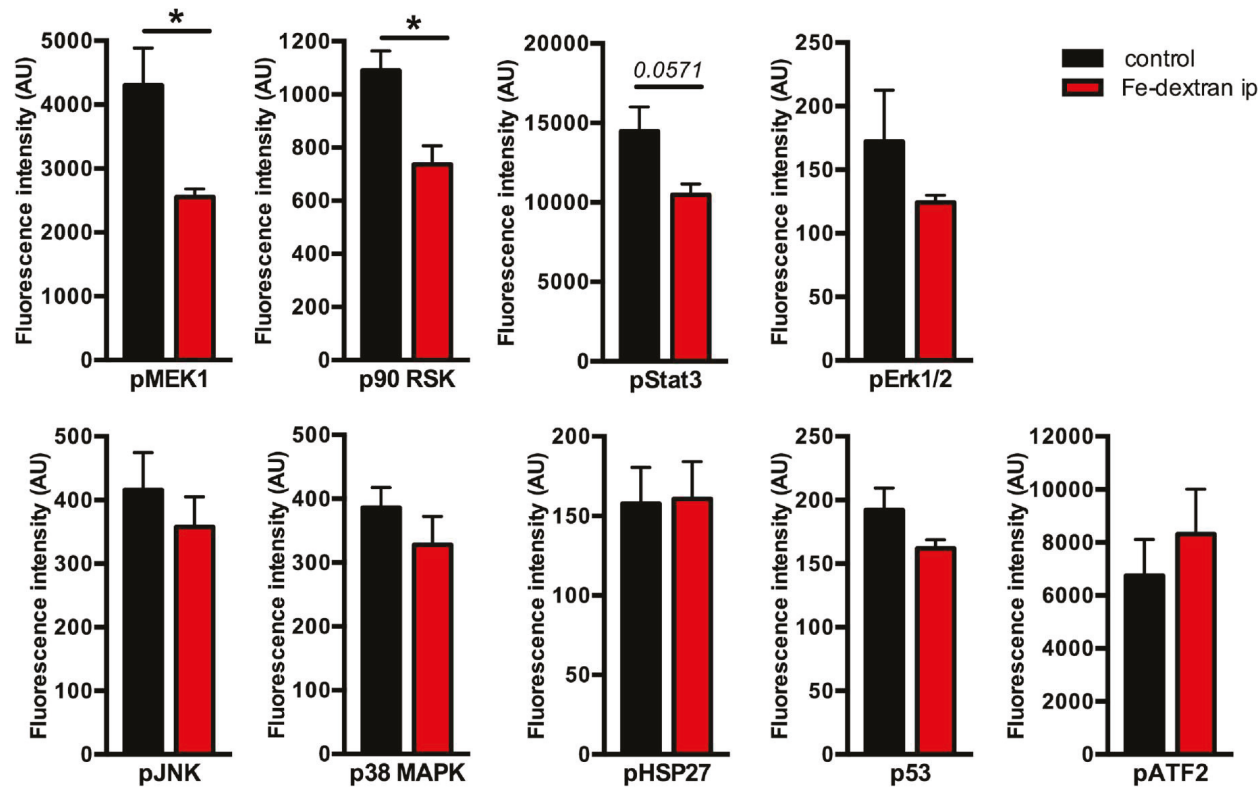

Figure 1. Identification of activated proteins in iron overloaded livers by Bio-Plex Pro Cell Signaling MAPK Panel 9-plex. Phosphorylation status of nine intracellular phosphoproteins was measured in the livers of iron-dextran injected mice and compared to controls. Data were analyzed using GraphPad Prism software and results are shown as mean \pm SEM (standard error of mean). For the statistical analysis, a nonparametric distribution and the unpaired Mann-Whitney U Test were used. * $p$-values < 0.05; AU: arbitrary units; $\mathrm{n}=4 ; 4$ per group.

Based on these results, we postulated that the presence of hepatic iron overload might associate with selective impairment of the Mek1/2-Erk1/2 pathway and its downstream pStat 3 and pp90 RSK targets. This idea is supported by recent investigations showing selective activation of JNK and the p38 MAPK signaling activity under cellular iron depletion [31]. Moreover, in response to growth factors, Erk1/2, but not JNK or p38, specifically phosphorylate Stat3 at Ser727, which is also stimulated by interleukine- 6 cytokine, however, in contrast to growth factors, the latter process occurs independent of Erk1/2 [32].

\subsection{Association of Mitogen-activated Protein Kinases (MAPK) Activity with Hepatic Iron Overload}

To test the above hypothesis we evaluated phosphorylation levels of Mek1/2, Erk1/2, Stat3 and p90 Rsk proteins in iron-loaded livers using immunoblotting analysis. This analysis revealed a significant decrease in the phosphorylation levels of Mek1/2, Erk1/2, and Stat3 (by 3.6-, 4.8-, and 3.8-fold, respectively), while the levels of p90Rsk were increased by 2.1-fold (Figure 2a). 
(a)
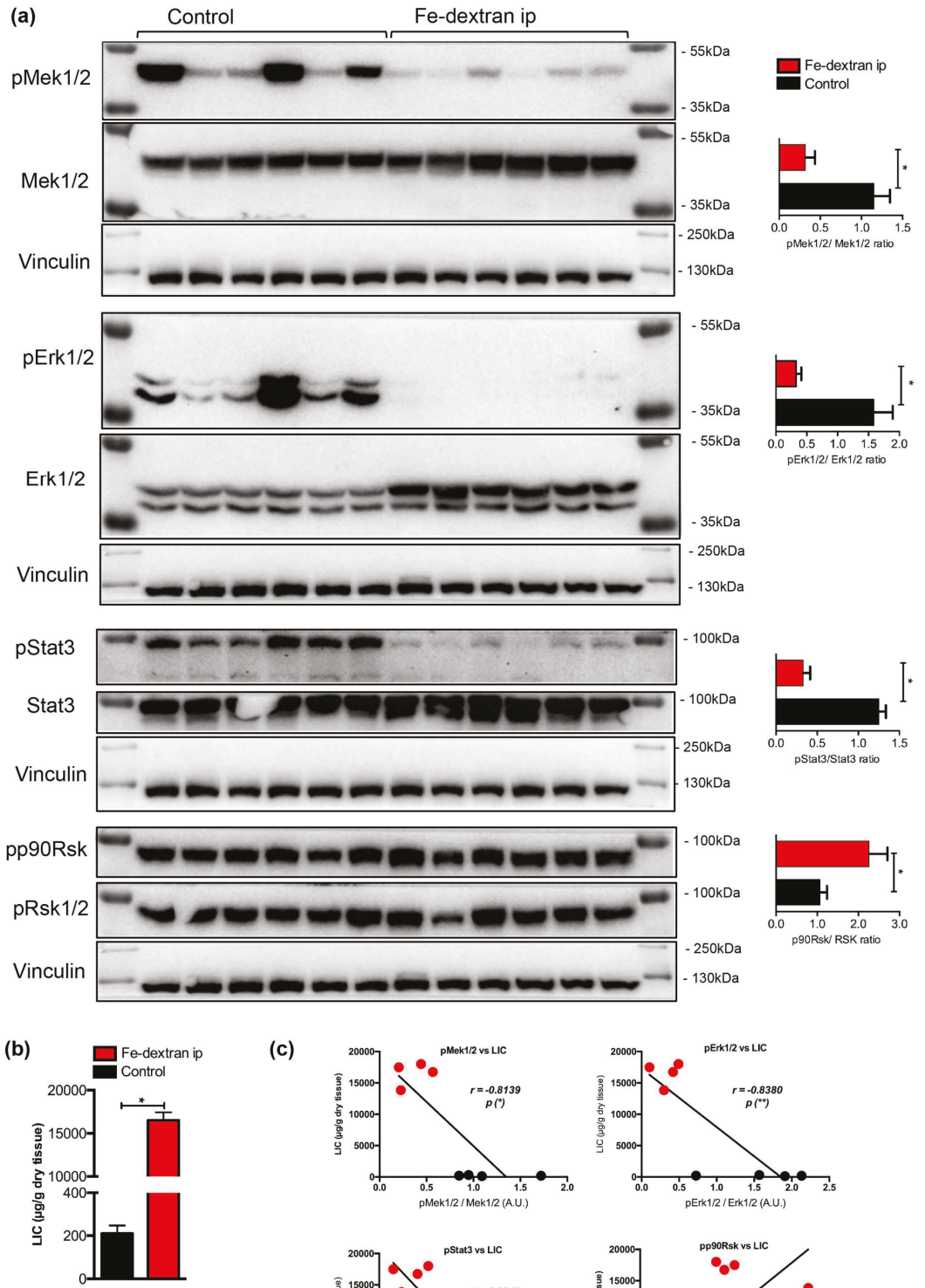

(c)
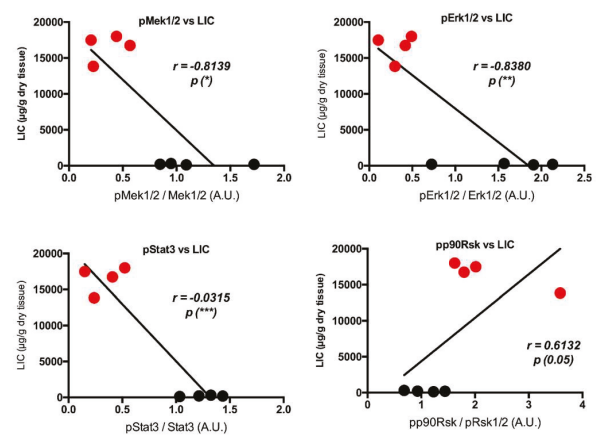

Figure 2. (a) Immunoblot analysis and relative quantification (shown in histograms on right) of pMEK1, pERK1/2, pStat3, and pp90Rsk in the livers of iron-dextran injected and control mice $(n=6 ; 6$ mice per group). (b) Liver iron content (LIC) of control and iron-dextran injected mice. (c) Correlation analysis between LIC and the levels of pMek1/2/Mek1/2, pErk1/2/Erk1/2, pStat3/Stat3, and pp90Rsk/pRsk1/2 in the livers of iron-dextran injected and control mice. M: Page Ruler Plus Prestained Protein Ladder (Thermo Scientific). Data were analyzed using GraphPad Prism software and results are shown as mean \pm SEM (standard error of mean). For the statistical analysis, a nonparametric distribution and the unpaired Mann-Whitney U Test were used. Linear regression and Pearson correlation coefficients were computed for every data set with $95 \%$ confidence intervals. ${ }^{*} p$ values $<0.05$. 


\subsection{Nutritional Iron Overload is Characterized by Low Hepatic Mek1/2-Erk1/2-Stat3 Signaling}

We next questioned whether a decrease in the Mek1/2-Erk1/2-Stat3 activity, measured during parenteral iron overload, is present in conditions of nutritional iron overload. We thus examined the phosphorylation status of Mek1/2-Erk1/2-Stat3 in the livers of wild type mice undergoing nutritional iron overload, induced by feeding mice with $3 \%$ carbonyl iron containing diet for six months starting at one month of age, as we previously described [33]. We show that hepatic iron overload, induced by iron-rich diet, associated with a 2.7-, 3.4-, and 1.7-fold decrease in the phosphorylation levels of Mek1/2-Erk1/2-Stat3 proteins, respectively, while the levels of p90Rsk were unchanged (Figure 3). However the data were only marginally under the level of statistical significance $(p<0.0571)$, which is, in our opinion, caused by stringent statistical analysis we applied (unpaired, nonparametric, Mann-Whitney test; $\mathrm{n}=3-4$ mice per group). Collectively, our data imply that hepatic response of mice receiving parenteral or dietary iron overload associates with a selective decline in the activity of Mek1/2-Erk1/2-Stat3 branch.

Future studies are needed to determine whether a decrease in phosphorylation of Mek1/2-Erk1/2 might be caused by diminished tyrosine kinase receptors (such as epidermal growth factor receptor, EGFR) mediated signaling activity and whether its activity may correlate with changes in the levels of extracellular ligands that can bind EGFR, such as EGF, transforming growth factor alpha, amphiregulin, heparin-binding EGF, and others. In addition, it will be informative to measure the levels of growth hormone (GH), as defective GH signaling impairs activation of EGFR and ERK signaling and affects liver regeneration [34].

\subsection{Low Hepatic Mek1/2-Erk1/2 Signaling is Present in Hfe-/-Mice in Spite of Low Bmp-Smad Signaling}

So far, our data indicate a decrease in pMek1/2-pErk1/2-pStat3 signaling under excessive systemic and hepatic iron overload. Contrary to Mek1/2-Erk1/2, the activity of Bmp-Smad signaling was shown to increase following iron overload subsequently causing increase in the expression of hepcidin and genes known to be coregulated with hepcidin [15]. Given that previous studies suggest co-involvement of Erk1/2 and Bmp/Smad signaling for induction of hepcidin in cells [18], it seemed logical to investigate the Mek1/2-Erk1/2 signaling activity in conditions characterized by hepatic iron overload and low hepcidin expression. To this end, we employed Hfe-deficient mice, a well-established mouse model of genetic iron-overload, which due to the lack of Hfe, an upstream hepcidin regulator, showed impaired Bmp-Smad signaling, low hepcidin expression, and increased hepatic iron stores [13-15]. We detected that the activation of Mek1/2-Erk1/2, measured by phosphorylation status using immunoblot analysis, was on average 2-fold lower in the livers of $\mathrm{Hfe}-/$ - mice (with marginal significance of $p=0.0571$ ), whereas the levels of pStat3 and pp90Rsk were not significantly changed (Figure 4). These data suggest that a decrease in Mek1/2-Erk1/2 signaling is uncoupled from Bmp-Smad signaling activity and Smad-mediated hepcidin regulation. 


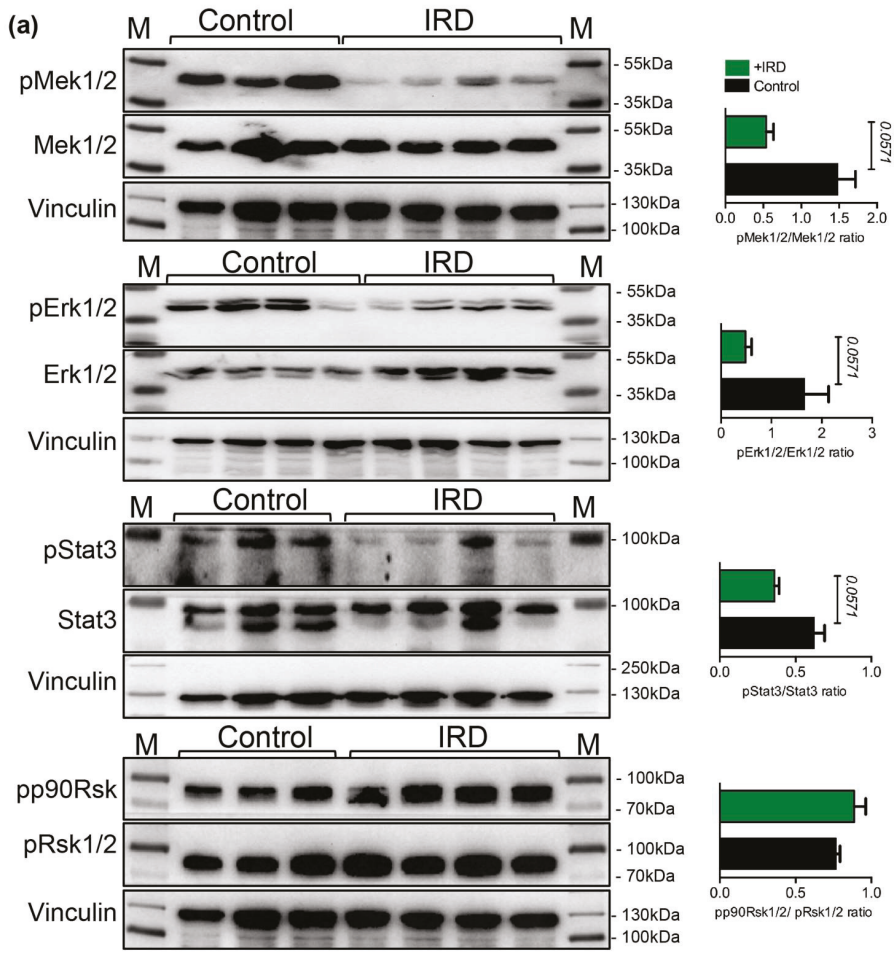

(b)

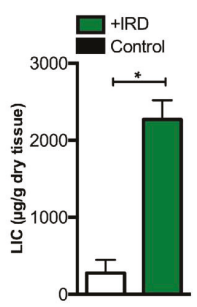

(c)
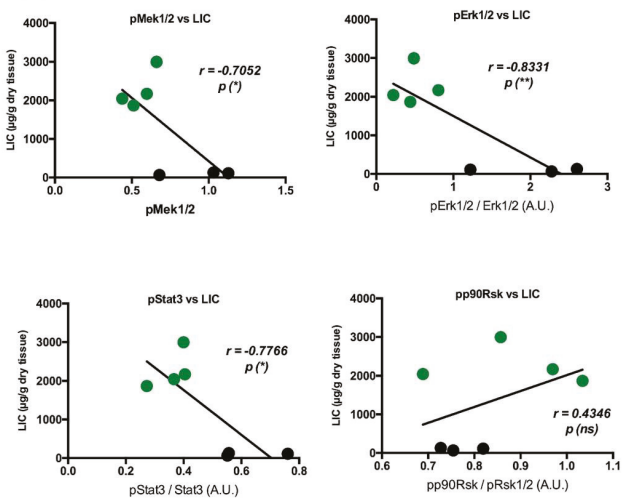

Figure 3. (a) Representative immunoblot analysis and relative quantification (shown in histograms on right) of pMek1/2, pErk1/2, pStat3, and pp90Rsk in the livers of mice maintained on an iron rich diet (IRD) and standard diet (control) ( $n=3-4$ mice per group). (b) Liver iron content (LIC) of control and of mice maintained on an iron rich diet ( $\mathrm{n}=3-4$ mice per group). (c) Correlation analysis between LIC and the levels of pMek1/2/Mek1/2, pErk1/2/Erk1/2, pStat3/Stat3, and pp90Rsk/pRsk1/2 in the livers of mice maintained on an iron rich diet (IRD) and standard diet (control) ( $n=3-4$ mice per group). M: Page Ruler Plus Prestained Protein Ladder (Thermo Scientific). Data were analyzed using GraphPad Prism software and results are shown as mean \pm SEM (standard error of mean). For the statistical analysis, a nonparametric distribution and the unpaired Mann-Whitney U Test were used. Linear regression and Pearson correlation coefficients were computed for every data set with $95 \%$ confidence intervals. ${ }^{*} p$-values $<0.05$. 

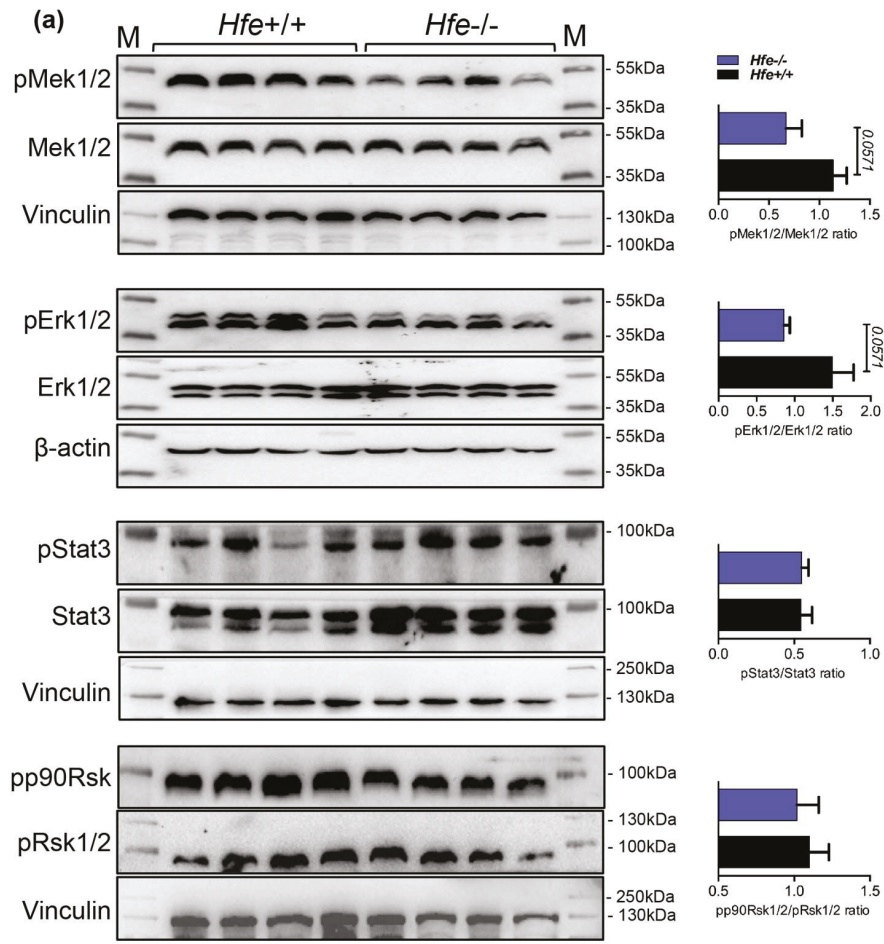

(b)

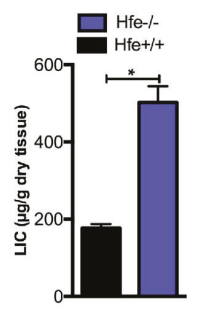

(c)
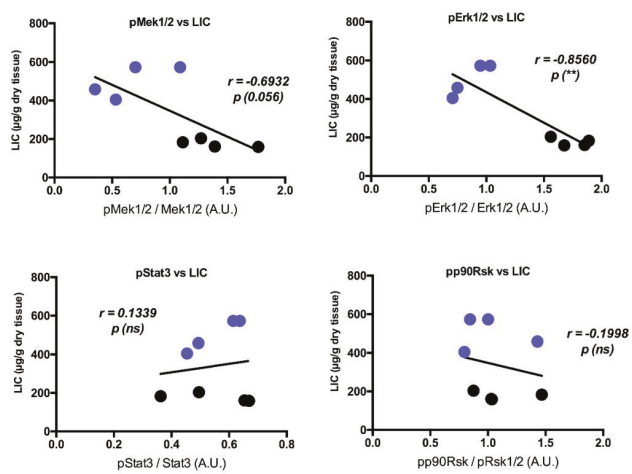

Figure 4. (a) Representative immunoblot analysis and relative quantification (shown in histograms on right) of pMek1/2, pErk1/2, pStat3 and pp90Rsk in the livers of Hfe+/+ control and Hfe-/- mutant mice ( $\mathrm{n}=8 ; 10$ mice per group). (b) Liver iron content (LIC) of Hfe $+/+$ and Hfe-/- mice ( $\mathrm{n}=4 ; 4$ mice per group). (c) Correlation analysis between LIC and the levels of pMek1/2/Mek1/2, pErk1/2/Erk1/2, pStat3/Stat3, and pp90Rsk/pRsk1/2 in the livers of $\mathrm{Hfe}+/+$ and Hfe-/- mice ( $\mathrm{n}=4 ; 4$ mice per group). M: Page Ruler Plus Prestained Protein Ladder (Thermo Scientific). Data were analyzed using GraphPad Prism software and results are shown as mean \pm SEM (standard error of mean). For the statistical analysis, a nonparametric distribution and the unpaired Mann-Whitney U Test were used. Linear regression and Pearson correlation coefficients were computed for every data set with $95 \%$ confidence intervals. ${ }^{*} p$-values $<0.05$. 


\subsection{Low Hepatic Mek1/2-Erk1/2 Signaling is Present in Hepcidin-Deficient Mice and is Further Aggravated by} Iron Excess

We next investigated Mek1/2-Erk1/2 activation status in the livers of hepcidin knock-out mice (Hamp-/-), which are deficient for hepcidin expression but maintain an appropriate Bmp-Smad signaling activity as a response to liver iron overload [15]. Similarly to the observation in the livers of $\mathrm{Hfe}-\mathrm{-}$ mice, a 2.5- and 3.8-fold decrease in the levels of pMek1/2-pErk1/2 proteins were measured in the livers of Hamp-/- mice (with marginal significance of $p=0.0571$ ), while the pStat3 and pp90Rsk levels were not significantly changed (Figure $5 \mathrm{a}-\mathrm{c}$ ). Interestingly, the activation of Mek1/2, Erk1/2, and Stat3, measured by their phosphorylated levels, was suppressed by 34-, 7.5-, and 1.5-fold, respectively (with marginal significance of $p=0.0571$ ), while the levels of pp90Rsk were unchanged in Hamp-/- mice fed an iron-rich diet for six months (Figure $5 \mathrm{~d}-\mathrm{f}$ ), which caused the development of chronic liver injury as we previously demonstrated [33].

Interestingly, the initially observed increase in pp90Rsk levels following iron-dextran injections in mice (Figure 2a,c) was not detected in the livers of mice maintained on an iron-rich diet nor in Hfe-/- or Hamp-/- mice. A possible explanation might be the differences in the route of iron application (i.p injections versus nutritional/enteral iron administration) and the duration of iron loading (3-weeks of iron-dextran injections versus six months of iron-rich diet). We suspect that fast influx of iron and excessive liver iron loading following i.p. iron-dextran injections might differentially affect cellular and humoral responses than nutritional iron administration or genetic iron overload.

Taken together, our data reinforce the view that attenuation of Mek1/2-Erk1/2 phosphorylation is a function of hepatic iron overload. Given the variety of iron-overload models used in this study, we speculate that changes in Mek1/2-Erk1/2 signaling may be categorized as initiating mechanism predisposing liver cells to toxic insults. Among them, inflammation, hepatic oxidative stress including the production of highly reactive lipid peroxidation products and iron-catalyzed oxidant stress $[35,36]$ could ultimately lead towards the progression of a chronic liver disease. This hypothesis is supported by recent studies demonstrated that inhibition of ERK1/2 signaling sensitized the cells to chemotaxic stimuli [37].

The collective data let to a working model (Figure 6), in which high hepatic iron burden associates with a decrease in phosphorylation levels of Mek1/2-Erk1/2. This in turn may contribute to a number of liver pathologies in addition to toxic effects of iron.

Data presented in this study raise a number of questions as to whether (i) low Mek1/2-Erk1/2 activity occurs as a selective response to high hepatic iron levels or is triggered by high transferrin and/or non-transferrin-bound iron, (ii) in which hepatic cells (hepatocytes or nonparenchymal cells) and in which cellular compartments does Erk1/2 function, (iii) what is the level of Mek1/2-Erk1/2 cross-talk with parallel pathways such as the PI3K/AKT/mTOR pathway in iron-loaded livers, and (iv) what are the consequences of inhibition of the Erk1/2 pathway in iron-loaded livers on hepatic gene transcription?

Finally, our findings may be of relevance to other conditions where hepatic iron levels are increased such as alcoholic liver disease, characterized by low hepcidin expression, suppressed hepatic Erk1/2 activity and liver injury [27,38-43]. In addition, hepatic iron overload is present in approximately one-third of patients with nonalcoholic fatty liver disease [44-47], which is recognized as the most common chronic liver disease that can progress to non-alcoholic steatohepatitis and liver cancer [48-50]. Hepatic iron overload is also observed in patients with chronic hepatitis $\mathrm{C}$ virus infections (and rarely in chronic hepatitis B infections) and in end-stage liver disease [3,46,47,51-54]. Whether hepatic iron overload and the presence of suppressed Mek1/2-Erk1/2 signaling may either accelerate disease progression or whether maintaining low Mek1/2-Erk1/2 signaling may be protective from the induction of $c-M y c$ and $c$-Jun as a part of increased proliferation, and therefore reduce the incidence of liver damage, are certainly important questions to address in the future. An equally interesting aspect would be to monitor Mek1/2-Erk1/2 activation from early steps of iron overload until development of liver pathologies and establish whether the activity of MAPK module is accordingly modulated. 
Understanding the underlying mechanisms associated with hepatic iron overload and progressive liver failure may provide new modalities for therapeutic interventions. We believe that the data provided here will advance our understanding of cellular signaling events in the liver during iron overload of different etiologies.
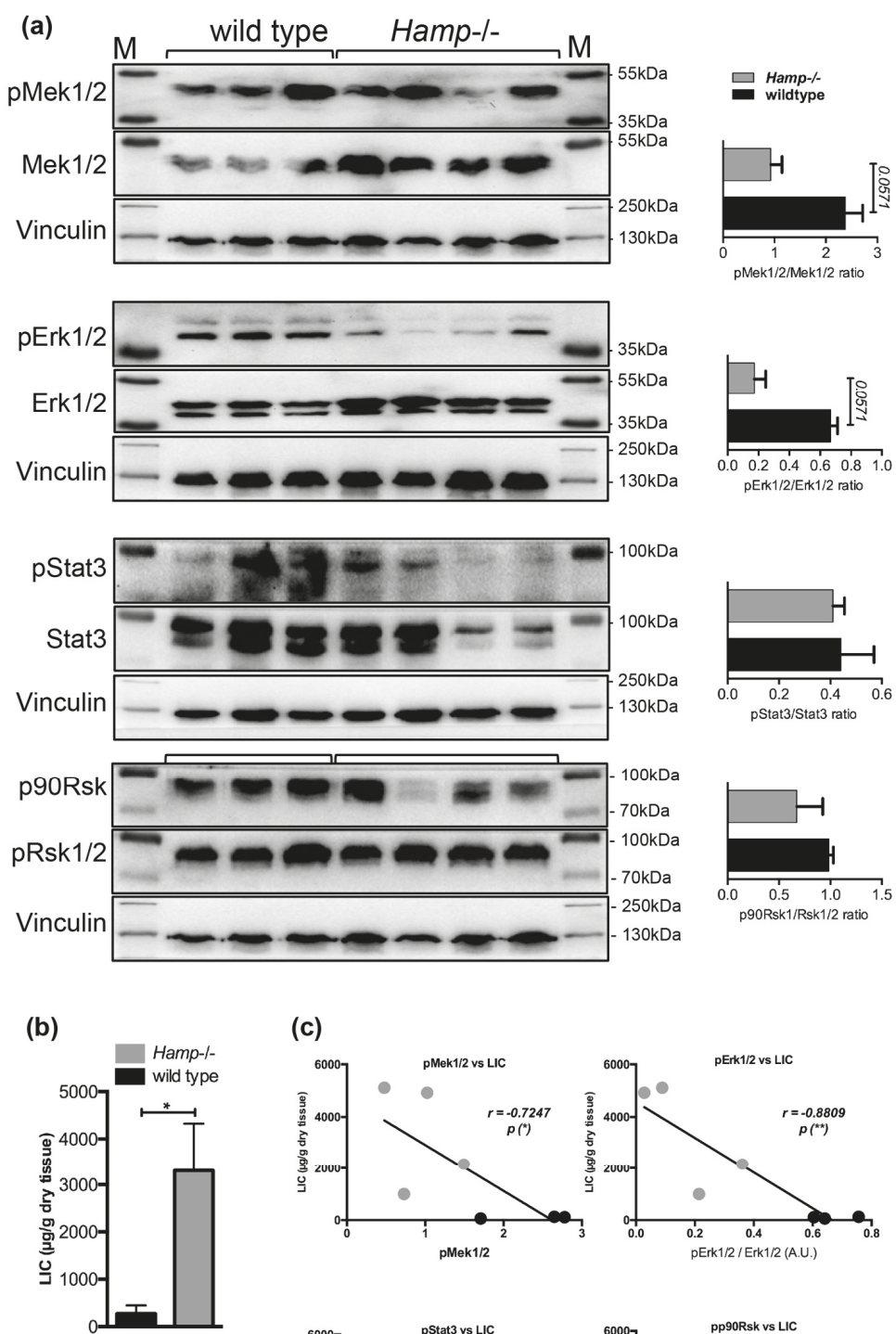

(c)
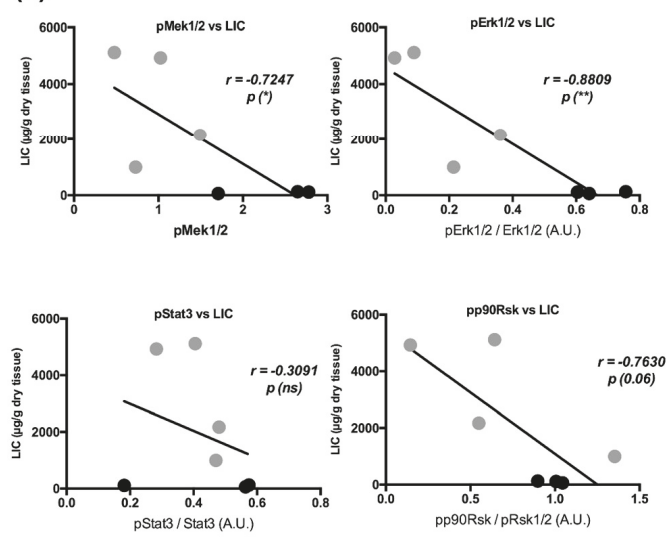

Figure 5. Cont. 

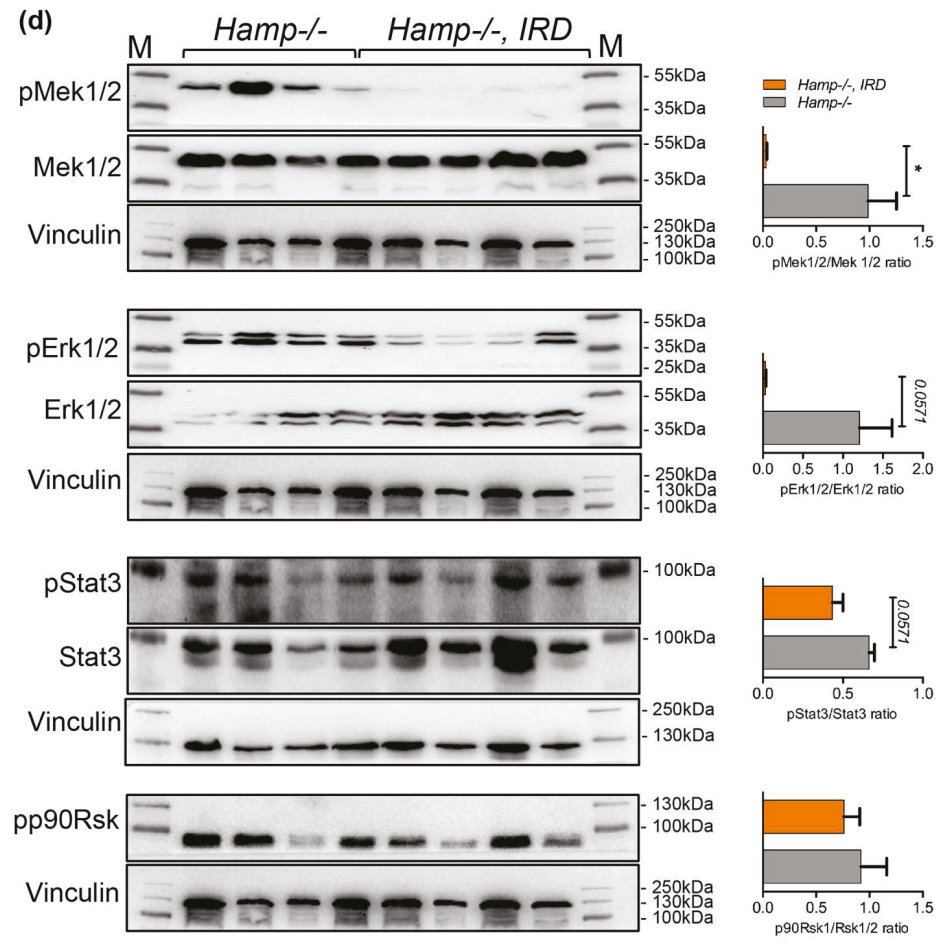

(e) Hamp--, IRD

(f)
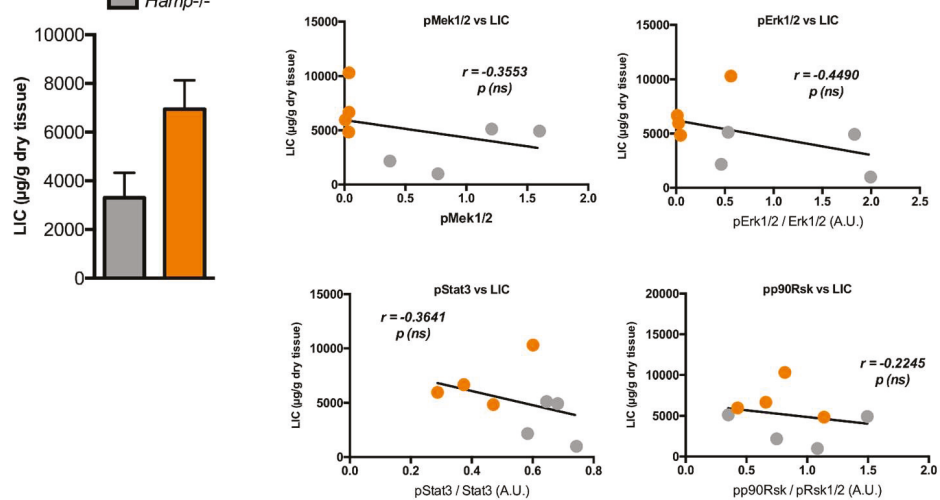

Figure 5. Immunoblot analysis and relative quantification (shown in histograms on right) of pMek1/2, pErk1/2, pStat3 and pp90Rsk in the livers of (a) control and Hamp-/- mice and (d) Hamp-/- mice maintained on an iron-rich diet (IRD) ( $\mathrm{n}=3 ; 4 ; 4$ mice per group). Liver iron content (LIC) in (b) control, Hamp-/- and (e) Hamp-/- mice maintained on an iron-rich diet ( $\mathrm{n}=3 ; 4 ; 4$ mice per group). Correlation analysis between LIC and the levels of pMek1/2/Mek1/2, pErk1/2/Erk1/2, pStat3/Stat3, and pp90Rsk/pRsk1/2 in the livers of (c) control, Hamp-/- and (f) Hamp-/- mice maintained on an iron rich diet (IRD) ( $\mathrm{n}=3 ; 4 ; 4$ mice per group). M: Page Ruler Plus Prestained Protein Ladder (Thermo Scientific). Data were analyzed using GraphPad Prism software and results are shown as mean \pm SEM (standard error of mean). For the statistical analysis, a nonparametric distribution and the unpaired Mann-Whitney U Test were used. Linear regression and Pearson correlation coefficients were computed for every data set with $95 \%$ confidence intervals. ${ }^{*} p$-values $<0.05$. 


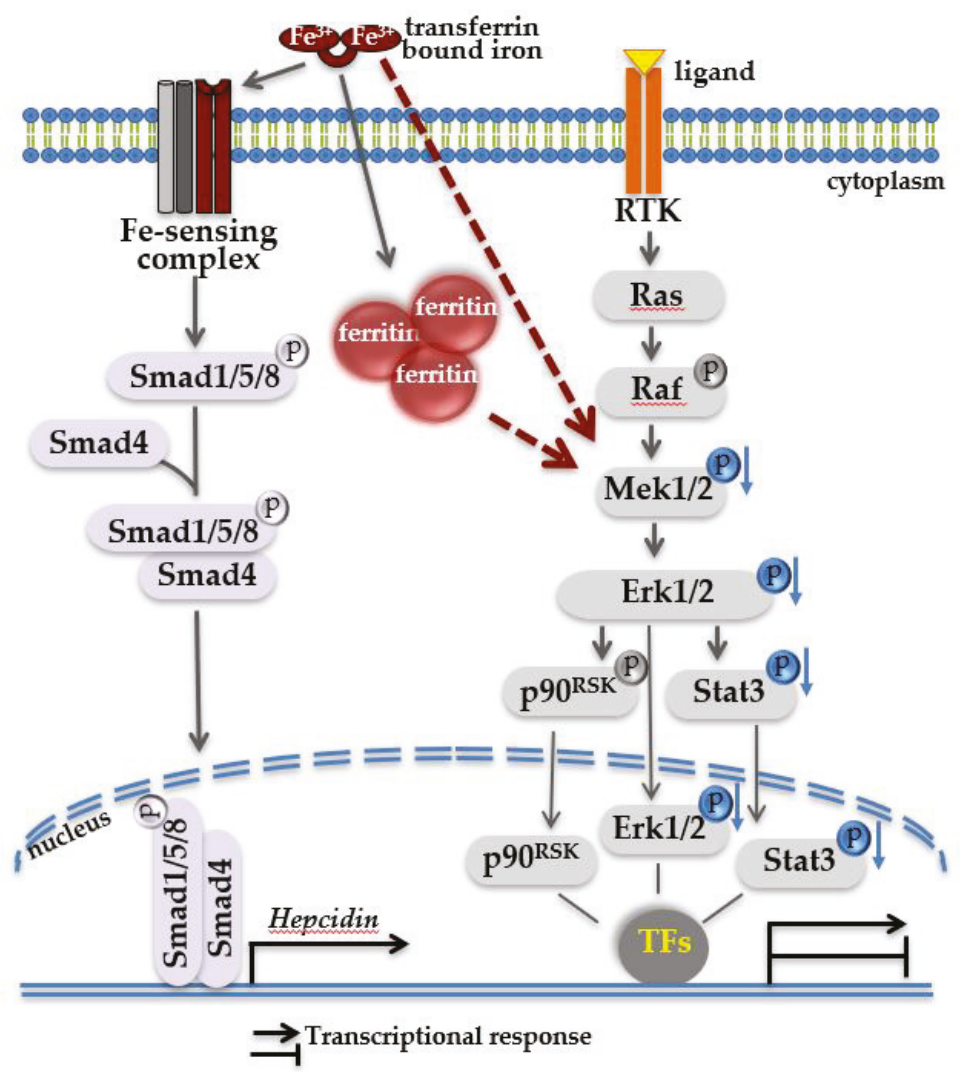

Figure 6. Proposed model of two signaling pathways operating in iron-loaded livers. Systemic iron overload results in heavy iron deposition in the liver, illustrated here in form of high ferritin. Under these conditions, high levels of circulating transferrin-bound iron is sensed by cell membrane multiprotein iron-sensing complex, resulting in the activation of intracellular Bmp-Smad signaling cascade and increased hepcidin transcription in the nucleus. Independent of Bmp-Smad-mediated hepcidin activation, through a yet unknown mechanism (proposed here by red arrows), a decrease in phosphorylation of Mek1/2-Erk1/2-Stat3 (indicated in blue) occurs which in turn may affect the property of pErk $1 / 2$ and pStat 3 signaling molecules to regulate gene transcription, alone or in cooperation with other transcription factors (TFs). A decrease in the activity of Mek1/2-Erk1/2 signaling cascade can be considered as liver response to iron overload. We propose that a decrease in Mek1/2-Erk1/2 signaling activity may accelerate liver pathologies in addition to toxic effects of iron.

\section{Materials and Methods}

\subsection{Mice and Treatments}

Wild type Hfe-/- and Hamp-/- mutant mice, all males, were kept under a standard mouse diet containing $180 \mathrm{mg} / \mathrm{kg}$ iron (Ssniff, Soest, Germany). For the analysis livers were used from previously described wild-type mice undergoing intra peritoneal (i.p.) injection of iron-dextran solution [15,33] and from Hamp-/- and wild type mice fed with 3\% carbonyl iron (Sigma, Germany) for 6 months [15,33]. Animal experiments were approved and performed in accordance to the Ulm University Animal Care 
Committee and German Low for Welfare of laboratory animals in Baden-Württemberg, Germany (Project ID: 35/9185.81-3 / 972 / 1143).

\subsection{Phosphoprotein Analysis in Liver Lysates}

Protein lysates $(10 \mu \mathrm{g}$ in $50 \mu \mathrm{L})$ were prepared from liver tissues using Bio-Plex Cell Lysis Kit (BioRad Laboratories, Munich, Germany). The levels of intracellular phosphoproteins were measured using Bio-Plex Pro Cell Signaling MAPK Panel, 9-plex (BioRad Laboratories, Munich, Germany) according to the manufacturer's instructions. The data were analyzed using Bio-Plex Manager 6.1 Software Package.

\subsection{Protein Isolation and Immunoblot Analysis}

Protein extracts were prepared from flash-frozen tissue after homogenization in RIPA lysis buffer (Incomplete RIPA buffer, $7 \times$ protease inhibitor cocktail, $200 \mathrm{mM}$ sodium orthovandate, $1 \mathrm{M}$ sodium fluoride, 100mM PMSF) as previously described [15]. Total proteins $(30-50 \mu \mathrm{g})$ were subjected to Western blot analysis with the following antibodies; anti-pMek1/2, anti-Mek1/2, anti-pErk1/2, anti-Erk1/2, anti-pp90Rsk, anti-pRsk1/2, anti-pStat3, and anti-Stat3 (all rabbit, Cell Signaling Technology, MA, USA; 1:1000 concentration). Mouse anti-vinculin (Santa Cruz, CA, USA; 1:2000) and mouse anti- $\beta$-actin (Sigma Aldrich, Missouri, USA; 1:10,000) were used as loading controls. Furthermore, membranes were washed and incubated with anti-rabbit or anti-mouse (Invitrogen, CA, USA; 1:5000) horseradish peroxidase-conjugated antibody. Western blot images were acquired using EMD Millipore Luminata HRP chemiluminescence substrate (Millipore, MA, USA) and signal acquired in Bio-Rad chemiluminescence detector (Bio-Rad Laboratories, CA, USA). The signals were semiquantified using image J (ImageJ; www://rsb.info.nih.gov/ij/).

\subsection{Statistical Analysis}

Data were analyzed using GraphPad Prism software and results are shown as mean \pm standard error of mean. For the statistical analysis, a nonparametric distribution and the Mann-Whitney U test were used. Linear regression and Pearson correlation coefficients were computed for every data set with $95 \%$ confidence intervals. Statistically significant differences are indicated as $p<05\left({ }^{*}\right), p<01\left({ }^{* *}\right)$, and $p<005\left({ }^{* * *}\right)$.

Author Contributions: N.K.T. and N.B. performed the experiments; P.S. and I.C.C. provided resources and edited the manuscript; and M.V.S. designed the study, analyzed the data, and wrote the manuscript.

Funding: This research was funded by the Deutsche Forschungsgemeinschaft (DFG) grant number VU75/2-1 and by the Ulm University to M.V.S. P.S. is supported by the Deutsche Forschungsgemeinschaft (DFG) Konsortium SFB/TRR57 'Liver fibrosis. I.C.C. is supported by the Deutsche Forschungsgemeinschaft (DFG) grant number CI216/2-1 and Bundesministerium für Bildung und Forschung (BMBF) grant number 01GM1519F (GeNeRaRe).

Acknowledgments: We thank the staff of the Animal Facility at the Ulm University.

Conflicts of Interest: The authors declare no conflicts of interest.

\section{References}

1. Lesbordes-Brion, J.C.; Viatte, L.; Bennoun, M.; Lou, D.Q.; Ramey, G.; Houbron, C.; Hamard, G.; Kahn, A.; Vaulont, S. Targeted disruption of the hepcidin 1 gene results in severe hemochromatosis. Blood 2006, 108, 1402-1405. [CrossRef] [PubMed]

2. Deugnier, Y.; Turlin, B. Pathology of hepatic iron overload. World J. Gastroenterol. 2007, 13, 4755-4760. [CrossRef]

3. Kowdley, K.V. Iron Overload in Patients with Chronic Liver Disease. Gastroenterol. Hepatol. 2016, 12, $695-698$.

4. Feder, J.N.; Gnirke, A.; Thomas, W.; Tsuchihashi, Z.; Ruddy, D.A.; Basava, A.; Dormishian, F.; Domingo, R., Jr.; Ellis, M.C.; Fullan, A.; et al. A novel MHC class I-like gene is mutated in patients with hereditary haemochromatosis. Nat. Genet. 1996, 13, 399-408. [CrossRef] 
5. Levy, J.E.; Jin, O.; Fujiwara, Y.; Kuo, F.; Andrews, N.C. Transferrin receptor is necessary for development of erythrocytes and the nervous system. Nat. Genet. 1999, 21, 396-399. [CrossRef] [PubMed]

6. Vujic Spasic, M.; Kiss, J.; Herrmann, T.; Galy, B.; Martinache, S.; Stolte, J.; Grone, H.J.; Stremmel, W.; Hentze, M.W.; Muckenthaler, M.U. Hfe acts in hepatocytes to prevent hemochromatosis. Cell Metab. 2008, 7, 173-178. [CrossRef]

7. Wallace, D.F.; Summerville, L.; Subramaniam, V.N. Targeted disruption of the hepatic transferrin receptor 2 gene in mice leads to iron overload. Gastroenterology 2007, 132, 301-310. [CrossRef]

8. Wallace, D.F.; Summerville, L.; Crampton, E.M.; Frazer, D.M.; Anderson, G.J.; Subramaniam, V.N. Combined deletion of Hfe and transferrin receptor 2 in mice leads to marked dysregulation of hepcidin and iron overload. Hepatology 2009, 50, 1992-2000. [CrossRef]

9. Roetto, A.; Daraio, F.; Alberti, F.; Porporato, P.; Cali, A.; De Gobbi, M.; Camaschella, C. Hemochromatosis due to mutations in transferrin receptor 2. Blood Cells Mol. Dis. 2002, 29, 465-470. [CrossRef]

10. Niederkofler, V.; Salie, R.; Arber, S. Hemojuvelin is essential for dietary iron sensing, and its mutation leads to severe iron overload. J. Clin. Investig. 2005, 115, 2180-2186. [CrossRef] [PubMed]

11. Babitt, J.L.; Huang, F.W.; Wrighting, D.M.; Xia, Y.; Sidis, Y.; Samad, T.A.; Campagna, J.A.; Chung, R.T.; Schneyer, A.L.; Woolf, C.J.; et al. Bone morphogenetic protein signaling by hemojuvelin regulates hepcidin expression. Nat. Genet. 2006, 38, 531-539. [CrossRef] [PubMed]

12. Steinbicker, A.U.; Bartnikas, T.B.; Lohmeyer, L.K.; Leyton, P.; Mayeur, C.; Kao, S.M.; Pappas, A.E.; Peterson, R.T.; Bloch, D.B.; Yu, P.B.; et al. Perturbation of hepcidin expression by BMP type I receptor deletion induces iron overload in mice. Blood 2011, 118, 4224-4230. [CrossRef] [PubMed]

13. Ryan, J.D.; Ryan, E.; Fabre, A.; Lawless, M.W.; Crowe, J. Defective bone morphogenic protein signaling underlies hepcidin deficiency in HFE hereditary hemochromatosis. Hepatology 2010, 52, 1266-1273. [CrossRef]

14. Corradini, E.; Rozier, M.; Meynard, D.; Odhiambo, A.; Lin, H.Y.; Feng, Q.; Migas, M.C.; Britton, R.S.; Babitt, J.L.; Fleming, R.E. Iron regulation of hepcidin despite attenuated Smad1,5,8 signaling in mice without transferrin receptor 2 or Hfe. Gastroenterology 2011, 141, 1907-1914. [CrossRef] [PubMed]

15. Vujic Spasic, M.; Sparla, R.; Mleczko-Sanecka, K.; Migas, M.C.; Breitkopf-Heinlein, K.; Dooley, S.; Vaulont, S.; Fleming, R.E.; Muckenthaler, M.U. Smad6 and Smad7 are co-regulated with hepcidin in mouse models of iron overload. Biochim. Biophys. Acta 2013, 1832, 76-84. [CrossRef] [PubMed]

16. Calzolari, A.; Raggi, C.; Deaglio, S.; Sposi, N.M.; Stafsnes, M.; Fecchi, K.; Parolini, I.; Malavasi, F.; Peschle, C.; Sargiacomo, M.; et al. TfR2 localizes in lipid raft domains and is released in exosomes to activate signal transduction along the MAPK pathway. J. Cell Sci. 2006, 119, 4486-4498. [CrossRef] [PubMed]

17. Poli, M.; Luscieti, S.; Gandini, V.; Maccarinelli, F.; Finazzi, D.; Silvestri, L.; Roetto, A.; Arosio, P. Transferrin receptor 2 and HFE regulate furin expression via mitogen-activated protein kinase/extracellular signal-regulated kinase (MAPK/Erk) signaling. Implications for transferrin-dependent hepcidin regulation. Haematologica 2010, 95, 1832-1840. [CrossRef] [PubMed]

18. Ramey, G.; Deschemin, J.C.; Vaulont, S. Cross-talk between the mitogen activated protein kinase and bone morphogenetic protein/hemojuvelin pathways is required for the induction of hepcidin by holotransferrin in primary mouse hepatocytes. Haematologica 2009, 94, 765-772. [CrossRef]

19. Cargnello, M.; Roux, P.P. Activation and function of the MAPKs and their substrates, the MAPK-activated protein kinases. Microbiol. Mol. Boil. Rev. 2011, 75, 50-83. [CrossRef] [PubMed]

20. Lawan, A.; Bennett, A.M. Mitogen-Activated Protein Kinase Regulation in Hepatic Metabolism. Trends Endocrinol. Metab. 2017, 28, 868-878. [CrossRef] [PubMed]

21. Roskoski, R., Jr. ERK1/2 MAP kinases: Structure, function, and regulation. Pharmacol. Res. 2012, 66, 105-143. [CrossRef] [PubMed]

22. Sabio, G.; Davis, R.J. TNF and MAP kinase signalling pathways. Semin. Immunol. 2014, 26, 237-245. [CrossRef]

23. Gehart, H.; Kumpf, S.; Ittner, A.; Ricci, R. MAPK signalling in cellular metabolism: Stress or wellness? EMBO Rep. 2010, 11, 834-840. [CrossRef] [PubMed]

24. Sumara, G.; Formentini, I.; Collins, S.; Sumara, I.; Windak, R.; Bodenmiller, B.; Ramracheya, R.; Caille, D.; Jiang, H.; Platt, K.A.; et al. Regulation of PKD by the MAPK p38delta in insulin secretion and glucose homeostasis. Cell 2009, 136, 235-248. [CrossRef] [PubMed] 
25. Barger, P.M.; Browning, A.C.; Garner, A.N.; Kelly, D.P. p38 mitogen-activated protein kinase activates peroxisome proliferator-activated receptor alpha: A potential role in the cardiac metabolic stress response. J. Boil. Chem. 2001, 276, 44495-44501. [CrossRef]

26. Manieri, E.; Sabio, G. Stress kinases in the modulation of metabolism and energy balance. J. Mol. Endocrinol. 2015, 55, R11-R22. [CrossRef]

27. Bost, F.; Aouadi, M.; Caron, L.; Binetruy, B. The role of MAPKs in adipocyte differentiation and obesity. Biochimie 2005, 87, 51-56. [CrossRef] [PubMed]

28. Samuel, V.T.; Shulman, G.I. Nonalcoholic Fatty Liver Disease as a Nexus of Metabolic and Hepatic Diseases. Cell Metab. 2018, 27, 22-41. [CrossRef] [PubMed]

29. Khan, A.S.; Subramaniam, S.; Dramane, G.; Khelifi, D.; Khan, N.A. ERK1 and ERK2 activation modulates diet-induced obesity in mice. Biochimie 2017, 137, 78-87. [CrossRef]

30. Kujiraoka, T.; Satoh, Y.; Ayaori, M.; Shiraishi, Y.; Arai-Nakaya, Y.; Hakuno, D.; Yada, H.; Kuwada, N.; Endo, S.; Isoda, K.; et al. Hepatic extracellular signal-regulated kinase 2 suppresses endoplasmic reticulum stress and protects from oxidative stress and endothelial dysfunction. J. Am. Heart Assoc. 2013, 2, e000361. [CrossRef]

31. Yu, Y.; Richardson, D.R. Cellular iron depletion stimulates the JNK and p38 MAPK signaling transduction pathways, dissociation of ASK1-thioredoxin, and activation of ASK1. J. Boil. Chem. 2011, 286, 15413-15427. [CrossRef]

32. Chung, J.; Uchida, E.; Grammer, T.C.; Blenis, J. STAT3 serine phosphorylation by ERK-dependent and -independent pathways negatively modulates its tyrosine phosphorylation. Mol. Cell. Boil. 1997, 17, 6508-6516. [CrossRef]

33. Lunova, M.; Goehring, C.; Kuscuoglu, D.; Mueller, K.; Chen, Y.; Walther, P.; Deschemin, J.C.; Vaulont, S.; Haybaeck, J.; Lackner, C.; et al. Hepcidin knockout mice fed with iron-rich diet develop chronic liver injury and liver fibrosis due to lysosomal iron overload. J. Hepatol. 2014, 61, 633-641. [CrossRef] [PubMed]

34. Zerrad-Saadi, A.; Lambert-Blot, M.; Mitchell, C.; Bretes, H.; Collin de l'Hortet, A.; Baud, V.; Chereau, F.; Sotiropoulos, A.; Kopchick, J.J.; Liao, L.; et al. GH receptor plays a major role in liver regeneration through the control of EGFR and ERK1/2 activation. Endocrinology 2011, 152, 2731-2741. [CrossRef]

35. Poli, G.; Schaur, R.J. 4-Hydroxynonenal in the pathomechanisms of oxidative stress. IUBMB Life 2000, 50, 315-321. [CrossRef] [PubMed]

36. Tsukamoto, H.; Horne, W.; Kamimura, S.; Niemela, O.; Parkkila, S.; Yla-Herttuala, S.; Brittenham, G.M. Experimental liver cirrhosis induced by alcohol and iron. J. Clin. Investig. 1995, 96, 620-630. [CrossRef]

37. Jazirehi, A.R.; Vega, M.I.; Chatterjee, D.; Goodglick, L.; Bonavida, B. Inhibition of the Raf-MEK1/2-ERK1/2 signaling pathway, Bcl-xL down-regulation, and chemosensitization of non-Hodgkin's lymphoma B cells by Rituximab. Cancer Res. 2004, 64, 7117-7126. [CrossRef]

38. Rouault, T.A. Hepatic iron overload in alcoholic liver disease: Why does it occur and what is its role in pathogenesis? Alcohol 2003, 30, 103-106. [CrossRef]

39. Ioannou, G.N.; Dominitz, J.A.; Weiss, N.S.; Heagerty, P.J.; Kowdley, K.V. The effect of alcohol consumption on the prevalence of iron overload, iron deficiency, and iron deficiency anemia. Gastroenterology 2004, 126, 1293-1301. [CrossRef]

40. Harrison-Findik, D.D.; Klein, E.; Crist, C.; Evans, J.; Timchenko, N.; Gollan, J. Iron-mediated regulation of liver hepcidin expression in rats and mice is abolished by alcohol. Hepatology 2007, 46, 1979-1985. [CrossRef]

41. Aroor, A.R.; Shukla, S.D. MAP kinase signaling in diverse effects of ethanol. Life Sci. 2004, 74, $2339-2364$. [CrossRef] [PubMed]

42. Sampey, B.P.; Stewart, B.J.; Petersen, D.R. Ethanol-induced modulation of hepatocellular extracellular signal-regulated kinase-1/2 activity via 4-hydroxynonenal. J. Boil. Chem. 2007, 282, 1925-1937. [CrossRef] [PubMed]

43. Chen, J.; Ishac, E.J.; Dent, P.; Kunos, G.; Gao, B. Effects of ethanol on mitogen-activated protein kinase and stress-activated protein kinase cascades in normal and regenerating liver. Biochem. J. 1998, 334 Pt 3, 669-676. [CrossRef]

44. Marmur, J.; Beshara, S.; Eggertsen, G.; Onelov, L.; Albiin, N.; Danielsson, O.; Hultcrantz, R.; Stal, P. Hepcidin levels correlate to liver iron content, but not steatohepatitis, in non-alcoholic fatty liver disease. BMC Gastroenterol. 2018, 18, 78. [CrossRef] [PubMed]

45. Datz, C.; Felder, T.K.; Niederseer, D.; Aigner, E. Iron homeostasis in the metabolic syndrome. Eur. J. Clin. Investig. 2013, 43, 215-224. [CrossRef] 
46. Kowdley, K.V.; Belt, P.; Wilson, L.A.; Yeh, M.M.; Neuschwander-Tetri, B.A.; Chalasani, N.; Sanyal, A.J.; Nelson, J.E.; Network, N.C.R. Serum ferritin is an independent predictor of histologic severity and advanced fibrosis in patients with nonalcoholic fatty liver disease. Hepatology 2012, 55, 77-85. [CrossRef] [PubMed]

47. Nelson, J.E.; Klintworth, H.; Kowdley, K.V. Iron metabolism in Nonalcoholic Fatty Liver Disease. Curr. Gastroenterol. Rep. 2012, 14, 8-16. [CrossRef]

48. Younossi, Z.; Henry, L. Contribution of Alcoholic and Nonalcoholic Fatty Liver Disease to the Burden of Liver-Related Morbidity and Mortality. Gastroenterology 2016, 150, 1778-1785. [CrossRef]

49. Ma, C.; Zhang, Q.; Greten, T.F. Nonalcoholic fatty liver disease promotes hepatocellular carcinoma through direct and indirect effects on hepatocytes. FEBS J. 2018, 285, 752-762. [CrossRef]

50. Michelotti, G.A.; Machado, M.V.; Diehl, A.M. NAFLD, NASH and liver cancer. Nat. Rev. Gastroenterol. Hepatol. 2013, 10, 656-665. [CrossRef]

51. Fracanzani, A.L.; Valenti, L.; Bugianesi, E.; Vanni, E.; Grieco, A.; Miele, L.; Consonni, D.; Fatta, E.; Lombardi, R.; Marchesini, G.; et al. Risk of nonalcoholic steatohepatitis and fibrosis in patients with nonalcoholic fatty liver disease and low visceral adiposity. J. Hepatol. 2011, 54, 1244-1249. [CrossRef] [PubMed]

52. Manousou, P.; Kalambokis, G.; Grillo, F.; Watkins, J.; Xirouchakis, E.; Pleguezuelo, M.; Leandro, G.; Arvaniti, V.; Germani, G.; Patch, D.; et al. Serum ferritin is a discriminant marker for both fibrosis and inflammation in histologically proven non-alcoholic fatty liver disease patients. Liver Int. 2011, 31, 730-739. [CrossRef] [PubMed]

53. Fujita, N.; Sugimoto, R.; Takeo, M.; Urawa, N.; Mifuji, R.; Tanaka, H.; Kobayashi, Y.; Iwasa, M.; Watanabe, S.; Adachi, Y.; et al. Hepcidin expression in the liver: Relatively low level in patients with chronic hepatitis C. Mol. Med. 2007, 13, 97-104. [CrossRef] [PubMed]

54. Nishina, S.; Hino, K.; Korenaga, M.; Vecchi, C.; Pietrangelo, A.; Mizukami, Y.; Furutani, T.; Sakai, A.; Okuda, M.; Hidaka, I.; et al. Hepatitis C virus-induced reactive oxygen species raise hepatic iron level in mice by reducing hepcidin transcription. Gastroenterology 2008, 134, 226-238. [CrossRef]

(C) 2019 by the authors. Licensee MDPI, Basel, Switzerland. This article is an open access article distributed under the terms and conditions of the Creative Commons Attribution (CC BY) license (http://creativecommons.org/licenses/by/4.0/). 
Concept Paper

\title{
Unraveling Hepcidin Plasma Protein Binding: Evidence from Peritoneal Equilibration Testing
}

\author{
Laura E. Diepeveen ${ }^{1, *}$, Coby M. Laarakkers ${ }^{1}$, Hilde P.E. Peters ${ }^{2}$, Antonius E. van Herwaarden ${ }^{1}$, \\ Hans Groenewoud ${ }^{3}$, Joanna IntHout ${ }^{3}$, Jack F. Wetzels ${ }^{4}$, Rachel P.L. van Swelm ${ }^{1}$ and \\ Dorine W. Swinkels ${ }^{1}$ \\ 1 Department of Laboratory Medicine, Radboud University Medical Center, 6525 Nijmegen, The Netherlands \\ 2 Department of Nephrology, Isala Hospital, 8025 Zwolle, The Netherlands \\ 3 Department of Health Evidence, Radboud University Medical Center, 6525 Nijmegen, The Netherlands \\ 4 Department of Nephrology, Radboud University Medical Center, 6525 Nijmegen, The Netherlands \\ * Correspondence: Laura.Diepeveen@radboudumc.nl; Tel.: +31-(0)24-3668960
}

Received: 10 July 2019; Accepted: 14 August 2019; Published: 23 August 2019

\begin{abstract}
Peptide hormone hepcidin regulates systemic iron metabolism and has been described to be partially bound to $\alpha 2$-macroglobulin and albumin in blood. However, the reported degree of hepcidin protein binding varies between $<3 \%$ and $\approx 89 \%$. Since protein-binding may influence hormone function and quantification, better insight into the degree of hepcidin protein binding is essential to fully understand the biological behavior of hepcidin and interpretation of its measurement in patients. Here, we used peritoneal dialysis to assess human hepcidin protein binding in a functional human setting for the first time. We measured freely circulating solutes in blood and peritoneal fluid of 14 patients with end-stage renal disease undergoing a peritoneal equilibration test to establish a curve describing the relation between molecular weight and peritoneal clearance. Calculated binding percentages of total cortisol and testosterone confirmed our model. The protein-bound fraction of hepcidin was calculated to be $40 \%( \pm 23 \%)$. We, therefore, conclude that a substantial proportion of hepcidin is freely circulating. Although a large inter-individual variation in hepcidin clearance, besides patient-specific peritoneal transport characteristics, may have affected the accuracy of the determined binding percentage, we describe an important step towards unraveling human hepcidin plasma protein binding in vivo including the caveats that need further research.
\end{abstract}

Keywords: iron homeostasis; hepcidin; protein binding; peritoneal dialysis

\section{Introduction}

The peptide hormone hepcidin, produced by hepatocytes, regulates iron entry into the circulation and iron distribution throughout the body by degradation of the cellular iron exporter ferroportin [1]. Hormones can circulate freely or partially bound to carrier proteins in the human body $[2,3]$. These carrier proteins allow transport of non-soluble hormones through the blood plasma, prevent excretion, and function as a reservoir thereby regulating hormone bioavailability. The free hormone hypothesis indicates that most hormones are not capable of exerting their physiological effect in a protein-bound form [2,4-6]. Hence, for partially bound hormones, such as thyroxine, testosterone, triiodothyronine, and cortisol, assays were designed to specifically quantify the bioactive free hormone concentration [5,7-9].

It is suggested that hepcidin in blood is partially bound to both $\alpha 2$-macroglobulin $(\alpha 2 \mathrm{M})$ and albumin [10]. However, there is large controversy on the subject since the reported plasma protein-bound fraction of hepcidin varies between $<3 \%$ and $\approx 89 \%$ [10-12]. Consequently, it is uncertain to what degree currently available analytical assays quantify (only) bioactive hepcidin. Differences in extent of quantification of the freely circulating hepcidin relative to the protein bound compound between 
assays may influence interpretation and comparability of hepcidin measurement and hampers recent achievements on standardization of hepcidin assays [13]. Characterization of the measured analyte will add the final aspect to the metrological traceability chain of hepcidin, which describes an unbroken calibration hierarchy from a measurement result to a defined reference in SI units. Additionally, unraveling the protein binding properties of hepcidin will improve our understanding of its biology and will allow its correct quantification, which is essential in the assessment and interpretation of the pharmacokinetic and pharmacodynamic effects of hepcidin agonist or antagonist therapies $[1,14]$. To address these issues, we aimed to study the degree of hepcidin protein binding in a functional human setting for the first time, rather than using previously reported in vitro (research) techniques [10,11], mice in vivo studies [11], or human ex vivo serum analysis [12]. Especially since current in vitro techniques to assess free hormone concentrations in diagnostic medicine, such as equilibrium dialysis and ultrafiltration methods, have limitations amongst which are risk for leakage, non-specific absorption of the hormone leading to low reproducibility, and bias of results, osmotic effects or the Gibbs-Donnan effect [15].

To circumvent the limitations of in vitro studies, we aimed to unravel hepcidin plasma protein binding with a new approach using the principle of peritoneal dialysis (PD). PD is a treatment option for patients with end-stage renal disease (ESRD), in which the peritoneal cavity is filled with dialysis fluid. During a certain dwell time, plasma components are transported into the peritoneal cavity. Transport of molecules is mainly driven by diffusion and ultrafiltration and depends on peritoneal membrane characteristics [16]. To assess these individual characteristics, all patients treated with PD frequently undergo a standardized and highly reproducible peritoneal equilibration test (PET) [17-19]. During a four-hour dialysis exchange, the peritoneal membrane transport function of a patient treated with PD is characterized to classify them as either a high, low, or average transporter in order to optimize the dwell time [17]. These peritoneal equilibration rates reflect peritoneal clearance (PC) and can be calculated using the dialysate-to-plasma ratio (D/P ratio) for any given solute that is transported from the peritoneal capillary blood into dialysate fluid. The transport rate over the peritoneal membrane into the peritoneal cavity is largely size-selective and thus the PC is inversely related to the radius or molecular weight (MW) of a molecule, regardless of molecular properties such as charge or hydrophobicity [20-24]. Therefore, the transport rate of small molecules that are bound to large plasma proteins will be determined by the size of the complex. This has been verified using the protein-bound solute p-cresol (MW: $108 \mathrm{Da}$ ), since its PC was found to be similar to $\beta 2$-microglobulin (MW: 11,815 Da) [25]. Although a high PC was expected based on the low MW of p-cresol, its clearance was much lower, confirming protein-binding.

In this study, we measured hepcidin, along with known freely circulating and protein-bound solutes, in blood and dialysate of patients with ESRD undergoing PET. We used this model to explore its suitability to quantify hormone binding, and therefore to unravel the extent of hepcidin binding in the circulation, by studying if the measured PC of hepcidin fits the curve describing the relation between MW and PC of free circulating solutes.

\section{Results}

In total, 14 patients with ESRD participated in this study. Mean age was 67 years, total creatinine clearance was between 56.4 and $129.5 \mathrm{~L} /$ week $/ 1.73 \mathrm{~m}^{2}$, and residual creatinine clearance was between 25.7 and 100.0 L/week/1.73 $\mathrm{m}^{2}$ (Table 1). The start time of the PET after an overnight dwell was between 8:30 a.m. and noon. Four patients used prednisone (Table 1), which interferes with both total and free cortisol measurement due to metabolism into prednisolone. Therefore, cortisol measurements were not performed in these patients. 
Table 1. Patient characteristics.

\begin{tabular}{|c|c|c|c|c|c|c|}
\hline ID & $\begin{array}{l}\text { Age } \\
\text { (yrs) }\end{array}$ & $\begin{array}{l}\text { Gender } \\
(\mathrm{M} / \mathrm{F})\end{array}$ & Underlying Disease & $\begin{array}{c}\text { Use of } \\
\text { Prednisone }\end{array}$ & $\begin{array}{c}\text { Creatinine } \\
\text { Clearance } \\
\text { (L/week } / 1.73 \mathrm{~m}^{2} \text { ) } \\
\text { Total (residual) }\end{array}$ & $\begin{array}{l}\text { Start Time } \\
\text { PET (a.m.) }\end{array}$ \\
\hline 1 & 73 & $\mathrm{~F}$ & Primary amyloidosis & No & $61.1(32.3)$ & 10:00 \\
\hline 2 & 82 & M & $\begin{array}{c}\text { Renal vascular disease due to } \\
\text { hypertension }\end{array}$ & No & $56.4(25.7)$ & 09:30 \\
\hline 3 & 55 & $\mathrm{~F}$ & Lupus erythematosus & $1 \times 7.5 \mathrm{mg}$ & $99.3(73.7)$ & 10:00 \\
\hline 4 & 74 & M & $\begin{array}{l}\text { Renal vascular disease due to } \\
\text { hypertension }\end{array}$ & No & $68.2(34.5)$ & 08:30 \\
\hline 5 & 72 & M & $\operatorname{IgA}$ nephropathy & No & $118.2(69.6)$ & 10:00 \\
\hline 6 & 64 & M & Renal vascular disease type unspecified & $1 \times 7.5 \mathrm{mg}$ & $70.5(37.1)$ & $12: 00$ \\
\hline 7 & 66 & M & Diabetes mellitus type 2 & No & $100.8(63.9)$ & 10:15 \\
\hline 8 & 53 & M & $\begin{array}{l}\text { Chronic renal failure etiology } \\
\text { unknown/uncertain }\end{array}$ & No & $71.7(43.2)$ & 12:00 \\
\hline 9 & 76 & M & $\begin{array}{c}\text { Renal vascular disease due to } \\
\text { hypertension }\end{array}$ & No & $114.0(75.7)$ & 12:00 \\
\hline 10 & 72 & M & Renal vascular disease type unspecified & No & $128.6(100.0)$ & 10:00 \\
\hline 11 & 55 & $\mathrm{~F}$ & IgA nephropathy & $2 \times 5 \mathrm{mg}$ & $122.6(77.8)$ & $11: 30$ \\
\hline 12 & 61 & $\mathrm{~F}$ & Renal vascular disease type unspecified & $1 \times 5 \mathrm{mg}$ & $129.5(96.7)$ & 11:00 \\
\hline 13 & 64 & $\mathrm{~F}$ & Diabetes mellitus type 2 & No & $101.8(35.9)$ & 09:30 \\
\hline 14 & 77 & M & $\begin{array}{c}\text { Renal vascular disease due to } \\
\text { hypertension }\end{array}$ & No & $118.1(73.1)$ & 09:00 \\
\hline
\end{tabular}

${ }^{1}$ Since use of prednisone was found to decrease the serum cortisol concentrations and interferes with measurement of both free and total cortisol, these measurements were not performed in patients using prednisone.

We measured and subsequently calculated the PC of free circulating solutes urea, creatinine, ß2-microglobulin, albumin, and IgG (Table 2), and plotted the logarithmically transformed PC of each analyte against its MW for each patient. By applying a linear mixed model, we obtained a curve with a 95\% prediction interval describing the relation between MW and PC of free circulating solutes (Figure 1, solid dots). We found the equation defining the curve to be:

$$
\log 10(\mathrm{PC})=4.5744-0.05063 * \sqrt[3]{\mathrm{MW}}
$$

Table 2. Molecular weight, measured plasma, and dialysate concentrations (mean $\pm \mathrm{sd}$ ) and subsequent calculated peritoneal clearances (mean $\pm \mathrm{sd}$ ) for all solutes.

\begin{tabular}{|c|c|c|c|c|c|}
\hline Solute & MW (Da) & $\begin{array}{c}\text { [Plasma] } \\
t=0 \mathrm{~h} \\
\text { Mean (sd) }\end{array}$ & $\begin{array}{c}\text { [Dialysate] }^{1} \\
t=1 \mathrm{~h} \\
\text { Mean (sd) }\end{array}$ & $\begin{array}{c}\text { Peritoneal } \\
\text { Clearance } \\
(\mu \mathrm{L} / \mathrm{min}) \mathrm{t}=0-1 \mathrm{~h} \\
\text { Mean }(\mathrm{sd})\end{array}$ & $\mathbf{N}$ \\
\hline Urea (mmol/L) & 60.0 & $21.5(6.6)$ & $15.0(6.1)$ & $26,959.1(6211.8)$ & 14 \\
\hline Creatinine $(\mu \mathrm{mol} / \mathrm{L})$ & 113.1 & $542.0(172.6)$ & $296.9(119.9)$ & $21,499.6(5861.6)$ & 14 \\
\hline Testosterone, total $(\mathrm{nmol} / \mathrm{L})^{2}$ & 288.0 & $8.6(7.3)$ & $0.1(0.1)$ & $507.7(260.5)$ & $13^{3}$ \\
\hline Cortisol, total $(\mathrm{nmol} / \mathrm{L})^{4}$ & 362.5 & $229.1(134.4)$ & $8.4(5.8)$ & $1439.0(490.8)$ & $10^{5}$ \\
\hline Cortisol, free (nmol/L) & 362.5 & $12.7(7.7)$ & $8.4(5.8)$ & $25,030.8(8123.9)$ & $9^{5,6}$ \\
\hline Hepcidin (nmol/L) & 2789.4 & $10.6(9.1)$ & $1.2(1.1)$ & $4337.5(1713.1)$ & $13^{7}$ \\
\hline ß2-microglobulin (mg/L) & $13,713.0$ & $18.7(5.0)$ & $1.4(0.9)$ & $2804.0(1587.8)$ & 14 \\
\hline Albumin $(\mathrm{g} / \mathrm{L})$ & 66437.0 & $32.1(4.9)$ & $0.2(0.1)$ & $242.3(164.2)$ & 14 \\
\hline $\operatorname{IgG}(\mathrm{mg} / \mathrm{L})$ & $150,000.0$ & $7496.0(1730.3)$ & $23.1(12.7)$ & $129.3(84.7)$ & 14 \\
\hline
\end{tabular}

${ }^{1}$ Average dialysate volumes were $2364 \mathrm{~mL}$ (range $1500-2250 \mathrm{~mL}$ ). ${ }^{2}$ Approximately $2 \%$ of the total plasma testosterone is circulating free in both men and women $[9,26]$; in men $44-65 \%$ of testosterone is bound to sex hormone binding globulin and $33-54 \%$ bound to albumin; in women $66-78 \%$ of testosterone is bound to sex hormone binding globulin (MW $90 \mathrm{kDa}$ ), and 20-32\% to albumin (MW 66,437 Da) [9]. ${ }^{3}$ One patient was excluded since dialysate concentrations of testosterone were below the LLOD. ${ }^{4}$ Approximately $5 \%$ of the total plasma cortisol is circulating free, since $80-90 \%$ of cortisol is bound to corticosteroid binding globulin (MW $52 \mathrm{kDa}$ ) and 10-15\% to albumin (MW $66,437 \mathrm{Da}$ ) [6]. ${ }^{5}$ Patient $3,6,11$, and 12 used prednisone, which interferes with cortisol measurement. The results of these patients were excluded. ${ }^{6}$ For one patient material was insufficient to measure free cortisol. ${ }^{7}$ One patient was excluded since both plasma and dialysate concentrations of hepcidin were below the LLOD. 


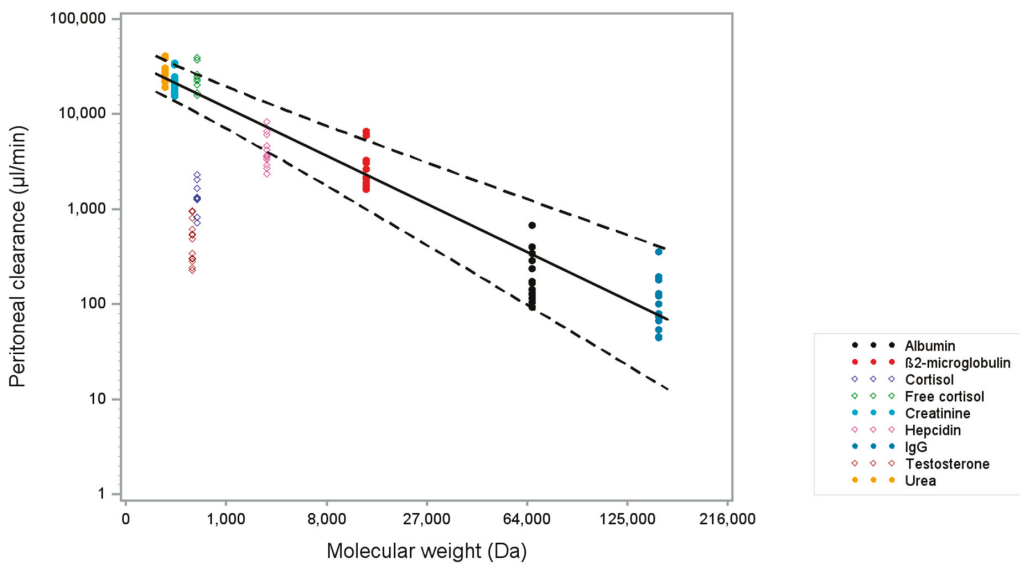

Figure 1. Peritoneal clearances $(\mu \mathrm{L} / \mathrm{min})$ as a function of molecular weight (Da). The logarithmically transformed peritoneal clearance (y-axis) of each specific analyte for each patient was plotted against the cube root of their molecular weight (x-axis). Based on the known free circulating analytes, i.e., urea, creatinine, $\beta 2$-microglobulin, albumin, and IgG (solid dots), a curve was established describing the relation between clearance and molecular weight (solid line) with a $95 \%$ prediction interval (dashed lines). Hepcidin, free cortisol, total cortisol, and total testosterone measurements (open dots) were plotted in the figure thereafter.

We tested the validity of our model by measuring both total (i.e., free and protein-bound) and free cortisol and total testosterone. As expected, the PC measurements of total cortisol (Figure 1, open blue dots) and total testosterone (Figure 1, open brown dots) plotted against the MW of the unbound molecules were below the free solutes curve, confirming their predominantly bound status. Their binding percentages were calculated to be $91 \%( \pm 3 \%)$ and $97 \%( \pm 1.5 \%)$, respectively, corresponding to what is described in literature [6,9]. The mean of free cortisol PC measurements (Figure 1, open green dots) fell within the $95 \%$ confidence interval to the free solutes curve, confirming its unbound status.

We subsequently plotted the hepcidin PC measurements against the MW of hepcidin in the graph (Figure 1, open pink dots). Interestingly, the mean PC for hepcidin was found to lie below the established free solute curve. The calculated binding percentage is $40 \%( \pm 23 \%)$, suggesting that hepcidin circulates in a more unbound than bound status, with a large inter-individual variability. Since several hepcidin PC measurements fell within the 95\% confidence interval, we can exclude a predominantly protein-bound status of hepcidin, as we found for total cortisol and testosterone.

Last, we correlated the PC of all analytes with the PC of urea (Figure 2) to ensure that the variation in PC measurement of each analyte is solely caused by patient-specific transport characteristics. We have chosen urea for this since its PC measurements showed the lowest variation. We found a strong correlation between urea and creatinine (Spearman $\mathrm{r}=0.9604, p<0.0001), \beta 2$-microglobulin (Spearman $r=0.7890, p=0.0008$ ), free cortisol (Spearman $r=0.9333, p=0.0002$ ), total cortisol (Spearman $r=0.7697, p=0.0092$ ), and total testosterone (Spearman $r=0.6593, p=0.0142$ ). We observed a weaker correlation between urea and IgG (Spearman $\mathrm{r}=0.5516, p=0.0408$ ) and urea and albumin (Spearman $\mathrm{r}=0.5077, p=0.0638$ ). However, we did not find any correlation between urea and hepcidin (Spearman $r=0.2198, p=0.4706)$. Further analysis showed that hepcidin does not correlate with any of the other analytes (Figure 3), except albumin (Spearman $r=0.6648, p=0.0132$ ). These results confirm a large inter-individual variation in hepcidin clearance, independent of peritoneal transport characteristics. Although this might influence the accuracy of the determined binding percentage, we conclude that a substantial proportion of hepcidin is freely circulating and exclude that circulating hepcidin is predominantly bound to plasma proteins. 

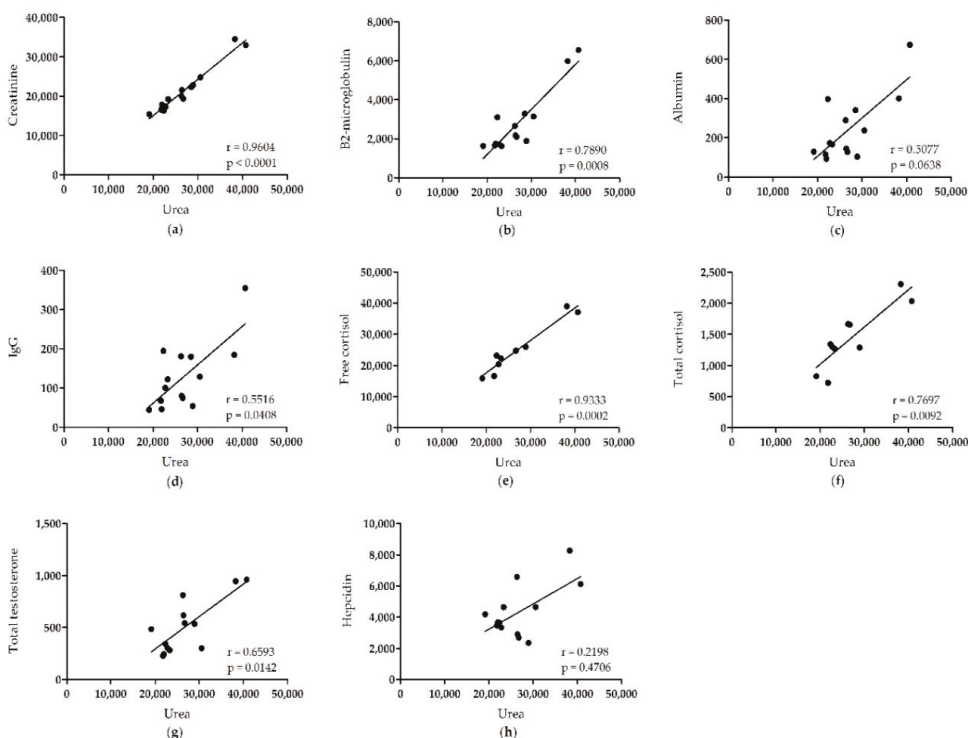

Figure 2. Correlations among the peritoneal clearance of urea with all analytes in patients with end-stage renal disease undergoing a peritoneal equilibration test. The peritoneal clearance of urea was correlated to the peritoneal clearance of (a) creatinine, (b) $\beta 2$-microglobulin, (c) albumin, (d) IgG, (e) free cortisol, (f) total cortisol, (g) total testosterone, and (h) hepcidin. The strength of the correlation was measured using Spearman's correlation coefficient (r).
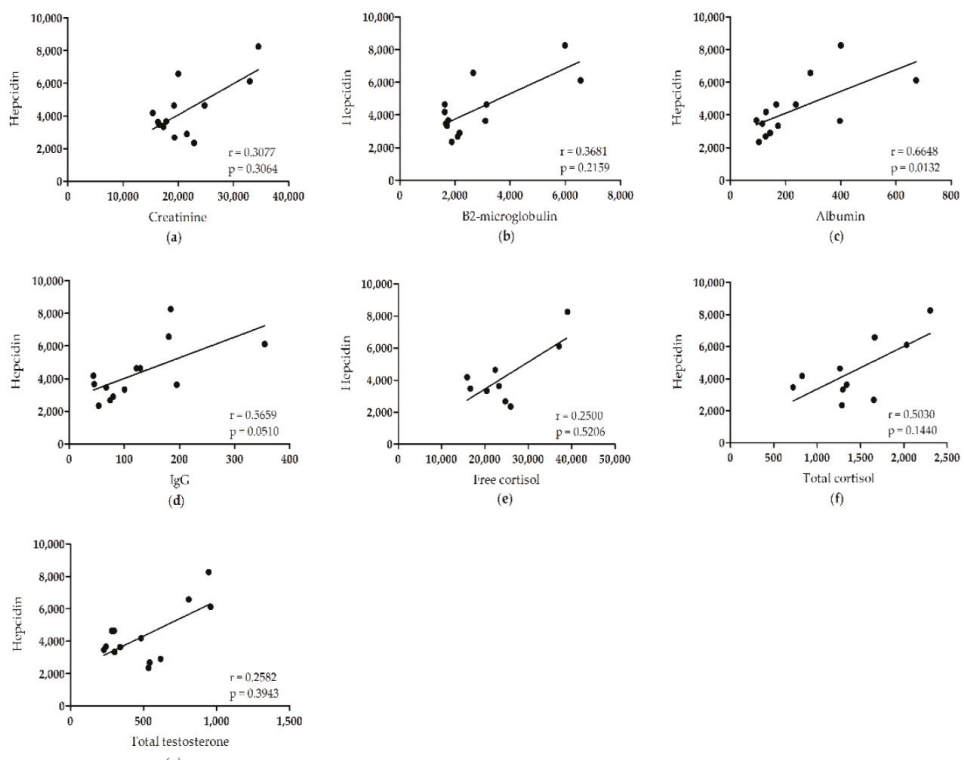

(g)

Figure 3. Correlations among the peritoneal clearance of hepcidin with all analytes in patients with end-stage renal disease undergoing a peritoneal equilibration test. The peritoneal clearance of hepcidin was correlated to the peritoneal clearance of (a) creatinine, (b) $\beta 2$-microglobulin, (c) albumin, (d) IgG, (e) free cortisol, (f) total cortisol, and (g) total testosterone. The strength of the correlation was measured using Spearman's correlation coefficient $(r)$. 


\section{Discussion}

We applied the principle of PD to study the plasma protein binding of hepcidin in a functional human setting for the first time. To this end, we measured hepcidin along with known freely circulating and predominantly protein-bound solutes in blood and dialysate of patients with ESRD treated with PD undergoing PET. Our findings exclude that circulating hepcidin is predominantly bound to plasma proteins; however, the lack of correlation between hepcidin clearance and the clearance of the other analytes question the suitability of this model to determine an accurate binding percentage for this hormone.

Our finding that hepcidin is not predominantly bound is in line with other literature, in which a merely freely circulating hepcidin was observed using gel chromatography on human serum samples, followed by Liquid Chromatography-Mass Spectrometry (LC-MS/MS) [12]. In fact, other peptide hormones such as human growth hormone [27], insulin [28], and cardiac natriuretic hormones [29] circulate freely, since peptide hormones are often water-soluble and can, therefore, easily be transported via the cardiovascular system without requiring carrier proteins [30,31]. In addition, hepcidin is rapidly excreted by the kidneys, leading to a short half-life of only several hours [32-34]. Moreover, circulating hepcidin concentrations can change rapidly with subsequent effects on the circulating iron levels within 1-2 h [35,36]. Theoretically, this potential of a fast production $[33,35,37]$ and quick turnover of hepcidin would preclude the need for protein binding [30].

Our observations differ from previous findings describing high hepcidin binding [10,11]. We believe this reported high binding percentage of $\approx 89 \%$ might be attributed to the excess of hepcidin (i.e., 100 times higher than physiological conditions) that was used in the experimental set-up, in combination with physiological $\alpha 2 \mathrm{M}$ concentrations. This might have caused nonspecific binding of hepcidin, which the molecule is prone to due to its amphipathic character [38].

To the best of our knowledge, there are currently no established in vivo models to study protein binding and free drug or biomarker concentrations, which makes our explorative approach to study the functional protein binding of hormones unique. PET is regularly used as diagnostic test to characterize the functionality and transport properties of the peritoneal membrane in PD patients. Therefore, the strength of using PET is that dialysate sampling for research purposes provides human data with no additional burden for patients and it is a relatively simple, quick, and affordable method. Albeit we circumvent the disadvantages of in vitro techniques used to assess free hormone concentrations in diagnostic medicine, several limitations of our method were discovered during the study.

First, hepcidin did not correlate with urea or any of the other analytes, except albumin, suggesting that other variables besides patient-specific peritoneal transport characteristics may have affected hepcidin PC quantification. This raises the question if we can infer an accurate binding percentage for hepcidin, despite the fact that the validity of our model is confirmed by total cortisol and testosterone measurements and deduction of their binding percentages.

One of the possible explanations for the lack of correlation is the circadian rhythm of hepcidin, with plasma levels increasing during the day [39-43]. Due to practical concerns, blood and dialysate samples were not collected at the same time point, which could influence the determined hepcidin clearance differently for each patient. Nonetheless, in our previous study [43], the serum hepcidin median increased only by $2.5 \%$ between 11:00 and 13:30 amongst 24 participants. Therefore, the influence of hepcidins circadian rhythm seems unlikely since we used a time interval of only $1 \mathrm{~h}$ between blood and dialysate collection and PET start times were between 8:30 and noon. In addition, we did find a strong correlation between urea and both free and total cortisol, a hormone which also follows a circadian rhythm [44], suggesting the influence of a circadian rhythm is negligible.

Second, our study population suffers from ESRD and may therefore differ from healthy subjects, although there is no data to support the idea that peritoneal transport is affected by kidney function. It is described, however, that renal failure leads to the accumulation of uremic toxins in blood and tissues. These toxins can compete with other substrates for plasma protein binding to, for example, albumin [45]. As a result, the free fraction of a substrate of albumin will be increased. The strong 
correlation between hepcidin and albumin could imply binding of hepcidin to albumin and, therefore, the presence of uremic toxins might explain the observed inter-individual variability between hepcidin measurements. This might have led to an overestimation of the free fraction of hepcidin. However, testosterone and cortisol are also partially bound to albumin and we see no effect on their measurements. Therefore, interference of uremic toxins appears less likely. Nonetheless, we suggest our data should be validated and confirmed in healthy individuals or patients with a normal glomerular filtration rate.

Third, we cannot exclude our results are affected by production of hepcidin by mesothelial cells of the peritoneal membrane [46]. However, we feel that this is rather unlikely due to the high volume $(2000 \mathrm{~mL})$ new dialysate infused at $\mathrm{t}=0$ and the short dialysate time of $60 \mathrm{~min}$.

Fourth, it is known that macromolecules may be removed from the peritoneal cavity by lymphatic absorption, which is independent of molecular size [47]. We observed a weak correlation between the small molecule urea and both macromolecules albumin and IgG. This might indicate that transport of these molecules is not solely dependent on permeability of the peritoneum, but also on lymphatic absorption, which would influence the established curve and could possibly introduce the observed inter-individual variation.

Last, clearance measurements of both hepcidin and albumin might be affected by their adherence to the dialysis bag, since both molecules possess nonspecific binding characteristics $[38,48]$. Due to their amphipathic character and suggested subsequent adherence to laboratory plastics, an extra factor of inter-individual variation is introduced, independent of patient specific peritoneal transport characteristics. This could explain the lack of correlation with other analytes. Regarding the assessment of hepcidins binding percentage, this would imply that the hepcidin concentration in dialysate, and therefore its clearance, might be underestimated and the free fraction would actually be higher.

Knowledge on the binding percentage of hepcidin is of great importance for correct quantification of the bioactive hormone, which in turn is key for both interpretation and standardization of hepcidin measurements in diagnostics of iron related disorders [1]. Characterization of hepcidin as measurand will add a key aspect to its metrological traceability chain that has recently been established, which is needed to obtain global uniform reference intervals and clinical decision limits for diagnostics [13]. Furthermore, correct analysis and interpretation of hepcidin measurement is essential in target assessment of clinical trials with hepcidin agonists and antagonists. These therapeutics are in development for treatment of several iron metabolism disorders such as hereditary hemochromatosis or anemia of inflammation [1,14]. A strong correlation has been observed between hepcidin-25 results of a wide variety of assays $[13,49,50]$. However, possible protein-binding could be an issue in correct hepcidin quantification when measuring target engagement of hepcidin antagonists that directly bind hepcidin in the circulation. These compounds display a high affinity for hepcidin and therefore specifically for the assessment of hepcidin antagonist efficiency, the remaining free, non-antagonist bound hepcidin should be quantified [51] rather than total hepcidin [52-54].

We can conclude that hepcidin is not predominantly bound and suggest that a substantial proportion is freely circulating, enabling direct and rapid bioactivity of the hormone. This is an important step towards unraveling human hepcidin plasma protein binding, although refinement of the model by inclusion of more patients and using more analytes with different MWs could help improve accuracy of our findings. Thereby, analytes with a high MW should preferably be excluded to circumvent influence of lymphatic absorption. Moreover, to definitively unravel hepcidin plasma protein binding, future studies must include studies on hepcidin production by mesothelial layer of the peritoneum and the prevention of nonspecific adherence of hepcidin in pre-analysis, which currently hampers (standard) dialysis techniques in diagnostic medicine. 


\section{Materials and Methods}

\subsection{Sample Collection}

PET was performed according to the protocol of Isala hospital, Zwolle, The Netherlands. After an 10-12 h overnight dwell, a 2-Liter bag of 3.86\% glucose solution (Baxter Healthcare Ltd., Newbury, UK) was instilled and allowed to dwell for $4 \mathrm{~h}$ [18]. Dialysate sampling was performed at $1 \mathrm{~h}$ of dwell time $(t=1 \mathrm{~h})$, since peritoneal transport of solutes with a low MW $(<200 \mathrm{Da})$ will decrease over a longer period of time due to saturation of the dialysate [22]. For sampling, all dialysate fluid was collected in a plastic (PVC) bag and mixed ex vivo before a sample was taken, to assure dialysate samples were representative for the fluid in the peritoneal cavity. Thereafter, the remaining dialysate was returned into the peritoneal cavity. Dialysate from 14 consecutive patients with ESRD who underwent PD was collected in tubes both with and without bovine serum albumin $(1 \mathrm{~g} / 50 \mathrm{~mL}$, Sigma-Aldrich, Saint Louis, MO, USA), as for measurements of hepcidin and IgG, addition of albumin prevents adhesion to the tubes and subsequent loss. Blood samples were drawn prior to dialysis $(t=0 \mathrm{~h})$ in both heparin plasma and serum tubes. All were centrifuged at $2000 \mathrm{~g}$ for $10 \mathrm{~min}$. Blood and dialysate samples were aliquoted and immediately stored at $-80^{\circ} \mathrm{C}$ until measurement.

\subsection{Laboratory Measurements}

We measured total hepcidin concentrations (i.e., the sum of bound and unbound full length hepcidin-25), as well as freely circulating solutes urea, creatinine, $\beta 2$-microglobulin, albumin, IgG, total testosterone (free and protein-bound), total cortisol (free and protein-bound), and free cortisol in blood and dialysate.

Analytical methods are described in Appendix A. All measurements were performed in freshly thawed aliquots within 8 months after collection.

\subsection{Ethics}

The study was approved by the Ethics Committee and the Board of Directors of Isala hospital, Zwolle, The Netherlands, and has been in accordance with the Helsinki Declaration. All patients signed informed consent prior to participation and all samples were blinded.

\subsection{Calculations and Statistical Analysis}

Measurement results for solutes below the lower limit of detection (LLOD) were excluded. We calculated PC $(\mu \mathrm{L} / \mathrm{min})$ for each analyte using the dialysate sample taken at $\mathrm{t}=1 \mathrm{~h}$ and blood sample taken at $\mathrm{t}=0 \mathrm{~h}$ of each analyte, using the patient-specific dialysate volume and a dialysis time of $60 \mathrm{~min}$ as:

Peritoneal clearance $(\mu \mathrm{L} / \mathrm{min})=[$ Dialysate $] /[$ Blood $] \times($ Volume dialysate $) /($ Duration of dialysis $)$.

Logarithmic transformation was used for PC data before statistical analysis, as the data was not normally distributed. In addition, we used a cube root scaling for MW, since transport rates are related to size and thus radius ( $\mathrm{r}$ ), and considering volume as a three-dimensional characteristic of the radius $\left(\mathrm{r}^{3}\right)$. The curve describing the relation between MW and PC of all analytes was estimated with a linear mixed model using a random slope and random intercept. The expected PC of each analyte could be calculated using its MW and the equation of the curve. We calculated the binding percentage as:

$$
\text { Binding percentage }(\%)=(1-(\text { Measured PC }) /(\text { Expected PC })) \times 100 \% \text {. }
$$

In this equation, the measured PC divided by the expected PC represents the free hormone fraction. The strength of a linear association between the clearances of two analytes was measured using Spearman's correlation coefficient. 
All statistical analyses were performed with SAS software, version 9.4 (SAS Institute, Inc. Cary, NC, USA) and GraphPad Prism 5.03 (GraphPad Software Inc., La Jolla, CA, USA).

Author Contributions: Conceptualization, C.L.; H.P.; J.W. and D.S.; methodology, L.D.; C.L.; H.P.; J.W. and D.S.; software, H.G.; validation, A.H. and D.S.; formal analysis, H.G. and J.H.; investigation, L.D.; C.L. and H.P.; resources, C.L.; data curation, L.D.; writing—original draft preparation, L.D.; writing-review and editing, A.H.; R.S., J.W. and D.S.; visualization, H.G. and J.H.; supervision, D.S.; project administration, L.D.

Funding: This research received no external funding.

Acknowledgments: We would like to thank the nurses of the dialysis department of Isala hospital for their help with collecting the samples during PET.

Conflicts of Interest: The authors declare no conflict of interest.

\section{Appendix A}

\section{Laboratory Chemistry Measurements}

Measurements of urea, creatinine, and IgG were performed on a Cobas C8000 random access analyzer (Roche Diagnostics, Basel, Switzerland). Albumin was measured by nephelometry on a BNII system (Siemens, München, Germany). $\beta 2$-microglobulin was measured by a direct sandwich-ELISA, using two polyclonal rabbit anti-human $\beta 2$-microglobulin antibodies, of which one was HRP labeled. The $\mathrm{pH}$ of all peritoneal dialysate samples was 7.5 allowing accurate measurements of $\beta 2$-microglobulin.

\section{Measurement of Hepcidin in Serum and Peritoneal Dialysate}

Measurements of hepcidin were performed by a combination of weak cation exchange chromatography and time-of-flight mass spectrometry (WCX-TOF MS) using a stable hepcidin- $25^{+40}$ isotope as internal standard for quantification [55]. This MS-based assay determines total hepcidin (i.e., the sum of bound and unbound fraction). Peptide spectra were generated on a Microflex LT matrix-enhanced laser desorption/ionisation TOF MS platform (Bruker Daltonics, Hamburg, Germany). Hepcidin concentrations were expressed as $\mathrm{nmol} / \mathrm{L}$. The lower limit of quantification of this method was $0.5 \mathrm{nM}$.

\section{Measurement of Total Cortisol and Total Testosterone in Serum}

Cortisol and testosterone were analyzed by Liquid Chromatography-Mass Spectrometry (LC-MS/MS) after protein precipitation and solid-phase extraction. Internal standard $\left[{ }^{2} \mathrm{H}_{4}\right]$-cortisol and $\left[{ }^{13} \mathrm{C}_{3}\right]$-testosterone (Isoscience, Ambler, PA, USA) was added to $100 \mu \mathrm{L}$ serum. Subsequently, $300 \mu \mathrm{L}$ acetonitrile with $0.1 \%$ formic acid was added for protein precipitation and $300 \mu \mathrm{L} \mathrm{H}_{2} \mathrm{O}$ was added to $200 \mu \mathrm{L}$ supernatant followed by solid phase extraction (Oasis HLB 1cc, Waters, Milford, MA, USA). The eluate (methanol:isopropanol 95:5) was dried under a stream of $\mathrm{N}_{2}$ gas, reconstituted in methanol:water (3:7) and injected $(10 \mu \mathrm{L})$ into an Agilent Technologies 1290 Infinity Ultra High Performance Liquid Chromatography (UHPLC)-system (Agilent Technologies, Agilent, Santa Clara, CA, USA) equipped with a BEH C18 $(1.7 \mu \mathrm{m} 2.1 \times 50 \mathrm{~mm})$ analytical column (Waters Corp.) at $60{ }^{\circ} \mathrm{C}$. Mobile phase A (methanol:water 20:80 $+2 \mathrm{mM} \mathrm{NH}_{4} \mathrm{CH}_{3} \mathrm{COO}+0.1 \%$ formic acid) and $\mathrm{B}$ (methanol:water 98:2 $+2 \mathrm{mM} \mathrm{NH}_{4} \mathrm{CH}_{3} \mathrm{COO}+0.1 \%$ formic acid) were run in a gradient $(0.4 \mathrm{~mL} / \mathrm{min}$ ). Start gradient 70:30 A:B for $2.5 \mathrm{~min}$; then to $40: 60 \mathrm{~A}: \mathrm{B}$ in $3.5 \mathrm{~min}$; followed by a gradient in $0.5 \mathrm{~min}$ to $2: 98$ to remain such for $0.5 \mathrm{~min}$ and thereafter to $70: 30 \mathrm{~A}: \mathrm{B}$ in $0.5 \mathrm{~min}$ and remain such for $0.5 \mathrm{~min}$. Retention time was $1.41 \mathrm{~min}$ and $4.37 \mathrm{~min}$ for cortisol and testosterone, respectively. Total run time was $8 \mathrm{~min}$. A 9-point calibration curve was used (cortisol and testosterone, Steraloids). An Agilent 6490 tandem mass spectrometer (Agilent Technologies, Agilent, Santa Clara, CA, USA) was operated in the electrospray positive ion mode, with a capillary voltage $3.5 \mathrm{kV}$, fragmentor voltage $380 \mathrm{~V}$, sheath gas temperature $350^{\circ} \mathrm{C}$, and gas temperature $150{ }^{\circ} \mathrm{C}$ with $\mathrm{N}_{2}$ collision gas. Two transitions (qualitative and quantitative) were monitored. Transitions (Q1 > Q3) were m/z $363.4>97.1(34 \mathrm{~V})$ and m/z $363.4>$ 
$121.1(25 \mathrm{~V})$ for cortisol; m/z $367.4>97.1(34 \mathrm{~V})$ and m/z $367.4>121.1(25 \mathrm{~V})$ for [2H4]-cortisol. m/z $289.2>109.1(30 \mathrm{kEV})$ and $\mathrm{m} / \mathrm{z} 289.2>97.1(30 \mathrm{kEV})$ for testosterone; $\mathrm{m} / \mathrm{z} 292.3>112.1(30 \mathrm{kEV})$ and $\mathrm{m} / \mathrm{z} 292.3>100.1$ (30 kEV) for 13C3-testosterone. Dwell time was $100 \mathrm{~ms}$ and $50 \mathrm{~ms}$ for cortisol and testosterone, respectively. The method was linear assessed by CLSI EP6 protocol [56]. For cortisol total $\mathrm{CV}$ is $3.6 \%$ at $300 \mathrm{nmol} / \mathrm{L}$ and $3.1 \%$ at $1080 \mathrm{nmol} / \mathrm{L}$. For testosterone total $\mathrm{CV}$ is $6.0 \%$ at $0.9 \mathrm{nmol} / \mathrm{L}$ and $5.3 \%$ at $19 \mathrm{nmol} / \mathrm{L}$.

Measurement of Free Cortisol in Serum by Equilibrium Dialysis_Liquid Chromatography Tandem Mass Spectrometry (LC-MS/MS)

Serum was dialyzed in a multi-cell equilibrium dialyzer using Teflon dialyzing cells consisting of two identical parts between which a flat membrane is fitted (Dianorm-Geräte). The dialysis cells are incubated in a water bath with constant agitation by a rotating apparatus and temperature during dialysis was maintained at $37 \pm 0.5^{\circ} \mathrm{C}$, by constant monitoring with an immersion thermostatic system (Tinytag TGP-4020 logger and PB5001-1M5 sonde; Gemini data loggers). The dialysis membranes were prepared from Dianorm (Diachema dialysis membranes 10.14) with a cut-off of $5 \mathrm{kDa}$. Equilibrium dialysis was performed for $5 \mathrm{~h}$ with $180 \mu \mathrm{L}$ serum against $180 \mu \mathrm{L}$ HEPES buffer; while rotating the dialysis apparatus at $20 \mathrm{rpm}$. The HEPES buffer used for equilibrium dialysis was composed to reflect the electrolyte composition and $\mathrm{pH}$ of serum and contained in addition to $12.570 \mathrm{~g} / \mathrm{L}$ $\mathrm{N}$-(2-hydroxyethyl)piperazine-N'-(2-ethanesulfonic acid (HEPES), $5.353 \mathrm{~g} / \mathrm{L} \mathrm{NaCl}, 0.200 \mathrm{~g} / \mathrm{L} \mathrm{KCl}$, $0.224 \mathrm{~g} / \mathrm{L} \mathrm{KH} \mathrm{PO}_{4}, 0.275 \mathrm{~g} / \mathrm{L} \mathrm{MgSO}_{4} \cdot 7 \mathrm{H}_{2} \mathrm{O}, 0.300 \mathrm{~g} / \mathrm{L}$ urea, $0.275 \mathrm{~g} / \mathrm{L} \mathrm{CaCl}_{2} \cdot 2 \mathrm{H}_{2} \mathrm{O}, 0.900 \mathrm{~g} / \mathrm{L} \mathrm{NaOH}$, and $0.520 \mathrm{~g} / \mathrm{L} \mathrm{NaN}_{3}$ (Merck, Darmstadt, Germany). The $\mathrm{pH}$ was adjusted with $\mathrm{HCl}$ to $\mathrm{pH} 7.40$ (at $37^{\circ} \mathrm{C}$ ). The buffer was diluted by ultrapure water produced with a Milli Advantage A10 and $100 \mu \mathrm{L}$ dialysate was subsequently used for total cortisol measurement by LC-MS/MS as described above.

\section{Measurement of Total Cortisol and Total Testosterone in Peritoneal Dialysate}

Testosterone and cortisol in peritoneal dialysate were analyzed by LC-MS/MS after solid-phase extraction. Sample preparation consisted of internal standard addition [13C3]-testosterone (Isoscience, Ambler, PA, USA) and $\left[{ }^{3} \mathrm{H}_{4}\right]$-cortisol (Isoscience) to $1000 \mu \mathrm{L}$ dialysate and solid phase extraction (SPE) using Oasis ${ }^{\circledR}$ MCX 1cc cartridges (Waters Corp, Milford, MA, USA).

Columns were pre-equilibrated with $1 \mathrm{~mL} \mathrm{MeOH}: \mathrm{IPA}$ (95:5) and subsequently washed with $1 \mathrm{~mL}$ $\mathrm{H}_{2} \mathrm{O}$. After application of the sample, columns were washed with $1 \mathrm{~mL} \mathrm{H}_{2} \mathrm{O}: \mathrm{NH}_{4} \mathrm{OH}$ (95:5) and $1 \mathrm{~mL}$ $\mathrm{MeOH}: \mathrm{H}_{2} \mathrm{O}(20 / 80)+2 \% \mathrm{HCOOH}$. The $300 \mu \mathrm{L}$ eluate $(\mathrm{MeOH})$ was dried under a stream of $\mathrm{N}_{2}$ gas, reconstituted in $\mathrm{MeOH}: \mathrm{H}_{2} \mathrm{O}$ (30:70). A nine-point calibration series was used (using testosterone and cortisol both from Steraloids). Calibrators, quality controls, and samples (reconstituted in $100 \mu \mathrm{L}$ ) were injected $(10 \mu \mathrm{L})$ into an Agilent Technologies 1290 Infinity VL UHPLC-system (Agilent Technologies, Santa Clara, USA), equipped with a BEH C18 $(1.7 \mu \mathrm{m} 2.1$ X $50 \mathrm{~mm})$ analytical column (Waters Corp., Milford, MA, USA) at $60{ }^{\circ} \mathrm{C}$. Mobile phase A $\left(\mathrm{MeOH} / \mathrm{H}_{2} \mathrm{O}(20: 80)+2 \mathrm{mM} \mathrm{NH}_{4} \mathrm{CH}_{3} \mathrm{COO}+0.1 \%\right.$ $\mathrm{HCOOH})$ and $\mathrm{B}\left(\mathrm{MeOH} / \mathrm{H}_{2} \mathrm{O}(98: 2)+2 \mathrm{mM} \mathrm{NH}_{4} \mathrm{CH}_{3} \mathrm{COO}+0.1 \% \mathrm{HCOOH}\right)$ were run in a gradient $(0.4 \mathrm{~mL} / \mathrm{min})$. The gradient program was as follows: Start gradient A:B (70:30) for $2.5 \mathrm{~min}$; followed by a gradient in 2 min to $\mathrm{A}: \mathrm{B}(60: 40)$ and subsequent $2.5 \mathrm{~min} \mathrm{~A}: \mathrm{B}$ (35:65). For column washing, a gradient $0.5 \mathrm{~min} A: B(98: 2)$ was established to remain such for $0.5 \mathrm{~min}$. The column was re-equilibrated to A:B (70:30) in $0.5 \mathrm{~min}$ and remained such for $0.5 \mathrm{~min}$. Retention times were $1.5 \mathrm{~min}$ and $4.5 \mathrm{~min}$ for cortisol and testosterone, respectively. An Agilent 6490 tandem mass spectrometer (Agilent Technologies, Santa Clara, CA, USA) was operated in the electrospray positive ion mode. Operating conditions were as follows: Capillary voltage $3.5 \mathrm{kV}$, fragmentor voltage $380 \mathrm{~V}$, sheath gas temperature $350^{\circ} \mathrm{C}$, and gas temperature $150^{\circ} \mathrm{C}$. The collision energy was optimized between 25 and $34 \mathrm{eV}$ for all solutes and Nitrogen was used as collision gas. Two mass transitions were monitored for each analyte and the internal standards. The first transition was used for quantification, the second for confirmation. The transitions (Q1 > Q3) were m/z 289 > 97 and m/z 289 > 109 for testosterone; m/z $292>100$ and m/z 
$292>112$ for [13C3]-testosterone; m/z $363>121$ and m/z $363>97$ for cortisol; m/z $367>121$ and m/z $367>97$ for [3H4]-cortisol. Total run time was $9 \mathrm{~min}$.

For both total and free cortisol PC calculations, we used total cortisol measurements in dialysate, since we assume that all cortisol present in dialysate after $1 \mathrm{~h}$ of dwell time is free considering the large MW of its main binding protein corticosteroid binding globulin (MW $52 \mathrm{kDa}$ ).

\section{References}

1. Girelli, D.; Nemeth, E.; Swinkels, D.W. Hepcidin in the diagnosis of iron disorders. Blood 2016, 127, 2809-2813. [CrossRef] [PubMed]

2. Ekins, R. Measurement of free hormones in blood. Endocr. Rev. 1990, 11, 5-46. [CrossRef] [PubMed]

3. Ekins, R. The free hormone hypothesis and measurement of free hormones. Clin. Chem. 1992, 38, 1289-1293.

4. Mendel, C.M. The free hormone hypothesis: A physiologically based mathematical model. Endocr. Rev. 1989, 10, 232-274. [CrossRef] [PubMed]

5. Faix, J.D. Principles and pitfalls of free hormone measurements. Best Pract. Res. Clin. Endocrinol. Metab. 2013, 27, 631-645. [CrossRef] [PubMed]

6. Bae, Y.J.; Kratzsch, J. Corticosteroid-binding globulin: Modulating mechanisms of bioavailability of cortisol and its clinical implications. Best Pract. Res. Clin. Endocrinol. Metab. 2015, 29, 761-772. [CrossRef]

7. Thienpont, L.M.; Van Uytfanghe, K.; Poppe, K.; Velkeniers, B. Determination of free thyroid hormones. Best Pract. Res. Clin. Endocrinol. Metab. 2013, 27, 689-700. [CrossRef]

8. Morley, J.E.; Patrick, P.; Perry, H.M. Evaluation of assays available to measure free testosterone. Metabolism 2002, 51, 554-559. [CrossRef]

9. Shea, J.; Wong, P.; Chen, Y. Free Testosterone: Clinical Utility and Important Analytical Aspects of Measurement. Adv. Clin. Chem. 2014, 63, 59-84.

10. Peslova, G.; Petrak, J.; Kuzelova, K.; Hrdy, I.; Halada, P.; Kuchel, P.W.; Soe-Lin, S.; Ponka, P.; Sutak, R.; Becker, E; ; et al. Hepcidin, the hormone of iron metabolism, is bound specifically to alpha-2-macroglobulin in blood. Blood 2009, 113, 6225-6236. [CrossRef]

11. Huang, M.L.; Austin, C.J.; Sari, M.A.; Rahmanto, Y.S.; Ponka, P.; Vyoral, D.; Richardson, D.R. Hepcidin bound to alpha2-macroglobulin reduces ferroportin-1 expression and enhances its activity at reducing serum iron levels. J. Biol. Chem. 2013, 288, 25450-25465. [CrossRef] [PubMed]

12. Itkonen, O.; Stenman, U.H.; Parkkinen, J; Soliymani, R.; Baumann, M.; Hamalainen, E. Binding of hepcidin to plasma proteins. Clin. Chem. 2012, 58, 1158-1160. [CrossRef] [PubMed]

13. Diepeveen, L.E.; Laarakkers, C.M.M.; Martos, G.; Pawlak, M.E.; Uguz, F.F.; Verberne, K.; van Swelm, R.P.L.; Klaver, S.; de Haan, A.F.J; Pitts, K.R.; et al. Provisional standardization of hepcidin assays: Creating a traceability chain with a primary reference material, candidate reference method and a commutable secondary reference material. Clin. Chem. Lab. Med. 2019, 57, 864-872. [CrossRef] [PubMed]

14. Crielaard, B.J.; Lammers, T.; Rivella, S. Targeting iron metabolism in drug discovery and delivery. Nat. Rev. Drug Discov. 2017, 16, 400-423. [CrossRef] [PubMed]

15. Bowers, W.F.; Fulton, S.; Thompson, J. Ultrafiltration vs. equilibrium dialysis for determination of free fraction. Clin. Pharmacokinet. 1984, 9 (Suppl. 1), 49-60. [CrossRef] [PubMed]

16. Khanna, R. Solute and Water Transport in Peritoneal Dialysis: A Case-Based Primer. Am. J. Kidney Dis. 2017, 69, 461-472. [CrossRef] [PubMed]

17. Twardowski, Z.J;; Nolph, K.D.; Khanna, R.; Prowant, B.F.; Ryan, L.P.; Moore, H.L.; Nielsen, M.P. Peritoneal equilibration test. Perit. Dial. Bull. 1987, 7, 138-147.

18. Ho-dac-Pannekeet, M.M.; Schouten, N.; Langendijk, M.J.; Hiralall, J.K.; de Waart, D.R.; Struijk, D.G.; Krediet, R.T. Peritoneal transport characteristics with glucose polymer based dialysate. Kidney Int. 1996, 50, 979-986. [CrossRef] [PubMed]

19. Trivedi, H.; Khanna, R.; Lo, W.K.; Prowant, B.F.; Nolph, K.D. Reproducibility of the peritoneal equilibration test in CAPD patients. ASAIO J. 1994, 40, M892-5. [CrossRef]

20. Krediet, R.T.; Boeschoten, E.W.; Struijk, D.G.; Arisz, L. Differences in the peritoneal transport of water, solutes and proteins between dialysis with two- and with three-litre exchanges. Nephrol. Dial. Transplant. 1988, 3, 198-204.

21. Teitelbaum, I.; Burkart, J. Peritoneal dialysis. Am. J. Kidney Dis. 2003, 42, 1082-1096. [CrossRef] [PubMed] 
22. Kagan, A.; Bar-Khayim, Y.; Schafer, Z.; Fainaru, M. Kinetics of peritoneal protein loss during CAPD: I. Different characteristics for low and high molecular weight proteins. Kidney Int. 1990, 37, 971-979. [CrossRef] [PubMed]

23. Kabanda, A.; Goffin, E.; Bernard, A.; Lauwerys, R.; van Ypersele de Strihou, C. Factors influencing serum levels and peritoneal clearances of low molecular weight proteins in continuous ambulatory peritoneal dialysis. Kidney Int. 1995, 48, 1946-1952. [CrossRef] [PubMed]

24. Struijk, D.G. Monitoring of the peritoneal membrane. NDT Plus 2008, 1, 29-35. [CrossRef] [PubMed]

25. Bammens, B.; Evenepoel, P.; Verbeke, K.; Vanrenterghem, Y. Removal of middle molecules and protein-bound solutes by peritoneal dialysis and relation with uremic symptoms. Kidney Int. 2003, 64, 2238-2243. [CrossRef] [PubMed]

26. Bhasin, S.; Cunningham, G.R.; Hayes, F.J.; Matsumoto, A.M.; Snyder, P.J.; Swerdloff, R.S.; Montori, V.M. Testosterone therapy in men with androgen deficiency syndromes: An Endocrine Society clinical practice guideline. J. Clin. Endocrinol. Metab. 2010, 95, 2536-2559. [CrossRef] [PubMed]

27. Frantz, A.G.; Rabkin, M.T. Human Growth Hormone. N. Engl. J. Med. 1964, 271, 1375-1381. [CrossRef]

28. Hua, Q. Insulin: A small protein with a long journey. Protein Cell 2010, 1, 537-551. [CrossRef]

29. Clerico, A.; Del Ry, S.; Giannessi, D. Measurement of cardiac natriuretic hormones (atrial natriuretic peptide, brain natriuretic peptide, and related peptides) in clinical practice: The need for a new generation of immunoassay methods. Clin. Chem. 2000, 46, 1529-1534.

30. Malandrino, N.; Smith, R.J. Synthesis, secretion, and transport of peptide hormones. In Principles of Endocrinology and Hormone Action; Belfiroe, A., LeRoith, D., Eds.; Springer International Publishing: New York, NY, USA, 2018; Volume 1, pp. 29-42.

31. Kronenberg, H. Williams Textbook of Endocrinology, 13th ed.; Elsevier: Amsterdam, The Netherlands, 2016; Chapter 1; pp. 1-11.

32. van Swelm, R.P.; Wetzels, J.F.; Verweij, V.G.; Laarakkers, C.M.; Pertijs, J.C.; van der Wijst, J.; Thevenod, F.; Masereeuw, R.; Swinkels, D.W. Renal Handling of Circulating and Renal-Synthesized Hepcidin and Its Protective Effects against Hemoglobin-Mediated Kidney Injury. J. Am. Soc. Nephrol. 2016, 27, 2720-2732. [CrossRef]

33. Nemeth, E.; Rivera, S.; Gabayan, V.; Keller, C.; Taudorf, S.; Pedersen, B.K.; Ganz, T. IL-6 mediates hypoferremia of inflammation by inducing the synthesis of the iron regulatory hormone hepcidin. J. Clin. Investig. 2004, 113, 1271-1276. [CrossRef] [PubMed]

34. Rivera, S.; Liu, L.; Nemeth, E.; Gabayan, V.; Sorensen, O.E.; Ganz, T. Hepcidin excess induces the sequestration of iron and exacerbates tumor-associated anemia. Blood 2005, 105, 1797-1802. [CrossRef] [PubMed]

35. Kemna, E.; Pickkers, P.; Nemeth, E.; van der Hoeven, H.; Swinkels, D. Time-course analysis of hepcidin, serum iron, and plasma cytokine levels in humans injected with LPS. Blood 2005, 106, 1864-1866. [CrossRef] [PubMed]

36. Rivera, S.; Nemeth, E.; Gabayan, V.; Lopez, M.A.; Farshidi, D.; Ganz, T. Synthetic hepcidin causes rapid dose-dependent hypoferremia and is concentrated in ferroportin-containing organs. Blood 2005, 106, 2196-2199. [CrossRef] [PubMed]

37. Moretti, D.; Goede, J.S.; Zeder, C.; Jiskra, M.; Chatzinakou, V.; Tjalsma, H.; Melse-Boonstra, A.; Brittenham, G.; Swinkels, D.W.; Zimmermann, M.B. Oral iron supplements increase hepcidin and decrease iron absorption from daily or twice-daily doses in iron-depleted young women. Blood 2015, 126, 1981-1989. [CrossRef] [PubMed]

38. Hunter, H.N.; Fulton, D.B.; Ganz, T.; Vogel, H.J. The solution structure of human hepcidin, a peptide hormone with antimicrobial activity that is involved in iron uptake and hereditary hemochromatosis. J. Biol. Chem. 2002, 277, 37597-37603. [CrossRef]

39. Galesloot, T.E.; Vermeulen, S.H.; Geurts-Moespot, A.J.; Klaver, S.M.; Kroot, J.J.; van Tienoven, D.; Wetzels, J.F.; Kiemeney, L.A.; Sweep, F.C.; den Heijer, M.; et al. Serum hepcidin: Reference ranges and biochemical correlates in the general population. Blood 2011, 117, 218-225. [CrossRef]

40. Kemna, E.H.; Tjalsma, H.; Podust, V.N.; Swinkels, D.W. Mass spectrometry-based hepcidin measurements in serum and urine: Analytical aspects and clinical implications. Clin. Chem. 2007, 53, 620-628. [CrossRef]

41. Ganz, T.; Olbina, G.; Girelli, D.; Nemeth, E.; Westerman, M. Immunoassay for human serum hepcidin. Blood 2008, 112, 4292-4297. [CrossRef] 
42. Schaap, C.C.; Hendriks, J.C.; Kortman, G.A.; Klaver, S.M.; Kroot, J.J.; Laarakkers, C.M.; Wiegerinck, E.T.; Tjalsma, H.; Janssen, M.C.; Swinkels, D.W. Diurnal rhythm rather than dietary iron mediates daily hepcidin variations. Clin. Chem. 2013, 59, 527-535. [CrossRef]

43. Kroot, J.J.; Hendriks, J.C.; Laarakkers, C.M.; Klaver, S.M.; Kemna, E.H.; Tjalsma, H.; Swinkels, D.W. (Pre)analytical imprecision, between-subject variability, and daily variations in serum and urine hepcidin: Implications for clinical studies. Anal. Biochem. 2009, 389, 124-129. [CrossRef] [PubMed]

44. Chan, S.; Debono, M. Replication of cortisol circadian rhythm: New advances in hydrocortisone replacement therapy. Ther. Adv. Endocrinol. Metab. 2010, 1, 129-138. [CrossRef] [PubMed]

45. Santana, M.T.; Cerini, C.; Burtey, S. Emerging Roles of Aryl Hydrocarbon Receptors in the Altered Clearance of Drugs during Chronic Kidney Disease. Toxins 2019, 11, 209. [CrossRef] [PubMed]

46. Evans, P.; Cindrova-Davies, T.; Muttukrishna, S.; Burton, G.J.; Porter, J.; Jauniaux, E. Hepcidin and iron species distribution inside the first-trimester human gestational sac. Mol. Hum. Reprod. 2011, 17, 227-232. [CrossRef] [PubMed]

47. Krediet, R.T.; Struijk, D.G.; Koomen, G.C.; Hoek, F.J.; Arisz, L. The disappearance of macromolecules from the peritoneal cavity during continuous ambulatory peritoneal dialysis (CAPD) is not dependent on molecular size. Perit. Dial. Int. 1990, 10, 147-152. [PubMed]

48. Finn, T.E.; Nunez, A.C.; Sunde, M.; Easterbrook-Smith, S.B. Serum albumin prevents protein aggregation and amyloid formation and retains chaperone-like activity in the presence of physiological ligands. J. Biol. Chem. 2012, 287, 21530-21540. [CrossRef] [PubMed]

49. Kroot, J.J.; Kemna, E.H.; Bansal, S.S.; Busbridge, M.; Campostrini, N.; Girelli, D.; Hider, R.C.; Koliaraki, V.; Mamalaki, A.; Olbina, G.; et al. Results of the first international round robin for the quantification of urinary and plasma hepcidin assays: Need for standardization. Haematologica 2009, 94, 1748-1752. [CrossRef]

50. Kroot, J.J.; van Herwaarden, A.E.; Tjalsma, H.; Jansen, R.T.; Hendriks, J.C.; Swinkels, D.W. Second round robin for plasma hepcidin methods: First steps toward harmonization. Am. J. Hematol. 2012, 87, 977-983. [CrossRef]

51. Hohlbaum, A.M.; Gille, H.; Trentmann, S.; Kolodziejczyk, M.; Rattenstetter, B.; Laarakkers, C.M.; Katzmann, G.; Christian, H.J.; Andersen, N.; Allersdorfer, A.; et al. Sustained plasma hepcidin suppression and iron elevation by Anticalin-derived hepcidin antagonist in cynomolgus monkey. Br. J. Pharmacol. 2018, 175, 1054-1065. [CrossRef]

52. Boyce, M.; Warrington, S.; Cortezi, B.; Zollner, S.; Vauleon, S.; Swinkels, D.W.; Summo, L.; Schwoebel, F.; Riecke, K. Safety, pharmacokinetics and pharmacodynamics of the anti-hepcidin Spiegelmer lexaptepid pegol in healthy subjects. Br. J. Pharmacol. 2016, 173, 1580-1588. [CrossRef]

53. van Eijk, L.T.; John, A.S.E.; Schwoebel, F.; Summo, L.; Vauléon, S.; Zöllner, S.; Laarakkers, C.M.; Kox, M.; van der Hoeven, J.G.; Swinkels, D.W.; et al. Effect of the antihepcidin Spiegelmer lexaptepid on inflammation-induced decrease in serum iron in humans. Blood 2014, 124, 2643-2646. [CrossRef] [PubMed]

54. Cooke, K.S.; Hinkle, B.; Salimi-Moosavi, H.; Foltz, I.; King, C.; Rathanaswami, P.; Winters, A.; Steavenson, S.; Begley, C.G.; Molineux, G.; et al. A fully human anti-hepcidin antibody modulates iron metabolism in both mice and nonhuman primates. Blood 2013, 122, 3054-3061. [CrossRef] [PubMed]

55. Laarakkers, C.M.; Wiegerinck, E.T.; Klaver, S.; Kolodziejczyk, M.; Gille, H.; Hohlbaum, A.M.; Tjalsma, H.; Swinkels, D.W. Improved mass spectrometry assay for plasma hepcidin: Detection and characterization of a novel hepcidin isoform. PLoS ONE 2013, 8, 75518. [CrossRef] [PubMed]

56. NCCLS; Tholen, D.W.; Kroll, M.; Astles, J.R.; Caffo, A.L.; Happe, T.M.; Krouwer, J.; Lasky, F. Evaluation of the Linearity of Quantitative Measurement Procedures: A Statistical Approach; Approved Guideline; Clinical Laboratory Standard Institute: Wayne, PA, USA, 2003. 
Article

\title{
L-Ferritin: One Gene, Five Diseases; from Hereditary Hyperferritinemia to Hypoferritinemia-Report of New Cases
}

\author{
Beatriz Cadenas ${ }^{1,2,3}$, Josep Fita-Torró ${ }^{4}$, Mar Bermúdez-Cortés ${ }^{5}$, Inés Hernandez-Rodriguez ${ }^{6}$, \\ José Luis Fuster ${ }^{5}$, María Esther Llinares ${ }^{5}$, Ana María Galera ${ }^{5}$, Julia Lee Romero ${ }^{7}$, \\ Santiago Pérez-Montero ${ }^{4}$, Cristian Tornador ${ }^{1,4}$ and Mayka Sanchez ${ }^{4,8,9, *}$ \\ 1 Whole Genix SL., 08021 Barcelona, Spain; Beatriz.cadenas@wholegenix.com (B.C.); \\ cristian.tornador@wholegenix.com (C.T.) \\ 2 Iron Metabolism: Regulation and Diseases Group, Josep Carreras Leukemia Research Institute (IJC), \\ Campus Can Ruti, Badalona, 08916 Barcelona, Spain \\ 3 Experimental Sciences and Technology Department, Universitat de Vic-Universitat Central de Catalunya, \\ 08500 Vic, Spain \\ 4 BloodGenetics SL, Esplugues de Llobregat, 08950 Barcelona, Spain; josepfita@hotmail.com (J.F.-T.); \\ sperez@bloodgenetics.com (S.P.-M.) \\ 5 Pediatric OncoHematology Service, Clinic University Hospital Virgen de la Arrixaca, Instituto Murciano de \\ Investigación Biosanitaria (IMIB), 30120 Murcia, Spain; mariam.bermudez2@carm.es (M.B.-C.); \\ josel.fuster@carm.es (J.L.F.); mariae.llinares@carm.es (M.E.L.); anam.galera@carm.es (A.M.G.) \\ 6 Hematology Service, University Hospital Germans Trias i Pujol (HGTiP), Institut Català d'Oncologia (ICO), \\ Badalona, 08916 Barcelona, Spain; agnesrh@iconcologia.net \\ 7 Biomedical Engineering Department, University of Texas at Austin, Austin, TX 78712, USA; \\ julialromero@utexas.edu \\ 8 Program of Predictive and Personalised Medicine of Cancer (PMPPC), Institut d'Investigació Germans Trias \\ i Pujol (IGTP), Campus Can Ruti, Badalona, 08916 Barcelona, Spain \\ 9 Iron Metabolism: Regulation and Diseases Group, Faculty of Medicine and Health Sciences, \\ Universitat Internacional de Catalunya (UIC), 08195 Barcelona, Spain \\ * Correspondence: msanchezfe@uic.es; Tel.: +34-935-042-000
}

Received: 23 December 2018; Accepted: 19 January 2019; Published: 23 January 2019

\begin{abstract}
Ferritin is a multimeric protein composed of light (L-ferritin) and heavy (H-ferritin) subunits that binds and stores iron inside the cell. A variety of mutations have been reported in the L-ferritin subunit gene (FTL gene) that cause the following five diseases: (1) hereditary hyperferritinemia with cataract syndrome (HHCS), (2) neuroferritinopathy, a subtype of neurodegeneration with brain iron accumulation (NBIA), (3) benign hyperferritinemia, (4) L-ferritin deficiency with autosomal dominant inheritance, and (5) L-ferritin deficiency with autosomal recessive inheritance. Defects in the FTL gene lead to abnormally high levels of serum ferritin (hyperferritinemia) in HHCS and benign hyperferritinemia, while low levels (hypoferritinemia) are present in neuroferritinopathy and in autosomal dominant and recessive L-ferritin deficiency. Iron disturbances as well as neuromuscular and cognitive deficits are present in some, but not all, of these diseases. Here, we identified two novel FTL variants that cause dominant L-ferritin deficiency and HHCS (c.375+2T > A and 36_42delCAACAGT, respectively), and one previously reported variant (Met1Val) that causes dominant L-ferritin deficiency. Globally, genetic changes in the FTL gene are responsible for multiple phenotypes and an accurate diagnosis is useful for appropriate treatment. To help in this goal, we included a diagnostic algorithm for the detection of diseases caused by defects in FTL gene.
\end{abstract}

Keywords: ferritin; hereditary hyperferritinemia; hereditary hypoferritinemia; iron metabolism; cataracts syndrome; neurodegenerative disease 


\section{Introduction}

Ferritin is an iron-binding protein that stores and releases iron and thus contributes to maintaining and controlling iron homeostasis. Iron is stored in ferritin in the $\mathrm{Fe}^{+3}$ form and released in the $\mathrm{Fe}^{+2}$ form. Tissue ferritin is a multimeric protein formed from the assembly of 24 peptide subunits, known as the light $(\mathrm{L})$ and heavy $(\mathrm{H})$ ferritin subunits. The $\mathrm{H}$ subunit has ferroxidase activity and converts iron from $\mathrm{Fe}^{+2}$ to $\mathrm{Fe}^{+3}$, which enables iron storage; it also serves to regulate $\mathrm{pH}$ and increase concentrations of free radicals in the body, which can be extremely damaging to cellular structures and proteins [1]. The L-ferritin subunit helps with electron transport in and out of the ferritin core protein and plays a role in iron release, as $\mathrm{Fe}^{+2}$, from ferritin. Unlike tissue ferritin, serum ferritin is partially glycosylated and nearly completely iron-free [2,3] and is mainly composed of L-ferritin subunits [4-6].

Focusing on the L-ferritin ( $F T L$ ) gene, five diseases have been identified as directly resulting from mutations in this gene. These diseases include hereditary hyperferritinemia with cataract syndrome (HHCS), neuroferritinopathy, benign hyperferritinemia (or hyperferritinemia without iron overload), autosomal dominant L-ferritin deficiency and autosomal recessive L-ferritin deficiency.

HHCS (OMIM\#600886, ORPHA163) is associated with mutations located in the iron responsive element (IRE) at the $5^{\prime}$ untranslated region (UTR) of the L-ferritin mRNA, which results in the disruption of binding with iron regulatory proteins (IRP1 and 2), this is known as the IRP-IRE post-transcriptional regulatory system [7-9]. Mutations in this RNA motif result in the loss of ferritin translation repression and excess ferritin production, even though iron levels remain normal. Ferritin overproduction leads to deposits in the lens of the eye, resulting in the development of cataracts [10]. Up to now, there are 47 known mutations associated with HHCS [11].

In 2001, Curtis and collaborators [12] described for the first time neuroferritinopathy (OMIM\#606159, ORPHA:157846), an autosomal dominant condition characterized by normal to low serum ferritin levels, progressive chorea or dystonia, and subtle cognitive deficits. Neuroferritinopathy is classified as a member of the group of diseases known as neurodegeneration with brain iron accumulation (NBIA). So far, there have been ten reported mutations causing this condition, mostly located at the C-terminal region of the FLT gene [13]. FTL mutations diminish ferritin's ability to store iron so, in an attempt to control free iron levels, neurons produce more ferritin, resulting in iron and ferritin accumulation in the basal ganglia of the brain and leading to movement and cognitive disabilities [14].

Benign hyperferritinemia or genetic hyperferritinemia without iron overload (OMIM\#600886, ORPHA:254704) is another FTL mutated disorder where patients have high (greater than 90\%) glycosylated serum ferritin levels. There are three known mutations in the $\mathrm{N}$-terminal region of the FTL gene that cause benign hyperferritinemia [15]. Despite serum ferritin hyperglycosylation, no other harmful effects have been detected in patients with this disorder [16].

Finally, two variants in FTL have been reported causing L-ferritin deficiency, i.e., hypoferritinemia (OMIM\#615604, ORPHA:440731). Mutation Glu104Ter was described in a single patient with inheritance in autosomal recessive mode and consists of a $\mathrm{G}>\mathrm{C}$ nucleotide substitution in exon 3 (c.310G > T). This mutation causes a complete lack of translation of the FTL gene with subsequently undetectable levels of serum ferritin. This patient presented with seizures and restless leg syndrome [17]. The FTL mutation Met1Val, resulting in a change at the start codon (c.-1A > G), has also been described in a single case; however, this mutation was inherited in an autosomal dominant manner. The patient presented with decreased levels of serum ferritin, but no history of iron deficiency anemia or neurologic dysfunction [18].

In this study, we report the identification of two novel mutations in the FTL gene detected by gene sequencing. One mutation is associated with a diagnosis of HHCS and the other with a diagnosis of dominant L-ferritin deficiency. We also describe an additional dominant L-ferritin deficiency case with a previously described (Met1Val) mutation in the FTL gene. Moreover, we have performed an extensive review of all reported variants in the FTL gene linked with the previously described five conditions to help in the understanding of the phenotypes. 


\section{Results}

We completely sequenced the entire coding region, intron-exon boundaries and $5^{\prime}$ and $3^{\prime}$ regulatory regions for the FTL gene either by Sanger sequencing or by next generation sequencing (NGS).

\subsection{Case Studies}

\subsubsection{Family 1-A Case with Autosomal Dominant L-Ferritin Deficiency}

Proband II.1 from family 1 (Figure 1A and Table 1) is a four-year-old female of Spanish origin referred to the department of Pediatric OncoHematology Service of the Clinic University Hospital Virgen de la Arrixaca because of refractory hypoferritinemia (serum ferritin 4-9 ng/mL) unresponsive to oral iron supplementation, without any accompanying sign or symptoms. Physical examination was normal with normal weight and size for age. At the age of six, the proband complained of recurrent severe headaches. Cerebral CT and MRI were normal except for a small (non-specific) subcortical area of gliosis in the right frontal lobe. This was considered an incidental finding by pediatric neurologists who established a provisional diagnosis of primary headache and recommended treatment with flunarizine.

A

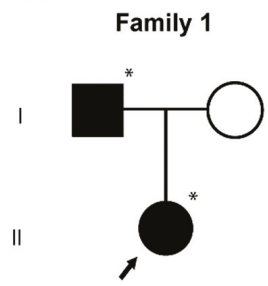

FTL: NM_000146.3:c.[375+2T >A];[=] NP_000137.2:p.(?);(=)
B

Family 2

।

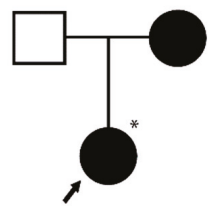

FTL: NM_000146.3:c.[1A>G];[=] NP_000137.2:p.(Met1Val);(=)

L-Ferritin deficiency, Dominant

C

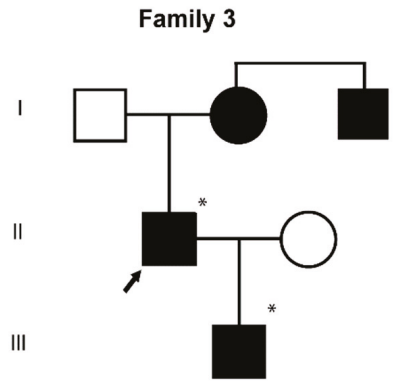

FTL: NM_000146.3:c.[-164_158del7];[=] NP_000137.2:p.(?);(=)

\section{HHCS}

Figure 1. Pedigree trees from three studied families affected from dominant L-ferritin deficiency and HHCS. Squares indicate males and circles females. Probands are pointed with an arrow. Filled symbols indicate affected members and asterisks indicate subjects with genetic studies done at BloodGenetics SL. Mutations are named according the HGVS nomenclature.

Mutation analysis revealed the presence of $\mathrm{T}>\mathrm{A}$ change in the intron 3 of the FTL gene, at position $375+2$ (NM_000146.3:c.[375 + 2T > A]; [=], HGSV nomenclature). This variant was also found in a heterozygous state in the father of the proband (I.1). Human Splicing Finder software predicted that this variant alters the wild type splicing donor site, affecting mRNA splicing. This mutation is novel and has not been previously reported either in the literature or in any public database (ENSEMBL, NCBI, 1000Genomes, public HGMD). However, another variant without a known clinical significance exists at the same position, c.375 + 2T > C, reported in the SNP database as rs1371561306 and with a very low allele frequency $(\mathrm{MAF}=0.000008$ reported in TOPMED database). 
Pharmaceuticals 2019, 12, 17

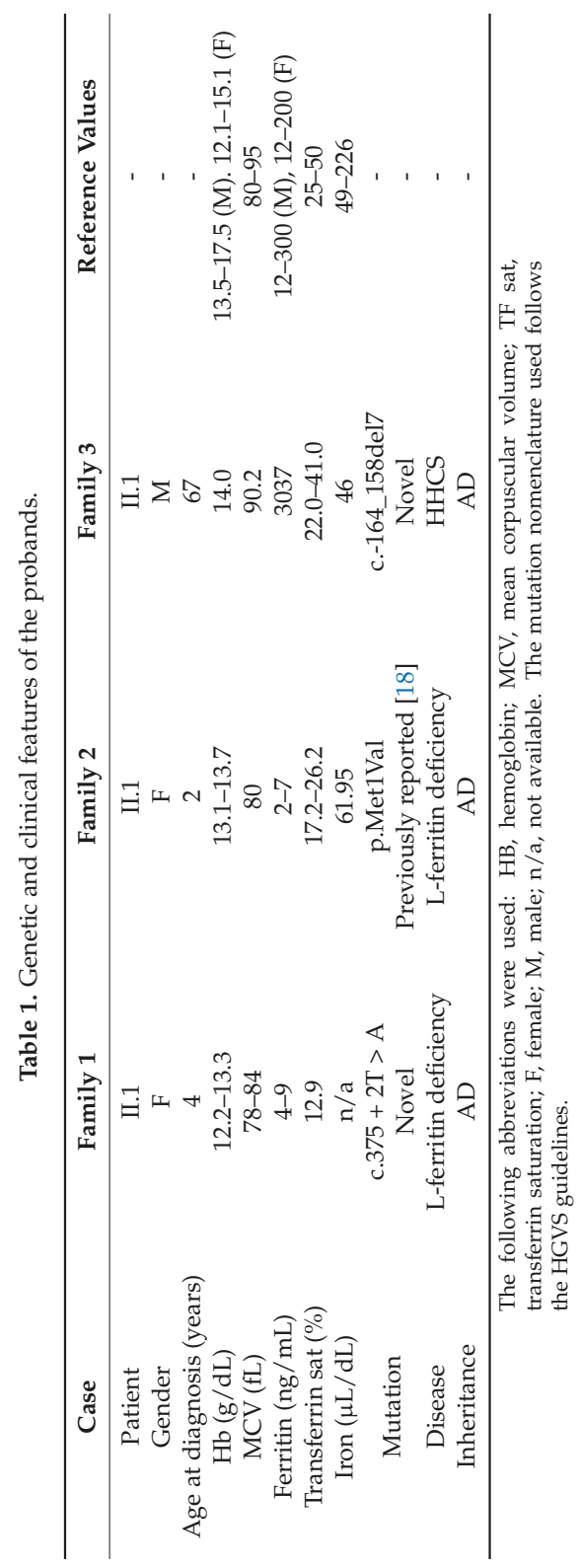




\subsubsection{Family 2-A Case with Autosomal Dominant L-Ferritin Deficiency}

Proband II.1 from family 2 (Figure 1B and Table 1) is an asymptomatic two-year-old girl evaluated at the department of Pediatric OncoHematology Service of the Clinic University Hospital Virgen de la Arrixaca for further investigation of mild neutropenia and eosinophilia. The patient had been previously diagnosed with a small ventricular septal defect. During her follow-up, we did not find neutropenia or other hematological anomalies, but rather marked hypoferritinemia without anemia. Hypoferritinemia was unresponsive to oral iron supplementation. She occasionally complained of mild asthenia and an occasional mild headache, which were found to be tension headaches after a full evaluation by a pediatric neurologist. The proband's mother had low serum ferritin levels $(<6 \mathrm{ng} / \mathrm{mL})$, low transferrin saturation $(9.6 \%)$ with normal levels of transferrin.

Sequencing analysis of this proband (Figure 1B, II.1) showed an A > G substitution at position 1 in the heterozygous state, causing the start codon methionine to change into valine. This mutation was previously reported in 2004 [18] and was described in the SNP database as rs139732572 with a very low allele frequency (MAF $=0.000008$ reported in the ExAc database). This variant has been classified in ClinVar database as pathogenic (Variation ID 96689), causing L-ferritin deficiency in dominant inheritance mode. Here we report the second case of a patient with hypoferritinemia and this same mutation in the FTL gene (NM_000146.3:c[1A > G];[=], NP_000137.2:p(Met1Val);(=), HGSV nomenclature).

\subsubsection{Family 3-A Case with HHCS}

The proband I.1 in family 3 (Figure 1C and Table 1) is a 65-year-old man with a history of enolism and dyslipidemia, showing high levels of serum ferritin (>3000 ng/mL), motive for what he was referred to the Hematology Service at the University Hospital Germans Trias i Pujol (HGTiP). At age of 45 , he underwent cataract surgery. Initially, he underwent three therapeutic phlebotomies, but they were suspended due to the development of anemia. Magnetic resonance (MR) imaging showed normal deposits of liver iron $(30 \mu \mathrm{mol} / \mathrm{g})$. The family history suggests the presence of HHCS due to the existence of additional cases of hyperferritinemia (proband's son and uncle) and cataracts (proband's mother). The proband's son (II.1) is a 39-year-old male with history of stage 1 orchiectomized and disease-free seminoma and no surgical removed cataracts. He was contacted by the same hematology service (HGTiP) under suspicion of HHCS because of hyperferritinemia (>2000 ng/mL) and cataracts. The hematological evaluation was normal except for the high ferritin levels, and liver magnetic resonance showed normal levels of hepatic iron $(20 \mu \mathrm{mol} / \mathrm{g})$.

The genetic studies performed on family 3 showed the presence a heterozygous deletion c.[-164_-158del7] located in the 5' FTL IRE in the proband (I.1) and his son (II.1), both affected with hereditary hyperferritinemia with cataracts syndrome (Figure 1). Genetic analyses were not available for the mother and the uncle of the proband. This variant consists of a deletion of seven nucleotides (CAACAGT), excising part of the hexanucleotide loop and upper stem of the FTL IRE (Figure 2). Following the traditional nomenclature for FTL IRE mutations, we refer to these mutations as Esplugues +36_42del7 mutation (HGVS nomenclature as NM_000146.3:c.[-164_158del7];[=]). This deletion is predicted to impair the IRE structure. RNA secondary structure modelling of WT and mutated FTL $5^{\prime}$ IRE sequences was performed using the Sfold web server, which predicted that -164 -158del7 mutation, located at the hexanucleotide loop, is likely to disturb the WT IRE conformation (Figure 3). In addition, the SIREs web server prediction [19] indicate loss of the IRE structure, as the mutated query returned no results. This mutation has not been previously described in the literature, but other similar IRE deletions have been previously demonstrated to be pathogenic for HHCS [11]. The location and severity of this mutation, together with the clinical manifestations of HHCS present in the affected individuals of this family, indicates that this variant is most probably the genetic cause of disease in this family. 


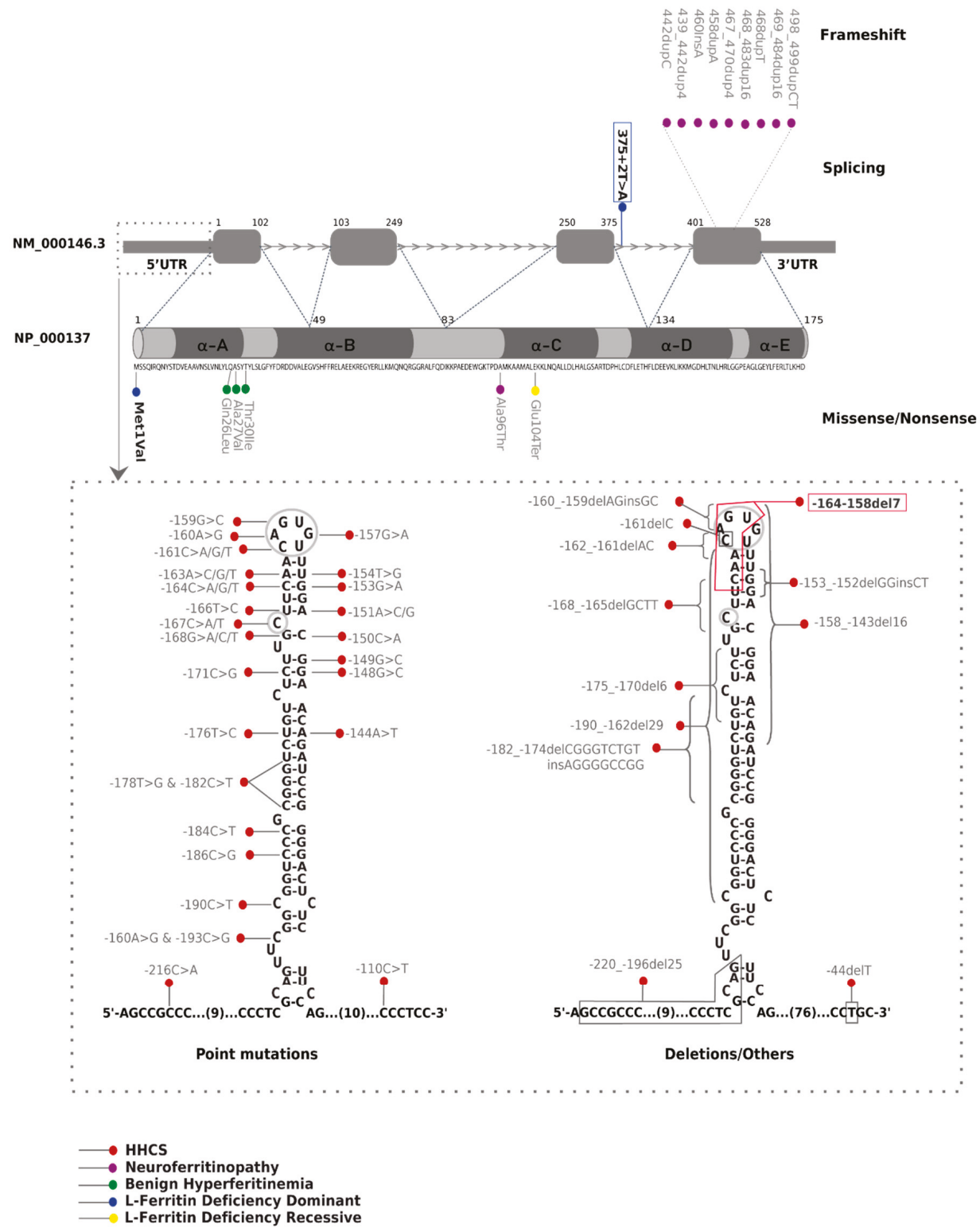

Figure 2. Schematic localization of literature reported and new FTL mutations. Mutations described in this work are in bold and new mutations are boxed. The domains of the five alpha helices (A to E) are represented in the protein (NP_000137.2). Mutations are classified as nonsense, frameshift, missense, or splicing. Here we report FTL protein changes using the three-letter amino acid code. 


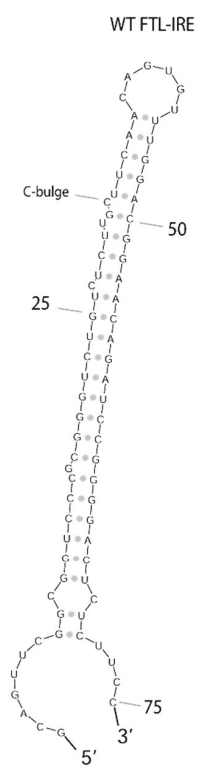

$\Delta G^{s}=-29.70$

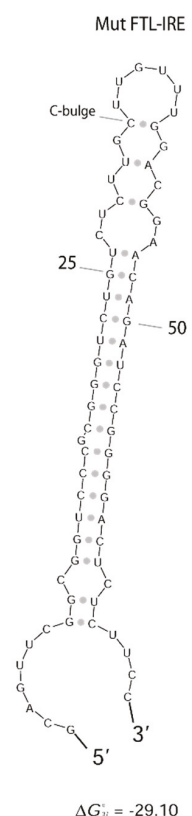

$\Delta G_{*}^{\bullet}=-29.10$

Figure 3. WT and mutated FTL-IRE fold prediction. Predicted secondary structure of WT and mutated FTL-IRE using Sfold web server [20]. Deletion in hexanucleotide loop (c.-164_158del7) is expected to disturb completely the IRE structure. Nucleotides are numbered from the transcription starting site. Free energy $(\Delta G)$ is detailed.

\subsection{Update on L-Ferritin Mutations and Diseases}

Mutations in L-ferritin gene causes five different phenotypic diseases, as summarized in Table 2. After an extensive literature search, we have collected all 63 different mutations reported so far for these five diseases, including the two novel mutations reported in the present work (Figure 2 and Supplementary Material: Table S1).

Most of the FTL mutations described correspond to hereditary hyperferritinemia with cataract syndrome (HHCS), including 36 point mutations, 9 deletions, and 2 insertion-deletions. All the mutations for HHCS are located at the 5'UTR of the FTL gene (chr19:49468566-49468764), affecting the primary sequence and structure of FTL-IRE (Figure 2). HHCS is an autosomal dominant disorder, and all reported variants are in heterozygous state except for three cases $[11,21,22]$ where homozygous mutations have been described. Patients with HHCS do not present clinical manifestations other than high serum ferritin levels and congenial bilateral nuclear cataracts.

Neuroferritinopathy is the only NBIA disorder with an autosomal dominant inheritance. It is caused by mutation in the FTL gene. Up to now, nine insertions from one to 16 nucleotides located in the exon 4 of FTL gene have been reported to cause this neurodegenerative disorder (Figure 2). These insertions alter the reading frame of the C-terminal region, generating a longer protein with additional aberrant amino acids. In addition, a missense Ala96Thr mutation (rs104894685) has been also described to cause neuroferritinopathy; amino acid 96 is predicted to be situated at the same tertiary structure region as the pathogenic insertions [13]. Mutations in the C-terminal region of FTL disrupt $\alpha$-helix D or E, which seems to be essential for the stability of the peptide $[23,24]$. Clinical and biochemical manifestations of this disease include low serum ferritin levels, iron accumulation in the basal ganglia and progressive and severe neurological dysfunctions with subtle cognitive deficits in some cases. 


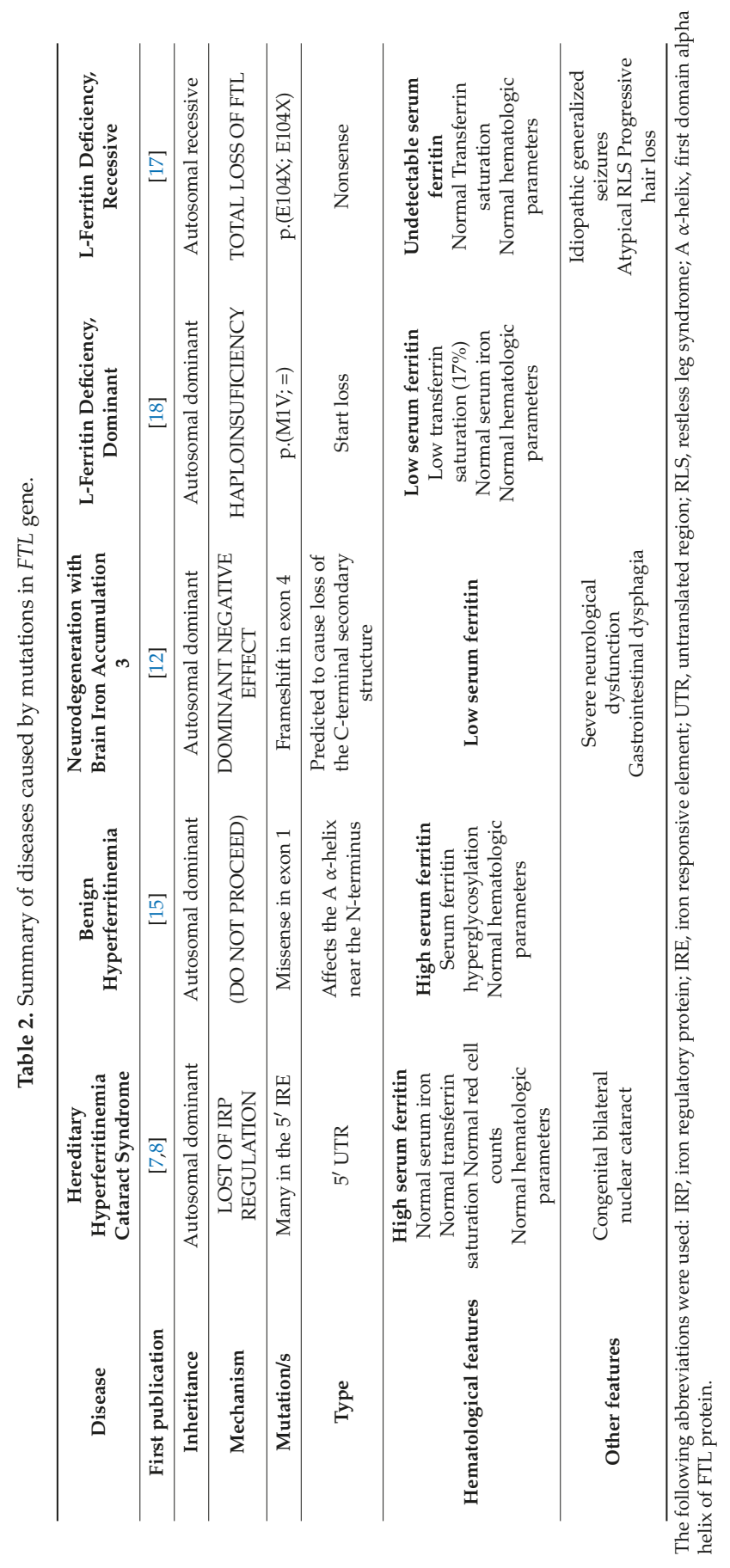


Three heterozygous mutations in FTL exon 1 have been associated with hyperferritinemia without iron overload where cataracts were absent; this condition has also been named benign hyperferritinemia. The Thr30Ile mutation (rs397514540, ExAc MAF = 0.000008) has been identified in French and British families [15,25]. Two further pathogenic mutations-p.(Ala27-Val) and p.(Gln26Ile) - have been reported in two additional patients [26]. Mutations in exon 1 of FTL are associated with higher than normal serum ferritin glycosylation. These three variants alter the A $\alpha$-helix near the $\mathrm{N}$ terminus of L-ferritin; it has been hypothesized that the aberrant peptide extends the length of the hydrophobic cluster of amino acids at the $\mathrm{N}$ terminus, increasing the secretion of L-ferritin [15]. However, the reason for the development of hyperferritinemia and hyperglycosylation associated with these mutant ferritin forms is still not fully elucidated [25].

We have described in this report a novel intronic splicing mutation in the FTL gene (NM_000146.3:c.[375 + 2T > A];[=]) associated also with autosomal dominant L-ferritin deficiency. Including this novel splicing mutation, two heterozygous mutations have been described to cause L-ferritin deficiency with autosomal dominant transmission. Cremonesi and collaborators identified in 2004 a heterozygous A > G substitution in the first nucleotide of FTL, which change the ATG start codon (methionine) into a valine [18]. This mutation is predicted to encode a non-functional and unstable protein. Despite the low serum levels of L-ferritin, the proband presenting this mutation does not show either serious neurological problems (other than headaches) indicating that the molecular mechanism of L-ferritin deficiency with autosomal dominant inheritance is haploinsufficiency.

Finally, only one Italian case has been reported to cause L-ferritin deficiency with autosomal recessive inheritance; a homozygous substitution at nucleotide $310 \mathrm{G}$ to $\mathrm{T}$ that produces a premature stop codon (E104X) [17]. This amino acid change is predicted to be located in the middle of the $\alpha$-helix $\mathrm{C}$ domain, a critical region for the stability of the protein. In silico analysis predicted that a stop codon at this position produces a truncated protein unable to fold into a functional peptide and, therefore, leads to the generation an L-ferritin subunit with a complete loss of function. This homozygous mutation is associated with a more aggressive phenotype, which is characterized by undetectable ferritin levels, idiopathic generalized seizures and atypical restless leg syndrome.

\section{Discussion}

L-ferritin disease is a clear case of Mendelian disease-related genes that are associated with multiple diseases, including hyperferritinemia linked with cataracts in HHCS, isolated hyperferritinemia (benign hyperferritinemia), hypoferritinemia associated with other symptoms (neurological symptoms as in neuroferritinopathy, or muscular symptoms in autosomal recessive L-ferritin deficiency), or isolated hypoferritinemia (autosomal dominant L-ferritin deficiency). For improving the diagnosis of these different diseases, we have created a clinical diagnostic algorithm of diseases caused by mutations in FTL gene (Figure 4).

The underlying mechanisms for these disease patterns are not fully elucidated for all these diseases. In HHCS, it is known that the pathological molecular mechanism is linked to the disruption of the IRP-IRE post-transcriptional regulatory system, with the de-repression of L-ferritin mRNA and the subsequent overproduction of L-ferritin protein that precipitates and deposits in the lens of the eyes, producing cataracts. In HHCS, authors have argued that an association exists between the clinical severity of the disease and the location of the mutation in FTL-IRE [11,27,28]. Higher serum ferritin levels are mostly associated with mutations in the apical loop or the C-bulge area, compared with mutations in the upper or lower stems. These findings are consistent with our cases in family 3, i.e., a father and son with a seven-nucleotide deletion in the IRE of the FTL gene (5'-CAACAGU3'). The deletion partially affects the hexanucleotide loop of the IRE, and patients show considerably high serum ferritin levels (2071-3037 ng/mL) and develop early bilateral cataracts (Table 1).

Mutations in exon 4 of FTL gene that alter the C-terminal sequence and the length of the protein have been reported to cause neuroferritinopathy. These mutations affect the D- or E $\alpha$-helix (see Figure 2), leading to significant disruption of the tertiary and quaternary structure of the FTL protein 
and producing an unstable and leaky ferritin. Studies have shown that mutant ferritin maintains the normal spherical shell structure and size [29]. However, mutant FTL C-termini, rich in amino acids with iron-binding properties, may be extended and unravel out of the shell. These mutant structures could initiate aggregation, forming ferritin inclusion bodies/precipitates [29,30]. Previous in vitro functional analysis and in vivo mouse models have revealed that these molecular-level defects have two main consequences: (1) the loss of normal protein function, reducing iron incorporation; (2) and the acquisition of toxic function through radical production, ferritin aggregation, and reactive oxygen species (ROS) generation [14,31-33]. It has been demonstrated that mutations in the $\mathrm{C}$ terminus have a dominant-negative effect, which explains the dominant transmission of the disorder [34].

In benign hyperferritinemia, missense variations in exon 1 of $F T L$ increase the hydrophobicity of the ferritin $\mathrm{N}$-terminal site. The $\mathrm{A}-\alpha$-helix of the protein is altered and hyperglycosylated, although the precise molecular mechanism is not clear yet.

L-ferritin deficiency is characterized by haploinsufficiency of the FTL protein in autosomal dominant L-ferritin deficiency, or complete loss of function in autosomal recessive L-ferritin deficiency. Mutations associated with this condition are predicted to affect protein expression. The inactivation of one allele of $F T L$, which occurs in the two described heterozygous cases of autosomal dominant L-ferritin deficiency, produces a significant reduction of L-ferritin in serum. The phenotype of this dominant condition is normal apart from low levels of serum ferritin and low transferrin saturation. However, the homozygous mutation Glu104Ter causes a total loss of function of L-ferritin and leads to ferritin missing the FTL chain. Previous mutational studies have suggested that the presence of $\mathrm{H}$ homopolymer ferritin in fibroblasts is associated with reduced cellular iron availability and increased ROS production, which triggers cellular damage. These findings were also found in neurons derived from patient fibroblasts and correlate with the neurological phenotype of this more severe condition [17].

In this study, we have identified two new cases of autosomal dominant L-ferritin deficiency, one due to a new mutation in intron 3 of the FTL gene that most probably affects splicing. The $\mathrm{T}>\mathrm{G}$ substitution in nucleotide $375+2$ (genomic coordinates g.49469665 in Assembly GRCh37.p13) modifies a highly conserved dinucleotide GT donor site, a key sequence recognized by the spliceosome during splicing. Mutations in splice site junctions are likely to lead to exon skipping or total or partial intron retention in the mRNA transcript in most cases [32]. Our in silico analysis using Human Splicing Finder suggests that our variant would activate a new alternative donor site onwards $(375+5 \mathrm{G}$ and $+6 \mathrm{~T}$ ), leading to the insertion of four additional nucleotides in the mRNA sequence between exon 3 and 4 and altering the reading frame of the transcript [33]. Therefore, this change would lead to a premature stop codon formation and the putative generation of a truncated FTL protein of 128 amino acids, if the aberrant mRNA is not detected and degraded by the nonsense mediated decay (NMD) system. According to our bioinformatics prediction, the c. $375+2 \mathrm{~T}>$ A mutation will not generate a dominant-negative version of FTL protein, but a truncated FTL protein completely missing the E- $\alpha$-helix domain and partially lacking the D- $\alpha$-helix domain. Supported by the clinical manifestations found in this family (low serum ferritin levels, low transferrin saturation and lack of serious neurological or movement abnormalities), the molecular mechanism in this case is most probably due to the loss of function of FTL and it will be not expected that the disease derives in neuroferritinopathy. However, we cannot totally and completely exclude the later development in life of brain iron overload and neuroferritinopathy in these patients by a yet unknown and novel mechanism.

Patients with hereditary hyperferritinemia could be misdiagnosed as patients suffering from hereditary hemochromatosis, liver dysfunction or inflammation. Some patients have received unnecessary invasive diagnostic techniques, such as liver biopsy, and are inappropriately treated with venesections and phlebotomies that can cause severe iron-deficiency anemia. On the other hand, clinical manifestations of neuroferritinopathy including tremor, parkinsonism, psychiatric problems, and abnormal involuntary movements, the presence of ferritin-iron precipitation in glia cells 
and neurons [30], are often misdiagnosed and treated as Huntington's or Parkinson's disease. Potential treatment targets for neuroferritinopathy may include an optimized iron chelator to induce the re-solubilization of iron aggregations, in combination with radical scavengers to prevent oxidative ferritin damage [35]. Patients with benign hyperferritinemia could be misdiagnosed as patients with HHCS due to the presence of high ferritin levels and the possible late-onset appearance of cataracts. Apart from the surgical removal of cataracts in HHCS, HHCS and L-ferritin deficiency have no specific therapy.

These facts emphasize the importance of a correct and early genetic diagnosis for the subsequent implementation of proper treatment, avoiding detrimental or inappropriate treatments. Following clinical algorithms, such as the one included in this publication (Figure 4) and also HIGHFERRITIN Web Server (http://highferritin.imppc.org/) [36] will surely help in this goal.

\section{Materials and Methods}

\subsection{Patients}

All subjects gave their informed consent for inclusion before they participated in the study. The study was conducted in accordance with the Declaration of Helsinki, and the protocol was approved by the Ethics Committee on 10th July 2015.

\subsection{DNA Extraction, PCR Amplification, and DNA Sequencing}

Genetic studies were performed with minor differences for all the pedigrees. Genomic DNA was extracted from peripheral blood using the FlexiGene DNA kit (Qiagen) according to manufacturer's instructions.

Ferritin gene regions (exonic, intron-exon boundaries, and untranslated regions) were sequenced using the Sanger method or next generation sequencing (NGS).

For the Sanger method, the FTL gene was amplified using $50 \mathrm{ng}$ of genomic DNA. Primer sequences and PCR conditions are available upon request. The resulting amplification products were verified on a $2 \%$ ethidium bromide agarose gel. The purified PCR products were sequenced using a conventional Sanger method. Sequencing results were analyzed using Mutation Surveyor software (SoftGenetics LLC, PA, USA).

For NGS methods, patients were analyzed using a targeted NGS gene panel (v14) for hereditary hemochromatosis and hyper/hypoferritinemia that included the following nine genes: HFE, HFE2, HAMP, TFR2, SLC40A1, BMP6, FTL, FTH1, and GNPAT.

Briefly, the capture of genomic regions was conducted starting from $225 \mathrm{ng}$ of gDNA using a custom design HaloPlex ${ }^{\mathrm{TM}}$ Target Enrichment 1-500 kb kit (Agilent Technologies, Santa Clara, CA, USA) according to the manufacturer's instructions. Library quality was determined using the Agilent 4200 TapeStation System. The quantity was measured using a QubitdsDNA assay kit with a Qubitfluorometer (Life Technologies, Carlsbad, CA, USA) and fluorescence was detected using a SpectraMax Gemini EM microplate reader (Molecular Devices). Libraries were sequenced using MiSeq reagent kit v2 (300 cycles) (Illumina, San Diego, CA, USA) on an Illumina or a MiSeq or MiniSeq sequencer (Illumina, San Diego, CA, USA), generating 150-bp paired-end reads. Samples were aligned with the reference human genome GRCh37/hg19 and data analysis was performed using our algorithms. Mutations detected by NGS were confirmed by conventional Sanger sequencing.

Genetic variants are reported following the official Human Genome Variation Sequence (HGVS) nomenclature and refer to NM_ 000146.3 for the Homo sapiens FTL transcript variant and NP_000137.2 for the Homo sapiens FTL protein.

Reported mutations in this study have been submitted to the Leiden Open Variation Database (http:/ / www.lovd.nl) or to ClinVar (http:/ / www.ncbi.nlm.nih.gov/clinvar). 


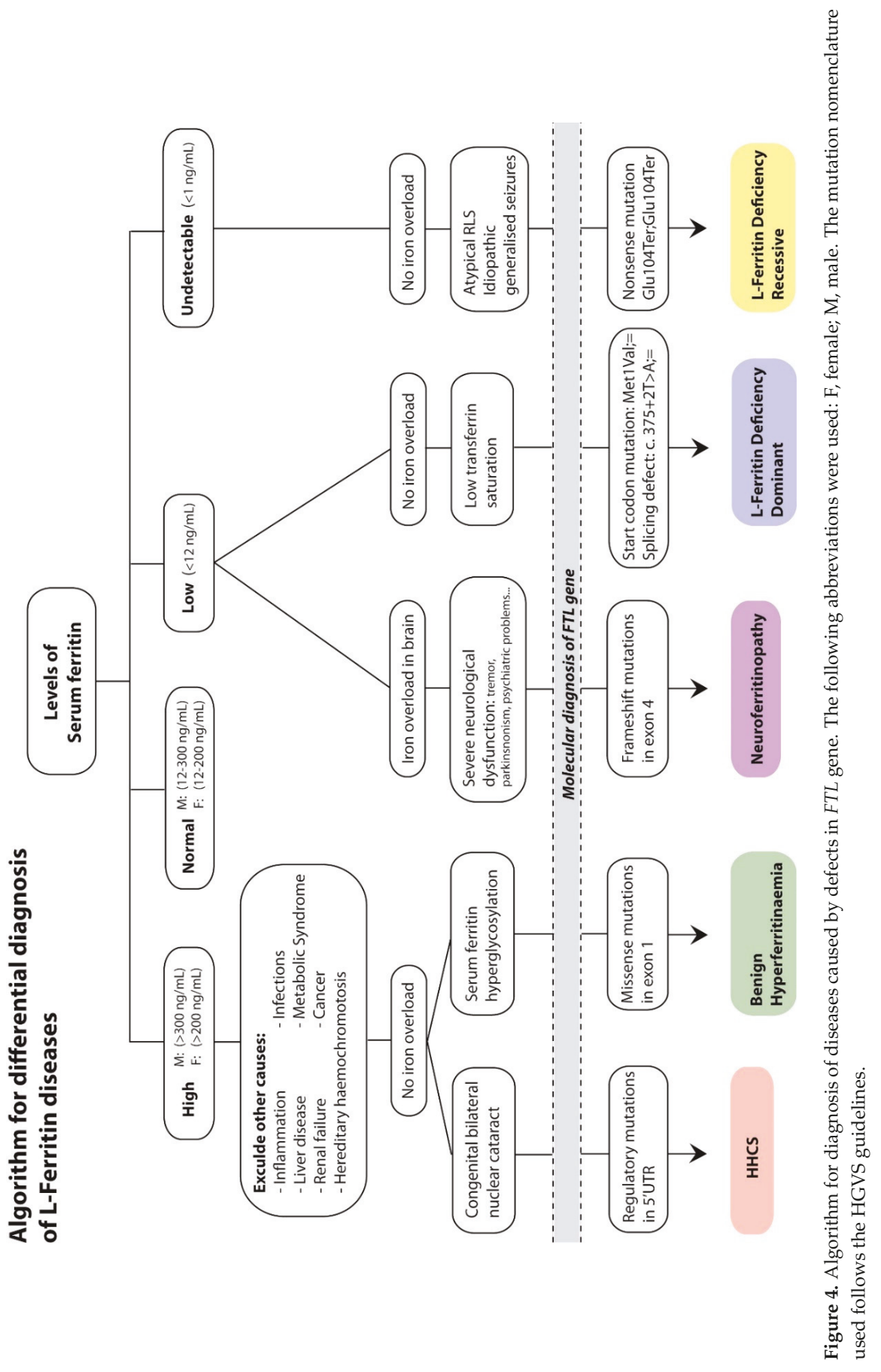




\subsection{FTL RNA Fold Predictions}

RNA folding analysis was carried out to predict the IRE structure of wild-type (WT) and mutated FTL-IRE using the Sfold web server (http:/ / sfold.wadsworth.org/) [20]. DNA sequences used for folding predictions are shown in Supplementary Material Table S2. The SIREs web server tool was also used to predict iron-responsive elements [19].

Supplementary Materials: The following are available online at http://www.mdpi.com/1424-8247/12/1/17/s1, Table S1: Table summarizing all FTL mutations identified up now in the literature, including the two novel mutations described here. Table S2: DNA sequence for FTL RNA fold predictions.

Author Contributions: Conceptualization, M.S. and B.C.; Methodology, C.T., B.C., and M.S.; Software, C.T.; Validation, J.F.-T.; Formal Analysis, J.F.-T.; Investigation, J.F.-T. and B.C.; Resources, S.P.-M., I.H.-R., J.L.F., M.E.L., A.M.G., and M.B.-C.; Data Curation, J.F.-T.; Writing-Original Draft Preparation, B.C., J.L.R., and M.S.; Writing-Review and Editing, M.S., I.H.-R., J.L.F., and M.B.-C.; Visualization, B.C. and M.S.; Supervision, M.S.; Project Administration, M.S.; Funding Acquisition, M.S.

Funding: This research was partially supported by grant SAF2015-70412-R from Spanish Secretary of Research, Development and Innovation (MINECO) Spain to M.S.

Acknowledgments: The authors would like to thank all patients and their family members for their participation in the study.

Conflicts of Interest: The authors declare no conflict of interest.

\section{References}

1. Arosio, P.; Ingrassia, R.; Cavadini, P. Ferritins: A family of molecules for iron storage, antioxidation and more. Biochim. Biophys. Acta 2009, 1790, 589-599. [CrossRef] [PubMed]

2. Arosio, P.; Yokota, M.; Drysdale, J.W. Characterization of serum ferritin in iron overload: Possible identity to natural apoferritin. Br. J. Haematol. 1977, 36, 199-207. [CrossRef] [PubMed]

3. Fardet, L.; Coppo, P.; Kettaneh, A.; Dehoux, M.; Cabane, J.; Lambotte, O. Low glycosylated ferritin, a good marker for the diagnosis of hemophagocytic syndrome. Arthritis Rheum. 2008, 58, 1521-1527. [CrossRef] [PubMed]

4. Harrison, P.M.; Arosio, P. The ferritins: Molecular properties, iron storage function and cellular regulation. Biochim. Biophys. Acta 1996, 1275, 161-203. [CrossRef]

5. Santambrogio, P.; Cozzi, A.; Levi, S.; Arosio, P. Human serum ferritin G-peptide is recognized by anti-L ferritin subunit antibodies and concanavalin-A. Br. J. Haematol. 1987, 65, 235-237. [CrossRef] [PubMed]

6. Cohen, L.A.; Gutierrez, L.; Weiss, A.; Leichtmann-Bardoogo, Y.; Zhang, D.L.; Crooks, D.R.; Sougrat, R.; Morgenstern, A.; Galy, B.; Hentze, M.W.; et al. Serum ferritin is derived primarily from macrophages through a nonclassical secretory pathway. Blood 2010, 116, 1574-1584. [CrossRef]

7. Beaumont, C.; Leneuve, P.; Devaux, I.; Scoazec, J.Y.; Berthier, M.; Loiseau, M.N.; Grandchamp, B.; Bonneau, D. Mutation in the iron responsive element of the L ferritin mRNA in a family with dominant hyperferritinaemia and cataract. Nat. Genet. 1995, 11, 444-446. [CrossRef]

8. Girelli, D.; Olivieri, O.; De Franceschi, L.; Corrocher, R.; Bergamaschi, G.; Cazzola, M. A linkage between hereditary hyperferritinaemia not related to iron overload and autosomal dominant congenital cataract. $\mathrm{Br}$. J. Haematol. 1995, 90, 931-934. [CrossRef]

9. Muckenthaler, M.U.; Rivella, S.; Hentze, M.W.; Galy, B. A Red Carpet for Iron Metabolism. Cell 2017, 168, 344-361. [CrossRef]

10. Mumford, A.D.; Cree, I.A.; Arnold, J.D.; Hagan, M.C.; Rixon, K.C.; Harding, J.J. The lens in hereditary hyperferritinaemia cataract syndrome contains crystalline deposits of L-ferritin. Br. J. Ophthalmol. 2000, 84, 697-700. [CrossRef]

11. Luscieti, S.; Tolle, G.; Aranda, J.; Campos, C.B.; Risse, F.; Morán, É.; Muckenthaler, M.U.; Sánchez, M. Novel mutations in the ferritin- $L$ iron-responsive element that only mildly impair IRP binding cause hereditary hyperferritinaemia cataract syndrome. Orphanet J. Rare Dis. 2013, 8, 30. [CrossRef] [PubMed]

12. Curtis, A.R.; Fey, C.; Morris, C.M.; Bindoff, L.A.; Ince, P.G.; Chinnery, P.F.; Coulthard, A.; Jackson, M.J.; Jackson, A.P.; McHale, D.P.; et al. Mutation in the gene encoding ferritin light polypeptide causes dominant adult-onset basal ganglia disease. Nat. Genet. 2001, 28, 350-354. [CrossRef] [PubMed] 
13. Maciel, P.; Cruz, V.T.; Constante, M.; Iniesta, I.; Costa, M.C.; Gallati, S.; Sousa, N.; Sequeiros, J.; Coutinho, P.; Santos, M.M. Neuroferritinopathy: Missense mutation in FTL causing early-onset bilateral pallidal involvement. Neurology 2005, 65, 603-605. [CrossRef] [PubMed]

14. Muhoberac, B.B.; Vidal, R. Abnormal iron homeostasis and neurodegeneration. Front. Aging Neurosci. 2013, 5, 32. [CrossRef]

15. Kannengiesser, C.; Jouanolle, A.-M.; Hetet, G.; Mosser, A.; Muzeau, F.; Henry, D.; Bardou-Jacquet, E.; Mornet, M.; Brissot, P.; Deugnier, Y.; et al. A new missense mutation in the L ferritin coding sequence associated with elevated levels of glycosylated ferritin in serum and absence of iron overload. Haematologica 2009, 94, 335-339. [CrossRef]

16. Ravasi, G.; Pelucchi, S.; Mariani, R.; Casati, M.; Greni, F.; Arosio, C.; Pelloni, I.; Majore, S.; Santambrogio, P.; Levi, S.; et al. Unexplained isolated hyperferritinemia without iron overload. Am. J. Hematol. 2017, 92, 338-343. [CrossRef]

17. Cozzi, A.; Santambrogio, P.; Privitera, D.; Broccoli, V.; Rotundo, L.I.; Garavaglia, B.; Benz, R.; Altamura, S.; Goede, J.S.; Muckenthaler, M.U.; et al. Human L-ferritin deficiency is characterized by idiopathic generalized seizures and atypical restless leg syndrome. J. Exp. Med. 2013, 210, 1779-1791. [CrossRef]

18. Cremonesi, L.; Cozzi, A.; Girelli, D.; Ferrari, F.; Fermo, I.; Foglieni, B.; Levi, S.; Bozzini, C.; Camparini, M.; Ferrari, M.; et al. Case report: A subject with a mutation in the ATG start codon of L-ferritin has no haematological or neurological symptoms. J. Med. Genet. 2004, 41, e81. [CrossRef] [PubMed]

19. Campillos, M.; Cases, I.; Hentze, M.W.; Sanchez, M. SIREs: Searching for iron-responsive elements. Nucleic Acids Res. 2010, 38, W360-W367. [CrossRef] [PubMed]

20. Ding, Y.; Chan, C.Y.; Lawrence, C.E. Sfold web server for statistical folding and rational design of nucleic acids. Nucleic Acids Res. 2004, 32, W135-W141. [CrossRef]

21. Alvarez-Coca-Gonzalez, J.; Moreno-Carralero, M.I.; Martinez-Perez, J.; Mendez, M.; Moran-Jimenez, M.J. The hereditary hyperferritinemia-cataract syndrome: A family study. Eur. J. Pediatr. 2010, 169, 1553-1555. [CrossRef] [PubMed]

22. Van de Sompele, S.; Pecheux, L.; Couso, J.; Meunier, A.; Sanchez, M.; De Baere, E. Functional characterization of a novel non-coding mutation "Ghent $+49 \mathrm{~A}>\mathrm{G}$ " in the iron-responsive element of L-ferritin causing hereditary hyperferritinaemia-cataract syndrome. Sci. Rep. 2017, 7, 18025. [CrossRef] [PubMed]

23. Kubota, A.; Hida, A.; Ichikawa, Y.; Momose, Y.; Goto, J.; Igeta, Y.; Hashida, H.; Yoshida, K.; Ikeda, S.-I.; Kanazawa, I.; et al. A novel ferritin light chain gene mutation in a Japanese family with neuroferritinopathy: Description of clinical features and implications for genotype-phenotype correlations. Mov. Disord. 2009, 24, 441-445. [CrossRef] [PubMed]

24. Baraibar, M.A.; Muhoberac, B.B.; Garringer, H.J.; Hurley, T.D.; Vidal, R. Unraveling of the E-helices and Disruption of 4-Fold Pores Are Associated with Iron Mishandling in a Mutant Ferritin Causing Neurodegeneration. J. Biol. Chem. 2010, 285, 1950-1956. [CrossRef] [PubMed]

25. Bhuva, M.; Sen, S.; Elsey, T.; Atoyebi, W.; Dreau, H.; Bradbury, C.; Johnston, R.; Bignell, P.; Griffiths, W. Sequence analysis of exon 1 of the ferritin light chain (FTL) gene can reveal the rare disorder "hereditary hyperferritinaemia without cataracts". Br. J. Haematol. 2018. [CrossRef] [PubMed]

26. Thurlow, V.; Vadher, B.; Bomford, A.; DeLord, C.; Kannengiesser, C.; Beaumont, C.; Grandchamp, B. Two novel mutations in the $\mathrm{L}$ ferritin coding sequence associated with benign hyperferritinaemia unmasked by glycosylated ferritin assay. Ann. Clin. Biochem. 2012, 49, 302-305. [CrossRef] [PubMed]

27. Faniello, M.C.; Di Sanzo, M.; Quaresima, B.; Nisticò, A.; Fregola, A.; Grosso, M.; Cuda, G.; Costanzo, F. Bilateral cataract in a subject carrying a $\mathrm{C}$ to $\mathrm{A}$ transition in the $\mathrm{L}$ ferritin promoter region. Clin. Biochem. 2009, 42, 911-914. [CrossRef]

28. Allerson, C.R.; Cazzola, M.; Rouault, T.A. Clinical severity and thermodynamic effects of iron-responsive element mutations in hereditary hyperferritinemia-cataract syndrome. J. Biol. Chem. 1999, 274, 26439-26447. [CrossRef]

29. Baraibar, M.A.; Barbeito, A.G.; Muhoberac, B.B.; Vidal, R. Iron-mediated Aggregation and a Localized Structural Change Characterize Ferritin from a Mutant Light Chain Polypeptide That Causes Neurodegeneration. J. Biol. Chem. 2008, 283, 31679-31689. [CrossRef]

30. Vidal, R.; Ghetti, B.; Takao, M.; Brefel-Courbon, C.; Uro-Coste, E.; Glazier, B.S.; Siani, V.; Benson, M.D.; Calvas, P.; Miravalle, L.; et al. Intracellular ferritin accumulation in neural and extraneural tissue characterizes 
a neurodegenerative disease associated with a mutation in the ferritin light polypeptide gene. J. Neuropathol. Exp. Neurol. 2004, 63, 363-380. [CrossRef]

31. Garringer, H.J.; Irimia, J.M.; Li, W.; Goodwin, C.B.; Richine, B.; Acton, A.; Chan, R.J.; Peacock, M.; Muhoberac, B.B.; Ghetti, B.; et al. Effect of Systemic Iron Overload and a Chelation Therapy in a Mouse Model of the Neurodegenerative Disease Hereditary Ferritinopathy. PLoS ONE 2016, 11, e0161341. [CrossRef]

32. Vidal, R.; Miravalle, L.; Gao, X.; Barbeito, A.G.; Baraibar, M.A.; Hekmatyar, S.K.; Widel, M.; Bansal, N.; Delisle, M.B.; Ghetti, B. Expression of a Mutant Form of the Ferritin Light Chain Gene Induces Neurodegeneration and Iron Overload in Transgenic Mice. J. Neurosci. 2008, 28, 60-67. [CrossRef]

33. Muhoberac, B.B.; Baraibar, M.A.; Vidal, R. Iron Loading-Induced Aggregation and Reduction of Iron Incorporation in Heteropolymeric Ferritin Containing a Mutant Light Chain that Causes Neurodegeneration. Biochim. Biophys. Acta 2011, 1812, 544-548. [CrossRef] [PubMed]

34. Luscieti, S.; Santambrogio, P.; Langlois d'Estaintot, B.; Granier, T.; Cozzi, A.; Poli, M.; Gallois, B.; Finazzi, D.; Cattaneo, A.; Levi, S.; et al. Mutant ferritin L-chains that cause neurodegeneration act in a dominant-negative manner to reduce ferritin iron incorporation. J. Biol. Chem. 2010, 285, 11948-11957. [CrossRef]

35. Baraibar, M.A.; Barbeito, A.G.; Muhoberac, B.B.; Vidal, R. A mutant light chain ferritin that causes neurodegeneration has enhanced propensity toward oxidative damage. Free Radic. Biol. Med. 2012, 52, 1692-1697. [CrossRef] [PubMed]

36. Altes, A.; Perez-Lucena, M.J.; Bruguera, M. [Systematic approach to the diagnosis of hyperferritinemia]. Med. Clin. (Barc.) 2014, 142, 412-417. [PubMed]

(c) 2019 by the authors. Licensee MDPI, Basel, Switzerland. This article is an open access article distributed under the terms and conditions of the Creative Commons Attribution (CC BY) license (http://creativecommons.org/licenses/by/4.0/). 
Review

\title{
Emerging and Dynamic Biomedical Uses of Ferritin
}

\author{
Brian Chiou and James R. Connor * \\ Department of Neurosurgery, Penn State College of Medicine, Hershey, PA 17033, USA; bbc5138@psu.edu \\ * Correspondence: jconnor@pennstatehealth.psu.edu; Tel.: +1-717-531-4541
}

Received: 24 October 2018; Accepted: 12 November 2018; Published: 13 November 2018

\begin{abstract}
Ferritin, a ubiquitously expressed protein, has classically been considered the main iron cellular storage molecule in the body. Owing to the ferroxidase activity of the H-subunit and the nucleation ability of the L-subunit, ferritin can store a large amount of iron within its mineral core. However, recent evidence has demonstrated a range of abilities of ferritin that extends well beyond the scope of iron storage. This review aims to discuss novel functions and biomedical uses of ferritin in the processes of iron delivery, delivery of biologics such as chemotherapies and contrast agents, and the utility of ferritin as a biomarker in a number of neurological diseases.
\end{abstract}

Keywords: ferritin; iron; iron delivery; nanotechnology; nanocage; drug delivery; inflammation; serum biomarker

\section{Ferritin Introduction}

Ferritin, a protein originally identified in 1937 by Vilém Laufberger [1], is a ubiquitously expressed iron storage protein most commonly characterized by its ability to accumulate and store up to 4500 atoms of iron [2]. Ferritin consists of 24 subunits, typically comprised of different ratios of the $\mathrm{H}$ and $\mathrm{L}$ chain subunit. The ratios vary by organ and even by cell type. Importantly, the different subunits have divergent functions- $\mathrm{H}$-ferritin utilizes ferroxidase activity that is necessary for the oxidation of ferrous $\left(\mathrm{Fe}^{2+}\right)$ to ferric $\left(\mathrm{Fe}^{3+}\right)$ iron while $\mathrm{L}$-ferritin contains acidic residues on the surface cavity of the protein that facilitate ferroxidase turnover and are crucial for the nucleation of ferric iron within the core of the fully formed protein. Historically, the primary function of the 24-mer protein has been to sequester extracellular and cytosolic iron and store this iron within its core for future use by the cell. This functionally prevents the formation of harmful reactive oxygen species (ROS) created through Fenton chemistry. Many reviews in the past few decades have focused on various aspects of the normal biological function of ferritin and its regulation pertaining to iron homeostasis [3-6]. In this review, we will outline novel and dynamic functions of ferritin that have recently come to light, specifically focusing on the novel uses for ferritin as an iron delivery protein, a delivery agent for numerous other biologics, and as a biomarker for various diseases.

Although traditionally characterized as a cytosolic protein, ferritin has also been found in mitochondria [7], plant plastids [8], the nucleus [9-11], and extracellularly in serum [12] and cerebrospinal fluid [13]. The different subcellular localizations of ferritin suggest a unique function for it in a variety of cell types. For example, nuclear ferritin reportedly binds to and protects DNA from UV-induced damage [9] as well as iron-induced damage [11]. The presence of ferritin in nuclei led to a series of studies by our group on the role of ferritin in cancer cells that revealed knockdown of ferritin increases sensitivity to radiation and chemotherapy in cancer cells [14]. Mitochondrial ferritin, while coded by a different gene than either L- or H-ferritin, shares $79 \%$ homology to H-ferritin and forms the classic ferritin shell [15]. In the mitochondria, free iron can cause potentially devastating effects; mitochondrial ferritin serves to sequester potentially harmful iron using ferroxidase activity [4]. 


\section{Ferritin as an Iron Delivery Protein}

Iron delivery throughout the body is a vitally important process that is very tightly regulated. Iron deficiency may result in a number of longstanding and severe phenotypes such as anemia [16]. Similarly, iron overload, known as hemochromatosis, may result in organ failure [17] or significant inflammatory conditions [18]. Moreover, iron dyshomeostasis in the brain may result in significant neurodegeneration [19-21]. Excess organ and cellular accumulation in disease states occurs because the regulation of iron uptake is altered. The primary mechanism for iron uptake has historically been thought to be through the action of transferrin (Tf) delivering iron through transferrin receptor (TfR) (Figure 1). However, this paradigm may not address times of extreme iron need, such as during development and growth. While transferrin typically delivers two atoms of iron at a time, ferritin can potentially deliver a much more substantial amount of iron at a single time, allowing for rapid growth and iron utilization.

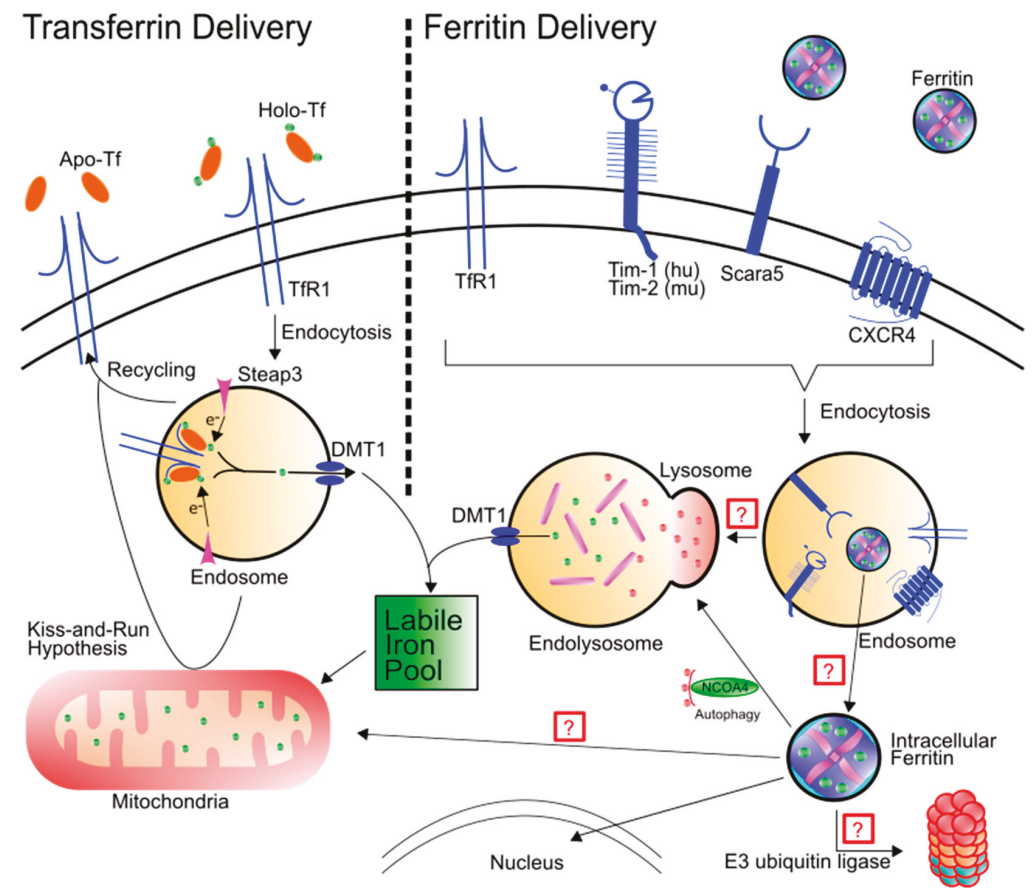

Figure 1. Schematic of transferrin and ferritin uptake and intracellular destiny. Left: Holo-Tf can bind to TfR1 and deliver iron into the labile iron pool through the endosome via DMT1. TfR1 can also be recycled to the cell surface, depositing apo-Tf into the extracellular matrix. An alternative hypothesis termed "kiss-and-run" results in endosomal delivery of iron to the mitochondria by brief interactions between the endosome and the mitochondria. Right: Ferritin binding has been shown for TfR1, Tim-1, Tim-2, Scara5, and CXCR4. After binding, ferritin is endocytosed. Note, while not all receptors are simultaneously required for endocytosis of ferritin, the schematic is demonstrating that all of the receptors in question have been found in the endosome. Ferritin trafficking after endocytosis has yet to be fully elucidated. Hypotheses include trafficking to the lysosome for protein degradation or for ferritin to leave the endosome through another means. Once ferritin is cytosolic, it can be shuttled to the lysosome via NCOA4 or it may be transported to the nucleus. There are a number of other potential hypotheses as well: (1) Ferritin may be poly-ubiquitinated and degraded by the proteasome or (2) ferritin may be shuttled to the mitochondria to deliver iron. 
In particular, serum ferritin represents an important consideration in iron delivery; saturation of serum ferritin can range wildly depending on a number of factors, such as inflammation or development, with values ranging between $5 \%$ and $50 \%$ saturated [22]. It remains to be determined the extent to which serum ferritin functions to deliver iron; iron saturation of ferritin is largely ignored in the clinic. This is particularly important as around $90 \%$ of patients that present in the clinic with hyperferritinemia do not have iron overload [23]. While serum ferritin reportedly has a lower level of iron saturation than liver ferritin [24], the iron contained within serum ferritin was still a relatively higher amount than transferrin iron. Cohen et al. found that while liver ferritin contained 2074 atoms of iron per molecule of ferritin, serum ferritin contained 689 atoms of iron per molecule of ferritin [24]. Thus, despite the common tendency to refer to serum ferritin as "iron poor" that one consistently sees in the literature, it stands that if serum ferritin participates in iron delivery it is a significant source of iron.

In order for ferritin to serve as an iron delivery protein, it must be released from cells (Figure 2). Secretion of ferritin has been demonstrated in many cell types, such as macrophages $[18,25,26]$, hepatocytes [27], and Kupffer cells of the liver [28], in both healthy and disease settings. While the exact mechanism of ferritin secretion is still very much open for debate, the lack of glycosylation of extracellular ferritin suggests a non-classical secretion route. Cohen et al. have demonstrated the secretion of ferritin through the lysosomal secretory pathway, a cell-specific directed pathway that is not the product of damaged cells [24]. In this pathway, specialized secretory lysosomal granules are created both as degradative/modulatory compartments as well as storage areas, eventually followed by secretion of its contents to the extracellular milieu [29]. Subsequently Truman-Rosentsvit et al. found that in addition to the lysosomal secretory pathway, ferritin can also be secreted via the multivesicular body-exosome pathway [30]. Consistent with the secretion in membrane bound vesicles, Mrowcyznski et al. has demonstrated the presence of H-ferritin in exosomes [31]. Recently, Kimura et al. have further described this secretion mechanism as dependent upon the tripartite motif containing 16 (TRIM16) secretory autophagy receptor, avoiding autolysosomal degradation by pivoting ferritin cargo to the plasma membrane for secretion [32]. Thus, the data appear to support an active rather than passive release mechanism for ferritin from cells. Consequently, the amount of serum ferritin may be reflective of cellular processes and not a by-stander to inflammation and non-specific product of cell damage. This indicates that ferritin secretion may be an active response to physiological conditions and identifying those conditions that promote ferritin secretion are an area that could lead to new knowledge about ferritin function and iron requirements.

Recent studies have demonstrated ferritin ability for iron delivery. In particular, studies have provided evidence for $\mathrm{H}$-ferritin uptake into the brain parenchyma [33], regulation of $\mathrm{H}$-ferritin trafficking across the blood-brain barrier (BBB) [34-38], and H-ferritin uptake into the developing mouse brain (Unpublished Observations). In these experiments, radioactive ${ }^{59} \mathrm{Fe}$ loaded into H-ferritin was used to track the transport of iron directly across the BBB in vitro [34] or directly into the brain in vivo [33]. This was further corroborated by inductively coupled plasma mass spectrometry (ICP-MS) studies of iron delivery by H-ferritin [35]. Todorich et al. demonstrate the importance of $\mathrm{H}$-ferritin-mediated iron delivery to the brain, demonstrating that $\mathrm{H}$-ferritin can replace transferrin as an obligate iron source for oligodendrocytes in vitro [39]. Further evidence has demonstrated both $\mathrm{H}-$ and L-ferritin binding and endocytosis in a number of different cell types, including hepatocytes [40], reticulocytes [41], lymphoid cells [42], and erythroid precursors [26,43,44]. In all of these cell types, binding and endocytosis of ferritin results in increased intracellular iron levels. The ability of ferritin to deliver a significantly higher amount of iron relative to transferrin suggests the existence of a more efficient iron delivery system perhaps especially in times of high iron demand, such as neural development and rapid growth [45]. 


\section{Mechanisms of Ferritin Export}

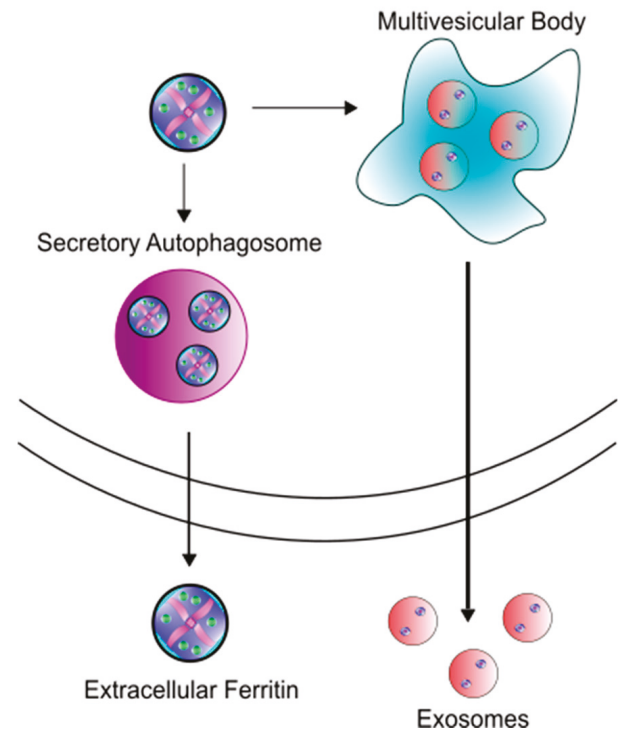

Figure 2. Schematic of iron export mechanisms. Ferritin has been hypothesized to be secreted in two different paradigms: (1) Ferritin is trafficked from the cell via secretory autophagy or (2) ferritin encapsulated in exosomes is released extracellularly from multivesicular bodies.

There is considerable debate regarding the mechanism for ferritin uptake. While previous studies have demonstrated clathrin-dependent endocytosis of ferritin [46], there is not yet a consensus on the specific receptor mediating the uptake. Further complicating matters is the report that both $\mathrm{H}$-ferritin and L-ferritin utilize different receptors. As previously stated, ferritin typically exists in a ratio of $\mathrm{H}$ - and $\mathrm{L}$-ferritin; the ratio of $\mathrm{H}$ - to L-subunits may dictate the specific receptor preferred. While L-ferritin has been shown to bind to Scara5 [47], H-ferritin has thus far been shown to bind to Tim-2 in rodents [48-50], Tim-1 in humans [34,51], as well as CXCR4 [52] and TfR1 [53] (Figure 1). There is discrepant literature describing the ability for ferritin binding to saturate to Tim-2; one study found ferritin binding to be saturable [49] while another found it is not [50]. Importantly, we are not aware of any literature testing for respective contributions of ferritin binding between the TfR1 and Tim receptors. To this point, most cells in the studies studying TfR1 binding to ferritin did not assay for Tim- $1 / 2$ as a second uptake receptor. It is likely that both systems exist side-by-side and display different expressions for TfR 1 and Tim- $1 / 2$ depending on cell type. This suggests that in cells that do not have TfR1, such as mature oligodendrocytes [54], ferritin internalization is dependent on Tim-1/2. Furthermore, it is well known that Tf receptors are saturated to almost $100 \%$ capacity when Tf saturation is normal ( $30 \%$ ) - further suggesting that ferritin binding to Tim- $1 / 2$ may represent the preferred method for uptake of ferritin into the cell.

While binding and endocytosis of ferritin have been previously demonstrated, the eventual downstream fate of endocytosed ferritin has yet to be studied. An important consideration for ferritin uptake is that ferritin can transport anywhere from 100 to 1000 times as much iron as transferrin and therefore improper delivery and regulation of this delivery may have devastating consequences for the cell. As such, it is clearly critical to cell viability to have a route for handling iron release after exogenous ferritin uptake. For example, does ferritin get moved to the endosome and/or lysosome after uptake? If so, what happens to the iron contained within ferritin after ferritin degradation? $\mathrm{Li}$ et al. have previously demonstrated H-ferritin delivery to a human T lymphoblast cell line (MOLT-4), 
showing $\mathrm{H}$-ferritin trafficking to the endosome as well as to the lysosome [53]. It remains to be seen if this delivery route is the same for all cell types, especially in cells lacking TfR1 such as mature myelinating oligodendrocytes [54]. It may also possible for ferritin to leave the endosome without being transported to the lysosome; the diameter of ferritin is only $12 \mathrm{~nm}$, leading to a hypothesis that ferritin may leave the endosome through pores created under cellular stress [55] (Figure 1).

Previous characterization of the Tf-TfR axis has shown the ability for endosomal divalent metal transporter 1 (DMT1) to facilitate exit of iron from the endosome to be utilized by the cell [36,38]. Furthermore, previous studies have also demonstrated that $\mathrm{H}$-ferritin transport is affected by pharmacological inhibition of DMT1 [34]. A second possibility for the fate of ferritin after uptake can be seen again in the Tf-TfR axis. Das et al. have shown that Tf may deliver iron to the mitochondria after uptake while still in the endosome, a process that has been termed "endosomal kiss-and-run" [56]. It is likely that this process, namely the delivery of extracellular iron to the mitochondria, is highly upregulated especially in times of high iron demand. Thus, the possibility exists for ferritin to perform a similar function as Tf to deliver a substantially higher amount of iron directly to the mitochondria either through "kiss-and-run" activity or through a directed transport mechanism (Figure 1).

Once ferritin is within the cytosol either via exogenous (uptake) or endogenous (translation) means, the fate of the protein itself and the iron contained within has been the subject of many studies, but the literature is inconsistent. Some studies suggest that intracellular ferritin is transported to the lysosome to be degraded and the iron inside the ferritin core to be recycled [27]. In particular, nuclear receptor coactivator 4 (NCOA4) was found to be essential in the transport of cytosolic ferritin to the lysosome, a process termed "ferritinophagy" [57]; NCOA4 knockout cells had reductions in ferritin degradation as well as lower intracellular labile iron [57,58]. These studies demonstrated that NCOA4 binds specifically to H-ferritin, but not L-ferritin, at the Arg23 residue [58]. Furthermore, NCOA4 is importantly recognized by the HECT-type E3 ubiquitin ligase HERC2 which itself is iron-sensitive, suggesting NCOA4 is degraded under conditions of iron excess. However, since NCOA4 only recognizes $\mathrm{H}$-ferritin, there is still the question of how L-ferritin is degraded. Other literature suggests that ferritin in general is largely degraded in the proteasome and this degradation can be regulated based on proteasomal activity [59]. Still, others suggest that both lysosomal-mediated and proteasome-mediated degradation of cytosolic ferritin are indeed important contributors to overall ferritin homeostasis [60]. In 2010, Zhang et al. examined the degradation pathway by inhibiting either the lysosome or the proteasome and found that lysosomal proteolysis is the major contributor to ferritin degradation, with proteasomal-mediated degradation conferring a smaller proportion of the degradation [61]. Whether this finding is relevant to all cell types or only the mouse B cell line used in the Zhang et al. study is unclear.

\section{Ferritin as a Delivery Agent}

In addition to iron, ferritin has the unique ability to encapsulate and deliver other molecules. Indeed, ferritin is a highly preferred molecule in the field of nanotechnology owing to its self-assembly properties, precise cage alignment, and the ability to modify the surface of the fully formed protein with various conjugates to increase specificity and functionality. Importantly, despite the rigid structure under normal physiological conditions, ferritin can be disassembled when the $\mathrm{pH}$ becomes very acidic ( $\mathrm{pH} 2-3$ ) or very basic ( $\mathrm{pH} 11-12)$ [62]. This process can be reversed by changing the $\mathrm{pH}$ back to neutral conditions, spontaneously forming ferritin into the full 24-mer [62] (Figure 3). Many researchers have utilized these assembly properties to load various compounds and molecules within the ferritin core. This flexibility in loading and assembly allows for numerous non-classical uses of ferritin. Moreover, even though ferritin has a high molecular weight $(\sim 474 \mathrm{kDa})$, the total diameter of the assembled $24-m e r$ is roughly $12 \mathrm{~nm}$. This diameter is easily smaller than many nanoparticles that are currently in development as drug delivery vehicles; the small diameter of ferritin permits wide movement across membranes, including into the nucleus and potentially out of endosomes [10]. Furthermore, while typically containing a negative surface charge, the charge on ferritin can vary depending on 
subunit composition, which allows for further flexibility when targeting ferritin molecules across different membranes [63]. Taken together, the unique characteristics of ferritin allow for robust nanocage assembly and targeted delivery.

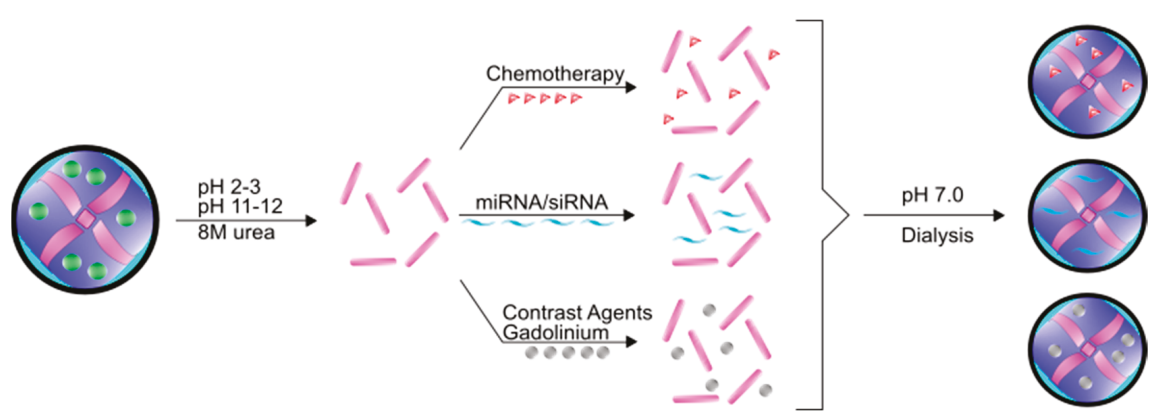

Figure 3. Schematic of encapsulation paradigms for ferritin. Fully formed 24-mer ferritin molecules can be disassembled using $8 \mathrm{M}$ urea or acidic $(\mathrm{pH} 2-3)$ or basic $(\mathrm{pH} 11-12)$ conditions. A number of different molecules can be mixed with the disassembled ferritin, including chemotherapies, siRNAs/miRNAs, and contrast agents. Upon returning the ferritin mixture to neutral conditions ( $\mathrm{pH}$ 7.0) coupled with dialysis, ferritin will spontaneously form the 24-mer around the molecule of interest. Free molecules can be dialyzed away from solution.

One prominent area of investigation in the application of ferritin nanocages is in the treatment of cancer. Taking advantage of the fact that cancer cells require a higher amount of iron, many researchers have begun to use ferritin nanocages with encapsulated chemotherapies as delivery agents both in vitro $[64,65]$ and in vivo $[65,66]$ to great effect. Typically, chemotherapeutics such as doxorubicin, are modified by either forming a complex of the drug with transition metals such as $\mathrm{Cu}(\mathrm{II})$ [67] or by adding a charged accessory molecule such as poly-L-aspartic acid [68]. Not only does this complex facilitate entry into the ferritin core, but it also allows the transition metal or accessory molecule to stay associated with the ferritin protein while the drug is gradually released from ferritin [68]. For several chemotherapies that target the nucleus or DNA, the ability of ferritin to translocate into the nucleus represents a potential added benefit therapeutically $[9,10]$. Though the mechanism for drug release from ferritin either in the cytosol or in the nucleus has not yet been elucidated, there is strong evidence that delivery of chemotherapies via ferritin is an effective method that results in reduced non-specific cytotoxicity $[69,70]$. These reduced off-target effects suggest that cancer cells preferentially take up the ferritin nanocages in an attempt to obtain more iron from circulating ferritin. To further promote the uptake of ferritin by cancer cells, Li et al. conjugated epidermal growth factor (EGF) to H-ferritin as a way to target epidermal growth factor receptor (EGFR)-overexpressing breast cancers in mice [71].

While many studies of ferritin delivery of chemotherapies reveal strong efficacy in non-central nervous system (CNS) cancers [72-74], the use of ferritin nanocages is even more promising for therapeutics targeting brain cancers. Owing to the BBB, effective chemotherapeutic treatment of brain cancers has been extremely difficult. However, as previously described, new evidence suggests ferritin can traffic across the human BBB through Tim-1 [34], potentially allowing for the delivery of directed therapeutics into the brain parenchyma. In diseases such as neuroblastoma or glioblastoma that are extremely aggressive and have a severe phenotype with limited treatment options, ferritin nanocages represent a highly exciting and novel delivery route (Figure 2). As an example, Chen et al. have recently demonstrated that apoferritin loaded with doxorubicin can reliably cross the BBB and deposit the chemotherapy specifically within the tumor in a mouse model resulting in increased survival [75]. This example again demonstrates the preferential uptake of ferritin by cancer cells, likely in an attempt to obtain more iron. 
In addition to loading the ferritin molecule with chemotherapies such as doxorubicin, the ferritin molecule may allow for delivery of small interfering RNAs (siRNAs) in a number of different biological paradigms. For example, Li et al. have demonstrated a simple method for encapsulating siRNA and using this ferritin-siRNA combination to perform high efficiency transfections of human primary mesenchymal stem cells (hMSCs) and peripheral blood mononuclear cells (PBMCs) in vitro when compared to commercially available Lipofectamine [70]. This study demonstrated that ferritin-siRNA could achieve high gene expression silencing with a low siRNA concentration of $10 \mathrm{nM}$. This work has large implications in the treatment of various immune-related disorders, as in vivo delivery of this ferritin-siRNA complex did not show any immune activation of the PBMCs but was preferentially taken up by activated B- and T-cells. Furthermore, it has been shown that delivery of H-ferritin siRNA sensitizes glioma to radiation $[14,76]$ which brings up the possibility of using ferritin containing $\mathrm{H}$-ferritin siRNA in order to sensitize various cancers to radiation.

In 2013, Kanekiyo et al. detailed an exciting use for ferritin as a natural delivery agent for vaccines [77]. In this study, the authors fused the influenza virus haemagglutinin (HA) to the ferritin protein and immunized mice with this fusion protein. As a result, mice produced broad-scale neutralizing antibodies against common and vulnerable targets of universal influenza vaccines. Furthermore, the HA-ferritin fusion protein elicited ten times as high of a response as the naïve vaccine, demonstrating increased potency and breadth of influenza immunity. Kanekiyo and colleagues have also extended this approach to the creation of a potential vaccine for Epstein-Barr Virus [78]. This seminal study spawned other studies such as one by Han and colleagues-priming of dendritic cells using ferritin nanocages conjugated to ovalbumin antigenic peptides OT-1 and OT-2 [79]. In this study, the dendritic cell-based vaccine was developed by putting OT-1 and OT-2 on the exterior surface and interior cavity, respectively, resulting in effective priming of $\mathrm{CD}^{+}$and $\mathrm{CD} 8^{+} \mathrm{T}$ cells after antigen presentation by the dendritic cell. Immunization of mice with this vaccine resulted in differentiation and proliferation of $\mathrm{CD}^{+}$and $\mathrm{CD} 8^{+} \mathrm{T}$ cells specifically targeting OT-1 and OT-2.

\section{Ferritin as a Mineralization Chamber}

Magnetic resonance imaging (MRI) is a powerful diagnostic technique with extensive uses in the detection of tumor development [80], white matter development and injury [81,82], and aberrant vascularization $[83,84]$. To create a clinically useful image that is both highly sensitive and accurate, contrast agents are typically used to aid the visual interpretation of MRI scans. The most common contrast agents used are different formulations of gadolinium (Gd), owing to the strong paramagnetism of $\mathrm{Gd}$ from seven unpaired electrons. However, a significant problem with $\mathrm{Gd}$ is that it nonspecifically labels all highly vascularized tissues, resulting in false positives and a loss of spatial resolution.

Ferritin represents a viable alternative to Gd labeling for MRI. Both endogenous and exogenous ferritin have found great utility in improving MRI contrast capabilities and disease monitoring [85]. In particular, an increased amount of iron within the ferritin core directly correlates with T2* contrast power. It has been shown that Gd can also be loaded within the ferritin core and used as a more prominent imaging agent $[72,86]$ (Figure 2). This function of improved contrast has many applications, especially in the diagnosis or monitoring of cancer progression. Other functionalities of ferritin use in MRI rely on preferential uptake of ferritin by resident macrophages within a cancer tumor [73] or by the tumor cells themselves either by native uptake or by enhancing uptake with further conjugations [87].

An interesting use of ferritin on an industrial process-scale level is the use of thermostable ferritin from Pyrococcus furiosus as a water treatment biologic [88]. In this example, ferritin is used to sequester excess phosphate and arsenate due to the high phosphate and arsenate content of seawater and industry waste. While current phosphate removal methods use a system that is heavily reliant on calcium and aluminum sulfates or bacteria that adsorb calcium, the removal of phosphates by ferritin represents a lower maintenance cost and a method that can be recycled [88]. 


\section{Ferritin as a Marker for Inflammation}

There are three main regulatory pathways for the expression of ferritin: The iron response proteins (IRPs)/iron responsive element (IRE) system [89], the regulation of transcription through NF-KB [90], and transcriptional regulation through the hypoxia inducible factor 1 alpha (HIF-1 $\alpha$ ) binding to a HIF responsive element (HRE) upstream of the IRE system [91]. The IRP/IRE system functions by the binding of IRPs to the IRE at the 5' untranslated region (UTR) of ferritin mRNA under conditions of low iron, inhibiting its translation. However, in conditions of high iron, IRP binding to the IRE is decreased, leading to increased ferritin expression. Similarly, ferritin gene transcription is upregulated in conditions of inflammation where inflammatory cytokines such as tumor necrosis factor alpha (TNF- $\alpha$ ) and interleukin-2 (IL-2) signal to increase binding of NF- $\mathrm{KB}$ to the transcription enhancer FER2 upstream of the IRE and coding region [90]. It has been shown that the NF- $\mathrm{KB}$ pathway is highly responsive to inflammation [92]. Evidence for this pathway stems from activation of toll-like receptor 2 (TLR2) in macrophages resulting in IRP-independent upregulation of $\mathrm{H}$-ferritin, as well as direct pharmacological activation of the NF- $\mathrm{KB}$ pathway [93]. Similarly, it has been shown that H-ferritin expression is also responsive to tumor necrosis factor alpha (TNF- $\alpha$ ) [94], interleukin-2 (IL-2) [95], and IL-10 [96]. Consequently, the elevated presence of ferritin in serum has long been considered in clinical settings to be an acute phase inflammatory marker, as elevated serum ferritin levels have been correlated with increased levels of pro-inflammatory cytokines [97,98]. Potential sources of serum ferritin during inflammation include secretion by macrophages $[24,25]$ and/or release from cells due to tissue damage [99], both indicators of inflammation or infection. Importantly, there is disagreement in the literature about whether serum ferritin is a pro-inflammatory marker [100], an anti-inflammatory marker [101,102], or is simply a byproduct of release during the course of infection by damaged cells [99]. Understanding mechanisms of release of ferritin and how those mechanisms are influenced at the cellular level could provide insights into the biological and clinical meaning of ferritin in serum.

Serum ferritin has also been routinely interpreted in the clinic as a surrogate measure of iron storage in the body [103]. There are numerous studies that examine the correlation between serum ferritin and iron deficiency anemia or hemochromatosis in which serum ferritin levels are decreased or elevated, respectively [104]. However, inflammation or infection is known to drastically change the amount of serum ferritin present [105]. Accordingly, in an individual with acute or chronic inflammation, the extent to which serum ferritin levels reflect inflammation may reflect the total body iron stores. To further complicate this understanding, there are studies demonstrating that serum ferritin is not the most reliable marker for total body iron stores, especially when there are other complicating factors such as liver or kidney damage [12]. Put together, it seems that clinically, serum ferritin may be used as a marker for total body iron stores in the healthy individual, however, in a disease setting serum ferritin may be more indicative of the underlying pathophysiology such as organ damage or infection.

Another important consideration is while serum ferritin may be used clinically to suggest inflammation, serum ferritin measurements are focused largely on the L-ferritin subunit and as such, remain a poor indicator of iron status of the patient in this inflammatory state [97], as described earlier it is $\mathrm{H}$-ferritin that is mostly responsive to the inflammatory process. H-ferritin has been detected in serum [106] and has the potential to be much more dynamic and informative than L-ferritin. A critical question that has yet to be answered clinically is: Is the iron saturation of serum ferritin in any given individual more informative to the total body iron stores than serum ferritin levels itself? Currently, it is rather trivial to measure serum ferritin levels but to measure the iron contained within serum ferritin is considerably more difficult. One recent study has looked at ferritin secretion from macrophages and determined that iron saturation of the ferritin was about a third as saturated as liver ferritin [24]. This is important as many consider serum ferritin to be iron-free or iron-poor, but the reality is that it contains a significant amount of iron. Thus, ferritin saturation may be the better measure of total body iron stores rather than the serum ferritin molecules themselves. 
In addition to the utility of serum ferritin clinically, intracellular ferritin has also been implicated in the host response to microbial infection. Recent evidence demonstrates that $\mathrm{H}$-ferritin confers tolerance to malaria and sepsis during infection by limiting reactive oxygen species (ROS) and overall oxidative stress. For example, Gozzelino et al. shows evidence that the activity of $\mathrm{H}$-ferritin confers a metabolic adaptation to Plasmodium infection [107]. This activity is through the chelation ability of H-ferritin to limit labile iron from activating the pro-apoptotic c-Jun $\mathrm{N}$-terminal kinase (JNK). Furthermore, the authors found that JNK activity inhibits H-ferritin expression and causes increased susceptibility of malaria coupled with tissue damage and oxidative stress. To extend this study, Weis et al. also looked at this metabolic adaptation in sepsis, a devastating syndrome resulting from a maladaptive host response to infection [108]. Much in the same way as Gozzelino et al., Weis and colleagues demonstrated a disease tolerance to sepsis that was facilitated by $\mathrm{H}$-ferritin. Importantly, activity of $\mathrm{H}$-ferritin to sequester cytosolic iron was critical for the setup of disease tolerance. Weis et al. showed that $\mathrm{H}$-ferritin iron chelation prevents iron-driven oxidative inhibition of the glucose-6-phosphatase to sustain glucose production via liver gluconeogenesis. Another recent study that demonstrates the importance of H-ferritin in response to microbial infection was by Reddy et al. [109]. In this study, the authors infected H-ferritin knockout mice or wild-type mice with Mycobacterium tuberculosis, demonstrating that knocking out $\mathrm{H}$-ferritin specifically in myeloid cell populations decreased survival after infection, increased the overall inflammatory response, and increased the total bacterial loads. These studies highlight the general importance of ferritin in the inflammatory response as well as for normal host iron homeostasis.

In contrast, ferritin has also been shown to have a role as an anti-inflammatory molecule. Ferritin in serum reportedly binds to high molecular weight kininogen (HK) [110]. Normally, HK is a co-factor in the intrinsic coagulation pathway; HK cleavage by the serine protease kallikrein leads to release of bradykinin and two-chain high molecular weight kininogen [111]. This particular pathway has large implications in the progression of a number of inflammatory diseases such as asthma [112], inflammatory bowel disease [113], and rheumatoid disorders [114,115]. Ferritin binding to HK serves as an anti-inflammatory signaling pathway, as the direct interaction of ferritin with HK prevents HK cleavage and a concomitant reduction in bradykinin release [102]. This overall interaction diminishes the total inflammatory response. In a similar paradigm, Fan and colleagues demonstrated that L-ferritin can play an important anti-inflammatory role in lipopolysaccharide (LPS)-stimulated macrophages [101]. In this study, Fan et al. show that overexpression of L-ferritin in macrophages can inhibit LPS-mediated transcription of TNF- $\alpha$ and IL- $1 \beta$, both critical pro-inflammatory cytokines. Conversely, they showed that L-ferritin is significantly downregulated after LPS stimulation. From this study, the authors conclude that L-ferritin has an underappreciated role in the anti-inflammatory resolution cascade. Importantly, both of these studies are direct evidence of ferritin playing an anti-inflammatory role.

\section{Ferritin as a Disease Biomarker}

While the amount of iron has been shown to increase throughout the body with age [116-118], abnormal iron homeostasis can lead to devastating diseases. Typically, a concomitant increase in ferritin levels are paired with increased iron levels [119], attempting to ensure safe handling of this increase in iron. However, a failure of ferritin levels to concomitantly increase with iron may impact normal physiology and induce pathology as a result of iron-mediated induction of oxidative stress. This role for ferritin and a mishandling of systemic iron has been shown to be implicated in a number of diseases such as Still's disease, hemophagocytic syndrome, and sideroblastic anemia-implications of serum ferritin in these diseases and others have been critically reviewed in numerous other reviews $[12,104,106]$. Similarly, serum ferritin as a bioindicator for cancer has been extensively reviewed as well $[120,121]$. Here we will focus specifically on neurological disorders and the impact that ferritin has on diagnosis as a biomarker for disease or progression. One interesting new development has been proposed in Friedreich's Ataxia where the authors discuss the hypothesis 
that the mitochondrial protein frataxin may oligomerize like ferritin and perform functions redundant with mitochondrial ferritin, acting as another iron storage molecule [122]. Loss of frataxin and this iron storage property may result in Friedreich's Ataxia and subsequent neurodegeneration.

\subsection{Neuroferritinopathy}

Neuroferritinopathy (NF), an autosomal dominant disease resulting from mutations in L-ferritin, is classified as belonging to a group of movement disorders known as Neurodegeneration with Brain Iron Accumulation (NBIA). This disease is an extrapyramidal syndrome typically characterized by excessive iron accumulation in the basal ganglia. NF was originally characterized as a disease arising from an additional adenine at c.460 of exon 4 in the L-ferritin gene, but other mutations around the same region were quickly identified as contributing to disease pathology [123]. These mutations cause a frameshift in the C-terminus of the L-ferritin subunit resulting in reduced or ablated iron storage and subsequent iron-mediated damage, as this mutation creates a larger than normal pore [123]. In 2010, Barbeito et al. showed that fibroblasts from NF patients have higher levels of $\mathrm{H}$ - and L-ferritin as well as increased levels of total iron stores [124]. Furthermore, Maccarinelli and colleagues showed in 2014 that mice with the same L-ferritin mutation had a progressive impairment in motor coordination and a propensity to accumulate iron within post-natal hippocampal neurons [125]. Interestingly, this mutation in NF patients is present in all cells, but there is no evidence for iron mismanagement or dyshomeostasis by the rest of the body. It is currently unclear whether brain cells are simply more sensitive to iron-dependent toxicity or if there is a separate function for L-ferritin within the brain parenchyma. It is likely that the high oxygen and glucose consumption of the brain leads to an increase in iron utilization and therefore ROS/oxidative stress. Without functional L-ferritin, brain cells are rendered unable to survive this oxidative damage.

\subsection{Parkinson's Disease}

One of the most prominent neurodegenerative diseases with marked neurodegeneration as well as substantial iron accumulation in the substantia nigra pars compacta (SNpc) is Parkinson's disease (PD). In general, there is agreement that iron accumulation in the SNpc increases with age, but the additional increase in iron in the SNpc as a result of PD depends heavily on the stage and progression of PD [126]. With regard to ferritin in $\mathrm{PD}$, there are a number of conflicting reports regarding the expression of ferritin within the SNpc; biochemical studies have shown both increased [126] and decreased [127] levels of ferritin within the SNpc in PD. In the 1-methyl-4-phenyl-1,2,3,6-tetrahydropyridine (MPTP) model of $\mathrm{PD}, \mathrm{H}$-ferritin overexpression in neurons is protective against disease progression [128]. Although there seems to be altered iron management specifically within the SNpc, cerebrospinal fluid (CSF) levels of ferritin and serum ferritin levels were not significantly different between PD and non-PD patients [127]. In contrast however, there is a recent study detailing how serum ferritin may serve as a potential biomarker for diagnosis in PD [129]. In this study, the authors found an increased level of serum ferritin in PD patients when compared to non-PD patients. Unfortunately, the sample size of the patient cohort used in this study was relatively small (40 healthy vs. 40 PD patients) and was limited to a cross-sectional analysis. Furthermore, there is a lack of consensus about the reliability of using serum ferritin as an indicator of brain iron status or even, as previously discussed, systemic iron status. Another consideration in the utilization of serum/CSF ferritin as a biomarker in PD is that peripheral inflammation plays a large role in PD disease progression [130]. As such, serum/CSF ferritin levels will likely be altered as a result and may not be informative of brain iron status.

\subsection{Restless Legs Syndrome}

In Restless Legs Syndrome (RLS), a disorder characterized by an irresistible urge to move the limbs and unpleasant sensations in the legs, a well-established neurobiological abnormality is low brain iron despite normal peripheral iron levels [131]. However, RLS is about five times more prevalent in iron deficient populations $[132,133]$. It is clear that ferritin levels are significantly impacted by and 
are important in RLS pathology, but it is not yet known how ferritin may specifically contribute to disease progression or disease symptoms. We have previously shown that Tf, TfR, and H-ferritin levels are decreased in the endothelial cells of RLS patients, indicating iron mismanagement at the level of the BBB, suggesting decreased brain iron acquisition in RLS brains [134]. Furthermore, studies have also demonstrated a decrease in H-ferritin and iron levels specifically in the SNpc of RLS brains compared to controls [135]. Currently, serum ferritin is used to guide treatment, but we have discussed the concerns regarding the utility of serum ferritin both as a measure of total body iron stores and serum ferritin levels are of no value in predicting response to treatment. Lammers et al. studied serum ferritin, bodily iron, and RLS, finding no association between early-onset RLS and longitudinal measures of iron stores [136]. Similarly, while serum ferritin is currently used clinically to guide treatment, it has been shown that serum ferritin levels have no predictive value in the response to treatment [131]. This is an important consideration as it underlines the fact that serum ferritin levels are not necessarily predictive of brain ferritin levels or total brain iron status.

\subsection{Amyotrophic Lateral Sclerosis}

Amyotrophic Lateral Sclerosis (ALS), a progressive and devastating disease, is characterized by loss of motor neurons in the cortex, brainstem, and spinal cord. While ALS is a relatively common disease, the exact mechanisms for this neurodegeneration is currently unknown, with a number of factors such as oxidative stress, excitotoxic stimulation, and genetic factors all implicated to play a role. It has long been known that in the ALS iron homeostasis is disrupted; there is higher iron in the CSF and spinal cord of ALS patients [137]. While there are a large number of studies that demonstrate elevated levels of serum ferritin in ALS [137-139], there is not yet a consensus regarding whether serum ferritin is predictive $[139-141]$ or unrelated $[137,138]$ to disease progression and survival rates.

\section{Conclusions}

Classically, ferritin has been described as a critical iron storage protein whose dual roles as both an antioxidant and an iron sink were essential to cellular survival. The importance of ferritin can directly be seen in knockout mouse models; both $\mathrm{H}$ and L homozygous knockout mice are embryonic lethal $[128,142]$. While not disputing the importance of these intracellular roles, it is clear that ferritin has highly dynamic and novel functions outside of the cells. Recent evidence has demonstrated the ability of ferritin to participate in iron delivery, delivery of macro/micromolecules, and as a potential biomarker in many neurologic diseases. Though serum ferritin is largely comprised of the L subunit, iron levels in ferritin remain much higher than transferrin; there is significant potential for serum ferritin to deliver anywhere between 10 to 100 times higher iron than transferrin [35]. Furthermore, while it is clear that ferritin can deliver iron to various organs throughout the body, it is still unclear as to why the body needs multiple iron delivery routes, especially with such drastic differences in amount of iron delivered. Besides iron, the delivery of ferritin-encapsulated macro- and micromolecules has important implications in the treatment and diagnoses of various disorders. While serum ferritin has been implicated in a number of diseases, the exact role and mechanism for serum ferritin in these disorders has not yet been fully characterized. There is a large volume of literature dedicated to exploring ferritin biology, but a number of questions and topics remain to be explored regarding ferritin delivery, downstream fate, role of ferritin in many diseases, and the utility of ferritin clinically.

Author Contributions: B.C. and J.R.C. were responsible for writing, editing, and overseeing all final drafts of the review.

Funding: This research received no external funding.

Conflicts of Interest: J.R.C. is the founder and chairman of the board of Sidero Biosciences LLC, a company with a product involving oral consumption of ferritin for management of iron deficiency. 


\section{References}

1. Laufberger, V. Sur la cristallisation de la ferritine. Bull. Soc. Chim. Biol. 1937, 19, 1575-1582. (In French)

2. Bradley, J.M.; Le Brun, N.E.; Moore, G.R. Ferritins: Furnishing proteins with iron. J. Biol. Inorg. Chem. 2016, 21, 13-28. [CrossRef] [PubMed]

3. Arosio, P.; Levi, S. Ferritin, Iron Homeostasis, and Oxidative Damage. Free Radic. Biol. Med. 2002, 33, 457-463. [CrossRef]

4. Arosio, P.; Ingrassia, R.; Cavadini, P. Ferritins: A family of molecules for iron storage, antioxidation and more. Biochim. Biophys. Acta Gen. Subj. 2009, 1790, 589-599. [CrossRef] [PubMed]

5. Arosio, P.; Elia, L.; Poli, M. Ferritin, cellular iron storage and regulation. IUBMB Life 2017, 69, 414-422. [CrossRef] [PubMed]

6. Wang, Z.; Gao, H.; Zhang, Y.; Liu, G.; Niu, G.; Chen, X. Functional ferritin nanoparticles for biomedical applications. Front. Chem. Sci. Eng. 2017, 11, 633-646. [CrossRef] [PubMed]

7. Corsi, B.; Cozzi, A.; Arosio, P.; Drysdale, J.; Santambrogio, P.; Campanella, A.; Biasiotto, G.; Albertini, A.; Levi, S. Human mitochondrial ferritin expressed in HeLa cells incorporates iron and affects cellular iron metabolism. J. Biol. Chem. 2002, 277, 22430-22437. [CrossRef] [PubMed]

8. Waldo, G.S.; Wright, E.; Whang, Z.H.; Briat, J.F.; Theil, E.C.; Sayers, D.E. Formation of the ferritin iron mineral occurs in plastids. Plant Physiol. 1995, 109, 797-802. [CrossRef] [PubMed]

9. Surguladze, N.; Thompson, K.M.; Beard, J.L.; Connor, J.R.; Fried, M.G. Interactions and Reactions of Ferritin with DNA. J. Biol. Chem. 2004, 279, 14694-14702. [CrossRef] [PubMed]

10. Surguladze, N.; Patton, S.; Cozzi, A.; Fried, M.G.; Connor, J.R. Characterization of nuclear ferritin and mechanism of translocation. Biochem. J. 2005, 388, 731-740. [CrossRef] [PubMed]

11. Alkhateeb, A.A.; Connor, J.R. Nuclear ferritin: A new role for ferritin in cell biology. Biochim. Biophys. Acta Gen. Subj. 2010, 1800, 793-797. [CrossRef] [PubMed]

12. Knovich, M.A.; Storey, J.A.; Coffman, L.G.; Torti, S.V.; Torti, F.M. Ferritin for the clinician. Blood Rev. 2009, 23, 95-104. [CrossRef] [PubMed]

13. Kuiper, M.A.; Mulder, C.; van Kamp, G.J.; Scheltens, P.; Wolters, E.C. Cerebrospinal fluid ferritin levels of patients with Parkinson's disease, Alzheimer's disease, and multiple system atrophy. J. Neural Transm. 1994, 7, 109-114. [CrossRef]

14. Liu, X.; Madhankumar, A.B.; Slagle-Webb, B.; Sheehan, J.M.; Surguladze, N.; Connor, J.R. Heavy chain ferritin siRNA delivered by cationic liposomes increases sensitivity of cancer cells to chemotherapeutic agents. Cancer Res. 2011, 71, 2240-2249. [CrossRef] [PubMed]

15. Yang, H.; Yang, M.; Guan, H.; Liu, Z.; Zhao, S.; Takeuchi, S.; Yanagisawa, D.; Tooyama, I. Mitochondrial ferritin in neurodegenerative diseases. Neurosci. Res. 2013, 77, 1-7. [CrossRef] [PubMed]

16. Algarín, C.; Peirano, P.; Garrido, M.; Pizarro, F.; Lozoff, B. Iron Deficiency Anemia in Infancy: Long-Lasting Effects on Auditory and Visual System Functioning. Pediatr. Res. 2003, 53, 217-223. [CrossRef] [PubMed]

17. Tomatsu, S.; Orii, K.O.; Fleming, R.E.; Holden, C.C.; Waheed, A.; Britton, R.S.; Gutierrez, M.A.; Velez-Castrillon, S.; Bacon, B.R.; Sly, W.S. Contribution of the H63D mutation in HFE to murine hereditary hemochromatosis. Proc. Natl. Acad. Sci. USA 2003, 100, 15788-15793. [CrossRef] [PubMed]

18. Nixon, A.M.; Neely, E.; Simpson, I.A.; Connor, J.R. The role of HFE genotype in macrophage phenotype. J. Neuroinflamm. 2018, 15, 30. [CrossRef] [PubMed]

19. Stephenson, E.; Nathoo, N.; Mahjoub, Y.; Dunn, J.F.; Yong, V.W. Iron in multiple sclerosis: Roles in neurodegeneration and repair. Nat. Rev. Neurol. 2014, 10, 459-468. [CrossRef] [PubMed]

20. Peters, D.G.; Connor, J.R.; Meadowcroft, M.D. The relationship between iron dyshomeostasis and amyloidogenesis in Alzheimer's disease: Two sides of the same coin. Neurobiol. Dis. 2015, 81, 49-65. [CrossRef] [PubMed]

21. Biasiotto, G.; Di Lorenzo, D.; Archetti, S.; Zanella, I. Iron and Neurodegeneration: Is Ferritinophagy the Link? Mol. Neurobiol. 2016, 53, 5542-5574. [CrossRef] [PubMed]

22. ten Kate, J.; Wolthuis, A.; Westerhuis, B.; van Deursen, C. The Iron Content of Serum Ferritin: Physiological Importance and Diagnostic Value. Clin. Chem. Lab. Med. 1997, 35, 53-56. [CrossRef]

23. Hearnshaw, S.; Thompson, N.P.; Mcgill, A. The epidemiology of hyperferritinaemia. World J. Gastroenterol. 2006, 12, 5866-5869. [CrossRef] [PubMed] 
24. Cohen, L.A.; Gutierrez, L.; Weiss, A.; Leichtmann-Bardoogo, Y.; Zhang, D.L.; Crooks, D.R.; Sougrat, R.; Morgenstern, A.; Galy, B.; Hentze, M.W.; et al. Serum ferritin is derived primarily from macrophages through a nonclassical secretory pathway. Blood 2010, 116, 1574-1584. [CrossRef] [PubMed]

25. Connor, J.R.; Zhang, X.; Nixon, A.M.; Webb, B.; Perno, J.R. Comparative evaluation of nephrotoxicity and management by macrophages of intravenous pharmaceutical iron formulations. PLOS ONE 2015, 10, e0125272. [CrossRef] [PubMed]

26. Leimberg, M.J.; Prus, E.; Konijn, A.M.; Fibach, E. Macrophages function as a ferritin iron source for cultured human erythroid precursors. J. Cell. Biochem. 2008, 103, 1211-1218. [CrossRef] [PubMed]

27. Kidane, T.Z.; Sauble, E.; Linder, M.C. Release of iron from ferritin requires lysosomal activity. Am. J. Physiol. Cell Physiol. 2006, 291, C445-C455. [CrossRef] [PubMed]

28. Briley-Saebo, K.; Bjørnerud, A.; Grant, D.; Ahlstrom, H.; Berg, T.; Kindberg, G.M. Hepatic cellular distribution and degradation of iron oxide nanoparticles following single intravenous injection in rats: Implications for magnetic resonance imaging. Cell Tissue Res. 2004, 316, 315-323. [CrossRef] [PubMed]

29. Blott, E.J.; Griffiths, G.M. Secretory lysosomes. Nat. Rev. Mol. Cell Biol. 2002, 3, 122-131. [CrossRef] [PubMed]

30. Truman-Rosentsvit, M.; Berenbaum, D.; Spektor, L.; Cohen, L.A.; Belizowsky-Moshe, S.; Lifshitz, L.; Ma, J.; Li, W.; Kesselman, E.; Abutbul-Ionita, I.; et al. Ferritin is secreted via 2 distinct nonclassical vesicular pathways. Blood 2018, 131, 342-352. [CrossRef] [PubMed]

31. Mrowczynski, O.D.; Madhankumar, A.B.; Slagle-Webb, B.; Lee, S.Y.; Zacharia, B.E.; Connor, J.R. HFE genotype affects exosome phenotype in cancer. Biochim. Biophys. Acta Gen. Subj. 2017, 1861, 1921-1928. [CrossRef] [PubMed]

32. Kimura, T.; Jia, J.; Kumar, S.; Won Choi, S.; Gu, Y.; Mudd, M.; Dupont, N.; Jiang, S.; Peters, R.; Farzam, F.; et al. Dedicated SNAREs and specialized TRIM cargo receptors mediate secretory autophagy. EMBO J. 2017, 36, 42-60. [CrossRef] [PubMed]

33. Fisher, J.; Devraj, K.; Ingram, J.; Slagle-Webb, B.; Madhankumar, A.B.; Liu, X.; Klinger, M.; Simpson, I.A.; Connor, J.R. Ferritin: A novel mechanism for delivery of iron to the brain and other organs. Am J. Physiol. Cell Physiol. 2007, 293, C641-C649. [CrossRef] [PubMed]

34. Chiou, B.; Neal, E.H.; Bowman, A.B.; Lippmann, E.S.; Simpson, I.A.; Connor, J.R. Endothelial cells are critical regulators of iron transport in a model of the human blood-brain barrier. J. Cereb. Blood Flow Metab. 2018, in press. [CrossRef] [PubMed]

35. Chiou, B.; Neal, E.H.; Bowman, A.B.; Lippmann, E.S.; Simpson, I.A.; Connor, J.R. Pharmaceutical iron formulations do not cross a model of the human blood-brain barrier. PLOS ONE 2018, 13, e0198775. [CrossRef] [PubMed]

36. Simpson, I.A.; Ponnuru, P.; Klinger, M.E.; Myers, R.L.; Devraj, K.; Coe, C.L.; Lubach, G.R.; Carruthers, A.; Connor, J.R. A Novel Model for Brain Iron Uptake: Introducing the Concept of Regulation. J. Cereb. Blood Flow Metab. 2015, 35, 48-57. [CrossRef] [PubMed]

37. Duck, K.A.; Connor, J.R. Iron uptake and transport across physiological barriers. BioMetals 2016, 29 , 573-591. [CrossRef] [PubMed]

38. Duck, K.A.; Simpson, I.A.; Connor, J.R. Regulatory mechanisms for iron transport across the blood-brain barrier. Biochem. Biophys. Res. Commun. 2017, 494, 70-75. [CrossRef] [PubMed]

39. Todorich, B.; Zhang, X.; Connor, J.R. H-ferritin is the major source of iron for oligodendrocytes. Glia 2011, 59, 927-935. [CrossRef] [PubMed]

40. Adams, P.C.; Chau, L.A. Uptake of ferritin by isolated rat hepatocytes. Effect of metabolic inhibitors and iron. Clin. Investig. Med. Médecine Clin. Exp. 1993, 16, 15-21.

41. Blight, G.D.; Morgan, E.H. Ferritin and iron uptake by reticulocytes. Br. J. Haematol. 1983, 55, 59-71. [CrossRef] [PubMed]

42. Moss, D.; Powell, L.W.; Arosio, P.; Halliday, J.W. Characterization of the ferritin receptors of human T lymphoid (MOLT-4) cells. J. Lab. Clin. Med. 1992, 119, 273-279. [PubMed]

43. Sakamoto, S.; Kawabata, H.; Masuda, T.; Uchiyama, T.; Mizumoto, C.; Ohmori, K.; Koeffler, H.P.; Kadowaki, N.; Takaori-Kondo, A. H-Ferritin is Preferentially Incorporated by Human Erythroid Cells through Transferrin Receptor 1 in a Threshold-Dependent Manner. PLoS ONE 2015, 10, e0139915. [CrossRef] [PubMed]

44. Gelvan, D.; Fibach, E.; Meyron-Holtz, E.G.; Konijn, A.M. Ferritin uptake by human erythroid precursors is a regulated iron uptake pathway. Blood 1996, 88, 3200-3207. [PubMed] 
45. Beard, J.L.; Connor, J.R. Iron status and neural functioning. Annu. Rev. Nutr. 2003, 23, 41-58. [CrossRef] [PubMed]

46. Hulet, S.; Heyliger, S.; Powers, S.; Connor, J. Oligodendrocyte progenitor cells internalize ferritin via clathrin-dependent receptor mediated endocytosis. J. Neurosci. Res. 2000, 61, 52-60. [CrossRef]

47. Li, J.Y.; Paragas, N.; Ned, R.M.; Qiu, A.; Viltard, M.; Leete, T.; Drexler, I.R.; Chen, X.; Sanna-Cherchi, S.; Mohammed, F.; et al. Scara5 is a Ferritin Receptor Mediating Non-Transferrin Iron Delivery. Dev. Cell 2009, 16, 35-46. [CrossRef] [PubMed]

48. Chen, T.T.; Li, L.; Chung, D.H.; Allen, C.D.C.; Torti, S.V.; Torti, F.M.; Cyster, J.G.; Chen, C.Y.; Brodsky, F.M.; Niemi, E.C.; et al. TIM-2 is expressed on B cells and in liver and kidney and is a receptor for H-ferritin endocytosis. J. Exp. Med. 2005, 202, 955-965. [CrossRef] [PubMed]

49. Todorich, B.; Zhang, X.; Slagle-Webb, B.; Seaman, W.E.; Connor, J.R. Tim-2 is the receptor for H-ferritin on oligodendrocytes. J. Neurochem. 2008, 107, 1495-1505. [CrossRef] [PubMed]

50. Han, J.; Seaman, W.E.; Di, X.; Wang, W.; Willingham, M.; Torti, F.M.; Torti, S.V. Iron uptake mediated by binding of H-ferritin to the TIM-2 receptor in mouse cells. PLoS ONE 2011, 6, e23800. [CrossRef] [PubMed]

51. Chiou, B.; Lucassen, E.; Sather, M.; Kallianpur, A.; Connor, J. Semaphorin4A and H-ferritin utilize Tim-1 on human oligodendrocytes: A novel neuro-immune axis. Glia 2018, 66, 1317-1330. [CrossRef] [PubMed]

52. Li, R.; Luo, C.; Mines, M.; Zhang, J.; Fan, G.H. Chemokine CXCL12 Induces Binding of Ferritin Heavy Chain to the Chemokine Receptor CXCR4, Alters CXCR4 Signaling, and Induces Phosphorylation and Nuclear Translocation of Ferritin Heavy Chain. J. Biol. Chem. 2006, 281, 37616-37627. [CrossRef] [PubMed]

53. Li, L.; Fang, C.J.; Ryan, J.C.; Niemi, E.C.; Lebrón, J.A.; Björkman, P.J.; Arase, H.; Torti, F.M.; Torti, S.V.; Nakamura, M.C.; et al. Binding and uptake of H-ferritin are mediated by human transferrin receptor-1. Proc. Natl. Acad. Sci. USA 2010, 107, 3505-3510. [CrossRef] [PubMed]

54. Hulet, S.; Powers, S.; Connor, J. Distribution of transferrin and ferritin binding in normal and multiple sclerotic human brains. J. Neurol. Sci. 1999, 165, 48-55. [CrossRef]

55. Akinc, A.; Battaglia, G. Exploiting Endocytosis for Nanomedicines. Cold Spring Harb. Perspect. Biol. 2013, 5, a016980. [CrossRef] [PubMed]

56. Das, A.; Nag, S.; Mason, A.B.; Barroso, M.M. Endosome-mitochondria interactions are modulated by iron release from transferrin. J. Cell Biol. 2016, 214, 831-845. [CrossRef] [PubMed]

57. Mancias, J.D.; Wang, X.; Gygi, S.P.; Harper, J.W.; Kimmelman, A.C. Quantitative proteomics identifies NCOA4 as the cargo receptor mediating ferritinophagy. Nature 2014, 509, 105-109. [CrossRef] [PubMed]

58. Mancias, J.D.; Vaites, L.P.; Nissim, S.; Biancur, D.E.; Kim, A.J.; Wang, X.; Liu, Y.; Goessling, W.; Kimmelman, A.C.; Harper, J.W. Ferritinophagy via NCOA4 is required for erythropoiesis and is regulated by iron dependent HERC2-mediated proteolysis. Elife 2015, 4, e10308. [CrossRef] [PubMed]

59. Mehlhase, J.; Sandig, G.; Pantopoulos, K.; Grune, T. Oxidation-induced ferritin turnover in microglial cells: Role of proteasome. Free Radic. Biol. Med. 2005, 38, 276-285. [CrossRef] [PubMed]

60. Linder, M.C. Mobilization of stored iron in mammals: A review. Nutrients 2013, 5, 4022-4050. [CrossRef] [PubMed]

61. Zhang, Y.; Mikhael, M.; Xu, D.; Li, Y.; Soe-Lin, S.; Ning, B.; Li, W.; Nie, G.; Zhao, Y.; Ponka, P. Lysosomal Proteolysis Is the Primary Degradation Pathway for Cytosolic Ferritin and Cytosolic Ferritin Degradation Is Necessary for Iron Exit. Antioxid. Redox Signal. 2010, 13, 999-1009. [CrossRef] [PubMed]

62. Kim, M.; Rho, Y.; Jin, K.S.; Ahn, B.; Jung, S.; Kim, H.; Ree, M. pH-Dependent Structures of Ferritin and Apoferritin in Solution: Disassembly and Reassembly. Biomacromolecules 2011, 12, 1629-1640. [CrossRef] [PubMed]

63. Ghinea, N.; Hasu, M. Charge effect on binding, uptake and transport of ferritin through fenestrated endothelium. J. Submicrosc. Cytol. 1986, 18, 647-659. [PubMed]

64. Mazzucchelli, S.; Truffi, M.; Baccarini, F.; Beretta, M.; Sorrentino, L.; Bellini, M.; Rizzuto, M.A.; Ottria, R.; Ravelli, A.; Ciuffreda, P.; et al. H-Ferritin-nanocaged olaparib: A promising choice for both BRCA-mutated and sporadic triple negative breast cancer. Sci. Rep. 2017, 7, 7505. [CrossRef] [PubMed]

65. Mazzucchelli, S.; Bellini, M.; Fiandra, L.; Truffi, M.; Rizzuto, M.A.; Sorrentino, L.; Longhi, E.; Nebuloni, M.; Prosperi, D.; Corsi, F. Nanometronomic treatment of $4 \mathrm{~T} 1$ breast cancer with nanocaged doxorubicin prevents drug resistance and circumvents cardiotoxicity. Oncotarget 2016, 8, 8383-8396. [CrossRef] [PubMed] 
66. Liang, M.; Fan, K.; Zhou, M.; Duan, D.; Zheng, J.; Yang, D.; Feng, J.; Yan, X. H-ferritin-nanocaged doxorubicin nanoparticles specifically target and kill tumors with a single-dose injection. Proc. Natl. Acad. Sci. USA 2014, 111, 14900-14905. [CrossRef] [PubMed]

67. Kwon, C.; Kang, Y.J.; Jeon, S.; Jung, S.; Hong, S.Y.; Kang, S. Development of Protein-Cage-Based Delivery Nanoplatforms by Polyvalently Displaying $\beta$-Cyclodextrins on the Surface of Ferritins Through Copper(I)-Catalyzed Azide/Alkyne Cycloaddition. Macromol. Biosci. 2012, 12, 1452-1458. [CrossRef] [PubMed]

68. Luo, Y.; Wang, X.; Du, D.; Lin, Y. Hyaluronic acid-conjugated apoferritin nanocages for lung cancer targeted drug delivery. Biomater. Sci. 2015, 3, 1386-1394. [CrossRef] [PubMed]

69. Truffi, M.; Fiandra, L.; Sorrentino, L.; Monieri, M.; Corsi, F.; Mazzucchelli, S. Ferritin nanocages: A biological platform for drug delivery, imaging and theranostics in cancer. Pharmacol. Res. 2016, 107, 57-65. [CrossRef] [PubMed]

70. Li, L.; Muñoz-Culla, M.; Carmona, U.; Lopez, M.P.; Yang, F.; Trigueros, C.; Otaegui, D.; Zhang, L.; Knez, M. Ferritin-mediated siRNA delivery and gene silencing in human tumor and primary cells. Biomaterials 2016, 98, 143-151. [CrossRef] [PubMed]

71. Li, X.; Qiu, L.; Zhu, P.; Tao, X.; Imanaka, T.; Zhao, J.; Huang, Y.; Tu, Y.; Cao, X. Epidermal Growth Factor-Ferritin H-Chain Protein Nanoparticles for Tumor Active Targeting. Small 2012, 8, 2505-2514. [CrossRef] [PubMed]

72. Conti, L.; Lanzardo, S.; Ruiu, R.; Cadenazzi, M.; Cavallo, F.; Aime, S.; Crich, S.G. L-Ferritin targets breast cancer stem cells and delivers therapeutic and imaging agents. Oncotarget 2016, 7, 66713-66727. [CrossRef] [PubMed]

73. Alkhateeb, A.A.; Han, B.; Connor, J.R. Ferritin stimulates breast cancer cells through an iron-independent mechanism and is localized within tumor-associated macrophages. Breast Cancer Res. Treat. 2013, 137, 733-744. [CrossRef] [PubMed]

74. Uchida, M.; Flenniken, M.L.; Allen, M.; Willits, D.A.; Crowley, B.E.; Brumfield, S.; Willis, A.F.; Jackiw, L.; Jutila, M.; Young, M.J.; et al. Targeting of cancer cells with ferrimagnetic ferritin cage nanoparticles. J. Am. Chem. Soc. 2006, 128, 16626-16633. [CrossRef] [PubMed]

75. Chen, Z.; Zhai, M.; Xie, X.; Zhang, Y.; Ma, S.; Li, Z.; Yu, F.; Zhao, B.; Zhang, M.; Yang, Y.; et al. Apoferritin Nanocage for Brain Targeted Doxorubicin Delivery. Mol. Pharm. 2017, 14, 3087-3097. [CrossRef] [PubMed]

76. Wu, T.; Li, Y.; Liu, B.; Zhang, S.; Wu, L.; Zhu, X.; Chen, Q. Expression of Ferritin Light Chain (FTL) is Elevated in Glioblastoma, and FTL Silencing Inhibits Glioblastoma Cell Proliferation via the GADD45/JNK Pathway. PLoS ONE 2016, 11, e0149361. [CrossRef] [PubMed]

77. Kanekiyo, M.; Wei, C.J.; Yassine, H.M.; McTamney, P.M.; Boyington, J.C.; Whittle, J.R.R.; Rao, S.S.; Kong, W.P.; Wang, L.; Nabel, G.J. Self-assembling influenza nanoparticle vaccines elicit broadly neutralizing H1N1 antibodies. Nature 2013, 499, 102-106. [CrossRef] [PubMed]

78. Kanekiyo, M.; Bu, W.; Joyce, M.G.; Meng, G.; Whittle, J.R.R.; Baxa, U.; Yamamoto, T.; Narpala, S.; Todd, J.-P.; Rao, S.S.; et al. Rational Design of an Epstein-Barr Virus Vaccine Targeting the Receptor-Binding Site. Cell 2015, 162, 1090-1100. [CrossRef] [PubMed]

79. Han, J.-A.; Kang, Y.J.; Shin, C.; Ra, J.S.; Shin, H.H.; Hong, S.Y.; Do, Y.; Kang, S. Ferritin protein cage nanoparticles as versatile antigen delivery nanoplatforms for dendritic cell (DC)-based vaccine development. Nanomedicine 2014, 10, 561-569. [CrossRef] [PubMed]

80. Puttick, S.; Bell, C.; Dowson, N.; Rose, S.; Fay, M. PET, MRI, and simultaneous PET/MRI in the development of diagnostic and therapeutic strategies for glioma. Drug Discov. Today 2015, 20, 306-317. [CrossRef] [PubMed]

81. Dubois, J.; Dehaene-Lambertz, G.; Kulikova, S.; Poupon, C.; Hüppi, P.S.; Hertz-Pannier, L. The early development of brain white matter: A review of imaging studies in fetuses, newborns and infants. Neuroscience 2014, 276, 48-71. [CrossRef] [PubMed]

82. Benders, M.J.N.L.; Kersbergen, K.J.; de Vries, L.S. Neuroimaging of White Matter Injury, Intraventricular and Cerebellar Hemorrhage. Clin. Perinatol. 2014, 41, 69-82. [CrossRef] [PubMed]

83. Essig, M.; Shiroishi, M.S.; Nguyen, T.B.; Saake, M.; Provenzale, J.M.; Enterline, D.; Anzalone, N.; Dörfler, A.; Rovira, À.; Wintermark, M.; et al. Perfusion MRI: The Five Most Frequently Asked Technical Questions. Am. J. Roentgenol. 2013, 200, 24-34. [CrossRef] [PubMed] 
84. Bhogal, P.; Uff, C.; Makalanda, H.L.D. Vessel wall MRI and intracranial aneurysms. J. Neurointerv. Surg. 2016, 8, 1160-1162. [CrossRef] [PubMed]

85. He, D.; Marles-Wright, J. Ferritin family proteins and their use in bionanotechnology. New Biotechnol. 2015, 32, 651-657. [CrossRef] [PubMed]

86. Cutrin, J.C.; Crich, S.G.; Burghelea, D.; Dastrù, W.; Aime, S. Curcumin/Gd Loaded Apoferritin: A Novel "Theranostic" Agent To Prevent Hepatocellular Damage in Toxic Induced Acute Hepatitis. Mol. Pharm. 2013, 10, 2079-2085. [CrossRef] [PubMed]

87. Geninatti Crich, S.; Cadenazzi, M.; Lanzardo, S.; Conti, L.; Ruiu, R.; Alberti, D.; Cavallo, F.; Cutrin, J.C.; Aime, S. Targeting ferritin receptors for the selective delivery of imaging and therapeutic agents to breast cancer cells. Nanoscale 2015, 7, 6527-6533. [CrossRef] [PubMed]

88. Sevcenco, A.-M.; Paravidino, M.; Vrouwenvelder, J.S.; Wolterbeek, H.T.; van Loosdrecht, M.C.M.; Hagen, W.R. Phosphate and arsenate removal efficiency by thermostable ferritin enzyme from Pyrococcus furiosus using radioisotopes. Water Res. 2015, 76, 181-186. [CrossRef] [PubMed]

89. Muckenthaler, M.U.; Galy, B.; Hentze, M.W. Systemic Iron Homeostasis and the Iron-Responsive Element/Iron-Regulatory Protein (IRE/IRP) Regulatory Network. Annu. Rev. Nutr. 2008, 28, 197-213. [CrossRef] [PubMed]

90. Kwak, E.L.; Larochelle, D.A.; Beaumont, C.; Torti, S.V.; Torti, F.M. Role for NF-kB in the Regulation of Ferritin H by Tumor Necrosis Factor- $\alpha$. J. Biol. Chem. 1995, 270, 15285-15293. [CrossRef] [PubMed]

91. Peyssonnaux, C.; Zinkernagel, A.S.; Schuepbach, R.A.; Rankin, E.; Vaulont, S.; Haase, V.H.; Nizet, V.; Johnson, R.S. Regulation of iron homeostasis by the hypoxia-inducible transcription factors (HIFs). J. Clin. Investig. 2007, 117, 1926-1932. [CrossRef] [PubMed]

92. Hoesel, B.; Schmid, J.A. The complexity of NF-kB signaling in inflammation and cancer. Mol. Cancer 2013, 12, 86. [CrossRef] [PubMed]

93. Xue, Y.; Yun, D.; Esmon, A.; Zou, P.; Zuo, S.; Yu, Y.; He, F.; Yang, P.; Chen, X. Proteomic Dissection of Agonist-Specific TLR-Mediated Inflammatory Responses on Macrophages at Subcellular Resolution. J. Proteome Res. 2008, 7, 3180-3193. [CrossRef] [PubMed]

94. Miller, L.L.; Miller, S.C.; Torti, S.V.; Tsuji, Y.; Torti, F.M. Iron-independent induction of ferritin H chain by tumor necrosis factor. Proc. Natl. Acad. Sci. USA 1991, 88, 4946-4950. [CrossRef] [PubMed]

95. Lissoni, P.; Cazzaniga, M.; Ardizzoia, A.; Rossini, F.; Fiorelli, G.; Tancini, G.; Pittalis, S.; Barni, S. Cytokine regulation of iron metabolism: Effect of low-dose interleukin-2 subcutaneous therapy on ferritin, transferrin and iron blood concentrations in cancer patients. J. Biol. Regul. Homeost. Agents 1993, 7, 31-33. [PubMed]

96. Gray, C.P.; Franco, A.V.; Arosio, P.; Hersey, P. Immunosuppressive effects of melanoma-derived heavy-chain ferritin are dependent on stimulation of IL-10 production. Int. J. Cancer 2001, 92, 843-850. [CrossRef] [PubMed]

97. Dignass, A.; Farrag, K.; Stein, J. Limitations of Serum Ferritin in Diagnosing Iron Deficiency in Inflammatory Conditions. Int. J. Chronic Dis. 2018, 2018, 9394060. [CrossRef] [PubMed]

98. Ruscitti, P.; Cipriani, P.; Di Benedetto, P.; Liakouli, V.; Berardicurti, O.; Carubbi, F.; Ciccia, F.; Guggino, G.; Triolo, G.; Giacomelli, R. H-ferritin and proinflammatory cytokines are increased in the bone marrow of patients affected by macrophage activation syndrome. Clin. Exp. Immunol. 2018, 191, 220-228. [CrossRef] [PubMed]

99. Kell, D.B.; Pretorius, E. Serum ferritin is an important inflammatory disease marker, as it is mainly a leakage product from damaged cells. Metallomics 2014, 6, 748. [CrossRef] [PubMed]

100. Gomes, A.; Moreira, A.; Mesquita, G.; Gomes, M. Modulation of Iron Metabolism in Response to Infection: Twists for All Tastes. Pharmaceuticals 2018, 11, 84. [CrossRef] [PubMed]

101. Fan, Y.; Zhang, J.; Cai, L.; Wang, S.; Liu, C.; Zhang, Y.; You, L.; Fu, Y.; Shi, Z.; Yin, Z.; et al. The effect of anti-inflammatory properties of ferritin light chain on lipopolysaccharide-induced inflammatory response in murine macrophages. Biochim. Biophys. Acta Mol. Cell Res. 2014, 1843, 2775-2783. [CrossRef] [PubMed]

102. Parthasarathy, N.; Torti, S.V.; Torti, F.M. Ferritin binds to light chain of human H-kininogen and inhibits kallikrein-mediated bradykinin release. Biochem. J. 2002, 365, 279-286. [CrossRef] [PubMed]

103. Cohen-Solal, A.; Leclercq, C.; Deray, G.; Lasocki, S.; Zambrowski, J.J.; Mebazaa, A.; de Groote, P.; Damy, T.; Galinier, M. Iron deficiency: an emerging therapeutic target in heart failure. Heart 2014, 100, 1414-1420. [CrossRef] [PubMed] 
104. Wang, W.; Knovich, M.A.; Coffman, L.G.; Torti, F.M.; Torti, S. V Serum ferritin: Past, present and future. Biochim. Biophys. Acta 2010, 1800, 760-769. [CrossRef] [PubMed]

105. Ueda, N.; Takasawa, K. Impact of Inflammation on Ferritin, Hepcidin and the Management of Iron Deficiency Anemia in Chronic Kidney Disease. Nutrients 2018, 10, 1173. [CrossRef] [PubMed]

106. Recalcati, S.; Invernizzi, P.; Arosio, P.; Cairo, G. New functions for an iron storage protein: The role of ferritin in immunity and autoimmunity. J. Autoimmun. 2008, 30, 84-89. [CrossRef] [PubMed]

107. Gozzelino, R.; Andrade, B.B.; Larsen, R.; Luz, N.F.; Vanoaica, L.; Seixas, E.; Coutinho, A.; Cardoso, S.; Rebelo, S.; Poli, M.; et al. Metabolic Adaptation to Tissue Iron Overload Confers Tolerance to Malaria. Cell Host Microbe 2012, 12, 693-704. [CrossRef] [PubMed]

108. Weis, S.; Carlos, A.R.; Moita, M.R.; Singh, S.; Blankenhaus, B.; Cardoso, S.; Larsen, R.; Rebelo, S.; Schäuble, S.; Del Barrio, L.; et al. Metabolic Adaptation Establishes Disease Tolerance to Sepsis. Cell 2017, 169, 1263-1275. [CrossRef] [PubMed]

109. Reddy, V.P.; Chinta, K.C.; Saini, V.; Glasgow, J.N.; Hull, T.D.; Traylor, A.; Rey-Stolle, F.; Soares, M.P.; Madansein, R.; Rahman, M.A.; et al. Ferritin H Deficiency in Myeloid Compartments Dysregulates Host Energy Metabolism and Increases Susceptibility to Mycobacterium tuberculosis Infection. Front. Immunol. 2018, 9, 860. [CrossRef] [PubMed]

110. Torti, S.V.; Torti, F.M. Human H-kininogen is a ferritin-binding protein. J. Biol. Chem. 1998, 273, 13630-13635. [CrossRef] [PubMed]

111. Kaplan, A.P. The Bradykinin-Forming Cascade: A Historical Perspective. In Chemical Immunology and Allergy; Karger: Basel, Switzerland, 2014; Volume 100, pp. 205-213.

112. Barnes, P.J. Bradykinin and asthma. Thorax 1992, 47, 979-983. [CrossRef] [PubMed]

113. Stadnicki, A. Intestinal tissue kallikrein-kinin system in inflammatory bowel disease. Inflamm. Bowel Dis. 2011, 17, 645-654. [CrossRef] [PubMed]

114. Sharma, J.N. Involvement of the kinin-forming system in the physiopathology of rheumatoid inflammation. Agents Actions 1992, 38, 343-361. [PubMed]

115. Sharma, J.N.; Buchanan, W.W. Pathogenic responses of bradykinin system in chronic inflammatory rheumatoid disease. Exp. Toxicol. Pathol. 1994, 46, 421-433. [CrossRef]

116. Cook, C.I.; Yu, B.P. Iron accumulation in aging: Modulation by dietary restriction. Mech. Ageing Dev. 1998, 102, 1-13. [CrossRef]

117. Hagemeier, J.; Geurts, J.J.; Zivadinov, R. Brain iron accumulation in aging and neurodegenerative disorders. Expert Rev. Neurother. 2012, 12, 1467-1480. [CrossRef] [PubMed]

118. Pirpamer, L.; Hofer, E.; Gesierich, B.; De Guio, F.; Freudenberger, P.; Seiler, S.; Duering, M.; Jouvent, E.; Duchesnay, E.; Dichgans, M.; et al. Determinants of iron accumulation in the normal aging brain. Neurobiol. Aging 2016, 43, 149-155. [CrossRef] [PubMed]

119. Connor, J.R.; Snyder, B.S.; Arosio, P.; Loeffler, D.A.; LeWitt, P. A Quantitative Analysis of Isoferritins in Select Regions of Aged, Parkinsonian, and Alzheimer's Diseased Brains. J. Neurochem. 1995, 65, 717-724. [CrossRef] [PubMed]

120. Fonseca-Nunes, A.; Jakszyn, P.; Agudo, A. Iron and Cancer Risk-A Systematic Review and Meta-analysis of the Epidemiological Evidence. Cancer Epidemiol. Biomarkers Prev. 2014, 23, 12-31. [CrossRef] [PubMed]

121. Alkhateeb, A.A.; Connor, J.R. The significance of ferritin in cancer: Anti-oxidation, inflammation and tumorigenesis. Biochim. Biophys. Acta Rev. Cancer 2013, 1836, 245-254. [CrossRef] [PubMed]

122. Alsina, D.; Purroy, R.; Ros, J.; Tamarit, J. Iron in Friedreich Ataxia: A Central Role in the Pathophysiology or an Epiphenomenon? Pharmaceuticals 2018, 11, 89. [CrossRef] [PubMed]

123. Levi, S.; Rovida, E. Neuroferritinopathy: From ferritin structure modification to pathogenetic mechanism. Neurobiol. Dis. 2015, 81, 134-143. [CrossRef] [PubMed]

124. Barbeito, A.G.; Levade, T.; Delisle, M.B.; Ghetti, B.; Vidal, R. Abnormal iron metabolism in fibroblasts from a patient with the neurodegenerative disease hereditary ferritinopathy. Mol. Neurodegener. 2010, 5, 50. [CrossRef] [PubMed]

125. Maccarinelli, F.; Pagani, A.; Cozzi, A.; Codazzi, F.; Di Giacomo, G.; Capoccia, S.; Rapino, S.; Finazzi, D.; Politi, L.S.; Cirulli, F.; et al. A novel neuroferritinopathy mouse model (FTL 498InsTC) shows progressive brain iron dysregulation, morphological signs of early neurodegeneration and motor coordination deficits. Neurobiol. Dis. 2015, 81, 119-133. [CrossRef] [PubMed] 
126. Riederer, P.; Sofic, E.; Rausch, W.D.; Schmidt, B.; Reynolds, G.P.; Jellinger, K.; Youdim, M.B.H. Transition Metals, Ferritin, Glutathione, and Ascorbic Acid in Parkinsonian Brains. J. Neurochem. 1989, 52, 515-520. [CrossRef] [PubMed]

127. Dexter, D.T.; Carayon, A.; Vidailhet, M.; Ruberg, M.; Agid, F.; Agid, Y.; Lees, A.J.; Wells, F.R.; Jenner, P.; Marsden, C.D. Decreased Ferritin Levels in Brain in Parkinson's Disease. J. Neurochem. 1990, 55, $16-20$. [CrossRef] [PubMed]

128. Thompson, K.; Menzies, S.; Muckenthaler, M.; Torti, F.M.; Wood, T.; Torti, S.V.; Hentze, M.W.; Beard, J.; Connor, J. Mouse brains deficient in $\mathrm{H}$-ferritin have normal iron concentration but a protein profile of iron deficiency and increased evidence of oxidative stress. J. Neurosci. Res. 2003, 71, 46-63. [CrossRef] [PubMed]

129. Hemmati-Dinarvand, M.; Taher-Aghdam, A.A.; Mota, A.; Zununi Vahed, S.; Samadi, N. Dysregulation of serum NADPH oxidase1 and ferritin levels provides insights into diagnosis of Parkinson's disease. Clin. Biochem. 2017, 50, 1087-1092. [CrossRef] [PubMed]

130. Kozina, E.; Sadasivan, S.; Jiao, Y.; Dou, Y.; Ma, Z.; Tan, H.; Kodali, K.; Shaw, T.; Peng, J.; Smeyne, R.J. Mutant LRRK2 mediates peripheral and central immune responses leading to neurodegeneration in vivo. Brain 2018, 141, 1753-1769. [CrossRef] [PubMed]

131. Connor, J.R.; Patton, S.M.; Oexle, K.; Allen, R.P. Iron and restless legs syndrome: Treatment, genetics and pathophysiology. Sleep Med. 2017, 31, 61-70. [CrossRef] [PubMed]

132. Allen, R.P.; Auerbach, S.; Bahrain, H.; Auerbach, M.; Earley, C.J. The prevalence and impact of restless legs syndrome on patients with iron deficiency anemia. Am. J. Hematol. 2013, 88, 261-264. [CrossRef] [PubMed]

133. Akyol, A.; Kiylioglu, N.; Kadikoylu, G.; Bolaman, A.Z.; Ozgel, N. Iron deficiency anemia and restless legs syndrome: Is there an electrophysiological abnormality? Clin. Neurol. Neurosurg. 2003, 106, 23-27. [CrossRef] [PubMed]

134. Connor, J.R.; Ponnuru, P.; Wang, X.-S.; Patton, S.M.; Allen, R.P.; Earley, C.J.; Leader, G.M. Profile of altered brain iron acquisition in restless legs syndrome. Brain 2011, 134, 959-968. [CrossRef] [PubMed]

135. Connor, J.R.; Boyer, P.J.; Menzies, S.L.; Dellinger, B.; Allen, R.P.; Ondo, W.G.; Earley, C.J. Neuropathological examination suggests impaired brain iron acquisition in restless legs syndrome. Neurology 2003, 61, 304-309. [CrossRef] [PubMed]

136. Lammers, N.; Curry-Hyde, A.; Smith, A.J.; Eastwood, P.R.; Straker, L.M.; Champion, D.; McArdle, N. Are serum ferritin and transferrin saturation risk markers for restless legs syndrome in young adults? Longitudinal and cross-sectional data from the Western Australian Pregnancy Cohort (Raine) Study. J. Sleep Res. 2018, e12741. [CrossRef] [PubMed]

137. Zheng, Y.; Gao, L.; Wang, D.; Zang, D. Elevated levels of ferritin in the cerebrospinal fluid of amyotrophic lateral sclerosis patients. Acta Neurol. Scand. 2017, 136, 145-150. [CrossRef] [PubMed]

138. Su, X.W.; Clardy, S.L.; Stephens, H.E.; Simmons, Z.; Connor, J.R. Serum ferritin is elevated in amyotrophic lateral sclerosis patients. Amyotroph. Lateral Scler. Front. Degener. 2015, 16, 102-107. [CrossRef] [PubMed]

139. Nadjar, Y.; Gordon, P.; Corcia, P.; Bensimon, G.; Pieroni, L.; Meininger, V.; Salachas, F. Elevated Serum Ferritin Is Associated with Reduced Survival in Amyotrophic Lateral Sclerosis. PLoS ONE 2012, 7, e45034. [CrossRef] [PubMed]

140. Yu, J.; Wang, N.; Qi, F.; Wang, X.; Zhu, Q.; Lu, Y.; Zhang, H.; Che, F.; Li, W. Serum ferritin is a candidate biomarker of disease aggravation in amyotrophic lateral sclerosis. Biomed. Rep. 2018, 9, 333-338. [CrossRef] [PubMed]

141. Hu, X.; Yang, Y.; Su, J.; Yao, C. Meta-analysis of the relationship between amyotrophic lateral sclerosis and susceptibility to serum ferritin level elevation. Neurosciences 2016, 21, 120-125. [CrossRef] [PubMed]

142. Li, W.; Garringer, H.J.; Goodwin, C.B.; Richine, B.; Acton, A.; VanDuyn, N.; Muhoberac, B.B.; Irimia-Dominguez, J.; Chan, R.J.; Peacock, M.; et al. Systemic and cerebral iron homeostasis in ferritin knock-out Mice. PLoS ONE 2015, 10, e0117435. [CrossRef] [PubMed]

(C) 2018 by the authors. Licensee MDPI, Basel, Switzerland. This article is an open access article distributed under the terms and conditions of the Creative Commons Attribution (CC BY) license (http:/ / creativecommons.org/licenses/by/4.0/). 


\title{
Review \\ The Role of NCOA4-Mediated Ferritinophagy in Health and Disease
}

\author{
Naiara Santana-Codina and Joseph D. Mancias* \\ Division of Genomic Stability and DNA Repair, Department of Radiation Oncology, Dana-Farber Cancer \\ Institute, Harvard Institute of Medicine, Room 221, 4 Blackfan Circle, Boston, MA 02215, USA; \\ Naiara_SantanaCodina@dfci.harvard.edu \\ * Correspondence: joseph_mancias@dfci.harvard.edu; Tel.: +1-617-582-9379; Fax: +1-617-582-8213
}

Received: 8 September 2018; Accepted: 19 October 2018; Published: 23 October 2018

\begin{abstract}
Nuclear receptor coactivator 4 (NCOA4) is a selective cargo receptor that mediates the autophagic degradation of ferritin ("ferritinophagy"), the cytosolic iron storage complex. NCOA4-mediated ferritinophagy maintains intracellular iron homeostasis by facilitating ferritin iron storage or release according to demand. Ferritinophagy is involved in iron-dependent physiological processes such as erythropoiesis, where NCOA4 mediates ferritin iron release for mitochondrial heme synthesis. Recently, ferritinophagy has been shown to regulate ferroptosis, a newly described form of iron-dependent cell death mediated by excess lipid peroxidation. Dysregulation of iron metabolism and ferroptosis have been described in neurodegeneration, cancer, and infection, but little is known about the role of ferritinophagy in the pathogenesis of these diseases. Here, we will review the biochemical regulation of NCOA4, its contribution to physiological processes and its role in disease. Finally, we will discuss the potential of activating or inhibiting ferritinophagy and ferroptosis for therapeutic purposes.
\end{abstract}

Keywords: NCOA4; ferritinophagy; iron homeostasis; erythropoiesis; ferroptosis; cancer

\section{Introduction}

Iron is required in multiple biological processes [1] including oxygen binding and transport [2], ATP production (as a cofactor in the citric acid cycle and electron transport) [3], and DNA biosynthesis and repair [4,5]. Iron deficiency is the main cause of anemia [6], which causes significant morbidity and mortality worldwide. Likewise, when iron deficiency affects other tissues (skeletal muscle, heart or brain) it can have fatal consequences [4]. Conversely, iron overload can generate Reactive Oxygen Species (ROS) by the Fenton reaction of the Haber-Weiss cycle thereby contributing to the pathophysiology of iron overload in diseases such as hereditary hemochromatosis $[7,8]$. Thus, cells must establish a delicate balance between iron availability and storage. This is accomplished through the orchestrated action of a network of proteins involved in iron transport/import (transferrin: Tf, transferrin receptor: TfR, DMT1), export (i.e., the iron export transporter, ferroportin: FPN), storage (ferritin: FTH1/FTL), and a host of additional iron homeostasis regulatory circulating and intracellular proteins [3]. Recently, our lab and others identified a role for Nuclear Receptor Coactivator 4 (NCOA4) in regulating iron homeostasis by binding to ferritin and facilitating its autophagic degradation in a process termed "ferritinophagy [9]." This process is itself regulated by intracellular iron levels that promote or inhibit ferritinophagy depending on iron availability and demand [10]. Here, we will review the biochemical regulation of NCOA4, its role in intracellular and systemic iron homeostasis, and its importance in physiological processes (such as erythropoiesis) and in disease. We will discuss the role of ferritinophagy in ferroptosis, a new type of cell death triggered by iron accumulation and lipid peroxidation. Finally, we will explore the therapeutic potential of modulating NCOA4-mediated ferritinophagy. 


\section{NCOA4 Mediates Ferritin Transport to the Lysosome for Degradation}

Cellular iron is mainly stored in ferritin, a protein complex composed of 24 subunits of ferritin light and heavy chains (FTL, FTH1). Ferritin can chelate up to 4500 iron atoms in its ferric-Fe(III) form [11]. Iron is incorporated into ferritin via ferritin iron pores as $\mathrm{Fe}(\mathrm{II})$, which is further oxidized to Fe(III) by FTH1 inside the ferritin cage, leading to inert deposits of $\mathrm{Fe}(\mathrm{III})$ that are unavailable for intracellular use or generation of ROS [12]. For utilization, iron needs to be released from ferritin and reduced again to $\mathrm{Fe}(\mathrm{II})$ [13]. While there are studies showing iron can exit ferritin via the ferritin pore, the most likely mechanism of iron release involves proteolytic degradation of the ferritin shell. This degradation process takes place primarily in the lysosome [14] although some minor proteasomal contribution has been observed [15].

Multiple groups reported ferritin degradation as dependent on autophagy, a conserved catabolic cellular process that degrades cellular proteins and damaged organelles via the lysosome as part of a recycling and protective process to ensure cellular homeostasis basally and in response to stress $[14,16,17]$ (for in-depth reviews on the molecular mechanisms of autophagy we point the reader to several excellent reviews on the subject [18-20]). Canonical autophagy requires the coordinated action of approximately 30 autophagy-related (Atg) proteins to form double-membrane vesicles (autophagosomes) that capture cellular cargo in both non-selective and selective manners for eventual lysosomal degradation. Autophagy initiation requires activation of the ULK complex followed by production of phosphatidylinositol-3-phosphate (PI3P) by the class III PI3K complex (VPS34, Beclin1, and $\mathrm{p} 150$ ) and membrane contribution from ATG9 vesicles. Pro-MAP1LC3B ('LC3B' and related ATG8 family members) is cleaved to LC3B-I by ATG4B and further conjugated to phosphatidylethanolamine by ATG7, ATG3 and the ATG5-ATG12-ATG16L1 complex. Lipidated LC3B-II binds to the growing membrane of autophagosomes and contributes to its elongation and fusion and also acts as a recruitment platform for autophagic molecular machinery $[16,21]$. Autophagosomes fuse with lysosomes thereby delivering cargo for degradation via lysosomal enzymes. Autophagy was initially described as a survival response to nutrient starvation; however, it is now appreciated that autophagy is active basally in all cells and can be induced by multiple stressors, such as hypoxia or ROS [22,23]. Recently, selective autophagic processes have been reported involving specific receptor proteins that target select cargo for autophagic degradation including mitochondria (mitophagy), endoplasmic reticulum (ER-phagy) or pathogens (xenophagy) [16]. Using autophagy-deficient MEFs (Atg7 ${ }^{-/-}$), Asano et al. showed that in iron-depleted cells, autophagy is required for ferritin degradation via the lysosome. Based on their work they hypothesized a selective ferritin autophagic process dependent on an as yet undetermined cargo receptor [17]. We recently identified NCOA4 as the cargo receptor targeting ferritin to the autophagosome in a selective autophagic process (ferritinophagy) [9].

We used a combination of autophagosome enrichment, stable isotope labelling by amino acids in cell culture (SILAC), and liquid chromatography-mass spectrometry (LC-MS) to profile proteins enriched in autophagosomes. One of the most robustly and reproducibly enriched autophagosomal proteins was NCOA4 [9]. While NCOA4 was originally identified as a nuclear receptor coactivator (discussed below), we demonstrated that NCOA4 localized to autophagosome and lysosome structures. To understand the role of NCOA4 in autophagy, we performed affinity purification-mass spectroscopy and identified ferritin subunits as interacting partners (FTL, FTH1) [9]. We also identified HERC2 and NEURL4, subunits of an E3 ubiquitin ligase complex, but this interaction was not seen in FTH1 immunoprecipitates, suggesting distinct NCOA4-ferritin and NCOA4-HERC2/NEURL4 complexes [9]. NCOA4 colocalized with ferritin in autophagosomes and lysosomes. Critically, NCOA4 depletion inhibited delivery of ferritin to the lysosome and thereby ferritin degradation. Reduced ferritin turnover led to a significant decrease in bioavailable intracellular iron that altered the intracellular iron homeostasis network of proteins [9]. In parallel, Dowdle et al. also identified NCOA4 as an autophagy receptor for ferritin [24].

There is limited structural information for NCOA4 except for a N-terminal coiled-coil domain that has been reported as a protein interaction [25] and self-oligomerization domain [26]. Phylogenetic 
studies show no paralogs for NCOA4, although the ARA70-I family domain (which overlaps with the $\mathrm{N}$-terminal coiled coil domain) is conserved in NCOA4 orthologs through metazoans [27]. NCOA4 has multiple splice variants in rodents and two transcript variants in humans (Figure 1a): NCOA4 $\alpha$ $(614 \mathrm{Aa}, 70 \mathrm{kDa}$ ) and the splice isoform NCOA4 $\beta$ (286 Aa, $35 \mathrm{kDa})$ [28]. The isoforms share the $\mathrm{N}$-terminal coiled-coil domain (Aa 1-238) and a small portion of the C-terminus (Aa 566-614). In vitro assays with recombinant NCOA4 and FTH1 mapped the interaction to the NCOA4 C-terminal domain (Aa 383-509), a domain only present in NCOA4 $\alpha$ and not in NCOA $4 \beta$, and a conserved surface arginine (R23) on FTH1 [10]. An independent study confirmed this interaction and demonstrated that FTH1 can bind up to 24 NCOA4 fragments (Aa 383-522) [29]. Site-directed mutagenesis on NCOA4 identified W497, I489, S492, L494, and L498 as residues important for ferritin binding. Importantly, NCOA4 $4^{1489 \mathrm{~A} / \text { W497A }}$ expression in HCT116 NCOA4 knockout (KO) cells abolished FTH1 binding and ferritin delivery to autophagosomes. Likewise, FTH1 ${ }^{\mathrm{R} 23 \mathrm{~A}}$ mutants prevented an interaction with NCOA4 in cells thereby inhibiting ferritin delivery to the lysosome even under conditions of iron deprivation when ferritinophagy is normally activated.

Flux through the ferritinophagy pathway is dependent on NCOA4 levels which are tightly regulated by intracellular iron levels (Figure 1b,c) [10]. Under iron-replete cellular conditions, NCOA4 binding to HERC2, an E3 ubiquitin ligase, is increased, leading to proteasomal degradation of NCOA4. Decreased NCOA4 levels inhibit ferritinophagy and increase ferritin iron storage [10]. NCOA4-FTH1 binding appears to be inhibited by high levels of iron, which would similarly decrease ferritinophagy and favor ferritin iron storage [29]. Interestingly, the site for HERC2 binding on NCOA4 (Aa 383-509) overlaps with the site for FTH1 binding raising the possibility that HERC2 and FTH1 binding are mutually exclusive. Future experiments are necessary to determine whether NCOA4 can simultaneously bind HERC2 and FTH1 or whether there is competitive binding. While NCOA4 co-purifies with iron, the mechanism of iron binding and the iron-binding pocket is unclear at this time. Under iron-deficient conditions, presumably when iron occupancy of NCOA4 decreases, HERC2 binding to NCOA4 is decreased, leading to NCOA4 stabilization and induction of ferritin degradation and iron release [10].

The mechanism by which NCOA4-FTH1 reaches the lysosome is not entirely clear. Despite NCOA4 association with multiple ATG8 proteins in in vitro binding assays, no canonical LC3-interaction region (LIR) motif has been identified in NCOA4, although the presence of other non-canonical ATG8-binding motifs may suggest the use of this alternative motif for interaction [31]. While classical autophagy appears to play a prominent role in ferritin delivery to the lysosome, other reports suggest that multiple pathways, including the ubiquitin-proteasome system, can contribute to ferritin degradation. Contribution of each degradation pathway may be different according to cell type or even type of iron deprivation, e.g., one report suggests that ferroportin-mediated iron export promotes ferritin degradation by the proteasome while iron chelation agents induce degradation in the lysosome [32]. Recent studies have suggested an ESCRT complex-mediated endosomal sorting pathway as an alternative, ATG8-independent, lysosomal trafficking pathway for NCOA4 and ferritin. Goodwin et al. report a highly regulated alternative pathway for ferritin degradation involving TAX1BP1, FIP200, ATG9A, VPS34, and components of the ESCRT machinery that is independent of the classical ATG8 macroautophagy pathway [33]. Likewise, the ESCRT-III endosomal pathway has been shown to mediate rapid starvation-induced degradation of autophagy receptors such as NCOA4, p62, NBR1, TAX1BP1, and NDP52 [34]. Further studies are required to explore the mechanism that directs NCOA4 complexes to the lysosome as well as the contribution of different pathways to ferritinophagy. 


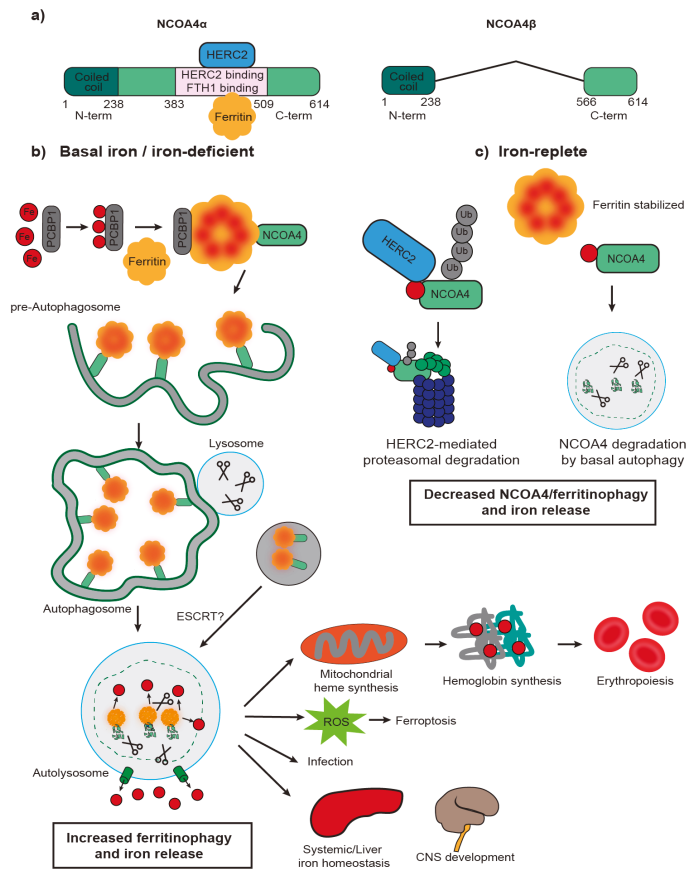

Figure 1. NCOA4-mediated ferritinophagy pathway is regulated by intracellular iron. (a) Schematic of NCOA4 transcript variants in humans: NCOA $4 \alpha$ and NCOA4 $\beta$. NCOA $4 \alpha$ is a 614 Aa protein $(70 \mathrm{kDa})$ with an N-terminal coiled coil domain and a C-terminal domain that contains a FTH1 and HERC2 binding domain (Aa 383-509). NCOA4 3 (286 Aa, $35 \mathrm{kDa}$ ) shares with NCOA4 $\alpha$ the N-terminal domain and a portion of the C-terminal domain. (b) Poly rC-binding protein 1 (PCBP1) binds to iron (Fe) and delivers it to ferritin. Fe is stored in ferritin complexes containing ferritin heavy and light chains. NCOA4 binds to ferritin through its C-terminal domain and delivers it to the nascent autophagosome. The mechanisms involved in NCOA4 delivery to the autophagosome are unclear but could involve non-canonical LIR motifs. Fusion of the autophagosome with the lysosome leads to degradation of ferritin and iron release in a process known as "ferritinophagy." Some studies also suggest alternative pathways for lysosomal delivery of NCOA4-ferritin complexes involving the endosomal pathway (endosomal sorting complex required for transport: ESCRT). Iron is exported to the cytosol where it can be used in several physiological processes that involve iron such as mitochondrial heme synthesis and erythroid differentiation. Increased ferritinophagy flux correlates with reactive oxygen species (ROS) production and a type of cell death known as ferroptosis. Increased ferritinophagy flux has also been observed in certain E. coli urinary tract infections [30]. Finally, iron is also likely required for other physiological processes like liver iron homeostasis and central nervous system (CNS) development, although further research is required to clarify NCOA4's role in the CNS disease under normal and pathological conditions such as neurodegeneration. (c) NCOA4 levels and ferritinophagy are regulated by intracellular iron levels. In iron-replete conditions, HERC2 (an E3 ubiquitin ligase) binds NCOA4 in an iron-dependent manner and mediates its proteasomal degradation. NCOA4 can also be degraded by basal autophagy. Decreased NCOA4 levels lead to stabilization of ferritin by decreased ferritinophagy flux and decreased intracellular levels of iron.

While the role of NCOA4 in mediating ferritin degradation and cellular iron homeostasis appears to be a conserved function of NCOA4 across cell types, earlier reports suggested NCOA4 acts as a nuclear receptor coactivator. NCOA4 was originally identified in a yeast-two hybrid screen as a coactivator of the androgen receptor (AR), enhancing its transcriptional activity in prostate cancer [35]. Subsequent studies suggest that NCOA4 also regulates a number of additional 
nuclear receptors [36-40]. A recent study suggests that NCOA4 can be regulated by thyroid hormone, promoting NCOA4 recruitment to chromatin regions that induce a transcriptional program supporting erythropoiesis [41]. Finally, Bellelli et al. suggest NCOA4 inhibits DNA replication origin activation by binding to the MCM2-7 helicase complex via the NCOA4 N-terminal domain [42]. Further work is required to reconcile these various reported functions of NCOA4.

\section{NCOA4 Mediates Ferritin Iron Release to Support Erythropoiesis}

Given the importance of NCOA4 in intracellular iron homeostasis, several studies have addressed the role of NCOA4 in physiological cellular processes that depend upon iron availability, such as erythropoiesis. Erythropoiesis consists of several differentiation steps between the hematopoietic stem cell progenitor stage and the mature enucleated red blood cell (RBC) that are characterized by gradual degradation of cellular content [43] and production of hemoglobin [12]. Hemoglobinization requires large amounts of iron for heme synthesis with approximately $2 \mathrm{~g}$ of iron from the total $3-5 \mathrm{~g}$ in the human body incorporated in RBC hemoglobin [3]. Iron is delivered to RBCs by circulating transferrin (Tf) that is internalized via TfR-mediated endocytosis [2]. Next, iron is reduced to its $\mathrm{Fe}(\mathrm{II})$ form and exported from the endosome by DMT1. Two different mechanisms by which iron is transported to mitochondria for heme synthesis have been proposed: (1) by direct delivery from the endosome [44] or (2) by export to the cytoplasmic labile iron pool followed by intermediate storage in ferritin, lysosomal ferritin degradation, and delivery to the mitochondria [45,46]. NCOA4 depletion in the K562 human erythroleukemia cell line, an in vitro model of erythroid differentiation, impaired hemoglobinization and differentiation [10], supporting a role for ferritinophagy in mitochondrial iron delivery and heme synthesis. This finding has been confirmed in a murine cellular model of erythropoiesis (G1E-ER4 cells), showing defects in hemoglobinization after NCOA4 depletion albeit without affecting differentiation [47]. These studies support a model whereby iron exported from the endosome enters the cytoplasmic iron pool and is stored in ferritin prior to NCOA4-mediated ferritinophagy and subsequent delivery to the mitochondria for heme synthesis. Based on temporal evaluation of hemoglobinization in their model system, Philpott and collaborators described a model that involves sequential binding of poly rC-binding protein 1 (PCBP1), an iron chaperone, and NCOA4 to ferritin to balance iron storage or use depending on the erythroid differentiation stage [47]. In early erythroid stages, PCBP1 delivers iron to ferritin for storage while low levels of NCOA4 decrease ferritinophagy to further favor iron storage. At the midpoint of erythroid differentiation during the orthochromatic erythroblast stage, a period that correlates with high iron demand and hemoglobin synthesis, PCBP1 and NCOA4 coordinate to increase iron flux through ferritin and ferritinophagy to provide sufficient iron for heme synthesis (Figure 1). Finally, at late stages of erythrocyte development (reticulocyte) as cells lose organelles, iron import is decreased, ferritin levels decrease, and any remaining endosomes may transfer iron directly to mitochondria for ongoing heme synthesis [12,47].

Initial connections between NCOA4 and erythropoiesis on an organismal level were made in zebrafish developmental studies where NCOA4 mRNA expression was found to be upregulated at sites of erythropoiesis [48]. Consistent with this, transcriptional profiling of erythroblasts at sequential stages of differentiation showed that NCOA4 was one of the top upregulated genes in orthochromatic erythroblasts, where hemoglobin synthesis is maximal [49]. NCOA4 depletion in a zebrafish model revealed defects in globin synthesis and hemoglobinization [10]. Using a NCOA4 KO mouse model, Bellelli et al. identified NCOA4-mediated ferritinophagy as critical for iron availability for heme synthesis [50]. NCOA4 KO mice developed a mild hypochromic microcytic anemia together with ferritin and iron accumulation in tissues, indicating inefficient iron mobilization from ferritin. Mice fed an iron-deficient diet developed severe anemia with a compensatory activation of the Erythropoietin (Epo) pathway. Mice fed an iron-enriched diet developed significant accumulation of iron-laden ferritin and excess cytoplasmic iron that precipitated ROS-associated toxicity in the liver and premature death in comparison to controls [50]. This suggests that mice unable to efficiently degrade ferritin may eventually develop an 'overflow' of iron into the cytoplasm leading to higher susceptibility to oxidative 
damage as discussed in greater detail below. NCOA4 appears to be more important at various stages of development as NCOA4 KO mice examined at the immediate postnatal period showed a more severe anemia [41]. This study suggests a differential temporal requirement of NCOA4-mediated ferritinophagy in periods of high iron demand. As the observed anemia is less severe in adult NCOA4 KO mice compared to young mice, this could suggest cell-autonomous or non-autonomous mechanisms that compensate for NCOA4 loss over time.

NCOA4 KO mice had higher ferritin in serum [50], suggesting that tissues overloaded with iron "leak" ferritin to the blood. This data suggests that there is a mechanism independent of NCOA4-mediated lysosomal delivery and non-classical lysosomal-mediated secretion that promotes ferritin secretion. In agreement with the NCOA4 KO mouse model, NCOA4 depletion in a monocytic cell line did not impair ferritin secretion but in fact increased it, suggesting that NCOA4 is not required for ferritin secretion [51]. Recently, Meyron-Holtz and collaborators demonstrated ferritin secretion via two independent pathways: a non-classical secretory-autophagy pathway and a multivesicular-body-exosome pathway [52].

To date, multiple studies have evaluated the role of NCOA4 in erythropoiesis in vivo but all of them have evaluated it in a systemic KO setting. Despite in vitro evidence in K562 and G1E-ER4 cells suggesting NCOA4 has a cell-autonomous role in erythropoiesis, it remains to be elucidated whether there are non-autonomous contributions of NCOA4 to erythropoiesis. Since NCOA4 knockout is non-fatal in these models, compensatory mechanisms may develop in erythroid cells or other cell types to overcome NCOA4 loss to support hemoglobin synthesis. Identifying these mechanisms will be of interest in the future. Finally, these data support study of NCOA4 in the context of multiple pathological conditions with imbalances in iron homeostasis like hemochromatosis or iron deficiency anemia [53].

\section{NCOA4-Mediated Ferritinophagy Modulates Ferroptosis}

Ferroptosis is an iron-dependent form of regulated cell death characterized by lipid peroxidation [54,55]. Given the central role of NCOA4-mediated ferritinophagy in regulating intracellular iron levels, ferroptosis sensitivity has recently been shown to be modulated by NCOA4 [56,57]. Ferroptosis is distinct from other identified types of cell death (apoptosis, necrosis or autophagy) at the morphological level, with absence of plasma membrane rupture or blebbing, presence of small mitochondria with reduced cristae, and lack of chromatin condensation [58]. In general, the main ferroptosis-inducing event is lipid peroxidation, which is triggered by inactivation of the lipid repairing phospholipid peroxidase, GPx4 (directly by compounds such as RAS-selective lethal 3 (RSL3) and indirectly by blocking cystine metabolism and glutathione synthesis (erastin, sorafenib and $\mathrm{BSO})$ ), or by iron accumulation leading to ROS and lipid peroxidation production (Figure 2). Here, we will focus on how ferroptosis is regulated by alteration in iron homeostasis pathways and specifically NCOA4-mediated ferritinophagy. For in-depth details on the ferroptosis pathway and biochemical regulation, comprehensive reviews are available $[54,55,59]$. 


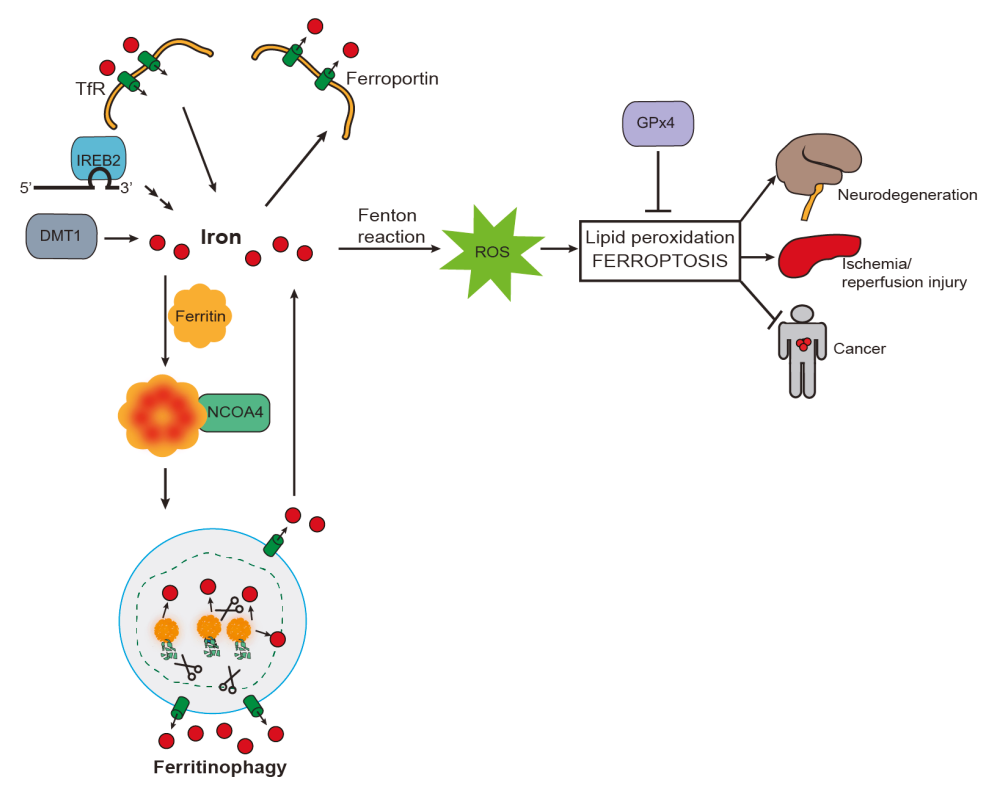

Figure 2. Iron and ferritinophagy are required for ferroptosis induction. Iron release in the cytosol can generate Reactive Oxygen Species (ROS) by the Fenton Reaction. ROS leads to lipid peroxidation and ferroptosis. Iron increase in the cytosol is mediated by increased import (by the transferrin receptor: TfR), decreased export (by ferroportin), increased translation of iron-metabolism related mRNAs via Iron Response Element Binding Protein 2 (IREB2) and increased cytosolic flux by Divalent Metal Transporter 1 (DMT1). Iron can also be stored in ferritin and delivered to the lysosome for NCOA4-mediated iron release from the lysosome. Increased ferritinophagy flux contributes to ferroptosis. Glutathione Peroxidase 4 (GPx4) repairs lipid peroxidation and inhibits ferroptosis. Ferroptosis is a promising therapeutic target. Inhibiting ferroptosis could protect from iron-induced cell death in neurodegeneration and ischemia/reperfusion injury while triggering ferroptosis could be effective in cancer patients.

As iron is necessary for the generation of lipid peroxides and thereby initiation of ferroptosis, ferroptosis sensitivity is impacted by compounds that decrease iron availability (iron chelation: deferoxamine (DFO)) and alterations in proteins involved in iron homeostasis that ultimately affect the cellular labile iron pool [58]. For instance, ferroptosis sensitivity is increased with overexpression of TfR (higher import of iron) and decreased expression of FTH1 and FTL (less ability to store iron) [60,61]. As NCOA4 directly regulates ferritin levels and thereby bioavailable levels of iron in the cell, it is not surprising that NCOA4-mediated ferritinophagy has recently been shown to modulate ferroptosis. While early studies were equivocal with respect to the role of autophagy in modulating ferroptosis [49,50], initial reports of NCOA4 depletion showed a decrease in intracellular free iron with a concomitant decrease in oxidative stress [9] accompanied by an increase in glutathione production [56]. Accordingly, NCOA4 deletion inhibited ferroptosis by blocking ferritinophagy and ferritin degradation [56,57]. Conversely, NCOA4 over-expression increased sensitivity to ferroptosis [56]. In fact, treatment with sorafenib, a ferroptosis-inducing drug [54,62], increased NCOA4 expression correlating with its role as mediator of ferroptotic cell death by promoting ferritinophagy and ROS production [63]. While the authors report upregulation of ELAVL1, a transcriptional regulator, as necessary for induction of autophagy/ferritinophagy, it is unclear whether there is a direct relationship between sorafenib, ELAVL1 function, NCOA4 expression levels, and flux through the ferritinophagy pathway [63]. 
Interestingly, Bellelli et al. showed the in vivo relevance of altering ferritinophagy to the ferroptosis pathway. They showed that NCOA4 depletion in mice fed with an iron-rich diet increased expression of GPx and SOD, likely due to overloaded FTH1 leading to iron leakage in tissues followed by upregulation of GPx and SOD as a compensatory mechanism to cope with oxidative stress [50]. Additional studies are required to address the in vivo regulation of autophagy/ferritinophagy as it relates to their contribution to ferroptosis. Also, it remains an open question whether ferroptosis occurs as part of a normal physiological process, perhaps during development.

\section{Ferritinophagy and Ferroptosis in Disease}

Ferroptosis has been linked to several pathological conditions including neurodegenerative disease, ischemia/reperfusion injury and cancer. As such, there is significant interest in identifying pharmacologic means of blocking (neurodegenerative disease, reperfusion injury) or triggering (cancer) ferroptosis for therapeutic purposes. Given NCOA4 can modulate ferroptosis sensitivity, understanding whether NCOA4 has a role in the pathophysiology of these various diseases is critical.

\subsection{Neurodegenerative Disease}

Neurodegenerative diseases (ND) have historically been associated with inappropriate iron accumulation and oxidative stress. More recently, ferroptosis has been shown to play a part in neurodegeneration pathophysiology [64]. In Parkinson's Disease (PD), increased iron accumulation and ROS lead to dopamine oxidation, contributing to an oxidative state that promotes dopaminergic neuronal cell death [65]. Elevated DMT1 expression [66] and activating mutations in Tf both lead to increased cytosolic iron and are correlated with worse outcomes for PD patients. Conversely, mutations in TfR2 that decrease cellular iron import correlate with better disease outcomes [67]. Similar observations have been made in Alzheimer's Disease (AD) [55], where iron is found to co-aggregate with pathogenic amyloid deposits [68]. Indeed, immunofluorescence of brains from patients with AD showed decreased expression of ferroportin, the iron export transporter [69]. Direct evidence that ferroptosis can modulate neuronal cell death initially came from in vitro rat organotypic hippocampal slice cultures treated with glutamate to mimic the pathophysiology of stroke and ND [58]. Glutamate induced ferroptosis that could be prevented by iron chelators and ferrostatin [58]. Studies with genetic [70] or pharmacological inhibitors of ferroptosis [71,72] in a variety of in vitro models and multiple ND disorders (PD, AD, Huntington's) subsequently confirmed that inhibition of ferroptosis is a potential strategy to prevent neuronal cell death.

To date there is no direct evidence linking ferritinophagy, ferroptosis, and ND. While elevated ferritinophagy sensitizes cells to ferroptosis, the data connecting autophagy and ND instead suggest that decreases in global autophagy activity are correlated with development of ND. Indeed, defective autophagy can cause ND in genetic mouse models of autophagy loss [73,74]. Mutation in WDR45, leading to decreased autophagy, has been identified in a number of patients with Neurodegeneration with Brain Iron Accumulation (NBIA) [75]. In general, as autophagy levels decrease with age [76], iron levels increase [77]. As defective autophagy is associated with ND, this suggests a more complex relationship of ferritinophagy activity to ND. Interestingly, in long term NCOA4 KO, mice have increased serum iron and were more sensitive to iron overload [50]. This could suggest that long-term ablation of ferritinophagy in vivo leads to an iron overload phenotype, albeit with decreased utilization of iron for erythropoiesis leading to anemia. Additional studies are necessary to clarify the expression, regulation and function of NCOA4 in the central nervous system (CNS). Given the possible role of ferritinophagy in mediating neuronal cell death, further studies will clarify NCOA4's role in ferroptosis in the CNS and establish the potential of ferroptosis inhibition in ND, either by iron chelation or by modulating ferritinophagy flux. 


\subsection{Cancer}

Many cancers accumulate large amounts of iron to support increased proliferation. This is accomplished in a cell-autonomous manner by increasing iron import or decreasing export [78-82] and in a non-autonomous manner by increasing iron supply from other cell types like macrophages $[83,84]$. Initial data suggests NCOA4 may be relevant to tumorigenesis and that the intersection of the ferritinophagy and ferroptosis pathways may represent a therapeutic avenue. A positive correlation between NCOA4 mRNA and NCOA4 $\alpha$ protein levels and transformation has been described in ovarian carcinoma $[85,86]$. Here, overexpression of several oncogenes (MYC, H-Ras, p53 inactivation) in normal endometriotic cells to induce transformation led to an upregulation of NCOA4 $\alpha$ and NCOA4 $\beta$ expression. Interestingly, NCOA $4 \alpha$ knockdown in transformed cells decreased survival whereas NCOA4 $\beta$ overexpression decreased colony formation. On the other hand, in studies of prostate cancer, NCOA $4 \alpha$ acts as a tumor suppressor while NCOA4 $\beta$ expression correlated with proliferation and invasion [87]. Similar roles were identified for the two isoforms in MCF7 breast cancer cells [88]. Whether NCOA4 functions differently depending on the cancer context and understanding whether the ferritinophagy specific function of NCOA4 drives tumor effects are critical questions for future study.

While robust evidence for the role of ferritinophagy in tumorigenesis is lacking, there is a significant evidence for the importance of autophagy in cancer with recent links between ferroptosis sensitivity and tumor autophagy dependence. The role of autophagy in cancer is exceedingly complex with autophagy acting in a tumor suppressive or tumor promoting manner depending on the tumor context (reviewed in detail [21]). Autophagy is activated in a variety of cancers [21,89-93] to support metabolism, redox homeostasis and probably iron turnover. In particular, many Kras-driven tumors, such as pancreatic cancer, depend on high autophagic flux [89] and have significant iron accumulation due to elevated TfR expression [94]. Notably, pancreatic cancer cell lines have increased NCOA4 expression and a corresponding high flux through the ferritinophagy pathway [9]. These baseline characteristics would suggest a high sensitivity to ferroptosis. In fact, ferroptosis inducers erastin and RSL3/5 were originally discovered as part of a synthetic lethality screen to determine synergies with the Ras oncogene $[60,95]$. More direct evidence for the role of NCOA4 in modulating ferroptotic cell death in pancreatic cancer cells came from Yang et al. who showed that artesunate-mediated ferroptotic cell death is attenuated by NCOA4 depletion [96]. In general, autophagy (and therefore ferritinophagy) has been shown to be a positive regulator of ferroptosis [56,57]; therefore, triggering ferroptosis in cancers with high autophagy levels might reveal a potential vulnerability. One possible future therapeutic strategy would be to increase iron flux through the ferritinophagy pathway, leading to increased labile iron and ROS, thereby sensitizing cancer cells to ferroptosis-inducing agents.

\subsection{Infectious Disease}

Ferritinophagy is also involved in modulating susceptibility to infectious diseases. Uropathogenic Escherichia coli survive by forming reservoirs within urothelial cell autophagosomes. These bacteria traffic with ferritin-bound iron to the autophagosome to support their proliferation. The authors show that ferritin trafficking is NCOA4-dependent and that NCOA4 depletion reduces bacterial load [30]. Autophagy inhibitors and iron chelators were able to reduce bacterial burden and host cell death, suggesting a therapeutic potential to modulating NCOA4-dependent ferritinophagy in certain bacterial infections. Human cytomegalovirus (HCMV) protein pUL38 blocks the function of USP24, a deubiquitinase, to prevent an iron-dependent, endoplasmic reticulum (ER)-stress induced premature cell death [97]. USP24 deubiquitinase activity stabilizes NCOA4 protein thereby promoting ferritinophagy, which in turn increases cellular iron levels promoting iron-dependent ER stress-induced cell death. Therefore HCMV protein pUL38, via inhibition of USP24, decreases ferritinophagy in order to protect HCMV-infected cells from a premature cell death [97]. These studies suggest that modulating NCOA4-mediated ferritinophagy levels may be an effective strategy to inhibit certain bacterial or viral infections. 


\section{Conclusions and Future Directions}

NCOA4-mediated ferritinophagy is integral to iron homeostasis in normal and pathological conditions. Significant progress has been made identifying the molecular mechanisms that regulate NCOA4 activity. However, a number of outstanding questions regarding the biochemical regulation of NCOA4 remain. First, how NCOA4 is regulated on a transcriptional and post-transcriptional level has yet to be determined. Importantly, NCOA4 mRNA does not appear to have a 5' or 3' Iron Regulatory Element (IRE) that would engage the iron responsive IREB1/ 2 system of post-transcriptional regulation. NCOA4-FTH1 and NCOA4-HERC2 binding appears to be regulated by iron levels; however, the mode of NCOA4 iron binding as well as the structural requirements for FTH1 and HERC2 binding are unclear. Further, where and when NCOA4 first interacts with FTH1 or HERC2 in the cell is unclear. The precise mechanism of NCOA4-FTH1 delivery to lysosomes is unclear and there may be multiple routes including a canonical autophagic route and/or an ESCRT complex dependent endosomal-lysosomal transport pathway $[33,34]$. NCOA4 has been reported to localize to and function in the nucleus as a nuclear receptor coactivator and as a regulator at DNA replication origins. How cytoplasmic versus nuclear NCOA4 localization is determined is an unanswered question, especially given NCOA4 lacks a canonical nuclear localization sequence. Interestingly, the two NCOA4 isoforms, NCOA4 $\alpha$ and NCOA $4 \beta$, differ in that NCOA $4 \beta$ does not contain the C-terminal elements for binding FTH1 and HERC2; however, their relative functions and expression levels in cells is undetermined at this time.

The role of NCOA4-mediated ferritinophagy in physiological processes has so far been assessed mainly in the context of erythropoiesis in zebrafish and murine models of systemic NCOA4 depletion. However, these studies have been unable to identify if the impact on erythropoiesis is due to cell-autonomous effects on iron metabolism in erythrocytes or due to impairment of whole body iron availability. Further studies are required to address this question using conditional knockout mouse models that interrogate NCOA4 in red blood cells or in other cell types that contribute to erythropoiesis. Furthermore, results from Gao et al. suggest there might be a temporal variation in NCOA4 dependency [41], with a higher reliance at early developmental stages. Defining the importance of NCOA4 at different developmental stages as well as comparing acute vs. long-term $\mathrm{KO}$ will be key to understanding the mechanisms triggered in erythrocytes or other cell types to compensate for NCOA4 loss. In addition, understanding the relative importance of NCOA4-mediated ferritinophagy in other organs and cell types, especially those highly involved in systemic iron homeostasis, such as the liver and the macrophage system, is critical and will depend on conditional NCOA4 KO mouse models.

The role of ferritinophagy in disease is an underexplored area. Based on the importance of NCOA4 in erythropoiesis and systemic iron homeostasis, future studies of NCOA4 function in the context of anemia and hemochromatosis and whether inhibition or upregulation of ferritinophagy can impact these and other disease processes where iron homeostasis is dysregulated will be informative. The recent discovery that ferritinophagy can modulate sensitivity to ferroptosis, an iron-dependent form of cell death linked to neurodegeneration, cancer and ischemia/reperfusion injury, suggests ferritinophagy may be similarly important in these diseases. Understanding how ferritinophagy contributes to ferroptosis sensitivity in each pathological setting in vivo will be key to designing therapeutic interventions that could trigger or block ferroptosis. The recent discovery of NCOA4 has opened a new area of biology with connections to a wide range of physiologic and pathophysiological processes. Future studies will clarify the above described unanswered biochemical and in vivo functional questions fundamental to our understanding of NCOA4 biology.

Author Contributions: N.S.C. and J.D.M. performed literature searches and wrote and edited the manuscript.

Funding: This research was supported by a Burroughs Wellcome Fund Career Award for Medical Scientists, Brigham and Women's Hospital MFCD Award, Sidney Kimmel Foundation Kimmel Scholar Program, and Dana-Farber Cancer Institute Claudia Adams Barr Program for Innovative Cancer Research Award to J.D.M.

Conflicts of Interest: J.D.M. is an inventor on a patent pertaining to the autophagic control of iron metabolism. 


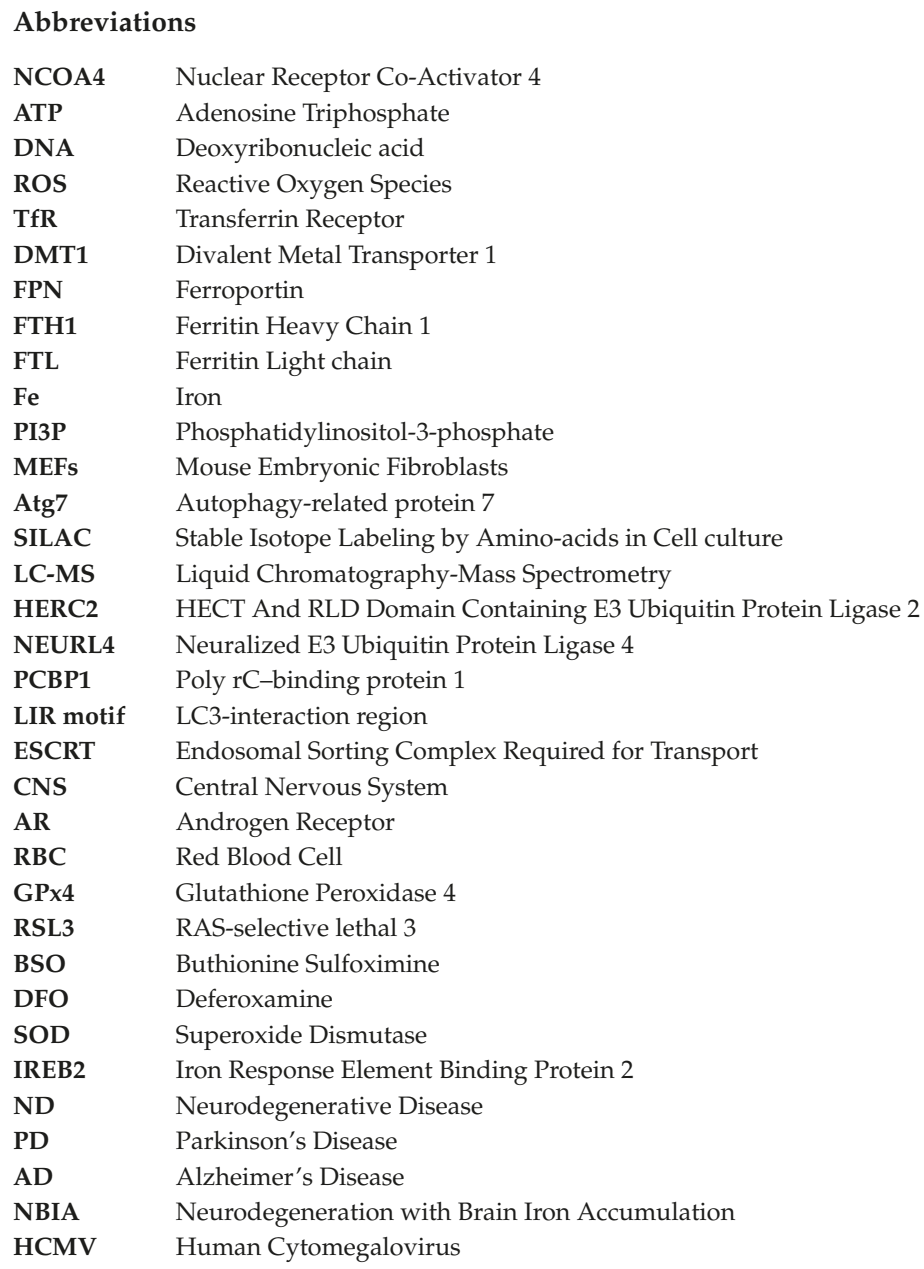

\section{References}

1. Bogdan, A.R.; Miyazawa, M.; Hashimoto, K.; Tsuji, Y. Regulators of Iron Homeostasis: New Players in Metabolism, Cell Death, and Disease. Trends Biochem. Sci. 2016, 41, 274-286. [CrossRef] [PubMed]

2. Muckenthaler, M.U.; Rivella, S.; Hentze, M.W.; Galy, B. A Red Carpet for Iron Metabolism. Cell 2017, 168, 344-361. [CrossRef] [PubMed]

3. Pantopoulos, K.; Porwal, S.K.; Tartakoff, A.; Devireddy, L. Mechanisms of mammalian iron homeostasis. Biochemistry 2012, 51, 5705-5724. [CrossRef] [PubMed]

4. Camaschella, C. New insights into iron deficiency and iron deficiency anemia. Blood Rev. 2017, 31, 225-233. [CrossRef] [PubMed]

5. Weis, S.; Carlos, A.R.; Moita, M.R.; Singh, S.; Blankenhaus, B.; Cardoso, S.; Larsen, R.; Rebelo, S.; Schäuble, S.; Del Barrio, L.; et al. Metabolic Adaptation Establishes Disease Tolerance to Sepsis. Cell 2017, 169, 1263-1275. [CrossRef] [PubMed]

6. Camaschella, C. Iron-deficiency anemia. N. Engl. J. Med. 2015, 372, 1832-1843. [CrossRef] [PubMed]

7. Fenton, H.J.H. Oxidation of tartaric acid in presence of iron. J. Chem. Soc. Trans. 1894, 65, 899-910. [CrossRef]

8. Sadrzadeh, S.M.; Graf, E.; Panter, S.S.; Hallaway, P.E.; Eaton, J.W. Hemoglobin. A biologic fenton reagent. J. Biol. Chem. 1984, 259, 14354-14356. [PubMed] 
9. Mancias, J.D.; Wang, X.; Gygi, S.P.; Harper, J.W.; Kimmelman, A.C. Quantitative proteomics identifies NCOA4 as the cargo receptor mediating ferritinophagy. Nature 2014, 509, 105-109. [CrossRef] [PubMed]

10. Mancias, J.D.; Pontano Vaites, L.; Nissim, S.; Biancur, D.E.; Kim, A.J.; Wang, X.; Liu, Y.; Goessling, W.; Kimmelman, A.C.; Harper, J.W. Ferritinophagy via NCOA4 is required for erythropoiesis and is regulated by iron dependent HERC2-mediated proteolysis. eLife 2015, 4, e10308. [CrossRef] [PubMed]

11. Arosio, P.; Ingrassia, R.; Cavadini, P. Ferritins: A family of molecules for iron storage, antioxidation and more. Biochim. Biophys. Acta 2009, 1790, 589-599. [CrossRef] [PubMed]

12. Philpott, C.C. The flux of iron through ferritin in erythrocyte development. Curr. Opin. Hematol. 2018, 3, $183-188$. [CrossRef] [PubMed]

13. Kidane, T.Z.; Sauble, E.; Linder, M.C.; Theodros, Z.; Sauble, E.; Re, M.C.L. Release of iron from ferritin requires lysosomal activity. Am. J. Physiol. Cell Physiol. 2006, 291, 445-455. [CrossRef] [PubMed]

14. Radisky, D.; Kaplan, J. Iron in cytosolic ferritin can be recycled through lysosomal degradation in human fibroblasts. Biochem. J. 1998, 336, 201-205. [CrossRef] [PubMed]

15. Zhang, Y.; Mikhael, M.; Xu, D.; Li, D.; Soe-Lin, S.; Ning, B.; Li, W.; Nie, G.; Zhao, Y.; Ponka, P. Lysosomal Proteolysis Is the Primary Degradation Pathway for Cytosolic Ferritin and Cytosolic Ferritin Degradation Is Necessary for Iron Exit. Antioxid. Redox Signal 2010, 13, 999-1009. [CrossRef] [PubMed]

16. Mancias, J.D.; Kimmelman, A.C. Mechanisms of selective autophagy in normal physiology and cancer. J. Mol. Biol. 2016, 428, 1659-1680. [CrossRef] [PubMed]

17. Asano, T.; Komatsu, M.; Yamaguchi-iwai, Y.; Ishikawa, F.; Mizushima, N.; Iwai, K. Distinct Mechanisms of Ferritin Delivery to Lysosomes in iron-depleted and iron-replete cells. Mol. Cell. Biol. 2011, 31, 2040-2052. [CrossRef] [PubMed]

18. Mizushima, N.; Komatsu, M. Autophagy: Renovation of cells and tissues. Cell 2011, 147, 728-741. [CrossRef] [PubMed]

19. Galluzzi, L.; Baehrecke, E.H.; Ballabio, A.; Boya, P.; Bravo-San Pedro, J.M.; Cecconi, F.; Choi, A.M.; Chu, C.T.; Codogno, P.; Colombo, M.I.; et al. Molecular definitions of autophagy and related processes. EMBO J. 2017, 36, 1811-1836. [CrossRef] [PubMed]

20. Kaur, J.; Debnath, J. Autophagy at the crossroads of catabolism and anabolism. Nat. Rev. Mol. Cell Biol. 2015, 16, 461-472. [CrossRef] [PubMed]

21. Santana-Codina, N.; Mancias, J.D.; Kimmelman, A.C. The role of autophagy in cancer. Annu. Rev. Cancer Biol. 2017, 1, 19-39. [CrossRef]

22. Scherz-Shouval, R.; Shvets, E.; Fass, E.; Shorer, H.; Gil, L.; Elazar, Z. Reactive oxygen species are essential for autophagy and specifically regulate the activity of Atg4. EMBO J. 2007, 26, 1749-1760. [CrossRef] [PubMed]

23. Amaravadi, R.K.; Yu, D.; Lum, J.J.; Bui, T.; Christophorou, M.A.; Evan, G.I.; Thomas-Tikhonenko, A.; Thompson, C.B. Autophagy inhibition enhances therapy-induced apoptosis in a Myc-induced model of lymphoma. J. Clin. Investig. 2007, 117, 326-336. [CrossRef] [PubMed]

24. Dowdle, W.E.; Nyfeler, B.; Nagel, J.; Elling, R.A.; Liu, S.; Triantafellow, E.; Menon, S.; Wang, Z.; Honda, A.; Pardee, G.; et al. Selective VPS34 inhibitor blocks autophagy and uncovers a role for NCOA4 in ferritin degradation and iron homeostasis in vivo. Nat. Cell Biol. 2014, 16, 1069-1079. [CrossRef] [PubMed]

25. Van de Wijngaart, D.; van Royen, M.; Hersmus, R.; Pike, A.; Houtsmuller, A.; Jenster, G.; Trapman, J.; Dubbink, H. Novel FXXFF and FXXMF motifs in androgen receptor cofactors mediate high affinity and specific interactions with the ligand-binding domain. J. Biol. Chem. 2006, 281, 19407-19416. [CrossRef] [PubMed]

26. Monaco, C.; Visconti, R.; Barone, M.; Pierantoni, G.; Berlingieri, M.; De Lorenzo, C.; Mineo, A.; Vecchio, G.; Fusco, A.; Santoro, M. The RFG oligomerization domain mediates kinase activation and re-localization of the RET/PTC3 oncoprotein to the plasma membrane. Oncogene 2001, 20, 599-608. [CrossRef] [PubMed]

27. Kollara, A.; Brown, T.J. Variable Expression of Nuclear Receptor Coactivator 4 (NcoA4) During Mouse Embryonic Development. J. Histochem. Cytochem. 2010, 58, 595-609. [CrossRef] [PubMed]

28. Alen, P.; Claessens, F.; Schoenmakers, E.; Swinnen, J.; Verhoeven, G.; Rombauts, W.; Peeters, B. Interaction of the putative androgen receptor-specific coactivator ARA70/ELE1alpha with multiple steroid receptors and identification of an internally deleted ELE1beta isoform. Mol. Endocrinol. 1999, 13, 117-128. [PubMed]

29. Gryzik, M.; Srivastava, A.; Longhi, G.; Bertuzzi, M.; Gianoncelli, A.; Carmona, F.; Poli, M.; Arosio, P. Expression and characterization of the ferritin binding domain of Nuclear Receptor Coactivator-4 (NCOA4). Biochim. Biophys. Acta Gen. Subj. 2017, 1861, 2710-2716. [CrossRef] [PubMed] 
30. Bauckman, K.; Mysorekar, I. Ferritinophagy drives uropathogenic Escherichia coli persistence in bladder epithelial cells. Autophagy 2016, 12, 850-863. [CrossRef] [PubMed]

31. Von Muhlinen, N.; Akutsu, M.; Ravenhill, B.J.; Foeglein, Á.; Bloor, S.; Rutherford, T.J.; Freund, S.M.V.; Komander, D.; Randow, F. LC3C, bound selectively by a noncanonical LIR motif in NDP52, is required for antibacterial autophagy. Mol. Cell 2012, 48, 329-342. [CrossRef] [PubMed]

32. De Domenico, I.; Vaughn, M.B.; Li, L.; Bagley, D.; Musci, G.; Ward, D.M.; Kaplan, J. Ferroportin-mediated mobilization of ferritin iron precedes ferritin degradation by the proteasome. EMBO J. 2006, 25, 5396-5404. [CrossRef] [PubMed]

33. Goodwin, J.M.; Dowdle, W.E.; DeJesus, R.; Wang, Z.; Bergman, P.; Kobylarz, M.; Lindeman, A.; Xavier, R.J.; McAllister, G.; Nyfeler, B.; et al. Autophagy-Independent Lysosomal Targeting Regulated by ULK1/2-FIP200 and ATG9. Cell Rep. 2017, 20, 2341-2356. [CrossRef] [PubMed]

34. Mejlvang, J.; Olsvik, H.; Svenning, S.; Bruun, J.; Abudu, Y.; Larsen, K.; Brech, A.; Hansen, T.; Brenne, H.; Hansen, T.; et al. Starvation induces rapid degradation of selective autophagy receptors by endosomal microautophagy. J. Cell Biol. 2018, 217, 3640-3655. [CrossRef] [PubMed]

35. Yeh, S.; Chang, C. Cloning and characterization of a specific coactivator, ARA70, for the androgen receptor in human prostate cells. Proc. Natl. Acad. Sci. USA 1996, 93, 5517-5521. [CrossRef] [PubMed]

36. Heinlein, C.; Ting, H.; Yeh, S.; Chang, C. Identification of ARA70 as a ligand-enhanced coactivator for the peroxisome proliferator-activated receptor gamma. J. Biol. Chem. 1999, 274, 16147-16152. [CrossRef] [PubMed]

37. Lanzino, M.; Amicis, F.; McPhaul, M.; Marsico, S.; Panno, M.; Ando, S. Endogenous coactivator ARA70 interacts with estrogen receptor alpha (ERalpha) and modulates the functional ERalpha/androgen receptor interplay in MCF-7 cells. J. Biol. Chem. 2005, 280, 20421-20430. [CrossRef] [PubMed]

38. Gao, T.; Brantley, K.; Bolu, E.; McPhaul, M. RFG (ARA70, ELE1) interacts with the human androgen receptor in a ligand-dependent fashion, but functions only weakly as a coactivator in cotransfection assays. Mol. Endocrinol. 1999, 13, 1645-1656. [CrossRef] [PubMed]

39. Ting, H.; Bao, B.; Hsu, C.; Lee, Y. Androgen-receptor coregulators mediate the suppressive effect of androgen signals on vitamin D receptor activity. Endocrine 2005, 26, 1-9. [CrossRef]

40. Kollara, A.; Brown, T. Expression and function of nuclear receptor co-activator 4: Evidence of a potential role independent of co-activator activity. Cell. Mol. Life Sci. 2012, 69, 3895-3909. [CrossRef] [PubMed]

41. Gao, X.; Lee, H.; Li, W.; Jeffrey, R.; Barrasa, M.I.; Ma, Q. Thyroid hormone receptor beta and NCOA4 regulate terminal erythrocyte differentiation. Proc. Natl. Acad. Sci. USA 2017, 114, 10107-10112. [CrossRef] [PubMed]

42. Bellelli, R.; Castellone, M.D.; Guida, T.; Limongello, R.; Dathan, N.A.; Merolla, F.; Cirafici, A.M.; Affuso, A.; Masai, H.; Costanzo, V.; et al. NCOA4 transcriptional coactivator inhibits activation of DNA replication origins. Mol. Cell 2014, 55, 123-137. [CrossRef] [PubMed]

43. Nguyen, A.; Prado, M.; Schmidt, P.; Sendamarai, A.; Wilson-Grady, J.; Min, M.; Campagna, D.; Tian, G.; Shi, Y.; Dederer, V.; et al. UBE2O remodels the proteome during terminal erythroid differentiation. Science 2017, 357, eaan0218. [CrossRef] [PubMed]

44. Sheftel, A.D.; Zhang, A.-S.; Brown, C.; Shirihai, O.S.; Ponka, P. Direct interorganellar transfer of iron from endosome to mitochondrion. Blood 2007, 110, 125-132. [CrossRef] [PubMed]

45. Vaisman, B.; Fibach, E.; Konijn, A. Utilization of intracellular ferritin iron for hemoglobin synthesis in developing human erythroid precursors. Blood 1997, 90, 831-838. [PubMed]

46. Shvartsman, M.; Cabantchik, Z.I. Intracellular iron trafficking: Role of cytosolic ligands. Biometals 2012, 25, 711-723. [CrossRef] [PubMed]

47. Ryu, M.S.; Zhang, D.; Protchenko, O.; Shakoury-Elizeh, M.; Philpott, C.C. PCBP1 and NCOA4 regulate erythroid iron storage and heme biosynthesis. J. Clin. Investig. 2017, 127, 1786-1797. [CrossRef] [PubMed]

48. Weber, G.J.; Choe, S.E.; Dooley, K.A.; Paffett-Lugassy, N.N.; Zhou, Y.; Zon, L.I. Mutant-specific gene programs in the zebrafish. Blood 2005, 106, 521-530. [CrossRef] [PubMed]

49. An, X.; Schulz, V.P.; Li, J.; Wu, K.; Liu, J.; Xue, F.; Hu, J.; Mohandas, N.; Gallagher, P.G. Global transcriptome analyses of human and murine terminal erythroid differentiation. Blood 2014, 123, 3466-3477. [CrossRef] [PubMed]

50. Bellelli, R.; Federico, G.; Matte, A.; Colecchia, D.; Iolascon, A.; Chiariello, M.; Santoro, M.; De Franceschi, L.; Carlomagno, F. NCOA4 Deficiency Impairs Systemic Iron Homeostasis. Cell Rep. 2016, 14, 411-421. [CrossRef] [PubMed] 
51. Kimura, T.; Jia, J.; Kumar, S.; Choi, S.W.; Gu, Y.; Mudd, M.; Dupont, N.; Jiang, S.; Peters, R.; Farzam, F.; et al. Dedicated SNAREs and specialized TRIM cargo receptors mediate secretory autophagy. EMBO J. 2017, 36, $42-60$. [CrossRef] [PubMed]

52. Truman-Rosentsvit, M.; Berenbaum, D.; Spektor, L.; Cohen, L.A.; Belizowsky-Moshe, S.; Lifshitz, L.; Ma, J.; Li, W.; Kesselman, E.; Abutbul-Ionita, I.; et al. Ferritin is secreted via 2 distinct nonclassical vesicular pathways. Blood 2018, 131, 342-352. [CrossRef] [PubMed]

53. Doulatov, S.; Vo, L.; Macari, E.; Wahlster, L.; Kinney, M.; Taylor, A.; Barragan, J.; Gupta, M.; McGrath, K.; Lee, H.; et al. Drug discovery for Diamond-Blackfan anemia using reprogrammed hematopoietic progenitors. Sci. Transl. Med. 2017, 9, eaah5645. [CrossRef] [PubMed]

54. Xie, Y.; Hou, W.; Song, X.; Yu, Y.; Huang, J.; Sun, X.; Kang, R.; Tang, D. Ferroptosis: Process and function. Cell Death Differ 2016, 23, 369-379. [CrossRef] [PubMed]

55. Tang, M.; Chen, Z.; Wu, D.; Chen, L. Ferritinophagy / ferroptosis: Iron-related newcomers in human diseases. J. Cell Physiol. 2018. [CrossRef] [PubMed]

56. Hou, W.; Xie, Y.; Song, X.; Sun, X.; Lotze, M.T.; Zeh, H., III; Kang, R. Autophagy promotes ferroptosis by degradation of ferritin. Autophagy 2016, 12, 1425-1428. [CrossRef] [PubMed]

57. Gao, M.; Monian, P.; Pan, Q.; Zhang, W.; Xiang, J.; Jiang, X. Ferroptosis is an autophagic cell death process. Cell Res. 2016, 26, 1021-1032. [CrossRef] [PubMed]

58. Dixon, S.J.; Lemberg, K.M.; Lamprecht, M.R.; Skouta, R.; Zaitsev, E.M.; Gleason, C.E.; Patel, D.N.; Bauer, A.J.; Cantley, A.M.; Yang, W.S.; et al. Ferroptosis: An Iron-Dependent Form of Nonapoptotic Cell Death. Cell 2012, 149, 1060-1072. [CrossRef] [PubMed]

59. Stockwell, B.R.; Angeli, P.F.; Bush, A.I.; Conrad, M.; Dixon, S.J.; Fulda, S.; Gasco, S.; Linkermann, A.; Murphy, M.E.; Overholtzer, M.; et al. Ferroptosis: A Regulated Cell Death Nexus Linking Metabolism, Redox Biology, and Disease. Cell 2017, 171, 273-285. [CrossRef] [PubMed]

60. Yang, W.; Stockwell, B. Synthetic lethal screening identifies compounds activating iron-dependent, nonapoptotic cell death in oncogenic-RAS-harboring cancer cells. Chem. Biol. 2008, 15, 234-245. [CrossRef] [PubMed]

61. Sun, X.; Ou, Z.; Xie, M.; Kang, R.; Fan, Y.; Niu, X.; Wang, H.; Cao, L.; Tang, D. HSPB1 as a Novel Regulator of Ferroptotic Cancer Cell Death. Oncogene 2015, 34, 5617-5625. [CrossRef] [PubMed]

62. Louandre, C.; Marcq, I.; Bouhlal, H.; Lachaier, E.; Godin, C.; Saidak, Z.; François, C.; Chatelain, D.; Debuysscher, V.; Barbare, J.; et al. The retinoblastoma $(\mathrm{Rb})$ protein regulates ferroptosis induced by sorafenib in human hepa- tocellular carcinoma cells. Cancer Lett. 2015, 356, 971-977. [CrossRef] [PubMed]

63. Zhang, Z.; Yao, Z.; Wang, L.; Ding, H.; Shao, J.; Chen, A.; Zhang, F.; Zheng, S. Activation of ferritinophagy is required for the RNA-binding protein ELAVL1/HuR to regulate ferroptosis in hepatic stellate cells. Autophagy 2018, 14, 1-21. [CrossRef] [PubMed]

64. Guiney, S.; Adlard, P.; Bush, A.; Finkelstein, D.; Ayton, S. Ferroptosis and cell death mechanisms in Parkinson's disease. Neurochem. Int. 2017, 104, 34-48. [CrossRef] [PubMed]

65. Jenner, P.; Dexter, D.; Sian, J.; Schapira, A.; Marsden, C. Oxidative stress as a cause of nigral cell death in Parkinson's disease and incidental Lewy body disease. The Royal Kings and Queens Parkinson's Disease Research Group. Ann. Neurol. 1992, 32 (Suppl. 1), S82-S87. [CrossRef] [PubMed]

66. Salazar, J.; Mena, N.; Hunot, S.; Prigent, A.; Alvarez-Fischer, D.; Arredondo, M.; Duyckaerts, C.; Sazdovitch, V.; Zhao, L.; Garrick, L.; et al. Divalent metal transporter 1 (DMT1) contributes to neurodegeneration in animal models of Parkinson's disease. Proc. Natl. Acad. Sci. USA 2008, 105, 18578-18583. [CrossRef] [PubMed]

67. Rhodes, S.; Buchanan, D.; Ahmed, I.; Taylor, K.; Loriot, M.; Sinsheimer, J.; Bronstein, J.; Elbaz, A.; Mellick, G.; Rotter, J.; et al. Pooled analysis of iron-related genes in Parkinson's disease: Association with transferrin. Neurobiol. Dis. 2014, 62, 172-178. [CrossRef] [PubMed]

68. Everett, J.; Céspedes, L.; Shelford, C.; Exley, J.; Collingwood, J.; Dobson, G.; van der Laan, C.; Jenkins, E.; Arenholz, N.; Telling, D. Ferrous iron formation following the co-aggregation of ferric iron and the Alzheimer's disease peptide $\beta$-amyloid (1-42). J. R. Soc. Interface 2014, 11, 20140165. [CrossRef] [PubMed]

69. Raha, A.; Vaishnav, R.; Friedland, R.; Bomford, A.; Raha-Chowdhury, R. The systemic iron-regulatory proteins hepcidin and ferroportin are reduced in the brain in Alzheimer's disease. Acta Neuropathol. Commun. 2013, 1, 55. [CrossRef] [PubMed] 
70. Chen, L.; Hambright, W.S.; Na, R.; Ran, Q. Ablation of ferroptosis inhibitor glutathione peroxidase 4 in neurons results in rapid motor neuron degeneration and paralysis. J. Biol. Chem. 2015, 290, 28097-28106. [CrossRef] [PubMed]

71. Do Van, B.; Gouel, F.; Jonneaux, A.; Timmerman, K.; Gelé, P.; Pétrault, M.; Bastide, M.; Laloux, C.; Moreau, C.; Bordet, R.; et al. Ferroptosis, a newly characterized form of cell death in Parkinson's disease that is regulated by PKC. Neurobiol. Dis. 2016, 94, 169-178. [CrossRef] [PubMed]

72. Skouta, R.; Dixon, S.; Wang, J.; Dunn, D.; Orman, M.; Shimada, K.; Rosenberg, P.; Lo, D.C.; Weinberg, J.M.; Linkermann, A.; et al. Ferrostatins Inhibit Oxidative Lipid Damage and Cell Death in Diverse Disease Models. J. Am. Chem. Soc. 2014, 136, 4551-4556. [CrossRef] [PubMed]

73. Hara, T.; Nakamura, K.; Matsui, M.; Yamamoto, A.; Nakahara, Y.; Suzuki-Migishima, R.; Yokoyama, M.; Mishima, K.; Saito, I.; Okano, H.; et al. Suppression of basal autophagy in neural cells causes neurodegenerative disease in mice. Nature 2006, 441, 885-889. [CrossRef] [PubMed]

74. Komatsu, M.; Waguri, S.; Chiba, T.; Murata, S.; Iwata, J.; Tanida, I.; Ueno, T.; Koike, M.; Uchiyama, Y.; Kominami, E.; et al. Loss of autophagy in the central nervous system causes neurodegeneration in mice. Nature 2006, 441, 880-884. [CrossRef] [PubMed]

75. Saitsu, H.; Nishimura, T.; Muramatsu, K.; Kodera, H.; Kumada, S.; Sugai, K.; Kasai-Yoshida, E.; Sawaura, N.; Nishida, H.; Hoshino, A.; et al. De novo mutations in the autophagy gene WDR45 cause static encephalopathy of childhood with neurodegeneration in adulthood. Nat. Genet. 2013, 45, 445. [CrossRef] [PubMed]

76. Lipinski, M.; Zheng, B.; Lu, T.; Yan, Z.; Py, B.; Ng, A.; Xavier, R.; Li, C.; Scherzer, C.; Yuan, J. Genome-wide analysis reveals mechanisms modulating autophagy in normal brain aging and in Alzheimer's disease. Proc. Natl. Acad. Sci. USA 2010, 107, 14164-14169. [CrossRef] [PubMed]

77. Buijs, M.; Doan, N.T.; van Rooden, S.; Versluis, M.J.; van Lew, B.; Milles, J.; van der Grond, J.; van Buchem, M.A. In vivo assessment of iron content of the cerebral cortex in healthy aging using 7-Tesla T2*-weighted phase imaging. Neurobiol. Aging 2017, 53, 20-26. [CrossRef] [PubMed]

78. Pinnix, Z.K.; Miller, L.D.; Wang, W.; D’Agostino, R.J.; Kute, T.; Willingham, M.C.; Hatcher, H.; Tesfay, L.; Sui, G.; Di, X.; et al. Ferroportin and iron regulation in breast cancer progression and prognosis. Sci. Transl. Med. 2010, 2, 43-56. [CrossRef]

79. Basuli, D.; Tesfay, L.; Deng, Z.; Paul, B.; Yamamoto, Y.; Ning, G.; Xian, W.; McKeon, F.; Lynch, M.; Crum, C.; et al. Iron addiction: A novel therapeutic target in ovarian cancer. Oncogene 2017, 36, 4089-4099. [CrossRef] [PubMed]

80. Wu, K.; Polack, A.; Dalla-Favera, R. Coordinated regulation of iron-controlling genes, H-ferritin and IRP2, by c-MYC. Science 1999, 283, 676-679. [CrossRef] [PubMed]

81. Zhang, F.; Wang, W.; Tsuji, Y.; Torti, S.; Torti, F. Post-transcriptional modulation of iron homeostasis during p53-dependent growth arrest. J. Biol. Chem. 2008, 283, 33911-33918. [CrossRef] [PubMed]

82. Kakhlon, O.; Gruenbaum, Y.; Cabantchik, Z. Repression of ferritin expression modulates cell responsiveness to H-ras-induced growth. Biochem. Soc. Trans. 2002, 30, 777-780. [CrossRef] [PubMed]

83. Recalcati, S.; Locati, M.; Marini, A.; Santambrogio, P.; Zaninotto, F.; De Pizzoi, M.; Zammataro, L.; Girelli, D.; Cairo, G. Differential regulation of iron homeostasis during human macrophage polarized activation. Eur. J. Immunol. 2010, 40, 824-835. [CrossRef] [PubMed]

84. Mertens, C.; Mora, J.; Ören, B.; Grein, S.; Winslow, S.; Scholich, K.; Weigert, A.; Malmström, P.; Forsare, C.; Fernö, M.; et al. Macrophage-derived lipocalin-2 transports iron in the tumor microenvironment. Oncoimmunology 2018, 7, e1408751. [CrossRef] [PubMed]

85. Shaw, P.; Rittenberg, P.; Brown, T. Activation of androgen receptor-associated protein 70 (ARA70) mRNA expression in ovarian cancer. Gynecol. Oncol. 2001, 80, 132-138. [CrossRef] [PubMed]

86. Rockfield, S.; Flores, I.; Nanjundan, M. Expression and function of nuclear receptor coactivator 4 isoforms in transformed endometriotic and malignant ovarian cells. Oncotarget 2018, 9, 5344-5367. [CrossRef] [PubMed]

87. Peng, Y.; Li, C.; Chen, F.; Wang, Z.; Ligr, M.; Melamed, J.; Wei, J.; Gerald, W.; Pagano, M.; Garabedian, M.; et al. Stimulation of prostate cancer cellular proliferation and invasion by the androgen receptor co-activator ARA70. Am. J. Pathol. 2008, 172, 225-235. [CrossRef] [PubMed]

88. Wu, X.; Chen, F.; Sahin, A.; Albarracin, C.; Pei, Z.; Zou, X.; Singh, B.; Xu, R.; Daniels, G.; Li, Y.; et al. Distinct function of androgen receptor coactivator ARA70alpha and ARA70beta in mammary gland development, and in breast cancer. Breast Cancer Res. Treat. 2011, 128, 391-400. [CrossRef] [PubMed] 
89. Yang, S.; Wang, X.; Contino, G.; Liesa, M.; Sahin, E.; Ying, H.; Bause, A.; Li, Y.; Stommel, J.M.; Dell'antonio, G.; et al. Pancreatic cancers require autophagy for tumor growth. Genes Dev. 2011, 25, 717-729. [CrossRef] [PubMed]

90. Lazova, R.; Camp, R.; Klump, V.; Siddiqui, S.; Amaravadi, R.; Pawelek, J. Punctate LC3B Expression Is a Common Feature of Solid Tumors and Associated with Proliferation, Metastasis, and Poor Outcome. Clin. Cancer Res. 2012, 18, 370-379. [CrossRef] [PubMed]

91. Guo, J.Y.; Chen, H.Y.; Mathew, R.; Fan, J.; Strohecker, A.M.; Karsli-Uzunbas, G.; Kamphorst, J.J.; Chen, G.; Lemons, J.M.S.; Karantza, V.; et al. Activated Ras requires autophagy to maintain oxidative metabolism and tumorigenesis. Genes Dev. 2011, 25, 460-470. [CrossRef] [PubMed]

92. Lock, R.; Roy, S.; Kenific, C.M.; Su, J.S.; Salas, E.; Ronen, S.M.; Debnath, J. Autophagy facilitates glycolysis during Ras-mediated oncogenic transformation. Mol. Biol. Cell 2011, 22, 165-178. [CrossRef] [PubMed]

93. Yuan, W.; Wu, S.; Guo, J.; Chen, Z.; Ge, J.; Yang, P.; Hu, B.; Chen, Z. Silencing of TKTL1 by siRNA inhibits proliferation of human gastric cancer cells in vitro and in vivo. Cancer Biol. Ther. 2010, 9, 710-716. [CrossRef] [PubMed]

94. Ryschich, E.; Huszty, G.; Hartel, M.; Büchler, M.; Schmidt, J. Transferrin receptor is a marker of malignant phenotype in human pancreatic cancer and in neuroendocrine carcinoma of the pancreas. Eur. J. Cancer 2004, 40, 1418-1422. [CrossRef] [PubMed]

95. Dolma, S.; Lessnick, S.L.; Hahn, W.C.; Stockwell, B.R. Identification of genotype-selective antitumor agents using synthetic lethal chemical screening in engineered human tumor cells. Cancer Cell 2003, 3, 285-296. [CrossRef]

96. Eling, N.; Reuter, L.; Hazin, J.; Hamacher-brady, A. Identification of artesunate as a specific activator of ferroptosis in pancreatic cancer cells. Oncoscience 2015, 2, 517. [CrossRef] [PubMed]

97. Sun, Y.; Bao, Q.; Xuan, B.; Xu, W.; Pan, D.; Li, Q.; Qian, Z. Human Cytomegalovirus Protein pUL38 Prevents Premature Cell Death by Binding to Ubiquitin-specific Protease 24 and Regulating Iron Metabolism. J. Virol. 2018, 92, e00191-18. [CrossRef] [PubMed]

(C) 2018 by the authors. Licensee MDPI, Basel, Switzerland. This article is an open access article distributed under the terms and conditions of the Creative Commons Attribution (CC BY) license (http:/ / creativecommons.org/licenses/by/4.0/). 
Review

\title{
Impairment of the Developing Human Brain in Iron Deficiency: Correlations to Findings in Experimental Animals and Prospects for Early Intervention Therapy
}

\author{
Veronika Markova 1,2,3, Charlotte Holm ${ }^{1}$, Anja Bisgaard Pinborg ${ }^{4}$, Lars Lykke Thomsen ${ }^{2,3}$ \\ and Torben Moos ${ }^{3, *}$ \\ 1 Department of Obstetrics and Gynaecology, Hvidovre Hospital, Copenhagen University Hospital, \\ 2650 Hvidovre, Denmark \\ 2 Pharmacosmos A/S, 4300 Holbæk, Denmark \\ 3 Laboratory of Neurobiology, Department of Health Science and Technology, Aalborg University, \\ 9220 Aalborg, Denmark \\ 4 Fertility Clinic, Juliane Marie Centre, Rigshospitalet, University of Copenhagen, 2100 Copenhagen, Denmark \\ * Correspondence: tmoos@hst.aau.dk
}

Received: 17 July 2019; Accepted: 13 August 2019; Published: 14 August 2019

\begin{abstract}
Due to the necessity of iron for a variety of cellular functions, the developing mammalian organism is vulnerable to iron deficiency, hence causing structural abnormalities and physiological malfunctioning in organs, which are particularly dependent on adequate iron stores, such as the brain. In early embryonic life, iron is already needed for proper development of the brain with the proliferation, migration, and differentiation of neuro-progenitor cells. This is underpinned by the widespread expression of transferrin receptors in the developing brain, which, in later life, is restricted to cells of the blood-brain and blood-cerebrospinal fluid barriers and neuronal cells, hence ensuring a sustained iron supply to the brain, even in the fully developed brain. In embryonic human life, iron deficiency is thought to result in a lower brain weight, with the impaired formation of myelin. Studies of fully developed infants that have experienced iron deficiency during development reveal the chronic and irreversible impairment of cognitive, memory, and motor skills, indicating widespread effects on the human brain. This review highlights the major findings of recent decades on the effects of gestational and lactational iron deficiency on the developing human brain. The findings are correlated to findings of experimental animals ranging from rodents to domestic pigs and non-human primates. The results point towards significant effects of iron deficiency on the developing brain. Evidence would be stronger with more studies addressing the human brain in real-time and the development of blood biomarkers of cerebral disturbance in iron deficiency. Cerebral iron deficiency is expected to be curable with iron substitution therapy, as the brain, privileged by the cerebral vascular transferrin receptor expression, is expected to facilitate iron extraction from the circulation and enable transport further into the brain.
\end{abstract}

Keywords: developmental; iron deficiency anemia; neonatal; transferrin receptor; treatment

\section{Introduction}

Iron deficiency is the most common type of malnutrition in humans [1-4]. Iron deficiency occurs due to an inadequate intake, excess loss, or increased need, and gradually leads to insufficient functions of many organs, including the bone marrow, and as a consequence, iron deficiency leads to iron deficiency anemia [5-7]. According to the WHO, anemia affects 1.8 billion people worldwide, equivalent to approximately $25 \%$ of the world's population. Among this group, approximately 0.5 billion are women of a reproductive age, and in developing countries, the incidence of anemia is even higher 
and varies during pregnancy from $35 \%$ to $56 \%$ for Africa, $37 \%$ to $75 \%$ in Asia, and $37 \%$ to $52 \%$ in Latin America.

Women of a reproductive age are particularly at risk for developing iron deficiency due to menstrual bleeding and pregnancy. The prevalence of iron deficiency anemia in pregnant women is high, even in industrialized countries with well-established iron supplementation policies, e.g., in Denmark, where iron deficiency with anemia affects roughly $12 \%$ of pregnant women. The state of pregnancy greatly increases the demand of iron used in foetal organogenesis and growth. The pregnant body prioritizes the fetal iron supply over the maternal utilization up until a threshold of the maternal iron stores being adequate, with a maternal plasma ferritin concentration of approximately $14 \mu \mathrm{g} / \mathrm{L}$ [8]. When the maternal iron stores exceed this threshold, the placenta actively transports iron into the fetal circulation to ensure adequate iron supply to the fetus [9].

Iron deficiency can adversely affect brain development in fetuses and infants. Whereas most knowledge on the fetal needs for iron during pregnancy has been obtained within hematological, nephrology, and gastrointestinal disciplines, the impact on the fetal brain of maternal iron deficiency during pregnancy remains quite understudied. A higher turnover of iron in the developing brain [10], in addition to the widespread expression of iron-containing proteins, nonetheless dictate the importance of iron for the developing brain [11-14]. This is particularly underscored by the profound expression of transferrin receptor 1 by dividing neuroprogenitor cells $[15,16]$ and signifies that cells of the developing brain with respect to their need for iron share a range of common conditions with precursor cells participating in bone marrow erythropoiesis and the formation of duodenal enterocytes of the fully developed organism. This review aims to summarize the current evidence on the significance of iron for the developing brain, how iron deficiency may impair functioning of the central nervous system (CNS) in the human brain and brains of experimental animals, and which therapeutic advances available can prevent damage to the developing CNS.

\subsection{Transport of Iron into the Brain}

The brain acquires iron during life in a privileged manner in that its capillary endothelial cells are the only endothelial cells of the entire body that express transferrin receptors [17]. Iron circulates in blood exclusively bound to transferrin, unless pathological conditions like hemochromatosis occurs, which will result in the presence of low-molecular-weight forms of non-transferrin bound iron. The brain capillary endothelial cells form the blood-brain barrier (BBB) that prevents paracellular, non-specific entry of the iron-containing transferrin into the brain [17]. Rather, the brain capillary endothelium regulates iron transport into the brain via the expression of transferrin receptors $[9,13,17]$. Iron-transferrin attaches to the transferrin receptor, which results in the formation of endocytic vesicles. Recent studies have also shown that the transferrin receptor of the BBB can bind and take up circulating ferritin [18-21]. These vesicles are slightly acidic, and the lower $\mathrm{pH}$ reduces the binding affinity of iron to transferrin, which loosens their binding. The iron, present on its ferric form, is reduced to ferrous iron, which can be transported out of the endosome and into the cytosol by divalent metal transporter 1 (DMT1) [22]. The release of iron from transferrin within the endosome causes the iron-free apo-transferrin to detach from the transferrin receptor, which allows unbound apo-transferrin to recycle to the luminal surface [17].

Unbound ferrous iron is a potent pro-oxidative molecule that needs immediate oxidation [23,24]. Consequently, ferrous iron is either oxidized within the cytosol by ferrous oxidases, e.g., ceruloplasmin, or gets transported into the brain's extracellular space via the efflux transporter ferroportin, while undergoing oxidation during passage of the cellular membrane [23]. The iron transported across the brain endothelium accordingly occurs in a non-transferrin bound iron form and thereby is a candidate for binding to transferrin present within the brain extracellular space [17].

Iron in the cytosol participates in essential metabolic processes, e.g., participation in mitochondrial respiration via incorporation mitochondrial enzymes. Many cell types of the body also store residual iron as ferritin-iron, as ferritin also has pro-oxidant activity and is capable of oxidizing ferrous iron 
to store around 4500 iron atoms $[25,26]$. Of note, however, is that brain capillary endothelial cells hardly express ferritin, except for during development [27], suggesting that virtually all iron present within the brain capillary endothelial cells is immediately directed toward transport across the BBB to ensure its function further inside the brain.

Iron is also transferred to the brain via transfer across choroid plexus epithelial cells that form the blood-cerebrospinal fluid (CSF) barrier [17]. Like the endothelial cells forming the BBB, the epithelial cells of the choroid plexus also express transferrin receptors [24], but the quantitative relevance of the choroid plexus for iron transport into the brain is of less significance due to their much lower surface than that of brain endothelial cells of the BBB. The choroid plexus nonetheless very likely makes an important contribution to cerebral iron homeostasis, as transferrin of the blood plasma is filtered through the blood-CSF barrier and enters the brain ventricles, while transferrin in parallel is also synthesized and secreted from the choroid plexus to enter the brain ventricles [24]. In sum, this suggests that transferrin of the brain ventricle, and likely also elsewhere in the brain's extracellular space, is derived from the choroid plexus. In the extracellular compartment of the brain, transferrin is needed to capture non-transferrin-bound iron transported across the BBB or released from neurons and glia. The need for transferrin in the brain's extracellular space is further underscored by the presence of transferrin receptors on neurons [28]. Surprisingly, transferrin receptors and DMT1 are hardly detected on major glial cells like astrocytes, oligodendrocytes, and microglia [23,28], which suggests that iron enters glial cells as non-transferrin-bound iron, possibly via specific transporters like ZIP14 [29].

\subsection{Transport of Iron into the Developing and Iron-Deficient Brain}

The uptake of iron-containing transferrin at the BBB and blood-CSF barriers and the further transportation of iron into the brain are dramatically upregulated in the developing brain [30-32]. The higher iron uptake strongly correlates to a higher expression of transferrin receptors by brain endothelial cells in the developing brain, as evidenced from studies on the rodent brain [30,31]. The upregulated iron transport is attributable to a generally higher need for iron as the progenitor cells of the brain proliferate and differentiate into their final phenotypes [15,16,32,33]. Interestingly, as the cerebral turnover of iron is extremely low and ceases with increasing age, virtually all the iron transported across the brain barriers during development is believed to remain within the brain [10-12].

Correspondingly, when the events take place during development, the brain also adapts to conditions with deprivation in iron accessibility by the upregulation of transferrin receptors [28]. When cerebral iron deficiency occurs, the brain profoundly increases the internalization of transferrin receptors in the capillary endothelial cells. The brain also increases the expression of transferrin receptors in neurons in iron deficiency, whereas glial cells, even in stages with robust iron deficiency, fail to express transferrin receptors [28].

Combining iron deficiency with stages of development produces the maximal demand for the brain to mobilize transferrin receptors, but in this context, it is of note that there seems to be an upper limit for the extent to which the brain can adapt. Supporting this notion, the brain failed to increase the expression of transferrin receptors when iron deficiency was subjected to experimental animals during development [31,34]. Therefore, the failure to further increase transferrin receptor expression suggests that the developing brain is particularly vulnerable to severe iron deficiency.

\subsection{The Significance of Iron for Precursor Cells of the Developing Brain}

The availability of iron for the brains' cells must be adequate to undertake several iron-dependent processes, not only to ensure important functions such as cellular division and differentiation, but also the development of the entire brain $[9,11,12]$, e.g., (i) the complex cellular architecture consisting of neuronal axons ensheathed with myelin synthetized by oligodendrocytes, (ii) the complicated brain-barrier interface supported by astrocytes and pericytes to regulate transport in and out of the brain, and (iii) the establishment of an innate immune system in the brain via the formation of microglia. 
The significance of iron for maintaining cellular functions has been covered in former reviews [11,12,35-37]. Iron denotes an essential part as the co-factor of several proteins that can be organized into four groups: Non-enzymatic iron-containing proteins; enzymes that use iron-sulfur as a co-factor; enzymes with an iron-containing heme group; iron-containing enzymes without heme or an iron-containing sulfur group. Together, these four groups of proteins undertake essential iron-dependent cellular events, i.e., electron transfer in the mitochondria, regulation of the expression levels of several genes, regulation of cellular division and differentiation, the binding and transport of oxygen, the synthesis of neurotransmitters (in particular serotonin, norepinephrine, and dopamine), the packaging of neurotransmitters in the axon terminal, the reuptake and degradation of neurotransmitters, and the co-factor function for peroxide- and nitrous oxide-generating enzymes for the functioning of immune cells and the intracellular killing of pathogens [11,12,35-37]. More specifically, for the developing brain, these above-mentioned cellular iron-dependent processes make their contribution to adequately ensure series of important events ranging from early formation of the neuronal tube to later differentiation of neuronal precursor cells into neurons and glial cells. Iron is very important for the formation of the neuronal tube, of which the formation is abrogated during a conditional lack of transferrin receptors $[15,16]$. Severe iron deficiency early in life is also expected to impair the forming brain due to the loss of function of the iron-containing enzyme ribonucleotide reductase that is essential for cellular division [38]. This leads to the major concern that remains unexploited, which predicts that developmental iron deficiency during early gestation can cause a permanent reduction in the number of neuronal and glial cells in spite of iron being supplied later in life, e.g., by admitting iron to the neonate [39]. Concerning glial cells, their formation in the developing brain depends on iron-containing enzymes to ensure cellular division and differentiation. Regarding oligodendrocytes, the lack of iron availability during development is thought to significantly affect their capability to form myelin [11,12,40], and current hypotheses concern whether the formation of myelin is permanently affected, even if the iron supply is restored later in life, hence hinting towards a certain time-window during development where iron availability must be adequate to promote myelination [41].

\subsection{Translational Models of the Brain Development}

The effects of iron deficiency on the brain will likely manifest, with the earlier the impacts taking place representing the worst condition. The gestational ages vary dramatically between mammalian species, which is very important to notify when comparing experimental data on the effects of iron deficiency.

The normal brain development of different mammalian species can be compared (http: //www.translatingtime.org/translate) [42]. Events like neurogenesis and myelination in the brains of rats and mice time wise are almost identical (Figure 1), but differences dramatically occur when comparing rodents and humans. Figure 1 also shows that myelination of the human brain compared to myelination in rats and mice is clearly different regarding both timing and the time period of gestation, i.e., myelination of the human brain takes places around post-conception (PC) day 250, which translates to PC day 30 in the rat. The latter is very important to emphasize, because it shows that opposed to the human brain, myelination takes places after birth in the rodent (around P7), which must be taken into account when designing an experimental study on brain development with the purpose of detecting correlations between species. 


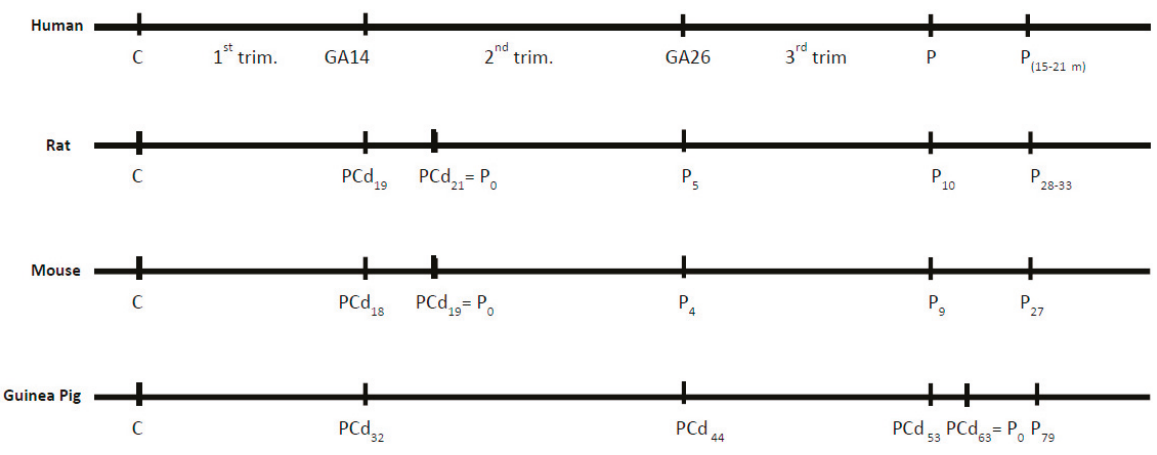

Figure 1. Comparison of the developmental ages of the human, rat, mouse, and guinea pig with respect to myelination of the entire brain. $\mathrm{C}=$ day of conception. Psuffixnr $=$ postnatal day. $\mathrm{PCd}=$ post-conception day. $\mathrm{P}=$ partus. $\mathrm{GA}=$ human gestation week corresponding to $\mathrm{PCd}$. trim. $=$ Trimester.

\subsection{Evidence of Deleterious Effects of Iron Deficiency on the Developing Brain}

The effects of iron deficiency on the gastro-intestinal tract and hematological system are well-described, with the effects being reversible. In contrast, the developing CNS differs from many organs of the body as the impacts are much more prone to be irreversible, even when iron supplies are restored, because the neurons are post-mitotic from the time of birth. The following paragraphs will outline the studies that have been conducted to delineate the effects of iron deficiency on the developing brain, with an emphasis on whether effects were reversible or irreversible. To facilitate the translational relevance, the different species are reported separately based on changes in neuronal and glial functioning, and probable changes in behavior. The selected studies were identified based on a search strategy using PubMed to identify primary research on experimental animal studies and human studies using the following MESH words: iron deficiency, development, brain, or neuro, which revealed approximately 60 relevant studies on experimental animals and observations of the developing human brain during the most recent two decades.

\subsection{Experimental Animals}

The experimental animal data point towards significant effects on the brain during periods of iron deficiency during both the gestational period and after birth (Table 1). The data on small rodents like rats and mice clearly show that the most dramatic effects on the brain development occur when iron deficiency is introduced in pregnancy, whereas data from larger animals like the domestic pig and non-human primates show an influence when iron deficiency is introduced to the offspring (Table 1).

Rodents, especially the laboratory rat, denote the most popular experimental animal for studies of iron deficiency. The gestational period in the rat principally covers the first two trimesters in humans, with the transition between 1st and 2nd trimesters occurring only two days before delivery, whereas the third trimester in the human is reflected in the first weeks after birth in the rat (Figure 1).

The latter points towards a significant difference in the possibilities to compare human and rodent studies, as feeding of this early postnatal rodent no longer occurs via the transfer of nutrients across the placenta, but instead relies on a functioning gastrointestinal system of the neonate. The absorption of iron mainly occurs in the proximal duodenum and is regulated by the iron availability of the duodenal enterocytes. These are mainly under regulation of the general iron status in the neonate via signaling via circulatory levels of hepcidin, which is a hormone synthetized and released from the liver in response to inflammatory stimuli and high circulatory levels of iron [43]. However, inflammation in the neonate may lead to increased levels of hepcidin, as this will negatively affect iron uptake from the gut [6], and hence the rodent as a model of development equal to the third semester in the human fetus 
represents a model of potential risk. On the other hand, for the study of the effects of iron deficiency during development, the early postnatal rodent represents an accessible model with many possibilities for intervention.

Table 1. Studies in experimental animals showing cerebral effects of iron deficiency (ID) subjected to pregnant females or their offspring. References are listed chronologically after species rather than after specific topics, as the many studies addressed more than a single objective. Most data were obtained from studies on rats. Abbreviations: ABR, auditory brainstem responses; DPOAE, distortion product of otoacoustic emissions; IHC, immunohistochemistry; PUFA, long-chain polyunsaturated fatty acids.

\begin{tabular}{|c|c|c|c|c|c|}
\hline Species & Study Design & Method & Offspring Age & Conclusion & Reference \\
\hline \multirow[t]{11}{*}{ Rat } & $\begin{array}{l}\text { ID before conception } \\
+ \text { Gestational ID }\end{array}$ & $\begin{array}{l}\text { Electrophysiological } \\
\text { recordings }\end{array}$ & P15-P30, P65 & $\begin{array}{c}\text { Late term effects on } \\
\text { synapses in hippocampus } \\
\text { in spite of cerebral iron repletion }\end{array}$ & [44] \\
\hline & ID before conception & Behavior & P10-Adult & $\begin{array}{l}\text { Some persistent effects in spite } \\
\text { of iron repletion }\end{array}$ & [45] \\
\hline & $\begin{array}{l}\text { ID before conception } \\
+ \text { Gestational ID }\end{array}$ & $\begin{array}{c}\text { Brain iron } \\
\text { Neurotransmitters }\end{array}$ & P35 & $\begin{array}{l}\text { Behavioral impairments } \\
\text { related to persistent } \\
\text { loss in dopamine in spite } \\
\text { of brain iron reversal }\end{array}$ & [46] \\
\hline & $\begin{array}{l}\text { Gestational ID } \\
+ \text { Lactational ID }\end{array}$ & mRNA & P6-P21 & $\begin{array}{c}\text { ID from E15 leads to } \\
\text { alteration in tyrosine } \\
\text { hydroxylase and reversibility } \\
\text { in behavior }\end{array}$ & [47] \\
\hline & $\begin{array}{l}\text { Gestational ID } \\
+ \text { Lactational ID }\end{array}$ & $\begin{array}{l}\text { mRNA, proteins } \\
\text { morphology }\end{array}$ & P7-P15; P30 & $\begin{array}{c}\text { Lower BDNF, } \\
\text { impaired neuronal differentiation }\end{array}$ & [48] \\
\hline & $\begin{array}{l}\text { ID before conception } \\
+ \text { Gestational ID }\end{array}$ & Behavior & Adult & $\begin{array}{l}\text { Detrimental effects of behavioral } \\
\text { tasks, sex dependency }\end{array}$ & [49] \\
\hline & Gestational ID & Myelination & P25 & $\begin{array}{l}\text { Impaired myelination with } \\
\text { correlation to impairment }\end{array}$ & [50] \\
\hline & Gestational ID & mRNA, proteins & P32-P69 & $\begin{array}{l}\text { Effect of behavior, no effects on } \\
\text { motor skills in hippocampus }\end{array}$ & [51] \\
\hline & $\begin{array}{l}\text { Gestational ID } \\
+ \text { Lactational ID }\end{array}$ & Behavior & P65 & $\begin{array}{l}\text { Permanent changes } \\
\text { in behavioral tasks }\end{array}$ & [52] \\
\hline & $\begin{array}{l}\text { Gestational ID } \\
+ \text { Lactational ID }\end{array}$ & $\begin{array}{l}\text { mRNA } \\
\text { morphology }\end{array}$ & P7-P65 & $\begin{array}{l}\text { Permanent changes in mRNA } \\
\text { of neuronal markers and dendritic } \\
\text { branching in spite of postnatal } \\
\text { reversal to normal diet }\end{array}$ & [53] \\
\hline & Gestational ID & mRNA, T3, T4 & P12 & Marked reduction in $\mathrm{T} 3, \mathrm{~T} 4$ & [54] \\
\hline \multirow[t]{8}{*}{ Rat } & $\begin{array}{l}\text { ID before conception } \\
+ \text { Gestational ID }\end{array}$ & ABR, DPOAE & P0-P45 & $\begin{array}{l}\text { First trimester displays } \\
\text { profound changes in auditory } \\
\text { brain stem response }\end{array}$ & [55] \\
\hline & $\begin{array}{l}\text { Gestational ID } \\
+ \text { Lactational ID }\end{array}$ & MRI, NMR & P7-56 & $\begin{array}{l}\text { Restoration of brain iron, permanent } \\
\text { size reduction in hippocampus and } \\
\text { neurochemical hall-markers in spite } \\
\text { of postnatal reversal to normal diet }\end{array}$ & [56] \\
\hline & Gestational ID & mRNA & P7-P56 & $\begin{array}{l}\text { Impaired formation of neuronal } \\
\text { network and impaired neuronal } \\
\text { plasticity in spite of postnatal } \\
\text { reversal to normal diet }\end{array}$ & [57] \\
\hline & Gestational ID & Morphology & $\mathrm{P} 21-\mathrm{P} 40$ & $\begin{array}{l}25 \% \text { reduction in dendritic length } \\
20 \% \text { reduction in axonal diameter }\end{array}$ & [58] \\
\hline & $\begin{array}{l}\text { ID before conception } \\
+ \text { Gestational ID }\end{array}$ & $A B R$ & P40 & $\begin{array}{c}\text { Increased ABR latencies in ID } \\
\text { depending on stage of ID }\end{array}$ & [59] \\
\hline & $\begin{array}{l}\text { Gestational ID } \\
+ \text { Lactational ID }\end{array}$ & mRNA & P10-P15 & $\begin{array}{l}\text { Elevated angiogenic/vasculogenic } \\
\text { signaling with increased blood } \\
\text { vessel complexity }\end{array}$ & [60] \\
\hline & $\begin{array}{l}\text { ID before conception } \\
\quad+\text { gestational ID }\end{array}$ & mRNA, T3, T4 & E13-P10 & $\begin{array}{l}\text { Marked reduction in } \mathrm{T} 3, \mathrm{~T} 4 \\
\text { Lowering of thyroid hormone } \\
\text { responsive genes }\end{array}$ & [61] \\
\hline & Embryonic brain & mRNA & $\begin{array}{l}\text { Not available } \\
\text { (Cultures at E16) }\end{array}$ & $\begin{array}{l}\text { DFO-induced ID lowers expression } \\
\text { of series of markers of dendritic } \\
\text { and synaptic development, } \\
\text { and mitochondrial function }\end{array}$ & [62] \\
\hline
\end{tabular}


Table 1. Cont.

\begin{tabular}{|c|c|c|c|c|c|}
\hline \multirow[t]{2}{*}{ Species } & Study Design & Method & Offspring Age & Conclusion & Reference \\
\hline & Gestational ID & Tactile stimuli & P1-P32 & $\begin{array}{c}\text { Tactile stimuli reverse defect } \\
\text { myelination and alteration } \\
\text { in oligodendrocytes and microglia, } \\
\text { but not astrocytes }\end{array}$ & [63] \\
\hline \multirow[t]{2}{*}{ Rat } & Gestational ID & Pro/anti-oxidant & P0-P70 & $\begin{array}{l}\text { Age- and iron-dependent levels } \\
\text { of oxidative stress profiling }\end{array}$ & {$[64]$} \\
\hline & Gestational ID & mRNA, IHC & P21, P35 & $\begin{array}{l}\text { Defect myelination, } \\
\text { alteration in glial cells }\end{array}$ & {$[65]$} \\
\hline \multirow[t]{2}{*}{ Mouse } & $\begin{array}{l}\text { Gestational ID } \\
\text { Brain iron }\end{array}$ & Hematology & E17-E18 & $\begin{array}{l}\text { Effect of brain weight, } \\
\text { lower brain iron }\end{array}$ & {$[66]$} \\
\hline & ID in offspring & Brain iron & Adult & $\begin{array}{l}\text { Correction of cerebral ID } \\
\text { with parenteral iron }\end{array}$ & {$[67]$} \\
\hline \multirow[t]{2}{*}{ Guinea Pig } & $\begin{array}{l}\text { Gestational ID } \\
+ \text { Lactational ID }\end{array}$ & $\mathrm{ABR}$ & P9-P24 & $\begin{array}{c}\text { Effect of ABR in ID } \\
\text { Part restoration } \\
\text { with PUFA treatment }\end{array}$ & {$[68]$} \\
\hline & $\begin{array}{r}\text { Gestational ID } \\
+ \text { Lactational ID }\end{array}$ & $\mathrm{ABR}$ & P24 & Effect of ABR in ID & {$[69,70]$} \\
\hline \multirow[t]{4}{*}{ Domestic Pig } & $\begin{array}{r}\text { Gestational ID } \\
+ \text { Lactational ID }\end{array}$ & Cognitive tasks & $0-4$ weeks after birth & No cognitive deficits & {$[71]$} \\
\hline & ID in offspring & MRI & $0-6$ weeks after birth & $\begin{array}{c}\text { Cerebral ID, } \\
\text { alteration in brain tissue } \\
\text { composition persists in spite } \\
\text { of iron repletion }\end{array}$ & {$[72]$} \\
\hline & Lactational ID & RNA analysis & 4 weeks after birth & $\begin{array}{l}\text { Change in hippocampal DNA } \\
\text { methylation and gene regulation }\end{array}$ & [73] \\
\hline & Gestational ID & MRI, IHC & PD 2-30 & $\begin{array}{l}\text { ID after PD } 14 \text { detriments } \\
\text { white matter }\end{array}$ & [74] \\
\hline \multirow[t]{5}{*}{ Monkey } & ID in offspring & 1H NMR & Infancy & $\begin{array}{l}\text { Change in metabolomic } \\
\text { profile in CSF }\end{array}$ & {$[75]$} \\
\hline & ID in offspring & Proteomic & Infancy & $\begin{array}{l}\text { Persistent change in proteomic } \\
\text { profile in CSF }\end{array}$ & {$[76]$} \\
\hline & ID in offspring & $1 \mathrm{H}$ NMR & Infancy & $\begin{array}{l}\text { Metabolomic profile in CSF } \\
\text { predicts effects of ID } \\
\text { on brain iron metabolism }\end{array}$ & {$[77]$} \\
\hline & ID in offspring & Cognitive tasks & Infancy & $\begin{array}{l}\text { Only initial cognitive } \\
+ \text { behavioral deficits }\end{array}$ & {$[78]$} \\
\hline & $\begin{array}{l}\text { Gestational ID } \\
+ \text { Lactational ID }\end{array}$ & Cognitive tasks & Infancy & $\begin{array}{l}\text { Cognitive and emotional effects } \\
\text { present, but vary with protocol }\end{array}$ & [79] \\
\hline
\end{tabular}

The studies pertained on the developing rodent brain all point towards a deleterious effect of dietary iron deficiency subjected to the mother during pregnancy (Table 1). The effects range from observations based on a direct comparison with normal fed mothers to reports on permanent effects on the brain of the offspring in spite of iron being admitted even early after birth. The effects on the developing rat brain concern structural, biochemical, and behavioral impairments (Table 1). Structurally, influences include structural defects in general brain development [48], and more specifically, the development of dendritic length and arborization, and effects on the formation of synapses [44,53,57,58]. A particular focus in many studies has been the effects of changes in the expression level of genes related to the functioning of synaptic transmission [55,59], vascularization [55], and hormones improving metabolism [61]. Studies have also reported on defects in the synthesis of monoaminergic neurotransmitters [46,47,57], and growth factors [48]. Additionally, studies have reported on behavioral disturbances [44,49,51,52]. A single study has reported on the impaired development of glial cells [65] and the impaired formation of myelin has also been reported $[44,63,65]$, suggesting that earlier studies demonstrating that changes in the profiles of fatty acids in phospholipids are present in iron deficiency relate back to the functioning of the developing oligodendrocytes [11-13,40].

The significance of dietary iron deficiency on the developing mouse has gained less attention than that of the rat. Iron deficiency negatively affects the brain weight, iron content, and formation of oligodendrocytes and their myelination [66,80]. As previously mentioned, genetic depletion 
of the transferrin receptor in the mouse results in severe fetal effects and impaired neurotransmitter formation $[15,16]$. In the guinea pig, a series of studies have been made on neural transmission in the brain stem, and reportedly deleterious effects of iron deficiency were partly restored by dietary supplementation with polyunsaturated fatty acids, indicating a beneficial effect on otherwise impaired myelination [72-74].

Most studies of larger animals have been conducted in postnatal animals, which, for practical reasons, make this approach durable [8]. Studies of gestational iron deficiency performed in the domestic pig report on impaired myelination, but without cognitive effects [72]. Impaired myelination was also reported in piglets, who were only subjected to postnatal iron deficiency [75]. Interestingly, epigenetic regulation is also affected when iron deficiency is present in the piglet brain [74]. Another intriguing study using MRI reports on permanent changes in the brain of the domestic pig in spite of the reversal of brain iron with dietary treatment [73].

In terms of the non-human primate brain, a single study has reported on cognitive effects following gestational iron deficiency, but the effects were not consistent and were largely dependent on the induced dietary regimen [79]. Studies on iron deficiency induced in the offspring have demonstrated that this led to significant changes in nuclear magnetic resonance (NMR)-detectable metabolites and proteomic profiles in CSF, clearly hinting towards impaired cerebral metabolism [76,77]. Another study has concluded that iron deficiency subjected to the offspring led to behavioral deficits that were compensable, suggesting that the effects of iron deficiency were less deteriorating [78].

\subsection{The Developing Human Brain}

In humans, the brain forms very early, and maternal iron deficiency is likely to impair the developing brain during the entire period of pregnancy. Compiling the studies reporting the negative impact of iron deficiency on the formation of the developing brain in experimental animals, the following factors stand out as being particularly important: The timing and the severity of the iron deficiency regimens. These factors are also very important to keep in mind when considering the impact of iron deficiency or iron deficiency with anaemia in the human brain, as they are likely to be the most determinant concerning whether damage is at risk of being irreversible [81,82]. The effects of iron deficiency on brain development were suggested to include the genesis of dendrites and synapses, hence clearly addressing the effects of iron deficiency on differentiation during formation of the human brain, and specifically suggesting an impact on particular brain regions such as the cerebral cortex (i.e., frontal cortex, prefrontal-striatal network, auditive cortex), hippocampus, and striatum $[3,82]$. Prior studies were clearly limited in access to measurements on brain functioning in real-time and merely relied on correlations between the iron status measured in blood and putative changes in behavior. Infants with low cord-blood s-ferritin and haemoglobin were prone to negative emotions, and they were less alert and difficult to sooth, and in a 5-year follow-up, the children had poorer behaviour and development outcomes, trouble with auditory language skills, and fine motor skills [82-84]. A single trial showed that maternal anaemia in pregnancy could be linked to $14 \%$ of cases of mental retardation at a 7-year follow-up. It should, however, also be kept in mind that iron deficiency in humans is not likely to be as extreme as can be instituted in experimental animals, and this should indeed be kept in mind when translating data from animal models to hypotheses in human physiology. A valid indicator of the severity in humans is seen when iron deficiency is complicated with anemia. In this situation, the iron transport to the fetus will be prioritized over the maternal iron need unless a certain threshold (ferritin $\approx 14 \mu \mathrm{g} / \mathrm{L}$ ) is met $[8,83]$. Furthermore, in severe cases of iron deficiency with anemia, fetal erythropoiesis is more highly prioritized than neurodevelopment [33,58].

The data obtained from several studies in humans all congregate towards the conclusion that there are significant effects on brain development, both pre-and postnatally (Table 2). Compared to the more extreme situations that invariably relate to the experimental animals, the impairment in iron statuses is not so dramatic in the human brain, and hence also the reported results [83-106]. The studies of humans have mainly involved structural analyses on brain growth in real-time [83-89], neurophysiological measurements 
of basic functions related to myelination and cranial nerve development [90-96], and neuropsychological tests of cognition, memory, and personal traits [97-106].

Table 2. Studies of humans showing cerebral effects of iron deficiency (ID) or iron deficiency with anemia (IDA) subjected to pregnant females or their offspring. References are listed after specific topics. Abbreviations: ABR, auditory brainstem responses; LBW, low birth weight; No. F/O, numbers of patients (females/offspring); PND, postnatal day; VEP, visually evoked potentials.

\begin{tabular}{|c|c|c|c|c|c|}
\hline Study Objective & Evidence of ID & Infant Age & No. F/O & Conclusion & Reference \\
\hline \multicolumn{6}{|l|}{ Fetal brain development } \\
\hline Normal development & Maternal IDA & PND $3-5$ days & $/ 70$ & $\begin{array}{l}\text { Maternal IDA adversely affects } 1 \\
\text { hippocampal morphogenesis and fetal } \\
\text { production of BDNF }\end{array}$ & [83] \\
\hline Normal development & Maternal IDA & 18 months & $331 /$ & $\begin{array}{c}\text { Maternal ID at } 34 \text { weeks associated } \\
\text { with lower motor scores }\end{array}$ & [84] \\
\hline Normal development & Normal iron status & $7-11$ years & $/ 39$ & $\begin{array}{l}\text { MRI iron content in basal ganglia } \\
\text { influences spatial intelligence }\end{array}$ & [85] \\
\hline Brain connectivity & Infant IDA & Mean 21.5 years & $/ 31$ & $\begin{array}{l}\text { Different patterns of functional } \\
\text { connectivity between former IDA } \\
\text { and control young adults }\end{array}$ & [86] \\
\hline Risk of schizophrenia & Maternal IDA & Prospective study & $/ 6872$ & $\begin{array}{l}\text { Maternal ID as risk factor for } \\
\text { schizophrenia in offspring }\end{array}$ & [87] \\
\hline Cerebral functions & IDA in adults & Adult & $/ 2957$ & $\begin{array}{l}\text { IDA associated with increases } \\
\text { in psychiatric disorders }\end{array}$ & [88] \\
\hline Autism & Infant IDA & $2-7$ years & $/ 102$ & No evidence between IDA and autism & [89] \\
\hline \multicolumn{6}{|l|}{ Basic cerebral functions } \\
\hline $\mathrm{ABR}$ & LBW & PND 42-6 months & $/ 285$ & $\begin{array}{c}\text { Iron supplements did not improve ABR, } \\
\text { but ABR was discarded as measure } \\
\text { of impairment in ID }\end{array}$ & [90] \\
\hline $\mathrm{ABR}$ & Maternal IDA & PND 2, 3 months & & $\begin{array}{l}\text { ABR closely related to severity of maternal } \\
\text { and neonatal iron status }\end{array}$ & [91] \\
\hline $\mathrm{ABR}$ & Infant IDA & 6-24 months & & Prolonged latencies in ABR traces in IDA & [92] \\
\hline ABR & Infant IDA & $<48 \mathrm{~h}$ & $/ 90$ & $\begin{array}{c}\text { Latent iron deficiency associated } \\
\text { with abnormal ABR }\end{array}$ & [93] \\
\hline VEP & Infant IDA & 6-24 months & $/ 50$ & $\begin{array}{l}\text { Negative correlation between severity } \\
\text { of IDA and VEP latencies }\end{array}$ & [94] \\
\hline Eye-blinking rates & Infant IDA & 9-10 months & 61 & $\begin{array}{l}\text { Increased eye-blink rats consistent with low } \\
\text { dopamine function in IDA }\end{array}$ & [95] \\
\hline EEG recordings & Infant IDA & 0,9 months & $/ 80$ & ID associated with EEG asymmetry & [96] \\
\hline \multicolumn{6}{|l|}{ Memory } \\
\hline Memory & Infant IDA & $8-10$ years & $/ 201$ & $\begin{array}{l}\text { Iron supplementation substantially restores } \\
\text { cognitive capabilities }\end{array}$ & [97] \\
\hline Execution, memory & Infant IDA & 19 years & $/ 114$ & $\begin{array}{l}\text { Chronic impairment of functions } \\
\text { related to frontostriatal-connections } \\
\text { (executive functions), and hippocampus } \\
\text { (recognition memory) }\end{array}$ & [98] \\
\hline Recognition memory & Infant IDA & 6-18 months & $/ 209$ & $\begin{array}{l}\text { Sustained effects on memory in } 10 \text {-year } \\
\text { follow-up in spite of oral } \\
\text { supplement in early life }\end{array}$ & [99] \\
\hline \multicolumn{6}{|l|}{ Higher cerebral functions } \\
\hline Social-emotional behavior & Infant IDA & $9-10$ years & $/ 77$ & $\begin{array}{l}\text { Social-emotional behavior } \\
\text { associated with ID }\end{array}$ & [100] \\
\hline Behavior & Normal & $6-8$ years & $/ 264$ & $\begin{array}{l}\text { Fe supplementation in pregnancy without } \\
\text { consistent effect on behavior }\end{array}$ & [101] \\
\hline Cognition & Infant IDA & $1-3$ years & $/ 3$ & $\begin{array}{l}\text { Improvement in cognition once iron } \\
\text { stores were restored }\end{array}$ & [102] \\
\hline Cognition & Infant IDA & Mean age 12.0 & & Reduced cognitive performance & [103] \\
\hline Cognition & Infant IDA & 12 months & $828 / 828$ & $\begin{array}{c}\text { No effect of IDA on cognition } \\
\text { or motor development }\end{array}$ & [104] \\
\hline ADHD symptomology, IQ & Infant IDA & $2.5-5$ years & $/ 123$ & $\begin{array}{l}\text { Effects of early deprivation and ID } \\
\text { on ADHD symptoms and IQ years } \\
\text { after adoption }\end{array}$ & [105] \\
\hline ADHD symptomology & Infant IDA & Mean age 11.0 & & IDA associated with ADHD & [106] \\
\hline
\end{tabular}


Concerning the studies on the development of the brain that took morphological approaches, reports indicate that brain volumes, neurogenesis, and iron content are reduced [83-85]. This also led to permanent defects in neuronal connectivity years after developmental iron deficiency was recovered [91], which was further associated with a higher risk for psychiatric disorders [87,88], but not for causing autism [89].

Influences of impaired sensory function and neuronal development were also attributed to developmental iron deficiency using auditory brainstem responses (ABR) [90-93]. However, at least one study brought the reliability of this measure into question [90] and hinted that changes in ABR can have other explanation. Other studies taking a neurophysiological approach showed impairment in the visual input and general brain activity [94-96], suggesting that, e.g., dopaminergic neurotransmission is affected [95].

Examining higher functional tasks, the impact on structures and their function in the forebrain have been reported in many studies of the hippocampus (various memory tasks) [97-99] and cerebral cortex (social behavior, cognition, association with ADHD) [100,102,103,105,106]. Conversely, behavior was reportedly not affected in two other studies [101,102], which suggest that effects on the developing brain could be subtle unless dramatic maternal iron deficiency occurs.

\section{Conclusions}

The human brain develops throughout the gestational period, ranging from the formation and proliferation of neuroprogenitor cells, to their later migration, and later differentiation into fully developed neurons and glial cells. Severe iron deficiency can negatively impact cell division, neurotic outgrowth and formation of the neuronal network, and myelination in glial cells. Experimental studies in animals, especially the laboratory rat, clearly support that these cellular events can be impacted by developmental iron deficiency. In the human brain, where events in the third semester are reflected in the initial postnatal weeks, reports also point towards the negative impact of iron deficiency during development. The quality of the identified studies reported here, including the number of involved subjects, appears valid, but some limitations subtract the possibilities for overall conclusions. The translational value of the result of the experimental animal is high, but more data obtained in higher animals with a longer gestation than the rodent brain would be appreciated. Concerning the human data, a certain shortage in the number of available studies prevails and more studies monitoring the cerebral function postnatally are needed. With respect to the validity of the results, it must also be emphasized that publication bias may exist towards the demonstration of effects of iron deficiency on brain development. This would leave out negative results that may remain unpublished, and this may play an important role as scientific results on the developing human brain are rather scarce. Investigations on the brain in the gestational period are obviously very complicated, so research on biomarkers from the umbilical cord or chorion villus biopsy would be highly appreciated.

In terms of the prevention of iron deficiency, strategies have not yet been developed to specifically address the developing brain. Supplementation with oral or parenteral iron is possible in pregnancy and postnatally [2], and strategies to halt iron deficiency anemia will likely also improve cerebral iron deficiency as the brain is able to extract iron from the blood due to the expression of transferrin receptors on brain capillaries [39]. Parenteral iron supplementation is being assayed in pregnant women and women with post-partum hemorrhage to generally improve their iron status $[2,4,107,108]$, and this will likely also improve the cerebral iron status.

Author Contributions: Conceptualization, V.M. and T.M. Writing-Original draft preparation, V.M. and T.M.; Writing-Review and editing C.H., A.B.P. and L.L.T.

Funding: V.M. is a PhD student funded by the Innovation Fund Denmark (grant No. 5189-00027) and Pharmacosmos.

Conflicts of Interest: Authors declare no conflicts of interest with respect to this review manuscript. L.L.T. and V.M. are employed by Pharmacosmos. C.H. served on advisory boards for Pharmacosmos. 


\section{Abbreviations}

BBB

blood-brain barrier

CNS central nervous system

$\mathrm{CSF}$ cerebrospinal fluid

\section{References}

1. Zimmermann, M.B.; Hurrell, R.F. Nutritional iron deficiency. Lancet 2007, 370, 511-520. [CrossRef]

2. Breymann, C.; Bian, X.M.; Blanco-Capito, L.R.; Chong, C.; Mahmud, G.; Rehman, R. Expert recommendations for the diagnosis and treatment of iron-deficiency anemia during pregnancy and the postpartum period in the Asia-Pacific region. J. Perinat. Med. 2011, 39, 113-121. [CrossRef]

3. Hernandez-Martinez, C.; Canals, J.; Aranda, N.; Ribot, B.; Escribano, J.; Arija, V. Effects of iron deficiency on neonatal behavior at different stages of pregnancy. Early Hum. Dev. 2011, 87, 165-169. [CrossRef] [PubMed]

4. Khalafallah, A.; Dennis, A.; Bates, J.; Bates, G.; Robertson, I.K.; Smith, L.; Ball, M.J.; Seaton, D.; Brain, T.; Rasko, J.E. A prospective randomized, controlled trial of intravenous versus oral iron for moderate iron deficiency anaemia of pregnancy. J. Int. Med. 2010, 268, 286-295. [CrossRef] [PubMed]

5. Milman, N. Serum ferritin in Danes: Studies of iron status from infancy to old age, during blood donation and pregnancy. Int. J. Hematol. 1996, 63, 103-135. [CrossRef]

6. Camaschella, C. Iron deficiency. Blood 2019, 133, 30-39. [CrossRef] [PubMed]

7. Bashiri, A.; Burstein, E.; Sheiner, E.; Mazor, M. Anemia during pregnancy and treatment with intravenous iron: Review of the literature. Eur. J. Obs. Gyn. Reprod. Biol. 2003, 110, 2-7. [CrossRef]

8. Shao, J.; Lou, J.; Rao, R.; Georgieff, M.K.; Kaciroti, N.; Felt, B.T.; Zhao, Z.Y.; Lozoff, B. Maternal serum ferritin concentration is positively associated with newborn iron stores in women with low ferritin status in late pregnancy. J. Nutr. 2012, 142, 2004-2049. [CrossRef] [PubMed]

9. Duck, K.A.; Connor, J.R. Iron uptake and transport across physiological barriers. Biometals 2016, 29, 573-591. [CrossRef] [PubMed]

10. Dallman, P.R.; Spirito, R.A. Brain iron in the rat: Extremely slow turnover in normal rats may explain long-lasting effects of early iron deficiency. J. Nutr. 1977, 107, 1075-1081. [CrossRef]

11. Beard, J.L. Iron biology in immune function, muscle metabolism and neuronal functioning. J. Nutr. 2001, 131, 568S-579S. [CrossRef] [PubMed]

12. Beard, J. Iron deficiency alters brain development and functioning. J. Nutr. 2003, 133 (Suppl. 1), 1468s-1472s. [CrossRef] [PubMed]

13. Moos, T.; Morgan, E.H. A morphological study of the developmentally regulated transport of iron into the brain. Dev. Neurosci. 2002, 24, 99-105. [CrossRef] [PubMed]

14. Siddappa, A.M.; Rao, R.; Long, J.D.; Widness, J.A.; Georgieff, M.K. The assessment of newborn iron stores at birth: A review of the literature and standards for ferritin concentrations. Neonatology 2007, 92, 73-82. [CrossRef] [PubMed]

15. Hoyle, C.; Henderson, D.J.; Matthews, D.J.; Copp, A.J. Transferrin and its receptor in the development of genetically determined neural tube defects in the mouse embryo. Dev. Dyn. 1996, 207, 35-46. [CrossRef]

16. Matak, P.; Matak, A.; Moustafa, S.; Aryal, D.K.; Benner, E.J.; Wetsel, W.; Andrews, N. Disrupted iron homeostasis causes dopaminergic neurodegeneration in mice. Proc. Natl. Acad. Sci. USA 2016, 113, 3428-3435. [CrossRef] [PubMed]

17. Jefferies, W.A.; Brandon, M.R.; Hunt, S.V.; Williams, A.F.; Gatter, K.C.; Mason, D.Y. Transferrin receptor on endothelium of brain capillaries. Nature 1984, 312, 162-163. [CrossRef]

18. Meyron-Holtz, E.G.; Cohen, L.A.; Fahoum, L.; Haimovich, Y.; Lifshitz, L.; Magid-Gold, I.; Stuemler, T.; Truman-Rosentsvit, M. Ferritin polarization and iron transport across monolayer epithelial barriers in mammals. Front. Pharmacol. 2014, 5, 194. [CrossRef]

19. Fan, K.; Jia, X.; Zhou, M.; Wang, K.; Conde, J.; He, J.; Tian, J.; Yan, X. Ferritin nanocarrier traverses the blood brain barrier and kills glioma. ACS Nano 2018, 12, 4105-4115. [CrossRef]

20. Fiandra, L.; Mazzucchelli, S.; Truffi, M.; Bellini, M.; Sorrentino, L.; Corsi, F. In vitro permeation of FITC-loaded ferritins across a rat blood-brain barrier: A model to study the delivery of nanoformulated molecules. J. Vis. Exp. 2016, 114. [CrossRef] 
21. Chiou, B.; Neal, E.H.; Bowman, A.B.; Lippmann, E.S.; Simpson, I.A.; Connor, J.R. Endothelial cells are critical regulators of iron transport in a model of the human blood-brain barrier. J. Cereb. Blood Flow Metab. 2018. [CrossRef]

22. Skjørringe, T.; Burkhart, A.; Johnsen, K.B.; Moos, T. Divalent metal transporter 1 (DMT1) in the brain: Implications for a role in iron transport at the blood-brain barrier, and neuronal and glial pathology. Front. Mol. Neurosci. 2015, 8, 19. [PubMed]

23. Burkhart, A.; Skjørringe, T.; Johnsen, K.B.; Siupka, P.; Thomsen, L.B.; Nielsen, M.S.; Thomsen, L.L.; Moos, T. Expression of iron-related proteins at the neurovascular unit supports reduction and reoxidation of iron for transport through the blood-brain barrier. Mol. Neurobiol. 2016, 53, 7237-7253. [CrossRef] [PubMed]

24. Skjørringe, T.; Møller, L.B.; Moos, T. Impairment of interrelated iron- and copper homeostatic mechanisms in brain contributes to the pathogenesis of neurodegenerative disorders. Front. Pharmacol. 2012, 3, 169. [CrossRef] [PubMed]

25. Theil, E.T. Ferritin: Structure, gene regulation, and cellular function in animals, plants, and microorganisms. Ann. Rev. Biochem. 1987, 56, 289-315. [CrossRef] [PubMed]

26. d'Estaintot, B.L.; Santambrogio, P.; Granier, T.; Gallois, B.; Chevalier, J.M.; Precigoux, G.; Levi, S.; Arosio, P. Crystal structure and biochemical properties of the human mitochondrial ferritin and its mutant Ser144Ala. J. Mol. Biol. 2004, 340, 277-293.

27. Møllgård, K.; Dziegielewska, K.M.; Saunders, N.R.; Zakut, H.; Soreq, H. Synthesis and localization of plasma proteins in the developing human brain. Integrity of the fetal blood-brain barrier to endogenous proteins of hepatic origin. Dev. Biol. 1988, 128, 207-221. [CrossRef]

28. Moos, T.; Oates, P.S.; Morgan, E.H. Expression of the neuronal transferrin receptor is age dependent and susceptible to iron deficiency. J. Comp. Neurol. 1998, 398, 420-430. [CrossRef]

29. Knutson, M.D. Non-transferrin-bound iron transporters. Free Radic. Biol. Med. 2019, 133, 101-111. [CrossRef]

30. Taylor, E.M.; Morgan, E.H. Developmental changes in transferrin and iron uptake by the brain in the rat. Dev. Brain Res. 1990, 55, 35-42. [CrossRef]

31. Moos, T.; Morgan, E.H. Restricted transport of anti-transferrin receptor antibody [OX26] through the blood-brain barrier in the rat. J. Neurochem. 2001, 79, 119-129. [CrossRef] [PubMed]

32. Chen, Q.; Connor, J.R.; Beard, J.L. Brain iron, transferrin and ferritin concentrations are altered in developing iron-deficient rats. J. Nutr. 1995, 125, 1529-1535. [PubMed]

33. Laskey, J.; Webb, I.; Schulman, H.M.; Ponka, P. Evidence that transferrin supports cell proliferation by supplying iron for DNA synthesis. Exp. Cell Res. 1988, 176, 87-95. [CrossRef]

34. Taylor, E.M.; Crowe, A.; Morgan, E.H. Transferrin and iron uptake by the brain: Effects of altered iron status. J. Neurochem. 1991, 57, 1584-1592. [CrossRef]

35. Richard, C.; John, M.; Wrigglesworth, H.B. Iron-dependent enzymes in mammalian systems. In Transport and Storage; Chapter: Iron-Dependent Enzymes in Mammalian Systems; Ponka, P., Schulman, H.M., Woodworth, R.C., Richter, G.W., Eds.; CRC Press: Stockholm, Sweden, 1990; pp. 17-39.

36. Lozoff, B.; Georgieff, M.K. Iron deficiency and brain development. Semin. Pediatr. Neurol. 2006, 13, 158-165. [CrossRef] [PubMed]

37. Georgieff, M.K. Nutrition and the developing brain: Nutrient priorities and measurement. Am. J. Clin. Nutr. 2007, 85, 614-620.

38. Wright, J.A.; Chan, A.K.; Choy, B.K.; Hurta, R.A.; McClarty, G.A.; Tagger, A.Y. Regulation and drug resistance mechanisms of mammalian ribonucleotide reductase, and the significance to DNA synthesis. Biochem. Cell Biol. 1990, 68, 1364-1371.

39. Moos, T.; Skjorringe, T.; Thomsen, L.L. Iron deficiency and iron treatment in the fetal developing brain-A pilot study introducing an experimental rat model. Reprod. Health 2018, 15 (Suppl. 1), 93. [CrossRef]

40. Oloyede, O.B.; Folayan, A.T.; Odutuga, A.A. Effects of low-iron status and deficiency of essential fatty acids on some biochemical constituents of rat brain. Biochem. Int. 1992, 27, 913-922.

41. Möller, H.E.; Bossoni, L.; Connor, J.R.; Crichton, R.R.; Does, M.D.; Ward, R.J.; Zecca, L.; Zucca, F.A.; Ronen, I. Iron, myelin, and the brain: Neuroimaging meets neurobiology. Trends Neurosci. 2019, 42, 384-401. [CrossRef]

42. Workman, A.D.; Charvet, C.J.; Clancy, B.; Darlington, R.B.; Finlay, B.L. Modeling transformations of neurodevelopmental sequences across mammalian species. J. Neurosci. 2013, 33, 7368-7383. [CrossRef] [PubMed] 
43. Ganz, T. Hepcidin, a key regulator of iron metabolism and mediator of anemia of inflammation. Blood 2003, 102, 783-788. [CrossRef] [PubMed]

44. Jorgenson, L.A.; Sun, M.; O'Connor, M.; Georgieff, M.K. Fetal iron deficiency disrupts the maturation of synaptic function and efficacy in area CA1 of the developing rat hippocampus. Hippocampus 2005, 15, 1094-1102. [CrossRef] [PubMed]

45. Eseh, R.; Zimmerberg, B. Age-dependent effects of gestational and lactational iron deficiency on anxiety behavior in rats. Behav. Brain Res. 2005, 164, 214-221. [CrossRef] [PubMed]

46. Felt, B.T.; Beard, J.L.; Schallert, T.; Shao, J.; Aldridge, J.W.; Connor, J.R.; Georgieff, M.K.; Lozoff, B. Persistent neurochemical and behavioral abnormalities in adulthood despite early iron supplementation for perinatal iron deficiency anemia in rats. Behav. Brain Res. 2006, 171, 261-270. [CrossRef] [PubMed]

47. Unger, E.L.; Paul, T.; Murray-Kolb, L.E.; Felt, B.; Jones, B.C.; Beard, J.L. Early iron deficiency alters sensorimotor development and brain monoamines in rats. J. Nutr. 2007, 137, 118-124. [CrossRef] [PubMed]

48. Tran, P.V.; Carlson, E.S.; Fretham, S.J.; Georgieff, M.K. Early-life iron deficiency anemia alters neurotrophic factor expression and hippocampal neuron differentiation in male rats. J. Nutr. 2008, 138, 2495-2501. [CrossRef]

49. Bourque, S.L.; Iqbal, U.; Reynolds, J.N.; Adams, M.A.; Nakatsu, K. Perinatal iron deficiency affects locomotor behavior and water maze performance in adult male and female rats. J. Nutr. 2008, 138, 931-937. [CrossRef]

50. Wu, L.L.; Zhang, L.; Shao, J.; Qin, Y.F.; Yang, R.W.; Zhao, Z.Y. Effect of perinatal iron deficiency on myelination and associated behaviors in rat pups. Behav. Brain Res. 2008, 188, 263-270. [CrossRef]

51. McEchron, M.D.; Cheng, A.Y.; Liu, H.; Connor, J.R.; Gilmartin, M.R. Perinatal nutritional iron deficiency permanently impairs hippocampus-dependent trace fear conditioning in rats. Nutr. Neurosci. 2005, 8, 195-206. [CrossRef]

52. Schmidt, A.T.; Ladwig, E.K.; Wobken, J.D.; Grove, W.M.; Georgieff, M.K. Delayed alternation performance in rats following recovery from early iron deficiency. Physiol. Behav. 2010, 101, 503-508. [CrossRef]

53. Brunette, K.E.; Tranm, P.V.; Wobken, J.D.; Carlson, E.S.; Georgieff, M.K. Gestational and neonatal iron deficiency alters apical dendrite structure of CA1 pyramidal neurons in adult rat hippocampus. Dev. Neurosci. 2010, 32, 238-248. [CrossRef]

54. Bastian, T.W.; Prohaska, J.R.; Georgieff, M.K.; Anderson, G.W. Perinatal iron and copper deficiencies alter neonatal rat circulating and brain thyroid hormone concentrations. Endocrinology 2010, 151, 4055-4065. [CrossRef]

55. Mihaila, C.; Schramm, J.; Strathmann, F.G.; Lee, D.L.; Gelein, R.M.; Luebke, A.E.; Mayer-Pröschel, M. Identifying a window of vulnerability during fetal development in a maternal iron restriction model. PLoS ONE 2011, 6, e17483. [CrossRef]

56. Rao, R.; Tkac, I.; Schmidt, A.T.; Georgieff, M.K. Fetal and neonatal iron deficiency causes volume loss and alters the neurochemical profile of the adult rat hippocampus. Nutr. Neurosci. 2011, 14, 59-65. [CrossRef]

57. Callahan, L.S.; Thibert, K.A.; Wobken, J.D.; Georgieff, M.K. Early-life iron deficiency anemia alters the development and long-term expression of parvalbumin and perineuronal nets in the rat hippocampus. Dev. Neurosci. 2013, 35, 427-436. [CrossRef]

58. Greminger, A.R.; Lee, D.L.; Shrager, P.; Mayer-Proschel, M. Gestational iron deficiency differentially alters the structure and function of white and gray matter brain regions of developing rats. J. Nutr. 2014, 144, 1058-1066. [CrossRef]

59. Greminger, A.R.; Mayer-Proschel, M. Identifying the threshold of iron deficiency in the central nervous system of the rat by the auditory brainstem response. ASN Neuro 2015, 7. [CrossRef]

60. Bastian, T.W.; Santarriaga, S.; Nguyen, T.A.; Prohaska, J.R.; Georgieff, M.K.; Anderson, G.W. Fetal and neonatal iron deficiency but not copper deficiency increases vascular complexity in the developing rat brain. Nutr. Neurosci. 2015, 18, 365-375. [CrossRef]

61. Hu, X.; Wang, R.; Shan, Z.; Dong, Y.; Zheng, H.; Jesse, F.F.; Rao, E.; Takahashi, E.; Li, W.; Teng, W.; et al. Perinatal iron deficiency-induced hypothyroxinemia impairs early brain development regardless of normal iron levels in the neonatal brain. Thyroid 2016, 26, 891-900. [CrossRef]

62. Bastian, T.W.; von Hohenberg, W.C.; Mickelson, D.J.; Lanier, L.M.; Georgieff, M.K. Iron deficiency impairs developing hippocampal neuron gene expression, energy metabolism, and dendrite complexity. Dev. Neurosci. 2016, 38, 264-276. [CrossRef] 
63. Horiquini-Barbosa, E.; Gibb, R.; Kolb, B.; Bray, D.; Lachat, J.J. Tactile stimulation partially prevents neurodevelopmental changes in visual tract caused by early iron deficiency. Brain Res. 2017, 1657, 130-139. [CrossRef]

64. Vieyra-Reyes, P.; Millan-Aldaco, D.; Palomero-Rivero, M.; Jimenez-Garces, C.; Hernandez-Gonzalez, M.; Caballero-Villarraso, J. An iron-deficient diet during development induces oxidative stress in relation to age and gender in Wistar rats. J. Physiol. Biochem. 2017, 73, 99-110. [CrossRef]

65. Rosato-Siri, M.V.; Marziali, L.; Guitart, M.E.; Badaracco, M.E.; Puntel, M.; Pitossi, F.; Correale, J.; Pasquini, J.M. Iron availability compromises not only oligodendrocytes but also astrocytes and microglial cells. Mol. Neurobiol. 2018, 55, 1068-1081. [CrossRef]

66. Hubbard, A.C.; Bandyopadhyay, S.; Wojczyk, B.S.; Spitalnik, S.L.; Hod, E.A.; Prestia, K.A. Effect of dietary iron on fetal growth in pregnant mice. Comp. Med. 2013, 63, 127-135.

67. Unger, E.L.; Earley, C.J.; Thomsen, L.L.; Jones, B.C.; Allen, R.P. Effects of IV iron isomaltoside-1000 treatment on regional brain iron status in an iron-deficient animal. Neuroscience 2013, 246, 179-185. [CrossRef]

68. Jougleux, J.L.; Rioux, F.M.; Church, M.W.; Fiset, S.; Jacques, H.; Surette, M.E. Dietary LC-PUFA in iron-deficient anaemic pregnant and lactating guinea pigs induce minor defects in the offsprings' auditory brainstem responses. Nutr. Neurosci. 2016, 19, 447-460. [CrossRef]

69. Jougleux, J.L.; Rioux, F.M.; Church, M.W.; Fiset, S.; Surette, M.E. Mild maternal iron deficiency anemia during pregnancy and lactation in guinea pigs causes abnormal auditory function in the offspring. J. Nutr. 2011, 141, 1390-1395. [CrossRef]

70. Jougleux, J.L.; Rioux, F.M.; Church, M.W.; Fiset, S.; Surette, M.E. Mild iron deficiency anaemia during pregnancy and lactation in guinea pigs alters amplitudes and auditory nerve velocity, but not brainstem transmission times in the offspring's auditory brainstem response. Nutr. Neurosci. 2014, 17, 37-47. [CrossRef]

71. Antonides, A.; van Laarhoven, S.; van der Staay, F.J.; Nordquist, R.E. Non-anemic iron deficiency from birth to weaning does not impair growth or memory in piglets. Front. Behav. Neurosci. 2016, 10, 112. [CrossRef]

72. Mudd, A.T.; Fil, J.E.; Knight, L.C.; Dilger, R.N. Dietary iron repletion following early-life dietary iron deficiency does not correct regional volumetric or diffusion tensor changes in the developing pig brain. Front. Neurol. 2017, 8, 735. [CrossRef]

73. Schachtschneider, K.M.; Liu, Y.; Rund, L.A.; Madsen, O.; Johnson, R.W.; Groenen, M.A.; Schook, L.B. Impact of neonatal iron deficiency on hippocampal DNA methylation and gene transcription in a porcine biomedical model of cognitive development. BMC Genom. 2016, 17, 856. [CrossRef]

74. Leyshon, B.J.; Radlowski, E.C.; Mudd, A.T.; Steelman, A.J.; Johnson, R.W. Postnatal iron deficiency alters brain development in piglets. J. Nutr. 2016, 146, 1420-1427. [CrossRef]

75. Rao, R.; Ennis, K.; Oz, G.; Lubach, G.R.; Georgieff, M.K.; Coe, C.L. Metabolomic analysis of cerebrospinal fluid indicates iron deficiency compromises cerebral energy metabolism in the infant monkey. Neurochem. Res. 2013, 38, 573-580. [CrossRef]

76. Rao, R.; Ennis, K.; Lubach, G.R.; Lock, E.F.; Georgieff, M.K.; Coe, C.L. Metabolomic analysis of CSF indicates brain metabolic impairment precedes hematological indices of anemia in the iron-deficient infant monkey. Nutr. Neurosci. 2018, 21, 40-48. [CrossRef]

77. Patton, S.M.; Coe, C.L.; Lubach, G.R.; Connor, J.R. Quantitative proteomic analyses of cerebrospinal fluid using iTRAQ in a primate model of iron deficiency anemia. Dev. Neurosci. 2012, 34, 354-365. [CrossRef]

78. Lubach, G.R.; Coe, C.L. Selective impairment of cognitive performance in the young monkey following recovery from iron deficiency. J. Dev. Behav. Pediatr. JDBP 2008, 29, 11-17. [CrossRef]

79. Golub, M.S.; Hogrefe, C.E.; Germann, S.L.; Capitanio, J.P.; Lozoff, B. Behavioral consequences of developmental iron deficiency in infant rhesus monkeys. Neurotox. Teratol. 2006, 28, 3-17. [CrossRef]

80. Guitart, M.E.; Vence, M.; Correale, J.; Pasquini, J.M.; Rosato-Siri, M.V. Ontogenetic oligodendrocyte maturation through gestational iron deprivation: The road not taken. Glia 2019, 67, 1760-1774. [CrossRef]

81. Szudzik, M.; Starzyński, R.R.; Jończy, A.; Mazgaj, R.; Lenartowicz, M.; Lipiński, P. Iron supplementation in suckling piglets: An ostensibly easy therapy of neonatal iron deficiency anemia. Pharmaceuticals 2018, 11, 128. [CrossRef]

82. Lozoff, B. Iron deficiency and child development. Food Nutr. Bull. 2007, 28 (Suppl. 4), S560-S671. [CrossRef]

83. Basu, S.; Kumar, D.; Anupurba, S.; Verma, A.; Kumar, A. Effect of maternal iron deficiency anemia on fetal neural development. J. Perinatol. 2018, 38, 233-239. [CrossRef] 
84. Berglund, S.K.; Torres-Espinola, F.J.; Garcia-Valdes, L.; Segura, M.; Martinez-Zaldivar, C.; Padilla, C.; Rueda, R.; Pérez García, M.; McArdle, H.J.; Campoy, C. The impacts of maternal iron deficiency and being overweight during pregnancy on neurodevelopment of the offspring. Br. J. Nutr. 2017, 118, 533-540. [CrossRef]

85. Carpenter, K.L.H.; Li, W.; Wei, H.; Wu, B.; Xiao, X.; Liu, C.; Worley, G.; Egger, H.L. Magnetic susceptibility of brain iron is associated with childhood spatial IQ. Neuro Image 2016, 132, 167-174. [CrossRef]

86. Algarin, C.; Karunakaran, K.D.; Reyes, S.; Morales, C.; Lozoff, B.; Peirano, P.; Biswal, B. Differences on brain connectivity in adulthood are present in subjects with iron deficiency anemia in infancy. Front. Aging Neurosci. 2017, 9, 54. [CrossRef]

87. Insel, B.J.; Schaefer, C.A.; McKeague, I.W.; Susser, E.S.; Brown, A.S. Maternal iron deficiency and the risk of schizophrenia in offspring. Arch. Gen. Psychiatry 2008, 65, 1136-1144. [CrossRef]

88. Chen, M.H.; Su, T.P.; Chen, Y.S.; Hsu, J.W.; Huang, K.L.; Chang, W.H.; Chen, T.J.; Bai, Y.M. Association between psychiatric disorders and iron deficiency anemia among children and adolescents: A nationwide population-based study. BMC Psychiatry 2013, 13, 161. [CrossRef]

89. Lane, R.; Kessler, R.; Buckley, A.W.; Rodriguez, A.; Farmer, C.; Thurm, A.; Swedo, S.; Felt, B. Evaluation of periodic limb movements in sleep and iron status in children with autism. Pediatr. Neurol. 2015, 53, 343-349. [CrossRef]

90. Berglund, S.K.; Westrup, B.; Haraldsson, E.; Engstrom, B.; Domellof, M. Effects of iron supplementation on auditory brainstem response in marginally LBW infants. Pediatr. Res. 2011, 70, 601-606. [CrossRef]

91. ElAlfy, M.S.; El-Farrash, R.A.; Taha, H.M.; Ismail, E.A.; Mokhtar, N.A. Auditory brainstem response in full-term neonates born to mothers with iron deficiency anemia: Relation to disease severity. J. Matern.-Fetal Neonatal Med. 2018, 4, 1-8. [CrossRef]

92. Sundagumaran, H.; Seethapathy, J. Auditory brainstem response in infants with iron deficiency anemia. Int. J. Pediatr. Otorhinolaryngol. 2019, 117, 78-81. [CrossRef] [PubMed]

93. Choudhury, V.; Amin, S.B.; Agarwal, A.; Srivastava, L.M.; Soni, A.; Saluja, S. Latent iron deficiency at birth influences auditory neural maturation in late preterm and term infants. Am. J. Clin. Nutr. 2015, 102, 1030-1034. [CrossRef] [PubMed]

94. Monga, M.; Walia, V.; Gandhi, A.; Chandra, J.; Sharma, S. Effect of iron deficiency anemia on visual evoked potential of growing children. Brain Dev. 2010, 32, 213-216. [CrossRef] [PubMed]

95. Lozoff, B.; Armony-Sivan, R.; Kaciroti, N.; Jing, Y.; Golub, M.; Jacobson, S.W. Eye-blinking rates are slower in infants with iron-deficiency anemia than in nonanemic iron-deficient or iron-sufficient infants. J. Nutr. 2010, 140, 1057-1061. [CrossRef] [PubMed]

96. Amony-Sivan, R.; Zhu, B.; Clark, K.M.; Richards, B.; Ji, C.; Kaciroti, N.; Shao, J.; Lozoff, B. Iron deficiency (ID) at both birth and 9 months predicts right frontal EEG asymmetry in infancy. Dev. Psychobiol. 2016, 58, 462-470. [CrossRef] [PubMed]

97. Otero, G.A.; Pliego-Rivero, F.B.; Porcayo-Mercado, R.; Mendieta-Alcantara, G. Working memory impairment and recovery in iron deficient children. Clin. Neurophysiol. 2008, 119, 1739-1746. [CrossRef] [PubMed]

98. Lukowski, A.F.; Koss, M.; Burden, M.J.; Jonides, J.; Nelson, C.A.; Kaciroti, N.; Jimenez, E.; Lozoff, B. Iron deficiency in infancy and neurocognitive functioning at 19 years: Evidence of long-term deficits in executive function and recognition memory. Nutr. Neurosci. 2010, 13, 54-70. [CrossRef] [PubMed]

99. Congdon, E.L.; Westerlund, A.; Algarin, C.R.; Peirano, P.D.; Gregas, M.; Lozoff, B.; Nelson, C.A. Iron deficiency in infancy is associated with altered neural correlates of recognition memory at 10 years. J. Pediatr. 2012, 160, 1027-1033. [CrossRef] [PubMed]

100. Lozoff, B.; Clark, K.M.; Jing, Y.; Armony-Sivan, R.; Angelilli, M.L.; Jacobson, S.W. Dose-response relationships between iron deficiency with or without anemia and infant social-emotional behavior. J. Pediatr. 2008, 152, 696-702. [CrossRef]

101. Parsons, A.G.; Zhou, S.J.; Spurrier, N.J.; Makrides, M. Effect of iron supplementation during pregnancy on the behaviour of children at early school age: Long-term follow-up of a randomised controlled trial. Br. J. Nutr. 2008, 99, 1133-1139. [CrossRef]

102. Qubty, W.; Renaud, D.L. Cognitive impairment associated with low ferritin responsive to iron supplementation. Pediatr. Neurol. 2014, 51, 831-833. [CrossRef] [PubMed]

103. Ji, X.; Cui, N.; Liu, J. Neurocognitive function is associated with serum iron status in early adolescents. Biol. Res. Nurs. 2017, 19, 269-277. [CrossRef] [PubMed] 
104. Mireku, M.O.; Davidson, L.L.; Boivin, M.J.; Zoumenou, R.; Massougbodji, A.; Cot, M.; Bodeau-Livinec, F. Prenatal iron deficiency, neonatal ferritin, and infant cognitive function. Pediatrics 2016, 138. [CrossRef] [PubMed]

105. Doom, J.R.; Georgieff, M.K.; Gunnar, M.R. Institutional care and iron deficiency increase ADHD symptomology and lower IQ 2.5-5 years post-adoption. Dev. Sci. 2015, 18, 484-494. [CrossRef] [PubMed]

106. Islam, K.; Seth, S.; Saha, S.; Roy, A.; Das, R.; Datta, A.K. A study on association of iron deficiency with attention deficit hyperactivity disorder in a tertiary care center. Ind. J. Psychiatry 2018, 60, 131-134. [CrossRef] [PubMed]

107. Holm, C.; Thomsen, L.L.; Norgaard, A.; Langhoff-Roos, J. Single-dose intravenous iron infusion or oral iron for treatment of fatigue after postpartum haemorrhage: A randomized controlled trial. Vox Sang. 2017, 112, 219-228. [CrossRef] [PubMed]

108. Markova, V.; Norgaard, A.; Jørgensen, K.J.; Langhoff-Roos, J. Treatment for women with postpartum iron deficiency anaemia. Cochrane Database Syst. Rev. 2015, 13, CD010861. [CrossRef] [PubMed]

(C) 2019 by the authors. Licensee MDPI, Basel, Switzerland. This article is an open access article distributed under the terms and conditions of the Creative Commons Attribution (CC BY) license (http://creativecommons.org/licenses/by/4.0/). 
Article

\title{
Iron Release from Soybean Seed Ferritin Induced by Cinnamic Acid Derivatives
}

\author{
Xuejiao Sha, Hai Chen, Jingsheng Zhang and Guanghua Zhao * \\ Beijing Advanced Innovation Center for Food Nutrition and Human Health, College of Food Science and \\ Nutritional Engineering, Beijing Key Laboratory of Functional Food from Plant Resources, \\ China Agricultural University, Beijing 100083, China; cau3060509@163.com (X.S.); chenhai2509@163.com (H.C.); \\ zhangjingsheng@cau.edu.cn (J.Z.) \\ * Correspondence: gzhao@cau.edu.cn; Tel./Fax: +86-10-6273-8737
}

Received: 4 March 2018; Accepted: 2 May 2018; Published: 4 May 2018

\begin{abstract}
Plant ferritin represents a novel class of iron supplement, which widely co-exists with phenolic acids in a plant diet. However, there are few reports on the effect of these phenolic acids on function of ferritin. In this study, we demonstrated that cinnamic acid derivatives, as widely occurring phenolic acids, can induce iron release from holo soybean seed ferritin (SSF) in a structure-dependent manner. The ability of the iron release from SSF by five cinnamic acids follows the sequence of Cinnamic acid $>$ Chlorogenic acid $>$ Ferulic acid $>p$-Coumaric acid $>$ Trans-Cinnamic acid. Fluorescence titration in conjunction with dialysis results showed that all of these five compounds have a similar, weak ability to bind with protein, suggesting that their protein-binding ability is not related to their iron release activity. In contrast, both $\mathrm{Fe}^{2+}$-chelating activity and reducibility of these cinnamic acid derivatives are in good agreement with their ability to induce iron release from ferritin. These studies indicate that cinnamic acid and its derivatives could have a negative effect on iron stability of holo soybean seed ferritin in diet, and the $\mathrm{Fe}^{2+}$-chelating activity and reducibility of cinnamic acid and its derivatives have strong relations to the iron release of soybean seed ferritin.
\end{abstract}

Keywords: cinnamic acid derivatives; soybean seed ferritin; iron release; binding ability; $\mathrm{Fe}^{2+}$-chelating activity; reducibility

\section{Introduction}

Iron plays an essential role in living organisms, such as oxygen transfer, DNA synthesis, electron transport, and tricarboxylic acid and nitrogen fixation. Actually, iron deficiency is one of the most serious global nutritional problems, which affects about two billion people in the world [1]. Although the prevalence of iron deficiency anemia (IDA) is higher in developing countries, iron deficiency is still common among women and young children in industrial countries. More importantly, IDA can cause a series of consequences, such as reduced cognitive, motor development in infants and poor pregnancy outcomes. Ferritin is a natural and ubiquitous iron storage protein occurring widely in plants, animals, bacteria and fungi [2]. It consists of 24 subunits that assemble in a highly symmetric manner to a hollow protein shell with the outside diameter of about 12-13 nm and inner diameter of about 7-8 nm [3]. One ferritin molecule contains six four-fold, eight three-fold, and twelve two-fold channels (Figure 1a), which connect the inner cavity to bulk solution and serve as multiple pathways for iron entry and exit. Ferritin can store up to $4500 \mathrm{Fe}^{3+}$ in its cavity, and therefore, natural ferritin, especially plant ferritin from legume seeds, has been considered as a novel alternative dietary iron supplement against IDA [1]. As compared to other iron supplements with a small size, ferritin has three major advantages: the protection of protein shell from interaction with other dietary factors, the safer form of iron stored as ferric cores rather than ferrous iron, and the possible intact absorption by receptor-mediated endocytosis [1]. 
a

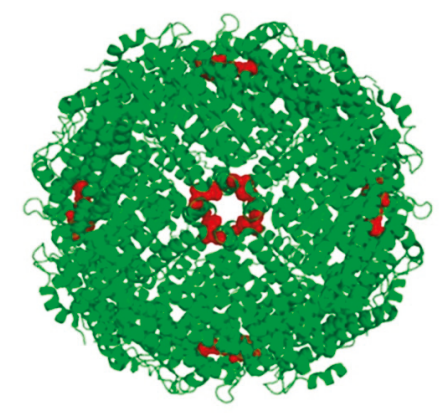

b

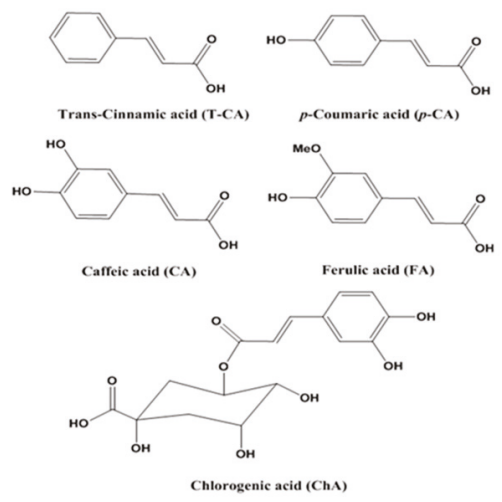

Figure 1. (a) Crystal structure of plant ferritin with views down the four-fold axes (channels) of the protein shell. The tryptophan residue of each subunit is highlighted in red; (b) Chemical structure of cinnamic acid derivatives: Trans-cinnamic acid (T-CA); $p$-Coumaric acid ( $p$-CA); Caffiec acid (CA); Ferulic acid (FA); Chlorogenic acid (ChA).

So far, $\mathrm{Fe}^{2+}$ oxidation and mineral deposition in ferritin have been studied intensively and extensively [1,4]. Although some reductants such as ascorbate, 6-hydroxydopamine, 5-aminolevulinic acid, superoxide anion radical, 1,2,4-benzenetriol, benzene metabolites, NADH and anthocyanins have been shown to induce iron release from ferritin $[5,6]$, and several iron chelators including 2 , 2'-bipyridine, salicylate, citrate, nitrilotriacetate, and desferroxamine B can also induce iron release from ferritin at a slower rate [7-9]. However, there has been less attention paid to the iron release of ferritin induced by nutrients and the stability of ferritin iron core in food systems.

Phenolic acids are secondary metabolites, which are widely distributed in various plant foodstuffs. Among these phenolic acids, cinnamic acid derivatives (Figure 1b), such as caffeic, chlorogenic, $p$-coumaric and ferulic acids, are reported to possess functional activities like cancer prevention, antituberculosis, antileukaemic, hepatoprotective, antidiabetic, antioxidative, and hypocholesterolemic activities [10-12]. However, to date, whether these phenolic acids have an effect on the function of protein through intermolecular interaction has received much less attention. Based on the fact that phenolic acids such as cinnamic acid derivatives and ferritin co-exist in plant foodstuffs, and that cinnamic acid derivatives have a strong reducing activity, while ferric iron within phytoferritin exhibits a relatively strong oxidative activity, it is of special interest to know if the two kinds of molecules could interact with each other, and if so, what is the consequence of such interaction, which is the focus of this work.

\section{Results and Discussion}

\subsection{Isolation and Characterization of SSF and $r H-2$}

Ferritin can stay in two forms, holo and apo ferritin. Naturally occurring ferritin is a holo form which contains hydrous ferric oxide nanoparticles as iron cores within its cavity. Holo plant ferritin usually consists of two $\mathrm{H}$ type subunits of $26.5(\mathrm{H}-1)$ and $28.0 \mathrm{kDa}(\mathrm{H}-2)$, while their ratios vary among species. In this study, natural holo soybean seed ferritin (SSF) was used for iron release experiments because it is most extensively studied among all known plant ferritins $[1,13]$. However, our recent studies have showed that SSF is unstable during storage, because the extension peptide (EP) of the H-1 subunit exhibits significant serine protease-like activity, which is located at the N-terminal extremity. Consequently, recombinant soybean seed $\mathrm{H}-1$ ferritin ( $\mathrm{rH}-1)$ is prone to degradation, whereas its analogue, recombinant soybean seed $\mathrm{H}-1$ ferritin $(\mathrm{rH}-2)$, becomes very stable under 
identical conditions [14]. Therefore, apo $\mathrm{rH}-2$ was used to study the interaction between cinnamic acid derivatives and protein.

After purification, these two kinds of ferritins were analyzed by PAGE and TEM. Nondenaturing gel electrophoresis (native PAGE) revealed the purified SSF and rH-2 as a single complex (Figure 2a), suggesting that they have been purified to homogeneity. SDS-PAGE indicated that SSF consists of nearly 28.0 and $26.5 \mathrm{kD}$ subunits, a result consistent with previous observations [15]. As expected, $\mathrm{rH}-2$ was composed of only one $28.0 \mathrm{kD}$ subunit (Figure $2 \mathrm{~b}$ ). TEM analyses revealed that $\mathrm{rH}-2$ molecules were well dispersed with an outside diameter of $\sim 12 \mathrm{~nm}$ (Figure $2 \mathrm{c}$ ) after being negatively stained with uranyl acitate. In contrast, without negative staining, iron cores can be clearly observed in holo SSF (Figure 2d) as isolates contains $\sim 1800 \mathrm{~g}$ atom of iron [1].
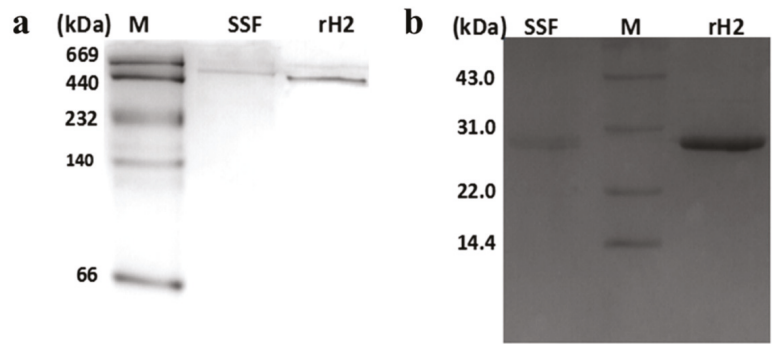

c

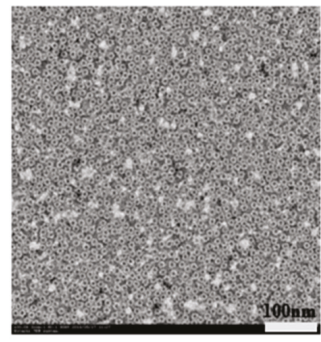

d

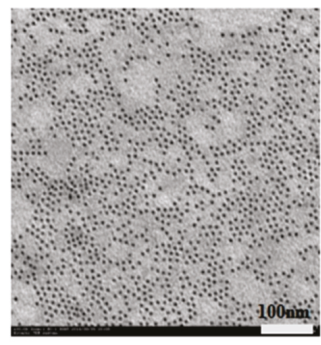

Figure 2. (a) Native PAGE analyses and (b) SDS-PAGE of soybean seed ferritin (SSF) and recombinant $\mathrm{H} 2$ ferritin ( $\mathrm{rH}-2$ ); (c) TEM picture of purified $\mathrm{rH}-2$ after beingnegatively stained by $2 \%$ uranyl acetate;

(d) TEM picture of holo soybean seed ferritin (SSF) without negative staining of uranyl acetate.

\subsection{Iron Release from SSF Induced by Cinnamic Acid Derivatives}

Subsequently, we analyzed the possibility of all cinnamic acid derivatives to induce iron release from SSF at a concentration of $25 \mu \mathrm{M}$ [5], and results are displayed in Figure 3. It was found that all of them not only were able to cause iron release from protein shell, but also such iron release showed a structure-dependent manner. For example, CA induces iron release from SSF at the initial rate of $0.104 \pm 0.006 \mathrm{mM} / \mathrm{min}$, which is fastest among all tested compounds. The rate of iron release follows the sequence $\mathrm{CA}>\mathrm{ChA}>\mathrm{FA}>\mathrm{p}-\mathrm{CA}>\mathrm{T}-\mathrm{CA}$ in Mops buffer $(\mathrm{pH} 7.0)$ at $25^{\circ} \mathrm{C}$. CA has the higher ability to induce iron release from ferritin as compared to its analogue, ChA $(0.092 \pm 0.021) \mathrm{mM} / \mathrm{min}$. This might be derived from the fact that $\mathrm{ChA}$ contains a sinapic acid group in its structure, thereby its large size prevents it from diffusion into the protein shell to some extent. These results suggest that the rate of iron release is inversely proportional to the size of phenolic acids, which is in agreement with a previous report [16]. Thus, it seems that the molecular size of phenolic acids plays an important role during the iron release from SSF induced by reductants. 


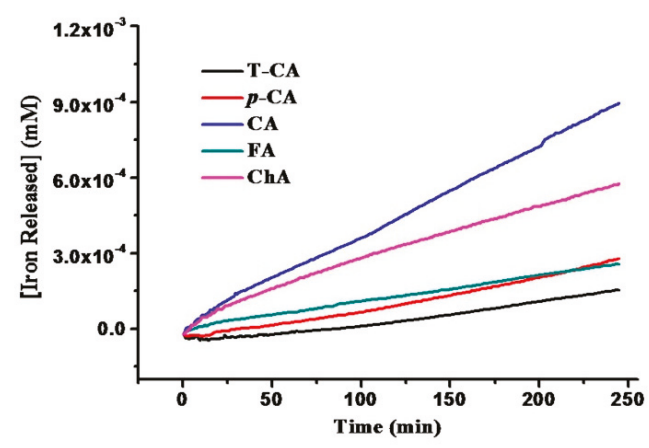

Figure 3. Kinetics of iron release from holo SSF induced by cinnamic acid derivatives. Iron release from SSF in the presence of reductants was followed by measuring the increase in absorbance at $562 \mathrm{~nm}$ about $250 \mathrm{~min}$ due to the chelation of $\mathrm{Fe}^{2+}$ by ferrozine. Conditions: $0.15 \mu \mathrm{M}$ SSF, $25 \mu \mathrm{M}$ cinnamic acids, $50 \mathrm{mM}$ Mops, $\mathrm{pH} 7.0,0.15 \mathrm{M} \mathrm{NaCl}, 500 \mu \mathrm{M}$ ferrozine, $25^{\circ} \mathrm{C}$.

Besides, it was observed that the number of $\mathrm{HO}$ groups of cinnamic acid derivatives has a marked effect on the rate of iron release from ferritin. For example, with an increase in the number of $\mathrm{HO}$ from 0,1 , to 2 , the rate of the iron release from ferritin increased from $0.002 \pm 0.001 \mathrm{mM} / \mathrm{min}$ for T-CA, $0.014 \pm 0.004 \mathrm{mM} / \mathrm{min}$ for $p-\mathrm{CA}$, to $0.104 \pm 0.006 \mathrm{mM} / \mathrm{min}$ for CA, respectively, suggesting that the number of $\mathrm{HO}$ group in cinnamic acid derivatives is closely associated with their ability to induce iron release from ferritin. Consistent with this idea, the rate of iron release from ferritin induced by CA was greatly decreased by $\sim 50 \%$ after one $\mathrm{HO}$ group was replaced by OMe in FA $(0.046 \pm 0.011 \mathrm{mM} / \mathrm{min})$ as shown in Figure 3.

\subsection{Fluorescence Quenching Analyses}

The above results demonstrated that all of these cinnamic acid derivatives are able to facilitate iron release from ferritin to different extents. To shed light on the mechanism by which iron release from ferritin was induced by these phenolic acids, we investigated the binding activity of these small molecules to ferritin through their interaction with protein. Protein intrinsic fluorescence mainly from Trp residues has been widely used to study their interaction with small molecules because of its sensitivity to microenviroment surrounding the fluorophore residue. As shown in Figure 1a, there are 24 Trp residues in one soybean seed ferritin molecule [17]. By taking advantage of this, we used intrinsic emission spectroscopy to study the interaction between these small molecules and apo $\mathrm{rH}-2$, and results were shown in Figure 4. It was observed that all of cinnamic acid and its derivatives were able to quench the protein fluorescence, showing similar fluorescence quenching curves, indicative of similar interaction between cinnamic acid derivatives and apo $\mathrm{rH}-2$. Thus, it seems that their interaction with apoferritin is independent of chemical structure, inconsistent with the above iron release results.

To determine whether these cinnamic acid derivatives can interact with proteins through binding, dialysis experiments were carried out wherein apo $\mathrm{rH}-2(0.55 \mu \mathrm{M})$ was firstly incubated with these phenolic acids $(22 \mu \mathrm{M})$, followed by dialysis against buffer for four times to remove free small molecules, respectively, and results are given in Figure 5. It was found that after dialysis for $5 \mathrm{~h}$, the fluorescence of apo $\mathrm{rH}-2$ could return to an original state upon treatment with these phenolic compounds, respectively (Figure 5). These results indicated that the fluorescence quenching of apo $\mathrm{rH}-2$ caused by these compounds is dynamic, resulting from collisional encounters between the fluorophore and quencher. Instead, it is difficult to form a complex between ferritin and each of these cinnamic acid derivatives under the present experimental conditions; at most, the binding of the small 
compounds to apo $\mathrm{rH}-2$ is very weak, and therefore, dialysis can remove them from their mixture with apo $\mathrm{rH}-2$.

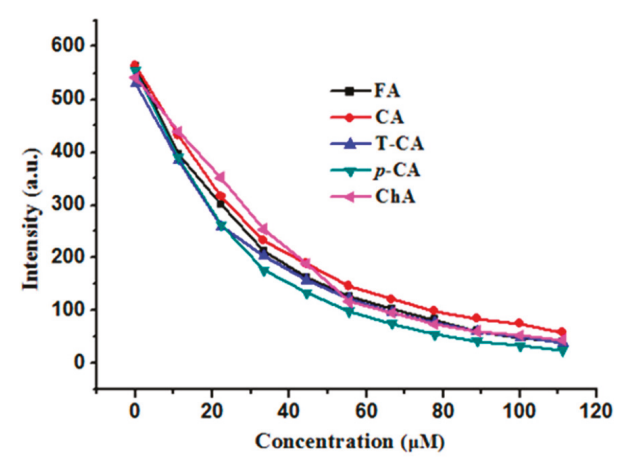

Figure 4. Comparison of cinnamic acids on the fluorescence quenching of apo rH-2. Conditions: $0.55 \mu \mathrm{M} \mathrm{rH}-2$ in $50 \mathrm{mM}$ Tris- $\mathrm{HCl}$, [phenolic acids] $=0-110 \mu \mathrm{M}, \mathrm{pH} 7.0,25^{\circ} \mathrm{C} . \lambda \mathrm{Ex}=280 \mathrm{~nm}$, slits for excitation and emission are $5 \mathrm{~nm}$ and $10 \mathrm{~nm}$.
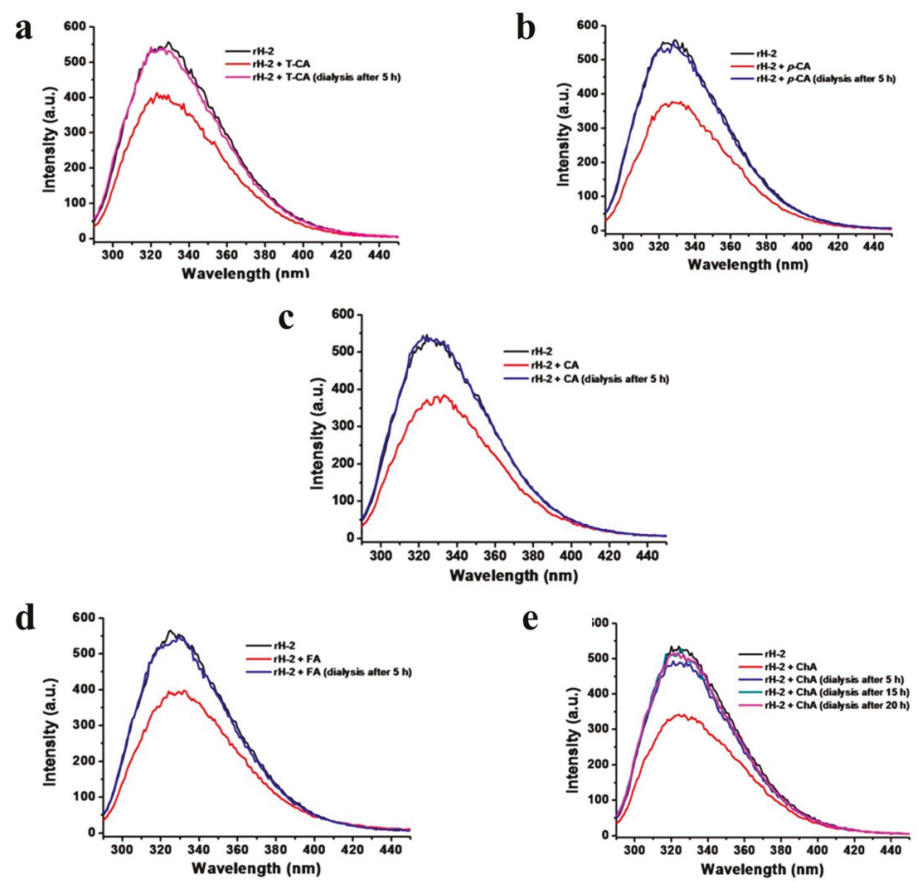

Figure 5. Dialysis study of $\mathrm{rH}-2$ with cinnamic acids at $\mathrm{pH}$ 7.0. (a) Trans-Cinnamic acid; (b) $p$-Coumaric acid; (c) Caffeic acid; (d) Ferulic acid; (e) chlorogenic acid. Conditions: $0.55 \mu \mathrm{M} \mathrm{rH}-2$ in $50 \mathrm{mM}$ Tris-HCl, [cinnamic acids] $=22 \mu \mathrm{M}, 25^{\circ} \mathrm{C}$. $\lambda_{\mathrm{Ex}}=280 \mathrm{~nm}$, slits for excitation and emission are $5 \mathrm{~nm}$ and $10 \mathrm{~nm}$.

The weak binding activity of the cinnamic acid derivatives to ferritin might be derived from the fact that they contain less than three hydroxyl groups in the structure. Consistent with this view, our recent study showed that gallic acid, methyl gallate and propyl gallate having three HO groups 
can bind to rH-2 tightly, while their analogues with two HO groups cannot [18]. Thus, the number of the hydroxyl groups is closely associated with the interaction mode between phenolic acids and protein, and more hydroxyl groups in the structure favors the binding of phenolic acids to protein. Further support for this idea comes from a recent study showing that tannic acid with many hydroxyl groups can facilitate ferritn association through strong hydrogen bonds [19].

\subsection{Effect of the $\mathrm{Fe}^{2+}$ Chelating Activity of Cinnamic Acid Derivatives on the Iron Release from Ferritin}

It was previously reported that the chelating activity of reductants on iron ion was an important factor which is related to iron release from the ferritin shell [20]. Therefore, in this study, the iron chelating activity of cinnamic acid derivatives was determined, respectively, to gain insight into the mechanism of iron release from ferritin. As shown in Figure 6a, the chelating activity of cinnamic acid derivatives on ferrous ions follows the sequence of $\mathrm{CA}>\mathrm{ChA}>\mathrm{FA}>\mathrm{T}-\mathrm{CA} \approx p$-CA. The chelating activity of CA and ChA with catechol moiety was $\sim 63 \%$ and $58 \%$, respectively, which was almost six-fold stronger than their analogue, FA $(\sim 11 \%)$ where one hydroxyl group was replaced with OMe. The large difference in the chelating activity between CA/ChA and FA suggested that two hydroxyl groups in the benzene ring of $\mathrm{CA}$ and $\mathrm{ChA}$ were required for $\mathrm{Fe}^{2+}$ chelating, while one hydroxyl group in the benzene ring of FA is not enough to chelate iron. Agreeing with this idea, both T-CA $(\sim 7.0 \%)$ and $p$-CA $(\sim 6.5 \%)$ with zero or one hydroxyl group exhibited even much weaker chelating activity than CA or ChA. Additionally, it was found that CA and ChA exhibited nearly the same chelating activity, suggesting that the carboxyl group might not be involved in iron chelating, and at most it contributed much less to iron chelating as compared to the hydroxyl group.
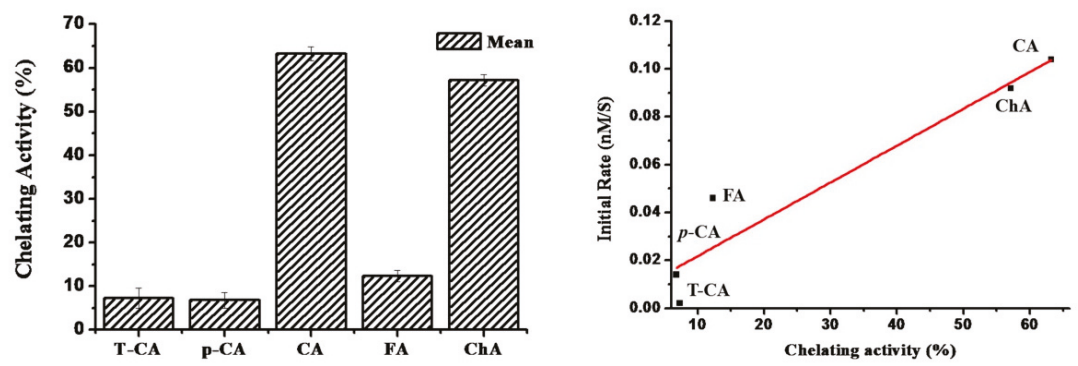

Figure 6. Chelating activity of cinnamic acid derivatives on ferrous ion. Vertical bars represent the standard error from means of three separate tests.

More importantly, it was observed that the chelating activity of these phenolic acids was in good agreement with the above iron release results (Figure 3); namely, the stronger the chelating activity, the faster rate of the iron release from ferritin. Consistent with this conclusion, there is a linear relationship between the rate of iron release from ferritin induced by these phenolic acids and their chelating activity as shown in Figure 6b. Based on these findings, it is reasonable to believe that the chelating activity of cinnamic acid derivatives has an important effect on the rate of iron release from ferritin induced by these compounds. This might be because these cinnamic acid derivatives can act as iron chelators to help iron to move out of SSF.

\subsection{Effect of Reducibility of Cinnamic Acid Derivatives on the Iron Release from Ferritin}

To better understand the mechanism of iron release from ferritin, we also studied the voltammetric oxidation of these phenolic acids in $\mathrm{pH} 7.0$ phosphate buffer by cyclic voltammetry, and results are shown in Figure 7a. Cyclic voltammograms of CA, FA, $p$-CA and ChA at a sweep rate of $100 \mathrm{mM} \mathrm{s}^{-1}$ exhibited one anodic peak and one cathodic peak, suggesting that the oxidation process for these four 
investigated compounds was reversible. However, cyclic voltammograms of T-CA showed no peak, indicating that T-CA has no reducibility [21]. As shown Table 1, ChA (0.31 V) has the largest anodic peak potential among all of the five compounds.

$\mathbf{a}$

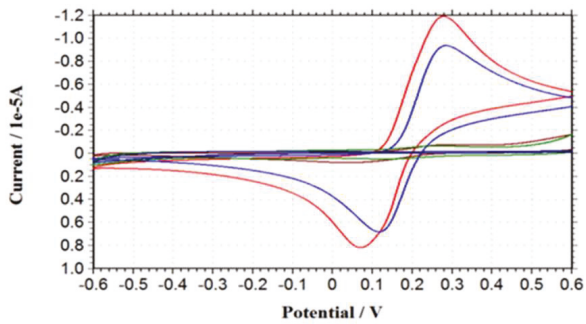

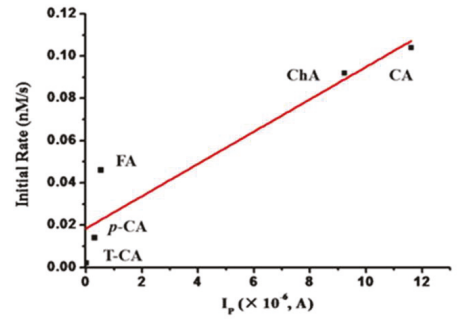

Figure 7. Cyclic voltammograms taken with a 3-mm glassy carbon electrode at $100 \mathrm{mVs}^{-1}$ of: $0.5 \mathrm{mM}$ cinnamic acid (mazarine line), $p$-coumaric acid (green line), caffeic acid (red line), ferulic acid (carmine red), and chlorogenic acid (blue red) in $50 \mathrm{mM}$ phosphate buffer of $\mathrm{pH}$ 7.0.

Table 1. Evaluation of the anodic peak potentials of the studied cinnamic acid derivatives ( $\mathrm{E}_{\mathrm{p}}$-anodic peak potential $(\mathrm{V}))$ at $\mathrm{pH}$ 7.0, as well as the anodic peak currents at $\mathrm{pH} 7.0$ (I $\mathrm{I}_{\mathrm{P}}$-anodic peak current (A)) during the cyclic voltammetry experiment.

\begin{tabular}{ccc}
\hline Phenolic Compound & $\mathbf{E}_{\mathbf{p}}$ & $\mathbf{I}_{\mathbf{p}}\left(\times \mathbf{1 0}^{-\mathbf{6}}\right)$ \\
\hline T-CA & 0 & 0 \\
p-CA & 0.27 & $0.31 \pm 0.12$ \\
CA & 0.28 & $11.61 \pm 0.35$ \\
FA & 0.24 & $0.53 \pm 0.07$ \\
ChA & 0.31 & $9.23 \pm 0.46$ \\
\hline
\end{tabular}

Interestingly, the oxidation peak current of the cinnamic acid derivatives follows the sequence of $\mathrm{CA}>\mathrm{ChA}>\mathrm{FA}>p$-CA $>$ T-CA (Table 1). This trend is in good agreement with the initial rate of iron release from SSF induced by these compounds. For reversible systems, the oxidation peak current, $\mathrm{I}_{\mathrm{p}}$ could represent the reducibility of the analyte in the solution bulk [22]. Caffeic acid and chlorogenic acid with two hydroxyl groups in their benzene ring structure show the stronger oxidation peak current as compared with chlorogenic acid. In contrast, FA and $p$-CA with only one hydroxyl group have weaker oxidation peak current, while T-CA with no HO group has no reducibility. These results indicated that the reducibility of cinnamic acids can greatly influence the rate of iron release from SSF. Indeed, there is also a linear relationship between the oxidation peak current of the cinnamic acid derivatives and their ability to induce iron release from ferritin as shown in Figure $7 \mathrm{~b}$. Therefore, the reducibility of phenolic acids also is another important factor affecting their ability to induce iron release from the ferritin shell.

\section{Materials and Methods}

\subsection{Chemicals}

Five cinnamic acid derivatives used in this study were purchased from J\&K Chemical (Beijing, China). Ferrous ion chelator 3-(2-pyridyl)-5,6-bis(4-phenylsulfonic acid)-1,2,4-triazine (ferrozine) was obtained from Sigma-Aldrich Chemical Co. (Beijing, China). Sephacryl S-300, DEAE Sepharose Fast Flow, native electrophoresis marker, and SDS electrophoresis marker were purchased from GE Healthcare Bio-Sciences AB (Beijing, China). Sodium citrate, terephthalic acid (TA) and magnesium chloride hexahydrate were obtained from Beijing Chemical Reagents Co. (Beijing, China). All other reagents used were of analytical grade or purer. 


\subsection{Preparation of Soybean Seed Ferritin (SSF) and Recombinant Soybean Seed H-2 Ferritin (rH-2)}

SSF and apo rH-2 were purified as previously described with some modification $[23,24]$. Typically, approximately $1 \mathrm{~kg}$ of soybean seeds was soaked in distilled water for $8 \mathrm{~h}$ and mixed with three volumes of extraction buffer $\left(50 \mathrm{mM} \mathrm{KH}_{2} \mathrm{PO}_{4}, \mathrm{pH} 7.5,1 \%\right.$ polyvinylpolypyrrolidone). After filtration, the filtrate was incubated for $15 \mathrm{~min}$ at $60^{\circ} \mathrm{C}$ and then was centrifuged at $5000 \times g$ for 5 min to separate the insoluble material. The supernatant was adjusted to $0.5 \mathrm{M} \mathrm{MgCl}_{2}$ and the mixture stood for $30 \mathrm{~min}$ at $4{ }^{\circ} \mathrm{C}$ followed by addition of sodium citrate (final concentration of $0.7 \mathrm{M}$ ) to complex the magnesium. After $10 \mathrm{~h}$, the resultant supernatant was centrifuged at $12,000 \times \mathrm{g}$ for $20 \mathrm{~min}$ at $4{ }^{\circ} \mathrm{C}$. The brown precipitate thus obtained was dissolved in $50 \mathrm{mM} \mathrm{KH}_{2} \mathrm{PO}_{4} \bullet \mathrm{Na}_{2} \mathrm{HPO}_{4}$ buffer (pH 7.5) and was dialyzed against the same buffer three times.

Escherichis coli strain BL21 (DE3) which contained $\mathrm{rH}-2$ expression plasmids was grown at $37^{\circ} \mathrm{C}$. Protein expression was induced with $1 \mathrm{mM}$ IPTG (isopropyl $\beta$-D-1-thiogalactopyranoside) for $7 \mathrm{~h}$. The system was centrifuged and re-suspended in buffer solution (50 mM Tris-HCl, pH 8.0), followed by disruption by sonication. The supernatant of the crude extract was collected by centrifugation and further purified by ammonium sulfate fractionation ( $40 \%$ saturated fraction). After washed by distilled water to remove other proteins, the sediment was dissolved by solution buffer. Next the solution was dialyzed against the same buffer three times to remove the ammonium sulfate. SSF and rH-2 protein were further purified by Sephacryl S-300 gel filtration chromatography (GFC) and DEAE-Sepharose Fast Flow column, respectively. Finally, protein purity was analyzed by SDS-PAGE and Native-PAGE analysis. Protein concentrations were determined according to the Lowry method as previous reported [25].

\subsection{Kinetic Measurement of Iron Release from Holo Soybean Seed Ferritin}

The assay system ( $1 \mathrm{~mL}$ of total volume) contained $0.21 \mu \mathrm{M}$ ferritin, $500 \mu \mathrm{M}$ ferrozine, $0.15 \mathrm{M}$ $\mathrm{NaCl}$, and $25 \mu \mathrm{M}$ cinnamic acid derivatives in $50 \mathrm{mM}$ Mops buffer, $\mathrm{pH} 7.0$ as previously described [5]. The same solution but just using buffer instead of cinnamic acid derivatives was used as control. Experiments were conducted at $25^{\circ} \mathrm{C}$. The iron release was measured with the development of $\left.[\mathrm{Fe} \text { (ferrozine })_{3}\right]^{2+}$ at $562 \mathrm{~nm}$ using a Varian Cary 50 spectrophotometer, and $\varepsilon_{562}=27.9 \mathrm{mM}^{-1} \mathrm{~cm}^{-1}$. The absorbance at $562 \mathrm{~nm}$ from the control was deducted from that of all sample mixtures. The initial rate $\left(v_{0}\right)$ of iron release measured as $\left[\mathrm{Fe}(\text { ferrozine })_{3}\right]^{2+}$ formation was obtained from the linear $A_{1}$ term of third-order polynomial fitted to the experimental data as reported previously: $Y=A_{0}+A_{1} \mathrm{t}+A_{2} \mathrm{t}^{2}+A_{3} \mathrm{t}^{3}$ and $\mathrm{d} Y / \mathrm{dt}=A_{1}+2 A_{2} \mathrm{t}+3 A_{3} \mathrm{t}^{2}\left(\right.$ at $\left.\mathrm{t}=0,(\mathrm{~d} Y / \mathrm{dt})_{0}=v_{0}\right)$. Here $\mathrm{t}$ is the time in minutes and $Y$ is the concentration of [Fe(ferrozine $\left.)_{3}\right]^{2+}$ at time $\mathrm{t}$ in minutes [16].

\subsection{Fluorescence Titration Analysis}

Fluorescence titration measurements were recorded on a Cary Eclipse fluorescence spectrophotometer (Varian, Polo Alto, CA, USA), using quartz cuvettes of $1 \mathrm{~cm}$ path length at room temperature. In this measurement, apo $\mathrm{rH}-2(0.55 \mu \mathrm{M}, 150 \mathrm{mM} \mathrm{NaCl}$ and $50 \mathrm{mM}$ Tris- $\mathrm{HCl}, \mathrm{pH} 7.0)$ was titrated with $1 \mu \mathrm{L}$ cinnamic acid derivatives $(5 \mathrm{mM}, 50 \mathrm{mM}$ Tris- $\mathrm{HCl}, \mathrm{pH} 7.0)$, respectively. The excitation wavelength was $280 \mathrm{~nm}$, and the emission wavelength was $325 \mathrm{~nm}$. Furthermore, dialysis measurements were conducted to analyze the binding affinity of cinnamic acids to apo rH-2. Typically, a mixture of apo $\mathrm{rH}-2(0.55 \mu \mathrm{M})$ plus cinnamic acid derivatives $(22 \mu \mathrm{M})$ was dialyzed (100 $\mathrm{kDa}$ cutoff) for $5 \mathrm{~h}$ against the solution buffer $(50 \mathrm{mM}$ Tris- $\mathrm{HCl}$ and $150 \mathrm{mM} \mathrm{NaCl}$, at $\mathrm{pH} 7.0)$ to detect this kind of interaction [18].

\subsection{Chelating Activity of Cinnamic Acid Derivatives on Ferrous Ion}

The chelating activity of cinnamic acid derivatives on ferrous ion was measured as described previously with some modifications [5]. The reaction system (1 mL) contained $20 \mu \mathrm{M} \mathrm{FeSO}_{4}, 60 \mu \mathrm{M}$ ferrozine, and $60 \mu \mathrm{M}$ cinnamic acid derivatives in $50 \mathrm{mM}$ Mops buffer ( $\mathrm{pH}$ 7.0). After reaction for 
$5 \mathrm{~min}$ at $25^{\circ} \mathrm{C}$, the absorbance of system was detected at $562 \mathrm{~nm}$ spectrophotometrically. The ability of cinnamic acids to chelate $\mathrm{Fe}^{2+}$ was calculated as follows: chelating activity $(\%)=\frac{A 0-A}{A 0} \times 100$, where $A$ and $A_{0}$ are the absorbance in the presence or absence of the cinnamic acid derivatives, respectively.

\subsection{Cyclic Voltammetry}

Cyclic voltammetry experiments were performed using a potentiostat (microAutolab Type III with an Autolab Faraday Cage) and voltammograms were obtained with a scan rate of $100 \mathrm{mV} \mathrm{s}^{-1}$ with an increment potential of $2.4 \mathrm{mV}$, between $-0.6 \mathrm{~V}$ and $0.6 \mathrm{~V}$. The working electrode was a $3 \mathrm{~mm}$ glassy carbon disk in combination with a Metrohm tipholder, cleaned by polishing with $3 \mu \mathrm{m}$ alumina powder during $30 \mathrm{~s}$ followed by fixing the potential in ultrasonication during $5 \mathrm{~s}$, between acquisitions. A saturated calomel electrode was used as a reference electrode in conjunction with a platinum counter electrode. Each acquisition required $40 \mathrm{~mL}$ of sample. Oxygen was removed with a $\mathrm{N}_{2}$ current flow during 5 min prior to analysis. Cyclic voltammetry experiments were controlled by the CHI600E Electrochemical Workstation. Cyclic voltammograms were taken in the absence and in the presence of cinnamic acid derivatives.

\subsection{Statistical Analysis}

All data analyses were performed using Origin 8.0 software and the structural formula was processed by ChemDraw 7.0. All experiments were carried out in triplicate.

\section{Conclusions}

The present study demonstrates that cinnamic acid derivatives, a class of naturally occurring phenolic acids, can induce iron release from holo soybean seed ferritin (SSF) in a structure-dependent manner for the first time. The ability of iron release from SSF by five cinnamic acids follows the sequence of $\mathrm{CA}>\mathrm{ChA}>\mathrm{FA}>p$-CA $>\mathrm{T}$-CA. Although the five phenolic acids exhibit a weak ability to bind with ferritin, they are able to induce iron release from holo ferritin through their $\mathrm{Fe}^{2+}$-chelating activity and reducibility. These studies indicate that cinnamic acid and its derivatives could have a negative effect on iron absorption in humans, because they can result in loss of a certain amount of iron from holo ferritin through interactions. Therefore, the interactions between cinnamic acid derivatives and holo SSF should be avoided as much as possible during food processing.

Author Contributions: G.Z. and X.S. conceived and designed the experiments; X.S. performed the experiments; X.S., H.C. and Z.J analyzed the data; X.S. and H.C. wrote the paper.

Acknowledgments: This project was supported by the National Natural Science Foundation of China (31671805).

Conflicts of Interest: The authors declare no conflict of interest.

\section{References}

1. Zhao, G. Phytoferritin and its implications for human health and nutrition. BBA-Gen. Subj. 2010, 1800, 815-823. [CrossRef] [PubMed]

2. Theil, E.C. Iron, ferritin, and nutrition. Annu. Rev. Nutr. 2004, 24, 327-343. [CrossRef] [PubMed]

3. Harrison, P.M.; Arosio, P. The ferritins: Molecular properties, iron storage function and cellular regulation. BBA-Bioenerg. 1996, 1275, 161-203. [CrossRef]

4. Zhao, G.; Bou-Abdallah, F.; Arosio, P.; Levi, S.; Janus-Chandler, C.; Chasteen, N.D. Multiple pathways for mineral core formation in mammalian apoferritin. The role of hydrogen peroxide. Biochemistry 2003, 42, 3142-3150. [CrossRef] [PubMed]

5. Deng, J.; Cheng, J.; Liao, X.; Zhang, T.; Leng, X.; Zhao, G. Comparative study on iron release from Soybean (Glycine max) seed ferritin induced by anthocyanins and ascorbate. J. Agric. Food Chem. 2010, 58, 635-641. [CrossRef] [PubMed] 
6. Lv, C.; Bai, Y.; Yang, S.; Zhao, G.; Chen, B. NADH induces iron release from pea seed ferritin: A model for interaction between coenzyme and protein components in foodstuffs. Food Chem. 2013, 14, 3851-3858. [CrossRef] [PubMed]

7. Castruita, M.; Elmegreen, L.A.; Shaked, Y.; Stiefel, E.I.; Morel, F.M.M. Comparison of the kinetics of iron release from a marine (Trichodesmium erythraeum) Dps protein and mammalian ferritin in the presence and absence of ligands. J. Inorg. Biochem. 2007, 101, 1686-1691. [CrossRef] [PubMed]

8. Crichton, R.R.; Roman, F.; Roland, F. Iron mobilization from ferritin by chelating agents. J. Inorg. Biochem. 1980, 13, 305-316. [CrossRef]

9. Laulhere, J.P.; Briat, J.F. Iron release and uptake by plant ferritin: Effects of $\mathrm{pH}$, reduction and chelation. Biochem. J. 1993, 290, 693-699. [CrossRef] [PubMed]

10. De, P.; Baltas, M.; Bedos-Belval, F. Cinnamic acid derivatives as anticancer agents-A review. Curr. Med. Chem. 2011, 18, 1672-1703. [CrossRef] [PubMed]

11. Giles, F.; Fischer, T.; Cortes, J.; Garcia-Manero, G.; Beck, J.; Ravandi, F.; Masson, E.; Rae, P.; Sova, M. Antioxidant and antimicrobial activities of cinnamic acid derivatives. Mini-Rev. Med. Chem. 2012, 12, 749-767.

12. Sharma, P. Cinnamic acid derivatives: A new chapter of various pharmacological activities. J. Chem. Pharm. Res. 2011, 3, 403-423.

13. Lv, C.; Zhao, G.; Lönnerdal, B. Bioavailability of iron from plant and animal ferritins. J. Nutr. Biochem. 2015, 26, 532-540. [CrossRef] [PubMed]

14. Fu, X.; Deng, J.; Yang, H.; Masuda, T.; Goto, F.; Yoshiara, T.; Zhao, G. A novel EP-involved pathway for iron release from soya bean seed ferritin. Biochem. J. 2010, 427, 313-321. [CrossRef] [PubMed]

15. Masuda, T.; Goto, F.; Yoshihara, T. A novel plant ferritin subunit from soybean that is related to a mechanism in iron release. J. Biol. Chem. 2001, 276, 19575-19579. [CrossRef] [PubMed]

16. Hynes, M.J.; Coinceanainn, M.Ó. Investigation of the release of iron from ferritin by naturally occuring antioxidants. J. Inorg. Biochem. 2002, 90, 18-21. [CrossRef]

17. Masuda, T.; Goto, F.; Yoshihara, T.; Mikami, B. Crystal structure of plant ferritin reveals a novel metal binding site that functions as a transit site for metal transfer in ferritin. J. Biol. Chem. 2010, 285, 4049-4059. [CrossRef] [PubMed]

18. Wang, Q.; Zhou, K.; Ning, Y.; Zhao, G. Effect of the structure of gallic acid and its derivatives on their interaction with plant ferritin. Food Chem. 2016, 213, 260-267. [CrossRef] [PubMed]

19. Li, M.; Jia, X.; Yang, J.; Deng, J.; Zhao, G. Effect of tannic acid on properties of soybean (Glycine max) seed ferritin: A model for interaction between naturallyoccurring components in foodstuffs. Food Chem. 2012, 133, 410-415. [CrossRef] [PubMed]

20. Boyer, R.F.; McCleary, C.J. Superoxide ion as a primary reductant in ascorbate mediated ferritin iron release. Free Radic. Biol. Med. 1987, 3, 389-395. [CrossRef]

21. Madrakian, T.; Soleimani, M.; Afkhami, A. Simultaneous determination of mycophenolate mofetil and its active metabolite, mycophenolic acid, by differential pulse voltammetry using multi-walled carbon nanotubes modified glassy carbon electrode. Mat. Sci. Eng. C 2014, 42, 38-45. [CrossRef] [PubMed]

22. Hoyos-Arbeláez, J.; Vázquez, M.; Contreras-Calderón, J. Electrochemical methods as a tool for determining the antioxidant capacity of food and beverages: A review. Food Chem. 2017, 221, 1371-1381. [CrossRef] [PubMed]

23. Laulhere, J.P.; Lescure, A.M.; Briat, J.F. Purification and characterization of ferritins from maize, pea, and soyabean seeds. J. Biol. Chem. 1988, 263, 10289-10294. [PubMed]

24. Masuda, T.; Goto, F.; Yoshihara, T.; Ezure, T.; Suzuki, T.; Kobayashi, S.; Shikata, M.; Utsumi, S. Construction of homo- and heteropolymers of plant ferritin subunits using an in vitro protein expression system. Protein Expr. Purif. 2007, 56, 237-246. [CrossRef] [PubMed]

25. Lowry, O.H.; Rosebrough, N.J.; Farr, A.L.; Randall, R.J. Protein measurement with the Folin phenol reagents. J. Biol. Chem. 1951, 193, 265-275. [PubMed]

(C) 2018 by the authors. Licensee MDPI, Basel, Switzerland. This article is an open access article distributed under the terms and conditions of the Creative Commons Attribution (CC BY) license (http:/ / creativecommons.org/licenses/by/4.0/). 


\title{
The Functional Versatility of Transferrin Receptor 2 and Its Therapeutic Value
}

\author{
Antonella Roetto *, Mariarosa Mezzanotte and Rosa Maria Pellegrino \\ Department of Clinical and Biological Sciences, University of Torino, 10043 Orbassano, Torino, Italy; \\ mariarosa.mezzanotte@unito.it (M.M.); rosamaria.pellegrino@unito.it (R.M.P.) \\ * Correspondence: antonella.roetto@unito.it; Tel.: +39-011-6705462
}

Received: 28 September 2018; Accepted: 21 October 2018; Published: 23 October 2018

\begin{abstract}
Iron homeostasis is a tightly regulated process in all living organisms because this metal is essential for cellular metabolism, but could be extremely toxic when present in excess. In mammals, there is a complex pathway devoted to iron regulation, whose key protein is hepcidin (Hepc), which is a powerful iron absorption inhibitor mainly produced by the liver. Transferrin receptor 2 (Tfr2) is one of the hepcidin regulators, and mutations in TFR2 gene are responsible for type 3 hereditary hemochromatosis (HFE3), a genetically heterogeneous disease characterized by systemic iron overload. It has been recently pointed out that Hepc production and iron regulation could be exerted also in tissues other than liver, and that Tfr2 has an extrahepatic role in iron metabolism as well. This review summarizes all the most recent data on Tfr2 extrahepatic role, taking into account the putative distinct roles of the two main Tfr 2 isoforms, Tfr $2 \alpha$ and Tfr $2 \beta$. Representing Hepc modulation an effective approach to correct iron balance impairment in common human diseases, and with Tfr2 being one of its regulators, it would be worthwhile to envisage Tfr2 as a therapeutic target.
\end{abstract}

Keywords: Tfr2; iron metabolism; hepcidin; erythropoiesis; SNC

\section{Tfr2 Gene and Proteins}

Tfr2 is a type II transmembrane glycoprotein, a member of the transferrin receptor family and homologous to Tfr1 [1].

It is encoded by TFR2, a 2471 bp long gene localized on the long arm of human chromosome 7 (7q22.1) that consists of 18 exons, and gives origin to two main variants regulated by different specific promoters: Tfr $2 \alpha$ and Tfr $2 \beta$ (Figure 1).

Tfr $2 \alpha$ results from the transcription of all exons, and is prevalently and highly expressed in hepatocytes and erythroid cell lines. Tfr2 $\alpha$ cDNA is $2.3 \mathrm{~kb}$ long (AF067864), and the Tfr2 $\alpha$ is a protein of about $89 \mathrm{kDa}$ encompassing 801 amino acids [2]. As Tfr $1, \operatorname{Tfr} 2 \alpha$ has a short cytoplasmic tail (aa 1-80) that contains a consensus sequence YQRV for endocytosis, a transmembrane domain (aa 81-104) with four cysteines (aa 89-98 and 108-111), involved in disulphide bonds, likely responsible for TFR2 homodimerization, and a large extracellular domain (aa 105-801) comprising a protease-associated domain and two RGD motifs that bind di-ferric Tf (Fe2Tf). Furthermore, an $\mathrm{N}$-terminal mitochondrial targeting sequence (MTS) has been found in Tfr2 intracellular domain [3]. In vitro analysis demonstrated that Tfr $2 \alpha$ on cell membranes can be shed and give origin to a soluble form, and that this process is inhibited by Fe2Tf [4]; however, this form could not be found in animal or human sera.

Tfr2 $\alpha$ transcription is upregulated in mouse embryonic fibroblast cells (NIH3T3) by erythroid GATA1, EKLF, and cEBP $/ \alpha$ transcriptional factors, while FOG1 seems to inhibit GATA1 enhancement [5]. Also, hepatic Hnf $4 \alpha$ stimulates Tfr2 $\alpha$ transcription, since it is significantly decreased 
in liver-specific HNF4 $\alpha$-null mice [6]. There is no Tfr2 $\alpha$ IRE/IRP-dependent post-transcriptional regulation [7], while the hepatic tetraspanin CD81 is able to interact with Tfr2 $\alpha$ and induce its degradation [8].

Tfr2 $\beta$ has an in-frame transcription start site in exon 4, so the Tfr2 $\beta$ cDNA (NM_001206855.1) transcript lacks exons $1-3$, and presents 142 additional untranslated base pairs at its $5^{\prime}$ end. Tfr $2 \beta$ is ubiquitously expressed at low level, and mostly expressed in spleen, heart, and brain. The resulting protein lacks the cytoplasmic and the transmembrane domain [2]. Since no signal peptide involved in the secretory pathway could be evidenced in Tfr $2 \beta$ isoform, it is supposed to be a cytosolic $60 \mathrm{kDa}$ protein identical to the Tfr $2 \alpha$ extracellular domain. At the moment, no transcriptional/translational regulatory pathway is known for Tfr2 $\beta$ isoform (Figure 1 ).

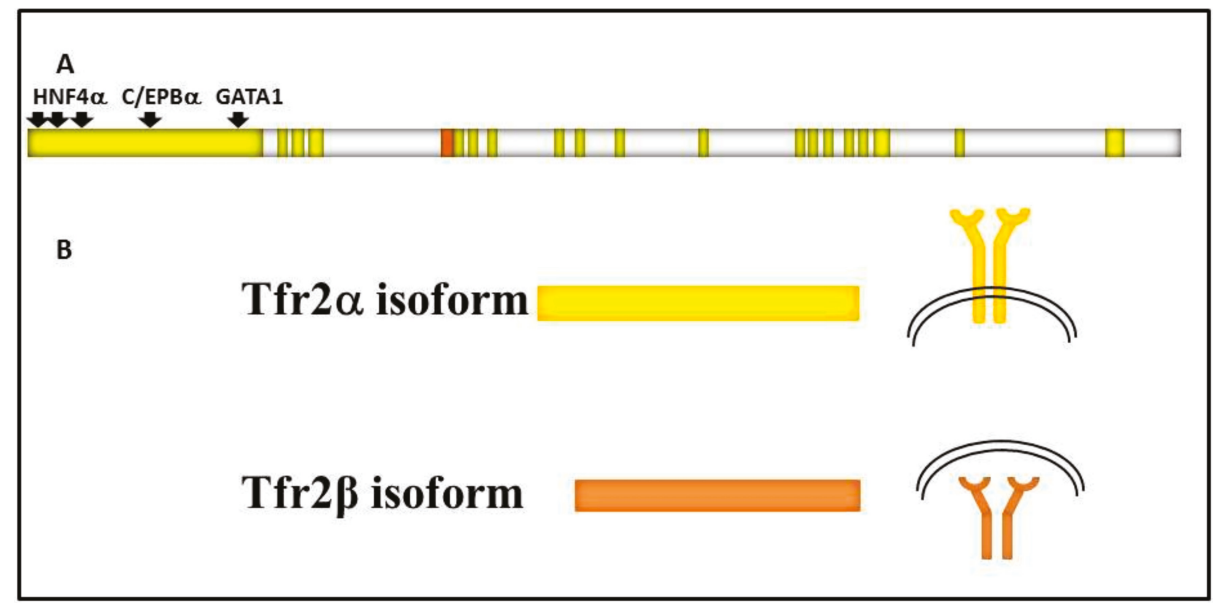

Figure 1. Schematic representation of: (A) TFR2 gene structure. TFR2 18 exons are in bright yellow, TFR $2 \alpha$ promoter is shown upstream of the gene, and transcriptional factors binding sites are highlighted by black arrows. $5^{\prime}$ untranslated region (142 bp long) of TFR $2 \beta$ transcript is shown in orange; (B) the two main transcripts and of $\operatorname{Tfr} 2 \alpha$ and Tfr $2 \beta$ isoforms, that are identical in the common sequence, and the two protein localizations, on the cell surface or in the cytosol, respectively.

\subsection{Tfr2 and HFE3}

Inactivating mutations of TFR2 gene (OMIM: 604720) lead to type 3 hereditary hemochromatosis (TFR2-HHC or HFE3), a rare recessive disorder characterized by increased transferrin saturation and serum ferritin concentration and iron overload [9].

HFE 3 is one of the 5 different forms of hereditary hemochromatosis, a genetically heterogeneous disorder due to the deregulation of iron protein hepcidin (Hepc) [10] (Table 1). TFR2-HHC presents an earlier age of onset than type 1 hereditary hemochromatosis (HFE-HHC), and some pediatric patients have been reported so far. However, the majority of the affected individuals are young adults with abnormal serum iron indices [11].

Most of the mutations involved in HFE3 pathogenesis cause an inactivation of both Tfr2 isoforms, but some of them, occurring in exons from 1 to 3 , impair the production of the $\operatorname{Tfr} 2 \alpha$ isoform only [12-14]. Three patients with homozygote mutation M172K, that impairs Tfr2 $\beta$ translation initiation codon, were identified, all presenting typical hemochromatosis symptoms (cirrhosis, hypogonadism, cardiomyopathy, arthritis) at an average age of $38 \pm 5$ years [13,15].

Unfortunately, few clinical data are available on patients with these mutations to allow an exhaustive genotype/phenotype analysis. 
Table 1. Hereditary hemochromatosis (HHC types) and their relationship with hepcidin.

\begin{tabular}{cccccc}
\hline HH type & Acronym & Inheritance & Gene & Protein & Function \\
\hline HFE1 & HFE-HHC & AR & HFE & Hfe & Hepc regulator \\
HFE2a & HJV-HHC & AR & HJV & Hemojuvelin & Hepc regulator \\
HFE2b & HEPC-HHC & AR & HAMP & Hepc & Fe absorption inhibitor \\
HFE3 & TFR2-HHC & AR & TFR2 & Tfr2 & Hepc regulator \\
HFE4 & FPN1-HHC & AD & SLC40A1 & Fpn1 & Hepc receptor \\
\hline
\end{tabular}

\subsection{Systemic Iron Metabolism: The Hepc-Fpn1 Axis and the Proteins Involved in Hepc Regulation}

In mammals, the hepatocyte-secreted hormone Hepc regulates systemic iron homeostasis [16]. Hepc is codified by HAMP gene, which encodes for an 84 amino acids precursor protein, from which active 20-25 amino acids peptides are generated [17]. It is expressed primarily in the liver, although low levels of Hepc transcripts have been also reported in other organs [18].

How HAMP gene expression is regulated is mostly unknown. There are no IRE elements in its transcript, but the transcriptional factor CCAAT/enhancer binding protein- $\alpha$ is highly expressed in the liver, and seems to stimulate HAMP expression, while the hepatocyte nuclear factor 4- $\alpha$ (HNF-4) represses Hepc expression [19].

The molecular processes involved in hepatic Hepc regulation are quite complex. Basal Hepc expression is regulated through the bone morphogenetic protein 6 (Bmp6) and Smad protein signaling pathway. In iron excess condition, Bmp6, produced and secreted by liver sinusoidal endothelial cells (LSECs) [20], binds to bone morphogenetic protein receptors, ALK2 and/or ALK3 [21], activin receptor type 2A (Actr2a) [22], Hemojuvelin (Hjv) and Neogenin [23]. The protein complex activates signals transducers Smad1/5/8, leading to their interaction with the common mediator Smad4. As a consequence of this interplay, Smad4 translocates into the nucleus and promotes Hepc transcription [16].

More recently, it has been demonstrated that bone morphogenetic protein 2 (Bmp2), expressed in LSECs, can also trigger Hepc transcription increase [24].

A second Hepc regulatory pathway involves di-ferric Tf (Fe2Tf) as the signaling of increased iron availability, transferrin receptor 1 (Tfr1), hemochromatosis type 1 protein (Hfe), and transferrin receptor 2 (Tfr2). It has been demonstrated that Fe2Tf competes with Hfe for binding Tfr1 then, when circulating, Fe2Tf increases as a consequence of iron raising, Hfe dissociates from Tfr1 and binds Tfr2 [25]. Hfe/Tfr2 complex is then responsible for Hepc response to iron increase, through the activation of Erk1/2 and MAPK cascade that has been proposed to potentially converge on the Bmps/Smad1/5/8-mediated pathway [26].

The hierarchy of the two pathway activations, and their relationship, are still not completely defined. In vitro data support the hypothesis that the complex Hfe/Tfr2 interacts with membrane Hjv (mHjv) on cell surface, thereby, the link between the two signaling pathways occurs [27]. It has been found, in vivo, that both Hfe and Tfr2 knock-out (KO) mice present lower pErk1/2 [28] and $\mathrm{pSmad} 1 / 5 / 8$ proteins $[29,30]$, meaning that these two proteins regulate both signal translation pathways. Hepatic Hepc upregulation is inhibited by matriptase 2 (MT-2 or Tmprss6), that acts as Hepc inhibitor cleaving mHjv expressed on the plasma membrane [31]. TMPRSS6 gene expression has been found to be induced by chronic dietary iron loading and Bmp6 injection [32], and its interaction with Neogenin facilitates mHjv cleavage and inactivation in transfected cells [23] (Figure 2).

On the contrary, in iron deficient conditions, this signaling pathway is inhibited by soluble Hjv (sHjv) and Tmprss6, which physically interacts with mHjv, causing its fragmentation.

Hepc expression in hepatocytes is systemically regulated by multiple signals: body iron availability, such as iron-loaded transferrin and hepatic iron stores, erythropoietic activity, hypoxia, and inflammation [33]. Hepc secreted by hepatocytes regulates iron release from duodenal enterocytes, splenic macrophages, and hepatocytes, which are responsible for dietary iron absorption, contain large amounts of iron from erythrocyte recycling, and act as an iron reservoir and export iron when 
needed, respectively. Hepc exerts its function, binding the iron exporter ferroportin 1 (Fpn1) [34] and stimulating complex internalization and degradation, leading, de facto, to cellular retention of iron [35]. Elevated plasma Hepc, as in inflammatory state, downregulates iron efflux from several cell types, and this leads to an overall reduction in plasma iron. On the contrary, low Hepc, as seen in iron-depleted or erythropoietic expansion conditions, causes an increased iron release by macrophages and by the basolateral site of villi duodenal cells.

A potent Hepc inhibitor signal is iron demand for erythropoiesis, mediated by three Hepc modulators (Gdf15, Twgs1, Erfe). Their roles and precise mechanisms in Hepc regulation are still not completely clear, but Erfe, in particular, has emerged as a potent Hepc negative regulator in conditions of acute erythropoietic demand, acting in conjunction with erythropoietin (Epo) signaling, as well as in anemia of inflammation (AI) condition [36].

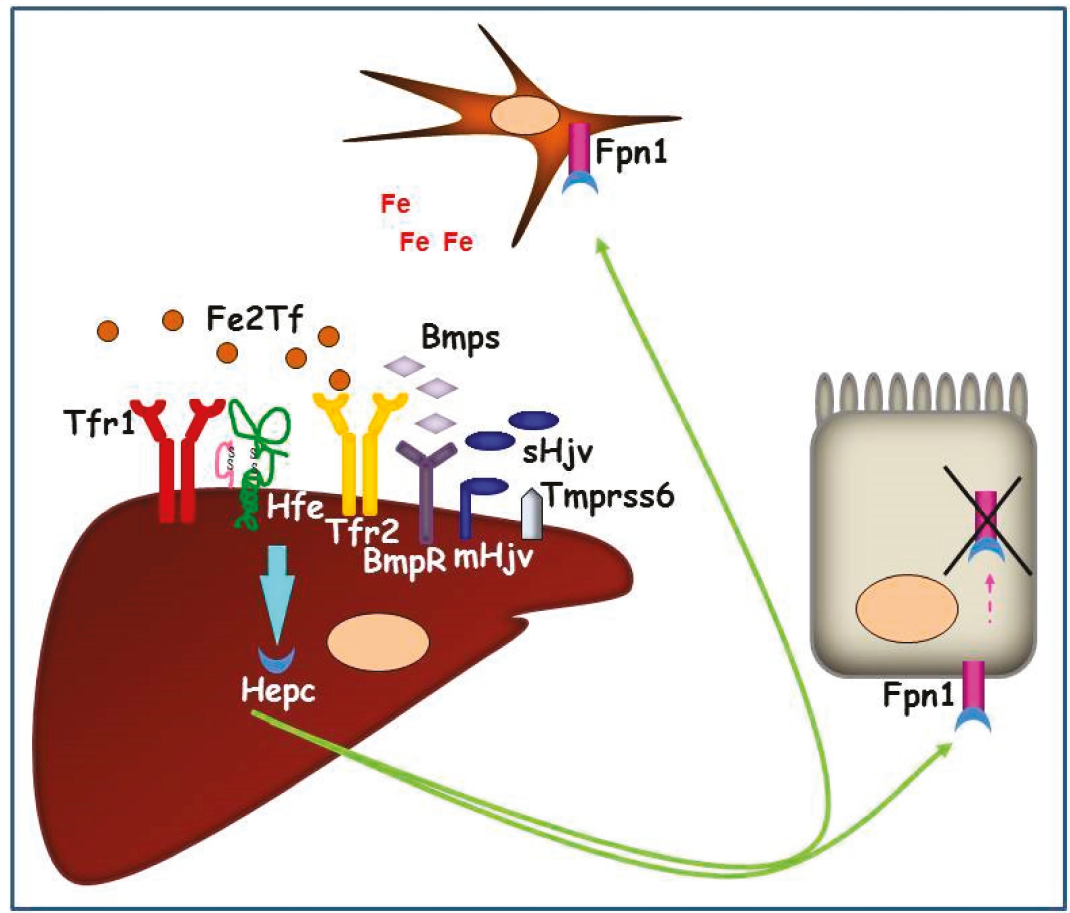

Figure 2. Graphic representation of the hepatic Hepc pathway in conditions of systemic iron increase. The iron signaling proteins (Fe2Tf and Bmps) interact with iron sensors (Tfr1, Hfe, Tfr2, BmpRs) and their co-activator (mHjv) to promote Hepc production. Hepc, secreted by hepatocytes, is transported in plasma and binds iron exporter Fpn1 on duodenal and reticuloendothelial cell surfaces causing its internalization and intracellular degradation. As a consequence, iron remains entrapped in these cells, systemically reducing the metal availability.

HAMP expression is induced by inflammation and infection. This acute phase response involves a different pathway from the ones described above, and is mainly mediated by interleukin 6 (IL-6) inflammatory cytokine, and requires the signal transducer and activator of transcription 3 (STAT3) activation, and the binding of STAT3 to a STAT3-binding motif in the Hepc promoter [37]. In addition, cytokine IL-22, involved in immunological response to extracellular infections, as well as Toll-like receptor 5 (TLR5) agonist flagellin, seem to upregulate Hepc, strengthening the hypothesis of a possible Hepc role in innate immunity [38]. 
Conversely, HAMP expression is repressed by hypoxia both in vitro and in vivo in animal models [33] and humans [39,40]. The mediator of Hepc response to hypoxia seems to be the hypoxia inducible factor (HIF), even though it is not clear if it acts directly or indirectly on Hepc regulation [16]. The fact that Hepc inhibitor, Tmprss6, presents a hypoxia responsive element (HRE) in its promoter [41] might make Tmprss6 the linking protein between hypoxia and iron homeostasis.

Mutations in HAMP gene and in genes codifying for Hepc regulatory proteins (HFE, TFR2, and $H J V)$ cause the lack of upregulation of Hepc as a response to increased liver iron stores. In fact, inappropriately low levels of liver Hepc are observed in patients and mouse models of hereditary hemochromatosis [42,43]. These conditions promote a continuous dietary iron absorption that leads to iron overload. On the contrary, inappropriately high Hepc has been found in animal models and patients with iron resistant iron deficient anemia (IRIDA), a genetic disorder due to mutations in TMPRSS6 gene [44-46].

Mutations in HAMP gene and in genes codifying for Hepc regulatory proteins (HFE, TFR2, and $H J V)$ cause the lack of upregulation of Hepc as a response to increased liver iron stores. In fact, inappropriately low levels of liver Hepc are observed in patients and mouse models of hereditary hemochromatosis $[42,43]$. These conditions promote a continuous dietary iron absorption that leads to iron overload. On the contrary, inappropriately high Hepc has been found in animal models and patients with iron resistant iron deficient anemia (IRIDA), a genetic disorder due to mutations in TMPRSS6 gene [44-46].

\section{Tfr2 in Liver}

In the liver, Tfr $2 \alpha$ is a sensor of circulating iron, but the knowledge about the Tfr $2 \alpha$ hepatic function is still incomplete. It is known that Tfr2 $\alpha$ localizes in caveolar microdomains [47], membrane structures involved in the recruitment of receptors that can be activated by ligand binding [48]. Also, $\operatorname{Tfr} 2 \alpha$ localizes in lipid raft domains on the exosomal cell membrane, where it is internalized by clathrin-mediated endocytosis, if transferrin saturation (TS) is low [49].

Tfr $2 \alpha$ protein regulation occurs mainly through its stabilization on the cell membrane as a consequence of the binding to Fe2Tf [50,51]. An in vitro study showed that, in the presence of Fe2Tf, $\operatorname{Tfr} 2 \alpha$ has an increased half-life and is recycled, while in presence of apo-Tf membrane, Tfr $2 \alpha$ is mainly subjected to lysosomal degradation [52]. It has been recently demonstrated that CD81 is also able to induce $\operatorname{Tfr} 2 \alpha$ degradation, but the correlation between this $\operatorname{Tf} 2 \alpha$ regulatory route and Hepc pathway is still obscure [8].

Therefore, increased TS has an opposite effect on the two Tfrs via two different mechanisms: it causes a decrease of Tfr1, regulated by the IRE/IRP system, but a stabilization of Tfr2 $\alpha$ on the cell surface [1].

This supports the hypothesis that Tfr2 $\alpha$ exerts its function(s) as a signaling receptor more than as an iron importer.

According to the available in vitro data, hepatic Tfr $2 \alpha$ interacts, on the cell membrane, with two main iron proteins, Tfr1 and Hfe.

The current model assumes that Tfr $2 \alpha$, in conjunction with HFE and Tfr1, is a partner of a sensor complex of circulating iron that activates Hepc in response to elevated TS [53]. In physiological conditions (TS 30-35\%) Hfe and the complex Tf/Tfr1 are bound on the plasma cells; when TS increases in response to increased iron availability, loaded Tf impairs Hfe binding to Tfr1/Tf complex, leading it to bind $\operatorname{Tf} 2 \alpha$, that is stabilized on the membrane by the same $\mathrm{Fe}^{2} \mathrm{Tf}$. The resulting complex Tfr2 $\alpha / \mathrm{Fe} 2 \mathrm{Tf} / \mathrm{Hfe}$ causes the activation of Hepc transcription [25]. On the HuH7 hepatoma cell surface, this Tfr $2 \alpha /$ HFE interaction occurs within a multiprotein complex, that also includes $\mathrm{mHjv}$ [27]. It remains to be demonstrated if this complex activates the intracellular signaling to upregulate Hepc expression, also, in vivo.

In the presence of Fe2Tf, Tfr2 $\alpha$ is able to activate Erk1/2 and p38 MAPK kinase signaling transduction pathway [47], since Tfr2 KO mice present a decrease of pErk1/2 [28]. Furthermore, 
the Smad1/5/8 pathway also seems to be involved in Tfr $2 \alpha$-mediated signal transduction, since pSmad1/5/8 is decreased in Tfr2 KO animals, as well [29].

Erk $1 / 2$ phosphorylation could be increased also by Hfe overexpression, and both Tfr2 and Hfe cause an increase of the pro-hormone convertase furin [29], previously demonstrated to be involved in Hepc regulation [54]. Whether it is the sole and/or the main Tfr2 dependent Hepc regulatory pathway is still not clear.

\section{TFR2 Mouse Models}

The first Tfr2 $\mathrm{KO}$ animal model was generated by targeted mutagenesis, introducing a premature stop codon (Y245X) in the murine Tfr2 coding sequence [55]. This mutation is homologous to the Y250X variant, originally detected in humans and responsible for HFE3 [9]. Even young homozygous Y245X mice maintained on a standard diet had high liver iron concentration, in agreement with the observation of early iron overload in HFE3 patients [11]. As in humans, heterozygous animals were normal. The histological distribution of iron resembles the features of HFE3, with the typical liver periportal accumulation.

Subsequently, different murine models of Tfr2 inactivation were developed, including Tfr2 total (Tfr2 KO) and liver-specific (Tfr2 LCKO) knockouts [56,57] as well as a Tfr2/Hfe double KO [28]. All these models are characterized by an inadequate hepatic Hepc expression and liver iron overload with variable severity. However, when generated in the same genetic background, Tfr $2 \mathrm{KO}$ mice were shown to have a more severe iron overload than Hfe KO, although less severe than the Tfr2/Hfe double $\mathrm{KO}$ [58]. These observations are in agreement with the model of Tfr2/Hfe proteins' cooperation in the liver.

In a double Tfr2/Hjv KO mouse model, plasma Hepc and Hepc transcription was lower than in Tfr2, and similar to Hjv single KOs, respectively. The same was true for the Tfr2/Hfe double $\mathrm{KO}$ [59]. Also, a recent study on a mouse model with inactivation of both Bmp6 and Tfr2 (Tfr2/Bmp6 double KO) demonstrated that loss of functional Tfr2 further represses Hamp expression, Smad5 phosphorylation, and plasma Hepc amount in Bmp6 KO mice. The same results were obtained in the $\mathrm{Hfe} / \mathrm{Bmp} 6$ double $\mathrm{KO}$, and the Hfe/Bmp6/Tfr2 triple KO [60]. All these data support the hypothesis that Tfr2 and Hfe act downstream Bmp6 and upstream Hjv in Hepc regulatory pathway.

Last, Tfr2 germinal vs liver-specific $\mathrm{KO}$ animals highlighted a distinct function of Tfr2 outside the liver in maintaining iron balance. In fact, Tfr2 $\mathrm{KO}$ mice have less severe iron overload, slightly higher hemoglobin $(\mathrm{Hb})$ levels $[57,61]$, and moderate macrocytosis than Tfr2 LCKO [56,57].

To study the specific function of Tfr $2 \beta$ isoform in iron metabolism, a specific mouse model was generated, introducing the M167K substitution in the Tfr2 protein [57]. This mutation, homologous to the one found in naturally mutant individuals with HFE3, substitutes the start codon methionine of the Tfr $2 \beta$ isoform, with a lysine. Interestingly, this knock-in mouse model (Tfr2 KI), specifically lacking the Tfr $2 \beta$-isoform $\left(\alpha^{+} \beta^{0}\right)$, is characterized by normal transferrin saturation, liver iron concentration, Hepc, and Bmp6 levels, but shows transient anemia at a young age. In addition, adult Tfr2 KI animals accumulate iron in the spleen, due to a significant reduction of iron exporter Fpn1 mRNA, thus suggesting a possible regulatory effect of Tfr $2 \beta$ isoform on splenic Fpn1 expression. These data are further supported by the results obtained in Tfr2 macrophage-specific KO mouse model. These animals present normal systemic iron parameters, but lower Fpn1 transcript and protein in peritoneal macrophages [62]. Recent studies demonstrated that Tfr2 $\beta$ is well expressed in reticuloendothelial cells of different tissues, where it exerts its role in modulating iron availability in these tissues, acting on Fpn1 transcription (see below). Since Fpn1 protein has several regulatory systems both at the transcriptional $[63,64]$ and post-transcriptional level through IRE/IRP system [7], and origins from different Fpn1 transcripts with or without IREs [65], it remains to be clarified how and when Tfr2 $\beta$ acts on Fpn1 regulation. 


\section{Tfr2 in Extrahepatic Tissues}

\subsection{Tfr2 in the Erythropoietic Compartment}

A Tfr $2 \alpha$ erythropoietic role was firstly hypothesized in genome-wide association studies that identified Tfr $2 \alpha$ polymorphisms affecting hematologic parameters [66,67]. These data were further strengthened by the identification of Tfr $2 \alpha$ as a component of the erythropoietin receptor (EpoR) complex in erythroid progenitor cells. Tfr $2 \alpha$ was shown to be crucial for efficient transport of EpoR to the cell surface and for its terminal differentiation, since human erythroid progenitors with silenced $\operatorname{Tfr} 2 \alpha$ showed a delayed differentiation [68]. Another hint was provided by the increased $\mathrm{Hb}$ content present only in Tfr2 germinal KO, but not in liver-specific KO mice. Since both mouse models manifest comparable iron overload, the lack of enhanced hemoglobinization in Tfr2 LCKO mice suggests that the erythroid function of Tfr2 $\alpha$ is preserved [68]. Also, double Tmprss6/Tfr2 KO mice develop erythrocytosis while, in double Tmprss6/Tfr2 LCKO mice, where Tfr $2 \alpha$ is functional in erythroid cells, red blood cells (RBC) number is normal [61].

Recently, a mouse model lacking Tfr2 in bone marrow cells ( $\mathrm{Tfr}^{\mathrm{BMKO}}$ ) was developed injecting $\mathrm{BM}$ cells from Tfr2 $\mathrm{KO}$ mice in lethally irradiated C57/BL6 mice. Tfr $2^{\mathrm{BMKO}}$ mice manifest reduced mean corpuscular value (MCV) and low Hepc levels as a typical response to iron deficiency, but an enhanced terminal erythropoiesis, demonstrated by increased RBC and $\mathrm{Hb}$ content [69]. Interestingly, erythropoiesis and Epo level in these mice do not change in a mild dietary restriction setting, as happens for WT animals, where the Epo level is drastically increased.

As a whole, these data suggest that the lack of Tfr2 confers increased Epo sensitivity to erythroid progenitor cells, a hypothesis that is further supported by the induction of Epo target genes, like Hamp regulator Erfe [70], in these animals.

A similar animal model was recently developed crossing Tfr2 floxed mice with Vav-Cre expressing mice to obtain Tfr2 silencing in erythroid compartment [62]. Results differed from previous work since decreased RBC and splenomegaly were observed, but these discrepancies might be explained by the different procedures used to create the two mouse models since, in the first case, Tfr2 is silenced in all bone marrow (BM) cell lines after a BM transplant procedure while, in the latter, only the erythroid cell lines are Tfr2 null.

In another study, Tfr2 erythropoietic role was further investigated studying the erythropoiesis of two Tfr2 mice with one or both Tfr2 isoforms silenced (Tfr2 KI and Tfr2 KO), and with normal or increased iron availability [57]. The evaluations were performed in bone marrow and spleen, in young and adult animals to unravel the erythropoietic role of Tfr2 isoforms at different ages, and in the two main erythropoietic organs. It resulted that the lack of Tfr2 in Tfr2 $\mathrm{KO}$ mice leads to macrocytosis with low reticulocyte number and increased $\mathrm{Hb}$ value, together with an anticipation of erythropoiesis in young mice both in BM and in the spleen [71], probably because the increased systemic iron amount present in these animals allows them to reach mature erythropoiesis even at a young age.

Although different animals and approaches were used in these studies, and partially contradictory results were obtained, they all demonstrate that erythropoiesis is impaired by a lack of Tfr2 in BM, independently from its activity in hepatic tissues.

Moreover, results obtained studying Tfr2 $\mathrm{KI}\left(\alpha^{+} \beta^{0}\right)$ mice [57] demonstrated, for the first time, the involvement of Tfr $2 \beta$ in favoring iron availability for erythropoiesis. In fact, the sole lack of Tfr $2 \beta$, in normal systemic iron condition, causes an increased but immature splenic erythropoiesis seen only in young mice, as if they had insufficient iron availability during animal growth, that is normalized in animal adult age. Decreased iron availability for erythropoiesis in Tfr2 KI young mice is demonstrated by increased ferritin (Ft) and decreased divalent metals transporter 1 (DMT1) in their splenic monocyte, the increase of Erfe transcription in BM and spleen, and the low hepatic Hepc transcription that could, in turn, be responsible for the increased splenic Fpn1 amount in these animals [71].

This effect, due to Tfr $2 \beta$ absence, in aged matched Tfr $2 \mathrm{KO}\left(\alpha^{0} \beta^{0}\right)$ mice, was compensated by the increased amount of circulating iron available that may be used for erythrocyte production (Figure $3 \mathrm{~A}$ ). 
A

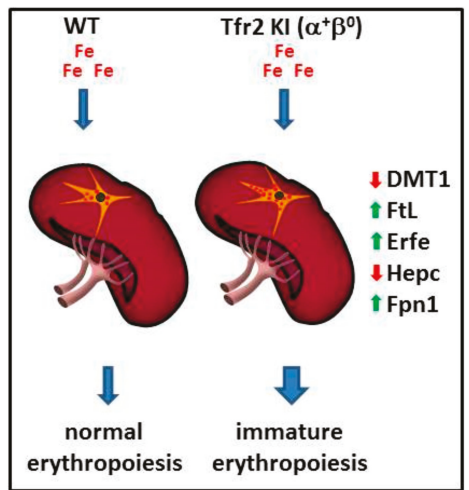

B

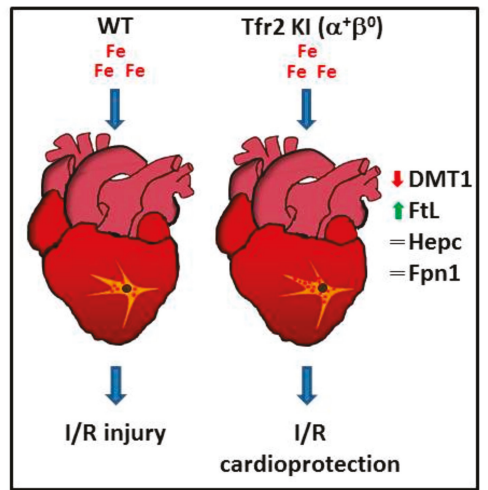

Figure 3. Schematic model illustrating Tfr $2 \beta$ function in regulation iron export from reticulo-endothelial (REL) cells. Lack of Tfr $2 \beta$ causes an increased iron retention in REL cells that (A) causes the onset of an immature erythropoiesis in the spleen, and (B) induces a cardioprotection against the effect of the reperfusion of oxygenated solutions after an ischemic event in heart (see text).

\section{2. $T f r 2 \beta$ in the Heart}

The cardiac muscle is a major site of oxygen consumption, so an adequate intracellular iron pool is essential to its aerobic activity. This is demonstrated by the finding that deletion of cardiac Tfr1 in mice causes fatal energetic failure in cardiomyocytes [72]. Cardiomyocytes express relatively high levels of Hepc and Fpn1, despite the fact that these cells have no role in systemic iron control [73].

Studies on mouse models demonstrated that the cardiac Hepc/Fpn1 axis is essential for heart cells' autonomous control of the intracellular iron pool that guarantees a normal cardiac functionality [73], and that Hepc/Fpn1 appears to protect the heart from the effects of systemic iron deficiency [74].

On the other side, cardiomyocytes are particularly susceptible to ROS-mediated damage because they are rich in mitochondria and consume large amounts of oxygen [75]. Therefore, when labile iron pool (LIP) expansion occurs, oxidative stress can affect cardiac functions, as it happens in severe juvenile HHC forms [10].

Although ubiquitously expressed, Tfr2 $\beta$ is highly transcribed in heart [2], such that a role for Tfr $2 \beta$ isoform in cardiac iron management has been postulated.

Indeed, in the hearts of two Tfr2 $\beta$ null mice with normal or increased systemic iron amount, Tfr2 KI and Tfr2 LCKO [57], the silencing of Tfr2 $\beta$ induces a selective activation of different proteins involved in cell survival, antioxidant enzymes, and kinases involved in cardioprotective pathways that are usually activated by stressful stimuli.

In particular, Tfr2 KI and Tfr2 LCKO mice develop a greater resistance against acute ischemia/reperfusion $(I / R)$ challenge, irrespective of animals' systemic iron content, via the activation of the RISK or SAFE/GSK3 $\beta$ cardioprotective pathways, respectively. The iron imbalance present in these mice hearts was demonstrated by the finding that both models present the activation of antioxidant proteins, pro-apoptotic markers, and catalase, even before I/R [76]. They also have a slightly increased synthesis of cardiac ferritins, similarly to what happens in ischemic preconditioning, in which a small increase of ferritin protects cardiac cells from iron-mediated oxidative damage associated with ischemia/reperfusion injury [77].

Since previous data demonstrated a significant decrease of Fpn1, and an increased iron deposit in splenic macrophages in Tfr2 $\beta$-null mice [57,71], one might hypothesize that Tfr $2 \beta$ isoform inactivation, in the heart, causes an iron retention in cardiac reticuloendothelial cells that is able to induce cardioprotective pathways activation and to reduce iron availability to form free oxygen radicals during the reperfusion phase (Figure 3B). 


\subsection{Tfr2 in the Central Nervous System (CNS)}

Iron levels in the brain vary during life. The iron amount increases with aging in the striatum and the brain stem [78] and it is present in most CNS cell types: neurons, oligodendrocytes, microglia, and astrocytes [79]. A well-regulated iron homeostasis is important for brain development and function. Iron deficiency negatively impacts neurodevelopmental processes [80], and is also implicated in a number of psychiatric and neurological conditions, learning disabilities, attention deficit hyperactivity disorder (ADHD), and pediatric restless legs syndrome (RLS) [81,82]. On the contrary, brain iron overload is present in Alzheimer's and Huntington's neurodegenerative disorders, as well as in Parkinson's disease (PD) [83]. Nevertheless, the exact role of iron in these diseases' onset/worsening is still debated, and it remains to be clarified whether brain iron overload is directly involved in their pathogenesis, or it is a secondary effect that contributes to their clinical symptoms' progression.

The main sites of brain iron uptake are the brain vascular endothelial cells (BVECs) present in the blood-brain barrier (BBB) [84]. As in other organs, there are two main pathways responsible for CNS cells' iron uptake, the Tf-Tfr1 pathway, and the NTBI transport pathway. Traditionally, Tf-Tfr1 is considered a major pathway, and works as in all the other cell types of the organism, through a receptor-mediated endocytosis of plasma Tf circulating in the ventricles [85].

The NTBI transport pathway has been recently revaluated as a significant way to introduce iron in CNS, and it could be done through vesicular or non-vesicular mechanism. In the first case, Tf homologues, such as lactoferrin and melanotransferrin, might be involved in Tfr-mediated iron transport; moreover, the newly characterized Ft receptors, Tim 2 and Scara5, can introduce iron inside the cells through a Ft-FtR pathway. Non-vesicular iron uptake can be exerted by iron importer DMT1, that is present in endothelial cells of the brain microvasculature, as well as other importers like IN4/5/6 [86].

In CNS, the iron exporter Fpn1 is found in BVECs, neurons, oligodendrocytes, astrocytes, the choroid plexus, and ependymal cells and microglia, together with ceruloplasmin (CP) or hephaestin (Hp), the two ferroxidases that cooperate with Fpn1 to facilitate iron export [87]. Fpn1 could be the main protein responsible for iron release from CNS cells, even if other proteins and mechanisms have been brought into play for these processes [86].

Inside brain cells, the majority of iron is bound to ferritin heteropolymers ( $\mathrm{Ft} \mathrm{H} / \mathrm{L})$ [88]. Their cellular distribution and ratio varies with iron status, age, and disease conditions [89].

CNS iron homeostasis is intracellularly modulated by (IRE/IRPs) system [90], and by local and systemic Hepc. Injection of Hepc into the mouse lateral cerebral ventricle decreases Fpn1 protein levels and treatment of primary cultured rat neurons with Hepc decreases Fpn1 expression and reduces these cells release of iron [91]. More recently, it was demonstrated that injection of adenovirus expressing Hepc (ad-hepcidin) in brain ventricles reduces brain iron in iron-overloaded rats through the downregulation of iron transporter [92]. This data indicates that Hepc/Fpn1 axis is present and acts in CNS, as in the other districts of the organism.

It remains a matter of debate whether Hepc acting in brain is locally produced or comes from the systemic circulation crossing the BBB or both [93].

Similar to other Hepc regulatory proteins, Tfr2 gene expression has been shown in total brain extracts [2,94], in brain tumor cell lines [95], or in specific neuronal subtypes as dopaminergic neurons [3]. Furthermore, a transcriptome study on Tfr2-null mice revealed that several genes involved in the control of neuronal functions are abnormally transcribed [96]. Of note, the same experimental approaches, applied to Hfe-null mice, revealed that a consistent percentage of transcripts are modified in the same way in the two models [96]. This highlights the possibility of a cooperation between Tfr $2 \alpha$ and Hfe protein in CNS iron regulation, as in the rest of the organism.

Immunofluorescence studies using a Tfr $2 \alpha$-specific antibody demonstrate that the protein is significantly produced in mouse hippocampus, amygdala, central nucleus, and in the hypothalamic paraventricular nucleus [97]. 
A recent study assessed the situation of iron in the brain of Tfr2 $\mathrm{KO}$ mouse model vs WT sib pairs subjected to an iron-enriched diet (IED). They both are iron overloaded animals, so one could distinguish the effects of Tfr2 silencing from those due to Tfr2-independent iron load modifications.

It has been demonstrated that Tfr2 causes a lack of brain Hepc response to the systemic rise of iron levels, with altered iron mobilization and/or cellular distribution in the nervous tissue [98].

Moreover, Tfr2 $\mathrm{KO}$ mice present a selective over activation of neurons in the limbic circuit and the emergence of an anxious-like behavior.

Also, microglial cells showed sensitivity to iron perturbations of Tfr2 $\mathrm{KO}$ mice, being more reactive, dystrophic, and with a high level of apoptosis [97]. In light of these data, Tfr2 appears to be a key regulator of brain iron homeostasis, and could have a role in the regulation of the brain regions that are involved in the anxiety onset, mainly, the basolateral and central nucleus subregions of the amygdala [98].

\section{Tfr2 in Intracellular Iron Trafficking}

It is still under debate if Tfr $2 \alpha$ contributes to iron introduction inside the cells. When the protein was characterized, it was reported that, in vitro, it was able to introduce iron inside cells [2], but its contribution to intracellular iron amount in vivo seems to be quite negligible, since Tfr1-deficient mice present severe iron deficiency not compensated by the presence of Tfr2 [1].

Conversely, Tfr $2 \alpha$ seems to have a role in intracellular iron trafficking, at least in specific cell types. The first evidence about it was found in dopaminergic neurons, where a novel Tf/Tfr $2 \alpha$-mediated iron transport pathway to the mitochondria has been reported [3]. Disruption of this Tf/TfR2 $\alpha$-dependent system has been associated with PD, and this finding highlights the role of iron accumulation in this movement disorder [3]. In this regard, a protective association between some $\operatorname{Tf}$ and $\operatorname{TfR} 2 \alpha$ genetic haplotypes and PD was reported, suggesting that $\operatorname{Tf}$ or a Tf/TfR $2 \alpha$ complex may play a role in the etiology of these disorders [99].

More recently, a similar TfR $2 \alpha$ function in iron delivery to mitochondria has been convincingly demonstrated in erythroid cells. In an intermediate stage of human erythroid cell maturation, $\operatorname{Tfr} 2 \alpha$ was present in cytoplasmic multi-organellar complexes, formed by lysosomes surrounded by mitochondria, and found to be co-regulated with several proteins, among which, ionic channels and proteins involved in lysosomal modification and in mitochondrial membrane contacts to other intracellular organelles [100]. Therefore, Tfr2 $\alpha$ in lysosomes has been proposed to be involved in iron delivery from these organelles to mitochondria, for $\mathrm{Hb}$ synthesis. Considering the abovementioned evidence about a specific role for Tfr $2 \alpha$ in erythropoiesis, this data might represent one of the molecular processes at the basis of Tfr $2 \alpha$ erythropoietic function/s (Figure 4).

In light of the above data, Tfr $2 \alpha$ involvement in iron delivery to the mitochondria, notably, seems to work at least in the two compartments in which this protein is significantly produced: brain and bone marrow. Although a similar mechanism has been evidenced also in cell lines derived from other organs (HeLa and hepatoma cell lines) [52,101], it remains an open question if this TfR $2 \alpha$ function is present also in other cell types. 


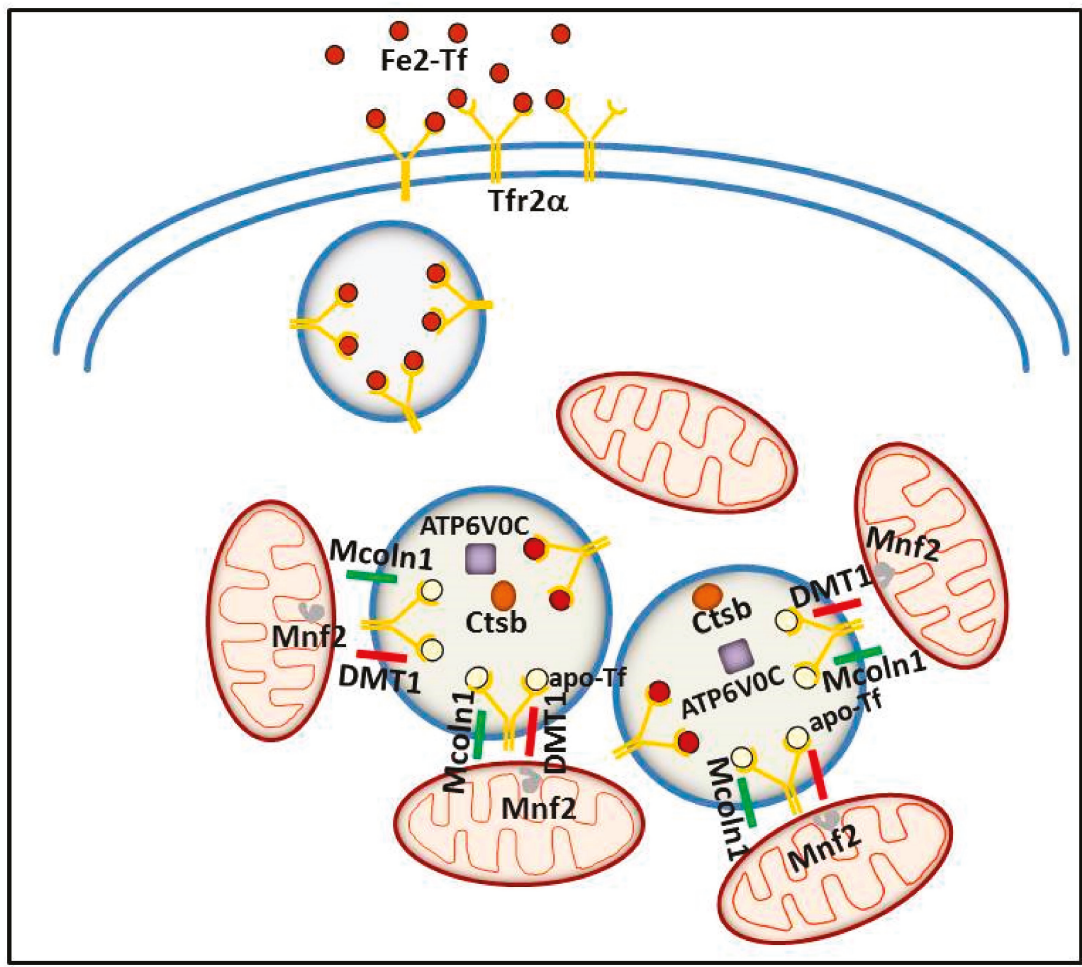

Figure 4. Schematic model illustrating the putative intracellular $\operatorname{Tfr} 2 \alpha$ role in erythroid cells. Tfr2 $\alpha$-together with ATPV0C, a V-ATPase that contributes to vesicular acidification and lysosomal activity; Mcoln1, a lysosomal divalent cation channel; lysosomal cathepsin B (CTSB); and iron importer DMT1-could be involved in iron delivery from lysosome to mitochondria, with the collaboration of Mitofusin-2 (MFN-2), a mitochondrial outer membrane protein involved in mitochondria-endoplasmic reticulum contacts.

\section{Tfr2 in Other Diseases}

Being a "regulator of the iron regulator" hepcidin, Tfr2 transcriptional analysis was attempted to unravel if the Tfr2 isoforms could be reliable markers for some disorders in which iron perturbations occur.

\subsection{Tfr2 in Cancer}

Cancer cells need an increased amount of iron for their growth, and iron importers upmodulation confer a selective advantage to these cells.

Since its characterization, the significant transcription of TFR2 gene appeared evident in BM cancer cells, in particular, erythroid leukemic cells [5], but also in myeloid malignant cells [2], while $\operatorname{Tfr} 2 \beta$ seemed much more prevalent than the TfR $2 \alpha$ isoform in chronic B cells lymphocytic leukemia (B-CLL) cells [102].

Due to high TFR2 expression in erythroid lineage, and to its functional relationship with the erythropoietin receptor (EpoR) [68], TFR2 transcription was evaluated in patients with myelodysplastic syndromes (MDS), a hematopoietic disorder with a variable risk to evolve in acute myeloid leukemia (AML), and in which chronic anemia can be corrected by Epo injection [103]. It has been found that Tfr $2 \alpha$ and Tfr $2 \beta$ isoforms, as well as EPOR transcript, have a lower level of transcription in BM from high risk MDS patients, such as RAEB2, compared to controls and low risk MDS cells [104]. Likewise, 
AML patients with high level of Tfr2 $\alpha$ and Tfr2 $\beta$ present an increased survival [105]. Therefore, Tfr2 isoforms might represent good predictive markers for MDS/AML prognosis.

Calzolari et al. 2007 [106] demonstrated TFR2 expression in colon and ovarian cancer cell lines, as well as in lymphoma and glioblastoma (GBM). Moreover, in glioblastoma TB10 cell line under hypoxic condition, a marked increase of TFR2 transcription was observed. In these cell lines, TFR2 high expression is probably correlated with cell proliferation, since Tfr2 silencing inhibited GMB cell growth. Surprisingly, tumor cells from GBM patients with high TFR2 transcriptional levels present a better prognosis compared to patients with low transcripts. Although, this is probably due to the fact that Tfr2-expressing cells have a highly increased proliferation, so they are more sensitive to temozolomide, the anti-proliferative drug used in GBM therapy, more than to a direct involvement of Tfr2 in the disease course [107].

\subsection{Tfr2 in Alzheimer's Disease (AD)}

Alzheimer's disease (AD) is another common degenerative disorder in which iron perturbation has been demonstrated [108].

A recent genetic study from $116 \mathrm{AD}$ patients has found that a Tfr2 single nucleotide polymorphism (rs 7385804) and a Tfr2 haplotype, composed by two SNPs (rs 7385804 and rs 4434553) are associated with a decreased AD susceptibility [109].

In the same study, a significant decrease of Tfr2 transcription was found in peripheral blood mononuclear cells (PBMC) from AD patients, compared to healthy controls $(p<0.001)$ [110].

\section{Tfr2 as a Therapeutic Target}

In our opinion, three might be the major application of $\operatorname{Tfr} 2 \alpha$ as a therapeutic target: (a) as Hepc regulator, it could be a target in disorders in which Hepc amount is, in some way, inadequate to body iron availability; (b) since Tfr $2 \alpha$ production is selective in specific organs and cell types, it could represent a selective target to correct iron perturbation in these organs; (c) Tfr2, being a membrane protein that is able to bind plasma Tf and to be internalized with it, this property could be utilized as a vector for drugs.

As mentioned above, TfR $2 \alpha$ is involved in regulation of Hepc and, in consequence, in iron modulation according to body/organs needs. Among the Hepc-related disorders there are all the hereditary hemochromatosis forms (Table 1) and the secondary iron overload disorders, like hemoglobinopathy, where abnormally low Hepc amounts lead to iron overload.

In this regard, just published data demonstrate that Tfr2 KO BM transplantation in beta-thalassemia intermedia ( $\beta$-TI) mouse models significantly improved these animals' erythropoiesis, opening a new way to the therapy of this very common disorder [111].

In IRIDA and anemia of chronic disease (ACD), where abnormally high Hepc causes the onset of an iron deficiency condition [111], Tfr2 downmodulation might be beneficial to decrease Hepc hyperproduction. A preliminary study on mice revealed that Tfr2 silencing, through small interfering RNAs (Tfr2-siRNA) in a single dose, led to a significant Hepc downmodulation, and increased transferrin saturation within $24 \mathrm{~h}$ post-administration, persisting for more than two weeks, and to a recovery from anemia in animal models of ACD [112].

Beside the liver, in brain, Tfr2 regulates the production of local Hepc and iron amount in the CNS, since Tfr2 KO mice brain have a blunted Hepc response to brain iron overload [97]. In recent time, it has emerged that brain Hepc production is altered in several neurodegenerative disorders: downmodulated in Alzheimer's and Parkinson's disease [113,114] and upmodulated in restless legs syndrome (RLS) [115]. It might be worthwhile to further investigate if Tfr2 is involved in these Hepc variations, and consider using anti Tfr2 antibodies or siRNA-based therapy to rescue Hepc physiologic values in RLS. Nowadays, siRNA delivery to brain is quite difficult, due to the presence of the BBB, but the ongoing studies on nanoparticles' use, to target siRNA in specific sites, could allow an increase in the efficacy of this therapy [116]. 
An alternative therapeutic approach aims to deliver blocking antibody in the brain, exploiting the BBB physiologic activities. This is based on the use of anti-Tfr1 antibodies, since Tfr1 is well expressed in BBB endothelial cells and is involved in receptor-mediated transcytosis. Indeed, it has been demonstrated that the bispecific Tfr1/BACE1 ( $\beta$-amyloid cleaving enzyme-1) antibody resulted in being effective in decreasing $\beta$-amyloid concentration in the brain [117].

Due to high Tfr1/Tfr2 homology and the common cellular internalization through a receptor-mediated endocytosis pathway, one could hypothesize a parallel Tfr2-based approach for CNS, blocking antibody delivery. Nevertheless, it should be further confirmed, the presence of Tfr2 on BBB endothelial cells and its involvement in transcytosis.

Recent studies have aimed at exploiting the Tfr1 as a vehicle for drug delivery inside the cells through endocytosis, often utilizing Tfr1 natural ligand, Tf, conjugated with different synthetic molecules [1]. Moreover, since Tfr1 is able to bind and internalize FtH also [118], FtH nanocages conjugated with a PARP inhibitor, olaparib, were developed for breast cancer therapy [119].

Due to its strict homology to Tfr 1 , one might hypothesize that Tfr $2 \alpha$ could also be utilized to deliver drugs inside cells. This approach would be particularly useful for two main Tfr $2 \alpha$ features; $\operatorname{Tfr} 2 \alpha$-selective expression in particular tissues (hepatic, erythroid, and in CNS) and Tfr $2 \alpha$ high expression in several tumor cells, sometimes with Tfr1 and sometimes without it. High expression of Tfr 1 and Tfr $2 \alpha$ were, in fact, detected in tumor and para-cancerous normal liver tissues collected from 41 patients with hepatocellular carcinoma (HCC) [120]. Tfr2 $\alpha$ is also highly expressed in brain tumor cells in several cases of anaplastic astrocytoma and glioblastoma, but not in normal brain or endothelial brain cells [121].

Furthermore, in the light of the new data on Tfr $2 \alpha$ function in delivery iron to mitochondria, Tfr $2 \alpha$ could, possibly, represent a good vehicle for drug delivery in these organelles [122], paving the way to tailored therapies for mitochondrial iron disorders, notably Friedreich's ataxia [123].

Unfortunately, too few functional data are available at the moment on Tfr2 $\beta$ isoform to foresee possible therapeutic applications.

\section{Conclusions}

The process of body iron homeostasis is complex, and since there is no apparent significant excretory pathway, the amount of iron absorbed from mature duodenal enterocytes and that is recycled by macrophages needs to be tightly regulated. From the last decades, iron pathways have been enriched of new regulatory proteins whose functions remains to be elucidated from the molecular point of view. Each of them could represent a potential target for a focused pharmacological therapy of disorders with iron unbalance, that still represents the most prevalent of diseases all around the world.

Author Contributions: A.R. wrote the manuscript, M.M. and R.M.P. significantly contributed to the paper conceptualization, data curation, original draft preparation, review \& editing.

Funding: The APC was funded by project ROEA_RILO_18_01.

Acknowledgments: We would like to acknowledge Marco De Gobbi, Paolo Porporato, Myriam Hsu, and Delia Galeno for their help in manuscript editing.

Conflicts of Interest: The authors declare no conflict of interest.

\section{References}

1. Kawabata, H. Transferrin and transferrin receptors update. Free Radic. Biol. Med. 2018. [CrossRef] [PubMed]

2. Kawabata, H.; Yang, R.; Hirama, T.; Vuong, P.T.; Kawano, S.; Gombart, A.F.; Koeffler, H.P. Molecular cloning of transferrin receptor 2. A new member of the transferrin receptor-like family. J. Biol. Chem. 1999, 274, 20826-20832. [CrossRef] [PubMed] 
3. Mastroberardino, P.G.; Hoffman, E.K.; Horowitz, M.P.; Betarbet, R.; Taylor, G.; Cheng, D.; Na, H.M.; Gutekunst, C.A.; Gearing, M.; Trojanowski, J.Q.; et al. A novel transferrin/TfR2-mediated mitochondrial iron transport system is disrupted in Parkinson's disease. Neurobiol. Dis. 2009, 34, 417-431. [CrossRef] [PubMed]

4. Pagani, A.; Vieillevoye, M.; Nai, A.; Rausa, M.; Ladli, M.; Lacombe, C.; Mayeux, P.; Verdier, F.; Camaschella, C.; Silvestri, L. Regulation of cell surface transferrin receptor-2 by iron-dependent cleavage and release of a soluble form. Haematologica 2015, 100, 458-465. [CrossRef] [PubMed]

5. Kawabata, H.; Germain, R.S.; Ikezoe, T.; Tong, X.; Green, E.M.; Gombart, A.F.; Koeffler, H.P. Regulation of expression of murine transferrin receptor 2. Blood 2001, 98, 1949-1954. [CrossRef] [PubMed]

6. Matsuo, S.; Ogawa, M.; Muckenthaler, M.U.; Mizui, Y.; Sasaki, S.; Fujimura, T.; Takizawa, M.; Ariga, N.; Ozaki, H.; Sakaguchi, M.; et al. Hepatocyte Nuclear Factor $4 \alpha$ controls iron metabolism and regulates transferrin receptor 2 in mouse liver. J. Biol. Chem. 2015, 290, 30855-30865. [CrossRef] [PubMed]

7. Muckenthaler, M.U.; Galy, B.; Hentze, M.W. Systemic iron homeostasis and the iron-responsive element/iron-regulatory protein (IRE/IRP) regulatory network. Annu. Rev. Nutr. 2008, 28, 197-213. [CrossRef] [PubMed]

8. Chen, J.; Enns, C.A. CD81 promotes both the degradation of transferrin receptor 2 (TfR2) and the Tfr2-mediated maintenance of hepcidin expression. J. Biol. Chem. 2015, 290, 7841-7850. [CrossRef] [PubMed]

9. Camaschella, C.; Roetto, A.; Calì, A.; De Gobbi, M.; Garozzo, G.; Carella, M.; Majorano, N.; Totaro, A.; Gasparini, P. The gene TFR2 is mutated in a new type of haemochromatosis mapping to 7q22. Nat. Genet. 2000, 25, 14-15. [CrossRef] [PubMed]

10. Brissot, P.; Cavey, T.; Ropert, M.; Guggenbuhl, P.; Loréal, O. Genetic hemochromatosis: Pathophysiology; diagnostic and therapeutic management. Presse Med. 2017, 46, e288-e295. [CrossRef] [PubMed]

11. De Gobbi, M.; Roetto, A. TFR2-Related Hereditary Hemochromatosis. In GeneReviewss ${ }^{\circledR}$; Adam, M.P., Ardinger, H.H., Pagon, R.A., Wallace, S.E., Bean, L.J.H., Stephens, K., Amemiya, A., Eds.; University of Washington: Seattle, WA, USA, 2005; pp. 1993-2018.

12. Biasiotto, G.; Belloli, S.; Ruggeri, G.; Zanella, I.; Gerardi, G.; Corrado, M.; Gobbi, E.; Albertini, A.; Arosio, P. Identification of new mutations of the HFE, hepcidin, and transferrin receptor 2 genes by denaturing HPLC analysis of individuals with biochemical indications of iron overload. Clin. Chem. 2003, 49, 1981-1988. [CrossRef] [PubMed]

13. Roetto, A.; Totaro, A.; Piperno, A.; Piga, A.; Longo, F.; Garozzo, G.; Calì, A.; De Gobbi, M.; Gasparini, P.; Camaschella, C. New mutations inactivating transferrin receptor 2 in hemochromatosis type 3. Blood 2001, 97, 2555-2560. [CrossRef] [PubMed]

14. Bardou-Jacquet, E.; Cunat, S.; Beaumont-Epinette, M.P.; Kannengiesser, C.; Causse, X.; Sauvion, S.; Pouliquen, B.; Deugnier, Y.; David, V.; Loréal, O.; et al. Variable age of onset and clinical severity in transferrin receptor 2 related haemochromatosis: Novel observations. Br. J. Haematol. 2013, 162, 278-281. [CrossRef] [PubMed]

15. Majore, S.; Milano, F.; Binni, F.; Stuppia, L.; Cerrone, A.; Tafuri, A.; De Bernardo, C.; Palka, G.; Grammatico, P. Homozygous p.M172K mutation of the TFR2 gene in an Italian family with type 3 hereditary hemochromatosis and early onset iron overload. Haematologica 2006, 91, ECR33. [PubMed]

16. Finberg, K.E. Regulation of systemic iron homeostasis. Curr. Opin. Hematol. 2013, 20, 208-214. [CrossRef] [PubMed]

17. Hunter, H.N.; Fulton, D.B.; Ganz, T.; Vogel, H.J. The solution structure of human hepcidin; a peptide hormone with antimicrobial activity that is involved in iron uptake and hereditary hemochromatosis. J. Biol. Chem. 2002, 277, 37597-37603. [CrossRef] [PubMed]

18. Ganz, T.; Nemeth, E. Hepcidin and iron homeostasis. Biochim. Biophys. Acta 2012, 1823, 1434-1443. [CrossRef] [PubMed]

19. Courselaud, B.; Pigeon, C.; Inoue, Y.; Inoue, J.; Gonzalez, F.J.; Leroyer, P.; Gilot, D.; Boudjema, K.; Guguen-Guillouzo, C.; Brissot, P.; et al. C/EBPalpha regulates hepatic transcription of hepcidin;an antimicrobial peptide and regulator of iron metabolism. Cross-talk between C/EBP pathway and iron metabolism. J. Biol. Chem. 2002, 277, 41163-41170. [CrossRef] [PubMed]

20. Canali, S.; Zumbrennen-Bullough, K.B.; Core, A.B.; Wang, C.Y.; Nairz, M.; Bouley, R.; Swirski, F.K.; Babitt, J.L. Endothelial cells produce bone morphogenetic protein 6 required for iron homeostasis in mice. Blood 2017, 129, 405-414. [CrossRef] [PubMed] 
21. Steinbicker, A.U.; Bartnikas, T.B.; Lohmeyer, L.K.; Leyton, P.; Mayeur, C.; Kao, S.M.; Pappas, A.E.; Peterson, R.T.; Bloch, D.B.; Yu, P.B.; et al. Perturbation of hepcidin expression by BMP type I receptor deletion induces iron overload in mice. Blood 2011, 118, 4224-4230. [CrossRef] [PubMed]

22. Mayeur, C.; Leyton, P.A.; Kolodziej, S.A.; Yu, B.; Bloch, K.D. BMP type II receptors have redundant roles in the regulation of hepatic hepcidin gene expression and iron metabolism. Blood 2014, 124, 2116-2123. [CrossRef] [PubMed]

23. Enns, C.A.; Ahmed, R.; Zhang, A.S. Neogenin interacts with matriptase-2 to facilitate hemojuvelin cleavage. J. Biol. Chem. 2012, 287, 35104-35117. [CrossRef] [PubMed]

24. Canali, S.; Wang, C.Y.; Zumbrennen-Bullough, K.B.; Bayer, A.; Babitt, J.L. Bone morphogenetic protein 2 controls iron homeostasis in mice independent of Bmp6. Am. J. Hematol. 2017, 92, 1204-1213. [CrossRef] [PubMed]

25. Schmidt, P.J.; Toran, P.T.; Giannetti, A.M.; Bjorkman, P.J.; Andrews, N.C. The transferrin receptor modulates Hfe-dependent regulation of hepcidin expression. Cell Metab. 2008, 7, 205-214. [CrossRef] [PubMed]

26. Gao, J.; Chen, J.; Kramer, M.; Tsukamoto, H.; Zhang, A.S.; Enns, C.A. Interaction of the hereditary hemochromatosis protein HFE with transferrin receptor 2 is required for transferrin-induced hepcidin expression. Cell Metab. 2009, 9, 217-227. [CrossRef] [PubMed]

27. D'Alessio, F.; Hentze, M.; Muckenthaler, M.U. The hemochromatosis proteins HFE; TfR2; and HJV form a membrane-associated protein complex for hepcidin regulation. J. Hepatol. 2012, 57, 1052-1060. [CrossRef] [PubMed]

28. Wallace, D.F.; Summerville, L.; Crampton, E.M.; Frazer, D.M.; Anderson, G.J.; Subramaniam, V.N. Combined deletion of Hfe and transferrin receptor 2 in mice leads to marked dysregulation of hepcidin and iron overload. Hepatology 2009, 50, 1992-2000. [CrossRef] [PubMed]

29. Poli, M.; Luscieti, S.; Gandini, V.; Maccarinelli, F.; Finazzi, D.; Silvestri, L.; Roetto, A.; Arosio, P. Transferrin receptor 2 and HFE regulate furin expression via mitogen-activated protein kinase/extracellular signal-regulated kinase (MAPK/Erk) signaling. Implications for transferrin- dependent hepcidin regulation. Haematologica 2010, 95, 1832-1840. [CrossRef] [PubMed]

30. Corradini, E.; Rozier, M.; Meynard, D.; Odhiambo, A.; Lin, H.Y.; Feng, Q.; Migas, M.C.; Britton, R.S.; Babitt, J.L.; Fleming, R.E. Iron regulation of hepcidin despite attenuated Smad1,5,8 signaling in mice without transferrin receptor 2 or Hfe. Gastroenterology 2011, 141, 1907-1914. [CrossRef] [PubMed]

31. Silvestri, L.; Pagani, A.; Nai, A.; De Domenico, I.; Kaplan, J.; Camaschella, C. The serine protease matriptase-2 (TMPRSS6) inhibits hepcidin activation by cleaving membrane hemojuvelin. Cell Metab. 2008, 8, 502-511. [CrossRef] [PubMed]

32. Meynard, D.; Vaja, V.; Sun, C.C.; Corradini, E.; Chen, S.; López-Otín, C.; Grgurevic, L.; Hong, C.C.; Stirnberg, M.; Gütschow, M.; et al. Regulation of TMPRSS6 by BMP6 and iron in human cells and mice. Blood 2011, 118, 747-756. [CrossRef] [PubMed]

33. Nicolas, G.; Chauvet, C.; Viatte, L.; Danan, J.L.; Bigard, X.; Devaux, I.; Beaumont, C.; Kahn, A.; Vaulont, S. The gene encoding the iron regulatory peptide hepcidin is regulated by anemia; hypoxia; and inflammation. J. Clin. Investig. 2002, 110, 1037-1044. [CrossRef] [PubMed]

34. Donovan, A.; Lima, C.A.; Pinkus, J.L.; Pinkus, G.S.; Zon, L.I.; Robine, S.; Andrews, N.C. The iron exporter ferroportin/Slc40a1 is essential for iron homeostasis. Cell Metab. 2005, 1, 191-200. [CrossRef] [PubMed]

35. Nemeth, E.; Tuttle, M.S.; Powelson, J.; Vaughn, M.B.; Donovan, A.; Ward, D.M.; Ganz, T.; Kaplan, J. Hepcidin regulates cellular iron efflux by binding to ferroportin and inducing its internalization. Science 2004, 306, 2090-2093. [CrossRef] [PubMed]

36. Papanikolaou, G.; Pantopoulos, K. Systemic iron homeostasis and erythropoiesis. IUBMB Life 2017, 69, 399-413. [CrossRef] [PubMed]

37. Wrighting, D.M.; Andrews, N.C. Interleukin-6 induces hepcidin expression through STAT3. Blood 2006, 108, 3204-3209. [CrossRef] [PubMed]

38. Armitage, A.E.; Eddowes, L.A.; Gileadi, U.; Cole, S.; Spottiswoode, N.; Selvakumar, T.A.; Ho, L.P.; Townsend, A.R.; Drakesmith, H. Hepcidin regulation by innate immune and infectious stimuli. Blood 2011, 118, 4129-4139. [CrossRef] [PubMed]

39. Piperno, A.; Galimberti, S.; Mariani, R.; Pelucchi, S.; Ravasi, G.; Lombardi, C.; Bilo, G.; Revera, M.; Giuliano, A.; Faini, A.; et al. Modulation of hepcidin production during hypoxia-induced erythropoiesis in humans in vivo: Data from the HIGHCARE project. Blood 2011, 117, 2953-2959. [CrossRef] [PubMed] 
40. Talbot, N.P.; Lakhal, S.; Smith, T.G.; Privat, C.; Nickol, A.H.; Rivera-Ch, M.; León-Velarde, F.; Dorrington, K.L.; Mole, D.R.; Robbins, P.A. Regulation of hepcidin expression at high altitude. Blood 2012, 119, 857-860. [CrossRef] [PubMed]

41. Maurer, E.; Gütschow, M.; Stirnberg, M. Matriptase-2 (TMPRSS6) is directly up-regulated by hypoxia inducible factor-1: Identification of a hypoxia-responsive element in the TMPRSS6 promoter region. Biol. Chem. 2012, 393, 535-540. [CrossRef] [PubMed]

42. Kawabata, H.; Fleming, R.E.; Gui, D.; Moon, S.Y.; Saitoh, T.; O’Kelly, J.; Umehara, Y.; Wano, Y.; Said, J.W.; Koeffler, H.P. Expression of hepcidin is down-regulated in TfR2 mutant mice manifesting a phenotype of hereditary hemochromatosis. Blood 2005, 105, 376-381. [CrossRef] [PubMed]

43. Nemeth, E.; Roetto, A.; Garozzo, G.; Ganz, T.; Camaschella, C. Hepcidin is decreased in TFR2 hemochromatosis. Blood 2005, 105, 1803-1806. [CrossRef] [PubMed]

44. Du, X.; She, E.; Gelbart, T.; Truksa, J.; Lee, P.; Xia, Y.; Khovananth, K.; Mudd, S.; Mann, N.; Moresco, E.M.; et al. The serine protease TMPRSS6 is required to sense iron deficiency. Science 2008, 320, 1088-1092. [CrossRef] [PubMed]

45. Finberg, K.E.; Heeney, M.M.; Campagna, D.R.; Aydinok, Y.; Pearson, H.A.; Hartman, K.R.; Mayo, M.M.; Samuel, S.M.; Strouse, J.J.; Markianos, K.; et al. Mutations in TMPRSS6 cause iron-refractory iron deficiency anemia (IRIDA). Nat. Genet. 2008, 40, 569-571. [CrossRef] [PubMed]

46. Folgueras, A.R.; de Lara, F.M.; Pendás, A.M.; Garabaya, C.; Rodríguez, F.; Astudillo, A.; Bernal, T.; Cabanillas, R.; López-Otín, C.; Velasco, G. Membrane-bound serine protease matriptase-2 (Tmprss6) is an essential regulator of iron homeostasis. Blood 2008, 112, 2539-2545. [CrossRef] [PubMed]

47. Calzolari, A.; Raggi, C.; Deaglio, S.; Sposi, N.M.; Stafsnes, M.; Fecchi, K.; Parolini, I.; Malavasi, F.; Peschle, C.; Sargiacomo, M.; et al. TfR2 localizes in lipid raft domains and is released in exosomes to activate signal transduction along the MAPK pathway. J. Cell Sci. 2006, 119, 4486-4498. [CrossRef] [PubMed]

48. Simons, K.; Toomre, D. Lipid rafts and signal transduction. Nat. Rev. Mol. Cell Biol. 2000, 1, 31-39. [CrossRef] [PubMed]

49. Chen, J.; Wang, J.; Meyers, K.R.; Enns, C.A. Transferrin-directed internalization and cycling of transferrin receptor 2. Traffic 2009, 10, 1488-1501. [CrossRef] [PubMed]

50. Johnson, M.B.; Enns, C.A. Diferric transferrin regulates transferrin receptor 2 protein stability. Blood 2004, 104, 4287-4293. [CrossRef] [PubMed]

51. Chen, J.; Enns, C.A. The cytoplasmic domain of transferrin receptor 2 dictates its stability and response to holo-transferrin in Hep3B cells. J. Biol. Chem. 2007, 282, 6201-6209. [CrossRef] [PubMed]

52. Johnson, M.B.; Chen, J.; Murchison, N.; Green, F.A.; Enns, C.A. Transferrin receptor 2: Evidence for ligand-induced stabilization and redirection to a recycling pathway. Mol. Biol. Cell 2007, 18, 743-754. [CrossRef] [PubMed]

53. Goswami, T.; Andrews, N.C. Hereditary hemochromatosis protein; HFE; interaction with transferrin receptor 2 suggests a molecular mechanism for mammalian iron sensing. J. Biol. Chem. 2006, 281, 28494-28498. [CrossRef] [PubMed]

54. Valore, E.V.; Ganz, T. Posttranslational processing of hepcidin in human hepatocytes is mediated by the prohormone convertase furin. Blood Cells Mol. Dis. 2008, 40, 132-138. [CrossRef] [PubMed]

55. Fleming, R.E.; Ahmann, J.R.; Migas, M.C.; Waheed, A.; Koeffler, H.P.; Kawabata, H.; Britton, R.S.; Bacon, B.R.; Sly, W.S. Targeted mutagenesis of the murine transferrin receptor-2 gene produces hemochromatosis. Proc. Natl. Acad. Sci. USA 2002, 99, 10653-10658. [CrossRef] [PubMed]

56. Wallace, D.F.; Summerville, L.; Subramaniam, V.N. Targeted disruption of the hepatic transferrin receptor 2 gene in mice leads to iron overload. Gastroenterology 2007, 132, 301-310. [CrossRef] [PubMed]

57. Roetto, A.; Di Cunto, F.; Pellegrino, R.M.; Hirsch, E.; Azzolino, O.; Bondi, A.; Defilippi, I.; Carturan, S.; Miniscalco, B.; Riondato, F.; et al. Comparison of 3 Tfr2-deficient murine models suggests distinct functions for Tfr2-alpha and Tfr2-beta isoforms in different tissues. Blood 2010, 115, 3382-3389. [CrossRef] [PubMed]

58. Fleming, R.E.; Feng, Q.; Britton, R.S. Knockout mouse models of iron homeostasis. Annu. Rev. Nutr. 2011, 31, 117-137. [CrossRef] [PubMed]

59. Gutschow, P.; Schmidt, P.J.; Han, H.; Ostland, V.; Bartnikas, T.B.; Pettiglio, M.A.; Herrera, C.; Butler, J.S.; Nemeth, E.; Ganz, T.; et al. A competitive enzyme-linked immunosorbent assay specific for murine hepcidin-1: Correlation with hepatic mRNA expression in established and novel models of dysregulated iron homeostasis. Haematologica 2015, 100, 167-177. [CrossRef] [PubMed] 
60. Latour, C.; Besson-Fournier, C.; Meynard, D.; Silvestri, L.; Gourbeyre, O.; Aguilar-Martinez, P.; Schmidt, P.J.; Fleming, M.D.; Roth, M.P.; Coppin, H. Differing impact of the deletion of hemochromatosis-associated molecules HFE and transferrin receptor-2 on the iron phenotype of mice lacking bone morphogenetic protein 6 or hemojuvelin. Hepatology 2016, 63, 126-137. [CrossRef] [PubMed]

61. Nai, A.; Pellegrino, R.M.; Rausa, M.; Pagani, A.; Boero, M.; Silvestri, L.; Saglio, G.; Roetto, A.; Camaschella, C. The erythroid function of transferrin receptor 2 revealed by Tmprss 6 inactivation in different models of transferrin receptor 2 knockout mice. Haematologica 2014, 99, 1016-1021. [CrossRef] [PubMed]

62. Rishi, G.; Secondes, E.S.; Wallace, D.F.; Subramaniam, V.N. Hematopoietic deletion of transferrin receptor 2 in mice leads to a block in erythroid differentiation during iron-deficient anemia. Am. J. Hematol. 2016, 91, 812-818. [CrossRef] [PubMed]

63. Marro, S.; Chiabrando, D.; Messana, E.; Stolte, J.; Turco, E.; Tolosano, E.; Muckenthaler, M.U. Heme controls ferroportin1 (FPN1) transcription involving Bach1; Nrf2 and a MARE/ARE sequence motif at position -7007 of the FPN1 promoter. Haematologica 2010, 95, 1261-1268. [CrossRef] [PubMed]

64. Chiabrando, D.; Fiorito, V.; Marro, S.; Silengo, L.; Altruda, F.; Tolosano, E. Cell-specific regulation of Ferroportin transcription following experimentally-induced acute anemia in mice. Blood Cells Mol. Dis. 2013, 50, 25-30. [CrossRef] [PubMed]

65. Zhang, D.L.; Hughes, R.M.; Ollivierre-Wilson, H.; Ghosh, M.C.; Rouault, T.A. A ferroportin transcript that lacks an iron-responsive element enables duodenal and erythroid precursor cells to evade translational repression. Cell Metab. 2009, 9, 461-473. [CrossRef] [PubMed]

66. Soranzo, N.; Spector, T.D.; Mangino, M.; Kühnel, B.; Rendon, A.; Teumer, A.; Willenborg, C.; Wright, B.; Chen, L.; Li, M.; et al. A genome-wide meta-analysis identifies 22 loci associated with eight hematological parameters in the HaemGen consortium. Nat. Genet. 2009, 41, 1182-1190. [CrossRef] [PubMed]

67. Auer, P.L.; Teumer, A.; Schick, U.; O'Shaughnessy, A.; Lo, K.S.; Chami, N.; Carlson, C.; de Denus, S.; Dubé, M.P.; Haessler, J.; et al. Rare and low frequency coding variants in CXCR2 and other genes are associated with hematological traits. Nat. Genet. 2014, 46, 629-634. [CrossRef] [PubMed]

68. Forejtnikovà, H.; Vieillevoye, M.; Zermati, Y.; Lambert, M.; Pellegrino, R.M.; Guihard, S.; Gaudry, M.; Camaschella, C.; Lacombe, C.; Roetto, A.; et al. Transferrin receptor 2 is a component of the erythropoietin receptor complex and is required for efficient erythropoiesis. Blood 2010, 116, 5357-5367. [CrossRef] [PubMed]

69. Nai, A.; Lidonnici, M.R.; Rausa, M.; Mandelli, G.; Pagani, A.; Silvestri, L.; Ferrari, G.; Camaschella, C. The second transferrin receptor regulates red blood cell production in mice. Blood 2015, 125, 1170-1179. [CrossRef] [PubMed]

70. Kautz, L.; Jung, G.; Valore, E.V.; Rivella, S.; Nemeth, S.; Ganz, T. Identification of erythroferrone as an erythroid regulator of iron metabolism. Nat. Genet. 2014, 46, 678-684. [CrossRef] [PubMed]

71. Pellegrino, R.M.; Riondato, F.; Ferbo, L.; Boero, M.; Palmieri, A.; Osella, L.; Pollicino, P.; Miniscalco, B.; Saglio, G.; Roetto, A. Altered Erythropoiesis in Mouse Models of Type 3 Hemochromatosis. Biomed. Res. Int. 2017, 2408941. [CrossRef] [PubMed]

72. Xu, W.; Barrientos, T.; Mao, L.; Rockman, H.A.; Sauve, A.A.; Andrews, N.C. Lethal cardiomyopathy in mice lacking transferrin receptor in the heart. Cell Rep. 2015, 13, 533-545. [CrossRef] [PubMed]

73. Lakhal-Littleton, S.; Wolna, M.; Carr, C.A.; Miller, J.J.; Christian, H.C.; Ball, V.; Santos, A.; Diaz, R.; Biggs, D.; Stillion, R.; et al. Cardiac ferroportin regulates cellular iron homeostasis and is important for cardiac function. Proc. Natl. Acad. Sci. USA 2015, 112, 3164-3169. [CrossRef] [PubMed]

74. Lakhal-Littleton, S.; Wolna, M.; Chung, Y.J.; Christian, H.C.; Heather, L.C.; Brescia, M.; Ball, V.; Diaz, R.; Santos, A.; Biggs, D.; et al. An essential cell-autonomous role for hepcidin in cardiac iron homeostasis. Elife 2016, 5, e19804. [CrossRef] [PubMed]

75. Gammella, E.; Recalcati, S.; Rybinska, I.; Buratti, P.; Cairo, G. Iron-induced damage in cardiomyopathy: Oxidative-dependent and independent mechanisms. Oxid. Med. Cell. Longev. 2015. [CrossRef] [PubMed]

76. Boero, M.; Pagliaro, P.; Tullio, F.; Pellegrino, R.M.; Palmieri, A.; Ferbo, L.; Saglio, G.; De Gobbi, M.; Penna, C.; Roetto, A. A comparative study of myocardial molecular phenotypes of two $\operatorname{Tfr} \beta$ null mice: Role in ischemia/reperfusion. Biofactors 2015, 41,360-371. [CrossRef] [PubMed]

77. Chevion, M.; Leibowitz, S.; Aye, N.N.; Novogrodsky, O.; Singer, A.; Avizemer, O.; Bulvik, B.; Konijn, A.M.; Berenshtein, E. Heart protection by ischemic preconditioning: A novel pathway initiated by iron and mediated by ferritin. J. Mol. Cell. Cardiol. 2008, 45, 839-845. [CrossRef] [PubMed] 
78. Aquino, D.; Bizzi, A.; Grisoli, M.; Garavaglia, B.; Bruzzone, M.G.; Nardocci, N.; Savoiardo, M.; Chiapparini, L. Age-related iron deposition in the basal ganglia: Quantitative analysis in healthy subjects. Radiology 2009, 252, 165-172. [CrossRef] [PubMed]

79. Pfefferbaum, A.; Adalsteinsson, E.; Rohlfing, T.; Sullivan, E.V. MRI estimates of brain iron concentration in normal aging: Comparison of field-dependent (FDRI) and phase (SWI) methods. Neuroimage 2009, 47, 493-500. [CrossRef] [PubMed]

80. Carlson, E.S.; Fretham, S.J.; Unger, E.; O'Connor, M.; Petryk, A.; Schallert, T.; Rao, R.; Tkac, I.; Georgieff, M.K. Hippocampus specific iron deficiency alters competition and cooperation between developing memory systems. J. Neurodev. Disord. 2010, 2, 133-143. [CrossRef] [PubMed]

81. Millichap, J.G. Etiologic classification of attention-deficit/hyperactivity disorder. Pediatrics 2008, 12, e358-e365. [CrossRef] [PubMed]

82. Benton, D. The influence of dietary status on the cognitive performance of children. Mol. Nutr. Food Res. 2010, 54, 457-470. [CrossRef] [PubMed]

83. Xu, H.; Wang, Y.; Song, N.; Wang, J.; Jiang, H.; Xie, J. New Progress on the Role of Glia in Iron Metabolism and Iron-Induced Degeneration of Dopamine Neurons in Parkinson's Disease. Front. Mol. Neurosci. 2018, 10, 455. [CrossRef] [PubMed]

84. McCarthy, R.C.; Kosman, D.J. Mechanistic analysis of iron accumulation by endothelial cells of the BBB. Biometals 2012, 25, 665-675. [CrossRef] [PubMed]

85. Benarroch, E.E. Brain iron homeostasis and neurodegenerative disease. Neurology 2009, 72, 1436-1440. [CrossRef] [PubMed]

86. Mills, E.; Dong, X.P.; Wang, F.; Xu, H. Mechanisms of brain iron transport: Insight into neurodegeneration and CNS disorders. Future Med. Chem. 2010, 2, 51-64. [CrossRef] [PubMed]

87. Wang, J.; Jiang, H.; Xie, J.X. Ferroportin1 and hephaestin are involved in the nigral iron accumulation of 6-OHDA-lesioned rats. Eur. J. Neurosci. 2007, 25, 2766-2772. [CrossRef] [PubMed]

88. Morris, C.M.; Candy, J.M.; Keith, A.B.; Oakley, A.E.; Taylor, G.A.; Pullen, R.G.; Bloxham, C.A.; Gocht, A.; Edwardson, J.A. Brain iron homeostasis. J. Inorg. Biochem. 1992, 47, 257-265. [CrossRef]

89. Connor, J.R.; Boeshore, K.L.; Benkovic, S.A.; Menzies, S.L. Isoforms of ferritin have a specific cellular distribution in the brain. J. Neurosci. Res. 1994, 37, 461-465. [CrossRef] [PubMed]

90. Rouault, T.A. Iron metabolism in the CNS: Implications for neurodegenerative diseases. Nat. Rev. Neurosci. 2013, 14, 551-564. [CrossRef] [PubMed]

91. Wang, S.M.; Fu, L.J.; Duan, X.L.; Crooks, D.R.; Yu, P.; Qian, Z.M.; Di, X.J.; Li, J.; Rouault, T.A.; Chang, Y.Z. Role of hepcidin in murine brain iron metabolism. Cell. Mol. Life Sci. 2010, 67, 123-133. [CrossRef] [PubMed]

92. Du, F.; Qian, Z.M.; Luo, Q.; Yung, W.H.; Ke, Y. Hepcidin suppresses brain iron accumulation by downregulating iron transport proteins in iron-overloaded rats. Mol. Neurobiol. 2015, 52, 101-114. [CrossRef] [PubMed]

93. Vela, D. Hepcidin, an emerging and important player in brain iron homeostasis. J. Transl. Med. 2018, 16. [CrossRef] [PubMed]

94. Moos, T.; Rosengren Nielsen, T.; Skjørringe, T.; Morgan, E.H. Iron trafficking inside the brain. J. Neurochem. 2007, 103, 1730-1740. [CrossRef] [PubMed]

95. Hänninen, M.M.; Haapasalo, J.; Haapasalo, H.; Fleming, R.E.; Britton, R.S.; Bacon, B.R.; Parkkila, S. Expression of iron-related genes in human brain and brain tumors. BMC Neurosci. 2009, 10, 36. [CrossRef] [PubMed]

96. Acikyol, B.; Graham, R.M.; Trinder, D.; House, M.J.; Olynyk, J.K.; Scott, R.J.; Milward, E.A.; Johnstone, D.M. Brain transcriptome perturbations in the transferrin receptor 2 mutant mouse support the case for brain changes in iron loading disorders, including effects relating to long-term depression and long-term potentiation. Neuroscience 2013, 235, 119-128. [CrossRef] [PubMed]

97. Pellegrino, R.M.; Boda, E.; Montarolo, F.; Boero, M.; Mezzanotte, M.; Saglio, G.; Buffo, A.; Roetto, A. Transferrin Receptor 2 Dependent Alterations of Brain Iron Metabolism Affect Anxiety Circuits in the Mouse. Sci. Rep. 2016, 6, 30725. [CrossRef] [PubMed]

98. Adhikari, A. Distributed circuits underlying anxiety. Front. Behav. Neurosci. 2014, 8, 112. [CrossRef] [PubMed] 
99. Rhodes, S.L.; Buchanan, D.D.; Ahmed, I.; Taylor, K.D.; Loriot, M.A.; Sinsheimer, J.S.; Bronstein, J.M.; Elbaz, A.; Mellick, G.D.; Rotter, J.I.; et al. Pooled analysis of iron-related genes in Parkinson's disease: Association with transferrin. Neurobiol. Dis. 2014, 62, 172-178. [CrossRef] [PubMed]

100. Khalil, S.; Holy, M.; Grado, S.; Fleming, R.; Kurita, R.; Nakamura, Y.; Goldfarb, A. A specialized pathway for erythroid iron delivery through lysosomal trafficking of transferrin receptor 2. Blood Adv. 2017, 1, 1181-1194. [CrossRef] [PubMed]

101. Robb, A.D.; Ericsson, M.; Wessling-Resnick, M. Transferrin receptor 2 mediates a biphasic pattern of transferrin uptake associated with ligand delivery to multivesicular bodies. Am. J. Physiol. Cell Physiol. 2004, 287, C1769-C1775. [CrossRef] [PubMed]

102. Smilevska, T.; Stamatopoulos, K.; Samara, M.; Belessi, C.; Tsompanakou, A.; Paterakis, G.; Stavroyianni, N.; Athanasiadou, I.; Chiotoglou, I.; Hadzidimitriou, A.; et al. Transferrin receptor-1 and 2 expression in chronic lymphocytic leukemia. Leuk. Res. 2006, 30, 183-189. [CrossRef] [PubMed]

103. Gangat, N.; Patnaik, M.M.; Tefferi, A. Myelodysplastic syndromes: Contemporary review and how we treat. Am. J. Hematol. 2016, 91, 76-89. [CrossRef] [PubMed]

104. Di Savino, A.; Gaidano, V.; Palmieri, A.; Crasto, F.; Volpengo, A.; Lorenzatti, R.; Scaravaglio, P.; Manello, A.; Nicoli, P.; Gottardi, E.; et al. Clinical significance of TFR2 and EPOR expression in bone marrow cells in myelodysplastic syndromes. Br. J. Haematol. 2017, 176, 491-495. [CrossRef] [PubMed]

105. Nakamaki, T.; Kawabata, H.; Saito, B.; Matsunawa, M.; Suzuki, J.; Adachi, D.; Tomoyasu, S.; Phillip Koeffler, H. Elevated levels of transferrin receptor $2 \mathrm{mRNA}$, not transferrin receptor $1 \mathrm{mRNA}$, are associated with increased survival in acute myeloid leukaemia. Br. J. Haematol. 2004, 125, 42-49. [CrossRef] [PubMed]

106. Calzolari, A.; Oliviero, I.; Deaglio, S.; Mariani, G.; Biffoni, M.; Sposi, N.M.; Malavasi, F.; Peschle, C.; Testa, U. Transferrin receptor 2 is frequently expressed in human cancer cell lines. Blood Cells Mol. Dis. 2007, 39, 82-91. [CrossRef] [PubMed]

107. Calzolari, A.; Larocca, L.M.; Deaglio, S.; Finisguerra, V.; Boe, A.; Raggi, C.; Ricci-Vitani, L.; Pierconti, F.; Malavasi, F.; De Maria, R.; et al. Transferrin receptor 2 is frequently and highly expressed in glioblastomas. Transl. Oncol. 2010, 3, 123-134. [CrossRef] [PubMed]

108. Crichton, R.R.; Dexter, D.T.; Ward, R.J. Brain iron metabolism and its perturbation in neurological diseases. J. Neural. Transm. 2011, 118, 301-314. [CrossRef] [PubMed]

109. Crespo, Â.C.; Silva, B.; Marques, L.; Marcelino, E.; Maruta, C.; Costa, S.; Timóteo, A.; Vilares, A.; Couto, F.S.; Faustino, P.; et al. Genetic and biochemical markers in patients with Alzheimer's disease support a concerted systemic iron homeostasis dysregulation. Neurobiol. Aging 2014, 35, 777-785. [CrossRef] [PubMed]

110. Artuso, I.; Lidonnici, M.R.; Altamura, S.; Mandelli, G.; Pettinato, M.; Muckenthaler, M.U.; Silvestri, L.; Ferrari, G.; Camaschella, C.; Nai, A. Transferrin Receptor 2 is a potential novel therapeutic target for beta-thalassemia: Evidence from a murine model. Blood 2018. [CrossRef] [PubMed]

111. Girelli, D.; Nemeth, E.; Swinkels, D.W. Hepcidin in the diagnosis of iron disorders. Blood 2016, 127, $2809-2813$. [CrossRef] [PubMed]

112. Akinc, A.; Chan-Daniels, A.; Sehgal, A.; Foster, D.; Bettencourt, B.R.; Hettinger, J.; Racie, T.; Aubin, J.; Kuchimanchi, S.; Epstein-Barashand, H.; et al. Targeting the hepcidin pathway with RNAi therapeutics for the treatment of anemia. Blood 2011, 21, 688.

113. Raha, A.A.; Vaishnav, R.A.; Friedland, R.P.; Bomford, A.; Raha-Chowdhury, R. The systemic iron-regulatory proteins hepcidin and ferroportin are reduced in the brain in Alzheimer's disease. Acta Neuropathol. Commun. 2013, 1, 55. [CrossRef] [PubMed]

114. Chen, D.; Kanthasamy, A.G.; Reddy, M.B. EGCG protects against 6-OHDA-induced neurotoxicity in a cell culture model. Parkinsons Dis. 2015. [CrossRef] [PubMed]

115. Clardy, S.L.; Wang, X.; Boyer, P.J.; Earley, C.J.; Allen, R.P.; Connor, J.R. Is ferroportin-hepcidin signaling altered in restless legs syndrome? J. Neurol. Sci. 2006, 247, 173-179. [CrossRef] [PubMed]

116. Zheng, M.; Tao, W.; Zou, Y.; Farokhzad, O.C.; Shi, B. Nanotechnology-Based Strategies for siRNA Brain Delivery for Disease Therapy. Trends Biotechnol. 2018, 36, 562-575. [CrossRef] [PubMed]

117. Couch, J.A.; Yu, Y.J.; Zhang, Y.; Tarrant, J.M.; Fuji, R.N.; Meilandt, W.J.; Solanoy, H.; Tong, R.K.; Hoyte, K.; Luk, W.; et al. Addressing safety liabilities of TfR bispecific antibodies that cross the blood-brain barrier. Sci. Transl. Med. 2013, 5. [CrossRef] [PubMed] 
118. Li, L.; Fang, C.J.; Ryan, J.C.; Niemi, E.C.; Lebrón, J.A.; Björkman, P.J.; Arase, H.; Torti, F.M.; Torti, S.V.; Nakamura, M.C.; et al. Binding and uptake of H-ferritin are mediated by human transferrin receptor-1. Proc. Natl. Acad. Sci. USA 2010, 107, 3505-3510. [CrossRef] [PubMed]

119. Mazzucchelli, S.; Truffi, M.; Baccarini, F.; Beretta, M.; Sorrentino, L.; Bellini, M.; Rizzuto, M.A.; Ottria, R.; Ravelli, A.; Ciuffreda, P.; et al. H-Ferritin-nanocaged olaparib: A promising choice for both BRCA-mutated and sporadic triple negative breast cancer. Sci. Rep. 2017, 7, 7505. [CrossRef] [PubMed]

120. Sakurai, K.; Sohda, T.; Ueda, S.; Tanaka, T.; Hirano, G.; Yokoyama, K.; Morihara, D.; Aanan, A.; Takeyama, Y.; Irie, M.; et al. Immunohistochemical demonstration of transferrin receptor 1 and 2 in human hepatocellular carcinoma tissue. Hepatogastroenterology 2014, 61, 426-430. [PubMed]

121. Voth, B.; Nagasawa, D.T.; Pelargos, P.E.; Chung, L.K.; Ung, N.; Gopen, Q.; Tenn, S.; Kamei, D.T.; Yang, I. Transferrin receptors and glioblastoma multiforme: Current findings and potential for treatment. J. Clin. Neurosci. 2015, 22, 1071-1076. [CrossRef] [PubMed]

122. Murphy, M.P.; Smith, R.A. Drug delivery to mitochondria: The key to mitochondrial medicine. Adv. Drug Deliv. Rev. 2000, 41, 235-250. [CrossRef]

123. Bürk, K. Friedreich Ataxia: Current status and future prospects. Cerebellum Ataxias 2017. [CrossRef] [PubMed]

(C) 2018 by the authors. Licensee MDPI, Basel, Switzerland. This article is an open access article distributed under the terms and conditions of the Creative Commons Attribution (CC BY) license (http:/ / creativecommons.org/licenses/by/4.0/). 


\title{
What Is Next in This "Age" of Heme-Driven Pathology and Protection by Hemopexin? An Update and Links with Iron ${ }^{\dagger}$
}

\author{
Luis Montecinos ${ }^{1}$, Jeffrey D. Eskew ${ }^{2}$ and Ann Smith ${ }^{3, *}$ \\ 1 Department of Physiology \& Biophysics, School of Medicine, University of Chile, Santiago 838-0453, Chile; \\ lmontecinos@med.uchile.cl \\ 2 KITE Pharma, Inc., Santa Monica, CA 90404, USA; Jeskew@kitepharma.com \\ 3 Department of Biochemistry \& Molecular Biology, School of Biological \& Chemical Sciences, University of \\ Missouri-Kansas City, MO 64110, USA \\ * Correspondence: smithan@umkc.edu \\ + Dr. Eskew carried out this research while at the University of Missouri-Kansas City.
}

Received: 25 July 2019; Accepted: 19 September 2019; Published: 24 September 2019

\begin{abstract}
This review provides a synopsis of the published literature over the past two years on the heme-binding protein hemopexin (HPX), with some background information on the biochemistry of the HPX system. One focus is on the mechanisms of heme-driven pathology in the context of heme and iron homeostasis in human health and disease. The heme-binding protein hemopexin is a multi-functional protectant against hemoglobin $(\mathrm{Hb})$-derived heme toxicity as well as mitigating heme-mediated effects on immune cells, endothelial cells, and stem cells that collectively contribute to driving inflammation, perturbing vascular hemostasis and blood-brain barrier function. Heme toxicity, which may lead to iron toxicity, is recognized increasingly in a wide range of conditions involving hemolysis and immune system activation and, in this review, we highlight some newly identified actions of heme and hemopexin especially in situations where normal processes fail to maintain heme and iron homeostasis. Finally, we present preliminary data showing that the cytokine IL-6 cross talks with activation of the c-Jun N-terminal kinase pathway in response to heme-hemopexin in models of hepatocytes. This indicates another level of complexity in the cell responses to elevated heme via the HPX system when the immune system is activated and/or in the presence of inflammation.
\end{abstract}

Keywords: hemopexin; heme homeostasis; iron homeostasis; hemolysis; haptoglobin; ferroptosis; inflammation; biomarker; heme oxygenase; liver; microbiome; trauma; hemorrhage

\section{Introduction}

The first direct evidence that hemopexin (HPX)-mediated heme transport links heme (iron-protoporphyrin IX) and iron metabolism was published in 1988 [1]. In that study, heme-HPX complexes were as effective as diferric-transferrin as a sole source of iron for the growth of mouse hepatoma cells that were used as models of liver parenchymal cells (i.e., hepatocytes). The rate of heme uptake via HPX is linked with cell growth and shows highest uptake in the period just before exponential growth and slowest in the stationary phase. Also, the iron status of hepatoma cells affects the extent of heme uptake. For example, decreasing intracellular iron with the chelator deferoxamine increased HPX-mediated heme transport, as did inhibiting iron-dependent ribonucleotide reductase (required for DNA synthesis).

Plasma HPX rapidly targets heme to hepatocytes [2] that respond with a cytoprotective program involving safe trafficking of heme, its iron, and, uniquely, also copper [3]. This copper is needed 
for the coordinate induction of heme oxygenase-1 (HO1) and metallothionein genes for antioxidant protection [4-7]. Within cells, heme delivered by heme-HPX endocytosis is quickly transported to the nucleus relieving Bach 1 repression, thus activating HO-1 gene transcription [8,9]. Heme also travels to the smooth endoplasmic reticulum for degradation by heme oxygenases and into mitochondria, presumably via the mitochondrial heme exporter, FLVCR1b [10]. The heme-iron is utilized for the Fe/iron regulatory protein (IRP)/iron response element (IRE) system to regulate proteins of iron homeostasis at the translational level in part via storage on ferritin, thus keeping intracellular iron levels low [6]. Overall, the regulated delivery of heme by HPX maintains cell redox homeostasis. This is not the case when cultured cells are incubated with free "heme", which is rapidly and extensively taken up compared with heme-HPX endocytosis (at approximately a five-fold higher rate on a molar basis) [11]. Heme generates ROS and, thus, is readily toxic [12]. Intracellular heme levels of $3 \mu \mathrm{M}$ are rapidly reached, equivalent to 1 million heme molecules in the volume of the mitochondria [13].

The liver is the principle organ that responds to changes in systemic iron signals in order to maintain body iron homeostasis. Iron stores are regulated solely at the level of absorption not excretion. Interestingly, the bioavailability of heme from the diet as an iron source is superior to that of inorganic iron. However, iron, not heme, is exported into the systemic circulation because after $\left[{ }^{59} \mathrm{Fe}\right]$ heme is placed in the lumen of isolated rat duodenum, iron-transferrin not heme-HPX is present in the mesenteric vein [13]. This supports extensive catabolism of heme by HOs in duodenal enterocytes.

In addition, the liver is the first site of defense against dietary antigens and pathogens from the gut. Furthermore, low levels of heme are normally present in bile providing a source of heme and iron for gut bacteria and, thus, biliary heme is poised to influence the composition of the microbiome. In fact, using intravenous hemin to mimic a heme overload in the plasma of mice leads to the secretion of "black" bile [14].

The liver is an immune-responsive organ. Although, hepatocytes comprise $~ 90 \%$ of the liver mass, it also has many different types of cells including immunologically active Kupffer cells, stellate cells, and trafficking monocytes. As reviewed by Crispe [15], hepatocytes act in both innate and adaptive immunity. Hepatocytes synthesize and secrete several proteins needed for cell defenses during distinct pathologies ranging from ischemia, physical trauma, infections, and sepsis. These cells act not only by providing acute phase proteins in response to the cytokine IL-6 but also to direct T- cells [15]. They also respond to factors such as hepatocyte growth factor to synthesize IL-6. Rapid, short-term elevations in IL-6 are part of the early warning signals to activate the immune system in response to infections and injury. However, when IL-6 levels are sustained chronic inflammation occurs that can become life threatening, as in sepsis. Additionally, IL-6 is often dramatically elevated in patients receiving chimeric antigen receptor $\mathrm{T}$ cell therapy (CAR-T) and has been associated with both cytokine release syndrome (CRS) and neurotoxicity in these patients. Importantly, increased CRS grade was associated with peak IL-6 levels, peak ferritin (Ftn), and peak C-reactive protein [16]. Predictive models of CRS based on various cytokines and biomarkers are currently being researched [17].

Here, we provide preliminary data showing that IL- 6 alters the response of models of liver cells to heme-HPX significantly limiting the extent of activation of the mitogen-activated protein kinase C-Jun kinase activation (JNK) pathway and changing levels of its substrates that are transcription factors. While the gene targets have not yet been identified completely, our data raise the possibility that when IL-6 is present in the short term, such cross talk may reprogram cell responses to heme-HPX that are normally beneficial. On the other hand, if certain protective signaling cell responses set in motion by the HPX system are attenuated by sustained IL-6, then there may be dire consequences. Such interactions between IL-6 and HPX may contribute to the worsening of sepsis including the development of septic shock. In the brain, these responses might exacerbate the pathology of intracerebral hemorrhage, traumatic brain injury or stroke where tissue and red blood cells injury is accompanied by inflammation.

The extent of damage by heme to the brain is beginning to be understood and several studies in mice provide evidence that HPX is protective in intracerebral hemorrhage (ICH), subarachnoid hemorrhage, and stroke. Hemopexin is present in human and rat CSF [18-20] and HPX mRNA has been 
located in ependymal cells [21], neurons [22], and glial cells [23]. Studies using HPX-null mice have revealed a role for HPX in myelin basic protein expression by oligodendrocyte and oligodendrocyte differentiation [23]. Hemolysis in the brain leads to disruption of the blood-brain barrier. However, a recent study [24] on patients with brain hemorrhage (intracerebral and subarachnoid) provides evidence that iron toxicity may be principally responsible for pathology rather than heme clearance. A review on heme in the context of neurodegeneration, where there are known mitochondrial defects, has recently been published in this Pharmaceutical special issue [25].

The purpose of this review was to assess from recently published research the biochemical role for HPX in protecting against heme toxicity in hemolysis and the accompanying inflammation in order to better define how heme- and iron-driven pathology develops in patients. Evidence supports that $\mathrm{HPX}$ is protective in both the presence and absence of bacterial/pathogen infection [26]. Hemopexin has two functions: firstly, as an extracellular antioxidant by sequestering heme and thereby protecting molecules in biological fluids from oxidation by heme and secondly by regulating heme uptake via heme-endocytosis which ensures redox metal homeostasis after heme and iron metabolism without leading to oxidative stress. Our focus was predominantly on recent clinical studies. Children are vulnerable to depletion of HPX because HPX is a developmentally regulated protein. Several studies included have investigated HPX as a candidate biomarker, generally in a panel with additional proteins; however, it is not always clear if the observed changes in HPX metabolism are linked solely to hemolysis or to inflammation or, as we contend here, to both. A more thorough understanding of the biochemistry of the HPX system may lead to novel therapeutic approaches for ameliorating or preventing heme-related pathologies. For example, the physiologically relevant role of the scavenger receptor LRP1/CD19 in the endocytosis of heme from Heme-HPX varies with cell type and is not fully understood in the context of the HPX system.

\section{Mechanisms of Heme Toxicity}

The cell damage by hemoglobin $(\mathrm{Hb})$, by its heme (and by heme's iron) are often ascribed to "oxidative stress" - an all-encompassing term for many different events encompassing inflammation and cytotoxicity. Both $\mathrm{Hb}$ and heme damage lipoproteins in the circulation $[27,28]$. Several recent studies show that high levels of heme consistent with that seen in patients with hemolytic disorders have several effects on cells. For example, heme inhibits the proteasome; generates aggresome-like induced structures (ALIS); activates the unfolded protein response (UPR); and activates several plasma systems including the coagulation cascade, binding to immunoglobulins and activating the alternative pathway of complement (see reviews by Roumenina et al. [29,30]).

Understanding these various aspects of heme toxicity for cells is of interest as well as assessing differences among various cell types (e.g., hepatocytes, macrophages, neurons, glia, endothelial cells, myocytes, kidney cells, and certain stem cells) in terms of their cell defenses. This information is also needed to better define panels of biomarkers in hemolysis, oxidative stress, and inflammation to aid in the diagnosis, prognosis, and response to therapy of patients with various hemolytic diseases and conditions.

\subsection{Heme-Related Inhibition of the Proteasome}

To identify the proteins and processes involved in heme stress, changes in the proteome phenotype of $\mathrm{HO}^{+/+}$and $\mathrm{HO}^{-/-}$mouse fibroblasts were investigated using mass spectrometry (MS) in combination with stable isotope labeling by amino acids of cultured fibroblasts in response to a range of heme concentrations [31]. The fibroblasts were incubated for 12 or $24 \mathrm{~h}$ with non-toxic levels of heme (5 or $10 \mu \mathrm{M})$ or with $40 \mu \mathrm{M}$ that was deemed toxic and led to impaired mitochondria as evident by low ATP levels. Toxic heme caused nuclear condensation together with disorganization of the cytoskeleton. Furthermore, heme at levels greater than $10 \mu \mathrm{M}$ induced caspase 3/7 activity, suggesting activation of apoptosis. It should be noted that $10 \mu \mathrm{M}$ heme is often used in many in vitro studies in the literature. These heme-related toxicities were prevented by adding HPX to the cell 
culture medium. The MS analyses revealed 2068 proteins that responded to heme. Mass spectrometry MetaCore analyses showed protein networks involved in the UPR, general protein folding, and, as expected, anti-oxidant defenses. Also, heme stress, perhaps not surprisingly, had clearly made an impact on iron metabolism because the most strongly induced proteins were the proteins of iron storage $\mathrm{H}$ - and L-Ftn. Specifically, L-Ftn increased independent to initial HO1 protein levels in the two sets of fibroblasts. Heme had an impact on the proteasome because ubiquitin and the ubiquitin adapter protein sequestosome 1 (SQSTM1)/P62 were induced by heme. This is a scaffold protein with multiple domains central to a variety of functions. Principally, it is part of a signaling hub to control cell viability when there is cytotoxicity [32]. Various heat shock proteins and proteins involved in antioxidant defenses (e.g., peroxiredoxin, glutathione (GSH)-S transferase, and thioredoxin reductase) were also increased but to a lesser extent. As expected, heme levels were higher in the $\mathrm{HO}^{-/-}$cells but changes in response to toxic levels of heme were also found in cells expressing functional HO1, as well as in a murine macrophage cell line and human embryonic kidney cells. Intriguingly, heme bound the $19 \mathrm{~S}$ ATPase subunit of the $26 \mathrm{~S}$ complex of the proteasome. However, proteasome inhibition may not be due to the redox activity of heme because cobalt-protoporphyrin IX, which is redox inert, also inhibited the proteasome. The cell toxicity from heme was proposed to be due to the changes in proteasome structure likely from the effects of other reactive molecules such as lipid peroxides as well as from chemical reactions involving heme.

Consistent with these observations on the effects of high intracellular heme, it is not surprising that genetic hemolytic diseases are protein disaggregation disorders. In $\beta$-thalassemia, the erythrocyte precursors use protein quality control to protect themselves [33]. Due to the mutations in the $\beta$-globin gene in $\beta$-thalassemia, $\alpha$-globin chains accumulate in erythrocyte precursors and precipitate due to the fact of their inherent instability. However, they are polyubiquitinated and degraded by the proteasome. Enhanced proteasome activity due in part to the induction of protein subunits of the proteasome is found in cells from $\beta$-thalassemic patients. This was shown by transcription profiling to be due to the stress response transcription factor Nrf1. Brief inhibition of the proteasome led to $\alpha$-globin chain accumulation; however, $\alpha$-globin did not accumulate in the erythrocyte precursors of $\beta$-thalassemic mice treated with the proteasome inhibitor bortezomib. Thus, the means to regulate protein quality control may differ between erythroid precursor cells in vitro and in vivo in mice perhaps due to the differences in activity of the $\mathrm{Hb}$ stabilizing protein.

\subsection{Heme-Related Aggresome-Like Structure Formation}

In 2016, Travassos and colleagues [34] were the first to report that heme, at high levels (30-100 $\mu \mathrm{M})$, would produce protein aggregates intracellularly. These aggregates also known as aggresome-like induced structures (ALIS) had a distinct composition, which included ubiquitinated proteins and SQSTM1/P62 in RAW macrophages [34]. The transcription factor NF-E2-related factor (NRF2) was required, which increases the transcription of SQSTM1/P62 raising protein levels. By using the HO1 inhibitor tin-protoporphyrin and cells derived from mice lacking FtnH, these ALIS were shown to be formed in response to oxidative stress from the intracellular heme and its iron. Furthermore, the response to heme was reversible because there were changes in the number of the ALIS over time. Interestingly, the maximum formation occurred $12 \mathrm{~h}$ after heme and declined over the following $12 \mathrm{~h}$. Importantly, this indicates that there is an active cell recovery response to clear these structures. Even at these high levels, heme did not activate autophagy-the cell survival mechanism that allows the controlled degradation and replacement of cell components and can induce cell cycle arrest and inhibit apoptosis.

\subsection{Heme-Related Unfolded Protein Response (UPR)}

During the course of atherosclerosis, plaques undergo defined changes as the pathology develops. Ultimately, this can lead to a high risk of acute ischemic events. Plaque instability is increased depending upon the lipid content and the presence of a thin fibrous cap. Intraplaque hemorrhage 
occurs after activation of neovascularization and new bloods vessels enter the plaques. When these plaques (i.e., atheromas) rupture, both smooth muscle cells and resident macrophages are exposed to high heme levels, to oxidized forms of cell-free $\mathrm{Hb}$, and to the accompanying oxidative stress.

Addition of heme to cells in vitro increases intracellular reactive oxygen species (ROS) [35] and evidence supports that oxidatively damaged proteins are likely to be partially misfolded, thus generating endoplasmic reticulum (ER) stress. When this occurs, the UPR (for reviews, see References [36,37]) is activated to prevent ER overload, restore homeostasis in the ER, and to promote cell survival. The UPR consists of the activation of several intracellular signal transduction pathways and operates at both transcriptional and translational levels. For example, mobilization of the transcription factors ATF6, ATF6B, CREB3, and the inositol-requiring enzyme 1 leads to increased transcription of genes encoding chaperones such as HSP90, HSP70 and GRP94. Mobilization of the pancreatic ER kinase-like ER kinase (PERK, pancreatic eIF2 $\alpha$ kinase, EIF2AK3) leads to phosphorylation of the translation initiation factor eIF $2 \alpha$, leading to a global downregulation of protein synthesis.

The analysis of human carotid artery specimens from patients undergoing carotid endarterectomy showed significant amounts of heme in atherosclerotic plaques Human aortic smooth muscle cells are key players in the development of atherogenesis. To evaluate how high levels of heme cause ER stress and activate the UPR, the levels of markers of ER stress were measured after human aortic smooth muscle cells were incubated with heme for up to $6 \mathrm{~h}$ [38]. In cultured cells isolated from complicated lesions with hemorrhage, even those obtained some distance from the border of intraplaque bleeding, had increased expression of glucose-regulated protein 78kDa (Grp78) and CCAAT-enhancer binding protein homologous protein (CHOP) in response to heme compared with atheromas or healthy arteries. The $\mathrm{CHOP}$ is a multi-functional transcription factor that down regulates the anti-apoptotic mitochondrial protein BCL2 which is an apoptosis regulator supporting pro-apoptotic activities of the mitochondria; and, thus, a robust marker for apoptosis. Low levels of heme $(1 \mu \mathrm{M})$ did not activate the UPR; however, heme at 10 or $25 \mu \mathrm{M}$, activated all three "arms" or "sensors" of the UPR. Inositol-requiring enzyme activation, PERK activation, and ATF6 activation were detected after $3 \mathrm{~h}$ of incubation. These data support that, in complicated lesions from patients with atherosclerosis, heme triggers ER stress and cell death.

Based on these changes in UPR marker proteins in response to the high heme, a model was presented that heme, depending upon its concentration, activates both pro-apoptotic and pro-survival pathways. Significantly, incubating human smooth muscle cells in vitro with heme caused a transitory pro-apoptotic response and permanently activated the pro-survival responses (ATF6, GRP78). There was also a high level of induction of heme-responsive genes including $\mathrm{HO1}$, which is cytoprotective. This research provides evidence for interaction between heme and iron metabolism together with the UPR activating pathways to help cells survive heme-induced stress. Furthermore, $\alpha-1$ microglobulin and HPX, which both bind heme in plasma, significantly decreased the effects of heme on ER stress markers when added to the medium of human smooth muscle cells in vitro. Thus, patients with atherosclerosis may benefit from plasma replenishment with HPX.

\subsection{Heme-Related Activation of Complement}

The complement system consists of $\sim 70$ proteins and is another part of the human immune system that contributes to immune defenses but can also exacerbate inflammatory diseases and conditions. Complement proteins rapidly sense tissue changes and the antigens presented by invading pathogens. By binding to these molecular signals on the surface of pathogens, they facilitate pathogen destruction by bringing in phagocytic macrophages and neutrophils that also produce cytokines [39]. Complement signaling and activation pathways have now been linked with $\mathrm{T}$ cells, which act in homeostatic responses.

Merle and colleagues [29] showed that the complement system is activated in sickle cell disease (SCD) patients and is the likely cause of nephropathy because deposits of complement components $\mathrm{C} 3$ and $\mathrm{C} 5 \mathrm{~b}$ were present within the tissues of kidney biopsies taken from patients. Using a combination of 
in vitro and in vivo approaches with a mouse model of SCD, the mechanism of complement activation triggered by intravascular hemolysis was shown to be due to the effects of heme on endothelial cells. Furthermore, intravenous (IV) HPX was protective limiting the complement activation.

In a mice model of phenylhydrazine (PHZ)-induced intravascular hemolysis (IVH), C3 deposits were detected predominantly in the kidney and in the glomeruli. The role of $\mathrm{C} 3$ was confirmed because the renal injury was markedly less in C3 null mice. In WT mice, IV hemin or IV purified human $\mathrm{Hb}$ also led to activation of complement with extensive C3 deposits in the kidney. Significantly, there were no detectable deposits after HPX was given IV providing strong evidence that HPX effectively prevented complement activation in response to heme and, importantly, also to $\mathrm{Hb}$. As an avid heme-binding protein, this protection by HPX also supports that the pathological effects of $\mathrm{Hb}$ are due in part to the release of heme with activation of complement. In contrast, human serum albumin that can bind two molecules of heme but significantly lower affinity than HPX, was not protective. Phenylhydrazine causes a huge IV $\mathrm{Hb} /$ heme load with extensive acute kidney injury as shown by tissue and vascular markers of inflammation (e.g., IL-6, P-selectin), as well as ultrastructural changes in the renal tubules. Surprisingly, this kidney damage was resolved and renal function restored without treatment. In contrast, these changes in the kidney did not occur in response to IV heme. In addition, HPX was not protective in the PHZ-treated mice that were dying possibly from acute pancreatitis [40]. While the overall conclusion was that HPX is a sentinel for the kidney in IVH against heme toxicity, it was suggested that events generating hemolysis-derived products before the release of heme might be the damaging species. Degradation of RBCs produced heme-loaded microvesicles and heme induced both the alternate and complement pathways and activated complement either in serum in vitro or on endothelial surfaces. Complement proteins can be inactivated with blocking antibodies, although this type of treatment is still under development. Nevertheless, the identification of a role for complement in vascular injury and organ pathology raises the possibility that such antibodies would be useful as adjunct therapeutics with plasma protein replenishment to minimize or preclude development of the pathology of heme toxicity.

\subsection{Hb-Related Globin Toxicity}

It has been known for some time that globin is potentially toxic to cells. $\mathrm{Hb}$ (from RBCs) and myoglobin (from myocytes) are the principal sources of globin in plasma. There are clear differences in the structure of these two molecules that drive their chemical responses to agents such as $\mathrm{CO}$, which is released only from heme catabolism [41] and from lipid peroxidation. Due to the fact of its inherent instability, $\alpha$-globin aggregates within red blood cells at various stages of their development and sites in the body causing much of the pathology in $\beta$-thalassemia (see Section 2.1). An excess of $\alpha$-globin chains without sufficient $\beta$-globin due to the point mutations in this disease is potentially toxic and to counteract this, an $\alpha$-globin chain stabilizing protein is expressed in erythroid precursor cells solely, which is a chaperone for the $\alpha$-globin [42].

The mechanism by which heme itself and $\mathrm{Hb}$ contribute to cell and protein damage in hemolysis has been extensively investigated during the past ten years or so and is well understood. Early studies on the transfer of heme to HPX from $\mathrm{Hb}$ in vitro revealed denaturation of the globin, apparent in the absorbance spectra [28]. In vivo studies with mice or rats or in vitro studies with non-neuronal cells have not yet pinpointed globin as a toxic agent. However, a recent in vitro study with mixed mouse neurons and glia in culture incubated with hemoglobin $(\mathrm{Hb})$ and HPX (i.e., in the absence of haptoglobin $(\mathrm{Hp})$ led to white precipitates of globin protein in the medium on the surface of cells and within cells [43]. This was associated with significant levels of neurotoxicity, based on lactate dehydrogenase release from neurons, although not glia, after incubation with $\mathrm{Hb}(4 \mu \mathrm{M}$, i.e., $16 \mu \mathrm{M}$ heme) and HPX $(1 \mathrm{mg} / \mathrm{mL}$, i.e., $\sim 17.5 \mu \mathrm{M})$. When the mixed cells were incubated with heme, HPX completely protected both types of cells from heme toxicity. Protective effects of HPX were not considered due to the extracellular "scavenging" but rather were ascribed to intracellular protection 
against heme toxicity via heme breakdown by HOs and protection against iron toxicity by Ftn, which was shown to be induced [44,45].

Published studies on Hp knockout mice have not recorded obvious globin precipitation, not even after PHZ-induced hemolysis, which is extensive, and not even after IV HPX. Also, Hb clearance from the plasma occurs at essentially the same rate in Hp-null mice and wild-type mice without obvious toxicity [46]. However, $\mathrm{Hb}$ clearance in mice differs from humans because although human $\mathrm{Hp}$ binds to $\mathrm{CD} 163$, mouse $\mathrm{Hp}$ does not and mouse $\mathrm{Hb}$ binds more tightly to CD163 than human $\mathrm{Hb}$ [46]. Without $\mathrm{Hp}$, the kidney and muscle of mice [47] are the tissues most affected by oxidative damage in response to $\mathrm{Hb}$. The globin toxicity detected in neuronal cells in vitro may be due to the very defined medium that may not contain the proteins and other molecules normally present in CSF (or at their normal concentrations). Perhaps further research on Hp-null mice and human brain cells will help determine if there are protective factors in cells and biological fluids in vivo, for example, other heme binding molecules that mitigate against globin precipitation or oxidation reactions, or if there are additional differences to be discovered between heme and $\mathrm{Hb}$ clearance in humans and mice.

\subsection{Heme and Iron-Dependent Cell Death by Ferroptosis}

There are clearly defined programs and mechanisms for cell death such as apoptosis or necroptosis in response to toxic agents and/or a variety of environmental conditions and stresses. Distinct morphological changes including abnormal mitochondrial size may also be manifest. An iron-dependent cell death pathway termed ferroptosis has been investigated and defined [48-50]. This requires intracellular oxidative stress that increases lipid peroxidation, decreases GSH levels, thus changing GSH/GSSG and increasing $\gamma$-glut amyl transferase, together with the instigator iron. Ferroptosis, as has been pointed out in Reference [49] has a distinct biochemical, morphological, and genetic "fingerprint". Clearly, heme catabolism by HOs raises intracellular ferrous iron presumably predominantly in the cytosol. Several studies carried out with primary neuronal mouse cells, immortalized neuronal cells, and mice models of intracranial hemorrhage (ICH) [51] provide evidence that heme-mediated ferroptosis is part of heme toxicity in human hemolytic disorders. The responses of cells, including primary human hepatocytes [35], to heme-HPX where the intracellular redox state is maintained without ROS production have therefore been proposed to be anti-ferroptotic [3]. Also, studies with immortalized proximal renal tubule cells from $\mathrm{HO}^{+/+}$and $\mathrm{HO}^{-/-}$mice have provided strong evidence that it is not the generation of ferrous iron from heme catabolism solely that leads to ferroptosis. Furthermore, $\mathrm{HO} 1$ can have an anti-ferroptotic role in these kidney cells [52].

Heart attacks and stroke occur after blood vessel injury that activates platelets causing occlusion and thrombosis. Also, platelet micro particles are seen in patients with hemolysis including SCD. Intriguingly, heme increased P-selectin expression that drives vaso-occlusion in SCD is evident by not only endothelial cells but also by platelets (see Sections 4.1 and 4.2).

When human platelets suspended in Tyrode's buffer were incubated with heme, filopodia-like structures appear at the cell surface in the presence of 5-10 $\mu \mathrm{M}$ heme [53]. Further changes in the cell surface consistent with damage-“"blebbing"- were seen in response to $25 \mu \mathrm{M}$ heme. Using sets of biochemical inhibitors and activators for various death pathways in conjunction with heme, the data supported that the platelets were neither undergoing apoptosis nor necrosis. There was a 5 fold increase in ROS and in markers of lipid peroxidation together with elevated HO1 and cytosolic iron in response to heme. In addition, oxidative stress was generated including effects on GSH with evidence for a role for the amino acid antiporter system $\mathrm{Xc}_{\mathrm{c}}$, which transports cystine into cells that is needed and used for GSH synthesis. The ROS production (i.e., increased hydroxynonenal) by heme was controlled when the iron-chelator deferoxamine, the ferroptosis inhibitor ferrostatin-1 or the HO inhibitor tin-PPIX were present. Thus, $10-25 \mu \mathrm{M}$ heme generated ferroptosis in platelets in vitro.

Protection of neurons against ferroptosis may come from the development of inhibitors of double-stranded RNA-dependent protein kinase, as shown recently in mouse hippocampal H22 cells [54]. This kinase responds to oxidative stress and ER stress and may be part of the pathology of 
neurodegeneration with mitochondrial impairment as in Parkinson's disease and Alzheimer's disease that are both associated with increased brain iron [55-57].

Brain damage after ICH includes irreversible damage to neurons in primary and secondary injury, the latter is generally considered to be due to the $\mathrm{Hb}$ and heme from lysed RBCs. Apoptotic cells and necrotic cells have both been identified in the perihematomal region after ICH. Both ferroptosis and necrosis were identified as being involved in $\mathrm{Hb}$ - and heme-induced toxicity in primary cultured neurons, immortalized hippocampal neurons (HT22 cells), and in male mice after ICH [58].

Human monocytes may also be susceptible to ferroptosis induced by heme in transfusiondependent patients, who often develop iron-overload. When human monocytic THP-1 cells in serum-free medium were incubated for $2 \mathrm{~h}$ with $20 \mu \mathrm{M}$ heme, there was an increase in ROS production together with an increase in cells with markers of necrosis but not markers of apoptosis [59]. The ROS production was prevented by $\mathrm{N}$-acetyl cysteine (which can chelate metals), by iron chelators deferoxamine and deferasirox (the latter being more effective), or an inhibitor of NADPH oxidase that generates ROS. Ferrostatin- 1 decreased cell death in response to heme, whereas erastin, which induces ferroptosis by inhibiting the system $\mathrm{X}_{\mathrm{c}}$, increased cell death implicating ferroptosis as the cause. The protective effects of serum proteins against heme toxicity by binding heme was clearly shown because the addition of albumin or fetal bovine serum decreased the amount of heme associated with the cells and heme toxicity even at very high concentrations of heme $(20-80 \mu \mathrm{M})$.

Overall, these studies demonstrate the potential that heme toxicity can kill cells by ferroptosis opening up an additional therapeutic approach in the clinic especially for neurodegenerative conditions and ischemic and hemorrhagic stroke. A review on the nexus between iron dyshomeostasis, excitotoxicity, and ferroptosis in stroke with a focus on ferroptosis has recently been published [60].

\section{Potential Therapies to Replete HPX Levels for Protection against Heme Toxicity}

As previously reviewed, HPX plasma levels can become depleted in patients with genetic hemolytic anemias (e.g., SCD, $\beta$-thalassemia) and hyper-hemolytic states for example after extensive blood transfusions [61,62]. In mice models of these hemolytic conditions, HPX replenishment by intraperitoneal (I.P.) or I.V. injection or by hepatic over-expression of HPX is often lifesaving. Thus, these animal studies formed the foundation for the concept of plasma protein replenishment therapies with HPX to combat the various damaging effects of heme in biological fluids. Unfortunately, $\mathrm{Hp}$ is often virtually undetectable in patients with hemolysis and so the current view is that a combination of HPX with Hp may prove most beneficial. Given the information on the effects of heme that include complement activation and activation of ferroptosis, additional combinations of therapies may prove even more beneficial to certain groups of patients.

\subsection{Plasma Protein Replenishment Therapy}

There are some unique aspects to the lipid profiles of patients with SCD, who overall have hypocholesterolemia, with low levels of both low- (LDL) and high-density (HDL) lipoproteins. In mice models of SCD, heme activates endothelial cells via toll-like receptor 4 driving events leading to vaso-occlusion [63]. Two independent studies of SCD patients describe differences in heme and HPX content of LDL and HDL [64,65]. Both addressed that oxidation of lipoproteins by heme and $\mathrm{Hb}$ is due to the ongoing hemolysis. In addition to HPX, $\alpha-1$ microglobulin, albumin, and lipoproteins all bind heme. Vendrame and colleagues [64] considered that the varying levels of HPX would determine how much heme might intercalate in the lipoproteins in SCD patients. The LDL fraction had a higher heme concentration than did HDL, but the HDL fraction had a higher concentration of HPX. Thus, HDL is considered an important defense with potentially anti-inflammatory activity against heme toxicity but appears to be insufficient to protect endothelial cells from heme. Nevertheless, and intriguingly, HPX is linked with lipid metabolism because the cholesterol levels in the SCD patients were inversely correlated with circulating plasma HPX concentrations. 
In the second study [65], the level of lipid peroxidation in SCD patients undergoing regular transfusions was measured using a sensitive assay-the end product of lipid peroxidation malondialdehyde. In SCD patients, Hp is essentially absent; however, HPX is present albeit significantly decreased. Consequently, as might be expected, both LDL and HDL oxidation were increased demonstrating the loss of protection against heme-mediated damage by the plasma proteins. At the postmortem of an SCD patient, oxidized LDL was found in the pulmonary artery. These observations reinforce the conclusion from other studies on SCD that replenishment therapy with HPX together with $\mathrm{Hp}$ may prove useful therapeutically; and this is also supported by studies with mice models of SCD (see Section 8).

\subsection{Plasma Exchange}

Plasmapheresis or therapeutic plasma exchange may provide another means to raise HPX and Hp plasma levels and may be more cost effective than recombinant proteins. Plasmapheresis is an established therapy and has been described as a symptomatic treatment for critically ill patients. Whole blood is removed, the plasma and cells separated, and the plasma replaced with another solution that may be specially prepared plasma from another person. Plasma is normally rapidly frozen after separation from RBCs and used after thawing within $24 \mathrm{~h}$. The plasma is often used to remove and replace a patient's plasma when they have autoimmune disease. Plasma exchange was effective in reversing organ dysfunction in children with thrombocytopenia-associated multiple organ failure [66]. However, while generally considered safe, it can cause bleeding, allergic reactions, and also potentially increase the chances of developing a bacterial infection. Using a small group of three patients, plasma exchange was found to successfully replete HPX and Hp in two SCD patients that were refractory to RBC exchange [67]. There were significant increases in both HPX and Hp while heme decreased $~ 30 \%$. Unfortunately, the condition of one patient deteriorated, their circulating HPX and Hp levels were not increased by plasmapheresis presumably because their liver was not able to sustain and synthesize plasma proteins.

\subsection{The Scavenger Receptor LRP1/CD91 as a Target for Therapies When There Is Hemolysis in the Brain}

In a murine model of $\mathrm{ICH}$, the administration of an antagonist (a potential inhibitor of agonist action) and agonists (producing a known effect) of TLR7 led to changes in mRNA and protein levels of the scavenger receptor LRP1/CD91 that binds heme-HPX tightly (Kd 4 nM, [68]). The expression of LRP1/CD91, HPX itself, and TLR7 were all increased when mice were treated after ICH induction with the TLR agonist imiquimod and decreased by TLR7 inhibitor ODN2088 [69]. The authors proposed that these studies reveal the potential for a role for TLR7 in the uptake of heme-HPX, although this was not shown directly. (See also Section 8.5.)

\section{Protective Functions of HPX in Various Pathologies}

The published clinical research on HPX within the past two years covers diverse clinical states: SCD, $\beta$-thalassemia, thrombolytic conditions, trauma with hemorrhage, intracerebral hemorrhage, hemorrhagic stroke, spinal cord injury, carotid artery disease, tuberculosis and diabetes, liver disease, kidney injury, pre-eclampsia, and microbial invasion of the amniotic cavity. In several studies, HPX has been investigated as a biomarker, used as a parameter to establish hemolysis or, in some cases, to assess the extent of hemolysis ("hemolytic index"). Depending upon the cause, extent, and duration of hemolysis there are significant differences in the amount of heme load from $\mathrm{Hb}$ that HPX counteracts. Additional factors arise when the immune system has been activated. Intriguingly, there are compensatory changes in the immune system in depression, bipolar disorder, chronic widespread pain and fatigue, and HPX expression in the CSF is increased in these patients. Notably, HPX is not an acute phase reactant in humans unlike Hp [70]. Furthermore, even when there is extensive or chronic hemolysis, as in SCD, high levels of $\mathrm{Hb}$ readily deplete plasma Hp but HPX is often still present 
albeit at lower than normal levels. Evidence from both clinical and animal research now supports that changes in HPX may differ depending upon the source of $\mathrm{Hb}$, i.e., IV $\mathrm{Hb}$ or RBC lysis.

In patients with traumatic hemorrhage, high levels of heme and $\mathrm{Hb}$ (four times greater than heme) were present in plasma and heme levels were overall greater than $5 \mu \mathrm{M}$. Both were higher than plasma non-transferrin bound iron. Interestingly, the plasma heme levels were proportional to the number of units transfused rather than to the length of storage time of the RBCs. Thus, plasma transfusions are anticipated to provide significant HPX and $\mathrm{Hp}$ for protection against the $\mathrm{Hb} /$ heme from RBCs. Nevertheless, in the face of high levels of $\mathrm{Hb}, \mathrm{HPX}$ levels rapidly and extensively decline. Information on HPX's recovery time is needed in a variety of clinical situations and historical studies show that it may take several days [62]. In contrast to the recycling of HPX from liver, $\mathrm{Hb}-\mathrm{Hp}$ complexes are degraded after endocytosis via the scavenger receptor, CD 163, in macrophages predominantly in the spleen. The extent of uptake by tissue resident macrophages including Kupffer cells in the liver is not known. When this $\mathrm{Hb}-\mathrm{Hp}$ scavenger system is impaired or saturated, $\mathrm{Hb}-\mathrm{Hp}$ remains in the plasma [71]. It is anticipated that in the clinic, information on the collective levels of heme, Hb, HPX, and $\mathrm{Hp}$ will prove important for assessing and determining patient treatments [72].

When using HPX as a biomarker, it is important to consider that HPX expression and its activity as a cytoprotectant differ with development, aging, and gender; as well as in response to the various diseases and conditions investigated. The age-dependent changes in HPX levels make newborns and young children vulnerable to heme-related pathology including oxidative stress and inflammatory responses, and can, under certain circumstances, drive inflammation. Furthermore, inflammatory responses generally are more prevalent with age and are exacerbated by genetic factors and by auto-immunity.

As described above (Section 2.4), the complement system is an integral part of the immune system and is composed of a plethora of plasma proteins that interact to fight infection in a variety of ways. Significantly, heme from $\mathrm{Hb}$ activates the complement system in vivo and in plasma in vitro. As with other immune system cells and proteins, this provides a means to protect in the early stages of disease including infections, and also to exacerbate inflammation and accompanying heme-driven pathology. These inflammatory conditions as well as the source of heme (IV heme, IV Hb or RBC lysis), determine which major organs and cells are affected. The lung is a more recently identified site of hemorrhage and heme injury, in addition to the liver, heart, kidney, and brain. Hemorrhagic brain damage weakens the integrity of the blood-brain barrier and heme is deleterious for the vascular system because of toxic effects on endothelial cells, smooth muscle cells, and, thus, blood vessel integrity.

\subsection{HPX in Sickle Cell Disease}

Unbiased analyses of the plasma proteome revealed several novel proteins that correlated with a therapeutic response (i.e., decreased hemolysis in young patients with SCD) during treatment with hydroxycarbamide (HC). Hydroxycarbamide is also known as hydroxyurea (an inhibitor of ribonucleotide reductase). As a long-time treatment for SCD, HC is thought to help prevent vaso-occlusion and vasculopathy by increasing $\gamma$-globin synthesis, altering adhesion factor expression by the endothelium, and by reducing the population of neutrophils. Plasma HPX levels significantly increased as the rate of hemolysis declined in response to $\mathrm{HC}$, demonstrated by an increase in $\mathrm{HbF} \%$ [73]. In addition, the levels of $\alpha-, \beta-$, and $\gamma$-globin chains, the Hp-related protein, and complement C9 decreased. Thus, these protein changes were all associated with decreased hemolysis. Two other biomarker panels were investigated: one for inflammation (including ceruloplasmin, lower $\alpha 1$ acid glycoprotein, CD5 antigen-like protein, and factor XII among others), and another for decreased coagulation (including lower factor XII, carboxypeptidase, and platelet basic protein). Overall, the changes in these biomarkers also support significant improvements in these children in response to $\mathrm{HC}$, which may prove useful therapeutically in other conditions with extensive hemolysis. 


\subsection{HPX Status in Platelets in Hemostasis and Thrombosis}

When normal hemostasis is overwhelmed by pathological factors, there is uncontrolled clot formation that leads to blocked arteries or veins. Platelets together with endothelial cells and coagulation factors are crucial mediators of both vascular hemostasis and thrombosis. The thrombi that develop in arteries are rich in platelets and form at the sides of or around thrombotic plaques even where there is a high shear flow. Thrombi in veins have fibrin and RBC, but form on intact endothelial cell wall only in areas where there is a low shear force. Hemopexin may have specific roles in trauma injury with hemorrhage, which is one example of a thrombotic condition. A clot is also an example of thrombosis where there is a local obstruction of blood flow. Clots can also form on wounds and in those circumstances aid healing. Thus, depending upon the site of injury monitoring changes in $\mathrm{HPX}$ in plasma and other biological fluids may be a helpful in diagnosis, prognosis, and to predict the response to therapies in these patients.

In the setting of hemorrhage, hemostasis may occur by normal vasoconstriction and narrowing of blood vessels by an abnormal obstruction that includes atherosclerotic plaque via activation of the coagulation cascade (clot formation) or by physical ligation during surgery. These processes regulate vascular integrity and, thus, blood flow. The responses involve complex biochemical systems with multi-factorial processes that may even drive pathology in cancer. Hemopexin has been linked to various cancers (reviewed in Reference [74]) and approximately half of deaths of cancer patients with malignant tumors are associated with thrombotic events. Vascular occlusive diseases include atherosclerosis and lead to carotid artery disease and heart attacks, which is a leading cause of death in developed countries.

Evidence supports that the risk for thrombosis increases when there are larger platelets. Recent presumptive evidence supports that there are different populations of platelets, and two populations of human EDTA platelets were separated and identified based upon their mean volumes. Not only do platelets vary in size; but based on their diverse protein content that includes differences in HPX content, platelets have different functions [75]. Consistent with the link to thrombosis, large platelets were found to have more glycoproteins expressed on their cell surface and were found to be able to adhere better to collagen surfaces. Proteomic analyses revealed that 80/894 proteins differed in abundance between the large and small platelets. The differences among them are beginning to be defined. For example, the activation of integrin by ADP was greater in small platelets. Intriguingly, the proteins most relevant for heme and iron homeostasis including HPX, Hp and $\alpha-1$ anti-trypsin, transferrin, and vitronectin, as well as immunoglobulins, were all more abundant in small platelets. It will therefore be interesting to understand the physiological relevance of these observations.

\section{Hemopexin as a Biomarker for Concomitant Changes in Hemolysis, Inflammation, Heme, and Iron Metabolism-Some Challenges Include Age, Gender, and Type of Infection}

Due to the developmental expression of HPX and of Hp and transferrin, the potential exists for key differences in the changes in these proteins as biomarkers (among other parameters of disease progression) between children and adults during therapy. This will be important especially in conditions complicated by inflammation in the presence of heme- (and iron-) toxicity known to be related to pathology. There will also be gender differences not solely because of estrogen-related effects in women but also to documented differences in iron-metabolism between men and women. Men with coronary artery disease have lower levels of plasma iron-transferrin and HPX but higher levels of inflammatory markers, macrophage infiltrates, and iron stores. There are increased levels of plasma $\mathrm{Hb}$, increased numbers of $\mathrm{Hb} \mathrm{CD} 68^{+/+}$macrophages, together with ferritin and transferrin receptor 1 in atheromas [76]. Thus, there are differences in both heme and iron metabolism in men and women with atherosclerosis. Such differences need to be fully established to help physicians better assess the progress of their patients from diagnosis through therapy.

Women are more prone to inflammatory diseases and are three times more likely than men to develop rheumatoid arthritis. Once more, this is not solely due to the presence of estrogen because 
several disease-associated genes reside on the $\mathrm{X}$ chromosome. Increases in inflammatory markers were recently found in the CSF of seven rheumatoid arthritis patients, which also correlated with fatigue. Fatigue is considered to be related to changes in the central nervous system. For over twenty years it has been known that tumor necrosis factor (TNF), which is an inflammatory cytokine, plays a major role in arthritis [77] and that targeting TNF (for example with a monoclonal antibody such as infliximab) is effective and improved the symptoms of fatigue. An "arthritis proteome" identified that TNF blockade with infliximab decreased 35 proteins in the CSF. Hemopexin was one out of seven candidate proteins and changes in HPX are known to be associated with arthritis [78]. Contactin 1 and complement factor B, both known to increase with systemic inflammation, were also decreased. Both fibrinogen $\gamma$-chain and complement factor B decreased in response to the TNF inhibitor. The decrease in HPX in response to infliximab was considered to be due to the amelioration of both systemic and CNS inflammation because markers of inflammation were decreased in the CSF. Overall, these data support a relationship between arthritis symptoms and CNS inflammatory pathways as targets of the TNF inhibition. Although the infliximab is stated to not cross the blood-brain barrier, $\mathrm{TNF} \alpha$ crosses via receptor transport. Thus, systemic TNF $\alpha$ can damage the endothelial cells of the barrier creating localized permeability and infliximab peptides were detected in the CSF. Intriguingly, the circumventricular organs were proposed as an alternative route into the brain. These are brain structures with extensive and permeable capillaries, which allow the passage of molecules both into and from the brain (e.g., certain hormones [79]), and which contain cells with TLR4, a target of LPS and heme [80].

Pregnant women are at risk for heme-related toxicity when they develop the potentially lethal condition of preeclampsia, typically in the third trimester. Preeclampsia is associated with life-threatening high blood pressure among other symptoms and occurs in about $3-7 \%$ of all pregnancies. The pathology is not well understood but is thought to originate from changes in the placenta. It has been associated with autoimmune disorders and blood vessel problems, and there are several other risk factors including a history of diabetes, high blood pressure or kidney disease. Several studies have provided evidence that changes in the level of the heme-binding protein alpha- 1 microglobulin (A1M) may correlate with the severity of this condition. As this condition becomes more severe, A1M levels increase and may reflect increased endogenous oxidative stress [81]. Hemopexin levels also changed in women with preeclampsia and may be related to changes in cardiac function. Hemopexin was proposed to become depleted in the early stages of pregnancy and to rise in the third trimester when the high blood pressure symptoms of preeclampsia become apparent. However, confirmation of this will require further analyses to fully elucidate. Nevertheless, biomarkers for $\mathrm{Hb}$ sequestration and degradation pathways may prove informative in assessing the mother's status in preeclampsia.

\section{HPX as a Biomarker for Sepsis}

Evidence from both clinical and animal studies [35,61] shows that HPX has potential as a biomarker in sepsis, as reviewed previously [62]. A panel of biomarkers is urgently needed for sepsis and septic shock patients due to the prevalence and high incidence of mortality and health issues. Patients who recover from sepsis endure long-term effects that include both physical and mental problems.

Vimentin may prevent lymphocyte apoptosis and be anti-inflammatory and, thus, may be a useful new target in sepsis [82]. Vimentin is one of the main constituents of the intermediate filament proteins that maintain cell shape, in part, by stabilizing the interactions of the cytoskeleton and perhaps more importantly by helping cells resist damage including apoptosis. Both serum and lymphocyte levels of vimentin were significantly increased in these two groups of patients. Hemopexin was one of 56 proteins identified in plasma, finally ranking fourth in a protein network of 12 based upon interactions with eight other proteins in the network (defined as "betweenness centrality"). Thus, HPX has been linked in a co-expression protein network with vimentin in patients diagnosed with sepsis and septic shock [82]. 
Ekregbesis and colleagues [83] tested the hypothesis that inflammation- or infection-associated hemolysis contributes to sepsis-associated anemia and also leads to detectable HO1 in plasma. Hemopexin levels were used as one of several parameters of hemolysis. The prevalence and extent of anemia, the presence of inflammation and levels of $\mathrm{HO} 1$ were determined in a cohort of ICU patients within $12 \mathrm{~h}$ of admission. Most patients ( 83\%) were deemed anemic and hemolysis was evident because of heme in the plasma (median levels $\sim 21 \mu \mathrm{M}$ ), low Hp, decreased HPX (median levels $9.6 \mathrm{mg} / \mathrm{dL}$, normal levels $\sim 77 \mathrm{mg} / \mathrm{dL}$ ) together with elevated HO1. Hemolysis was accompanied by IL-10-associated inflammation and the presence of IL- 6 and TNF $\alpha$. In this study, HPX was neither associated with the anemia nor with morbidity. However, all of the cytokines that were increased, including IL-6 and IL-10, were weakly inversely correlated with HPX. The IL-6 levels correlated with IL-10 levels and HO1 induction was associated with IL-10 levels rather than the extent of hemolysis. In contrast to other studies on sepsis $[35,84]$, the severity of sepsis was considered better indicated by the rise in plasma IL-10 and the HO1 levels rather than the low HPX levels on admission.

Iron is needed by pathogens for cell growth and to establish an infection. Circulating ferritin light chain (L-ferritin, FtL), needed for iron homeostasis, has recently been shown to play a protective role in the cecal ligation and puncture model in mice that produces, as the gut contents leak, polymicrobial sepsis. [85]. There are known gender differences in iron markers and, in the clinic, serum ferritin levels together with several other markers are used to assess iron stores. Ferritin light chain is a secreted form of ferritin and low in iron content, which predominates in the circulation and whose function has been enigmatic for decades. The increase in serum ferritin in response to infection indicates a role in the acute phase response and this study supports such a link. The role of myeloid cell specific ferritin, using ferritin $\mathrm{H}(\mathrm{FtH})$ deleted cells, was also addressed. The FtH deficiency dampened the inflammatory response in vivo and decreased the response in vitro of bone marrow derived macrophages to LPS. However, it did not alter phagocytosis or bacterial clearance. Hemopexin levels have been implicated as protective in a previous study with this model of sepsis [35] but were not apparently affected by the loss of FtH in the myeloid cells (perhaps due in part to the wide range of individual values among the mice compared with those of Hp). FerritinH and FtL chains were both increased. FerritinL is anti-inflammatory because when it was elevated there were lower levels of liver injury, decreased inflammatory cytokine levels and increased inducible nitric oxide synthase, which is protective in the recovery from post-ischemic inflammation.

As noted by Chaim Hershko [86] in a review entitled "Iron, Infection and Immune Function", the term "nutritional immunity" was first used in 1973 to demonstrate the importance of preventing human pathogens from multiplying and dividing to establish an infection [87]. It is well known that both iron and heme (the latter presumably as an iron source), are necessary for the growth of pathogenic bacteria. The need for heme is apparent from the plethora of uptake systems that bacteria employ to ensure the capture of heme, many of which are redundant ready to bind: heme itself, $\mathrm{Hb}$, heme-HPX or $\mathrm{Hb}-\mathrm{Hp}$ [88]. Therefore, HPX by sequestering heme acts in nutritional immunity and to overcome this heme/iron limitation many human pathogens express receptors for heme-HPX uptake. HPX has recently been linked to host immunity and the anti-microbial action of IL-22 because, in mice, limiting infection depends upon HPX but not on Hp, in spite of the fact that the expression of both proteins in the liver is induced by IL-22. Mice were infected with either Escherichia coli that causes sepsis in humans or Citrobacter rodentium that normally resides in the gut of mice and can also cause a wide range of infections in humans. Citrobacter rodentium shares several features with $E$. coli in how it establishes infections. After WT and IL22 $2^{-/}$mice were infected, C-reactive proteins, serum amyloid A1, $\alpha 2$-macroglobulin as well as HPX and Hp were increased in plasma. Hepatic levels of HPX and Hp mRNA rose after infection in WT mice and in the IL22-/- mice, but to a significantly lesser extent; consequently, $\mathrm{Hb}$ accumulated in the plasma due to the ongoing hemolysis caused by the infection. The presence of HPX was sufficient to clear $C$. rodentium in WT mice but not in $\mathrm{HPX}^{-/-}, \mathrm{Hp}^{-/-} \mathrm{HPX}^{-/-}$ or $\mathrm{Hp}^{-/-}$mice. Furthermore, HPX reduced the level of infection (judged by decreased numbers of circulating bacteria) in IL22-/- mice regardless of whether it was from an intravenous or oral infection. 


\section{Organs That Endure the Worst Heme Toxicity Include the Lung, Liver, Kidney and Brain}

\subsection{Lung Disease/Injury}

Lung injury comes from exposure to many different kinds of inhaled compounds and can lead to pulmonary hemorrhage. Blood gets into the alveolar spaces when there is disruption of the alveolar capillary membrane (diffuse alveolar hemorrhage) [89]. The heme levels in plasma of patients with chronic obstruction pulmonary disorder (COPD) was significantly increased compared with non-smokers [90]. As described in Section 2.3, high intracellular heme levels lead to oxidative damage of proteins, which in turn activates the UPR. Consistent with this, the levels of one key regulator of the UPR, namely, GRP78, were extensively increased in the lung of COPD patients.

Chemical weapons were first used in World War 1; furthermore, chemical weapons such as chlorine may have been used in Syria within the past two years, while mustard gas and nerve agents were used against residents in Northern Iraq in 1988. The toxic gases chlorine and bromine damage lungs. Hemolysis developed in mice exposed to bromine by inhalation with heme-mediated lung damage that was ameliorated by a single IV treatment with recombinant human HPX [91]. Abnormally high levels of plasma heme were detected in the mice up to 14 days post bromine exposure. This was associated with increased lung elastase activity, which may induce the UPR via the PERK/CHOP arm [90]. The protection by exogenous human HPX was due to the counteracting high heme levels in part by sequestering heme, thus relieving RBC lysis after bromine exposure but also by stimulating the level of endogenous HPX circulating in plasma of these mice. The mechanism of the induction of endogenous HPX is currently unknown and may be occurring, but unrecognized or detected, in other mice models of hemolysis and HPX replenishment. Incidentally, bromine is present in cigarette smoke and, thus, represents a risk factor for chronic smokers.

Both these studies on patients support that HPX plasma replenishment is of potential therapeutic value in different kinds of lung injury that produce lung fibrosis and emphysema; and, especially, in combination with drugs that relieve the UPR and ER stress in lung cells.

\subsection{Liver Disease/Injury}

Many different types of liver pathology ultimately lead to liver cancer including chronic liver disease scarring such as cirrhosis. These pathologies can be caused by hepatitis B or C infection, by alcoholism or by fat accumulation (i.e., fatty liver). Hepatocellular carcinoma (HCC) is the most common type of primary liver cancer and there is a greater prevalence of HCC in men. Hepatocellular carcinoma can be cured if the liver disease is identified early enough. Hepatocellular carcinoma can develop when there is cirrhosis and the only cure is a liver transplant. Thus, identifying biomarkers of liver disease and especially HCC is of crucial importance.

Potential biomarkers including those for liver disease may be discovered in the content of exosomes, which are very small endocytic membrane bound vesicle derived from all cells (as far as is known). Exosomes were first discovered in maturing mammalian reticulocytes [92]. Their content of proteins and miRNA provides a window on the cells that release them providing information not only on the cell of origin but also potentially that of the tissues and organs from which the cell is derived. Thus, exosomes are providing useful biomarkers consisting of proteins and peptides that are readily being identified and quantitated by proteomic profiling. For example, HPX levels together with properdin were decreased in exosomes of patients with HIV with active drug use compared with HIV or with HIV patients with alcoholism. Properdin is the only known positive regulator of complement that stabilizes the alternative pathway convertases $\mathrm{C} 3 \mathrm{bBb}$ [93]. Thus, HPX and properdin are poised to be potential markers for co-morbidity in drug abusers who were HIV positive, [94] indicating both liver disease and complement activation.

Several changes in carbohydrate structure of glycoproteins have been linked to liver disease [74] and another means to monitor liver disease utilizes identification of aberrant core fucosylation of plasma glycoproteins as biomarkers. Such alterations are readily assessed from patient serum samples. 
Human HPX has one O-linked oligosaccharide chain at its N-terminal threonine and five additional N-linked chains [95]. Core fucosylation of glycoproteins is site specific and clearly identifies a protein. A multiplex LC-MS/MRM array was used for the serological assessment of liver disease and to determine the extent of fibrosis of the liver. Key and specific changes (both increases as well as decreases in fucosylation of several N-linked glycoproteins) were detected at the stage of fibrosis in a comparison of the data garnered from healthy control, fibrotic, and cirrhotic livers. While five proteins were identified that marked liver fibrosis including transferrin, ceruloplasmin, $\alpha-1$ antitrypsin, and vitronectin, there were also additional changes found in cirrhosis including HPX. Of relevance here, the changes included aberrant fucosylation at N630 of transferrin, N187 of HPX, and both N138 and N762 of ceruloplasmin, and N354 of clusterin [96]. Thus, detectable changes in fucosylation levels of several key plasma proteins including HPX, either increase or decrease as the liver disease worsens.

Additional monitoring of plasma proteins via glycan screening, including HPX [97], may also provide evidence of changes in liver function, thus aiding in the early detection and progress of HCC. This technique involves protein extraction using lectin-affinity binding of plasma samples. Preliminary data using MALDI-MS or ESI analysis show that glycan screens may prove useful to detect changes disease-related changes in HPX, Hp, and kininogen as liver function deteriorates.

\subsection{Kidney Disease/Injury}

It is well established that acute kidney injury occurs in hemolysis and that the kidney is susceptible to damage by $\mathrm{Hb}$ and heme. Thus, this organ is particularly vulnerable when plasma Hp and, eventually, HPX are both decreased.

Severe malaria pathology is associated with inflammation, endothelial cell activation and hemolysis. Furthermore, acute kidney disease is a known complication of malaria, especially in infection by Plasmodium falciparum and contributes to a high rate of mortality. One potential biomarker of acute kidney injury is chitinase-3 like 1 protein (CH3L1 YKL-40, HCgp39). It has also been associated with burn injury and bacterial infection. In spite of its name, CH3L1 is not an enzyme and does not act on chitin, which is an $\mathrm{N}$-acetyl glucosamine polysaccharide that is expressed by endothelial and immune cells. However, CH3L1 on epithelial cells may bind chitin binding proteins expressed by bacterial strains that are potentially pathogenic. Thus, CH3L1 has been proposed to enhance the adhesion and binding of pathogenic bacteria. A high ratio of heme to HPX in children with malaria indicated severe disease with adverse clinical outcomes, and $46 \%$ of the children had acute kidney injury [98]. Interestingly, children with the highest heme levels (and lowest HPX) had significantly lower levels of parasitemia and the heme to HPX ratio decreased with recovery demonstrating a useful parameter to assess the severity of malaria.

Following up on these studies, Conroy et al. [99] investigated in a clinical trial if inhaled NO was an effective adjunct therapy for severe malaria in children in Uganda and investigated changes in CH31L as a potential biomarker for kidney damage. The rationale and hypothesis that children with malaria might benefit from exposure to nitric oxide (NO) as an adjunct therapy was first proposed in 2011. This was based on the response of adults with malaria to nitric oxide as a therapy, where NO minimized endothelial cell activation, data from animal models of malaria, and the improvement of adults with severe malaria in response to the NO precursor arginine. Plasma biomarkers were measured for 4 days and, finally, at day 14. There was an increase in CH3L1 in pediatric severe malaria (0-18 years of age) consistent with acute kidney injury. Several panels of plasma biomarkers were investigated including those for endothelial activation (Ang-2, slCAM-1). Hemopexin was included in the panel for intravenous hemolysis together with lactate dehydrogenase (LDH) and heme. The levels of CH31L correlated with markers of inflammation (e.g., surface receptor triggering receptor-expressed myeloid cells, [100]).

Kidney transplants are carried out worldwide and generally have a high success rate, although they do have risks. Nevertheless, markers for rejection after kidney transplantation are needed. Some research supports that in certain cases due to low abundance in the circulation, proteins may 
be more readily detected in urine than in plasma. Hemopexin, together with tetraspanin-1, has the potential to be a novel urinary exosome marker in adult T-cell-mediated rejection (TCMR) in kidney transplant recipients detected by nanoscale liquid chromatography coupled to tandem mass spectrometry. Tetraspanin-1 is a member of a family of 4-pass transmembrane proteins implicated in cell adhesion, migration and proliferation, which interact with membrane proteins including integrins. Large multimolecular complexes organize cell-cell interactions and matrix-cell interactions and consequently activate signaling pathways. Tetraspanin- 1 is overexpressed in several different cancerous cells and plays a role in carcinogenic progression including the migration and invasion by malignant cells [101]. Intriguingly, both HPX and tetraspanin-1 were significantly increased in the TCMR patients [102].

\subsection{Brain/Injury and Neurotoxicity}

The brain is protected by the integrity of the blood-brain barrier that prevents toxic plasma components like heme, intact blood cells, and pathogens from reaching the brain. However, most brain injuries including stroke and hemorrhage (intracerebral, subarachnoid, stroke) cause damage within the brain that leads to damage of the protective blood-brain barrier and leakage of molecules across these cells. Neurotoxicity comes from the presence of $\mathrm{Hb}$, heme, and iron derived from its catabolism, as well as inflammatory events all with consequences for the different types of brain cells. In brain cells, the $\mathrm{HO} 2$ isozyme predominates although the heme-inducible $\mathrm{HO} 1$ is also present. The role for the various cell types in the response to brain injury is under active investigation. To better assess brain injury and the response to both the brain damage, markers in the CSF are being defined not just for hemolysis and heme toxicity but also for inflammation and the activation of endothelial cells. Such information will hopefully guide and improve therapeutic approaches. In this regard, iron uptake via transferrin and, intriguingly, via ferritin into the brain are influenced by gender and genotype [103].

Hemopexin is present in the CSF, likely produced by neurons and ependymal cells [22,23]. Several studies have revealed that CSF HPX levels change in response to neurological diseases including Alzheimer's [104] as well as brain hemorrhage [24]. Once more, HPX's role as a potential therapeutic was reinforced in a recent review on subarachnoid hemorrhage, which compared the pathophysiology in humans and rodents [105], and Hp is active in outcomes in patients after subarachnoid hemorrhage [106] or after ICH [107]. When there is impairment of the blood-brain barrier both brain and systemic HPX and Hp systems may interact. However, it is most likely that brain inflammation drives the local synthesis of HPX. Emerging treatment strategies for clearing hemoglobin/heme from the brain after intracranial bleeding were presented in a comprehensive review by Galea and colleagues [108]. Also, the clearance of heme through the inducible HO1 pathway as a treatment for ischemic stroke has recently been reviewed [109]. We refer the reader to these publications and have not presented these topics in detail here.

Further insight into the development of neurotoxicity and inflammatory conditions in the brain has now come from using the neurotoxic effects of lymphodepletion chemotherapy. Endothelial cell activation by cytokines leads to disseminated intravascular coagulation, capillary leakage, and increased blood-brain barrier permeability. When the blood-brain barrier is permeable, it no longer protects the CSF from exposure to high concentrations of systemic cytokines including IL6 and IL4 [110]. Such severe endothelial activation may lead to multiple areas of hemorrhage. Interferon- $\gamma$ (IFN- $\gamma$ ) induces brain vascular pericytes to secrete cytokines that activates endothelial cells. Most patients developed cytokine release syndrome initiated by $\mathrm{T}$ cell activation with fever and hypotension that was associated with high IL-6. As described in Section 12, IL-6 can alter the response of models of liver and neuronal cells to cytoprotective heme-HPX signaling.

One of the most detailed studies on the relationship between protection of human brain cells via heme clearance by the HPX and Hp systems and activation of localized inflammatory response comes from a study by Righy and coworkers [24] on patients after either intracerebral or subarachnoid hemorrhage. Hemorrhagic stroke depletes the CSF of HPX and Hp as does subarachnoid hemorrhage 
as heme and iron increased in the CSF [24]. A comparison of the levels of heme, iron, HPX, and $\mathrm{Hp}$ in the plasma and CSF at 24, 48, and $72 \mathrm{~h}$ post-ictus revealed that iron levels were extremely high throughout. Plasma HPX levels were essentially maintained and Hp was lower at the $24 \mathrm{~h}$ time point, but the values of both varied widely including some patients who had undetectable protein levels. The CSF HPX decreased over the first $48 \mathrm{~h}$ post ictus, but then appeared to increase by $72 \mathrm{~h}$. The Hp appeared to increase over this three-day period as it did in the plasma. Significantly, these changes were linked to survival in that plasma iron, and heme over the first $48 \mathrm{~h}$ were highest in the non-survivors. These data indicate that iron overload dominated perhaps more so than toxicity from heme per se. Nevertheless, extracellular $\mathrm{Hb}$ is clearly toxic, and when the defenses are overwhelmed, then some protection is derived from HPX. Furthermore, 3 days after admission, IL-4 levels in the CSF were higher in the survivors, whereas both IL- 6 and IL-8 in the circulation were significantly increased in the non-survivors. These cytokine responses suggest that some anti-inflammatory protection was taking place in the brain. Thus, treatments for brain hemorrhage using local anti-inflammatory agents may have a protective role in addition to heme toxicity attenuation.

\section{Hemopexin Metabolism Is Altered When Inflammation Occurs in the Brain in Non-Hemorrhagic Conditions}

There is a novel compensatory immune-regulatory reflex system (CIRS) in a large population of patients diagnosed with depression and bipolar disorders who are particularly affected. Markers to demonstrate that there was activation of an immune-inflammatory response system (IRS) are being sought. In this study, there is an associated increase in pro-inflammatory M1 macrophages and T-helper (Th)-1 pro-inflammatory cytokines including IL-6 trans signaling, together with positive acute phase proteins and complement. In fact, evidence for activation of the immune system during major episodes comes from the findings of increases in T-helper type 2 cells that protect and secrete several interleukins (IL-4, -5, -9, -13, and -17). These cells are required for humoral immunity as well as regulatory $\mathrm{T}$ cells that act against extracellular pathogens and facilitate cell repair but can contribute to chronic disease such as allergies and asthma. A larger increase was observed in IL-4 and IL-10 production with IL-6 signaling and transcription of the sIL-1 receptor antagonist soluble IL-2, TNF $\alpha$ receptors, and HPX together with four acute phase reactants Hp, $\alpha-1$ acid glycoprotein, $\alpha 1$-antitrypsin, and ceruloplasmin. (Based on clinical data, HPX is not an acute phase reactant in humans [62], although the human HPX gene contains an "active" IL-6 response element [111].) Therefore, this is evidence of the primary immune-inflammatory response with spontaneous recovery or in response to treatment with anti-depressants. Unfortunately, after each acute episode, the patients developed a sensitized IRS and CIRS response. Thus, there remains a need for composite biomarker(s) to estimate the relative ratio of these two responses in these and other mood disorders that clearly have a biochemical basis [112].

There is also a lack of biomarkers for chronic widespread pain. This occurs in chronic fibromyalgia syndrome that manifests as general muscle pain, tiredness, together with anxiety and depression. Even cognitive disabilities may exist. A preliminary proteome was analyzed using 2D electrophoresis of plasma samples to assess if different patterns in plasma proteins could be found that changed in response to pain or to the psychological distress. Hemopexin together with two complement components and clusterin were proteins associated with the psychological aspects of this condition. These were considered to represent immunity, iron, and lipid metabolism. On the other hand, proteins associated with metabolic and immunity process (kininogen, fibrinogen $\gamma$-chain, and ceruloplasmin) were linked to pain intensity. It seems that several psychiatric disorders have immune activation, where changes in HPX metabolism help to identify them [113]. Further study may provide new knowledge of factors that influence HPX metabolism and its levels in plasma and CSF.

\section{Animal Models of Human Hemolytic Diseases and Conditions}

Animal models of human diseases and potential therapies for them allow investigation of target tissues and cells that are not always possible in patients. As briefly summarized in the Introduction, the 
extracellular antioxidant protective role of HPX is only one means whereby the HPX system protects against heme toxicity. In a variety of animal models of hemolysis, the protective effect of HPX has been recently linked to increased $\mathrm{HO} 1$ activity in hepatocytes and other cell types. Importantly, it is the rate at which heme builds up in cells, the intracellular concentration of heme, and cofactors for HOs, which affect the extent of heme metabolism by HOs and, thus, the potential for toxicity either in response to heme or to increased ferrous iron from heme catabolism, as recently described [3]. When cells are incubated with "free" heme in vitro, even when albumin is present in culture medium, heme very rapidly accumulates in cells-within seconds and minutes. Also, because this process is unregulated compared with the endocytosis of heme-HPX, toxicity readily develops (see Section 2 above for the toxic effects of heme at $\sim 10-25 \mu \mathrm{M}$ or higher). Heme oxygenase enzymes are quickly induced upon entry of heme across the plasma membrane and into the nucleus. Under these conditions, we do not know what limits $\mathrm{HO}$ enzymatic activity or the rate of increases in ferrous iron in the cytosol or, simultaneously, carbon monoxide (CO) levels. What is a toxic threshold for intracellular heme concentrations? Does CO from heme catabolism inhibit the intracellular heme-proteins such as those in the electron transport chain as it does cytochrome P-450? Clearly, a certain amount of cytosolic ferrous iron from HOs can readily be dealt with by cells in response to the changes in the proteins of iron homeostasis via the Fe/IRP/IRE system. However, what might be a "breaking point" for toxicity? The cytosolic "labile" ferrous iron pool is $\sim 1 \mu \mathrm{M}$ whereas iron stored on ferritin is $0.7-0.36 \mathrm{mM}$. Certainly, defense against iron toxicity may be equally or perhaps more important than heme sequestration, for example, after brain hemorrhage in patients, ([24], see Section 6.4).

Protection of cells against heme involves both sequestration of extracellular heme as well as intracellular events that include induction of $\mathrm{HO} 1$ activity. Also, $\mathrm{HO} 1$ responds to many stimuli not heme solely. In animal and cell studies, evidence for a role for $\mathrm{HO} 1$ in cytoprotection often comes from the use of metal porphyrins (e.g., cobalt-, tin- or zinc-protoporphyrin IX) that have been shown to inhibit $\mathrm{HO}$ enzymatic activity in vitro (but also induce HO1 mRNA to very high levels). Thus, HOs have been linked to the cytoprotection of the HPX system because protective effects of HPX are "lost" in the presence of these heme analogs.

\subsection{Hemopexin Reduces Inflamation and Descreases Oxidative Stress in Models of SCD}

In mice models of SCD [114], a single infusion of human HPX (1 $\mu$ mole $/ \mathrm{kg} ; ~ 14 \mu \mathrm{M})$ together with equimolar amounts to $\mathrm{Hb}$ increased $\mathrm{HO} 1$ in liver, skin, and kidney within $1 \mathrm{~h}$. Hemopexin inhibited stasis from the $\mathrm{Hb}$ (less than $1 \%$ at $24 \mathrm{~h}$ ) compared with untreated mice (10-11\%). Plasma $\mathrm{Hb}$ and heme levels were unchanged $1 \mathrm{~h}$ after infusion of HPX. Also, and importantly, HPX did inhibit the induction of markers of inflammation such as inflammatory cytokines (chemokine 5), but did not affect the plasma levels of TNF $\alpha$, IL-10 or IFN $\gamma$. Furthermore, HPX inhibited NFkBphosphoP65, considered to promote stasis via activation of pro-inflammatory adhesion factors. Furthermore, the increased levels of hepatic oxidative stress indicated by the presence of hydroxynonenal were ameliorated by HPX. In previous studies from Vercellotti, Belcher, and colleagues [63], heme sequestration by HPX mobilization to the surface of endothelial cells of Weibel-Palade body protein P-selectin and von Willebrand factor that drive vaso-occlusion, a potentially lethal pathology of SCD. Because induction of hepatic HO1 and engineered hepatic over expression of $\mathrm{HO} 1$ inhibited stasis in these mice, the inhibitor tin-PP was administered at levels to block HO1 activity, which prevented the protection by HPX. Furthermore, $\mathrm{CO}$ administration to the mice before $\mathrm{Hb}$ fully restored protection by HPX. To support the relevance of the mice model to clinical SCD and to show directly that heme induces proteins such as P-selectin needed for vaso-occlusion, human umbilical vein endothelial cells were incubated with heme $(10 \mu \mathrm{M}$ for $30 \mathrm{~min}$ or histamine as a positive control), which readily induced P-selectin.

Overall, HPX was considered to inhibit stasis by inducing HO1 and, thus, raising CO levels. One challenge with mice as a model for human hemolytic conditions including SCD is that, unlike in humans, $\mathrm{Hb}$ is cleared via CD163 in macrophages and, thus, does not require Hp. Intriguingly, the authors point to novel hepatic uptake of $\mathrm{Hb}-\mathrm{Hp}$ complexes into hepatocytes as an additional clearance 
mechanism that will need defining. It may be related to the process in rats documented in1972, where $85-95 \%$ of the radioactivity from ${ }^{59} \mathrm{Fe}-\mathrm{Hb}$ was present with liver parenchymal cells whether injected IV alone or with Hp [115]. The conclusion was that plasma protein replenishment therapies with both HPX and Hp might be best for SCD patients, especially those with acute chest syndrome.

Evidence is accruing for differences in the response of $\mathrm{HPX}, \mathrm{Hp}$, and HOs to intravenous $\mathrm{Hb}$ or $\mathrm{Hb}$ from intravascular hemolysis compared with $\mathrm{Hb}$ release after the administration of RBCs. Graw et al. [116] showed that an infusion of stored red blood cells increased hepatic HO 1 mRNA and also in kidney and spleen. In addition, $\mathrm{HO} 1$ levels in all these organs were increased by co-infusion with HPX (or albumin or Hp).

The excessive heme from erythrophagocytosis causes the loss of resident red-pulp macrophages. In this context, there are some unexpected relationships in mice between $\mathrm{HO} 1$ activity and hepatic HPX expression (that drives plasma levels), which is altered when spleen function is impaired. Spleen macrophages may die due to the toxicity of heme when HO1 is inhibited or when heme export via plasma membrane transporter FLVCR1b [117] is impaired because proteins heme such as HPX or albumin are needed as extracellular heme acceptors to drive transport down the concentration gradient. Hepatic HPX is increased significantly when HO1 is inhibited or absent as shown in studies with HO1 knock out mice [118]. These studies showed that the status of spleen macrophages affects HPX levels both in the liver (HPX mRNA) and in the circulation. The implication of this includes whether some of the effects in mice given $\mathrm{Hb}, \mathrm{RBCs}$ or in hyper-hemolytic states (after phenylhydrazine) are due to the changes in endogenous levels of HPX, especially when inhibitors of HO1 are administered. Thus, when both spleen macrophages and Kupffer cells are involved in RBC clearance, there may be changes in the regulation and activity in the various defenses against plasma $\mathrm{Hb} / \mathrm{heme}$ including the HPX system compared with low levels of hemolysis (or IV heme or $\mathrm{Hb}$ in animal studies). In the light of observations on toxicity from globin, when $\mathrm{HPX}$ is present with $\mathrm{Hb}$ in $\mathrm{Hp}^{-/-}$mice or in humans with hemolysis sufficient to have depleted $\mathrm{Hp}$, there must be mechanisms in vivo that mitigate extracellular globin toxicity in Hp deficiency. Alternatively, globin precipitation is a key missing part of the complicated puzzle that is the mechanism of $\mathrm{Hb} / \mathrm{heme}$ toxicity.

\subsection{Hemopexin Protects the Blood-Brain Barrier}

Using a model of cerebral ischemia-reperfusion injury in rats, focal cerebral ischemic and reperfusion, Dong and colleagues [119] showed that HPX alleviated cognitive dysfunction rapidly when injected intracerebro-ventricularly once reperfusion was initiated. This protective effect was also linked to HO1 activity because it was reversed by the HO1 inhibitor, zinc-PPIX [119]. In a similar experimental approach, HPX was protective after cerebral ischemia/reperfusion injury and protection was lost when zinc-PPIX was given [119].

Importantly, HPX in the cerebral spinal fluid (CSF) helps to maintaining the integrity of the blood-brain barrier, in part, because HPX and the induction of HO1 helps new blood vessel formation by supporting both the migration and differentiation of endothelial progenitor cells [120]. The administration of HPX allowed the rats to recover after cerebral ischemia, as assessed by the magnitude of their synaptic plasticity, but this was blocked by administration of the HO1 inhibitor ZnPPIX. Thus, $\mathrm{HO} 1$ activity is implicated in the protection by HPX of both the endothelial cells and blood-brain barrier integrity in rats with cerebral ischemia [120].

The HPX, LRP1/CD91 positive cells, and heme were detected from day 1 in both the clot and in the tissue surrounding the brain hematoma, and perihematoma in piglets were injected with autologous blood into the right frontal lobe of the brain [121]. The administration of the iron-chelator deferoxamine significantly decreased all of these indicators of the HPX system. Unfortunately, the full significance of protection by HPX in these studies is not yet clear because deferoxamine does not cross the blood-brain barrier. Therefore, when this chelator is reported to be effective, it is presumptive evidence for an impairment of the blood-brain barrier allowing molecules from the plasma to reach the brain and potentially vice versa. 
Importantly, data from a rat model of the sports-related head injury supports that HPX is a potential diagnostic for a frequent form of traumatic brain injury—diffuse axonal injury. Biomarkers for brain damage are urgently needed because such injuries, as is now evident, occur even in recreational and professional sports. They represent a serious and complex brain injury with significant morbidity and mortality. Low linear and angular accelerations to the head [122] replicate axonal injury and hemorrhagic tears that represent the histology and neurological changes of axonal injury. Both HPX and glyceraldehyde-3-phosphate were 2 out of 58 proteins in plasma deemed potentially diagnostic for this type of brain injury.

A role in olfactory system development is perhaps one of the most intriguingly recent discoveries about HPX. Neurogenesis relies on neural stem cells of the subventricular zone that reside in a specialized niche. Abnormalities develop in the SV2/olfactory bulb pathways of HPX-null mice that impair neuroblast migration in the subventricular zone as well as the rostral migratory stream. Exogenous HPX inhibited apoptosis and promoted the migration and differentiation of cultured neural stem cells [123].

Furthermore, HPX is protective against bleeding and blood loss in trauma injury, which is the leading cause of death for the young, including infants, and in the middle aged. Trauma includes the severe injury from automobile accidents, industrial accidents, and on the battleground. These severe injuries lead to significant blood loss and internal bleeding may damage the lungs. Both blood loss and hemorrhagic shock after trauma are routinely treated with massive blood transfusions to maintain $\mathrm{Hb}$ oxygen levels. This may well be life saving for patients but also presents a hazard to their health because of extensive RBC lysis from blood transfusions. It is well established that RBCs deteriorate; the longer that blood and packed RBCs are stored, the more likely RBCs will lyse and release $\mathrm{Hb}$ leading to heme toxicity. Thus, extensive transfusions are associated with poor recovery due to the $\mathrm{Hb} /$ heme load for the patient and, significantly, there is an increase in organ injury. Furthermore, bacterial infection becomes more prevalent in part because nutritional immunity is overcome by the systemic heme and iron loads.

\subsection{Hemopexin Is a Part of Nutritional Iron Defense System in the Lung}

Mice have provided novel information on the dangers from heme leading to the development of pathology in the lung, which are exacerbated by bacterial infection of the lungs following, for example, trauma-induced hemorrhage [72]. Most human pathogens have multiple ways to acquire heme via surface receptors and transport systems for heme itself, or for $\mathrm{Hb}, \mathrm{Hb}-\mathrm{Hp}$, heme-HPX and for iron-transferrin. After trauma hemorrhage, the mice were resuscitated with plasma and leukocyte-reduced RBCs that were either fresh or stored for 14 days. Two days later, their lungs were infected by administering the opportunistic pathogen, the K-strain of Pseudomonas aeruginosa that has many virulence genes. This Gram-negative rod bacterium is associated with bronchial infections in patients with cystic fibrosis and is predominantly responsible for the nosocomial infections in hospital intensive care units. Also, it has developed resistance to many antibiotics. As expected and linked with hemolysis, infusion of stored RBCs increased lung injury and the severity of bacterial infection determined by a higher bacterial count in the lung and increased pulmonary edema. These changes were greater than the responses to fresh $\mathrm{RBC}$ infusion. Changes in plasma $\mathrm{Hb}$, heme, and non-transferrin bound iron were measured longitudinally over $48 \mathrm{~h}$ after trauma hemorrhage. When IV HPX (1 mg/kg) was administered immediately before resuscitation, the mice had significantly lower levels of $\mathrm{Hb}$ compared with mice exposed to stored RBCs. These data support that the increased lung injury (pulmonary edema and lung bacterial count) after resuscitation with stored RBCs is due to the heme. Following up on observations that heme can activate TLR4 driving the pathology of SCD in mice [63], it was shown that administration of HPX or pharmacological inhibition of TLR4, during the traumatic hemorrhage and resuscitation completely prevented the P. aeruginosa-induced mortality following resuscitation with stored RBC. The TLR4 ${ }^{--}$mice were similarly "protected". In addition, using murine alveolar macrophage line (MS1) heme inhibited bacterial phagocytosis of 
macrophages via the release of the damage-associated molecular pattern molecule HMGB1, a death high mobility group box transcription factor, which is released from apoptotic cells. Antibody to HMGB1 protected against death following the P. Aeruginosa infection. It was shown from a group of 50 patients with trauma hemorrhage that they received sufficient heme from resuscitation therapy transfusions to overwhelm HPX. However, it remains to be established how changes over time of the different products generated during hemolysis, including heme levels, are linked to adverse outcomes in after transfusions in these types of patients.

In mice, HPX has been shown to be involved in the nutritional iron defense system in the lungs. Pneumonic plague is highly contagious and the causative agent is Yersinia pestis. After mice received a lethal dose of pneumonic plague, both HPX and Hp increased $48 \mathrm{~h}$ later in the lung and serum. However, when this lethal plague dose was given together with a single injection of EV76 live attenuated Y. pestis, there was a more rapid increase, within $24 \mathrm{~h}$, of HPX and $\mathrm{Hp}$ in both lung and in serum. Some broad range antibacterial drugs are available to treat outbreaks of multi-drug resistance $Y$. pestis, but while they are effective in vitro and can be given intranasally (ideal for rapid absorption and incidentally a useful route for drug administration in humans), they are not effective in mice leading to an $\sim 86 \%$ rate of fatality. However, a combination treatment revealed that antibiotic treatment $48 \mathrm{~h}$ after a previously lethal dose of $Y$. pestis treatments was extremely effective-all the mice survived. When the mice were checked 21 days later, there were no signs of $Y$. pestis infection in the blood or in key organs such as the spleen, liver, and lungs. These studies are exciting because they reveal that live vaccine strains can activate not only lung immunity but also systemic immunity. They also show the potential for treatment via inhalants for acute lung infections and for patients whose lungs are rapidly deteriorating as in pneumonic plague. Finally, this research shows the importance of iron and heme sequestration for nutritional immunity that is protective and demonstrates a combination therapy that is effective to treat antibiotic resistant strains of pathogenic bacteria [124].

\subsection{Hemopexin Is Neuroprotective in Models for Intracerebral Hemorrhage}

Secondary brain injury is the term used for the damage produced by extracellular heme and leads to irreversible brain damage and enduring neurological deficits. The first studies showing that HPX protects the brain were published in 2009 and used a rat ischemia-reperfusion stroke model [125]. Recently, data from mice have revealed the therapeutic potential for a clinical grade HPX in neuroprotection for intracerebral hemorrhage (ICH) [107]. Brain HPX levels were increased using a CNS-targeted recombinant adeno-associated viral vector. This organ-specific expression of HPX resulted in smaller lesions and improved functional recovery from ICH including significantly reduced hematoma volumes compared with the control rats. Furthermore, although HO1 and iron levels were not elevated, there was increased microgliosis and decreased astrogliosis and lipid peroxidation. Importantly, the elevated HPX in brain improved both central and peripheral clearance mechanisms indicating some communication and interactions between the systemic and brain clearance systems. This may represent a situation where the blood-brain barrier is "leaky", as shown when the iron chelator deferoxamine, which does not cross the blood-brain barrier, is effective at reducing brain damage and symptoms. A role for the circumventricular organs (see Section 5) is also a possibility.

\subsection{Hemopexin Is Induced in Response to TLR7 Activation in Models of ICH}

Toll like receptors are expressed by all cells of the immune system and are integral to the innate and adaptive immune systems. Thus, TLRs are logical targets for interference by pharmacological means for development and maintenance of inflammatory conditions including inflammatory bowel disease, rheumatoid arthritis, and SLE. As described above (Section 8.3), when heme binds to toll-like receptor 4 on endothelial cells, P-selectin is induced leading to the assembly of structures on the cell surface that causes vaso-occlusion as seen in SCD [63]. The Bruton tyrosine kinase (BTK), which is needed for B-cell receptor signaling and the survival of B-cells in humans, has been identified downstream of five TLRs including TLR4 and TLR7. A BTK-LRP1 pathway has been proposed to aid 
in heme clearance by heme-HPX uptake into brain cells in a mouse model of ICH [126]. In this model, the stereo striatal injection of type VII collagen [69] causes traumatic brain injury that is hemorrhagic with the development of inflammation. The TLR7 activation improved neurological deficits including neurological scores for spatial learning and memory. Improvement was also seen in the physical changes to the brain such as edema, blood-brain barrier permeability and the hematoma volume. Compared with sham-operated mice, TLR7 activators increased the protein expression of HPX, the scavenger receptor LRP1/CD91 that binds heme-HPX, as well as BTK and other pathway components. Furthermore, all of these proteins were decreased in response to TLR7 inhibitors. Investigation of LRP1 as a therapeutic target in ICH is described in Section 3.3. The role of BTK in the TLR-mediated regulation of innate immunity and differences among how information from mice models and humans may affect the application to human therapeutics has recently been reviewed [126].

\section{Divergent Evolutionary Fate of Hp and HPX Reveals the Potential for Additional Roles for HPX}

The only vertebrates known to lack $\mathrm{Hb}$ and red blood cells are, among the notothenioids, Antarctic ice fishes. Ice fishes live in the Southern Ocean that encircles Antarctica and, to survive, they produce anti-freeze proteins, thus preventing ice crystals from forming in their thin blood. Thin blood is another adaptation because at cold temperatures, thin blood is easier to circulate. Also, ice fishes have developed large hearts and their blood vessel have large diameters [127]. A genetic accident allowed ice fish to survive when a gene needed for the assembly of $\mathrm{Hb}$ was completely corrupted. Although cold water offers more oxygen, fish living in cold waters do have fewer RBCs in their blood over the winter months to save energy. Sadly, now these species and the icefish are threatened by climate change and warming oceans; however, they provide a unique situation to gain insights into the function of HPX.

Compared with hundreds of red blooded notothenioids, these ice fish have very little Hp and its translation into a functional protein has actually been silenced [128]. Overtime, a degeneration of the Hp genotype manifested in a separate lineage. This was due to the distinct nonsense mutations including a deletion frame shift and a mutated poly A sequence. Significantly, the loss of $\mathrm{Hb}$ effectively reduced the selective constraints on Hp maintenance. Importantly, this took place without affecting either the HPX gene or its expression. The HPX genotype is preserved and the transcription rate of the $H P X$ gene is comparable to that in the red-blooded notothenioids. The authors of this study speculate that HPX persists due to the selective pressure to maintain mitochondrial function and to capture heme released from dead and dying cells. This had been previously proposed as a function for HPX, but to what extent there exists such intracellular sources of heme-proteins from dying and apoptotic cells is unknown. In addition, these fish have little bone but do have an extensive muscular system; and, thus, HPX may be conserved because it is needed for heme reclamation in myoglobin biology.

\section{Immune Cells as Therapeutic Targets in Intravenous Hemolysis}

Evidence supports that a calcium sensor "calprotectin" on the surface of immune cells may be an important target for reducing heme-mediated inflammation in patients with IVH. Human neutrophils and monocytes constitutively express this sensor, which is a heterodimer (S100A8 and S100A9). These proteins are currently possible candidates for both diagnostics and therapeutics when inflammation is causing disease-related pathology. They participate in cytoskeletal rearrangement and arachidonic acid metabolism. When the calprotectin dimer is released from cells, they modulate the inflammatory response by stimulating leukocyte recruitment and inducing cytokine secretion. Mechanistically, S100A8 drives the NLRP3 inflammasome and leads to IL-1 $\beta$ secretion. Myeloid-derived alarmin and S100A8 (AKA calgranulin A) have been shown to propagate hemolytic inflammation via leukocyte priming [129]. Thus, S100A8 alone may represent a novel target to reduce inflammation in hemolytic disorders. 
Human CD4+ cells were differentiated into human monocytes and used to address the question of whether heme-induced inflammation is amplified under sterile conditions. When these cells were incubated with S100A8, there was the expected increase in pro-IL1 $\beta$, which required the activation of NFkB, in turn partly dependent upon signaling via the TLR4. In addition, when these cells were incubated with heme, pro-IL1 $\beta$ secretion was secreted and the effect of heme was enhanced by addition of S100A8. Furthermore, S100A8 levels increased in plasma when IVH was induced in mice; and heme sequestration by HPX administration prevented this S100A8 production.

The S100A8 levels were found to be increased in human hemolytic and sickle cell anemias. With the evidence that some heme effects are amplified by autocrine S100A8 production, these studies provide a mechanism whereby leukocyte priming in the absence of bacterial infection could be harmful. Thus, S100A8 represents a potential therapeutic target to reduce heme-mediated inflammation in hemolytic disorders.

The presence of CNS trauma such as spinal cord injury (SCI) has limited therapy and the pathology of SCI is linked to the polarization of microglia to the M1 or M2 state. Heme is known to activate mouse macrophages to the pro-inflammatory M1 state [130]. Also, HPX increases at the lesion site after crush injury to the spinal cord during the time when intramedullary spinal cord hemorrhage is alleviated and is synchronously correlated with the M2 marker Arginase 1 in microglia. Loss of HPX in vivo decreased the number of "protective" M2 microglia relative to increased M1 microglia in the lesion site. This is consistent with a role for the M1 microglia in delaying recovery and exacerbating the behavioral dysfunction after SCI. In LPS-stimulated primary cultured murine microglia, the heme-binding activity of HPX led to a rapid increase in the cells in the M2 state and was associated with improvements such as less neuronal degeneration, less demyelination together with increased numbers of mature oligodendrocytes [131].

\section{Novel Metabolite Regulation of Tissue Resident Macrophages and Bone Marrow Macrophage Populations by Heme for Iron Recycling and Body Iron Homeostasis}

Senescent red blood cells are degraded daily by almost half a million macrophages and their heme iron recycled for all of the body's iron needs (see citations within Reference [132]). This link between heme and iron metabolism is important for normal iron homeostasis but also provides a special example of how heme, derived from citric acid cycle precursors, is involved in novel metabolite regulation in pathological hemolytic diseases and conditions. For example, in hemolysis, red pulp macrophages in the spleen not only phagocytose red blood cells but likely also take up $\mathrm{Hb}-\mathrm{Hp}$ complexes and heme-HPX complexes via surface receptors CD163 and LRP1/CD91, respectively. Intracellular heme levels in macrophages are therefore assumed to be normally limited by heme export by FLVCR and/or degradation by HOs. This exporter is a member of the major facilitator family of transporters and, as such, moves heme (the solute) down a concentration gradient. However, FLVCR heme export in vitro requires a heme-binding protein such as albumin or HPX to be present extracellularly to accept the heme. Presumably this is also needed in vivo and could be compromised in patients with hemolysis and decreased HPX or when heme-binding by circulating albumin is compromised. (Many pharmaceuticals occupy the hydrophobic site on albumin that accommodates heme.) Heme catabolism generates iron and this must be exported via ferroportin to transferrin or in macrophages via secretion on L-ferritin.

In pathological hemolysis, the increasing heme is toxic and excessive heme induces the loss of resident red-pulp macrophages. As macrophages die, the population of pulp macrophages and bone marrow cells is replenished by the relief by heme of Bach1-mediated transcriptional repression of the gene encoding the transcription factor Spi-C in monocytes [132] that drives their differentiation into macrophages. Circulating monocytes enter the spleen and upregulate SpiC, leading to macrophage differentiation, reestablishment of the splenic red-pulp macrophage compartment, and restoration of iron homeostasis. Thus, local signaling within tissues might be sufficient to promote the acquisition of specialized macrophage functions irrespective of their lineage. This further demonstrates a critical 
role of monocytes to repopulate the body with splenic red-pulp macrophages and bone marrow macrophages. Furthermore, this regulation is likely to take place at other sites of hemorrhagic damage including macrophages at atherosclerotic plaques and alveolar macrophages that regulate surfactant production. Other tissue-specific macrophages are found in bone (osteoclasts) and induction of HO1-inhibited osteoclast differentiation into osteoclasts in vitro and in vivo and may affect bone in rheumatoid patients who had increased serum bilirubin levels [133].

\section{Evidence for Cross Talk between IL-6 and the HPX System in Models of Liver and Neuronal Cells}

Evidence is mounting to show that HPX protects against heme toxicity from $\mathrm{Hb}$ in both sterile and infectious inflammation [26]. The cytokine IL-6 contributes to host defense via stimulation of the hepatic acute phase response, immune cell responses, and hematopoiesis. However, when IL-6 synthesis is sustained due to the perturbed regulation, chronic inflammation ensues, which is life threatening. Il-6 is elevated in several hemolytic states and in mice studies to model human sepsis [134]. Interleukin-6 interacts with specific receptors on many different cell types including hepatocytes and lymphocytes but also on bone marrow cells, synovial fibroblasts, CD4 and CD8T cells, and B cells. Interleukin-6 can activate the MAP3K upstream kinase MKK4 for the Jun N-terminal kinase (JNK) in human HepG2 hepatoma cells [135], a signaling pathway well known to regulate several normal biological processes, not solely stress-related responses. A substrate of phospho-JNK, the transcription factor c-Jun, is phosphorylated in mouse hepatoma cells in response to heme-HPX providing evidence for activation of the JNK pathway [136]. Because the HPX system is protective, we propose that JNK activation by heme-HPX is part of JNK's important role in normal biological processes needed for the maintenance and/or restoration of cell homeostasis in hemolysis and oxidative stress.

The purpose of this research was to determine if signaling pathways activated by the inflammatory cytokine IL-6 affect, and possibly override, the activation of the JNK pathway by heme- HPX, and if so, to what extent. Our hypothesis was that if there is cross talk between the IL- 6 and heme-HPX activation of the JNK pathway, then the target for inhibition by IL- 6 will be MKK4 rather than JNK. Elevated IL-6 cross talk in the early stages of inflammation when there is hemolysis may reprogram the cytoprotective cell response(s) to heme-HPX and/or perhaps impair them.

Our preliminary data showed that incubation of heme-HPX with mouse Hepa cells as models of hepatocytes (Figure 1A) and with rat PC12 cells that are models of cholinergic neurons (Figure 1B, [137]) led to the rapid phosphorylation of MKK4 and JNK. Furthermore, two JNK substrates c-Jun(Ser63) and c-Jun(Ser73) were also phosphorylated These phosphorylations occurred very rapidly with very high levels of p-MKK4(Thr261), p-JNK(Thr183/Tyr185), and p-c-Jun(Ser63, Ser73) detectable in cell extracts within 2 min after addition of $5 \mu \mathrm{M}$ heme-HPX to the cell medium. The time course data in Figure 1 show that they remain high for at least $30 \mathrm{~min}$ relative to total JNK levels supporting activation of the JNK pathway by heme-HPX.

When Hepa cells were incubated with increasing concentrations of IL-6 simultaneously with heme-HPX, the extent of phosphorylation of MKK4, JNK, and of c-Jun (Ser 63 and 73) was significantly decreased (Figure 2). The effect of IL-6 was dose-dependent. The IL-6 consistently decreased on average to $54.3 \%$ the levels of p-MKK4 and also decreased p-JNK levels to $60.4 \%$ (further details are in the legend of Figure 2). We used correlation analyses to assess for a possible association first between the IL- 6 and p-MKK4 levels as variables and, second, between the IL- 6 and p-JNK levels as variables to validate our hypothesis. Statistical analysis using Kendall's Tau and Spearman's rho rank correlation analyses show there was a strong negative correlation between the IL- 6 concentration and p-MKK4 levels and also the IL- 6 and p-JNK levels. Applying both types of correlation analyses the correlation was significant at the 0.01 level ( 2 tailed). The Kendall's tau correlation coefficients were -0.683 , significance 0.008 ( 2 tailed), and -0.730 , significance 0.005 (2 tailed) for p-MKK4 and $\mathrm{p}$-JNK, respectively, and the Spearman's rho correlation coefficients were -0.775 , significance 0.008 ( 2 tailed), and -0.825 , significance 0.003 ( 2 tailed) for p-MKK4 and p-JNK, respectively. Thus, IL-6 
significantly reduced JNK pathway activation by heme-HPX demonstrating for the first time cross talk on a heme-HPX signaling pathway with an inflammatory cytokine and confirming our hypothesis.

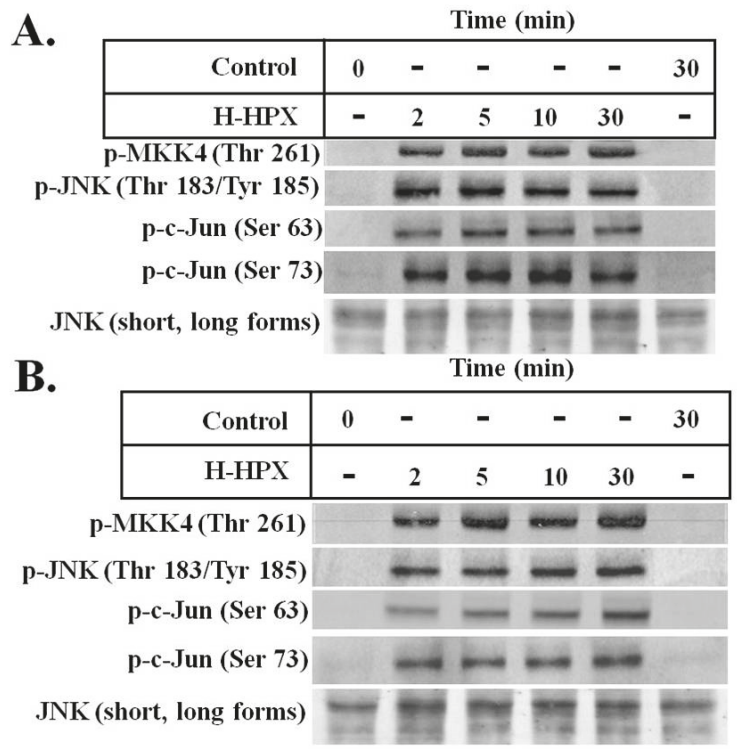

Figure 1. Heme-hemopexin activates the JNK pathway via MKK4 in hepatic and neuronal cells. In panel (A) Mouse Hepa cells were incubated with PBS (control) or heme-HPX ( $5 \mu \mathrm{M}, \mathrm{H}-\mathrm{HPX}$ in PBS) for up to 30 min as indicated. The levels of p-MKK4 and p-JNK-both kinases of the JNK pathway and of p-c-Jun, a substrate of JNK, together with total JNK levels-were detected by immunoblotting of cell extracts (40 $\mu \mathrm{g}$ protein/lane), as described briefly below. (B) Data shown are from a similar time course experiment to determine the effects of heme-HPX on the JNK pathway and c-Jun phosphorylation in rat PC12 cells. The data shown in both panels are from a representative experiment of two independent biological replicates. Hepa cells are minimal deviation hepatoma cells from a mouse solid tumor line BW 7756 and were grown and maintained as previously described [1]. Western blots were performed by loading the same amount of protein from the sample of cell lysate per lane (40 $\mu$ g protein/lane), and after electrophoresis on SDS-PAGE gels, the proteins were transferred to a nitrocellulose membrane (Bio-Rad, Hercules, CA, USA). Primary antibodies (Thermo-Fisher Scientific, Waltham, MA, USA) used at 1:1000 dilution, were detected by binding a secondary antibody of goat anti-rabbit IgG horseradish peroxidase (generally 1:5-10,000) and the peroxidase enzyme activity detected using the chemiluminescence ECL system (Amersham Pharmacia Biotech, Piscataway, NJ, USA). Data were collected using a multifunction phosphoimager/fluorimager laser scanner (Molecular Dynamic Storm Molecular Imager, LICOR, Lincoln, NE, USA).

Although, MKK4 is a master regulator against liver damage and for liver regeneration [138], the implications of this initial in vitro study for the effects of IL-6 on the HPX system in vivo in clinical hemolytic and inflammatory conditions and in rodent models of HPX replenishment remain to be established. Many stimuli of hepatocytes regulate the acute phase production of IL-6, both at the autocrine and endocrine/paracrine levels [139]. For example, when the liver itself is injured, the Kupffer cells are the primary source of IL- 6 that stimulates IL- 6 production by parenchymal cells for the acute phase response. There may be differences in the upstream events in different cell types because IL-6 alone did not phosphorylate MKK4 in the mouse hepatoma cells as it did in human HepG2 cells. In addition, there may be differences in the response to heme-HPX in the presence of IL- 6 between transformed cells and non-transformed cells. Preliminary data from PC 12 cells (not shown) revealed that IL-6 decreased pMKK4 levels in response to $5 \mu \mathrm{M}$ heme-HPX more effectively when added to the 
medium 30 min before heme-HPX. This suggests some differences in response to IL-6 cross talk with heme-HPX between liver and neuronal cells.

\begin{tabular}{|c|c|c|c|c|c|c|c|}
\hline H-HPX & + & + & + & + & + & - & - \\
\hline IL-6 (ng) & - & 0.5 & 1 & 50 & 100 & 100 & - \\
\hline p-MKK4 (Thr 261) & - & 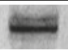 & Bin & $=$ & $=$ & 15 & \\
\hline p-JNK (Thr 183/Tyr 185) & 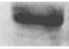 & bet & $=$ & $-\infty$ & cise & & \\
\hline p-c-Jun (Ser 63) & 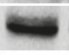 & $=$ & $=$ & 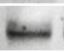 & $=$ & . & \\
\hline p-c-Jun (Ser 73) & $\infty$ & - & - & - & - & & \\
\hline JNK (short, long forms) & $2=$ & $=$ & $E$ & $E$ & ens & $=$ & $=$ \\
\hline
\end{tabular}

Figure 2. IL-6 crosstalk decreases JNK pathway component levels induced by heme-HPX. The data are from immunoblot analyses of cell extracts $(40 \mu \mathrm{g}$ protein/lane, as described in the legend to Figure 1). After incubation of Hepa cells with $5 \mu \mathrm{M}$ heme-HPX in the presence or absence of IL-6 at the concentrations shown, for $30 \mathrm{~min}$, IL-6 (1.0-100 ng/mL) consistently decreased to $54.3 \%$ the levels of p-MKK4 (mean +/- SD of three highest IL- 6 concentration datasets: $58.63+/-6.21 ; 49.97+/-9.66$ ). The IL-6 also decreased p-JNK levels to $60.4 \%$ (mean +/- SD of three highest IL- 6 concentration data sets $56.25+/-11.56$ and $64.5+/-4.96$ ). These data show that IL-6 decreases the levels of key kinases of the JNK pathway activated by heme-HPX in Hepa cells. The data shown are from a representative experiment of two independent biological replicates. Kendall's tau and Spearman's rho rank correlation analyses were used for the statistical analyses of the relationship between IL- 6 concentrations and the levels of p-MKK4 and p-JNK as described in the text.

Nevertheless, and overall, this research shows that further investigations of the interaction between IL-6 and the HPX system in different cell types including primary human hepatocytes are warranted. Our data provide a basis to gain a better understanding of the consequences of cross talk between the IL6 and other signaling pathways that may ultimately be used to improve patient diagnosis, therapy, and prognosis when there is hemolysis together with immune and inflammatory responses.

\section{Conclusions}

It is apparent from the research covered here, which builds on many previous studies in this area, that we now have a more detailed understanding of how the hemopexin system protects against both heme toxicity and iron toxicity. Many biological events are involved and include different types and sources of hemolysis; heme-driven activation of cells of the immune system and of endothelial cells; heme- and cytokine-mediators, among others, of inflammation; and specific parameters of heme and iron homeostasis, such as the activity of $\mathrm{HOs}$, the induction of $\mathrm{FtH}$, and the increase in plasma FtL. Many of these events and processes are depicted in Figure 3. Furthermore, identification of the activation of different kinds of cells reveals a significant number of sites in the body that can be perturbed by heme and, hence, the number of biological processes affected by hemolysis. For example, endothelial cells help to maintain the integrity of the blood-brain barrier and blood vessel walls and minimize the development of atheromas on the wall of blood vessels that can develop into hemorrhagic plaques. 


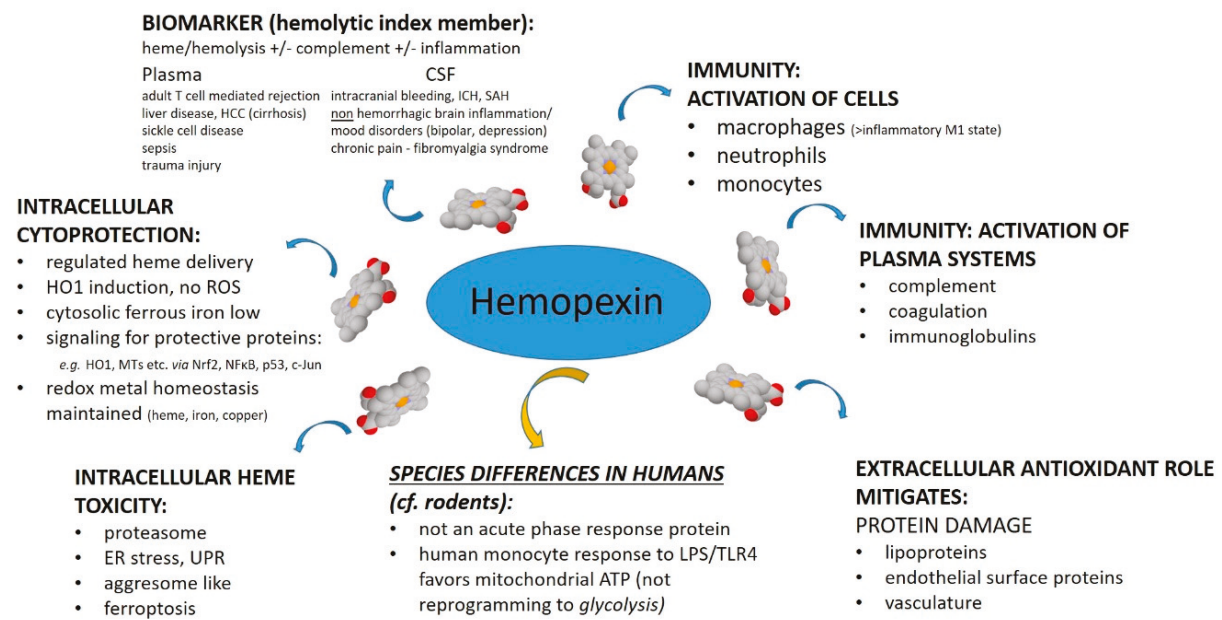

Figure 3. Summary of the current status of the hemopexin (HPX) system and the role it plays in the biological processes that protect the human body against heme- and iron-mediated toxicity. This depiction of the processes that are associated with the HPX system as it protects against heme toxicity provides a sense of the extensive nature of the biological systems and cells that are deleteriously affected by heme. Furthermore, in humans, C-reactive protein 1 and Hp levels rise when there is an acute phase reaction but HPX does not [62]. In addition, lipopolysaccharide-(LPS) stimulated human peripheral blood monocyte-derived macrophages rely on oxidative phosphorylation for ATP production and do not undergo the metabolic reprogramming to glycolysis as do mouse bone marrow-derived macrophages [140]. Such differences require assessing when using mice as pre-clinical models [141].

Experimental evidence shows that HPX protects against all identified damage by heme in more instances than not. After endocytosis of heme-HPX by hepatocytes, HPX recycles from the liver after delivering heme [2], but because the hepatic concentration of heme alters HPX turnover, this can change plasma HPX levels $[142,143]$. Heme-HPX taken up into non-hepatic tissues by LRP1/CD91 a receptor that directs its ligands to lysosomes, may thus deplete HPX without generating signals for compensatory hepatic synthesis and secretion of HPX to plasma. Clearly, HPX levels decrease quite quickly after massive hemolysis (reflected by the number of heme molecules and the duration of the heme load) and the heme can take about 6 days to clear in humans before returning to normal levels [62].

Plasma exchange therapy appears poised to be a useful means to increase HPX and Hp and reduce heme toxicity. Perhaps such treatment could be a means of "respite care" for cells and organs. There is already evidence from studies on proteasomes, ER stress, and UPR as well as ALIS formation that heme-toxicity related responses can be short- or long-lived or are reversible. It will be important to establish the amount of intracellular heme from which cells can recover, how long a period of high intracellular heme and/or iron can be tolerated, and how cells return safely to homeostasis. In the future, what will be needed to counteract heme and iron toxicity are treatments that combine raising HPX (perhaps with Hp depending upon Hb levels) with certain targeted iron chelators (or other means to prevent ferroptosis) and/or a means to increase plasma FtL. We draw the reader's attention to some challenges in the design of in vitro experiments to "mirror" heme toxicity in humans; as well as the differences between the response to heme/ $\mathrm{Hb}$ toxicity of humans and mice (see Figure 3 ). It is perhaps worth remembering that experimental animals generally live out their lives in sterile conditions. Also, there are numerous differences between the response of human and mouse immune cells as pointed out in 2004 [141], and include both the innate and adaptive immune systems. 
Analyses of the number and level of biomolecules in patient samples are currently extremely sensitive, thus generating a plethora of data. The plasma proteome contains thousands of proteins compared with those isolated by C18 chromatography including the normally abundant HPX [144]. Thus, future multiplexing analyses will generate so much data that very sophisticated software will be required for analysis, which may not be available to all researchers and physicians in the field. As the means to develop pathway analyses, pattern recognition networks are increasingly available through online bioinformatics programs. Ideally, a public repository for all this information is needed, which is accessible to researchers and physician-scientists to share and compare their patient data, especially for prognosis and response to treatments. In this review, juxtaposing a wide variety of studies will help researchers to more readily extend their sets of target molecules in the clinic, thus helping in the diagnosis, prognosis, and response to therapies of patients.

Author Contributions: Conceptualization, A.S., L.M., J.D.E.; methodology, A.S., L.M., J.D.E.; writing—original draft preparation, A.S.; writing—review and editing, A.S., L.M., J.D.E.; formal analyses, A.S., L.M., J.D.E.; data curation, A.S., L.M., J.D.E.; graphical abstract, L.M.; project administration, A.S.; funding acquisition, A.S.

Funding: This research was supported by grants from the University of Missouri Research Board and the American Heart Association.

Acknowledgments: The authors thank An-Lin Cheng, Director of Research \& Statistical Consult Services, Department of Biomedical \& Health Informatics (UMKC School of Medicine) for her valuable help with the statistical analyses for the research presented in Section 12. The authors also thank S. Gannavaran (SBC-UMKC) for her technical help, and T. Kapros (SBC-UMKC) and E. Bjes (SBC-UMKC) for their help with data processing and the final figures. The graphical abstract was generated by L.M. using BioRender web software.

Conflicts of Interest: The authors declare no conflict of interest. The funders had no role in the design of the study; in the collection, analyses, or interpretation of data; in the writing of the manuscript, or in the decision to publish the results.

\section{References}

1. Smith, A.; Ledford, B.E. Expression of the haemopexin-transport system in cultured mouse hepatoma cells. Links between haemopexin and iron metabolism. Biochem. J. 1988, 256, 941-950. [CrossRef] [PubMed]

2. Smith, A.; Morgan, W.T. Haem transport to the liver by haemopexin. Receptor-mediated uptake with recycling of the protein. Biochem. J. 1979, 182, 47-54. [CrossRef] [PubMed]

3. Vanacore, R.; Eskew, J.D.; Sung, L.; Davis, T.; Smith, A. Safe coordinated trafficking of heme and iron with copper maintain cell homeostasis: Modules from the hemopexin system. BioMetals Int. J. Role Met. Ions Biol. Biochem. Med. 2019, 32, 355-367. [CrossRef] [PubMed]

4. Sung, L.; Shibata, M.; Eskew, J.D.; Shipulina, N.; Morales, P.J.; Smith, A. Cell surface events for metallothionein-1 and heme oxygenase-1 regulation by the hemopexin-heme transport system. Antioxid. Redox Signal. 2000, 2, 753-765. [CrossRef] [PubMed]

5. Vanacore, R.; Eskew, J.D.; Morales, P.J.; Sung, L.; Smith, A. Role for copper in transient oxidation and nuclear translocation of MTF-1, but not of NFkB, by the hemopexin heme transport system. Antioxid. Redox Signal. 2000, 2, 739-752. [CrossRef] [PubMed]

6. Sung, L.; Morales, P.; Shibata, M.; Shipulina, N.; Smith, A. Defenses against extracellular heme-mediated oxidative damage: Use of iron and copper chelators to investigate the role of redox active iron, copper and heme in the hemopexin heme transport system. In Iron Chelators: New Development Strategies; Badman, D.G., Bergeron, R.J., Brittenham, G.M., Eds.; Saratoga Publishing Group: Sarotoga, FL, USA, 2000; pp. 67-86.

7. Smith, A. Links between cell surface events involving redox-active copper and gene regulation in the hemopexin heme transport system. Antioxid. Redox Signal. 2000, 2, 157-175. [CrossRef]

8. Alam, J.; Smith, A. Receptor-mediated transport of heme by hemopexin regulates gene expression in mammalian cells. J. Biol. Chem. 1989, 264, 17637-17640. [PubMed]

9. Alam, J.; Shibahara, S.; Smith, A. Transcriptional Activation of the Heme Oxygenase Gene by Heme and Cadmium in Mouse Hepatoma Cells. J. Biol. Chem. 1989, 264, 6371-6375.

10. Chiabrando, D.; Marro, S.; Mercurio, S.; Giorgi, C.; Petrillo, S.; Vinchi, F.; Fiorito, V.; Fagoonee, S.; Camporeale, A.; Turco, E.; et al. The mitochondrial heme exporter FLVCR1b mediates erythroid differentiation. J. Clin. Investig. 2012, 122, 4569-4579. [CrossRef] 
11. Smith, A. Transport of Tetrapyrroles: Mechanisms and Biological and Regulatory Consequences. In Biosynthesis of Heme and Chlorophylls; Dailey, H.A., Jr., Ed.; McGraw Hill Inc.: New York, NY, USA, 1990; pp. 435-489.

12. Smith, A. Mechanisms of Cytoprotection by Hemopexin. In Handbook of Porphyrin Science. Biochemistry of Tetrapyrroles; Kadish, K.M., Smith, K.M., Guilard, R., Eds.; World Scientific Publishing Co. Pte. Ltd.: Singapore, 2011; Volume 15, pp. 217-356.

13. Smith, A. Novel Heme-Protein Interactions: Some More Radical Than Others. In Tetrapyrroles: Birth, Life and Death; Warren, M.J., Smith, A.G., Eds.; Landes Bioscience and New York, Springer Science + Business, LLC: Austin, TX, USA, 2006; pp. 184-207.

14. Petryka, Z.J.; Pierach, C.A.; Smith, A.; Goertz, M.N.; Edwards, P.S. Biliary excretion of exogenous hematin in rats. Life Sci. 1977, 21, 1015-1020. [CrossRef]

15. Crispe, I.N. Hepatocytes as Immunological Agents. J. Immunol. 2016, 196, 17-21. [CrossRef] [PubMed]

16. Maude, S.L.; Frey, N.; Shaw, P.A.; Aplenc, R.; Barrett, D.M.; Bunin, N.J.; Chew, A.; Gonzalez, V.E.; Zheng, Z.; Lacey, S.F.; et al. Chimeric antigen receptor T cells for sustained remissions in leukemia. N. Engl. J. Med. 2014, 371, 1507-1517. [CrossRef] [PubMed]

17. Teachey, D.T.; Lacey, S.F.; Shaw, P.A.; Melenhorst, J.J.; Maude, S.L.; Frey, N.; Pequignot, E.; Gonzalez, V.E.; Chen, F.; Finklestein, J.; et al. Identification of Predictive Biomarkers for Cytokine Release Syndrome after Chimeric Antigen Receptor T-cell Therapy for Acute Lymphoblastic Leukemia. Cancer Discov. 2016, 6, 664-679. [CrossRef] [PubMed]

18. Davidsson, P.; Folkesson, S.; Christiansson, M.; Lindbjer, M.; Dellheden, B.; Blennow, K.; Westman-Brinkmalm, A. Identification of proteins in human cerebrospinal fluid using liquid-phase isoelectric focusing as a prefractionation step followed by two-dimensional gel electrophoresis and matrix-assisted laser desorption/ionisation mass spectrometry. Rapid Commun. Mass Spectrom. 2002, 16, 2083-2088. [CrossRef] [PubMed]

19. Saso, L.; Leone, M.G.; Mo, M.Y.; Grippa, E.; Cheng, C.Y.; Silvestrini, B. Differential changes in alpha2-macroglobulin and hemopexin in brain and liver in response to acute inflammation. Biochemistry 1999, 64, 839-844. [PubMed]

20. Stibler, $\mathrm{H}$. The normal cerebrospinal fluid proteins identified by means of thin-layer isoelectric focusing and crossed immunoelectrofocusing. J. Neurol. Sci. 1978, 36, 273-288. [CrossRef]

21. Morello, N.; Tonoli, E.; Logrand, F.; Fiorito, V.; Fagoonee, S.; Turco, E.; Silengo, L.; Vercelli, A.; Altruda, F.; Tolosano, E. Hemopexin affects iron distribution and ferritin expression in mouse brain. J. Cell Mol. Med. 2008, 13, 4192-4204. [CrossRef]

22. Morris, C.M.; Candy, J.M.; Edwardson, J.A.; Bloxham, C.A.; Smith, A. Evidence for the localization of haemopexin immunoreactivity in neurones in the human brain. Neurosci. Lett. 1993, 149, 141-144. [CrossRef]

23. Morello, N.; Bianchi, F.T.; Marmiroli, P.; Tonoli, E.; Rodriguez Menendez, R.; Silengo, L.; Cavaletti, G.; Vercelli, A.; Altruda, F.; Tolosano, E. A role for hemopexin in oligodendrocyte differentiation and myelin formation. PLoS ONE 2011, 6, e20173. [CrossRef]

24. Righy, C.; Turon, R.; Freitas, G.; Japiassu, A.M.; Faria Neto, H.C.C.; Bozza, M.; Oliveira, M.F.; Bozza, F.A. Hemoglobin metabolism by-products are associated with an inflammatory response in patients with hemorrhagic stroke. Rev. Bras. Terapia Intensiva 2018, 30, 21-27. [CrossRef]

25. Fiorito, V.; Chiabrando, D.; Tolosano, E. Mitochondrial Targeting in Neurodegeneration: A Heme Perspective. Pharmaceutical 2018, 11, 87. [CrossRef] [PubMed]

26. Lin, T.; Sammy, F.; Yang, H.; Thundivalappil, S.; Hellman, J.; Tracey, K.J.; Warren, H.S. Identification of Hemopexin as an Anti-Inflammatory Factor That Inhibits Synergy of Hemoglobin with HMGB1 in Sterile and Infectious Inflammation. J. Immunol. 2012, 189, 2017-2022. [CrossRef] [PubMed]

27. Schaer, C.A.; Deuel, J.W.; Bittermann, A.G.; Rubio, I.G.; Schoedon, G.; Spahn, D.R.; Wepf, R.A.; Vallelian, F.; Schaer, D.J. Mechanisms of haptoglobin protection against hemoglobin peroxidation triggered endothelial damage. Cell Death Differ. 2013, 20, 1569-1579. [CrossRef] [PubMed]

28. Miller, Y.I.; Smith, A.; Morgan, W.T.; Shaklai, N. Role of hemopexin in protection of low-density lipoprotein against hemoglobin-induced oxidation. Biochemistry 1996, 35, 13112-13117. [CrossRef] [PubMed]

29. Merle, N.S.; Grunenwald, A.; Rajaratnam, H.; Gnemmi, V.; Frimat, M.; Figueres, M.L.; Knockaert, S.; Bouzekri, S.; Charue, D.; Noe, R.; et al. Intravascular hemolysis activates complement via cell-free heme and heme-loaded microvesicles. JCI Insight 2018, 3. [CrossRef] 
30. Roumenina, L.T.; Rayes, J.; Lacroix-Desmazes, S.; Dimitrov, J.D. Heme: Modulator of Plasma Systems in Hemolytic Diseases. Trends Mol. Med. 2016, 22, 200-213. [CrossRef]

31. Vallelian, F.; Deuel, J.W.; Opitz, L.; Schaer, C.A.; Puglia, M.; Lonn, M.; Engelsberger, W.; Schauer, S.; Karnaukhova, E.; Spahn, D.R.; et al. Proteasome inhibition and oxidative reactions disrupt cellular homeostasis during heme stress. Cell Death Differ. 2015, 22, 597-611. [CrossRef]

32. Islam, M.A.; Sooro, M.A.; Zhang, P. Autophagic Regulation of p62 is Critical for Cancer Therapy. Int. J. Mol. Sci. 2018, 19, 1405. [CrossRef]

33. Khandros, E.; Thom, C.S.; D'Souza, J.; Weiss, M.J. Integrated protein quality-control pathways regulate free alpha-globin in murine beta-thalassemia. Blood 2012, 119, 5265-5275. [CrossRef]

34. Vasconcellos, L.R.; Dutra, F.F.; Siqueira, M.S.; Paula-Neto, H.A.; Dahan, J.; Kiarely, E.; Carneiro, L.A.; Bozza, M.T.; Travassos, L.H. Protein aggregation as a cellular response to oxidative stress induced by heme and iron. Proc. Natl. Acad. Sci. USA 2016, 113, 7474-7482. [CrossRef]

35. Larsen, R.; Gozzelino, R.; Jeney, V.; Tokaji, L.; Bozza, F.A.; Japiassu, A.M.; Bonaparte, D.; Cavalcante, M.M.; Chora, A.; Ferreira, A.; et al. A central role for free heme in the pathogenesis of severe sepsis. Sci. Transl. Med. 2010, 2. [CrossRef]

36. Wang, M.; Kaufman, R.J. Protein misfolding in the endoplasmic reticulum as a conduit to human disease. Nature 2016, 529, 326-335. [CrossRef]

37. Adams, C.J.; Kopp, M.C.; Larburu, N.; Nowak, P.R.; Ali, M.M.U. Structure and Molecular Mechanism of ER Stress Signaling by the Unfolded Protein Response Signal Activator IRE1. Front. Mol. Biosci. 2019, 6, 11. [CrossRef]

38. Gall, T.; Petho, D.; Nagy, A.; Hendrik, Z.; Mehes, G.; Potor, L.; Gram, M.; Akerstrom, B.; Smith, A.; Nagy, P.; et al. Heme Induces Endoplasmic Reticulum Stress (HIER Stress) in Human Aortic Smooth Muscle Cells. Front. Physiol. 2018, 9, 1595. [CrossRef]

39. Reis, E.S.; Mastellos, D.C.; Hajishengallis, G.; Lambris, J.D. New insights into the immune functions of complement. Nat. Rev. Immunol. 2019. [CrossRef]

40. Merle, N.S.; Grunenwald, A.; Figueres, M.L.; Chauvet, S.; Daugan, M.; Knockaert, S.; Robe-Rybkine, T.; Noe, R.; May, O.; Frimat, M.; et al. Characterization of Renal Injury and Inflammation in an Experimental Model of Intravascular Hemolysis. Front. Immunol. 2018, 9, 179. [CrossRef]

41. Sher, E.A.; Sholto, A.Y.; Shaklai, M.; Shaklai, N. Can gas replace protein function? CO abrogates the oxidative toxicity of myoglobin. PLOS ONE 2014, 9, e104075. [CrossRef]

42. Bank, A. Understanding globin regulation in beta-thalassemia: It's as simple as alpha, beta, gamma, delta. J. Clin. Investig. 2005, 115, 1470-1473. [CrossRef]

43. Chen-Roetling, J.; Ma, S.K.; Cao, Y.; Shah, A.; Regan, R.F. Hemopexin increases the neurotoxicity of hemoglobin when haptoglobin is absent. J. Neurochem. 2018, 145, 464-473. [CrossRef]

44. Chen-Roetling, J.; Liu, W.; Regan, R.F. Hemopexin decreases hemin accumulation and catabolism by neural cells. Neurochem. Int. 2012, 60, 488-494. [CrossRef]

45. Chen-Roetling, J.; Regan, R.F. Haptoglobin increases the vulnerability of CD163-expressing neurons to hemoglobin. J. Neurochem. 2016, 139, 586-595. [CrossRef]

46. Etzerodt, A.; Kjolby, M.; Nielsen, M.J.; Maniecki, M.; Svendsen, P.; Moestrup, S.K. Plasma clearance of hemoglobin and haptoglobin in mice and effect of CD163 gene targeting disruption. Antioxid. Redox Signal. 2013, 18, 2254-2263. [CrossRef]

47. Bertaggia, E.; Scabia, G.; Dalise, S.; Lo Verso, F.; Santini, F.; Vitti, P.; Chisari, C.; Sandri, M.; Maffei, M. Haptoglobin is required to prevent oxidative stress and muscle atrophy. PLoS ONE 2014, 9, e100745. [CrossRef]

48. Hirschhorn, T.; Stockwell, B.R. The development of the concept of ferroptosis. Free Radic. Biol. Med. 2019, 133, 130-143. [CrossRef]

49. Dixon, S.J.; Lemberg, K.M.; Lamprecht, M.R.; Skouta, R.; Zaitsev, E.M.; Gleason, C.E.; Patel, D.N.; Bauer, A.J.; Cantley, A.M.; Yang, W.S.; et al. Ferroptosis: An iron-dependent form of nonapoptotic cell death. Cell 2012, 149, 1060-1072. [CrossRef]

50. Stockwell, B.R.; Friedmann Angeli, J.P.; Bayir, H.; Bush, A.I.; Conrad, M.; Dixon, S.J.; Fulda, S.; Gascon, S.; Hatzios, S.K.; Kagan, V.E.; et al. Ferroptosis: A Regulated Cell Death Nexus Linking Metabolism, Redox Biology, and Disease. Cell 2017, 171, 273-285. [CrossRef] 
51. Li, Q.; Han, X.; Lan, X.; Gao, Y.; Wan, J.; Durham, F.; Cheng, T.; Yang, J.; Wang, Z.; Jiang, C.; et al. Inhibition of neuronal ferroptosis protects hemorrhagic brain. JCI Insight 2017, 2, e90777. [CrossRef]

52. Adedoyin, O.; Boddu, R.; Traylor, A.; Lever, J.M.; Bolisetty, S.; George, J.F.; Agarwal, A. Heme oxygenase-1 mitigates ferroptosis in renal proximal tubule cells. Am. J. Physiol. Ren. Physiol. 2018, 314, 702-714. [CrossRef]

53. NaveenKumar, S.K.; SharathBabu, B.N.; Hemshekhar, M.; Kemparaju, K.; Girish, K.S.; Mugesh, G. The Role of Reactive Oxygen Species and Ferroptosis in Heme-Mediated Activation of Human Platelets. ACS Chem. Biol. 2018, 13, 1996-2002. [CrossRef]

54. Hirata, Y.; Iwasaki, T.; Makimura, Y.; Okajima, S.; Oh-Hashi, K.; Takemori, H. Inhibition of double-stranded RNA-dependent protein kinase prevents oxytosis and ferroptosis in mouse hippocampal HT22 cells. Toxicology 2019, 418, 1-10. [CrossRef]

55. Ayton, S.; Diouf, I.; Bush, A.I. Evidence that iron accelerates ALzheimer's pathology: A CSF biomarker study. J. Neurol. Neurosurg. Psychiatry 2017, 89, 456-460. [CrossRef]

56. Lei, P.; Ayton, S.; Appukuttan, A.T.; Moon, S.; Duce, J.A.; Volitakis, I.; Cherny, R.; Wood, S.J.; Greenough, M.; Berger, G.; et al. Lithium suppression of tau induces brain iron accumulation and neurodegeneration. Mol. Psych. 2017, 22, 396-406. [CrossRef]

57. Ayton, S.; Lei, P.; Hare, D.J.; Duce, J.A.; George, J.L.; Adlard, P.A.; McLean, C.; Rogers, J.T.; Cherny, R.A.; Finkelstein, D.I.; et al. Parkinson's disease iron deposition caused by nitric oxide-induced loss of beta-amyloid precursor protein. J. Neurosci. 2015, 35, 3591-3597. [CrossRef]

58. Zille, M.; Karuppagounder, S.S.; Chen, Y.; Gough, P.J.; Bertin, J.; Finger, J.; Milner, T.A.; Jonas, E.A.; Ratan, R.R. Neuronal Death After Hemorrhagic Stroke In Vitro and In Vivo Shares Features of Ferroptosis and Necroptosis. Stroke 2017, 48, 1033-1043. [CrossRef]

59. Imoto, S.; Kono, M.; Suzuki, T.; Shibuya, Y.; Sawamura, T.; Mizokoshi, Y.; Sawada, H.; Ohbuchi, A.; Saigo, K. Haemin-induced cell death in human monocytic cells is consistent with ferroptosis. Transfus. Apher. Sci. 2018, 57, 524-531. [CrossRef]

60. DeGregorio-Rocasolano, N.; Marti-Sistac, O.; Gasull, T. Deciphering the Iron Side of Stroke: Neurodegeneration at the Crossroads Between Iron Dyshomeostasis, Excitotoxicity, and Ferroptosis. Front. Neurosci. 2019, $13,85$. [CrossRef]

61. Smith, A.; McCulloh, R.J. Hemopexin and haptoglobin: Allies against heme toxicity from hemoglobin not contenders. Front. Physiol. 2015, 6, 187. [CrossRef]

62. Smith, A.; McCulloh, R.J. Mechanisms of haem toxicity in haemolysis and protection by the haem-binding protein, haemopexin. ISBT Sci. Ser. 2017, 12, 119-133. [CrossRef]

63. Belcher, J.D.; Chen, C.; Nguyen, J.; Milbauer, L.; Abdulla, F.; Alayash, A.I.; Smith, A.; Nath, K.A.; Hebbel, R.P.; Vercellotti, G.M. Heme triggers TLR4 signaling leading to endothelial cell activation and vaso-occlusion in murine sickle cell disease. Blood 2014, 123123, 377-390. [CrossRef]

64. Vendrame, F.; Olops, L.; Saad, S.T.O.; Costa, F.F.; Fertrin, K.Y. Differences in heme and hemopexin content in lipoproteins from patients with sickle cell disease. J. Clin. Lipidol. 2018, 12, 1532-1538. [CrossRef]

65. Yalamanoglu, A.; Deuel, J.W.; Hunt, R.C.; Baek, J.H.; Hassell, K.; Redinius, K.; Irwin, D.C.; Schaer, D.J.; Buehler, P.W. Depletion of haptoglobin and hemopexin promote hemoglobin-mediated lipoprotein oxidation in sickle cell disease. Am. J. Physiol. Lung Cell Mol. Physiol. 2018, 315, 765-774. [CrossRef]

66. Nguyen, T.C.; Han, Y.Y.; Kiss, J.E.; Hall, M.W.; Hassett, A.C.; Jaffe, R.; Orr, R.A.; Janosky, J.; Carcillo, J.A. Intensive plasma exchange increases a disintegrin and metalloprotease with thrombospondin motifs-13 activity and reverses organ dysfunction in children with thrombocytopenia-associated multiple organ failure. Crit. Care Med. 2008, 36, 2878-2887. [CrossRef]

67. Louie, J.E.; Anderson, C.J.; Fayaz, M.F.K.; Henry, A.; Killeen, T.; Mohandas, N.; Yazdanbakhsh, K.; Belcher, J.D.; Vercellotti, G.M.; Shi, P.A. Case series supporting heme detoxification via therapeutic plasma exchange in acute multiorgan failure syndrome resistant to red blood cell exchange in sickle cell disease. Transfusion 2018, 58, 470-479. [CrossRef]

68. Hvidberg, V.; Maniecki, M.B.; Jacobsen, C.; Hojrup, P.; Moller, H.J.; Moestrup, S.K. Identification of the receptor scavenging hemopexin-heme complexes. Blood 2005, 106, 2572-2579. [CrossRef]

69. Wang, G.; Guo, Z.; Tong, L.; Xue, F.; Krafft, P.R.; Budbazar, E.; Zhang, J.H.; Tang, J. TLR7 (Toll-Like Receptor 7) Facilitates Heme Scavenging Through the BTK (Bruton Tyrosine Kinase)-CRT (Calreticulin)-LRP1 (Low-Density Lipoprotein Receptor-Related Protein-1)-Hx (Hemopexin) Pathway in Murine Intracerebral Hemorrhage. Stroke 2018, 49, 3020-3029. [CrossRef] 
70. Kushner, I.; Edgington, T.S.; Trimble, C.; Liem, H.H.; Muller-Eberhard, U. Plasma hemopexin homeostasis during the acute phase response. J. Lab. Clin. Med. 1972, 80, 18-25.

71. Drieghe, S.; Stove, V.; Decruyenaere, J.; Delanghe, J. Interpretation of hemolysis tests following administration of a second-generation hemoglobin-based oxygen carrier. Acta Clin. Belg. 2013, 68, 282-286. [CrossRef]

72. Wagener, B.M.; Hu, P.J.; Oh, J.Y.; Evans, C.A.; Richter, J.R.; Honavar, J.; Brandon, A.P.; Creighton, J.; Stephens, S.W.; Morgan, C.; et al. Role of heme in lung bacterial infection after trauma hemorrhage and stored red blood cell transfusion: A preclinical experimental study. PLoS Med. 2018, 15, e1002522. [CrossRef]

73. Brewin, J.; Tewari, S.; Menzel, S.; Kirkham, F.; Inusa, B.; Renney, G.; Ward, M.; Rees, D.C. The effects of hydroxycarbamide on the plasma proteome of children with sickle cell anaemia. Br. J. Haematol 2019. [CrossRef]

74. Smith, A. Protection Against Heme Toxicity: Hemopexin Rules, OK? In Handbook of Porphyrin Science; Ferreira, G., Ed.; World Publishing Co.: Cleveland, NY, USA, 2013; pp. 311-388.

75. Handtke, S.; Steil, L.; Palankar, R.; Conrad, J.; Cauhan, S.; Kraus, L.; Ferrara, M.; Dhople, V.; Wesche, J.; Volker, U.; et al. Role of Platelet Size Revisited-Function and Protein Composition of Large and Small Platelets. Thromb. Haemost. 2019, 119, 407-420. [CrossRef]

76. Yuan, X.M.; Ward, L.J.; Forssell, C.; Siraj, N.; Li, W. Carotid Atheroma From Men Has Significantly Higher Levels of Inflammation and Iron Metabolism Enabled by Macrophages. Stroke 2018, 49, 419-425. [CrossRef]

77. Mikuls, T.R.; Moreland, L.W. TNF blockade in the treatment of rheumatoid arthritis: Infliximab versus etanercept. Expert Opin. Pharm. 2001, 2, 75-84. [CrossRef]

78. Estelius, J.; Lengqvist, J.; Ossipova, E.; Idborg, H.; Le Maitre, E.; Andersson, M.L.A.; Brundin, L.; Khademi, M.; Svenungsson, E.; Jakobsson, P.J.; et al. Mass spectrometry-based analysis of cerebrospinal fluid from arthritis patients-immune-related candidate proteins affected by TNF blocking treatment. Arthritis Res. 2019, 21, 60. [CrossRef]

79. Ganong, W.F. Circumventricular organs: Definition and role in the regulation of endocrine and autonomic function. Clin. Exp. Pharm. Physiol. 2000, 27, 422-427. [CrossRef]

80. Bentivoglio, M.; Kristensson, K.; Rottenberg, M.E. Circumventricular Organs and Parasite Neurotropism: Neglected Gates to the Brain? Front. Immunol. 2018, 9, 2877. [CrossRef]

81. Kalapotharakos, G.; Murtoniemi, K.; Akerstrom, B.; Hamalainen, E.; Kajantie, E.; Raikkonen, K.; Villa, P.; Laivuori, H.; Hansson, S.R. Plasma Heme Scavengers Alpha-1-Microglobulin and Hemopexin as Biomarkers in High-Risk Pregnancies. Front. Physiol. 2019, 10, 300. [CrossRef]

82. Su, L.; Pan, P.; Yan, P.; Long, Y.; Zhou, X.; Wang, X.; Zhou, R.; Wen, B.; Xie, L.; Liu, D. Role of vimentin in modulating immune cell apoptosis and inflammatory responses in sepsis. Sci. Rep. 2019, 9, 5747. [CrossRef]

83. Ekregbesi, P.; Shankar-Hari, M.; Bottomley, C.; Riley, E.M.; Mooney, J.P. Relationship between Anaemia, Haemolysis, Inflammation and Haem Oxygenase-1 at Admission with Sepsis: A pilot study. Sci. Rep. 2018, 8, 11198. [CrossRef]

84. Jung, J.Y.; Kwak, Y.H.; Kim, K.S.; Kwon, W.Y.; Suh, G.J. Change of hemopexin level is associated with the severity of sepsis in endotoxemic rat model and the outcome of septic patients. J. Crit. Care 2015, 30, 525-530. [CrossRef]

85. Zarjou, A.; Black, L.M.; McCullough, K.R.; Hull, T.D.; Esman, S.K.; Boddu, R.; Varambally, S.; Chandrashekar, D.S.; Feng, W.; Arosio, P.; et al. Ferritin Light Chain Confers Protection Against Sepsis-Induced Inflammation and Organ Injury. Front. Immunol. 2019, 10, 131. [CrossRef]

86. Hershko, C. Iron, infection and immune function. Proc. Nutr. Soc. 1993, 52, 165-174. [CrossRef]

87. Kochan, I. The role of iron in bacterial infections with special consideration of host tubercle bacillus interaction. Curr. Top. Microbiol. Immunol. 1973, 60, 1-30.

88. Wandersman, C.; Stojiljkovic, I. Bacterial heme sources: The role of heme, hemopotein receptors and hemophores. Curr. Opin. Microbiol. 2000, 3, 215-220. [CrossRef]

89. Schwarz, M.I.; Fontenot, A.P. Drug-induced diffuse alveolar hemorrhage syndromes and vasculitis. Clin. Chest Med. 2004, 25, 133-140. [CrossRef]

90. Aggarwal, S.; Ahmad, I.; Lam, A.; Carlisle, M.A.; Li, C.; Wells, J.M.; Raju, S.V.; Athar, M.; Rowe, S.M.; Dransfield, M.T.; et al. Heme scavenging reduces pulmonary endoplasmic reticulum stress, fibrosis, and emphysema. JCI Insight 2018, 3. [CrossRef] 
91. Aggarwal, S.; Lam, A.; Bolisetty, S.; Carlisle, M.A.; Traylor, A.; Agarwal, A.; Matalon, S. Heme Attenuation Ameliorates Irritant Gas Inhalation-Induced Acute Lung Injury. Antioxid. Redox Signal. 2016, 24, 99-112. [CrossRef]

92. Lin, J.; Li, J.; Huang, B.; Liu, J.; Chen, X.; Chen, X.M.; Xu, Y.M.; Huang, L.F.; Wang, X.Z. Exosomes: Novel biomarkers for clinical diagnosis. Sci. World J. 2015, 2015, 657086. [CrossRef]

93. Hourcade, D.E. The role of properdin in the assembly of the alternative pathway C3 convertases of complement. J. Biol. Chem. 2006, 281, 2128-2132. [CrossRef]

94. Kodidela, S.; Wang, Y.; Patters, B.J.; Gong, Y.; Sinha, N.; Ranjit, S.; Gerth, K.; Haque, S.; Cory, T.; McArthur, C.; et al. Proteomic Profiling of Exosomes Derived from Plasma of HIV-Infected Alcohol Drinkers and Cigarette Smokers. J. Neuroimmune Pharm. 2019. [CrossRef]

95. Takahashi, N.; Takahashi, Y.; Putnam, F.W. Structure of human hemopexin: O-glycosyl and N-glycosyl sites and unusual clustering of tryptophan residues. Proc. Natl. Acad. Sci. USA 1984, 81, 2021-2025. [CrossRef]

96. Ma, J.; Sanda, M.; Wei, R.; Zhang, L.; Goldman, R. Quantitative analysis of core fucosylation of serum proteins in liver diseases by LC-MS-MRM. J. Proteom. 2018, 189, 67-74. [CrossRef]

97. Zhu, J.; Warner, E.; Parikh, N.D.; Lubman, D.M. Glycoproteomic markers of hepatocellular carcinoma-mass spectrometry based approaches. Mass Spectrom. Rev. 2019, 38, 265-290. [CrossRef]

98. Elphinstone, R.E.; Conroy, A.L.; Hawkes, M.; Hermann, L.; Namasopo, S.; Warren, H.S.; John, C.C.; Liles, W.C.; Kain, K.C. Alterations in Systemic Extracellular Heme and Hemopexin Are Associated With Adverse Clinical Outcomes in Ugandan Children With Severe Malaria. J. Infect. Dis 2016, 214, 1268-1275. [CrossRef]

99. Conroy, A.L.; Hawkes, M.T.; Elphinstone, R.; Opoka, R.O.; Namasopo, S.; Miller, C.; John, C.C.; Kain, K.C. Chitinase-3-like 1 is a biomarker of acute kidney injury and mortality in paediatric severe malaria. Malar. J. 2018, 17, 82. [CrossRef]

100. Vazquez, C.M.P.; Costa, J.O.; Bomfim, L.G.S.; Pires, L.V.; da Silva, D.G.; Fukutani, K.F.; de Jesus, A.R.; de Jesus Silva, N.; de Jesus Santana, G.; de Moura, T.R.; et al. Oxidized Low-Density Lipoprotein (Ox-LDL) and Triggering Receptor-Expressed Myeloid Cell (TREM-1) Levels Are Associated with Cardiometabolic Risk in Nonobese, Clinically Healthy, and Young Adults. Oxid Med. Cell Longev. 2019, 2019, 7306867. [CrossRef]

101. Hou, F.Q.; Lei, X.F.; Yao, J.L.; Wang, Y.J.; Zhang, W. Tetraspanin 1 is involved in survival, proliferation and carcinogenesis of pancreatic cancer. Oncol. Rep. 2015, 34, 3068-3076. [CrossRef]

102. Lim, J.H.; Lee, C.H.; Kim, K.Y.; Jung, H.Y.; Choi, J.Y.; Cho, J.H.; Park, S.H.; Kim, Y.L.; Baek, M.C.; Park, J.B.; et al. Novel urinary exosomal biomarkers of acute T cell-mediated rejection in kidney transplant recipients: A cross-sectional study. PLoS ONE 2018, 13, e0204204. [CrossRef]

103. Wade, Q.W.; Chiou, B.; Connor, J.R. Iron uptake at the blood-brain barrier is influenced by sex and genotype. Adv. Pharm. 2019, 84, 123-145. [CrossRef]

104. Castano, E.M.; Roher, A.E.; Esh, C.L.; Kokjohn, T.A.; Beach, T. Comparative proteomics of cerebrospinal fluid in neuropathologically-confirmed Alzheimer's disease and non-demented elderly subjects. Neurol. Res. 2006, 28, 155-163. [CrossRef]

105. Leclerc, J.L.; Garcia, J.M.; Diller, M.A.; Carpenter, A.M.; Kamat, P.K.; Hoh, B.L.; Dore, S. A Comparison of Pathophysiology in Humans and Rodent Models of Subarachnoid Hemorrhage. Front. Mol. Neurosci. 2018, 11, 71. [CrossRef]

106. Garland, P.; Durnford, A.J.; Okemefuna, A.I.; Dunbar, J.; Nicoll, J.A.; Galea, J.; Boche, D.; Bulters, D.O.; Galea, I. Heme-Hemopexin Scavenging Is Active in the Brain and Associates With Outcome After Subarachnoid Hemorrhage. Stroke 2016, 47, 872-876. [CrossRef]

107. Leclerc, J.L.; Santiago-Moreno, J.; Dang, A.; Lampert, A.S.; Cruz, P.E.; Rosario, A.M.; Golde, T.E.; Dore, S. Increased brain hemopexin levels improve outcomes after intracerebral hemorrhage. J. Cereb. Blood Flow Metab. 2018, 38, 1032-1046. [CrossRef]

108. Bulters, D.; Gaastra, B.; Zolnourian, A.; Alexander, S.; Ren, D.; Blackburn, S.L.; Borsody, M.; Dore, S.; Galea, J.; Iihara, K.; et al. Haemoglobin scavenging in intracranial bleeding: Biology and clinical implications. Nat. Rev. Neurol. 2018, 14, 416-432. [CrossRef]

109. Bereczki, D., Jr.; Balla, J.; Bereczki, D. Heme Oxygenase-1: Clinical Relevance in Ischemic Stroke. Curr. Pharm. Des. 2018, 24, 2229-2235. [CrossRef]

110. Gust, J.; Hay, K.A.; Hanafi, L.A.; Li, D.; Myerson, D.; Gonzalez-Cuyar, L.F.; Yeung, C.; Liles, W.C.; Wurfel, M.; Lopez, J.A.; et al. Endothelial Activation and Blood-Brain Barrier Disruption in Neurotoxicity after Adoptive Immunotherapy with CD19 CAR-T Cells. Cancer Discov. 2017, 7, 1404-1419. [CrossRef] 
111. Immenschuh, S.; Song, D.X.; Satoh, H.; Muller-Eberhard, U. The type II hemopexin interleukin-6 response element predominates the transcriptional regulation of the hemopexin acute phase responsiveness. Biochem. Biophys. Res. Commun. 1995, 207, 202-208. [CrossRef]

112. Maes, M.; Carvalho, A.F. The Compensatory Immune-Regulatory Reflex System (CIRS) in Depression and Bipolar Disorder. Mol. Neurobiol. 2018, 55, 8885-8903. [CrossRef]

113. Wahlen, K.; Ghafouri, B.; Ghafouri, N.; Gerdle, B. Plasma Protein Pattern Correlates With Pain Intensity and Psychological Distress in Women With Chronic Widespread Pain. Front. Psychol. 2018, 9, 2400. [CrossRef]

114. Belcher, J.D.; Chen, C.; Nguyen, J.; Abdulla, F.; Zhang, P.; Nguyen, H.; Nguyen, P.; Killeen, T.; Miescher, S.M.; Brinkman, N.; et al. Haptoglobin and hemopexin inhibit vaso-occlusion and inflammation in murine sickle cell disease: Role of heme oxygenase-1 induction. PLOS ONE 2018, 13, e0196455. [CrossRef]

115. Bissell, D.M.; Hammaker, L.; Schmid, R. Hemoglobin and erythrocyte catabolism in rat liver: The separate roles of parenchymal and sinusoidal cells. Blood 1972, 40, 812-822.

116. Graw, J.A.; Mayeur, C.; Rosales, I.; Liu, Y.; Sabbisetti, V.S.; Riley, F.E.; Rechester, O.; Malhotra, R.; Warren, H.S.; Colvin, R.B.; et al. Haptoglobin or Hemopexin Therapy Prevents Acute Adverse Effects of Resuscitation After Prolonged Storage of Red Cells. Circulation 2016, 134, 945-960. [CrossRef]

117. Yang, Z.; Philips, J.D.; Doty, R.T.; Giraudi, P.; Ostrow, J.D.; Tiribelli, C.; Smith, A.; Abkowitz, J.L. Kinetics and specificity of feline leukemia virus subgroup C receptor (FLVCR) export function and its dependence on hemopexin. J. Biol. Chem. 2010, 285, 28874-28882. [CrossRef]

118. Kovtunovych, G.; Eckhaus, M.A.; Ghosh, M.C.; Ollivierre-Wilson, H.; Rouault, T.A. Dysfunction of the heme recycling system in heme oxygenase 1-deficient mice: Effects on macrophage viability and tissue iron distribution. Blood 2010, 116, 6054-6062. [CrossRef]

119. Dong, B.; Yang, Y.; Zhang, Z.; Xie, K.; Su, L.; Yu, Y. Hemopexin alleviates cognitive dysfunction after focal cerebral ischemia-reperfusion injury in rats. BMC Anesth. 2019, 19, 13. [CrossRef]

120. Yang, Y.; Dong, B.; Lu, J.; Wang, G.; Yu, Y. Hemopexin reduces blood-brain barrier injury and protects synaptic plasticity in cerebral ischemic rats by promoting EPCs through the HO-1 pathway. Brain Res. 2018, 1699, 177-185. [CrossRef]

121. Hu, S.; Hua, Y.; Keep, R.F.; Feng, H.; Xi, G. Deferoxamine therapy reduces brain hemin accumulation after intracerebral hemorrhage in piglets. Exp. Neurol. 2019, 318, 244-250. [CrossRef]

122. Zhang, P.; Zhu, S.; Zhao, M.; Zhao, P.; Zhao, H.; Deng, J.; Li, J. Identification of plasma biomarkers for diffuse axonal injury in rats by iTRAQ-coupled LC-MS/MS and bioinformatics analysis. Brain Res. Bull. 2018, 142, 224-232. [CrossRef]

123. Zhu, Y.; Qiu, Y.; Chen, M.; Zhang, Y.; Cao, L.; Su, Z.; Yuan, Y.; Huang, A.; Pu, Y.; He, C. Hemopexin is required for adult neurogenesis in the subventricular zone/olfactory bulb pathway. Cell Death Dis. 2018, 9 , 268. [CrossRef]

124. Zauberman, A.; Gur, D.; Levy, Y.; Aftalion, M.; Vagima, Y.; Tidhar, A.; Chitlaru, T.; Mamroud, E. Post-exposure administration of a Yersinia pestis live vaccine potentiates second-line antibiotic treatment against pneumonic plague. J. Infect. Dis. 2019. [CrossRef]

125. Li, R.C.; Saleem, S.; Zhen, G.; Cao, W.; Zhuang, H.; Lee, J.; Smith, A.; Altruda, F.; Tolosano, E.; Dore, S. Heme-hemopexin complex attenuates neuronal cell death and stroke damage. J. Cereb. Blood Flow Metab. 2009, 29, 953-964. [CrossRef]

126. Weber, A.N.R.; Bittner, Z.; Liu, X.; Dang, T.M.; Radsak, M.P.; Brunner, C. Bruton's Tyrosine Kinase: An Emerging Key Player in Innate Immunity. Front. Immunol. 2017, 8, 1454. [CrossRef]

127. Hemmingsen, E.A.; Douglas, E.L. Respiratory and circulatory adaptations to the absence of hemoglobin in chaenichthyid fishes. In Adaptations within Antarctic Ecosystems; Llano, G.A., Ed.; Smithsonian Institution: Washington, DC, USA, 1977; pp. 479-487.

128. Bilyk, K.T.; Zhuang, X.; Murphy, K.R.; Cheng, C.C. A tale of two genes: Divergent evolutionary fate of haptoglobin and hemopexin in hemoglobinless Antarctic icefishes. J. Exp. Biol. 2019, 222. [CrossRef]

129. Silveira, A.A.A.; Mahon, O.R.; Cunningham, C.C.; Corr, E.M.; Mendonca, R.; Saad, S.T.O.; Costa, F.F.; Dunne, A.; Conran, N. S100A8 acts as an autocrine priming signal for heme-induced human Mvarphi pro-inflammatory responses in hemolytic inflammation. J. Leukoc. Biol. 2019, 106, 35-43. [CrossRef]

130. Vinchi, F.; Costa da Silva, M.; Ingoglia, G.; Petrillo, S.; Brinkman, N.; Zuercher, A.; Cerwenka, A.; Tolosano, E.; Muckenthaler, M.U. Hemopexin therapy reverts heme-induced proinflammatory phenotypic switching of macrophages in a mouse model of sickle cell disease. Blood 2016, 127, 473-486. [CrossRef] 
131. Han, D.; Yu, Z.; Liu, W.; Yin, D.; Pu, Y.; Feng, J.; Yuan, Y.; Huang, A.; Cao, L.; He, C. Plasma Hemopexin ameliorates murine spinal cord injury by switching microglia from the M1 state to the M2 state. Cell Death Dis. 2018, 9, 181. [CrossRef]

132. Haldar, M.; Kohyama, M.; So, A.Y.; Kc, W.; Wu, X.; Briseno, C.G.; Satpathy, A.T.; Kretzer, N.M.; Arase, H.; Rajasekaran, N.S.; et al. Heme-mediated SPI-C induction promotes monocyte differentiation into iron-recycling macrophages. Cell 2014, 156, 1223-1234. [CrossRef]

133. Zwerina, J.; Tzima, S.; Hayer, S.; Redlich, K.; Hoffmann, O.; Hanslik-Schnabel, B.; Smolen, J.S.; Kollias, G.; Schett, G. Heme oxygenase 1 (HO-1) regulates osteoclastogenesis and bone resorption. FASEB J. 2005, 19, 2011-2013. [CrossRef]

134. Jung, J.Y.; Kwak, Y.H.; Chang, I.; Kwon, W.Y.; Suh, G.J.; Choi, D. Protective effect of hemopexin on systemic inflammation and acute lung injury in an endotoxemia model. J. Surg. Res. 2017, 212, 15-21. [CrossRef]

135. Johnson, G.L.; Nakamura, K. The c-jun kinase/stress-activated pathway: Regulation, function and role in human disease. Biochim. Biophys. Acta 2007, 1773, 1341-1348. [CrossRef]

136. Eskew, J.D.; Vanacore, R.M.; Sung, L.; Morales, P.J.; Smith, A. Cellular protection mechanisms against extracellular heme: Heme-hemopexin, but not free heme, activates the N-terminal c-Jun kinase. J. Biol. Chem. 1999, 274, 638-648. [CrossRef]

137. Greene, L.A.; Aletta, J.M.; Rukenstein, A.; Green, S.H. PC12 pheochromocytoma cells: Culture, nerve growth factor treatment, and experimental exploitation. Methods Enzym. 1987, 147, 207-216.

138. Wuestefeld, T.; Pesic, M.; Rudalska, R.; Dauch, D.; Longerich, T.; Kang, T.W.; Yevsa, T.; Heinzmann, F.; Hoenicke, L.; Hohmeyer, A.; et al. A Direct in vivo RNAi screen identifies MKK4 as a key regulator of liver regeneration. Cell 2013, 153, 389-401. [CrossRef]

139. Norris, C.A.; He, M.; Kang, L.I.; Ding, M.Q.; Radder, J.E.; Haynes, M.M.; Yang, Y.; Paranjpe, S.; Bowen, W.C.; Orr, A.; et al. Synthesis of IL-6 by hepatocytes is a normal response to common hepatic stimuli. PLoS ONE 2014, 9, e96053. [CrossRef]

140. Vijayan, V.; Pradhan, P.; Braud, L.; Fuchs, H.R.; Gueler, F.; Motterlini, R.; Foresti, R.; Immenschuh, S. Human and murine macrophages exhibit differential metabolic responses to lipopolysaccharide-A divergent role for glycolysis. Redox Biol. 2019, 22, 101147. [CrossRef]

141. Mestas, J.; Hughes, C.C. Of mice and not men: Differences between mouse and human immunology. J. Immunol. 2004, 172, 2731-2738. [CrossRef]

142. Foidart, M.; Eiseman, J.; Engel, W.K.; Adornato, B.T.; Liem, H.H.; Muller-Eberhard, U. Effect of heme administration on hemopexin metabolism in the rhesus monkey. J. Lab. Clin. Med. 1982, 100, 451-460.

143. Foidart, M.; Liem, H.H.; Adornato, B.T.; Engel, W.K.; Muller-Eberhard, U. Hemopexin metabolism in patients with altered serum levels. J. Lab. Clin. Med. 1983, 102, 838-846.

144. Dufresne, J.; Florentinus-Mefailoski, A.; Bowden, P.; Marshall, J.G. A method for the extraction of the endogenous tryptic peptides (peptidome) from human EDTA plasma. Anal. Biochem. 2018, 549, 188-196. [CrossRef]

(C) 2019 by the authors. Licensee MDPI, Basel, Switzerland. This article is an open access article distributed under the terms and conditions of the Creative Commons Attribution (CC BY) license (http://creativecommons.org/licenses/by/4.0/). 
MDPI

St. Alban-Anlage 66

4052 Basel

Switzerland

Tel. +41616837734

Fax +41 613028918

www.mdpi.com

Pharmaceuticals Editorial Office

E-mail: pharmaceuticals@mdpi.com

www.mdpi.com/journal/pharmaceuticals

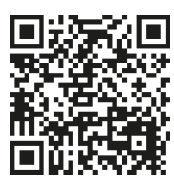



MDPI

St. Alban-Anlage 66

4052 Basel

Switzerland

Tel: +41 616837734

Fax: +41 613028918

www.mdpi.com 